\title{
Becoming an Anthropologist 1966-1971
}
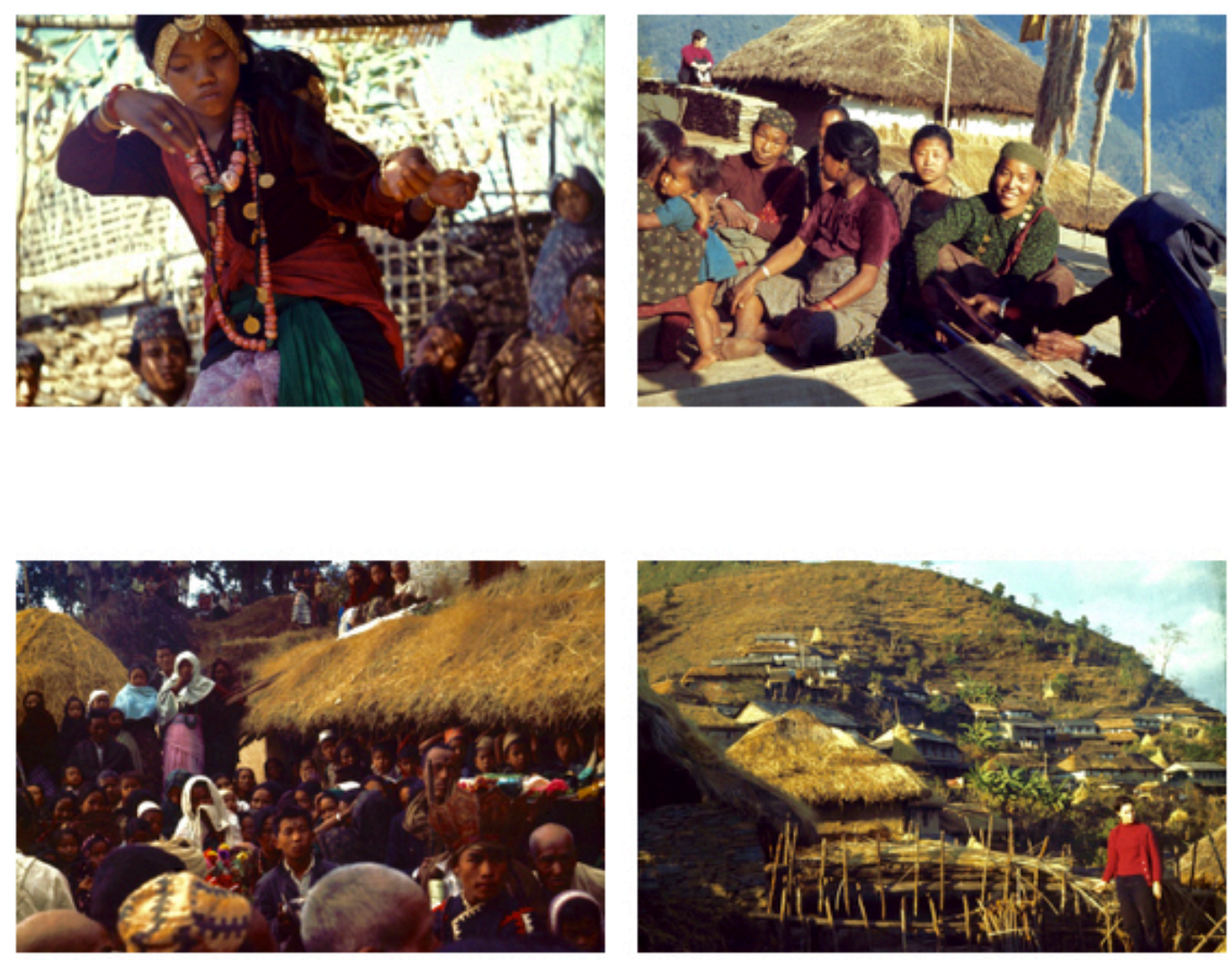

\section{Alan Macfarlane}




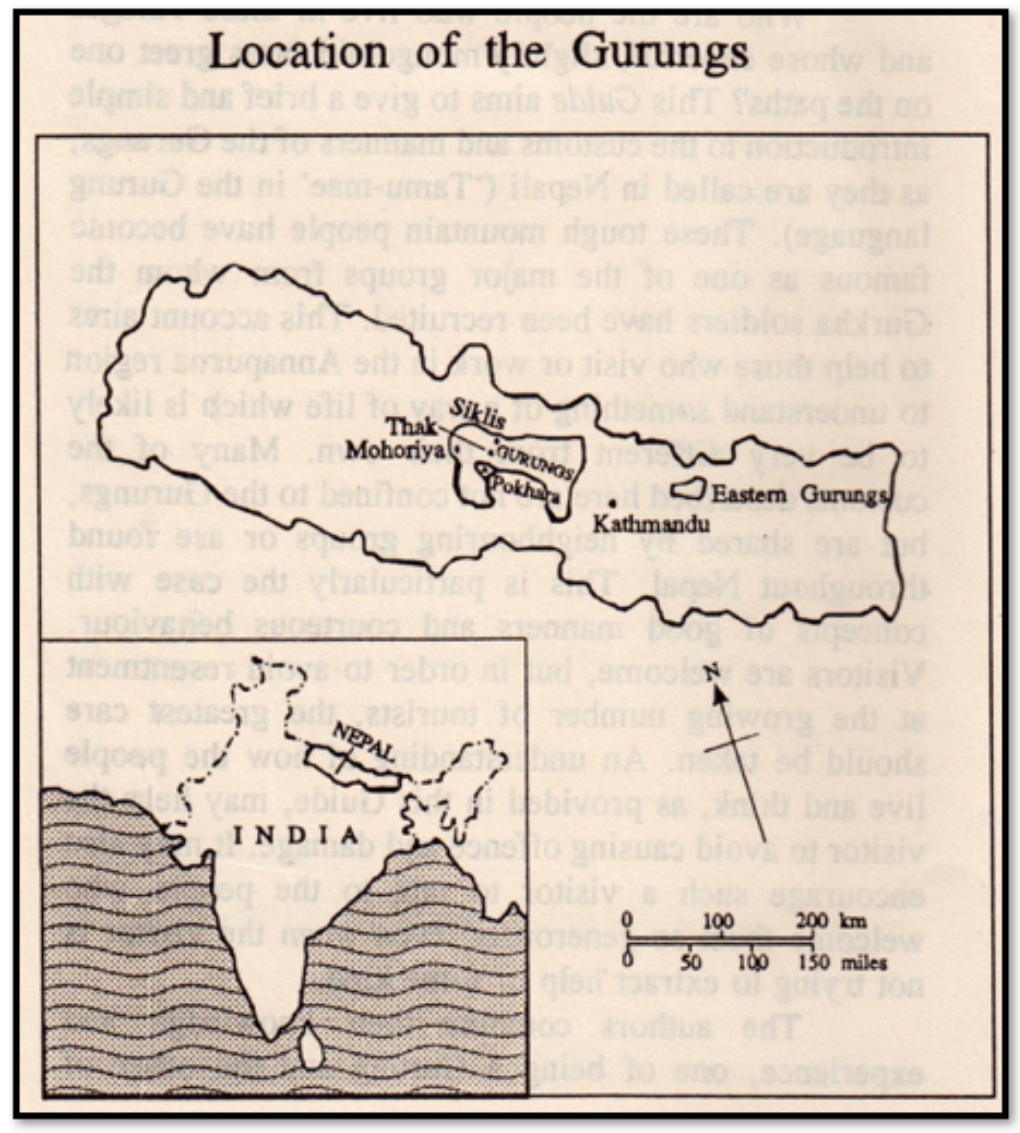

Contents

Early roots of the project and overview of the fieldwork in Nepal 3

Preparing for fieldwork

5

December 1968 - Leaving home and arriving in the field 14

January 1969

February 1969

March 1969

April 1969

May 1969

June 19696

July 1969

August 1969

September 1969

October 1969

November 1969

December 1969

January 1970

February 1970

Return from the field

Publications with arose from work in this period

Acknowledgements and dedication 


\section{Early roots of the project and overview of the fieldwork in Nepal}

The roots of my long involvement with the Gurungs go back to childhood experiences and family links. Two of my uncles served with the Gurkhas during the Second World War, regiments raised from the hill tribes of Nepal including the Gurungs. My father had helped raise the first two regiments of the Assam Rifles which had recruits from Nepal. I had been looked after as a baby by ayahs from the Tibeto-Burman hill peoples who were very similar to the Gurungs. So the hill peoples of the eastern Himalayas were around me in my infancy.

When I was unable to go back to the Assam hills for my Ph.D. in anthropology in 1968, my supervisor Christoph von Fürer-Haimendorf, had suggested I go to Nepal. He had been the first British anthropologist to work there in 1953 when Nepal had opened to outsiders only 15 years earlier. He knew there was much survey and documentation work to be done.

I had been trained as a historian, yet I knew that I would need to do fieldwork for my anthropological Ph.D. if I was to be accepted in the anthropological profession and teach and practice the discipline. I had already done preliminary studies of several historical communities in seventeenth century Essex and I felt that in order to understand what it might be like to live in a pre-industrial world I should experience this first hand. How could historians write about material and mental conditions of which they had no first-hand experience? I decided to participate in a world without roads, electricity, modern medicine, cars or television.

After a two-year conversion course in anthropology at the London School of Economics in 1966-8 I was ready to undertake fieldwork. The theme was to be the relation between population and resources. My interest in population had started at Oxford as I began to read about the danger of over-population. At the L.S.E. I attended demography lectures and classes and became increasingly concerned with the 'population bomb' as it was then known. I read books such as those by Paul Ehrlich, and my first published article (in 1968 in New Society) was on why anthropologists had tended to ignore that subject.

So I was determined to do a thorough survey and census of the village where I would settle. I would also try to gather as much historical material as possible and census records so I could trace the changing pressures on the fields and forests in the fragile ecological setting of the steep Annapurna mountains of central Nepal to which I was heading. I would do a 'total' village study in the conventional anthropological manner, but with an added emphasis on historical change.

\section{Fieldwork and later visits}

I went to Nepal with my wife Gill via Delhi to Kathmandu and then Pokhara. We walked from there up towards our goal of Siklis village. But we were taken on a circular route and after an exhausting journey decided to settle in the village of Thak.

I will elaborate later some of the loneliness and homesickness and the gruelling nature of the fieldwork in what was at the end of 1968 still a very remote community, a day's walk from the nearest town. There was no road, no electricity, no wheels, everything was carried on the human back, no hospital anywhere near and no school in the village. It was very difficult in every way. But we were able to collect a very large body of fieldnotes, surveys, censuses, maps, genealogies, and other materials. I did a little tape-recording, took photographs and bought a small movie camera and took a couple of hours of silent film.

When we returned from Nepal in early 1970 I spent over a year writing up the results as a Ph.D. entitled 'Population and Resources: A Study of the Gurungs of Central Nepal', which 
was examined in 1972. While I enjoyed the analysis, the mainly demographic and economic account, with over a hundred of statistical tables, did not seem to catch the multi-dimensional nature of the world I had visited. The emotional experience was missing and I found it impossible to share this with others. 


\section{PREPARING FOR FIELDWORK}

That charming and intelligent Austrian-American anthropologist Paul Radin has said that no one quite knows how one goes about field-work. Perhaps we should leave the question with that sort of answer. But when I was a serious young student in London I thought I would try to get a few tips from experienced fieldworkers before setting out for Central Africa. I first sought advice from Westermarck. All I got from him was "don't converse with an informant for more than twenty minutes because if you aren't bored by that time he will be.' Very good advice, even if somewhat inadequate. I sought instruction from Haddon, a man foremost in fieldresearch. He told me that it was really all quite simple; one should always behave as a gentleman. Also very good advice. My teacher, Seligman told me to take ten grains of quinine every night and to keep off women. The famous Egyptologist, Sir Flinders Petrie just told me not to bother about drinking dirty water as one soon became immune to it. Finally, I asked Malinowski and was told not to be a bloody fool. So there is no clear answer, much will depend on the man, on the society he is to study and the conditions in which he is to make it.

In science, as in life, one finds only what one seeks. One cannot have the answers without knowing what the questions are. Consequently the first imperative is a rigorous training in general theory before attempting fieldresearch so that one may know how and what to observe, what is significant in the light of theory.... It is useless going into the field blind. One must know precisely what one wants to know and that can only be acquired by a systematic training in academic social anthropology.

[These quotations come from E.E. Evans-Pritchard, 'Some Reminiscences and Reflections on Fieldwork', Fournal of the Anthropological Society of Oxford, 4:1-12 (1973). I had heard a number of the views in the article over the years when we talked and when I read Evans-Pritchard's work. But only recently, writing about my own fieldwork experience, have I come across the published article. I have used the article to head a number of chapters.]

\section{Theoretical background}

Just as a person would never be accepted to do a Ph.D. on medieval or early modern history without having read widely on the general background, and done some theoretical work on the philosophy of history, so anthropologists, from the time when the discipline was established as a University subject, have been expected to have done some general training in anthropology before they went to the field.

I did this over a period of about five years, the first three as an adjunct to my main historical study, and then in a two-year intensive conversion M.Phil. This meant that, by the time I went to Nepal, my mind was already filled with many ideas from other anthropologists and comparative models of tribal societies. This background clearly shaped what I saw and collected.

In the first year of my Oxford D.Phil, my supervisor Keith Thomas suggested that as my thesis was on the very anthropological subject of witchcraft, I should attend lectures at the Institute of Anthropology. There I heard lectures by the significant Oxford anthropologists of the day, John Beattie, Rodney Needham, Godfrey Lienhardt and above all E.E. EvansPritchard, and started to talk to them. I read a number of the classics in anthropology at this time. I wrote to my mother in March 1964 after a religious retreat I had attended:

The only books I read at Lee Abbey were on anthropology and they added to my conviction that that discipline can help historians a good deal by showing the close interrelationships between human activities which are usually treated as separate subjects - thus economic exchange also provides social \& political links and incorporates religious elements. Still, I'll work this out in more detail later. 
A flavour of lectures I attended in 1965 is contained in the following series.

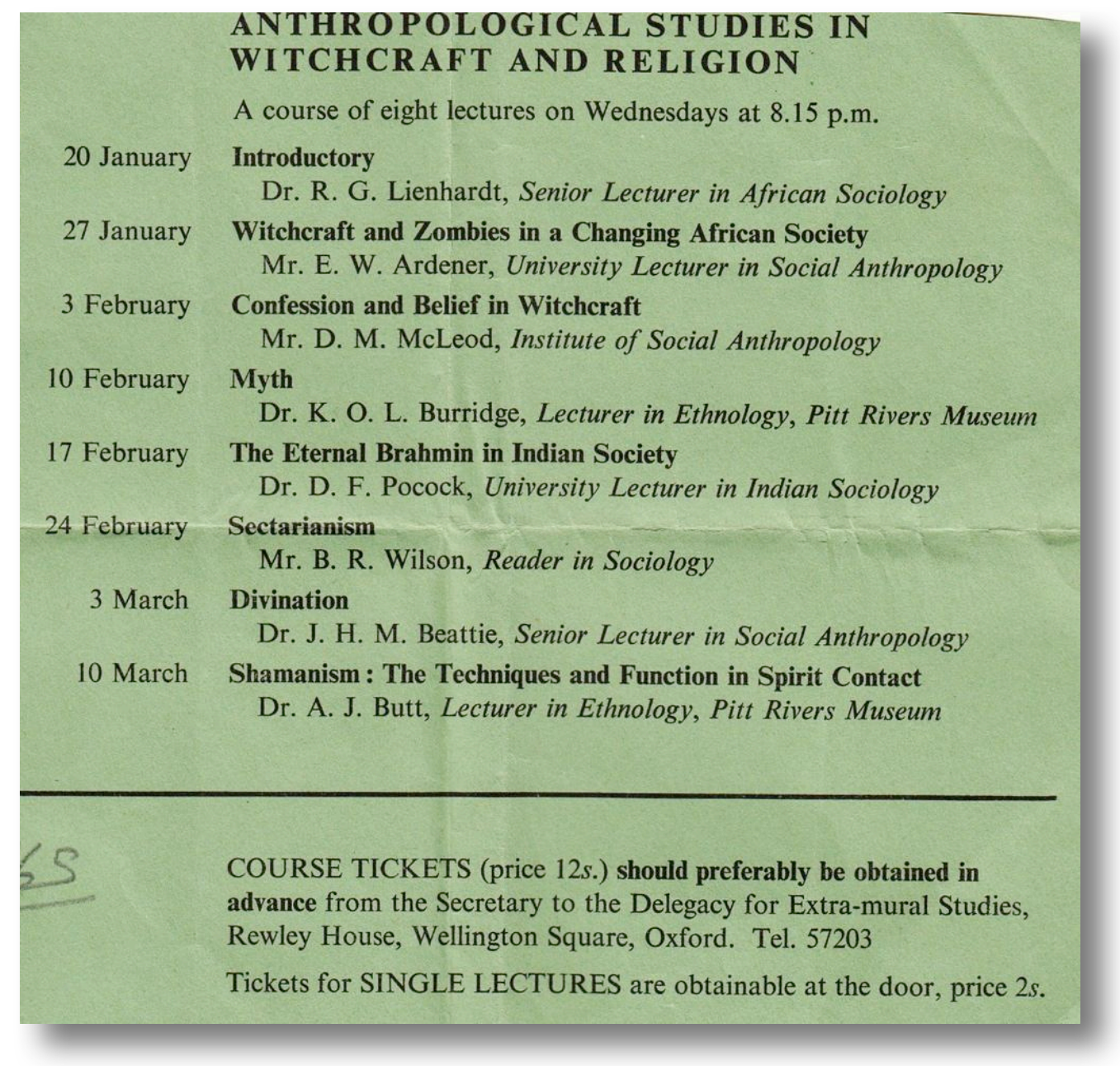

The stage of learning to be an anthropologist through meeting practitioners and studying their works can be encapsulated in one short vignette of the strongest influence on me in my years of anthropological training, namely the personality and writing of Edward EvansPritchard, Professor of Social Anthropology at Oxford at that time and author of several seminal books on the Nuer, Azande and general anthropology.

This was partly a personal influence. I had got to know E-P, as he was known, through chatting over coffee in the Institute and attending his lectures, and he advised me several times while I was writing on English witchcraft. He ended up as one of my two D.Phil. examiners. Later he wrote the preface to my first published book, Witchcraft in Tudor and Stuart England. His general books on social anthropology, his essays on history and anthropology, his famous Cairo lectures on magic, and above all his book on Azande witchcraft and his trilogy on the Nuer of the Sudan, became hugely influential. They have remained at the heart of my teaching and research since then. I soon came to believe that if I could read and internalize his corpus of work I would know enough to be a reasonable anthropologist. I liked his approach and above all the simplicity, combined with inner depth, of his writing. He was never dull. Every sentence told you something. He tackled huge subjects of global significance, yet made the answers seem simple. He changed the way I thought about the world. 
I took a copy of Nuer Religion to Nepal for my fieldwork, and there we used it as a model to help direct the questions we would ask of the Gurungs, as is indicated in these notes by Gill my wife.

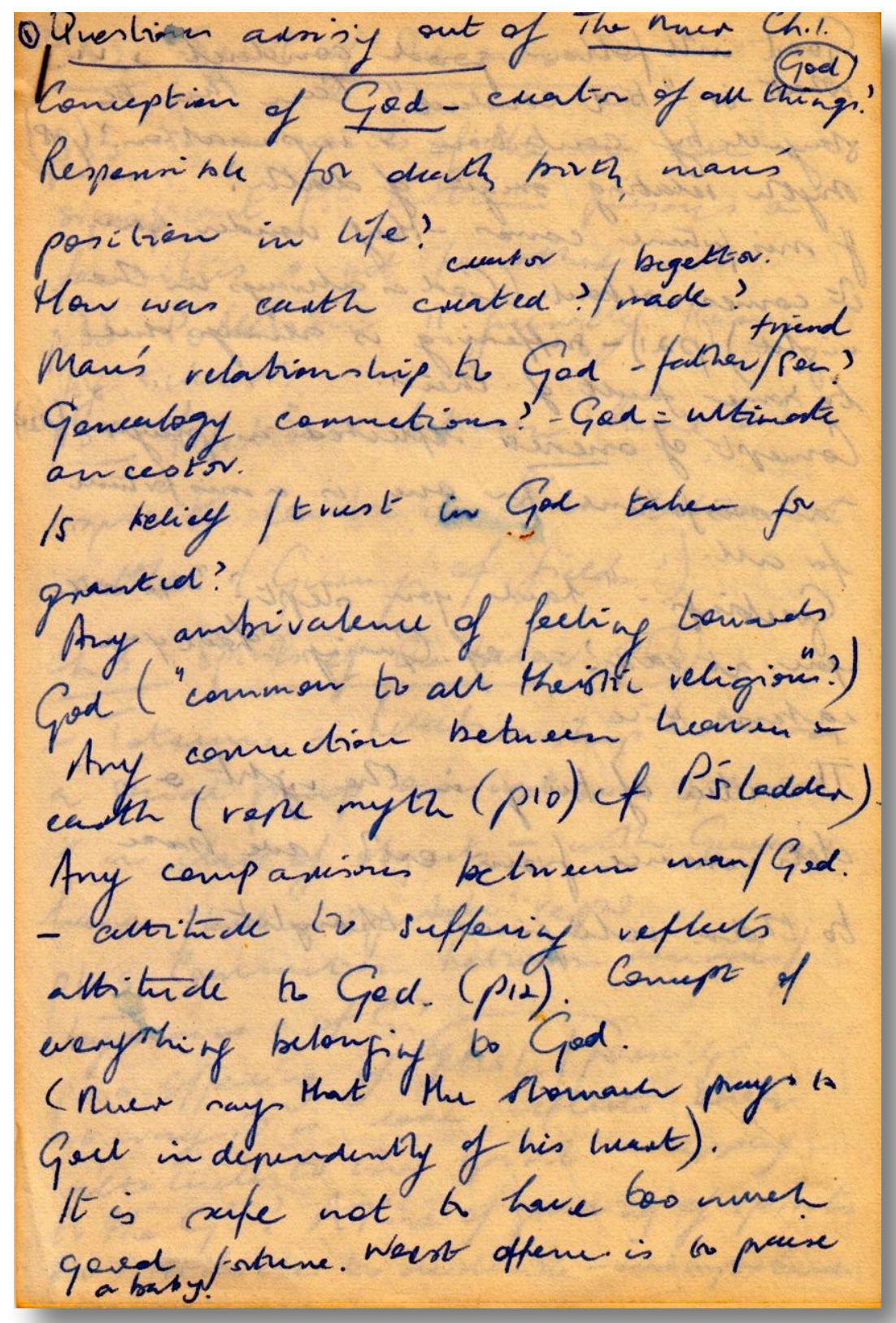

So by the time that I started on the M.Phil. course at the L.S.E. in the autumn of 1966 I already knew a certain amount about the Oxford style of anthropology. Going to London introduced me to a new set of distinguished anthropologists, and occurred at a time when French structuralist anthropology was just starting to have a major impact. I was lectured by a galaxy of interesting people, among them Raymond Firth, Lucy Mair, Maurice Freedman, Robin Fox, Mary Douglas and James Woodburn. For two academic years I absorbed anthropology through lectures, reading and attending the successor to the famous Malinowski seminar, run for the last of his two years as a teacher by Raymond Firth. I also wrote a long Master's dissertation on 'The regulation of marital and sexual relations in seventeenth 
century England', under the direction of Isaac Schapera. This drew heavily on anthropology for questions and models.

Just a hint of the explosion of new ideas from this formal conversion to anthropology can be seen from part of the rough index to some of the books, seminars and lectures on which I kept notes at the time. Many other books, of course, I bought and read are not included here.

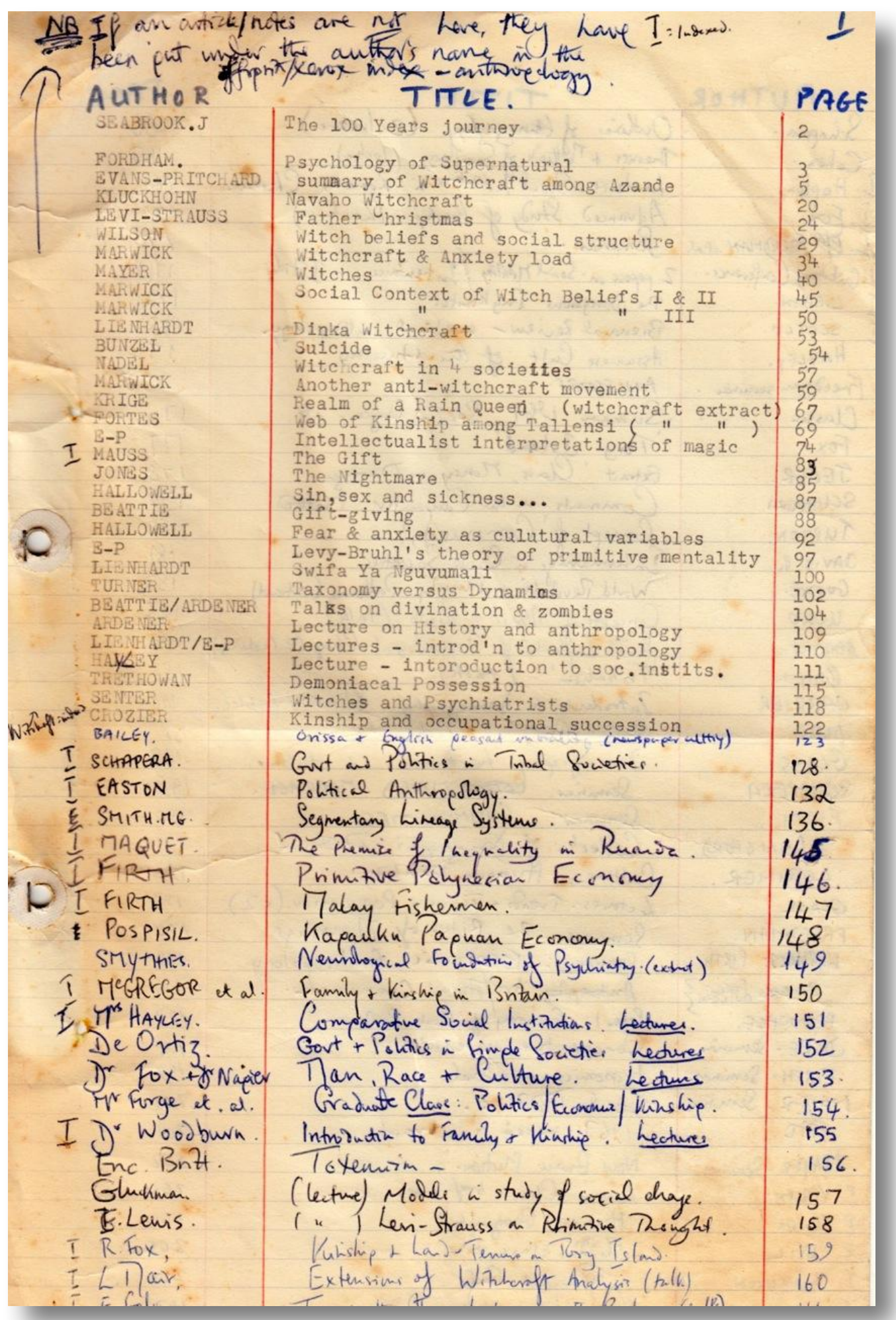


The M.Phil. course was to provide us with a solid grounding in theory, and in some detailed knowledge of classic ethnographies. Since we were surrounded by the people who had written many of the classic studies, it was a great privilege to actually meet and discuss with them. We learnt something about their fieldwork methods in the past, and some of them, such as Anthony Forge, James Woodburn and Robin Fox were still active fieldworkers. The Malinowski/Firth seminar was also attended by those who had returned from the field and were writing up their fieldwork, so we also heard about their experiences and how they were trying to shape them into a thesis.

I was already interested in demography, and the LSE was at the forefront of this field with David Glass, Chris Langford, and Keith Hopkins giving lectures on comparative and historical demography. Much of the formal technical training I needed for the simple demographic work I would do in the field was taught to me in this way. My wider interests in the philosophy of the social sciences was fed by lectures and seminars with Ronald Dore, Ernest Gellner and Stanley Cohen.

All this means that by the time I was awarded a grant by the London-Cornell Project to go to Nepal, my mind was already pretty full of anthropological theories, experiences, questions and methods of a general kind. What was not there was any formal training in the practical matters of living and working in the field.

\section{Why did I do fieldwork?}

There are many reasons for doing fieldwork and the reasons change over one's life. I can only speak from my own experience, both as a fieldworker in various parts of the world, and from observing a number of my colleagues and the many Ph.D. students I have supervised.

In my own case there was a jumble of motives which sent me out to Nepal in 1968. I had been trained as a historian and already written a D.Phil. on seventeenth century English witchcraft. I had learned a great deal from reading anthropologists on witchcraft and more generally on pre-industrial societies. This had made me feel that if I was really going to understand the history of a world before the industrial revolution, I should try to experience it at first hand - through fieldwork.

More specifically I had already started a study of several English villages and I thought it would be interesting to add a case study from outside Europe as a contrast and comparison.

A more personal reason was that I had been born in the eastern Himalayas (Assam) and wanted to return to the area of which I had strong memories.

A more practical motive was that I wanted to be trained as an anthropologist and to obtain the union card, a Ph.D. in anthropology, so that I would be taken seriously as a professional in the discipline. And behind this there would be the question of whether I really wanted to become an anthropologist, or would return to historical research to which I could apply anthropological questions.

Alongside this, as I trained as an anthropologist and read the monographs of others who had based their books on fieldwork, I knew that I could not properly estimate the value of their work without having undergone the experience myself.

In particular I wanted to find out whether anthropology is really possible. That is to say whether cross-cultural understanding across is really possible.

My mind had long been filled with broad questions about how the world works and I knew that I would need a much wider experience than just England, or even western Europe, in order to approach tentative answers to these questions. In particular, there was the basic question of what is universal about human beings and what is particular to certain cultures 
and societies. For instance, how much of my own upbringing and experience in England was peculiar, how much part of the basic human condition?

This was all part of an attempt to learn about myself, who I was, what I was like, how I fitted into wider frameworks. The continuing process of self-discovery, made more explicit by finding oneself in an alien environment where many of my unexamined assumptions would be challenged was central.

And of course I wanted to have an adventure with new people and ideas and perhaps to shake off some of the staleness of having spent my life between the age of eight and eighteen in boarding schools, and then eight years in Oxford and London accumulating another three degrees. I was still filled with idealism. I wanted to help people, but had moved beyond a simple idea of working directly in foreign aid but felt that perhaps I could contribute through helping to understand what was happening in societies less economically developed than my own. This hope was strongly supported by my idealistic mother who was, to a certain extent, hoping that I would be able to do some of the things to help alleviate suffering which she had tried when she had lived as a tea planter's wife.

There was one more reason, which fed directly into the research I pursued. This was that ever since my undergraduate days, and then increasingly in the three years before I went to the field, I had become very interested in population growth and the likely effects of what was known then as 'The Population Bomb'. Others will have other motives, some overlapping with these, many very different. The general point is that it is worth examining your motivation for going. Fieldwork can be very challenging and it is best not to undertake it unless you are pretty sure you want to do it.

\section{How did I choose a place to work?}

I have asked many distinguished anthropologists how they chose to work where they did. Many of their answers are in the more than eighty filmed interviews I have put up on the web. In theory, they often say, the choice should be dictated by a wide survey of places where the answers to a set of questions that are already of interest to you are thought to be best studied. They sometimes even talk of random sampling frames and other scientific approaches.

Yet, in practice, I have observed that the choice is usually made on the basis of some personal connection or interest in the place which one will study as in my case.

Unfortunately, I could not get a visa to study in Assam so my supervisor, so my supervisor Christoph von Fürer-Haimendorf, suggested that I go to Nepal instead. He had passed through the Gurung area earlier and thought it would be a suitable place in which to pursue my interests.

\section{Starting to fill in the background}

Once one knows the place that one hopes to go to, there is usually a period of some months of preparation before one leaves. Various activities fill this time. The first, if possible, is to start to learn the local language. In my case I could not do this since there were no published grammars or vocabularies of the fairly obscure Gurung language and also I only had a couple of months in which to prepare everything else.

There is usually a need to look at the theoretical literature in the topic one hopes to investigate - in my case demography and economics. In fact, most of my reading and ideas had been formed over the previous eight years of university education so I took one or two 
recent books with me and did much of my reading round the topic when I returned from my first fieldwork.

Obviously it is sensible to read as much as possible both about the civilization within which one will be working - in my case Nepal and the Tibeto-Burmese and Buddhist world of the high Himalayas - and, more specifically, if there is anything on the particular group one will be working on, to see what has already been done and to start to learn about the people and their way of life. In my case there was only one important book, by Bernard Pignède, published in 1966 in French, so I took this with me to the field and made a first translation of the book with my wife Gill. Otherwise there was very little published, except one or two monographs on Magars, Sherpas and other Tibeto-Burmese groups.

Obviously the preliminary reading, and general orientation, can be directed by one's research supervisor, if one is doing a degree. In my case Professor Furer-Haimendorf was the acknowledged leading expert on Nepal and so he could refer me to some of his own work and that of others. He could also put me in touch with other scholars who had worked in the area. Talking to such scholars, including several returned students back from their Ph.D. research, is an extremely important part of the initial orientation.

Alongside this there are various practical details to be worked out - the finances for the fieldwork (in my case a London-Cornell scholarship), the medical precautions, the visas, the travel tickets, and more generally finding out if there are any particular ethical or political problems. In my case I was already keen to use audio-visual collecting devices so there was discussion of cameras and tape-recorders and the purchasing or borrowing of appropriate ones.

\section{Training in fieldwork methods}

The early generations of fieldworkers did not have much, if any, explicit training in fieldwork methods. They might have taken out a copy of Notes and Queries in Anthropology. They may have had a talk to one or two senior anthropologists about their experiences, but certainly I do not remember any formal training sessions either at the School of Oriental Studies, where I went to do my Ph.D., or even when I went to Cambridge to teach anthropology in the mid-1970's. It was only after the 1980's that the funding bodies started to insist on a well worked-out set of pre-fieldwork training sessions.

Yet even by the time I retired from Cambridge in 2009, the training sessions were not very satisfactory for a number of reasons. When I gave such instruction I was always aware that in a group of a dozen or so pre-fieldwork researchers, the needs of each individual was so different that there was little of a generic nature that could be explained. What they needed if they were going to work in a city was very different to that for a rural village, someone working in Africa needed to know different things from someone going to India or Japan, someone working in their own culture, different from working in a distant one, someone working on medical anthropology different from economic anthropology.

Another reason for the unsatisfying nature was that it was all too intellectual. The actual practical and emotional difficulties, the anticipating of what fieldwork is really like, the deeper questions of trying to make friends and to understand alien beliefs were extremely difficult to convey through talking or getting the students to read introductory textbooks or do little exercises around the city.

To help alleviate some of these difficulties is, in fact, one of the purposes of this book. It is located in a very specific, and some would say, rather remote and old-fashioned type of 'total' fieldwork. But though each fieldwork is different, having now worked in a number of different cultures in different ways, I have come to the conclusion that there are indeed certain common features or stages in the work. 
There is the preparing for fieldwork, the shock of arriving, the difficulties of living, communicating, participating and so on. So it may well be that with the help of film and the hindsight of what has now been a wide set of fieldwork trips - including nineteen to a rapidly changing Nepal over forty years, as well as to Japan and China, it is possible to distil out some general features.

Using film can also overcome some of the emotional dryness of just talking and reading. It is partly possible to enter the actual process of fieldwork and see what is done, and to measure some of the reactions.

The films and book are based on the growing realization that fieldwork can be viewed as a form of the classic rite of passage which anthropologists often analyse. There is the leaving your own environment, the process of disaggregation, then the period of liminality or 'out of time and space' feeling of the actual fieldwork, and then the re-aggregation. And within each of these major three stages there are sub rites of passage - for example the first stage consists of disaggregation from the home, the liminality of the travel to the destination, and then a reaggregation into another world.

Like all rites of passage, which are analysed to show how the process can totally change the person who goes through it, whether in young people's dormitories or boarding schools, or through marriage or death rituals, so the process of fieldwork can, and certainly did in our case, totally change us. We do not come out of what is often a searing process as the same person who went into it. Very often we will understand ourselves and the world around us in a different way. It is like going through a portal into a magic land, Narnia or Alice's Wonderland. When we come back into our own world it is changed.

\section{How clearly were my questions and hypotheses formed before I went to the field?}

A research student in any discipline is caught in a tension between two positions.

One is the obvious fact that unless you have some questions in mind, you will find nothing. The mind is not an empty sheet upon which experiences are inscribed in a neutral way. Unless you have some questions to ask, however misguided, and also some hypotheses about what the answers could possibly be, you will find nothing of interest. As Einstein more generally put it, 'It is the theory which decides what we can observe'.

On the other hand, it is obvious that if you have too strong a set of assumptions, expectations, certainties, and too rigid a set of questions, you will not be open to the surprises, revelation and mind-shifting experiences which are what real fieldwork should be about. Fieldwork is based on uncertainty, on guesses that can be changed, a groping in the dark. Again putting it in Einstein's words, 'If we knew what we were doing it wouldn't be research'.

In all good research you have to suspend your own assumptions and too-strong models brought with you from a whole upbringing in a certain culture.

This latter position is particularly difficult if the researcher is making the huge leap from one mental world to another, for example as I was from a Judaeo-Christian, individualistic, capitalist, urban civilization - Britain in the 1960's - to a remote, oral, Buddhist, farming community on the slopes of the Himalayas.

I found, as I did again when studying Japan, that almost all the mental tools, the cosmology, logic, philosophical assumptions and training in history and the social sciences which I had absorbed over the first twenty-five years of my life were of very little value when faced with what I saw around me in Nepal.

Rosemary Firth described her first feeling on arriving in the field as being like a tiny baby - having to learn again how to survive, how to walk, how to talk, the manners and customs, 
the whole paraphernalia of culture which you do not understand. And yet you are an adult person. It can be very demanding.

So how does one reconcile these two positions? I suppose the point is to have specific questions and theories, and models available and ready as a preliminary set of tools. But not to let them become so fixed that you exclude the ambiguities, the things that do not fit, the unsteadying whittling away of your deeper assumptions. You are going through at a personal level what Thomas Kuhn called a paradigm shift. You go with one paradigm, that is a set of assumptions about what the framework for understanding must be, what the interesting questions are and where to look for answers to these questions. But as you work, the anomalies, the things that do not fit, the unexpected stumbling and confusion, mounts so that at a certain point you realize that you must jettison part or all of the paradigm and create a new one. Sometimes this happens gradually and you do not notice how much you have changed; sometimes it happens in that Eureka moment when, as happened to me when I suddenly saw the shamanic sub-structure of Japan, everything can be changed in a few minutes.

It is easy to reshape the past in our memories, so it is perhaps useful to use a contemporary document about my goals, written just before I set out. As will be seen, there were theoretical and practical goals, and included among the interests was collecting materials by taping and filming which would be useful for my future teaching. This is probably a part of my application for a London-Cornell Fellowship. There are some additions in pen to the typescript, which I have added in.

\section{FIELDWORK PROJEGT}

Area: Assam/Nepal/Kumaon hills (Delhi) (India) (Hebrides)

\section{Approach/problems:}

i) To undertake a conventional village study of one village - following the model of previous studies. Showing the interlinking of ecology, social structure and mental structure. Divided into chapters on physical background; the domestic cycle and kinship system; economic organization; political organization; ritual and beliefs. The aim of this would be to

a) provide training in the methods of collection and analysis of data and a consciousness of the problems implicit in other anthropological monographs.

b) provide a contribution to regional ethnography.

c) try, as far as possible, to include an awareness of social change and historical depth, intrinsic to the approach of an historian-cum-anthropologist and a study of social change in a village situation.

d) Provide a teaching comparative device/study for historians who are interested in comparing anthropological/historical approaches by collecting as much film/tape/illustrative data as possible and by, possibly, writing up the final version as part of a dual study of English pre-industrial life (on which considerable material has already been collected), and modern-day village life in Asia. 
ii) Within the general framework of a village study, to take as the central problem that of attitudes to and effects of demographic change. The sort of problems would be: what factors - e.g. kinship structure, mechanisms for risk-sharing and insurance, attitude to ancestor, ideals of virility or the necessity for producing an heir, effect the fertility levels of the society? What are the social effects of long-term changes in the demographic structure of the village - does it lead to changes on the emotional and mental level, eg. In the attitude to ancestors, or the attitude to the death of children? What are the attitudes in the village towards attempts to limit population growth by the outside government? What are the indirect ways in which decreases in fertility level are effected - e.g. changes in inheritance systems or laws re. re-marriage of widows, or provision of communal insurance? What are the indirect channels along which birth-control information flows and how are decisions to attempt control reached? What are the main obstacles once the decision has taken place?

The aim of this would be

a) to test the hypothesis (Lorrimer) that the decisive variable which made pre-industrial European patterns different from those of modern Asia was the presence of the nuclear family - and to test other hypotheses about factors effecting fertility levels. (e.g. Ariès thesis, Moni Nag list etc)

b) to provide information for those politicians and administrators trying to deal with the population explosion, by making limited predictions concerning the likely results of introducing birth-control.

c) try to get inside local views to see how they look at outside environment.

Models:

1) Fortes/A. Richards Demographic Surveys in Lorrimer.

2) Leach, Pul Eliya.

3) Nag's study of particular socs.

4) Depth study described by Draper, Birth Control, pp. 271-2 on India.

5) General fieldwork monographs on partic. Socs. By Firth, E-P, Fortes \& the new generation - Mitchell, Douglas, Stirling etc.

These ideas, especially in relation to demography, were summarized in my first published article, written exactly as I prepared to do fieldwork and published in New Society on 10th October 1968 as 'Population Crisis: Anthropology's Failure'. This gave an overview of what had been done by social anthropologists in demography and suggested ways in which the materials and theories could be improved. The urgency is suggested in the first paragraph:

'We are rapidly moving towards a population catastrophe which will make past plagues and two world wars seem insignificant by comparison. By 1900, world population had reached about one and a half billion: by the year 2000 it will be at least six billion, unless it is halted by thermonuclear war or massive epidemics...' 


\section{DECEMBER 1968}

\section{LEAVING HOME AND ARRIVING IN THE FIELD}

If we continue the metaphor of a rite of passage, then the first major stage is the rite of leaving your own familiar world and moving through various time and space zones to arrive in that liminal world, out of normal time and space, which is 'the field'. This experience has changed enormously since the early days of anthropology. Because it is now compressed into a few hours or days instead of weeks and months it can tend to be largely overlooked or invisible, so it is worth examining it in the more leisurely early days.

In the very early days of the founders of fieldwork anthropology, Boas, Haddon, Rivers or Malinowski, it often took several months travel by boat and then some further weeks at a local administrative centre before you could arrive 'in the field'. This allowed the researcher time to adjust their mind and body clock, to realize that they were going to a very different world, to savour the changes of smell, sights, food, body distances and humour.

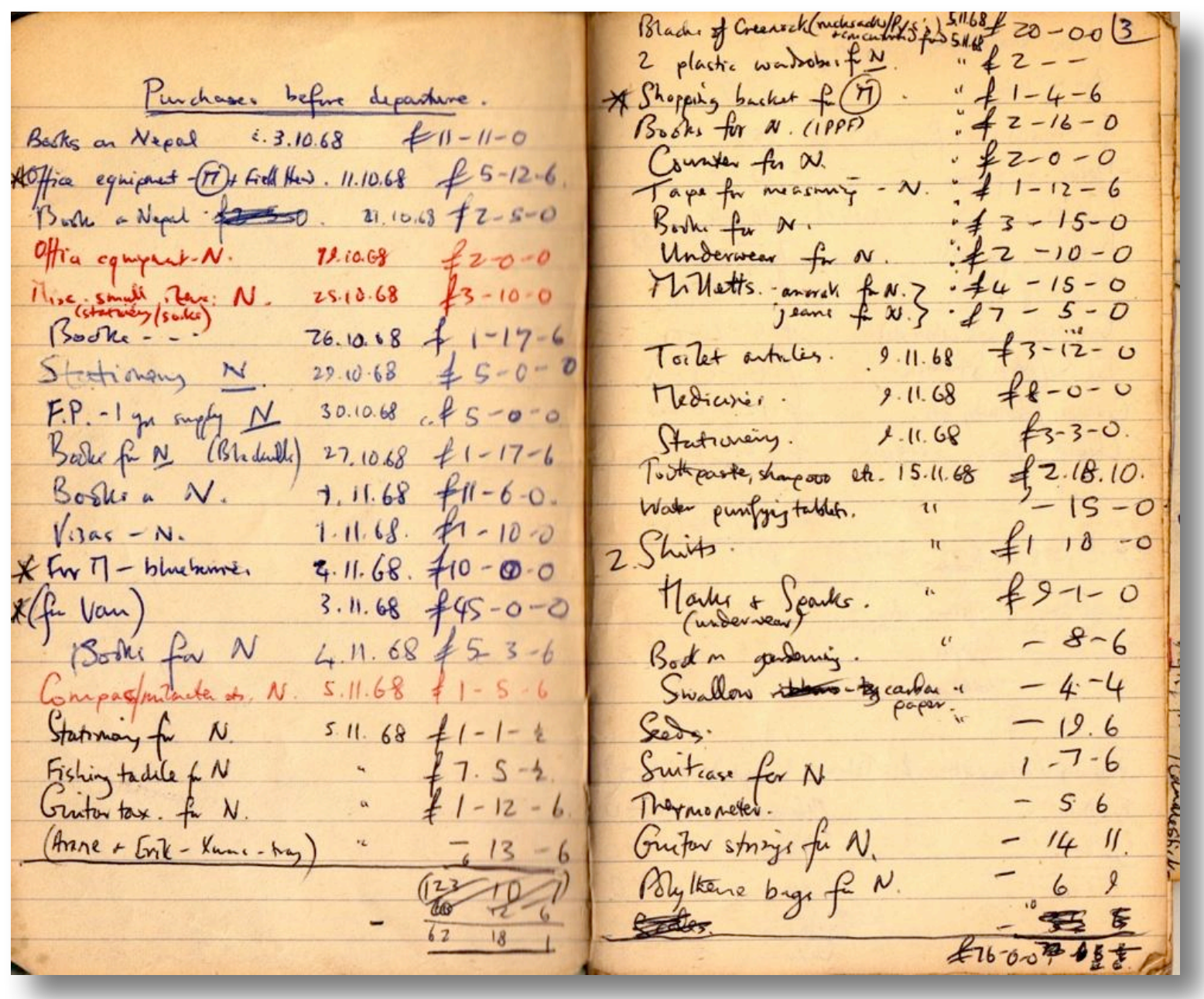

Although I always went to my fieldwork by aeroplane, even in the later 1960's it still felt, going from England to a remote village in Nepal, as if I was making a major expedition. This feeling persisted into the 1990's. The diving down into a different world could happen slowly 
as in 1968. The shock of arriving in Delhi and spending a few days there, was succeeded by a stay in Kathmandu which still felt like a medieval city, and then a week in a small town in central Nepal where there was no electricity and only a handful of cars. The last day's trek up to the village was the culmination of a process which felt like going back five hundred years in time and to somewhere in outer space.

Each stage was also made indelible and protracted because in those early days (and still in certain parts of the world) there were various 'gate keepers', local officials, academics, experts, who could grant or withhold permission to proceed to the next stage. So it was never certain that we would ever arrive at our goal until we actually reached it. "There" was always a possible, slightly hazy, target and we might easily be deflected or blocked. It was all rather anxiety inducing, especially as the arrangements for transferring and carrying money were primitive and we had little money with us.

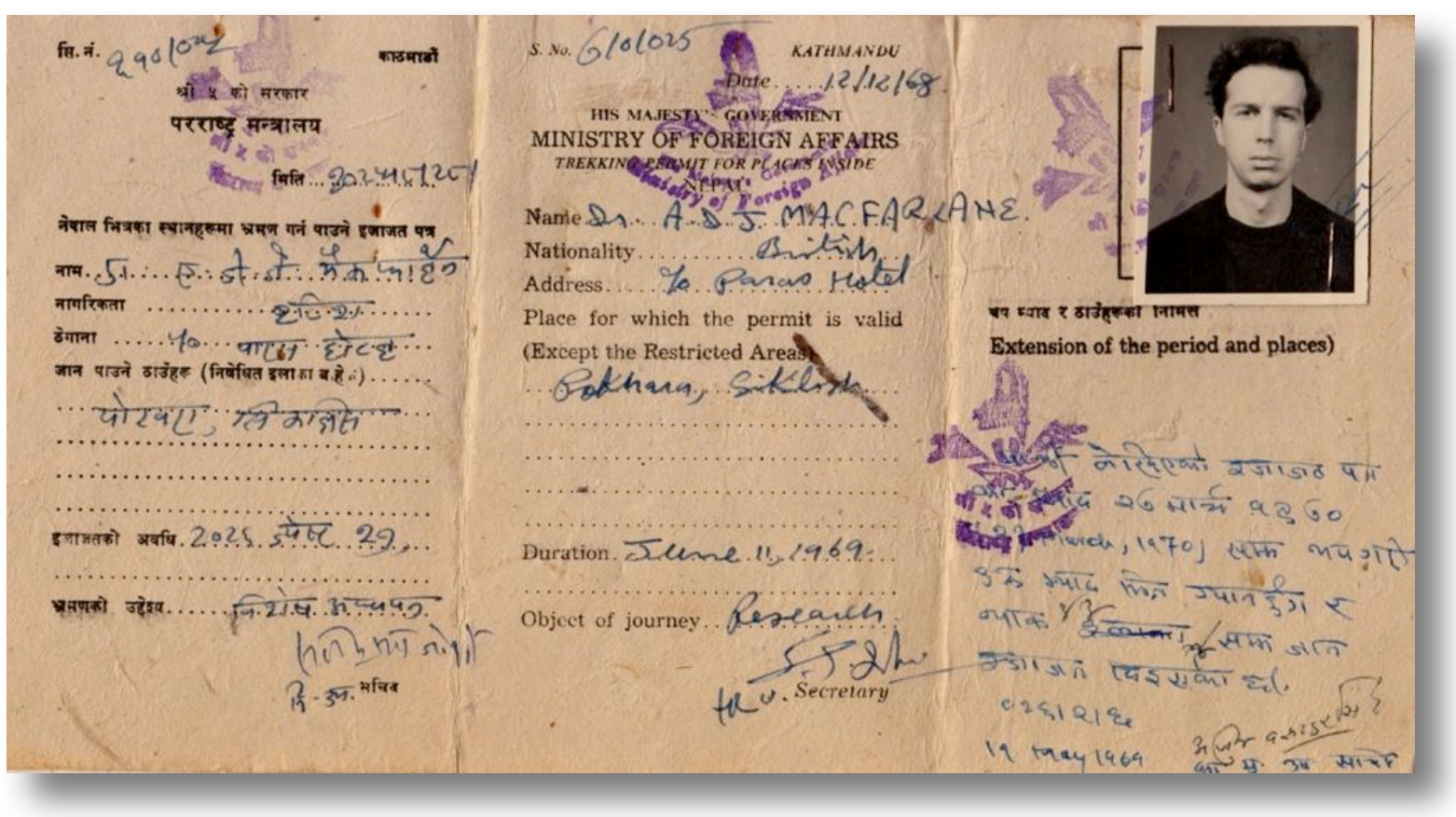

And along the last stages, from Kathmandu onwards, because there were so few shops or basic stores, we were also trying to work out the things we would need for a prolonged stay in a remote village, lamps, torches, medicines, basic foodstuffs and sleeping gear. If we missed the opportunity to obtain these at the right moment, months of discomfort or even danger might ensue.

So by the time we reached the village we both felt utterly exhausted - and already much changed by the experience. We were so far from any familiar roots or of anything we had previously experienced. It was similar to going into one of the 'total' institutions or asylums of which Goffman wrote. We were stripped of much of our outward shell and entered a new world culturally almost naked and with little of the enclosing cotton wool which surrounds us in our own familiar world.

If the process in the past was one of compression and de-compression through time and space, all this still happens, but when we now go to Nepal it is different. We know where we are going, we fly in a few hours to Kathmandu and stay in a familiar hotel and meet friends and then go on to other friends and familiar surroundings in Pokhara. There is a motorable road up to the village. It is really as easy to get there as going to parts of Scotland. 
Yet I suspect that many younger people going out of for their first fieldwork actually go through some of our first experience, even if in an age of the Internet, mobile phones and massive globalization there are few places one can go to which will now give one the immediate sense of shock which we experienced.

Another way of thinking about the experience of fieldwork is to think of it as like learning to swim. The aptness of the metaphors of learning the various useful strokes, the shock of immersion in a sometimes cold and alien element, the way in which all of one's body and senses are challenged, is obvious. But here I just want to mention another aspect of my own experience in both cases.

When I learnt to swim, the great break-through was when I realized that my body was naturally buoyant, when I learnt to relax and to float. I found I did not need to struggle, to paddle furiously, to fear drowning. I could stop striving, surrender myself to the water and just lie on the surface and enjoy the feeling of weightless security.

It is the same with fieldwork. At first I think I feared the thought of failure, was wary of letting down my guard, jealously guarded my privacy and my principles, felt suspicious of overtures of friendship. I felt I could easily drown, and there was a panic that I would never collect enough material upon which to base my Ph.D.

I had survived boarding schools from the age of eight by striving and pushing as hard as I could. There was a tendency to feel that only through struggle would I do so in Nepal. But gradually, I recall, I relaxed and the fear of failure or cultural suffocation dropped away.

As with swimming, it is worth remembering that the people with whom you are living - or most of them - will support and advise you on how to swim. It is in their interest, and a matter of self-satisfaction, if you enjoy yourself, can communicate with them, and can perhaps share some of your own knowledge and contacts with them. So they will want you to succeed.

So if you have any problems in understanding how to behave or what you should say, there will be people around whom you will learn to trust to give you good advice - 'mentors' in the modern jargon. Furthermore, by being dependent on them, as a child is dependent on an adult, it will help to make what might otherwise be an unequal relationship - at that time certainly I was potentially richer, more cosmopolitan, better educated - into the balanced relationship without which true communication based on friendship and mutual sympathy and empathy is difficult.

You will become an apprentice, and once you have served your apprenticeship you can be an effective ambassador, mediator, observer and recorder of the culture. They may be proud of you and you will become enmeshed in their world. 


\section{The Voyage Out}

In 1968, even reaching a remote Himalayan village was an adventure and took a good deal of time and effort. It was also full of a number of culture shocks, for Delhi, Kathmandu and then Pokhara at that time were enormously different from what we had experienced in Britain. The experience was like going through various rings of experience, a change in time, space, sights and smells, language, culture which gradually, as in entering a cold sea, acclimatised the body to a very different world. This first part of the rite of passage, the disaggregation from one's own world of assumptions and experiences, before the liminal period in the field, is often overlooked in accounts of fieldwork, but is an important part of the experience.

I will give a few letters and notes to show something of what we experienced.

We left England on Tuesday 3rd of December and flew to Athens. Our stay there is described in letters, and also in a short set of notes made by Gill as follows:

Here is a set of notes by Gill about the journey.

\section{ITINERARY LONDON-KATHMANDU}

DEC 1968

Dec. 3/68. Arrived Athens approx 6 pm. Glimpsed Acropolis from bus window after finding hotel in Plaken we went as far as poss up to Acrop(olis) - balmy moonlit night, columns glistened away under arc-lamps. Only other people there - police raiding place with searchlights. Their shadows crossed the pillars as they ascended - Greece 1968?

Dec 4/68. Visited i) Archaeological Museum - quite stunned by of tombs and could not get back enough to B.C. in one's imagination to appreciate anything. Smallest \& largest things thrilled me most - finds at Mycenae - gold pins with "spirited reproduction of goat" (G.B.) libation cups with figures dancing on their sides - \& the famous gold cups (C5 B.C.) depicting beautiful bulls which made even me admire them! Large objects - archaic sculpture - huge amphora (burial) orange \& black with 13 mourners depicted on it. Huge free-standing Kneises )c 520B.C) impression of striding out wonderfully caught - modelling on left leg perfect. Superb thing of course is the Poseidon Zeus (c 460 B.C.) - bronze salvaged from sea in 1928! To have remained intact all that time! The head - expression of stern arrogance I found most impressive $-\&$ Alan the balancing of the feet \& the aim of the arm. The other glory which one could gaze at for hours was Relief from Eleusis (440 B.C.) large slab of marble with 3 figures Demeter giving the ears of corn.

[There are another four pages to the same effect - and the small account ends on fifth December. still in Athens and visiting the Acropolis.]

We then went on to Delhi where we stayed a few days, as described in the following letters, and then on to Kathmandu.

We then flew to Kathmandu, where we arrived on XX and spent ZZ time there, buying necessities and getting permission to move on to the smaller city of Pokhara.

Are there any photos or other memorabilia for this stage?

To her parents from Gill on Friday 13th December 1968, Kathmandu

We are now in Nepal at last, and have been in Kathmandu since Wednesday]when we flew from New Delhi. The flight was quite exciting as we had good viewes of the Himalayas, and especially of Mount Everest and Annapurna - the latter is the one we hope to settle under. The mountains surround the plain of Kathmandu, which seems to be in the middle of a U shaped valley - they had a bad earthquake here in the 
1930's so maybe the valley was originally formed in this way. The valley is quite flat and seems to be well irrigated and farmed, although the actual city of Kathmandu is very dusty and quite hot in the day time, with a rapid reduction in temperature at night. Again the city is hard to describe - quite different from India and with a corresponding difference in the people. They seem to be apparently much more gentle, smaller in size, and somehow more ingenuous than the Indians. I think industrialization has hit them less with corresponding education, medical care etc. They only opened up to foreigners in the early 1950's so their tourist trade is only just beginning. I find less begging and poverty than in India, which is a relief, as that was emotionally wearing in New Delhi. Houses are quite sophisticated - built of wood, sometimes with elaborate carving, two or three floors in height. On the open bottom floor they keep their shops and their animals - shops are frequent and they seem to love their druggist's stores, filled with brown painted wooden cupboards filled with dusty packets for heaven knows what diseases. We managed to get some anti-sore throat mixture, as we have both started colds, and Dispirin and Enterovioform, which is for stomach complaints etc. They also have endless shoe shops, textile shops - most of the women seem to wear saris if they are fairly well off, as the Indian influence is quite considerable here.

The most beautiful shop I saw last night - which is the favourite time for shopping (they stay open until at least 9pm) was one filled with yard high candles - fat and brilliantly coloured. They had lit some of them, and the colours in the darkness, red, orange and yellow, with the tiny shrivelled woman, walnut brown with dark plaited hair and ornaments in her nose and ears who was selling them, seated in front seemed to epitomize the place. They probably use them for special Buddhist festivals - temples abound in the streets, most in pagodalike shapes with the ever watchful eye of Buddha painted on all four walls, brightly painted and most elaborately carved - mostly with the animal representing the particular god the temple is dedicated to - monkeys, elephant etc. I think I will look at them properly when we next come to Kathmandu, which will be in about 3 months, as then I will have learnt something of the religion, which is especially complex as it seems to be unique in that it is an amalgam of Hindu and Buddhist. The other striking fact on the streets are of course the cows, which wander quite happily around, less bullock-like than the Indian cows, somewhat like our Jersey cows. Last night I bumped into a magnificent black bull, who did not seem to mind and seemed quite impervious to humans! You can imagine my original reaction, knowing my love of the beasts!

We seem to be quite luck in our hotel (Paras Hotel), our room has an adjacent bathroom although there is no running hot water. You order it about 15 minutes before and they bring it up in buckets. The Western type lavatory was a relief, as I think this will be one of the problems in the village. However, Alan thinks he can rig up some kind of lavatory with the help of hydrochloric acid etc., that is if we can get the latter in Pokhara which will be the next biggest town to our village. We intend contacting the hospital there so they might be able to help us in that direction. We fly to Pokhara next Tuesday, and hope to be in the village in about ten days from then. The hotel people here do not seem to think that it will be difficult getting a local house.

We have seen quite a few other Europeans walking round the city, a lot of them hippies. We were stopped by a Nepalese sales man telling us where we could get drugs free with milk as well! The people as a rule don't like them as they say they are dirty etc. and they do seem pretty filthy and fed up. It must be difficult not having a base of a quite cushy hotel as we do, as apart from the main street the streets are just mud, the houses very close together and leaning over towards each other with people spitting generously from their windows - this seems to be quite au fair here - in fact we heard one girl say that they spit less than in Hong Kong where she was for a year! In fact, away from the main street and the cars which poop endlessly, the general impression is exactly like that of a C13 English village - I can quite imagine York in 1260 looking like Kathmandu 1968! The smells are quite well under control however, and for that it is relatively civilized.

We are both looking forward to getting to the mountains already however, as everyone says how beautiful they are, and the picture postcards they have sold us make them look like Swiss Alpine pastures! We have managed to get our extension visa today - at least Alan has, after a three-hour stint at the University getting letters of acknowledgement, and then another trudge to the Ministry of Foreign Affairs. They seem to have an intense liking for the most complicated of bureaucratic procedures, it is like a mock-up of the British Civil Service three times over!

We went to the British Embassy as soon as we got here, to learn that our rucksacks that we had sent by air freight has arrived safely, and had been picked up at the airport for us, but that the diplomatic bag we were 
pinning so many hopes on probably would not work, as they are thinking twice about sending letters through it even Embassy staff have difficulty - and that books would definitely come through the sea diplomatic bag, which takes anything up to five months. This will probably mean that all Alan's little parcels left in you care will have to come this way - and then they have to get them out to Pokhara, and then to the village. As for letters, we think that you will have to send them normally via air, probably to a poste restante in Pokhara - we will let you know definitely in the next letter or so. Alan is a bit worried about his grandfather but of course we cannot do anything at this distance, and this is going to be one of the hardest things to face up to. The other thing that will be essential is keeping well - we are taking all the precautions necessary against dysentery etc. but even so my tummy was upset this morning and I stayed in bed. it seems to have cleared up however as I went out this afternoon to look for meths for a lamp we've just bought, which we will need in the village as I don't think that even parts of Pokhara have electricity. Kathmandu has had it for 15 years. Alan thinks it will be better in a village as we can supervise our own food and treat and boil all the water we have to use. I am already getting used to living on a largely vegetarian died, and to not eating so much! We have seen beautiful hens and cocks for sale here, though, and hope to be able to rear them in the village. Eggs seem quite plentiful at the hotel, and we have a sweet little pseudo European breakfast consisting of two eggs (half boiled) and cornflakes which I think were in England around the war time - called 'Life' - do you remember them?

I think it is likely that we will have to borrow some money from you in these first few months, because of the initial outlay we are having to make in the beginning. Once we are established in a village we should be able to live very cheaply. Alan is not here at the moment - he is also trying to contact an American who is studying the tribe we are doing - the Gurungs - although linguistically - so I don't know how much this will entail, but when we discussed it briefly last night it will definitely only be a loan, and then it is not certain that we will have to ask - I'm only warning you! .

I then wrote my own account of the journey the following day.

Paras Hotel, Kathmandu, Nepal 14.12.68 From Alan (to all members of his family)

\section{Dear All,}

Before I begin, perhaps I'd better explain that I am sending one copy of this letter to the croft, one to 'Bryher', partly as an insurance against loss, partly because we don't know where you will all be spending Christmas. But to whoever eventually reads this HAPPY CHRISTMAS! Mummy and Daddy will know how hard it is to imagine you all sitting round drinking and eating christmas pud with the wind howling round outside when one is sitting amidst the dust and sun out here. But we will be with you all on the 25th especially E will drink a toast to you - even if it is only in rice beer or sterilized water!

So far we have had no news from England, so do not know what all your plans are, or Grandpa's state, but are, naturally, keeping our fingers crossed. It seems that the diplomatic bag is not very good for letters so it might be best to send them by ordinary mail if you could. We will send you our permanent address in our next letter. Could you therefore stop sending letters in parcels through the diplomatic bag, Daddy? We will send money for all stamps etc. shortly. Incidentally, I am sending off an exposed film [SEE FILM] along with this letter (of the Taj etc.) to the croft. Could you let me know how it comes out, but keep the slides. I hope the film sent from Athens arrived (Annie). I don't yet know if the camera works. But enough of business. Longing to hear new from you all, but until we do will concentrate on our own doings.

You will have gathered from the above address that we have almost reached our destination. We arrived here safely on Wednesday (hope you got our p.c's from Athens and New Delhi). All our luggage arrived intact and even the two knapsacks we sent in advance had arrived before us. The only thing to suffer, and that only temporarily, was the thermometer. Even the guitar, fishing-rod etc., were o.k. At one point we thought the camera was a gonner -we saw it disappearing down the road in a taxi we had hired to Teheran airport, having forgotten to take it out of the taxi. But the driver fortunately came back. Not even the biros leaked.

The actual flying was most luxurious and pleasant; meals on every flight, even on the one from Delhi to Kathmandu and most comfortable. The only snag was that one had to get up at about 4 a.m. to get to the 
terminal to arrive an hour and a half before the plane left. The hours we sat in those awful, nervous, sleek and expensive 'Transit' lunges were almost more than our flying time.

After the succession of such lounges and smooth airports it was quite a shock to arrive at Delhi, to see beggars, feel the temperature of 85 degrees and to find the whole place in shambles (partly the result of rebuilding). The official notice pointing to 'Gents' led to a pile of rubble, so ended up, as directed, in a pitchblack 'ladies' toilet!

When we got outside, about six boys struggled for our luggage, carrying it off in all directions $\mathcal{E}^{2}$ it took about fifteen minutes to sort it out. It felt like the description of the Durrell's arrival in Corfu at the beginning of "My Family and Other Animals". But I am jumping ahead in our journey.

You will have gathered that we enjoyed Athens. From our nice 'Pension' we did most of the obvious tourist sights, Acropolis, Byzantine Museum, Temple of Olympian Zeus, Agora, Theseion etc. Our last day was particularly nice, eating our sandwiches surreptitiously among the stones beside the Parthenon, the sun pouring down and, in the distance, the sea. In the evening we went to a Greek restaurant and sat, conspicuously touristlike, listening to three guitarists playing Zorba-the-Greek type music.

In Athens we first met with the signs of the struggle between motor-cars and pedestrian which has become almost the most unpleasant feature of our travels: endless pooping of horns; bad in Greece, worse in Teheran, aweful in Delhi and terrible in Kathmandu. Talk about the peace of the East! Diesel fumes and claxon horns make London seem a quiet paradise.

So we moved on to Teheran, still chewing our enterovioform tablets and trailing our eleven different parcels, guitars, tape recorders etc. with us. Teheran was the least pleasant of our stops. A mushroom city, built on the bubble of oil. Surrounded by stony desert, its streets muddy and thick with cars, its suburbs full of factories, it was made even less attractive by the rain or drizzle which was falling when we arrived; an unusual phenomenon we were told. Our hotel backed onto a night club and our first few hours of semi-sleep were disturbed by tenor saxophones etc. The following day we hurried to the bus-stop for Isfahan (a 7 hour journey) only to find that we had missed the bus by five minutes. Cursing ourselves, we spent the rest of a fruitless day trying to find a mosque at a nearby village. Misdirections and incomprehension sent us scurrying off to various distant villages, but we never found teh mosque. Our lunch we ate near a rubbish dump, but some nice mountains could just be discerned between the oil storage tanks in the distance.

New Delhi was, in contrast, incredibly beautiful - or rather the country round it was. On arrival we were immediately directed to the new (3 year old) and very luxurious IMCA tourist hostel. It cost only 40/- a night for a double room and breakfast and was spacious, very clean etc. A huge place. We did some shopping, wandering round Old Delhi, visited the tomb of Hanuman, the mosque opposite the Red Fort, and the Red Fort itself. At the last of these we watched an extremely vivid and dramatic son et lumiere on the history of the fort, full of the sound of charging horsemen, wailing masses being massacred, and the seductive singing of courtesans. The show was brought to a rousing end by an account of the monstrosities of the last tyrants - the British. I must say it was extremely well done E, along with Faitiphur Sikhri and the Taj, made me want to learn more about the fantastic Mughals and especially Akbar.

They must have been quite incredible, the mobilized 20,000 people for ten years to build the Taj: it took the Greeks 400 years to complete the Parthenon. It took thousands and thousands of elephants and camels to carry away the silver and jewels from the Red Fort when the Persians invaded it. But you will all know this .

We spent one day going to Agra. We went third class on the Taj express and consequently saw quite a bit of Indian life, though it was a very good train. We also went on the 2 nd class bus tour with an extremely competent and nice guide. The buildings were staggering $\mathcal{E}^{2}$ defy description here; the Red Fort, which we saw in the mellow glow of evening was especially impressive with its contrasting marble and sandstone. the Taj itself does not need my praise.

During the last day in Delhi I developed a streaming cold and wandered round with roll of toilet paper blowing vigorously as the sun beat down fiercely. Probably it was the cold, but the filth and poverty, especially of the area around the Red Fort, finally got me down. It really is very grim and I doubt if there is any hope of improvement. Rather more and more people will crowd in $\mathcal{E}$ the children teem. Meanwhile rich Indians drive round pooping in their large cars $\mathcal{E}^{2}$ westerners, like the BBC correspondent who kindly had us to lunch, live out of the centre in huge and pleasant bungalows. 
I kept getting ideas of how to improve the place - one of the best I thought was to develop fish-ponds all along the side of the railways. There are already small ponds in many places, and the earth has been taken away already to make the railway. Such fishponds could then be serviced - patrolled, fed and netted from the railway. The fish could easily be taken to distant markets also. Along with a far more vigorous programme of birth control, this might achieve something.

A similar two-pronged attack is needed here in Nepal where the problems, though on a mini-scale, are the same as India's in a number of ways. Gill will describe Kathmandu much better than I can. At present some of its original beauty is left -the temples, the carved wood of some of the houses, the incredibly beautiful face, the kindness and gentleness of the people. But it is rapidly turning into a min-Delhi with overcrowding, little sanitation, incredibly filthy children, the seeds of begging etc. Tomorrow we hope to go out to a neighbouring village to do some fishing: this evening we went to the film 'Some lit it Hot', by the gracious permission of the U.! made us homesick. In two days we move on to Pokhara $\mathcal{E}$, within the next weeks, to our village. Please forgive a self-centred letter. Lots of love, Alan \& Gill

\section{Gill wrote from Paras Hotel, Kathmandu, Monday 16th December}

\section{Dear Everyone, Everywhere,}

I have just come back from a dusty trudge to the British Embassy, and there were no letters from home, so it looks as though the Diplomatic Bag is going to fail us and it would be better, as Alan says, to send letters by ordinary air mail to a poste restante in Pokhara which we will give you in due course. It was a relief to get back to our relatively sophisticated hotel as the heat was beginning to hot up, and the dust to get more dusty and the cars more honky - even the bicycle here! I daringly ordered an orange squash from the hotel and felt I was having an unheard of luxury - Alan came in when I was in the middle of it and said I looked most guilty - so I thankfully offered half to him! It is amazing what leaps up to being a luxury - we bought some extra sticky peppermints in Athens and quite mourned the last one we chewed in Kathmandu!

I am just about to begin to get used to Nepal, probably because the tummy upset I have had for the last few days has just about cleared up. We were both sorry to leave India as I think to Alan it had something of home about it, and I was just beginning to absorb it when we had to fly on here. It was much more beautiful than I had ever imagined and I think it was the element of surprise that made it like that - a scarlet sari suddenly emerging out of acres of grey-brown allotments on the road from the airport, with a slight breeze moving the folds and making the wearer even more graceful; the creamy white herons and storks beside the mud trampled water holes paralleling the railroad to Agra; the emerald green and blue birds rushing from dusty tree to dusty tree beside Humayun's tomb and finally the Taj of course - its white coolness a fantastic relief after the miles of endless, flat pulverized plains surrounding it.

Most of all I think I enjoyed the fort at Agra more than anything - partly because I didn't know it existed, and secondly because it had such a lush variety of architecture which again contrasted with one another. One could have studied one marble pillar for hours what with the inlaid gem work, and the marble reliefs - endless lotus flowers most exquisitely cut out of the rock - and then there were the Persian scripts traced in black marble and a thin I couldn't get over - the perfect symmetry and the loving attention to detail - I sound as if I spent the day bounding about enthusiastically from stone to stone, but the 8r' prevented that! I guiltily became a real tourist and bought a peacock fan for one rupee, and still loved it even when a garrulous Bengali (Alan thought) on the train told us we could have bought three for one rupee!

In New Delhi I enjoyed the Fama Masjid mosque most of all - we managed to see it just before the sun went down and you will all know how effective the outline of buildings, especially onion-domes and minarets, is against the orange flush burning out all the lower horizon. Sunsets in India are most dramatic and I was just about getting a glimmer of how spell-binding it could all be when we flew last Wednesday to Nepal.

The airport seemed to consist of one clay parapet and one clay booking out office where one official stamped our passports, gave directions about hotels, answered questions re luggage and was generally the whole airport rolled into one.

There were endless Nepali hotel keepers outside waving credentials about their "superb and elegant" hotels, and lots of little boys all pretending to be four years older than they really were and saying they could take "all" 
our luggage (by this time it consisted of about 8 dusty and lumpy pieces all weighing a ton) as they were "bigstrong" - this from an 8 year old charmer who just reached my nose in height when I was sitting down talking to him! The children are gorgeous, even though very dirty with endless runny noses and clothed in filthy westerntype dresses - at least the little girls.

Generally the people seem to be very tiny - especially the hill people who we see coming in from the surrounding countryside carrying fantastically heavy burdens, the women having a wide cotton thong round their foreheads which strains down over their back and carries the sack inside it. Usually, the men have a bamboo cane swung over their shoulders with weighted baskets suspended from either end. I saw one this morning tottering towards the Embassy, carrying two wooden office desks and two matching chairs this way.

On our first evening here we went to do some elementary shopping, as the place is alive until about 9pm. Their shops are the lower storey of their houses, which are sometimes up to four storeys high, and one has to step up and into them as the lintel is low and sometimes elaborately carved. At other times it is covered in yellow or red pigment which is echoed on the foreheads of the Buddhas sitting at the centre of the temples, which abound.

The actual shopping space is about 4 yards square, and the shopkeeper squats in the middle, occasionally smoking a hookah and then spitting energetically into the half-cobbled streets. They sell shiny stainless steel cooking ware, ribbons and household things like - believe it or not 'Surf and Pears soap - in this way, and the most beautiful shop I saw was guarded over by a very old woman selling tall, fat candles of the most gorgeous colours - orange and red and yellow, which they must use at special festival times. She was walnut-brown and wrinkled, wearing her long black plait threaded with bright red cotton and the ornaments in her nose and ears shone in the light of the candles, some of which were lit.

There are other more sophisticated shops - mainly druggist stores which they seem to love, and which house yards of chocolate-brown cupboards, cased in with glass and housing the dustiest packets imaginable, brown constipated looking things that look as though they have been here since the revolution! (1951).

We have managed to get Entero-viaform and Dettol though, so we were pleased about that. The most avant-garde shop is called "The Blue Bucket" and has two appropriate dust-smothered enamel buckets hanging up outside, and here they claim "to sell everything, madam" - and I think they do. We bought a beautiful kerosene lamp there, but the only snag was that the one thing they didn't have was meths or kerosene, but we hope to get that in Pokhara. The only other snag about the Blue Bucket was that the boss was most nervous and had a twitch and of course Gill was quick to draw the moral - a push Kathmandu straight back into the middle ages. Business success still sticks out like a sore thumb here the only well-lit building is the Nepal State Bank, and as it shines out at night shouting its conspicuous consumption we wondered what the tiny, rat-infested, lamp-lit houses at the centre of Kathmandu

We had our most successful day here yesterday - interestingly out of Kathmandu. Alan chatted up some of the locals and heard there was a good fishing river, where one could swim as well, about 30 miles to the east of the city and it would take about an hour in a local bus. We got up accordingly at 6.45 a.m., staggered to our hotel breakfast, which has a background of Mike Holiday and the Beatles, and ate 'Life' cornflakes and two 'half boiled' eggs without an eggcup, and then went to the bus which was a blue and white, gaping at the seams affair, asking 8 people if it went to 'Dolalghat', they all said 'yes', but they always do, and clambered in. the only other Europeans were a German couple from the Peace Corps and we were much glanced at, especially by the women. Three hours late we came indeed to a large swirling river, with steeply rising banks covered in thin red soil and scrubby vegetation. This was Dolalghat and we spent an idyllic 4 hours here, Alan fishing and catching one baby mahseer and a light sunburn, and me reading about Gandhi in the shade, and then later paddling in the swift, bright-green water and generally frightening away the fish for Alan to catch! There were some lovely star shaped red and white flowers and masses of butterflies - ranging from coalblack to blue and white striped.

The journey home was wonderful for me and grim for Alan as the driver told me they were 'full house memsahib! .but!' and he rushed to the front of the bus lifted up two bundles of rags, that later turned out to be the most ancient Nepalese peasants, and produced a stool from under their seat, $12 \times 4$ "in shape. this he plonked beside his driver's seat, so the right so that every time he spat or gurgled through the window, or shouted rude things to drivers going the other way or alternatively handed them spanners which they thought the bus 
might need he had to lean over me and beyond. this was all rather nerve racking as the road itself was hairpin bend after hairpin bend, with sheer drops to one side and sheer cliff the other. However the view was a triumph - small brown hills surrounding the Kathmandu plain in the foreground, every inch channelled and carved into ridges for the crops and then the Himalayas in the distance, a whole jagged range of them with snow covered sides which turned bright pink and purple when the sun was setting.

Alan had a bad time of it, as he had scrabbled into the back of the bus, where there were 20 Nepalese already, clutching three sweaters, picnic bag (with tin opener) and his fishing rod, still with the bait stuck in the handle. At one point he thought he rod was going to shoot a hole in the ceiling of the ancient bus, and he hastily dismantled it and gave one of the sweaters to a shivering Nepali whose arm he had gone to sleep against! the only time he saw the viewes was when the bus stopped for various spitting exercises, and for a little boy to be sick and babies to be breast fed and for me to uncramp! We enjoyed the day tremendously and even tho we came back minus fish.

. We fly to Pokhara tomorrow and shall be thinking of you at Christmas time - I hope Grandpa is much better and that you all have a very happy time on the 25th-thank you, Annie, for gorgeous hankies which I found tucked into the rucksack safe and sound.

A very happy Christmas, All my love, Gill

We then went on to Pokhara by plane on Tuesday 17 th December. We flew as this was the only way to reach a small town which had no road contact with the outside world.

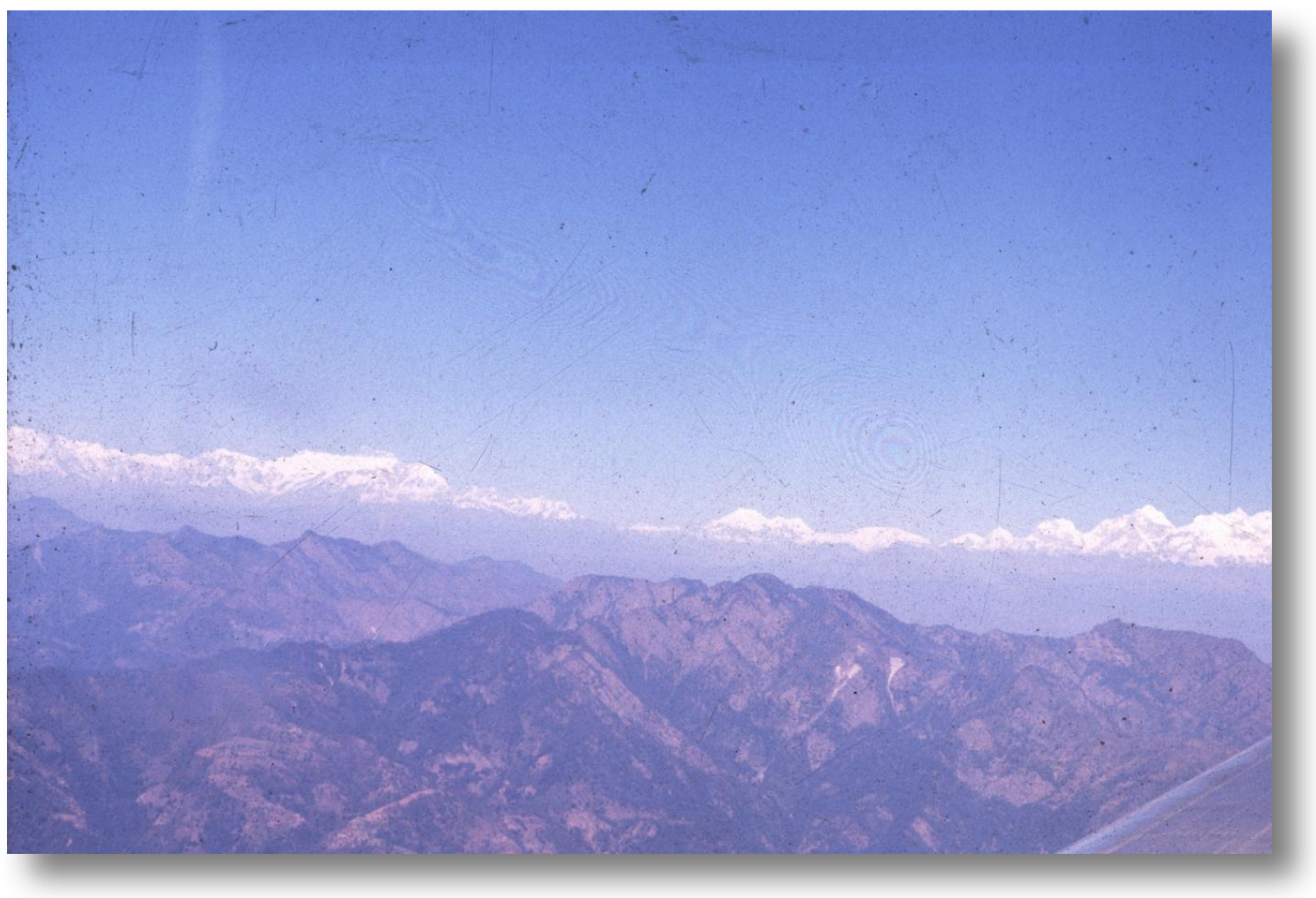

Looking out of the plane at the denuded hills on the way to Pokhara

We stayed six days in the small town that it then was, with only a very few taxis and three or four very rudimentary hotels, one of which the Annapurna hotel, we stayed at. 
.As you can see, we are one stop away from our village and at the moment Alan is seeing some official to get advice on which village we should choose, and which would probably be the most friendly. We plan to set off this coming Saturday (21st), taking about three Tibetan porters to carry most of the stuff, which has accumulated vastly by now, and one interpreter. The best area is about two day's walk away through the mountains, fortunately through the most beautiful country, so I should certainly lose some weight.

We flew to Pokhara on Tuesday, and we were both very relieved to get away from Kathmandu, as the dust and endless noise of traffic and bicycle rickshaw pooping of horns, in other words the great city was beginning to get us down. Also, I had a stomach upset there, which was only traveller's tummy and getting used to water etc., but was a bit depressing. We managed to get away on the Sunday and took a hair-raising journey about 30 miles east of Kathmandu on a local bus.

The road consisted entirely of hairpin bends rising it seemed almost sheer from the valley floor. The views were equally breathtaking though, and the people were delightful - I had a bird's eye view as the driver told me on the way back that they were 'house full' and unearthed a $6^{\prime \prime} \times 11^{\prime \prime}$ stool and plonked it beside his seat, on the right so I saw out of his window all the way. The only other Europeans were a German couple, who were Peace Corps workers so the locals were very intrigued by these weird pale foreigners. They were also interested to see if Alan had caught any fish, but we only managed a 9" one and threw that back in as the local people cutting firewood on the banks of the river didn't seem to want it. There were some lovely flowers there too, and butterflies and the temperature was about 800 at the hottest - Alan got quite sunburned.

The other most enjoyable thing about our stay was meeting another couple who have also lived in a Gurung village - which is the particular people we want to study. Alan heard of them when he went to the university and we went for dinner there on our last evening. They are a New Zealand couple (Jessie and Warren Glover) who are in the same line of research as fim Milroy - linguistics - only they did field work in it, learning the language phonetically and writing it down, so that particular dialect won't be lost. They are also interested in educating the Nepalese and this is the ultimate aim of their project. They only spent 3 months in their village, but Jessie took a 3 month old baby with her, which is more that I would have the courage to do! She was very nice indeed, and helpful about cooking hints and what herbs I could buy in the local bazaar. She was most relaxed and graceful, and wore a local Tibetan outfit, which was a long wrap-over dress made in some sort of tweed, which she said was most warm and an ideal maternity dress - she is having her next baby in March, and quite unperturbed about it. Apparently there is a very good obstetrician and the Kathmandu hospital - a Scottish one - so she was in good hands. They lent us quite a few of their notes on the language, and we are going to give them our notes when we collect enough together. They should be good to swap notes with when we go back to Kathmandu, which will be in about 4 months' time.

Pokhara itself is really just an enlarged village, and is important by the fact that it has an air strip, and there will soon be a road right through to India, which will ruin it, as far as we are concerned. At the moment it is just a long straggling line of orange mud, sun-baked houses, still with lovely carvings and tiny wooden framed windows. There are huge and ancient elm-like trees which give a lot of shade and where the tap for that particular stretch of houses is. Children are always playing round here, with the water or endless marbles, which the boys love. Older women collect the water in large brass urns, which they carry on their hips, with sometimes a child as well. Buffaloes also lie in the shade, and we can apparently have their meat every ten days in the village, as this is when one is killed. A real luxury is goat meat, someone said it even tasted like beef!

The other animal you most encounter in a walk to the village are about ten mules clustered together, carrying loads of firewood, and each with his bell around his neck whose sound floats through the air so you can hear it even at the far end of the village. The bazaar is a smaller version of the one at Kathmandu, and you sit on a stool in the shade and take half an hour to buy three tins of mackerel, brown rice and lentils. Everything is so relaxed and easy going that it is almost impossible to get flustered. Alan hopes to grow a lot of veg and some seem to do very well - the radishes about a foot long! .

We visited the main British run hospital here, the Shining Hospital, and they were most kind and have invited us out to tea on Friday. The clinic was packed out when we went, and they seemed desperately busy and we have heard they are doing very good work - I think it is some form of mission hospital and has been there for 
at least 12 years. There is a leper colony across the valley too, so it must have been quite bad at some time. The only lepers I have seen were in India. We have also got an invitation to lunch on the same day with an American couple who are also doing academic type work out here - a thesis on the economic effect of the road on Pokhara. They've been here for a year already, so are quite established.

There is a postcard, which I wrote to my grandparents.

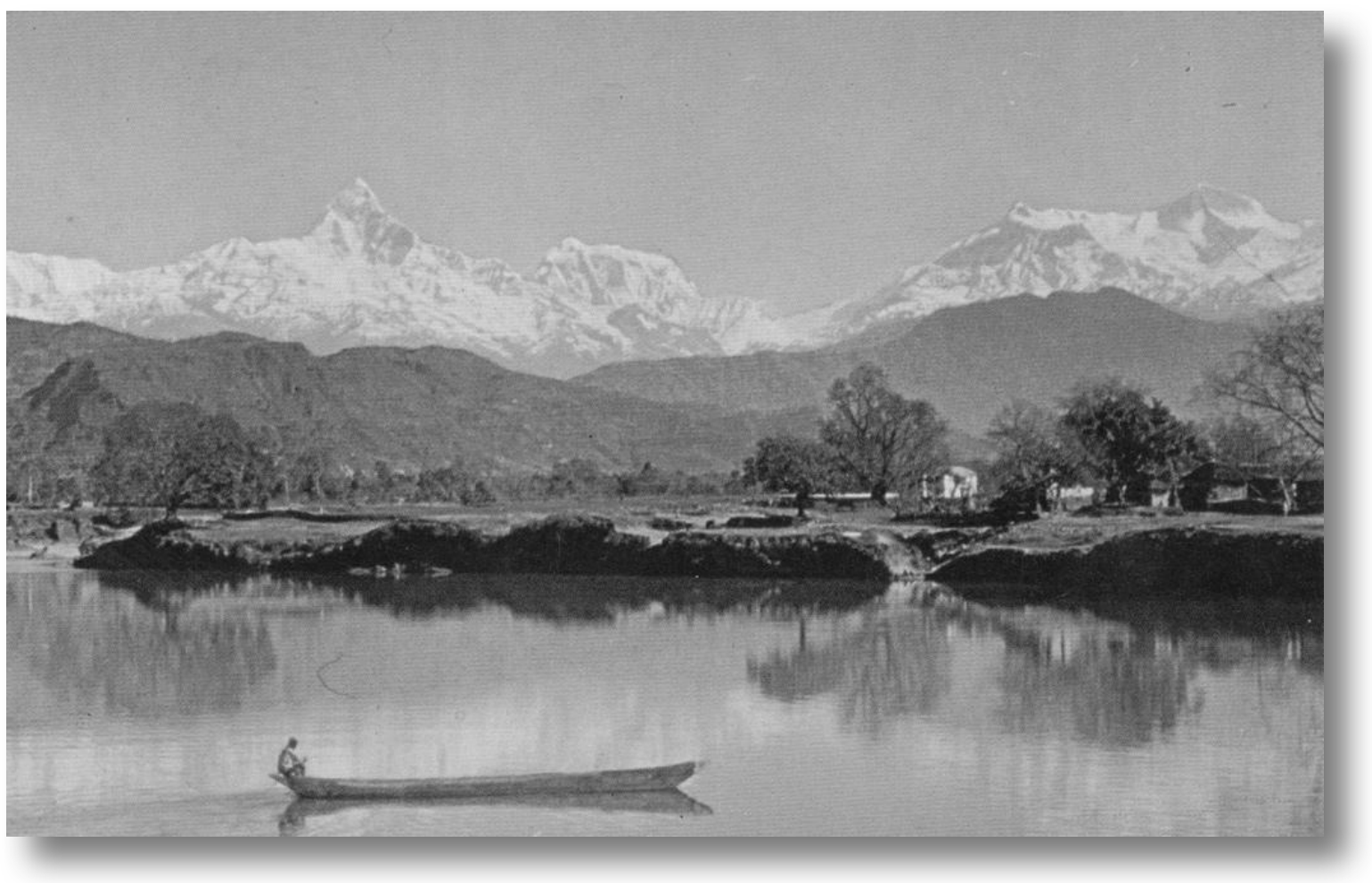

Pokhara, 20th December 1968 [My 27th birthday]

Dear $G$ \& $G$. (E everyone),

Hope you got our letter from Kathmandu $\mathcal{E}^{2}$ the letter sent off on the same day as this. this is just to give you some idea of the scene. We will be under the mountain to the right. Fantastically beautiful here - a very warm! Our permanent address is c/o BRITISH LIBRART, POKHARA, NEPAL. We are both fine here $\mathcal{E}^{2}$ hope all is well with you.

Lots of love, Alan and Gill

Letter to all family, including a carbon to grand-parents from which this is taken. Written in hand-writing c/0 British Library, Pokhara, Nepal 21.12.68 by Alan

Dear All,

Please forgive a short and hand-written letter, but we are just setting off in half an hour or so four our trek into the hills to find a village, so porters will be arriving, panting, soon. Also you should have got our letters from Kathmandu which will give you most of our news. the main purpose of this note is to give you our poste restante address which is as above. We will be coming down to pick up mail every 2-4 weeks, so don't expect prompt replies to your letters, but it would be lovely to hear from you all, all the same.

We arrived in Pokhara from Kathmandu on Wednesday and immediately liked the place far more than Kathmandu. The Himalayas are very close and are especially magnificent when lit up with a pink glow in late evening. Here the climate and vegetation is sub-tropical - with little red-clay, thatched, houses glowing 
between the palms and cactuses - all set against the vast, snowy mountains. You'll just have to wait for our slides to get some idea of it! At night it is cool, with innumerable stars clearly visible and the chirruping of crickets. In the huts pure oil lamps give off a steady \& warm glow. Friendly children and mule trains with jangling gong-bells are everywhere and tangerines, plum and juicy, are 10 a $1 /$-. We went up to the Tibetan refugee camp - an idyllic walk up a steep river valley, and admired the hand-woven Tibetan carpets. Could you possibly tell Annie $\mathcal{E}^{\mathcal{E}}$ Erik that we will be sending them a small carpet for their wedding present when our next grant portion comes in? I'm afraid it will probably arrive after the wedding. the Tibetans are a very astute, hard-working $\mathcal{E}$ good-looking people and the camp is not too depressing, though they are selling off all their relics.

I wonder how everything is at home? No news has seeped hrough to us yet. Yesterday, my birthday, we celebrated by going out to dinner at the poshest of the 3 hotels here - very nice (they even made me a special cake/pudding). Christmas we will be in our village. We don't yet know which village it will be - but have narrowed the choice down to three, all between 1-2 days walk from Pokhara. Will send a map in our next, which will not be for a month or so I'm afraid.

All our love E thinking of you often,

Alan \& Gill

(P.S. Am sending 2 copies of this as before to Bryher \& the croft) 


\section{Arriving at the field site}

We set off for a possible fieldwork site on Sunday 22nd December, but took the long, wet weather, route so that we did not arrive until Monday 23d. The first letter, written the next day, gives a detailed account of this traumatic journey and our first impressions of the village. We first arrived, exhausted and confused, in the village of Thak. There was then a period of very rapid readjustment to new food, sitting and sleeping arrangements, a constant audience of people watching, commenting, laughing and chattering in an unknown language. It is unlikely that young fieldworkers will now have such a strong physical and cultural shock. But be prepared for initial confusion. This is often what one feels going into a new, total, world.

Before that letter, it is worth including a couple of lists of what we took to the village.

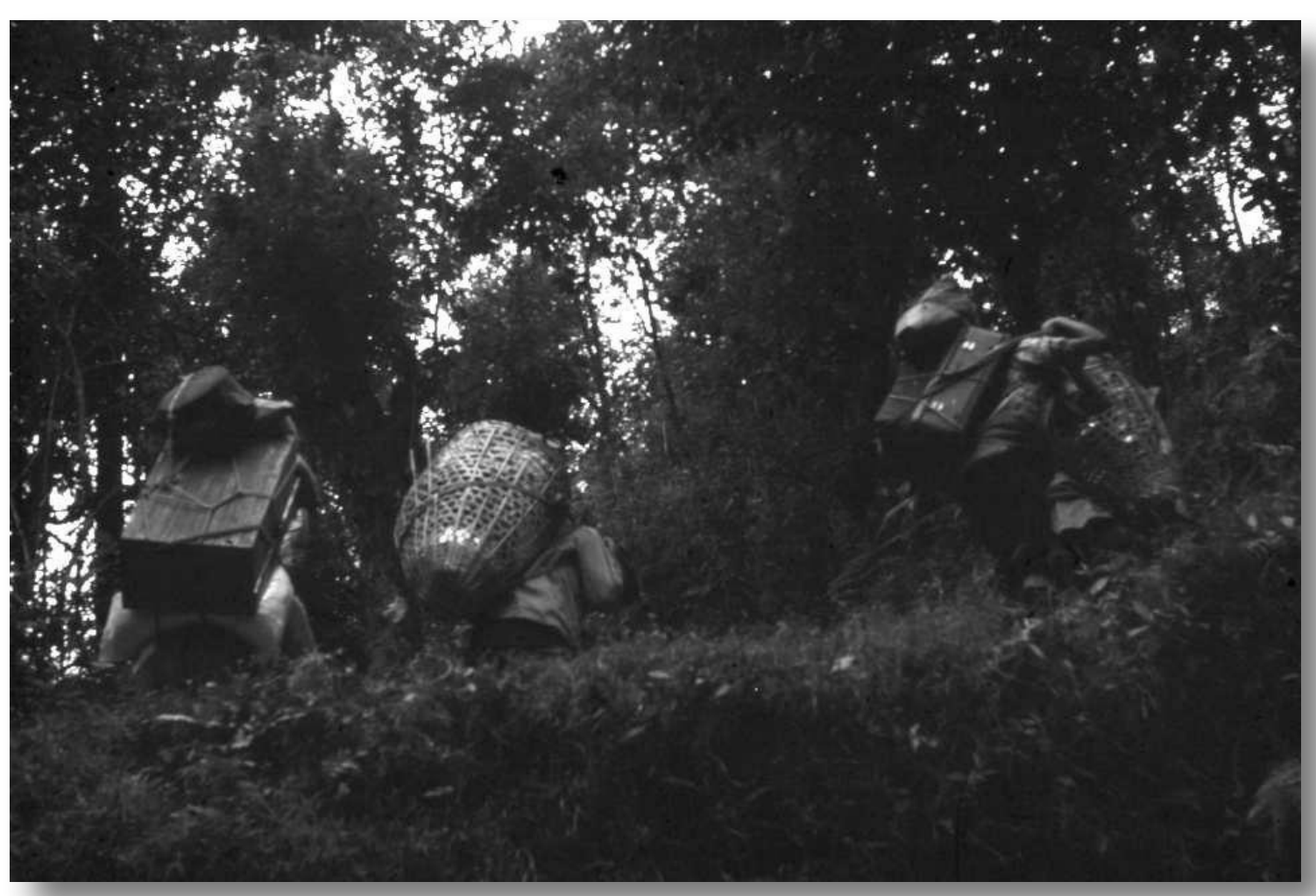




\section{Contents of blue knapsack.}

2 boxes of stationery.

2 plastic wardrobes.

2 small plastic bowl s. but no exuti ont

3 prirs socks.

7 handkerchiefs.

1 mirror

2 pairs py jamas.

I string vest.

1 pr. pants.

cotton wool.

t ampax cont ainer.

5,000 small cards.

8 pkts razor blades.

\section{dark green \\ Contents of rexay knapsack.}

3 pkts tampax

4 tubes toothpaste

8 toothbrishes 1 bex band-gid

2 boxes crayons 2 tubes large savion

1 spinning reel it tape measure ( $6 \mathrm{ft}$ )

1 reel of nylon 6 pkts toilet paper

8 pkts concentrated food.

4 pkts dried peas 1 box of 60 biros

1 polythane box

2tins shoe polish

1 compass/milometer/thermomexter.

5 books

1 box punched cards

1 counter

4 pall rs socks

I doz. pencils

1 pkt biro refills ( 36 )

1 biro (13 colour) Fishing tackle (gut/hooks)

2 typewriter ribbons

1 paint brush

2 vests.

1 roll celotape

2 pkts rubber bands

1 pen knife 


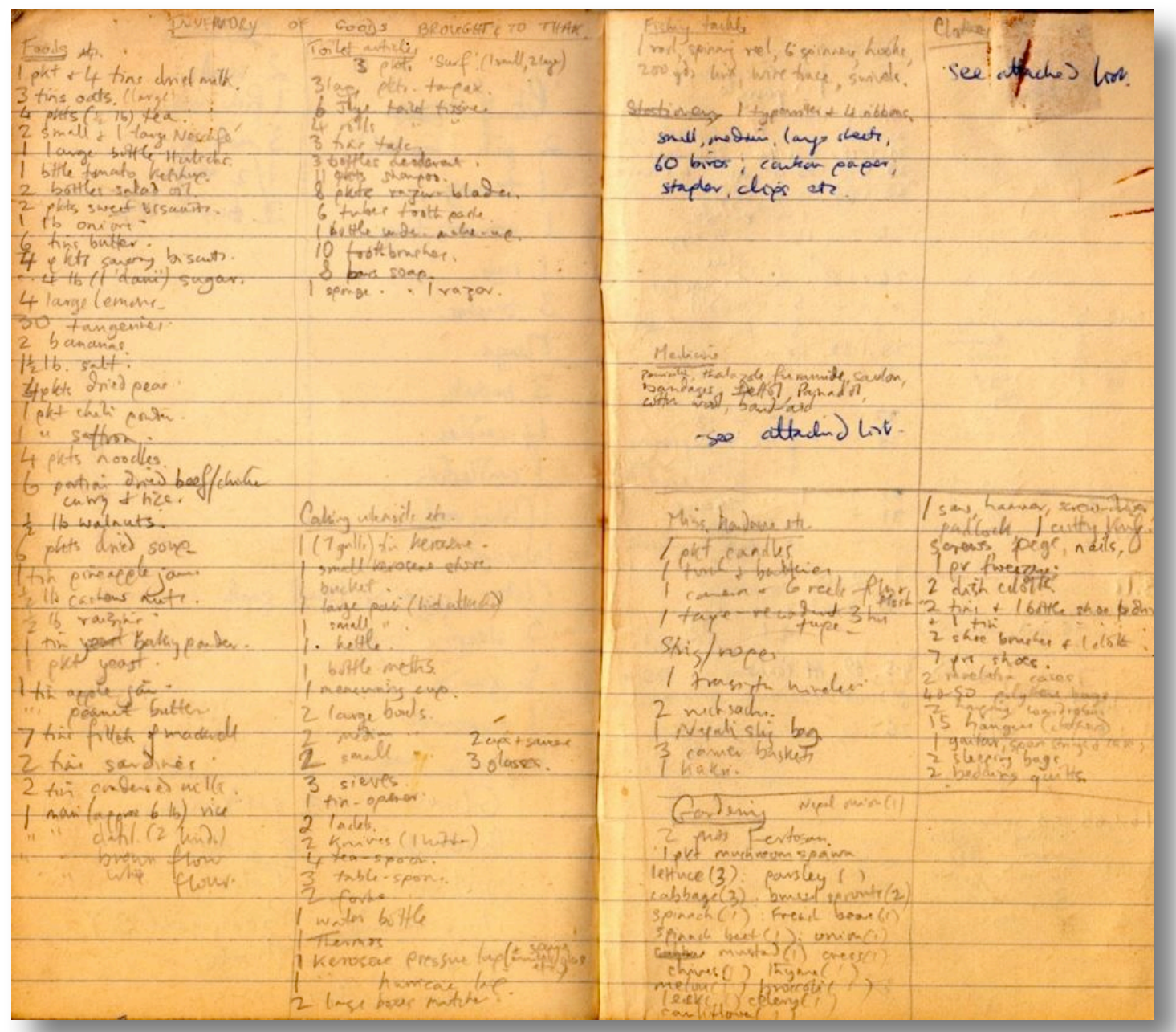

Inventory of goods taken up to the village

On the way up to the village:

\section{TAPE RECORDINGS}

Tibetan (Bhote), Nepalese and English - song and conversation. 22.12.1968

Starts with the porters singing in their Tibetan language. Then, it continues with a Nepalese song which also talks about the King Mahendra and the song goes as "radio bajai sor ramro...." They are also criticizing each other that the song wasn't sung correctly. Then a boy thanks (who?) for coming to look for them, in English and sings a song in his language. https://sms.cam.ac.uk/media/2732740

\section{English song}

Alan playing a guitar and singing an English song which goes as "Would you bring me a little water Sylvie."

https://sms.cam.ac.uk/media/2732757

Tibetan song

A lady singing a Tibetan song - https://sms.cam.ac.uk/media/2732774 


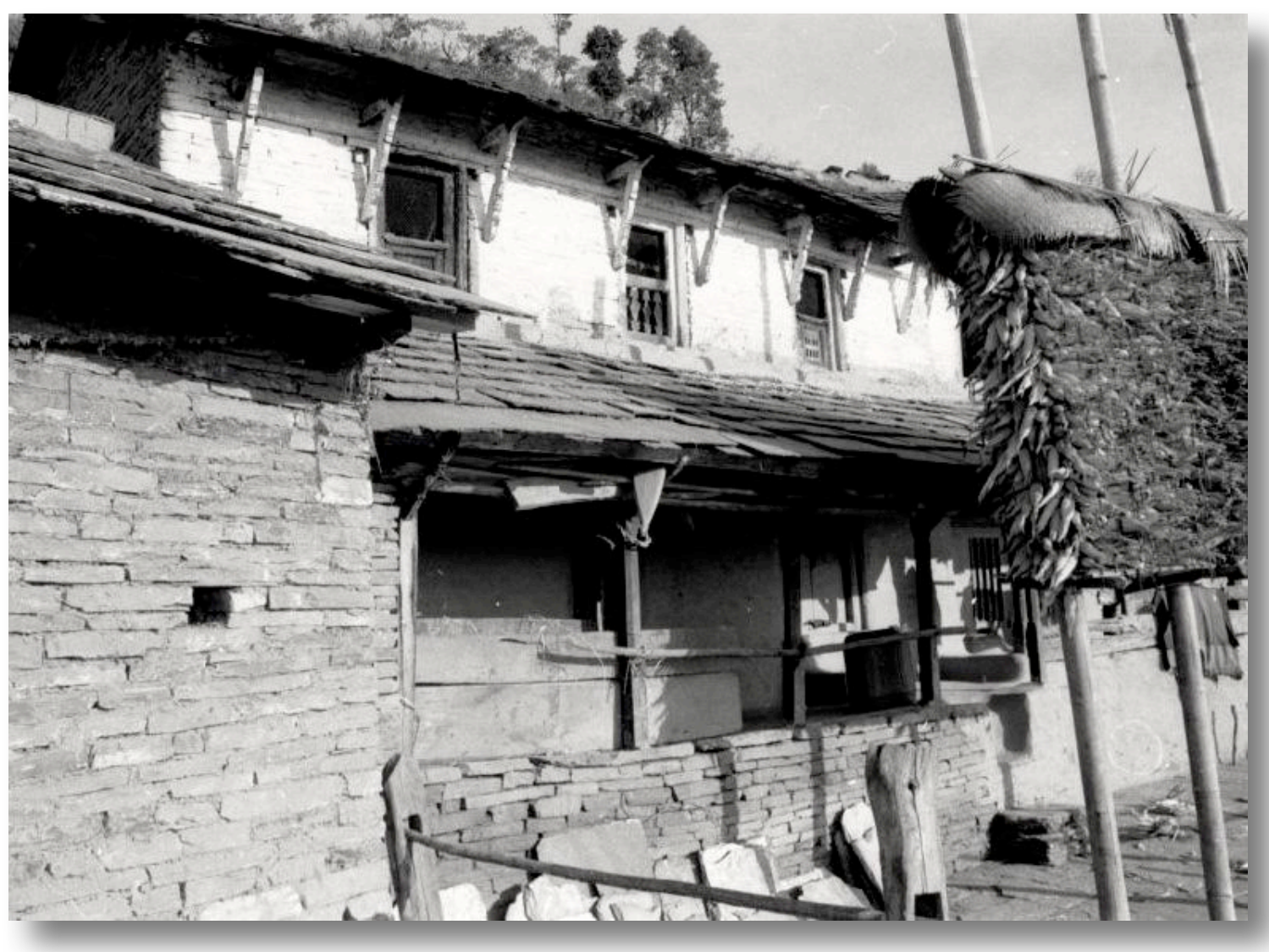

The Gurung house in which we lived throughout our fieldwork, taken in the autumn

Part of the first letter written from Thak, two days after arrival, on 24th December 1968, to show how our typed letters looked, is below. 


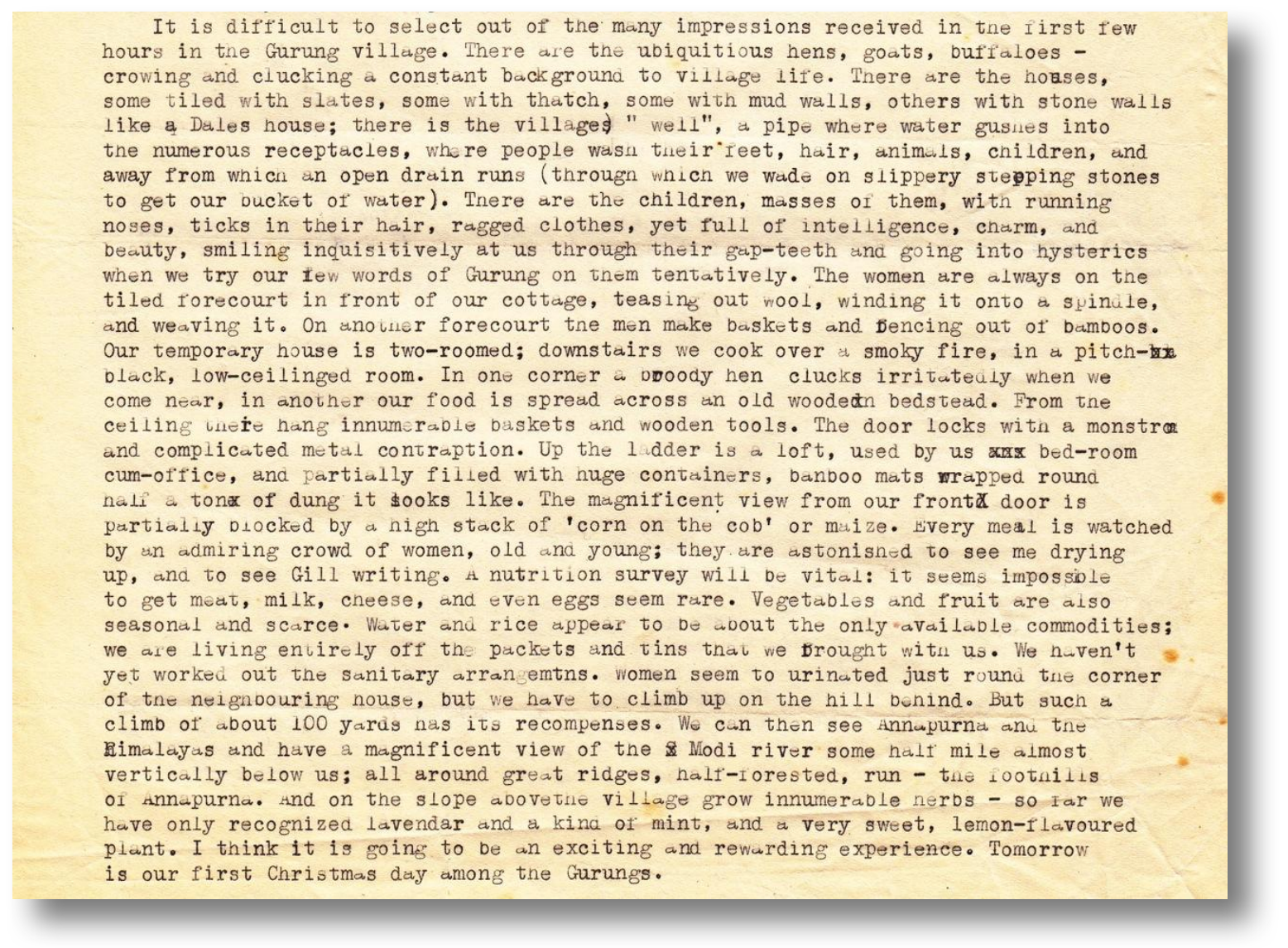

Second day in Thak - afternoon of 24.12.68 Alan to parents [the first page of this letter, of equal length, is unfortunately missing]

Although the temperature is only $550 \mathrm{~F}$. it feels cold with a medium breeze and heavy clouds. We arrived in Thak yesterday morning after quite a tough journey from Pokhara. Our Tibetan porters, although strong and cheerful, took us the long way round and we hump-backed over about four very steep ridges when we could have come along an almost flat road and taken half the time. The first night we slept in a tiny thatched lean-to, our rent was the purchase of 8 cups of tea, and the floor was mud. But sitting round the fire, watching the stars through a huge tree, and listening to the guitar was very nice. The following lunch-time we fortunately met the headman of Thak village (Pradhan Panch) and after handing him a government letter from the Anchelati and drinking cups of tea with him and his notables, we decided to stay at Thak. The headman seems very nice - a mild ex-Gurkha captain who speaks a little English called Ramchandra Gurung. He invited us to stay the night in the village school, so we struggled up a last ridge and threw our belonging down to the half-opened school. Before we had time to gasp, we were immediately asked for medicine, in fact, even at lunch the headman had asked us for some medicine for a friend. At the school an old woman asked us for further pills for her extremely sick-looking husband. All we could do was give him a tiny dose and suggest he get further ones from the "Shining Hospital" (Pokhara).

Almost immediately afterwards a heap of rags nearby produced some tiny, slant-eyed Tibetan children. They all had running noses and one had bad sores on her hand and head - Gill treated these with Savlon and a little penicillin. This appeared to be part of a band of wandering Tibetan beggars, their clothes in tatters, who went round the Gurung villages begging from the badly undernourished Gurungs. They have been round today begging. Despite their misery, however, in the evening we managed to coax them into singing the most exquisitely sad songs (one of them on a C60 tape) and then the little girls wanted to dance. It was a fascinating and 
strange sight to see these little emaciated figures stamping and singing lustily round a lantern, their voices carrying miles across the wooded ridges.

Next morning we climbed the last steep half-mile up to Thak village proper. When we arrived we had an unpleasant row with our porters who demanded half a day's full wages for carrying our stuff up the 20 minutes' walk that morning, although they had stopped work at 2.30pm. the previous day and could have easily carried the load up then. Fortunately a very confident, Nepali-speaking, ex-Peace Corps American named Fean Finger arrived at that moment and after hearing their story said that they "did not have a leg to stand on" and urged us not to pay. The porters filed off sulkily, we having agreed to put the dispute before Fred Barker, the local porter expert in Pokhara. So we left, hot and slightly depressed, in the middle of a crowd of curious and slightly amused villagers. Our money was now down to some 480rs. - which would have to last us for at least 4 weeks (ie. we would have to live on $f^{5}$ a week, fire-wood and rent for a house included.) That is assuming that our money comes through when it should.

It is difficult to select out of the many impressions received in the first few hours in the Gurung village. There are the ubiquitous hens, goats, buffaloes - crowing and clucking a constant background to village life. There are the houses, some tiled with slates, some with thatch, some with mud walls, others with stone walls like a Dales house; there is the village "well", a pipe where water gushes into the numerous receptacles, where people wash their feet, hair, animals, children, and away from which an open drain runs (through which we wade on slippery stepping stones to get our bucket of water). There are the children, masses of them, with running noses, ticks in their hair, ragged clothes, yet full of intelligence, charm, and beauty, smiling inquisitively at us through their gap teeth and going into hysterics when we try our few words of Gurung on them tentatively. The women are always on the tiled forecourt in front of our cottage, teasing out wool, winding it onto a spindle, and weaving it. On another forecourt the men make baskets and fencing out of bamboo.

Our temporary house is two-roomed; downstairs we cook over a smoky fire, in a pitch-black, low-ceilinged room. In one corner a broody hen clucks irritatedly when we come near, in another our food is spread across an old wooden bedstead. From the ceiling their hang innumerable baskets and wooden tools. The door locks with a monstrous and complicated metal contraption. Up the ladder is a loft, used by us as a bedroom cum-office, and partially filled with huge containers, bamboo mats wrapped round half a ton of dung it looks like. The magnificent view from our front door is partially blocked by a high stack of "corn on the cob" or maize. Every meal is watched by an admiring crowd of women, old and young; they are astonished to see me drying up, and to see Gill writing. A nutrition survey will be vital: it seems impossible to get meat, milk, cheese, and even eggs seem rare. Vegetables and fruit are also seasonal and scarce. Water and rice appear to be about the only available commodities; we are living entirely off packets and tins that we brought with us.

We haven't yet worked out the sanitary arrangements. Women seem to urinate just round the corner of the neighbouring house, but we have to climb up on the hill behind. But such a climb of about 100 yards has its recompenses. We can then see Annapurna and the Himalayas and have a magnificent view of the Modi river some half mile almost vertically below us; all around great ridges, half-forested, run the foothills of Annapurna. And on the slope above the village grow innumerable herbs - so far we have only recognised lavender and a kind of mint, and a very sweet, lemon-flavoured plant. I think it is going to be an exciting and rewarding experience. Tomorrow is our first Christmas day among the Gurungs.

The feelings in this first letter, echo earlier panics and dislocations. It is what I felt in my first term at both of my boarding schools and in a less pronounced way when I went to Oxford, and when I started my new job as a University teacher at Cambridge. It is a necessary part of the process of learning, the stripping away and of re-establishing of different roles, status and identities. And it is, of course, the time when we are learning a huge amount very quickly; things are strange and startling, but will soon become very familiar and more or less invisible. It is therefore important to record these first impressions in as much detail as possible.

From my own experience, it is the first and last period of the fieldwork, when you are arriving and when you know you will be going soon, that you learn most. The middle part of the fieldwork is when you fill in the details, add the factual data, go into depth. But it is the 
first impressionistic sketch, the shock of going and leaving which reaches down to deep levels of cultural difference which are covered over in much of the fieldwork. It is then that you can see the whole wood, rather than being lost in the trees.

The following day, we started to try to learn the Gurung language, of which we knew not a word when we arrived.

Gurung language learning TAPE RECORDING 25.12.1968

Alan and Gill learning Gurung language, with Budibahadur and other men, including Akayprasad, from English to Gurung.

https://sms.cam.ac.uk/media/2732791

Gurung song TAPE RECORDING 25.12.1968

Gurung song usually sung on the way and in the jungle - Comal https://sms.cam.ac.uk/media/2732808

The following day, using sign language, we were summoned to go to a ritual. Again, it was all chaos, as described in the letter. I will put in the three photos we took on the occasion, as it will help in the understanding of the following account. Panighat was a small hamlet down below the village. Funeral or 'Pae lava' at Panighat 26.12.1968

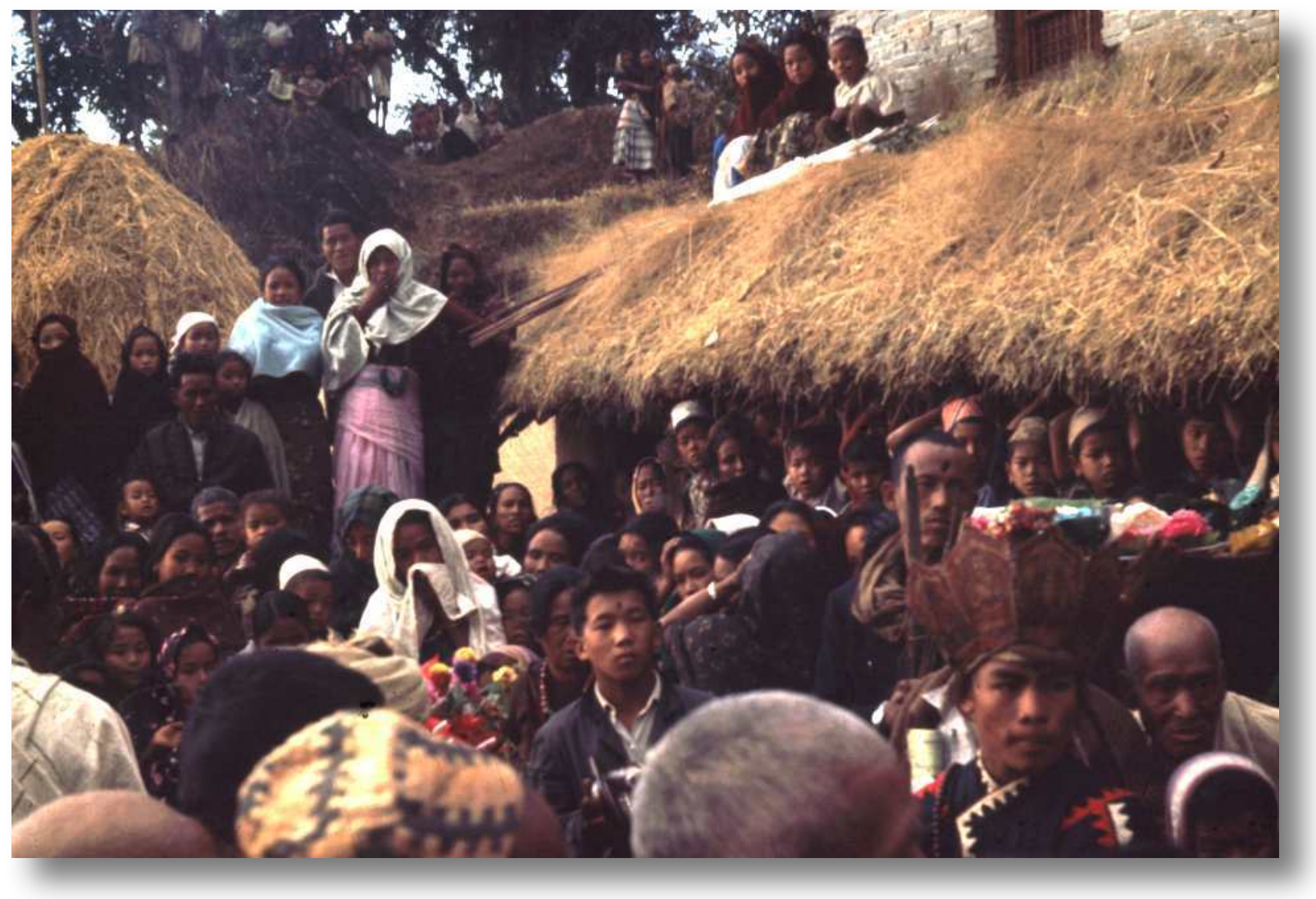

At the pae lava at Panighat 


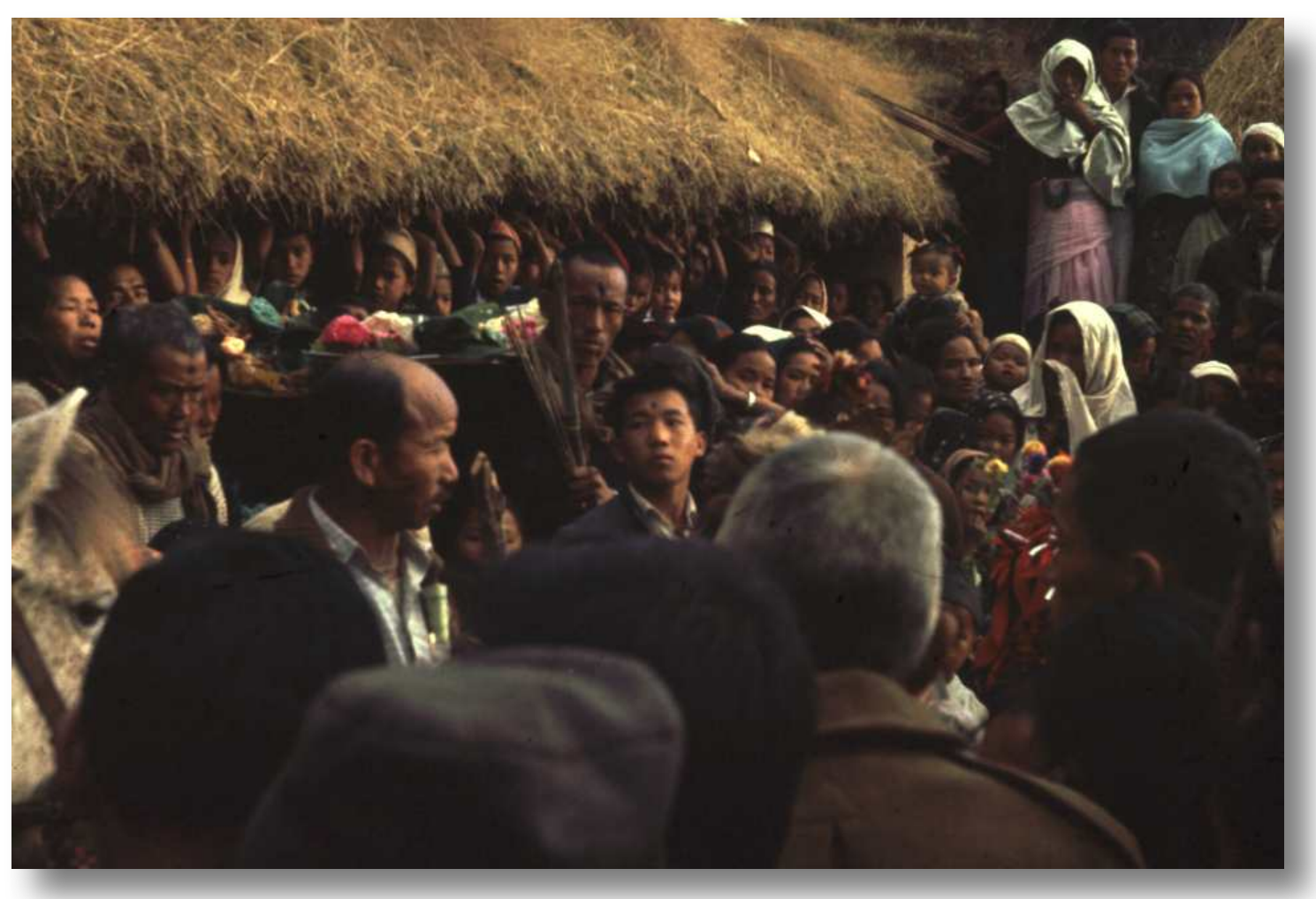

Indrajid among the crowd at the 'pae lava'

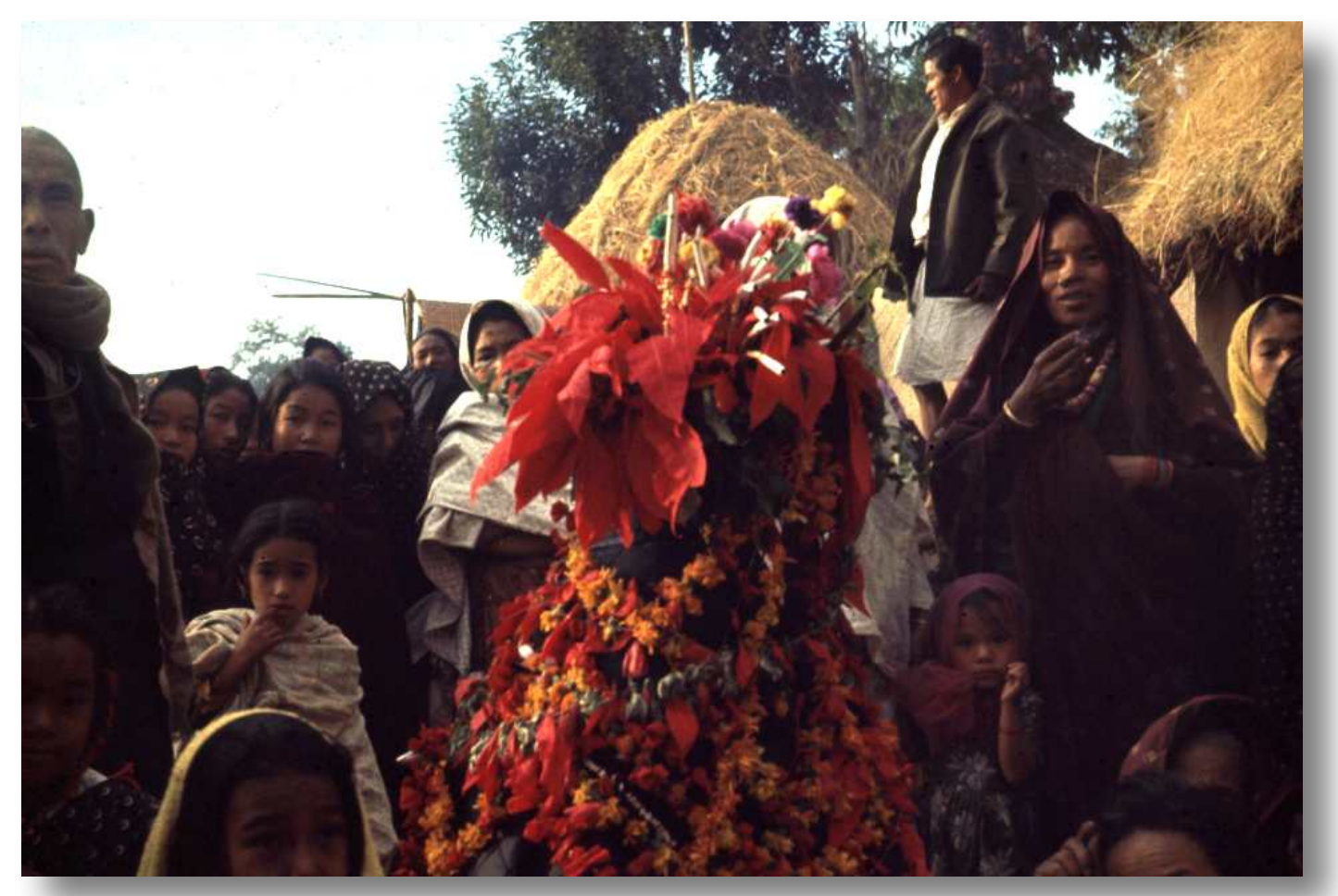

Decorated 'plah' or effigy at the pae lava 
It is not clear whether this was sent as a letter from Gill, or extensive notes kept by her. I will treat it as if it is a letter, since it is typed on the large, light, foolscap paper we used for letters.

Boxing Day, 26th December, 1968.

We woke about 6am, the children were squalling and playing outside as usual, rushing along the verandah, grandmother chasing them with her stridencies which as yet we couldn't understand. It was chilly, but the sky above the mountains was deep prussian blue, drifts of cloud still wavering in the valleys. There was still no sun and I wondered whether it would be an ideal day to catch up on irritating piles of washing, accumulated since our trek from Pokhara, five days ago. We had set off with five Tibetan porters on 21 st December and had arrived at Thak on 23rd, taking the most devious route possible as the porters, being from the Tibetan Camp, said they knew the way, but did not. We had therefore taken two and a half days to arrive instead of one, but had struggled up the final slope early Monday morning and had the rest of the day to settle in.

As we were having breakfast the slight boy who had adopted us then we first came, and whom the Lt. had called "lazy", came to the door and made gestures to Alan that we finally sorted out meant they were going to kill a goat today, and were we interested? As the Macfarlanes we were not but as dutiful anthropologists we were, so Alan strolled off with our adolescent informant (we had been told he was 14 but looked about 10 or 11) taking his tape recorder and camera. I stayed to get on with the washing as the sun had finally emerged warm and brilliant on the verandah. Our next door neighbours, from whom we are renting the house, showed their usual active interest and were especially proud when they could identify my bras but seemed disapproving of so many pairs of pants. Both these articles they thought redundant and indeed, for them, they were. They wear the usual Nepalese outfit of a length of sari skirt and then a tight bodice of a different material, sometimes with a zip down the side and then a tightly wound towel round the waist.

When I eventually got round to rinsing the clothes at the pipe which is a watery trek away at the back of our block of buildings I found everyone else was washing too, and I had obviously hit on the right day. Some women were washing their sari lengths at the pipe itself, beating with a wooden stick and rubbing hard with carbolic soap which seemed precious as they kept it in the original tin, or some had plastic soap holders. What with 'gauri' filling, which seems to be done by the little girls of the household, washing of clothes and also of the self, demand for the pipe was constant, but there were no squabbles even though some butted in before their turn. One of these was a man who was very carefully washing his hair and finally rinsed it by sticking it under the flow of water. As I came back with my pile of clothes I found our neighbours washing themselves, and particularly the feet, on a small bamboo outcrop whey have made, which they also seem to urinate through. There was some concern that I was not washing my hair too and also interest in a small nail brush I had which I used for scrubbing and which they seemed to think a good idea. At this point Alan came back and said the main ceremony was not until this afternoon and that the Lt. had promised to come about 2.00pm. and take us down. We therefore had a fairly early lunch, a great success as I discovered I could just about make pancakes which again our neighbours were curious about but did not seem too thrilled as the piece offered to Rupa [Haricola?], the prettiest and cheekiest of the children next door who is fast turning into my favourite, was taken to her mother for permission to eat and then I think tactfully thrown away! The Lt. duly came about 2, very smartly dressed in western style trousers and jacket with a Nepali hat at a jaunty angle. I had not changed from the morning and was made to feel that I was not sufficiently dressed for the occasion - which we were not sure was all about. Its seeming importance grew as the Lt. invited us into his house which is on the next level down from us. His eldest daughter was immaculately dressed in her best sari skirt, some dark blue silk material, topped with a pale blue angora cardigan. She had elaborate looped earrings, a small gold stud in her nose, and her long corded necklace made up of gold coins which she wore criss-cross fashion over her shoulder. She also had black leather sandals whereas usually she would go barefoot. Her hair was caught up in coils in a bun at the back of her hair, braided with red ribbon and held under by a net, also not everyday wear. The father told us she was 22, and not yet married as he was looking "for a good man" for the purpose. The Lt. introduced us to his wife, who also had a superb gold necklace ('mala') made of carefully fashioned pieces of gold interspersed with red 
felt. Next to her was the Lt.'s mother, aged 80 and going deaf and his mother-in-law whom he did not give any details about.

We chatted on some blue plastic chairs he had brought from Malaya and was proud about, and then he showed us a little round his house - up to one unoccupied bedroom, where we enthused over the bed and mattress, and then into the kitchen and dining room. This was very reminiscent of English kitchens at the beginning of the C19 as there were rows of brightly polished copper cups and plates, and steel-like saucepans, also gleaming in the light of the fire, kept going all the time, tended by the wife in the middle of the floor and made, like ours, scooped out of the earth with a three-footed iron grid in the centre. Above the fire there was some rush matting holding baskets where grasses etc. seemed to be drying.

We were ushered to our rice mat along one side of the fire which was also covered by a carpet and were given excellent coffee in china cups, flavoured with black pepper as sugar is scarce and can only be obtained from Pokhara. With this, also on a china plate obviously greatly prized and brought from Malaya and similar to late Victorian china, we had crisped up rice made through a mincer and baked into circular coils and very pleasant. We were shown the mincer which also seemed to be made of copper and in immaculate condition together with all the other shelves of kitchen ware. We chatted cross-legged like this, and admired a line of beer mugs and also a silver cup the Lt. had been given when he left the army 2 or 3 years ago. His youngest daughter climbed happily all over him, shared his food and was called affectionately "the youngest" ('Kaji') by her father; she must have been four or five and was also dressed in her best with a bright red ribbon carefully tieing up what little hair she had. There was not enough to be plaited as yet.

After these tasty formalities we started on our trek to the next ridge and then discovered that the formality we were trudging towards was a funeral of a young boy who had been killed in the army away from home. The descent as always was steep and one could see far below the tiny cluster of houses where the rite was going to take place, and small black dots of people struggling around the funeral house, which was marked out by a green freshly cut bamboo pole projecting out of the roof, which was decorated by garlands of orange and yellow flowers and baskets containing some sort of grass. Along the edge of the pole was hung a long white sheet reminiscent of the Tibetan prayer poles surrounding the Tibetan Camp. After about 15 minutes we reached the level of the house and the black dots developed into about 100-150. Women and children (and men) massed along the path mainly about three booths where the relatives of the deceased were cooking goodies into steaming oil which were being eaten at the time, and were also for later. The booths were hastily erected with dried bamboo poles and woven matting for a roof with benches outside where we were asked as guests to sit. The chattering of the other Gurung guests nibbling away at rice and baked roll sweetmeats was in marked contrast to the cooks inside each booth who were absorbed in their work, silent and somewhat grim. Their mourning struck me as considerable and we learnt that the boy had died away three months ago in the army, and his body had not come home, and he was the eldest and only son. His loss was therefore considerable. A funeral is an expensive affair as the whole of Thak had to be fed, if they wished, as well as the village on the opposite slope of the mountain where there were more relatives also living. The whole ceremony took three days, and we having come on the second day, after the animals have been killed for the feast, in this case about one buffalo and a goat. These have considerable value to the people and their slaughter was no light affair. The amount offood is a good indication of the wealth of the family, as is the dress of the guests, some of which was quite ornate and marked out with jewelly and western style overcoats which the women in particular seem to prize. After we had stopped perfunctorily at the eating booths, which were also giving away (selling.?) cigarettes and wrapped sweets, we heard drumming from the corner of the path in front of the funeral house. The 100 people became 200 or more, tightly clustered round the mainspring of activity and we saw dancing round a central effigy two men with drums and two with cymbals followed by a small boy holding a conch-type shell which he blew mournfully at distant intervals and a small hand bell, beautifully worked, which he rang in time to the main beat which was strong and forceful, carrying far into the distance with 3 or 4 different rhythms battening onto one's consciousness in a harsh and unavoidable manner. The small boy was learning his trade as a Klehbri, a type of priest hired for such occasions. The most outstanding figure in this thumping, swirling, thudding group was indeed this Klehbri, dressed in a long pleated gown of black cotton decorated by red and white zig-zag stripes of tape. Over this, crossed over his chest and shoulder was a necklace of nutty brown beads and attached to the towel round his waist was a carved bird in black wood, simply made with wings tucked 
into the side, leaning forward as if to drink from a pool. The most elaborate part of his dress was his crown and head gear, which rose up from a wooden base into five star-shaped points of metal tied with red tape at the back, which joined plaited wool lengths of black and white cotton which fell to his waist and swirled out as he moved in the dance. Each section of the crown was delicately decorated on a gold base with a seated figure of it seemed like a Buddha, who also wore a similar crown to that of the living priest. This crown was tied forward to the forehead and the woollen cap rose up behind it to come to a peak in yellow and red ribbons, and around this tuft was a circle of tiny shells which were a miniature of the one the novice boy held in his hands and occasionally blew. The other men were dressed in their day-to-day clothes but were just as earnest as their leader, each following the other in a ceaseless circle, starting low on the ground and gradually stretching full height until the drums and cymbals were being beaten together

Whilst they were still playing in a crouching position the wife and mother of the dead boy fell on their knees and clutched the central effigy with their hands crying loudly and burrowing their faces into the boy's coat which was draped round the main bulk of the centrepiece, as were the boy's torch, blanket and 'kukri' tied on by string. Their grief was very real and infected the onlookers who fell silent, some crying and other taking out appropriate handkerchiefs. The relatives, and in particular the men, were nearest the women at this point and looked strained and serious, the black ash mark of mourning standing out on their foreheads. As the beating of the priests got more intense the women lifted up their faces and stood aside to merge with other relatives, and the dancing continued round the garlanded effigy, strung with red and yellow flowers, with incense sticks smoking at the top and later artificial flowers made of blue, mauve and pink crepe paper added to the other living flowers with their long brilliant red leaves. The dancing continued for about half an hour and then a pathway was made through the crowd for the dancers who then wound their way down the hillside to a small piece of temple ground, still beating and followed by some of the villagers. Immediately following the dancers came six sisters of the boy each carrying head high a tray filled with foodstuffs, goodies made of rice and Tibetan bread brightly. coloured with synthetic dyes of blue, yellow and pink. There was also a silver tumbler on the first tray filled with liquid, and as the carrier made her way through the mass of the crowd she felt it slipping and stood for one of the onlookers to adjust it, which was done most sympathetically. The food was to accompany their dead brother presumably into some conception of the next world, and had been lovingly arranged and was finally placed round the effigy as the last gift made by the family.

Added to the dancing group was a tall lean man holding a bunch of banana leaves carefully wound together with a white strip of cloth, and this man seemed to enter into some sort of dance antagonism with the gowned priest, leaping in his way and teasing him with his bunch of leaves. They contra-danced like this on the sacred piece of ground for about 15 minutes and then wound their way back to the square outside the house, leading the way with a long strip of white cloth strung together on several poles. Their original exit was made with this as well, and several times the leader of the plainly dressed men made as if to leave the dancing circle, making movements outwards with his feet, and then retracted and joined the circle again When the dancers were thus at the third stage we were asked as guests if we would eat at the house which was of standard Gurung design, with a low square lintel, lovingly carved. It seemed pitch black inside after the brilliant light and sound outside and it was filled with other guests eating and drinking and chatting. Some were crouched round the low fire, the women drinking tea and the men drinking a form of whisky diluted with water out of smooth brass bowls. We were handed this, as well as rice goodies similar to those we had eaten earlier. The wife of the deceased stood in the doorway smoking through her fingers and appearing without bracelets as a sign of her widowhood. If the woman is older than 30 it seems rare for her to marry again, we were told.

When we finally emerged from the house, to make way for other guests who wished to share the food, eight or ten villagers had taken the place of the official dancers and were beating their way around the effigy and the little boys in particular entered into this with enthusiasm and somewhat of the gloom lifted from the proceedings. The main mass of the other village people were now seated in a semi-circle a little way in front of the house, women predominantly on one half and the men at the other, and were being offered large shiny green leaves as plates by relatives who took large baskets of rice and meat around. A bamboo pole was at the apex of the semicircle and had a lantern attached to the top and these proceedings were obviously going to go on far into the night. Indeed we learnt later that it was customary for guests to spend the whole night there, feasting and dancing, as the final part of the ceremony would take place on the following and third day and this would 
presumably involve the disposal of the effigy. We were asked very earnestly to eat in the circle and spend the night there but rather halfheartedly we refused and made as if to move back up the mountain. If had been a tiring and exciting experience and all the senses had been roused and at least my full sympathy for the plight of the family who had lost their only son early, and the one brother amongst six sisters.

TAPE RECORDING (Addenda from tape) Distance from main dance area to second one 200 yards. Second dance was a complex swirling pattern where the priest was completely taken up by it. Sacred area seemed to be open paddy field - women and men all around. Monotonous beat. Danced for half hour. Man beating cymbals in second dance - Klehbri. Before they left first stage about 8 relatives in turn advanced with bamboo "spear" (pole) to the edge of the circle and thrust at the effigy and then they turned round, lowering the spear, and various men just touched them sympathetically on the head. All the spear throwers were adult men. The throwers then went another ten yards and (I think) tried to hurl the spear into the ground, their efforts were greeted with much laughter by those nearby. All relatives take off their hats at this first stage, and appeared to weep and used handkerchiefs.

In the first stage a Gurung who had been a Major in the Nepali army cantered up to the dancing circle (whether for our photograph or for the ritual, not known). Pony was fine white animal with an orange rug as a saddle and came from the other village. It is customary for people to take away large quantities of food as well as eating there - we met some little girls coming away with saucepans of broth curry. Rich people kill up to 4 buffaloes and same number of goats. Wife and mother, when they fell on their knees, had their heads covered by cloths which women only usually use in the evening when they are cold. Cigarettes also on the effigy with the joss sticks at the top, all smoking. The whole effigy rested on a bed covered in a beautifully woven carpet, and at first glance the general effect was one of a coffin shape. All his blankets were taken down to the second stage, including his blanket and rice mat. From the temple they brought back sprigs, 6-8 inches long with white berry-like flowers which they later stuck in the top of the effigy. They gave some of the food to the children as well as placing it on the effigy when they returned from the second stage. People took their shoes off when they went into the house to drink whisky etc. When just the villagers were dancing round a two-ended drum was added. Third of a pint of whisky was drunk from brass bowls. Many members of the crowd smoked during the proceedings. 70 or perhaps 100 people were being fed afterwards, in the semi- circle. Rich people give butter and chutney also in this handout, but not this time.

[There is a tape recording of this: Alan and Gill describing 'Phai Rhe-theba', where the 'moh' of the dead person dress in a funny costume and holds the ashes of the dead person, and the klehbri chase them beating the music. Resume of the 'pwe' so far.] https://sms.cam.ac.uk/media/2732825 


\section{9}

JANUARY

N.B. 'Notes' on small cards have been included from 11.1.1969 to

Only longer notes of a more general kind are included if they indicate something about the general fieldwork conditions.

Asmaya in her best clothes standing outside House32

Nepalese song TAPE RECORDING

Gungadebi singing a Nepalese song "Ghar ta raya le, malai ke garyo timro maya le..."

https://sms.cam.ac.uk/media/2732842

Gurung language learning TAPE RECORDING

Learning Gurung language with group of people including Prem

https://sms.cam.ac.uk/media/2732859

Gurung song TAPE RECORDING

Prem singing a popular Gurung song. This song tells about a woman's feeling who is worried about how to go and how to stay in other's country. The song goes as "Qudai thulai dukha muna bharsa mula ri, Khailai tiba khailai yhaba ahwe hwu-lari ."

https://sms.cam.ac.uk/media/2732876

Gurung language learning TAPE RECORDING

Learning Gurung language with Prem, especially question-answer between two people.

https://sms.cam.ac.uk/media/2732893

Nepali song TAPE RECORDING

A group of men, including Nainasing, singing a 'thado bhaka' song in Nepalese.

https://sms.cam.ac.uk/media/2732910

Nepali song TAPE RECORDING

A group of women singing a 'lahare bhaka' song in Nepalese. The song goes as "Pani talai ma ..."

https://sms.cam.ac.uk/media/2732927

Nepali song TAPE RECORDING

A group of girls singing a Nepalese 'lahare song' and the song goes "Shir maathi..."

https://cam.ac.uk/media/2732992

Gurung song TAPE RECORDING

Prem singing a Gurung song "Tanga mhu jalari..."

https://sms.cam.ac.uk/media/2733027

Gurung speech TAPE RECORDING

Prem is asking all the sisters, friends and children not to disturb them, not to touch their things, not to stare at them, not to leave their own work and come there just to sit and look at them.

https://sms.cam.ac.uk/media/2733044 
Gurung language learning TAPE RECORDING

Prem recording phrases then Alan repeating Gurung words. Sound of a Tibetan beggar drumming outside. Next chatting round the fire. Prem helping Alan with Gurung conversation sitting beside the fire. Children amused.

https://upload.sms.cam.ac.uk/media/2733095

\section{Thak village, Nr., Pokhara, Nepal. 2.1.1969 c/o The British Library, Pokhara, Nepal}

Gill writing to her parents \& Alan's parents

Well, here I am sitting in front of our own little Gurung house, surrounded with two little girls and a runny nosed boy who are all chomping popcom, and getting in the way of the typewriter keys.

As I explained in my last letter there has been such a gap since I last wrote as there will be no chance to post this until we next go to Pokhara which will be in three or four days' time. We were told that it would take two days to walk here originally but when we'd got here and done the two days we found out from the village that it would have taken 4-6 hours going the proper way! The trouble was that we hired Tibetan porters who didn't know the country very well and they therefore took us the most devious route possible which included tortuous bills to clamber up and down, and sleeping out under the stars and eating nothing but rice - but this was fun nonetheless and Alan played his guitar to the delight of the porters, who joined in with great gusto, the clapping carrying far over the hills.

We couldn't have been luckier in finding our village since when we stopped for lunch on our second day half the village male committee happened to be walking by (we think now they must have heard from another village we stopped at previously that the Anthropologists were On The Warpath) and when we asked if the headman was there, of course he was and we arranged there and then to stay at his school house overnight and install ourselves in his village the next day!

Alan had got a letter of introduction to various headmen, as we didn't know definitely which village we would end up at, from some sort of Area District Officer at Pokhara, and the letters seemed to lessen suspicion as we might have been spies for the government or something equally dreadful, some to see if they were paying sufficient taxes or not!.

We did spend the night at the school, but found out later it was the wrong school and that Thak actually perched on top of a cliff, soaring above the place where we slept and taking at least half an hour to climb. We wondered why there were so few houses where we were, the nearest inhabitants being a family of Tibetan refugees who were camping out in the open and going to beg for food every morning from the village. They were a most pitiful sight, bundles of rags and covered in sores and yet retaining a dignity which was very much at variance with their physical appearance. Alan played his guitar round the camp fire at night and all the family clustered round and it was quite heartbreaking to see how the children's faces lit up with life again, beaming with joy at the music and clapping energetically, esp. after seeing them so listless and hungry thro'out the day.

They in their turn danced for us, stamping away in a rigorous chorus round a single lantern, their grandmother singing us evocative Tibetan songs, quite haunting, whose melodies we managed to get on the tape recorder. She sang of how once she had been rich, and now she was poor, fleeing from the Chinese and aiming for the Tibetan camp at Pokhara. I managed to dole out some medicine which made their sores better and then later when we were installed in the village they came on their begging expeditions and we gave them some food, along with the rest of the village.

The climb was pretty steep the next morning but the views at the top were quite beautiful, and I couldn't ask for a more idyllic spot to be rooted down into! Behind the village the Himalayan range towers, sometimes brilliant white with snow against an equally brilliant blue sky and at others wreathed in cloud, their peaks just tipping thro - I think Annapurna is the second highest mountain after Everest. Sloping away from this range are the forest covered slopes which drop sheer down from our village to rise again from the river bed, equally steep on the other side. 
We worked out that the village was $2000 \mathrm{ft}$. up from the river so that we have quite a climb when we do go down to fish, which we think will be about once every week. We celebrated Christmas Day by the Modi, which is quite a powerful stretch of water and had a lovely hot day there, about 70oF., bathing and reading and generally getting clean. The next week, New Year's Day, we went to a smaller stream on the other side of the Thak hill and this was very reminiscent of the Dales so you won't be surprised when I was quite enthusiastic. The only daunting thing so far is that Alan hadn't caught any fish yet and the locals are very sceptical about him ever doing so. This is a pity, food-wise, as there is a great shortage of meat and our only constant source of protein is eggs, which the children bring to sell nearly every day.

We were told we could have our present house for 3-4 days, and then at the end of that time they said for 4 months, so we hope in April they say we can have it until we leave! It is near the centre of the village, which has about 50 houses in all, ranged in rows of 5 or 6 , stepped up the hillside. There are just two floors, and the locals just use the bottom one and were very amused when we arranged our sleeping things on the top floor, when they usually just store grain and plaited grasses. It's a good thing that we are relatively small in height as the first floor is very low, the walls made of cream coloured clay set in with wooden window frames which are intricately carved, along the frame and across ways as there is no glass. The fire for heating and cooking is simply a square pit hewn out of the floor with an iron tripod in the centre and one cooks with firewood and generally gets choked with the smoke which has no official exit and just fumes up to our bedroom and through the three little windows which light this room. We climb up to it through another square hole in the ceiling of the first floor by a steep ladder and there is my dressing table (a tin trunk covered in a striped red and green and white tablecloth), our bed (two rice mats scantily disguising the bumps of the clay floor covered with two quilts bought in Pokhara with our sleeping bags on top), Alan's office (one table, 1'8" in height, two cane baskets on their side for in and out trays, one cane stool covered in buffalo hide and drooping in the middle placed on three planks to get above the height of the table!) We live, as you can see, simply - the food which we have is either stored in a tin trunk or, when in use, covers a wooden bed on the first floor. At the end of the letter I will add a desperate list of things for you to send off - you have no idea to what eminence a packet or dried soup has risen! When I wasn't feeling too good in Kathmandu I used to dream about Mummy's potato soup and her mushroom supper dishes!

Things are brightening up as far as food is concerned, however, as the local children have suddenly clicked that we are in need of things so we have little messengers at the door every hour or so, crying "Sahib" up at the window, where we struggle with the language every morning. They emerged with some minute, under-ripe tomatoes yesterday which I greeted with joy, plus some rock hard, bead-like vegetable which they assured us was "very good" if fried in oil.

Today a friendly, very astute neighbour who speaks English as he had been away in the army, told Alan that men from the neighbouring village had come to exchange their potatoes with our millet, and would we like to buy some - so we have a sack of those tucked in the corner of the room. They have also turned up with a spinach-like vegetable, which we were quite relieved to see as we were beginning to feel the lack of greens in various ways. I shudder to think what food of any real nutritional value the people eat in general - they only seem to eat rice and perhaps lentils and then this corn on the cob which they fry and eat dry as popcorn. They are amazed at our apparent endless bottles of tomato ketchup, Horlicks and oil, etc. which we managed to buy in Pokhara, and think we are very rich indeed - which we are, relative to them, but not until we can be sure that our next supply of money has come though!

On the whole we have found the villagers most friendly and cooperative, the Gurungs in general being renowned for their jolliness, apparently. They have been very good about helping us learn the language and will carry on banal conversations endlessly to make sure we have got one phrase correct. We were lucky in meeting some linguists in Kathmandu, whom I think I told you about, who lent us their notes on Gurung and the local schoolmaster has promised to teach us an hour every morning, which will start next week when we get back from Pokhara. We are also compiling a dictionary so I think are managing quite well and communicate on a noun-verb level just about at the moment.

We have particularly rousing evening sessions which began when the village found our they could hear themselves on our tape-recorder, and then could see Sahib play his guitar and Memsahib sing! We use the taperecorder as an aid to learn the language and get them to pronounce words and phrases which we play back later 
for the pronunciation. They loved hearing themselves chatter in the background, as well as babies crying and the chickens clucking - the entire place seems sometimes to be taken up with animals and babies - baby goats, chickens and buffaloes wander about our little verandah as well as the cows, cats and dog! The evenings eventually got so popular that we had people settling themselves down on our rice matting alongside the fire before I had even thought to light it for the evening meal! They solemnly sit through me prepare it, very amused at the way I do things, like not having rice one evening but pancakes instead, and then through Alan taping some grammar and then they are ready for the singing. We have got them organized to clap nowe, and the older women bring their wool teasing and the men supply brass bowls for accompaniment and the effect is quite enthusiastic!

We feel we are polluting them with western culture and Pop culture at that (they love throbby songs like Elvis Presley) but they love it - one evening we must have had thirty or more crammed in. The drawback to all this sociability is that they want a show every night, and there are always some hanging around who attract the others. Also when we have breakfast and lunch outside on the kerosene fire we have bought they are so intrigued by what we eat and how we cook it that there is always an audience of four or five children so a quiet intimate meal is difficult. The other problem is the toilet - we have to climb about ten minutes up the hillside to find our spot as there is no garden in which we could dig a latrine, but Alan is thinking of contriving some sort of Elsan. The advantage of the hillside is the view of course, which is tremendous as we are so high up. The weather is usually blue blue sky and warm winds - ideal, and we have only had one day when it rained. You can imagine how lovely the sunsets and sunrises are too. As you will have gathered if is a thousand times better than I anticipated - don't say anything! Alan has also managed to get a tiny piece of land for his garden and used the Fertozone with great care and prayers!

We are very well and manage not to get too homesick and might even manage to love this place quite a lot but thinking of yu an aweful lot and hope you are well - how was Xmas like?

All our loving,

Alan and Gill

\subsection{9 c/o British Library, Pokhara, Nepal From Alan to his parents}

Dear All,

Please forgive an odd assortment of letters, carbons etc., but I thought a carbon of gill's letter to her parents might amuse you $\mathbb{E}$ my laziness has induced me to send teh page of impressions I wrote on the second day after our arrival here. I am sending a carbon of this one page to Granny and Grandpa-just to let them know where we are and that we are alright. Perhaps you could send on the other bits $E$ pieces, or take them down at the wedding. We wonder how you all are E constantly think of you all; please give our love to Erik, Annie, Fiona etc. etc. when you see them $\mathcal{E}$ show them these bits and pieces. Will write to them when we hear from them. Could you give them our address?

As you will gather from the other pages "here" is the little village of Thak, some 10 miles from the small town of Pokhara - or about 5 hours walk. It's situation is absolutely superb; it is on a ridge about the height of the Langdale Pikes above the river valley below, and behind it is Annapurna and the Himalayas. On all the other sides there are lofty wooded ridges, with little villages hanging to their sides. The village itself consists of about 50 houses, half of them clay and thatch, half made of stone with slate roofs.

We have just started to conduct a census of the village, which is surprisingly easy although we do not know the language, since they all seem to know each other's ages down to the nearest year. On average there seem to be about 7 or 8 people per house - so the total population, counting the several scattered houses, would be about 500 people. Our little two-roomed house is sweet, despite its low, head-cracking beams, its dusty earth floors, a downstairs room which is practically pitch dark and, when the open fire is lit, filled with smoke. Most of the time we squat on the floor or sit on little stools.

Breakfast and lunch we eat outside over a kerosene stove, the evening meal we cook over the smoky fire. Meals are eaten with a constant audience of marvelling children and adults - though our food would be considered dreary in the extreme in England. Porridge for breakfast with coffee, rice or pancakes and an egg for lunch, rice or pancakes and 'dhal' and half a tin of sardines for supper. Meat is practically unobtainable, as is 
cheese, so protein comes from eggs and dried milk. Our packet soups now have tremendous value and even some stale biscuits with jam seem like heaven!

It is amazing the way in which every tiny thing has a value here. The children scour through our wastepaper basket and triumphantly carry away bits of broken biro, empty sardine tins and even brightly coloured bits of paper. One child even took Gill's empty contraceptive packet, tore out the little blue bits of paper from the empty capsules, and stuck them on her forehead and cheeks in imitation of their sacred markings. It would have made a fantastic photograph for "Family Planning News"! Talking of photographs, I wonder if the two films I sent ever arrived. If they did, I will send another couple soon. Only with the help of colour slides will you get any idea of what this place and people are like Our lighting consists of one little hurricane lamp and a brass, candle-like, lamp. We also have a kerosene pressure lamp, but kerosene is so expensive here and it is difficult to bring up to the village, so we have not used it much yet.

Most of our time, interspersed with 20 minute trips up the mountain side to relieve ourselves, we spend trying to learn the language. Although the Gurung villagers are very helpful and most good-natured, so far we can only say "No, I have not eaten" and "I am going to fetch water". As they are constantly asking us why we are dashing off up the mountain side, this makes conversation rather difficult. Next week we hope to get a young schoolmaster to give us some tuition each morning, which should help. The people are very good-looking, although most of the children have permanently running noses. They are perhaps especially friendly since many of the men served/are serving in the Gurkhas in Malaya. Several men in the village served in the Gth Gurkhas which, I think, was Bill's regiment wasn't it?

The little girls start to work - carrying huge loads of fire-wood from the distant jungle, or minding the numerous babies - when they are about 8 or 9, although they look about the size of a 5 year old English child. Boys of 18 often still have unbroken voices and look about 12 - while people age very fast, especially women, and women of about 50 look about 80. There seems to be a fairly strict segregation of the sexes in labour and leisure, though the women are by no means downtrodden or shy - they laugh at naughty jokes just as heartily as the men and banter away at the water hole (or rather pipe). The place where the water gushes, or, usually, trickles out of a pipe in the centre of the village is the focal point of human activity. There are always half a dozen women and children washing their clothes or themselves amidst the flies and cows. But in the evening, when there is still a glow to silhouette the banana and other trees and the house-tops, when a single bright star shines and the stones of the houses are still warm to the touch, I really begin to feel I could love the place. The moonlight is very bright, the Himalayas glimmer palely, the cicadas chirrup and the water gurgles into the huge water pots of the women, it is impossible to hurry things, impossible to be fretful. The back-cramping and topsy-turoy office, the lack of privacy, all is forgotten. Peace descends.

From that lyrical note, back to reality!

We soon hope to be able to have something to compare to the Essex and Westmorland villages. Any progress with K.L. [Kirkby Lonsdale study]? How does your book go, Mummy? And have you heard anything about fosselin or the witchcraft book. I suppose some proofs of the latter should appear fairly soon. It all seems a long way away, but I am missing not being able to write and am longing to get down to analysing the social structure here. We also wonder what is going on in the world: if England were to go to war with America it would take a long time to percolate out here.

I think I mentioned in our last letter that we would be sending Erik and Annie's wedding present when our first lot of grant arrived, but that they would not get it for a few months. Could you pass this news on to them. Also - what is the date of the wedding. We will try to send a card, but please give them all our love and best wishes if we do not manage.

Hope the Flea [van] goes alright and the croft is as wonderful as ever. Have the tumbleberries/blueberries arrived? My gardening is only at the compost-making stage now.

Lots of love to you all,

Alan and Sarah 
A colder day, mostly overcast and a stronger (force 4-5) wind in the morning. The prelude to the mini-monsoon? The Himalayas shrouded in cloud/mist. Thought we'd been burgled in the night, but only our old toothbrushes missing. We slept in and were exhausted all day after yesterday's terrible journey from Pokhara. We left Pokhara at $12.30 \mathrm{pm}$. (having waited vainly for the diplomatic bag) and didn't reach Thak until about 7pm. I suppose only about twelve miles, but the last climb up or 2,000 odd feet, the last half-hour in the dark, carrying both rucksacks (Gill exhausted) was terrible. Stumbling and staggering with tiredness, we arrived home and food, a bucket for an "Elsan", new grill plate for the fire, etc.

Today spent recovering - reading "Notes and Queries" etc. Too tired to carry on learning Gurung, as we have been doing for the last two weeks. Our neighbours also recently returned from Pokhara and are re-thatching the house over the byre. The young chickens have grown exasperatingly friendly in our absence and can't be kept out of our verandah - where we eat our meal over a kerosene stove and wash up in a little aluminium bowl. Our food today porridge and coffee for breakfast, rice, eggs (2), spring onion and tomato for lunch, potatoes (grown in next village and bought from Lt. for about 10d. per lb), cauliflower (bought in Pokhara - 2 for 2/-) and half a tin of fish (3.5rs. a tin in Pokhara) for supper. (NB. rice costs $7 \mathrm{rs} .20$ per 'dharni' in Pokhara; sugar about the same; oil - 2.5rs. per little jug full, 15rs. for a tin; the porter cost us 13rs. - 3rs. a day carriage, 3rs. a day for food (x2 days) and 1rs. for "rum".

The journey down to Pokhara, non-stop with the Sgt. Ramchandra. Only took us 4 hours. Annapurna hotel its usual greasy self and Pokhara seemed less pleasant than we remembered it, though it was amazing to see shops. Nice to be back in the village. Slight difference of opinion with local boy. We thought he did not deserve the 7rs. he asked for wood. But we gave it in the end. (We did not however have to pay Tibetan porters $36 \mathrm{rs}$.) 


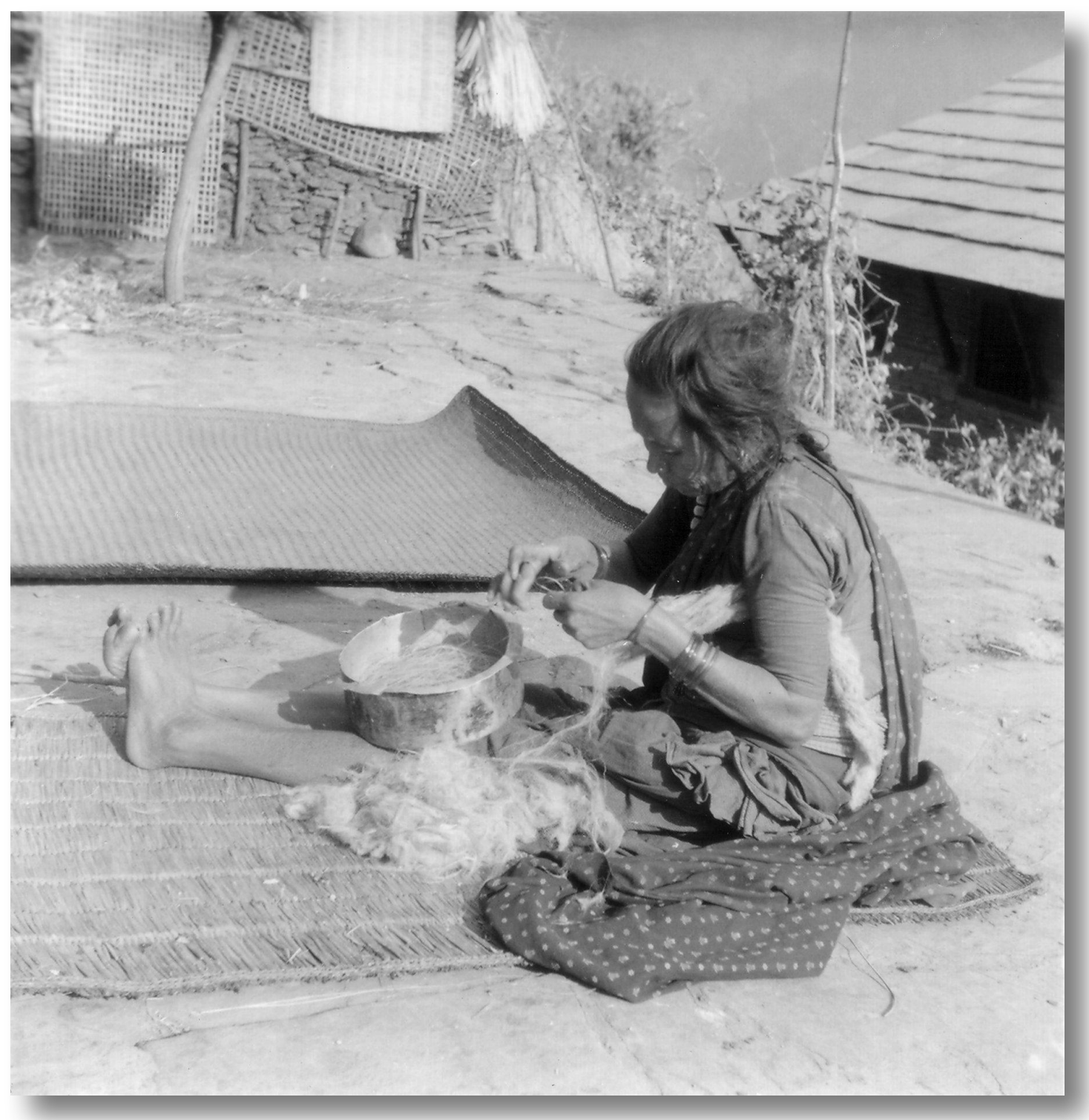

Nansubar teasing out 'nangi'

Notes by Gill on 9th January 1969 - dinner at Lt. Bhuwansing's

Alan went to see the Lt. in the morning to thank him for having a stool made for us; it was then that we were invited to dinner. We could come any time between 3 and 4 so that I could watch the wife cook. We go a little after 3, having dressed up somewhat (I polished my shoes, Alan put on a better sweater!) as we have a feeling that this might be quite an occasion. It takes a minute to descend as the house is only two layers down from ours and there seem to be two or three children in the courtyard, and a grandmother weaving, sitting cross-legged on the floor, a piece of cloth extending 6-7 feet in front of her fastened down by some stones at one end and by the wooden bars she weaves with at the other. She is deaf so is made uncertain by our greeting. We go into the house, bowing low under the lintel and there the Lt. is somewhere in the distance of the passage fumbling anxiously with a bundle from which he extracts a beautifully woven rug, Tibetan-like in colour and design, and which he places on our rice mat, parallel to the fire. He is very proud of this, I should think unusual in Thak, 
and I feel we have come a minute too early as before when we visited it was already laid out and we were not allowed to see that there was anything unusual about it.

The Lt. is shy, clears his throat loudly as he silently prepares an English sentence. He is very "correct" and kind. He sits at right angles to us; we greet his wife who is already seated by the fire, for the most part cross-legged, and who is calmer than her husband, having no responsibility of conversation and absorbed in the ritual of meal preparation. Her movements are smooth and rhythmical, she is highly organised and pours boiling water deftly, is calm when the rice boils over and mixes spices, chili, black pepper and a herb like thyme with water on a wooden board with a smoothly polished oval stone, rapidly. Her first action whilst were are settling ourselves is to wash the rice. She saves the water, slightly milk-coloured in a copper bowl by the side of the water and later uses this to supplement other dishes, or add water when she is rolling out the spices with her stone. She gives the impression of being an artist at her work, working up from basics, mixing every part herself and all her actions being completely integrated with her tools. When the water is drained more is added to the rice, and the whole is placed on a brightly burning fire in a large rounded iron pot which narrows at the neck and has a turned-out rim. This boils briskly and when the water rushes into the fire it is allowed to do so, even though embers arise from the fire, as of course the cook cannot exactly estimate how much water will be needed and this is one way of draining off excess. The rice itself was originally measured in a straight-sided copper container about 5 " high, carrying perhaps half a pound, one measure per person. The rice is occasionally stirred deeply with a copper ladle with a wooden handle. A kettle is always at hand on the other grid. The rice is eventually covered with a lid, and the burning sticks are withdrawn so as not to burn.

Above the entire fire a wooden grid-like structure is pegged onto the ceiling and comes down low to contain a basket where some of the goat's meat is drying off. The Lt. demonstrates by fetching more goat's meat from a larder-like room [or just a pan behind her? AM] behind the wife how some hang the meat up over the grills directly over the fire so that it is smoke cooked in this way. He seems to be proud of having killed his goat, and there is a little stream of neighbours who come to have the soup, which is at the side of the room, underneath the shelves containing all the cooking utensils, in a huge Macbeth-type cauldron. He explains, as he does not sell the meat, it is customary to give it. His attitude is vaguely that of the soup kitchens of the nineteenth century. If he had sold it there would have been no necessity to give any away; as it is, he must give some to "all my neighbours" which he reckons to be 9 households. ('sye zhomba' = to dry meat; 'sye chomba' = to hang meat

The next stage in the preparation is the potatoes; their skin is not cut off and I could not see whether they were ashes or not. They are a small sweet variety (the same as ours). They are cut into two or three sections with a knife and tossed in oil whilst spices are then added 'bissaro' (a type of saffron), 'miti' (thyme, marjoram?), 'kausani' (chili powder), rock salt kept in a blackened bamboo container about 18" high. The other spices are kept in smaller tins on the right of the wife. The potatoes are allowed to sizzle about 15 minutes and they are stirred often, sometimes by the daughter who has just returned from cutting grasses for the buffalo, when the mother is organising another pan at the other side of the room. The latter rarely has to move however and smokes contentedly while she cooks. She wears her beautiful red felt and gold necklace, a broad coin ring and her earrings.

Behind the Lt., as it were in the back stalls, sits an old lady who takes no part in the cooking and rarely says anything. When we enquire it is the Lt.'s mother; she takes no part in the cooking because of her senility - indicated by the Lt. by the fact that she would let things burn and forget to add the salt. She later comes into action however when I am trying to grind black peppers I have brought from Pokhara. I asked if they will show me how to do it - the daughter brings a heavy flattish stone, scooped out oval in the centre, together with a smaller 
black stone the length of one's hand and slim to grasp. The peppers are placed in the hollow of the large stone, almost impossible to lift with one hand, and then one takes the smaller pestle and grinds it over the peppers which crack as they are broken until one has a fine dusty pepper. I took over after the daughter had shown me and found it difficult simulating their rhythm which was even and effective. At this point the grandmother showed me how to place my hands so that the right one cradled the smaller stone and it was an extension of the arm, and the body and the tool became one and the left hand steadied the larger stone and some sort of balance was established. My hand ached after a while and I remain staggered at the detail and effort that went into the meal and their art of cooking generally. 5.20pm. Lights (broken) kerosene pressure lamp.

$5.30 \mathrm{pm}$. Puts on small pan, with oil and 'mihti' in - the latter has to cook for two or three minutes until reddish-black, also cools 'behsar', then adds goat's meat (about half a pound for the three of us - kidneys, liver and innards; this is the best part of the goat, we are told). Puts in pepper mixture (another lot, for ingredients see above). Fries ('butuwa').

$5.37 \mathrm{pm}$. Adds rock salt (from bamboo container).

$5.40 \mathrm{pm}$. Adds a little lemon juice from a bottle to the meat and potatoes ('tsuga'). (She is cooking on a two ring "hole in the floor", though she only uses one ring and the other has no flame under it. There is little smoke, except when the logs are pulled out to reduce flames. About 6 small logs are used at a time.

$5.42 \mathrm{pm}$. Daughter washed 'lobou' (large radishes) which had been purchased from another village since those in this village were over. Two large ones used. She then cubes them. 5.45pm. Mother again starts to make the pepper/salt mix on a board.

5.48pm. Adds some juice (rice water?) to the meat. (n.b. The head of the goat we are about to eat, and which had been killed this morning in front of the house - for us? - they are only killed once every six months or so, is resting against the wall on the other side of the fire, staring at us glassily.) The various peppers/salts etc. which the cook uses are within stretching distance of her arm, on shelves. The relative positions of the various people (although they all, and especially the Lt., move about) are as follows. (sketch) Most of the time they use either the pressure lamp, or two small kerosene candles. They put out the kerosene wicks when the pressure lamp (which characteristically ran out of fuel) was on. When the lamp ran out, just as when the child cried or another guest turned up, there was no flapping or anxiety. They just dealt with the situation calmly, almost resignedly.

Meanwhile the pan with the potatoes was kept in the ash near the fire to keep it warm. The water for the cooking was kept in a small (half gallon?) western-type bucket within easy reach. Apart from lighting the lamp the Lt. did not take any part in preparing the meal, though he soothed and cradles the little (about 5 year's old?) daughter, holding her in his arms and talking in a falsetto voice to her and, after the meal, when she was crying, rocking her in his arms, covering her over (including her head) with a blanket, and singing softly to her until she was asleep (she seemed to be in a trance-like sleep - rigid and did not wake when he prodded her

$5.50 \mathrm{pm}$. The wife washed her hands, pouring the water out of a small jug over her hands into a small basin.

$5.51 \mathrm{pm}$. The wife poured out glasses of "rum" (bought from another house or a merchant for 2rs. and said to be "not so good" - not strong enough). This was handed to each of us to drink with the meal; previously, when we had first arrived we had been given mugs of coffee (very tasty - flavoured with black pepper instead of sugar). The Lt. at this point proudly brought down and showed us his plastic "keep warm" coffee set, bought in Hongkong and not yet used. He told us that during the previous six months he had had 4 British officers to stay, some for one night, some for several nights. Gill was then given water to wash her hands with, 
thought to be dirtied when she prepared the pepper. We were told that meals were taken at 9am. ('kai tsava'), at 2pm. ('proken tsava') and at 5-6pm. ('kai tsava').

$5.55 \mathrm{pm}$. The meat was taken off and we were given a large bowl of soup each (with lumps of fairly tough goat meat in it). The Lt. out of politeness started to eat with a spoon but abandoned this after a while. Only the Lt. and ourselves eat now, the wife and daughter waiting until we have finished our complete meal before they eat - they did not seem to have all the foods we had. The soup, made in a huge (about 4 gallons at least) cauldron, was made of fried meat, spices, brown flour etc. It was heavily spiced (including ginger?). We were unable to finish ours, but they did not seem offended.

$6.00 \mathrm{pm}$. Some plates were cleaned with ashes from the fire (as we left, the daughter was preparing to wash up the rest on the edge of the verandah outside the house). Then a flat pan, about two feet across was put on with about half a pint of buffalo milk which was warmed and then put in bowls for us to drink or mix with our rice.

$6.05 \mathrm{pm}$. Bowls of rice were distributed; we were given a large soup bowl each of the "very best" (sweet indeed!) rice and the Lt. was given a large plate which must have held about 3 soup bowls worth. The wife served the food while the daughter carried and distributed it. We were each given 4 dishes and a bowl of milk. Rice, potatoes in spicy soup, radishes with red (pepper?) on them, fried meat - the latter especially delicious rather like Marmite. We waited until the Lt. is served and then begin. The Lt. washes his hand after eating rice with it. The meal is delicious though very hot and spicy and such a quantity that we are unable to eat it all. The rice that Gill leaves is given to the pet dog (which has been allowed in during the cooking), though the other left-overs are probably saved. The Lt. eats a vast amount. After the cooking is finished the cauldron with the soup is put on again.

At this point a "guest" is announced though we never see him and the Lt. merely communicates with him through the window by shouting. He has come from another, fairly distant, village (district no. 3) and has been sent to the Lt.'s house by other villagers for hospitality. We are told this often occurs, sometimes every night. The man will sleep on the verandah; he seems to be given a few things like salt, etc. and starts up a fire on the terrace outside (with given wood?).

After the meal the Lt. fills a hookah (price 36rs. in Pokhara) with embers from the fire, and starts smoking it making a bubbling sound. Apparently, not many people have hookah's in Thak. Between puffs he cradles his daughter. The tobacco is also bought in Pokhara, though it can be made in the village (similarly with pans, eg. the huge pan used for soup was made by the local blacksmith). We ask why some device is not used to draw off the smoke from the fire since the Lt. complains that it dirties all his nice shining pans. He says that it is useful to strengthen the wood and to prevent insects etc. eating it; unpainted as it is it would otherwise deteriorate more easily. (As Gill later pointed out - it would also mean that building would be a speedier and quicker operation since wood would not have to be cured. The little girl and grandmother curl up on a mat and go to sleep. We retire. It is about $7 \mathrm{pm}$. Apparently the sleeping positions are somewhat as follows: (sketch) 


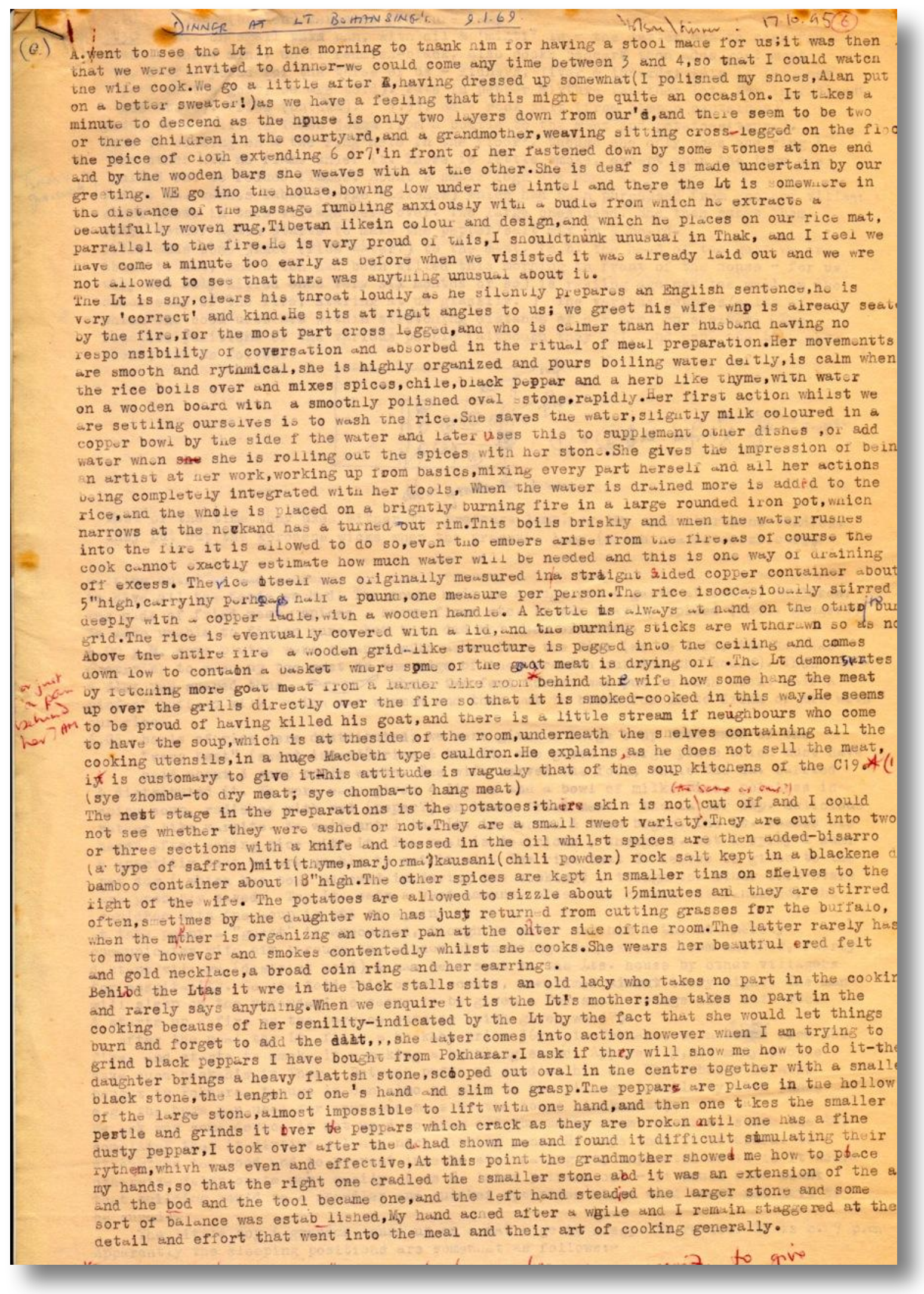

Part of the original description of the dinner at Bhuwansing's 
Yesterday evening (about 4-7pm.) we went out to supper with Lt. - hence no entry. Today we have spent at home, learning a little Gurung, digging a pit latrine on the mountain side, measuring our loft, etc. Gill's cold/sinus worse today and she felt bad when getting up. We both dream a lot - often hers are unpleasant and mine very vivid (last night about ballet dancing). We have argued a lot since coming back from Pokhara: I'm very irritable and Gill likewise. Discuss whether our marriage is breaking up. Decide not! Why? - external pressures? the break-down of my neurotic routine? the lack of privacy - people even come upstairs to watch us working, etc. The weather very overcast and cold - the Himalayas completely screened off in cloud. A few drops of rain in the night. A lot of people eg. Ramchandra, schoolmaster, off in Pokhara. Also seems to be the season for re-thatching houses. At least a dozen of these have been re-thatched in the last two days. People also busy at the forest gathering in extra firewood in case there is rain. Our old witch (grandma) next door, ill so gave her Enterovioform. Taking Aspro up to a house on the hill to an old woman who has rheumatism. She offered me some "rum" - as a payment?

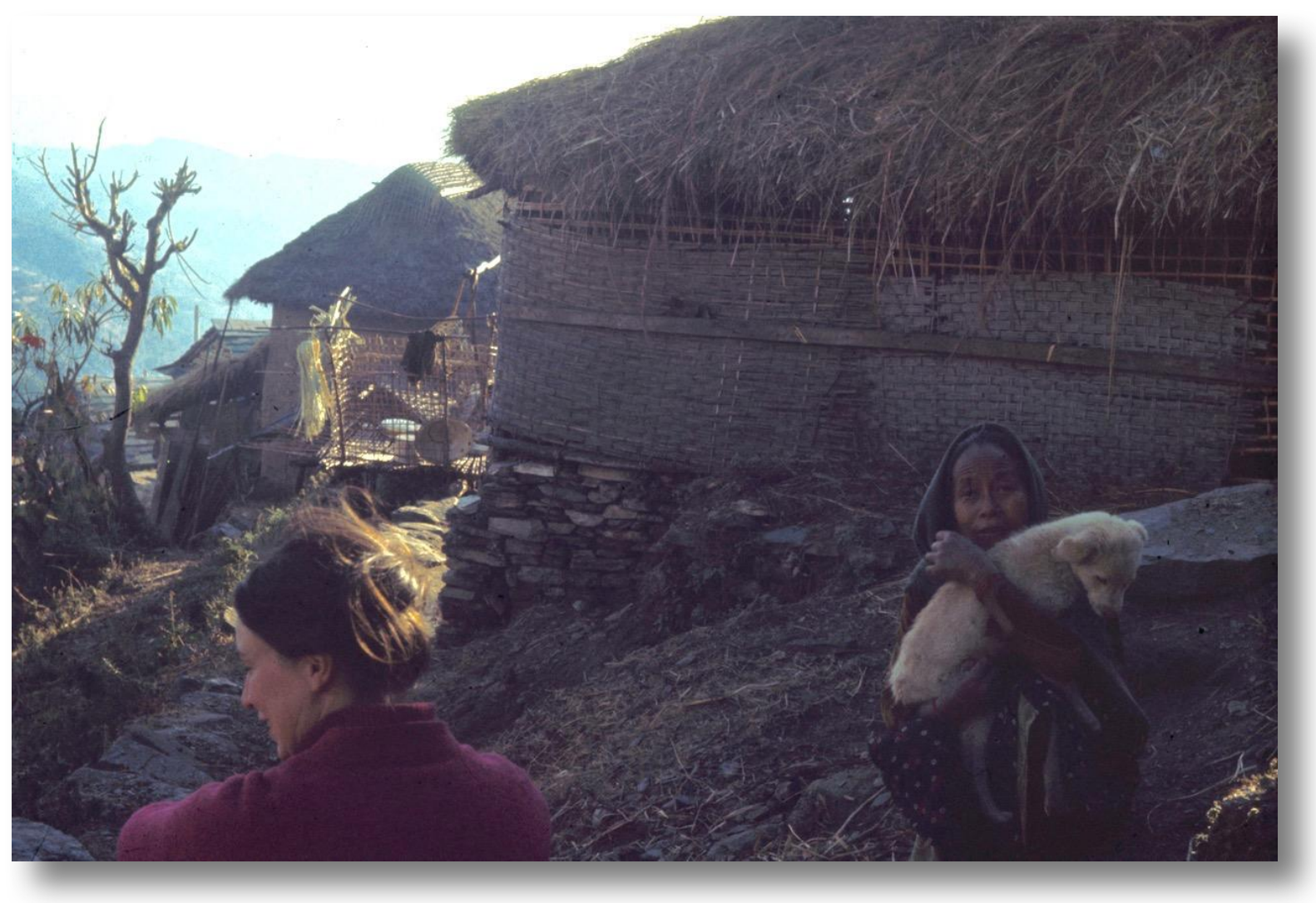

Baikumari ('chuckly granny') holding a dog, near her house at the top of the village

Just for the next ten days I will include all notes to show what they were like. After that I will include only longer notes.) 
ALAN NOTE 11.1.1969 Household goods

(Note vegetables. etc. bought in village). Our used bottles and tins are in great demand. The woman to whom we gave an empty tomato ketchup bottle gave us in return about 3lb. of tomatoes - a pleasant surprise! The woman who I am daily taking Aspro to for her rheumatism invited me in for a drink of 'pa'. There are apparently 8 pressure lamps in the village (not including ours), one household having three. They seem fairly (absolutely) closely correlated with service in the army. The family next door (House32) has one - kept in their attic - but don't seem to use it. Kerosene too expensive? There are also 5 radios (transistor) again excluding ours. We quite often hear these playing on the path above our house. For the educated Nepali they seem a great status symbol - being carried everywhere.

\section{ALAN 11.1.1969}

At our evening sessions, at the moment usually between 10-30 people come to watch us eat, to drink Horlicks, and to listen to tape- recorder or guitar. Mostly they are under 20 - boys and girls mixing fairly freely. There seems little restraint on conversation - eg. yesterday the married Prembahadur and the unmarried (23 year old F.) Tankowri both came for a cup of coffee for breakfast. She gave up her stool ('mora') for him, but they chatted quite happily to each other.

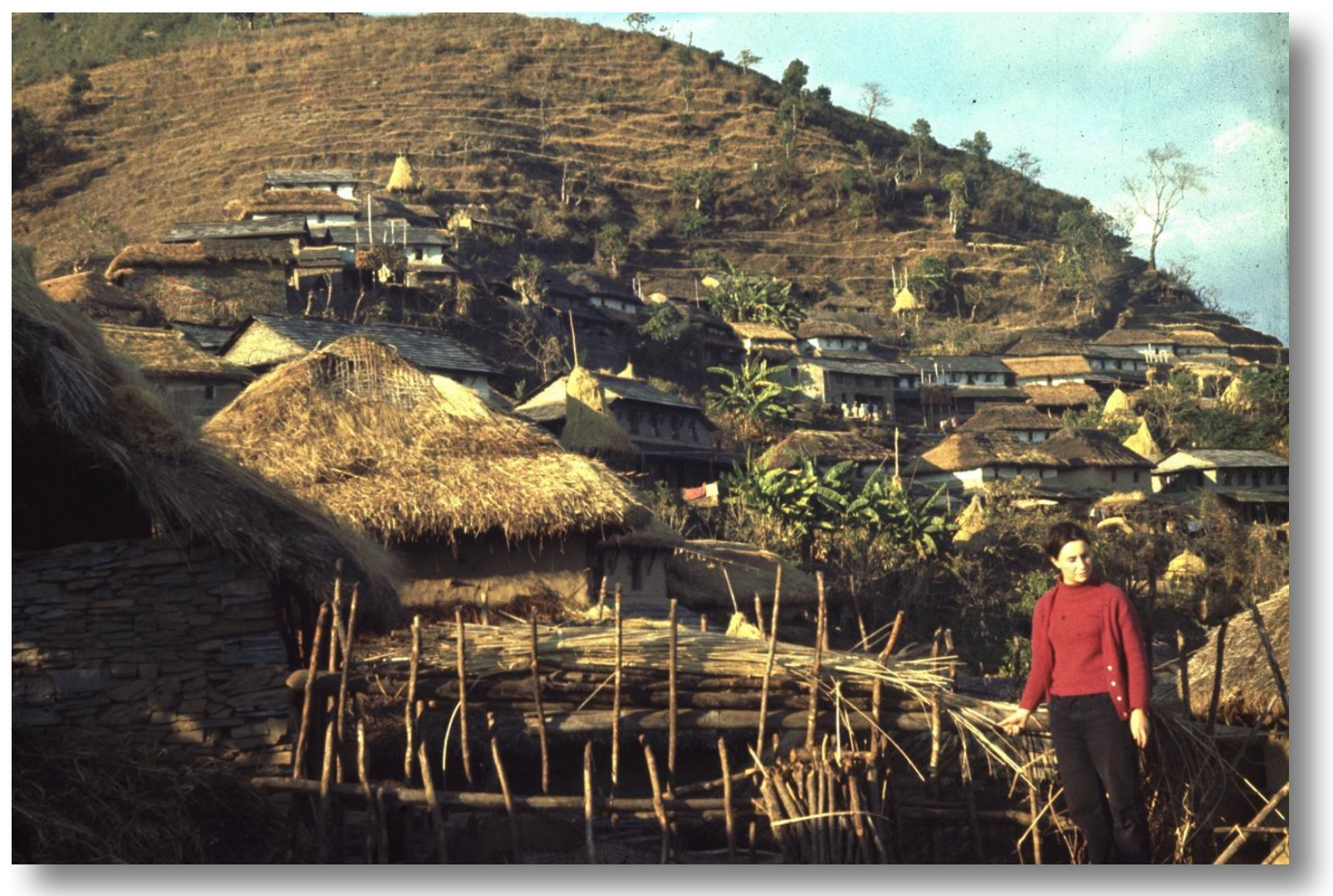

Looking up village from Kwi nasa, with Gill on the right, January 1969 


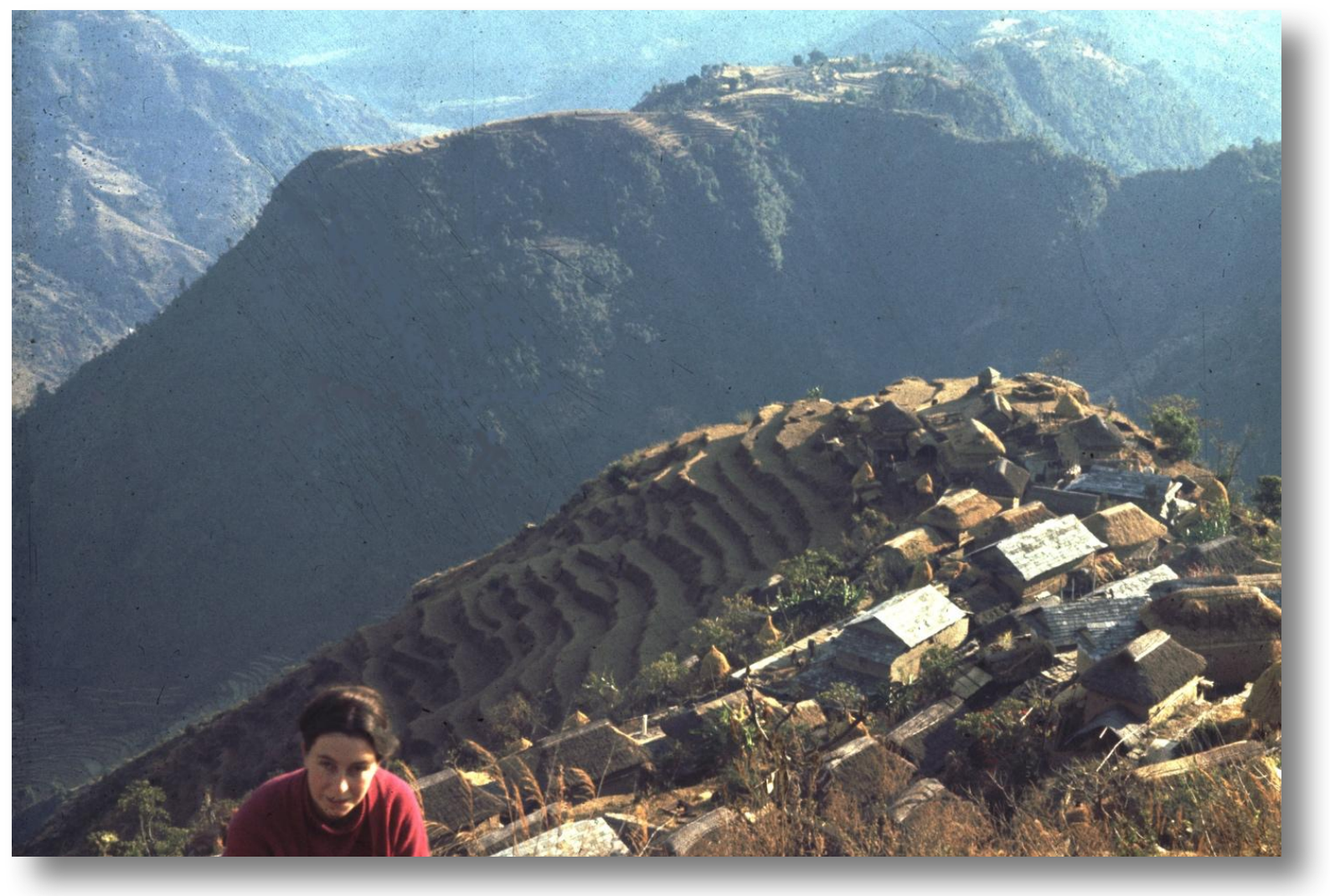

Village seen from above, with Gill in foreground, January 1969

\section{ALAN 11.1.1969}

The evening write-up disturbed by the arrival of two young male Gurungs who sat and smoked, wrapped up in Gill's coat? Then the evening journey to the rheumatic woman took longer than usual - her son-in-law had taken off his big toe nail and cracked his toe falling when herding animals? Applied Savlon etc. He wiped off the muddy-looking concoction of millet he had previously used. Gill meanwhile had been called away to watch the women mat-making and had earlier wandered round the village. The Lt. and daughter came to our sing-song - translating the "Owl and the Pussycat" etc. to the amusement of the Gurungs. Mat-making characteristic of this cold spell of winter monsoon? 


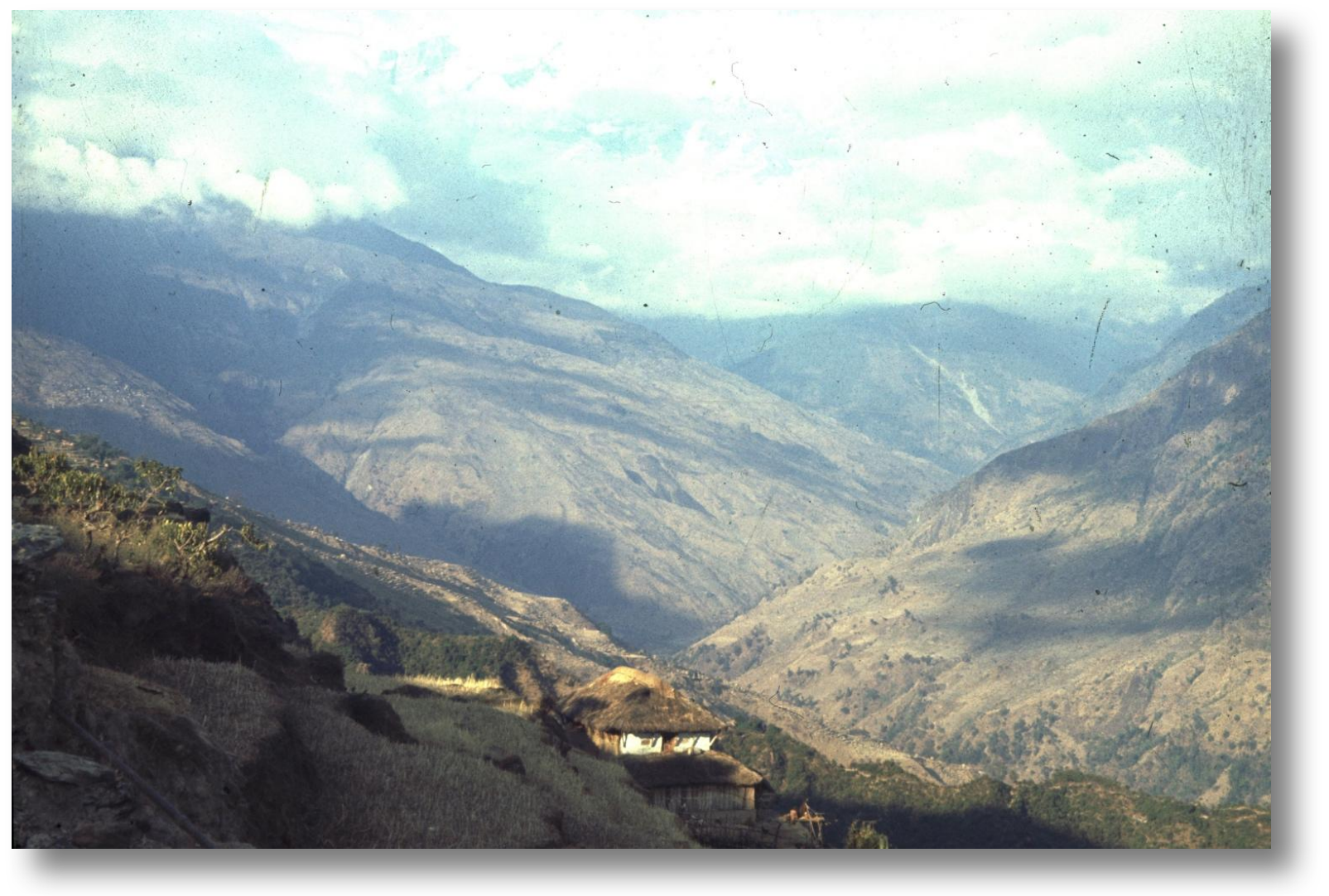

Looking up the valley towards Siklis village, from fields above Thak village, January 1969

ALAN 12.1.1969

Very cold again; sunless and temperature about $48-50$ at $8.00 \mathrm{am}$. We go in the evening to watch the Lt's daughters make rice rings ('kae jonva'). She prepares a flour from rice in a huge cauldron, then heats up about 7.5 inches of fat in a frying pan and then drops the rice in with a circular flowing motion. The rings are taken out after about half a minute - very like batter. No flavouring. She continues for about an hour, making a bucketful to take to Siklis. We are given 'pa' (rum) and then I play a couple of songs and the Lt. sings to tape- recorder.

12.1.1969 Alan

Distance travelled

Prem has been to Ghandrung three times; once for a funeral and twice for a marriage (Poju's - far wider travelled?).

Conversation and Nepali song TAPE REGORDING

Bhuwansing and women talking about the other song recording done earlier which weren't done properly because of the people talking in background and laughing in the middle of song. Then Bhuwansing sings a Nepalese song which goes as "Rato bhale kuribai karyo, garibai ko nisafhai harayo..." The song tells about how poor people live in the country side and how difficult it is to survive for them.

https://sms.cam.ac.uk/media/2732941 
Nepali Hindu Bhajan TAPE RECORDING

Bhuwansing singing a Hindu bhajan (i.e. song praying to God) and the song goes as "Jaya bhola nathaki damaru, Saab dukha hamro haru...."

Nepali - Hindu Bhajan

https://sms.cam.ac.uk/media/2732958

Bhuwan Sing bhaje singing a hindu bhajan and the song goes as "Bhajan garo hari naam aba ta...." TAPE RECORDING

https://sms.cam.ac.uk/media/2732975

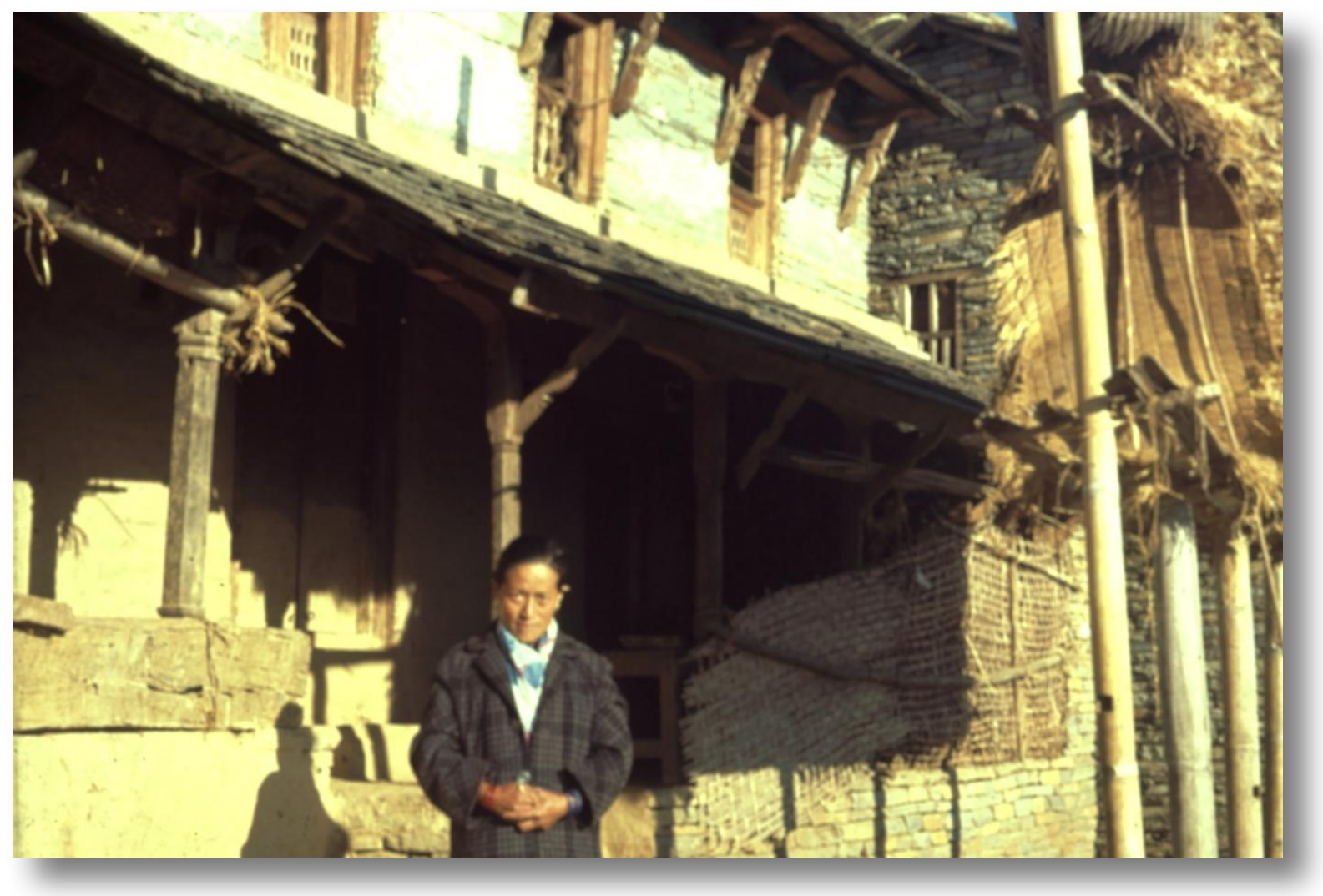

Asmaya, the daughter from next door, standing in her best clothes in front of our house

\section{DIARY ALAN 13.1.69}

Written in a loft in Parche village, waiting for the two inches of snow that fell in the night to melt so that we can go on to the festival at Siklis). Yesterday we journeyed from Thak, leaving after breakfast ('pa' and fried rice crisps followed by rice, spiced soup and meat (goat) stew, followed by coffee). We finally left at $10.30 \mathrm{am}$. It was teeming with rain and rained for half the journey. The Gurungs do not seem to mind rain - many of them carry umbrellas, the rest walk with bamboo matting over their heads or rugs. We took the journey easily, coming down to the river via Taprang and arriving here (about half a mile from Siklis) at 4.30pm. We were fed on omelettes and 'pa', and later on rice, chicken and 'daal' by the family fire. Apparently it is taboo for guests to watch the family eat, so we eat afterwards. Apparently it would be considered bad for a man to eat with his wife and daughters - they eat afterwards. But the Lt. who has travelled widely is prepared to do this. Reaction to snow - no one seems very pleased at it though not depressed. In the night tremendous hail and thunder 


\subsubsection{Alan}

Chetri's house

There is one only in Thak Panchayat - very near boundary with Taprang. Lt. Bhuwansing borrows fire from on return from Siklis and Chetri enters our and his house very freely, though he says Brahmins and Chetris's do not eat rice or intermarry with Gurungs

Brahmins

A few houses of - well out of Thak, lower down the slope. Bhuwansing says they do not eat with Gurungs - rice etc. - or intermarry, though when a young Brahmin came to his house the other day he was entertained quite willingly (given rice rings). Bhuwansing says this was because he was young.

Hygiene

On hill approaching Parche, a village lying on an open hillside with no woods at all around, about a quarter of a mile from village around a stream gulley, there are many faeces. This is obviously the village lavatory. Nothing like it in Thak; obviously geography a major deterrent.

Knowledge of 'Thar/Jhat' by Lt. Bhuwansing.

[List - see file - not very accurate]. When the children of a Thar meet they call each other brother/sister. Those who can marry are 'ngolong' or 'ngolsho' (= symbolic friends). Thus these are patrilineal/exogamous lineges - one cannot marry into one's own clan. There is preferential marriage between man and his mother's brother's daughter (ie. cross-cousin)

\subsubsection{Alan Diary}

Spent morning in freezing loft waiting for snow to unthaw. Afternoon to Siklis. Passed sacred spring where animals were sacrificed and also the graveyard for Siklis about half a mile from Siklis. At the stream there were many water-mills - at least a dozen. Apparently only two in Thak, since streams are so far away (on boundary with Taprang). We arrived at Siklis - a big village divided into sections (the Blacksmiths lived slightly apart from the rest, about 25 yards separating their houses from those of others) and on the sloping hillside. We were told about 4,050 people, but I reckon about 2,500 - about 300 houses. Houses much as at Thak, though several had corrugated iron roofs. We were immediately shown to house of Pospir Gurung (ex R.S.M. British Army - wife's name, Birimaya, daughter's, Premkumari) who insisted that we stayed the night. The Lt. unwillingly agreed and so, after usual meal (rice, 'daal', meat stew (goat) and much 'pa', we bedded in host's bed and slept. Very cold outside with snow slushy. Inside very cosy. Our host and friends talked until 12.00pm.

\subsubsection{Gill DIARY}

Recollections after 3 weeks in Thak. Dismay at height of village - it towered above on a seeming unscalable cliff and our anticipation had not reached that height. We had slept in the wrong school. Alan fretted about non-appearance of Ramchandra and set off early after breakfast to climb the height. I sat trying to avoid Tibetan tea which I wasn't in a mood to stomach. I was a bit angry about taking days instead of hours; I projected it onto those whom I considered could have been more helpful, and were not. Just as Alan disappeared, Ramchandra appeared round the corner. Loud yells up the hill for Alan to return. He does and we set off, the porters lumbering and tired, the elderly one who has TB and has developed a sore back taking it especially hard. 
Ramchandra moves surely, effortlessly, I think amused at my panting efforts, I still have not got used to walking on an empty stomach. Ramchandra says "walking is the only way of moving in this country". He steps on a craggy outcrop to look down on the stumbling TB porter and me. Alan is ahead, keen to see the village we might study. Even he mutters that we would choose one at the top of a cliff. The track deteriorates and merges into dusty rubble. A drooping banana tree is ahead and we stop climbing. I am too out of breath to take in my impressions but follow on Ramchandra as if in darkness. We trudge for 4 mins. to emerge into a small paved courtyard backed by two Gurung houses and a long, well-made open structure which we later find is where we should have spent the night.

The porters gladly drop their bundles and get into a huddle so that Alan can negotiate wages. Our interpreter is Gelsun, a schoolboy from the Tibetan camp, prematurely old with a business sense sharply belieing his 12 years. He looks discontented when Alan explains the wage amount. Thinking this will be over soon I can absorb the bystanders who are certainly absorbing us. There is a crowd of 20 or more villagers; the first thing that strikes me are the snotty noses of the children, bright brown shining eyes, their noses sticky with phlegm and grime. I have an urge to rush round with a handkerchief.

A dispute over the wages disturbs us all. Alan had to use the typewriter to put our terms in writing. We feel the Tibetans are really milking us; one, the strongest, is especially belligerent. Alan remains calm considering how he hates money and wrangles are we feel, always associated with it. The porters become depersonalised in the wrangle, as we inevitably do, machine taking over feelings; Alan typing, I wander on. We both feel depressed. The typewriter only thrills the villagers. There is a stir and a craning of necks. In the unpacking an orange, bought in Pokhara, falls out and splits. We offer it to the villagers and Ramchandra indicates that we give it to the baby, held at the back of the crowd.

Privacy and decency - Alan 14.1.69

Bhuwansing et al. - when sleeping in loft together with four others, all of us sleep, change (discreetly under bathing towel technique) etc. with no shame or embarrassment although two girls and four men.

Greetings Alan 14.1.1969

When we arrived at Parche, near Siklis, the Lt. greeted the host, the richest man in the village, by kissing his feet and the Lt.'s daughter did likewise. They both did the same to host's wife (we were not expected to do this)

Distribution of wealth

Difference between house 24 and 57 -

utensils. (Black and white photo 107-8). PHOTOS 


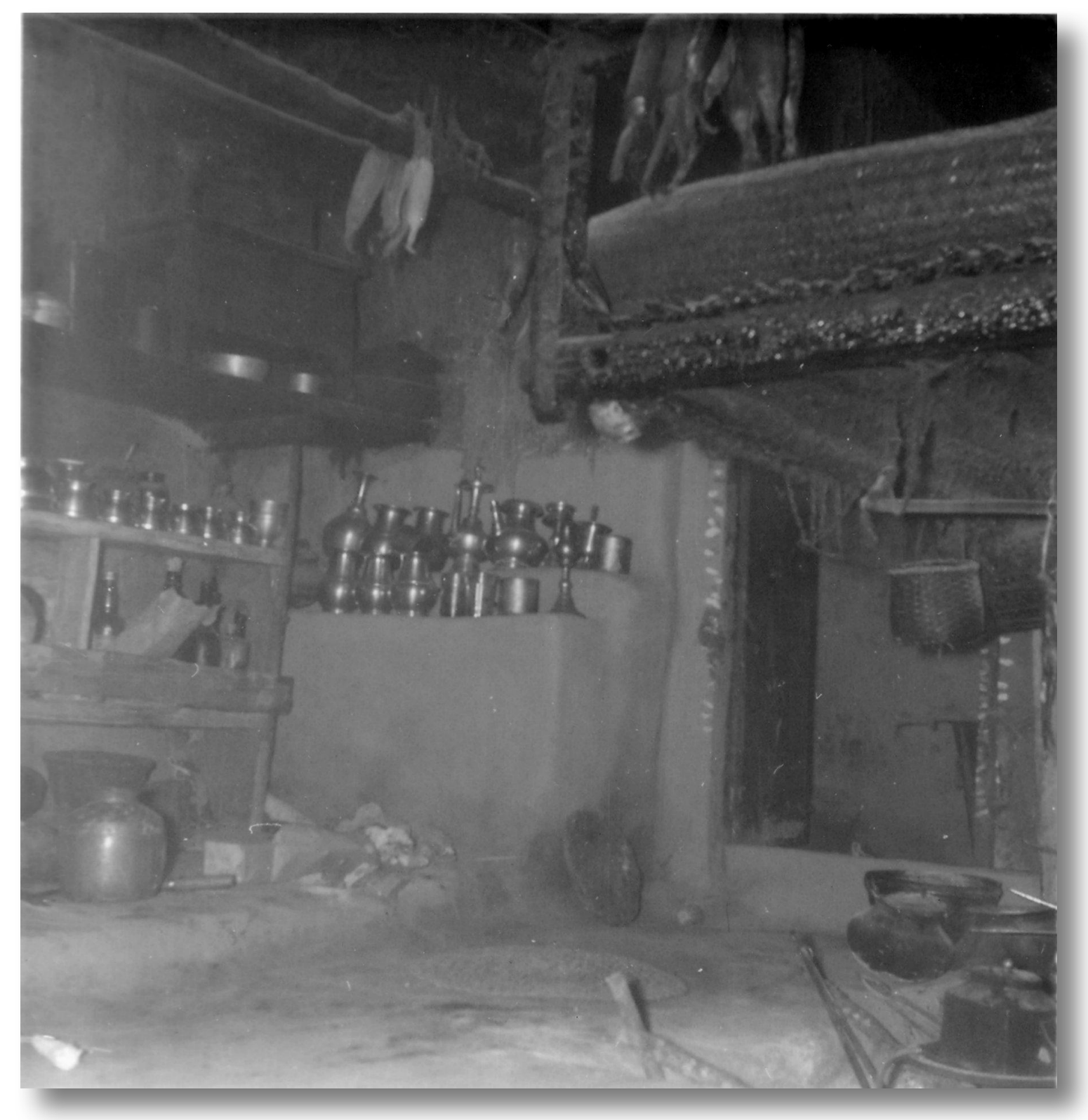

Utensils in a richer house 


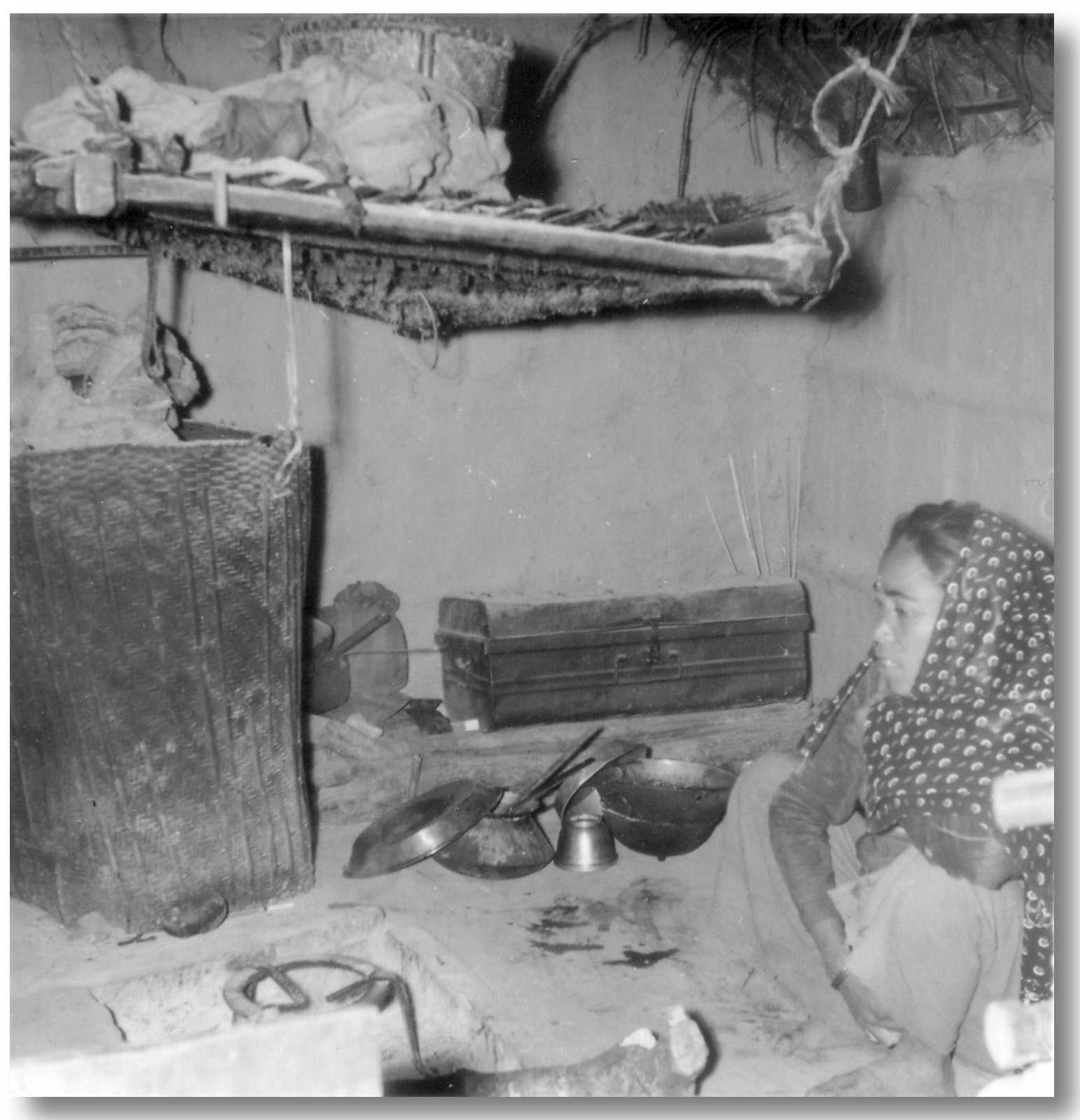

Utensils in a poorer house

Visiting and neighbourliness Alan 14.1.1969

On expedition to Siklis we stayed with various friends of the Lt's who fed and entertained us free. This the Lt. described as "one good custom" in our country and it is obviously reciprocal and necessitated by the absence of hotels and hostels. But Lt. took a few presents - three bottles of 'pa', some sweet potatoes, rice-rings etc. and gave them to various families.

Notes by Alan on 14th January 1969 'Tale pibha' - diviner (cunning man) Bhuwansing tells about thief-catcher, who uses rice and divining stick to find lost property; the person who has lost the property, apparently, goes into a trance, is given the divining stick (?) and rice is put on his or her head. He then seeks out the thief. A case happened two years ago when rice was stolen in the village and the thief was found (apparently he (the thief) is still in the village $=$ name?). Diviner uses "books". The name of the nearest one is Surjebahadur 
and he lives at Noledada (cf map - hamlet below Thak on way to Pokhara). He is "quite old" and learnt his skill from another diviner. Before going to such a diviner, which is quite a big step to take, a person should consult with village and get permission of Panchayat.

\section{Ritual at 1st Mark - Alan - 14.1.1969}

Fathers wash their unmarried daughter's feet three times - early in the morning - at Holy Spring if possible, or just in house? - (all unmarried daughters) - this is the only time in the year when this is done and only to unmarried daughters (?husband- wife?). Fathers then wash their own forehead and hair (?) (drink?) with same water. Also fathers give their unmarried daughters some money (a little) (Inf. Bhuwansing)

At dawn many people go to Poeba Kyu (Parche or Kyu phui (nr. Siklis) (washing places), where goats and cocks are sacrificed and people wash themselves ceremonially. On this day 'chura' (oat-like rice) mixed with sweet potatoes ('teme') and rice (and grey colouring?) is smeared on our and everyone's brow so that a few grains stick. We eat rice, 'chura' and 'teme' today.

Wealth display 14.1.1969

Clothes - Lt's. daughter (Bhuwansing). Each of the 21 cowries in daughter's necklace is worth about 250rs. Her six (?) bracelets are worth about 4,000rs - they were bought from Malaya. The Lt. disapproves of such extravagant customs (but is forced into following).

Separation, divorce and re-marriage 14.1.1969

Re-marriage tensions - when Bhuwansing's brother's wife died and he re-married the two children by the first mother moved out of the house; one into a house provided by Bhuwansing, one into Bhuwansing's own house, because their step-mother made them "work too hard" and generally made life difficult for them (= Subana (30) male; and Dilmaya - a little girl).

Daughter-father relations 14.1.1969 - Alan

(Lt. Bhuwansing (43) and Dankumari (23, unmarried). Lack of avoidance. On journey to Siklis they sleep in same bed, girl changes in father's presence etc. No shame or embarrassment. Cf. also under 'ritual at 1st mark' - father-daughter.

Investment of wealth - 14.1.1969 - Alan

Lt.'s daughter Dankumari wears a necklace of 21 coins, each of which is worth about 250rs. Her six bracelets of gold are worth about 4,000rs. These were bought in Malaya and Lt.'s wife has the same. Lt. thinks this is a bad (i.e. unproductive) custom and the money would be better spent on fields or put into the bank (but is obviously forced into conforming).

Food 14.1.1969 Alan

Tobacco is chewed by the Lt. 'Souti', a mixture of tobacco and black peppers etc. is, we are told, chewed by some men.

Reason for building villages on top of hills 14.1.1969 Alan

Gurungs like "the good air" and the "good view"; Brahmins and Chetris build lower down (compare Kirkby Lonsdale valley etc.) (Inf. Bhuwansing) 
Kinship Alan 14.1.1969

2 children of the same father by different wives are definitely considered brothers; while 2 children of the same mother by different fathers are not of the same family and may, theoretically, marry each other. (Inf. Bhuwansing)

Dankumari, Bhuwansing and Gill in Siklis for 'Mark Sangrati' festival

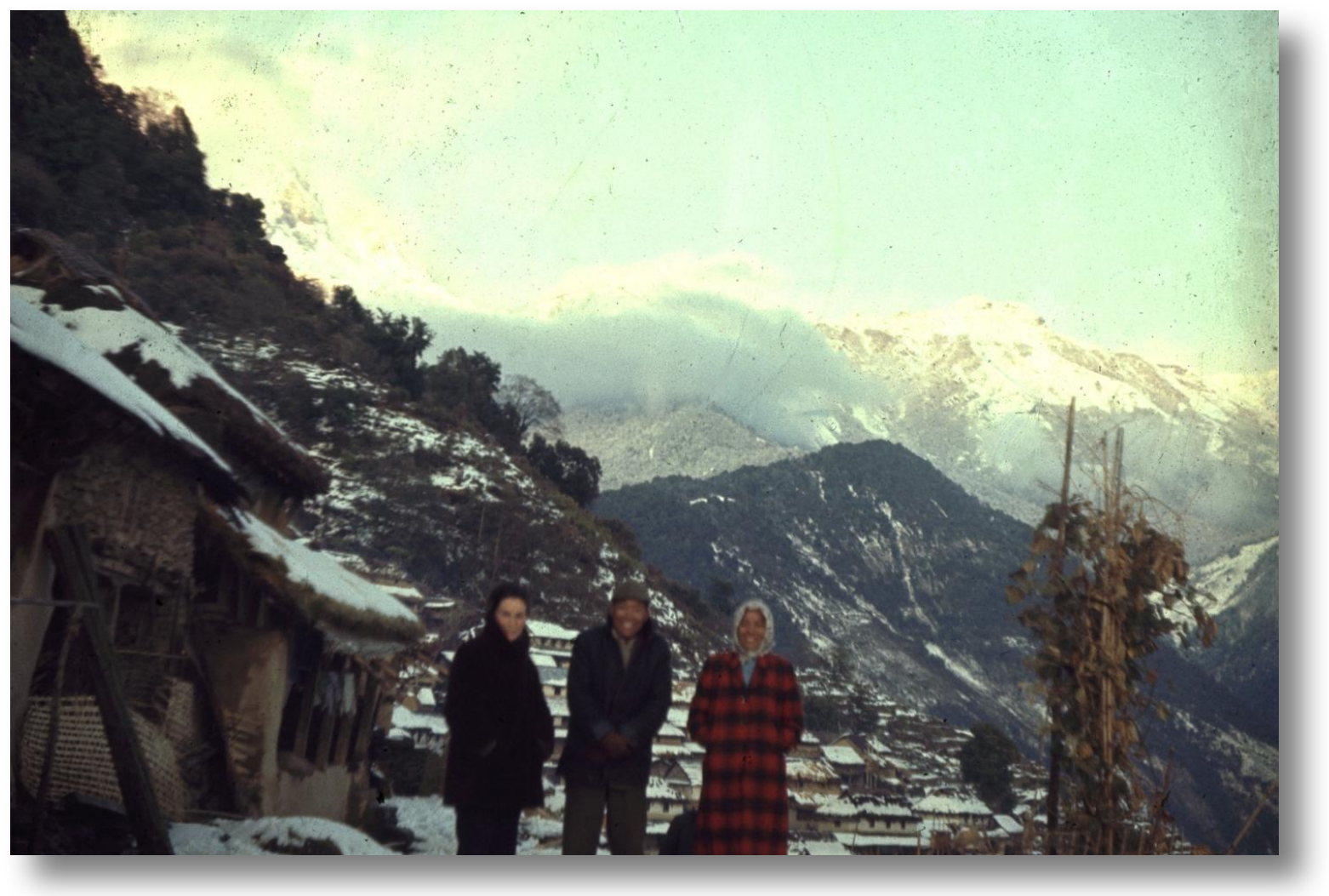

Gill, Bhuwansing and Dankumari in Siklis at festival

\section{DIARY 15.1.1969 Alan}

We spent the morning sitting round, drinking tea and 'pa' and eating - invited next door for tea and crispies. These house much as ours at Thak. Gill invited to be 'ngyelshaw' ("friend") of our host's daughter - a very pretty, but precocious 14 year old. Could not find out what this involved - except that they addressed each other at 'ngyelshaw'. Our host insistently tried to teach us Gurung, but Siklis dialect is considerably different to that of Thak (more clipped, less soft).

After hanging around, Lt. announced that we would not return until tomorrow, but we insisted on returning, so, after watching some putting of shot (competitive - overarm about 20 years towards a big rock; the winner's prize is gifts of money from proud relations - sometimes a relative will give up to 50rs. we were told, therefore prize money depends on the size of his group. This seemed to be the only corporate activity. We were told that if there had not been snow we could have watched dancing (paying up to 25rs. for this!). Above all, it seems to be a time when Gurungs meet up and chat. From Thak there seemed to be about eight others, apart from our party, mostly girls of about 20 (marriage mart?). All wore their best clothes (vide description of clothes 
So then about $1.30 \mathrm{pm}$. we set off back for Thak. A grim journey as the light began to fail before we reached Taprang and we seemed to take a long way back. Taprang is a pretty village - more spread out than Thak and with more barley fields, trees and groves, etc. - also a coffee shop (why not in Thak?).

We came the last 1.5 miles through the forest in the dark. Gill terrified and myself apprehensive, since the Lt. had said there were leopards/tigers here and had shown us the hoof of a cow killed by a tiger. He had wounded one a few days previously. Exhausted but relieved we arrived back. Glorious to eat hot rice. Lt. and party soon returned and we drank Horlicks together. The Lt. had been anxious to return since his "dream" was in Thak - ie. his wife and his thoughts. As well as rheumatism, we gathered she was suffering from postmenstrual bleeding - had been bleeding for some 15 days now (she stopped while we were away). He was obviously worried and was thinking of taking her to Pokhara. Interesting that he should (a) have discussed it with his wife (b) decide to discuss it with Gill. He obviously thought it a delicate subject, but did not seem embarrassed when discussing it. Throughout the journey he was very good-natured and friendly.

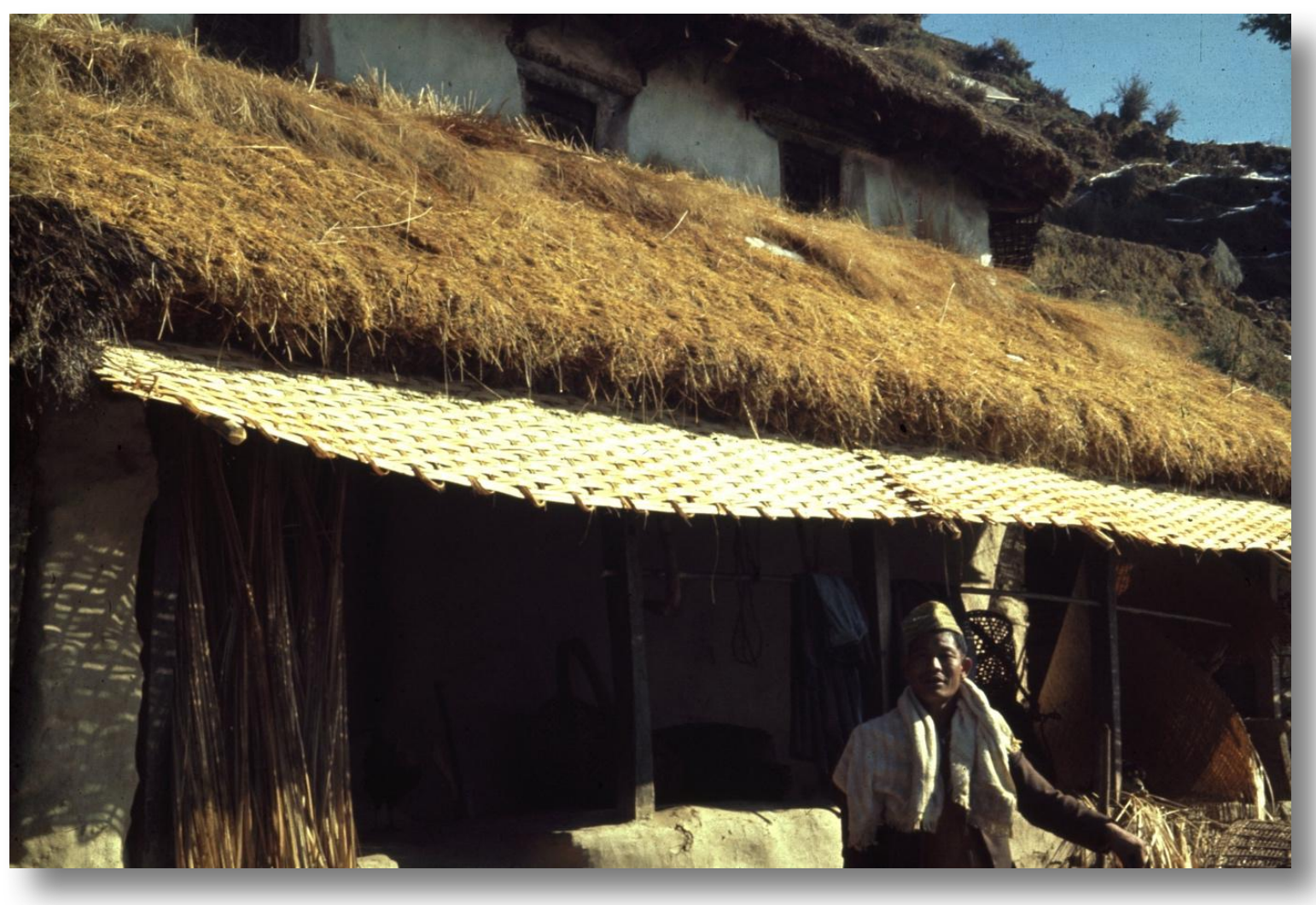

House of our host, Posbir, at Siklis

DIARY 16.1.1969 Alan

A friendly welcome from village: a number of people came to visit us and breakfast is a protracted affair. In our absence the water had dried up at the tap. I had to go down about half a mile to fetch some from another spring. No one seemed very perturbed and only after 2-3 days did people gather themselves together to see why the flow had stopped. Lt. set off for this purpose this morning, having gathered together three "machines" (mechanics?) which the village possesses for this purpose. 
Our major worry at the moment - apart from the rats which scuffle around at night and the toilet arrangements which have been improved by a bucket with disinfectant in the corner of our loft into which I urinate - is money. Having arrived with 480rs. nearly a month ago our money has still not come from England and we are now down to about 150rs. Keeping fingers crossed.

Army pensions 16.1.1969 Alan

One interesting fact we discovered in Siklis was the rates of British pensions. The Lt. gets about 120rs. (Nepali) a month, an R.S.M. gets about 90rs., a sergeant about 70rs. The Lt. is applying to be welfare officer for this region, which would mean that in two years he would leave here for three years to be about half hour's air-flight from Pokhara.

\section{DIARY 17.1.1969 Alan}

Very cold - temperature 45-50. I wandered round the village and noted various things and had two informants (Prembahadur, Benbahadur) in. Took second genealogy. Nani came in and disturbed all my filing system by taking millet out of big pannier under it. The Lt.'s wife visited us in afternoon and we entertained her by showing her photos of Europe, Gurungs, etc.

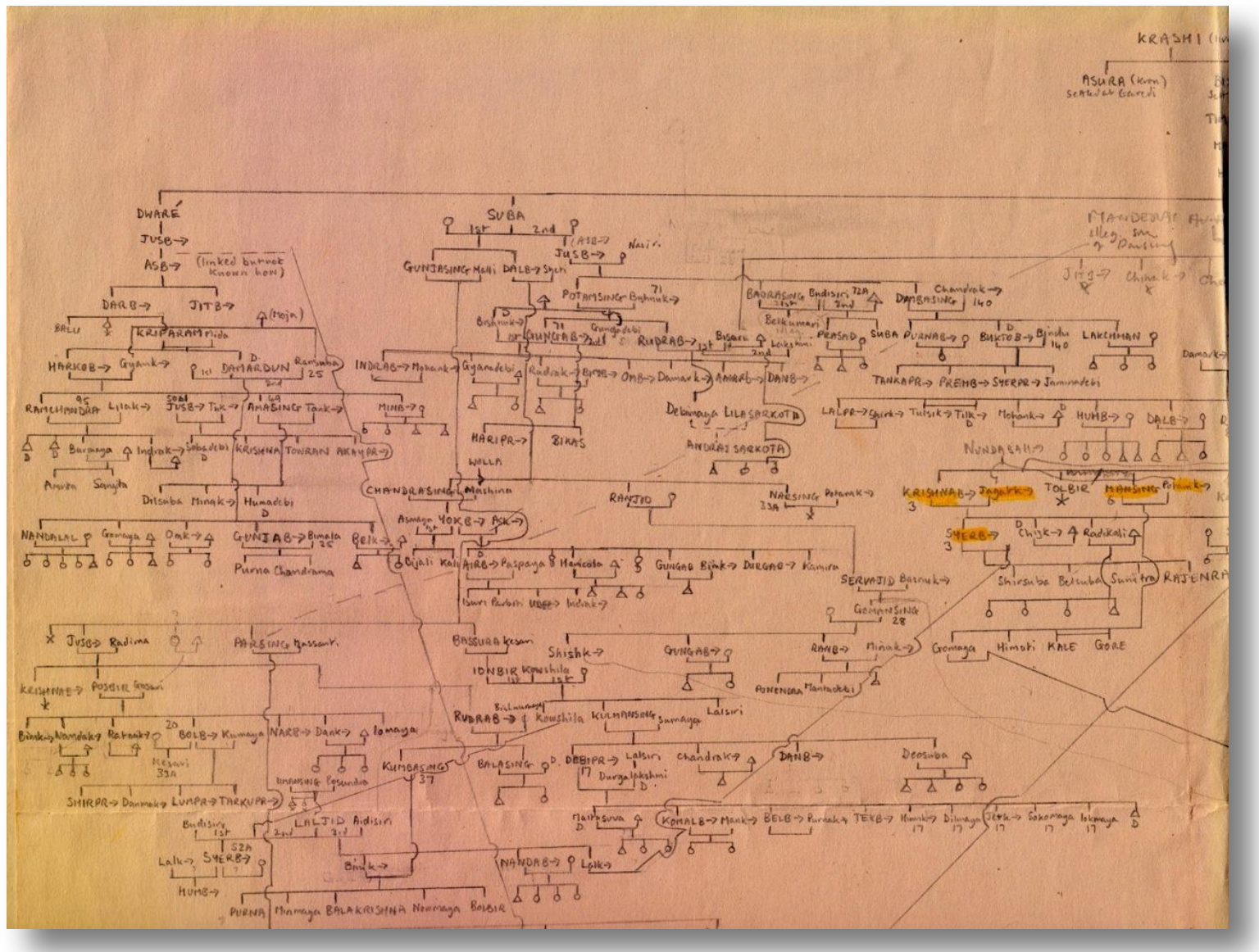

Part of a genealogy of the Kwonme clan 
Travel 17.1.1969 Alan

On journey to Siklis we stayed with friends of Lt. and obviously reciprocal hospitality is the most important means of allowing travel. People also sleep at 'tea-shacks' small 3-walled tea and biscuit stalls, dotted at about one to five mile intervals. Cost - a few sweets and cups of tea buying. Large parties, for example those visiting Siklis for festivals were put up in the Panchayat house and given a few cups of tea, rice-rings etc.

Law abidingness 17.1.1969 Alan

The young men of village (Prem, Bolbahadur etc.) seemed genuinely shocked when we openly admitted we did not have a licence for our radio (price 1rs purchased from

Panchayat?). Obviously there is no concept, as in England, of legitimate avoidance, the crime is being caught.

Poju 17.1.1969 Alan

Poju $=$ Prembahadur's grandfather, Prem will finally become one. He names children (after reading books etc. and working out astrological times); decides when houses should be built (astrologer?); tells people what sort of sickness they have. At Yagon (the village opposite Thak, on difficult way to Pokhara) there are three or four poju and at Siklis many. (Inform. Lt.

Bhuwansing)

Religion and temples 17.1.1969 Alan

At the end of the village near Housel there is a shrine ('Devi tana') in which they sacrifice chickens. In fact, about two fields below a chicken had been sacrificed only a few days previously (1st month). A few yards from this is a small stone enclosure ('kotha') in which buffaloes we are told are slaughtered. At the east side of the village is another shrine, roughly similar in shape, called a 'devi tana' at which goats are sacrificed.

Ritual at 1st Mark 17.1.1969 Alan

Big household in Parche (and other households?) send one man to "holy spring" to kill one "big" chicken and then this is brought back and eaten.

Ritual - degree of knowledge of 17.1.1969 Alan Bhuwansing - on journey to biggest (?) festival of Gurung year (1st Mark), Bhuwansing admitted that he did not know the significance or reason for the celebrations. "In our country we have no history" he explained (i.e. no written chronicles).

Incest rules 17.1.1969 Alan

(Bhuwansing) Marriage with father's brother's children prescribed, but favoured with mother's brother's.

Man and tool integration 


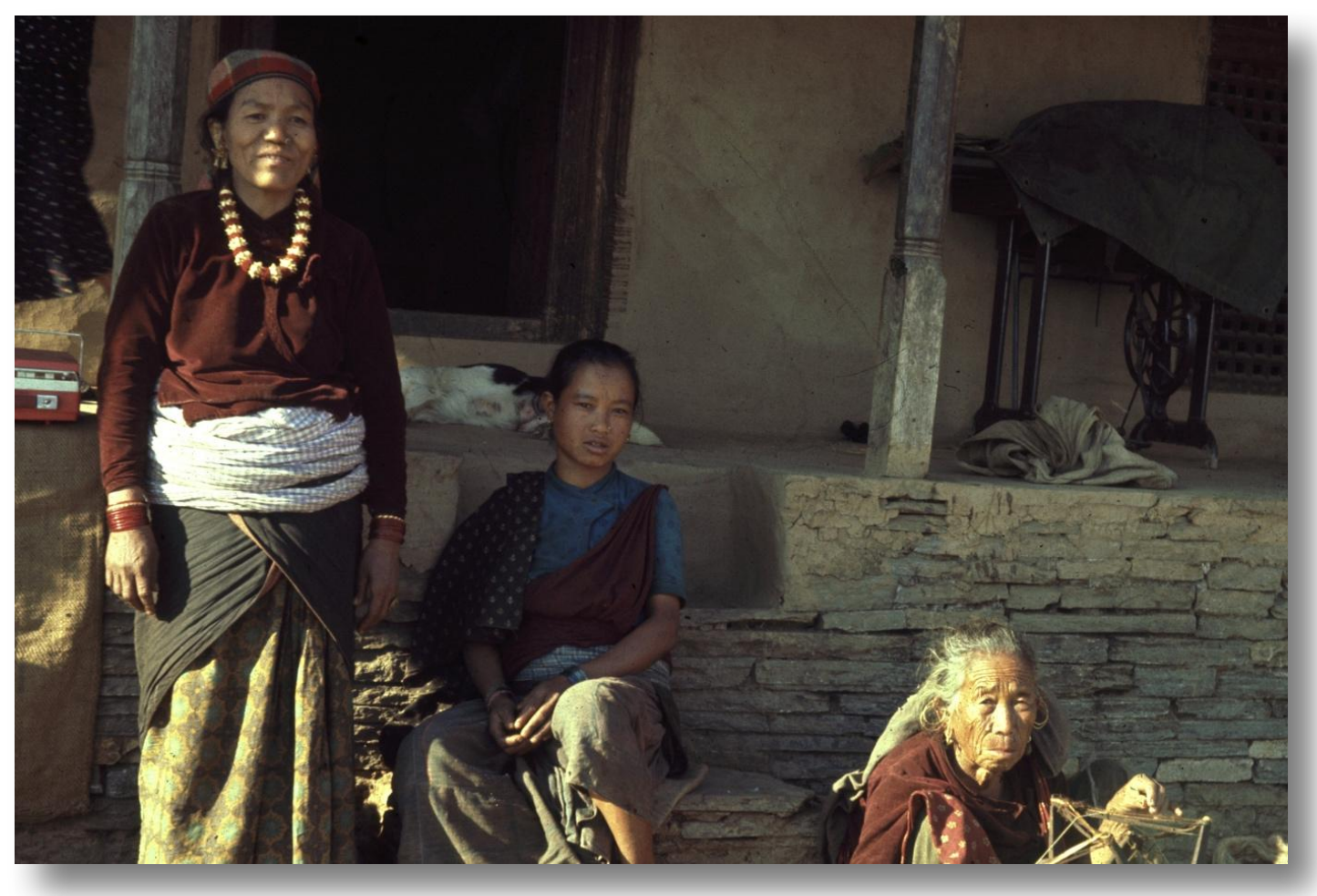

Nansumari, another young woman, and Saguna using a spinning wheel

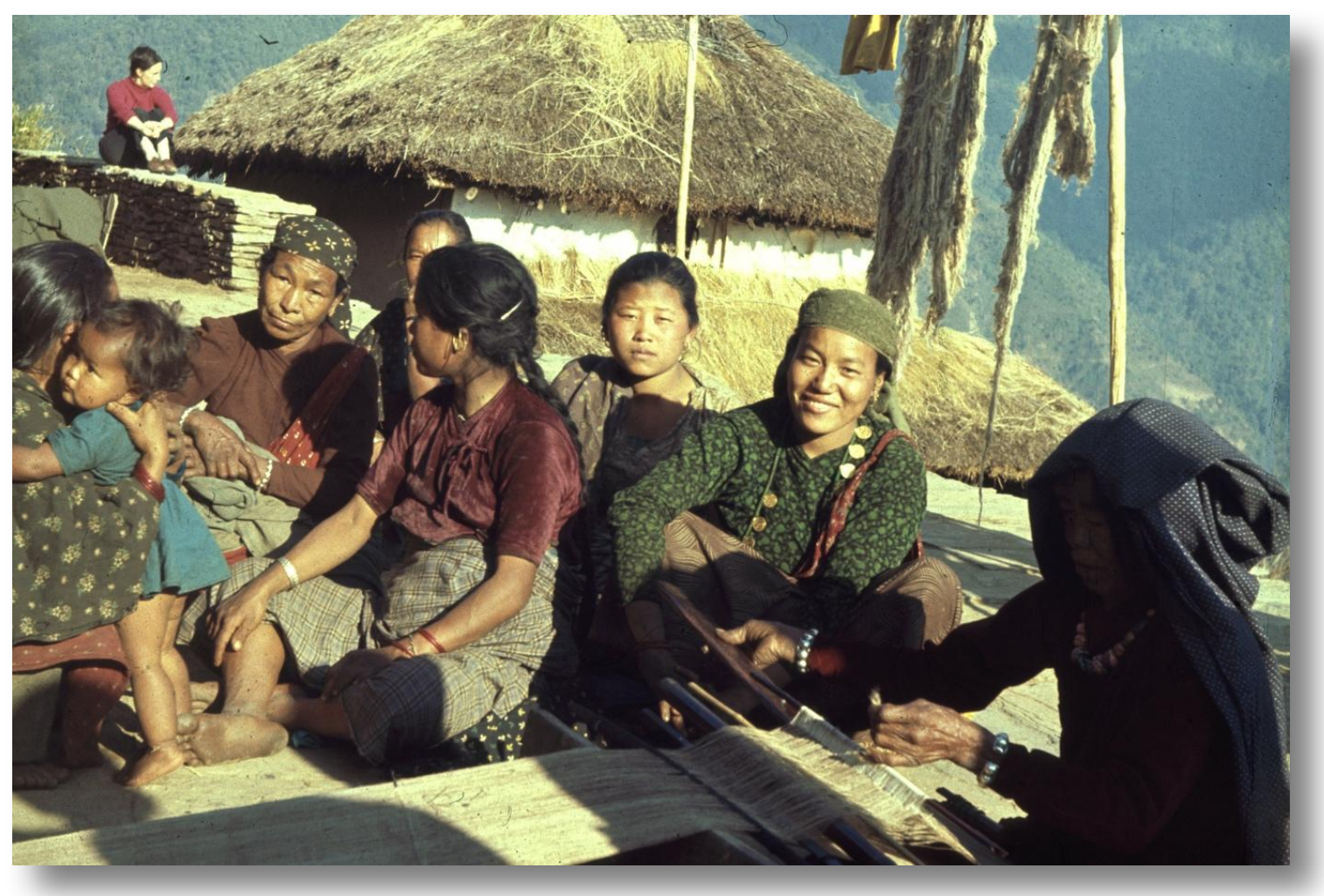

Nansumari weaving 'nangi' with Dankumari and other women, Gill in background 
weaving - 17.1.1969 Alan

a) preparing thread finger inserted in hole instead of handle

b) loom built around one

c) mat making

2) cutting vegetables and meat - knife held still, hand acts

almost as cutting edge

3) grinding black pepper - hand fits over pestle round mortar.

Property and fields 17.1.1969 Alan

Lt. Bhuwansing's fields are in about 12 parcels, though he does not know exactly how many fields he has.

Forestry 17.1.1969 Alan

the Thak panchayat are trying to stop people cutting smaller (younger) trees in the forest to let them grow, as they realize that wood shortage is likely. But the "less educated" disobey. Lt. realizes the danger of deforestation and makes comparisons to Parche where wood is extremely short.

Kinship perception 17.1.1969 Alan

Nansumari (Lt's wife) Great-grandfather not know "because I was only small when he was alive?" Therefore knowledge and personal perception very self-limiting?

Climate and weather 17.1.1969 Alan

the Gurungs seem to feel cold no more, and perhaps less than we do, considering how few clothes they wear and often no shoes; they shiver, but we would shiver, even more. And at night they probably wear less than we do. Considering low protein and energy diet this is amazing.

Flowers 17.1.1969 Alan

all called 'ta' - don't distinguish names? No, children know names of most common ones.

Clothes 17.1.1969 Alan

during this cold weather almost everyone seems to go about shivering. No-one except the very richest seem to have more than 2 layers - a shirt and jacket, jersey, cloak etc. Why so few reserves?

Mealtimes 17.1.1969 Alan

Prem. Eat at 9 o'clock in the morning and about 5 o'clock at night. Nothing in between.

\section{DIARY 18.1.1969 Alan}

A summer day. Gill washed (1.5 hours) - her oatcakes of previous night a success. Our crossness with each other has subsided - perhaps because we now prepare meals separately. Gill dressed quite a bad cut on a little boy's arm and we distributed penicillin to people with bad sores. Tonight - night to empty urine bucket. Feel I am burying treasure - every three nights. This afternoon we went to Lt.'s to watch rice preparation. It is not difficult to see why rice is central to thought/concern. It's preparation is fantastically complex/time- consuming: (trace its whole course from planting to eating and study labour returns on). 
People generally very friendly and seemed pleased to see us return from Pokhara [Siklis?]. Even our grumpy grandmother next door is friendlier. We are still a bit of an attraction at breakfast-time, people coming to watch us prepare porridge and coffee. This is also the time what they come with their various sores etc., which is not always conducive to breakfast eating. We are still being snowed under with eggs and almost every day brings a pleasant surprise present - a bowl of goat's liver from the Lt., a bowl of sweet potatoes from Major Ramchandra etc. etc. Vegetables are still a bit thin, also protein - but hopes of a chicken "when our money comes".

This "when - " is becoming a bit of a refrain as we still haven't received either money or letters since we left England some six and a half weeks ago. Often homesick - especially when snow fell at Siklis - but perhaps this is now wearing off. It would be lovely to get a letter though and I often wonder how Josselin and my witchcraft book are getting on. Gill misses her friends more, I think. But I really begin to feel that the language is beginning to come and ideas are beginning to froth to the surface at an increasing rate. I really think this attempt to "re-live" the C17 by going into a pre-industrial society will pay off big dividends, though, despite a really charming (gentle, courteous and gay) people, and superb scenery, it has been far from easy these first four weeks.

Meeting of Panchayat or just village "elders"? 18.1.1969

Meets outside night school, next to our house on this, the first warm day for quite a few days. About eight to ten middle-aged men (including Ramchandra) sit and discuss. Obviously such a committee is not considered full- time work since about half the men also weave carrying baskets as they discuss. 


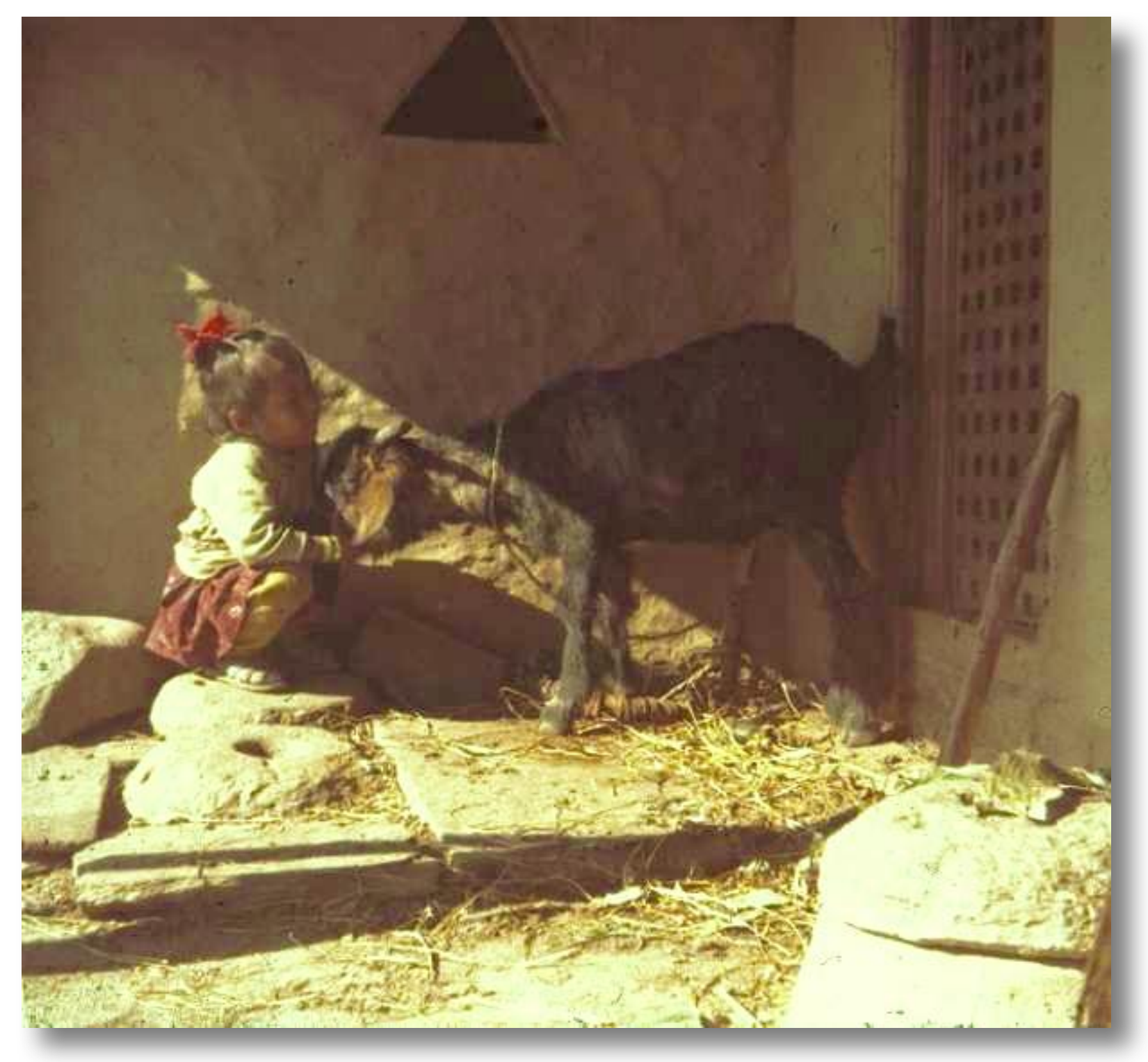

Sobadebi (daughter of Lt. Bhuwansing), with a goat - undated, January

\section{DIARY 19.1.1969 Alan}

The little monsoon seems to have broken as it was a warm sunny day today though still cloud over the Himalayas - temperature about 55o F. It begins to get light about 6.00am. and sun comes up over hills opposite us at about $6.50 \mathrm{am}$. In the evening the sun sets about $5.30 \mathrm{pm}$. and it is fairly dark by $6.00 \mathrm{pm}$. We start preparing our evening meal while it is still light at about $5.15 \mathrm{pm}$. though it is not eaten until about $7.00 \mathrm{pm}$. The inhabitants don't seem to eat until about $9.00 \mathrm{am}$. though they get up, with much spitting and clearing of throats, at about $6.00 \mathrm{am}$. They seem to eat only a very small amount, if anything, at mid-day. Pity - we were offered a blanket ('rari') from Parche, but could not afford it. Gill very under the weather depressed, coughing, sore-throat, headache, etc. 
Specimen of fibre ('noyin nangi)' 19.1.1969 Alan

just before it is spun and then woven into scarf - see description. Extremely coarse and tough. I gather it is made from a plant in the jungle which is then pounded and washed - a kind of fibre.

DIARY 20.1.1969 Alan

Gill not at all well either day - spent the second day in bed.

Weather very good.

I adapted a system of small index cards from my earlier training as a historian, and started to keep shorter notes on such cards, which were usually dated and could be sorted later. Here is an example of a few of these, when they had later been sorted under the heading of 'Marriage' 


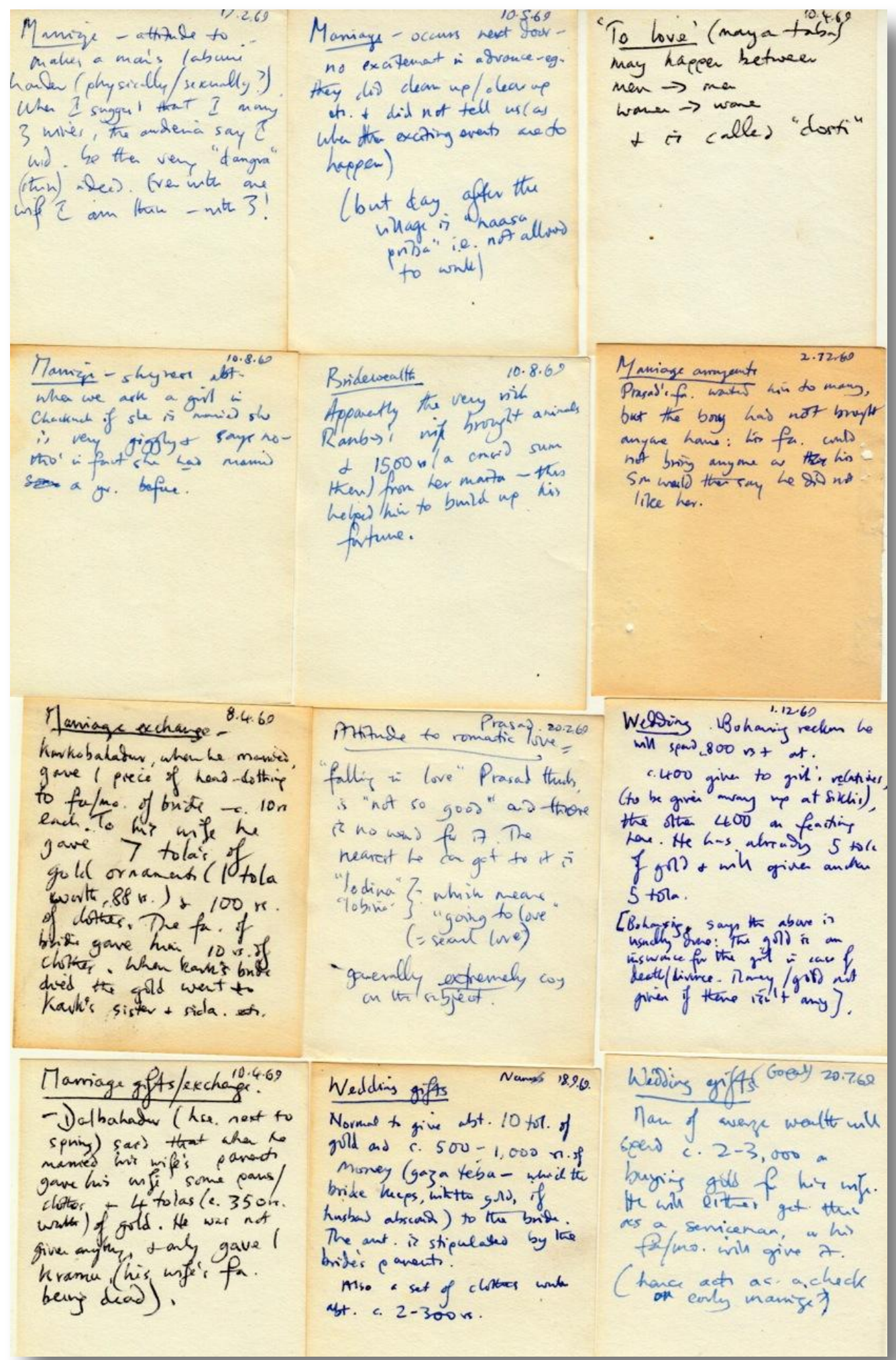

I will include a few of the earliest ones I made, on one day, 20th January 1969.

Contacts between villages 20.1.1969 Alan

"our Granny" goes to a village over the ridge opposite to our village to buy little gold decorations for Nani's ears. 
Mobility - horizontal 20.1.1969 Alan

Comalbahadur, aged twelve, had been to Pokhara three times in his life:- to Siklis, never, to Taprang, twice and had not been to the other side of the river.

Movement in village 20.1.1969 Alan

People follow the sun round the village (?) congregating on the SW slopes in the evening, where the sun lingers longest.

Caste 20.1.1969 Alan

Interesting that Blacksmiths employ 'poju' to sacrifice chickens.

Taxation 20.1.1969 Alan

Once a year (December-January) taxes (national?) are collected by Panchayat. With much shouting by town crier and arguing each household pays a tax of:- (large stone house) 6rs p.a. (for example our house, Prem's and Bhuwansing's houses; (medium) thatched house 2rs 25 pice (for example little house in front of us); (small) thatched house 1 rs 25 pice (for example Blacksmith's houses). These are annual taxes, for the whole panchayat the sum collected cannot amount to more than fifteen pounds.

Funerals and graves 20.1.1969 Alan

When asked if tombs etc. are put up, Prasad says one was put up at resting place to north of village (the little temple) "very old" but otherwise nothing. Some people are buried, some burnt. After burning a few ashes and bones are kept in the house for use in the 'pae lava'.

Children's work 20.1.1969 Alan

young girls of about eight to twelve carry their younger brothers and sisters on their backs with slings round their heads like water buckets in the seventeenth century.

Ash for agriculture 20.1.1969 Alan

its value seems to be realized in Thak - at least when I point to ours, but is it actually used?

What effect in sixteenth and seventeenth century England when wood gave over to coal? Had wood-ash been used before?

Winter feeding of animals 20.1.1969 Alan

In Thak a large number of journeys are made to the jungle to cut leaves etc. for the buffaloes (and chickens) stalled in the village. What would equivalent be in seventeenth century village? Turnips etc.?

Rhythm of labour 20.1.1969 Alan house-building takes place in December to February because then there is little or no work to be done in the fields. This is also the time of festivities etc.

Medicine 20.1.1969 Alan

Haricola ate a piece of rhodendendron flower - good for sore throats she said.

Herbal remedies 20.1.1969 Alan

used a lot - e.g. old woman applied 'bisarro' to cut on lip. 
Illness in village 20.1.1969 Alan

an untouchable (middle aged) called us, he was apparently suffering for 'Dumge' i.e. an illness whose chief characteristic he said, was panting. He was hot and sweating and said he had been ill for 10 days - sickness, failure to defecate etc. His arm was swollen, the Lt. said that a man with a similar illness died about 5-6 years previously after being ill for 5 or 6 years. This man, he said had been ill for 5 or 6 years.

Dish washing etc. 20.1.1969 Alan

In Thak dishes, hands, clothes and feet etc. are washed in cold water, perhaps because of shortage of energy and fuel perhaps because of ideas of cleanliness etc.

Kinship terminology 20.1.1969 Alan

'ali' - eldest son (in Siklis, but not called

here); 'aghi' - elder brother of someone; 'bhai' - younger brother of

someone.

List of lineages in Thak 20.1.1969 Alan

for details see original file. [Not very accurate].

Humour in Thak 20.1.1969 Alan

banana skin type very strong:- when (at what times), with whom - social context or joke itself; or what is seen to be in conflict with each other (ideas). Disharmony between individuals; disharmony between individual and environment; norms and practice; incompatible ideas.

House construction 20.1.1969 Alan

11 porters carrying stones up in small baskets on their back. Loads vary from 4-10 stones about. Mostly men but two women, who carry smaller loads. They come past in the evening and start work at about 7.15 a.m. (up steep hill).

Foliage and flora 20.1.1969 Alan

trees are (half of them) bare at this time of the year and there are few flowers; wild lavender is going over and bracken is turning.

Mark Sangrati 20.1.1969 Alan

Siklis on 1st Mark very similar to Scotland at Hogmonay - "first footing", getting drunk etc.

Notes by Alan on 21 st January on house-building

The house now being built of stone on s.w. slope of village costs about 6-8,000rs and has, to date, been being built for 1 month. It will probably finished in another 40-50 days.

Bhuwansing's grand house cost 12,000rs and took 3 months to construct and was built by 17 19 people. The smaller version, described above is being built by about 17-19 people. Stone is brought from a quarry down the hill, quite a way by porters male and female, who carry it in baskets and then back (in little houses 5 people are actually building. The brother of the future owner is acting as (unworking?) foreman and another 11 people are fetching water. The wood for doors and windows is brought from "our" 'bana' (forest) as is the slate for the roofs (village has its own slate mine). Villages such as Parche and Siklis have to bring slate from Taprang, hence spread of corrugated iron up there. The little house is built of the "best" blue stone (see chip sample). The shape of the little house being built is as follows (exact, smaller replica of Bhuwansing's). There will be a wall here (see sketch in original file) and room is used as a store for provisions. The house was built round the door and window 
frames (there are 2) which were there first fairly elaborately carved by the village carpenter on the spot. When the house is ready there will be a celebration - 'pa' drinking, eating, the sacrifice of a sheep etc. The house is being built for a young man who is now in Malaya. He lives with his brother and their 2 wives in a nearby house but they are both splitting since they have children etc. and the house is getting too cramped. Apparently most building occurs in December to February when people do not work on their fields. In about 2 months people will start to work more energetically.

\section{Gill to her parents 21.1.1969}

Alan is taking the five hour walk to Pokhara tomorrow. Enclosed are two rolls of film which we would be grateful if you would have developed - you will see Alan's note of contents. As they are coloured slides he suggests you could get a small portable viewer .then you could pass them on to the rest of the family.

There have been quite a few happenings since I last wrote a fortnight ago - mostly progressive. The uncomfortable things were the journey back from Pokhara which took us nearly seven hours instead of 4. As the crow flies it is not far, but as we have been foolish enough to choose a village 2000 feet up from river level the last haul is quite an effort. We were both carrying packs and were still parallel with the river when the daylight began to fail, and there was still the mountain to tackle. Alan had to take my pack, there was no moon, and I had a bit of a tummy upset so you can imagine our state when we collapsed into our little mud and wooden house. We just had some strength to make Horlicks on the kerosene stove and then we tottered up our ladder to our 'bed', sleeping bags and quilts on the floor.

It took us about 3 days to recover and get into some sort of routine again - which is most relaxing once established; we get up at about 7 am, have porridge outside and then coffee, deal with a little line of visitors ranging from little girls selling eggs, to curious onlookers who have just head the exciting newes that we are around, to men with head gashes that need a plaster and Dettol, and then we disentangle ourselves and say that we are going upstairs to 'tomagi khieva', which they just about grasp means to learn the language, and we bar the door, Alan has a 'little something' (crackers and peanut butter) this he hasn't dared to eat outside as they all look so hungry when we eat our porridge, never mind a second course, and then we climb the ladder and settle ourselves in the 'office'. Every hour or so there is still a line of visitors, but this isn't too frustrating as of course one has to speak Gurung to them so the theory ideally is rushed into practice.

As you will have gathered we have rapidly become a dispensary, and this as yet hasn't been too horrific involving arthritis, skin infections and gashes - the worst of these was a toe nearly sliced in two and I am just waiting for the day when I have a whole limb presented to me, detached from its owner; the people are so trusting and most stoic, even the children hardly flinch and return all bound up five minutes later with a little present of spinach-like veg, neatly bound up with bamboo like a bouquet, and rock green tomatoes to say 'thank you'for their bandages and antiseptic! Alan had to visit one of the poorer houses for the toe accident and he came reeling down every morning, post visit at about 8.30 quite drunk with neat spirit they had given him as their payment, and which they make locally, costing about $1 / 8$ a bottle - very like whisky and called cosily 'pa'.

' $P a$ ' was so prevalent at the time, as the Gurungs were celebrating their equivalent of New Year and it seems to flow freely then, breakfast, lunch, dinner. We made another expedition at the time, which turned out to be the second uncomfortable happening, to celebrate this festival. It involved a day's walk to the largest Gurung village in the area called Siklis, about 5 hours walk away from Thak, including the usual descent to the valley bottom and then the muscle-breaking climb up again to a height even more soaring than Thak, and reaching the snowline. The views of the mountains were superb though, but only one the way back, as it poured with rain and mist all the way there - our first bad weather in the country. We couldn't go at any other time though as the following day was the equivalent of New Year's day, and out guides were determined to go as they had missed the festival last year because of being snowed under.

Our guides consisted of a very friendly family who have rather fulsomely adopted us, the father having been in the Gurkhas and speaking good English. We stayed with some acquaintances of his in the village about half and hour away from Siklis, who happened to be the richest people of the area, owning most of the fields. This 
meant sleeping in a barn-like storage house attached to the main house and having our food brought there, the inevitable rice and chopped goat meat, as guests do not normally eat with the family. It was very cold and I had been dampened by the rain in the morning and then drenched with sweat when climbing the mountain in the afternoon so you can imagine all I wanted was a hot bath and a warm fire!

During the night there was the most fantastic hail and thunder storm which, clattering on the iron roof, sounded as if the world was coming to an end; in the morning it seemed even colder and when we opened the wooden shutter that covered the carved window frame, there was 6 " of snow smothering the corn on the cob stacked high in the courtyard outside the house. We couldn't move all morning as it would have been quite dangerous to cross the mountain without suitable footwear, and most of the Gurungs wear no shoes at all, or just the merest apology of rubber sandal. The thaw came fast and there was brilliant sunshine in the afternoon, and apart from the dripping cold, the village and the snow-covered mountains looked lovely. There were no fun and games in the snow and the children didn't seem thrilled with it, for the simple reason that they were too cold to enjoy it, with cotton saris and no shoes.

We spent the rest of the day being entertained by the Lt's friends in Siklis, as we walked over late afternoon. This time we slept in a much cosier and tiny Gurung house, on a bed which had a mattress (unbelievable luxury); the only disadvantage was that our hosts normally slept here, and had to have the floor instead, but they insisted and could not have been kinder. Two younger boys we came with also slept in the same room, whilst the daughter of the house slept upstairs, so the tiny, smoke-filled room was crammed with humans; there is no outlet for smoke even though they cook over an open wood fire, and the room was so low that one couldn't stand up in it, so you can imagine the effect was rather claustrophobic. However, they had given us so much ' $p a$ ' to drink that we weathered this as well, and came back to Thak the following day; the only disadvantage to this was that we set out rather late, all Gurung watches and mine being about an hour late for some reason, and this meant that we again came home in the dark.

We did not know the path too well, as we had come on it in mist two days ago, and Alan suddenly came out with hair-raising stories of tigers in that part of the world; they ate buffaloes and English people in particular - you can imagine that every rustle turned into a frothing beast and although we had been walking for 4 hours, we sprinted along that path as if we were as fresh as daisies! All this took its toll later however and I now have a shocking cold, sore throat, the lot, and have in fact been in bed all day. It has been hanging on for the last two days and I hope to clear it up this way.

Alan is fine however and learning the language by leaps and bounds; we always have people in in the evening and he makes the most valiant attempts at conversation which are helped by the use of a tap-recorder and also by the fact of his guitar, this the village seem to love; we have in fact a Saturday evening institution now as they were wanting it every evening and we couldn't manage that energy-wise or privacy-wise. He is also getting a lot of information, anthropology-wise and getting a census of the village (there are about 500 people here) and all the various families, and whose father is whose son etc. He grasps the poor people as soon as they set foot in the door, but they take it all in their stride and come up with superb bits of information. I have been taking notes on mat making and weaving and also on how they prepare their rice, which is a long and tortuous process.

I love to watch them cooking, as they take infinite pains and have the basest of instruments and really very poor quality food to work on; but they are masters of their craft and are really so relaxed and rhythmical in all their movements that it is a joy to watch. We have been invited out to dinner for this purpose and I had a lovely time making notes, I kept saying to Alan that I feel a bit of a fraud as these people are so far from a 'savage society' that we must be in the wrong place and will have to rush off to the depths of darkest Africa, however he shoots away such naivety and gives me a lecture on the stages of development and I feel a little happier - but really I feel these people are so much more harmonious than those in London, perhaps because they do not question .

\section{DIARY 22.1.1969 Alan}

Went to Pokhara, accompanying Dankumari. It only took 3.5 hours to Mahendra bridge, though we went pretty quickly. The little river valley exquisitely beautiful in the dawn. Left at 
6.30am. When arrived at Pokhara, dismayed to find a holiday on, but managed to catch $\mathrm{Mr}$ Pant in his garden and was absolutely thrilled to find that letters were at last getting through 4 letters from Mummy, Annie 1 and 2 postcards, Fiona, (Erik), Lady Clay, C.U.P. accepting Josselin, Max Marwick asking to include some of my thesis in collection on witchcraft, Gill's parents, etc. A lovely calendar from M. We retired to bed early and lingered over reading these - absolutely speechless with mirth over Mummy's letter. Delighted to hear Grandpa progressing. We immediately felt a lot happier and more relaxed. Also a letter from $\mathrm{Mr}$ Cooper saying he had sent money $(£ 50)$ on 2nd January - but on enquiring at the bank the money had not come, so I changed gold florin for 160rs. in market and bought a lot of medicine for Gill, raisins, tinned meat, etc. The journey back not too bad, though we raced back in 4 hours. Got back at 5.45pm.

Pregnancy 22.1.1969 Alan

"Hullo John's" wife is about six months pregnant, we are told - pregnancy freely discussed. When asked how many women pregnant in village, reply "'to shei"' - "8 or 9 or 10? 'Leh"' eight, nine or ten"? "leh".

\section{DIARY 23.1.1969 Alan}

Recovering from Pokhara journey. The day never really got going - didn't learn any Gurung, though I now find I can hold elementary conversations with them. I usually catch onto the drift of what they are saying. We are still waiting for the schoolmaster to appear to help us learn. In the afternoon various emergencies - Dankumari sprained her ankle, etc. We watched a wedding procession pass through the village - (SEE DESCRIPTION). Beginning to feel a part of the village as we wandered around. We managed to get the English news on Radio Nepal on our own radio - very nice to hear it (7.40pm.). It is also on in the morning (8.40am.)

\section{Gill Diary 23.1.1969}

At Alan's suggestion, I tried to write this with some regularity; it was especially good to have him back today as yesterday he went to Pokhara and I felt I couldn't exist another day on my own here. Got up all day and felt a little more energetic after spending the day in bed the day before. Thrill of getting bundle of letters from home - we stayed up reading until after $10.00 \mathrm{pm}$. by the kerosene lamp - all seem well and Iris' letters were most amusing. My mother is catching up on her typing and doing something every day and I know that will be quite an effort for her. She sounded the same as ever. Had a calm optimism of what a good team we would make out here that it almost shamed me out of my self-pity. Alan spoils me, so I indulge. Today even after a bad night full of rats and coughing and a hellishly uncomfortable sleeping bag I got up after Alan even though he half-suggested I should not.

Another beautiful, warm day - heat mists softening the mountains and little puffs of light cloud over Annapurna. We tried out 'chura' instead of oats, as they had run out of them at Pokhara so we ate something like hot rice-pudding for breakfast. There were a small number of patients today - none who came to the door; one who stopped me on my way down from the loo to say her foot was swollen 3" away from where a splinter had entered. Could not quite gather whether she had taken it out as swelling was sore and it happened 5 days ago. Applied Savlon and gave her penicillin.

She was gossiping with our granny who even hailed Alan this morning. She was weaving in front of the school - straight upright, apparently noticing nothing and yet taking everything in. She forms quite a gossip centre as she works hard weaving from approximately 8.30am.- 
$5.00 \mathrm{pm}$. with small breaks for meals. (Alan commented seems to get up at 5.00am. - at least our neighbours - they sweep in front of the house then). Alan heard her telling my patient that I had a rich mother. Result of his teasing Haricola! He feels like de-bugging "our granny". The other patient was Alan's.

Nani crashed in early, defying our new lock system - to grind some millet. It's a soft rhythmical sound when she gets going but the preparations are a bit rousing when one is trying to sleep. She then brought a man up to the bedroom, with Alan just about to step out of his pyjamas. Nani later swept out for me and re-caked the floor; I stored all my saffron and chilies and garlic away.

Spent the rest of the morning re-reading letters - Fiona's was a lovely one - and putting in nose-drops. Alan has bought me a whole stock of medicine and is determined to get me well, but I think he may have put his finger on it when he says I must want to get better. I wonder if it is my protest and is psychosomatic. The effects are physical enough and the sinus is very sore. I would (quite) cheerfully go home, pride less and gutless at the moment, but must stick it out. I will act as if I'm quite well.

Bumped into a whole flock of 100 or more sheep on the way to the loo. They held up the entire movements of the village as they leapt and butted their way along the main path, passed the tap. They were being taken to Siklis and seemed to be quite a sturdy variety. Thak has no sheep, it seems. Just after lunch, to my irritation, the Lt. called for Ramu and said that Dankumari had twisted her ankle carrying a heavy pile of dung. It was a bad sprain and she had been crying, which indicates how bad it was as this is the first time we have seen an injured Gurung crying out of pain. She didn't like me to see her like that either and somehow it was a relief not to have her usual sweet jolly self - more real. I made a cold compress and we had tea in the house (pepper made my throat burn) and the Lt. proudly showed us a jungle cock he had just shot. To Alan's dismay he had thrown away the red feathers used for spinners and flies.

The flies were a nuisance and it was quite hot. We then rushed out to catch the horns of the wedding procession, having been clued up by the Lt. as to bride-capture; threatened suicide of Dankumari if she disliked their choice and their subsequent capitulation after paying the bride-groom off (500rs.). Rushed after - taped it incorrectly; girl looked very glum and we gathered she wasn't too keen to marry. As I told the Lt., I think I'd run away at that point. We go to look at the Blacksmiths after this as they are the untouchables - the Lt. has finally admitted this bit of inhumanity.

\section{Notes by Alan on 23 January 1969 - A Wedding Ritual}

Wedding - saw one in the distance on way back from Pokhara. A procession of about 30-50 people, one big drum thudding slowly, progressing to Pokhara. They had apparently already drunk tea etc.

Wedding - man from Malaya, just returned, lives in Noleghat. A new houses being built (for him? but not yet ready). On 22nd he went to fetch the bride from Khilang, about four hours away. The next day the wedding. If one is invited one has to come; if not one may come. It is the custom to give something to the young bridal couple - money (from 2-20rs. Compare with the seventeenth century. How much is collected?).

Wedding passing through Thak - the bride was being taken to Noleghat from Khilang. She was to marry a man returned from Malaya. The procession consisted of (in order of marching through village, though just before the village it had been slightly different) musicians (about seven adult males) at the front a man carrying a huge horn ('totoro'); then two men holding long, straight, horns ('bobon'); then two or three drummers, playing two and one sided drums; then two small men with reed instruments (cf. clarinets); then four to six well-dressed small 
boys, then about six adult women followed by about 20 young women and girls, dressed in maroon velvet (holding head covers over face). Their general air was one of gloom; then about fifteen men, wearing the striped black and white blankets, including several men we recognized from Thak. A good many of the villagers watched the procession and the musicians struck up as they moved slowly through the village. The bride was towards the end of the women, indistinguishable in dress, as was the bridegroom (?). [See two colour photographs and short tape-recording of procession disappearing down the hill.

Apparently the musicians belong to the Tailor caste (who live at bottom of village). They would be paid about 50rs for journey from Khilang to Noleghat (about 5-6rs each).

Bhuwansing, when asked about the previous wedding ceremony, volunteered the following information. Apparently only the parents and/or two or three men went up to fetch the bride from Khilang. In some weddings fifty or so people go to fetch the bride, but only if she has been consulted about the wedding and is quite happy about it. In this case (as in the majority of cases, according to informant) the bride has not been consulted and her parents were afraid that if she heard a big procession coming she would run away. Such running away was fairly common, according to Bhuwansing, but is it the responsibility of the parents and bride's brothers to stop her running away. Apparently if the girl is desperately opposed to the match, saying she would rather die, weeping, etc. the parents may cancel it, paying the bridegroom's parents four or five hundred rupees in compensation. Normally however even an unwilling bride gets over her misery in "two or three" days. She is accompanied back to bridegroom's village by 50 to 100 of her co-villagers.

... Apparently the marriage is arranged when the girl is away from the house, at Pokhara or in the forest or something. As for brideprice etc. apparently the bridegroom's parents give the bride gold - necklaces with gold pieces, bracelets, rings etc. if they are rich. This should roughly equal the amount given to her by her own parents (which in Dankumari's case is a very considerable amount) or it may be more. But they do not, it seems, give the daughter's parents any present. Both sets of parents also give to their offspring, if they well off enough other goods - clothes, animals (buffaloes etc.) fields etc. Hence the system is very similar to pre-industrial England and means that considerable investment is made in the next generation at marriage and neither of the founding lineages gains wealth from the wedding, while the other gains a new member.

Musical instruments in procession:- (informants Bolbahadur and Prem) cymbals ('chene'), [curved horn] 'totoro', [straight horn] 'bobon', [basin-shaped drum] 'toingi', clarinet-like ('saugne'), [double-sided drum] 'dolalghi', big drum 'dama'.(for illustrations see original card).

\subsubsection{Alan to parents}

Dear All,

I gather air-letter forms are more likely to get through to England than ordinary air-letters, so pleased excuse a slightly shorter letter than usual. Perhaps you are still digesting the long one of two weeks back (c. 6 Jan.) which I hope you got. As I write this we have still had no newes from England since we left. If anything has come for us at Pokhara, I will add a note to the end of this. As you can imagine, we speculate much on what is happening to you all-you will remember from Assam days how one hangs onto letter-writing.

Unfortunately, we will only be able to pick up our mail once a fortnight as it is a five hour journey to fetch it. Our journey back after posting the last lot was an absolute nightmare: we had to leave after midday, waiting for the diplomatic bag, so we did not arrive home until about 7.30 - some hour and a half after dark. The last two hours, after a four hour walk up the river valley with heavy knapsacks of food, were straight up a mountain-side of about 2,000 feet. When we arrived we just sat exhausted for about an hour - still we learnt our lesson, I think. 
The superb weather that greeted us gave way about 10 days ago to a very cold (comparatively) spell - day temperatures of about 45-50oF. This is the mini-monsoon, which always comes at this time of year, we gather. We even had one night of torrential rain and hail, which turned to snow in the morning, as I will describe. This was accompanied by a terrible thunder and lightning storm - like those in the proper monsoon.

All this occurred during the three days we'd decided to leave our snug little house and go up to the biggest Gurung town, Siklis, some 15 miles to the north of here, just on the slopes of Annapurna. We'd been told that there was the biggest gathering of Gurungs of the year going to take place and we must go - so we accompanied the family of one of the villagers, a very nice and sophisticated ex-Gurkha Lt., who had been to England, etc. We shared a porter and after eating breakfast (the inevitable rice and very hot chilied meat and dhal - which the rich have at every meal (the poor just have rice and millet soup), we set off. It was the first rainy day since our arrival, but cleared later in the morning. We arrived at our host's house (we stayed with friends of the Lt. for both nights) late in the evening and drank the warming raksi (rice beer - highly potent, as you know) and then had a meal round his fire. We spent the night, all six of us, in a grain attic with a corrugated iron roof - and it was here that the thunderstorm hit us - bitterly cold.

The next day, after being daubed with rice and sweet potato and the Lt. having washed his daughter's feet three times, and the host's family having sacrificed a cock at the local sacred spring and other highly anthropological events, we went on to Siklis, a large village with fine viewes of Annapurna and about 500 houses. We were immediately heartily entertained with rice beer again and forced to eat further vast meals. The actual ceremony we had come to see was disappointing - it was merely the finals of throwing the weight (shotputting): a whole lot of muscley boys running about and hurling a lump of lead before an admiring audience; a sort of mini Grasmere Sports. Obviously it is the opportunity for visiting, for boys to meet girls, etc. that is important. Everyone was dressed in their best - which varied from superb gold ornaments to shooting sticks and golf caps! We again mis- timed the journey back and again had to rush the last bit in the dark - balancing exhaustion with fear, since we had been told there were leopards and tigers in the bit of jungle through which we had to go, and we had no torch, etc. Perhaps as a result of the journey and constantly squelching about in wet shoes, Gill's cold (a virus cold, with constant phlegm) has got worse and she is not at all well but we hope that the various medicines we are pumping her with will clear it all up.

Apart from Gill's health and a shortage of money - nothing has yet come through from the bank though I think it will shortly, everything is going fine. The language is coming on well - though conversations are still very banal, consisting of endless questions about what are you doing, have you eaten, how old is your grandmother, etc. But we are beginning to feel that something is being collected; half the central village has now been covered by a preliminary census and we have managed to gather a few genealogies. It is amazing how little they know about their relatives - often they don't even know the names of grandmothers, father's brothers etc., not at all what I expected. We've also investigated the type of houses they have, mat-making, weaving, rice threshing etc. We really need some black and white photographs and cine shots to complete these and will see what we can do about this gap when we are in Kathmandu, which will be in May, I think. At present it looks as if we may be able to finish the work in fifteen months and would then return in March of next year. More and more fascinating comparisons with the C17 are coming to mind, especially re lineages, houses, firewood, sense of humour, etc. I will develop these when I send my first field-work report in April.

Longing to hear how K.L. study progresses E̊ your book, Mummy. Incidentally, I am sending a couple of colour films to Gill's parents to get developed, [PHOTOGRAPHS] as it will be easier for them to do this than from the croft. I will send an accompanying description of the contents. If they come out, I hope the Ions will send them on to you; they will give you some idea of this glorious place.

Before I forget; Gill wondered if you could send the recipe for the griddle scones (those triangular things you make, Mummy) and also oatcakes - with instructions on how to make them. We've bought a piece of metal to put on the fire and they would be a great delight here.

Please send our love to all \& pass this letter on to anyone interested: will be writing separate letters to Erik and Annie, Granny, Fiona, in a couple of weeks. Do hope you are both very well.

Lots and lots of love from us both, and thinking of you lots. 
Spent most of the day down by the river - or rather small stream (Tadysyon Kola) to north of Thak. A delightful spot where we washed, ate, etc. On way back we were invited to stop at a house on the way up to the village where we gradually learnt that the woman's husband (aged 65) was very ill. On entering, we dimly made out the form of an old man huddled over the embers. He had been ill for years, apparently. His legs were shrunk and flesh on feet and hands, flabby. Not stomach or headache, but a general painfulness. Did not eat much. What can one do?

\section{DIARY 24.1.1969 Gill}

Although not certain it was wise, we decided to go to the river separating Thak from Taprang for a cleaning session. Alan worried that the lowering cloud would take over and there was more wind than yesterday. The point was I was still not at the point of thinking I was well. The Lt. showed us the lower path although I think we would have preferred retracing our steps in clear day to get over path that was dark with infested tigers on that dreadful walk back from Siklis.

We lost the small track of course with Alan cursing away we fought our way through jungle to emerge at last a minute away from the steam. Very pretty indeed with a tumbling dramatic waterfall upstream and lovely overhanging grasses which reached quite a height. I had an idyllic time washing my hair which had three weeks of Gurung dirt in it. Ghastly. I just dipped my head in the rushing stream and it came out immaculately shiny.

Alan fished, but with no luck; he was sad and restrained today - feeling homesick, I think, and cross about our lack of system lately. I read a bit of "The Idiot" which was superb. Mystikin's account of his happiness in Switzerland. Also washed and cut Alan's hair which was frothing with curls all over the place.

We came home early but were way-laid on the outskirts of the village by a friend of Bhuwansing's with a sick husband. Nice neat wealthy house. I even had a chair brought out for me. Husband been sick for a year - sitting immobile by his fire, legs thinned to a skeleton, feet very puffy. We both thought it might be leprosy but have no concrete reasons why. Must look it up.

Bought 9 eggs from her at the correct price (3 for 1r.) Saw all our patients on way through village. As Alan said, he felt like the family doctor on his round. Bound Dankumari's foot again - they are making rice curls tonight at great labour through a mincer - others invited us to see it. It was, as usual, a relief to get away from the village.

\section{DIARY 25.1.1969 Alan}

Gill better in health and more cheerful. We did a good morning's language and a short walk round the village in the afternoon was productive and I found I was able to (very simply) cross-question people about their activities. They were all more than anxious to give information. Not at all reticent or shy.

\section{DIARY 25.1.1969 Gill}

Alan happier as we did our set routine of Gurung this morning without interruptions; noticed difference with that child and his mum back next door. Mother knocking on the doorway with a bowl in her hand - I am getting more irritated by constant supervision of 
brown-eyed stares the nearer I get to my period. Must try and get away from it all this time and not take it out on the people who are utterly harmless, innocent and curious - thus they can't appreciate that one doesn't like being stared at all the time. Alan is much more constructive and gets into conversation with them and thus makes use of our embarrassment.

Translated Pignede in the afternoon and then Alan followed the women taking dung to the fields as they seem to be bound up with this at the moment - they work very hard. Thank god I wasn't born to a life of manual labour! Camus has a good passage on it in his short stories "The Silent Men".

A lovely balmy English day a.m. (Oxford summers lying in the grass, insects humming round) but clouded over to get chilly.

25.1.1969

Gill

Dung carrying - 'mal kova' NOTE 25.1.1969 Informant - Prem

Starts at 10.30 a.m. to 5.15 p.m. with lunch of 45 minutes at 2.30. The carriers are not paid for their work, but work for each other's houses in turn (eight men, eight houses). The dung heavers are mostly young men and girls under the age of 30 and over 15. They include people from all strata, e.g. include Bhuwansing's younger (quasi) daughter [DILMAYA]. Such dung- heaving is done almost exclusively by hand, hardly at all with tools, except a small hoe for actually digging the dung out. If they had a spade it would halve the work. Dung is then taken from the heaps in the village (stalled buffaloes) and placed in heaps on the fields (n.b. note quantity of dung per acre). Most of the dung is fairly well matured, but some is very fresh. It is mixed with straw. The woman whose dung it is, or her daughter, actually digs it up with a hoe; it is then loaded into medium baskets for the whole party and they all (about 6-8 is normal) set off together. The baskets probably carry about 30lb of dung. Apparently dung is carried for one month only - in Mark (?). The number of journeys depends, of course, on distance away of fields, e.g. Prem carried about 12 loads in a day, the fields he went to were 300-400 feet down from the village and half a mile away. Some fields to which dung carried, 1 mile, 500 feet away from village. The dung carriers work hard but are prepared to stop and have a short smoke with me, but soon hurry on. Don't seem to mind work - joke etc. not singing. Bol. Works at dung carrying five to six days a year. n.b. compare to Kirkby Lonsdale - how much dung carried, how far, who by, what amounts put on etc. effects of fuel shortage.

\section{DIARY 26.1.1969 Alan}

A cold day - no sun at all. Gill feeling better and we got quite a bit of work done. The general pattern of our day at the moment - though this is constantly interrupted by people selling eggs, wanting medicine, etc., is: 6.30am. - alarm; 6.45. get up. 7.00am. fetch bucket of water from well; 7.20 have breakfast (mix of porridge and 'chura') which I have cooked; $8.00 \mathrm{am}$. I retire to bedroom with coffee and 'chura' while Gill does the washing up. I write up notes, etc. till 9.00am. when Gill comes up. We learn Gurung until 12.00am. - with a gap of about 20 mins. in the middle. The Gill prepares lunch while I read/translate Pignede. Eat lunch 12.40, Gill retires to read Dostoevsky while I wash up; $2.00 \mathrm{pm}$. I retire and we continue Pignede and read till $3.00 \mathrm{pm}$. We then go to toilet on hill and wander round village chatting/observing until 5.00pm. - then write up this journal till 5.15, or so when we prepare for evening meal; fill lamps, prepare Horlicks drinks for hungry Gurungs, light fire, lay out sleeping bags on mat, get food things together. Make meal/conversation by hurricane lamp, try to listen to news, bake scones, cook water for washing up and for water bottle - some nights play guitar/tape-recorder. Then retire to bed about 8.45 and sometimes wash out of 
tin bowl, sometimes listen to classical music and dream of home, sometimes read letters from home. Sleep - only disturbed by late revellers, rats which squeak abominably, and dogs. (margin: amended slightly with arrival of schoolmaster)

\section{DIARY 27.1.1969 Alan}

Today weather clouded over and we had heavy rain, thunder and a rainbow. Quite cosy sitting on our verandah looking out and preparing the meal for Bhuwansing, which was the great event of the day. It all went off well, thanks to Gill's nice cooking, and we ate the fish, onions, potatoes, dried peas, cauliflower, rice, fruit salad, Horlicks, with great satisfaction and felt pleasantly hazy over the 'pa'. The Lt. had added to his many kindnesses a few days before by killing and preparing a plump (c.3-4lb.) chicken which we had bought for 10rs. We are now eating it. Just now Nani from next door has come in to fill her basked with 'mla'. She filled two baskets about a fortnight or less ago. Shows consumption rate, or do they have their own supply also?

\section{DIARY 27.1.1969 Gill}

Amused/annoyed at myself that the importance the Lt.'s visit has taken. I remember with horror my frantic rushing around kitchen at Milverton $\mathrm{Rd}$. Alan trying in vain to calm me down! We had planned the menu on our picnic day, I think. Alan too wants to get it over. He hates being in debt, especially socially. Funny, disturbing weather as I was preparing food warm and balmy in the morning and then black cloud over Siklis gradually engulfed the rest of the sky and a quick, gritty wind got up, blowing my clothes off the line. (Had a grand washing day in the morning and had the usual procession of little boys pinching my padded bra with interest!)

The animals were upset by it too - kid bleating loudly for its very neglectful mother goat,; chickens were squawking away, one poor old female hen being pursued by cocks who have suddenly invaded the courtyard. What with their copulations, and the moo-ing of the buffalo tethered in its shed further along the courtyards, there was a terrible row in progress. Children were crying too and the rain had just broken when a baby with a gashed head was brought in a great rush for me to bandage her up. The mother was the sister of one of Alan's informant - my favourite one, Bolbahadur. We are gradually getting all the families pieced together. I was in the midst of doing the potatoes, but Alan took over and I bandaged her up.

The thunder and lightning then crashed overhead, but opposite dipping into the valley and curving up over the side of the hill was a rainbow which was a soothing sight. The rain was clattering down over the verandah roof but we were cosy and dry, peeling potatoes, bandaging babies, and watching the rainbow.

The Lt. came on time $(6.15 \mathrm{pm}$.) with his wife and by that time we had everything just about organized. Alan had picked some brilliant yellow flowers from the mountain and they looked so pretty in our green toothpaste mug beside the long, cool brass candlestick with its pointed, curved unwavering flame - it always reminds me of that very stylised painting of a nude by Ingres (?). I think there was a lamp in that.

Everything went well. We used all their lovely brass utensils and their rice, oil, pepper, clove mixture, 'pa'! The Lt. loved being so useful. Alan

bunged up our grimy kettle with red tissue-paper as they do to keep in the gases of the 'pa'. This was strong and enjoyable and sadly we finished it. I like the Lt.'s wife very much - she is so graceful and very gracious, and has a vivid sense of humour, as do all the Gurungs, I think. She almost gave me a quick little hug when they went - they went quite early as they said the 
youngest child would be crying for them. They were very amused that I had to write a list our of "things to do". I explained how Lt.'s wife cooked so beautifully. The Lt. too seemed proud of her and said she could prepare the entire meal in 1.5 hours.

\section{DIARY 28.1.1969 Alan}

An overcast day, though beginning with warm sun. The major event was the arrival of Akayprasad, the headmaster of the local school (a shy and nice young man of 26 or so) who is to teach us Gurung for 1.5 hours per day during the next few months, four mornings a week for 2rs. per hour - ie. c10/- per week. This morning we found this a great help. At the moment we can only understand the simplest of conversations - those aimed at us. One thing we are fortunate in is that the people are all very curious - watching us, asking how much things cost, where we have been, what we have been doing, etc. Consequently they are all prepared, and seem quite happy, to answer our questions in turn. When we meet them around they are most friendly. They are still primarily pre-occupied with dung carrying.

\section{DIARY 28.1.1969 Gill}

Good constructive day as our arrangement with Prasad, the schoolmaster, has started and he came at 7.20am. while we were still in the middle of our 'chura'. He is hardworking, English good, and the 1.5 hours is even enjoyable, even if we do have to get up at 6.30am!

Alan is very good and prepares breakfast. I started a long letter home after he had gone. We are going to make it a four day arrangement. We then did an hour's more Gurung and I prepared some of the chicken we are joyfully eating at the moment. In the afternoon we translated Pignede and carried on with the letter - it is so good to be replying to theirs! Same weather with thunder and rain as we were eating the supper. Children very noisy at supper and a stranger came in to tell them off and they trooped off like sheep.

\subsubsection{Gill to parents}

I was feeling so much better last Friday that we decided to take a trip to the river to have a general clean up; to my imagination's horror and Alan's relief we had not been able to have a swim or wash our hair for nearly a month. I didn't want to get to the stage of careful looking in each other's hair for bugs, which mothers and daughters seem to do on warm afternoons in the village! I don't really know why this should be as they wash their hair perhaps weekly, but with no soap and in cold water. They use a lot of oil, some sort of mustard extract and I don't know whether this feeds the bugs or not. We had originally decided to go to the river each week, really to get a break from the village which one needs when you live in its centre and have relatively little privacy.

You may remember that we spent Christmas Day and New Year's Day like this, going to the largest river the first time, and then to a smaller one on the other side of our hill which was reminiscent of a Dales stream. Our routine was broken however, so it was a treat to get away again; we decided to try the third river in our area which we had to cross on our way to Siklis, which is the large Gurung village where they celebrate their equivalent of New Year (on 14th Fanuary, which is the beginning of the month). The last time we passed that way I was ready for a tiger or mountain leopard to pounce on us at the very least, so I thought it would be a pleasant contrast to re-tread the path slowly in broad daylight! We were persuaded to try and different path, however, as the locals said it would be shorter, we would not have to climb but just follow the curve of the hill half way up. Of course we got lost, as the paths are really the merest dust trail, about a foot across and used as much by goats and buffalo as by men.

(cont. 29th) The paths often go through the paddy fields, which just have the stubble in at this time of year and look very arid and dusty; they are often in the shape of a moon and tiny in area as they are built up steppes or stone every few yards or so, to prevent erosion. We got lost in some jungly type of vegetation however, where 
Alan insisted on taking a picture for some obscure reason - I was hot and sticky and my hair was descending as it had been pulled by thorns and jungle creepers; I think he likes the idea of us being intrepid explorers! We saw large piles of recently dug earth beside scooped out holes and think these might have been done by bears as there are some in the region; the other animals we saw were striped jackals which looked half way between a fox and a wolf. We often heard the latter howling when we were staying at Pokhara, but have not heard them here only the crickets chirrup at night, and the local village dogs bark, sometimes interminably.

We came upon the river at last and settled just beneath two dramatic waterfalls which were very beautiful tumbling down a steep gorge, with the mountains towering above; the stream itself was clear and fast flowing, very pretty, but Alan did not have much hope of catching any fish. He had made up a dough-like bait, as the hooks he has are too large and the fish apparently just nibble the work off and swim away, free, with a good feed inside them - all rather frustrating. Also we have been told it is too early in the year for fish and the locals go down in two months or so and catch them with nets .

.Other pitfalls to avoid when choosing a picnic spot by streams centre around the fact that Gurungs seem to use small ford crossing places for cremation grounds and on two of the rivers we have found a hefty pile of ashes with bamboo sticks tied around with flower garlands stuck in the ground. On the second expedition two men came down from the nearest village and made prayers and some sort of farewell gesture to the dead man, scooping up a handful of ash and putting this in a banana leaf and floating it on the stream. I felt I was committing a sacrilege sitting their reading and drying my hair in the sun, but they smiled at me and were quite accepting about it. We found a similar pile of ashes on this third trip, but no garlands and no rituals.

Our most exciting experience in the ritual line was about three days after we had arrived, and we heard from and informative little boy that they were going to slaughter goats and buffaloes and have some dancing, and would we like to go?' it sounded a bit gruesome but Alan still felt dutiful at this stage, and felt we ought to go. The whole affair turned out to be a funeral and a most precious experience .

In Kathmandu the temples seemed to be an amalgam of Buddhist and Hindu, which is most unusual, and I think peculiar to Nepal. We have not begun to sort out what they feel is their religion in the village, and I think this will be a very complex task involving a sound knowledge of the language. According to the present definitive work on the Gurungs, they have a strong belief in the supernatural and in the centre of this is a half wizard, half priest-like figure called a 'pucu' who is consulted for his clairvoyancy and powers of interpreting sacred books. The position is hereditary and it happens that we seem to have come into contact with the younger members of this family most consistently and one of them, the eldest son who will take his father's place, is quite a reliable informer on village events and Alan consults him quite a lot. It is also interesting to note that they are also a most independent bunch, intelligent and suite outstanding amongst the other children. I think they have quite a position of power in the village. Tomorrow the present poju has his 84th birthday and we have been invited to the celebrations, so shall report on that if it turns out to be exciting. His grandson, our informant, has just gone off to another village today to bring back 108 small candles so it sounds like quite a splendid party! - why 108 I can't imagine, maybe we translated wrong!

... The funeral was of a young man who had been killed in the army away in |Malaya; the whole village seemed to be invited and some of the poorer families have to wait for a year or more before they can hold the ceremony as it involves feasting and hiring of priests so there is a lot of expense as their wealth is vested in buffalo amongst other things and killing one of these is quite an occasion. I found the sending off of the spirit ceremony most moving; the priest was dressed in his official garb and there were four other lesser dignitaries who danced and played drums around the boy's effigy; his actual body had not been brought home. The music was of the throbbing stirring kind and rang in one's head for hours afterwards; the dancing was also more rhythmical and the mourning of the family considerable. There was a great feast afterwards, and they had goat and buffalo meat with huge baskets of rice and lentils with sweetened rice bread and Gurung cakes, all a form of some sort of rice. There were well over 100 people, and they stayed the night there sleeping out under the stars, dancing for part of it and not dispersing until late the following morning. I'm afraid we didn't enter into it as wholeheartedly as we should have done, and came back to our little Gurung house for dinner. There should be two photos of the funeral among those we sent you.

We also had a glimpse of a wedding and Alan took some films; this time the music was even more impressive, nine instruments being used and being played by the tailors of the village who do duty as musicians 
as well. They are also outcasts, as the untouchable system still lingers on here - the blacksmiths are another example and their houses are at the far end of the village, on a low level, and they cannot use the central village tap, just behind our house, but have to go quite a way out of the village to collect their daily supply of water. The bride in question was being brought from another village and we were told, officially, she does not know that she is getting married and is carried off on the day of the ceremony, sometimes most unwillingly, trying to run away and having to be captured. The boy had gone from Thak on the same morning as the ceremony, with some stealth as (unofficially) he knew the girl didn't want to marry him so he had to creep up on her, apparently! We saw the return procession which went past the back of our house and couldn't make out which was the uneager bride; there was a procession of about 10 girls after the musicians and all of them looked equally mournful and unwilling. We didn't know the family so couldn't go to the actual ceremony. We have been promised other weddings in the year though! .

\section{DIARY 29.1.1969 Alan}

A warmer day. Struggled to be ready for our schoolmaster at 7.30am. and he didn't turn up. Very disappointed. Wandered round the village observing from about 9.15 for 1.5 hours. Much of interest. They are dung carrying from next door. We watched them all eating lunch in the courtyards and Nani was taking out the pile of dung. I managed to obtain a piece for my mushrooms and planted the mushrooms in a small cardboard box. Went up the hill this afternoon and while we were sitting saw some men sitting on boards near the little northern temple, with axes and a goat. We immediately assumed they were about to sacrifice it for tomorrow's puja, and started to note their actions. But nothing happened and just as we left they rose and walked on with the planks of wood they had cut for the house building. Nothing to do with sacrifice. Another nice anthropological piece nipped in the bud!

\section{DIARY 29.1.1969 Gill}

Sad day - we scrambled up at 6.30am., with great effort, and the wretched schoolmaster did not come. We learnt his checked words though and made up sentences for us all (hopefully) to translate later. Alan put out as it had seemed so hopeful yesterday. I finished off a long letter and enjoyed typing it. We have heard poju is having his 84th birthday tomorrow and we hope to be invited as there will be 'pa' and music! Have to take little votive offerings - rice, a flower, 'pice', etc. Made Alan's favourite scones in the evening with the help of all the boys clustered round who carefully turned the pieces at their side for me, their reward (on demand) was "a tasting".

\section{DIARY 30.1.1969 Alan}

Spent much of the day at the poju's 84th birthday party or puja [see description]. An exhausting, if enjoyable, experience. Tottered back to the house at about $6.00 \mathrm{pm}$. only and found that a larger crowd than usual had gathered and expected us to play guitar, our taperecording of the morning's entertainment, etc. Even when we plodded back up to where the remains of the party were, we were asked to replay our recording - by the light of our kerosene lamp (which they had broken)! We took 15 pages of notes, but have no idea of what it was all about.

DIARY 30.1. 1969

Everyone rushing about early collecting spare candlesticks and huge copper rice bowls. No one was going anywhere as it was the poju's birthday. Two small boys had slept next door 
after coming from Pokhara and were irritatingly insistent on trying out their English on us. They said they had come for the Great Event too and it turned out they were 2 of 7 Brahmins who had come to chant at the poju - baby ones though they were.

The business started about 11.00am. and didn't finish until 6.00pm. Alan stuck it out nearly all the time, making notes, etc. (15 pages). They had erected a bamboo tent extending from the houses, garlanded for grandpa and main holy man. They sat opposite each other nearly all the time chanting away and throwing rice and flowers at each other. There was throbbing music all the time, which Alan taped and what with that and the incanted sanskrit, I developed a crushing headache and had to have a long break in the middle. We only had a few token bits of rice to eat at Prem's house - it is an old blackened beamed one with quite a lot of carving on the supports. Annoyingly I missed the most exciting bit when they lit 108 candles and shouted at each other, etc. We thought we would have a peaceful evening as they would be dancing, etc. but they all seemed to come to us instead and Alan's guitar was loudly demanded. He played 4 songs to a most appreciative audience. My headache receded, somewhat to my surprise.

Notes by Alan on 30th January 1969 - on Sorasi puja for 84th birthday On the day, horns are blown by one musician at about $10.00 \mathrm{am}$. and we take up our position then. School benches have been appropriated for the occasion, including the one from in front of our house; our kerosene lamp has also been borrowed. The actual setting is as follows: [diagram - fig.2 ]. The greens tied around the uprights are at the moment being chewed by goats and handfuls are taken off during the ceremony for use in the ritual. Notes on Sorasi Ceremony takes place in front of house by screening in a section of bamboo cane mats which are around the edge and also over the top to form the roof. The 'makhai suli' is used as a support for the mats, as well as separate poles which are forced into the ground between the slates - the whole appearance is one of a tent. Each of the main poles is decorated with grass and banana leaves. The "inner sanctuary" within the outer tent consists of four poles covered also with banana leaves, flowers and red leaves. All these are strung together in a continuous garland - over the top of the poles is a sort of panoply about 18" sq. of a piece of embroidered cloth, brought from India/Malaya with some inscription like "Present from Malaya". 30.1.1969 Alan 'Sorasi puja' - principally that for the 84th birthday of the poju On the square of earth beneath the panoply are chalked out astrological (?) signs (a white dust sprinkled to make this)., like a chess-board and at certain points are placed: 1 . banana leaves sewn together to make a saucer in which uncooked rice is placed 2. tall brass candlesticks in a shape similar to Georgian, except that the top had no cavity for holding a candle but was a hollowed out basin for oil wick 3 . brass vases, striped down the sides for the occasion with some kind of red pigment 4 . carefully placed off mid-centre a pile of dry firewood (later lit) [see diagram - fig.3 ] 5. a large blackened cauldron on which are placed green bamboos strips pegged together in the shape of a triangle with sides about $1 \mathrm{ft}$. long and a smaller brass bowl beside it.

Around this square the grandfather sits on the NW side and on the other three sides 7 other Brahmins sit ( 3 adults and 4 teenage boys). The main protagonists for the most part opposite the grandfather's right. Squatting beside grandfather on his right was his son. To the left of grandfather the least active of priests sit - the oldest of the three. Behind the holy man opposite grandfather is a pile of baskets and bowls for receiving rice and other cereals which people have brought for presents. About 4 other people are preparing things in this space, including conically shaped, 9" high piece of ground 'makhai' flour which they took about half an hour to knead and shape, red dye was later striped down it and joss sticks placed in it. When it was finished it was placed on a plate beside the grandfather. People were continually coming in with small offerings - bowls of rice, 'makhai', flowers, bananas, etc. - just a symbolic 
amount brought. People are dressed in their best clothes and various bowls etc. have been borrowed from other houses. A transistor is hung incongruously near the entrance. Birimaya arrives with a generous bunch of flowers etc.; it seems there is some variation of gift with wealth.

10.15am. About 20 children and 15 adults in or near the tent. Another 10 women are on the verandah preparing garlands (Nani, Ramu's mother). Birimaya sits down on the right of grandfather at talks to Bonmae. The dimensions of the tent are 6' high and about 15'sq.; there are 'gundri' round the central square covered in blankets for the main participants. None of those in the tent wear shoes. They are making wicks for the candles out of cotton thread. The approximate location of objects is as follows: [diagram]. At each point where there are chalk diagrams, small bowls made of banana leaves are placed. The rice bowls have little crosses or twigs stuck in the centre. Baskets of rice ring bread, plates of oranges, 'makhai' etc. are added to the table.

11.00am. musicians arrive and there are 10 long blasts on the horn (cf. church bells). [See tape recorder]. Many joss sticks are lit from the house. 11.30am. Narbir takes off hat; Holy man is reciting from 3 sanskrit books and from memory. Narbir asks questions holding leaves of flower in his hand, in prayer-like position. Everyone is chatting meanwhile and talking goes on throughout the ceremony. The women pass the finished garlands from the verandah and loop them over the bamboo leaves. (Preparations are going on at the same time as the actual ceremony is in progress). Narbir puts leaves he is holding into a bowl, having answered holy man. Lamps at 4 corners are lit. They add more garlands right round the tent and a plate of red and green dyed rice flaps is added. There is a general busyness but no particular jubilation. Nansubar brings .5rs., red flower, 'makhai' and rhubarb-like fruit chips on a brass bowl. Small quantities of fluid (cow's urine) are passed to children and others in a kind of joking gesture, the children told before that it was 'besare liba'; adults avoid or grimaced if they did take. 11.45am. Horn sounded again, men smoking and women, Prem handing round cigarettes. Joss sticks lit and put into bread and rice. $12.00 \mathrm{pm} .30$ children and 20 adults there. Holy man still muttering from holy books and Narbir still has hat off. The "table" now inundated with little bowls, plates, etc. - all the money is put together when it comes. 'Sorasi puja' - principally that for the 84th birthday of the poju

$2.15 \mathrm{pm}$. they light pile of kindling [take photo]. $12.30 \mathrm{pm}$. the tent is opened out at entrance to seat more people. Narbir holding leaves in praying position. Holy man reciting as fast as he can. Narbir has red and grey marks on his forehead. He is sprinkling from small bowls with a spoon and with various coloured flowers all over the table. He continues to do this throughout the ceremony. The stuff he his sprinkling is a greenish fluid and other liquids from 3 other bowls. He is dropping rice and flowers onto a leaf. Rice is being sprinkled onto the ashes of the fire. Narbir is being firmly instructed where to throw liquid etc. by his son. 12.30pm. Horn blown again. Pile of sticks is being kept burning, strong smell of joss sticks. Narbir scatters from various bowls onto the holy book which holy man passed across, and bows his head to touch it, as his son does. About 50 people present, half children, sexes equal, and a number of infants. The fire roars up.

We go into Narbir's house for a snack; it appears to be more or less the same size as other houses but old. Given buffalo milk with sugar and given a sample of things at the party coloured rice flaps, ground 'makhai' flour sweetened with honey and rolled into balls, rice rings. When we return the holy man is wearing a garland and still incanting.

$1.10 \mathrm{pm}$. transistor radio blaring whilst prayers are made. Flowers are placed in the big cauldron. Narbir is still holding flowers etc. between his hands, as if blessing then, and then throws towards the holy man. The latter unfolds a muslin square and draws a thread from it and puts it onto a small pile of leaves and flowers. 1.30pm. four more musicians come. Whilst reading, holy man makes quick offering gestures with his right hand (cf. benediction gesture 
of priests). In the cauldron banana leaf with rice is floating. Narbir and Bonmae sprinkle little bowls of rice, Narbir's son points out which rice plate should be sprinkles. Holy man is not incanting without books, he occasionally throws bundles of leaves to the older priest, the latter takes these and puts the green leaves on a flat brass bowl full of rice, which he has channelled with a spoon and which channels he later fills with liquid. By now the red clay vase is tied round with a muslin cloth at the neck, from which they get the water for sprinkling. The cauldron is now tied round with muslin. Bonmae now deals with this big pot and incants over it holding up his hand: he puts in milk and rice very delicately. He is handed things to put in by older priest. A small pretty garland is now put round the cauldron (music playing loudly all this time, which seems to irritate holy man and he asks if they can move further away as he can't hear himself think; there is a lot of anxiety among the hosts re this and a message is passed from the inner sanctuary outwards via about 5 people to the musicians. The music grows louder but the musicians later move away

\section{TAPE RECORDING}

Narbir's 84th birthday celebrations

Tailor's horn and in the background Brahmin priest chanting their holy lines, then the sound is followed by the Tailor's horn. Slow movement of full Tailors' band - 'jowri sheba'. Faster rhythm.

https://sms.cam.ac.uk/media/2733112

More wood is brought from the house for the fire, which is fanned by a banana leaf. Holy man gets up with a jug of water and leaves the canopy (to urinate?). Music stops and general relaxation. It starts to rain and rice mats ('pyoh') reinforce the other mats - much activity to get this done. A triangle of green sticks is put back on the cauldron with a small cupped brass bowl opposite that. Narbir gets up with flowers carefully held in his hand and goes round the tent with Bonmae lighting the lamps round the edge which are oil in a banana leaf. Narbir's son is scattering rice after them. Holy man has returned and is still muttering. Music starts up again. Narbir and Bonmae go round the tent a second time as well as son.

2.00pm. about 80 people in all. Narbir sits down again and he and Bonmae start throwing flowers (no animal sacrifice). Bonmae unrolls some yellow cotton which he takes from a bag which he seems to have brought from Pokhara (the novices have also come from Pokhara) winds it carefully round the green triangle on the cauldron. He then starts pouring water into the small brass bowl - which has a small hole (or mesh) at the bottom, so that water flows through slowly. Older priest has now started to incant from a book and the baby Brahmins have started from books, sitting cross-legged on the floor in a row to the left of the holy man. They rock backwards and forwards in time to their incantations. Bonmae fills the brass bowl again, unreels more cotton and prays with it between his fingers: he unblocks the brass bowl occasionally. The yellow thread connects up the cauldron and the clay pot, and then connects up with the Bonmae in one continuous loop. Narbir still has his hands in pray, the older priest has taken hat off and put glasses on and is still reading from a book. Musicians play on at a distance. Embers are collected for the fire from the house. Holy man rings brass bell, which is rung at about ten minute intervals approximately nine times. Four boys still sway. At the 7th bell the boys stop incanting, but holy man goes on rocking backwards and forwards slightly. Older priest still incants and soon after the boys start up again. (Everything designed so it is expendable and has to be repeated many times, eg. brass bowl with hole in it). $2.30 \mathrm{pm}$. Musicians in full flow ( 5 drummers, cymbals, 2 reed, 1 big straight horn, 1 curved horn) [recording]. The majority of spectators listening to them. Bell rung again by holy man. Bonmae pours more water into small bowl, holding yellow thread. Narbir still holding flowers in worshipping gesture. Holy man has moved round to north side. 2.50pm. Narbir's son 
fanning with banana leaves. (Whole ritual is very crowded with everything very detailed, full of colour and time consuming). Now over 100 people forming a crowd round entrance to tent. More and more rice presents arriving. The rest of the village is practically deserted. $2.55 \mathrm{pm}$. Bonmae pours more water into bowl; baby to my right urinates all over the floor. Her (wet nurse?) is unconcerned, but moves my feet out of the way. 3.00pm. Lt. arrives and listens to music. The four corner lamps are still burning. A huge cauldron of rice is taken out of the house for the Brahmins to eat later. Narbir still sprinkling. 3.15pm. Ramchandra's "mother" taking a considerable part in the actual ritual. One of the large vases is covered with a plate and over this a white cloth decorated with astrological diagrams on it. Fire has burnt out. The cup on the bamboo triangle is removed from the cauldron. 30.1.1969 Alan 'Sorasi puja' - principally that for the 84th birthday of the poju 3.20pm. Herbs are put on top of the white astrological cloth (the apparently useless and repetitive chanting, candles, etc. very like medieval pre-reformation rituals). Narbir still holding wet leaves in prayer and tossing them on the sheet. 4.00pm. Lt. gives following information: "There is a special puja for the year 84 but several other pujas are also intertwined with this one today. Everyone in the village is invited. There was once a very big puja given about 20 years ago by a very rich man in a house down below Thak near the river. People came from Siklis, Taprang, etc. 108 Brahmins sat round the fire chanting and throwing sackfuls of rice onto the flames. (10 big tins of 'ghee' and 30 sacks of rice). I attended. At the puja today the Brahmins are paid one cow and money". [Prem said that they were given now cow or animal but lots of rice and about 40rs 10rs. for an adult and 3rs. for boys]. The Lt. himself has already given 3 pujas. He says the women who are helping are not relatives of Narbir, they just like to help in things like this. The rich man's name was Ranbahadur. He had seven wives and no children - one wife alive who was pointed out to me.

4.00pm. A tray of 108 little lamps like brass egg cups is put on the centre of the table on a large 'mora' like ours. Meanwhile the Brahmin has been cooking food for the other Brahmins in a nearby shed into which nobody (according to the Lt.) can go. The poju is according to the Lt. to thank the gods (presumably for allowing him to reach his 84th year). Cigarettes are handed around by the hosts, music continues and Budibahadur does a swirly dance to it. The holy tapers are lit with a cigarette lighter. Oil is put into the small lamps and then Narbir lights them with a few brands of wood. Audience show marked interest - very like lighting candles on a birthday cake. Finally, about five people are helping to light 108 candles. (See photo). Brahmins pause in their recitation while this is being done. The lamps burn down in about 10 minutes. Narbir leaves with Prem for about 10 minutes. Women appear to take greater interest in the ritual than men.

$4.15 \mathrm{pm}$. Narbir is back, fire blazes up again and Brahmins continue muttering. About 40 people are watching the ritual and another 40 watching the musicians who are also dancing. The "chuckly granny" talks to her neighbour as she holds her hands in prayer position.

4.20pm. Lt. and wife leave. Small bowlful of unhusked rice(?) is being thrown onto the fire by Bonmae and one baby Brahmin; reading continues. (People are packed together very close in a small space and there are no apparent sexual or other restrictions.)

$4.30 \mathrm{pm}$. Conch horn sounded again and greenery is distributed to novices and Brahmins by Narbir and they hold it in praying position. (Among the things which now deck the small pot is a good two-sided shaving mirror). Budibahadur is summoned from the dancing, given some greenery and told to pray. Then they all throw the greenery into the centre of the table. The crowd now grabs pieces of greenery from the garlands and after a short prayer throw bits heartily onto the centre of the table. We all shout 6 times interspersed with very short readings of about 10 seconds by Brahmins just like three cheers times 2. Everyone now looks cheerful and amused by my participation. 
4.40pm. Conch sounded, bell rung, Narbir waves a flaming piece of wool on a banana leaf over a vase while his son waves a similar flame over a tuft of buffalo fur (large). The burning wool is gestured towards the pot and then put down. People resettle themselves and the flaming wood (fir?) is passed around the audience on the leaf. Each member of the audience seeming to warm their hands on it for a moment then rub their face three times with their warmed hands, the last time smoothing the hands over their body. Groups of ten or so people at a time do this. As the flames die down the banana leaf is rushed round the audience amidst great laughter, and they threw flowers on to keep the flame going.

$4.50 \mathrm{pm}$. Small dish (banana leaf) prepared for Prem with a little rice and corn and several ten rupee notes on it. There is much argument over this dish re arrangement. This is clearly pay for the Brahmins. (Prem later said they were paid 10rs. per adult, 3rs. for boys). 5.00pm. Garlands are put round the necks of the Brahmins. A half- naked holy man gets 4rs. and a garland and goes off (visitor). A Brahmin sprinkles the audience from his seat from the two pots in front of him, a mixture of which has been put into a small cup. Prem touches heads of Brahmins. A Brahmin (Bonmae?) goes round smearing black mixture on people's foreheads. About 120 people or more are packed into the little tent. We are smeared also ('budszaba'). One Brahmin tying yellow thread round wrists of women in audience (the musicians have been playing the same tune for the last 3 hours). There is more counting of money (notes). Yellow thread is tied round Budibahadur's arm.

$5.20 \mathrm{pm}$. Some of the small children now leave. The women assistants are given 3-4rs. The table is now cleared of banana bowls and flowers and these are handed to Narbir. 5.30pm. The bowl with a flame burning inside it covered with a banana leaf (which has been burning all through the ceremony?) is carried into the house. The 'prasad' (small quantities of each type of food) is distributed to each member of the audience - a considerably smaller amount than they brought. A small quantity of this 'prasad' is put on the forehead also. People now beginning to leave. We eat the sweetened, uncooked rice and a bit of 'mokhai' bread. All the goodies are being broken up and put into a basket; they are mixed up into a mush and a plateful of this mixture is given to each family. The table now looks a wreck. We leave giving the dancers (2) a cigarette which are thrown on a mat beside them, of a rupee.

Tailor's horn and in the background Brahmin priest chanting their holy lines, then the sound is followed by the Tailor's horn. Slow movement of full Tailors' band - 'jowri sheba'. Faster rhythm. 


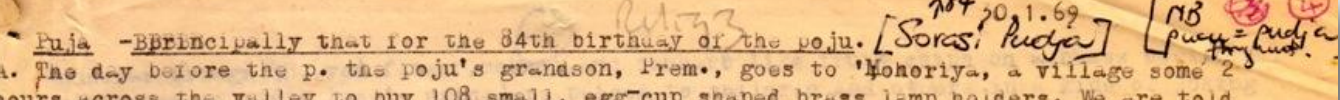

that every guest has to bring a little rice, a clower, $/ 2$ a rs. etc. and that one person irom each nousehold will be fed.

On the day, horns are blown by one musician at c.10 a.m. and we take up our position then. school boncies havo been appropriated for the occasion, including tho one from in front of our house; our kerosene lamp nas also been borrowed. The actual setting is as follows:-
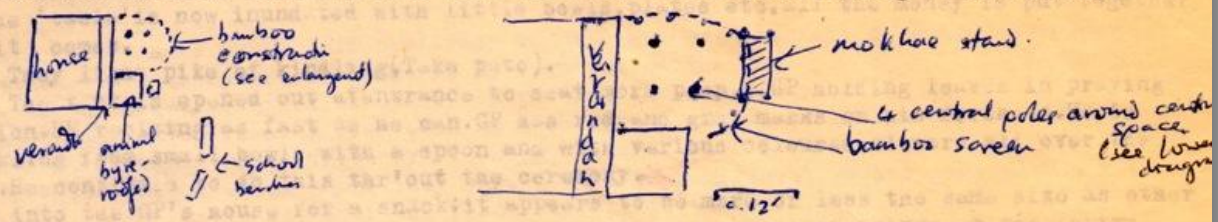

The greens tied around tis upriguts are at las moment boing crewed by gouts and hundfuls are taken of during the coremony for use in the ritual.

\section{G. Courtyard prepuration:-}

Coremony takes place in front of house by screening in a section of bumboo cane mats which are around the edge and aiso over the top to form the roof. Tho moknas frame is used as a support for the mats, as well as separate poles waich are forced into the ground between the slates - tne whole appe rance is one or a tent. sach of tile main poies ground veter with grass and bun na leaves. The "inner sanctuary" wituin the outer tent conglsts ol four poles covered also with bahaba leaves, xack flowors and rod leaves. All these are strung togetnor in a coninuous garland - over the top or the poles is a sort or panoply about 18 " sq. of a piece of embroidered cloth, brought from India/falaya with some inscription like 'Bresent Irom Nalaya'. On thu square of eurtn beneath the the punwoply are crialked out astrological (?) signs (a while dust sprinkled to make this). Iike a chess-board and at certain points are piaced 1) banana leaves sown together vo make a suucer in which uncooked rice is placed ii) tall brass candlesticks in a sign similar to Gorgian, except that the top had no cavity for holding a cundic but was a jollowod out busin for o11-wick 111) bruss vases, striped down tae sides lor the occasion witil some kind of red pigment iv) carefully placed off mid-centre a

thie (later 1it) (see diagram) v) a large blackenod cauldron on which pile of dry firewood (later lit) (see diagram) v) a large blackenod caularon on which about $1 \mathrm{ft}$. long and a smaller brass bowl beside $1 \mathrm{t}$. Around tnis square the grandiather sits on the NW side and on tho other three slees 7 other Branmins sit (3 wduit, 4 teenage brotagonist for the most part opuosite the granafather \& the most boys). The main protagonist rer 's right. Squatting beside grandiatier on his right was active one on the grandrather's right. Squatting beside granaratier on his right was Iiis soly Man - opposit to G.P - granapa) is a pile or baskt and bowis for receiving rice and ouner cereals which people fave brought for presenis. about 4 otrer people are preparing tulngs in tals space, including a conteallyy 9 shaped piece of grouna mokhwo flour waich thay took about half an nour to imeed and shave red dyo was later stripeu down it \& joss-sticks placed in it. When it was finigned it was placed on a plate beside the G.P. Pople were conuinually coming in finice, mokhae, flowers, bananas etc. -just a symbolic

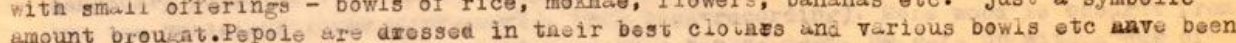
borrowed Irom othor nouses. A transistor is hung incongruouidy noar the ontrance to th tent(the $\mathrm{gr}$ bdson or the GP). ane was later played loudly in he background. Birimya arrives wite ganorous gunch or I iovers etcilt soems there is some variation oI gili will wouth. with gonorous gunch or I $10.15 \mathrm{a} . \mathrm{m}$. About 20 chilaron ana 15 adults in or near the iont.Another 10 womon are on the 10.15a.m. About 20 chilaren ana 15adults in or near the iont. Anotier fowom are on the vereandah preparing gariands (nani) Rumid's motier'). Birimya sits down to tac rigit or ee

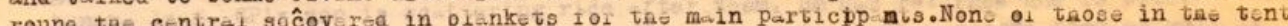

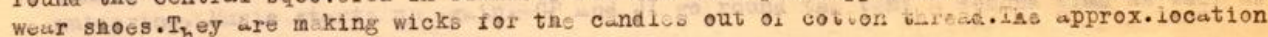
or objocts is as rollows:
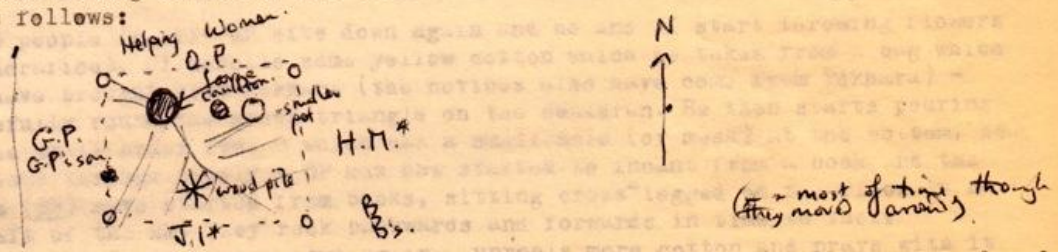

At each point where thcre are cnaik diugrams $x$ smallbowis mude of b nana leaves are placed. The ric powis huve it le crosses of twigs stuck in til contre.Baskuts ol rice ring bread plates or or nges, mokhal etc and are added to the table.

Account of the 84th birthday puja - notes and diagrams 
Difficult to remember what we did. Clouded over as usual about midday. Spent most of the day Gurung learning and letter writing. Quiet day with everyone except the poju who paid us a sprightly visit at breakfast! - a little worn out. Wrote letters, rested had a quiet evening when "our granny" paid a visit and dampened the occasion somewhat. She was very proud her father was poju. We shot them all out early, went to bed and listened to Haydn's "Surprise" symphony - music is heaven here and we wish we had more. Surprisingly, we don't feel like listening to the Beatles at all and have come to the conclusion that at home we needed relaxing and "taking out of ourselves". Here it is not really necessary. Very clouded over, cool day with no sun at all - first time this has happened.

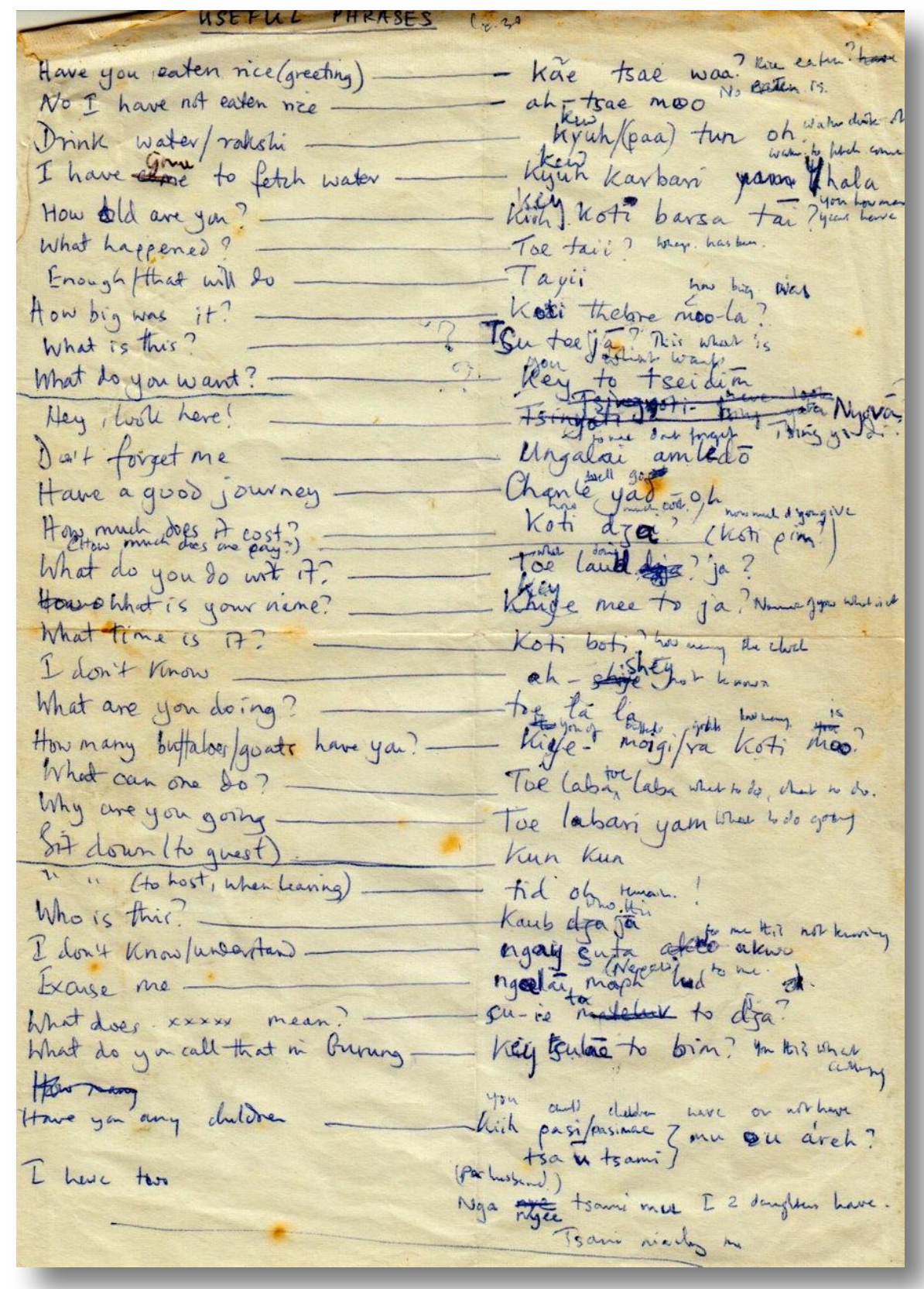

First useful phrases of Gurung 


\section{DIARY 31.1.1969 Gill}

Quiet day with everyone except the poju who paid us a sprightly visit at breakfast! - a little worn out. Wrote letters, rested had a quiet evening when "our granny" paid a visit and dampened the occasion somewhat. She was very proud her father was poju. We shot them all out early, went to bed and listened to Haydn's "Surprise" symphony - music is heaven here and we wish we had more. Surprisingly, we don't feel like listening to the Beatles at all and have come to the conclusion

that at home we needed relaxing and "taking out of ourselves". Here it is not really necessary. Very clouded over, cool day with no sun at all - first time this has happened.

\subsubsection{Gill to her parents}

Thank you also for the calendar which is hung up opposite me in the "office" ie. that part of the loft which isn't used for sleeping, storing next year's grain and the toilet (a bucket tucked coyly behind the millet). The pictures are gorgeous and, as you anticipated, were enjoyed as much by the village as by us. They have already been promised to a particularly helpful family, where the father was a Lt. in the Gurkhas, and he says he is going to frame then all - you can imagine Exeter Cathedral in the middle of Nepal! I think the village was as pleased about the letters as we were as they beamed and chattered about my squeaks of delight when I met Alan; they love it when we are happy about something.

We will have been in the actual village six weeks this coming Monday. Except for one rather mournful week on my part prior to getting the letters, it seems to have flashed past. We have managed to get a strict routine up as far as the language, food, washing and getting supplies, is concerned and this had been excitingly broken so far with one funeral, half a wedding, a trip to Siklis (the biggest Gurung village in the area) for their New Year (which begins on 14th Fanuary) and, yesterday, a birthday party cum Harvest Festival for the 'poju' of the village, who is the clairvoyant, astrologer, medicine man, age 84 and a sweetie. Seven Brahmins were hired, three venerables from Pokhara one of whom looked exactly like Judas in the Last Supper, and four tiny choir boys who were irritatingly precocious and in training to become adult 'bonme'. They chanted away for about 6 hours of their Sanskrit books, and the 'poju' chanted back and they occasionally threw leaves and flowers and rice at each other. 108 candles were lit in brass egg-cup holders and the women were weaving garlands and Tailors of the village playing loud and raucous music and it was quite exciting.

As you will have gathered from this rather bewildered description we didn't understand a thing that was going on, except that it was Grampa's birthday and a thanksgiving festival to the gods. We took 15 pages of notes and Aland the music beautifully and we are just praying we will be able to sort the whole jumble out when we come to write the book. We are hoping this sort of fuzzy haze is normal at this stage and that we will have a real command of the language in a month or so.

We were lucky enough to meet some linguists in Kathmandu who were starting to work on the Gurung dialect and they lent us all their notes and small dictionary which has proved indispensable. We have also started regular lessons with the first schoolmaster (there are three altogether) but having organized everything he failed to turn up after the first morning! We think he might have gone off to a wedding in the next village and will send a note when we hear he's back as he lives near the school at the bottom of the hill.

Alan is, as you can imagine, indefatigable in his pursuit of knowledge and we have endless jolly conversations in the evening when at least 5 to 10 people have already seated themselves before we have lighted the fire watching me spilling rice, crashing my head against 4'6" beams and sootying up my nose with blackened pans, and generally trying to cope. This is all the more frustrating as the women here cook exquisitely with very poor quality food, hardly stirring from their seat by the open fire, rhythmically and effortlessly producing a huge and subtly spiced meal for an entire household. They have the most beautiful brass and copper cooking utensils all in soothing womb-like shapes which they keep polished immaculately with cold water and ashes. The first shattering thing I remember was our aluminium washing up bowl, which reeked of leaked kerosene from the journey, being seized from me at the village tap and a Gurung woman heartily scouring it with 
a lump of cow dung scooped up from the ground around the spring. They are very enquiring of our hot water and Surf, bought in Kathmandu.

We have become particularly friendly with the Lt.'s household and whenever they are cooking some special Gurung dish they always fetch me down to watch, as their house is two layers down from ours. They have a beautiful one, newly built at a cost of approximately 8500 , with green painted window shutters - the only ones in the village and therefore of high prestige. Irritatingly, I prefer the simple blackened window struts - they have them prettily carved into tiny square holes or rounded pinpoint ones and they offer some sort of protection against the draughts, as of course there is no glass.

We had our first Gurung meal there, and we think with horror that they might have killed a goat in our honour. We had eaten no meat prior to this and had mainly subsisted on eggs (as a result I think I must have lost over a stone and my waist is 25" rather than 29"). The goat's head had been brought inside as a trophy and was drying off beside the fire and I knew exactly what Ghandi felt like when he vowed to become a vegetarian because he could feel the goat dancing about inside him! I had just read this bit in Fischer's biography and couldn't face up to eating the poor Lt.'s meat. You will be amazed to hear as a result I developed a reputation for a poor appetite so you can see there have been great adaptations.

I have become very fond of his wife, who is always most gracious and mothers us somewhat; they have 4 children of their own, as well as an adopted one who was thrown out by her stepmother, and endless grannys but no grandpas. I have found out about weaving and spinning and preparing the rice in their courtyard and have watched her mill her peppers and grind her chili and saffron - all with two polished stones and some water. I find material culture absorbing so it will be even more satisfying getting somewhere with more sophisticated stuff, and what they feel about things, as I used to say!

Also as anticipated, we have become a dispensary and our Gurung learning is often interrupted with plaintive cries at the windows and sore limbs presented to us for Savlon and lumbago mixture. To date the worst injuries have been bad cuts from axes and falls onto wood and stone in the forest - they go out every day to get firewood and vegetation for the buffaloes. I become very fond of my little patients and am always touched by little presents of spinach-like vegetables, tied up like a posy in bamboo cane, or the odd banana and rock hard green tomatoes.

Alan had one family where the man was immobile as he had practically sliced his toe off. He was originally giving the old Granny Aspro for her arthritis and was met by the prostrate man one morning. He had liked going there before this as they loaded him with ' $p a$ ', a sort of neat whisky and he would come back, warm and rolling, at 8.30 in the morning! I tried to patch up the toe, but had to go away to Siklis in the middle of it and when we came back the patient had disappeared to Pokhara, we hope to hospital there. We haven't seen him since and occasionally wonder what I earth I did to him - even with Dettol and bandages!

I had the same paranoid feelings after the Lt., his wife and eldest daughter had come on a return dinner - we didn't see them for a few days afterwards and then when Alan met the Lt., he said the hadn't slept for the last few nights as he had a bad blister! I worriedly rushed over the menu, dried peas, tinned fish, fried potatoes, and wondered if that could have produced such sleeplessness! It had been a pleasant evening as we used everything they had lent us, silver and brass bowls and all the food they had acquired for us, potatoes, 'pa' and oil. Alan had picked some brilliant yellow flowers from the mountain and had put them in our green enamel toothpaste mug so we had even looked a tiny bit festive amidst the unprofessionally swept mud floor and the grimy hurricane lamp . 


\title{
FEBRUARY 1969
}

\author{
DIARY 1.2.1969 Alan
}

Hazy bright, temperature about 50 - clouding over at lunchtime. Again spent most of the time indoors, translating Pignede, writing home and struggling on with Gurung. Some Tibetans camped in school house next door in evening. They were very rudely treated by our next-door neighbours when they asked for wood, etc. Obviously considerable guilt and tension over this question of begging: tension between old norms of hospitality and new, more acquisitive ethic/greater burden of increased Tibetan wanderers (cf. witchcraft). Our neighbours conformed to "guilt and reparation" theories by selling us eggs, etc.

\section{DIARY 1.2.1969 Gill}

Wrote letters. Unhappy incident with Tibetans who were camping out in school house next door. "Our granny" treated them most sternly, teaching children to do it too. They were asking for mat/knife, piece of wood. I became very angry and told Granny off as best I could. It seemed to have its effect as Granny came in later for ground corn and sighed away at the heaviness of labour as if expecting sympathy, which she didn't get; then Nani came in to sell us some eggs and then they left us in peace - not even $\mathrm{H}$ (Haricola) came in. Nani had previously told Alan not to give them things and he had said we would. Difficult situation, especially as I don't like giving that family anything.

\section{DIARY 2.2.1969 Alan}

We were going to river, but hearing a puja is organized for the afternoon, decided not to go. A bright, warm day so far. Taking a break from Gurung, spent the afternoon chatting to people and visiting the puja (a much smaller family affair with only one Brahmin, etc. [see description]. Didn't return until almost dark. Usual crisis as we were making supper: a man had fallen building the house - or a piece of stone had fallen on his knee. Amid the smoke etc. we patched him up.

\section{DIARY 2.2.1969 Gill}

Letters again - rather poured my heart out to Fiona. Did lot of washing which was a good feeling. I hate doing it but it washes me through somehow. Family next door now seem to be demanding things again when we eat, as if in reaction to their guilt and retribution yesterday.

\section{NOTES 2.2.1969 Alan - Sustani puja}

Today there are four such 'Sustani puja' in the village in all - in houses 5, 20 (or 17?), another house higher up in the village and ours at House3B. Only one of these is held per annum according to Comal. At them 'deota-lai kheba' (ie. godly books read?). I arrive at about $1.30 \mathrm{pm}$. to find the final touches being put to a small bamboo construction, similar to the construction for the 84th birthday puja, but a good deal smaller. The screen round the outsides is called 'barkari'. The whole is constructed of wooden poles, mats, etc At the moment there are about 8 young children present, 4 women making garlands. But as the Brahmin has been delayed nothing happens for about another two and a half hours. $1.45 \mathrm{pm}$. They have now taken the 'gundri' from the centre of the wooden construction and hung up a brightly coloured Xmas type hanging of silk or cotton, probably from India like the 
brightly coloured vaguely religious calendars of Hindu goddesses hung on the four corner posts. Leaves are put round the top and banana leaves are put up the sides. The central Xmas decoration ('sanoi') is in a crochet design and, Gill says, made of cotton. At last at about 4.00pm. something happens. One Brahmin and a baby Brahmin come to officiate - they are the same ones who officiated at the Poju's puja. The Brahmin fills two little 'pela' from a kettle, one with water, one with?. Pours milk into the second. The floor of the central space has been spread with dung (?) or just wetted, a little pile of ash and water is made in the centre. The Brahmin starts chanting, the father sits in the background and Pot. sits on his left. No one else is there. The Brahmin makes lines all over the central space with white powder sprinkling it very systematically working from the centre [see diagram - fig.4 ] and then round the sides. The powder was contained in a small bowl. The final diagram was as follows [see diagram 2 - fig.5 ].

Meanwhile the baby Brahmin prepared brews. Rice flour, bottles of fluid etc. have now been brought from the house. All participants are barefoot. Some cotton is brought and put beside the Brahmin - brought from the house. Brahmin scatters some pussy willow type plant a little and then pours about 3lbs. of 'mla' over the whole central area. He placed two large vases about $1 \mathrm{ft}$. high with red smears down the side. They are on banana leaf plates. On another area of table he places slightly less of a different type of 'mla', larger husks etc. Garlands of flowers have meanwhile been hung on the central pole. (Birimaya presumably having finished her own puja comes and sits opposite the priest on a rug with her children). On the central pile of rice is placed a bowl of rice and a red smeared jug. Various small bowls of rice are placed at various points and two small pots are placed in corners opposite. [See diagram fig.6 4.30pm. People start coming in; there are now about 20, mostly children. Birimaya is dealing with presents, the same are brought as at the 84th puja. A couple of awful photos of Hindu deities are placed at the corners against the poles in frames. The Brahmin is now making a sort of net with cotton thread from the central pot radiating to the four corners. Women comprise the only helpers so far; the obviously enjoy this ritual very much. The father is the only adult male attendant apart from myself. More garlands are hung up. All the bowls have now been filled with red leaves. Togari is hovering outside the tent, helping with various things. The Brahmin is crumbling straw into some water.

4.45pm. About 35 people are now here of whom 20 are children, 14 are middle-aged to old women. The baby Brahmin is drawing a diagram on a large brass plate with a yellow liquid [see diagram - fig.7 ]. Various further dishes have been added to the table and flowers and red leaves placed on most of them. The Brahmin has now lit a little light in the bowl nearest to him in which there is some rice at the bottom, and which is covered with a banana leaf.5.00pm. He is now reciting; he makes a bright red mark on the forehead of the three women helping who are the mother, father's brother's wife (Servajid ego), Birimaya. Cow's urine is passed round. Servajid does not drink himself saying it is 'alim'. (Eldest two sons absent during ceremony). The Brahmin starts to consult his book - a small one printed in Nepali. Another larger book is also passed to him. The Brahmin seems to know the wording as well as a long established Anglican priest at a communion service. Everyone carries on as if nothing was happening - talk, etc. The Brahmin stops occasionally to ask questions eg. the names of the members of the household from those participating who now consist of the father, his wife, and father's brother's wife, seated as follows [see diagram - fig.8 ]. 'Susteyni' occurs often in the reading. The husband and wife on the left of the Brahmin do all the sprinkling etc. The focus of interest seems to be a dish of banana leaves with a pile of wet ash and in the middle of this (which is about 9 inches high) an object like a large black acorn apparently placed in a brass setting [see diagram - fig.9] [and] a few red leaves and it is located just in front of the father and his wife. 
$5.10 \mathrm{pm}$. Joss sticks are lit with a cigarette lighter, one is stuck in the central pile of rice and one hear the acorn in the ash. 5.15pm. The bell is rung by baby Brahmin and the Brahmin sounds the conch horn. The mother is the main celebrant sprinkling and holding her hands in prayer, though her husband also helps.5.20pm. Further horn blowing etc. There is a short rest in the proceedings. Potamkumari is beginning to prepare things again, a large flat black pan of grains, flowers, etc. On the other side of the central rice pile on the other side of the acorn is a piece of "bread" as at the other puja, but smaller, still conical in shape. A bamboo shoot with pieces of cloth tied to it (as used in chicken sacrifices on the hillside) is propped against one of the posts. Potamkumari is counting the exact number of grains of rice and putting them in a piece of cloth (I show my drawing to the curious Brahmin and he is flattered and amused) Nansubar has rolled up and Birimaya has reappeared after a short absence). They take small sips of ?, passed round the inner circle. Both husband and wife have a little piece of straw twisted round the second finger of the right hand. Birimaya instructs them where and when to throw things. Two women (Potamkumari plus one) stand up, hold red leaves and pray with them for a moment, and then throw them right on top of the panoply. About 25 people now here, still only one male adult. Rice is being scattered on top of the panoply by husband and wife and also they scattered red leaves and small coins. $5.30 \mathrm{pm}$. Horn sounded. Bits of smoothed out wool are lit and burnt quickly, husband and wife holding them in a banana bowl and circle them with their hands. They are then placed in a bowl of embers. There is further sprinkling with flowers (Gundasing's father now attends - the only male apart from the father). We later learnt that he had a bad splinter in his hand. The flat plate with the drawings is now placed in the middle by Brahmin and another book is being read. Small coins are placed at the centre of the dish and it is gradually filled up with leaves and flowers by wife sprinkling them mostly. The Brahmin cleans his conch with water and then sounds it in a very long burst. Further circling with lighted wool (much laughter and chat and smoking during all this). The 10 pice in the centre of the dish is the absolute central pivot of the whole ritual, geographically. It feels as if the whole ritual is to ensure good harvest and wealth.

$5.35 \mathrm{pm}$. Further conches etc. sounded and circling with lighted wool. The little bowl of embers is flaring up and the light in the bowl in front of the Brahmin is still going. Further drinking of ? liquid. Various members of the audience throw flowers onto the central plate and also further coins. It is now full to the brim. A small coin is stuck into the pile of ash just by the acorn by the wife, an also another joss stick. Cow milk and water mixture is sprinkled on a central plate, a little of this or another fluid having been sprinkled on the acorn previously. Then a little bowl is placed on a central dish and a garland is put round it ('Sustenyi' is constantly repeated at this time by the Brahmin). A cotton cloth is put round the garland and the small dish is piled up gradually with small herbs, eg. weeping willow etc. Conch is sounded. A paper packet of something is placed in the central bowl by the wife. Pot. is giving instructions on how the ritual should be carried out. (Servajid has not been present for some time). Father's brother's wife circles with lighted wool. Further small coins are put on a book, along with various herbs. It is now $5.45 \mathrm{pm}$. and beginning to get dark. I am told that the ceremony goes onto $7.00 \mathrm{pm}$. I depart.

Letter from Gill to Fiona 2.2.1969

For the most part I find it stimulating and restful at the same time - which is an ideal combination; at other times I am immensely irritated by the lack of privacy and the endless people I can't communicate with except at the most banal level.

The fear I felt at the unknownness of everything evaporated as soon as I could see what I would be dealing with. The difficulties are much more insidious and complicated and I have been forced into a lot of soul 
searching which I never anticipated. I think my position was epitomised yesterday when some Tibetan refugees trailed through the village and prepared to settle here for the night. We have such a crowd of 7 or so on an average once every week and they go around each house begging for rice, firewood and a mat to sleep on. There is an empty school house next to us and thus we see quite a lot of them as they camp the night out here. It is open on the first floor and as they only have the rags and disintegrating wool Tibetan boots which they walk in they must get cold, huddled together in the darkness.

Alan is going down to Pokhara this coming Wednesday to collect any post that has arrived.

First let me say that the last time the money had come through, to Alan's immense relief; I think we had about 40rs to last us through (about 30/-) when we went in trembling to the bank, so you can imagine we were quite relieved at $\mathrm{E}$ 50! We bought in two large baskets of provisions that will last us for the next 1.5 months, and hired two Tibetan porters to get them back to the mountain. Most of what we spend seems to go on the basics that we can't get in the village - sugar, rice, flour - and then tinned meats, fish etc. which we supplement our fortnightly chicken and daily eggs.

We could actually get rice in Thak but it would be in its unhusked state and although I have been shown the techniques, one of them would take a life-time to learn, and the whole process in any case takes up a whole afternoon for about 2 lbs of rice. The part which is difficult is when they are separating the half-husked rice from the chaff, using a large round straw woven tray and sweeping it round and backwards and across so that all the various stages of the rice go to the right places. I'm sure the whole lot would fly off the tray in all directions if I even picked it up, as the movements really do constitute a work of art, and have been learnt from childhood upwards.

The chicken is also a bit of a sweat to get, as you have to find our which house has one ready of a suitable size, go and bargain for it, pick it up under your arm, kill it and pluck it and then, hopefully, cook it! Neither of us can bring ourselves to do the killing bit, so we ask a cooperative neighbour to do the deed - talk about the squeamish English! I can't even buy one from our immediate neighbours as I know all the hens off by heart now having watched them scrabble about during endless meal times, and would miss any that weren't on the scene!

We can also get vegetables such as potatoes, cauliflower and peas in Pokhara but availability of good tinned food is limited and we have decided to go to Kathmandu at the beginning of May to get in a really good stock, and buy things like cheese which we haven't seen since we've been here except a handful of what we would call cottage cheese, but which the villagers call butter, brought as a thank you for some medicine doled out. Generally we reckon on having one tin of meat, one of fish and one chicken every week (although the latter tends to be once a fortnight as we don't want to exhaust the village supply! They only eat chickens when they sacrifice them for special days, sometimes once a month or even less).

We eat a lot of eggs as I make endless pancakes as you can get huge beautiful lemons here and we have discovered a honey they make in the village which is rich, golden and quite delicious, and they are heavenly together over the pancake batter. I also manage to make brown ground flour scones for Alan as he bought an iron round tray at Pokhara which I put on the tripod which is in the middle of the fire on which the pans usually go, with the logs of wood underneath. I put the dough out on top of it, take the logs out to reduce the heat and cook very slowly, and it really works. As you can see, I think we are living quite well food-wise, and I hope we are keeping as fit as possible. I have felt very well in the last fortnight and managed the last trip to Pokhara quite well, and this physically is usually quite a strain.

We have got up a regular work routine, up at 6.30am, breakfast on the verandah with our small kerosene stove (porridge) and then usually the schoolmaster comes at 7.30am to teach us Gurung until 9.00 - he is a bit erratic but we had him three times last week. His English is very good and he is quite a good informant on events, although insisting 'we are a very simple people' and therefore don't have many rituals! To us every other day seems packed with them. We then type up any of the latter we have been to - the birthday party I mentioned in my last letter lasted 7 hours and Alan took 15 pages of notes, with three from me! There was much making of garlands, throwing offlowers, chanting from Sanskrit and drinking cow's urine, as well as music and lighting of candles and bringing of presents - rice and flowers and paise pieces (about .25d) - we didn't understand any of it but it had bursts of great fun, as well as being unbearably tedious in parts! We then learn some Gurung on our own and then I read some of the books . 
We then have lunch, again on the verandah, and then Alan washes up and brings me a Horlicks drink in our loft, where we work as well as sleep, and I read. We then go up the hill, which means to our toilet at about $3.00 \mathrm{pm}$ and sometimes we continue up to what I call the 'mountain', which is a tall outcrop of rock overlooking the village, with gorgeous views of the Himalayas and the valley plains in every direction. This is where I am at the moment. It is a gorgeously warm day with a slight breeze and a few cloud shadows dotting the hills, the grasses alive with butterflies and wasps, with bright yellow flowers, and blue star shaped ones like gentians peeking out of the rocks - quite idyllic and a haven of peace and privacy from the village. If I typed out there I would be surrounded by children and old women within seconds. Far below on the path the goats are being brought home, their bells tinkling away as they wander back with two or three boys vaguely in charge. The girls are all coming on the same path as the forest is in that direction, where they get huge bundles of greenery for the buffalo, tethered at home in the village.

We then go back and might translate the only other book on the Gurungs, which is by a French man and very good in detail and way of life. At 5.30pm I start preparing dinner which we cook inside over the fire, and then at about 8-9pm, depending on how many people come in and whether we have a sing-song or not, we go to bed. Sometimes we have a treat and listen to some Beethoven or Mozart which we have brought with us on tapes - it really is ideal, and yet, maddeningly, we would still without a shadow of a doubt rather be at home.

We have talked about this to find out why and can't really give a concrete answer; we talk about a lot of things here, essential issues arising out of comparison with this society and ours, and also from the books I am reading, stuff I have always wanted to look at. I think you will be able to tell from letters how relaxing it is here, even Alan is much more unwound and less pounding after work - though we are always busy here but it is at our own pressure .

After my explanation of how I would send letters to various members of the family, carbons etc. in my last letter.I am sorry to change everything but a frustrating hour in Pokhara post office, buying up their total stock of air letters (13) and then sticking something like 140 stamps onto the back of air-mail letters has persuaded me to send just two air-letter forms at a time.

All the village knows that my sister is getting married. They make a big splash with weddings here and it is the height of the wedding season at the moment. Almost every day wedding processions march through the village, usually about 30 people - the women dressed in purple velvet, the men in white with the occasional umbrella, dark glasses, BOAC back or transistor to show their status. They are proceeded by musicians who blow aggressive blasts on their curved horns and thump three different kinds of drum. You may have seen the, probably blurred, colour slide of one such procession and we have tape-recorded them.

The other evening a bridegroom turned up at this village, having brought his 10-days-married bride for a few days to her parents' village. They arrived as it cot dark, rushing up the steep steps, with all the young people of the village viciously lashing with banana leaves at the bridegroom's back (who has come to take away their "sister"). We trooped up to the bride's house and there circles were drawn with water round his feet, he was daubed with rice mixed with milk, and the young girls of the village splashed red powder all over his brother and friends' heads. Meanwhile I was vainly trying to light our pressure lamp which the bride's brother had, at the last moment, come to borrow.

That evening there was dancing in one of the houses lower in the village. We had to wait until after midnight until anything happened and then a chorus of men chanted slowly, intoning to the Gods in Sanskrit and two adolescent girls, sitting raised off the floor and muffled by the light of one flickering wick candle, swayed themselves into a trance. Later they danced, or rather swayed from the hips, gently turning and twisting a water jug round them. It was the first time that we both felt that we were in an alien society - sitting in the pitch dark, packed between Gurungs, almost becoming hypnotised ourselves. The following day the girls danced again, this time dressed in gorgeous gold headpieces and rich cloths - but then to same slow chant and drum beat. Despite being a wedding it all sounded very sad. They don't seem to have the fast vivid dances that I remember in Assam .

The other piece of ritual we have observed has been a couple of pujas or thanksgiving to the gods - each time involving Brahmins who muttered from their prayer books and occasionally rang bells and blew conch shells. The ritual went on for hours, everything like pouring water from one container into another, being repeated endlessly and tiny pieces of this and that being scattered around until in the end the square of earth under a 
bamboo shield in the front courtyard of the house where the puja occurred looked a real wreck. We (the audience) joined in at various points, throwing flowers, drinking sips of cow's urine (supposedly), being given the 'tika' mark on our foreheads by rascally-looking Brahmins who looked like Fudas Iscariot, and finally being handed a handful of mixed rice and various vegetables, the 'prasad' - we each having brought a plate of rice, a flower and a 'mori' (6d. piece) as our gift. We have a very detailed description of all this, but what it all means I don't know.

Another day I went to the forest with one of the young boys. Now is the time that all the men, working in gangs of thirty or forty, cut down the huge and beautiful trees, hack them to pieces and let them dry. In a couple of months they bring them back to the village and burn them throughout the five months when the monsoon makes it too wet to cut firewood (fune onwards). On the way up to the forest - which takes an hour and along which track they carry the huge bundles of firewood, even Grannys of over 60 carrying loads which I could hardly lift - the young guide (so of the local medicine man) and I discussed birth control - of which he seemed perfectly familiar through Radio Nepal.

The forest, or rather thick wood with huge trees, creeper entangled, rearing out of it, was very beautiful - full of glorious ferns and little mauve flowers (I will try to bring a sample of seeds of these back with me). Not at all frightening - in the day at least - though it contains tigers, leopards and bears, we are told. The wood cutting at which they worked very hard with small axes - was a sad affair. Many of the hills have already been cleared and in another ten years the forest, on which the whole economy now depends, will have evaporated. No replanting, needless to say, is being done.

The rest of our days we spend reading, learning Gurung - in which we can now hold elementary conversations - and thinking of sound anthropological questions to ask. Time slips past, with many thought of home but crowded with interesting things to observe. Odd moments are filled in handing our medicines (ironically mostly to the local medicine man's family - he himself was here for Aspro this morning), and tins, for which there is a craze.

\section{DIARY 3.2.1969 Alan}

Another gorgeous, warm day (indoor temperature nearly 60). To our delight the schoolmaster turned up and we did some Gurung. Finished our letters home and prepared for Pokhara. In the afternoon went up on the hill above the village to read poetry, etc.

\section{DIARY 3.2.1969 Gill}

Feel very explosive inside and had to go up the mountain to get away from village and our neighbours in particular. I must learn to control my projections onto the family as I give vent to all my frustrations with them. Read Book 1 of "Light of Asia" to Alan on mountain who enjoyed it very much. "The Idiot" becoming painful reading - describing his epileptic fits and the sense of reality he got from them.

3.2.1969

Gill

\section{DIARY 4-5.2.1969 Alan}

Went to Pokhara with Gill. A lovely walk down after an abortive attempt to get a porter. Just before we left - the evening before - and untouchable came saying that a man in his house was very ill. We went down to the tiny (about $20 \mathrm{ft}$. long, 1 floor, no windows, the partition only of grain baskets) house and the man complained of soreness, panting, etc. We were told later that this was 'dumgo', that he had had it for five years, that a man had died some three months before of this. He was streaming with sweat = ?

Anyhow we left for Pokhara at 7.30am. and arrived at bank at 1.00pm. - taking photos and rests on the way. Delighted and relieved to find some of my money had at last come 
through. Picked up the first of our "Diplomatic Bag" parcels (x2) of books and letters (about 7) from various - though none from home. Then spent the day shopping, chatting and having supper with Mark and Suki Schroeder (Agric. Economies Dept. Cornell Univ. - to be) and bed at Metyju Hotel (2rs. a night per bed - but very noisy till 1.00am.). Next day further shopping, crisis over porters who were finally located, and then returned with a heavy load, leaving Pokhara (me) about 11.45am. Arrived after an easier journey about 5.30pm. Put up porters for the night (Tibetan - paid 18rs. each). Glad to be back.

\section{DIARY 4.2.1969 Gill}

We then found Sukey in and they invited us to dinner - also Mama there, learning how to knit and looking quite pregnant. She will miss Sukey when they have gone - which is Feb. 24th. Mark Schroeder looked a different person from when I saw him a month ago. He was sunburned, smiling, relaxed. Now he openly admits he feels "frightened" at the thought of going back and is already tensing up for America. Sukey told me how much better they are with the children out here and that the middle girl, who is the difficult one, took only two weeks to potty train, whereas the eldest boy took two years. I like the family very much and Sukey reminds me of Lesley. In some ways, however, I think it might be better when they have gone as they remind me of a different world where I can communicate and talk about difficulties of being out here, and therefore it less in reality, when I get back. Pleasant supper there

- they have troubles with servants etc. and are finding it rather a strain at the moment. We spent night in a grimy looking Tibetan hotel on the main road.

NOTES 4.2.1969 Alan - on agriculture

Bhuwansing was working on his 'mokhai' (maize) fields (on path towards Taprang, high up, furthest north). These consisted of about five strips, in all about half an acre. The ploughing of this took yesterday and half of this morning. Then this morning his wife, daughter (Dankumari) and four other women were hoeing out the old mokhai stalks ('nor shwiba'). He said the four women were there by virtue of the fact that Dankumari had worked with them and were just "friends". It later appeared that one was Dankumari's aunt and another was a niece. They worked forwards, squatting and hoeing with usual hoes, talking and joking, wearing heavy velvets etc. even though it was a blistering day (75o in the shade). Bhuwansing said that young men and women liked to work together if possible and that such groups of young people sang and joked. He said they did not mind such work, though it was clear than Dankumari who complained to Gill of dirt/ chest, did not like it. This work started, Lt. said at $10 \mathrm{am}$. and would go on until about $5.30 \mathrm{pm}$. with a break for 'proken saba' at about $1.30 \mathrm{pm}$. Lt. boasts that he has "three strong" people in the family, daughters Dilmaya and Dankumari and his hired blacksmith boy. He says that he hopes these four will clear the land in under a day and be able to do another small plot nearby. This plot is in the 'Puje' area. It must be planted with 'mokhai' in Tsaita. The seeds are saved over from last year's crop. The fields have already been spread with goat dung, which would probably have taken two people a day to do, at least. The plot is approximately 85 yards in length and pear-shaped. He bought this land last year for 1800rs. His wife is in charge of the food arrangements and will decide if they will eat at the house or in the fields.

\section{DIARY 5.2.1969}

After shattering night - they were building a house just below our window up until about $1.00 \mathrm{am}$., woke up at about 5.00am., felt very depressed at the thought of going back and facing my favourite family; also problem of giving/not giving I find a great moral problem, exacerbated by the fact that Mark Schroeder seemed to think it odd as well. "One must learn 
not to say no" - trite but true, I think this is one of the major problems we will have to face with children. Alan too was worrying about whether porters would turn up even though he had arranged two Tibetan ones with Marion the day before. We had the usual misery at Pokhara scene, and I really will have to control this in the future as it is so wearing for both of us.

Had breakfast with Schroeders which was chaotic as children were fretful just having had a cholera shot the day before. Also, servants are embarrassing at that time of the morning. I think Alan is right about the bother they would cause - even less privacy thanwe have. Alan then flew round doing yet more shopping and I organized two dresses to be made with Sukey's help and one of her patterns. More confusion as Princess Margaret of Denmark was coming through Pokhara with her husband and they were putting cotton cloths on tubs, and tarting up drooping banana leaves. Alan just missed the porters, came back in a bit of a state but we later found them in the bazaar and managed to set out at $11.00 \mathrm{am}$. with two free baskets.

Schroeders had gone off at 10.00am. with some missionaries who were building a boarding school which has a bad reputation in the town, apparently. Schroeders are antimissionary, saying they stir up a lot of trouble and deliberately jam up the works with the Nepali Gov. Deliberate proselytising is punishable by a jail sentence and apparently there is one missionary and one convert both in Pokhara prison now. This pleased Mark but I thought it was too good a martyrdom situation.

I set off ahead with porters, and Alan caught us up after an hour. Very hot with sun beating down on the back of my neck across plain. Managed climb quite well though, and nothing as hideous as last time. Porters very tired, but pleasant. We ate together and then quickly collapsed into bed.

5.2. 1969 from Alan to his sister and future brother in law

Dear Annie and Erik,

[Comments on their forthcoming wedding]

. Although there is a bit of a monetary crisis at the moment as no money has yet come through for us (it should come any day now as $\mathrm{Mr}$ Cooper sent if off a month ago), once it arrives we will be relatively affluent,. Our rent per month is only c. 14/- and we live on about $f_{5} 5$ per week, saving about f10 per week or so, which is nice.

I'm expecting the galley proofs any time and I think it is meant to come out in the summer. I heard from Cambridge that they were more or less happy about Josselin, though they suggested I might amalgamate a couple of chapters. Perhaps Mummy will do this.

On the contrary, Erik, it was nice to hear about English politics: apart from the occasional crackly English news broadcast from Radio Nepal, we are very out of touch until our New Statesmen start arriving, so keep us informed on major events/problems if you have time. A pitiful (and guilt-inducing) comment on foreign aid is the fact that we are living off tinned mackerel bought in Pokhara bazar and labelled "The gift of the People's Republic of German" (presumably sold by Tibetan Refugee Camp

DIARY 6.2.1969 Alan

No schoolmaster, so spent day on Gurung, etc. Three bad wounds in morning: swollen hand with thorn, baby's eye, baby second degree burn on buttocks. In evening a more civilized chat with only three coming in (Haricola, Omkumari, Maldosing). 


\section{DIARY 6.2.1969 Gill}

Dispatched porters with no payment problems this time. Nice couple. I was still tired and slept off 3 hours of it in afternoon. Prasad did not come which upset Alan who is a bit depressed. Disappointed his witchcraft galley proofs have not come through.

\subsection{Alan to his sister Fiona}

But the constant battle between one's longing for peace and beauty and one's desire to contribute something to other people's lives etc. etc. goes on. Even Lochmaddy will seem a hectic city after this place - there are no shops selling anything beyond matches and soap for four hours in any direction. Pokhara is, as you saw in the magazine at Crowthorne, a sweet little town, about the size of Ambleside - full of mule trains carrying grain, distant viewes of teh Himalayas, and, as you saw, fields full of children learning their lessons outside squatting on the ground. There we buy our month's supply of sugar, rice, peanut butter, medicines and other goodies and load them onto one or two porters and trek back. . At the moment I am floundering in the attempt to understand this society. Frankly, I don't think I will make much of an anthropologist - I am too impatient, and insensitive to the subtler nuances in behaviour etc. But it certainly does make one think about basic things like - what is honesty, why does one give to people, what does humour consist of, as well as making one appreciate every little thing like warmth, a little extra food etc. The physical surroundings and food wold make the croft seem luxurious, but the rest of the surroundings couldn't be more ideal. The people are gentle, kind, full of mirth and gaiety, and immensely graceful and good-looking. They have re-christened us with Gurung names and accepted us, at least superficially, in the most generous manner. As they are very curious about everything we do, from going to the toilet to getting letters from England, they take all our many questions with patience. It is a universe filled with tiring work, endless minor illnesses, few obvious pleasures, and considerable malnutrition - crowded with animals and children, yet they find it immensely enjoyable, or seem to, as far as we have been able to discover so far. Anyhow, I hope you will be able to get a few glimpses, if only of the externals of this society, through the coloured slides we are sending home. .

\subsubsection{Alan to his grandparents}

\section{Dear Granny and Grandpa,}

As you know, the main reason for our time here is to get some comparisons for my historical work - to get to know what it really is like to live in a pre-industrial society. This is working out very well and I now have many theories which I would like to test out on the material Mummy is analyzing and that I collected in Essex. There are, naturally, many difficult times - when we are very tired, everything seems very dirty and we are oppressed by the lack of privacy. Then we lie back and long for one of those lovely relaxing, cleansing week-ends we used to spend with you; the lushious breakfasts and other meals, soothing walks through the autumn woods, tea in front of the fire. But time is passing very quickly now and we are enjoying things more and more. The people are quite delightful - humorous, gentle, gracious and good-looking: the weather and viewes are, for the most part, superb. We couldn't have chosen a nicer place and it will be a wrench to leave in just over a year (we hope to return in March, 1970).

Alan to parents 6.2.1969

Dear M. and D.,

So many letters to thank you for and to reply to I don't know where to begin: [list of numerous letters] I can't tell you how lovely it was to get all these letters after 6 weeks without any news. We have read and reread them, and, after Assam, you will fully realize how much they all mean. Thank you a million times - as Gill said, they kept us chortling for hours. The calendar does make us nostalgic, but was a wonderful idea. It was lovely to turn the page over to February - Swaledale, a few days back; and am also longing for the picture of Rannoch moor. .Perhaps when we return and I need to refresh my anthropological techniques I might (don't 
tell Fiona) do a little study of one of the West Coast communities. As you say, the comparisons one can now make between Assam, grout, Kirby Lonsdale, seagulls, Gurungs, Boreham and Locheport are many and fruitful. I don't think I will have times to develope many ideas in this letter, but the chief aim of this spell in a pre-industrial society is certainly being achieved - I am now bubbling over with new problems and types of analysis to make of the Essex and Westmorland data. Even if my thesis on the Gurungs is not first class, I think our joint study of K.L. will be a landmark. I sometimes long to be in front of a manor court book or parish register however; it is so much more difficult to do the observing oneself-I much prefer the analysing of fixed material that has already been collected. I am much better with books than with people - I think I have already spent too long sitting in front of a typewriter and a pile of index cards! It is really sometimes quite an emotional effort to go out and talk to people and ask them questions - perhaps partly shyness, as you say. Re. Richard's gracious remark about my being "welcomed back into the academic community" - in fact, as you know, I am of divided mind whether I would like such a welcome anyhow. The thought of teaching universitytype history, or working at LSE. is pretty dreary.

I think that what would give you the best sort of idea of our life here would be a description of a typical day; with the exceptions of visits to the local river, occasional excitements like weddings and funerals, and our fortnightly visit to the post office, the following is pretty much what we do every day. We are wakened at about Gam. or a little after by cocks crowing, people clearing their throats and spitting on the path just above our house, and the sky just beginning to turn grey through the little carved-wood window of our loft. At about 6.30am. we struggle from our sleeping bags which have be laid on a rush mat on the floor. I totter down the ladder to the ground floor, unbolt the door (removing the thermos flask which I have left to act as a burglar alarm - we were convinced at first that we were being burgled as tooth-brushes kept disappearing, but have now decided that it must be rats, though what they do with them I can't imagine).

Having lit the little tin kerosene stove on the front verandah I walk round to the well, about 50 yards away across a courtyard and along stepping stones up the local sewer which runs from the pipe. Usually there are only one or two women filling the huge brass water pots (which contain about 5 gallons and which they carry in baskets on their backs, with a forehead strap). I blearily blurt out a few remarks about coming to fetch water etc. and return with the two buckets which have been filled at the pipe which supplies the whole village with water (when it is not being used it is stopped with a corn-on-the-cob husk). We then eat breakfast as the sun comes up over the ridge opposite our house and immediately warms the whole village. Breakfast consists of a mixture of dried milk, 'chura' (dried, flattened, rice) and porridge oats and, sometimes, a bit of chocolate drink to flavour it. By now a few children with running noses and still shivering slightly in their thin shirts have gathered round and watch with interest. Baby chicks and mother hens tread all over our feet and the grandmother from next door takes out her simple weaving frame and starts weaving.

I then retire with a cup of coffee, a scone Gill had made the previous evening, and wrap myself up in my duffel coat while Gill washes up. Our "office" is in the sleeping, grain-loft, a tiny table and "in" and "out" trays consisting of two large carrying baskets tied together. We sit on little stools our backs against the wall and one of the central supporting beams, and spend a couple of hours learning and studying the language. One blissful morning the schoolmaster came to help us, but he has now disappeared, not for good, we hope. At about 10 am. we have a break - clear up the twigs, dust etc. from previous evening's entertainment. Then we do some translation of the French book on the Gurungs (which we are typing out, complete - it is superb and makes all our observations almost superfluous; wish we had Erik here to help us with it though). We also write up our journals, write letters, analyse observations from the previous day onto "great-thoughts" cards etc. Mid-day Gill goes to make lunch - being met now, or earlier, with requests for medicines for minor cuts and sores, requests for empty tins and bottles, little gifts of vegetables and meat from grateful patients, etc.

Lunch usually consists of rice or potatoes and eggs in some form - also often sweet pancakes which taste especially delicious. After lunch we retire to read for a while - me, some anthropology, Gill some Great Work of literature. Then we wander up the local hillside to our little pit-latrine among the shrubs, closely questioned by the natives as to where we are going and pretending that we have only gone to collect a handful of twigs for lighting our fire. Up on the hillside we get superb views of the Himalayas and of the village below us (I hope you will be able to see photographs of these views anon - one, taken with Gill in the foreground, we have already sent, as also of the Himalaya partly in cloud, taken from the path up to our toilet). 
We then wander round the village and neighbouring area, looking at the way houses are built, the number of people doing various jobs, the construction of mats and bamboo fences, the way untouchable Blacksmiths are treated, who is carrying dung to the fields etc. At about $5 \mathrm{pm}$. the sun begins to sink behind the village and the hills opposite are a soft pink. The goats have already come tinkling back to the village and though the walls are still warm from the sun the village is in shadow. The large hawks and buzzards which constantly circle and glide over the village disappear and only a few swallows are left.

We begin to prepare the evening meal - a delicate operation in the dusk, usually watched by the inevitable crowd of children. I then light a fire in the hearth, a rectangular hole in the centre of the downstairs floor (I will send a description of our house later) and prepare the glasses etc. for the evening drink of Horlicks or Bournvita. The Gurungs have their second meal of the day at dusk, so most disappear now and we start cooking rice and, often, some kind of meat or tinned fish, on the little metal pot stand in the centre of the hearth. People begin to troop in again as we finish the meal and wash the dishes from kettle water in our little tin bowl. Horlicks is made and several cups distributed among the guests as we try to ask intelligent questions. Gill puts on a circular piece of metal with scones on and, occasionally, I sing to the guitar or tape-record Gurung songs. Our light is provided by one beautiful kerosene wick candle-like burner. Sometimes we hear the newe on Radio Nepal. At about 8.30 we shoo them out and do our teeth into a little mug, try to protect the butter etc. against the rats, extinguish the embers and retreat to our sleeping bags. As a final treat to the end of the day we sometimes listen to a little tape-recorded classical music. Then, to the chewing and scampering of rats, occasional barking of dogs, etc. we go to sleep dirty, tired but contented .

\section{DIARY 7.2.1969}

Again, lovely weather - continuing the spell begun about a week ago. Himalayas fantastic to the north and not a cloud to be seen. Midday shade temperature about 60 . Always a nice cooling breeze. Further Gurung/Pignede. Felt tired - both of us. Just when I was feeling low because we seemed to be getting nowhere at all with the anthropology - no census, genealogies, etc. a great chunk came in. As dusk fell we were told that a wedding was coming up into the village. Our hurricane lamp was borrowed and in a flurry of excitement and whipping of groom, the men arrived. We watched, retired to a late supper (author's don't stress enough how often their observations clashed with their food and which won!) and then went up for the dancing that we were told would emerge. This did not finally begin until about 12.00am. - preceded by chanting and two girls going into a trance. We were incredibly sleepy but it was worth it to see shadowy figures swaying by a tiny light as we felt the Gurungs packed round us. Everyone, as usual, very friendly.

\section{DIARY 7.2.1969 Gill}

Alan more than I, rather miserable, worrying about his inability to write a good thesis and our stumblings with language. He had to have a rest after lunch, but we recuperated on the mountain later. Brilliant, hot day. Mountains very white. His depression culminated in the fact compost didn't work, therefore no garden.

However things picked up as I was wearily washing the tired cauliflower for dinner (6.00pm.) - great commotion as a wedding was coming through the village. The girl was coming home with her husband before settling in latter's village across the valley. This was the wedding Prasad has disappeared to last week - his cousin (father's brother's daughter). Gun shots were fired; the bridegroom came on ahead and was whipped vigorously by our village girls and he was then received into his in-law's home - a 'tika' of rice and milk, feet washed, flowers put on his right ear. We had some helpful translation from Prasad - it all took place in near pitch dark, and we lent them our tilley lamp.

They then said there would be dancing two hours later, so we went home, blew up the fire 
and roasted some 'mokhai' and listened to the Beatles on the tape and nearly fell asleep. When we heard drumming we went outside to a full moon this time and were directed to another house down in the village. Pitch-black inside - we waited for about an hour and then two young girls were put into a trance by chorus of singing which lasted about an hour. Hypnotism was effective and their spirits had been taken away by the gods. There was only a tiny kerosene lamp mirroring huge shadows over the copper utensils and making the girls' faced macabre and effective. They were drastically snapped out of it by cold water, and then the drum for dancing which took place in the same small place inside the house in which they had been hypnotised. Lovely flowing movements with vase. We left exhausted with the chanting and drumming and dancing, and came to bed at $12.55 \mathrm{am}$. !

\section{TAPE RECORDING}

Ghato song (Gurung): A group of men known as 'Guru aba' are singing the Ghato dance son in the Night School. New rhythm accompanied with drum.

https://sms.cam.ac.uk/media/2733129

NOTES on 7.2.1969 by Gill on Wedding return

We were told at about dusk that a wedding was coming up through the village. Mostly women and children, about 40 of them were watching on the path beside our house at this point. We were told (and subsequently confirmed) that the woman lived in the house above ours (House28) and had married a man from Yanjo (the village opposite and slightly to the right, on the opposite ridge to ours to which a path leads). The marriage had taken place ten days ago and we remembered that Boje, Akayprasad and others had been away the week before at a wedding. (Prasad had spoken of being at the wedding of a "sister", but later admitted that she was a classificatory sister, ie. cousin).

Nothing happened for half an hour and then we heard 2 gunshots (and later another) at the bottom of the village. It is growing almost pitch dark when, through a crowd of huddled onlookers (about 70 or more), and amidst the flickering of torches a group of men rush up the steep path. The last of these (?), the bridegroom, is being whipped with long thongs (probably made of banana leaves/stalks - as a little boy is imitating this the following day). The beating sounds quite severe on his back. Not clear who does the beating - if only one sex (I think women). My attention diverted by a last-minute request that I should lend my pressure lantern. Like many ritual things, the decisions are made at the last minute - preparations are not made in advance. The crowd accompanies the wedding party up to the girl's house, there, to the flickering of one torch and one small lamp and amidst a crowd of spectators, the visitors are received. About an hour later, with a torch to light them and with no loud welcome except the bowing of the occasional women then meet, three women come up the path, the last of them with the bride.

Later we go up to the house where benches (school) have been placed and a pressure lamp lit. About 15 men are sitting outside the house joking and talking. We sit on the bench and Prasad and Ramchandra act as out interpreters and we go over the previous events. They state that the whipping of the bridegroom is because he is from another village and is "taking away our sister". Apparently this return visit of the bridegroom sometimes occurs on the same day as the wedding, sometimes a few day later - on this occasion 10 days after. Apparently 5 men, including the bridegroom - one was a brother, the others were relations. When they arrived at the bride's house, as we observed, the bride's father and another man first sprinkled water round the feet of the bridegroom and then onto his shoes (gym shoes). Then rice and water was sprinkled on his head and a piece of leaf/flower over his right ear. He then bowed and kissed the feet of the bride's father and the grandmother (this grandmother, the same powerful woman as Ramchandra's mother, took the lead in sprinkling 
from now on - we were told that she did this by virtue of her position as eldest surviving member of the family). The bridegroom during this sprinkling, in which the grandmother spoke a kind of prayer/benediction in which I discerned the word 'babu' as she sprinkled, stood on a small piece of wood to raise him off the ground. Then the male visitors were treated in more or less the same fashion, though the ritual was only performed by the grandmother and there was no water sprinkling or standing on the board. As in the case of the bridegroom, 'tsoi' (or 'tika' - Nepali) of rice and milk was put on their foreheads One of the five male visitors had brought a basket containing 'pa' and rice, both to eat on their visit and to act as a gift to their hosts. No money is, apparently, brought. There is much laughter when they duck their heads to avoid being sprinkled with (? flowers) by the young women of our village. We are told that the following day they will return to the bridegroom's village and live there. Tonight there will be dancing. (It is now only about $7.00 \mathrm{pm}$., yet the dancing does not begin for another 5 hours - why this long spanning out in time?). We are told that though no gifts are given by one set of parents to the other, the bride's parents should give valuables to the bridegroom. We then get an account, from Prasad et. al. of what happens at a wedding.

Prasad obviously did not witness the actual wedding ritual, although he and others from Thak went to the village. He recalls how on the second day of their visit the bridegroom's parents gave 30rs. to the Thak party, which was divided between them at $2 \mathrm{rs}$. each (15 of them). There is no fixed sum apparently. The number of persons who go to the bridegroom's village depends on the bridegroom's parents - if they want a large party one person from each household in Thak would have gone. As it was, only 15 went. They say they only want to stay one day and make efforts to leave, but "the ladies of the village force us to stay" to stay longer, says Prasad. It was the ladies because the visiting party consisted entirely of men. If there had been women among the visitors they would have been "forced" to stay by the men etc. When asked how this forcing is done, we are told that pressure is put on by "talk" (ie. witty conversation?), by the singing of songs, and by the preparation of the "best foods". For this hospitality the guests give 70rs. - ie. for 5 people for 2 days.

Prasad then consulted with Ramchandra etc. and gave the following account of the actual wedding ceremony. The bride's entry is arranged for a certain time, but when the bride wants to enter the bridegroom's house, the sister of the bridegroom shuts the house up and the bride has to give one rupee and call "open the door" a number of times. Then the sister of the groom opens the door. Before the opening of the door, however, the bride's mother has hid herself inside the house and will not come out until the bridegroom says 'ngai nam' ("I will give you anything you need. I will always look after you"). Then the bride enters and a bowl is produced into which is placed milk and the sister of the bridegroom feeds her brother three times and also feeds the bride. (The word for bride in 'preshaw', for bridegroom 'dula' or 'byowlaw'). That is the end of the ceremony. There is no priest, no saying of prayers,

NOTES 7.2.1969 by Alan - Garda sheve (Ghatto)

Much later that evening, about 11.00am. we go down to a house next to Bhuwansing's where some 15 or so adults and two girls are assembled. We sit chatting (or sleeping) for about an hour. Finally about five men galvanise themselves into action at about 12.00am., and start chanting, or wailing, long drawn out notes in unison (cf. tape recording). This we are told is 'garta kwi' ('kwi' = song) and is an invocation to the deities whose names are chanted in turn in sanskrit. There are two young girls, swathed in cloths so that only their faces half show, squatting, one on a little table, the other on a piece of wood. They begin to sway rhythmically - one in a circling motion, the other backwards and forwards. They appear to be about 15 years old. We are told that they now have "no sense" ('gar nilba'), ie. they are in a trance. At first the leading singer, who sings with great vehemence, bows their heads with his hand and 
he continues, occasionally, to sway his hands as if shaping their movements. This (hypnotism?) goes on for at least an hour, a group of girls meanwhile hurriedly sewing strips of cloth by the light of torches near the door. At the end the girls are told rather brusquely to wash their faces with cold water - presumably to awaken them. They then retire a little way into the other part of the house and put on other clothes for dancing7.2.1969AlanGarda sheva. The girls had taken several minutes to come out of the trance, their eyes being closed tightly although one of the girls occasionally sniffled with her headpiece to wipe her nose; this was quite unconscious however. I think water was sprinkled on them to wake them up and when they did come round, then started and said something in a light childish voice, as if surprised to find out where they were. During this coming round session, which medically is supposed to be quite a dangerous point, the men, all adults were making jokes of some kind which judging from the raucous laughter were possibly sexual. It struck me that the two girls were at their most vulnerable at this point and the jokes might have been unconsciously dealing with some tension. The older girls at the back were still busy pleating their pieces of cloth together, which I presumed were going to be used for the dancing, and did not seem to laugh at the jokes; in fact I think one stalwart girl remonstrated with the men, who laughed all the louder. They seemed to avoid the fact, which might have been uncomfortable, that their fellow girls were being possessed spiritually by gods and incidentally by men. Wondered if has any conscious or unconscious link up with the physical meaning of marriage. Do they always do such dancing at marriages, and at the point when the bride is brought back, presumably no longer a virgin, to her village?

The girls took about 15 minutes to get ready, although their clothes seemed to be the same as when they were in their trance. They were subdued, and one hung behind a beam when she was ready, looking shyly at the men and appeared to be a bid dazed. The chief "conductor" who had lead the chanting, intoning low for a few bars and then the chant being caught up by 5 or other men, some sung polyphonically, indicated where they should stand, in the same minute space where they had been hypnotised. The girl who had seemed a bit dazed was told to empty water out of a brass jug, which she tipped up near her feet. They then stood tall, and rather incoherent drumming starting and chanting, this time much quicker (vide tape) and I think in Nepali. Everyone joined in this time and it did not have the heavy overcast overtones of the Sanskrit invocations. The chief singer then started conducting the girls, who paused upright for about 3 bars and then swayed from side to side, getting up an even rhythm. They held the ('bahuna') vases, neck downwards in the right hand in a curved relaxed position. They then swept this hand down to the ground, bending over with their whole bodies and letting the left hand join up with the right to cup the vase which was swept slowly nearer and nearer the floor and then up and round again, the girls turning always in a confined space, sometimes touching each other's arms. The climax of the dance was when the vases completely swept the floor and then the audience let out a whoop ('sae'), and then resumed their chant for a few bars more. The girls seemed entirely taken with their movement, which were almost in time together and didn't heed the cries of the audience. The vases were used beautifully, and the line of the arm curving down into the hand and over the vase was perfect and completely spontaneous. Vases cupped and dipped as if they were being filled and emptied with water. They did the same dance 3 times and then we left at 1.00am.

\section{DIARY 8.2.1969 Alan}

After our late night we planned to sleep in but were awakened by usual request for medicine and gift of 'teme'. The villagers were obviously in a generally excited mood and we learnt that there would be dancing in the afternoon. The usual superb day and we spent afternoon in the sun watching the two girls dancing again. Most frustrating not to be able to understand 
comments, etc. - but gratifying (and interesting) that we are accepted to the extent that they always smear our foreheads which whatever is going as 'tika'.

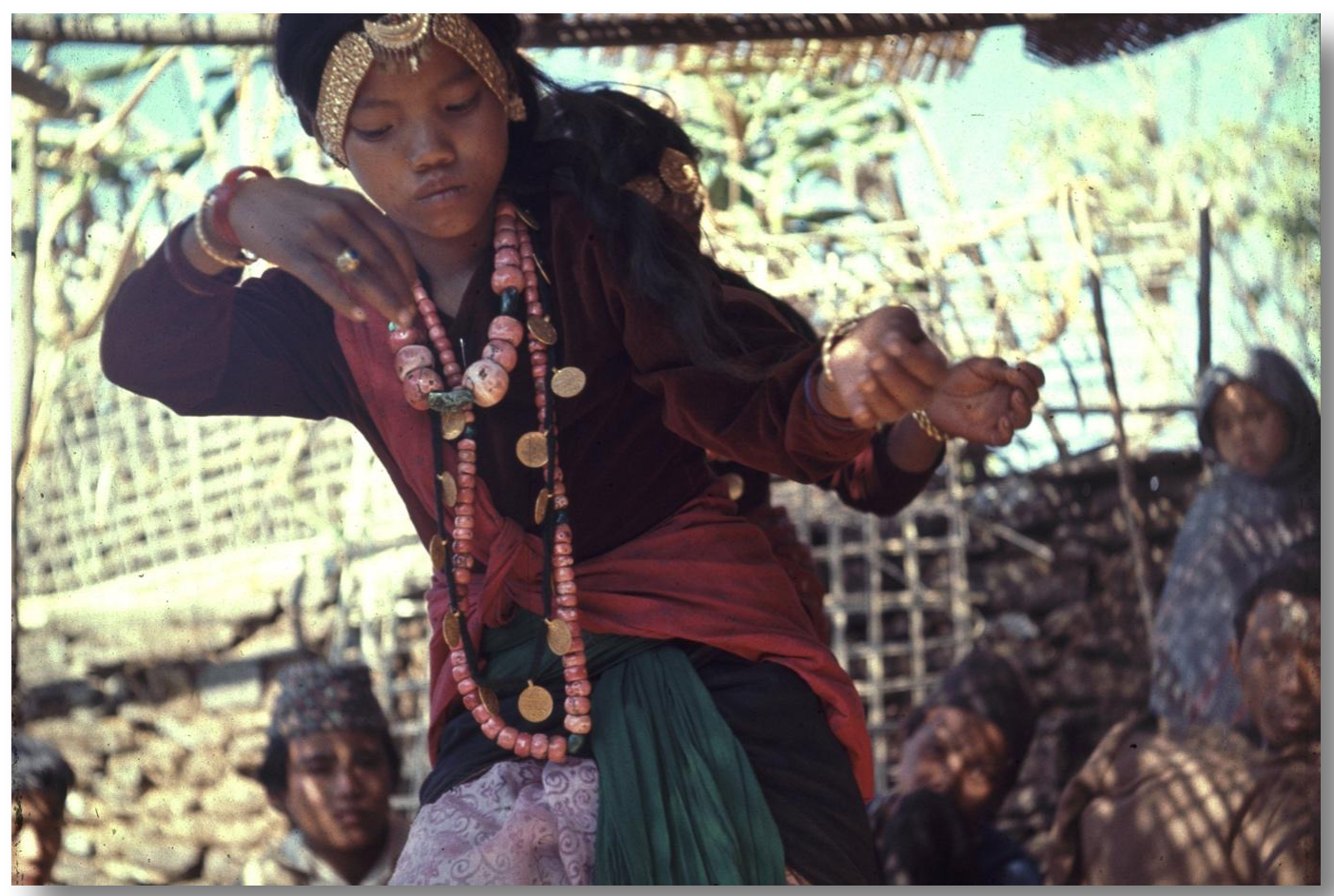

Tulsikumari dancing the 'garda sheba' on 8th February 1969

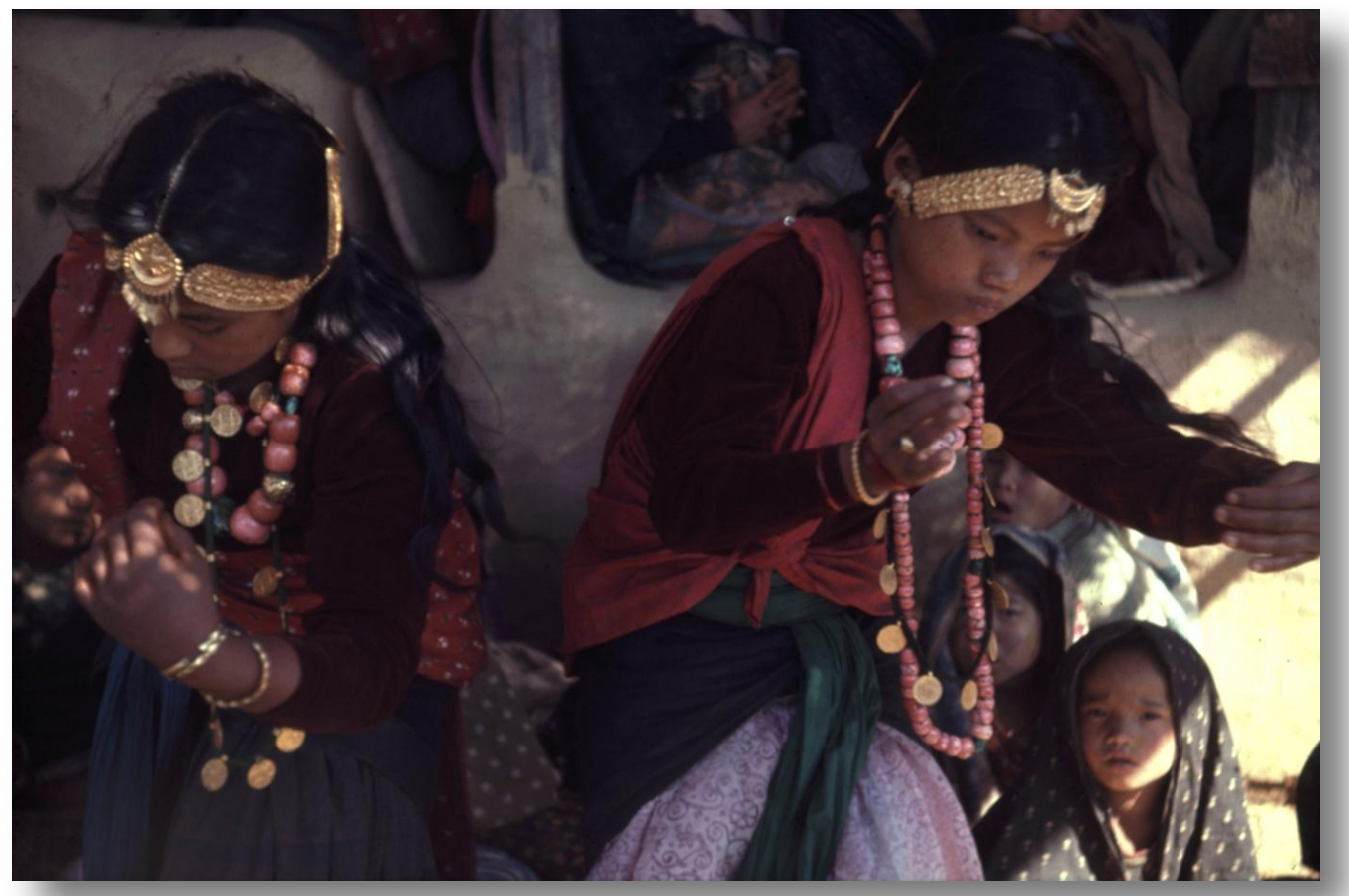

Tulsikumari and another girl dancing the Garda or Ghatto 
This was performed at the house higher up than ours, starting at about 12 when we could hear intermittent drumming as we had our lunch outside. When we went up a rough mat roof had been made, extending outwards from the house, with no walls this time so that all the spectators could see clearly. There was a rice mat on the floor for the two girl dancers who were performing when we went up. They were the same girls who had been in the trance and then danced the night before. The strips of cloth the other girls had been weaving they now wore, coming down over their shoulders and tucked into their cummerbunds. Also the girls wore their hair loose, coming down over their backs and had all their best jewellery on - necklaces and gold bangles. The other difference was the elaborate gold headdresses they were wearing, one piece coming over the forehead and two side pieces coming past the ears. They were held on by an elaborate system of tapes and for one girl they were obviously quite painful to wear as she had cotton wool stuffed behind the side pieces to prevent friction. She fiddled with these as each section of the dance ended.

Spectators consisted of the guests, who this time happened to be the family of the bridegroom from another village - the bridegroom, his brother, father and four other men took up one side of the rectangle around the mat the girls were dancing on; opposite them on the other long side were the singers and two drummers - the main singer, who also conducted the girls as they danced, was the man who had hypnotised them the previous night. There were about two other official singers, who also did the drumming, which was very unsophisticated, a laconic beat with the flat of the hand on the side of the drum; these sang in Sanskrit but other members of the audience joined in as a chorus and these people sat on the other side of the rectangle, and we took up the other half. [cf. Tape] At the beginning of the dance half the audience consisted of women but when the guests came these were shooed onto the verandah of the house by Ram's "mother" so that the people sitting immediately around the mat consisted mainly of men with a few children dotting in and out. There must have been 40-50 watching altogether.

Just after we arrived the guests are powdered with bright red chalk by a woman who pours it over each one with great glee, much to their discomforture. It is very bright and mess, the guests are very embarrassed, trying to retain their dignity, and all the more put out by the laughter of the audience, the men in particular; there is quite a lot of tension between the men of each village culminating in the criticism of the dance by the father of the bridegroom. This is done in a pause of one of the sections, and made to the chief singer and conductor who seems put out, as he has great pride in the proceedings and moulds the dancing of the girls with his hands, with his eyes half closed, a pleasurable look of absorption on his face. He hardly argues with the criticism, but it produces an uncomfortable silence, and the girls, sitting resting, look down and fidget unhappily. Ramchandra's brother explains this to me after he had asked whether we liked such dancing, saying he himself was "fed up" with it in a very blase way. It takes place frequently at this time of year when guests are to be entertained. This was a notably honest comment as this was obviously an occasion when all good Gurungs should have been proud of the proceedings and produced the suitable approbations.

The dance itself seemed to be split into 4 sections, with rests between each when the girls either stood up coyly and played with their costumes, putting a special pleated sash they wore from the waist and fanning it over their heads, or sitting down, faces lowered and not talking to each other. Sometimes the conductor would talk to them, as if encouraging them and discussing the next section of the dance.

In the first one they carried nothing in their hands and the movements seemed to be more decorative than descriptive, each gesture repeated several times, the hand curved round and sometimes the index finger being flicked against the next finger at a certain point in the 
descent of the arm. The other hand they hold palm outwards on the hip. The general structure seems to be swaying from the hips, first to the left and then the right four times. They gradually get lower to the ground and eventually repeat the above on their haunches. At no point in the dance do they seem to be completely upright. They do this facing the conductor and then make a clockwise turn and repeat the sequence to the guests. They finally turn round and describe a figure of eight in their movements starting high up and finishing the dance low on the ground. At each finish there is a mild whoop, but not as energetic as last night [cf. two photos].

The second section is similar in movement to the above, except they hold a slim bamboo stick in their left hand, and this is used with the same flicking movement together with the fingers as described above. In the third section they are given brass plates with a mixture of rice, milk and flowers (lavender) which the visitors had put on their foreheads when they arrived with the bride from their village. The plates they hold outstretched in their left hand, and there are different movements here with no drumming. They merely sway from left to right holding the plate with no alteration in height. The only complete turn is towards the bridegroom right at the end when they finish dancing and sprinkle his head with rice and flowers; this is done three times by each girl, to the brother of the bridegroom as well as himself. Finally the plate is placed on the flat of their heads and the girls do the final section holding the plate in this position first with the left hand and then with the right, depending on which way they are swaying. The men underneath remain immobile and dispassionate, even solemn as if this last including act of the entertained by the entertainers had some symbolic importance. The impression given is as if the guests had only now been accepted by the hosts. The drumming at this point is more noticeable as each turn of the plate is done to one beat of the drum. At the finish the girls then decorate all the male guests with rice and finally go around the audience so that everyone has a 'tika' on his forehead.

At the finish there is a general air of relaxation and expectation as this is when the entertainment is paid for. The money is put in the bowl which had the rice by the men from the other village and is approximately 60rs. This is apparently a moderate amount and the Lt. said how when he entertained a British officer he gave 60rs. and the officer gave 80rs. The girls try to pretend they do not know what is going on, sitting in the centre, heads bowed at their most coy earnestly scraping off the rice from their hands which have got sticky with their distributions. The money is handed to one of them who immediately gives it to one of the drummers who tucks it in the pocket of his shirt. They are then given 1rs. by the main conductor. The conductor then goes to the bridegroom, incants over him and puts more rice on his forehead. Another man does the same thing to the groom who is nursing a pile of money in front of him, about 5rs. in all. Ram's "mother" also does the same thing. The "roof" partially collapses amidst consternation and laughter. The dancing ended about 3.30pm. At the end there must have been about $80-100$ people. There is lengthy discussion of money at the end, rupee notes shooting backwards and forwards for some time. At the end various people, including ourselves, have our foreheads marked with the milk/rice mixture. As the bridegroom's brother leaves, a bottle of red ink is thrown over him - apparently ruining his clothes, again by the young women. We are told that the songs are in Sanskrit but the way in which casual men join in suggests that this is not so: the women do not sing at all during the procedure. In the discussion at the end with the Lt. and Ramchandra we are told that the leader of the songs is called Manseram and lived in this village. Apparently this dance can be put on to order or whenever guests from another village are to be entertained. This is confirmed by the fact that for several days afterwards various people suggest that we commission such a dance in front of our house (one of the girls herself suggesting about 30rs. as payment for this). We are told that after Baisak (ie. about April) this dance is no longer performed. We are told that the 60rs. paid to the dancers and singers collectively is saved up 
and later spent on a "party". Five rupees is also given to the headmaster and dancing girls. Ram's brother says that the girls were taught by previous dancers and will then hand on the dance to their successors. We are told that 50rs. is also given to the bridegroom by the bride's father, but this is the only payment so given. If the bride's father had been very rich he would have given cows etc. according to the Lt., but this father is only of middling wealth. The father's name is Kumansing. We are told that the bridegroom is aged between 22 and 24 and the bride is 24 , though there is uncertainty about the former especially. When we ask about "engagement" we are told that parents or other men come with 'pa' and rice to eat and talk at bride's house. There is no special ritual. Such an engagement can take place at any time between a few days to a year or more before the wedding. When Ramchandra is asked whether he had such an engagement he avoids the question, stating that a Brahmin was consulted for an auspicious day for the wedding. Apparently no day of the week is necessarily inauspicious or auspicious - eg. weddings are not always held on Mondays etc. In the days following the wedding we are several times asked if the dancing was beautiful and it seems that it has remained a topic of conversation for at least a week as we frequently hear the words 'garda sheba' used in conversation.

\section{DIARY 9.2.1969 Alan}

Spent a happy, if busy day at the little river (Tadsyon Kola), washing massed of clothes, having a picnic meal, washing ourselves and hair, etc. It is pleasant to spend a day away from the village, however nice the people are, and the river, with rushing over boulders stream, yellow flowers and sensational ferns, is lovely. The evening was peachy - with the tips of the Himalayas golden, floating above, their base covered by cloud - sensational.

\section{DIARY10.2.1969 Alan}

Been here seven weeks. Time moving fast now and we can hold fairly connected conversations. Schoolmaster came again and then I went to forest with Prem to watch woodcutting (see account) - a very pleasant walk. As usual, many people dropped in to chat etc. I don't know why one is so homesick in a place as beautiful as this and with such nice people. It really is idyllic. Partly language, I suppose, partly physical conditions, partly being away from one's family, for it is they, rather than one's friends, that one missed most. It is a fantastic help being with Gill - don't know how people manage on their own.

\section{NOTES on 10.2.1969 Alan on wood cutting}

Prem called for me, suggesting we went to the forest to cut wood. He said they were preparing wood for the monsoon, "many" people were out cutting. I went with him. He set off at 9.40 and stopping for a rest and to fill water on the way, it took us about 65 minutes. Track was uphill for three quarters of a mile and then level. Up and down a bit within jungle. Prem said he went to forest for eight months of the year. In a clearing were communal piles of wood, about three huge and five small trees partially cut up. We rested for about fifteen minutes while a fire was lit (for me?) and then men started work. There were four men, of various ages (Prem, Syebahadur's father, gentle one and another) and one woman and a baby. They had brought one lot of food (rice and 'lobou') and a kettle to cook it in - but nothing to drink. They had this meal at about $2.30 \mathrm{pm}$. or $3 \mathrm{pm}$. and came back at about $5 \mathrm{pm}$.At first they worked separately, shifting huge logs by themselves, then two men went off to fell medium trees (about 30') separately, while Prem and Syebahadur's father split logs lengthwise. These huge (about 2'6" diameter) loge had already been chopped into 3' lengths and split easily with them chopping alternately. But it was hard work and they worked very 
hard. No saw was used, though this would have facilitated things as would better axes. They had three axes like this (sketch - "L"-shaped blade) and one normal European type. The latter was heavier, longer shafted and far more effective. All had iron blades. They also carried the usual curved pruning knives ('ashi') in a little wooden holder ('koldo') on a string belt. Prem said that about fifteen people were working in this section and would be cutting wood for about 10-15 days. Obviously another vital function of the forest is to provide work for adult males when other agricultural activities are at an ebb...To guess at the present rate of cutting, in about 10 years the belt of forest will have been pushed back about one hour, i.e take four hours to go and return. This gives it an effective lease of life of 10-15 years. Prem, when asked what would happen when no forest replied, "Now there are many trees, we cut much, when there are few trees we will cut little" (no evidence of re-planting etc.)

\section{DIARY11.2.1969 Alan}

Amazing how difficult it is to remember what one did even two days ago! We went up to a house high on ridge above Thak to give medicine to a girl with a bad ear. Up there three brothers had obviously started a new hamlet and the soil looked better on top of the ridge. They were growing garlic and there were fields of barley (?) right on top of the ridge, which seemed to be growing well. The goats were being brought back across the fields - they graze over the empty rice fields and through the undergrowth of small bushes on steep hillsides.

We then went into the forest and watched Prem and his group cutting wood, for a short while. A large session of men (three schoolmasters) in evening. Togari returned with sugar, potatoes, kerosene, from Pokhara (paid him 13rs.) and I went down to Lt. with a small cock (10rs.) which he killed (in the house - holding back neck and sawing through it with 'ashi', then holding twitching bird over bowl for blood to drip out, then putting it into a pan of hot water, plucking and partially gutting it.

\section{DIARY12.2.1969 Alan}

A quiet day: no schoolmaster. Read H. King's "Exequy" on the hillside above our house. Felt a bit homesick, but did a good amount of work. Weather, as yesterday, warmish (c.60) but with a lot of cloud. We are both very fit, though, with all the rice-eating my stools have become shapeless - like those of the natives. We have a lot of ideas and discuss a good deal. My interest in intellectual problems / anthropology generally, which waned when faced with the shock of arrival is beginning to come back.

\section{DIARY13.2.1969 Alan}

Schoolmaster again came and another day ensued with same ritual, interspersed with occasional people demanding tins (this has become the fashion) or medicine - there is a bad cough going round the village which we hope is not caused by us (we had one when we came).

In the evening it clouded over and there was some lightning in the South. The wind became blustery - as it always seems to be before rain. In the night it rained hard and we thought mournfully of our firewood getting wet outside in the dark, and our book "The Light of Asia" which we left down by the river on our last picnic, getting sodden. We also missed the only vaguely sharp knife which we possess I think it must have been taken as a sharp knife would obviously be a great attraction here. This adds to the list of small things which have been pinched - possibly the work of only one person. When I complained of this to our neighbour Nansubar, she showed concern, not great surprise and indignation. 


\section{DIARY14.2.1969 Alan}

A wet morning, with cloud in all the valleys and even enveloping our village on occasions. I spent about 45 mins. at Lt.'s watching him pouring out two medium tins of oil for me, and the same amount for himself (price 6rs. a 'dharni' - same price as honey). The audience of about 10-12 various of his hunting friends had dropped in, were watching this procedure with vast interest, noting every drop that was spilt and whether there was really 9 'dharni' in the tin as stated, etc. Amazing what interest small events can have and the time it takes to do the simplest of actions: a funnel would have quartered the time!

Dankumari had sprained her ankle again - after another visit to Pokhara to buy cigarettes, sugar, etc. (We had been there together about 4 weeks ago). She had sprained it only a few feet away from her house. For the rest, a rather cold and uneventful day: as usual the crowd in the evening was rather too large - about 10 or so, though the evening sessions are beginning to be useful.

\section{DIARY 15.2.1969 Alan}

We remained in the village though it was a lovely sunny day, having been told that there might be some dancing - but there was not. In the afternoon, dug my minute garden which I had almost given up when the pile of bracken etc. I had so energetically cut and applied "Fertisan" too when opened was dry and useless. But when Nansubar offered to give me some manure if I gave her some seeds for her garden, I decided to go on and plant tiny quantities of different vegetables. - using only the soil etc. available in the village - ie. ash from the fire and manure.

15.2.1969

Alan

Gill to her parents, 15. 2.1969

Alan is going down to Pokhara this coming Wednesday to collect any post that has arrived...First let me say that the last time the money had come through, to Alan's immense relief; I think we had about 40rs to last us through (about 30/-) when we went in trembling to the bank, so you can imagine we were quite relieved at f50! We bought in two large baskets of provisions that will last us for the next 1.5 months, and hired two Tibetan porters to get them back to the mountain. Most of what we spend seems to go on the basics that we can't get in the village - sugar, rice, flour - and then tinned meats, fish etc. which we supplement the our fortnightly chicken and daily eggs.

We could actually get rice in Thak but it would be in its unhusked state and although I have been shown the techniques, one of them would take a life-time to learn, and the whole process in any case takes up a whole afternoon for about 2 lbs of rice. The part which is difficult is when they are separating the half-husked rice from the chaff, using a large round straw woven tray and sweeping it round and backwards and across so that all the various stages of the rice go to the right places. I'm sure the whole lot would fly off the tray in all directions if I even picked it up, as the movements really do constitute a work of art, and have been learnt from childhood upwards.

The chicken is also a bit of a sweat to get, as you have to find our which house has one ready of a suitable size, go and bargain for it, pick it up under your arm, kill it and pluck it and then, hopefully, cook it! Neither of us can bring ourselves to do the killing bit, so we ask a cooperative neighbour to do the deed - talk about the squeamish English! I can't even buy one from our immediate neighbours as I know all the hens off by heart now having watched them scrabble about during endless meal times, and would miss any that weren't on the scene! We can also get vegetables such as potatoes, cauliflower and peas in Pokhara but availability of good tinned food is limited and we have decided to go to Kathmandu at the beginning of May to get in a really good stock, and buy things like cheese which we haven't seen since we've been here except a handful of what we would call 
cottage cheese, but which the villagers call butter, brought as a thank you for some medicine doled out.

Generally we reckon on having one tin of meat, one of fish and one chicken every week (although the latter tends to be once a fortnight as we don't want to exhaust the village supply! They only eat chickens when they sacrifice them for special days, sometimes once a month or even less). We eat a lot of eggs as I make endless pancakes as you can get huge beautiful lemons here and we have discovered a honey they make in the village which is rich, golden and quite delicious, and they are heavenly together over the pancake batter. I also manage to make brown ground floor scones for Alan as he bought an iron round tray at Pokhara which I put on the tripod which is in the middle of the fire on which the pans usually go, with the logs of wood underneath. I put the dough out on top of it, take the logs out to reduce the heat and cook very slowly, and it really works.

As you can see, I think we are living quite well food-wise, and I hope we are keeping as fit as possible. I have felt very well in the last fortnight and managed the last trip to Pokhara quite well, and this physically is usually quite a strain. We have got up a regular work routine, up at 6.30am, breakfast on the verandah with our small kerosene stove (porridge) and then usually the schoolmaster comes at 7.30am to teach us Gurung until 9.00 - he is a bit erratic but we had him three times last week. His English is very good and he is quite a good informant on events, although insisting 'we are a very simple people' and therefore don't have many rituals! To us every other day seems packed with them. We then type up any of the latter we have been to - the birthday party I mentioned in my last letter lasted 7 hours and Alan took 15 pages of notes, with three from me! There was much making of garlands, throwing of flowers, chanting from Sanskrit and drinking cow's urine, as well as music and lighting of candles and bringing of presents - rice and flowers and paise pieces (about .25d) - we didn't understand any of it but it had bursts of great fun, as well as being unbearably tedious in parts! We then learn some Gurung on our own and then I read some of the books...

We then have lunch, again on the verandah, and then Alan washes up and brings me a Horlicks drink in our loft, where we work as well as sleep, and I read...

We then go up the hill, which means to our toilet at about 3.00 pm and sometimes we continue up to what I call the 'mountain', which is a tall outcrop of rock overlooking the village, with gorgeous viewes of the Himalayas and the valley plains in every direction. This is where I am at the moment. It is a gorgeously warm day with a slight breeze and a few cloud shadows dotting the hills, the grasses alive with butterflies and wasps, with bright yellow flowers, and blue star shaped ones like gentians peeking out of the rocks - quite idyllic and a haven of peace and privacy from the village. If I typed out there I would be surrounded by children and old women within seconds. Far below on the path the goats are being brought home, their bells tinkling away as they wander back with two or three boys vaguely in charge. The girls are all coming on the same path as the forest is in that direction, where they get huge bundles of greenery for the buffalo, tethered at home in the village. We then go back and might translate the only other book on the Gurungs, which is by a French man and very good in detail and way of life. At 5.30pm I start preparing dinner which we cook inside over the fire, and then at about 8-9pm, depending on how many people come in and whether we have a sing-song or not, we go to bed. Sometimes we have a treat and listen to some Beethoven or Mozart which we have brought with us on tapes - it really is ideal, and yet, maddeningly, we would still without a shadow of a doubt rather be at home. We have talked about this to find out why and can't really give a concrete answer; we talk about a lot of things here, essential issues arising out of comparison with this society and ours, and also from the books I am reading, stuff I have always wanted to look at. I think you will be able to tell from letters how relaxing it is here, even Alan is much more unwound and less pounding after work - though we are always busy here but it is at our own pressure...

\section{DIARY 16.2.1969 Alan}

Went down to the river (Tadsyon Kola) and though it was overcast, spent a blissful day, washing ourselves and clothes, reading the "Light of Asia", etc. It was lovely to have a cup of highly seasoned coffee when we returned at Lt.'s.

\section{DIARY17.2.1969 Alan}


Lovely weather - definitely getting hotter.

NOTES on 17.2.1969 by alan on Ancestors

Quite ready to talk about this. Ancestors are referred to as 'keh ama' and 'keh aba' meaning literally 'forefather' and not just one's mother or father. The plural is 'khyeme'. They are worshipped and appeased on the first day of the month of Sawan. After the evening meal, a rice tray is set out near the fireplace and a little of various types of food is set out on it ordinary soup, a little milk/'pa', a little piece of fish etc. if there are any of these. 'Lauwa' (rice and milk, cooked, unhusked rice) is sprinkled on the tray. The spirits are first called down by burning a little oil ('cugu') putting a burning piece of wood into it. The smoke rises (and calls the spirits?). The same procedure is done at the end. No meat is offered. The food is left for some fifteen minutes and the whole thing is done by a male member of the family, not necessarily the eldest. Any male aged over 12 (e.g. AK Prasad himself) can do this. When there is no man in the family, another family is invited to worship. Otherwise it is not necessary to invite anyone else, e.g. poju etc. not invited. Every family does this once a year. The procedure is called 'choma cheva' or 'kehme cheva' (worship). There is no other remembrance of dead. If the ancestors are not worshipped they will be "unhappy", if happy they protect people. They are addressed generally to call them to eat- 'keh buje, keh baje, keh ama' etc. - no names are given and it is said "we are giving your share, please take it, protect us from bad things". No other oblations are offered and we never go to ancestor's graves - no monument is erected to them.

\section{DIARY18.2.1969 Alan}

Gill badly bitten on legs by insects. Today much anthropological information of interest. Dancing in the school house next door.

\section{DIARY19.2.1969 Alan}

To Pokhara. A rather exhausting trek, but rewarded with the arrival of my witchcraft book typescript. Arrived back pretty tired. Heard that Fiona wanted to marry.

TAPE REGORDING Wedding procession and Tailor's band https://sms.cam.ac.uk/media/2733146

Alan to parents 19.2.1969

After my explanation of how I would send letters to various members of the family, carbons etc. in my last letter. I am sorry to change everything but a frustrating hour in Pokhara post office, buying up their total stock of air letters (13) and then sticking something like 140 stamps onto the back of air-mail letters . has persuaded me to send just two air-letter forms at a time.

All the village knows that my sister is getting married. They make a big splash with weddings here and it is the height of the wedding season at the moment. Almost every day wedding processions march through the village, usually about 30 people - the women dressed in purple velvet, the men in white with the occasional umbrella, dark glasses, BOAC back or transistor to show their status. They are proceeded by musicians who blow aggressive blasts on their curved horns and thump three different kinds of drum. You may have seen the, probably blurred, colour slide of one such procession and we have tape-recorded them. The other evening a bridegroom turned up at this village, having brought his 10-days-married bride for a few days to her parents' village. They arrived as it cot dark, rushing up the steep steps, with all the young people of the village viciously lashing with banana leaves at the bridegroom's back (who has come to take away their "sister"). We trooped up 
to the bride's house and there circles were drawn with water round his feet, he was daubed with rice mixed with milk, and the young girls of the village splashed red powder all over his brother and friends' heads. Meanwhile I was vainly trying to light our pressure lamp which the bride's brother had, at the last moment, come to borrow.

That evening there was dancing in one of the houses lower in the village. We had to wait until after midnight until anything happened and then a chorus of men chanted slowly, intoning to the Gods in Sanskrit and two adolescent girls, sitting raised off the floor and muffled by the light of one flickering wick candle, swayed themselves into a trance. Later they danced, or rather swayed from the hips, gently turning and twisting a water jug round them. It was the first time that we both felt that we were in an alien society - sitting in the pitch dark, packed between Gurungs, almost becoming hypnotised ourselves. The following day the girls danced again, this time dressed in gorgeous gold headpieces and rich cloths - but to the same slow chant and drum beat. Despite being a wedding it all sounded very sad. They don't seem to have the fast vivid dances that I remember in

Assam .

The other piece of ritual we have observed has been a couple of pujas or thanksgiving to the gods - each time involving Brahmins who muttered from their prayer books and occasionally rang bells and blew conch shells. The ritual went on for hours, everything like pouring water from one container into another, being repeated endlessly and tiny pieces of this and that being scattered around until in the end the square of earth under a bamboo shield in the front courtyard of the house where the puja occurred looked a real wreck. We (the audience) joined in at various points, throwing flowers, drinking sips of cow's urine (supposedly), being given the 'tika' mark on our foreheads by rascally-looking Brahmins who looked like Fudas Iscariot, and finally being handed a handful of mixed rice and various vegetables, the 'prasad' - we each having brought a plate of rice, a flower and a 'mori' (6d. piece) as our gift. We have a very detailed description of all this, but what it all means I don't know.

Another day I went to the forest with one of the young boys. Now is the time that all the men, working in gangs of thirty or forty, cut down the huge and beautiful trees, hack them to pieces and let them dry. In a couple of months they bring them back to the village and burn them throughout the five months when the monsoon makes it too wet to cut firewood (fune onwards). On the way up to the forest - which takes an hour and along which track they carry the huge bundles of firewood, even Grannys of over 60 carrying loads which I could hardly lift - the young guide (so of the local medicine man) and I discussed birth control - of which he seemed perfectly familiar through Radio Nepal. The forest, or rather thick wood with huge trees, creeper entangled, rearing out of it, was very beautiful - full of glorious ferns and little mauve flowers (I will try to bring a sample of seeds of these back with me). Not at all frightening - in the day at least - though it contains tigers, leopards and bears, we are told. The wood cutting - at which they worked very hard with small axes - was a sad affair. Many of the hills have already been cleared and in another ten years the forest, on which the whole economy now depends, will have evaporated. No replanting, needless to say, is being done. The rest of our days we spend reading, learning Gurung - in which we can now hold elementary conversations - and thinking of sound anthropological questions to ask. Time slips past, with many thought of home but crowded with interesting things to observe. Odd moments are filled in handing our medicines (ironically mostly to the local medicine man's family - he himself was here for Aspro this morning), and tins, for which there is a craze.

\subsection{Letter to Drs Lionel and Pat Caplan, fellow researchers in Nepal from SOAS in} London (lecturers there)

\section{Dear Lionel and Pat,}

.... frustrations with visas etc. Yes, we had to get a letter from the University too - it took hours and we have got to get an extension as we only have a permit for six months. A grizzly business dealing with the Kathmandu bureaucracy. We didn't get an interpreter, but have a very good schoolmaster in the village who speaks English pretty well and we are progressing moderately with Gurung. Much of our time is spent Pignede at the moment: as far as descriptive ethnography goes, his book is absolutely superb it seems - minutely detailed and accurate. It will save us a lot of work. Our village - Thak - is about 5 hours north of Pokhara, with fantastic views of Annapurna from its 3,000 ft. above the valley ridge. Of course we are very homesick but the people are very 
friendly and good-humoured and, apart from a bad cold and a little dysentery at the start we have been fine. Our main interest will be to study the interrelation of demographic/mental structures - but at the moment are just collecting simple stuff on kinship, economics etc....

19.2.1969 Letter from Alan to Keith Thomas, the supervisor of his Oxford D.Phil.

... The Gurungs, whose language we are painfully learning, are charming - friendly, gay, graceful, intelligent. I must say it doesn't feel as if one is living in a "primitive society", though the existence of two untouchable castes, of considerable underemployment, of strong magical beliefs, and frequent unpleasant diseases reminds one of this fact. As I had hoped, living here has suggested a lot of subjects for study in the C17 and I think my final study of Westmorland and Essex villages will be enriched by coming here. I hope so, at any rate, as we both often feel very homesick, especially for Oxford and my parents' home in the Hebrides. We are also getting a chance to read a good deal - Weber, Durkheim, Eisenstadt etc. - something I kept meaning to do but failed to achieve in England. ...

\section{DIARY 20.2.1969 Alan}

Spent morning, after Gurung, checking the witchcraft book and then went up the hill in the afternoon.

NOTES 20.2.1969 Alan - Cock sacrifice for medicine (Te ngoba)

About 7.30 Prem was called for through our window in Nepali - this must have been the Untouchable father who wanted a cock sacrificed for his wife - he didn't come in. Prem seemed reluctant to do this, but after a while we trouped off to the other end of the village. There in a tiny house whose construction was as follows: [diagram] sat a man, his wife (who I had been treating for some days for sores on her legs - which had now almost healed - she said hurriedly on being questioned that the sacrifice was for a sore patch further up her leg than where I had been treating). I was told that, as Untouchables, they did not speak Gurung, though from earlier and subsequent conversations, it was obvious that they did a little. There was no lamp of any kind in the room and the fire, using only very small sticks and the fireplace almost blocked with ashes, provided the only light.20.2.1969AlanCock sacrifice for medicine ('Te ngoba')Prem made bowls with banana leaves while Bolbahadur striped two 6" sticks with what looked like red and black mixture. The family was asked to provide various ingredients, many of which they did not have. A mixture of water and rice, with some brownish powder over it, was cooked in a ladle on the fire until all the water was gone. Bolbahadur cleaned his hands with water. Two pieces of cloth, both only a few inches long, were stuck into niches in the wood. The hosts apologised for not having cigarettes. The cooked rice was put in a banana leaf and put along with small quantities of 'masata', 'nari', 1rs. note, and the two decorated sticks onto a round plate. The husband goes out for a while and reappears with some oil. Prem asks the woman for her 'lho' ('pho') from which he works out her age. Two pieces of burning wood are tied together and then the sitting arrangements are changed - Prem, Bolbahadur, and man moving to the side of the fireplace nearest the door.)

Prem says various prayers for a few minutes and water is poured over the head and shoulders of the chicken. Corn ('mlasi') is also sprinkled on its head by Bolbahadur. Prem goes on muttering very fast for about 5 minutes, they are now all huddled over the woman and away from the fire. The long sing-song recitation is accompanied by circling movements over the head of the woman, in unison, Prem waving the bowl of oddments, Bolbahadur, the chicken, the man, a 'bahuna' of water and the brands of fire. Prem recites with eyes shut, very fast, and this is punctuated with the circling, two circles at a time. Each time the circling occurs they say "'oh shioda yo"'. This stage lasts some 10 minutes or so.20.2.1969AlanCock sacrifice for 
medicine ('Te ngoba')Prem half way through take the water and circles with this. In the latter part all the men stand above the woman who is still sitting. The recitation appears to be in Nepali and there is a lot of repetition. At one point Prem counts up to 9 in Nepali. Finally the three men ask to be excused and disappear to make the sacrifice - for about 15 minutes. On being asked, Prem says they have not gone to the fields but to his house, but since I have seen the remains of such sacrifices in the fields (an why else would they have brought the chicken back - which Prem was going to keep). When they return one of the children is sent to sprinkle ash outside. Prem perfunctorily touches the head of the woman on his return and says "'shiya"'. Then they smoke a cigarette together and we leave. Prem says he and Bolbahadur killed the chicken together. Prem is called 'Babu', even though he is acting as Poju. The ceremony, Prem says, is called 'Te ngwoba'. As payment for his services he is given a cock, price 7 rs., about 2 manas of rice and 1 rs.

\section{DIARY 21.2.1969 Alan}

As day before. Still feeling tired after Pokhara, but enjoying doing the witchcraft book. Both days brilliant sunshine and very hot in night - too hot for night clothes, etc. Now like May/June.

\section{NOTES 21.2.1969 ALAN Witchcraft beliefs}

I showed Prasad the proofs of my witchcraft book and asked if they had any similar beliefs in Thak. He replied with enthusiasm that they had and explained that people could not walk along at night because of the danger of witches, even within the village. "It is believed that there are many witchcrafts in this village", he said. The whole tone of the discussion was a mixture of seriousness with occasional remarks to show that he did not himself believe in witchcraft - though it seems obvious that he did. He continued that nobody should be told that there were "many witches in this village". Asked if people knew their names, he said they did but should not tell anybody.

In dark nights witches go out from houses, they mostly congregate at crossroads, eg., at the meeting of the ways at the water tap behind our house. There are many witches at this spring. Both men and women can be witches, but women are the more powerful witches. Both old and young people can be witches, and witches are those who are alive now - not the spirits of the dead. Every night they go to the graves (on the hill) and eat up the dead bodies (which they take back to their houses to devour). It is possible to see a fire in their hands in the nights they walk around with their hands clenched in front of them, these are flaming. "But I have not seen any witches", says AKP and "I do not believe in them".

About ten or twelve years ago there were many witches in the village and many people met them on the paths to the village Asked what will happen if one meets them, he says that "it is not so good" but nothing will happen. Likewise it is dangerous to "speak bad words of witches" in case they hear of this. Asked if they cause illness he says yes, eg. they cause a person to shake, and also cause head-aches. It seems that when an illness cannot be diagnosed, e.g. vomiting for a long time, then witchcraft is thought to be at work. Then people call the poju. The poju and witches are foes, it is said that many years ago they agreed to be thus (the witch harming and the poju healing). "The witches are very dangerous here, many persons have died", AKP continues. But only some deaths are thought to be caused by witchcraft.

Asked if witches are ever attacked or punished, AKP says, "No, we cannot punish witches". The word for witch is 'boshi' (female) and 'bosa' (male). Nowadays, AKP thinks, witchcraft is vanishing. There used to be many witches, now there are fewer. When asked how many witches there are, AKP replied that X's mother was a very strong witch indeed. Last year, for 
example, the elder of the two Garda Sheva dancers was very badly bewitched by X's mother. If the poju had not been around she would have died.

When the poju was called in he said a mantra over the bewitched party (accompanied by a spitting motion) and this forced the witch to come into her. The witch was then asked "why are you suffering this person?" and the witch replied, in the voice of the sufferer, "I am angry with this person because...." Apparently such possession is "true" says AKP, he has himself seen it happen. After this the poju cannot do anything against the witch, but can enquire how the witch would be appeased. The witch usually asks for a goat or a hen. In the Dilmaya case, in which the bewitched person shook a lot - (twitchings occurred for several minutes at a stretch and she was very frightened) we "gave her a goat" costing some 88rs. This goat was bought and killed by the dance group and they eat the flesh (after the witch had been satisfied by the spirit. Such mantra saying is "a good way of finding out the witch".

Asked if he had seen any other cases of such possession, AKP said that his own sister last year was shaking. Prasad's father, who knew the mantra, said it over her. If she had been reluctant to speak when the mantra was said it would be necessary to beat her over the body and head with hands and sticks (the witch gets this beating, not the victim). If she still does not speak, then a long ladle (for rice) is made red-hot in the fire and she is beaten on the cheek with this. Prasad's sister says that it is XX who lives in a nearby house who is to blame. Prasad does not know why this bewitching should have taken place. On this occasion the witch was not given anything. There was another case near Prasad's house when a woman was also shaking in her body. Prasad's father said a mantra and the witch possessed the woman saying that the cause of her anger was that she had lent the victim rice and did not receive the same amount back. She was not given any sacrifice, however, because "she is not very strong".

$\mathrm{X}$ 's mother has been a witch for a very long time. It is possible to learn from any witch, the art, but it is usual to learn from a relative; if a mother is a witch, "most of the children learn the witchcraft". Asked if there are any other witches, we are told that Y (the old woman with whom we have had some trouble about selling us clothes and begging - she, like X's mother, is a woman of peculiarly strong temperament) is also a witch. She is also very powerful. (This makes one witch each for Wards 6, 7, 8). Her married daughter is also said to be a witch, though less powerful. When we tell how she might have a motive to bewitch us, AKP says that she could not do this "because you do not believe" in witchcraft. Only people who believe in the power of witches can be bewitched thus. Apparently there are now "about 7 or 8 witches in the village", most of them women, though AKP does not know the other's names. The whole matter is a secret to the village and we are asked to keep quiet about it, though it is alright for us to publish on the subject.

Asked about punishment, AKP says that if the witch goes on making too much trouble then the "gentlemen of the village" (and Panchayat) will expel her from the village. This, as far as he knows, has not happened in Thak; but it happened in Khilang about 8 years ago. Witches eat the heart/blood of their victims - as for instance, $\mathrm{X}$ does. If any children are buried in the graves, she eats their flesh. Her husband, now dead, was also a witch. We must talk very carefully with a witch.

\section{DIARY 22.2.1969 Alan}

A cloudy day so we did not go to the river. Planted my garden in the afternoon with eight varieties - just to see if anything happened. Thought a lot about England where Annie was going to get married, today. Went to a cock-slaying with Prem and Bol. 
Went to river - as usual it clouded over, but it was nevertheless blissfully relaxing. In the evening, went to drink 'pa' with Lt. and eat rice noodles.

\section{DIARY 24.2.1969 Alan}

Prasad came and delighted me by his account of witchcraft in the village (q.v.). We continued proof-reading of witchcraft book. Our fears that eggs would run short were groundless. We now have 42 of these!

\section{DIARY 25.2.1969 Alan}

Another bright, fine day - very hot in the afternoon when we went up the hill. In the evening we went to watch dancing at the big 'tulmae' house down below Bhuwansing's This occurred in courtyard by moonlight most of the audience consisting of untouchables, but with a small group of (the unmarried) Gurung youths of both sexes present. It was called a 'rodili sheba' and before we went we were given horrific account of what would happen

\section{NOTES on 25.2.1969 by Alan - Tailor's wedding}

Watched marriage procession going to fetch bride. The bridegroom lived in house 43 in the village, his bride was from Tsozo. About thirty people went in procession, men and women. A fair amount of interest by group of Gurungs who watched. The bridegroom dressed all in white, was carried on someone's back (piggy-back) covered by an umbrella! The look of whole procession closer to Brahmins than Gurungs. That evening we heard there was dancing at groom's house - in his absence this was to be a 'rodili sheba', which we were told was only for women to watch; men would be driven away with sticks and stones etc. But we went and it was all fairly tame - at least until we left (q.v. under "dances"). The bride was brought back the following day, again in procession and accompanied by musicians. She was carried on piggy-back also and had her head and body covered with a white coverlet (like ours). The bridegroom was hoisted on man's shoulders and umbrella put over his head when at his house. Unable to see reception; by the time I arrived at the house the bride had disappeared. A crowd were watching some men dancing (about 12 a.m.), a wild, flinging dance. The same they did at the puja. Men, singly, but taking in turns. The same evening I returned to house 43. The four large (one immense) cauldrons of food (rice, soup, vegetables?) which had been made under a temporary shelter had been consumed and I was just in time to see bride and groom led across to a mat about thirty yards from house. Surrounded by a small crowd of amused spectators, both Gurungs and Tailors, they sat facing a medium cauldron filled with water and straw (and a little dung?). The bride was still completely covered with a coverlet, just her hand emerged and, with that of the bridegroom was immersed, groping, in the water. They were both searching for a small object wrapped in cloth, probably small coins. Much laughter, especially when it was retrieved (being re-hidden and retrieved three times) The bridegroom was turned round and part of bride's coverlet was held against him and where it touched his clothes, yellow powder was rubbed. Water was then sprinkled on his feet, three times and each time bride bowed and brought some of this water to her mouth. (Both Gurungs and Tumulmae had been watching this with interest, pressing up against each other and putting hands on each other's shoulders with no obvious fear of pollution). The bridegroom then took off his hat, to reveal his shaved head. The bridegroom has oil rubbed all over his head by bride - much laughter. She then combed the little tuft of hair at back of 
his head. Bride directed still blindfolded, by an older woman. Bridegroom then sprinkles a little oil on her head - lifting the coverlet a little to allow this. With some red powder he then makes a 'tika' mark on her head. She then bows to touch his feet with her head, he standing. This part of the ceremony (taking place at about 5.p.m.) is now obviously over. The groom pours away the bowl of straw and muck. The bride is led back to the house and sits out of sight on the verandah - still wrapped up. In front of the house a group of four or five men sits and argues/chats. Two appear to be visiting (relatives of bride), the rest from bride's house. After a while two or three men sound very long sustained blasts on long curved horns, almost as if competing ('narsing') and also on smaller reed instruments. About sixty people watching. A man then starts to dance. Very fast music and dancing. Arms waving and swirling round. Same tunes as played at Poju's 84th birthday party, except faster. The following day, still sounds of trumpets etc. come from the house. Festivities continue? That evening Haricola (aged about 9) describes the bride as 'a'chaba' (ugly) - demonstrating that she has a large lower lip and is 'mlongya' (black/dark skinned). The groom looked a youth of about eighteen to twenty at the most.

A 'Tulmae' wedding took place today. When the bridegroom and some men departed to fetch the bride in a distant village, in the evening, we were told that there would be dancing at the bridegroom's house - a 'rodoli sheba'. When we say we would like to go, the Gurungs around get very excited, saying men cannot go - they will be caught by the hair by the women dancers, beaten, stoned etc. But after a bit a man admits he has seen the dance, which involves dressing up as a man. He then sets off with us by moonlight to the bridegroom's house. The audience consists mostly of women, who sit around on mat or verandah, but there are also a group of young Gurung males (unmarried) who in fact do much of the organising of seating. There seems no objection to our being present. The dance, done by girls and older women in turn, is a fluttering, twirling affair, more like a singed moth (though with considerable grace) than a sexual orgy. But we only stay for half an hour until 10 p.m. so things may have hotted up later (cf. accounts in 'Magars of Bunyan Hill' and 'The Newars'). (The following day, n.b. discrepancy between ideal and real):- AKP laughs and says there are "very bad items of the dance". Only women can be present. If men go, the dancers catch the men and beat them up. "We should not see the dance of 'Rodili sheba' and can only do so by looking in through cracks (AKP admits he has seen this thus). Women are dressed as men and another "in the same dress" dance thus. Anyone who wants to dance, can but especially 'maba' do this dance. Gurungs also do this dance...it occurs when people go to bride's house.

\section{DIARY 26.2.1969 Alan}

Hot again and we are both well, though very sleepy. The battle against the rats continues: they still make a hell of a row downstairs, opening our tins, etc. but a piece of wood upstairs seems to have lessened their effect up here. An occasional cat through the window and increasing swarms of flies have, however, been added to the hazards. In the evening, I went down to watch a Tulemae wedding (q.v.) in the house no. 43. Later that evening, the youths of the village congregated to do down to Noleghat to sing/dance at ceremony marking the completion of the new house. The bad cough/sore throats ('flu) continue to go the round of the village.

DIARY 27.2.1969 Alan

A very hot day - the hottest yet. I even got to sitting typing upstairs with my torso uncovered. Gill tried wearing a kilt, with much trepidation - to the delight of the village. The temperature today c65 F. in the shade. Also the days are lengthening out - the sun comes up still at 
6.55am. (over the horizon), but it is still light enough to write until about $6.00 \mathrm{pm}$ - about $3 / 4$ hour longer than when we came. So we take a nap after lunch in the heat of the day. Time flowing past very fast - still reading through my witchcraft proofs in morning and groping with language.

27.2.1969

Alan

\section{DIARY 28.2.1969 Alan}

Again hot: every day it gets hotter and we are now having temperatures of about 65-70 in the shade though a nice breeze blowing. Gill a little under the weather over her period. A lot of information from Prasad.

NOTES 28.2.1969 by Alan - Inheritance

Asked why land is now split up and dotted about AKP says it is because at first only one person came to the village, he tilled where land was best, here and there. His sons inherited in various parts and did the same. Hence split up. When a man dies the "gentlemen of the village" (Panchayat) decide how the land is to be divided between the sons (all of them) equally. Unmarried girls get a little land (about half as much as men, AKP agrees, to my suggestion). If no sons, then the property goes to the daughter. It is also possible to give a daughter land at the wedding. Whenever a boy over the age of 21-25 wants to take land he may do so. The lands then have to be divided between them all. The sons do not have to wait for marriage for this, nor do the lands have to be divided at marriage. The youngest son usually gets the house, sometimes he gets less land because of this. A person usually asks for land only when he is going to live separately (with absence of cash economy and communal labour why should a person want land divided?). Often says AKP 30 or 40 year old sons have not asked for land. Land disputes, like other disputes are heard by the Panchayat. 


\section{MARCH 1969}

TAPE RECORDING No date - March.

Nepali song

A group of men, including Nainasing, and women singing a Nepalese song which goes as

"Batishai danta, batishai danta, bholu bholu nirimaya, laye rahancha yo manta..."

https://sms.cam.ac.uk/media/2733163

TAPE RECORDING - No date March

Akayprasad teaching Alan Gurung

https://upload.sms.cam.ac.uk/media/2733180

TAPE RECORDING - No date March

Nepali song

A group of women singing a 'thado bhaka' song which goes as "Khole bagyo oraley, Kina chadyo asha ko bharaley..." at Bhuwansing's house. Sound of hookah smoking in

background and dog barking.

https://sms.cam.ac.uk/media/2733197

\section{DIARY Saturday 1st March Alan}

Continued very hot: absolutely cloudless sky and paths getting dustier. Usual crowds of people it being a holiday. Again spent much of the morning on the witchcraft book. It is amazing how little one seems to get done, despite getting up at 6.30am. The days stream past, events piling on each other, and one can only catch a few impressions as they pile past. Today, officially, our study of a "Year in a Gurung Village" began, though didn't quite know what to study. The impression is that this is still the slack time for work - men still going to the forest to cut wood or grass for buffaloes. Trips to Pokhara fairly frequent. Women carrying dung, though nearly all the higher fields now done.

\section{DIARY Sunday 2nd March Alan}

Spent day by river - blistering hot and a little spoilt by the arrival of 4 boys from the village, who were reluctant to leave. Felt our special place was a bit "desecrated". Gill also not too well with period.

\section{DIARY Monday 3rd March Alan}

Spent on witchcraft book and writing letters home. Cabbages beginning to come through in my garden. Gill not too well. Weather continues hot. Many people in village, including whole of poju's family, sick with 'flu - was demand for Aspro's, and as before, a vast surplus of eggs (we have had over 40 for last week). At the well, an old women, Gunja's grandmother, pushed me away when I was getting water, she wanting to rinse her hair. Interestingly, she later came down asking for oil to put on her hair - guilt and desire to re- establish relationship? Rats now have a taste for peanut butter. Prasad very good this morning on dancing and the local spirits.

NOTES 3.3.1969 by Alan - on dirt and pollution

Dirt is 'kasi' (as in 'kasi piova' - to sweep up the floor). All animals are dirty, only those that have been washed such as small dogs should come into the house. The only polluting animal was the black pig which only Tailors can eat. One must cleanse oneself by drinking water 
which has been touch by gold ('mara kutumoa'). Another polluting situation if one is touched by one's younger brother's wife ('bunari'); "if I touch her then she must touch gold water". The cleansing is the same. Menstruation is also polluting; nobody or food should not be touched for a week (see further under menstruation). No uncleanliness association with childbirth. The only pollution associated with death that Prasad gave was that of the pall bearers, after they have carried the body to the grave. They can pollute until they do the following - a) wave their 'kule' over a fire on which 'chugu' had been put; b) stamp on a nettle on the way back; "if any bad things come with us they go away" (do they think bad spirits live in nettles?). Pollution from an Untouchable; this is cleansed by anyone touchable throwing water on one ('chit prabha') - pollution is contagious, and a person once polluted, pollutes others.

\section{NOTES 3.3.1969 bya Alan - Evil spirits}

There are two major kinds of evil spirits;: 'bhuts' and 'prets'. The latter have a very big stomach and if a person eats a lot he is described as 'preta'. They eat the normal food of human beings as well as human flesh and blood. Both types live in waterfalls, and congregate on crossroads at night. Prasad says he does not believe in them and that such beliefs are handed down from generation to generation. Asked if one can see them Prasad says "no" (but later says that they jump out at lone travellers to frighten them). When they eat the blood of a human being they make him ill and the poju is sent for. He consults his books and will say whether the illness is caused by a 'bhut' or 'pret' or a witch. He also prescribes how a cure can be effected which usually involves the sacrifice of a chicken or goat, since the spirits like the blood of such a sacrifice to replace the human blood. The poju also beats drums all night. One 'bhut' lives on the way to the Modi Kola; another on the way to Taprang in a small waterfall called Aneryshon (dark river); there are none on the path towards the forest. There is one on the way to Pokhara in the Lordborde chatra which is just beyond the second river crossing. If a person goes along passed the 'bhut' he appears to frighten them (Prasad often seems vague as to whether it is a 'bhut' or a 'pret'). There is another near the waterfall near Prasad's house called the Moigyan chatra (buffalo way waterfall). This dries up in winter but the 'bhut' stays there, living behind where the water would fall. Prasad does not know why 'bhuts' attack certain people.There are no spirits in the forest. The spirits of dead persons are called 'morsan'; they are "bad things" though they don't make people ill. They live near graves and at the Modi Kola where the bodies are burnt; they don't come into the village. Prasad looked slightly apologetic when he told us of the 'jogon buje' which is a grandmother spirit who lives in the pantry of the house ('jogon') to frighten away children (from pinching things?). To stop children crying people say 'jogon buje kilae soa a'. Grown-ups do not believe in this; no food is offered up to her.

\section{Letter Gill 3.3.1969 to her parents}

Anthropology-wise and weather-wise things are hotting up in the village, as it is over 70 in the shade today, and the whole of last week has been filled with brilliant sunshine, with all the butterflies of teh village coming out of their winter drabness, and filling the air with colour. the nights are equally bright, like Arnold's moonlit villages, and teh Himalayas glimmer away as a perpetual background and can be quite breathtaking. Our Gurung teacher, the first schoolmaster, has also proved to be our best informant so far and we are finding out more and more tempting anthropological details and less and less syntax!

The most exciting news to date is that the whole place is infested with witches and the most exciting correlations are emerging between Alan's book and the village which we are right in the centre of. The weirdest experience was checking galley proofs (me reading aloud and Alan correcting) and having the second most 
powerful witch come up to our loft and ask if we would buy clothes from her. As you know the mainspring of Essex witchcraft seemed to be the relationships between neighbours and the crisis which arose when a neighbour would come begging/demanding things, only to be refused - which was the exact parallel in our case. We only found out on the following day, and for quite a long time the schoolmaster couldn't bring himself to give us actual names, obviously frightened that the witches would come and suck his heart if he split on them. Their main meeting place is behind our house, at the spring and Alan finds it very curious to have the whole subject unearthed again and in such a peculiarly vivid way. The villagers' fear is very real, and the night before last we had three 12 year old boys crouched in haunted silence round our fire, as Alan had been whistling while I was frying up potatoes and whistling attracts witches; Alan was too efficient and talked too loudly as he delightedly took some notes, and had to enter the hushed conspiracy of apprehension in order to keep up the atmosphere and get more information. Bits of ash were flung all over the floor to keep the dreaded creatures away and they walk about at night with fire flickering from their fingers. The whole concept fits in very well with the social structure, as far as we have seen it, and prior to this Alan had been wondering why there seemed to be no mention of them as all the right concomitants were there.

Another important factor which is continuously intriguing us is the existence of two worlds of thought which the villagers can take and accept, quite unruffled. We have the son of the poju (the main anti-witch in the village) coming to give us. Nepali news read in English on his transistor, and then being called away by the Untouchable Blacksmiths to sacrifice a cock over a woman's sick leg; I couldn't go to this as women weren't allowed to watch. This same woman had been regularly draining our Savlon supply for the same leg for weeks previously. Even more frustrating is the situation over a bad burn I have been dressing, where the mother goes away and puts millet on the wound if the baby cries, and this turns the whole thing septic again and we are back at square one. It is only me who gets cross and says we can't give her any more if she persists with her home remedies; of course she is anxious and has to do something when the child cries. Perhaps the most interesting of these situations is that the most powerful witch of all (aged 88) is the mother of the most sophisticated man in the village, the Lt. in the Gurkhas I think I wrote about before whose family have been very kind, including the granny whom I like very much!

As you will realize we now never stop cogitating and A is feeling happier about the whole project. We are both very well, except for being endlessly bitten which is a nuisance. All our housework, cooking, washing etc. is now organized (washing days are a particular delight as we take everything down the local river and I scrub away there with my Marks and Spencer underwear slung across the water on a rope!). The house is even 'flower-filled' (like the ones in Homes and Gardens or what not) as the children bring us huge red rhodedendrons from the forest - mauve primulas and small white lilies and these look lovely in a copper cooking pt.... All my love, Gill

\section{DIARY Tuesday 4th March Alan}

Last night we were kept awake between 12-2am. by a 'garda sheba' which processed to the house next door and remained there for some 2 hours or more - with much laughing, drumming, etc. Today, much excitement as there was to be 'puja lava' to clean the village of illness. We witnessed this from about 2.00-5.00pm. Curious how paranoid we have been getting - pulling the society to pieces in self- defence and getting exasperated at the many people who come and stare, ask for tins, etc. The feelings of lack of privacy etc. fluctuate considerably. Today also all the little boys, and some little girls, very excited as it was 'ranga klionba' (colour playing) day and they spent the time rushing about spraying or splashing each other with colours - mauve and green. Still very hot, at 5.15pm., though sun set, still 63 in shade. 


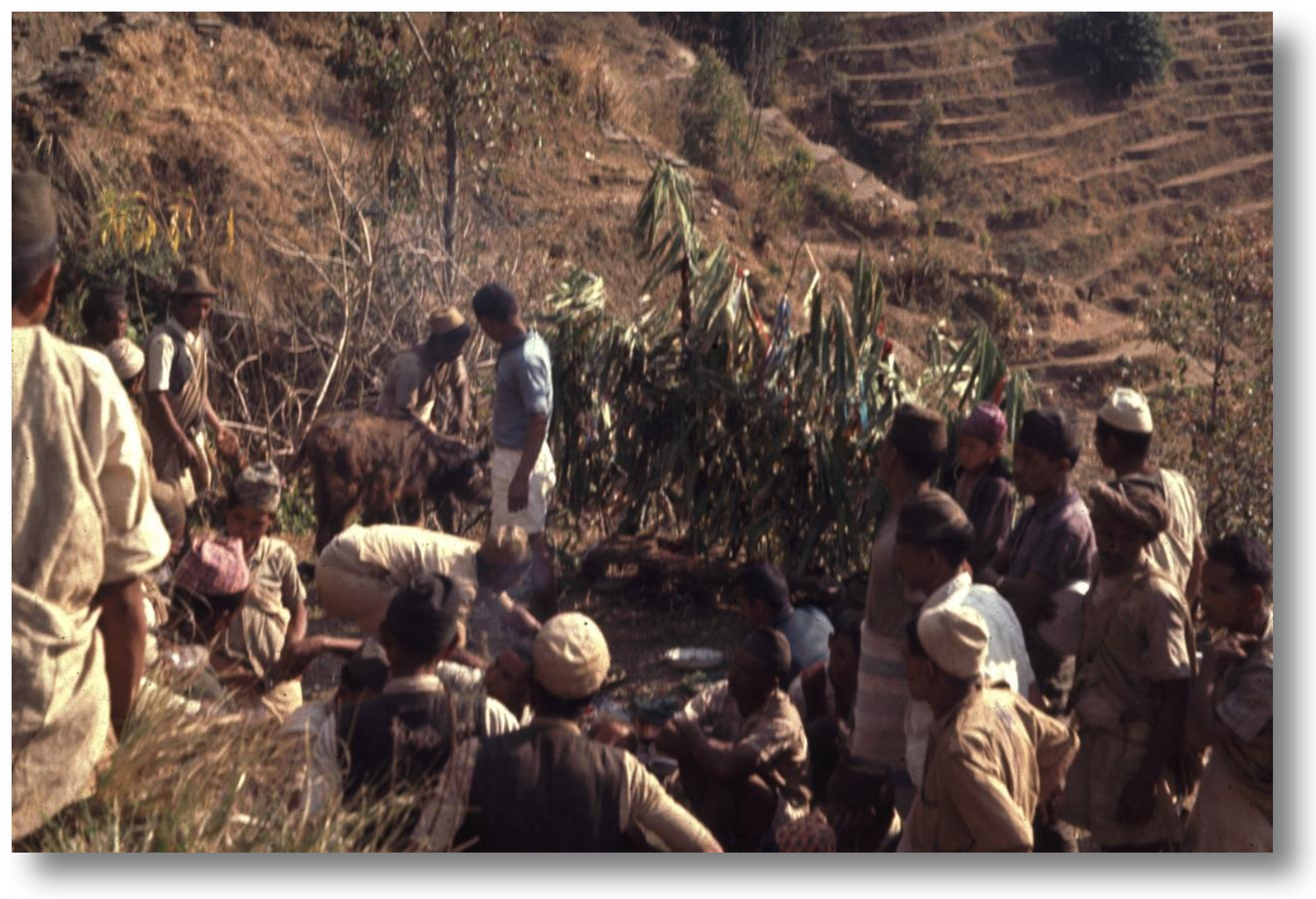

The 'panchaboli' ritual for sick animals

NOTES 4.3.1969 by Alan - Panja Boli Puja

(Pangaboli - live animals to god) The big 'puja lava' held in the afternoon, 1.30-5.30pm. which we had been told the night before was because of the degree of illness in the village, the 'puja lava' intended to clear this up. People of all ages and sexes, plus animals, assembled outside house 22. Many of them held banana fronds ('rhi linga') onto which were tied strips of coloured cloth about a foot long and half an inch wide ('daja bowa'). They also carried bowls with rice, husked, wrapped up in cloth in them (about half a pound each) ('achiti'). Apparently there was meant to be one representative from each house. The five animals to be sacrificed were a buffalo, goat, cock, duck ('haas') and pigeon ('parawa'). Apparently to Akayprasad who was my informant for a while, this puja is common to all the Nepalese peoples, Newars, etc. The buffalo, only a baby, was so weak, said Prasad, that it could hardly walk.

Panja Boli puja (Pangaboli - live animals to god)About 2.00pm. the procession moved off along the front of the houses; there were 75-80 people, men, women and children mingled together. Prasad said that they would be going to near a waterfall about 15 minutes away from the village, saying "it is better to worship a god far outside the village". Asked how payment would be made for the animals he said that each family would give one mana of rice and about 1rs. He said "first we worship the god and then cook and eat the animals". He said that the ceremony occurred every year at the beginning of the summer season, especially in Baisak or Tsait, and it was to prevent diseases, especially animal diseases, which would cause great distress in the villages. Every village must have such a 'puja lava' and Panighat were having one on the same day. Nolaghat also had a separate one and the one that we are going to comprises wards 6-9. The ceremony is a worship of the goddess Devi who can stop all kinds of disease. 
The stages of the worship are as follows: 1. washing the head, the feet and the body of the sacrificial creatures ('yopal kruva' - hand-feet washing). 2. Rice, flour and water are put on the heads of the animals, until they have stopped shaking their heads and then they are killed. "All this time we pray to god as, for instance, - please prevent us from all kinds of disease; we have given you 5 creatures". Only the Brahmins and old men know the exact words to us. It is called 'parsidiba'. 3. The killing of the creatures 'seba'. The sacrifice to the gods is usually called 'bholi piba' (to give to the gods an animal). Untouchables also do the worship but they have a separate sacrifice at the same time and they kill a black pig.2.30pm. Horn player sounds a blast on a curved long horn; the women who have hung back now come down the path to join the men. The place is a field where the sun strikes directly at about $3.00 \mathrm{pm}$., beside the path and near the village's emergency spring. Obviously a number of sacrifices take place here as there are several piles of ashes. One Brahmin is in attendance. Bol. is sent to one of the nearby trees to cut foliage. As usual there is great discussion of every move, the men standing around arguing. The women and girls sit a few feet away in a group and do not take part. The Lt. then acts as informant: he says that this is an "old custom" and only occurs when people are ill, not every year. Asked who is being worshipped, he hesitates for a while, and then tentatively suggests that it is probably the goddess Devi. Prasad at this time was writing down the names of all those who brought rice (tipped onto a sack) and money of .5rs. each. All this is written into a notebook. An altar has been made from the fronds and ten stones, [see diagram - fig.10 ], and this is being washed with water. A little dung is put on top of each of the 5 stones.

$2.45 \mathrm{pm}$. The Brahmin is drawing a small diagram with white powder on the ground, and a pile of sticks is put into the centre. There is now much thumbing of rupee notes and it seems that it seems the original cash is not enough and people are being asked to give more, their names being read out of Prasad's book. The Brahmin has finished making his dishes of this and that. (Akayprasad said the place had no name since the sacrifice was performed at different places each year)

\section{NOTES 4.3.1969 by Gill on Panja Boli Puja}

I came down to the 'puja lava' about half an hour after the procession, having been told it was originally by the small temple but later indicated that it was on the S.S.W. side of the village, lower down. Any "plans" are always vague and casually laid, if at all, and for the most part all arrangements are ad hoc; this fits with the usual air of relaxation the Gurungs have about most events. Everyone, from the children upwards, had seemed to be especially excited about this, the excitement starting on Saturday evening when we were told by a group of early adolescents round the fire that they were going to spray paint at everyone on Monday/Tuesday, and the argument followed as to which day it really was. We learnt from Prasad that it was a Kathmandu custom which had seeped into Pokhara, and hence to the hill villages. This might have been their reason for being doubtful about the actual day. Since Saturday there had been one private 'puja lava' (Rudrabahadur) and two 'garda sheva', (one at Bebi's, as her daughter had married some months previously and they danced at her house for a fee of 60rs., one underneath our window which finished at 2.00am. on Tuesday morning. Children were still therefore excited early Tuesday and were shrieking round the village, thundering past the house, the boys chasing the girls and when capturing them, smothering them in purple, pink and blue dyes sprayed through a special bamboo pump called 'pascari' (?) Whether these are made locally or imported from Pokhara, not known. Alan was asked to go out and spray the ladies, the third schoolmaster coming upstairs to our loft to request this. He was already blue throughout, and obviously the more luridly covered in colour you were the more "he-manship" was ascribed to you. 
When I went down to prepare the lunch as $12.00 \mathrm{pm}$. was somewhat daunted by the presence of 7 men from ward 9 on the verandah, come to view the first sight of Thak before going onto their specific engagement of the 'puja lava'. I immediately noticed that Nani next door was dressed in her best sari skirt and blouse top with hair freshly plaited and greased. This set off her new earrings, recently purchased by her mother from another village across the valley, and which she has been wearing for just about a week. She was very proud of these, coming to show them to me specially and being very coy and pretty when Alan noticed and congratulated her. She was carrying a long bamboo stem which had pieces of white and red cotton tied to it, and leant against the 'mokhai' frame provocatively in front of all these new men looking most relaxed and happy. Her mother also seemed to be dressed up and the whole adult family (three women) rushed off when the procession started, Granny carrying a white muslin bag carrying rice. Nani and her sister-in-law came back after about 10 minutes, and started doing the usual household tasks - Nani spinning thread and sister-in-law looking after the baby.

I left to go about 20 minutes later, and found people still struggling after the main procession looking hot and dusty as it must have been over 75o. However, the main bulk of people had arrived at the sacrifice ground, and had dispersed into groups [see diagram]. The main centre of activity was round a pile of rice collected on a piece of sacking, being the contributions of each family towards the general feast they were to have later. Round this were various eminent men of the village, the most active being Prasad, as he was calling each family and ticking off their rice contribution with a red biro we had given him in an exercise book. Opposite him was another youngish man who was collecting the money, carefully unwrapping each rupee note that was given, and putting coins in a brass plate which had stripes of red on it. The other men were carefully observing this and chatting amongst themselves. Two held children on their knees who eventually went to sleep there from the heat; one was howling for a long time before she dozed off, and the father took a long time before he got impatient and smacked her showing the Gurung's usual tolerance and patience with children

The second centre of activity, which technically should have been the foremost, was the ritual of the Brahmin doing the 'puja lava' opposite a temple made out of five large flat stones with the bamboo stems stuck in the ground behind them to make a kind of green wall with pieces of torn cotton fluttering from the leaves when a slight breeze blew. On each stone was a little pat of buffalo dung. The Brahmin was sitting cross-legged as usual opposite his little chalked chess board of astrological signs, on which at certain points were the usual bowls, banana leaves filled with rice, etc. The Brahmin had just had his hair cut and looked a little strained as he read out of his Sanskrit books, turning the pages rapidly and intoning sufficiently just to be able to be heard over the noise of the money transactions next to him. (In contrast to his actions - ancient/ritualistic - he was wearing a watch with an expanding strap and a windcheater of a blue synthetic material, throughout - twentieth century epitomised. Opposite him on a 'gundri', and looking very spruce in Western type white shorts and shortsleeved nylon light blue shirt was Ramchandra's brother. He too was sitting cross-legged and answered the Brahmin's intonations with a flick of faded rhododendron there and a dip here into a small brass bowl filled with water. He had one bright red 'tika' and one black ash mark next to it on his forehead. Ramchandra himself stood aside from the whole proceedings, doddering backwards and forwards but not contributing anything. The Lt. was sitting on the wall next to Alan. When I arrived, looking hot under a black umbrella he was carrying. When Alan left about half an hour later he moved off the wall and went to chat with Ramchandra who was still standing near the table. He then wandered behind the temple so that he faced me and sat on a pile of firewood later intended for cooking. Here he joked with an older man who speaks a little English and whom he might have been in the army with; the latter the Lt. 
seemed fond of, lighting up when he came over and laughing at his jokes as the older man seems to be somewhat the court jester of the group. Eventually Lt. got himself into the circle round the rice, which by now had dispersed somewhat as most of the names had been called and the main people were not there. It had taken the Lt. about an hour in all to get into some sort of central position, and this well illustrated his wish to absent himself from ritual/village happenings and his longing to be active and put his intelligence and gifts to use (is this because the village do not want it - would be become too powerful, or is he trying to break away from his status group/inheritance having seen and liked Western living?)

The Tailors also had their group at the other side of the field, and they played sporadically on their instruments, sometimes the wind just tuning up and letting out a raucous note which blew over the heads of the Gurungs who were still intent on the collection of money, rice etc. Apparently (the Lt. says) the Tulmae can't get a full band together as there are not sufficiently talented men amongst them to constitute one. The music only came together with some sort of force and beat just prior to the sacrifice of the four animals. (The Tulmae's were supposed to kill a black pig, but we never saw this happen). None of the women Tulmae seemed to be in the main field but were back on the path several 100 yards, sitting on the wall and contemplating from a distance. The next biggest group were the women Gurungs, the older women (whose husbands were dead or away?) made up one lot, chatting group, and the younger married women with some children the next one. They seemed to take no particular interest in any of the proceedings, and gossiped amongst themselves looking hot and somewhat dusty.

Notes made at the time: $3.00 \mathrm{pm}$. Puja proper starts when Brahmin starts reading. The head of the Tulmae comes over from their group and adds his banana leaves to the ones massed behind the stones of the temple. The long horn is played with a loud blasting note. Either Chetri or Brahmin brings cock [Prasad says he is a Gurung as Brahmin and Chetri do not send cocks. Physically he did not look like a Gurung]; boy sitting next to me on the wall, clutching the bird which squawks occasionally. The pigeon is held by another man in a basket, the duck egg is being consecrated by the Brahmin and the small baby buffalo is panting and tottering on its legs in front of us, hardly able to stand up it seems so weak. The goat is held by a piece of rope by another man near the temple. Going by the ticks in Prasad's book only about one third of the people have paid up or contributed. Brahmin chants on, occasionally putting grain from a brass bowl onto the small fire in front of him; this crackles as it burns up. The group around the rice are now making calculations; Prasad does it in his book; another does it on a used cigarette packet - his fountain pen (Parker) has run out of ink so he has to borrow another and another man (the ironic man) picks up a twig from the dust and writes on his arm. The money is then collected together and put into a muslin bag which Prasad later goes off with. More wood is brought for the Brahmin's fire.4.3.1969GillPanja Boli puja (Pangaboli - live animals to god)Ram's brother now gets up from his cross-legged position and places banana leaves filled with rice before shrine. Brahmin stops chanting. Prasad gets up and goes off to pee followed by his small black and white dog (Tibetan?). He follows the path to the spring around that side of the hill. The main rice group is dispersed, only the man dealing with the money sits in his former position, counting and checking it. There have been 9 men in this main group. Brahmin chants again, turning pages rapidly in another, smaller book. Music starts up discordantly. Pigeon is picked up in its basket and Ram's brother takes it out and offers it alive to the shrine, squatting down and holding the bird in his right hand whilst sprinkling rice and water over its back and head. The bird (a small dove-grey one) does not struggle and merely blinks when the grain and water are sprinkled on. The latter are taken from one of the sacrificial bowls in front of the Brahmin. A knife is handed over to Ram's brother to kill pigeon, a small hand knife with a curved blade 
('asye'). The killing is done neatly, and the blood is spotted in a circle on the first of the shrine stones. The pigeon is then laid on the stone.

The kid is then brought forward and is again sprinkled with water and rice, although more thoroughly this time, its brown fur going a darker shade with the water; it is restive and tries to eat a banana leaf. Finally its back legs are held taut and its head put over a log of wood and Ramchandra's brother cuts through the neck with one stroke with a large 'kukri'. The head and blood are sprinkled on the altar. The carcass is put to one side and kicks for a few minutes. The cock then goes through the same process (not decapitated) and laid on the stones. (The third one). The majority of the people there are taking no interest whatsoever in the actual sacrifice, the men are mainly interested in the money still, the women have their heads turned away, engrossed in the music which is playing. The only active interest is taken by those who are actually doing the killing - R's brother and two helpers. The calf bullock is then brought/dragged (as it is panting from exhaustion) to the shrine and the rice and water ritual is carried out. The beast seems laconic and worries at the banana leaves again. R's brother cuts off the head with one efficient stroke and it falls in front of the fourth stone, where it is finally laid. After the head had been held in position by a rope and the neck cut through, two children next to me yelled 'Sye!' triumphantly and laughed, looking at me for my reaction. There was no trace of anxiety or reflection in their attitude.

The one egg (duck) was then laid on the altar. The carcass of the buffalo, held by four men who drag at the legs in all directions, is taken to the next dusty terrace lower down, and the fur is burnt off by putting twigs etc. on the body and setting these alight. Maldosing appears to be the general factotum, doing all the menial work like fetching water, dealing with the fire, etc. The goat is being dismembered near the shrine. Music starts up again. A small group of boys from the village has come down with their spray pumps and are having battles in and out of the groups sitting on the terrace. The liver of the goat is closely examined, at the end by Ramchandra, and by the way different parts are pulled back and felt it looks very much as if they are examining it for omens (which they were). 11 people look at it including Prasad. There is a general air of relaxation and holidayness, and the whole with the different groups of waiting, chatting people, the animals being prepared for eating, wood and water being fetched and the great copper cauldrons being washed for the rice to the cooked, is reminiscent of a Victorian family picnic of some expansive household. Nothing appears to be done with particular care or order and the relaxation is considerable.

The Brahmin is the only one with an air of professionalism, and is still chanting; R's brother has moved his mat to the left of the Brahmin, immediately in front of the shrine. He has a twist of bamboo tied round the ring finger of his right hand. Potumkumari now arrives and first of all talks loudly to the group of women, and then comes over to the shrine, the first woman to do so, and sits behind the Brahmin's right shoulder, talking to him as he mutters. (Is Pot. the chief female ritual specialist in the village - she is quite at home within this group of men?)4.3.1969GillPanja Boli puja (Pangaboli - live animals to god). The degutting of the buffalo is done on freshly picked green branches, to protect the flesh from the dirt. Six men cut up the buffalo; the guts and entrails are eventually taken off to be washed at the spring. The stomach blows up into white balloons and when these are punctured they are full of grass, half-digested and this is scooped out; the same is done for the goat. The latter's meat is chopped up into small cubes and put into a small saucepan and fried briefly and then water is added. This is done over a small fire just away from the shrine. R's brother then distributes rice and goes round the whole group putting a 'tika' of orange rice on our foreheads. He seems pleased with his day's work and proud that the "group" selected him to do the slaughtering. He did not know the reason but was obviously efficient at the job. His attitude was in great contrast to his usual bored demeanour at ceremonies. (Prasad later told us that he elected himself - one has to have a knowledge of the Brahmin ritual however).Meat is then 
distributed (goat meat) and "our granny" gets the liver of the buffalo at which she is hugely delighted, the large 'kukri' is then returned to her, washed - is this the reason for the gift of the liver? There are eight women in her group - (therefore 8 manless households?).

Ribbons and tags of cotton are taken off the bamboo and tied round the necks of the men near the shrine. They do this themselves (the "joker" is the first to do this ). (Servajid was still wearing a strip of purple velvet the following day). The Brahmin has finished and wanders around, looking as though he is stretching his legs and generally unwinding. Prasad is now over by the buffalo and is chopping up the spine and ribs quite haphazardly. No ritual distribution of parts of the animal? (No - Prasad says quite haphazard). The Chetri? goes off with the Brahmin clutching the duck egg. The cock's head is put over the flames - to eat? (Apparently Ramchandra got this). They do not appear to skin the buffalo. There is a smell of burning fur in the air. The goat soup seems to be distributed to the children and meat as well, and then to the adults.

Cinders from the shrine fire are now being given out on banana leaves. A baby is now fully stretched on the 'gundri' in front of the altar and is crying her heart out - the final break-up of what little formality there was. The performance of the Brahmin was reminiscent of a nineteenth century opera where the audience did not go to see and listen to the music and the stage, but to see who else is there in the audience and have a general gossip catch-up even whilst the performance was still on. People continued working in the village as a whole making the house, fetching water etc. Only one third of the villagers were present at the ceremony. The cost of the animals: buffalo - 70rs.; goat - 20rs.; cock - 10rs. Prasad confirmed there was no special distribution of meat and that "granny" did get the liver because of her loan of her 'kukri'. He also said Jusbahadur wanted to do the job. Prasad said he did not know how the liver omens were read and said that at all sacrifices such investigation of the liver was made. It would show if the sacrifice would be successful or not; it is very important. This one was "not so good, but alright". If bad they do not do another sacrifice; old persons know how to read the liver. I is called 'wyeda nyova' (liver seeing). Many people other than Gurungs do this. This ceremony stops diseases spreading from other towns. Prem also states that the ceremony only occurs when there is much illness in the village and not every year. [Sketch below of group positioning - fig. 11 ].

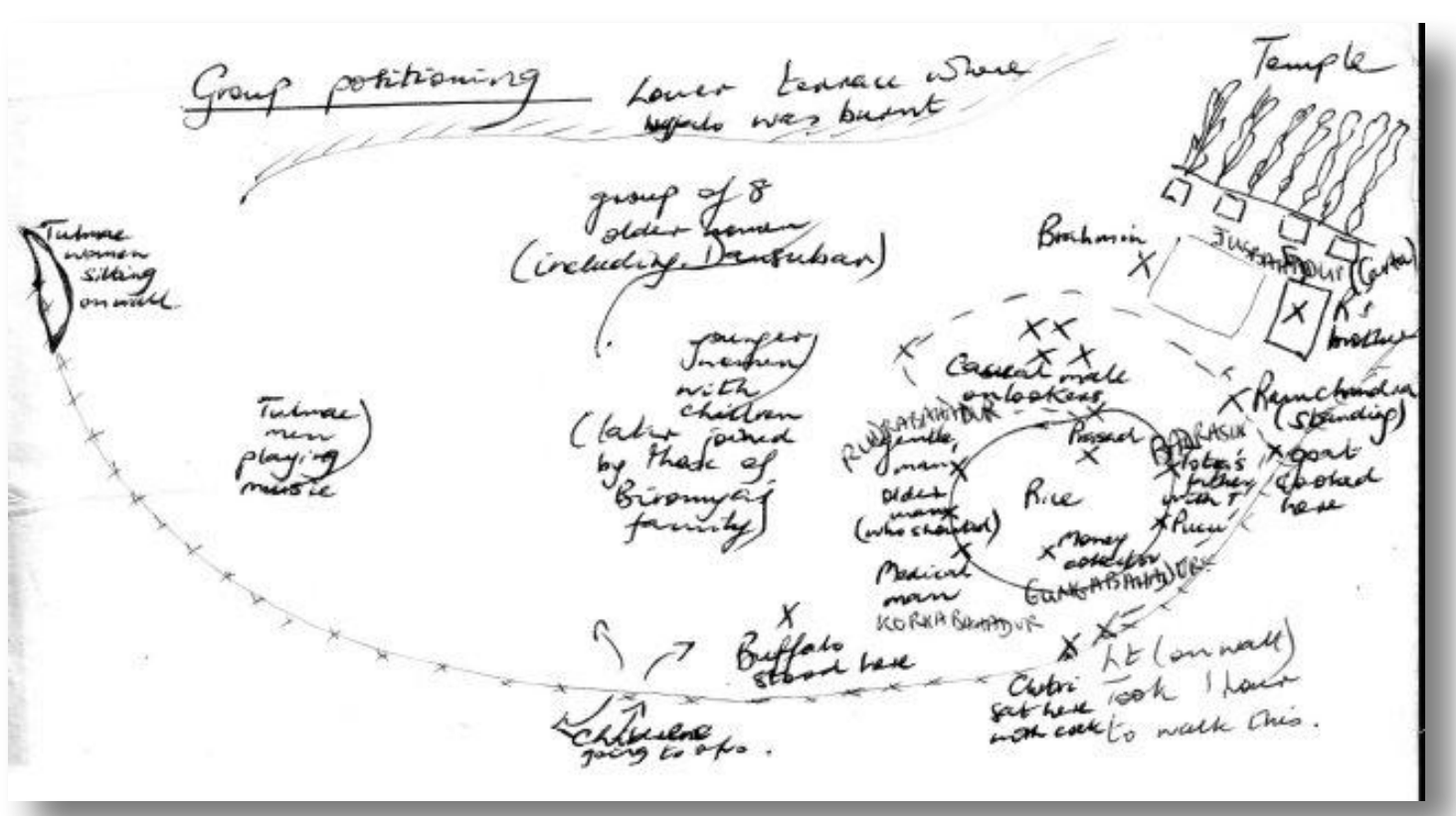




\section{DIARY Wednesday 5th March Alan}

Went to Pokhara, setting off with dawn at 5.45 and arriving back in semi-darkness at 6.30 hence on my feet for 11 hours. Exhausted. Delighted, however, at arrival of money ( 25 and $£ 160=4,500$ rs.), when we had got down to only 70rs. in all: if it had not come this time we would have been sunk. Took 2 months for my cheque to be credited and over a month for grant to come through. Also delighted by arrival of many letters - 15 in all (a record post) including a fantastic and very funny one from Mummy. Spent 1.25 hours trying to post off registered letter to Routledge with my witchcraft proofs: finally ended up eating my scones and boiled egg in Post Master's Office, with rucksack beside me, watching a man flick mail 3 ft. into crammed pigeon-holes. Pokhara P.O. deserves a short story!

Met a friendly East African (Emmanuel de Susa) in the "Lucky Dip" when I knocked him up for meat and wire. He said he was opening a cheap but good bar/restaurant/hotel down by the airport. As usual treated ourselves to reading letters by candlelight when we got back.

LETTER Alan to parents on 5th March 1969

\section{Dear Both,}

We were delighted to get your two letters last week, sent on 29 th Fan and Feb. 3rd. ... Gill has already thanked you for all your tips on primitive living, many of which we will adopt. flies are going to be a problem, as are rats, though the latter are only very small and merely keep us awake a bit. They also seem to adore peanut butter, going to great pains to open the peanut-butter tin on our 'pantry' table. ... Yes, I am going to try to grow vegetables. The Gurungs are, in fact, increasingly growing potatoes which are ideal since they do not need watering. I have put in 8 different varieties in the tiny plot I have been lent measuring about $6 \mathrm{ft}$. squarefrom chinese cabbage to melons. The idea is to see if anything thrives in this dusty, poor quality, soil. If it does, we will send for a large quantity of seed from England and really set too after the monsoon. Growing anything at the moment means, of course, carrying water up steep hills (unless the whole village co-operated and laid a few more pipes). ... In fact, of course, one has very little time for reading here, especially as the village has commandeered our pressure lamp for dances (actually kerosene being so difficult to obtain, we didn't' $t$ use it much) we have to stop work at 6 p.m. in the evening. After doing a couple of hours of Gurung, a couple of hours of translating the classic work on the Gurungs, two hours talking and observing, two hours writing up our observations, there is little time to read. gill is managing to get through some nice books, however, and I hope to read Weber, Durkheim etc. all of which we have out here.

Am continuing writing this after a rather sleepless night since the villagers decided to hold a "dance party" in front of the adjacent house, so we had chanting and drum beats and much laughter (not to mention our pressure lamp shining through the window) from midnight until after $2 \mathrm{pm}$. We both felt a mixture of irritation and guilt, thinking of all the hearty anthropologists who would have been out there making Significant Observations. Today also, we are lurking in the house rather worriedly as all the little boys are carrying pots of venomous looking purple and green dye and water pistols made out of bamboo; with this they spray each other, and even though the day is young, most of them are covered in colours. No doubt this is somewhat equivalent to the waterthrowing ceremonies which Erik filmed - at least it may partly have the same function, allowing aggression against people otherwise sacrosanct.

I have visions of my witchcraft proofs dripping with mauve dye. Fortunately we do not have to take much professional interest in this as it is a town custom spreading from Kathmandu. Of more interest will be a puja this afternoon in which one buffalo, one goat, one chicken and one egg will be sacrificed, and at which Brahmins will officiate. This is to clear the village of "Mao flu", victims of which have been crowding our door-step, craving Aspro for the last week. One of the most curious features of this place is the way what would seem to be disparate elements do not seem to conflict - this is especially obvious in medicine. For instance, as Gill writes, one woman can both ask us for Savlon and then get the local anti-witch to sacrifice a cock for her. Again the whole mental world is just beginning to emerge from behind the apparently prosaic details of everyday 
life. Not only is the village infested by witches, but also by 'pret' (beasts which can eat corpse flesh and have huge stomachs) and 'bhut' (sounds like the things which you met in Assam Mummy). Both of these live in waterfalls, one of them I will be passing on the way to Pokhara to post this letter. It is said that if a man travels alone he will see this particular 'bhut' and be very frightened. When a person is ill, this is often caused by 'bhut' or 'pret'; then the poju (witch-doctor) is called in and suggests that an animal be sacrificed. The 'bhut' eats the blood (and the people the flesh), and is happy. Only this morning, as we blearily ate our porridge, we saw, about 200 yards away at the bottom of the village, a family crouched over a stone altar. When they left, it was obvious that they had just sacrificed a cock. I wonder if it will ever be possible to probe this sort of world in Kirkby Lonsdale - I suppose the best one will be able to do will be to use analogies and draw on general northern folk-lore. We should be able to probe a long way in the economic and social organization, both of which will have fascinating parallels here, but I still have no real idea how people thought in Kirkby Lonsdale, have you?

We are hoping to take the census this month, as I think I mentioned. As yet, we haven't gathered much on agriculture and economics, etc. Land is obviously very much split up - people having bits all over the place. When I asked why this should be, the schoolmaster said it was because the first settlers cultivated only dispersed, relatively rich, pieces of land, and divided these up among their sons. And so on. This doesn't quite seem to explain why each family should have scattered holdings, even if it explains why lineages should. Land is inherited by males equally - all sons getting an equal share portioned out by the elders of the village, and unmarried daughters getting a half share. A person can ask for his share of land at any time when he is over 21, though it is not normal to do so until a person moves out to a new house. As so much labour is communal and, until recently, the surpluses from wealth were shared out throughout large groups, there doesn't seem to have been much motive for such splitting up. Only with the arrival of an active money economy, the possibility of accumulating money and buying prestige articles in Pokhara, does it seem increasingly worthwhile to have one's own share. Apparently there are land records going back for a few years in an office in Pokhara, as well as taxation and voters-list records, so it may be possible to go back a few years in depth, anyhow.

We also hope to visit the village studied by the French anthropologist Pignede, some ten years ago, to see what changes have there been made. Pessimistic as I am, it seems to me that unless something drastic turns up, the whole economy of this place will deteriorate over the next 15 years. Up to now they have been very heavily dependent on overseas service and pensions; this is being rapidly cut back by India and England. They have been very dependent on the forest - this is being hacked down and replaced. Despite high mortality rates, population has been increasing fairly rapidly - soon it will start to rocket up. Already some of the paddy fields are turning into dust bowls and I imagine yields will start to drop. All this will need elaboration and statistics. Meanwhile they dance and sacrifice, spin out the very small amount of work there is available, and send their children to learn western-style curriculums which can have little relevance or utility to them unless they can get into the small town bureaucracies. Outwardly everything is warmth, gaiety, relaxation; behind it disease and impending disaster. But I hope I am wrong!

\section{DIARY Thursday 6th March Alan}

Very bright and hot to start with, but in the evening cloudy, very windy and dust blowing: quite eerie. Like yesterday evening. Glad to see seeds, especially french dwarf beans, beginning to come. Dug another latrine on the hill. Our time here is marked by these. Again tired after Pokhara. Prasad on good form again.

\section{DIARY Friday 7th March Alan}

Another hot day, as before, spent in the usual pattern. 
Designed the census with Gill. Should be very good if they respond. Hot again. Gill had a bit of diarrhoea in the afternoon.

\section{Appendix I \\ Census schedule utilized}

Section one. De facto census.

(a) How many people slept in your house last night?

(b) What are their names starting with the eldest and including informant?

(c) Are they male or female?

(d) What is their tho (animal year)? How old are they now?

(e) What is their relationship to the informant?

$(f)$ How many years have they lived in Thak?

(g) Where else, including residence abroad, and rank if in army, have they lived, and where were they born?

(h) What is their jat (lineage)?

(i) Have they been to school, if so, for how many years?

(j) Can they read or write?

Section two. De jure census.

(a) How many members of the family who normally sleepin the house were temporarily absent (up to one month) last night?

(b) Questions continue as in (b) $-(j)$ above.

Section three. Semi-permanent absence.

(a) Have you any close relatives (parents, brothers, sisters, husband, wife or children) who are permanently abroad (over one month), away at school, living in another village, etc?

(b) Questions continue as in $(b)-(j)$ above, except that instead of $(f)$ and $(g)$ above substitute the following.

(c) How many years or months ago did the person leave?

(d) When do you expect him/her to return to the village permanently?

(e) Where are they now living?

$(f)$ What are they doing away from the village? If in the army, their rank?

Section four. Marital history.

(Fill in the names of all married persons in sections one to three above and then ask the following questions).

(a) What age was the man when he was married?

(b) How old was the woman when she was married?

(c) How many years ago did they marry?

(d) Where did the man live before they married?

(e) Where did the woman live before they married?

The first part of the census schedule, as it finally emerged, from my book 
To river. Finished reading "African Worlds". Re-read Mummy's description of wedding for third time. Rained a little bit but we sheltered under rock and read "Light of Asia". Called to untouchable with 'gwige' and also visited Durgabahadur. Beginning to pick up words and phrases in almost every sentence now. Gill's diarrhoea quite bad.

\section{DIARY Monday 10th March Alan}

Again to the 2 sick above, one of whom now had a temperature of 104. Said must go to Pokhara Hospital. Tried census on Prasad - didn't seem too taken aback. Started reading Eisenstadt "Essays". Gill still a bit wobbly in the stomach.

\section{DIARY Tuesday 11 th March Alan}

Again hot and dusty. Gill's diarrhoea better, but now has a dry cough. A new problem - ants which are infesting our used tins and the frying pan. At times it hardly seems worth the struggle versus all these and Gurungs! Went on with census interspersed with Lt. bringing of all unlikely things, 2 top guitar strings and a request for medicine. Tried to procure a chicken, but gave up after chasing it for 20 mins. Then wandered round village drawing map everyone very friendly and I don't feel so guilty walking through people's back/front yards. Also nice to be able to hold elementary conversations. Off to a chickenless supper!

\section{NOTES 11.3.1969 by Gill - Spirit possession}

We were finishing supper at about 8.00pm. and our "guests" - Comal, Nainasing, Servajid, etc., mostly men and boys - told us that there was going to be a session at Bhuwansing's, where 'deota kaba'. Kumbasing said this when we asked what it was all about. Alan had seen the Lt. earlier, in a surprisingly cheery mood, and he had not said anything about it....they seemed eager to go and pricked up their ears when they heard a single drum beating, and started going. Those without a light hovered behind, and in fact Nainasing started out but got as far as the doorway, hovered there bleating that he didn't have a light, and finally came back to the fire to wait for us. There had been some talk of witches earlier, Kumbasing telling us in a hushed voice that there were some in the village, and that they were 'achaba'; this is a man of 35, ironic and intelligent enough who was obviously as worried by their presence as the small boys of 12 or so.

It was an overcast night, with no moon, and even the stars were dulled by clouds; just a night for witches, one could imagine (note - do they come at full moon, or on nights such as this?). We did not hurry, thinking that like most of their nightly sessions it would take a long time to warm up; at about $8.30 \mathrm{pm}$. we left the house, carrying one torch which about 5 people used as we stumped down the steps to Bhuwansing's house level. There was a cluster of people on the verandah, to the right of the main door, opposite Dankumari's room, there the doors were closed. There was a square of people around a chalk-sprinkled diagram, reminiscent of the ones drawn by the Brahmins, only less complex and overlaid. A brass pot, with a pile of chalk lay beside one of the uprights of the verandah, and it seemed to have been quite recently drawn. Sitting on the verandah itself on two 'gundri' were Bhuwansing and a young Untouchable (Tulmae), cross-legged, earnest and somewhat strained. These two sat on the same 'gundri' next to each other and faced another Untouchable on the other side of the chalk rectangle, also sitting cross-legged on a 'gundri', holding an open-ended drum, which he 
started beating with a drumstick, attached to the instrument by a cord, soon after we came up.

Behind the drummer were Gurungs and Untouchables mixed up, sitting, knees up against the wall, or standing, hanging onto the verandah supports, about 4 deep on the actual verandah. On the other side of the rectangle, standing in the courtyard itself, and looking in onto the verandah were youths, small boys and two old men, gnarled and good-tempered, who sit on the Panchayat, and form some of the revered older section of the community. Crouched against another of the supports was an equally old Untouchable, very near to the younger one who was about to be put in touch with the gods. Leaning close to him, at one point his arms entwined round the old man's knees, was an adolescent boy, well-dressed, wearing a brightly coloured 'pule'. The whole scene was lit by a kerosene lamp, which was in sharp contrast to the darkness beyond.

Bhuwansing welcomes us in his usual polite way (when Alan asked who the drummer was, Bhuwansing replied, "My neighbour"), got up from his place and went to open Dankumari's bedroom door, and fetched two synthetic chairs which he brought back from Malaya, placed these in the doorway, so that we were a little to the right of the rectangle, and the drummer straight in front of us and, when we leant forward could see the boy in the process of being influenced. As Bhuwansing was settling himself back into his place the drummer started beating, single notes to begin with. He chanted at the same time in a hard, strident way, with sharp intakes of breath at the end of each phrase. He held the drum rigidly in front of him with his left hand, and when the beat quickened or changed and his chant became even more insistent and hard pitched, the muscles of the left arm tightened considerably, his whole body becoming clenched and hardened in the process. He wore shorts, a shirt and two strings of brown beads, which he would push to one side from time to time when then rattled together; the beads were crossways across his chest. Next to him was a bag with various sticks and bowls in it. He was a small man, nut brown, much darker in complexion than the Gurungs and we think is used as a general factotum, as the following day we saw him walking round the village, delivering letters.

The boy who was being influenced wore nothing special, was much younger than the other man and seemed to be in a state of considerable tension and anxiety. He relaxed somewhat after each seizure, which used up a considerable amount of energy; he asked for water three times, and drank three large tumblerfuls, his hand shook as he took the cup, and he was panting and perspiring generally. The two protagonists were linked by their eyes staring fixedly at each other, the younger man sometimes flinching and looking down, when he did not seem able to respond to the drum call. Intense feeling seemed to be generated between the two and I wondered what their relationship was; the wish of the drummer to draw out a reaction from the younger was most powerful, and all his energies were concentrated into this. The emotional sparks thus generated were powerful, and this was reflected in the audience who were quiet and uneasy, shifting about quite a lot, and staring with something like amazement and horror at the younger man when he became physically possessed. The younger boys were especially agitated, and one child (Totra) began to cry at one particularly intense point. The drum beat was hard rather than muffled, and drove the sound into one's temples which exacerbated one's emotions.

Very soon after we arrived the younger man was taken over physically; his hands are clasped in front of him tightly together, so that the knuckles show white, and these shake first, and then the whole of the upper body is seized, the head rolling backwards and forwards, the man appearing as if something is writhing with agony inside him; he made no sound this first time. The seizure lasted for at least one and a half minutes. The drummer quickened up his beat as if to extend the length of time, but the man gradually subsided, shaking and panting and barely able to ask for water; he gestured this rather. After a short pause the drummer starts up 
again, but can elicit no response from the younger man; the latter is quiet and strained, sitting in the same position. The drummer gets impatient, repeats 'sol!' several times, as if in command, he starts up a double rhythm, and chirrups encouragement, like a rider urging a horse into a gallop. He then spits, "sh,sh" at him across the rectangle, but with no success; the older man by the younger boy sings something verbally together with the drum, and also seems to be encouraging possession. The boy takes a second drink, is fully in control and conscious.

The audience around these antagonisms are quiet and thoughtful; they too are uneasy that he does not respond. After this gap however, the boy does start up again, this time moaning, and it seems to be more of a physical effort. An adolescent leaning against the old Untouchable who had previously acted as an intermediator between the drummer and the possessed, seemed to be in great distress that he too began to shake, clutching on to the older man's leg, and burying his face into his shoulder; he seemed to be sobbing at one point. It seems to be his lack of control that is frightening him, and the fact that he too is being taken over, when strictly he is out of the main area of influence. Now the audience begin asking questions, mainly one old Gurung who is quite calm and puts the questions succinctly. The questions are asked of the drummer, and there seems to be some doubt as to whether the goat can understand Gurung, and whether the questions should be put to him in Nepali. There is a bit of amused laughter at this point, but subdued. The boy takes another sip of water, and flicks away a moth which is circulating round his hands, attracted by the light. The drummer has stopped drumming and is conversing at length with the audience. There is a general asking of questions; women can be heard for the first time; they are clustered in the background, well away from the main circle which consists entirely of men and boys; male Gurungs and Untouchables seem to have become even more mixed up. Only one woman asks a question (I think Bhuwansing's wife) and the rest chatter occasionally amongst themselves, and sometimes giggle to relieve the tension.

After his short discussion with the audience, the drummer starts again, this time chanting in Nepali, the chant seems to be more wailing and long drawn out; 'babu' is heard distinctly. The drummer gradually get himself into more and more of a tense state, apparently angered that the opposing boy does not respond; the latter takes more water and shakes briefly for a space with some incoherent wailing. When he has subsided the drummer has not, as if there was a mistiming of climax, and rattles the drum even more sharply, drawing it suddenly in front of him with a sharp cry, then putting it down, and suddenly, so that it is a shock to all, springing across the gap between himself and the boy, so that he lands on all fours and takes up an aggressive animal position; the boy neither retreats or flinches, but stays staring straight ahead, above the drummer's head, even when the latter sniffs at him systematically, from the shoulders down to the waist. This lasts for more than a minute; the drummer's eyes are closed and he is absolutely concentrated on sniffing out the boy, who still remains unmoving. There is some worried laughter at this point. One man in the audience moves a silver plate from the rectangle which he would have hit when he returned to his sitting position, which he does after 2 minutes, eyes still closed.

He takes hold of the drum by the rim and hits his shoulders with it, and holds it clenched against the clay floor, beating it this way with such concentration that one might have expected the drum to break under such pressure. His whole body is rigid and trembling, and he begins to speak, at which the old men in the audience look eager, concentrate even more and eventually begin to ask questions. They seem to find it difficult to make out the man's stream of monosyllables, which come in a recurring pattern in a sharp, staccato way. He still bangs with the rim of the drum against the floor; his eyes are tightly closed. Alan deciphered such words as phrases as 'taro', 'yesai', 'parago', 'dolua', 'dareira', 'bir', 'masanko' ('masan' place of burial?). Drummer sometimes now opens his eyes. There are more questions from 
the audience, especially from old man (with bad eye). (Following day latter said he had been asking about a 20 year old woman who was sick, but the answers had been elusive?). The younger boy is still absolutely still and the audience are silent and very attentive, hardly moving their eyes from the drummer's face. The latter goes through the same list of chanted words before he answers a question. Finally he stops chanting suddenly, takes up the drum and taps himself lightly four times on the shoulders, as if to break a spell. Immediately he seems normal, is relaxed and cheerful and takes up a chatty, amused communication with the audience, in which he seems to be elaborating on what he had said in his trance, speaking broadly with wide gestures. There is quite a lot of laughter amongst the audience and people begin to drift away, the younger men especially; the two old Gurungs stay. The youngest Tulmae looks relieved but is still attached to the old Untouchable.

[fig.] The chalk sprinkled diagram was a rectangle, with a double edge and an outlet at one side. Apart from the four signs in the corners (fire, sun, moon, water?) there were four brass(?) outside (all similar), with overlaid triangles in the middle. In the centre was one small silver dish with a drop of cooked rice on it; one effigy type figure made of pieces of cotton rags, with a cluster at the head where three prongs were protruding; the figure seemed to be carrying an iron spear, the whole was about $9 "$ high. One large brass plate with rice, one rupee note, brass bell, black polished twisted horn, brass egg cup and several sticks of wood difficult to distinguish. The drum of the Tulmae had a half rubbed-out swastika sign.

Following evening we heard it was on again as last night's had been unsuccessful - the ill person had not recovered (employee of Bhuwansing's? Kalo Kami). In fact they didn't seem to do it again.

\section{DIARY Wednesday 12th March Alan}

Had to get up in middle of last night to go up mountain as Gill had diarrhoea. Felt a mixture of foolishness and exasperation. As we had just been to a spirit possession previously, felt slightly tired this morning and hence especially irritable that Prasad didn't come. My vegetables a failure except for beans (French Dwarf) and mustard. One of our problems disposal of tins - no facilities since they don't have them, otherwise 3 visits up to Kumansing who is obviously very worried about his son.

\section{NOTES 12.3.1969 Alan - Wooden bowl making}

('porkundina') 3 men making wooden vessels in space next to Bhuwansing's house. Two worked the "lathe" sitting on the ground and pulling back on leather strap in turn, their feet resting on a piece of wood. This revolved a wooden contraption at the end of which was a block of wood which was shaped by a third man (a Konme (kami?) from another village Talakoto) who obviously travelled round doing this. The two who provided the power were Maldosing (paid 3rs per day) and the man who would get the bowl (who also provided the wood). The carver was paid 5rs (a day?). The cutting was done by a curved metal instrument (of which he had 2 or 3 ) when the wood was revolving away from him. The necessary weight was provided by pressing down on the cutting instrument with a wooden bar, on which the carver sat. The name of the wood from which the big bowl was cut was 'kalago'; the better wood used for smaller bowls was 'dara'. We were told that we couldn't have one made unless we brought our own wood. (For sketch see original file).12.3.1969Alan 
Gill's tummy upset continues and Prasad did not come again so felt a bit depressed. Relieved a bit by watching wooden pot making and finding the poju grinding herbs for a 'puja'. Have got part of his genealogy. A noisy evening in which a little mouse kept interrupting our supper and "baby brother" suddenly turned up with a wobbly table, producing it as if it were a Christmas present. In the night had a long talk about why we longed to go home. Difficult to decide why we continue to be so homesick.

\section{DIARY Friday 14th March Alan}

Spent the day writing letters since we hope to prepare census in the next few days before going to Pokhara. As always this made us especially homesick. Yesterday wrote a summary of projected field research for Tribuvan. This afternoon suggested to Comal that he kept a register of what he and family did: illness: dreams. My garden a disappointment - only beans, melons and mustard coming up. Ants are a growing menace, infesting the frying pan, the biscuits, etc. Reading Eisenstadt but finding him extremely jargonistic, trendy and far from profound so far. Gill enjoying "From Max Weber" immensely.

\section{DIARY Saturday 15th March Alan}

Overcast today, with a shower this afternoon. Finished writing letters, etc. Went for a wander round the village and discovered Chuckly Gran having a lama who was ringing bells, etc. etc. We were given tea with honey in it, etc. Two requests for loans today - one for purchasing cigarettes, one in advance on a chicken. Re-read "Elegy to John Donne" on hillside. Felt busier and happier and the longings for home only occasional. The village seems obsessed with illness at the moment.

\section{TAPE RECORDING}

'Tasu waba'

Lama reading mantra at House29. (Illustrates lack of attention during ceremony). https://sms.cam.ac.uk/media/2733214

NOTES 15.3.1969 Alan - Cleansing ritual

'Tasu waba'(at "Chuckly Granny's" house). All afternoon we had heard a bell ringing in Baikumari's house and were told that there was a 'Tasu waba' conducted by a Lama. When we went up at about 5 p.m. we found the very affable Lama sitting in front of a large winnowing basket which had a pile of millet on it and there were one or two other jars etc. round. He was tinkling a little brass or copper bell and singing from a parchment sheet, occasionally sprinkling etc. Seemed quite happy to stop and chat to us. He was apparently a Gurung from Taprang. His style was very like Brahmin's except he sang. The central feature of winnowing bowl was a plate with 12 small (about one inch high) and one larger (about two inches) figures made of millet flour (brown). These were the 'Bara lho' (12 'lho') and were shaped thus [see diagram on original card]. While he conducted ritual, which was apparently to clear away illness, ordinary activities continued - people talking etc. The Lama gets out his glasses to read text. He is apparently not paid but given the pile of millet (about 3lb) and a little rice (cf tape recording). At the end the Lama cleaned all the plates etc. then set his little figures across the millet in a line, standing. When I next looked they were all lying on their front. He then asked of Baikumari if they were 'chaba' and she said "yes" (he had made them).Baikumari and her husband then washed their hands at entrance to room. All the 
leaves, sticks and little figures were then piled at the entrance and a coal brought, with which the Lama crushed the largest one and one or two of those under it. The whole pile was then taken out onto the doorstep (outside the verandah). There the husband, then wife wash their feet and then sprinkle hair, letting the water fall over the pile of leaves and little figures. This was the only point at which they seemed to be really earnest and group of children etc. were quiet. Then the pile of "rubbish" was taken to the path near the house and left there. Dogs eat up the little millet figures. The practitioner, name Tsumruh, aged 62 was then given a cup of tea (as we were - made with honey). He had a bead (brown) necklace ('mala') and on it a small cross about an inch long, of gold ('torje'). He also had a ring with a green stone on his finger ('chyar') but otherwise dressed ordinarily.

\section{Letter from Gill to Mac and Iris on 15 March 1969}

My dear Both, I felt I had to write, as well as A., to thank Iris for an absolutely marvellous letter re. teh wedding... Alan seems to have painted a somewhat dismal picture of me, health-wise, but my tummy is just about cleared up and it was almost worth it to be slightly under the weather, as he was so sweet and considerate, and I had other little treats all over the place too! Like honey on my scones every morning, and rather bilious looking orange tables in my water instead of pale mauve idodine. However, you are quite right, the joys of primitive living evaporate as soon as you are not compOletely fit enough to enjoy them, and that slight ache of homesickness, which A spoke about, comes to the fore and one really has quite a spiritual battle against $i t$. Things that one could normally cope with quite cheerfully, like flies and ants, and not being able to see anything you are doing at $6.30 \mathrm{pm}$. get ridiculously on top of one, and the people cease being sweet and vague and kind and become Goofy, hopelessly impractical (we laughed hollowly at that section of your letter) and much more numerous. This feeling of being two alone, alienated in the village, and cut off from any real communication because of the fumbling stage of our language, shoots up one's paranoid level and I can see myself interpreting actions negatively without any real foundation for my doing so. It this very strong tendency of disliking others because you don't happen to like yourself very much at that point, and everything becomes topsy turvy. I could very easily see how this kind of withdrawal and projection would finally lead to silence outside one and madness inside. It is a most valuable experience as far as my social work goes and $A$ is endlessly constructive in talking over these feelings; the most comforting thing of all, however, is that he feels this way too, occasionally and this of course reduces one's guilt immediately, as I still feel that the place is so beautiful, it is a unique experience, intellectually and emotionally most stimulating, and that one should be merely grateful for being here.

One is ultimately always saved by the environment however; a particularly beautiful butterfly (there is a leaf green variety fluttering about at the moment, with brilliant orange inner wings) or a scarlet bird with a coal black head; the flight of birds of prey as big as eagles and observation of the villagers making things all seem whole experiences and put ones pieces back together again. Yesterday, for instance, we heard a grinding hum two layers below us and tottered down the steps in 80' of heat, to find a visiting carpenter making huge wooden urns, turned on a kind of human lathe (two other men from our village were hired to work it); he was just finishing turning one, and the wood was pale yellow with lovely dark brown zig-zag markings, and when one put one's hand inside there seemed to be a smooth coolness of another world, of wood just out from the tree and still living and waiting for good things to be poured into it; this was a whole experience in itself.

There are the endlessly funny things too - one especially favourite neighbour, Nansubar, tall and gawky and gapetoothed who strides around the village like a sailor round his ship, heaving at the bony rear of an ox, trying to push it up the path; the arrival of a drunkenly rickety table with legs as thin as splints and as many nails as planks of wood, pushed shyly onto our verandah in the dead of night, its maker sitting on tenderhooks in the house waiting until all our visitors had gone until he, with silent excitement, pointed out he had finished it, and There it Was. We hardly dared lift it in, we thought it would collapse at the slightest ginger touch and our little carpenter would be demoralized for life. However it now leans with wobbly determination carrying three shoe boxes and some name index cards in our loft and a firm relationship is established with teh carpenter for ever. There is also one of our favourite Grannys (we call her the Chuckly Granny as she is always cackling at us 
affectionately as we sweat up the hill to the loo) who keeps reprimanding Alan with mock, loud sternness for not giving me babies, and who peers down the top of my jeans as well, with half the women present, reprimanding me for not having any and making broad obscene gestures to make sure I get the point! As a people they are most affectionate and sudden little presents of flowers or washed eggs can resurrect one's jaundiced spirit in a minute.

The bad moments are scarce, and do not come at all when we are well. We have also had one fascinating spirit possession session and a rather grisly bloody ritual, where A had to disappear behind the wall when they decapitated a buffalo, goat etc. I had to stick the thing out as I was taking the notes at the time! So, the actual work remains always fascinating and I am enjoying my reading enormously at the moment - Weber is a delight and has a superb style, and I have now got onto Kafka in the novel line, who is extraordinary.

We are already looking forward to going to Pokhara next Wednesday (19thy) for letters etc and hope you will both be back into our idyllic croft routine somewhat enlarged by the house.... All my love, Gill

\section{DIARY Sunday 16th March Alan}

Gill completely recovered from her tummy upset. Spent most of the day ruling out forms and devising questionnaire for the village census. We discovered however, that the day on which we hoped to hold it (Tuesday) there would be a large sacrifice at Bhuwansing's in the evening and in the morning the village would be trekking to the forest to sacrifice a sheep. As Prasad hasn't been for a week (off with a headache he said) to check census we would have had to delay it anyhow. The previous night an electric storm and a lot of wind and rushing. Today temperature dropped to about 55, overcast, quite a few showers and strong, gusty wind. People went around huddled in cloths.

\section{DIARY Monday 17th March Alan}

Warm again and we spent a very welcome, relaxed day at the river, washing etc. Enjoying Eisenstadt more on age groupings. Some letters arrived in evening brought by Nansubar.

\section{DIARY Tuesday 18th March Alan}

Bhuwansing's house - a 'di bar puja lava' ie. making the house fast against witches and other evil spirits. The whole took place during a rainy day, and in the evening the slaying of the cock, goat, etc. (q.v.) were most sinister against the lightning and thunder 

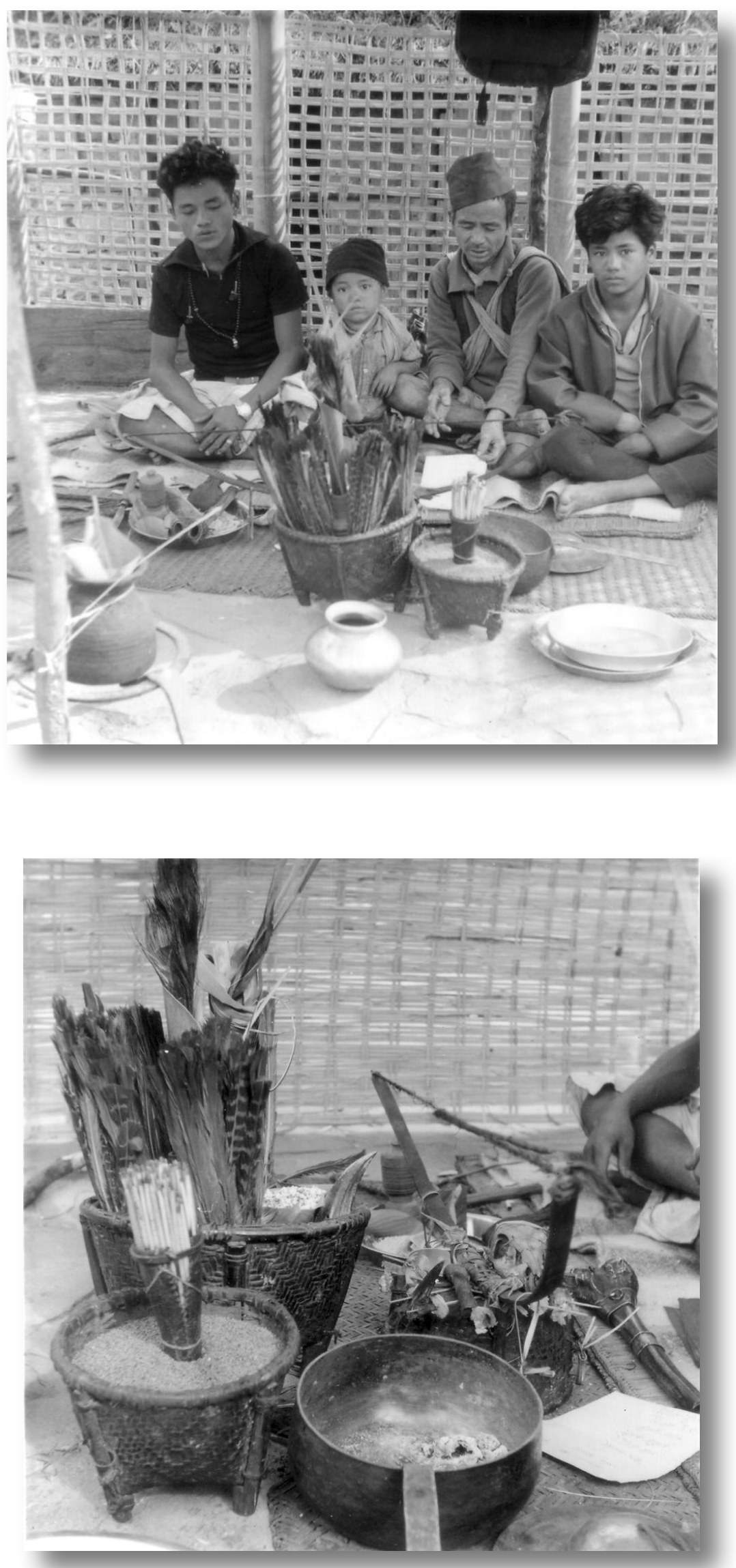


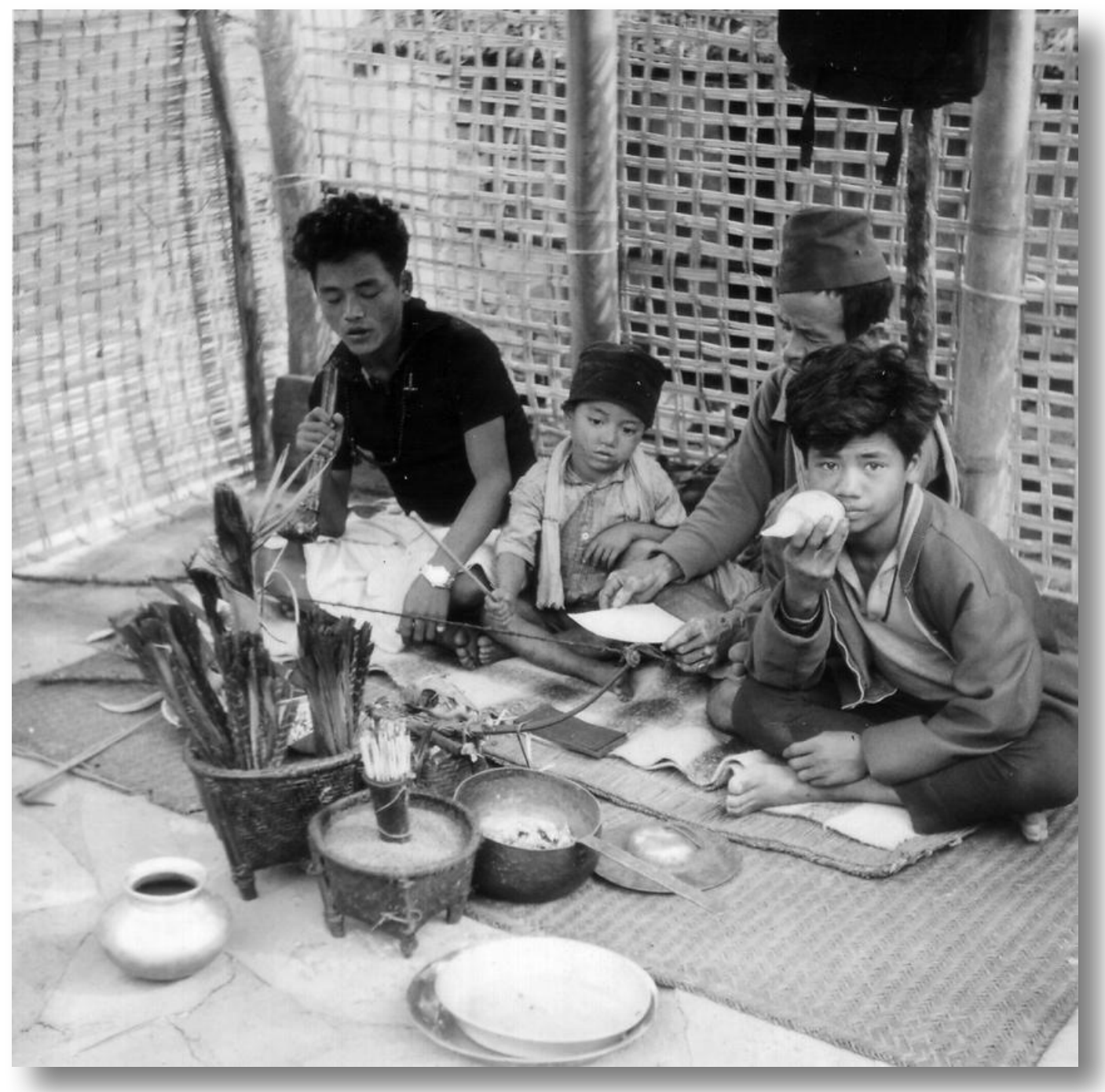

Prem, Bopal, Ujesing and Kaila performing the 'di bar lava'

\section{TAPE RECORDING}

Di bar lava at Bhuwansing's house

https://sms.cam.ac.uk/media/2733231

NOTES 18.3.1969 Alan - Di Bar Lava (house protection ritual)

'Di Bar Lava 'Took place at Bhuwansing's house [House24]. According to the Lt. it was to guard the house against "ghosts"; according to Totra's father it was to guard against 'bhuts, baramashi, prets, boshi'. The proceedings started at about 9am. when the poju and the family went to the Lt.'s house, and ended at about $7 \mathrm{pm}$. There are apparently only 4 or 5 of these per annum, but there was some dispute about it. They usually occur on Tuesdays in Tsaita, but sometimes in Sauwe also. A tent was erected in front of Bhuwansing's house, made of rice mats. [Sketch plan: Poju in middle, Budi on his right, Bol. on his left. In front of him and overturned basket on which an upturned bow ('tale') rests and on which are the head of a bird (bird of prey - long dead); a 'populo' (leg of deer); little splits with onion, garlic and a bit if omelette on them. Beyond that basket, a larger basket of millet with feathers in tufts planted in 'nari' (outside = 'maya pya' (feathers?) in centre a tuft of peacock feathers ('mojura pya'). 
From the poju's view, to right of this basket, a flat plate with rice on, a 5rs. note, a large bird of prey's head, pouch of medicine, scroll. Beyond that, a bowl of cinders. To the left of the central basket, a curved knife ('ashi') beyond which, a green plastic bowl with millet, 1rs. note, some quills in a sheaf (for killing 'boshimae'). Beyond the larger basket, a small firestand ('jongo'). The tent shape about 6' deep, 12' across, and 4' high in middle].

Inside the tent, Prem, his father, Bolbahadur and Budi recited throughout the day. Bolbahadur acted as general factotum, making garlands, etc. and did all the fetching and carrying. In the morning about half a dozen children sat round and watched, while the poju chanted in Gurung, intermittently striking the string of the bow in front of him with a bamboo wand. A list of all the members of the household, written on a piece of paper, was often consulted, and the names read out. Among the items in front of the poju was a bowl of quills which looked as though they were arrows for the bow. These were called 'dhoshi mro' and were, I was told, to kill the witches. The recitation was, as usual, informal - Bolbahadur holding a baby in his arms whilst he recited and the others smoking, etc. After a while, Prem took over from the poju and Bopal hit the bow. (Nansubar said the poju would be paid 5rs. and the others given free food and 1rs. each. Budi said Prem got 3rs. and Bol. got 1rs. The goat would cost $30 \mathrm{rs}$. and the cock 10rs.

We returned at about 5.30pm. to find the poju and Budi still chanting and Prem telling beads. The poju was wearing a special hat with little animals on it. Bhuwansing's family seemed to have just finished eating. There were about 15 people outside the house, and more inside. The poju and co. now have a rest and then start chanting. Just before we came back Maldo and medical gent came dripping found the houses (it was pouring with rain) with chips of wood which they put in the rafters of the verandah above our door to 'di bar lava'. When we came down again to the tent we found a wooden construction about 2' 6 " high in the shape of hoop with 8 bars across (sketch). This is called a 'modi', and was the frame on which the cock was tied. 5.30pm. chanting begins again; all 4 sing from within tent. The regular beating of the bow is heard. The entrance to the tent is crowded over and you cannot see inside from the verandah - one feels as if sacred things are going on which one must not interrupt, and look for curiosity's sake into the tent. The chant is in Gurung. Prem seems to read from an exercise book and goes through a list of illnesses. We note there have been white lily-like flowers stuck in Bhuwansing's roof, as well as the chips of wood.

The lightning flashed along the top of the hills, and the rain drips from the verandah; the goat to be slaughtered bleats in a corner of it. They get Bhuwansing's gun and he asks

Gunjabahadur (2nd. schoolmaster) if he can fire one - usual ad hoc arrangement. Gunja agrees. He sits on the far side of the verandah to the left of the tent, pointing the gun out into the wet night. The legs of the cock are washed; the goat is lead forward with a rope round its neck. String is tied onto the top of the frame. Three ploughs are put a little to the left of the tent and a bit of live coal is put in the middle of them. The cock, still alive has its feet tied to two rungs on the frame. It struggles. We were warned to move as everything happened at once and the egg intended for the cock might miss and hit us... there was a crowd of people in the house doorway and to the right of the verandah. Bhuwansing had organized the kerosene lamp so everything was very clear. People were excited.

When the chicken started flapping again, after a rest, (possessed we were later told by an evil spirit) the poju threw the egg at it then Bol. leapt towards it, cut off its head, smashed the frame and meanwhile the goat was slaughtered on the three ploughs, and the gun went off. Then the animals heads were put in front of the bow which was now on its side. Poju and Prem broke into a wild chant with cymbals and drums (hear tape). It was a bloody scene in the rain, the blood glistening in the wet darkness. People surge out of the house, laughing and talking. About 40 people were watching the cymbal and drum playing; these 40 consisting of family or nearby neighbours. The cymbal ended with a dramatic flourish after about 10 
minutes. Baby brother cut up the goat; the poju then dismantled the bow and tied it to the arrows. The liver was cut out of the goat with care; the bow and arrow and one piece of the frame put above the lintel of the door, and the basket on which the bow rested was taken into the house. Prem put three nails into each plough; the liver was brought into the house being examined on the way to see how "good" it was. Bol. and Budi went off with some sand and water which they were to sprinkle over the fields and houses. Small nails were taken into the house and then knocked into the threshold. Bhuwansing's wife asked nervously whether they would put sand etc. upstairs, but they laughed and said no.

They knock one plough into a hole near the verandah step, put another by the entrance to the courtyard, and a third at the other end, Bol. doing as the Lt. directs. One nail is put at every window upstairs (nail = 'karua'). Half the audience have gone, a few faithfuls left. Four bits of wood, each about 2" long are knocked into the earth in front of the door, one in front of each window on the verandah - 'bar taba'. Two staples are stuck in the threshold crossing each other at right angles, and also in the windows. One of the astrological woodcuts ('parga') is stuck on the door. These are made by the poju.

We then talked to Prasad, who says that this ceremony is to save people from evil things, such as 'nari, dungai, mashi': apparently the poju made a 'shya lava' (blessing) at the same moment as he threw the egg. He said that "something invisible" came to the cock and made it quiver and then the egg is thrown which drives the spirit infesting the cock away. When we asked if this would happen in other houses, and pointed out that bits of wood had been taken round to other houses, Prasad still maintained that it would only be of use to this particular house. The wood is called 'chyambo' and is put on the 4 sides of the house, and on the roof. Iron and wood prevent the invasion of bad spirits. Only when bad spirits are especially active is it done. This house is build next to a 'bhuts' home ('garibari holdon' - in the stream?). This makes it dangerous to walk alone at night. The whole village sometimes undertakes such a rite when there is a lot of disease. The last of these 'tale (bow) piba/rava' occurred about 10 years ago. Every family does this once a year (though Prasad has not had one - and Nansubar says she hasn't).

\section{DIARY Wednesday 19th to Tuesday 25th March Alan - Pokhara}

Went down to Pokhara for a two-day expedition, calling in on British Hospital, library, etc. But, after successful shopping and a lot of letters, on the Thursday evening I fainted in front of the new "Mogambo" restaurant. I was scarcely able to move for two days with 'flu and dysentery - rushing to the toilet 3-4 times per night. But Gill was fortunate in having the newly opened "Mogambo" restaurant nearby and as I improved we read a lot - Morris "Winter in Nepal"; Woodhouse "Plum Pie"; Kipling "Jungle Stories" and went for two picnics to the delightful lake. There was a lot of lightning and thunder and heavy rain at night. Finally returned with 2 porters on Tuesday 25th. Nice to be back and everyone was very kind.

ALAN Letter 19.3.1969 to parents

\section{Dear Mummy and Daddy,}

....For some reason we are still both homesick-you will know the feeling well, the constant dull ache inside one, often forgotten in moments of keen activity, but mounting when one wakes in the morning, or gets letters from home.... We still don't know the language well enough to feel we can communicate here and this may add to be longing to be home.....

.... Gill is still not terribly well - she has had mild diarrhoea for about a week which involves several visits up the hillside during the day, but only one midnight expedition through the bracken and thistles. She is also 
slightly coldy and has a dry cough. I am very well physically. When we go to Pokhara to post this letter she will be thoroughly examined. Giving her a few Entero-vioform and Furamide as the symptoms approach amoebic dysentery more than bacillary (though probably just a tummy upset). Since an open drain runs from the well nearby and the hill just south of the village is scattered with faeces, it is not surprising that many people are ill in the village. It would take a couple of men only a few days to dig a communal pit latrine and pave over the drain, but this does not seem likely for some time, despite the government of Nepal's directive that each house should build a latrine (quite impracticable given the shape of Gurung houses, lack of gardens, absence of drains, etc.)

Your suggestions about hiring servants, buying rubber mattresses, etc. set us thinking, but so far all we have acquired is an extremely rickety table and another delightful bamboo stool. Actually we omitted to mention that we already have a small kerosene stove on which we cook breakfast and lunch. Having a fire in the evening with a temperature of over 600 (in the day it is now c.75o in the shade) is hot work, but cosy. We are more or less used to sleeping on the floor (on our three eiderdowns) and I don't think Pokhara would rise to inflatable mattresses. As for a servant, yes this might be an idea and we had definitely decided to have one before we came. But our needs are very small - just a five minute sweep round, two buckets of water and a bit of washing up. He would be employed for one hour a day, apart from visits to Pokhara. The rest of the time would be hanging around, which seems rather a waste. I am hoping, however, to organize one of the schoolmasters into posting and collecting letters at Pokhara, which should meant that I only have to go down once a month. But we also find we have to buy fresh vegetables and fruit there since the village produces nothing in this line (or almost nothing). . Talking of photographs: I will sent only one more reel by registered post of colour photographs. Then, in the month before we return to England will take dozens of black and white and colour, if possible, and will bring those with us .

I have discovered that there are, supposedly, a number of historical records relating to this village in the dusty archives in Pokhara - records relating to the school, to land, to taxation and, I hope, lists of electors and their families for a number of years. All these should help to narrow the gap between here and Kirkby Lonsdale. In the very detailed census which we hope to start next week I also intend to ask as many questions as possible about the past - especially previous mortality and fertility trends. Very fortunately, the villagers have a twelveyear time cycle with names, so that they can usually tell to the nearest year how old they are, etc. All this will, I hope, be able to make it possible to study something about how the village has changed. It is very easy to see, however, how most anthropological studies have such a timeless quality about them, speaking about "tradition", things being "handed down from the grandfathers", etc. Unless one makes a real effort, being caught up in the highly repetitive and ritualistic way of life here makes one feel that things have always been thus. The fact that the villagers are very vague about the past - not knowing how long the village, their house, their ancestors, etc. have been here, makes it even more difficult to get a feeling of change. Yet I am pretty sure that the situation has been and is changing rapidly - that the village has doubled in size in the last 40 years, and was probably only founded about 150 years ago at the earliest. They are also extremely vague about relatives and kinship - in contrast to the normal societies that anthropologists seem to have studied where the informants were obsessed by kinship, here people find it difficult to name even their closest relatives - hardly going beyond parents and siblings - eg. often not knowing anything about aunts and uncles etc., not even their name.

Another thing which you may find slightly contrary to your image (based on Richard etc.'s account) is that the Gurungs, far from being stern, practical, war-like people are rather vague, docile, gentle and highly impractical people. They find it almost impossible to run a kerosene lamp, construct for us incredibly wobbly tables, are very difficult to organize into doing anything, are hopeless butchers, spend hours standing around discussing before they do the simplest thing. All religious rituals, for example, are extremely ad hoc and ill-organized affairs; but then, there is always plenty of time to do things. The women are sometimes fairly Amazonian, shrieking at each other by the well, or cackling heartily away, but the men are, for the most part, gentle, almost timid, eager to please, tolerant, almost soft. One can see how they would be very loyal and mingle in very easily with British officers; they spend all their time in groups and would like the groupy life of the army.

Work here still consists mainly of learning the language, translating Pignede, noting random things that go on. Many of the most interesting things only emerge by sheer chance when one happens, by accident, to brush against some belief. I mentioned that we were warned not to whistle at night because this would attract the 
witches; last night I was warned not to throw our chewed chicken bones etc. onto the fire as this would anger the god who dwelt there. We had not, of course, known that there was a god there at all. It then emerged that he (or she - they seemed unable to name "it") was offered a little bit of rice and vegetables before the morning and evening meals each day in every family. Only the day before I had been told, half-jokingly, not to lick the spoon on which the rice was served since it would lead to a wet wedding for me. Thus we slowly grope our way around the culture, stumbling across hidden boulders we had never suspected: it all confirms what one knew already, that one only really finds out what one already half knew was there. This is, of course, the central justification for living in a pre-industrial society before studying C17 England. It provides, to use the jargon, a "model" against which one can test the English material. Do you think the inhabitants of Kirkby Lonsdale had a god in their hearths?? Or a system of out-marrying clans, or sacrificed animals, or believed in evil spirits who lived near waterfalls, or tramped miles with bundles of wood, or suffered from endless tummy upsets and cut, bruises, splinters, sores etc. which hardly healed because of malnutrition?' And what about sanitation, and malnutrition and the rearing of infants etc. Another interesting comparison will be between the resources - in furniture, buildings, land, livestock, etc. in the two communities. I am already taking inventories which should be comparable to your probate inventories .

I hope that by now you will have got the letter we sent a week ago (19th March). I suppose this depends on many factors as well as the Nepal P.O. I am (like you in your letter of March 6th which we were delighted to pick up - by chance - at the British Hospital!') writing an in-between letter for a couple of reasons. Shortly after arriving in Pokhara I went down with an attack of 'flu combined with a bit of dysentery - they both lasted only 3 days under the assault of some 40 pills a day, but made us delay our stay here. Actually, after 3 months in the village, it is probably not a bad idea to get away for a week. We return to the village tomorrow with enough supplies for a couple of months (at which date mid/end May we will go to Kathmandu) and so I will probably only be down once, in about a month's time. We will ask one of the villagers who come down to post letters $\mathbb{E}^{\circ}$ collect letters for us - but the dates of such visits may be a little erratic so am writing now to make sure you get something soon. Apart from the bout of illness, the stay in Pokhara has been nice. Climate cool and very like overcast days in the Lakes in autumn: there is also a lake nearby, apparently full of fish, very like Ullswater in its setting and we are going to picnic there today. Gill's (and my) enjoyment have also been considerably increased by the recent opening of an inexpensive and extremely good restaurant by the airport where, as the first customers, we are given free gins, bananas, and eager service. Almost loath to return to the village, though I am eager to get on with the census up there which has been unduly delayed.

\section{Handwritten letter from Alan to his parents, 25 March 1969}

\section{Dear $M$ \& $D$.,}

I hope that by now you will have got the letter we sent a week ago (19th March). ... I am writing an inbetween letter for a couple of reasons. Shortly after arriving in Pokhara I went down with an attack of 'flu combined with a bit of dysentery - they both lasted only 3 days under the assault of some 40 pills a day, but made us delay our stay here. Actually, after 3 months in the village, it is probably not a bad idea to get away for a week. We return to the village tomorrow with enough supplies for a couple of months (at which datemid/end May we will go to Kathmandu) and so I will probably only be down once, in about a month's time. We will ask any of the villagers who come down to post letter/collect letters for us - but the dates of such visitors may be a little erratic so am writing now to make sure you get something soon.

Apart from the bout of illness, the stay in Pokhara has been nice. Climate cool Eं very like overcast days in the Lakes in autumn: there is also a lake nearby, apparently full of fish, very like Ullswater in its setting and we are going to picnic there today. Till's (and my) enjoyment have also been considerably increased by the recent opening of an inexpensive and extremely good restaurant by the airport where, as the first customers, we are given free gins, bananas, and eager service. Almost loath to return to the village, though I am eager to get on with teh Census up there which has been unduly delayed.

Thank you for your efforts with Fosselin... We assume Field Head will soon be up for sale. Let us know as soon as it is, as we already making plans to buy a large house near Kirby Lonsdale or Stirling and I spent 
yesterday in bed designing my perfect study - probably located in the grain loft at Middleton Hall! ... Very best love, as always, Alan \& Gill

\section{Letter to grandparents on 25 March 1969}

(Alan) .... We were sad to hear definitely re Field Head, but quite understand the motives for leaving. With Goodlands/Wooddalls/Beryls pressing in, it was no longer the free place of our youth. Our plans for when we return are still unfixed. Will depend a bit on whether any money comes from my two books which, you will have heard from Mummy, are progressing at the publishers... The work becomes ever more fascinating as our grasp of the language improves....

(letter from Gill) ...

Now that Alan is better we are both enjoying this break as the weather is hotting up again $\mathcal{E}$ there are magnificent views of teh Annapurna Range. which rises up like a white E glittering backdrop out of the Pokhara plain. We are living in a gay little Tibetan hotel facing the 'airport' (one dusty strip edged with white boulders, where the buffalo have to be herded off before the planes can go as well as the pilots dug out of the local shops where they are immersed in beer!). We are seeing something of Europeans, as tourists come in once a day from Kathmandu - so we can catch upon some of the international news, where we are about 6 weeks behind! However I am looking forward to going back to the peace of th village tomorrow.

\subsubsection{Letter to Caplans}

Very many thanks for your letter of 1st March which we picked up from Pokhara post office on 23rd. It was kind of you to let us know about the Nepal Research Centre. I have written to Haimendorf about this, though I don't know if arrangements will be made in time. Anyhow, we will call in there when we go to Kathmandu to see if you are around. It is now almost certain that we will be going to Kathmandu about 15th May and staying for four or five days, (depending on visas, inoculations, etc.) and then will return to Pokhara where we will stay until 24 th May. I do hope that we will overlap with you. As I think I may have mentioned, we will call in at the British Embassy to leave you a note, and to see if you have arrived, when we are there.

Nice to hear about your field-work. It sounds very familiar - especially the bit about spending 50 percent of your time dishing our Aspirins and cough medicine. Immensely depressed by the reproduction statistics especially in comparison to those here which are very low indeed, at least among the Gurungs (the Blacksmiths etc. are much higher). The survival rate seems similar, however - it is pretty good here too. Fust in the middle of carrying out a detailed census so can't back up my impressions with statistics as yet. As to what we are studying. It is the usual "village study" - to provide a sound basis in general anthropological methods - with an emphasis on demography and social change. Since the Gurungs are very knowledgeable about their ages it is possible to get a more than usually accurate picture of mortality etc.

Also, it appears that there are good land records going back for twenty or more years and this, combined with a most detailed land survey carried out by the government some five years ago should allow me to use my historical methods a bit and do a 'Pul Eliya' over time. All fairly staid stuff, but it will provide me with a valuable cf. to my historical training. I still prefer working from scraps of paper to the difficulty and occasional embarrassment of asking questions directly, but as the language comes (slowly) things get easier.

We still spend much of the time longing for England-especially when rats, flies, ants etc. become too oppressive - but I suppose this is normal. Our current slight depression is probably due to the fact that we both have had dysentery on and off for a couple of weeks, plus sore throats, head-aches etc. which are going round the village.

You ask if there is a British agriculturalist in Pokhara called Flatt. Gill thinks she has seen mail waiting for a Flack? - something to do with agriculture we think - at the British Library. His poste restante was the same as ours. 
Today is Dessain (small) and people are meant to be having a 'puja lava' but a break of sunshine is now gone and rolling thunder is almost continuous. Now it has begun to rain.

\section{NOTES 26.3.1969 Alan - Little Desain (Dassera)}

We had been told of this festival a considerable time in advance with excitement and Prasad had said that a party of young people (including himself) would be going to a village near Pokhara to watch putting the shot etc. As it happened, perhaps because of the bad weather, people don't seem to have gone. On 25th, four buffaloes were killed and another was killed in front of Bhuwansing's house, on the day. It was cut up by Prasad and divided out among various families. Most of the men however sat round playing cards in Bhuwansing's courtyard. We were invited out to 'pa' and eating rice rings with Bhuwansing's wife, then with Nani next door and finally Nansubar. Special rice rings (with honey) were made by Nani and other families for this occasion, which seems primarily to be a time of communal drinking and eating with plenty of buffalo. (Even the smallest Untouchable house where the man was (dying?) had some meat hanging above the tiny fire. We were told that there would be a 'puja lava' and at about twelve o'clock a group of men etc. gathered under umbrellas at the enclosure by the temple at the south end of the village. I was told this was a 'mla' puja for the whole village. But only about fifteen adults (only two or three of them important men) and about thirty children were there during proceedings. Ramchandra rolled up just after everything was over. The puja was also called 'Raja Sowri Devi'. A buffalo was sacrificed, being killed by a Gurung, but carried and horn blasts made by Untouchables. The Untouchables were given some husked rice as reward. Two cow pats ('mil boti'), one with a coil of string on top, the other with a little bowl with oil on top (about 2" across) were set in corner of enclosure. A little bowl of ashes was there, but later removed. It took about twenty minutes of chaos to carry off buffalo. Meanwhile Prasad and friends were playing cards in Bhuwansing's porch and did not attend.

\section{DIARY Thursday 27th March Alan}

Stormy weather temporarily ended (when we were again wearing sweaters, etc.). A lovely day: village did not officially work. Prasad came and translated the census: hope to start on Saturday. Ramchandra had muddled our message and Prasad very worried that he would have to work 15 days for us. We explained situation. Gill not well with stomach upset (diarrhoea) and into Sulphaquinadine. My stomach giving twinges but not diarrhoea. Not much seems to be happening in village. Days getting much longer. Starts getting light at about 5.30am. (Sun rising much further to North) and still decent reading light up to $6.15 \mathrm{pm}$. So we go to bed earlier and get up earlier. While we were away out Gran. put up a little wooden partition in our house to make a larder (add to house diagram) - about $4 \mathrm{ft}$. high. Called Bhuwansing in to act as witness.

\section{DIARY Friday 28th March Alan}

A fine day. Gill's tummy better and also mine. Spent most of the day from about 11.00am. at a cremation (q.v.). Went down to the river with the corpse and watched it being burnt - a rather shaking experience. Came back up hill with Lt. with whom I had a long chat about his life, etc. 


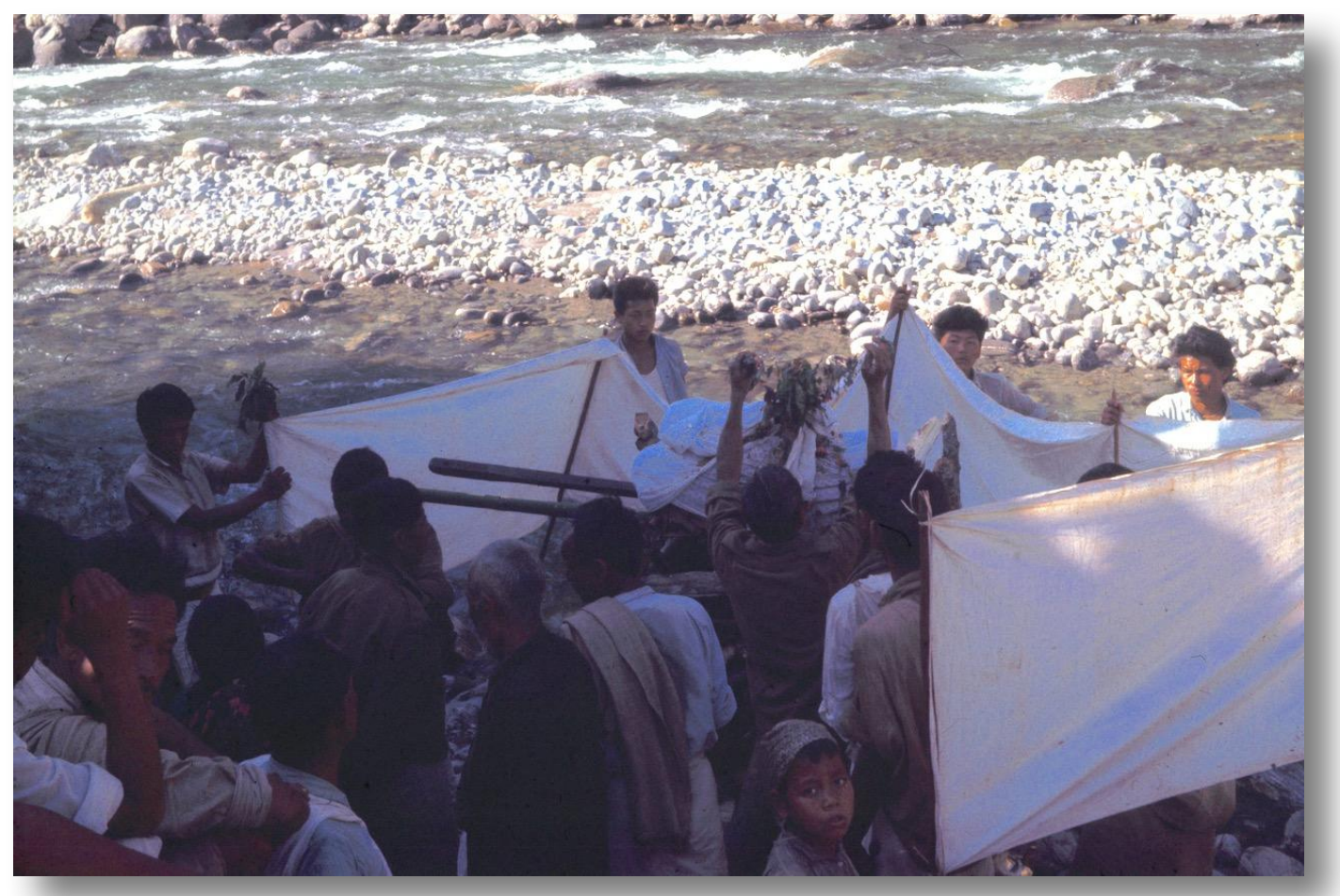

Cremating the body by the river

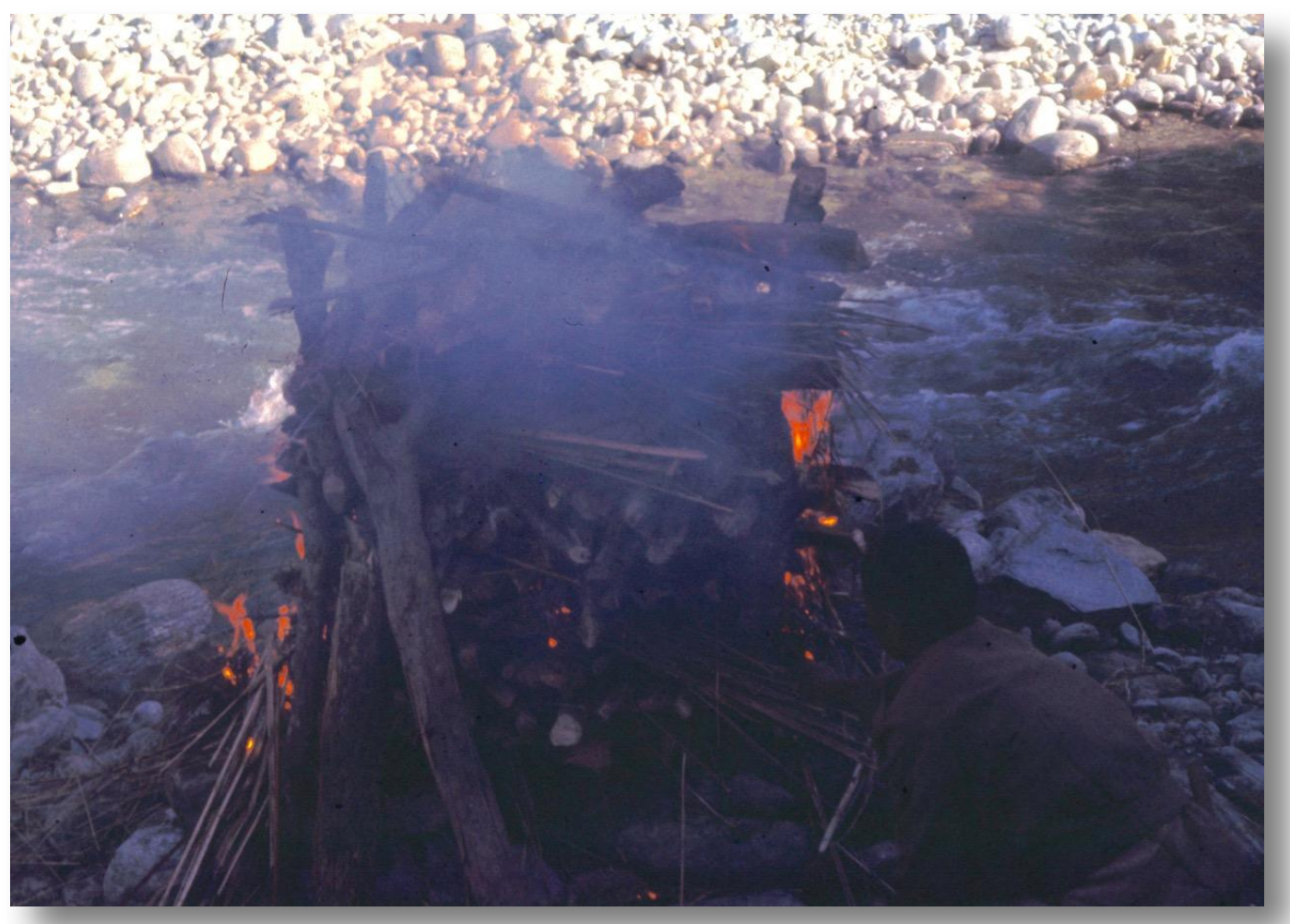

Funeral pyre by the river 
Evil spirits - 'Banketa'- kind of creature which grown-ups cannot see but children can ('ban' forest; 'keta' - small boy). About two to three feet high, he always carries a stick and a small bag. Lives in the forest, especially in Peepul trees. Can be man or woman. No wings. They eat fruits from the trees. Prasad: "I think this is a real thing because in the Peepul tree there is a small fruit which they always eat. They then defecate round the tree, like human 'khli', and you can see this after they have been. There are only a very few. Sometimes it makes people ill, or to die. We don't know how. We can see its foot tracks like humans. They sometimes hear the patter of its feet when it is leaving the tree; it sometimes cries out". Humans cannot understand it. It hits out with its stick and children are very frightened when they see it, it has a very ugly face. Up to 10 or 12 year-olds see it. Prasad has not seen but a girl friend has. They met near the Peepul tree; the girl terrified and ill for 15 days. She was 12 and told everyone what she had seen. The poju came and read a mantra and a chicken was sacrificed. Banketas are very harmful; if they come to the grain loft they will take the best of the grain 'sa bwoba' - and put it in their bag. Hence the precaution of 'di bar (fence) lava'. It is the only spirit which attacks the crops. When they are working in the fields the men do not mention the word 'banketa' or monkey as both of these are destructive.

\section{NOTES 28.3.1969 Alan - Funeral (cremation) ritual straight after death}

Death of man is announced by village crier so that people in the relative wards should not go to work. (In this case the man died at 5pm. 27th March, and the announcement was made at dawn on 28th March). Also only in immediate wards (in this case 6, 7, 8) are told not to work. A death in Noleghat would not affect this part of Thak, for example. - Range of death.

The day before he died many people visited him. When he is dead the Poju will go to the house and will read many things. Many people, especially the relatives will carry the dead body. They carry the body to the river at 2 or $3 \mathrm{pm}$. 'Malami' - funeral march. Relatives of the dead person must be in procession - 'gothar rava'. The family must not eat salt for 13 days; wife of dead person cannot wear 'tsura' - bangles; she must take red thread out of her hair and put in a black one - there is no special mourning colour generally. Women must wash their hair. Can work. Men must be shaved - near relations who are brothers, sons, etc. father, uncles. The daughter's husband will now take over farm. (Inf. Prasad). [See description of funeral].

Man died 5pm. 27th March and was cremated in the afternoon of 28th. We went to the house at about 11.00am. and found the courtyard filled with about 15 middle-aged men. Some women brought white flowers. A number of people went into the house, mostly boys and women. Ramchandra advised us not to go in. The youths congregated in the porch of a nearby house. Men were fairly dressed up, many of them wearing glasses. Some Untouchable children were perched up on the hill behind. We had been disconcerted to discover that it was the house of the man who we had visited earlier to give him some simple medicine, and whom we had found emaciated by the fireside. A bier of bamboo was propped against the house and the men seemed to include most of the notables of the village and some children, for instance, Comal, who had not gone to school because of this. We were told that as the poju was away a lama would be officiating from another village.

The women were sitting separately from the men, mostly in the porch and along the verandah. An old man washed his hair in the courtyard and then was shaved completely with a razor by a younger man. Only men of over 40 were members of this informal Panchayat meeting (it looked like one of these). They now tie a white flag to the verandah of the house, attached to a bamboo stick, and at the end of the flag 5 cigarettes are attached, one of which 
falls off whilst they are tying the flag up and no one bothers to pick it up. Later the whole thing was taken down and a bunch of green leaves was also attached which had just been picked. It appears that anyone who is at hand does these jobs without any organization, hurry or fuss. Small packages are put into a basket, food tied round with banana leaves to accompany the corpse down to the river. This food is for the dead man but is also eaten by members of lower jhat. Visiting women drop things in. Maldo is to carry it to the river. Joking and laughing is heard from the nearby porch where they are playing cards for money ('satra klionba'). It is very hot and they are doing it in the shade of the porch. Totra's father, Kumansing, and the young blades (including Togari) are playing, and there is great interest and concentration on the game, with quite an audience. The men in the courtyard are now making a sort of processional flag sheet, of white sheeting about 2' wide, attached to about 6 bamboo poles, which they split halfway down, insert the sheet through and then wrap it round the pole and so on to the next bamboo stick. The men are quiet and subdued. Another grey-headed man is shaved. We are told that these are the brothers of the deceased. They tie greenery to the flag poles. We are told that all the villagers give presents of food to the family which are put in the basket. On looking in I see rice rings etc. inside. We are told that the women who are relatives will not eat until afterwards.

A bit of banter breaks out between a woman sitting by the door of the house and the men across the courtyard - something about "giving birth to the lama", for whom they are all hanging about and waiting; he was 3 hours late. No one appears to be especially unhappy at this point, just quiet and relaxed and waiting. As usual there is a long period before anything happens when no one does anything, though it could be argued that people are sharing in the grief of the household by their quiet presence near the house. No one is smoking. Dankumari goes into the house and later plays an important part in the ritual. She is no relation but a close friend of the dead man's daughter. A fat man has just arrived and several people get up when he comes and there is some fuss about the seating arrangements on the verandah. He is the talkative, somewhat assertive, Pradhan Panch of Moja. Ramchandra gave me this information as we were sitting next to each other on the verandah, but he did not get up to greet him, and in fact did not speak to him at all.

The children on the verandah were introduced to the man, and it seems to be an occasion when a neighbouring village gets to know the population news in the next one. The young men are sitting in the shed to the right of the house, they giggle and chatter a lot amongst themselves. It seems also to be some sort of store cupboard as a woman from the house is always getting plates, grains, etc. from it and has to fight her way along the crowded verandah and into this filled room. There also seems to be a fire there as coals are later brought from it. An old woman arrives, the dead man's sister from Khilang, and just before she steps up to the verandah she raises her hands and starts wailing. She stopped at the threshold and renewed the wailing, raising her hands clasping a stick above her head and getting entangled with the flowers and anti-witch charms with which the lintel of the house was smothered. The entry is rather like keening women in a Synge tragedy. She goes on wailing for about an hour which comes through the emphatic and vigorous talk of the Pradhan Panch from the next village. No one seemed to mind the two levels going on at the same time. The Lt. seemed to shed a tear when she arrived and to look away over the wall into the far distance. He did not mix with any of the other men during the whole procedure, and seemed to keep himself deliberately aloof. He was the only one wearing western type clothing. Nansubar and Dansuba and a procession of middle-aged women arrived and went into the house, one or two of them depositing things into the basket. Birimaya leads her squadron in and then settle by the door.

$1.15 \mathrm{pm}$. The lama arrives, slowly with no apologies. He is a small, slight man with the usual brown beads round his neck, but with no other decoration. He is dressed in white with a 
string bag over his shoulder. The Lt. came over to tell me that this was the "most important person" they were all waiting for. On the verandah now where are about 15 women at either end, plus ten in the middle, plus us. The woman's wailing stopped when the lama went into the house. The daughter of the deceased comes out of the house occasionally and seems to be wearing her hair loose and unplaited underneath her 'kramu'. A drum with a long carved handle, two-sided, of wood and leather, about $1.5 \mathrm{ft}$. in diameter, is taken down from the verandah where it has been hanging, together with a bag containing the drum-stick (shaped like a question mark) and were taken inside. $1.30 \mathrm{pm}$. About ten young women arrive together and go into the room at the end at the far end of the verandah which is now very crowded, and there is more banter and chatter. Then four of the women go into the house. Mostly women go into the house; only men who were officiating seemed to go into the house. Soon after a bell begins to ring and the lama had obviously begun his rituals. A white powder, hot coals, and oil are taken from the room where all the girls are sitting by one man and a woman into the house.

$1.45 \mathrm{pm}$. A horn is blown, one long single note three times - the droning quickens inside the house and becomes louder. Horns are then blown at intervals of five and three minutes. About fifteen horns are blown altogether. Three other women come with pink flowers and wait outside. The giggling and chattering continues in the far right room. There is joking all along the verandah between the horn notes, mostly centred on the talkative Pradhan Panch. The droning of the lama continues and can be heard through all this. A small hand bell was rung for a few seconds. We were told that all the Kwonmae jhat would come since they were all "brothers" ('baime' - the dead man being a Kwonmae). Gundasing's father said it is not shameful for men to cry as well as women.2.20pm. They bring out another mat and a black and white striped wool blanket from the house, also a flat rice winnowing basket and a brass plate filled with 'mlassi', one rupee note and a brass jug with a spout with which they wash their hands, with its neck tied round with white cloth and herbs stuffed in the top. The blanket is folded likewise on the 'gundri' and the bowls etc. placed around the whole. The men drift in, more subdued, from the gambling verandah and interest mounting. The lama comes out, blows his nose and sits on the wall framing the courtyard, with the air of a good job done and finished with. Ramchandra and the Lt. do not seem to be here, however; the woman starts wailing from inside again. She is joined by some other women and it becomes a chorus. Outside the women have their heads closely covered with their 'kramu'. All the notables come back. They sit quietly framing the courtyard, about 40 men. The women sit closer to the house. Chicken are intermittently chased from off the rug and grains.

Karkobahadur and children do this unsuccessfully

The wailing stops. Tekansing comes out of the house to get more bamboo strips from the cow byre - they are obviously tying the man onto the bier which had been taken inside earlier. White cloths are also brought in. Karkobahadur stops shooing the chickens and takes up a conch shell. The lama now gets off the wall and gets two cymbals while another man holds the drum. They congregate in the doorway of the house and start playing (cf. tape). Men take their hats off (they keep them off from now until cleansed after return from procession). The lama stands in the doorway and takes hold of a sheet while playing the cymbals at the same time. The body is carried out from the house, heralded by the music. It is wrapped in a sheet and looks as if the knees were drawn up to the chin. The women start wailing as the body is lowered onto the rug. The lama sprinkles rice over the body and then takes up the cymbals again and the conch is blown by another man. Three women are now crouched over the body, crying and the daughter is made to wash her hands by people in the crowd who are now clustering round. She rubs her hands with greenery. A string is tied round the neck of the daughter by one of the women in the crowd, with some difficulty as she is muffled in her 
cloths. She is sobbing a lot. The men are very subdued and the women in the crowd are crying too.

Cigarettes and flowers and garlands are then put around the body, which already has a sprig of greenery stuck in the top of it. The musicians circle round the body, playing loudly. Money is then put on top of the body, the coins being washed by having water scattered over them from the jug. More cigarettes and matches are added. The money etc. will go to those who carry the body (who seem to consist of all willing, able-bodied men, from Pradhan Panch downwards - ie. they get their money back again). During this section the wife breaks her bangles and in "only now a widow" (Bhuwansing). Dankumari now unplaits her hair and takes out the red ribbon from it; she helps to distribute 'makhai' etc. which is later scattered onto the body by a group of circling women. Also 'makhai' etc. is scattered along the path to the pyre. Dankumari then goes in a circle behind the daughter of the dead man, followed by other younger women. One or two of the older men (brothers) were given a piece of bamboo in shape of a spear which they half-heartedly jabbed at a bamboo ring with a cross-piece (which the Lt. called a target) - this was 'tagra lava'. They were they touched on the head by several of those standing nearby. A long white flag ('gyan' = road) is then unfurled. Black ash marks are put on the foreheads. Two men pick up the bier (Benbahadur, brother's son and a brother - there is no son so these take their place). As they are leaving the homestead the sister of the dead man tries to follow the procession and is in a frenzy of grief. She is restrained by older women (eg. Dansuba), and is made to go back to the house. The other women are being comforted by Nansubar.

About half the people return to the village (mostly women) and the rest set off quickly on a very steep descent down to the river which takes about half an hour down and an hour up. Maldo carried the basket of goodies and another man carried the dead man's sleeping gundri and blanket (these were not burnt). The Lt. is my informant on the way down. We had to walk fast to keep up with the procession. He says that 4 or 5 men have been collecting firewood for the fire ('sala ruiba'). Men and women have the same funeral, but children under 12 do not. Lt. is given a bow to carry gown and 4 metal-tipped arrows ('meta'). He says that if the dead man had been rich, money would have been added in to the grains which are scattered along the path. This procession is called a 'malarmi'.

When I arrived at the river (just below the junction of the Tadsyon with the Modi) there was a large $4 \mathrm{ft}$. high pile of logs prepared about $3 \mathrm{ft}$. from the edge of the water. The long flag was held all round it with the opening towards the bank. The corpse was put on top of the pile but there was much shouting of 'ulta tai'! since they had put the head, which should have been facing downstream, at the wrong end. The flag then was processed round so that the opening was towards the river, flowers and some of the coverings were taken off but the corpse was left in one sheet. The flag was used as a screen so that people could not see too much of the preparations. They piled straw round the body, wetting some of it and putting this on top so this would conceal the body as long as possible. At this point there were about 16 young women, 20 men and a few boys present. All the way down the musicians had played a slow thumping beat which was quickened whenever we passed a house. The sheet is taken off discretely, the daughter sits and watches. The flag is dismantled, final arrangements are made by the men who have been close cropped; the cymbals and drums strike up, the lama is praying and scattering a few leaves, sitting just beside the body. A few small coins are put at the 4 corners of the pyre by two men; the women take no part in the proceedings. The bier is parallel to the stream and facing more or less north-south. Some of the women have already gone off to wash in the stream about 20 yards above the pyre.

Ramchandra and 3 other men now light torches of twigs, and circle the pyre with these 4 times as they apply the fire to the pyre. Everyone whistles aggressively and several men go "ho! ho! ho!"; one or two throw small bits of earth towards the pyre. Benbahadur 
halfhearteldy fires the bow, north, south, east and west. Then we all go upstream to wash hands, feet and head. Prasad is meanwhile shaving one of the men and later shaves

Benbahadur completely. We are told that his eye brows etc. would be shaved off but this did not seem to happen. They then put their hats back on. There is little interest in the pyre. The women leave and soon afterwards Bhuwansing and I leave also. About halfway up we pass a house where a man sprinkles water over us and the men circle their hats over a fire which is burning in the path. This was the equivalent of what happened to the women when they went straight back to the village: we stopped outside the Lt.'s house and Nansubar shouted at an old woman to sprinkle water over which she did liberally, and then she fetched a piece of glowing ember which was put on the path and some herb sprinkled on it so that it smoked up; the women then lifted their skirt and waved them above it, the men (Totra's father and Rudrabahadur) taking off their caps and doing the same. Before all this happened I was following Omkumari up the steps when we were both told to stay - 'tid' - the latter doing this with bad grace and boredom and getting told off by her mother for it. She said it was 'chaba lava'. The women then dispersed to their homes. Benbahadur, having been shaved, will wear a white cloth ('mreh noba' - to carry the white cloth).

\section{DIARY Saturday 29th March Alan}

Another hot day. In state of anxiety as Prasad was coming and we were setting out for census. Was convinced that people would not co- operate, but they did and we managed to do 9 families. Exhausting emotionally, though very friendly in most part (esp. Chuckly Gran, Pot., etc. thought Birimaya was a bit aggressive). Relieved at this first session. Prasad excellent. Gill's tummy not so good today.

\section{DIARY Sunday 30th March Alan}

Went to the river - very hot and we may have caught a touch of the sun, thought it was a very pleasant day, despite Gill's period starting. A good wash and read.

\section{DIARY Monday 31st March Alan}

Prasad came and on good form. Tried to arrange with untouchable woman to bring our water, etc. but she was worried about what the village's reaction would be so she is to go to Pokhara for us. About 10.00am. both Gill and I felt ill and we went to bed. Stayed in bed, our tummies roaring and heads thudding all day - but not diarrhoea. Hardly staggered up to make a meal. Wondered if we would be able to do the census the following day. 


\section{APRIL 1969}

\section{Undated photos of Alan and Gill}

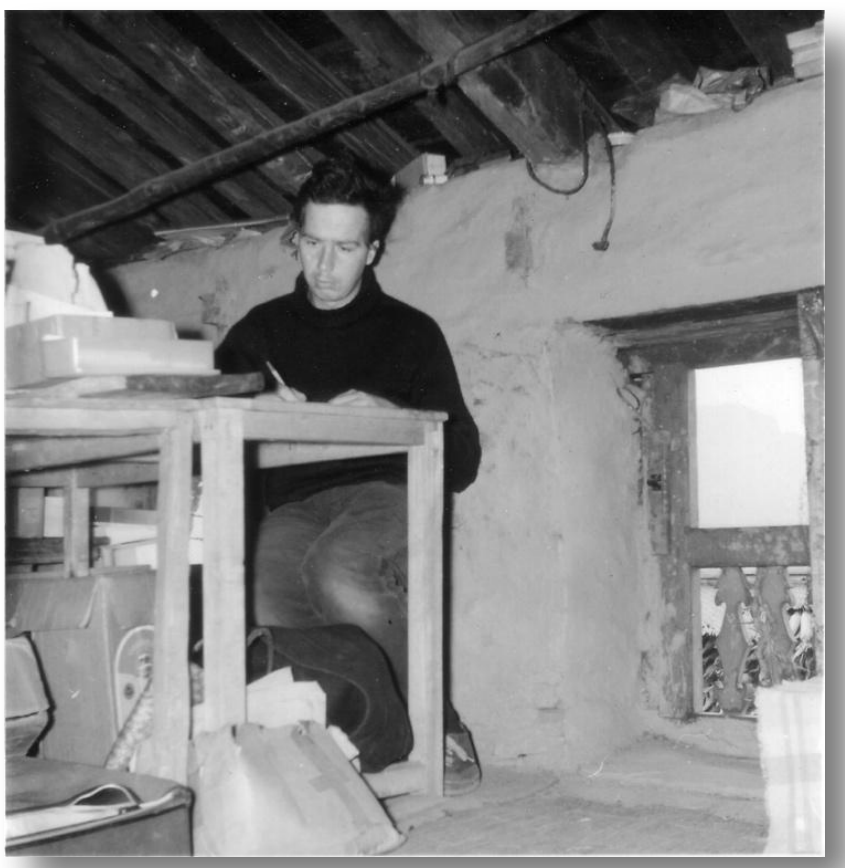

Working in the attic of our house

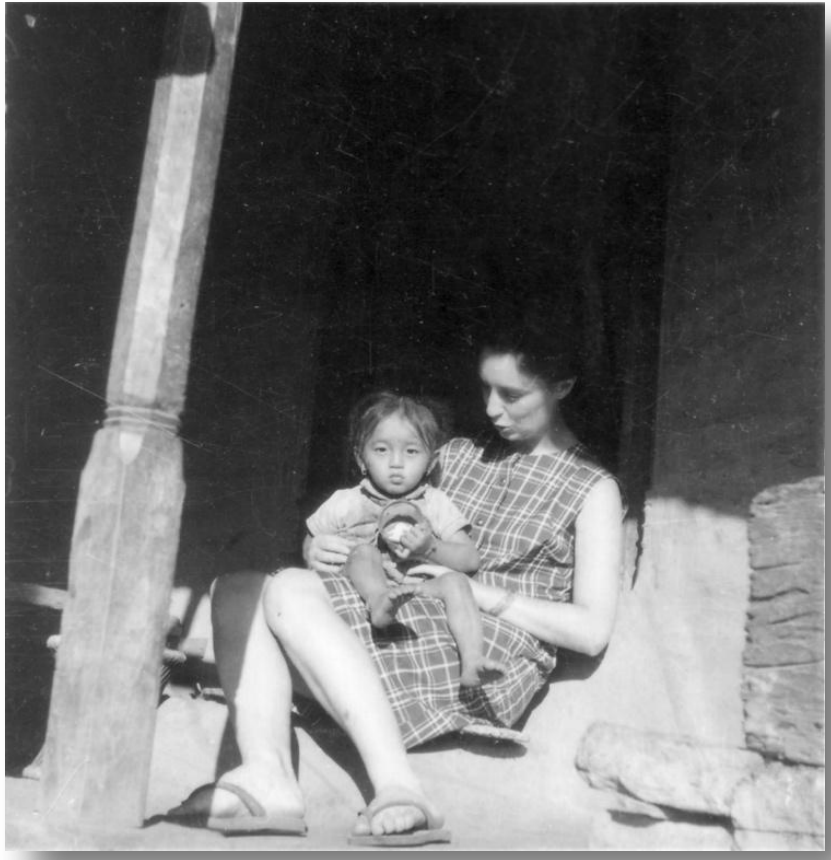

Gill sitting in a doorway with Ramu on her lap 


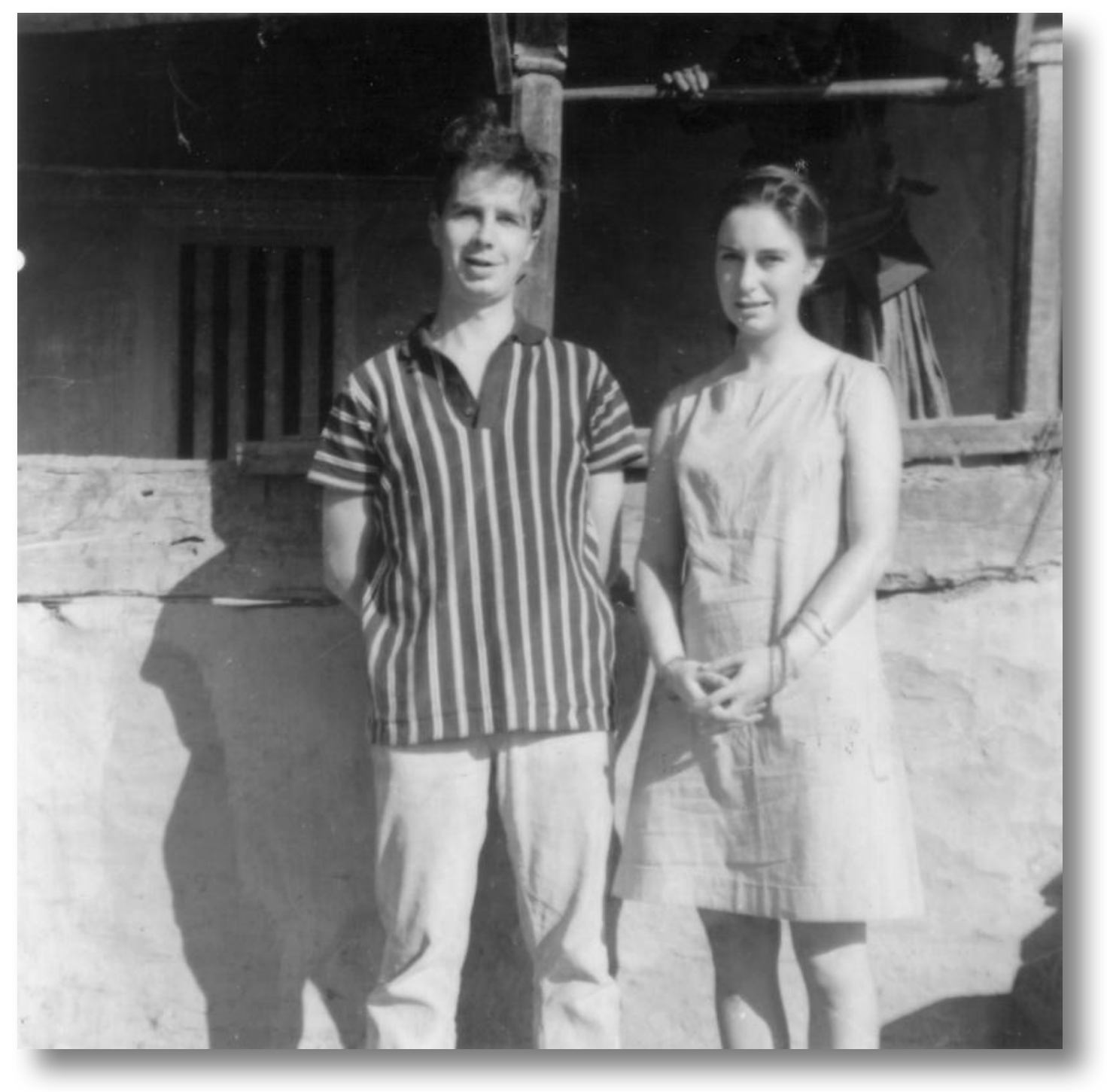

DIARY Tuesday 1st April Alan

I felt a bit better and went round with Prasad and did 9 household: he had gone to bed very late as only had 2 hour's sleep since he had be to a 'garda sheba' held at Pradhan Panch's house (in honour of visiting inspectors from Pokhara who were here to instruct re. grain storage records, and who had, much to AKP's amusement, only given 8rs. for entertainment). In the evening the band returned from 'Mae Pullo puja lava' - we had unfortunately been unable to go since Gill was ill and I was going round village with Prasad. 


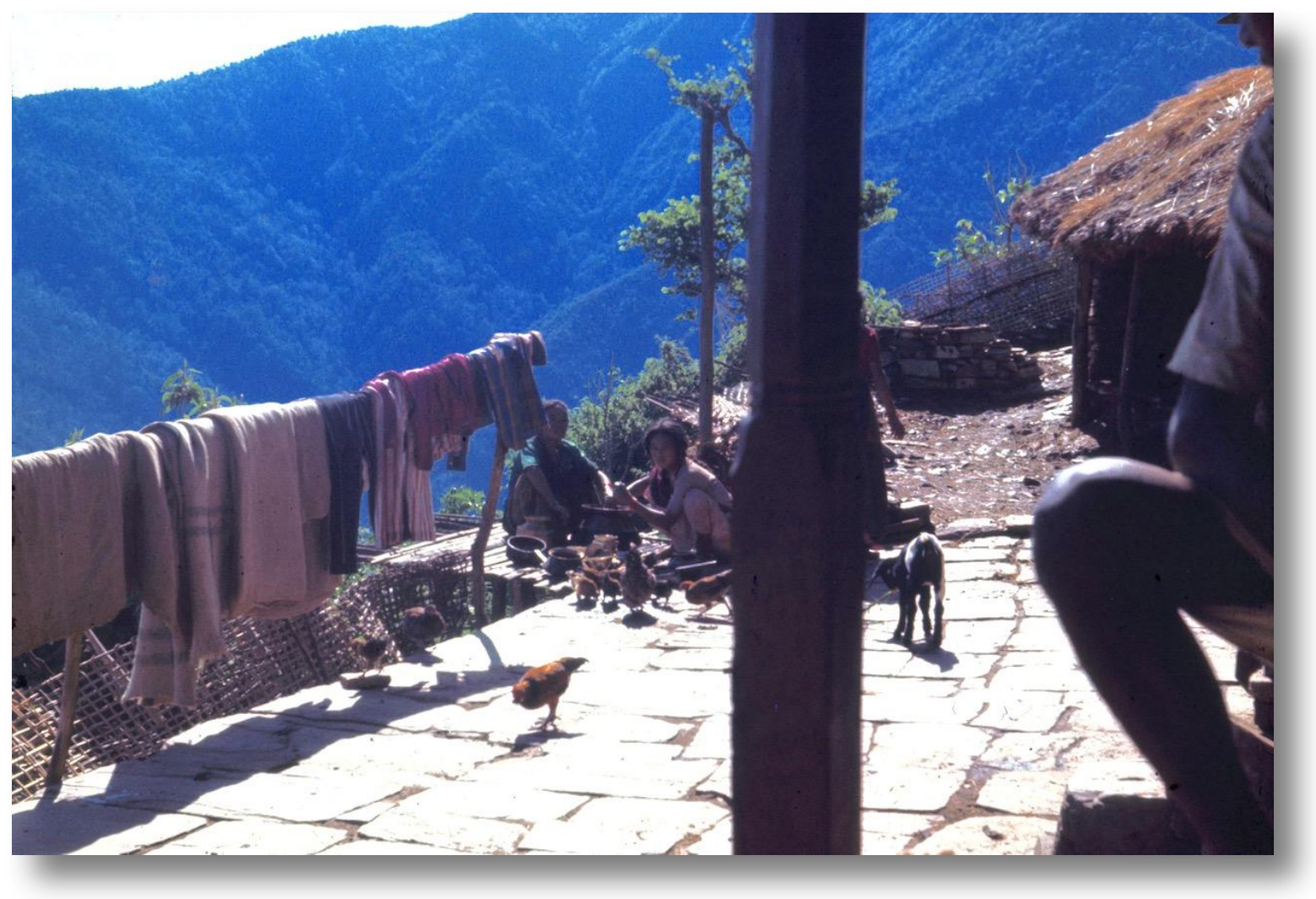

Looking towards a washing platform from our house - April

NOTES 1.4.1969 Alan - Suicide

None that he knew of in Thak, but there was one in Khilang about three years ago. An old woman of about 56 (Benbahadur's father's sister) hanged herself. Her husband always beat her and quarrelled with her. She was cremated, but her spirit wanders around as an evil spirit. There is no Gurung word for suicide - in Nepali 'atma hatia' (soul to kill). People were very upset. AKP said that often when students had failed exams two or three times they killed themselves. There are a considerable number also in Pokhara, for example an engineer who recently quarrelled with high-up people there killed himself. Prasad did not seem horrified at the idea of suicide. He agreed that people sometimes killed themselves for lack of food (called 'Akalmityu' in Nepali).

\section{DIARY Wednesday 2nd April Alan}

A very hot day, with usual mist. Got up late as I had been to dances the evening before. Staggered through the day as we both felt tired. Many flies, ants and a dead rat up above our food - plus filling lamps, burning Tampaxes, etc. It is like having a perpetual camping holiday - one longs for simple comforts like a bath, toilet, light, etc. etc. Even the croft seems epitome of luxury. Though much on whether we would go home after 1 year.

DIARY Thursday 3rd April Alan

Overcast a little and temperature dropped rapidly from 70 when the wind got up in the afternoon. A little thunder and splattering of showers. My beans beginning to flower, but 
disappointed that I will not be saviour of Thak with introduction of these as they are, apparently, widely grown. Neither of us particularly well with a little diarrhoea, wobbly tummies, my back and throat sore and Gill not too good generally. We seem to have been unsettled since Pokhara. Getting through the evenings is a considerable problem - my schedule disturbed by building of screen between parts of the house.

People now working hard in the fields - ploughing, hoeing, etc. The Lt. is trying to arrange a picnic with us, but so far abortively. Prasad and I did a couple of houses in the census. We have now done 20. People on the whole, cooperative, though occasionally grumbling a bit. "Koti tai, koti tai." Still reading Eisenstadt who is very windy, pompous and jargonistic, though occasionally interesting things emerge. Decided today to do an English edition of Pignede - abridged - along with a small volume of essays by me on various aspects of Gurung life - witchcraft, land tenure, medicine, social change, change in Mohoriya, etc. Wrote to Morris. 


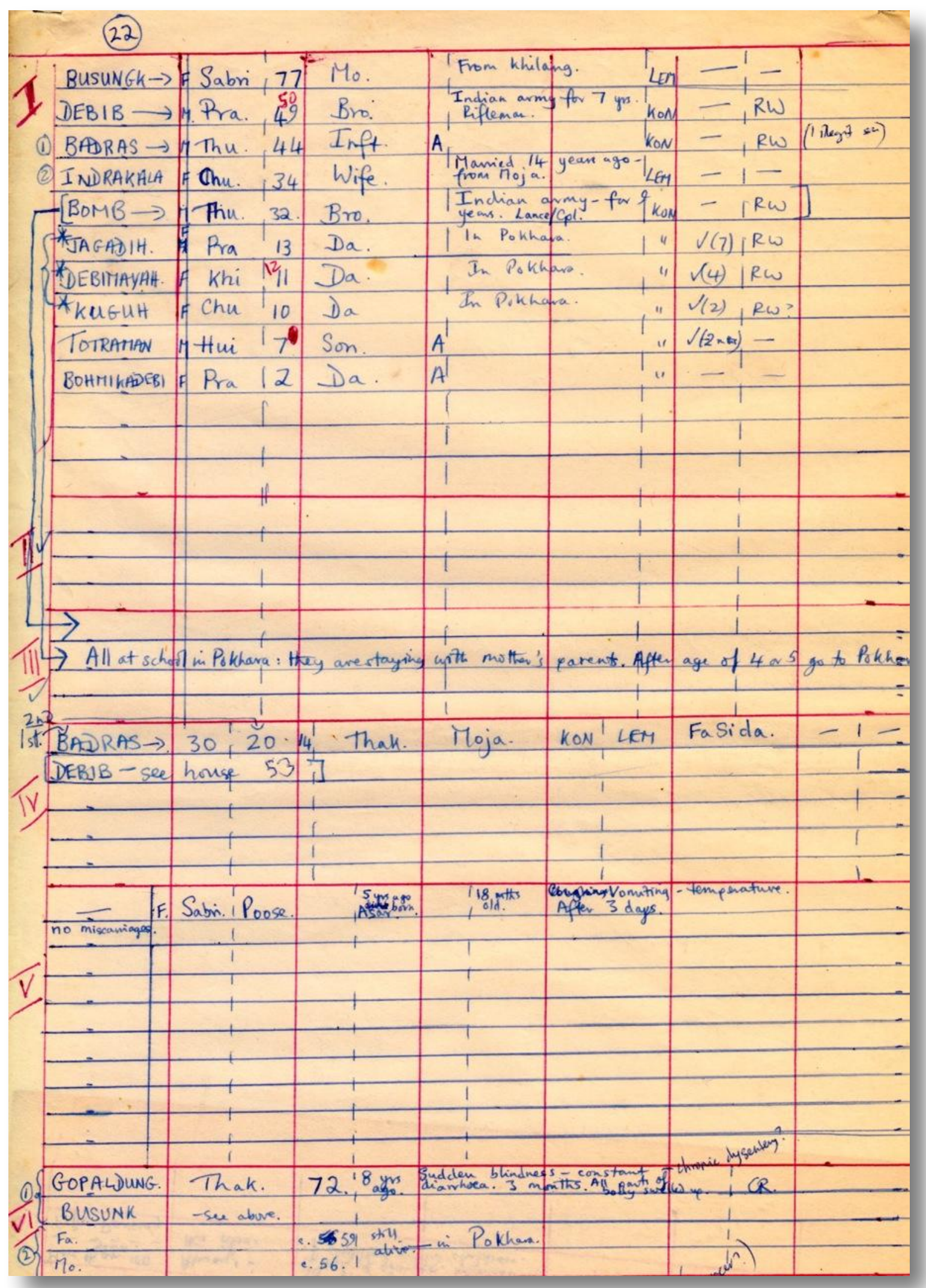

Census form for one of the 100 households 


\section{NOTES 3.4.1969 Alan - Dreams 'Morda moba'}

Prem says that he dreams every night because he thinks a lot in the daytime. Describes dreaming as his 'sae' strolling about. Asking for some typical dreams he suggests the following:- going to India, ploughing, fishing, father or mother dying (this is not a very bad dream portent-wise, although he cries a lot when he is dreaming it), being very ill, buying good clothes, being very frightened, flying, jumping off cliffs. Dream portents: 1) very bad trees falling over (mother or father dies, lose a lot of money etc.); teeth falling out, if the top row falls it is older kin (generation above) will die - father, mother, aunts, grandfather. If the bottom falls it is the younger and contemporaries - brothers, sisters, wife, sons, daughters etc. (not self); Being swept away by a river, seeing the setting sun. He agreed that bleeding from nose was a bad portent, and seeing a buffalo (equals a 'bhut'). 2) good dreams - climbing trees, anything to do with milk, drinking it, milking it etc. being covered in faeces on legs and knees, having spots, seeing a cow. People don't do anything special when they dream a bad dream, don't consult 'poju' or tell other people. Everyone knows the meaning of various dreams, old men and women are often very frightened by dreams, but Prem claims that he is not. While talking he showed no particular interest in the subject.

\section{NOTES 3.4.1969 Alan - Toilet training}

Ramu (17 months next door). Before they have eaten (7.15 a.m.) Granny takes him between her knees in a squatting position, knees open, anus close to ground and rhythmically moves up and down with him, making encouraging noises. He defecates on the verandah in this position; Granny wipes it up with an old corn on the cob and then takes it all from the verandah and feeds it to the chickens who gobble up greedily. Ramu continues playing on the verandah - does not see above, and when Rupa (elder sister) starts playing with him when he looks down through his legs and she fondles his penis as if wiping it dry. She also cleans up round his anus.3.4.1969

\section{DIARY Friday 4th April Alan}

One of the hottest days yet - about 73 in shade. We went up the hill and talked to Bhuwansing as his womenfolk prepared fields for 'mokhai'. Prasad ill so couldn't do census. Both of us feeling a bit better today - quite active. In the evening went for a nice walk through village. Cool and peaceful and a very heavily scented tree, full of bees plus a cuckoo, made it seem heartbreakingly like England in April. Our evening visitors have dwindled to two to four now - Haricola being a faithful attender. Beginning to get interested in ideas again - a sign of returning health.

\section{DIARY Saturday 5th April Alan}

Prasad again unable to come - presumably because of illness - to do the census. My leg exceedingly stiff and sore where I bruised it last week - difficult to walk. But we went up for a short walk to look at the mountains in the evening: the coolness was lovely after another boiling day and the peaks were just caught in the last rays of the sun. Magnificent. Earlier had seen a pathetic spectacle - Potam. looking after her incontinent old husband of 88. Old age is the same problem here as anywhere - and who will look after childless Pot.? I also managed to extract two 'Tirij' or land records from Pradhan Panch - of about 35 years. The problem is - who can translate them since they are apparently in an old script. Wrote to Mummy. 


\section{DIARY Sunday 6th April}

Went to river - a new place up above the bridge on main Thak- Taprang track. A lovely waterfall and pool with an overhanging tree and Gill swam, etc. A most restful day - though my foot at its worst.

\section{DIARY Monday 7th April Alan}

Hot at first, but clouding over about 3.00pm. with high wind and spattering rain. Gill very sleepy. My leg improving. Still wading through irritating Eisenstadt. Doing a lot of Pignede in preparation for 'pae lava'. Bought a chicken. Began to decode the Tirij. A larger gathering round our fire than there has been with Rudrabahadur, Maldo, etc. It was quite like old times.

\section{DIARY Tuesday 8th April Alan}

Again Prasad did not turn up. This was first day of 'pae lava' and we spent most of the day preparing for this - also started filling in the land tax records. We had an early supper to go to the 'pae lava' having been told it would start at about $7.00 \mathrm{pm}$. In the end it did not start until 10.30 and hardly anyone beyond the Lt. and ourselves - besides those officiating - attended. The ceremony, esp. simultaneous whistling, cutting of 'ala' pole, drumming by poju, wailing of daughter, etc. was effective - as was the flag flapping bravely against the stars. On the way back gave Prasad a rocket for not giving our pressure lamp to the person who asked for it from us, but instead using it for gambling. His constantly intermittent attendance is one of the most frustrating things about this place. He works so well when he comes that its very irritating when he does not.

\section{TAPE RECORDING}

'pae lava'

At House55. Conversation on porch: weeping inside and Klehbri ringing bells; making 'plah', weeping, cymbals and horn; fetching 'rhi'; inside house waiting for soul 'plah' to come down; dances at midnight (people laughing at anthropologist).

8.4.1969=9.4.1969

https://sms.cam.ac.uk/media/2733248

NOTES 8.4.1969 - Pae lava at house 55

We went down to the house at 8.00pm., after being dissuaded by the villagers from going earlier as nothing would be happening. We had been told the 'ala' would be made at $7.00 \mathrm{pm}$. In fact we waited on the verandah with several older men (3) and the Lt. from 2.5 hours for things to happen. The Lt. and another man tried to get their lamps working, to almost no avail. This occupied all their time, as well as desultory conversation about us, 'makhai' planting and buying and the difficulty of 'moditil' lamps. The family were inside the house, and only came out once to offer those on the verandah cigarettes.

$10.20 \mathrm{pm}$. very long, green bamboo pole got by three men and laid in the courtyard; a rice tray ('shyaku' - ['nowli']) and rice container also brought out of the house and out in the courtyard; 3 poju organize themselves in the corner of this, and one of them asks a relative for the dead man's name. They start chanting from a huddle in the courtyard; they can hardly be seen from the verandah, it is so dark. On to the rice tray a bowl of milk, rice rings, 'pa', arrow, rupee notes are put; they are preparing the milk, rice etc. for the 'kaidu' inside; they prepare 
to split the bamboo pole. The Lt. tells us that the klehbri is inside, the poju outside, and they will take it in turns to recite mantra. A goat will be sacrificed by the klehbri and then, through the night, he will eat its entrails. The men in the courtyard, the 'tah' (old man), 'ngyemai' and 'asyon' prepare split bamboo strips; the two latter recite all the dead man's names. A fine white sheet is then brought from the house and a man measures it with his arm (8 arm lengths); about a quarter strip is torn off. This is placed on the rice tray, together with a thick bunch of greenery. The poju are now silent; there is some bantering from the three crouched in the middle of the courtyard; the usual air of expectation. The 'ala', the drumming of the poju, and the cooking of the 'kaidu' have all to begin at the same time. The men in the courtyard take off their caps in preparation. There is a signal from a man standing in the gloom of the doorway, the Lt. and several others let out a long, shrill whistle and the drum begins, and the batting of a wooden mallet as they secure the sheet into the bamboo pole by inserting it firmly with a peg into slits already made.

The family had prepared the food the day before, including 'kyuni', 'jilgya', 'pa' and 'keh'. In the morning they prepared the house for cooking food, the Lt. and others milling around, vaguely, some people having gone to the forest to get wood. The Lt. has no idea what the 'ala' is meant to be though Benbahadur was more clued up on this and knew it was a representation of the dead man. The woman also starts wailing (daughter, see tape); Benbahadur has a string held round his neck and the 'tah' does the hammering with the mallet; it is split in 8 places; Benbahadur brings a fire in the form of smoking twigs and puts it near the 'ala'. Another tray full of rice presents is brought and put beside it. Daughter now comes out and ties, weeping with her hair unplaits, a three coloured bag to the 'ala', as well as a small woven basket. They finally secure the sheet, tying it in a bundle at the base and rear of the pole to its full height. Then two men (it seems to be no one in particular) climb onto the verandah roof, and fit the pole with bamboo strips to one of the house gables; the pole rears itself up in the night well above the height of the house, flapping strongly in the wind and outlined sharp white against the stars; this is a moving moment and one can almost feel the presence of the dead man. Benbahadur is sitting hunched on the verandah with a large black cinder mark on his forehead. When the pole is erected the three men, the 'tah' and Kumansing drink the 'pa' which had been offered to the dead man, after spilling a bit on the ground first. We then left the Lt. and arrived home just before 12.00am.

\section{DIARY Wednesday 9th April Alan}

Day started badly with constant changed of plan was people did not know when the 'pae lava' would start and we had gone to a seance the night before and come in late. But we finally went down at about $12.00 \mathrm{pm}$. - the fierce wind dropped and sun came out. Delighted that a lot of books came, plus 13 letters - from parents, Marwick (offer of a job at Stirling), publishers, offer of $£ 500$ Postgraduate Studentship. Books include L-Strauss, Banfield, etc. Two Japanese walkers came through the village and we gave them coffee. Didn't even mind that the goats had eaten all my garden (and Pradhan Panch's cabbage). In the evening also went to 'pae lava' and danced (much to amusement of village) and watched spirit come down. Arrived home about 12.00am. Prasad very contrite and promised he would come and help with census.

\section{NOTES 9.4.1969 Alan - Pae Lava at house 55 continued}

Went down about midday. A lot of people around, wandering about from the long cookhouse where food was constantly prepared and eaten, past the little tent for the 'asyon', in which crowded about 4 or 5 men (though there was only one 'asyon'), to the tea-shop where 
we had cups of tea and orange juice, etc. Noticed that the pieces of cloth on the pole were bag shape and there was also a tobacco pouch there.1.00pm. 'Plah' begins to be made; this has a wooden frame ('maitra' - side pieces of bamboo). About 3 to 4 feet in height, consisting of a framework of four pieces of split bamboo which came out from a flat base (shape as in Pignede). There was a canvas base put on top of the wood and round the whole a white muslin cloth was put ('quora'). 'Cugu tah' (butter leaves) was fixed firmly in the top. The men had their caps off while doing this; they drink 'pa' throughout. When they had finished the basis of the 'plah' (mostly done by the 'moh'), drumming starts up (cf. tape). A blanket is brought from the house and put under the 'plah', which is then put on a bed-stead in the middle of the courtyard. More rugs are fetched. It is all done with great care. Daughter comes out from the house and smears oil on the leaves. She then dresses the 'plah' with the dead man's clothes, a new 'kas' (men's skirt of white cloth), then the 'renga' (men's crossed carrying sack), a grey scarf ('kregi'), a green Gurkha blazer, and a silk necktie. All this is going on at the same time as making the 'gyan' which is also mainly done by the 'moh'. A garland is put round the neck and cigarettes stuck into the green leaves at the top. They light these and the joss-sticks also.9.4.1969Alan'Pae lava' at House552.15pm. The drumming stops when the 'plah' is finished. The daughter goes into the house and people sit casually on the bed where the 'plah' is. $2.30 \mathrm{pm}$. The klehbri dresses in a corner of the courtyard in his little home-made shrine, where there were various drums, pans of rice, a goat's head, etc. He puts on a black robe, striped and edges and zigzagged with orange, yellow and red, belted with one of the nasty wide Gurkha belts. On his head he puts a brown woollen cap, which has long woollen plaits protruding from it, then secures this with a white muslin band, and finally puts on his crown ('urba') cf. previous funeral description. When dressed he comes to the middle of the courtyard and starts dancing crouched low round the 'plah' (tape recording). The main body of the villagers now coming down. Men have their heads uncovered. Klehbri clashes cymbals while dancing, Budibahadur follows him with a big open-ended drum. The 'moh' is making arrows. Benbahadur had the bow and the 'tah' is holding the spear. (The 'tah' was an ancient man, the 'moh' quite young, and the 'asyon' of medium age). The daughter has come out again and is weeping with her arms around the 'plah'. She has brought out a large tray with a lot of food on it $(2.50 \mathrm{pm})$. The 'tah' whistles and jabs the 'plah' with the lance several times. A string has been tied round his neck. The 'moh' touches him on the head after each spearing. Potamkumari who has been sitting on the table with 'plah' gets off to comfort the daughter. The 'gyan' is gathered together and begins to be unfurled. The daughter finally takes up the basket to follow the 'gyan' (a tray of food-stuffs - as at previous funeral q.v.). This is the beginning of the 'rhi teba yaba' (going to get the 'rhi')9.4.1969Alan'Pae lava' at House55The 'moh' has earlier gone off to a nearby dried up spring and retrieved the 'rhi', small piece of bamboo with a piece of white cloth tied round it, with leaves jammed in the top. He lays a blanket on the ground just before the procession arrives; he gives the 'rhi' to the 'tah'. The procession is led by the 'gyan' held by small boys who whistle and shout as they go. The 'gyan' is then wrapped up and the klehbri faces the 'tah' across the blanket, the 'tah' being about 15 yards back; klehbri bangs cymbals (tape?) and obviously drawing the 'rhi' towards him. This is turned slowly from side to side, hidden in the hands of the 'tah' and done in time to the music. The basket of food and one woman holding a 'pela' of milk was just near the blanket. The audience, mainly consisting of women, most of the men having stayed near the house, were attentive, men had their hats off. Took approximately 10 minutes to cross the 15 yards, the klehbri reciting slowly and inexorably as the 'tah' advanced step by step; as the 'tah' gets nearer the rug the klehbri leans forward and the rhythm speeds up a little. The 'rhi' is put on the rug and immediately throw milk and food over it. Klehbri swoops over it with his cymbals and then doubles the rhythm and dances a swirling dance (of triumph?) round the 'rhi'. The 'moh' and 'tah' are given the remnants of the food and the rest is destroyed. (Approximately 
3.15pm.) 'Tah' picks up the 'rhi' again, Benbahadur is standing by with his bow and arrows, 'tah' takes the 'gyan'. The procession goes back to the house. They stuff the 'plah' with more greenery and insert the 'rhi' near the top. There are women still weeping on the table near the 'plah'. Women in the audience begin to replait their hair.9.4.1969Alan'Pae lava' at House553.30pm. The poju takes over and dances round the 'plah' - various from the audience. Potamkumari again restrains one of the women from crying so much. (We then leave to get our mail which we gather has arrived, plus parcels of books and read these until supper time). We return at about 7.30pm. The 'plah' is now in the main part of the house with bowls of rice etc. in front of it and smouldering joss-sticks stuck in the top. The poju has a basket of millet in front of him, on top of which is a bottle with a leaf stuck in it, and underneath a plate of 'mlassi'. This ceremony is called the 'plah uiba' ('plah' coming down). The poju and his several assistants chant ceaselessly (cf. tape). Incidentally, several villagers have commented on the poor attendance at this funeral - from other villages). The poju is apparently naming all the places in the village - or so it would seem. The 'asyon' in a Gungabahadur from Atigar.9.4.1969Alan'Pae lava' at House55The 'moh' bars the house door and takes the chicken held by "baby brother", attaching a string to one of its feet, with the other end of the string to the door bar. The chicken struggles and squawks and the 'moh' had to hold it for five minutes to get it quiet. Much bellowing and shouting from the outside when people wanted to come in, but they weren't allowed in. A large rice tray is brought from the $[$ and put in front of the door, it had the usual 'pa', cigarettes, rice rings in different colours, banana, and a 'pela' of milk on it. Three brass plates are then handed up with the same things on it. Also several bowls of 'pa'. Men take their hats off. Singing begins again by poju, the 'moh' still holds the chicken and presents of food are still passed over, the person who gives them being named (eg. Kaji). The old poju throws some rice over all the trays etc. He holds in one hand a clicking instrument (like mini-castanets) which he clicked throughout. The last rice present on a banana leaf is put right under the chicken's head beside the door presumably it would make the chicken flap and also feed the spirit when it came. A light is brought. The 'moh' has now let go of the cock which is now quite still, eyes closed. The chicken remains like this for about ten minutes and the poju are obviously concerned that it is not reacting as it should. The 'moh' chirrups endlessly at it to encourage it and torches are shone at its head. The old poju threw more rice, at the chicken this time and there are still cries of people wanting to come in from outside. The chicken finally flaps and there are sighs of relief all round. The 'moh' untied the chicken and they stopped chanting (for chant hear tape). The food in the trays are grabbed by the various poju and the 'moh', Prem first of all selected the banana for himself. The 'moh' stuffs most of the rice rings into his 'renga'. The rest is given to children and the pojus eat (why repeated association of food and spirit?). The people disperse.9.4.1969Alan'Pae lava' at House55People hang around for a while and then, with a group of women sitting in the middle (mostly young unmarried), the men danced round in a circle, anti-clockwise. Led by Prasad with cymbals, Karkobahadur with a drum, Prem with cymbals. There are 32 variations of this dance called 'chowdu', each lasting about 5 minutes. We stayed for the first 4, I joined in these; fairly simple steps, involving sweeping actions with arms, and a little bit of pirouetting, all rather soothing, slow, graceful and female. With the dancing at the end the music (cf. tape) was finally taken away from the hands of the priests, and secularisation set in. Interestingly there was an altercation earlier between Prem and Prasad about the possession of the drum - symbolising this conflict? (Why do many of the most significant rites occur at night?). The music and dancing was still fighting the evil spirits. The spirit was not in the house - was the courtyard being protected? 


\section{DIARY Thursday 10th April Alan}

Got up late and wrote letters. After lunch, starting to read "Moral Basis of Backward Society" - a welcome and stimulating change after finishing Eisenstadt. I went down to the last day of the funeral. Exciting, though a little spoilt by rain at the end. Prasad failed to come again, though he had promised to yesterday. Gill still not at all well - spells of sickness and diarrhoea. Been taking pills (Thalazole) for some time, so we are confused as to what to do. Interesting to compare the groupiness of the Gurungs to the "amoral familism" of Banfield's village. Reasons for difference.

\section{NOTES 10.4.1969 - Alan - Pae Lava - third day}

Alan went down at about 3.00pm. The pojus singing and moving in an anti-clockwise ring in the courtyard round a group of men sitting in the middle (old and middle-aged). They are followed by 25 young women, heads uncovered, who shuffle round. These include daughter and other relations. There are about 70 other people about, mostly children and women, not many adult men. The dance is called 'sherga sheva' (the last dance). In the centre is a winnowing tray with an empty 'pa' bottle, a few rice rings and rupee notes on it. Various people give small sums of money eg. Kumansing give a 'mori' and put on tray. Two of the men in the centre are slightly tipsy and aggressive, demanding that the pojus do a better dance for their money which goads them into more elaborate dance ('io sheva'). People tell me that this dead man is now going to 'sorga' as the pojus do a little mimic battle, two of them advancing, turning and twisting and chanting, and then retreating while three more advanced towards them. They seemed to enjoy this dance very much. One lot seemed to be singing about 'sorga' and the other about 'norga'.

The women danced again and then the pojus start moving in the opposite direction. Benbahadur has also joined in, holding a bow and some arrows, two arrows having been stuck above the door and a thin strip of bamboo tied from the verandah and leading into the house. There is now about 40rs. in the tray and when the pojus stop dancing this is distributed to them, 1rs. being stuck in the hat of each first of all. Bolbahadur gets no money, though Prem does. As usual there is more interest in the division of money than anything else. Mats and a blanket are laid out and various foods are brought from inside the house. Two of the pojus start drumming very fast and two sheep are encouraged to eat the food at which they nibble halfheartedly. This is 'kuh chuloh saba'. The food is then open to a mob of children who scramble for it with gusto ('pwe quoba').

The 'moh', who has had his head shaved, then kills the two sheep, sawing their throats with a 'kukri'; he takes a piece of the intestine of one and wanders off round the house looking for someone to give it to. Tekansing takes down the 'ala', apparently the sheep will be given to all those officiating and close relatives as well as water carriers, etc. The 'kaidu' are taken out in a small bamboo bag by the 'moh' and hung on a wall near the house. The 'tah' gets the foodstuffs from the 'ala', while Maldo drinks the 'pa' being the nearest willing person. I go into the house where I find the klehbri squatting and reciting near the doorway. Just behind him is the 'plah' onto which he is holding. Maldo is standing beside the 'plah' waving a 'kukri' about. A small chick is brought and Prem holds onto it. The 'moh', just behind Maldo, starts whistling and yodelling; the people have formed a semicircle in the courtyard and are awaiting the exit with interest. A boy arrives dressed in the klehbri's costume. Facing the doorway outside is the 'tah' with his spear; women start weeping again and obviously the spirit is leaving the house for the last time. Five weeping women leave the house while others remain behind with the 'plah'. Majority of the women sitting outside are tearful eg. Dilmaya (Lt.'s adopted daughter). Whistling increases inside the house and the klehbri inches forward, 
reciting all the time holding the 'plah' behind him and shaking it so that it looked as though it were walking. Suddenly the 'plah' is knocked over by the klehbri and he strides out of the house, the drums and cymbals start crashing and a few seconds later the 'moh' brings the 'plah' out to which the wife is still clinging. This rite is called 'pae liba'. The female relatives are waiting in group under the 'ala' which is being held up and the 'poju' is circling the small chick over their heads. Klehbri dances round the 'plah' banging his cymbals; 'gyan' is unfolded and disappears with the 'ala', southwards/west.

A white string is tied round Benbahadur's neck and he takes the arrows down from the house. The 'plah' and a large number of the audience progressed a quarter of a mile to the spot just above the temple on the way to the river, despite the heavy rain. The 'moh' undresses the 'plah', cut the four bamboo sides and tossed it down the hillside. The klehbri and two assistants were all the time clashing cymbals. The 'rhi' was split and the contents poured onto a bright piece of cloth where there were already some grains given by a few members of the audience, this was immediately covered by the klehbri with his cymbals. I left at this point but gathered that the clothes would be taken back to the house and that there would be dancing by the women that night.

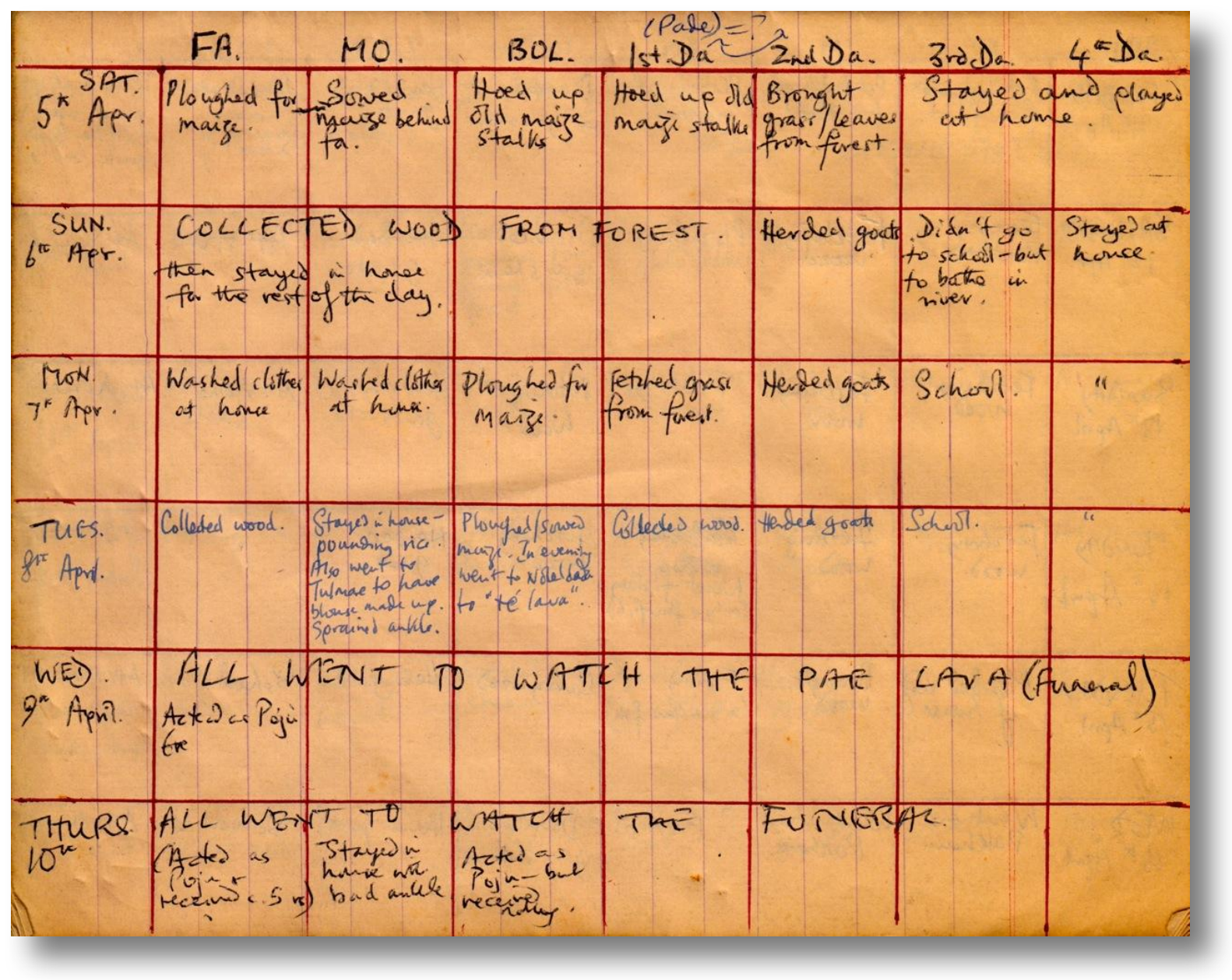

Daily work pattern in a Gurung family 


\section{DIARY Friday 11 th April Alan}

Starting warm, but later thunder and rain. Pottered about doing bits and pieces, but growing increasingly irritated as Prasad once more did not come. By evening was in a state of real anger/anxiety, but there is just nothing we can do. Went to one of the two Garda Sheba that occurred. A nice evening by the fire with Rudrabahadur, Nani, etc. Gill still with diarrhoea, but more cheerful on the whole. A lot of sore eyes and two bad cuts today.

\section{DIARY Saturday 12th April Alan}

Another frustrating, bitty, day as Prasad again did not come, though he had promised to. But I caught him at a Garda Sheba and he promised to come the next day. I chomped around, irritable. Gill writing letters and feeling slightly better. In the late afternoon, heavy rain.

\section{DIARY Sunday 13th April Alan}

At last Prasad came, having been reminded yesterday, and we started at $8.00 \mathrm{am}$. and continued till 4.30pm. doing census - did 11 houses. Had nice honey/teme tea at Totra's father's. Gill worked in house on Pignede, letters, etc. She is now feeling much better and sickness after breakfast seems better. In the evening an electric storm and atmosphere very hot and sticky.

\section{Letter from Gill to Mac and Iris, 13th April}

... Thanks you for the tips re depressive side effects of Furamide etc. It has been a bit grim for the last fortnight, like having a continual period, as I can't seem to shake off this diarrhea; Thalazole didn't seem to touch it, and I began feeling sick in the mornings ... However, this is now stopped and I am giving pills a break and things have improved a little. Fortunately it only involves one dash up the hillside per day, so I've been relatively lucky. We are taking multivitamin pills, but $A$ says he will get VB on its own, after what you said. A. is fine, only being frustrated by our feckless, linen shirted school master, who promises to come down and help him with the census (which should be most exciting if we could get a big enough sample - 100 families) and then doesn't turn up. It's all the more frustrating, as when he does he is excellent, very intelligent with a good grasp of English.

Things are complicate by the fact he is the head of the Dance Party, which has had 4 dances in the last two days (and nights), working up to the grand climax at full moon of this month (today is the New Year Day) where they go through an entire song cycle, lasting 5 days... membership of the party has rather the same status as belonging to a London Club. Prasad (schoolmaster) being of a superior clan anyway, enhanced by a rich father, and having gone to college in Kathmandu. Education has got an aura here - one of teh prettiest eligible girls in the village telling us last night she would only marry a boy who had reached 10th Grade (there are 2 in the village, one being Prasad). He also lives half way up the hill, so it requires some devotion to steam up it; he is being paid however, and says he understands how important it is for the village. ...

To compensate for teh above, we did enjoy the funeral, really grasping something of what was going on this time (there was one in our first week), Your comment on how much they are surrounded by the dead in a more solid way, was very a propos here as the entire rite consisted in fighting off the evil spirits who might claim the dead man's soul before reaching the land of its ancestors; this was made concrete through vivid double symbols, effigies made of the dead man, with bamboo, sheeting, greenery and ribbons, garlands and teh actual retrieving of the dead man demonstrated twice, once through sheep and once through a chicken. The latter was hung upside down, ad midnight, by a string to the dead man's door, the pojus changing away, clicking minute castanets, in complete gloom, half the village and us crammed into the mud walls; the 'sign' that the spirit had come to rest back in the sanctity of its own house was when the chicken flapped its wings, the spirit inhabiting it. The wretched thing wouldn't cooperate, and the changing and clicking and throwing of rice and offerings of rice rings 
became more and more frantic; after about 8 mins it did flap and there were heaves of relief, the pojus grabbing all the nicest rice goodies and the whisky, intended for the soul, and champing away with gratification; I love the way they carry on with the mundane and the magical at the same time!' If only one could get a real glimpse into their way of perceiving things, one is always tempted to think of this as being simplified, causal because they haven't been lumbered up with excess education; I still can't feel what it would be like not to be able to read a book, or not tell the time from a watch you are wearing. We have been having long discussions along this line, but not getting anywhere...

I must stop, as there are lines to be ruled for the census and Pignede to be translated (we are hoping to look up his notes if we come back through Paris),

\section{DIARY Monday 14th April Alan}

Went to river; a lovely day climate-wise, though it all seemed a great effort at the river. But at this new place at least no one can disturb us. Came back with Lt. and his daughter who were happy and relaxed after a day in the fields planting 'toyo'. Now caught a cold - ridiculous when temperature is about 80 in the shade.

\section{LETTER from Alan to parents 14.4.1969}

Dear Mummy and Daddy,

I have managed to repair Erik's typewriter so letters should now he a bit more legible, even though the ribbon is getting a bit low. I hope you got our two letters from Pokhara - about a week apart. As usual will probably get your next letter just before this is posted, so will write about our life here first and then add on a bit at the end to reply to, your letter at the end. You will gather that we managed to get back from Pokhara to our village after my touch of dysentery. An easy journey back, but, as usual, our stay in Pokhara somehow dislocated us.

We are just beginning to pick up again. Both of us have felt under the weather on and off for ten days, mostly slight sickness and diarrhoea with one day in bed probably suffering from an overdose of the sun on our river picnic the day before. With sore throats, Gill with slight conjunctivitis, me with a braised shin from slipping in the drain while fetching water, we begin to realize forcefully how pre-industrial living is one long series of minor pains. Have you managed to get anything on illness etc. in Kirby Lonsdale? It is difficult to think of what source one could use except on mortality. Anyway, we have both been much better for the last two days and so DON'T WORRY. We have masses of medicine and neighbours pop in with sympathy and little bowls of medicine and advice that we should be drinking rice beer to steady our stomachs. There are occasional cool, wet, days but mostly it is pretty hot - or so it seems to us at 75 degrees in the shade, though I suppose this is nothing on Assam and there is always a lovely cool breeze.

The villagers are increasingly busy now. The season of dancing and sacrifices is nearly over and they are just beginning to plough and then plant the maize fields. They work in the fierce heat, heavily clothed, squatting and hacking out the old stalks with tiny hoes after the oxen and wooden plough have scratched up the dusty surface. They will start to plant any day now. The village should look lovely in a sea of green. The evenings have grown long and cool and this is the time to wander round the village and chat. Never having witnessed an agricultural community at work I have never been interested in crops and methods, but now I long to see the tools they used, in K.L. and the crops they sowed in various parts of the village. Is it possible to work out the distribution of the main crops e-g, from the inventories or surveys? The staple here is, of course, rice, but maize and millet are also extremely important. Am trying to work out the amount of work that goes into each acre of land, and then find out if there is a labour surplus or labour shortage in the village. For instance they take just over a day to plough half an acre, and it takes about 5 women a day to hoe the same area. I don't suppose it will be possible to do the same thing for Kirby, except in a very general way. I think there is probably a considerable labour surplus here, and it is this which has allowed over $70 \%$ of the adult males to be away for much of their time in the army. Even with this absence there is a lot of conspicuous 'wastage' of time - eg. they 
can't work when a person dies, on the day of the funeral, when there is a village 'puja' etc. Work is also done with a high degree of inefficiency - the tools (mostly hands and back) being very adaptable but making every job very time-consuming. But why 'save' time?' Like becoming more than averagely rich here, there is nothing really to spend money/time on, hence no incentive to hoard or acquire. But I imagine things are changing.

Our main work has been directed to the census which has finally got off the ground. I go round with the schoolmaster and squat in the verandahs of the houses and ask them a great stream of questions concerning who is living there, their age, degree of education, age and distance of marriage, number of children died, cause of death of parents, age of the house they live, in, why and when the family lands were last divided etc. etc. So far we have only done 20 out of the 100 families I want to do - it takes nearly an hour to do each house - but the results should be fascinating and., I hope, comparable to K.L. the average number of children born varies between about 5 and 3 , of whom about one third die before they reach the age of ten. Causes of death have varied from a considerable number of T.B. cases to one death by an "invisible bullet" sent by a witch. Most of the houses seem to be less than 50 years old, a large number of them were built just after the first world war, presumably when villagers were returning with money from the fighting. The impression is that land is handed over at death if there is only one son, but divided between brothers when they are all married and have one or two children - ie. when the parental house becomes too small to hold them.

I think that the comparisons with population and land-tenure changes in K.L. should be most interesting as various sources are beginning to emerge which will make it possible to trace land ownership and hence wealth distribution, inheritance etc. over at least 40 years -possibly longer. I don't know if I described in my last letter that a government team came to the village some 5 years ago and made a derailed survey - there were 25 of them apparently and they stayed for 6 months, so it must be pretty detailed - this is in the local government office in Pokhara and shows exactly who owns every field, the value of each field, size etc. This will give me the complete layout now. There are also records kept by the ward headmen, going back for 35 or more years, showing who held land and its value then. I have just extracted a couple of these documents from the village headman and written in Nepali though they are, they look extraordinarily like the surveys we have for K.L. It may, therefore, be possible to show social mobility, population change, and, I hope, the extent of the problem of poverty, over at least two generations. Not only would this be good practice for K.L. it would, I think, he something which no anthropologist has yet done. Let me have your view on this, plus any special problems you are interested in in K.L.

Enough of that, it must be very boring for you Daddy - or at least for Fiona, who is getting the carbon of this letter. But it will at least show that I have managed to create the nearest possible conditions to the shed \& Essex Record Office that I can! A lovely lump of mail has just been brought up to the village three parcels of hooks, including Levi-Strauss etc and thirteen letters. Two of these, both delightful, were from you. Many thanks indeed. I must say the little typewriter in the shed seems to be working very well. Will deal with other mail first, had a letter from Marwick, suggesting I took a job at Stirling University - but the post was for a Gaelic-speaker, which he assumed me to be with our North Uist address. I gently disillusioned him and said that anyhow I hoped to keep out of universities. I suggested that he looked in on you if he wanted to see the kind of work we are doing on Kirby Lonsdale. I hope you don't mind, also a letter from School of Oriental and African Studies, offering me a Postgraduate exhibition worth $\$ 500$ for one year when I return from the field. I had applied before I left. With the money which we will have saved from this trip this should enable us to live comfortably for a year while I write up my thesis.

Thank you for sending me the cutting on the Horne bequest - I might well apply the year after, even though it seems mainly intended for modern European historians. If the calculation that a history book should make $\mathrm{f}, 5,000$ is anywhere near true in my case we should manage to survive a few years on that. Also two letters from Cambridge, one a copy of a letter to you about proofing, indexing etc. I'm sorry they've landed you with so much, but thank you very much for nobly undertaking to do the index. I've never done an index, hut I've asked them to send you a booklet on this. I believe that the best way is to get hundreds of scraps of paper (e.g. like my Great Thoughts cards) and every time you come to a name/place/subject which is of interest jot it down with the page number. This is quicker, in the long run than having a card for each name etc. and writing all reference to that name on this card which involves searching for that card among many others each time one wants to write on it, i.e, it is quicker to write only one reference on one card and then shuffle them out at the 
end.

Hope the proofs ore not too much of a burden. We found it best with the witchcraft ones to get Gill to read aloud, and I checked. As Mrs Skinner suggested, I'll also check them and send you any corrections as soon as possible. I think your idea for a Facket is probably better than hers and am not too happy about her new title. Have written to her about this. Incidentally, had a letter from Granny a month ago - delighted to hear from her.

Masses of things to comment on in your two letters so I will be brief. Sorry to hear about Celia Edye send my commiserations. Glad to hear that the Land Rover has been sold and, of course, we quite understand about Field Head. It is very sweet of you to think of helping towards buying us a cottage, but of course you must take as much money as you need and give some to F. and A. I agree that living in K.L. would not be too good somewhere abut 10 miles away would be better, he would very much like to look around for somewhere when we return, so don't feel you must find somewhere for us quickly. Above all, Gill would like somewhere fairly high up on moors if possible, and I would like somewhere with a big barn(s) or outhouses where I can house an enlarged 'shed'. If money comes from the books, we should be able to find somewhere nice.

Hope clearing of Field Head and arranging its sale went o.k. Thank you for looking after my notes etc. so well. Presumably Daddy will have come down in the Flea by now - hope it did the long journey well \& you will be able to carry quite a few awkward shaped things up in it. Hope you managed to fit in a few books from Freddy as well. I enclose, incidentally, a cheque for f60, dated from May 1st, when there will be a fresh deposit in our account. This is to go towards Freddy's bill (let me know how much it is) and also for you for a) expenses connected with K.L. and Fosselin b) food parcel I asked for c) could you possibly buy Fiona and Granny small birthday presents out of it? Will send some more in the autumn.

Much intrigued by your analysis of the Incredible String Band and Vashti and co. Are they going to land up on your doorstep on the croft. Delighted to hear that the croft, despite the Scavenger, is progressing and look forward to snap of the new and magnificent version. I imagine the fishing is just beginning to improve rapidly. Any sign of life in the little loch we stocked?

Many thanks for the notes from the Dewar MSS, which were fascinating - so many parallels with this place. The fact that 'the living are surrounded by the dead' was brought home to us afresh during the last three days by a funeral which has been going on for three days and nights. Ten or more 'priests' officiate in an incredibly complicated ritual with much dancing, sacrifices, singing, building and destroying of effigies which the dead man inhabits etc. He has finally been forced off to "heaven", despite the monstrous intrigues of countless evil spirits. If we really can, as you believe, penetrate through to this dimension in the K.L. study it would be wonderful. Keep at the -wood work. Glad to hear your book is almost finished: hope it gets enthusiastic reception.

Forgive a dull and factual letter in return for your vivid ones. We think of you both very often. With all our love, Alan and Gill

\section{DIARY Tuesday 15th April Alan}

Went down to school at about 7.00am. and Prasad showed me the records while he was meant to be teaching. Quite extensive and interesting. Also watched the school in action and cogitated on how we might use all this labour. Then went round to Prasad's house and was given tea and a bit of omelette. Talked to his father and did his and neighbour's census. Then Prasad left with a sore eye so came up to house and did bits and pieces.

\section{NOTES 15.4.1969 Alan - Visit to school}

Equipment and building: building is about two and a half times the size of our house, divided into three parts, the central part being enclosed while the other two have no wall facing the path. The classes are distributed as follow: left - beginners; middle 2; right - 4 front, 5 back left, 3 back right. The school had about 20 benches, 2 chairs, one of them broken, 2 tables, one ropey blackboard and the roof badly needs repair. There is no board rubber and they use paper to wipe material off. No books, writing equipment, science equipment, or other 
materials are provided and the students must bring their own. As a result the poorer students have very little to write on; no school meals, milk etc. are provided. Recently the British Camp gave 1,000rs. and with this Prasad hopes to repair the building, buy 4 blackboards, tables, chairs etc. The school was established 11 years ago, and has been receiving financial help from the Government for 9 years. There is no sports ground or play facilities; they have played football (having one ball) on a nearby field, but this is now planted so no more games, except on the path in front of the school. No latrine.

Finances: The Government gives a grant of 220rs. paid in quarterly installments, and out of this has to come the teachers' pay (which last year came to 2,248rs.), examination stationary, etc. The students supplements this by paying small feed (see record of fees) of 393rs. and there may also be a tax of 25rs. per ropani of land, paid by all landowners, if this is needed. Last year with a balance of $137 \mathrm{rs}$. this was not called for. The masters' money is kept by the treasurer of the school committee and when the schoolmasters want money they have to go and ask for it from the treasurer. Last year Prasad had to wait from Katik to Asar before being paid. Whether they are paid depends on whether there is money in the school fund. Prasad estimates that a schoolmaster needs 150rs. minimum per month to live on, therefore second and third schoolmasters must live off their land also. If they were teaching in another village they would have to be paid 150rs. minimum. For more detailed account of finances, see yearly report, monthly report etc.15.4.1969AlanVisit to the day school Curriculum: To judge from the letters from the Jila Panchayat there is little control of the curriculum (qv.). Classes 3,4, and 5 (for number and size of classes see monthly reports) learn English, Nepali, mathematics, history, geography and simple science. Classes 1 and 2 learn simple maths and Nepali, and a class of beginners learn the Nepali alphabet. All teaching is in Nepali and an equal amount of time is spent on each subject, theoretically 1.5 hours is spent per subject, half an hour being given to each of the three classes. Prasad teaches the top three classes, and Gunja the other three. Mathematics is apparently their favourite subject, though they do not in 5 years get up to algebra or geometry which they start in the 6th class at Pokhara. Class 2 is not [?] subtraction and multiplication. Normally people are in a class for one year, though quite a few fail the annual exams and do not move up (see exam results). 1, 2 and 3 are given prizes. There is no art or music teaching, though Prasad hops to start art teaching next year. A very small percentage of students goes on to further education in Pokhara. There are now 4 students in Pokhara. For instance Durgakumari who is the most intelligent girl in class 4 will not go on to Pokhara Prasad thinks because "her parents are not so rich".

On the whole the students seem to be quite well equipped with books, bringing all their books in a satchel every day. Some of them have to carry this from about an hour's walk from the school, and all the Thakians have a long walk down the hill and back every day. The books they use are quite well illustrated and the content matter seems reasonable, for instance the book on science has sections on gravitation, matter, winds, clouds, magnets (though there is no magnet to demonstrate with) life histories of bees, diet and hygiene. When there is morning school, school lasts from 6-10am. with a quarter hour break between classes, and a half holiday on Fridays, and a whole holiday on Saturday. Normal school is from 10-4pm. with a break in the morning. This stops when it gets hot and work is done in the cool mornings.

Girls and boys tend to sit separately, age range is from 8-12 years. Beginner's class seem to do hardly any work, just sit on planks on the floor, and another on benches, fighting, scuffling around; they were supposed to be learning Nepali alphabet, and nothing else. A few were grasping one sheet of paper with letters on it. Class 1 were slightly less restless, and were chanting aloud from a book, girls seemed more attentive and industrious than the boys. Neither class stood up or did anything when I came, although the top three classes stood up when I came in. Schoolmaster appears to leave them on their own for quite a bit. The second 
class in the central partition is already much quieter and more attentive. They bring sums through for the schoolmaster to correct. Classes 3,4 and 5 are orderly and quiet. On the whole each class gets on with its work while another class is being taught. The teaching is modelled on English schools, the teacher standing at the front and the children in a semicircle facing him. There is more informality and it is all very relaxed, for instance, one of the little girls is asleep on her satchel, she has a cold, and Comal sits in the mater's chair when Prasad is doing sums on the board. The technique seems to be that each class gets on with work on their own for an hour, this is then corrected by showing the right way of doing sums on the board. While demonstrating the right way there is not much attempt to make the children themselves do the sums, no direct questions asked of the class as a whole, or individuals.

Prasad explained that all the school was providing was demonstration of how the thing should be done, and they should actually do the work at home, but the villagers on the whole misguidedly thought that reading should only be done at school. When I asked about punishment Prasad said they usually used words, but for the beginners, who are unruly, he had to use a "stick", sometimes once or twice a week. He hits them on the hand. He never hits the upper classes. Sometimes they are punished for coming late to school, sometimes by making them stand for the whole lesson. There doesn't seem to be much competition among the students. I asked Prasad what was the purpose of education, especially girls, and he said it was very important "for the present condition of the country". When a mother was well educated, then her children would be well taught.

On this morning there were only ten pupils in the first three classes (top three) so the teacherpupil ratio was high. An interesting example of the lack of conflict between education and older beliefs was the presence in one corner of the schoolroom of a small shrine (bamboo, cow dung, table of stones, etc. to the goddess Sarasati, which had been made recently (see notes). Some girls in class 4 were reading a book on hygiene and diet, so I got Prasad to ask them a few questions about what they had been reading. They stood up to answer and were very shy. To the question "what made a good diet", they said calcium, protein, vitamins, etc. but found it difficult [to say] what vitamins actually came from. When I asked how one should deal with the problem of flies infecting food as illustrated in the diagram, one little girl said that food (rice) should be eaten immediately after it is cooked and not kept. She also said that a latrine should be at a "fixed point". The lesson ended just after ten and a primitive school bell was hit by one of the children and all the young children went off screaming.

Letters from Department of Education (Jila Panchayat) - file of, showing date of receipt etc. mostly printed circulars. 1. Every primary school must have a teacher(s) who has had government "normal training" (6 months) - Prasad has S.L.C. which is considered equivalent. 2. If school needs stationary, books etc. must contact Jila Panchayat - in fact, AKP says, it is easier to go to bookshop oneself - difficult to contact Jila Panchayat. 3. Secretary of village Panchayat cannot be a member of the school committee. 4. School must fill in yearly reports. 5. Government money will henceforth be paid quarterly (not annually). 6 . Must be a minimum of 3 teachers in a primary school. How many rupees do you collect from village? 7. If a roof of tin is needed for the school contact Jila Panchayat. 8. What building repairs are needed for school?

Income - 2025-4-21 Sarkar 2,200rs.; Balance for the previous year 84.50rs.; Monthly fees for students 397rs. Total 2,681.50rs. Expenditure - 2025-4-21 Akayprasad (this includes paper etc. for school) 1,350rs.; Gungabahadur 693.50rs.; Syebahadur (treasurer) 36rs.; Ramchandra schoolmaster 205rs. $=$ total 2,284.50rs.

Separate sheet 2023-2024 - 3 record books, teachers attendance etc. 18.50rs., 2 packets of chalk 6rs., 2 rulers 3rs., 1 gum 3rs., decorating paper 1rs., 2 dozen pins 2rs. total 33.50rs. 2024-2025 total 41.75rs. 
Taxation for school25 paise per ropani of land - records with Pradhan Panch? = 'chanda' Committee Members 1969Ramchandra (Chairman - ex-officio), Jusbahadur (House49) (Secretary), Syebahadur (Treasurer), Brikaras, Sujebahadur, Badrasing (House22), Gungabahadur. They sometimes meet once a month or in 2 months. They will soon be meeting about the repair of the school building etc. with the 10050rs. given by the British Camp. (Prasad seems to know already what this money will be spent on).

TAPE RECORDINGS - Village dance (Tetera sheba) on 15th April

'Tetara sheba' - Nepali song

Untouchable women singing "Gaye dayu gita ta nache dayu gobini, bajai dau basauri Krishna..."

https://sms.cam.ac.uk/media/2733265

'Tetara sheba' - Nepali song

Untouchable women singing

https://sms.cam.ac.uk/media/2733282

'Tetara sheba' - Nepali song

Untouchable women singing "Dajhu bhai kamrai kasera, himala ko kakhai ma basera..." https://sms.cam.ac.uk/media/2733296

'Tetara sheba' - Nepali song

Untouchable women singing "Sitara bhare ko dori, chudera fhijiyo bhan bhari..."

https://sms.cam.ac.uk/media/2733313

'Tetara sheba' - Nepali song

Untouchable women singing "Kasto maya, kasto maya, kasto maya lacha re, udi jane yo chola lai..."

https://sms.cam.ac.uk/media/2733330

\section{NOTES 15.4.1969 Alan - Dance at Bhuwansing's}

'Tetara sheba' at Bhuwansing's. A primitive 'stage' with a blanket as a curtain was rigged up in Bhuwansing's courtyard (Bhuwansing's was chosen because it had a good courtyard; also presumably because he would give money, $5 \mathrm{rs}$ in this case. Most of village seemed to attend. Lasted from 8 p.m. to 10.30 p.m. Audience joined in clapping, singing and dancers wore dark glasses, sari etc. On the first dance boy with "flute" (i.e. fingers) has girl in sari, dark glasses, and gold necklace with symbolic hand gestures (very Indian). She uses the necklace in the dance and finally gives it to him and they retire behind the rug. The second dance done by some young man and woman, the third, another girl and same man. Later a middle-aged "clown" mimics them, dancing well. Also a very sexy young man dances jive-like which audience love. He also dresses up in mufflers, tight trousers etc. and mimics a pregnant woman? or sick person, the songs are a cycle re 'Ram Shita (cf tapes). Money will go on a buffalo. Five people later possessed (see elsewhere).

DIARY Wednesday 16th April Alan

Went down to Prasad's at 10.30am. and did another six houses of the census in the region of his house. A thundery day with rain in the evening. Rather tired after climb down and back and four hour's interviewing. Gill plodded on with 6 pages of Pignede. People busily bringing 
in the wood now, eg. our neighbours stacking it high in front of our house. Both of us have coughs and colds. Have finished reading Banfield's "Moral Basis" - a most stimulating, wellwritten and enjoyable book with many fruitful cfs. to Thak and an intriguing central thesis worth exploring further - though only scratching surface.

\section{DIARY Thursday 17th April Alan}

A bitty day. Drizzling most of the day and temp. down to 50. Visited by Dankumari who brought us some venison shot by her father, and also by Prem who was cheerful and provided a lot of information. Otherwise did Pignede, school, etc. Two untouchables zipped off to Pokhara and bought kerosene, etc. for 12rs. each.

\section{DIARY Friday 18th April Alan}

A fine day - very beautiful in the morning when we went down early (c.7.30am.) to the school for Gill to see how it worked. We attended a "school meeting" at which the children sang very sweet. Then we went round near Prasad's house and did six more of the census. Gill came. Very hot and longish tramp, but some interesting houses. Came back fairly exhausted to feast on venison which the Lt. had killed in the forest. Villagers still busy bringing in wood.

\section{NOTES 18.4.1969 - Alan - Education}

(From Easy English Reader 5th class). Health is very important. Without it we cannot enjoy life. We can't do anything without good health...good food is necessary for good health. Our body needs some meat, egg(s) or milk. So we must eat one or two eggs a day or we must have one or two pieces of meat once or twice a day. We must also drink about half a litre of milk a day. There must be some beans and two or three vegetables in our daily food. One of the vegetables must be green and leafy. Another necessary thing for us is water. Ordinary water is not safe for drinking. Such water brings diseases. We must boil the water. To filter the water before drinking is still better. Another rule for good health is to be clean. Our house must be clean, our clothes must be clean. A dirty man often falls ill. Exercise is also a necessary thing for health. Walking is a good kind of exercise. Our country Nepal - exercise.

Our Country Nepal. We now have good roads, postal service, more food each year, factories, sugar, matches and 'many good things', schools, hospitals and good doctors.

The boy (Lakchman) of twenty-five who, with Prasad, was the only one to have passed the SLC examination (10 years) in the village was definitely surly and discontented when we met him this morning.

\section{NOTES 18.4.1969 - Alan - Child rearing}

A baby is first fed four to five times a day, on demand (this was with reference to a 3-month old baby). There is no special time and the mother feeds it when it is crying or when she thinks it is hungry. After 5-6 months it is also given buffalo milk. She stops feeding this last baby as soon as she is sure she is pregnant again. If baby is the last child mother goes on feeding until 5-7 years old (oldest child so far seen being fed was 4 years). She stops feeding because she thinks her milk is bad because of the new pregnancy and the baby will get dysentery. Weans gradually, takes about a month. Feeds it 2-3 times a day the first day, 1-2 the second and so on. Some families use a 'zudani' glass for feeding (but rare?) others dip their fingers in the milk and feed their finger to the baby. If a mother has a child every year, then the last child is only breast fed for 7-8 months. Weaning process not thought of as difficult - 
"the baby is given rice with butter etc. so it does not cry". Toilet training - no special effort made, child can manage on its own at 3-4 years old.

\section{DIARY Saturday 19th April Alan}

Another somewhat fiddly day as Prasad, despite constant promises, again failed to turn up. For some reason my temper is very bad and I tend to snap a lot at Gill, especially now that she has a bad cough and cold and is unable to hear what I say very well. Got on with Pignede, etc. Thundery, with rain in the evening. Most people either getting in wood or making fences, or doing Garda Sheba. Long for home. Started reading Levi-Strauss "Structural Anthropology" - very exciting: a useful essay on history and anthropology. Not as good as E-P's, but along the same lines.

\section{DIARY Sunday 20th April Alan}

Went for a "picnic" to the river with Lt. and family. More pleasant than we either expected and we reeled about filled with 'pa' and feasted on chicken and deer, etc. Swam and washed and started reading "Taboo" by Steiner. Arrived back weary and rested. Still longing for England.

\section{DIARY Monday 21st April Alan}

A day crammed with visitors since this was a puja in the school next door and no one in the village was allowed to work. Prem came in morning and evening - for 2rs. a time - and gave some very valuable information on 'nogara', village scandals, etc. Then went round on census with Prasad and did ten houses. Thunder and rain. Gill continues with her bad cough, etc. Under the weather, but I feel better working.

\section{DIARY Tuesday 22nd April Alan}

Starting hot with thunder in evening. Prasad again unable to come as he wanted to buy buffalo flesh in the forest - off a buffalo that had fallen and died there. Wrote letters, etc. After lunch we were disturbed by someone asking if we could swim and found a Tulemae boy of 15 had drowned [son of Chandrasing (House44A)]. He was fished out before we got down to Tadsyon Kola. Family very sad.

LETTER from Alan to parents, dated 24.4.1969 but written on 22nd

Hope you received our letter entrusted to a little Gurung boy going to school in Pokhara, and sent about ten days ago. As in that letter, I will give our news first and answer any points in your letter when I go to Pokhara to post this. This will be our last letter before we go to Kathmandu about 13th May, so the next letter will be about two and a half weeks after this one

We continue to have lovely picnics at the river - or rather beck - each Sunday. Last week I went fishing and caught a couple of minute fish, but it is difficult to find bait. Two days ago we went for a picnic with the Gurung Lt. and his wife and children whom I think we mentioned earlier. It was much more pleasant than anticipated with rice beer to make us fuzzy and a delicious meal of chicken and venison curry (the Lt. had just shot a deer in the forest). Gill swam and I lazed in the shade.

Otherwise my time has been mainly spent in trying to organise the reluctant schoolmaster into climbing the hill from his house to do the census. Each household takes a little under an hour, so it is a slow business, but we have now done 55 houses and only have 35 or so more to do. We might even get it done before our Kathmandu trip. Poor Gill has to spend much of her time drawing lines for the census schedule, and the rest of 
the time translating Pignède's work on the Gurungs

I'm afraid that, since we don't do much outside watching and analysing the village this letter will be mainly on "work" subjects. Most of our efforts at the moment, apart from the census and funeral etc. are concerned with analysing the economic structure. Taking one assessment of each household's wealth graded in five divisions from very rich, rich, middling, poor, very poor, there are the following number of persons in each category in the 71 occupied houses in the central part of the village: very rich (1), rich (12), middling (16), poor (36), very poor (mostly Untouchable households) (13). Thus one finds a structure which is I think fairly characteristic of pre-industrial societies - approximately half the population poor, and not so many either very poor or very rich. I hope, of course, to find out how this structure has changed over the last thirty years and it will be very interesting to $\mathrm{cf}$. with K.L., Boreham etc. Wealth is still largely defined by the number of fields, especially rice fields, one has.

Almost everyone in the village eats rice at least once a day (and usually very little else), but of the 71 households in this part of the village, only 17 have enough rice fields to supply their own wants. The rest have to buy or work for it - mainly for the six families which have large surpluses. I wonder if there was anything similar in K.L.? The really poor families are those with no lands - or the 71 there are 17 without any land, all but five of them Untouchables. One or two have pensions to raise them from the lowest level. Another seven families only have one or two small millet fields. Again the proportions will have changed over time and will bear comparison to K.L.

As well as fields most families have a small amount of livestock. A rich family would have, for example, 2 buffaloes, 7 cowes, 2 oxen, no goats, 6 chickens (this is an actual case), a middling family might have 2 buffaloes, 6 goats, an ox, 8 chickens, a poor family 1 buffalo and 7 chickens, a very poor family 4 chickens (these are all instances). Given that an average buffalo costs about $\mathcal{L}_{20}$, an average ox about $\mathrm{E} 14$, an average goat $\mathcal{E}_{2}$, a cow about $\mathrm{f} 10$, and an average chicken about $7 s 6 d$, it can be seen that livestock ownership runs from about $f 130$ for the rich family, f68 for the middling one, E22 for the poor family, and 30s. for the very poor family. I don't know yet what proportion of the total wealth of a family this represents, but I would like to know how it compares to the livestock in the K.L. inventories.

The houses here are not a direct index of family wealth - some of the rich families live in thatched middling-sized houses which would cost about $\mathrm{f} 400$ to buy or build, while there are several stone-roofed ones which are owned by middling families which cost $\ldots 500$. The Lt. whose fields make him a middling wealth man, last year bought his large and splendid house for 6600 . Have you any clue as to the amount invested in building houses in K.L. and how this changed over time, or differentiated out the classes? A re-working of Fosselin would show what proportion of his wealth was invested in building activities. As yet the only clue I have as to the amount of wealth in land held by each person is that the Lt. reckoned to be of a middle position, says he has spent about f 700 on land. From this one could guess that rich people have more than f 1,000 in land, while the poor probably only have E100-200 worth of land.

Considering that this is their total capital, from which they have, often to feed 5 or 6 mouths, one can begin to see why sugar is a luxury which even the richest can scarcely afford and meat is only eaten by the rich and poor alike after some special puja, funeral etc.

I have the impression from all this that their per capita wealth is therefore considerably lower than that of K.L., (at least by the end of the C17) - but maybe I'm wrong. When I have done the study of landownership I will write more definitely about this. I am particularly interested to find out why certain families are rich in this generation and others poor - I have a feeling that it will largely be explained by demographic factors, the age at death of mother and father in the last generation, and above all, the number of sons among whom land has been divided over the last two generations. Where the original fertile lower rice fields have not been divided for two generations, the family is now rich (comparatively) and vice versa. Land is equally divided between all sons.

Since writing the last paragraph we have had lunch and just after lunch someone shouted up to our window to ask if we could swim. We admitted we could and it emerged that a boy had fallen into the little river/beck to which we go for out picnics and had just drowned. They could not recover his body which had sunk behind a waterfall and wanted us to retrieve it. So we went down with ropes etc., about an hour's steep walk down. But the body had already been retrieved with a long stick and the relatives were squatting round it wailing. We recognised him vaguely - a boy of about 15, the eldest son and one of the two bread-winners in a 
very poor Untouchable family. Naturally the relatives were very miserable. It brought home the crushing economic effects of death in a society such as this. The few Gurungs who can swim were either at the forest or away in Pokhara at the time. He had been cutting grass high above the river, slipped and fallen down a short cliff, badly hitting his head on the way and was probably unconscious when he hit the water. There was no one around who could swim. Gill tried a little artificial respiration but he had been dead for at least two hours so there was little hope.

Otherwise life in the village continues at its unhurried pace; a rhythm which is reflected and symbolized in the one Gurung dance of importance, the 'gar sheba', which I think we have already described. The slow thudding of drums and long, repetitive, chant of the men echo through the village almost every night now as the season for this dance draws to a close. In ten days there will be five days of dancing when the whole cycle and myth are danced through, then there will be a huge feast with the money that has been collected at every childbirth, wedding and stranger's visit to the village. Ten or more of the adult men spend several days a week doing this; combined with this are various prohibitions on work - for instance, yesterday the whole village was forbidden to work as seeds of rice, millet etc. were sprinkled with water and earth in each household in order to ensure the future good harvest.

I am keeping a record of the activities of two of the families of the village - a rich and a poor one, and it is obvious that there is not enough work, at least in the slack months between mid-November and April, to go round. But I think I have harped on this subject already. Have been learning some interesting facts about what happens to government money sent to the village, but will not entrust these to the post. Another future project is the study of the little village school. We have been down two days to see how they teach (it is half an hour down a sheer (almost) cliff to the building). The equipment is pitiable, the subject matter only moderately useful or interesting, but the teaching reasonable and the children adorable and intelligent. There are good school records attendance, finances of, etc. for the last year and possibly, in Pokhara, for eight or nine years. We hope to set one or two competitions for the school - a drawing on, an essay one etc.

What are K.L. school records like? I forget. Not much good until the C18 or C19 I imagine. The proportion of their total wealth which the villagers are prepared to give to the school is minute; the total school fees for about 60 children for one year would not buy a buffalo, ie. less than \&20. The schoolmasters are paid by the government - the second and third masters get $\mathcal{E}^{4}$ per month and it is reckoned they cannot live for less than f6-7, hence they help with their fathers' farms in their spare time. It is not surprising that the school has no books, one almost useless blackboard, one chair, no duster, no playground etc. But when some wandering Hindu priests turn up to lecture the villagers on how they should live purely, large cauldrons of rice are produced, rupees collected, kerosene light found (ours!). But perhaps the villagers are right. Western type literacy can hardly help the women who form half the school children and only the richest families can afford to send their children to school beyond the age of twelve. Even if they are fully "educated" what is there for them to do? Nepal has a tiny bureaucracy and only two towns - the rush to education will probably have as harmful results as the introduction of Western medicine without birth control will have (and is having) in the East. But that is a subject best kept to another letter! Will leave a space here to answer any urgent point in your letter. 


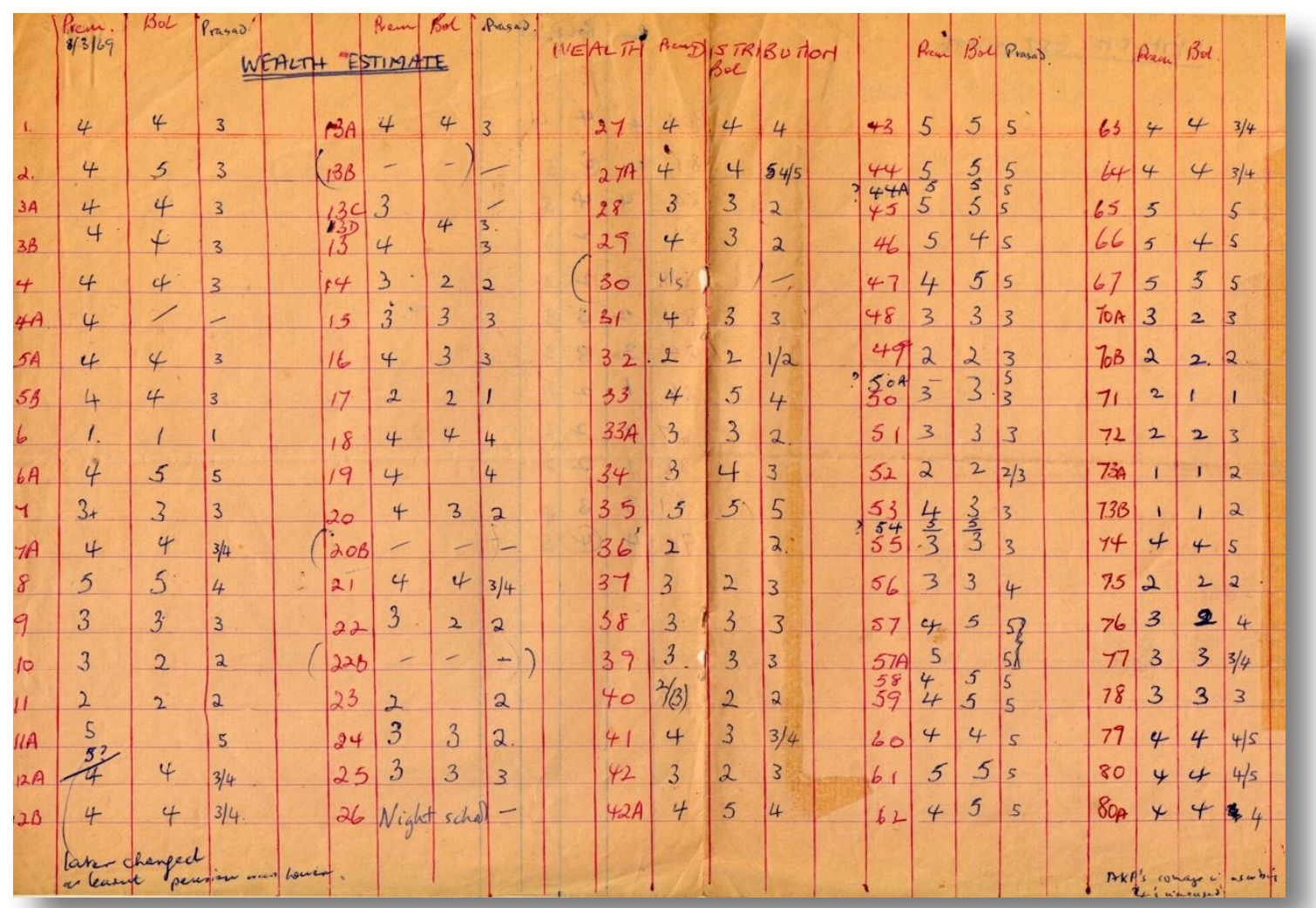

Estimate of relative wealth - referred to in letter

DIARY Wednesday 23rd April Alan

Went round on census and did another ten families - now up to 65. Wrote letters and prepared for Pokhara.

DIARY Thursday 24th April Alan

To Pokhara - very hot and tiring with an hour and a half in Post Office posting and retrieving bits of the witchcraft book. A lot of pamphlets, parcels, etc. arrived plus some nice letters, but none from Mummy. Left at 5.15 and only staggered home at about $7.00 \mathrm{pm}$.

\section{DIARY Friday 25th April Alan}

Again very hot, but we didn't notice the heat so much. Prasad again failed us and we spent a leisurely day reading, translating Pignede, and, finally checking my witchcraft proofs for a couple of hours. Again refreshing to read this and brings back memories. Gill homesick. Reorganized my minute working space.

\section{DIARY Saturday 26th April Alan}

Another hot day - checked proofs in the morning and Prasad turned up at 10.30 and we did another ten houses. Now $7 r$ ??? done. Gill working hard at Pignede. The village quiet, though quite a lot of people coming for medicine, especially eyes and stomach. Gave 35rs. for a tin of kerosene for the Garda Sheba and also our kerosene lamp - (total of 160rs.). The rest of our 
contribution will be in medicine at the end. Read first issue of "Local Population Studies" (Camb. Grp.) - interesting, if provincial and narrow. No inkling of sociological horizons. A new orthodoxy of FRF's [Family Reconstitutions Forms] has been born.

\section{DIARY Sunday 27th April Alan}

To the river in the morning - hot and restful. Gill swam and we feasted on mushroom soup. Came back at about 3.00pm. to do some more census. Prasad turned up 3.30 and we did five families in the next three hours. Gill now fairly well, having thrown off tummy trouble and cough.

\section{DIARY Monday 28th April Alan}

Hot again and Prasad failed to turn up once again. Spent some of the day chasing a chicken for supper with Comal, also did usual stint of proof-reading, plus finishing off proof-reading. Prem came for a couple of hours and we discussed horoscopes used by poju and other subjects. Gill's appetite good - but she is still having bad dreams and tires easily. I still long for home as much as she does, but try to busy myself in Levi-Strauss work, etc. Ate chicken in evening and tape-recorded Gurung songs.

\section{TAPE RECORDING}

Nepali song

Prem singing a 'lahare bhaka' song which goes as "Jali todera katai na jhau ae mayalu malai chode ra ..."

https://sms.cam.ac.uk/media/2733347

Gurung song

Bopal singing a Gurung song "Till till bhyosi tiba, rosa remai yosi jhan dil tiba, danda kamala, mero ko chara saathi..."

https://sms.cam.ac.uk/media/2733364

\section{DIARY Tuesday 29th April Alan}

Gill's birthday. Had a special supper of tinned fruit, tinned fruit cocktail, etc. Actually she was more homesick than usual, weeping at least six times. No Prasad, but started collecting information on harvest figures and also expenditure in Pokhara. 


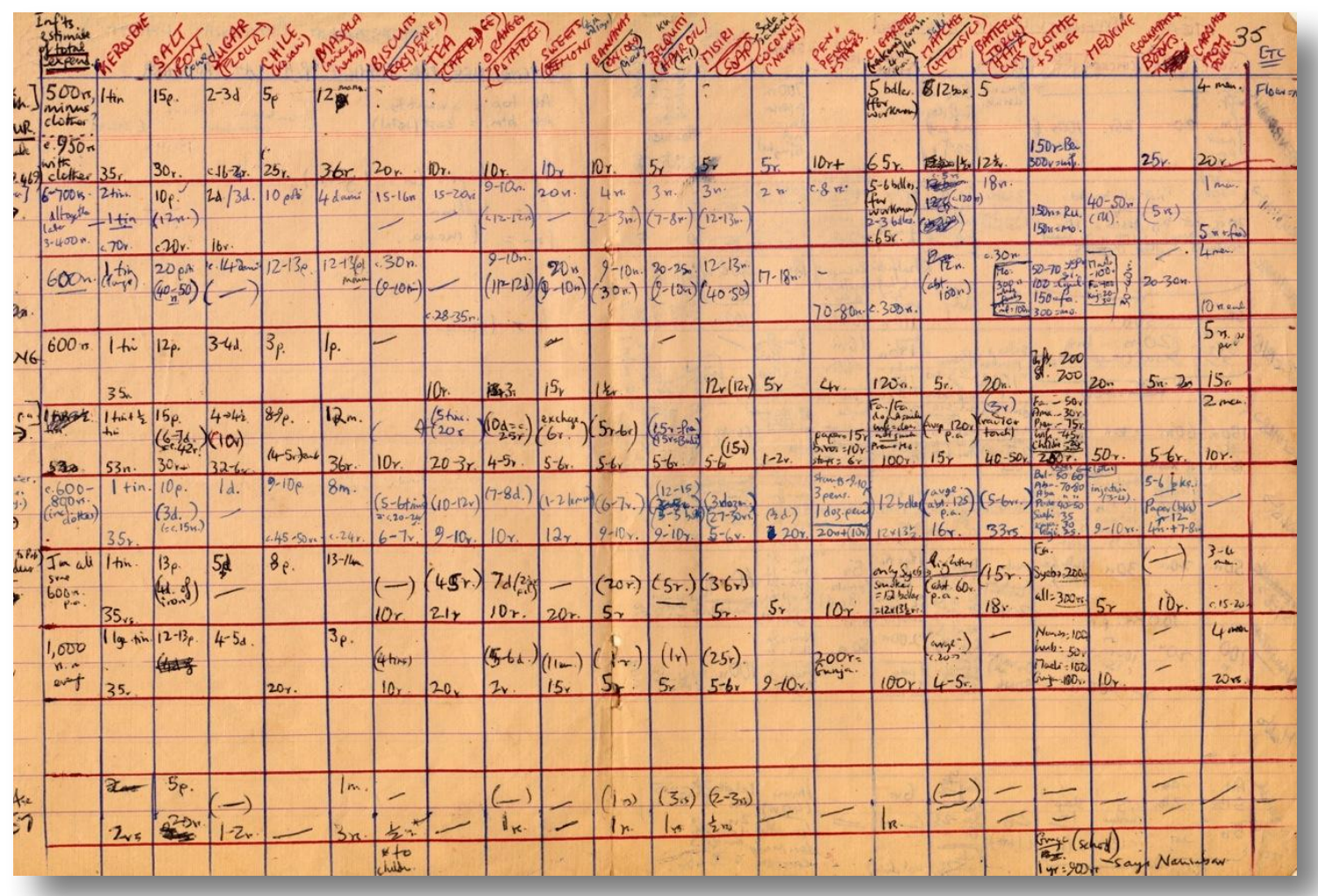

Figures for various families and their annual expenditure in Pokhara 


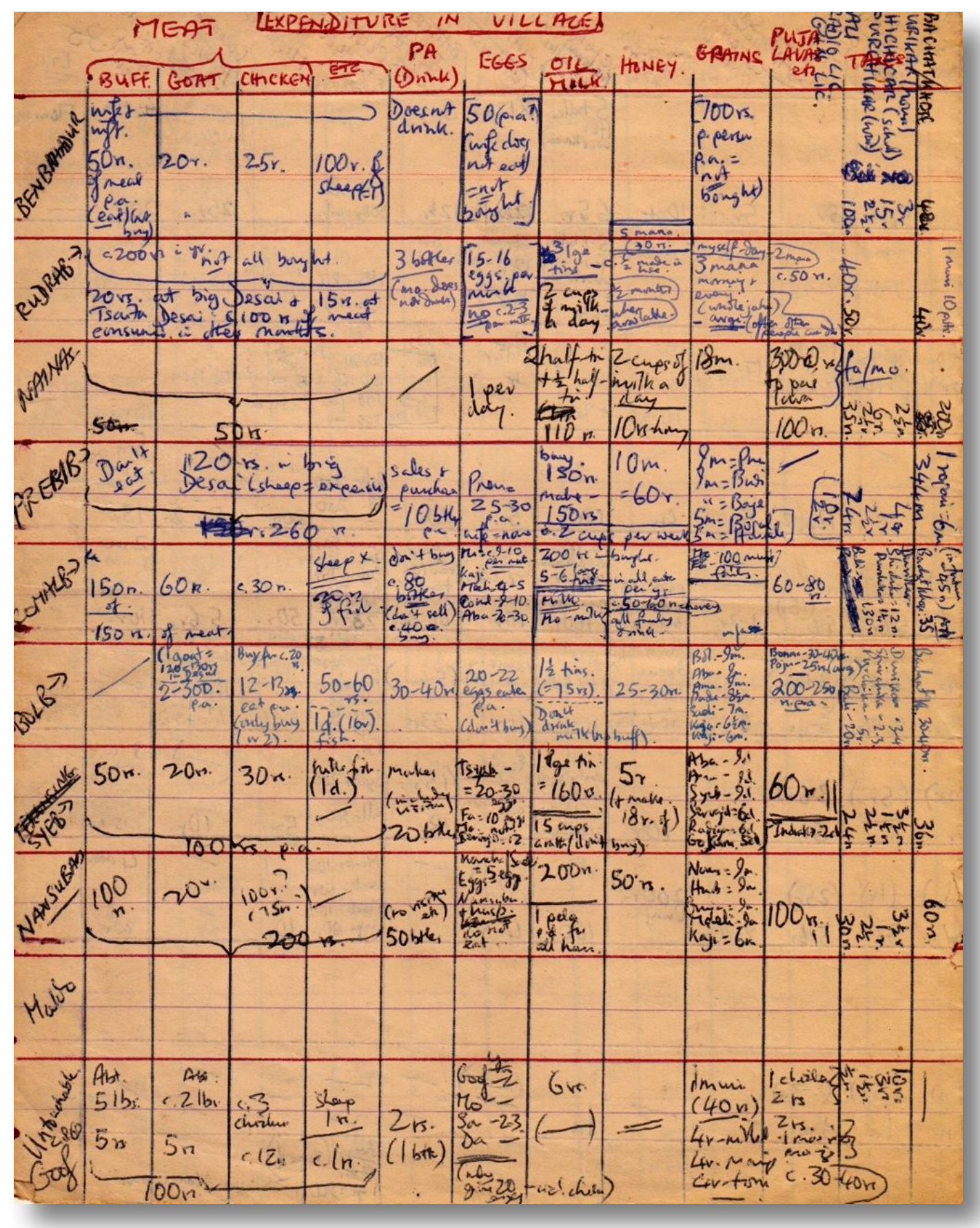

Expenditure in the village on various items

People beginning to be excited at the thought of Baisak Purne. A Garda Sheba was held (I think) in honour of us - we having given our kerosene lamp and kerosene (1 tin) to village. We were too tired to go.

\section{DIARY Wednesday 30th April Alan}

Heavy rain in the morning, but cleared in the evening and we went up the hill to read, etc. Started the analysis of the village into 'jats' - map of. Dug a new toilet. Our wood - apparently donated by various other villagers, has started to arrive. 


\section{MAY 1969}

\section{Undated photographs of individuals and family groups}

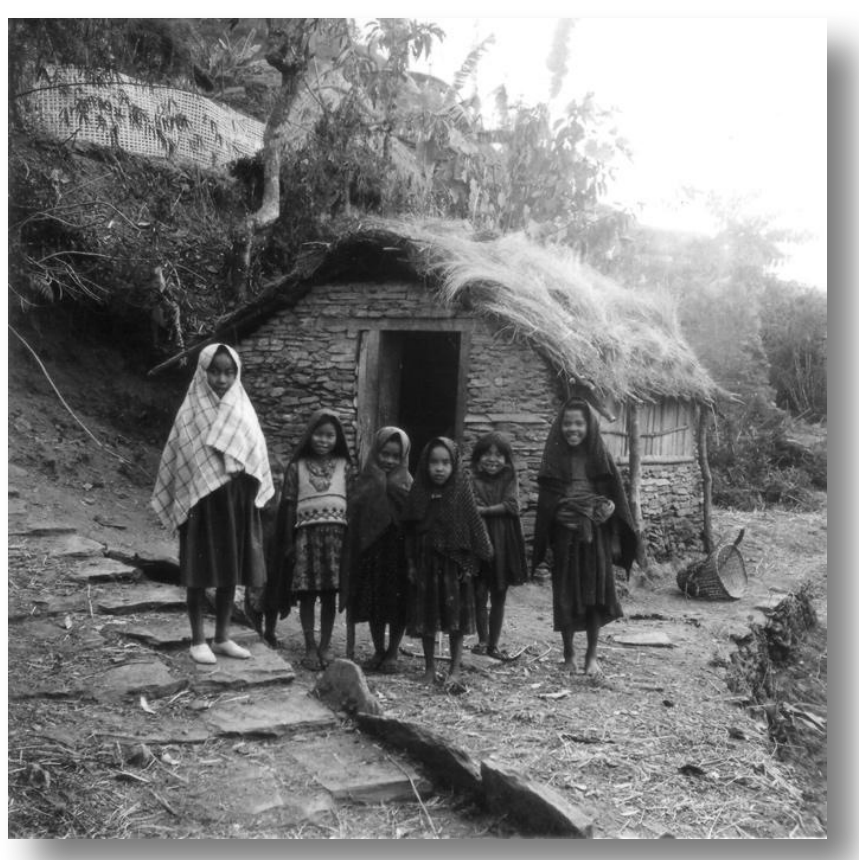

Little girls standing in front of a small teahouse [later House92].

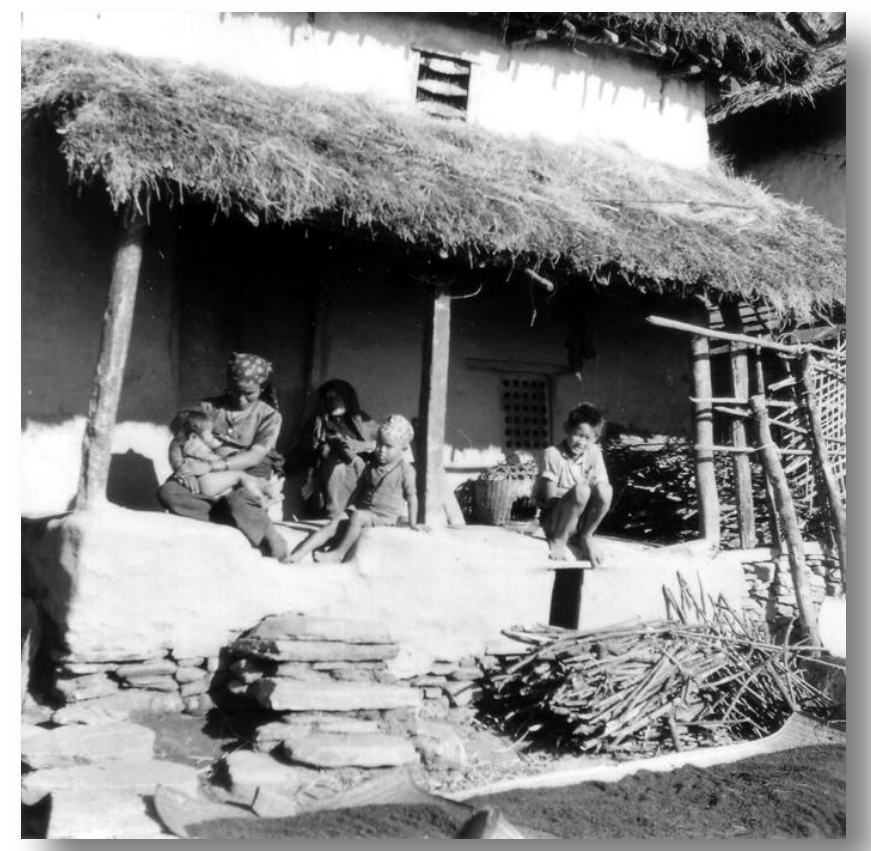

Woman nursing a small girl at House33 


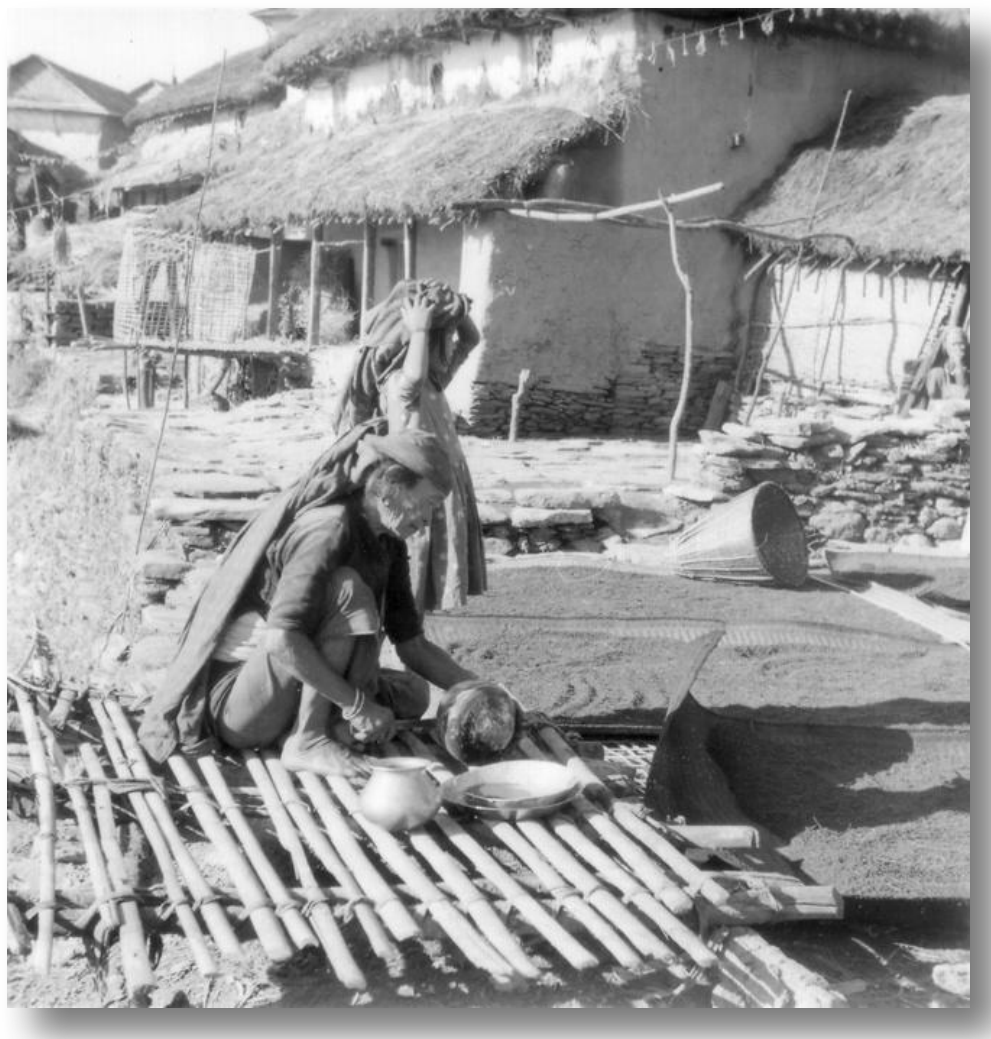

Budisiri washing up on a bamboo frame outside her house

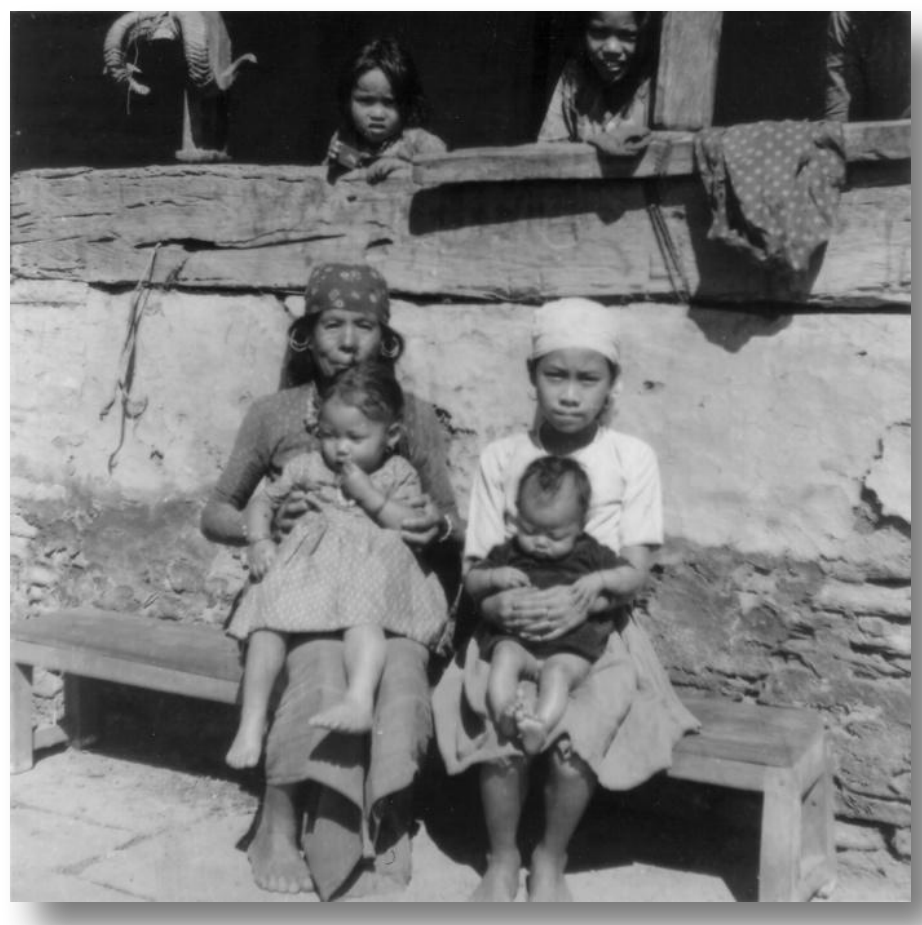

Tikmaya and daughter, Himadebi, sitting outside house with Humkumari and Dilmaya on their laps 


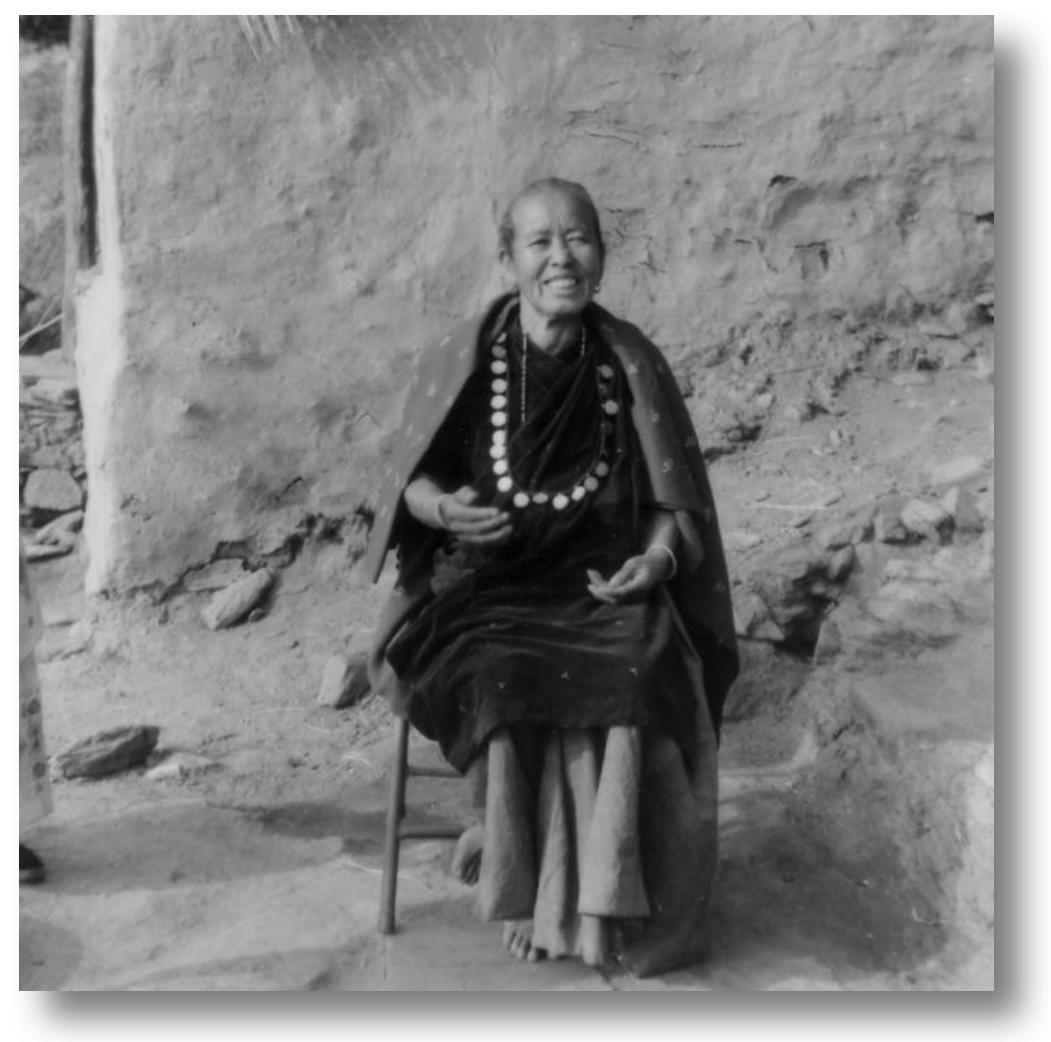

Shirshuba, aged 66, wearing a coin necklace

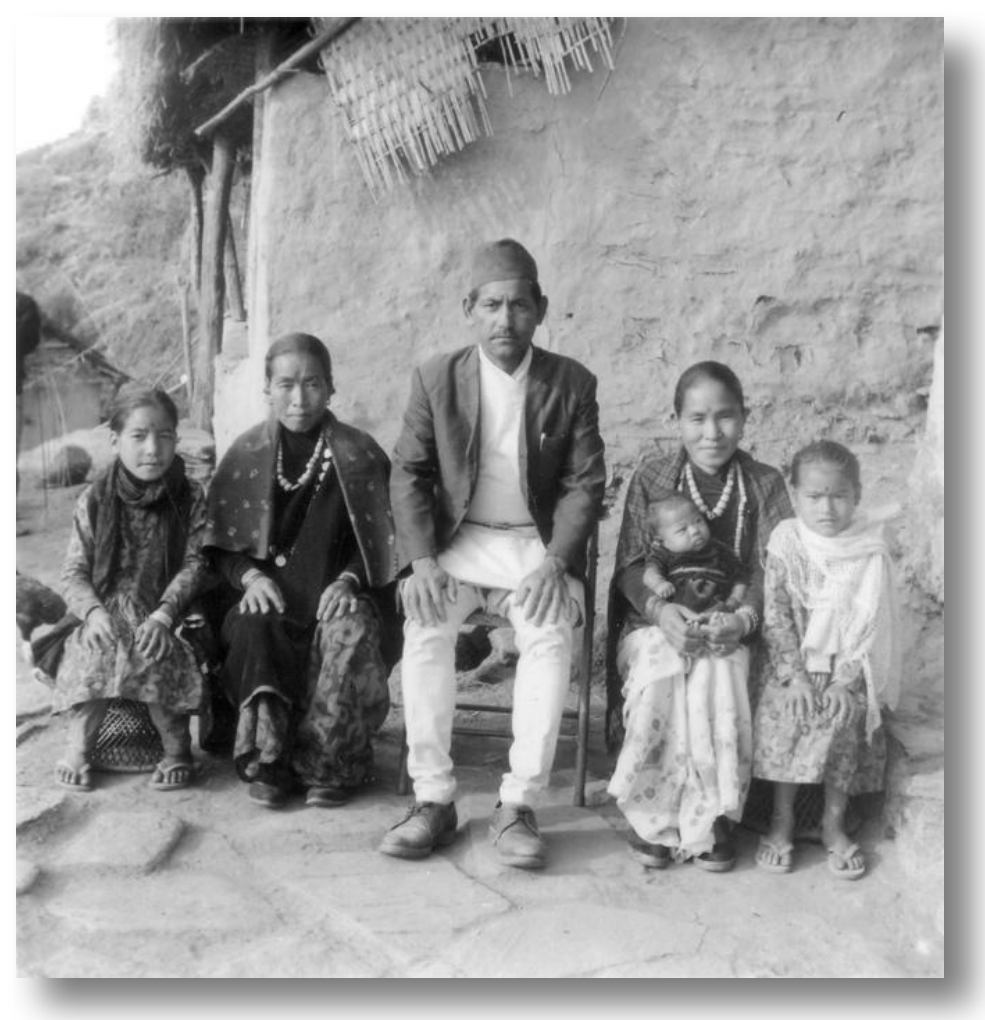

Ramchandra and his family with sister-in-law from Mohoriya (right) 


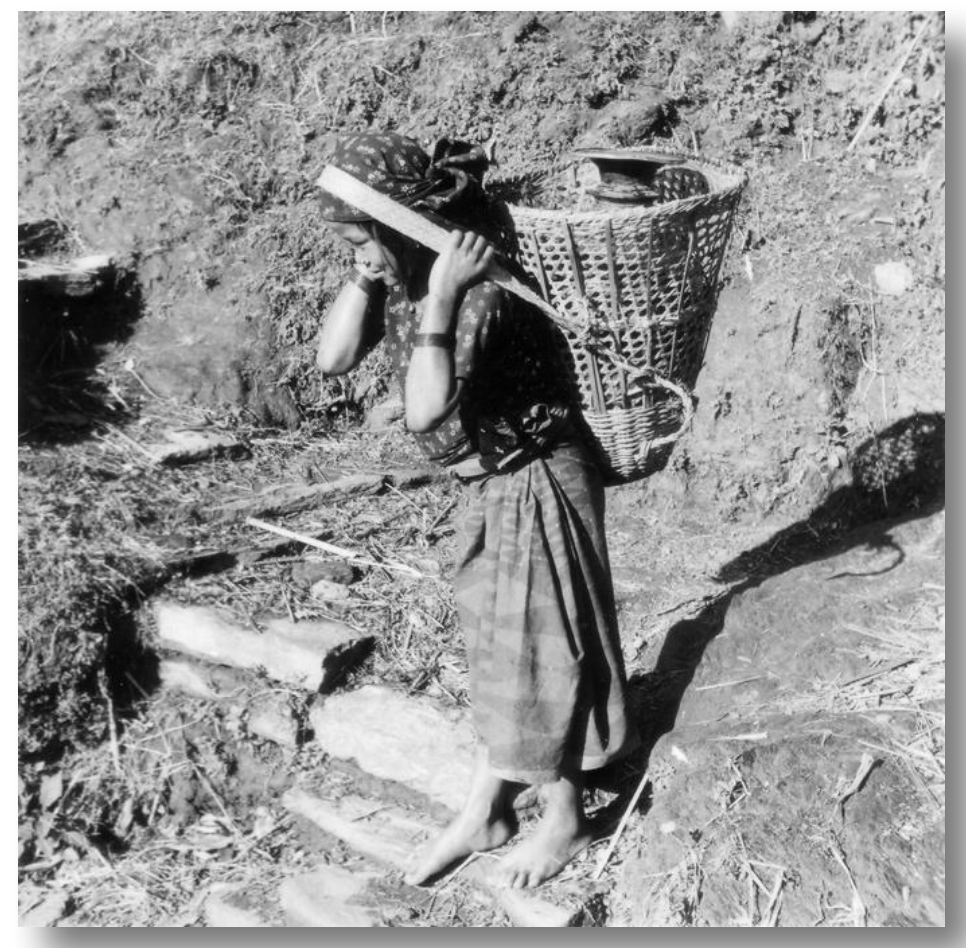

Belkumari carrying water

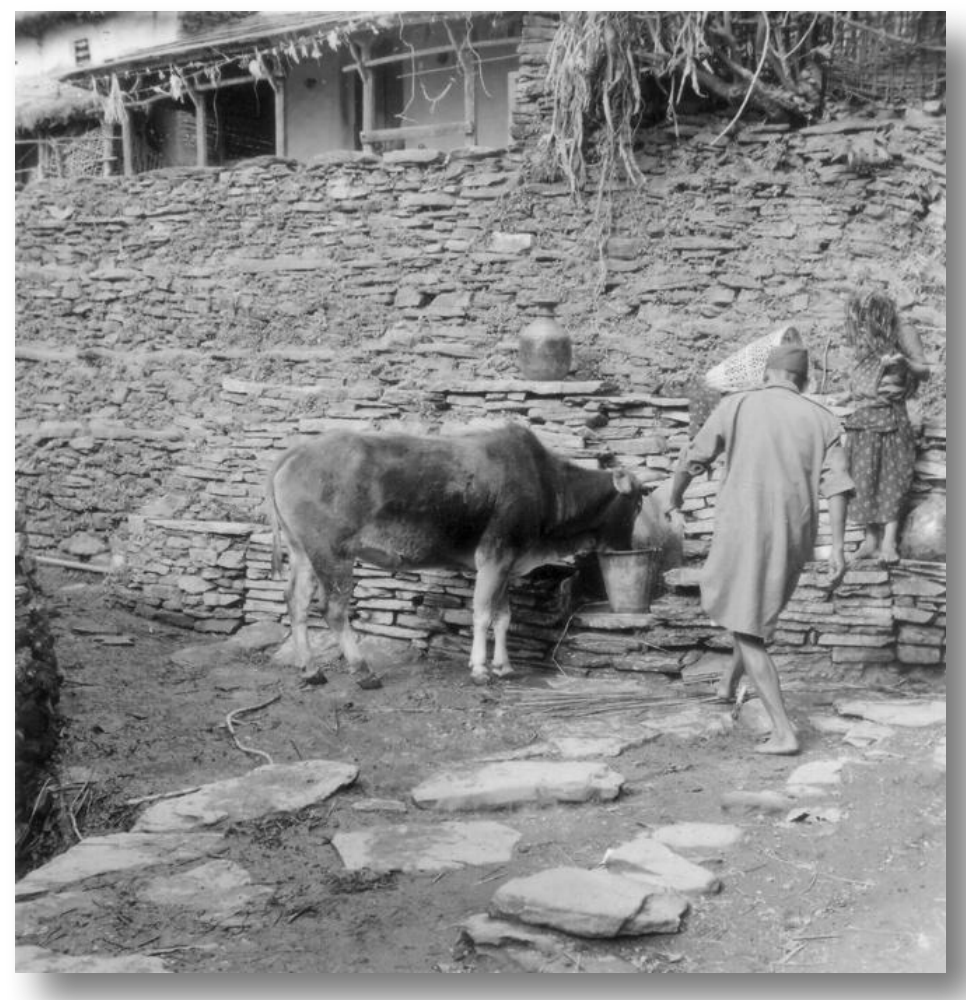

Narbir watering an ox next to the water pipe 


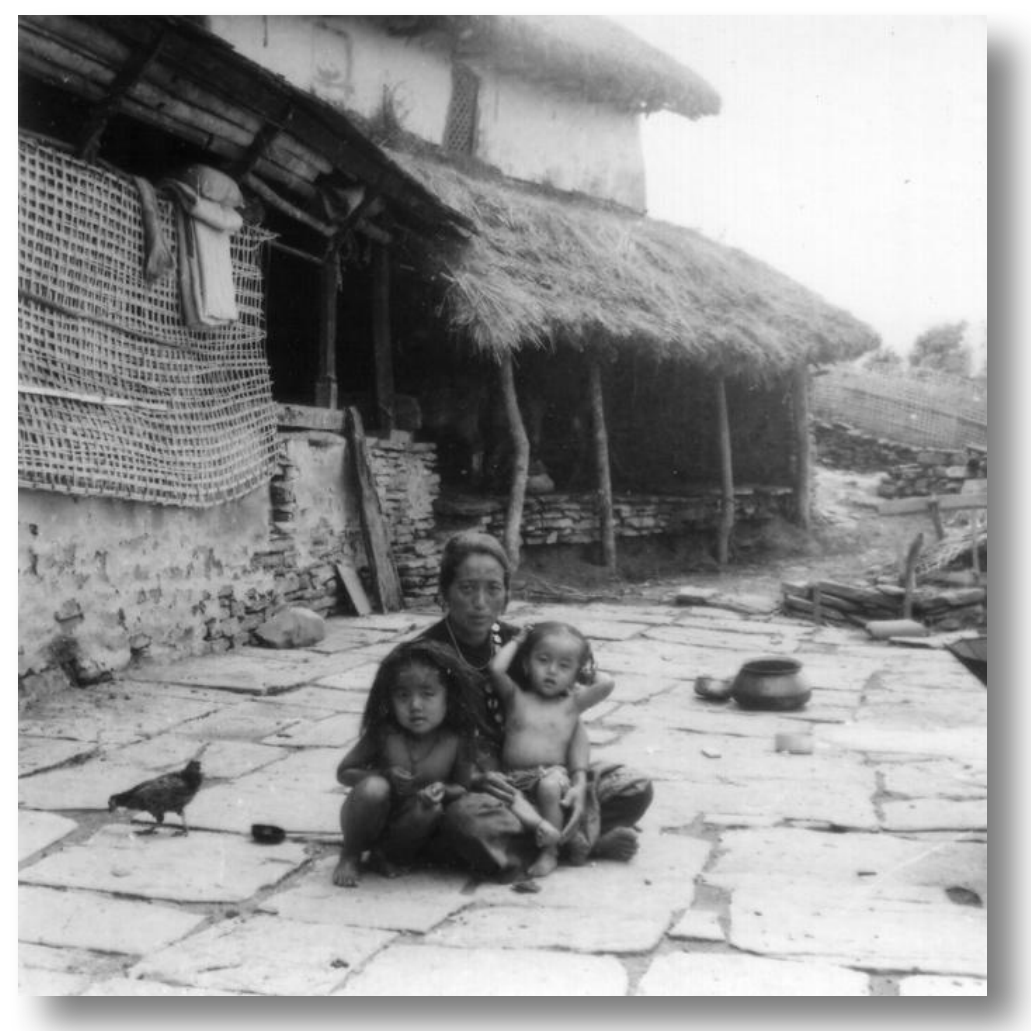

Asmaya with Rupa and Ramu (Robin)

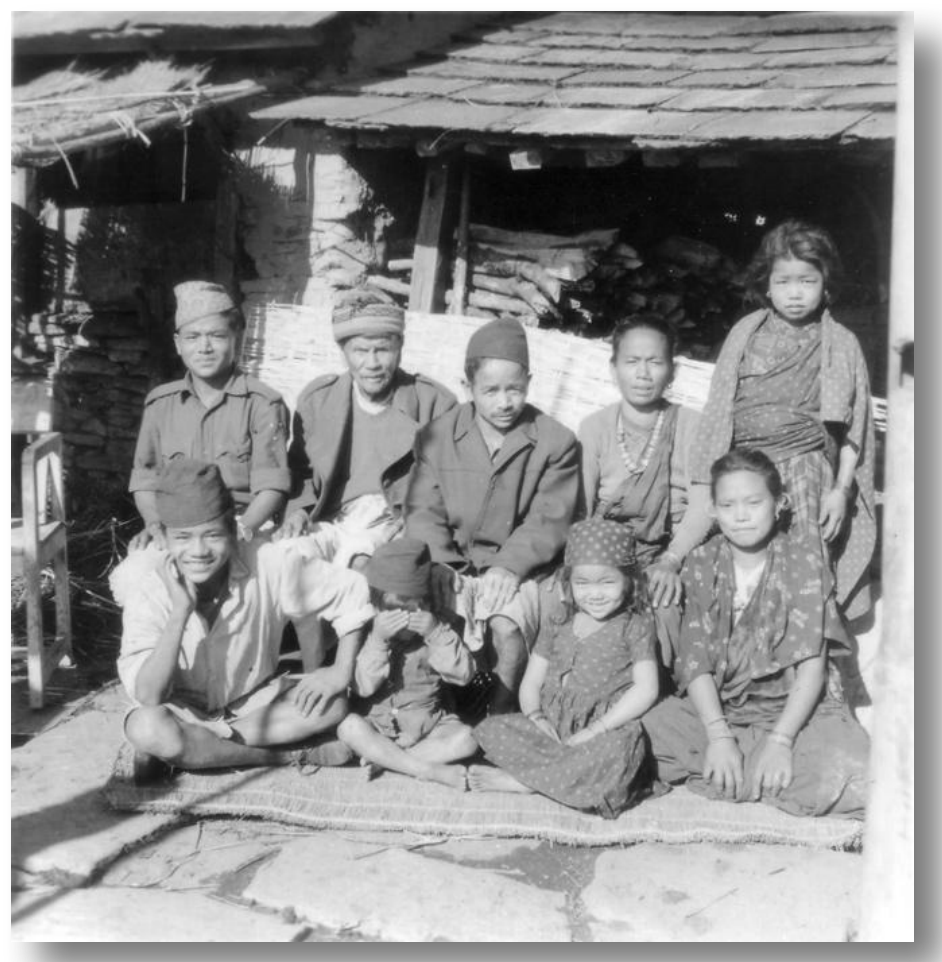

Poju's family group 


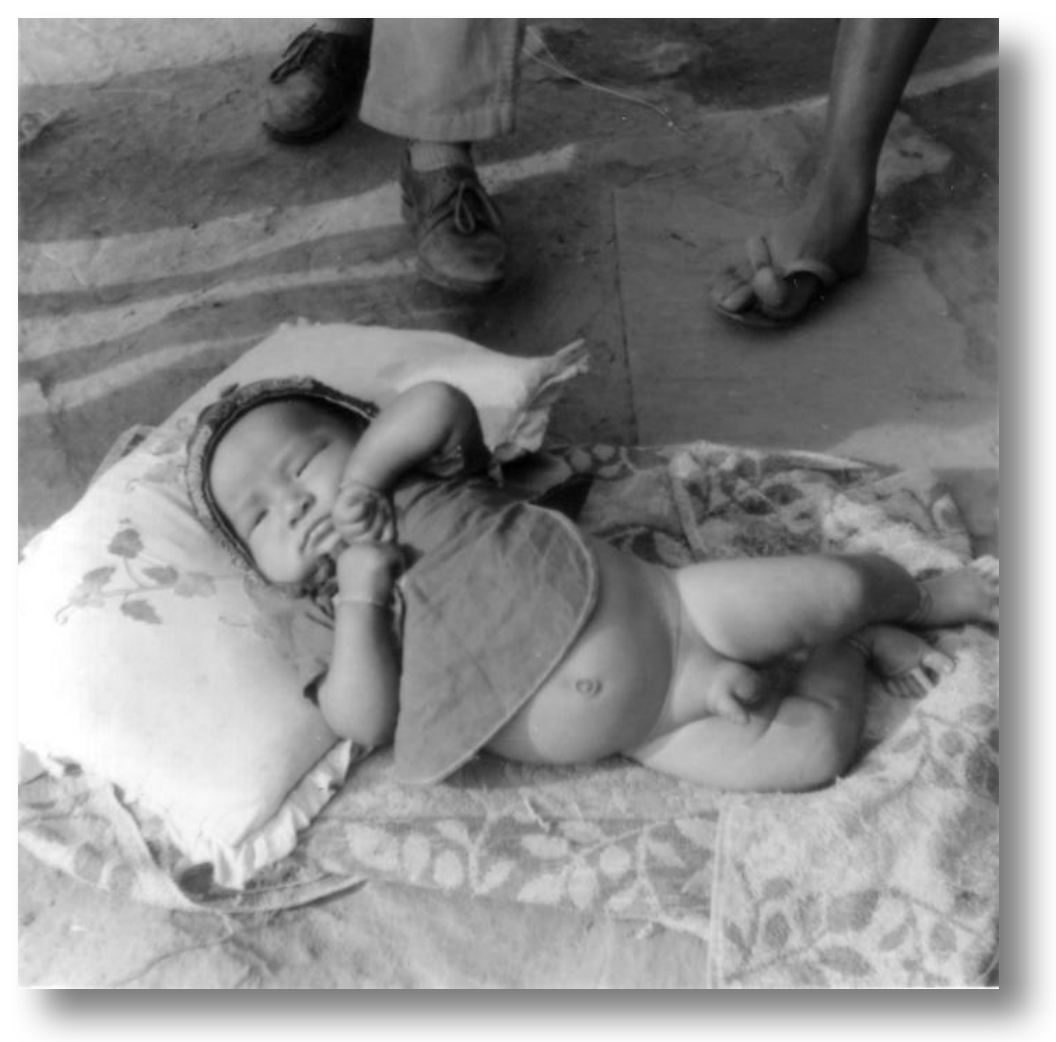

Hariprasad, son of Gungadebi (House36) and Gungabahadur (House73A)

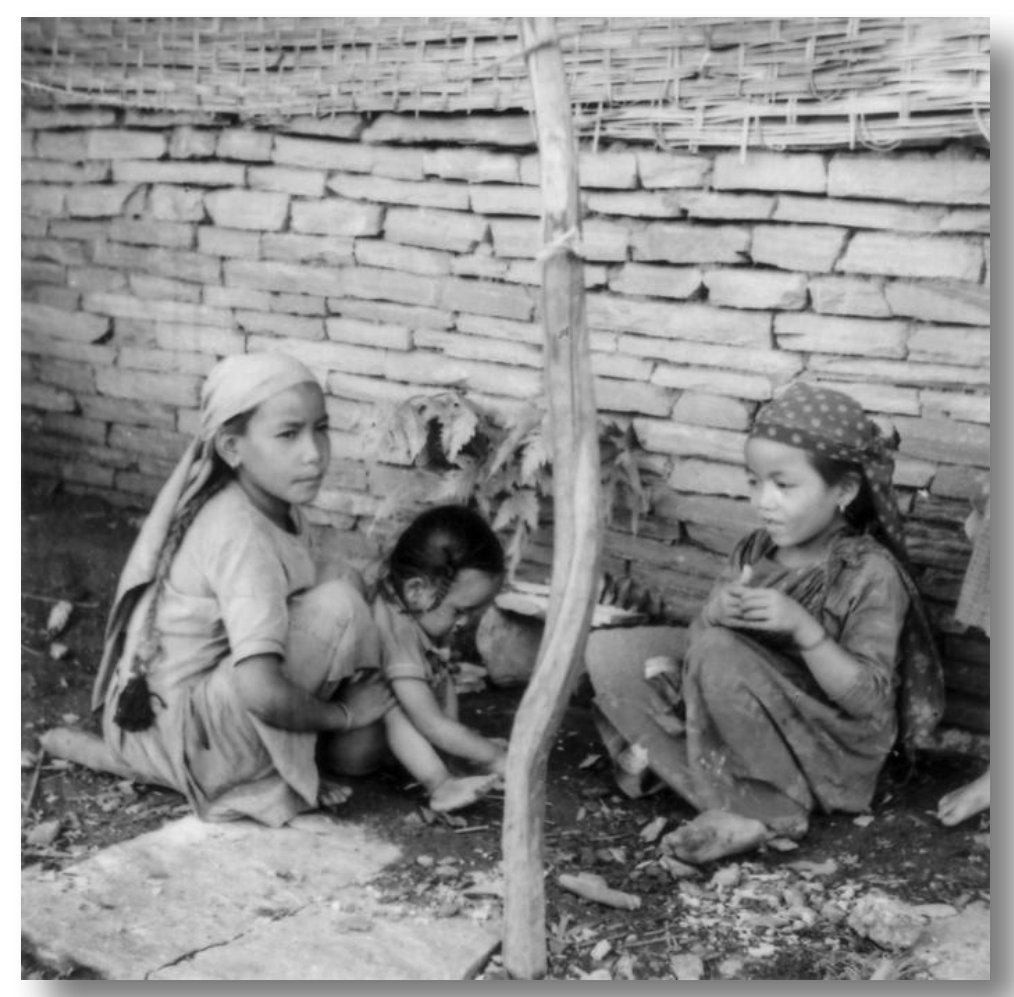

Birimaya, Haricola and a small child sitting on the ground 


\section{DIARY Thursday 1st May}

Great excitement as we turned the calendar over to May 1st - thought of gay sparks under Magdalen Bridge at Oxford. Again heavy rain and thunder. I filled bucket from the water flowing from roof. Again cleared in the afternoon. Started analysing the 80 censuses which we had already collected - surprising amount of deaths in 40's and 50's - infant mortality at c.23 percent in last 17 years - considerably lower than in Pignède's time. Read Foster on "Interpersonal Relations" in an interesting prelude to "Limited Good". Main difference of Thak to those societies he cites is that here the prey is not, as yet, hunted or seen to be hunted.

\section{DIARY Friday 2nd May}

In the morning, early, we went to watch sacrifices to Bhaio. Worked in morning and then, after lunch, were called down to the Sarki's house where a woman was suffering from bad bleeding (from womb). In the evening went to Birimaya's where there had been a 'di bar lava', then a fire was made inside and oil put on top of it. 'Pa' was added and the whole thing exploded, filling the room with fire, and setting light to bits of matting, etc. on the roof. This was done 3 or 4 times. Terrifying - we left hurriedly! Then watched some invigorating and relaxing 'tetara sheba' dancing at the new house. Went to bed c.11.00pm.

\section{NOTES 2.5.1969 Alan - Possibility of social mobility}

No opportunities for getting on here, but in the army, you can get wealthy. However if you are 'chalak' (clever, perhaps more - cunning) in village where there is a lot of counterbidding for land - then you could make large profit. Cited man who sold his house to Bhuwansing for 15000 rs and then bought an equally good one out of village for 6000rs. Said Bhuwansing prepared to pay this because he wanted to stay in village where there were a lot of people. 'Konmae naja' resentful 'ti ashiva' - when Bhuwansing joined that row of house. Bhuwansing is example of man formerly poor and now middling rich. Totra's father is example of decline - first generation very rich, second did not work hard, spent money, became poor, then next worked hard and they are now a bit better. Concept of being able to control one's fortunes (by work) to some extent even in village, certainly not an absolute fatalism. Gomansing (chucky gran's husband) - his father very rich, son played cards a lot, lazy, wandered about Pokhara - now they are middling. Benbahadur - grandfather rich, father middling. Bibi middling rich (husband), son in Assam Rifles, sold fields, now very poor.

\section{NOTES 2.5.1969 Alan - Bhaio puja lava}

People mentioned this several days before and it seemed to be of some importance in their eyes. We were taken down at 6.00am. by Comal who had been asked to help the widow in House 31 who had no man in the house. We went out half a mile, just beyond the 'pae lava di' and Comal told us that all houses 17, 20, 22, and 31 (ie. the row minus Bhuwansing) would be doing their sacrifices in this region. We were told that different jhats did not sacrifice on the same altar. It later became clear that they might sacrifice only a few yards away and Untouchables also sacrificed in the same region. People apparently went to all points of the compass out of the village, and there was a general vagueness as to where other people went, eg. they did not know where Bhuwansing went. Apparently the places where the sacrifices 
occurred had always been associated with the particular families, most of them seemed to be just off a path on the edge of a recently planted maize field, preferable up against a terrace or boulders, the stones of which were utilised for the altars (3). Comal's place seemed to be a permanent shrine, whereas the widow had to construct a new altar.

The widow carried on a plate, some wrapped up in banana leaves, some 'lha' (roasted unhusked rice), 'chugu', cooked rice sprinkled with 'bisarro', 'prasad' (ground rice flour mixed with oil), 6 torn bits of cloth, three of each colour, bundle of firewood, jug of water, two chicken, one pat of buffalo dung and a saucepan for carrying live embers. Comal made the altars of 6 little stone tables joined together, which are called 'deota di', while widow went to fetch coals from nearest house, not having brought matches. Comal said that the 'bhaiyo' lived in a hole in the rock. Part of the buffalo dung was used to smear over the tops of the stones, ('di shia lava' - to make the floor) thus it would seems, making them into proper houses.

Then he puts the strips of cloth, the red representing the woman and three of them on the right, the black and red patter representing the men, on the left. The rice/'bisarro' mixture was put on leaves each in front of the six tiny altars; a drop of 'prasad' was added to each. Then the 'lha' was sprinkled over everything by Comal and the widow took one chicken out of the basket. She and Comal washed its feet by pouring water over from the jug. She then empties rice which she had tucked up in her cummerbund, into the plate and Comal picks lavender leaves. Embers from the fire are put in front of one altar and the 'chugu' onto the this, so that it sizzles and smokes for a moment. The rice and lavender are put on the chicken's head, plus water from the jug, whilst the widow recites; she seems to invoke the god Premasar. Comal kills the chicken with the 'ashi', and hastily sprinkles the blood from the neck onto each of the six altars. The head is also put on one. The same ritual is done with the second chicken. The Comal puts a pat of dung on each altar, tearing a feather from the chicken and sticking this in. Again the 'chugu' is put on the fire. We then eat a bit of 'prasad' and prepare to go, the altar showing a colourful, bloody sight - red, white, green, yellow; it begins to rain. The widow kneels down as she leaves in a praying position and says, "Premasar", mentioning also various names of relatives. Later in the morning she came up to the house with a leg of chicken for us.

On the way back we came on Comal's family and Totra's father doing the same thing on their particular maize field. Ten yards further along, Kumbasing's family were also busy tending a fire and making 'prasad' on the spot, they had four chickens, Comal's father had three. Totra's father had two, which he explained to us (ironically) were his 'pupu' and 'amajhon' who were dead and had been seduced by witches into making members of his family ill - the first making Kaji ill and the second his wife's breasts sore, but now healed thus not for a current or fatal illness. They had gone to the puja with the names of recently dead relatives in mind, three or four, and had asked who was most likely to have caused present illness.

On this more permanent altar there were four little stones in the dung on top of one, and two on the one beside it. The grandfather of Totra's father was officiating [dead - his brother?], sprinkling the various things etc. Comal's father dealt with the slaughter of the chickens, and then degutted them over a fire, roasting some of the entrails whilst Comal held the umbrella over all as by now it was streaming with rain - the Gurungs were cold and wanted to get on with it. (Entire lack of an "appropriate" religious attitude). Also sharing the same altar was Posbir's daughter. (About 8 chickens slaughtered in all). The old man tied strips of cloth to the overhanging branches and roots. Twenty yards along the Tulmae were doing theirs. Totra's father said that if this was not done people and animals would become ill later on. No concept of guilt/punishment, it seems. Totra's father thinks this is unnecessary, but may as well do it to eat the chickens. (Ambivalence here). All draggle back in the rain. 


\section{DIARY Saturday 3rd May}

Wakened by the witch Bibi banging on our door for medicine. Read Geertz on Ritual - a telling and thought-provoking article illustrating an interesting, if obvious, point about the need to study cultural/social structures as interdependent yet independent variables. Prem came in for 1.5 hours and got some most interesting information on Gurung psychology.

\section{DIARY Sunday 4th May}

A lovely warm, sunny day, and another river trip with delicious onion soup. As usual very relaxing and all the time looking forward to the possibility that the schoolmaster might have brought us some letters - he turned up at dusk with a parcel of books from the IPPF and 10 letters - most of them business but two nice ones from Mummy re the possibility of buying a house in Dent. Mixed feeling re this prospect, though it did sound a sweet house. Mummy sounded a bit sad. Read some of Lloyd Warner on "Social Stratification", a bit dull.

\section{NOTES 4.5.1969 Alan - Possession}

About four days ago a 'tetara sheba' at Rupa's father's house - after about two hours of dancing the audience noticed that 'garda sheba saili' was shaking, this immediately made the 'guru aba', the Tulmae who had previously been possessed and one other Untouchable (Sarki - organiser and announcer) start shaking. They were taken into the middle of the stage and each held round the middle by a man, presumably to stop them bouncing too violently. Then Gopal started drumming intensely and loudly, varying the rhythm. The four shook up and down, their eyes open. Then at the climax they bounced right up - partly lifted, about four times. The whole lasted about five minutes. But the girl was not cured and still shook, so the others had to start again. This time the whole thing lasted about two minutes and she came safely out. Audience interested and sympathetic.

I went to watch a 'garda sheba' in front of House49, but before it began Nainasing started drumming in a certain way (he had learnt a few days before at Yangjakot) and the older 'garda sheba' girl started swaying and then got out of control, hitting out at those around her, scratching herself, throwing things etc. A man brought a buffalo neck-thong and put it round her neck (this forces the possessed person to say what is possessing her) according to Jusbahadur, the owner of the house, she said it was witches, but everyone else denied she had said anything about witches. She apparently said that the song-masters from Yangjakot had to be brought (on implied criticism of this villages 'gura aba') and two men (Nainasing and another) immediately left to fetch them, even though this meant a five-hour journey. Prasad was sure that if they did not come she would die. She was apparently undergoing, doing, the 'kusun sheba', a new dance in which the god 'Kusun' possessed her. A whole party of Thak people had just seen this dance done at Yangjakot and had obviously been very impressed and obviously 'Saili' was imitating this. Other facts about the girl - part of her frustration might have been due to the delay of the 'garda sheva', which should have been at Baisak purne. Prasad said that her elder sister died eight years ago, implying that she had died after such a fit, but later we were told she had died because of a miscarriage. She is not living with her parents, her mother died seven years ago, - disturbed family history? Father living out of the village, up on the hill. Prasad said that if one word was omitted from the 'garda sheva' the girl would realise this and die. Admitted this was likely to happen because the song-master was old and forgetful. Song-master was clearly unhappy at all this, and fully realised implications; however he would only be replaced at this death (by Totra's father). Girl 
eventually taken inside the house by Totra's father, who was the only man with any presence of mind, and she sat on the bed with various people half holding her in turn. Prem and Benbahadur, etc. She insisted on everyone speaking Nepali, saying she did not understand Gurung. When she did talk in Gurung she spoke like a baby, and regressed. She made the other 'garda sheva' girl dance for her, playing the drum and singing the song, thus reversing her role. Prior to this she had insulted her, saying she was a better dancer etc. and the younger girl was cowed and did anything she wanted. Everyone indulged her every wish, giving her drums, cigarettes, drinks and laughed at her jokes, and every time the interest of the audience subsided she pretended some aggressive act, like standing up on the bed, throwing sticks. She would demand that Prasad came back when he left, and caused trouble when we eventually went; when she thought she would get more attention outside then she came back onto the verandah. We were told she was 'sae achiva' unaware of what she was doing, but on a psychotic level she was highly aware of everything going on round her. She spoke fast and intensely, changing her position often, reclining on the bed seductively or going underneath the bed to retrieve the drums etc. The audience were anxious but covered it up by joking and saying it was a "good thing". Prem later said that the god Kusun had been wandering around the mountains for some time and had now come down into this girl. No one in the village had previously undergone this. Hindu influences here? We were later told she would be very angry if anyone mentioned the word 'moigi' (buffalo), but it seems necessary for the trance to be acted through for the word to be spoken, as she hits the speaker, several of the men being hit later. Some boys told us that if one said, 'hey! raja, rani kie ngwirar moigi kwovar ngana' (oh! third daughter, first daughter, your sari buffalo dung has) she would take her skirt off (i.e. possess her?).

Later that evening the two song-masters from Yangjakot arrived and a big healing session took place at the night school, with everyone present - about 130 people were crammed in the room and the Untouchables peered through the bars. The possessed girl now looked very well and combed and arranged the hair of the other girl (retribution?). She ate some food under her 'kramu', the babble of voices dropped to a silence when the song-masters blew all over her and touched her head. Bhuwansing's Dilmaya seemed to be the general bringer of food and water (related to grandmother being a witch, and the same girl having been possessed before because of Dilmaya being left out of the dance party?). Started doing an ordinary 'garda sheva' so A. left.

\section{DIARY Monday 5th May}

Spent morning on analysis etc. Prasad said he could not come until 3.30pm. because of Garda Sheba. I went down to Garda Sheba, but after a few minutes, one of the girls - the elder - became possessed and the rest of the day was spent trying to cure her - [q.v.].

\section{NOTES 5.5.1969 - Alan - Possession}

Next morning asked Prasad what happened and he said that she well when the song-masters came and read a mantra, but they induced another fit by drumming and a special song, at which she swayed and fell down, various boys and girls called 'moigi' out and she hit them. The dancers then begged money and cigarettes, but they were only given four or five rupees, she was still "senseless" at this point. The drums were then rebeaten and she again shook her body and then recovered. This would all be repeated at final 'garda sheva', and later we were told that this had been the case and that she had duly hit various people. Prasad said that people were glad that this had happened, and that it was a very dramatic dance. There had been nothing like this up to this time. A. was asked not to tape record the drumming in the 
school house, since the girl was worried that if she heard it again on the tape she would be repossessed. Apparently the Glovers at Gajok had in fact recorded such a session and several people did become repossessed (and then were cured by replaying the drumming to get them out of it).

\section{DIARY Tuesday 6th May}

Went down to school and then accompanied Prasad around and we did another 10 houses. Only 10 more to go! Gill in bed all day with cough, sore chest, aching body, etc. - 'flu and cough? Overcast with several showers during the day.

\section{DIARY Wednesday 7th May}

Prasad unable to come because he is hunting for a missing buffalo! Gill in bed all day with a slight temperature and cold. Prem came for 1.5 hours in the morning, and Bol. for half an hour in the evening. Otherwise tried to get notes of the last few hectic days up to date. A lovely hot day - several people holding "thank you" 'puja lava'. People don't seem very busy many people listlessly around their houses.

\section{Letter from Gill to Mac and Iris 7th May 1969}

...we have just learnt that the village headman had had a big, beautiful house two years ago, which he promptly destroyed and had a smaller, much inferior one built, as the village wise man/sorcerer had said his wife wasn't having any more children because their first house was unlucky for them (his only two sons had been killed by disease) - sadly she hasn't had another child yet. There is one other case among the Untouchables (Blacksmith)... We have just about finished the census (7 to go to make up the 100) and which Alan was hoping to finish completely today, but out schoolmaster who helps him sent a note up from the school which read, 'Dear Sir, One of my buffaloes missed yesterday in the forest. So today I am going in search of it', so it looks as though it will have to be tomorrow.

However, we have some rough analysis of mortality rates, age distribution etc. and as would be expected the highest death rate is between 0-5 years (with half of those occurring before 1 year), but surprisingly, a consistent high peak between 36-50, tapering off to 8 dieing between 81-85 and 1 between 86-90; there are two men alive over 80 at the moment, and four women, the women seem to live on the whole much longer - ratio of $m / w$ being 10/23 over 60 years. This latter figure is especially intriguing as there are supposed to be exactly 23 witches in the village at the moment, so it seems the poor old widows, and generally unwanted ones, have rather a rough time of $i$. (Although, including those away in the army who will eventually return, we covered approximately 530 people in the census). It seems, according to the doctor in Pokhara hospital, that most of the villagers have some form of dysentery nearly all their lives; another frequent explanation of death is also witchcraft, or other evil spirits, or in the case of children under 20 days when the buffaloes were given the leftovers of human food (the animals are quite often blended in with magic and evil in this way) - I found this very thought provoking.

The most exciting event of the past week were again to do with magic and spirit possession, in their most dramatic forms. The first event was then a house was being cleared out of all its evil spirits - by practically setting fire to it, which certainly cleared Alan and I out, if not the witches, goblins, sprites etc! The poju was called in with his assistants and at the end of the usual slaughter of chickens and goats went into the house, made a fire of carefully placed wood facing the doorway, heated a black pot of oil for about 20 minutes so that flames were licking round the inside of the pot on the surface of the oil, as well as underneath and finally poured the local version of whisky, a whole ladleful of alcohol, onto the oil, and you can imagine the result! Streams of flame whooshed up from the pot and seemed to settle permanently on the ceiling, so the entire room was ablaze, with the spectators crouching on the floor, faces buried as the heat was scorching; the Gurungs loved it, squealing with delight every time the ladle was poured over (about 6 times) and getting into a happy hysteria 
every time bamboo strips, matting etc. which they store along the beams of the ceiling, caught fire. After the third go Alan and I both made a dash for the door; I think it is the first time I have felt the beginnings of real fear, and I can now imagine the horror of a sinking boat and felt then very much akin to those people in the C19 who were always being put in barns and burnt alive! They loved us above all, for being frightened and the whole village had their version of our dash for sanity the next morning! Immediately after this we went to cool down by watching a display of the local dancing, more Indian style than Gurung, but very charming with pretty tunes which we have recorded. At the end of this there was a bit of drama however, as one of the village girls who is part of the team for their own special village dance became possessed by the god of the dance, and was shaking away, with competition from the local song-master who I think felt he had to compete; it is a matter of some prestige that the 'gods come into them'; they are held by a man who is not susceptible to this sort of thing and are drummed out of this state, which is dangerous to remain in for any length of time. What with the fire and Gurungs shaking away under the light of a brilliant full moon, with the mountains stretching away with precipitous drops in every direction, it was quite an evening!

Again, the day before yesterday when Alan was hoping to do some households for the census, the dancer who had been possessed above got into a much more serious state during one of their own dances, which they perform every time a stranger comes to the village. This time she became quite mad, shouting abuse, hitting people, hurting herself with cigarettes, throwing glasses of tea on the floor etc. Usually the Gurungs are the least aggressive and most gentle of people, this girl particularly, so it was all the more frightening. The others were really frightened, thinking she would die, killed by the evil spirit that was infesting her, so they colluded with her every wish which varied from an insistence they speak in Nepali and not in Gurung and her playing the drum and getting another girl to dance, to a demand that the song-master from across the valley should come and play for her-a journey of five hours walking there and back, which was promptly undertaken. This superior man arrived at about 7pm and 'untranced' her as it were, so she got better to everyone's relief. Our version of this very complicated event, it is the first time it had happened, was of a very highly strung girl (there was no doubt in my mind the became schizophrenic and it was not 'put on'), peeked about the low attendance at this performance (only two watching) and angered but the fact that the consummation of all this dancing had been put off - if you remember the entire song cycle and myth had to be sung through, without stopping, at full moon, but the older people in the village said they were too busy in their fields and could this be put off until next week? Also, there is a great magic about this event as the song-master (who is getting old and incompetent) must not forget a single sequence: if he does the dancers immediately feel this and will die - so the emotional build up to this event is considerable. Finally, the village from across the valley where the other song-master was demanded from had just completed their version of this, and it had been reckoned a great success and their dancer had been possessed in this dramatic way, although the outcome had been controlled by the superior arts of their song-master. I think it is much more complicated than this, but we will have to ask questions and observe more before we get it into its right perspective...

\section{DIARY Thursday 8th May}

A rather frustrating day since, though Prasad came at about $1.00 \mathrm{pm}$. we weren't able to find anyone in for quite a time and hence only got 3 censuses done. Still 5 to do! Gill still poorly and in bed all day. Worked out the mortality statistics - showed these to Prasad and was gratified, in asking him, to discover that my budding theory that the degree of differentiation into poor/rich classes did, if we compared this village to others, seem to be related to the oldness of the village, and hence to the distance away from the forest and the population/fields ratio.

\section{DIARY Friday 9th May}

Overcast and hot. Writing letters mostly and continuing analysis of our census and wealth distribution results. Gill's cough bad, but up and about. Oh, for a decent table as things are 
very crowded here. Most of the population away planting, etc. Re-started Levi-Strauss "Structural Anthropology". Hoping to finish census in next two days if Prasad comes.

\section{DIARY Saturday 10th May}

Census finished! Prasad came at 7.00am. and last five were done by $9.00 \mathrm{am}$. Now to analysis. Then, at lunch time, went with Comal to Atigar - a tiring walk of three hours. Feasted and drank and given great hospitality - singing in the evening and slept on the floor.

\section{TAPE RECORDINGS - 10TH May in Atigar}

Nepal song

A group of men (untouchables) singing a Nepalese song which goes as "Ha..ha.. hai himalai jharyo himalai..."

https://upload.sms.cam.ac.uk/media/2733381

Nepal song

A group of women (untouchables) singing a Nepalese song which goes as "Bar ko daali ma, timi lai laijaula arko pale ma..."

https://sms.cam.ac.uk/media/2733398

Nepali song

A group of women and men singing a Nepalese sing which goes "Ghau ma tori byasi ma aruko til, sora barse maya sanga basyo dil..."

https://sms.cam.ac.uk/media/2733415

\section{DIARY Sunday 11 th May}

Returned from Atigar with Comal - via suspension bridge. Filled with 'pa' so braved the bridge, barking dogs, etc. Covered with sweat. The moment I returned we were informed that we would have to leave this sweet little house in a couple of months and move into the school: very depressed for a while, but cheered up when we heard we would be upstairs and they were going to build some steps, etc. People generally excited with two Garda Sheba, and 'tetera sheba' and a 'Kusun deowta' (q.v. note) late at night all next door. The bride from next door came in and shared our loneliness etc. Made lists for Kathmandu. Gill still very run down - cough, etc.

Letter from Gill to Mac and Iris, 11th May

It is just after 9 in the morning and that peaceful period when the Gurungs are trudging off to the fields with their ploughs, or washing their copper dishes with earth outside the house, after their first main meal of the day. It has also just stopped raining after pattering down all night, and the wet has brought out all the colours of the thatch and the stacked wood and the blues and creams in the slates. There are drifts of cloud in between all the ridges of the hills which makes it look as if each little valley had its own steam engine puffing away down the morning.

Alan has been away at another village over-night, both to get some idea of another Gurung settlement and also to please a twelve year old boy as this is his mother's home village and he wanted to show Alan off to his Granny! I decided not to go as I have a bad cough and cold at the moment and didn't take to the idea of panting up and down too

many hills. 
Alan has also just finished the census yesterday, after a tremendous effort, mostly spent $n$ rounding up our casual schoolmaster, and even Alan felt he owed himself a break, so he went off with Comal after completing household 100. The effort was worth it, as you will be able to see even from our very first rough analysis with only 80 sheets in.

.... As Alan hinted, the last few weeks have been quite exciting with all sorts of unprecedented things happening. I have just looked out of the window and seen the Lt., whom I think I have mentioned in previous letters being especially kind to us, toiling up the steps with a dirty towel wrapped round his waist, looking downcast and gloomy....

On the same day she trudged off, we also had an entire afternoon and evening of schizophrenic possession sessions, so the whole village was in an absolute uproar before the above happened - it was really rather a wearing day! Alan, as usual, had tramped off having lost the schoolmaster somewhere near the tea-house, with about twenty houses for the census still to go, and came back half an hour later, poked his head dismally into the loft and said he may as well give up for the day as one of the two Gurung dancers was throwing cigarettes about, scratching herself and hitting all the nearest restraining males available, and was generally "possessed".

They were trying to sort out whether it was a witch of a wandering mountain spirit/got who was responsible. They had already put a buffalo halter round her neck, practically strangling her in the process, but she hadn't said the name of any witch, so it must be some sort of god, benign or otherwise. They had carried her bodily into the house in whose courtyard they had been performing, and she was holding forth with the whole village at her beck and call, very frightened and loving every minute of it (ie. the village).

When we arrived there was a shivering group of adolescent girls round the doorway, leaping away every time the girl threw sticks and cigarettes at them and rushing back in a chattery crowd for more; the older men were sitting on their rice mats, round the disrupted dancing square, nodding earnestly away, debating as the nature of the thing; the young sparks were inside happily being attacked by the girl and rushing round doing whatever she told them to do. The children were bored and Alan wanted to give

her a hearty slap to get her out of these "hysterics"!

The girl herself was sitting cross-legged on the bed opposite the door, where visitors usually sit (if they are not intimate enough with the family to sit by the fire), and reminded me of Cleopatra and "the chair she sat on like a burnished throne", at least in her attitude, if not in actuality! She was ordering everybody to speak in Nepali, as she didn't understand Gurung and when she did speak the latter she chattered like a baby; she wanted a renowned song master to come and play for her from across the valley, and a messenger was promptly sent off, saying he had to come and untrance her or she would die.

The Gurungs' version of this was that one of the drummers had idly begun a rhythm which she had picked up when at this same village for their dance session a few nights previously. At the end of this, one of their dancers had also become possessed, but had been controlled by the power of their songmaster; it was all a very prestigious occasion and, to us, very reminiscent of Durkheim with his infective psychological epidemics!

There was also no doubt that the girl is very highly strung and was in a highly pitched emotional state at the time; she had been very angry that the culmination of the dance season, where they dance the entire dance saga through, taking about five nights non-stop, had been put off until next week, as some of the older villagers had complained there was too much work at the time originally fixed and they would not be able to come.

The physical effort involved for the two dancers much be tremendous, and there is also a lot of emotional tension as there is a saying that if the songmaster forgets any of the sequence, upsetting the balance in any way, then the dancers will immediately feel this, and die. Our present songmaster, who is a sweet old man and from whom I want to get the whole of the myth (he says it will take three days to write down!), is also getting rather doddery and incompetent and in part the above was an attack on him - he was no longer good enough for her and she wanted another man. In a way it was also an attack on the whole system, as one of the things the girl insisted on was that she should play the drums, and her partner dance for her-having just completed about thirty evenings of dancing the one thing her whole being must have been shrieking to do was for someone else to dance and for her to be in control, which she most certainly was at this point.

She was also lashing out with her tongue and saying all the things one thinks but normally never dares to say, plus seductive behaviour which was overtly sexual. The whole performance was heightened by the fact that 
normally she is the most timid and retiring of girls and seemed quite transformed in the eyes of everyone. The same night the other man did come, she was put into a state again, but brought out of it this time, and was quite recovered, although exhausted. There was some play with the name of the buffalo, with reference to his droppings, and throughout the animal seemed to have some magical connotations, which we haven't sorted out yet. However, all food for thought.

Our other exciting experience was being practically burnt alive, something akin to those "cultural shocks" you talked about in your last letter. It happened in the usual pitch black evening after the richest house [House6] in the village, belonging to a towering, plump widow with a bad goitre and several daughters, had protected the house against evil spirits by sacrificing cocks, goats etc. The poju then made a fire inside the house opposite the doorway, heated a black pot of oil on it for 20 minutes, waited until the flames were licking the inside of the pot as well as underneath, and then ladled in about half a pint of the local whisky-you can imagine the result.

The flames roared out, settling as if permanently on the low wooden ceiling and catching light to the bamboo strips and matting they store along the beams. The Gurungs, mostly women, loved it and crouched on the floor squalling with delight at every ladleful and smothering their heads and pigtails in head cloths as the heat was scorching. The list of illnesses caused by witches, 'banketa' (a kind of malignant fairy), 'bhut' and 'pret' had been appropriately consumed, held over the fire with a bamboo pole, and so, practically, had we, fleeing after the third explosion! This was loved even more than the fire, and the whole village next day was laughing with delight at how 'ngeeba' (frightened) we had been!

I have been trying to sort out connections between this primitive sort of animism, projection and magic with both their childhood rearing and relation to the environment as a whole. I think their low control over their environment has to do with the high belief in magic, and in turn their super-relaxed upbringing with the ease in which they project any guilt, be it onto 'banketa' or witches. From some linguistics I have done, very elementary with different people giving examples of what makes their worried, unhappy, pleased, etc. I

have found they feel more shame than guilt as a culture, that is as long as they are not seen doing wrong, then they feel okay.

Thus they relate their standards to the group as a whole and have not much internalised feelings of "wrong". As usual, when thoughts are churning around and one is reading a lot I found an exact counterpart of what I had been trying to piece together in a book by the Freudian Erikson "Childhood and Society": he tries to synthesize psychopathology with biology and cultural aspects so the comments are exciting and broader in spirit than most analysis: "it is that faith (in a primitive economy) which makes the primitive hang on to the methods of ancient tools and of magical influences over the forces of nature; it is that faith, which, in turn, provides him with a simple remedy for any sense of sin: projection. Badness all lies in evil forces, in spirits, in curses: you must regulate them with magic - or be possessed by them". (p. 386-7).

This could be tied in with the decline of witchcraft in England of course - it is so exciting when things begin to connect - "only connect the prose and the passion"! We are looking forward to our break this Thursday, sadly there is some threat we will lose our house, but something else will be provided; they never promised it permanently anyway.

\section{DIARY Monday 12th May}

A quiet day recovering from Atigar and working out details of the census as a preliminary report to Furer-Haimendorf. Gran, perhaps guilty at evicting us, brought round some beans most welcome as we have run out of vegetables. Gill's cough still bad and she seems very easily tired - worried least this is a recurrence of T.B. Villagers busy planting and hoeing. Rained various showers - magnificent views and rainbows. Too wet to go to river. 


\section{DIARY Tuesday 13th May}

Rained heavily in the morning, but cleared by about $9.30 \mathrm{am}$. so we could go to the river. But all the wood was sodden so it was a hell of a job getting the washing done and packet soup lunch done. Superb views of Taprang on the way back with the mountains half shrouded in cloud. Bitten by two leeches which somehow managed to get through shoes and socks.

\section{DIARY Wednesday 14th May}

Prem came for 5 hours and learnt a lot of useful stuff. Started preparing for Kathmandu.

Off to Kathmandu

$$
\text { DIARY Thursday15th May }
$$

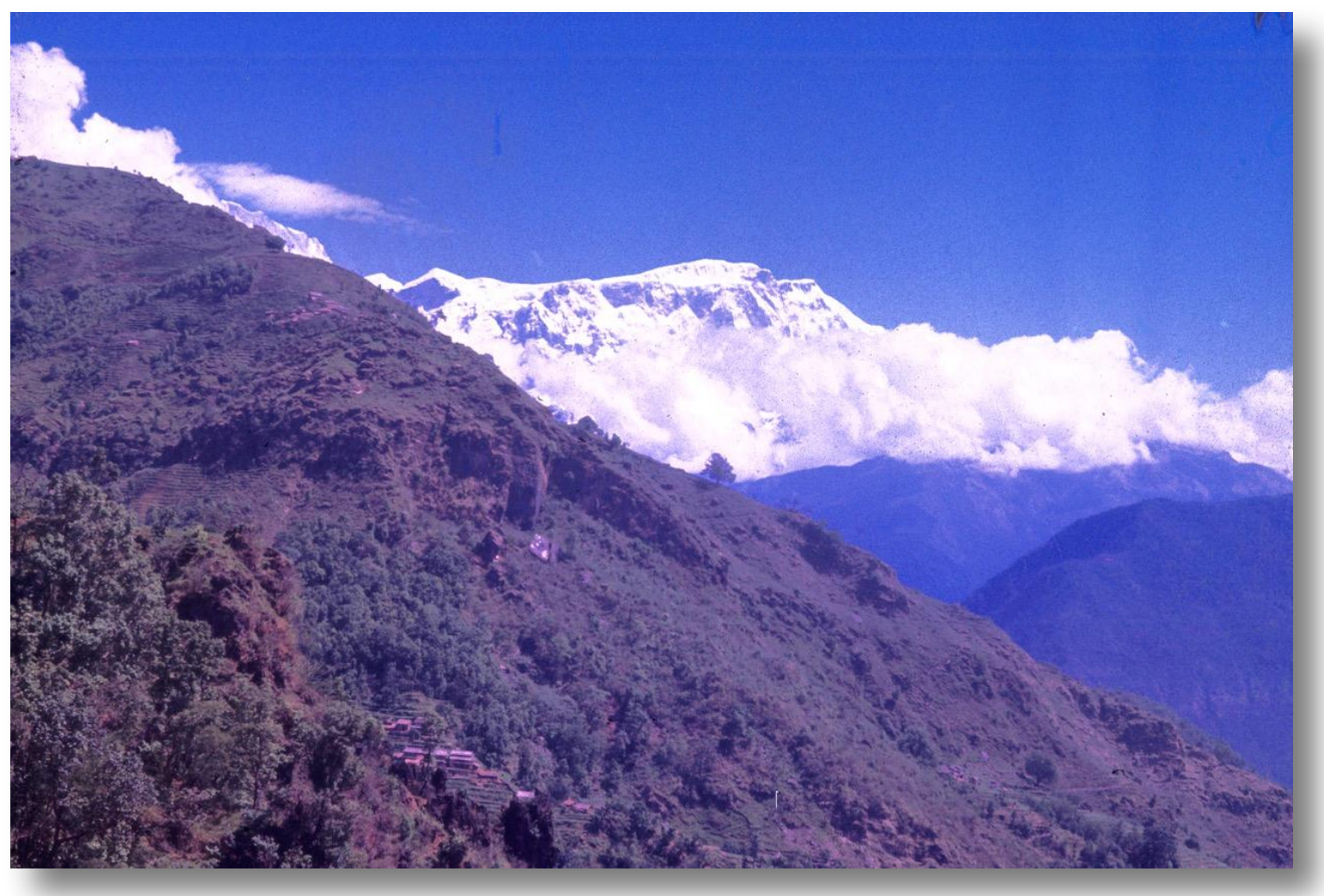

Looking back at the village, top left, from Noledada ridge, on 15th May 1969

Letter from Alan to parents 15th May 1969

Two letters from you came back with the village second schoolmaster when he returned from Pokhara a couple of weeks ago - one written on Fan 19th (only 9d. stamps on it, so it had gone by sea mail) and another April 16th. Will answer the points in your two letters first and also comments re writing, and then give a few facts from the census which, by the time this is posted, should be finished. (9th May, It is finished now (12th). Re the first letter.

Yes, there is masses of TB here, but, as far as I yet know, they are quite prepared to go to hospital for treatment if they can afford it. The economics of medicine are the problem, I think. Occasionally, however, it is true that the poju (medicine man) tells a family it is bewitched and that the witch will be angry if they go to 
hospital. But as he himself is always popping off to Pokhara for vitamin pills and injections people now are probably a bit sceptical ...

The little streams here are bombed, diverted, netted, trapped, etc. It is hardly surprising that there is hardly anything over $6 "$ in them. I hope to do some fishing in Pokhara lake, however, and it seems to be swarming with fish. It would be possible to develop extensive fish-farming here, but one would have to own land, organise labour, etc. and it does not seem right to spend my time doing this when I am meant to be doing anthropology.

Even introducing our pressure lamp and giving it to the village dance party has had considerable effects. For instance, they now no longer depend on the full moon and have moved the big dance festival back two weeks - which has led to various tensions and difficulties

\section{Letter to Arthur Searle 15.5.}

The work here is getting absorbing, though our language is still pretty poor. The census of 100 families is almost finished and showes many interesting things, for instance that there are exactly the same number of women over 60 (23) as there are supposed to be witches. It appears that cancer and TB are jointly the two major causes of adult death, while a quarter of infant deaths are caused by dysentery. I wonder if one could ever find out such facts for a historical group. A quarter of the children die before they are 17, and few adults survive over the age of 50. Almost all the males between 25 and 45 are away in the army - those that remain have families (on an average) of two more children each. There is only enough work to keep people busy for, at most, 200 days in the year - the rest of the time is occupied with ritual etc. People eat hardly anything above and beyond rice - an adult male of reasonable wealth (in a month) might eat 3 eggs, $1 \mathrm{lb}$ of meat and half a dozen glasses of milk - hardly any veg. and no fruit. Yet these people, supported by the British and Indian army are, compared to the rest of Nepal and India, healthy and prosperous. Things are delicately balanced at the moment, but, in my normal morbid way, I foresee catastrophe soon.

\section{Letter from Alan to Gill's parents 15.5}

We are both keeping OK. I have been well since the Pokhara bout, though Gill is a bit under the weather today with a touch of 'flu and a cough - despite the vitamin pills we pour into ourselves. The whole place here is riddled with minor (and major) disabilities. As you say, with the drainage it is surprising that any of them stay alive. What is perhaps even more astonishing is that they are so active on the incredibly poor diet they have. An adult male will only consume (apart from two large bowlfuls of rice a day) about 1 egg, $1 / 4 l b$ of meat and a cup of milk a week - practically no green veg. or fruit (and the above is quite a good diet here). I am getting very interested in how they feed themselves - how many days a year they have to work to get enough food and how many days they are forced into idleness, how dependent the economy is on foreign loans etc. I am doing various surveys to find this out. It is pretty obvious that there is only between 100 and 150 days work per adult in the village. The rest of the time is leisure - but most of the time they manage to look as if they are working. Practically nothing is sold out of the village, yet most moderately wealthy families spend about f 20 p.a. in Pokhara on kerosene, cigarettes, sugar, salt etc. This money is earned by servicemen. There are practically no men in the village aged between 25 and 40 - they are all in the British or Indian armies earning salaries which are ten or more times higher than if they were working in the village. If these 25 men were in the village there would be an even greater problem of underemployment - as it is they bring in the cash surplus that allows the Gurungs to live at a higher standard than most people in Asia. The other pivot of the system is the forest. This provides all the fuel they need (an vast quantities are consumed - about one large bundle every 3 days per household) and also buffalo fodder. Without buffaloes there would be no milk and little manure for the fields. But the forest is being hacked down mercilessly and is moving further and further away and, on the other hand, foreign governments, particularly the British, are rapidly lowering their recruiting of foreign soldiers. All this would be bad enough even if the population was not growing considerably - probably by about a third each generation. Such population growth will soon sharply increase as a result of two factors - less men recruited abroad will mean bigger families here (we have discovered a difference of two children between those families 
where the husband was in the army and those where he stayed in the village) and, secondly, medical improvements. At the moment about 1 in 4 children died before they reach 17 and this is already a lower rate than it was before the war. Most people who survive to the age of 17 will die before they are 60. 'Explosion' is the only word for the effects of Western medicine on this situation .

\section{Gill from Kathmandu to Mac and Iris 21 May 1969}

Am sitting in the cool depths of a German library, using a German typewriter, hence a multitude of dots which will probably emerge, about 15 minutes bike ride from the centre of the bazaar and all the Kathmandu temples. I thought this break would just have to be endured, what with the heat, the dust and the dirt, but it has turned out to be most luxurious and Western, and a delicious break. We are getting superb German food, tinned hams, rye bread and liver sausage and endless chilled orange drinks, so after rice and dubious tinned Indian mutton in the village it is superb...

...Alan is very well, even he enjoying the civilization of the place, and is rushing round seeing Family Planning people and getting propaganda for the village, as well as endless packets of pills, condoms etc., as quite a few of the women have expressed an interest in birth control, and we hope to encourage a few more... ...We went for dinner to the Australian linguists, whom I think I have mentioned before, a very relaxed and kind couple and the wife, Jessie just having had her second baby, a girl born in the mission hospital in Kathmandu... They have also lived in a Gurung village, tabulating the language, so it was fascinating to compare notes as of course they had picked up a lot of anthropological material, incidentally. They brought Gurung servants into Kathmandu, the wife helping Jessie in the kitchen etc., and the husband being the chief informant for the language; it was rather nice that we were able to communicate with this couple in Gurung, and they (the Glovers) were very flattering as to how fluent we were. It is comforting that even they, as linguists, have difficulty in sorting out all the tone variants, that that 'keh', for example, has ten different meanings, depending on your stress and how much you nasalize it.

We also had no difficulty in getting our cholera injections, and hired a bike for the first two days so we got round quickly and it was fun - cycling through the bazaar at night was beautiful, the stone and gold lions and gods with huge sleepy gentle bulls dozing in the roadways...

We fly back to Pokhara tomorrow and organize sugar, grains, flour etc. - we shall probably need 4-5 porters, and then we hope to fish in the lake and so some swimming and then early next week we shall go back to the village. They were very sweet before we left saying how sad they would be without us, so I wonder if we are being missed...

PS. Alan sent a registered parcel with one film plus list of contents off yesterday to you. Do hope you get them. There are two shots of Gurung girls dancing - if these are at all good could you get a couple of enlarged colour prints done as the village has asked us for this... do hope they come out - last 3 were taken on our way down to Pokhara this time.

\section{4th May 1969 Handwritten from Pokhara by Gill to her parents}

So pleased to have your last two letters ...we got in from K(athmandu) yesterday spending a blissful few days in a German research centre, pale green bathrooms with taps!, marble patios, rose gardens, German sausage and soups - can you imagine! The house was originally intended for the Indonesian embassy so it was pretty lush. We got in about 56 months supplies and then flew back here to our cheerful, dirty Tibetan hotel-good spiritually to do the moving back into primitive living gradually but I still yearn for my taps and cool white corridors, here the heat is oppressive and about 90, you wake at 3 am longing for a shower, drenched in sweat and listening sleepily to mosquito droans. We went to the lake tho yesterday and took out a dug out tree for a boat; the clouds were piling up for a monsoon drenching session and the water was bottle green with flurries of waves crisping over the surface - lovely with the Hindu temple on its island jangling in the wind dead crows strung in the trees, just like a S. Maugham set which irritatingly keeps you gripped. ... As you can see it will be an effort to go back to the loneliness of the village and I wonder how exhausting the rains will be. However I 
think I prefer 'our' Gurungs to the curious and wonderful selection we get around the airport, pink haired Germans from Frankfurt who preach Marxism and then get put in goal for selling hash at a considerable profit. Weary, bushy-bearded Peace Corps monsters, none under 7', all reducing A. to the level of their tummy button, tired of their Brahmin villages where they are 'teaching'; incoherent hairy chested Frenchmen who haven't even to the energy to flirt... And so on.

Letter to parents Sunday 25th May

\section{NOTE: ONLY PARTS OF THIS LONG (HAND WRITTEN) LETTER TYPED - RELATED TO NEPAL}

I don't really know where to begin since I have three long letters to answer - April 29th, May 4th, May 12th. Wonderful. Many thanks. I'll go through the various points in your letter first and give you a bit of our news

It is getting hot now - especially in Pokhara where we are collecting ourselves together before returning to the village for the monsoon. We lie sweating under our mosquito netting and think of our cool village on the hill. But we will be returning tomorrow.

Our stay in Kathmandu only lasted 4 days but has cleared away all out coughs and other minor ailments. We went there mainly to get our visas extended until the end of March, to get injections for cholera, and to buy in provisions for next five months. It was a most successful visit, largely because we stayed at the luxurious Nepal Research Centre (hope you get the picture post card we sent of the place). A library, Westernstyle bathroom, lovely garden of snapdragons and roses, and a private car for us to use. A bit of a jolt returning here. We brought back 140kg. of assorted tins and packets and should be well fed during the rains. Visited the head of the two family planning agencies in Kathmandu - government and private. At the latter we were immediately ushered in to see a vasectomy and loaded down with pills, condoms, etc. The forecast of future trends unless birth control is very effective seem pretty gloomy, however, A couple of anthropologists from S.O.A.S. were also present at the Research Centre so it was especially pleasant - with gorgeous dinners of German food flown specially out. It was all arranged through Furer-Haimendorf.

But I am looking forward to getting back to the work in the village - accompanied by the 7 Tibetan porters who will be needed to carry our stuff up to the hill: [Before I forget, I hope you got my letter of about 10 days ago with a preliminary analysis of the census in it.]

We have also sent Fohn and Mary one more colour film of eight slides - including two of the village against the mountains. You could enquire to see if these came out/arrive. Talking of films, we are intending to buy a cine camera out here - or get one sent out in tax free Nepal Research Centre bag. I am wondering what camera to buy. They have very neat "cassette" type "Super 8" Fapanese cameras here - for f20 - which cannot really go wrong. I will be getting on by about the end of October when we revisit Kathmandu . .... We are just beginning to organize our next short break - at the end of October/early November. Do you think it would be worth visiting Calcutta-Assam? I gather from the Indian Embassy that we would be allowed a 7-day permit to visit Shillong etc $\mathcal{E}^{2}$ we could come back via Darjeeling. ... I would like to have a very quick look at the Khasis and also show Gill Cherideo, Tinglebam if possible. Of course it also depends on finances...

Spent the morning hunting round the various government offices in Pokhara for land records. There seems to be a lot of material - at least 20 files (fat). Very fortunately the Nepali British librarian has very kindly offered to translate these. It will take at least 10 days just to copy them out, I think. Among the records are a survey of money and land loans which should be very interesting, if accurate. Unfortunately, however, the big map of Thak which I was specially looking for did not come to light. There is possibly a copy in a bundle of sealed documents in one office - but it needs and order from the Supreme Court before they can be looked at.

The Government Bureau of Statistics [in Kathmandu] was a real nightmare - rather like Pokhara Post Office on a large scale and all the records ready for burning in wind-blown piles in the courtyard. The place stank of urine. It is not surprising that government and privately sponsored surveys come up with wildly different results. The only ones I accepted readily (from government family planning) was that, unless family. planning is successful, the standard of living in Nepal will drop by about a third in the next 25 years. As things 
are pretty bad already - eg. the lowest expenditure per person on health in the world - I can't imagine what they will be like then.

\section{Letter on 25th May 1969 from Gill to Mac and Iris}

We are back in Pokhara, getting in from Kathmandu the day before yesterday (Thursday). It is so hot and oppressive here that we will go back sooner than anticipated - probably day after tomorrow. I think it must be at least 900, with no apparent drop during the night - at 3 am I was drenched with sweat, and trying to avoid listening to the mosquitoes - we have some netting anyway but the sad point about that is that once they are in they can't get out and have a lovely meal instead! Fortunately they are not malarial.

However, feel much better generally for the break, all mild tummy complaints gone and a cough I had picked up also gone. Also, after our glorious few days at Thyssen House, everything has been washed and ironedincluding my 2 dresses made in the bazaar which have come up even better by being treated properly, and are certainly making life worth living at Pokhara. So are your summer pyjamas by the way. Cannot understand what happened to your clothing parcel. We went to the Post Office as soon as we got back to be told there was a parcel for us - but an 'Epicure's Delight'... as it has tins of roast duck, goose and turkey as well as veal and pork cutlets...

... Have had to move inside our bedroom (one whitewashed cell with a corrugated iron roof) as it is lashing with rain, the airstrip a white sheet of water, and very much as the monsoon will be - such a relief to have water. However, the tin roof leaks here... I wonder if out Gurung slate roof will leak? We might have to move out of the house into the school house as Granny next door says she wants to store maize in the roof - they tie the corn on the cobs up in bunches to dry out, apparently, so we would have to crouch more than ever. We will see if offering her more money does the trick - ie. a fl a month, instead of $14 s !$ as we are rather fond of our little one-up, one-down.

...I'm sorry if I conveyed the idea of feeling sorry for myself most of the time - it is only occasionally that I feel this overwhelmingly - why am I stuck in the god-forsaken place when I could be helping 90 people in pain somewhere else - but this is the most unproductive pitch I get to, and then just before periods or when I have crashed my head against the beams for the 10th time, or the people just get too claustrophobic and inquisitive! I notice I am better, ironically, if Alan is away, and I have to use my language fully - he is better at picking this up anyway as I have discovered I am practically tone deaf, tonal variations being vital in this Tibeto-Burmese dialect as each inflection on one word means something entirely different. Also, people naturally address him first being the man, and expect me to be rather helpless! I am going to make more of an effort when I get back to talk when Alan is not around, and this will deal with the loneliness as well as interesting material emerging, of course... 


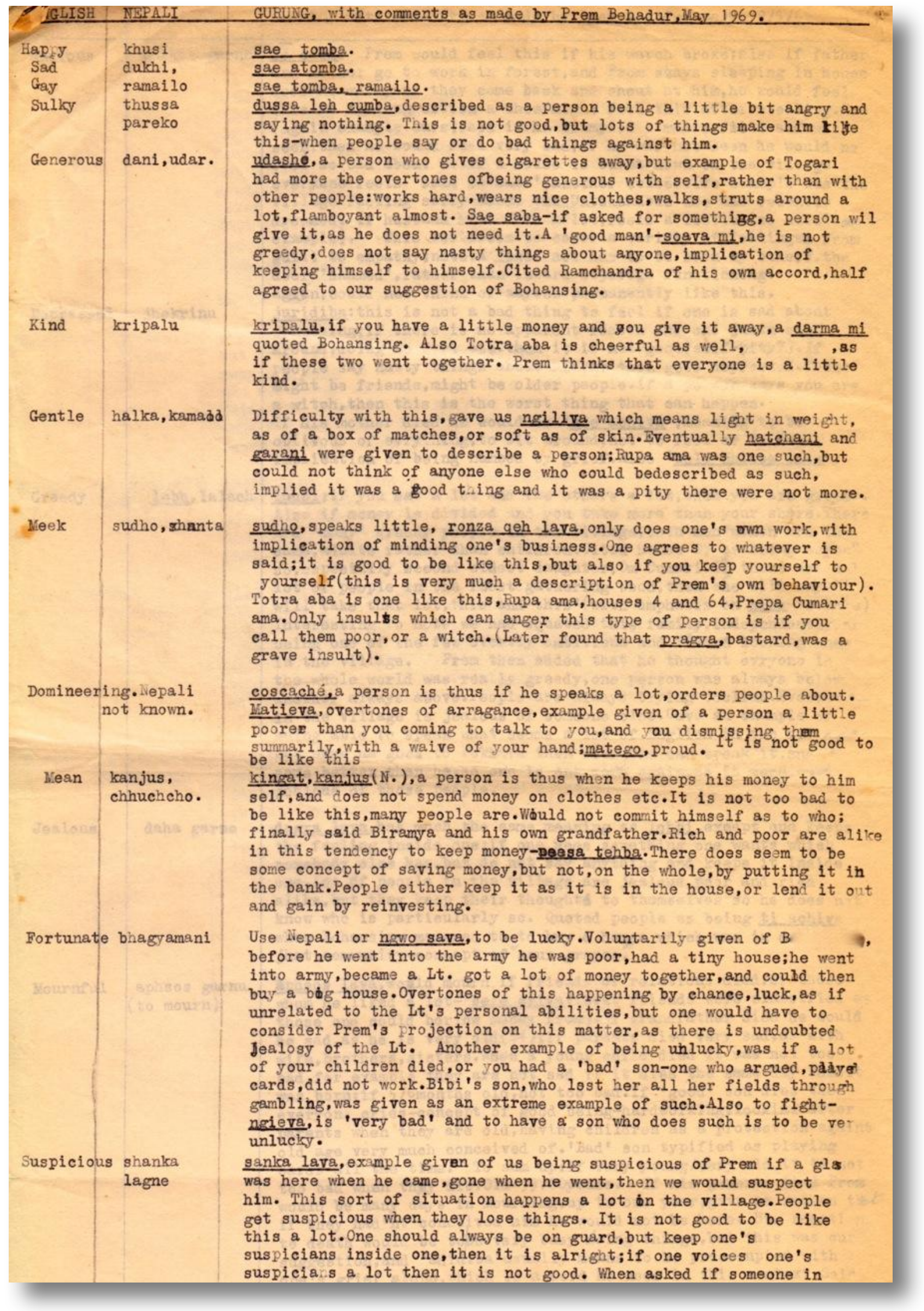

Gurung language, with comments as made by Prembahadur in May 1969 
Returned from Kathmandu, and seven porters, about 210 kilos of goods and 1,300rs. A most refreshing time, especially at the lush Nepal Research Centre, and we felt much better for our time. Everyone very friendly and welcoming on our return, especially Prem. Our porch, however, blocked with next-door's wood.

\section{DIARY Tuesday 27th May}

Spent the day sorting out great pile of tins, etc. - 42 tins of meat, 29 of fish, etc. Great mounds of dust and dirt and quite an effort.

\section{DIARY Wednesday 28th May}

A red-letter day as we at last got a table from the carpenter (50rs.) and after sawing off the legs a bit it fitted well and will be a great improvement. Prem came for five and a half hours work and we checked the census. Comal also turned up trumps by keeping a daily account of what his family did for the last two weeks. [SEE] The only blot is the water which is only trickling and consequently I spent two hours waiting for it last night. Gill is very well and seems much refreshed and cheered by her break.

\section{DIARY Thursday 29th May}

A cool, pleasant day and we both fell well, though very sleepy. Prem came $6.30 \mathrm{am}$. and we did two hours, including making a start on the kinship diagram which looks as if it will be very complicated indeed. [SEE] Prasad rolled in for medicine and looked a bit taken aback by Prem's presence. People busy so we didn't get any calls except for selling fruit. Village a sea of green maize. Continuing Levi-Strauss and exploring possibility that Carjat/Sorajat represent entirely different cultural/ethnic groupings and correspond to Levi-Strauss' dichotomy in essay on "Linguistics and Anthropology" - Indo- European/Sino-Tibetan.

\section{DIARY Friday 30th May}

Very heavy rain last night, but I had to go out at $1.30 \mathrm{am}$. to fetch water since the tap has not been working properly lately and there have been vast queues. The "gentlemen of the village" have been too busy playing cards and dice to go and mend it for three days. Today sunny over the village, but lowering over the Himalayas and occasional clouds over Thak. Prem came promptly again and after finishing here, I went down to see Prasad's father and a Magar boy, both of them ill. Betta's father gave them Cycloper injections (which cost him 1.5rs. each and then pay him at the end). A long sleep after lunch and dug a new loo.

\section{DIARY Saturday 31st May}

A fine sunny, and fairly hot day. Gill woke up feeling sick and slept all day, with a little diarrhoea. A very busy day with Prasad coming from 6.30-9.30 and Prem for five hours later in the day. Got stacks of information - as much today as in the first month of our time here on friendship patterns, kinship, etc., etc. Rather exhausted. 


\section{JUNE 1969}

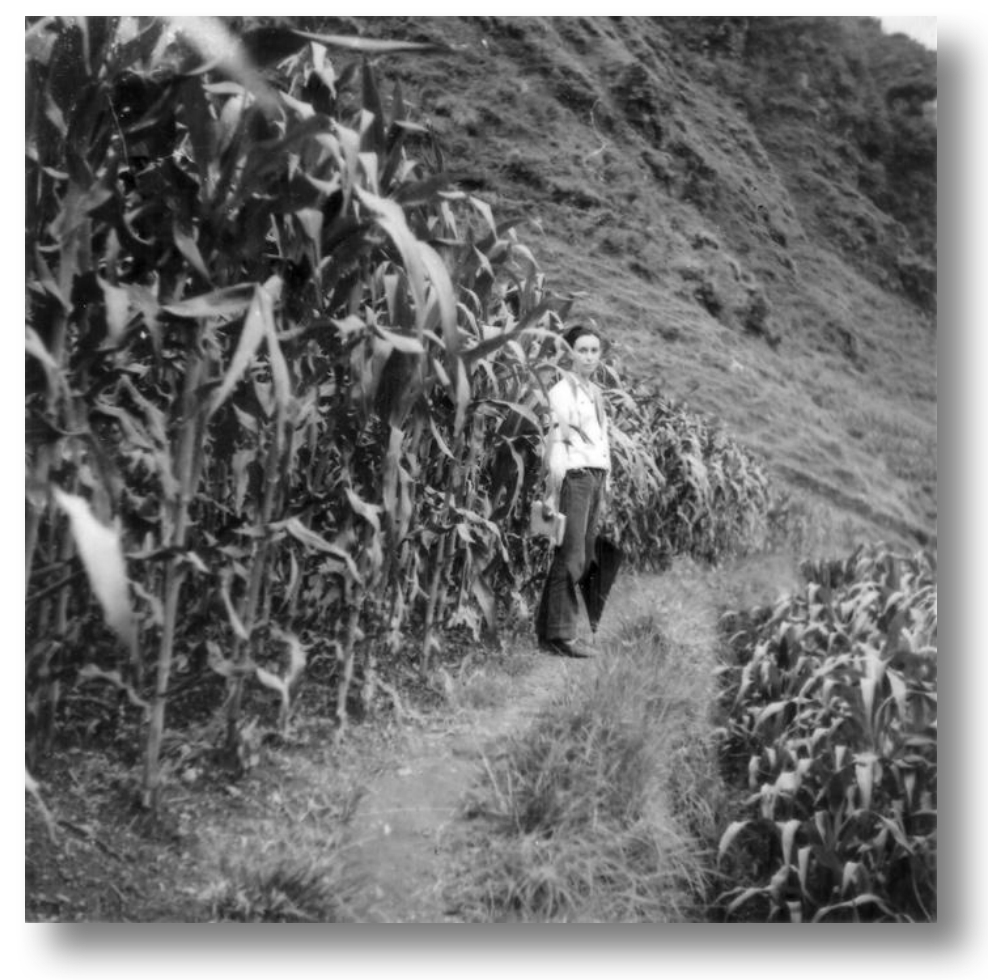

Gill walking on a narrow path by a maize field - June

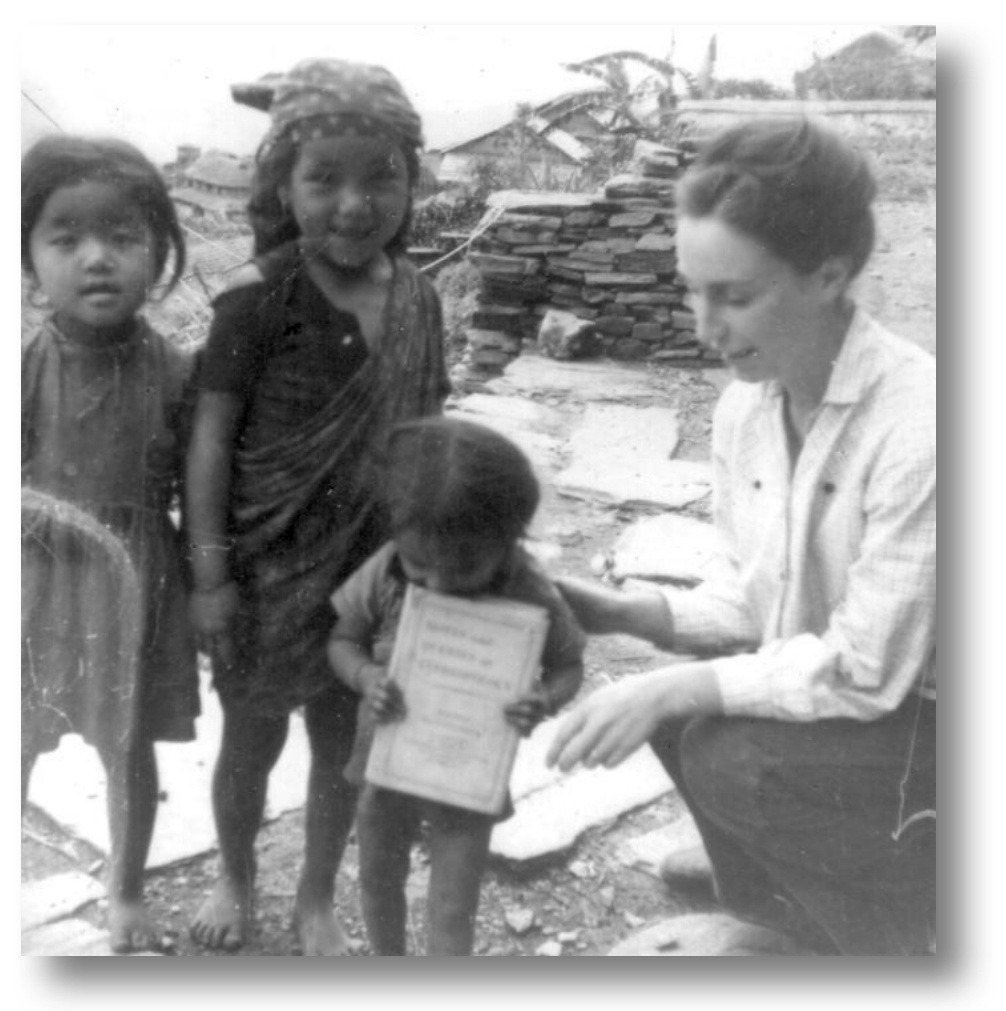

Gill with Rupa (left), Haricola, and Ramu, who is holding a copy of 'Notes and Queries' - 


\section{DIARY Sunday 1st June}

Gill a little better but still rather queasy and had a bad night - rested most of the day. Prem came again and we continued kinship chart. Nice to turn over the calendar - we still both spend much of the time longing to be home and counting the hours - curious after all this time. Language coming on though I still can't follow conversations of other people except for a few words here and there. Continuing reading Levi-Strauss. Many repetitions and many unnecessary jibes or asides, but he is still very stimulating and makes one want to go off and test his hypotheses.

\section{DIARY Monday 2nd June}

Now in thick cloud and rain - after a very hot, sultry day - though it rained last night. The rivers in spate - or brown at least. The mountains very beautiful and the trees all green. Gill much better today and even feeling fairly hungry. Prem came for 5 hours again and we made a start on the village's own census (Janasangkia Faram). Quite easy and good progress. I foresee a future when anthropology will be entirely swamped with document and will not have time to actually observe/talk etc. Prem complaining a lot of headaches, etc.

\section{DIARY Tuesday 3rd June}

A lot of cloud and drizzle. Prem made a small awning for our wood and also did 4 hour's work - at last have most of the kinship terms, thank God, and doing well with 'Janasangkia Faram'. Hoped to go to river but too wet. Gill much better also. Read 'Under Milk Wood' up on the slope - really beautiful, with clouds and sunlight in all the valleys. 


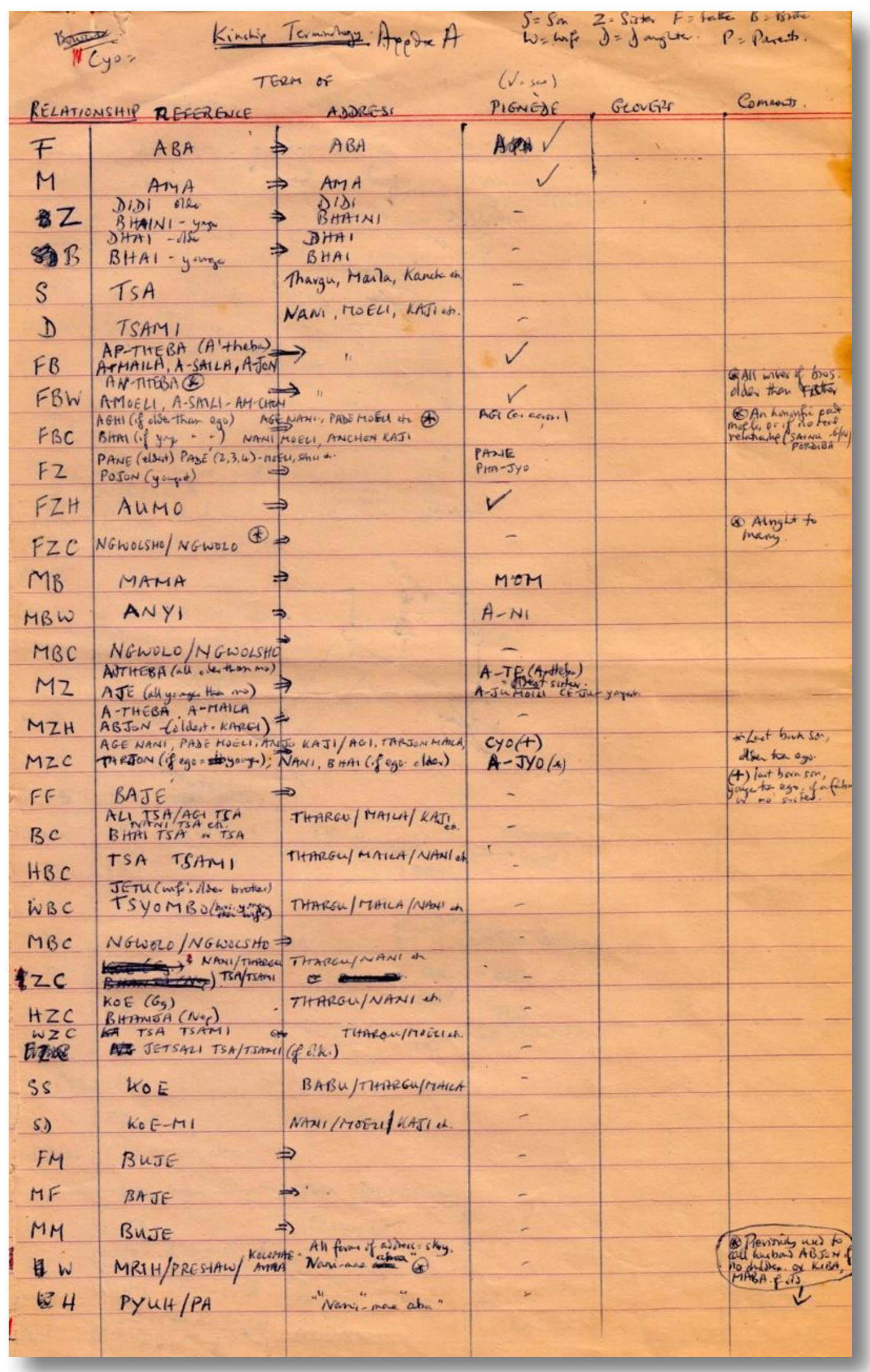




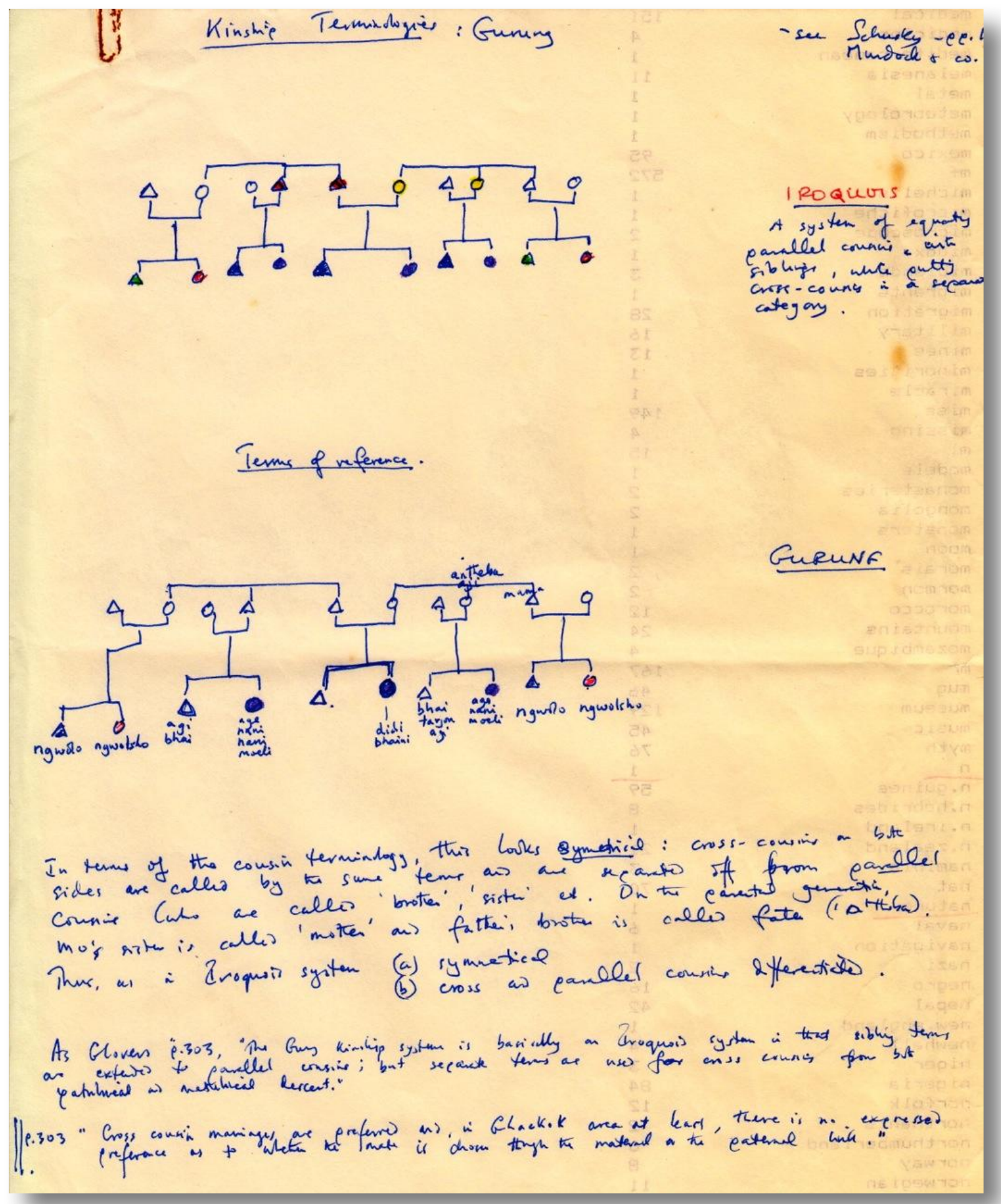

DIARY Wednesday 4th June

A hot, beautiful day and we were at last able to go to the river to wash a mound of clothes and ourselves. Rivers still not swollen. On way back met Gungadebi's mother, Potamkumari and Nansubar who were off to find why the pipe was producing no water at all - since the men (including Ramchandra) seemed incapable of doing anything. I went with them - quite a way. One break merely mended with bits of cloth. Our wood house - made by Prem - leaks 
badly and is, in fact, really pretty useless. Started "Social and Genetic Influences on Life and Death" - sound and sensible stuff.

DIARY Thursday 5th June

Rained almost all the day - a bit worried about our wood which is still out and sodden, but at least the water shouldn't be a problem! A leech bit me for the first time in the village. Prem came for 2 hours and spent the day generally clearing up, ruling lines and doing 4 pages of Pignede. Much cooler with the rain and work progressively more interesting - but still long for home. Hoping for some letters. Gill's stomach still unsettled.

\section{NOTES 5.6.1969 Alan - Salt trade}

Before eight or nine years ago people went a lot to get salt. They went up to Tukche (see map near Dauligiri to NW of Thak), a journey which took 10-12 days there and back, or to the nearby villages. At Tukche a measure of rice was exchanged for a measure of salt, if one took the rice further north one got twice the quantity of salt. The men did this. But since Tibet was occupied by China this has not been done. Then people went down to Butwal, south of Pokhara, which took about the same time. Now (since six to seven years) they have bought salt at Pokhara. (Inf. Prem)5.6.1969Alan

DIARY Friday 6th June

Dried off wood and stored it in school-house - lucky as downpour this evening. Started just as I was returning from trying (rather unsuccessfully) to mend the water-pipe with string and polythene. Spent the day quietly - Pignede, starting doing the Bali tax records (very detailed) and reading Levi-Strauss. No letters last night, hoping again tonight [only 4 came]. Gill with cough, cold, stomach - back to her old state, but quite cheerful and reading up on Hinduism/Buddhism avidly. My stomach feeling a bit queasy. Village pretty empty with everyone down in the fields working hard.

\section{DIARY Saturday 7 th June}

Prasad failed to turn up - but Prem came for 5 hours and was very good. Continued translating Bali and Census records. Went up hill this evening and some beautiful views. Reminisced about home and past events - we do a lot of this nowadays. A bright, warm day. My and Gill's stomach still upset.

\section{DIARY Sunday 8th June}

The wettest day so far - almost all the time in cloud, and frequent drenchings. Gill's cough worse, but her tummy a little better, as also was my tummy which seems completely better. Prem again this morning - he is really turning up trumps and increasing in keenness. Comal also came for a short time to give house names. Read Levi-Strauss on myth - brilliant, but entirely intuitive and his oppositions/relations merely reflect his own interests. Amused that he advocated/longed for, a workshop with large boards, etc. - as I envisage when I get back. 


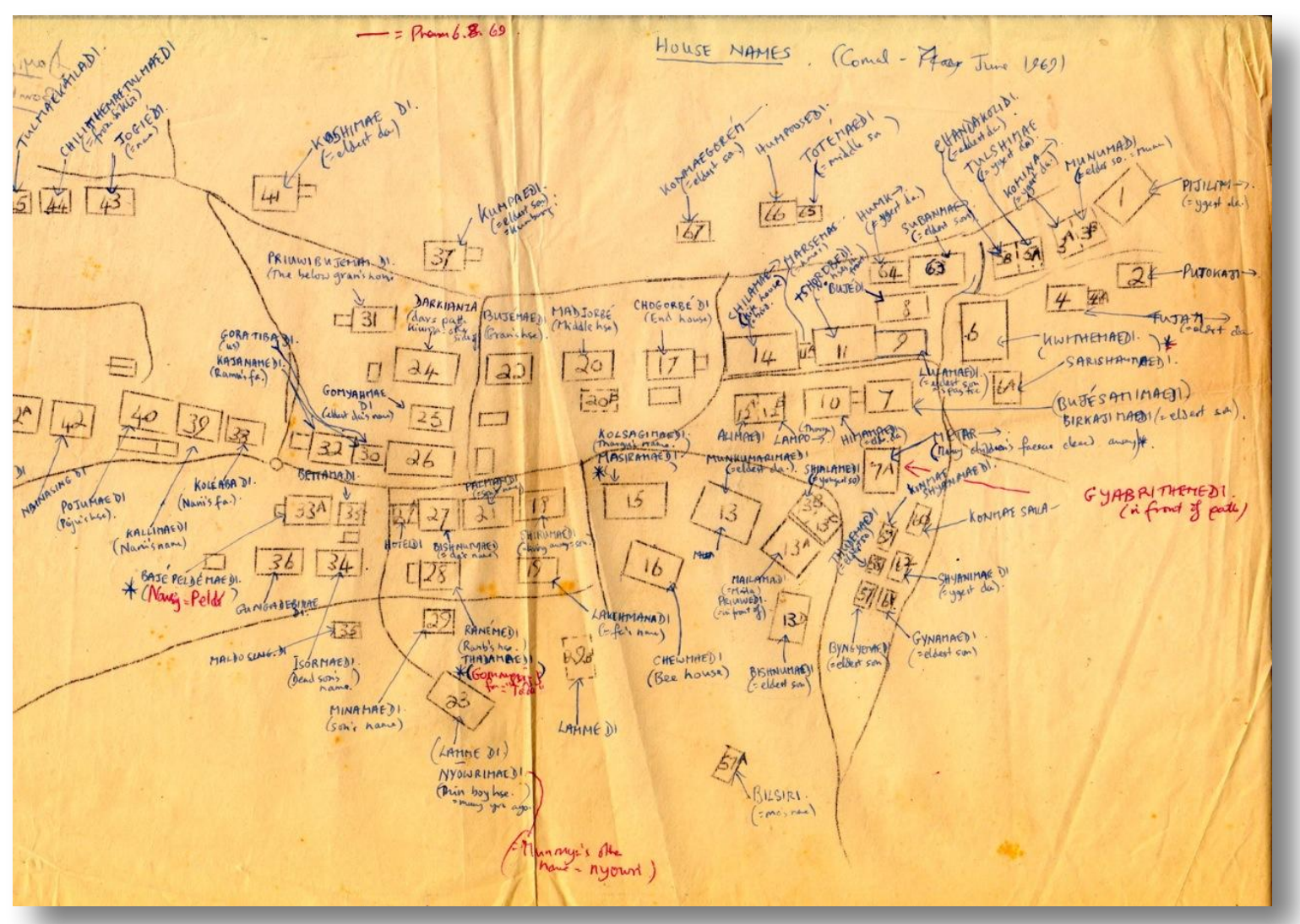

Gurung house names

DIARY Monday 9th June

Rent day. Arrived here exactly 6 months (4 week) ago. Paid Dansuba double rent (30rs.) to ensure our stay here - seemed to work. Prem off to Pokhara but Prasad came in instead for an hour with a dozen pictures and some essays from the school. Bolbahadur also came in, as did Comal to give us some song texts. Gill's cough as bad as ever and its wearing her health down - she looks tired and is listless. Finished Levi-Strauss. A strange mixture of brilliance and banality: not a deep mind, I think, but stimulating and provocative. Hot and sticky - just waiting for it to rain and fill our water buckets from the piping. 


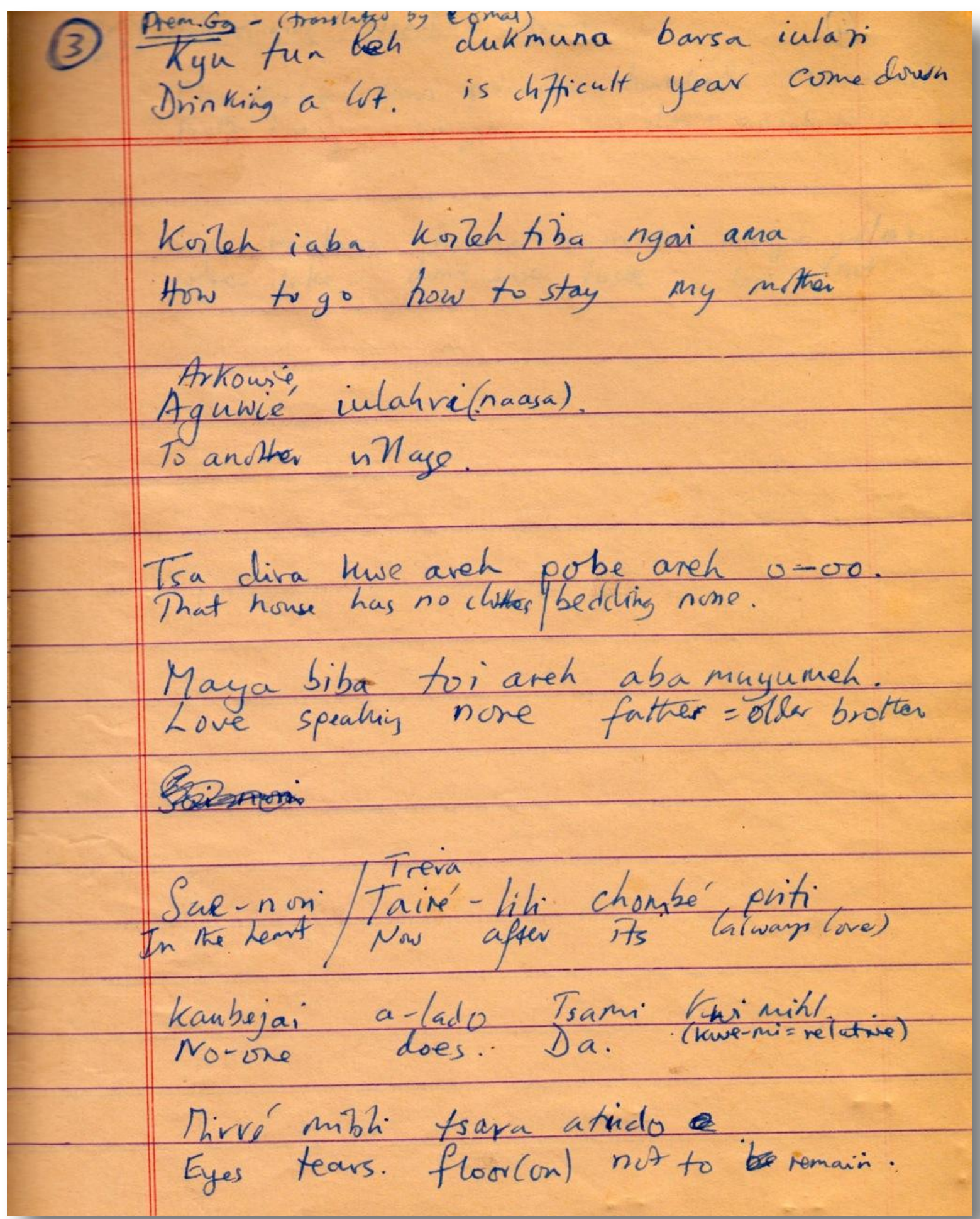

Translation of a Gurung song

DIARY Tuesday 10th June

A hot day - the monsoons still haven't broken properly. Had Bolbahadur in for three hours good informant - and Comal for another hour with songs. Started 'From Max Weber' - what a poor, afflicted man - but makes Levi-Strauss seem like an intellectual shadow. Gill's cough 
and stomach a little better today. Got the 'Tiriges' into my hands - about 12 of them - but then Ramchandra needed them again. Our diet - 3 meat meals, 1 fish, 1 eggs and then repeat.

\section{DIARY Wednesday 11 th June}

Very hot during day, rolling into thunder in the evening. Gill still coughing a little, but definitely better. Started to put census and other material onto punch cards (or rather to work out the system). The work is really beginning to get exciting, especially the economics where I hope to work out accurate consumption/production units so as to be able to work out demographic/economic patterns, eg. degree of under-employment, the burden of young/old, etc. For all this Weber is more congenial than Levi-Strauss. Hope it can be applied to historical data and used as a multiplier for land-surveys, censuses, etc.

\section{DIARY Thursday 12th June}

Hot again and still no rain proper. We went down to the school at lunch-time to watch school prize-giving and speechifying (combined with King's birthday). Prem returned from Pokhara and Prasad also bumbled in. Carried on with the 'Bali' which I managed to retrieve from Pradhan Panch and which are a most exciting source.

If only I can get the map as well. People cleaning steps and making little drains in preparation for rains. School-house next door an ideal indoor playroom for children.

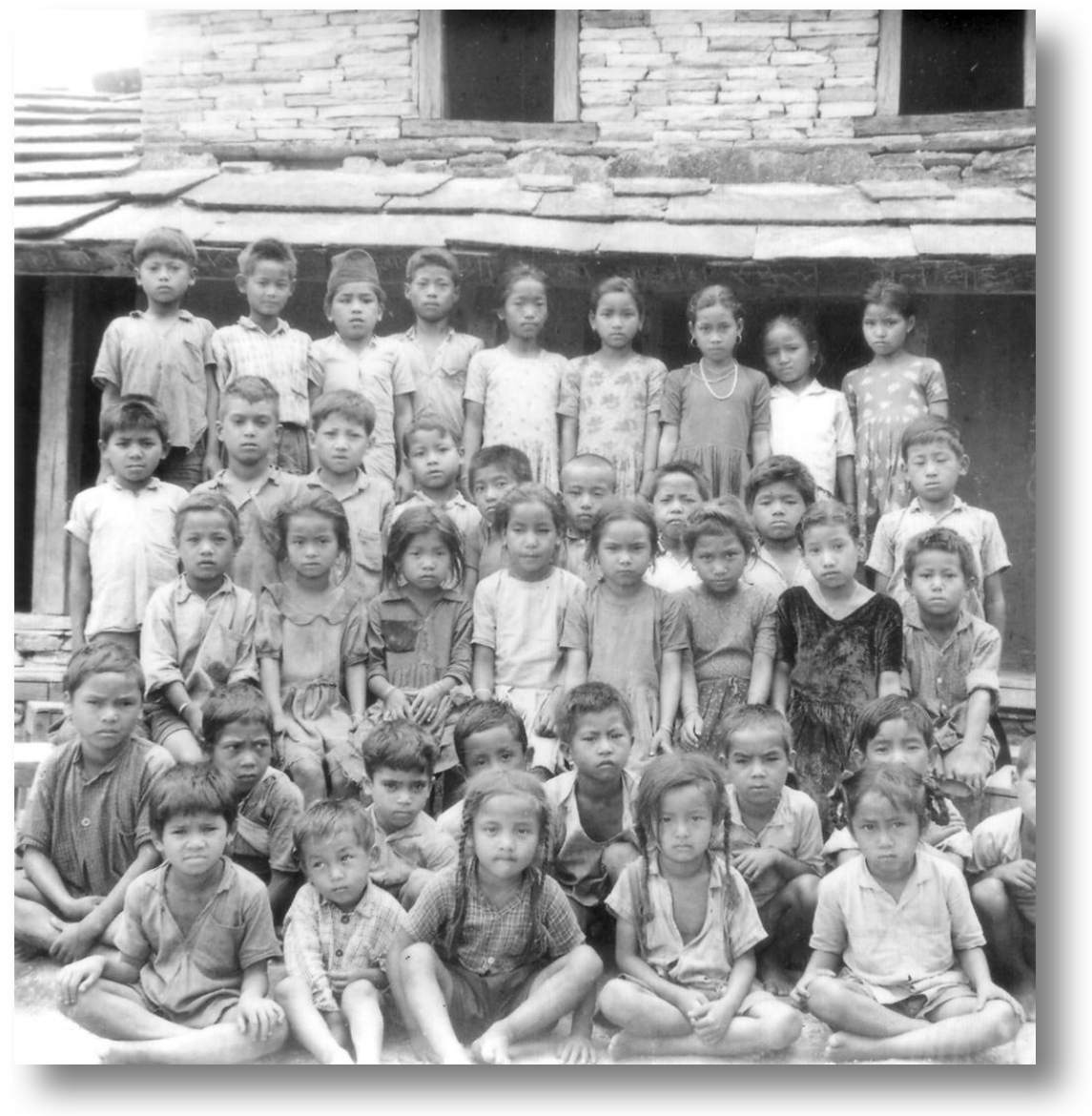

School photo 


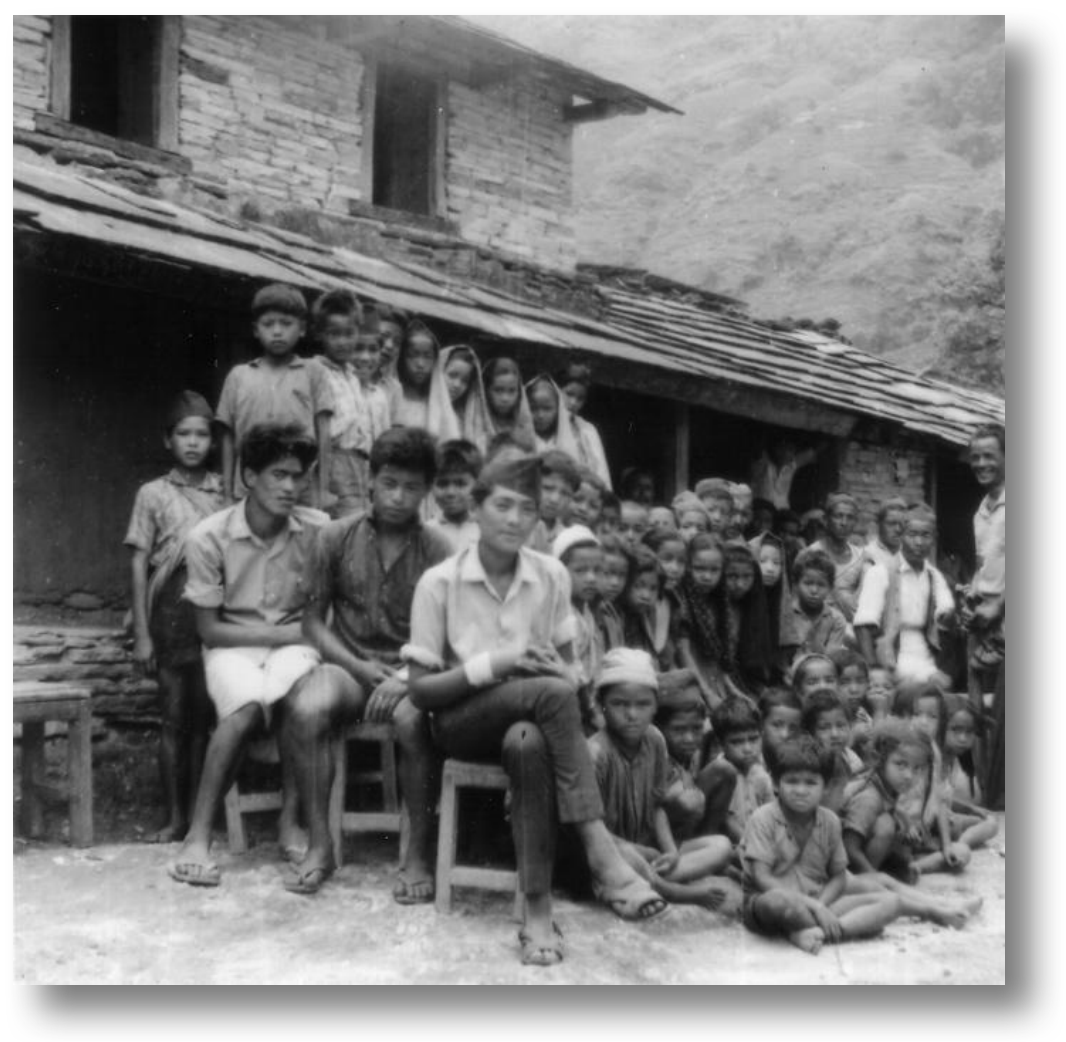

Schoolmasters, Gunjabahadur (left), Sherbahadur (middle) and Akayprasad (right)

DIARY Friday 13th June

A man died in the morning, much to Prem's wonder/consternation (he heard as he was working with me) so we spent the afternoon watching the burial up on the hill (q.v.).

Thundery, but only a sprinkle of rain. Headache in the evening and tummy still a little upset. 


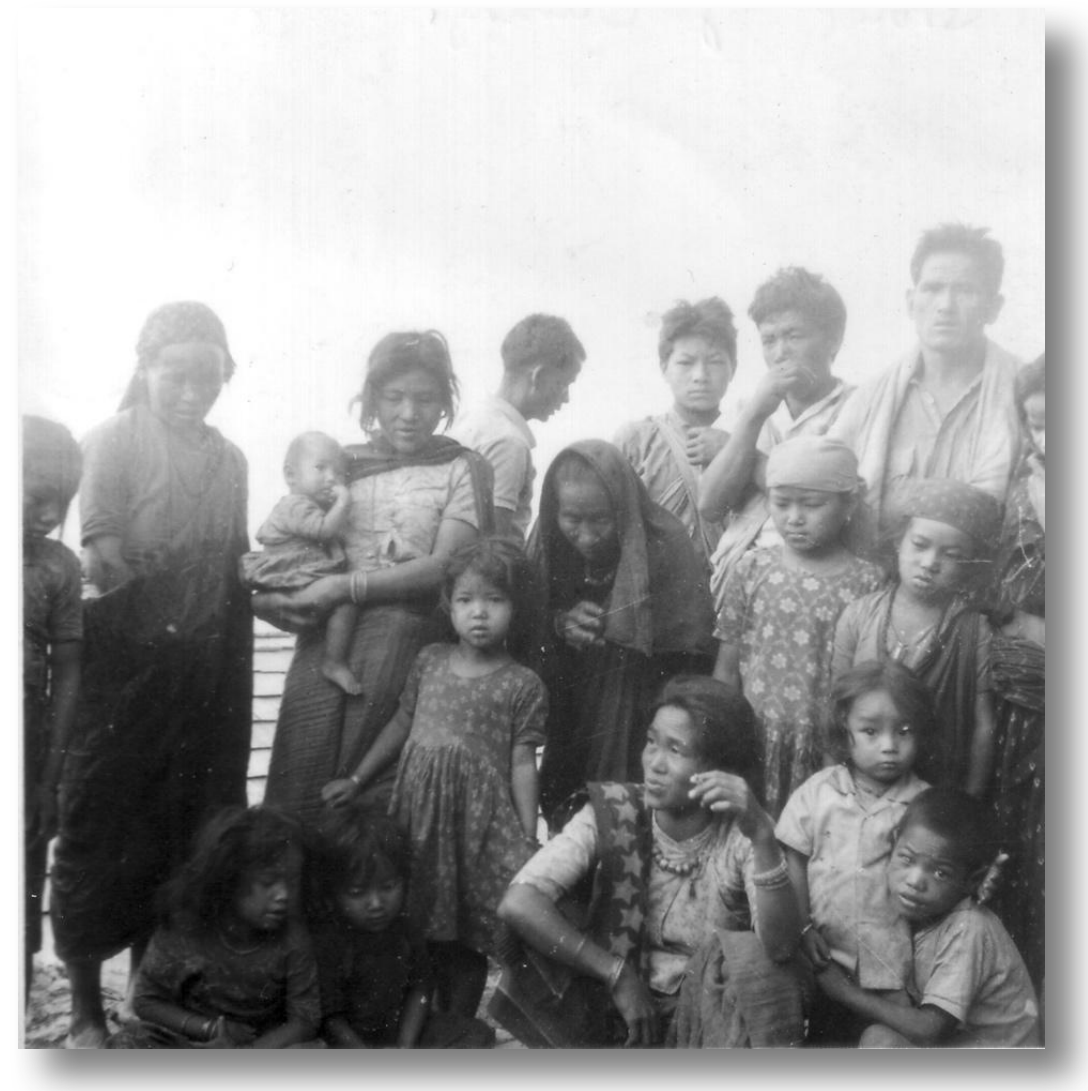

Women at the funeral

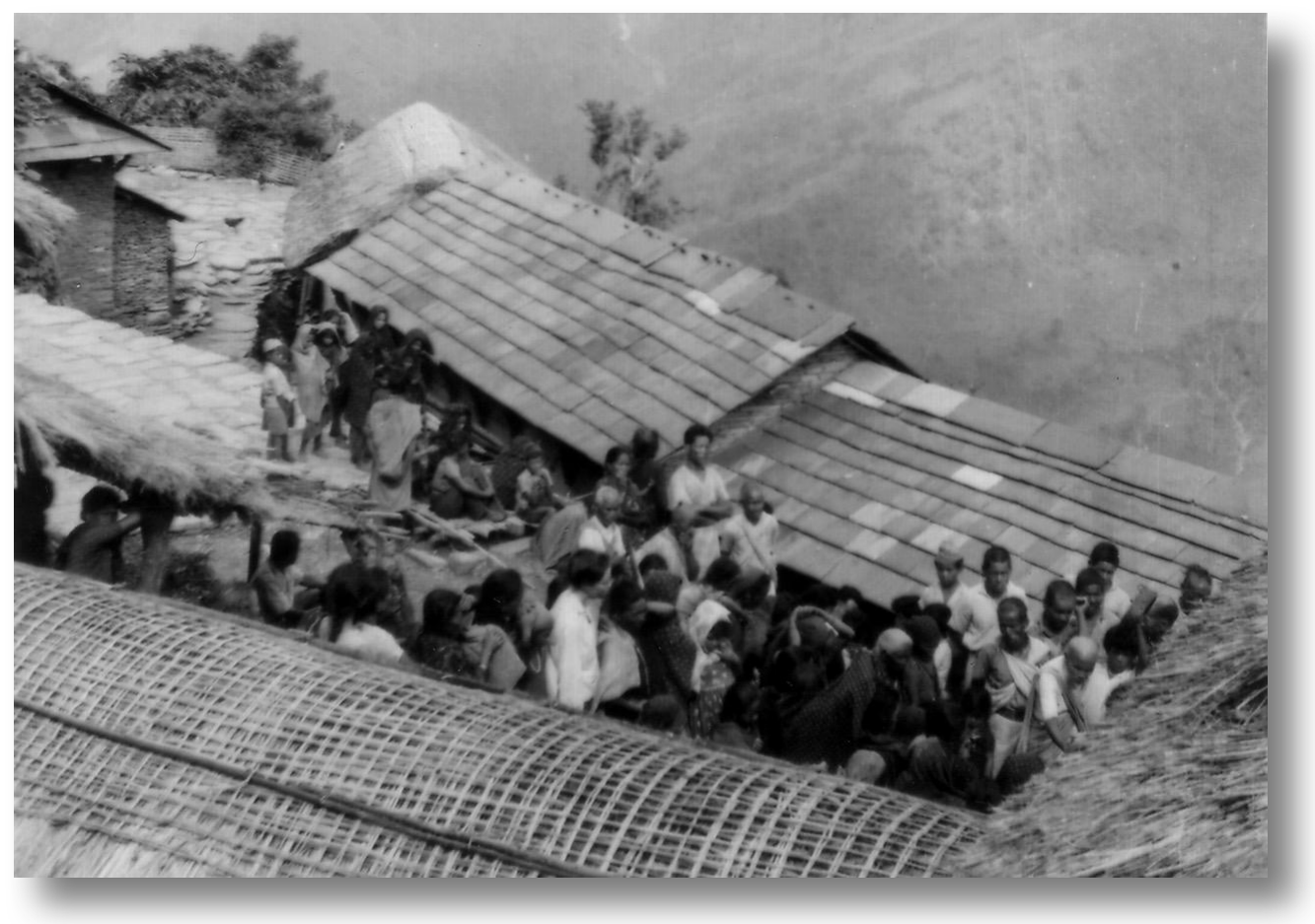

Crowd at the funeral 


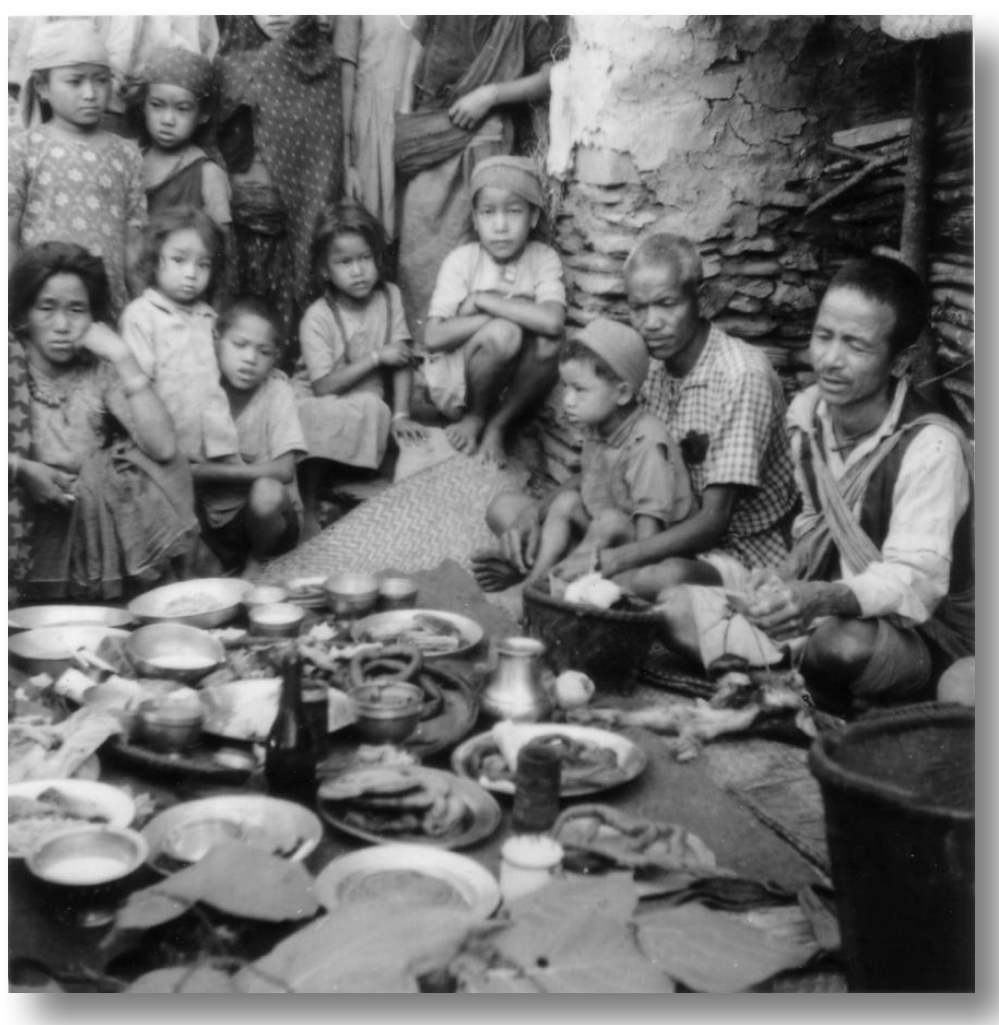

Food and poju with presents to the 'plah' at funeral

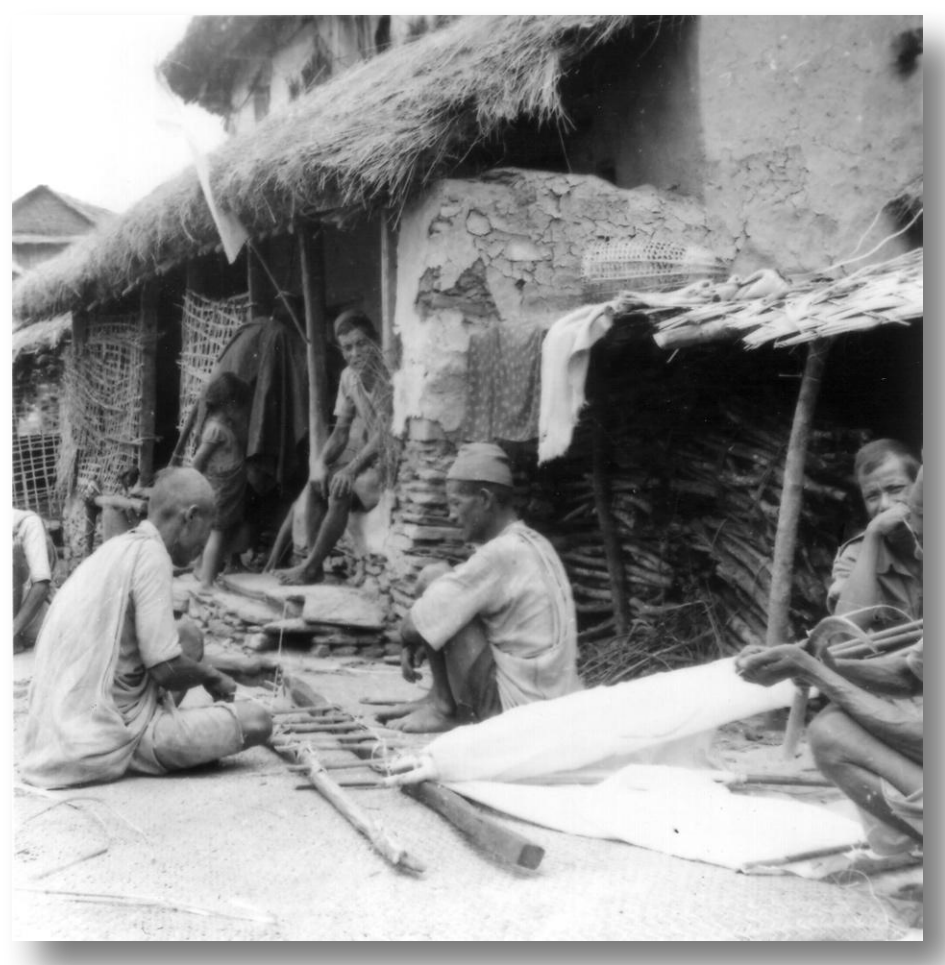

Preparing for Birban's funeral at house 27 
An old man (from House27) died and Prem said he would be buried (his jhat = lower one). At about 11 o'clock various people started to make the stretcher [see photo] - the 'moh' (Tekansing (House7) and Gumansing) most of this, though others helped. A very small white flag was put up over the door of the deceased's house. The poju (Prem - as father was away) stayed to read a 'mantra' in the house - near the dead body which was shrouded. He had a bell, rice, beads and conch shell in front. The widow sat hunched at the far end. Prem said the Lama was only used in Lamme jhat funerals and the Khlevri (klehbri) lived too far away to be called for this occasion. Kumbasing (House41) ('absaila') played the leading role in the funeral and wore the white cloth afterwards. He was asked to give 1.5rs. A 'mohre' piece was put into the dead man's mouth and water sprinkled on him - both done by Kumbasing three times over the beads. Then poju went on reading. A small piece of white muslin was brought by daughter and tied round one of the upright drinking vessels nearby poju. Poju then rung bell, blew conch, etc. - a bowl of glowing embers. The poju was reading from an old, narrow book ('Manichuri').

Pieces of white cloth ('pyruh') were endlessly tied round various officials and spectators' necks (= a form of 'shaa lava' - to protect their souls which were "frightened/astonished" at death). Then Kumbasing threw rice balls towards the 4 points of the compass - accompanied by whistling. Drums were beaten and now the poju was reading outside while the body was being tied to the stretcher inside. Kumbasing pretended to fire the bow to the four directions. All this happened just beside the house. Prem - lectured by his grandfather - continued to read - in front of him rice etc. and also millet pieces which had been used to make 'pa'. During the tying on a stretcher, both mother and daughter were weeping and drumming continued most of this time.

Meanwhile neighbours and kin had been bringing small offerings or rice and other foods which were put in a basket and would be taken up to the grave. Hats were taken off by males. To the noise of clashing cymbals, Bolbahadur's father and the 'moh' brought the body out the widow clung to it and wept as it was lowered gently onto a blanket. The old poju sprinkled water onto it. A plate of flowers and some oil was brought and the next half hour was spent arranging flowers, cigarettes, leaves, etc. onto the top of the shroud - various herbs, etc. were also stuck in. At this point the widow's hair was untied and her bangles rather harshly broken (by next door widow). Before this, Bhuwansing's mother, the most notorious old witch, had gone round 'shya lava'ring everyone - ironic.

People crowded in round the body and there was the usual haggling over small sums of money which were collected for the deceased. Kumbasing and Gomansing (Lamme) did the "stabbing ritual" with the pole. Then the white flag leading, the long 'gyan' second, the drummers next, the corpse next, and the procession of about 70 or more men, women and children (almost entirely lower jhat) followed - carried by Kumbasing and Prem's neighbour (the broad-faced young man).

We went up the easy way to the burial ground - ie. twisting round the small temple (and hence had to come down the same way) and were met just by the spring by a smouldering faggot into which was dropped some 'shuri' herb (like yew?) and we had to step over this and wash our face, hands and hair with "gold water". At the 'chogon' at the top of the hill there was more discussion as to where the body should be put - most of the men seeming vague as to where various people were buried. It appeared however that jhats were buried together on the western slope of the hill thus: $\quad$ LOGU POJU__ NGOB YOJM LEM_ KEB KWON LAM[see diagram] Note the upper jhat buried on crown of the hill (having come first) and the other jhats further down. 
Some water and a lighted match (fire) were put in the dead man's mouth and all those watching threw a little earth and a twig (wrapped in a leaf) at him. This was 'daubati lava'. Three arrows were fired to the west by Kumbasing and then the bow was broken. The women then put on their 'kramu' and went off - the men urgently bidding them to go - but Gill was allowed to stay. The widow also went.

About 20 men, all belonging to the Sorajat, were now left on the slope. Kumbasing's head was shaved and he took the white cloth 'mreh toba' - and was not to eat meat, salt, milk, cigarettes, to sleep on a bed or sit on wood etc. for 13 days. Some men fetched some large stones - which would be piled on top of the dead body. Though I was told that lower jhat sometimes cremated dead - this again seemed a difference. Meanwhile Maldo and Tekansing had dug a grave - about 3 feet long and one and a half feet across among the bushes. (In the distance could be seen several women planting millet - though they were not meant to work this day). As we said, Bhuwansing calmly informed us that he thought we were sitting on his father's grave, but he was not sure - it might be the next pile of stones! Bhuwansing said he would like to be buried, not cremated. Bhuwansing said that hair and nails (but not tongue) of the dead person were kept for the 'pae lava'. Those who had helped at funeral would get the food/money collected: the man 'wearing the white' was chief mourner ('aphsos lava'). I asked how soon the 'pae' would be. A rich man would have it within 3 days, or it might be after 13, or 45 days - or later. At the end of 13 days, a 'kule' (hat) would be given by 'a-syon mae' to Kumbasing (the mreh gnoba').

We asked if there was a god of the cemetery. They (Prem and Bhuwansing) said no - but when we pressed them said that Sildo(-Naldo) lived (in a large rock) just above. He was worshipped twice a year (at Dassarat and Naik Punchu) by the poju - at about 1 or 2 o'clock at night. Only rice was given - not animal sacrifice. The bedding and clothes and shoes (except those worth keeping which were taken by the grave-diggers) were burnt and a little flag left over the place. Then we returned to the village. For several evening there seemed to be singing etc. outside the deceased's house.

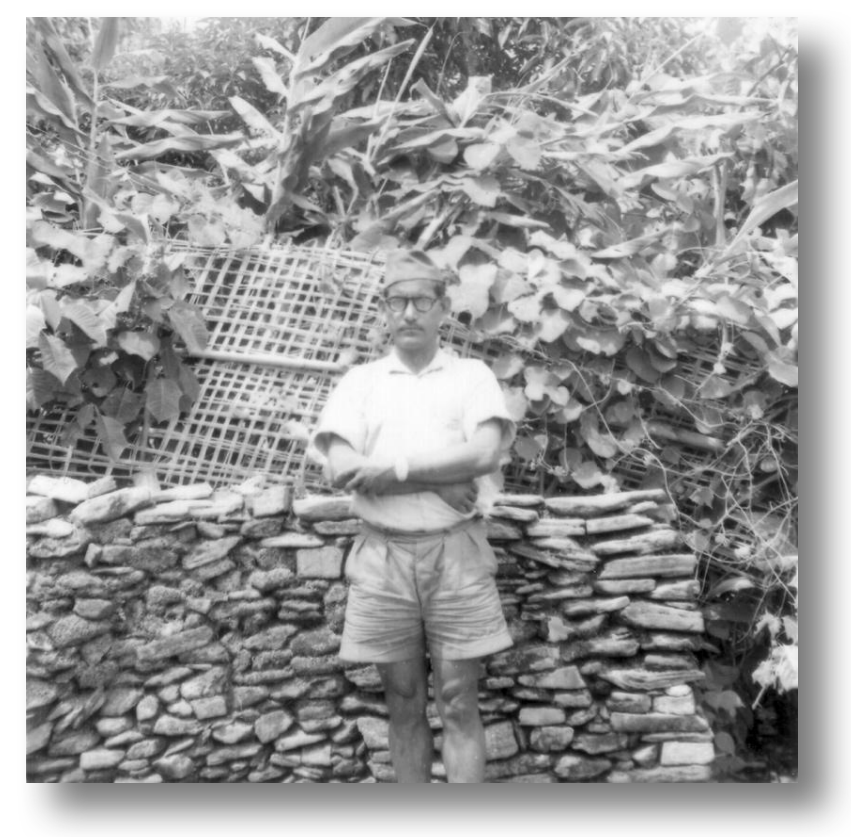

Ramchandra, Pradhan Panch, wearing borrowed watch and biro on 13th May 


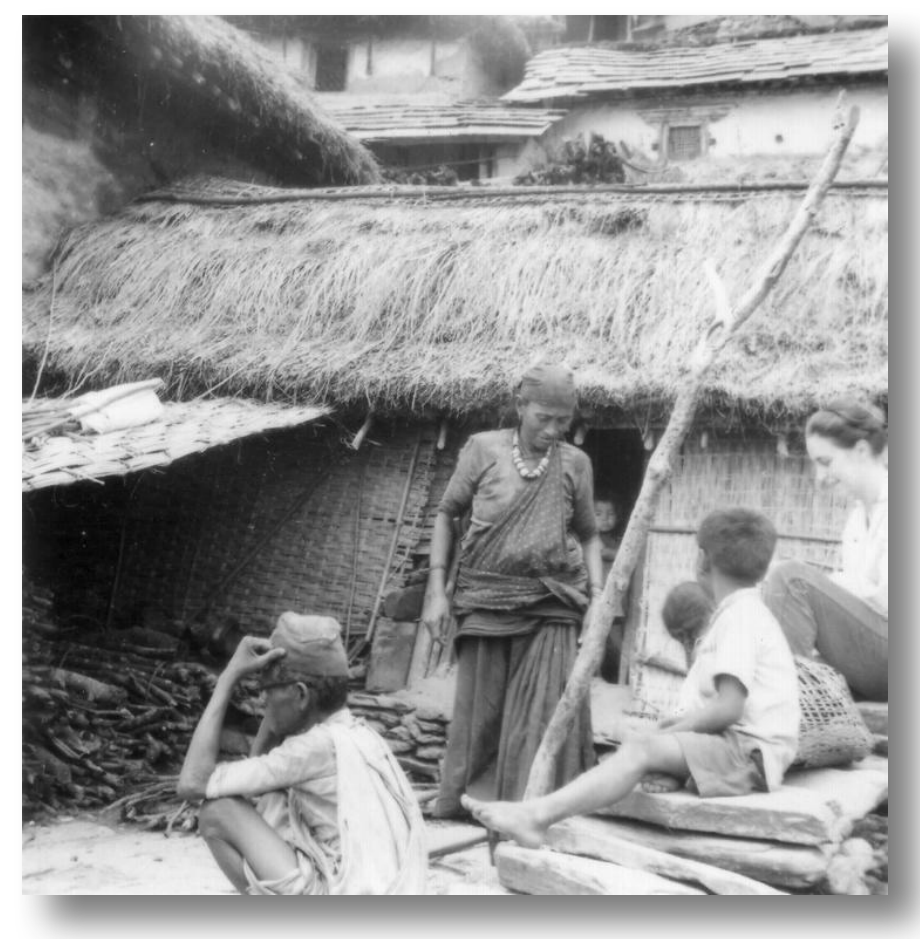

Tea house ('Hotel') with Nansubar outside

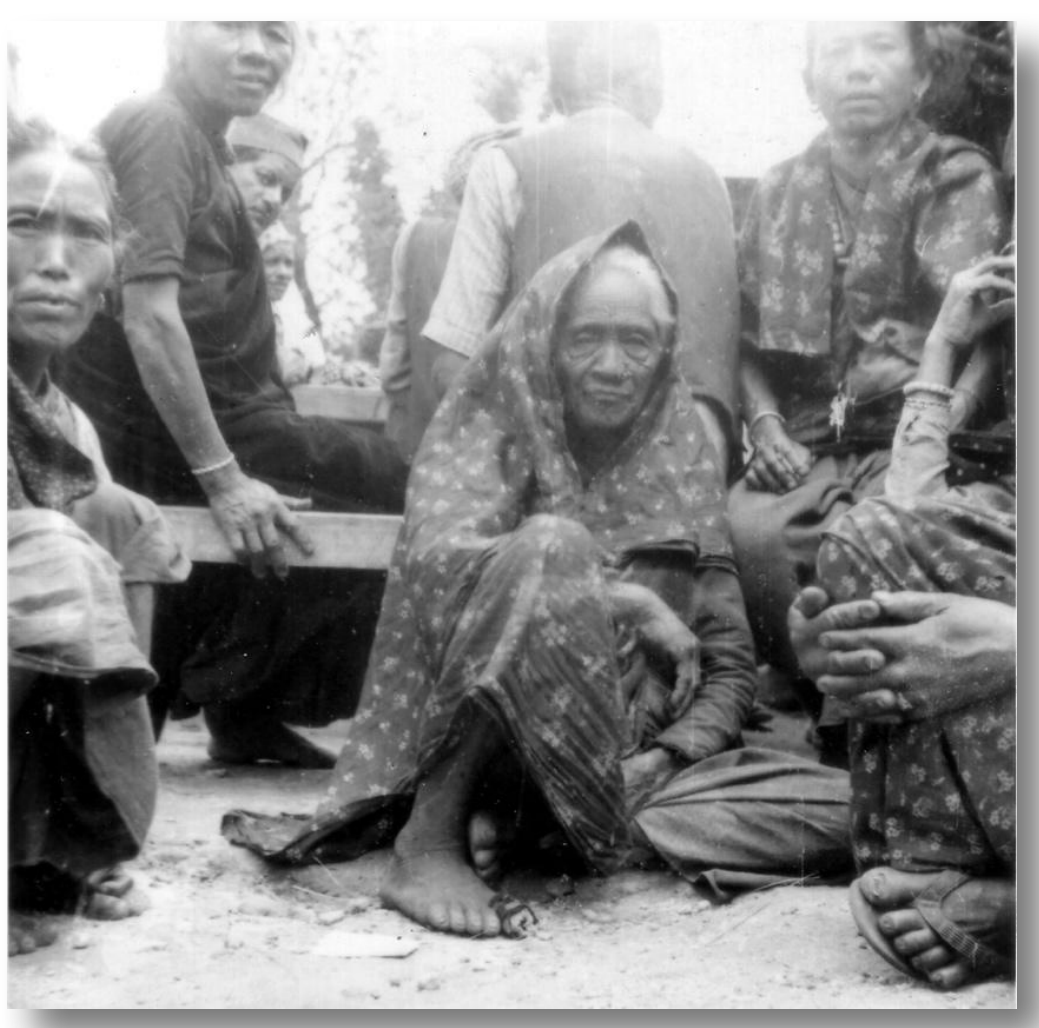

Elderly woman, Nundakumari, on 13th June 1969 
DIARY Saturday 14th June

A brilliant fine day so we went washing to the river and spent a very relaxed, quiet time there - reading 'Middlemarch', etc. We found some (child) had been into the house in out absence and filched some biscuits - unusual for Gurungs. Spend much time wrestling with the temptation to return to England for Christmas. I don't know why I, especially, long to be back so much, but the homesickness is a perpetual ache.

\section{DIARY Sunday 15th June}

Started raining heavily about 4.30pm. Up till then, hot. Headache when I awoke and cold and cough. Gill the same, though her cough much worse than mine. Spent the day writing up notes on funeral and also 3 letters - to T-Roper, M \& D and Richard. Meditated what it would be like to be a fellow of All Souls. Also read 'Middlemarch' a bit which should have deflated this idea.

\section{Letter from Gill on 15th June 1969}

Alan is hoping to go to Pokhara this coming Wednesday, 18th June, to collect letters and do some last minute shopping before the rains come in earnest: he has just started a cold today though, and doesn't feel like bounding about too much, so we might have to put it off...

We were so pleased you had enjoyed the photos, and it was nice to have you so enthusiastic about them. Alan was a bit apprehensive when you said you were taking them to an expert photographer, as this is the first time Alan has tried taking any, with quite a complicated camera lent by the college... by now you'll have another lot we sent off from Kathmandu, registered this time. We are just taking black and white snaps at the moment as coloured film in Kathmandu is fiendishly expensive, so we are trying to arrange it via another source... ...monsoon...must be late this year as there is a little rain towards evening every day but we are hardly swamped out yet. When I got your letter, it was about $6 o^{\prime}$ 'clock, and I was sitting on our verandah peeling potatoes, the rain pattering down into the bucket which we have fixed under a bamboo guttering for channeling the rain water...It has been very hot and oppressive though, and on the return journey back with out 7 porters, I have never been so hot in my life. The main part of the journey is over a wide sandy river bed, with startlingly white sand in places and the sun thrown back from this was exhausting. The men, who were barefoot were blowing on their toes to cool them down when we stopped at one of the tea-houses, and on the climb up our mountain, which I hope you will get a good idea from these last photos, the sweat was running down my face and dripping off onto the steps below!... We had quite a deputation when we got back to the village, everyone clustering round to welcome us back, very intrigued with all our boxes and sacks, and thrilled with presents we had brought for next door neighbours etc. - packets of tea, ribbons and chocolate. We were quite surprised to find that they seemed pleased to have us back, and I was quite amazed at myself in feeling fond of the funny old village and even funnier inhabitants! I thought it would be quite difficult adjusting back to the elementary life again, but it was not too bad, and I didn't yearn for the bathroom at Thyssen House as much as I thought! I did contract some tummy upset almost as soon as I got back, though, but some drugs have cleared this up and we are just rather coldy at the moment. I think it must be the change in temperature we are having difficulty with, as it is very hot during the day and then quite chilly when it does start raining. Perhaps it will be better when and if it rains almost continually, as at least it will be consistent and I find rain rather soothing, as it is very cosy in our little house.

There was some threat that we might have to move out into the school house next door which would have been very trying, as it is just a double storied barn-like building where they store the grain in half of the upper half - where we would have been. There are no amenities for cooking (ie. hole in the floor!) and we would have had to do everything in the one room. However, we have had various representatives speak to Granny next door, from whom we rent the house, saying we won't mind when they tie the corn on the cob downstairs on the ceiling, as we can stoop even more than we do now, and would she like some more rent? She is a canny, bad-tempered, 
sharp old so and so and the latter won the day, especially when Alan doubled what we have been giving her which makes it 30 rs a month, about 25s instead of $14 s !$

We have just about got everything organized, with a new table made for working on, and a new bamboo stool for me to cook on, to add to the two on which we work upstairs. I also bought some blue plastic to cover the bed which is my food-store downstairs, and I bought some mosquito netting curtain, also blue to cover the windows with if the flies get too bad, so we are really quite organized and get lots of compliments on our little house! So far we have got the flies well under control, as we managed to get come fly-killing spray in Kathmandu, and the rain seems to clear them all away - much to my relief as Jessie, a friend made in Kathmandu who had also lived in a Gurung village, had said they were appalling when they were there in the monsoons. We also seem to have controlled the ants, not to have too many bed bugs as yet, and the rats have also disappeared from upstairs, as most of the grain has gone. Food is also quite well organized as we are still getting plenty of eggs in, and have a fresh supply of honey... Even when our supply of beans and carrots I had brought from Kathmandu ran out, and we happened to bemoan the fact to some little boys we had round the fire that night, they turned up next day with green tomatoes and green tops of radishes, which tastes like a kind of spinach! (cont.)

... Things have been fairly quiet during the last three weeks since we returned, as the Gurungs are starting their busiest agricultural season, digging irrigation channels for the rice, planting millet in between the maize, and ploughing the rice lands which are at the bottom of the valley, taking an hour to get down and more to struggle up at the end of the day. More often than not, it is raining and pitch dark by the time the women come up from next door, and as they get up at about 4.30-5am, you can imagine they are pretty exhausted. Sometimes the younger men stay in the fields permanently, if they are ploughing, sleeping in the same huts as the oxen and generally being in fear and trembling of all the witches and evil spirits that are abounding down there, having no one but the animals to comfort them. We gather that when they are transplanting the rice everyone stays down until it is finished, and the village is almost deserted except for old people and children.

We have also had less requests for medicine, as they seem to be too busy to think of being ill, and only one ritual, another funeral which took place three days ago. Even here if anyone dies, everyone should down tools and help with the funeral. It was an old man of 78 who died in the fields tending the buffalo, the family seemed quite a poor one and of the lower 'jhat' - a kind of lower class, there being two main ones of very old historical origin we think, intermarriage between the two being forbidden, and other more insidious things distinguishing them like choice of friends, house position in the village and attendance at ritual. We found it quite interesting, however, as it was not a cremation this time but a burial, which again the lower jhat seem to favour as opposed to the upper one. The burial ground is on the hill behind the village, just above our toilet, and what we had thought of as a chance collection of stones turned out to be kind of memorial blocks to the dead, who a buried without much ceremony, naked, put straight into the ground, into the hole which took 15 minutes to dig, and that it that. Their old clothes and bedding are burnt beside the grave, the new clothes being distributed amongst the funeral helpers - it made the distribution of Christ's clothes at his death seem less macabre, as it is the sensible thing to do! Two days after this they have a kind of picnic where food is prepared for the dead man (ostensibly) and for the living (really) - a goat is slaughtered, everyone brings rice rings and goodies, dyed a hideous synthetic purple and pink, and whisky is drunk and roasted corn on the cob sneaked out for the children. The dead man's share, put on a green leaf and consisting mainly of flowers and a few crumbs of this and that is taken to the crossroads and left there for his spirit to feed on, which will be wandering about the village and the fields until the next stage of the funeral, which is the three day one where the spirit is finally lead to the land of the dead. If this does not succeed he falls into the hands of evil spirits and will be an evil influence on the village ever after. One of the pleasanter parts of all this is the custom for people to go and sing Gurung songs at the house of the dead man, to comfort the remaining relatives, in this case the widow and the daughter and granddaughter; as the house is just behind ours we had this for a good few hours the first night, very slow haunting songs which weren't too sleep shattering...

DIARY Monday 16th June 
Prem busy, so in a fit of restlessness I went down to Prasad's house and he agreed to start the 'Tirij' the following day. He asked me to go fishing and so went to the Tadsyon Kola where we caught about 3-4lb of fish by damming the stream in 3 places and then pulping up some leaves ('kiru') which we dropped in the water and which partially stunned the fish. Thought what great prospects there would be for fish-farming here, but how does one make such a thing catch on? Very wet when I returned.

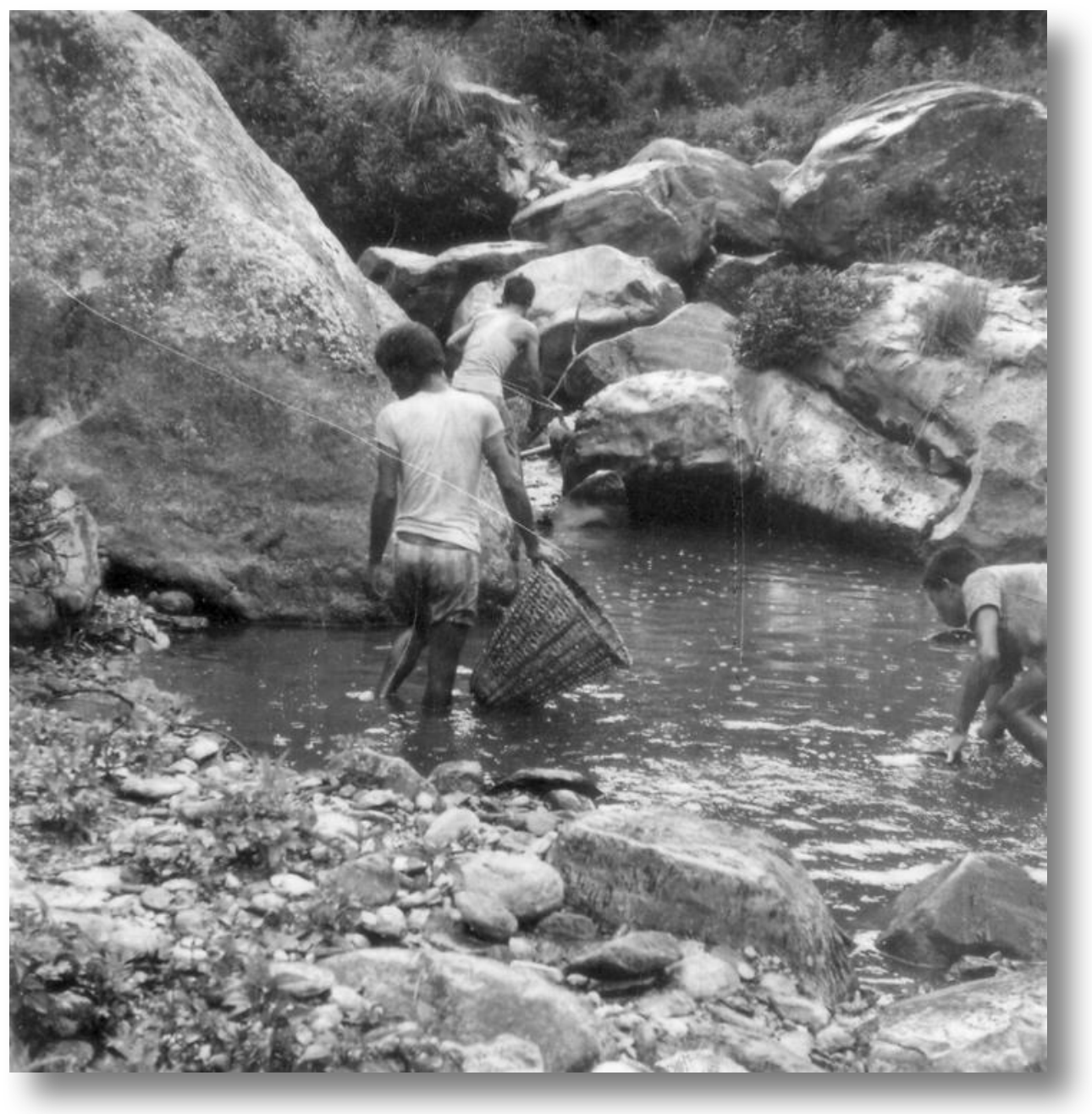

Trapping fish poisoned with 'kiru' on 16th June 1969 Letter from Gill on 16th June

... The village is much more peaceful nowadays, with little witch-hunting and less sacrifices to the gods, as everyone except the old people and children are down in the valley preparing the terraces for the rice, and sowing millet in between the maize. This is nearly 7' high by now, and mauve tassels are sprouting out of the stems... funeral (three days ago) this time it was a burial and not a cremation, and we were not surprised at the rather haphazard way of doing things, as the Gurungs are the most relaxed of beings. The body was buried naked in a hole that took about 15 minutes to dig, the

men wandering round the burial ground making half-hearted guesses as to where people were buried already, only a few scattered boulders marking the place, if at all. Happily, they guessed right and the poor man was squashed in, the women being told to go away (with me remaining, crouching behind a fern leaf trying to look like a Gurung male), and a few boulders bonked over him, and that was that. 
His old clothes and bedding were burnt, and the good ones distributed amongst the relatives who had scraped at the hole. Yesterday they had a picnic and killed a goat and offered the spirit some titbits, but really an excuse for the living Gurungs to live it up a bit, much arguing about who should have the rice ring, the widow sad without her bracelets,

but the girls coming in the evening to sing slow, haunting, cheer-up, Gurung songs so that she would forget. It is all a curious combination of sense and sympathy...

. This coming Wednesday (18th Fune) will be the first time Alan has been down again to post letters, and get in more supplies before the monsoons will cut off communications altogether. It will certainly be more of a slog to Pokhara, which is about 12 miles away on the valley route, and much longer via the ridges which we shall have to take since the rivers will be flooded.

Otherwise I have found the rain rather soothing so far, pattering on our slate roof in the evening and reducing us all to wet human beings instead of Gurungs and 'goramae' (white people). We have finally got back into some sort of satisfying routine again, after our civilized break, where we met other anthropologists, sharing all our paranoid experiences, and having a bath with taps, hot and cold, and a loo to sit on...

\section{DIARY Tuesday 17th June}

Went down to Prasad's and started the 'Tirij'. Not as bad as I thought it might be, though it took about two and a half hours to do about a third of one long 'Tirij'. Fascinating however. Hot. Gill and I both wrote letters today. Yesterday opened our final tin from Helios - veal cutlets, suitably delicious. Both of us continue in our minor ailments - colds, coughs, and slight tummy upsets. 


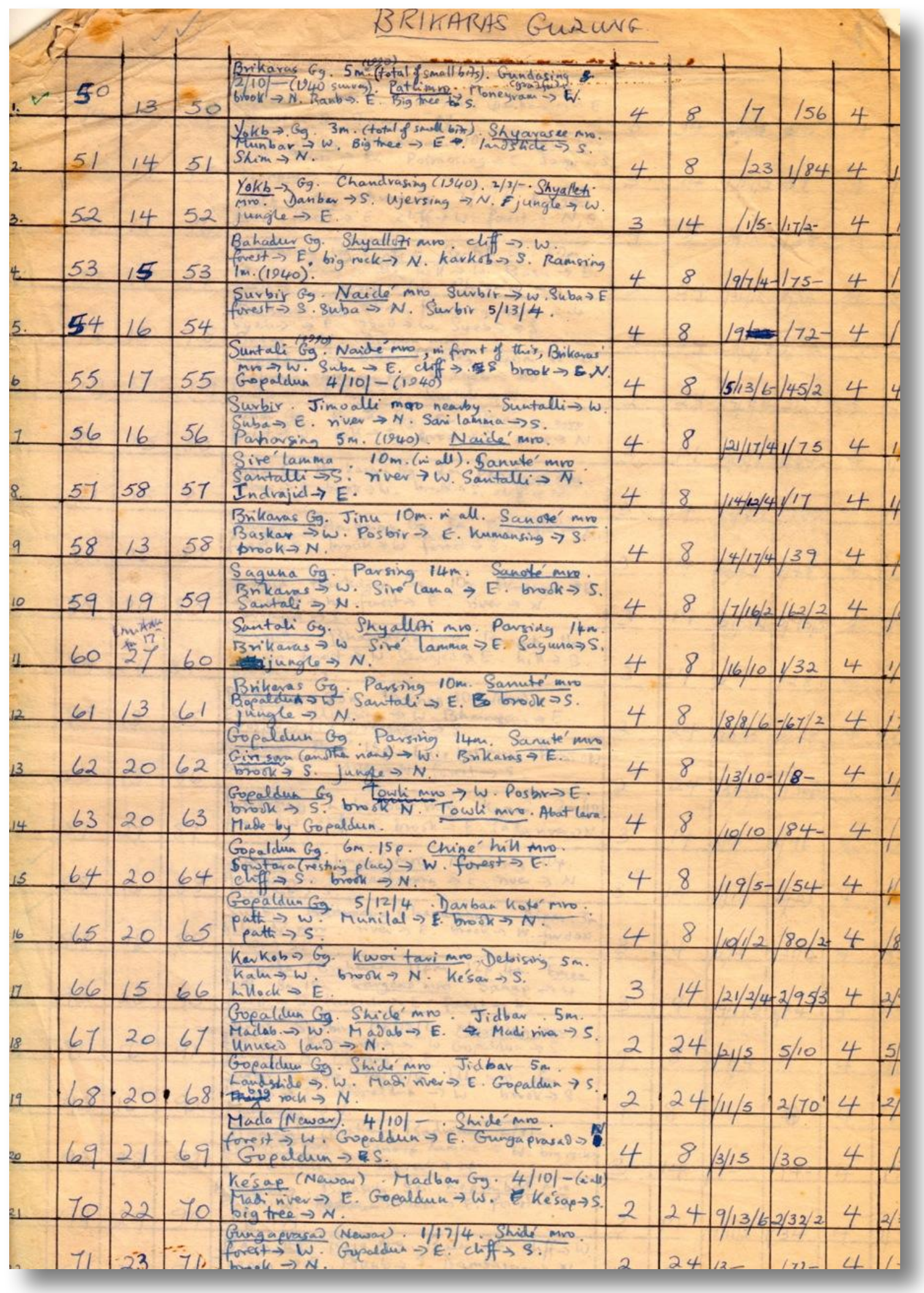

Part of the old land records (tiriges) transcribed 
DIARY Wednesday 18th June

Had intended to go to Pokhara today, but a combination of the death of Potamkumari's husband yesterday, and the fact that I was a bit tired from going down fishing two days prevented me. Rained heavily so am a bit worried that the river will be very flooded. Watched burial in maize field - rather macabre. Prem came for several hours so did his inventory and also some more 'Bali' tax. Read more of 'Middlemarch'. Interesting how much one enjoys reading, especially novels, away from home. Why, I wonder. Gill still a bit under the weather. Off to Pokhara tomorrow, I hope.

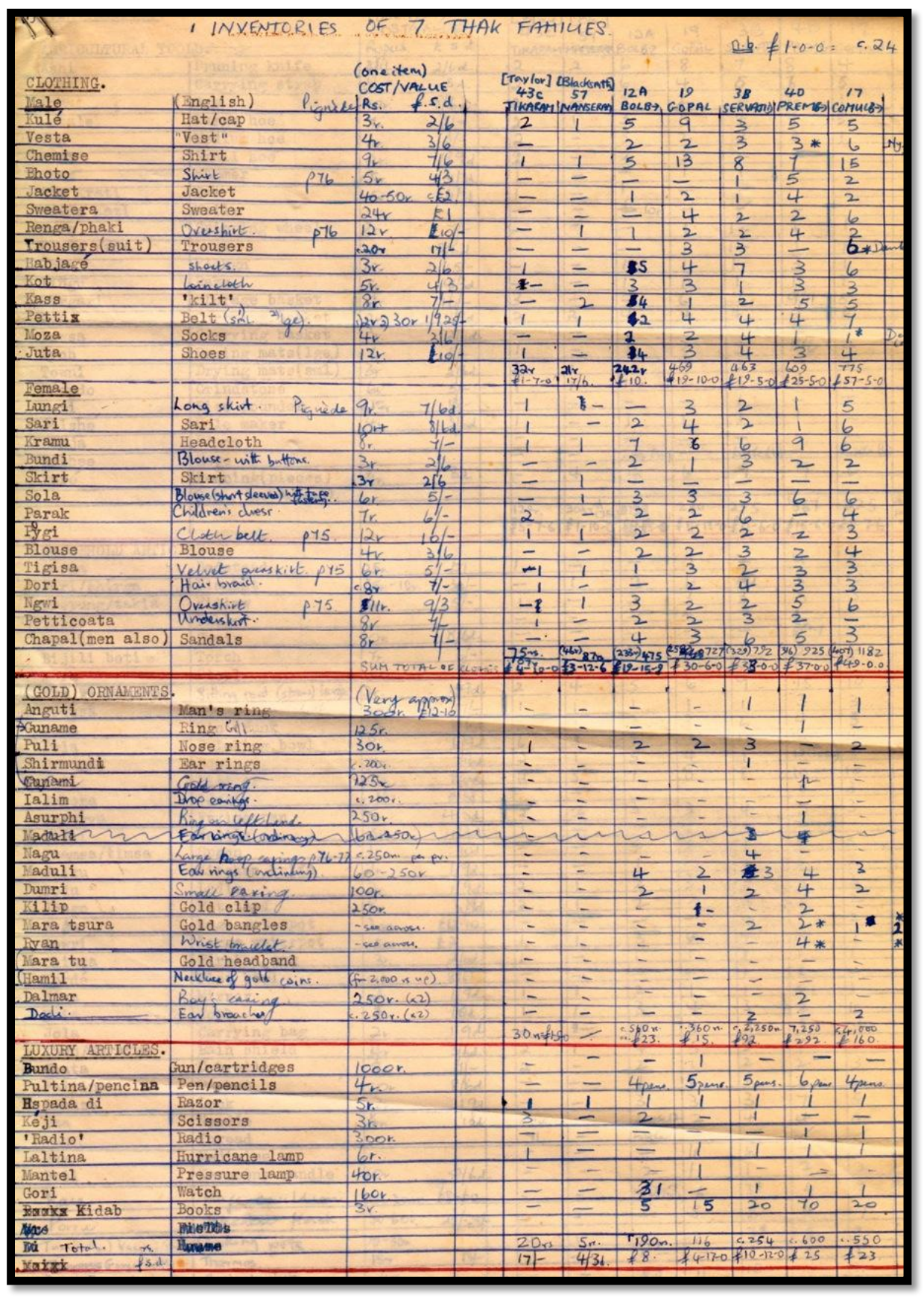

Part of the inventories of seven Gurung families 
18.6.69 c/British Library, Pokhara.

P.S. A carbon of work part of this + Gill's letter sent to Erik and Annie

Dear Mummy and Daddy,

Sitting typing at the new table which we have finally managed to have made after 3 months effort. A burst of hot weather just before the monsoon begins in earnest, and ironically we both have coughs and colds! It is one of the surprising (for me) things about a society such as this: I expected a large amount of people to be chronically ill - leprosy, mutilations, TB. etc. But, perhaps because I don't know the symptoms of more serious illnesses, it is the universal spread of minor illnesses - coughs, running noses, mild dysentery, conjunctivitis, minor cuts etc. which is striking. But enough of that, or you will be fretting!

Hope you got my hand-written letter posted just before we left Pokhara towards the end of May. I expect there will be a letter from you waiting when I post this at Pokhara; our last post, brought to the village only 8 days after we had left Pokhara, mainly consisted of letters from Lady Clay and Richard (E Gills parents). Richard's letter contained the news of Fiona's wedding - will reserve comment until we hear more about this. Anyhow we look forward to hearing all your news - especially of the croft and mean that things are going smoothly. A long silence from Routledge and C.U.P. which, presumably, mean that things are going smoothly. Although I won't be officially reading the proofs, I am wondering whether I ought to have a typescript of fosselin out here? On thinking it over, I don't think it is necessary, but I am afraid it means a heavy burden on your checking as I won't be able to check the quotations.

For quotations I found it easiest to get someone else to read them out in typescript (i.e. Gill) and I checked them in the proofs. Incidentally, could you possibly send me a list of the people I asked you to send complimentary copies of the witchcraft book to - so that I know when I write to them whether a copy has been sent (also of those who want a reduced price copy - if I made such a list, otherwise I will send you one)? Richard's letter brought me up to date with his news and bit on Robert etc. Was amused to learn that Robin had been catching trout in my old fishing spots - it will be fun to take him out and to take Gill round my favourite Sedbergh haunts when we are at Dent. Any more news of the cottage? And how goes K.L - but I will get on to work later. Richard obviously found it rather difficult to write to me and the result was a terrible ultra-schoolmaster-report style. e.g. "I hope the evidence about your tribe is mounting fast and that you will have substantial discoveries to communicate to the world of anthropology when you return to civilization" - it makes me feel like Livingstone or some other C19 explorer! But it was sweet of him to write.

Work has gone extremely well since we returned - my best informant (not the feckless schoolmaster) turning up for a couple of hours each morning before he goes off to work in the fields. But there is likely to be a lull now since the next six weeks are the busiest in the year with the transplanting of the rice. All the available labour in the village - apart from children and old people - will go down and live in little huts in the fields for two weeks. They will work in the torrential rain among the leeches, little basket rain-shields like tortoise-shells on their backs, and eating roasted corn-on-the-cob which is ripening in the neighbouring fields. They were very irritated when an old man died two days ago and all the village had to stop working for a day to attend his funeral - but it gave us some excellent material as hitherto we had only seen a cremation. We discovered, for example, that each lineage had a special burial area on the hill - I wonder if this was so in K.L. - or on that sandy hillocks that serve for cemeteries over on the west side of your island? Anyhow I will describe some of the types of information I have begun to collect systematically for the village and perhaps you could reflect and comment on whether we will be able to get comparable for Kirby Lonsdale.

a. Inventories. I hope to collect four of these - two for rich, two for poor families. They are lists of property. I have only collected one so far - there are some 90 items, to hear how it compares to poor K.L. families at different periods (the family concerned is perhaps the poorest Gurung one in the village - though many of the untouchables are poorer. The totals are for the whole family: man (aged c. 50), his wife, about the same, one grown son and one grown daughter, and two other daughters and one other small son.

Clothes:- (the totals are rough, and probably exaggerated) - c. \&20; ornaments, $c$ \&20: luxury articles (watches constituting 85\% of total), f8; agricultural equipment, f 9 ; livestock (2 goats $\& 5$ chickens), $c$. f5; household articles (of which water-carrying bottles constituted one fifth), $\mathcal{E}^{26}$. They have no fields of 
their own and do not own the house they live in. total: f88 - or about f12-10s. capital per head. I look forward to comparing this to rich Gurung families and those in Boreham/K.L. this is obviously an area where we can do a good deal of work.

b. Production/consumption units.

The aim here is to work out how much individuals of various ages and male/female can a) produce as workers b) consume in food and other goods. Once one has this one can multiply the households to find out how these balance. One will also be able to find out things such as how much wealth is consumed by children who later die; how much economic 'weight' various societies carry in the form of old age; what is the relation between the available labour resources and the amount of work to be done in the available land. It is not too difficult to discover these things in the field; I ask people when they start to work, at what age people work most and at what tasks, how much various categories of person eat and spend on clothing etc. this, of course, then has to be checked with what actually happens. For this, for example, I am keeping a day-to-day account of what each member of two families does, and we hope to do spot checks on diet. How to set about this in our historical studies? I imagine contemporaries must have made estimates on labour and consumption at various ages and, as you know, I gathered a few things together re. this in R.F. But if you come across anything on these lines with special reference to K.L. I will be most interested.

\section{c. Labour expenditure and methods of agricultural work.}

The main crops here are rice, maize and millet and for these, as well as for about five other crops, for activities such as water-fetching, wood-fetching, house-building, housework etc. I am getting estimates on how long is spent (and in which month) on the various operations involved. Thus, for example, one informant gave estimates that suggested that it took about 85 man days (8 hr days) to produce enough grains for a person to last on for a year. If this is so, one can work out, for instance, the difference between working on one's own land, where one gets the whole profit, and farming out land - usually on a system of crop-sharing where owner and cultivator get half each. One can also discover, since I should be able to find out the total acreage under various crops, the amount of days people must be idle in the year. How about K.L? Are there any hints on this in the Agrarian History of England. What were the main crops in K.L. and how long did it take to grow them. How much time was spent on fetching wood and water - e.g. it is reckoned that women spend some 3 hrs. a day fetching water from the nearby tap here. If the pipe was kept in good repair this time would be cut in half. Living in Fountain Cottage we will be in a good position to study this! (Also under this head am gathering information on how much manure is applied - a fair amount - but no fertilizer is used at all otherwise.

\section{d. Distribution of land and crops.}

The records on this subject go back for 35 years. For the last three years, since all the land was surveyed, very detailed records, showing under each owner the fields they owned and the amount of crops (down to the last pint) they produced, have been kept. The field names are also present. So it should be able to study not only ownership but also productivity of land and comparative wealth of families. I suppose one of the main problems you will have is that lands are often owned in different parishes by one individual. Can you think of any way of working out yields? I suppose there is nothing on this in the manor court books? A lot of land is also loaned out - mostly on the share-cropping system which usually equally divides the harvest. I have got some estimates of who loans to whom, but this should be given precision by the records of every land (and money) loan three years ago taken by the Land Reform Commission. I hope to try and correlate these with friendship, lineage and other patterns. What system of land loaning was there in K.L. and what proportion of the harvest went to the owner and cultivator respectively? The way in which inheritance has broken up land-holdings over the last 35 years will be especially interesting to compare. Here, wills cannot effect the equal partition between all legitimate sons. I wonder what effects on social differentiation the possibility of favouring one son would have? Here richer families are constantly being broken back into medium wealth - what happened in K.L?

e) Labour services and organization of labour. 
For various reasons some families have too much labour, others too little. The two major ways of dealing with this, apart from loaning out the land, as described above, is to hire individual labour - usually in the form of ploughmen or cowherds who are untouchables and who work on a yearly basis for a certain measure of rice or b) to hire the ward work team (called gola) which is used, for instance, when a big task such as fetching in the monsoon-season wood is to be done and which is paid per person for the day. Most of the rich families have at least one permanent dependent labourer and I hope later to go through the careful record of gola work which our friendly Lt. has kept. Those who have roughly the same amount of land usually join together to work it, forming nogora or communal work teams who go from field to field of those participating. These seem to be informally based on age groups - mixed of men and women. In the bad old days they used to sing and dance after the work and all sleep together in one of the houses; the immorality which ensued has led to this being stopped in this village, though it still occurs further up the valley. There are no payments for such work. How about K.L? Apart from road-building, I wonder which tasks were done communally - one imagines sheep-clipping and harvesting, but are there any hints of this in manorial court or other records? Perhaps we may find something when we have got some more of those Chancery court cases at the P.R.O. done. I think it is fairly indicative of the whole economic ethos of 'individualism etc - the way in which work is done and the degree to which the community acts together. Your islanders, for instance, appear to be the opposite of this place. One wonders why.

Well, I think that is about as much as Daddy (and you) will be able to stand for now. You will see that there is plenty of intellectual interest here - even if it is a long way from the study of witchcraft, religion etc. which I thought I would be doing. But that will come when our language improves. Gill is reading hard on Hinduism, Buddhism etc. Only 8 months and a bit before we are home.

Thinking of you very often, with all our love, Alan

P.S. Could you possibly send out 3 yards of the tweed of which you sent me a sample? (grey with a red stripe). Could you address it to Mr M.B.Pant, c/o British Library - Let me know how much it costs and I will repay you - plus postage. Unless it is fiendishly expensive, could you send it by airmail?? Many thanks. 


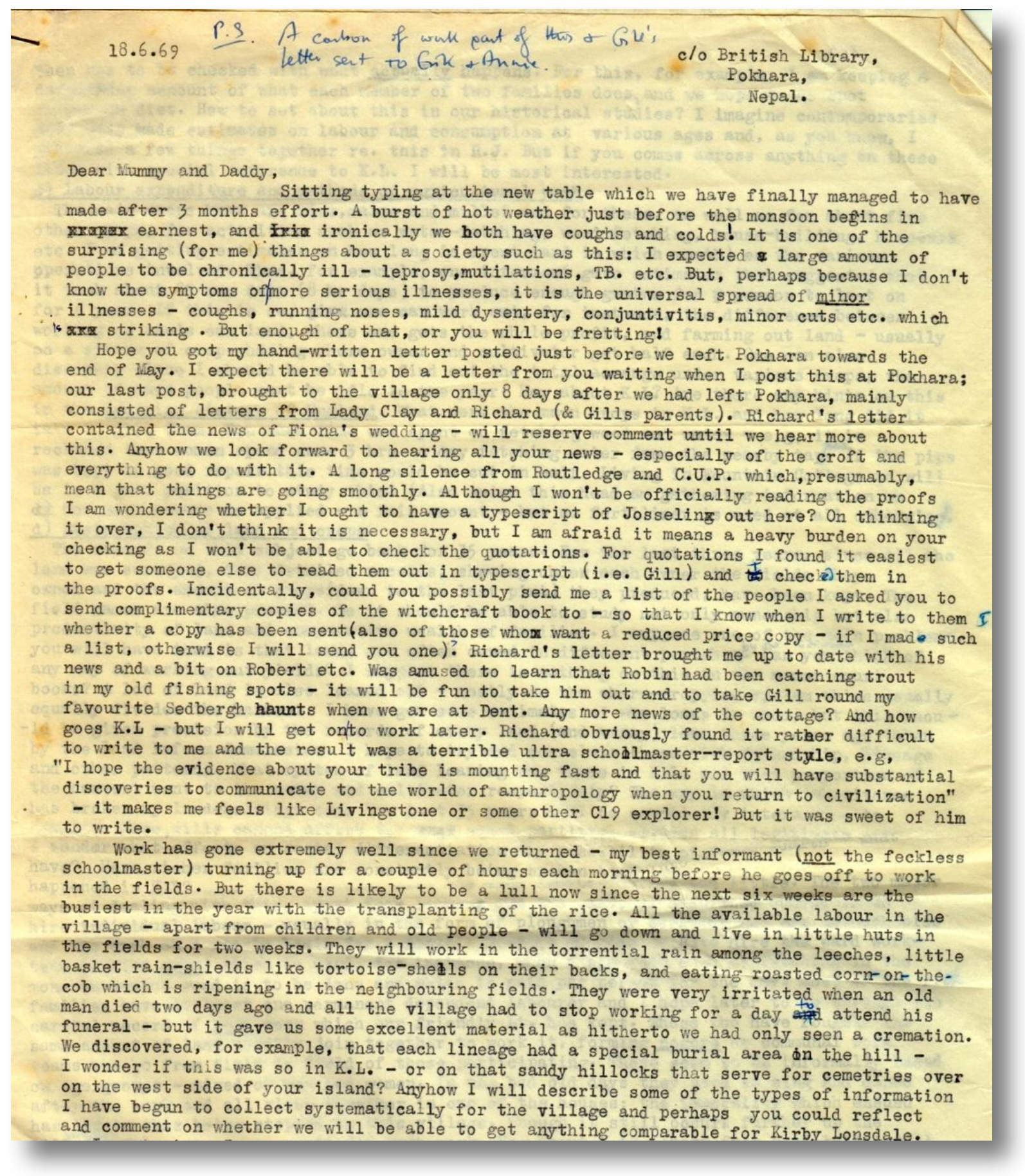


a. Inventories. I hope to collect four of these - two for rich, two for poor families. They are lists of property. I have only collected one so far - there are some 90 items, but I will just give you the totals of each section - value wise. I would be interested to hear how it compares to poor K.L. families at different periods (the family concerned is perhaps the poorest Gurung one in the village - though many of the untouchables are poorer.The totals are for the whole family: man(aged c.50), his wife, about the same, one grown son and one, grown daughter, and two other daughters and one other small son. Clothes:- (the totals are rough, and probably exaggerated) - c. £20: ornaments, c.£20: luxury articles (watches constituting $95 \%$ of total), \&8; agricultural equipment, , 9 ; livestock( 2 goats \& 6 chickens), c.£5; household articles (of which water-carrying bottles constituted one fifth), \&26. They have no fields of their own \& do not own the house they live in. Total: $\$ 88$ - or about $12-10$ s. capital per head. I look forward to comparing this to rich Gurung families and those in Boreham /K. L. This is obviously an area where we can do a good deal of work.

b. Production/consumption units.

The aim here is to work out how much individuals of various ages and male/female can a)produce as workers b) consume in food and other goods. Once one has this one can multiply the households to find out how these balance. One will also be able to find out things such as how much wealth is consumed by children who later die; how much economic 'weight' various societies carry in the form of old age; what is the relation between the available labour resources and the amount of work to be done in the available land. It is not too difficult to discover these things in the field; I ask people when they start to work, at what age people work most and at what tasks, how much various categories of person eat and spend on clothing etc. This, of course,

then has to be checked with what actually happens. For this, for example, (2) day=tollday account of what each member of two families checks on diet. How to set about this in our historical so wust have hade estimates on labour and ouraries gathered a few things to on labour and consumption at various ages and, as you know, I lines with special reference to this in R.J. But if you come across anything on these

c) Labour expenditure and methods of agricultural work.

The main crops here are rice,maize and millet and for these, as well as for about five other crops, for activities such as water-fetching, wood-fetching, house-building, housewo etc. I am getting estimates on how long is spent (and in which month) on the various pperations involved. Thus, for example, one informant gave estimates that suggested that it took about 85 man days ( $8 \mathrm{hr}$ days) to produce enough grains for p person to last on for a year. If this is so, exxx one can work out, for instance, the difference between working on one's own land, where one gets the whole profit, and farming out land - usually on a system of crop-sharing where owner and cultivator get half each. One can also discover, since I should be able to find out the total acreage under various crops, the amount of days people must be idle in the year. How about K.L? Are there any hints on this in the Agrarian History of Bngland. What were the main crops in K. I. and how long did it take to grow them. How much time was spent on fetching wood and water - e,g, it is reckoned that women spend some $3 \mathrm{hrs}$. a day fetching water fom the nearby tajpous the pip was kept in good repair this time would be cut in half. Living in Fountain Cottage we will be in a good position to study this! (Also under this head am gathering information on d) how much manure is applied - a fair amount - but no fertilizer is used at all otherwisd.

The records on this subject go back for 35 years. For the last three years, since all the land was surveyed, very detailed records, shwing under each owner the fields they owned and the amount of crops(down to the last pint) they produced, have been kept. The field names are also present. So it should he able to study not only ownership but also productivity of land and comparative wealth of families. I suppose one of tha main problems you will have is that lands are often owned in different parishespy can you think of any way of working out yields? I suppose there is nothing on this in the manor court books? A lot of land is also loaned out - mostly on the share-cropping system which usually equally divides the harvest. I have got some estimates of who loans to whom, but this shou. -ld be given precision by the records of every land (and money) loan three years ago taken by the Land Reform Comission. I hope to try and correlate these with friendship, lineage and other patterns. What system of land loaning was there in K.L. and what proportion of the harvest went to the owmer and cultivator respectively? The way in which inheritance has broken up land-holdings over the last 35 years will be especially interesting to compare. Here, wills eannot effect the equal partition between all legitimate sons. I wonder what effects on social differentiation the possibility of favouring one son would have? Here richer families are constantly being broken back into medium wealth - what happened in K.L? 


\section{e) Labour services and organization of labour.}

For various reschss some families have too much labour, others too little. The two major ways of dealing with this, apart from loaning out the land, as described above, is to hire individual labour - usually in the form of ploughmen or cowherds who are untouchables and who work on a yearly basis for a certain measure of rice or b)to hire the ward workteam (called gola) which is used, for instance, when a big task such as fetching in the monsoon-season wood is to be done and which is paid per person for the day. Most of the ridh families have at least one permanent dependent labourer and I hope later to go through the careful record of gola work which our friendly Lt. has kept. Whose who have roughly the same amount of land usually join together to work it, forming nogora or communal work teams who go from field to field of those participating. These seem to be informally based on age groups - mixed of men and women. In the bad old days they used to sing and dance after the work and all sleep together in one of the houses; the immorality which ensued has valed to this being stopped in this village, though it still occurs further up the There are no payments for such work. How about K.L? Apart from road-building, I wonder which tasks were done communally - one imagine's sheep-clipping and harvesting, but are there any hints of this in manorial court or other records? Perhaps we may find gomething when we have got some more of those Chancery court cases at the P.R. 8 done. way in which work is done and the degree to which the community acts together. Your islanders, for instance, appear to be the opposite of this place. One wonders why.
Well, I think that is about as much as Daddy (ahd you) will be able to stand for now. You will see that there is plenty of intellectual interest here - even if it is a long way from the study of witchcraft, religion etc. which I though I would be doing. But that will come when our language improves. Gill is reading hard on Hinduism, Buddhism etc. Only

8 months and a bit before we are home. Thinking of you very often, with all our love,

PS. Could your poscribly send

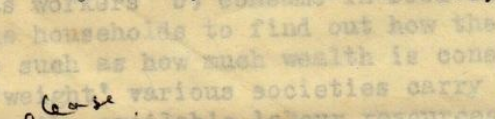

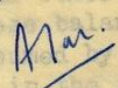
you sent me a sanele? (No border. of the tweed of which it to Mr M.B.PANT \& British hibrom plair). Conld you addres much 7 corts \& E wik' reary British hibromy - hat me know how

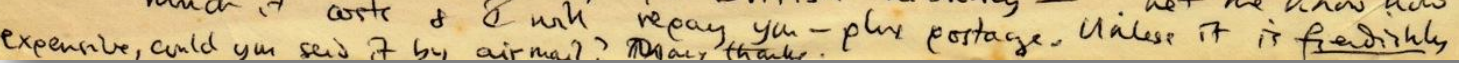

The original of one (long) letter from Nepal 


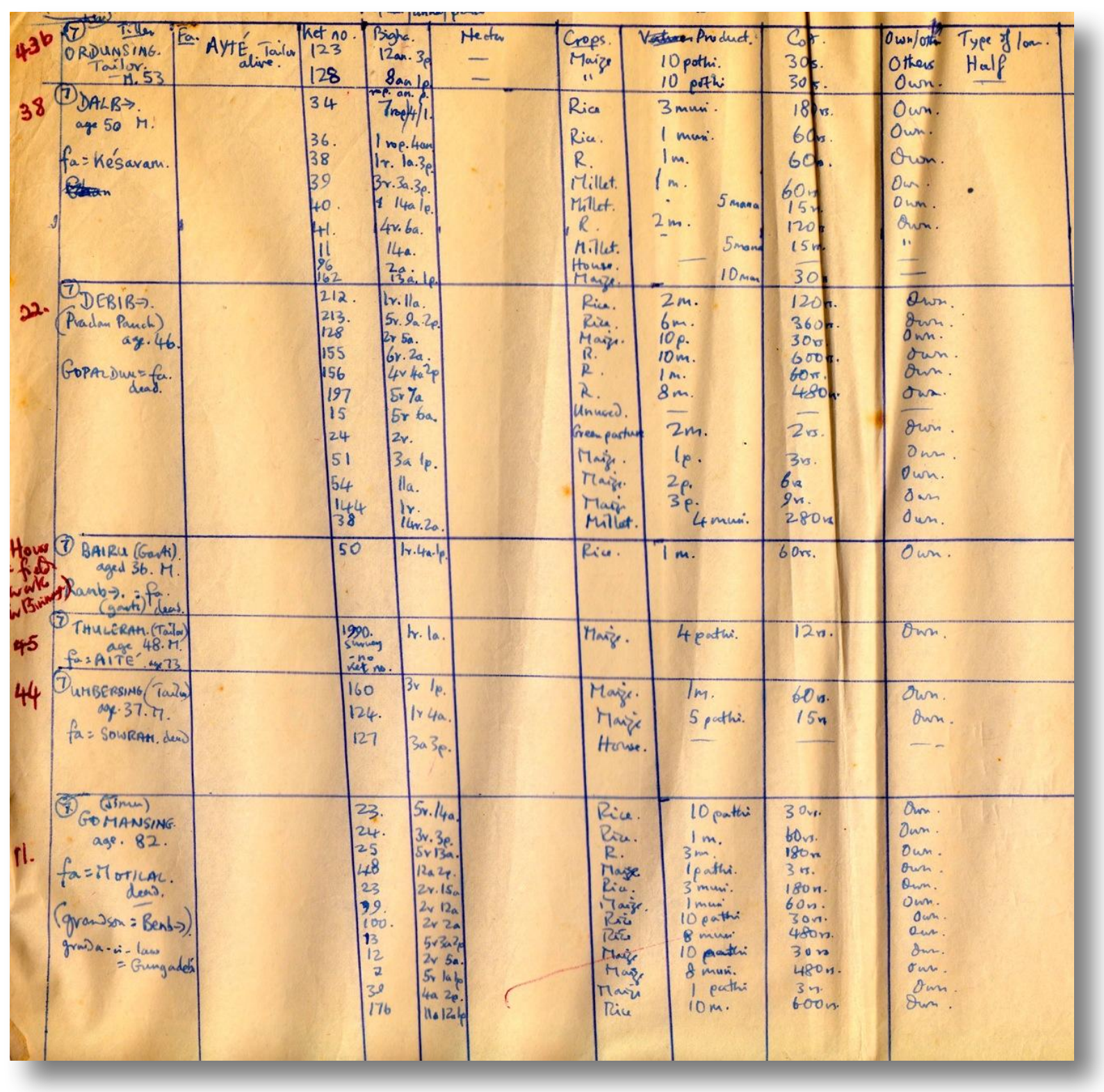

Loans and land records

\section{DIARY Thursday 19th June}

Went to Pokhara - fairly cool, mercifully, with some rain on the way back. The stream not too swollen, thank goodness. A successful trip as there were 10 letters, including nice ones from Mummy, Fiona, Anne and Gill's parents. Also three parcels of clothes, dried food, etc. on which I had to pay 50rs. Also Josselin contract - Syndics have advanced f608 on it. Got a rather importunate young porter to bring back potatoes, sugar, parcels, etc. We had to read out letters in a whisper as he was sleeping below. Gill still coughing a lot in the night. A letter from Fiona re her wedding - very moving. All these letters brought on a bad attack of homesickness. Oh dear, how often I count the days! 
DIARY Friday 20th June

Spent the day gently recovering from yesterday - sorting out dried peas, having a shave and sleep, reading a bit of 'Middlemarch' and re- reading letters, also doing some Pignede and a little other work. Gill enjoying Durkheim on religion and I am rather labouring on Weber on politics. Maize now really high almost dwarfing the houses, especially at end of the village.

\section{DIARY Saturday 21st June}

A rather dragging day. Did some more 'Tirige' with Prasad's father, then came back and read 'Middlemarch' and did some Pignede, etc. Rained on and off. Felt a little under the weather headache, etc. The village mostly very quiet. Obviously the busiest few weeks work of 'Asar lava' has started.

DIARY Sunday 22nd June

Arrived at village 6 calendar months ago. Rather a dragging day. Had to rush up the hill last night with diarrhoea and having eaten 8 Sulphaguinadine I suffered a bit of

depression/headache the next day. Gill worked a Pignede while I mostly read 'Middlemarch'. Untouchable woman died in childbirth - after asking for our help. Felt very guilty.

DIARY Monday 23rd June

Felt better. Little rain today, though overcast. Did some work with Prasad's father on 'Tirije' and continued with punch cards etc. Much debating of whether we should go home at Christmas.

DIARY Tuesday 24th June

A pretty overcast day, but we decided to go to the river all the same as we were feeling very grubby. It drizzled a bit but we happily managed to get everything washed and it was a nice break. Came back to chocolate and re-reading of my mother's letter. Missed Comal in the evening - who had gone off to the lower field, but can't say the same about Gran next door who had also gone off the day before. 


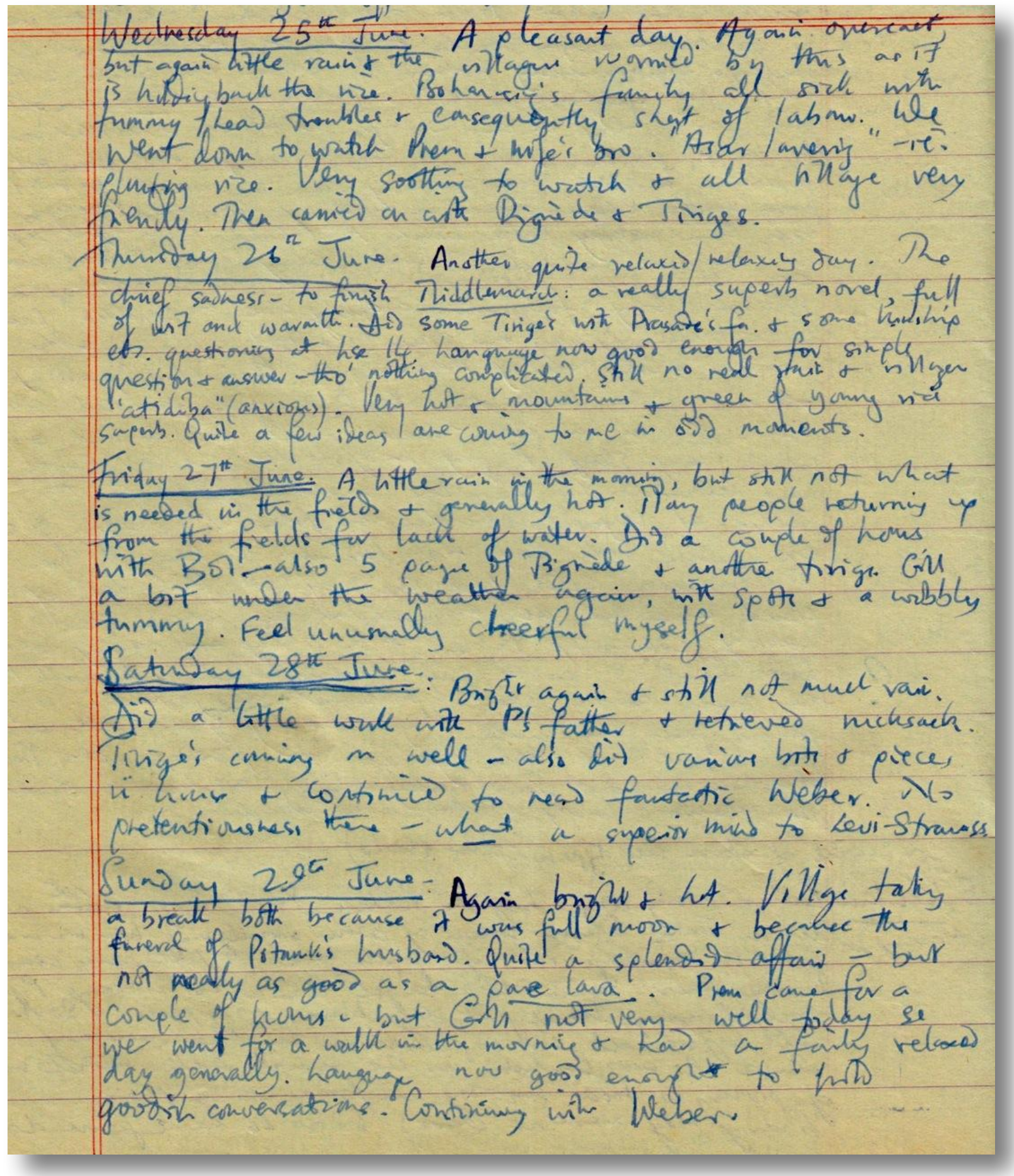

A page of Alan's diary, 25-29 June.

DIARY Wednesday 25th June

A pleasant day. Again overcast, but again little rain and the villagers worried by this as it is holding back the rice. Bhuwansing's family all sick with tummy/head troubles and consequently short of labour. We went down to watch Prem and wife's brother 'Asar lava', ie. 
planting rice. Very soothing to watch and all village very friendly. Then carried on with Pignede and 'Tirige'.

\section{DIARY Thursday 26th June}

Another quiet, relaxed/relaxing day. The chief sadness - to finish 'Middlemarch': a really superb novel, full of wit and warmth. Did some 'Tirige' with Prasad's father, and some kinship, etc. questioning at House 14. Language now good enough for simple question and answer - though nothing complicated. Still no real rain and village 'atidiba' (anxious). Very hot and mountains and green of young rice, superb. Quite a few ideas are coming to me in odd moments.

\section{DIARY Friday 27th June}

A little rain in the morning, but still not what is needed in the fields, and generally hot. Many people returning up from the field for lack of water. Did a couple of hours with Bolbahadur, also 5 pages of Pignede and another 'Tirige'. Gill a bit under the weather again, with spots and a wobbly tummy. Feel unusually cheerful myself.

\section{DIARY Saturday 28th June}

Bright again and still not much rain. Did a little work with Prasad's father and retrieved rucksack. 'Tirige' coming on well - also did various bits and pieces in house and continued to read fantastic Weber. No pretentiousness there - what a superior mind to Levi- Strauss.

\section{DIARY Sunday 29th June}

Again bright and hot. Village taking a break both because it was full moon and because the funeral of Potamkumari's husband. Quite a splendid affair - but not nearly as good as 'pae lava'. Prem came for a couple of hours but Gill not very well today so we went for a walk in the morning and had a fairly relaxed day generally. Language now good enough to hold goodish conversations. Continuing with Weber. 


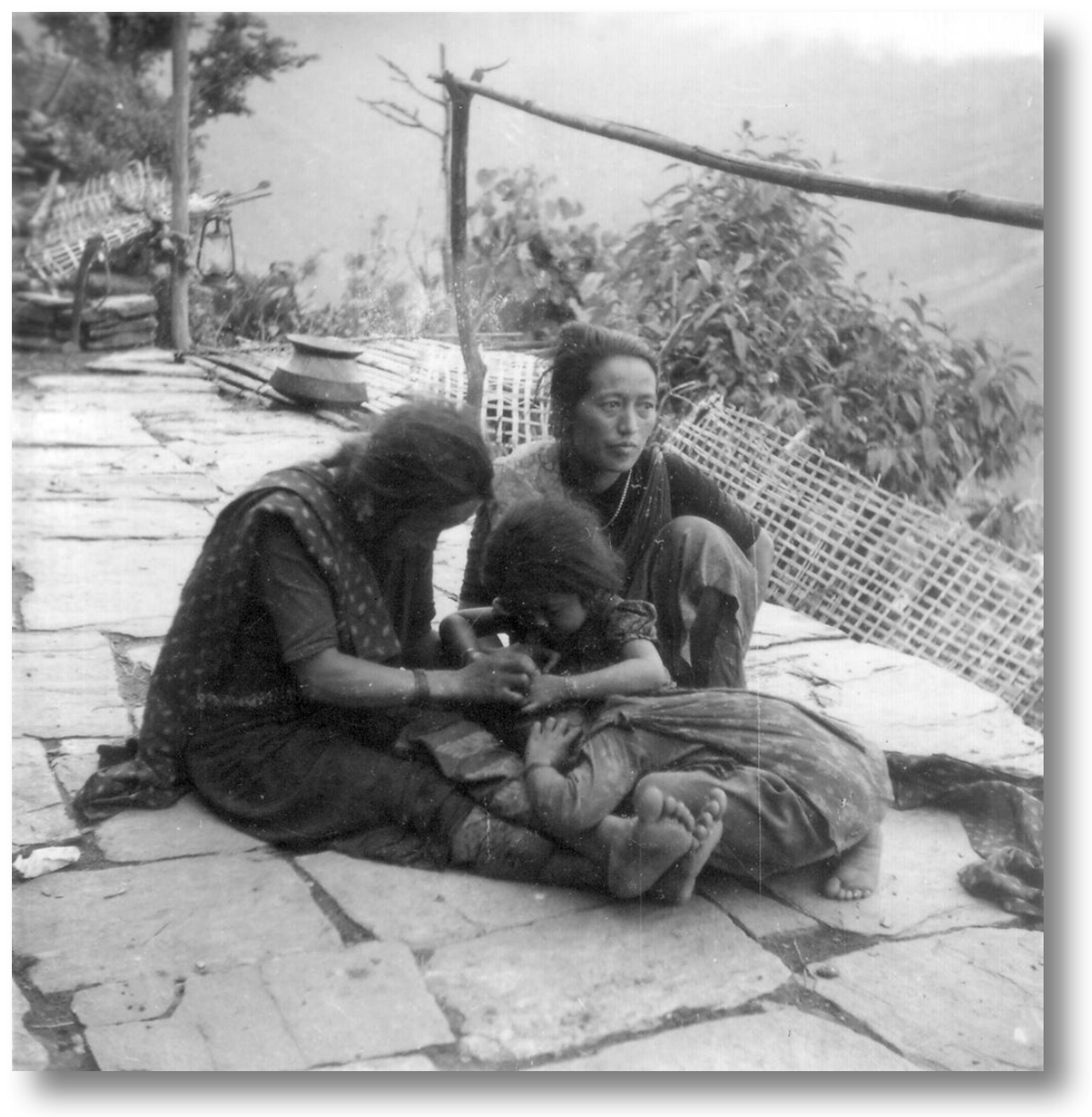

Dansuba delousing Harikola, Asmaya sitting beside her with Rupa, 29th June 


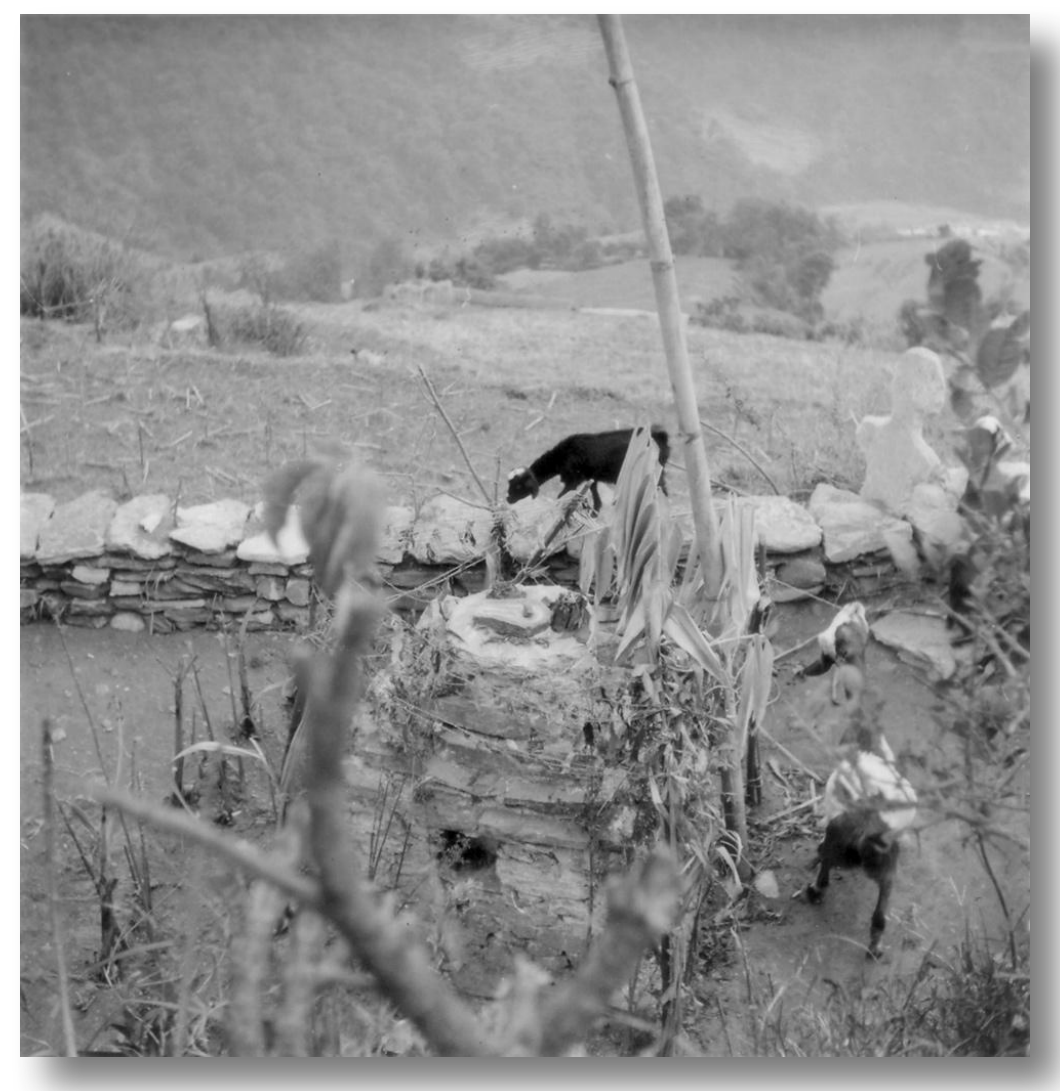

Burial mound for Narsing in his maize field 29th June

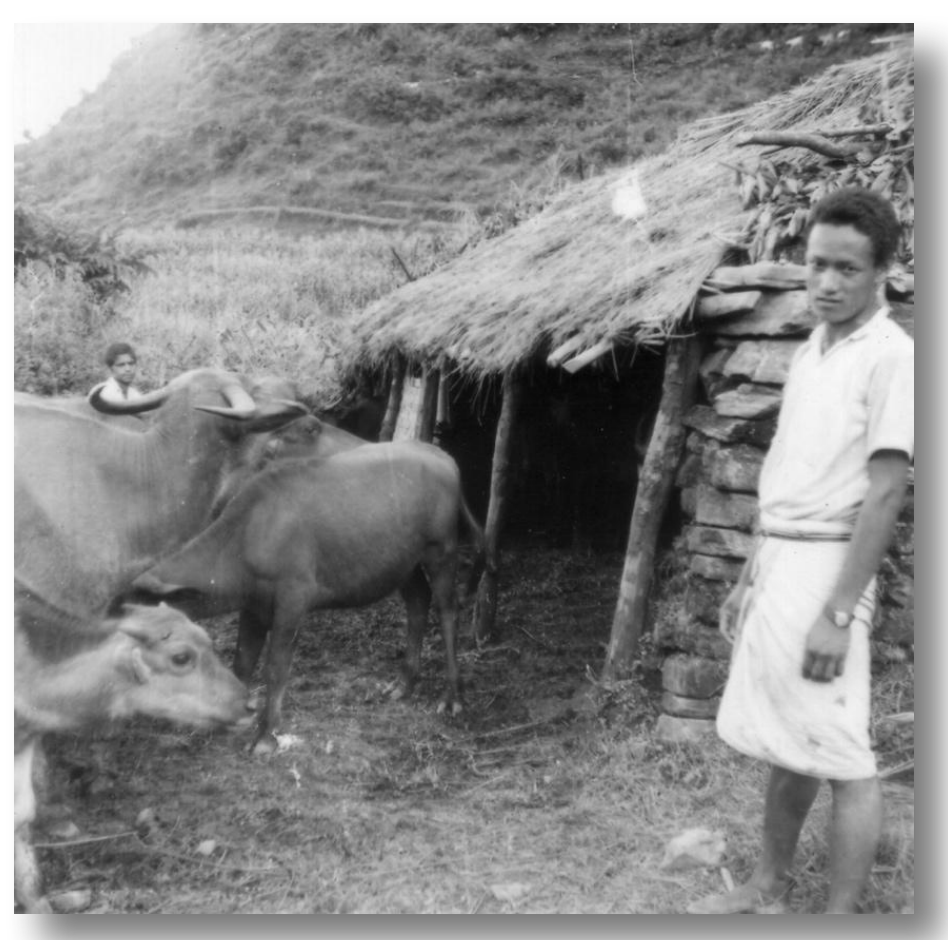

Benbahadur beside his buffalo shed 29th June 


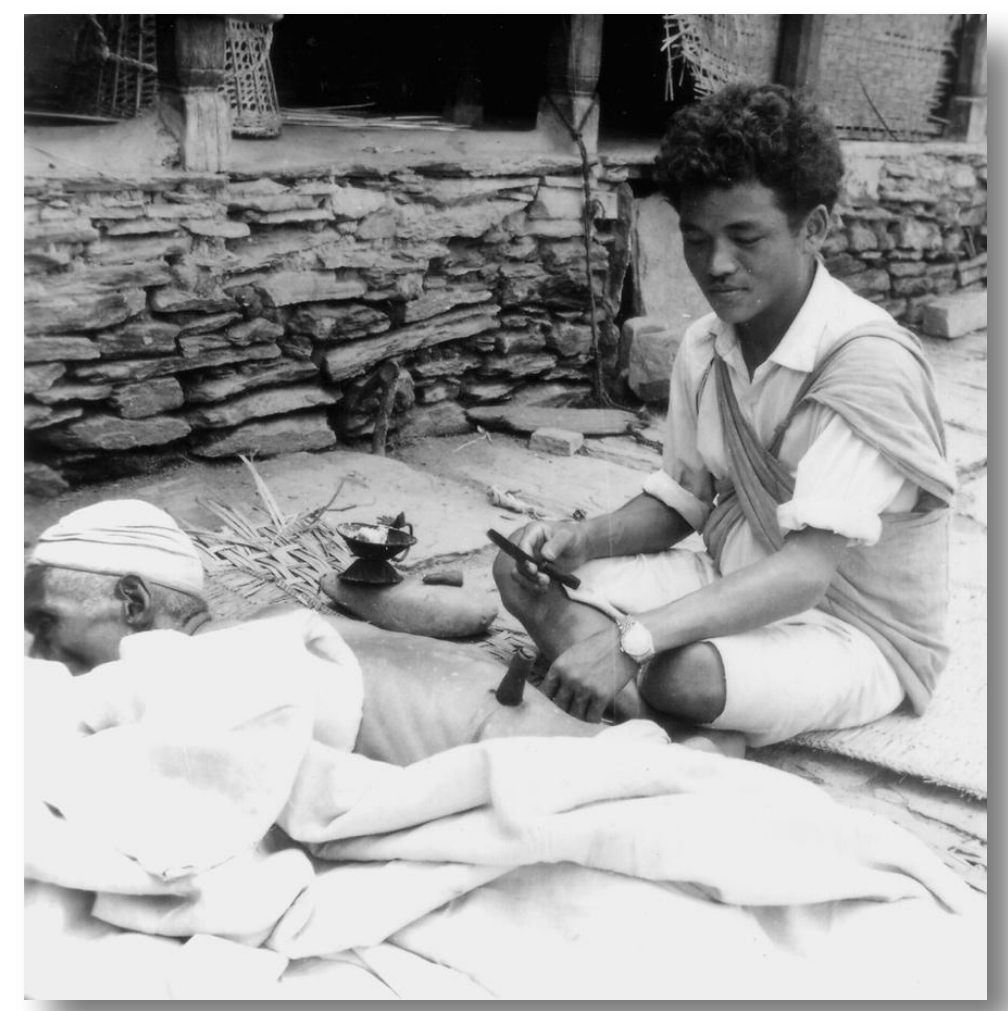

Prem cupping a sick man - 29th June

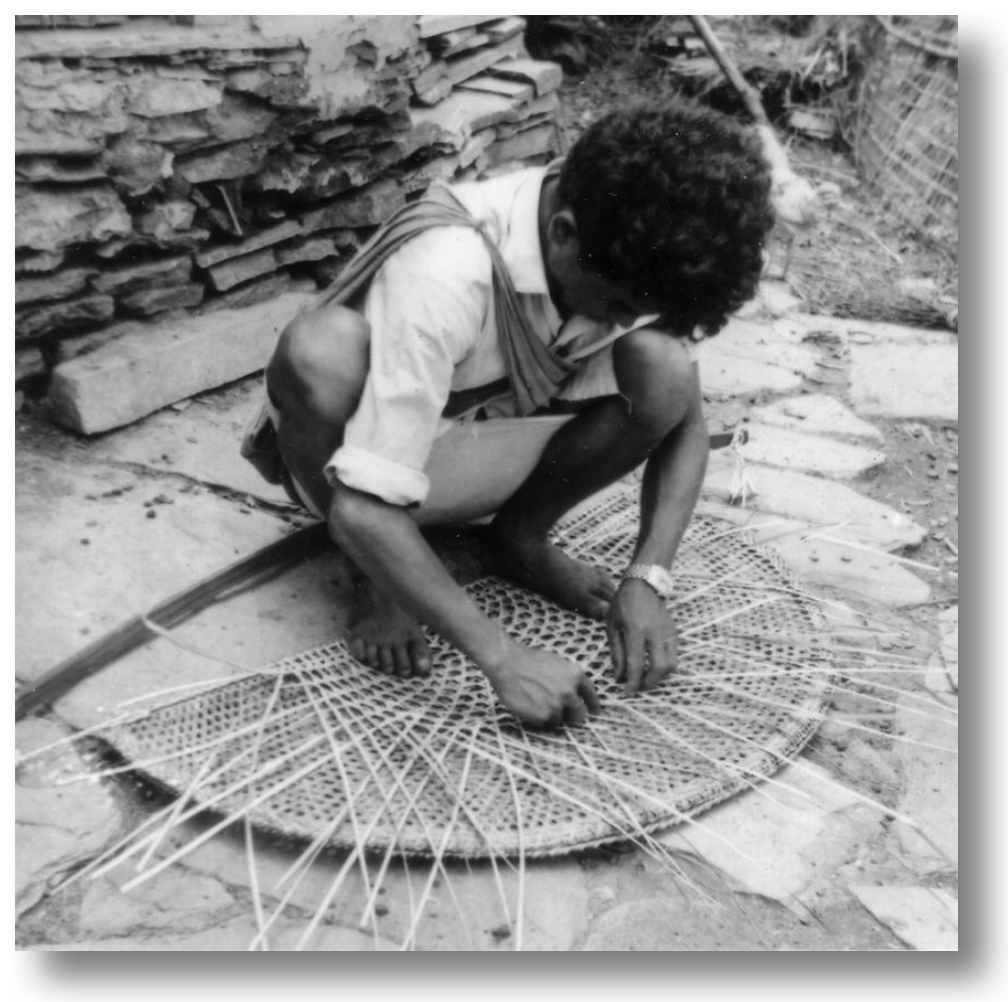

Prem making a 'syaku' or rain shield - 29th June 


\section{DIARY Monday 30th June}

Did another 'tirige' with Prasad's father. Still no real sign of the heavy rain that is needed for the fields - hot, shade temperature c70 or more. Did quite a bit more Pignede, etc. Feeling interested in the work and eager to be writing it up. Gill still under the weather. Longing to turn over the calendar to 1st July all the same! Villagers mostly in the fields but rather anxiously awaiting the rains.

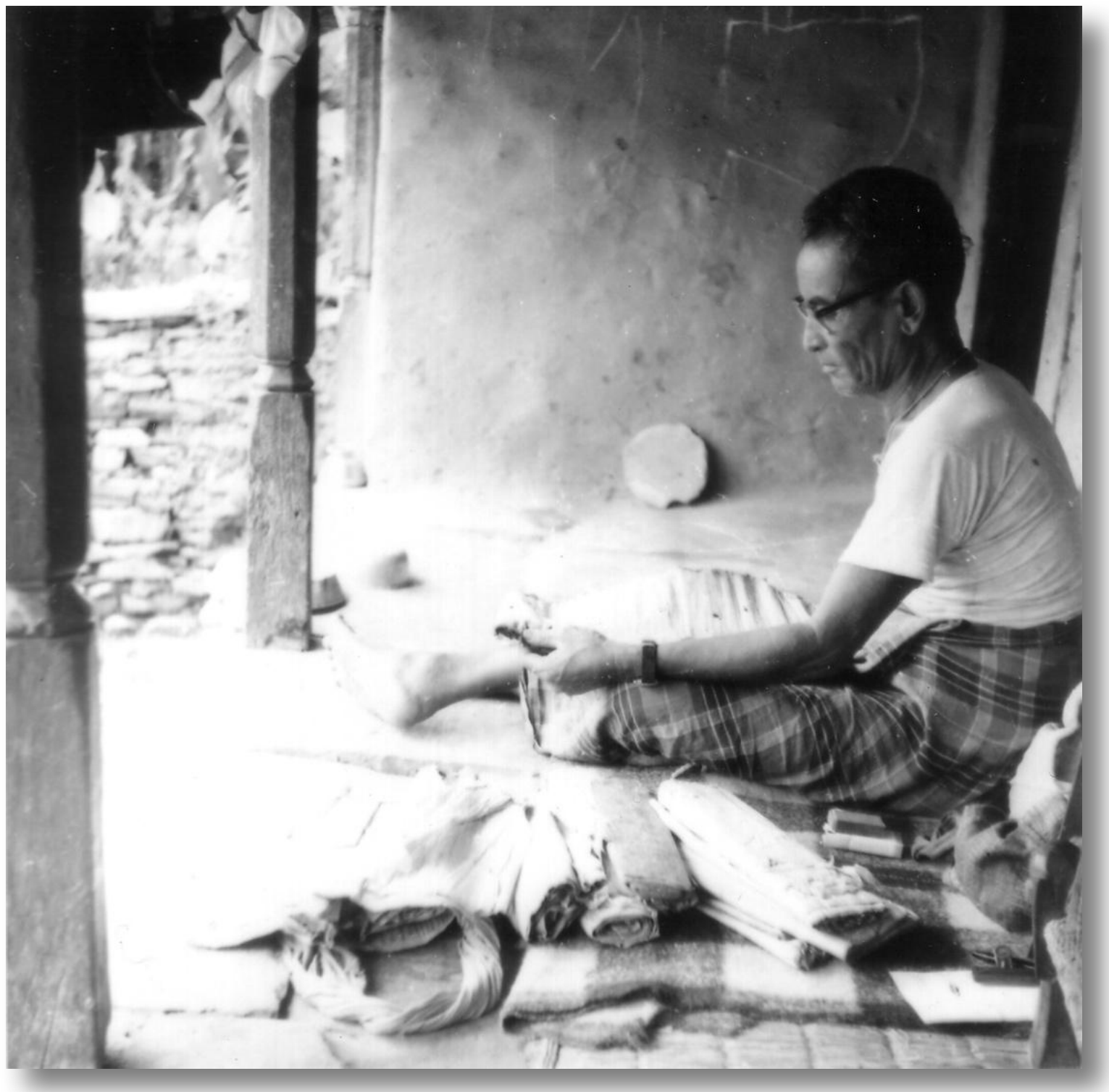

Prasad's father, Brikaras, reading a tirige or land register document 


\title{
JULY 1969
}

\author{
DIARY Tuesday 1st July
}

Prem came for three hours and we started to check Pignede - interesting. Gill under the weather - feeling sick and tummy churning. Continued with 'tirige' and Pignede. Still not real rain and fairly warm. Longest day now over - still very light at about $6.30 \mathrm{pm}$. A cock in neighbouring loft, along with rats/cats/dogs/flies (and Gurungs) keep us awake. Calendar turning over day. Our diet good with instant, tinned meats, eggs, scones, peanut butter, etc. Still reading Weber. Would be nice if we could do something in medicine later.

\section{NOTES 1.7.1969 Alan - Prem's daily routine}

Prem's daily activities - got up, smoked cigarette; urinate; tea; go to 'Barli' to see if enough water to do 'Asar lava'; urinate; go to blacksmith village to get 'kotali' blade done, left it there; came to work for one hour here; to house for breakfast (rice, potatoes, 'korsani', 'maas', milk, 'khlali'; snack of honey and potatoes and short rest; bring half rs of sweets - give one to Baje, two to Bopal, one to Haricola, one to Ramu and one to Tekansing's son; came here again (10 a.m. for two hours; defecated; helped sort letters for postman; go to hours, ate one fried egg; made small fence for ten minutes; weeded in garden for ten minutes; went to fetch 'kotale' from blacksmith; eat three cupfuls of roasted maize and one cup of tea; tested to see if he knew the village fields, made a map for half an hour; evening meal (rice, 'dala ta', onion sauce, 'korsani, 'kola' ; urinated; rested.

\section{DIARY Wednesday 2nd July}

Hot during day with the usual downpour about 5.30pm. Still not enough rain to do the 'Asar lava'. Hills look exceptionally beautiful with all this cloud about. Went down to Prasad's father and did one 'tirige', then talked at some length about local and national politics - he shows a healthy scepticism. His leg still bad and I intend to do something about it if possible. Prem very friendly and loyal, despite attempts of Nansubar, etc. to subvert us re food etc. Gill not at all well today - feeling sick and with diarrhoea - constantly a slight worry. We are both looking forward to our break in Pokhara.

\section{DIARY Thursday 3rd July}

Again no rain, though a lot of cloud and overcast. Gill still not well and I am feeling tired and need a break. Started writing letters, continued with 'tirige' and Pignede, etc. Also drew a couple of kinship diagrams. Children as usual playing in the school-house. Gran very friendly nowadays. People showering us with eggs, also beans, potatoes and maize coming in.

Letter from Gill on 3rd July 1969

We are hoping to go to Pokhara this coming Monday (7th Fuly) and stay for a week, to have a break after our 6 weeks in the village, and for Alan to do some work on land and usury records which are deposited there. I will help in the transcriptions, as they are all in Nepali, of course. The librarian at the British Library has offered to help, this is most kind, and he has been a great boon and the library very useful...I am looking forward to this, as towards the sixth week I am getting a bit weary of out simple living, cooking on the floor, 
getting water in buckets (which Alan does), trotting up the hill to the toilet and being generally grubby all the time, except for the say we can go to the river...Also I have had some dysentery for the last few days, feeling a bit sick after meals etc., and a change in environment usually clears this up. Alan is well and working hard. Things have been much the same in the village since I last wrote, only growing anxiety about the rain not coming. Usually all the able-bodied people go right down to the rice fields in the valley and stay there until all the rice and millet seedlings are transplanted, and the fields flooded. They came back en masse to the village though, after only a few days, with no water, and are hanging about with nothing to do. A big diversion was another funeral (we had three last month) of an 88 year old man, much revered and a kind of lay priest, so there were special rituals and an influx of orange robed Buddhists (I think( to take a special service. The man was buried in pouring rain, with a lot more ceremony than the previous burial, but still pretty grizzly, deposited straight on the earth, in all his priests clothes, garlands, and his walking stick with orange cloth carrier bag looped over it, ashes and salt sprinkled over him, and the widow tipping the earth in herself, putting in at the end a little brass cup with sacred water and a flower. A big celebration took place about 11 days later, when an altar had been built with stones from the hillside, and put over him in a corner of one of his maize fields where he was buried; lots of flower throwing and water sprinkling and lighting of tiny butter lamps, with everyone bringing little gifts of food - we took some rice, a pink cream-filled biscuit and some sweeties, which were much appreciated! The other death we felt more involved with, as we were woken one night, just having gone to bed, to be told that an Untouchable woman was in childbirth and the placenta would not come away, and would we go and help? I have never felt so useless standing there underneath our beams... holding a kerosene candle and trying to think how on earth we could help. I rushed to the nearest medical book but all it said was that if the afterbirth wasn't away in 20 minutes this was serious, and call in a doctor, and take the woman to hospital, not a thing about what one did. We had to say we could not help, and give some painkillers. She died the same night, eight other children, and as usual pitiably poor. Alan met the funeral procession going down the next day. It made me rather depressed...

\section{DIARY Friday 4th July}

A refreshing day at the river. Stream very high and nice butterflies. We are slowly retreating up the stream. Still no rain for the rice. Had an argument about philanthropy etc. this evening.

\section{DIARY Saturday 5th July}

Two more 'tirige' done - had a very good sleep and consequently felt very dozy. Morning work enlivened by fresh corn-on-the-cob. Then wrote to Fiona and bank in the afternoon. Village in thick cloud, but still little rain. Gill better today.

\section{Letter from Gill on 5th Fuly 1969}

The rain has never been as late as this for the last fwe years, and we are wondering when it will dawn of them that we are the baleful influence, and turf us out! Fortunately the maize crop, which was ruined by hail last year, is flourishing... There has been some diversion in the form of three funerals, the only rituals during the last month, which everyone is supposed to attend, working or not. The rites were all rather perfunctory

however...You asked if there was any juvenile delinquency and what size population it is. The core of the village which we live in and are studying has about 500 people all told, with over 100 households, which we have got on the census. As for the first, there is no Gurung word for "adolescence", which is symptomatic, I think, and even more interesting, no initiation rites. If there is any conflict because of physical change at this time, it might be controlled by the fact that the transition from child-man is pretty smooth, teenagers being absorbed into adult work patterns early, and having work groups, which certainly act as a control and outlet. The men as a race are very gentle, the women seem to have the most drive... 


\section{DIARY Sunday 6th July}

A quiet day writing letters to Mummy, Fiona, etc. Gill again a little under the weather with illness - tummy, etc. though she also wrote letters. Went for a nice short walk to the buffalo house and back by upper path - raining across the valley and now raining hard here. Rained a bit last night so people's hopes of transplanting rice, growing.

\section{Letter from Gill on 6th Fuly 1969}

Feeling a bit low at the moment, but a break in Pokhara next week should clear this up. I have had some dysentery for the last week or so and that is causing me to drag round a bit I think. Alan is fine though and bounding around getting all kinds of good information on land tenure, and the thesis is shaping (mentally) which is always exciting. We are going to dig out a huge map in Pokhara housed in a brown, wooden, tatty Dickensian building opposite a Hindu temple covered in purple creepers, with a lovely arch of steps up to it, what a lovely place to work. A little different from out sweet little loft with soot accumulating on the beams, which floats up through the hole floor when we have the fire burning, and the clay floor crying out for a bit of sticky dung to patch it up, not liking barbaric things like tables, and two days washing strung across on a rope as the monsoons put pay to things getting dry... However the rain also brings out the most beautiful ferns and mosses in the pathways, and silver-grey moths with violet inside wings, and the kites fly high in profile against the mountains, all black and gloomy and wreathed in blue mists, and in its own way it is perfect.

Ritual wise it had been a bit slack, the rice transplanting season on, and everyone toiling down to the valley if there is enough rain for them to toil - we went down to watch one day, sitting prim and neat on the bank, with our black umbrellas and notebooks whilst the men squelched through the mud like black treacle, riding on the rakes behind the oxen whilst the women came behind, darting the bright green seedlings in, the young boys making mud walls at the end of the terrace and then popping other seeds in those. I love the way every space is used, a sort of wholeness about the procedure where nothing is alienated from anything else - this is echoed in the houses where the humans stay in the middle, the chickens underneath, the buffaloes on the side and the bees in the roof-gorgeous!

The one thing that seems to march on regardless is people dying, we had three in the last month and two rather grisly burial scenes where the body was put naked straight into the ground, a few boulders bonked on top, and that was that. Yesterday and 4' snake was found housing itself in one of the shrines kept for one of the dead men, next to the house, and there was much shrieking and milling about, at 7.00 in the morning, until the wretched thing was stoned to death. They don't kill you, we were happily told round the fire that night, but your leg swells up like a tree trunk, and its agony for days; then there are porcupine quills which really do hurt, and come then the maize is ripe and gnaw at the base so they can bring the cobs down, and also bears, which, you know the man round the corner with the bitten off arm, well, a bear did that as well..and so on, whilst I sweat even more, dropping the rice into the flames and not being soothed by tender adolescents stroking my ankles, the latest craze... 
Ploughing fields and transplanting rice
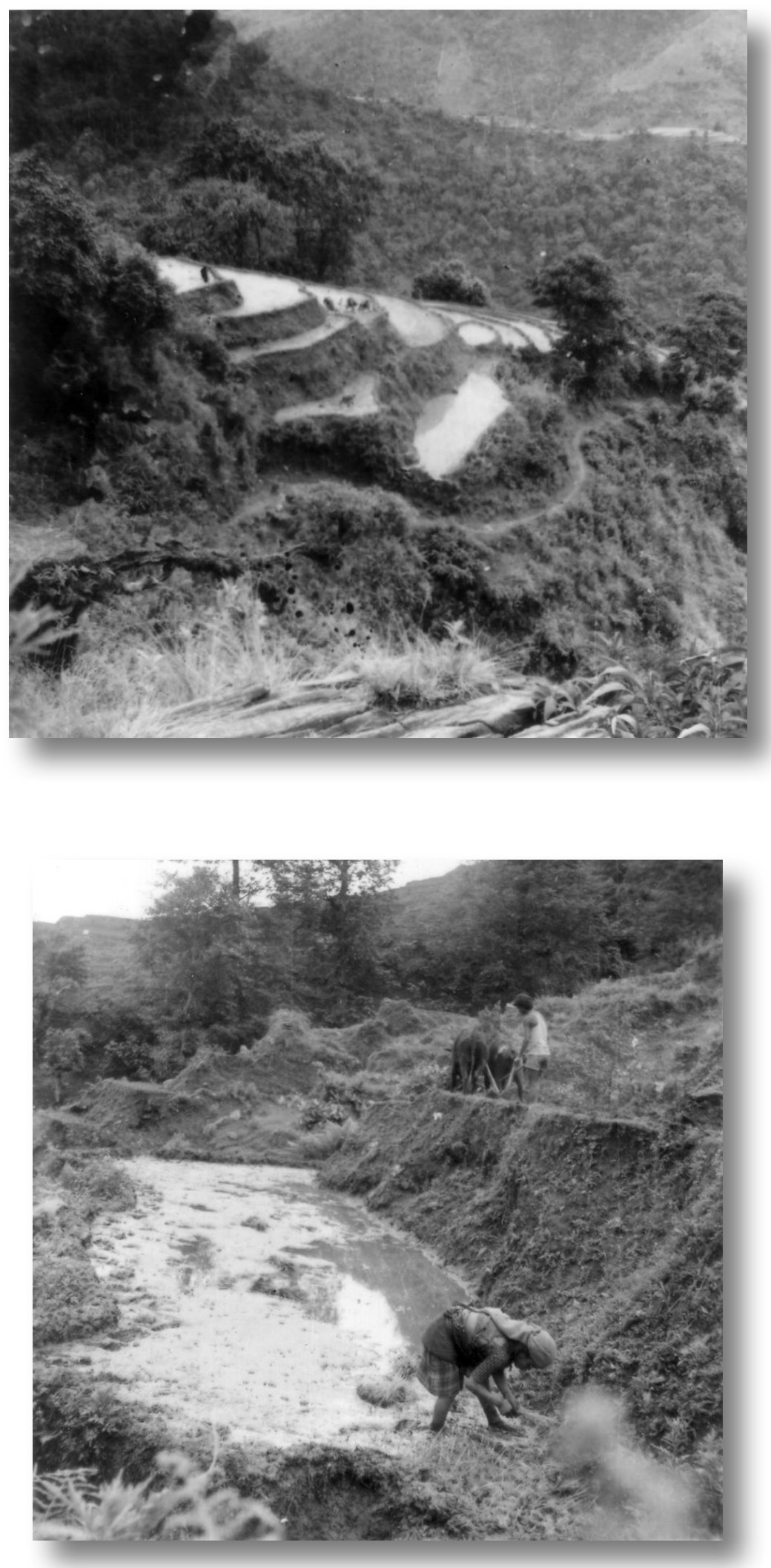

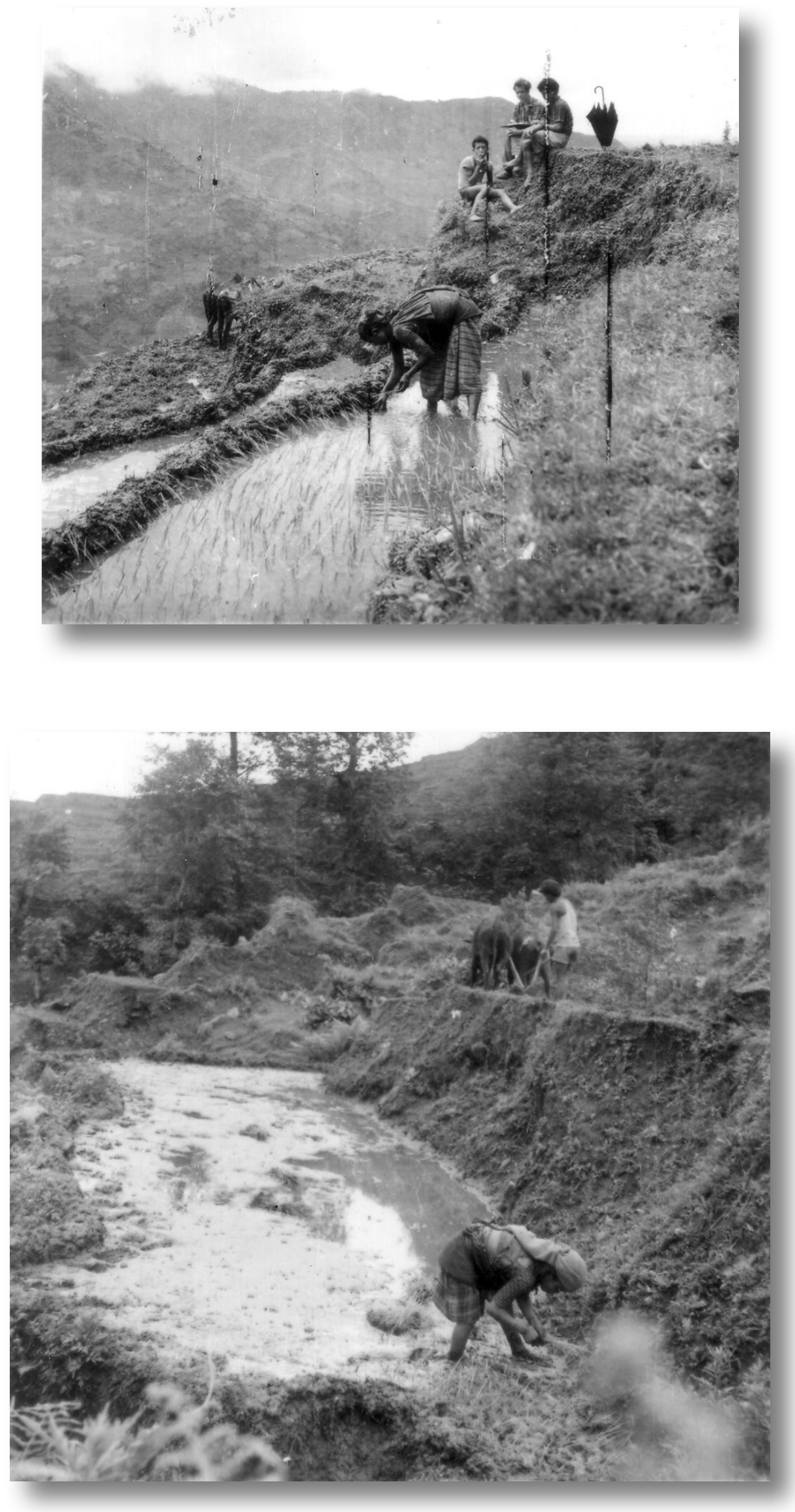

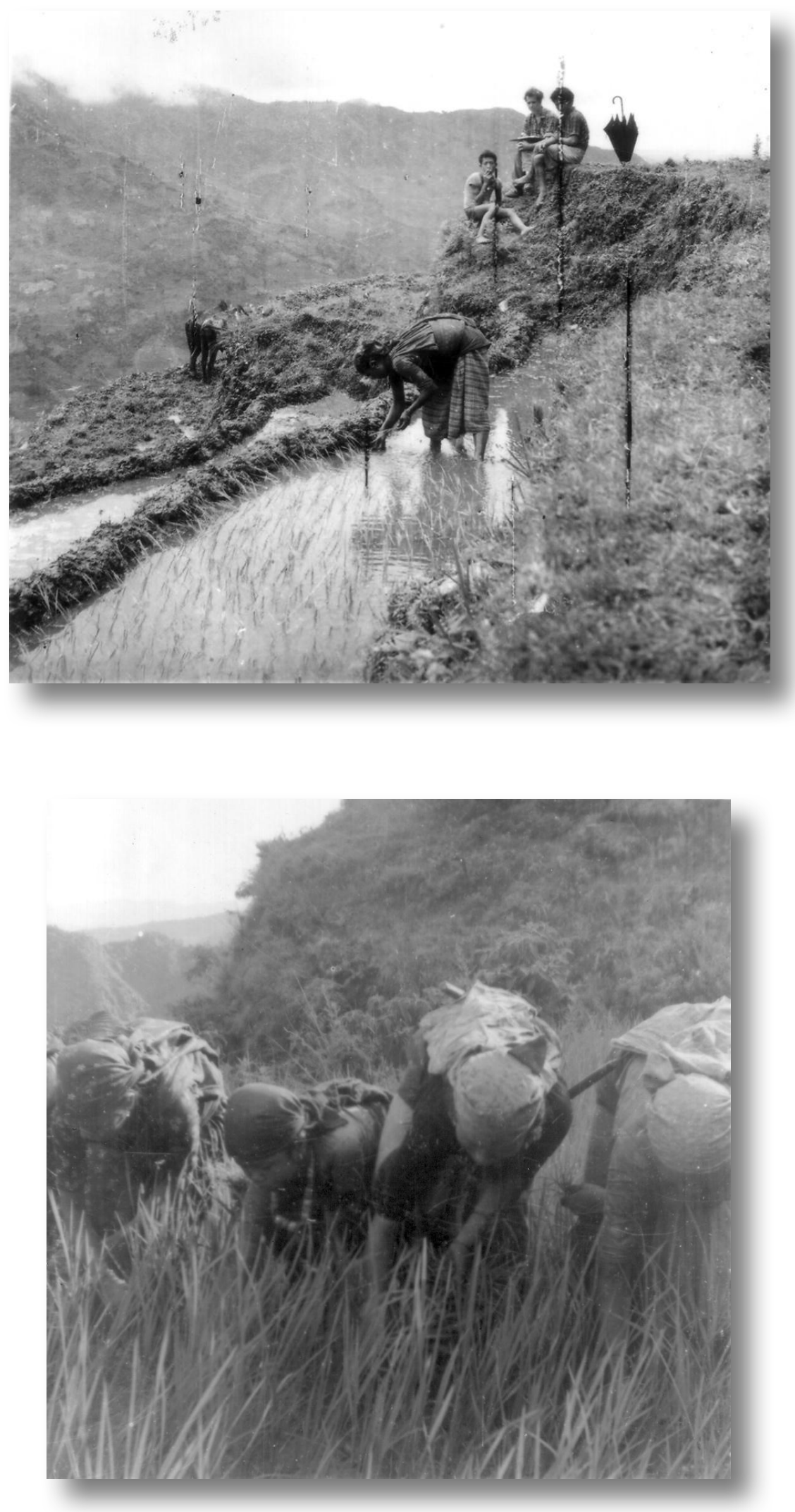

Transplanting rice 

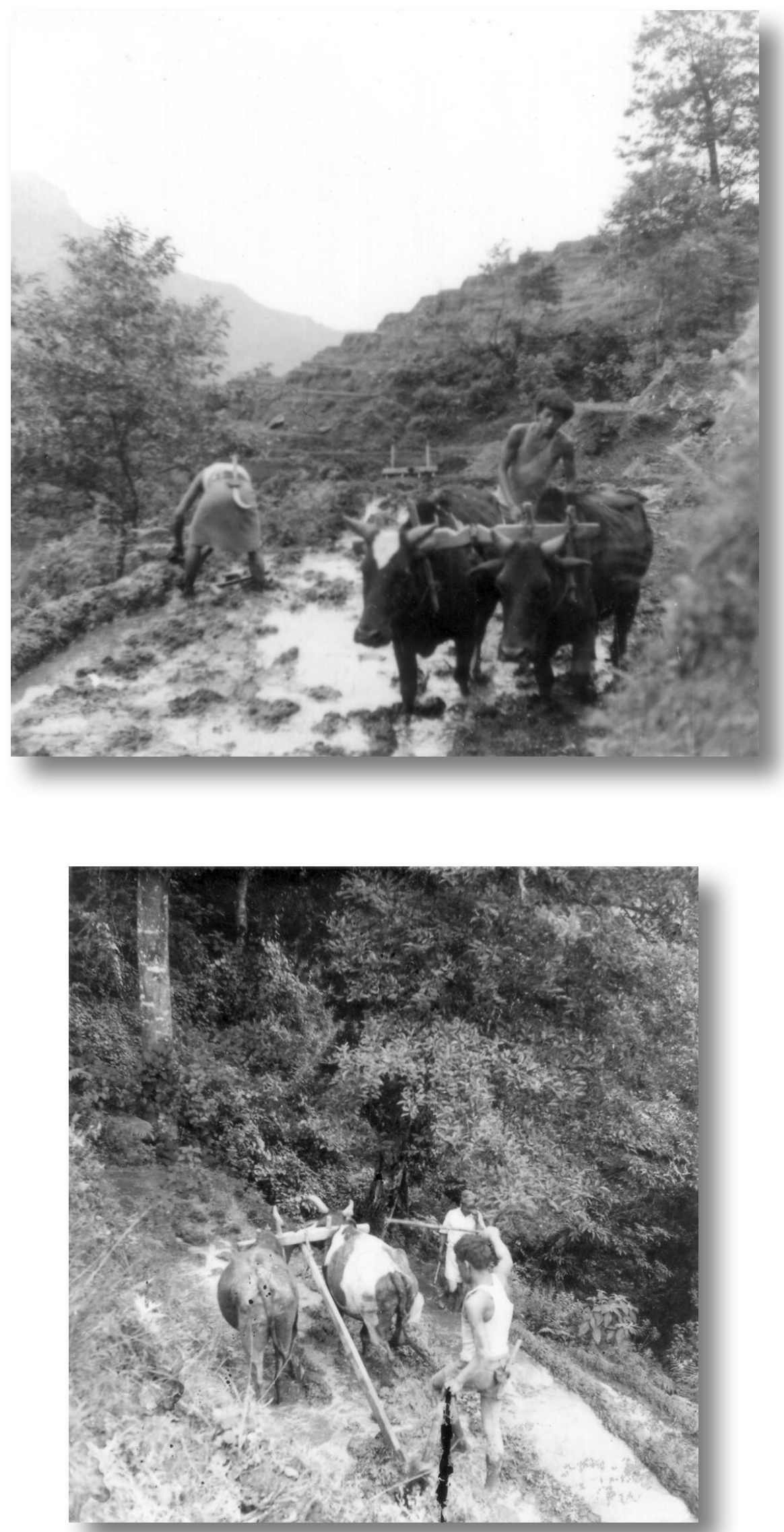


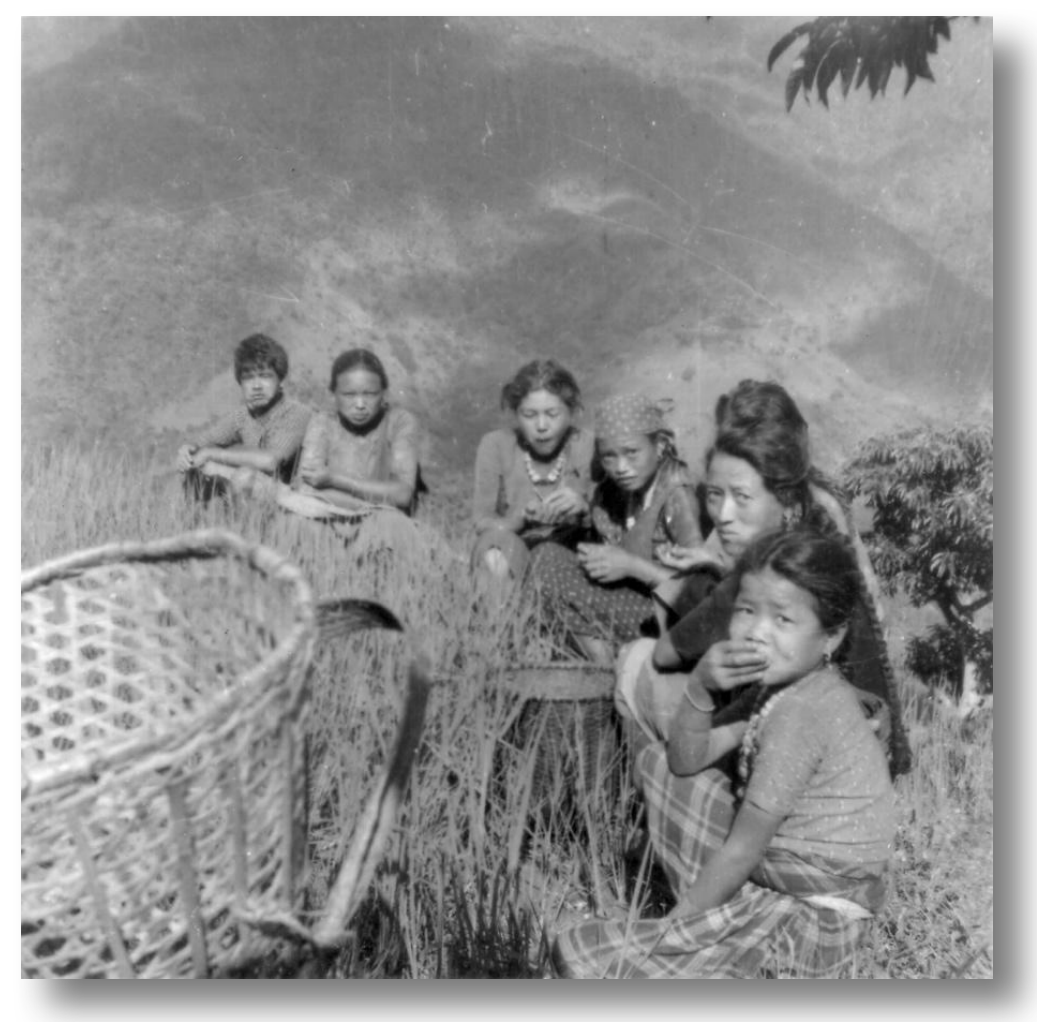

Work group eating in fields during rice planting

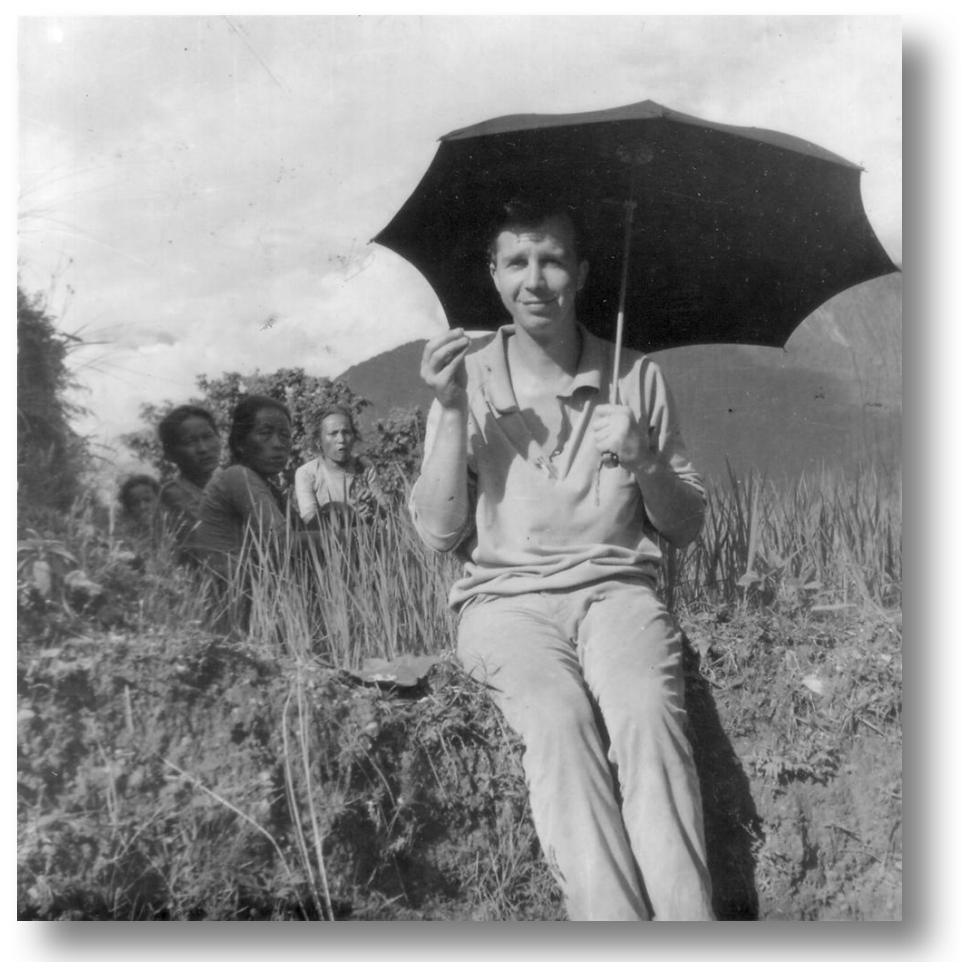

Alan eating in fields during rice planting 


\section{DIARY Tuesday 8th to Thursday 17 th July}

To Pokhara. A tiring journey down, taking over 7 hours as the river above our knees and plain hot. Usual pattern in Pokhara, except did some work in Bomissidar offices on land records and forced to go to Kathmandu to get letter from Tribuvan. An exhausting and mosquito- bitten time there, though the evening walks were lovely. Gill confirmed in her amoebic dysentery, but feeling better after the break. Came back the long way via Bisgu and Moja. Very tiring, though some superb views. About 6,000ft. of climbing and took us 10 hours or so. Porter very good. Nice to be back. [Read: Naipaul "Area of Darkness", Berne "Games People Play", "Family Economy in West Nepal"].

\section{[Letters from Pokhara]}

\section{Letter from Gill to Mac and Iris, 7th Fuly 1969}

Loved the description of the croft. I find Alan in corners drawing plans for the byre on the back of Elephant Exercise Books, with my kitchen where the loo now is, and cabinets and desks and drawers in the rest of the 90 percent of the space (the latest thing is a filing cabinet under the bed).... Alan is delighted with the work he has done since we got back, one of the informants (the poju's son) getting very keen, and Alan not having to rely on the schoolmaster any more... The rains have at last begun to trickle down (only during the night though) so the village is almost deserted, and I have only had children with little sores to deal with and grannies selling 8 eggs and unground millet. Rather a depressing set of rituals since I last wrote, with two more funerals, one of a revered 89 year old lay priest, and the other of an Untouchable woman dying in childbirth. The husband knocked us up about the latter, in a terrible state and we gathered the placenta wouldn't come away and would we go and help? You can imagine what I felt like, sleepy and in pink pyjamas scrabbling through the medical manual with one candle, and finding it was serious if it wasn't away after 20 mins. and to call the doctor or go to hospital, not a thing on what one did. We gave her some painkiller and that was that. Alan met the funeral procession next morning, eight other children and pitiably poor. It made me wonder what we were here for...

\section{Letter from Alan to parents on 7th Fuly 1969}

The work is going well now, as the language progresses. The thesis looks as if it is going to be mainly on population and economics... I wonder how reactions have been to the contraceptives you took back to Dailekh. We haven't introduced ours yet, but it would be interesting to compare notes when we have. If you ever get hold of that Hawaiian health survey I would love to have a look; I hope to get one of the doctors from the Pokhara Missionary hospital to come up here for a few days to do a health survey and to check the medical data I collected in the census.... Will certainly give your regards to Flatt. I would like to go up to his experimental farm and see how far it is working. There are considerable areas where agriculture could be improved and diet improved here - eg. American wheat, two crops of rice a year, more potatoes etc. But there are the usual difficulties - lack of capital, demands of kin on any individual who makes successful innovations etc. It would be interesting to see how Flatt copes with this. Using the traditional methods the land in this area is pretty well used up. Despite the fact that 90 percent of the adult males can find work in the army and bring back a lot of cash into the village there is already considerable underemployment and an informant told me that people were poorer and worse fed than 30 years ago. What will happen when the very high mortality rates are slashed by antibiotics I dread to think. I am thinking of calling my future book "The Doomed Village"! Yet the Gurungs remain delightful, cheerful in spite of all my gloom...

Letter from Alan on 8th Fuly 1969

Our present plans are to spend one week from today in Pokhara, then return to the village for another 12 weeks - with another week's break in Pokhara at the beginning of September. After the festivities of Dessain are 
over we will then go for one more trip to Kathmandu in the last week of October. When we return we will have another 12 weeks, 3 or 4 weeks of which will be spent in another Gurung village for comparisons. We will leave Thak during the first week of February, spend a few days in Kathmandu (these visits to Kathmandu and Pokhara are not wholly holidays as there are a lot of records re. Thak deposited there) and leave Nepal about mid-February. We hope to return via. Calcutta - spending two or three days there and, if possible, flying for a week to Assam - ie. towards the end of Feb. What will the weather be like then, and would there be anyone you know we could visit? Then return via Isfahan and Istanbul to arrive in England approx. 1st March. But, of course, this plan may have to be changed.

Curious how, despite all the interest and beauty of this place, one constantly longs for home and gazes wistfully at the calendar. Gill especially longs in this way since her heart is not quite as much embedded in the work and she seems much more sensitive to the local bugs than I am. For the last couple of weeks she had been off-and-on feeling sick and wobbly - mild amoebic dysentery we suspect, though will have to have this checked in the next few days at the hospital. I keep annoyingly well.. Written wills are rarely made here; the fact that however disliked a son may be he has a legal right to an equal share in the father's property much have considerable effects on parent-children relationships etc. The effect of inheritance customs on population growth, age at marriage, distribution of wealth in a community, the size of land-holdings is a wide open subject which we must explore.

Our main work in the last few weeks has been to continue with the old land records which I must have mentioned. These, of course, show how the land has been more and more split up over the last 90 years - it will be fascinating to see why, in England, there was a growing gap between rich and poor and whether this happened in Thak and if not, why not. There are some 15 documents, each listing about 60 pieces of land, (about 36 years ago and 86 years ago), so you can gather how many small bits there must be. Each landholder has about 10 pieces on average; most of them consisted of between 10 and 20 terraces, about 12 yards by 6 yards in size. Now, I imagine, the parcels will be much smaller. Will give you more detail when we have finished copying out and started analysing. Gill is a great help in this rather tedious preliminary stage...

Also trying to sort out the whole kinship diagram of the village... So far have only gone back about 4 generations since most informants don't know the names of people further back than their grandparents. Unlike most societies I have read about they are not interested in genealogy. But already, of course, one is finding many interesting things - for instance that each lineage has spread along one part of the village, and that the village is really divided up into about four really old families, who held all the political positions of power until recently, and a collection of newer families. How this will tie up with land-holding I don't yet know..

Did I stress the importance of army service abroad enough? Even as I write one of my best young informants has just left to join up - his friends are very sad and say he will be crying in Pokhara or wherever he is. The emotional effects must be terrific but, without the 40,000 odd rupees per annum (about f2,000) that pensions and saved army wages bring in, the villagers would really be in a terrible state and underemployment would be chronic. Even as it is the lateness of the monsoon rains this year means that all the lower caste ploughmen etc. who rely on being fed this month while they work for the Gurungs are in a very difficult position since there is no work to be done until there is more water and they are not fed until they work. Last night it rained fairly heavily and now the village is practically deserted as all hands have gone off to work and sleep in the fields again. It is only for about 6 weeks of the year that everyone is fully occupied. The rest of the year jobs are eked out by using the maximum labour possible for the simplest job - buffaloes are herded in ones and twos with about 3 children and an adult per pair of buffaloes - as well as another adult going off each day to fetch a load of grass. In return they get manure and a cup or two of milk per day. The land is now cultivated to its extreme I should say the population could be reduced by a third and the general standard of living as well as meaningful activity would be considerably increased...

You ask about overpopulation and army service. Yes, it is true that the fact that most of the adult males being away from the village and bringing back army money temporarily alleviates the problem. The point is, however, that the army is not the only source of wealth. Ninety years ago about a quarter of the fields in the village were cultivated, the total number of families was under sixty, the forest was near. Now the forest has been pushed 3 miles back, there are between 200 and 300 houses and families, all the nearby land has been used up. Men go off to the army for an average of 15 years - but for the first 20 years and last 20 they are 
here, as are their wives and families. Each generation the number of families living off a given area of land, (land which each year is deteriorating in quality through erosion etc.) almost doubles. When Western medicine really gets a grip on infant and child mortality this growth rate will be even faster. Thus one sees many families who three generations ago were wealthy, now the land is divided between 6 sons, and even though most of them are away some of the time in the army, their wives, retired army people, and children have very little to do.

I don't know if it is true, but one villager told me that the Americans are giving 100 dollars per person in Nepal in aid per annum, yet I think not more that 2 or 3 dollars seeps through (in education) to the village. If only a quarter of this sum were spent on birth control the growing crisis might be averted. Walking round Pokhara, teeming with schoolchildren and mothers suckling babies, but absolutely barren of industry or budding bureaucracy in which these children can later be employed is a depressing experience. Nor will army service always continue. The number of recruits being taken by the British, for instance, is being extensively pruned. If American aid (and Chinese aid) to Nepal - which provide it with over a third of its income are cut off, the whole system will crumble. It seems to me, in my prejudiced way, criminal stupidity of the West to have, for over a century, introduced death control (medicine) without balancing it with birth control. It is only making this stupidity worse if foreign aid continues to be poured in to bolster up economics, encourage further population growth, and fail to raise the standard of living. Even, as optimists argue, the situation is only stagnant - and there are merely more people living at an intolerable low standard of living than twenty years ago, not a large total proportion, this does not seem good enough. In twenty or thirty years the catastrophe will only be worse. But I think Erik will disagree - or will he?

You also ask about illegitimacy. It rather depends on the situation. It usually seems to occur when a higher status man sleeps with a lower status woman. I think that probably this was more condoned in olden days when there used to be communal sleeping clubs etc. This is now frowned on. Always a bastard had been penalised by being given a smaller share of land than legitimate heirs. But there does not seem to be a horror associated with sexual offences - the whole field is treated in a relaxed manner. Work is very interesting at the moment, concentrating on the economic and kinship side. Look forward to arguing and discussing this when we return... I think the thesis will be centred round land and population

\section{Letter from Gill on 10th July 1969 to Mac and Iris from Annapurna Hotel, Pokhara}

Feel a bit deflated at the moment as Alan has just rattled off in and extremely loose plane to Kathmandu (not only the nuts and bolts but the air hostess too - untwining and retwining her plait on the pilot's steps and showing yards of tum to advantage in a lovely sari).... We have just had a classically abortive day with Dickensian type bureaucracies - coming down to transcribe land and usury records which we thought we had permission for but "they" are now demanding a letter from the university at Kathmandu. Alan thought the quickest way was to go there, but we have no idea how long this will take. Actually I am relieved to have a real break, reading, writing and gazing at tawny gladiolus, as I think I have picked up some sort of amoeba and feeling slightly debilitated. Having lav tests at the Mission Hospital tomorrow, so that will definitely settle treatment. The Gurungs are riddled with dysentery, apparently... Pokhara thank heavens is not so clammy as last time, but the monsoon still hasn't broken and the farmers are getting frantic. Had one night of complete rain.... We had what I fondly imagined a Livingstonian journey down, wading bottom deep through swollen rivers and we will not be able to get back the short way. This means a real sweat on a longer route back (10 hours walking?') and not sure of the route, so heaven knows when we will get another letter.

\section{Letter from Gill on 11th July 1969}

Rather a frustrating trip so far though, as the work we wanted to do on the records (usury and land records) hasn't even started yet. Local Government officials are demanding letters from Kathmandu University which approve our looking at them (they have already had a general letter, but are now demanding a specific one, with numbers of cases etc.). Even our endlessly helpful librarian (a Nepalese) thought they were being silly and awkward and agreed that it couldn't be harder if we were wishing to organize a Communist revolt with Bureaucracies permission (lot of left-wing activity in Pokhara, it seems). All this involved a whole day visiting 
officials, and grinding from one end of Pokhara to the other, as there is no system of communication and, typically, one set of local government offices is at one end of Pokhara and the other near the hospital...neither know what the others do either...Result of all this pettifogging was that Alan decided to go to Kathmandu the same day, and luckily got a ticket on the plane. Have a feeling the University will demand a letter from the King... and so on. I think one of the most abortive jobs is trying to help a country like this. Have been chatting to a very nice American who is on US AID staff in Kathmandu and his experiences are gloomy......[Dr Turner] has been at the Mission Hospital for over 11 years, terribly nice and has promised to come and stay in the village for a few days probably in November, when he can get relief, and check our medical findings, and examine people fully. This is super as it means we can really use our medical data which, of course, is very amateurish at the moment. I will quite enjoy entertaining too, even in our conditions but he is pretty used to rough conditions, I think. The staff on the whole are sweet and don't proselytize too much (if at all?). Anyway, they have been very kind to us, and good to the people from the village we have referred to them. (There is a Government run Nepali hospital, but hygiene is not good - we hear, but this may be merely propaganda).Hope Alan's notes about the film are clear enough - and that it will not be too much fiddly trouble. The connections are that Professor Hellmich is a friend of Prof. von Furer Haimendorf who is head of Alan's department at London University. Thus there is a close liaison between Munich and England and this is why we were allowed to use Thyssen House, sponsored by the Germans. Took some black and white film in a shop here, with trepidation yesterday, and to my delight and from what I can see of the negatives, they have come out beautifully. Will get reprints and send some copies off to you. The village will love them - they are always asking us for copies!

\section{Letter from Gill on 13th July 1969}

Sitting in rather a wobbly frame of mind, drinking Three Lions Gin with an otherwise incoherent German, at the Tibetan hotel in Pokhara, and hoping Alan will get off the next plane from Kathmandu - at least to save me from getting drunk, as gin is rather strong and horrible and I thought water with iodine tablets would not improve it. Can hear the plane rumbling over the hills and as this is the third time I have hopefully gone out to meet him. I hope he comes. Later. Well he did, very hot, dirty and constipated having spent 15 hours at the airport and three useless days in the city, hanging about for planes. There was a crash near Simra (32 people killed) yesterday, so that was rather dreary-making too, all the relatives frantic at the airport with officials refusing to say anything definite.

\section{Letter from Gill in Pokhara 15th July 1969}

Sitting in the reading room of the British Library in Pokhara, the afternoon downpour pattering on the corrugated roofs, the warble of a flute drifting in through the shutters, and the children crying and watching the raindrops and the orange clay puddles. The rain has some, but about one and a half months late, and so far very refreshing and bearable, except at night in our Tibetan hotel where it seems like a volley of machine gun fire cracking straight onto the iron roof. Am fitting this letter in where there is a typewriter, as Alan is working with our indefatigable librarian, Mr Pant, at transcribing Thak records which are held in the Land Reform Office here. I have done all the form preparing that I can do, so catch up with letters at the other end of town... We have been here for a week, with a somewhat exciting journey down, as the rivers were quite swollen and there was much wading and clutching onto Alan, who was clutching onto a $6^{\prime}$ stick, the water about my bottom deep, and five places to cross. It was beautiful in the valley near Pokhara, the rice just about ripe, acres of green heat, with frogs chirruping in between the stalks, and coffee-coloured dragonflies with pale blue inside wings clicking past in clouds. But so clammy, the clay burning underfoot. In our naive way we were hoping to start work the next day, but when we got to the office where we had already spent hours the time before, we were told they wanted a letter from this office, and this office wanted one from this dept., and this dept wanted one from the University, and the University one from the King. Am reading "An Area of Darkness" by Naipaul at the moment and we got to his screaming stage, inside at any rate. They would not agree that our current authorising letters from the University would do, not having specific requests in them, so Alan had to take the plane to 
Kathmandu, waste 300rs. and three days in getting a covering letter from the Registrar. However, it is done, and the office have been most helpful so far, but we will only get three days work in, going back to the village the day after tomorrow.

Have just come back from having lunch with Alan, egg sandwiches, pears and bananas, near the old Hindu temple opposite the creaky, Dickensian type Land Reform Office. The temple is on a little hill with a lovely arch of steps up to it, smothered with purple creeper, and the children ringing the old brass bells and scrabbling for mangoes as the boys throw stones up into a whole mango grove to bring them down. Its a gorgeous spot, and we crumble our eggs under the peepul tree facing the hill, and then climb up and have a pear on the old wall looking out over the maize fields and the green and purple hills beyond. Already feel much better for the break, and relieved to find that I did have amoebic dysentery after all, so at last I can settle on what drugs to take. Also feel relieved that by feebleness of the last six weeks in the village had some foundation, and hoping things will be much easier this time when we go back. The Mission Hospital here have been awfully kind, and have just got at German girl in to do lab. tests, which they didn't have before - very funny giving in the specimen as they handed me an ice cream carton and vaguely gestured it had to be filled, all of us looking round for a hump in the landscape where I could cooperate; eventually tripped back to the hospital compound and used their loo and then casually carried my ice cream back, for all the world as if it were Brighton beach.

We are thrilled that Dr Turner has finally agreed to come to the village sometime in November and do a survey of a few families we can pick out, as this will validate our very sketchy and amateurish attempts so far. He is fluent in Nepali and had been at the Shining Hospital for over 11 years, so has considerable knowledge of local diseases. Apparently what we had been putting down as "stomach cancer" can just mean "tummy ache", so you can see why we are delighted he can spare the time. He says cancer is very rare here, about one case to every 500 patients, which is what you said of course. He hasn't been out to the villagers for the last five years so it will be interesting if he sees much difference; I think living in a Gurung house will also give him some insight, so that he won't say, as he did before we went out last December, that if we do have any influence with them, to get them to raise their fires off the floor, as this will prevent children getting very badly burnt. The position of the fire, and the activities round it are so essential to their social and everything else life, that if they positioned them differently they would be a different tribe. Actually, I have only had one bad burn so far, and this did heal eventually, after about six weeks.

There have also been an interesting crowd at the Annapurna Hotel, the seedy Tibetan place where we stay, ranging from a tiny taut little man from Frankfurt making "natural coal" (don't know what this is yet, as the conversation was entirely from a 3/6d dictionary, but he did say, "radio and metro it in went", so I don't think he's a miner) to a huge, incredibly courteous Texan working for AID in Kathmandu. The latter didn't seem to have a clue what he was doing, couldn't speak. Nepali and had all his food flown in from the States; however he made me feel I was in Europe in a Fames novel circa 1899, rising to his feet every time I came through the Tibetan porch of the hotel, murmuring, "what a charming colour", to my bazaar-sewn dress, sipping neat whisky out of a silver flask, playing chess and telling me of rides up the Bosphorus and eating fresh fish and Turkish wines in the river-side villages. Then there was a bubbly, chubby American writer, who wanted a style like Gunter Grass and Foyce all rolled into one, and who had taught three years in Africa and translated Maasai proverbs and sayings, and would never stop talking about his beloved continent... He came with a silent, blue lean American reading the sayings of Zen Buddhism quietly at the table, and telling me he didn't have a camera for the mountains, but he took them in here, tapping his thin head, and perhaps that's the only place where they have any real meaning. My favourite was the plumber from Stoke Pogis, on the overland trek to Australia where he was going to settle; he had picked up orphans in Kathmandu, called them Charlie and had fed and reclothed them, waving goodbye through the green glass of the local buses and then in Pokhara had picked up a baby monkey that the children were maltreating, buying it from them for 2.5rs., and letting it cuddle into his shirt at night, and wanting to take it to Australia...Alan had just come back from the office, as the library opens again at 5.00 pm., and looks pleased and well contented, he will add to this letter probably tomorrow. I might pop into see a German girl whose husband is an engineer and helping with a farm project 22 miles out of Pokhara. Apparently she hates it here, has nothing to do, I think it would be easier in the village than here. 
Our visit here to Pokhara was, officially, to look at the map and land records in various government offices Gill has told you the result. My wait in Kathmandu was lengthened by the crash of a plane we were meant to catch (on its previous journey). But now we are at last into the records they are fascinating - it had taken us 10 hours merely to copy out two of the 15 forms filled in by the villagers: all are on land/money loans and ownership, I think. The map is obviously going to be inaccessible - a tragedy, but we will just have to make a primitive one ourselves. Landholdings are tiny - average size well under an acre each. Crops per acre are also given. It will take years to analyse all this information - meanwhile population continues to rocket. Read a lot of UN and other things on population while in Kathmandu and the situation really is awful. No wonder the vast international aid over the last 20 years has failed to improve the living standards in Asia. And yet there are still endless futile little projects floating around here to do with educational psychology, fruit farming, etc. which only scratch the surface and probably make things worse. As Gill said, our data on medicine should be improved by a short visit by Shining Hospital doctor. Will be fascinating to see if all the many assumptions and generalizations about the poor being shorter lived, etc. work for Kirkby Lonsdale. Relieved in a way that Gill's lingering illness is diagnosed - even if amoebic dysentery is miserable. The new medicine she is taking (and vitamin B) seems to have settled it..

\section{DIARY Friday 18th July}

Spent nearly whole day asleep: amazingly tired after our journey. The village quiet occasional rain and clouds, with everyone down in the fields, though children pretty manic with new songs. Occasionally roused ourselves to dry out the damp sugar and dress various small cuts. Both Servajid and Comal had written in daily routine very well. Children very friendly.

\section{DIARY Saturday 19th July}

Drizzly and cloudy today and fairly cool. Went down to watch Prem etc. 'Asar lava'. Water only slight, therefore much leisure. Started a rough sketch-map of the fields. Came back at lunch-time and then slept soundly for an hour or so. Strange how deeply we sleep now - must be very tired from Pokhara. Then checked the land records from Pokhara against the census. Gill a lot better, though still finds children staring a bit trying. Continuing reading Weber, though find it a little boring at the moment - find it hard to concentrate.

\section{DIARY Sunday 20th July}

Rather a frustrating and boring day. Hot and oppressive - waiting for it to pour. Children screaming about outside a lot. Went down to Prasad's father, but his leg very swollen again and he was in pain, therefore gave him medicine and unable to do any work. Came back and did a little Pignede, etc. Frustrating to have so many things half-way through, and depending on Prem and Prasad's father. I suppose this is always a feeling in the middle of one's work. Really long for my historical material now - where one can start at the beginning, plan how long it will take, and plough on day in day out. We have already become so acclimatized that I no longer notice the "strangeness" of life here. Apart from various problems which interest me, tend to take everything for granted, which is bad. People still mostly in fields 'Asar lava'. The Gurungs delighted at the photos we brought back - though tend to look at them upsidedown, etc. Snowed under with vegetables at the moment.

Impressions in the village after a week in Pokhara - Gill on 20th July 1969 
On our second day back we went with Prem to watch them doing the rice, which is still far from finished, the rain only coming down at night and very far from being a continual downpour. It was clammy, with drifts of cloud climbing up the hills, the hills very blue over Pokhara, sometimes the mist obliterated the opposite side of the valley completely. Kites soared above, three or four, an ominous collection waiting for death. They must be about 4' across in wing span, their backs creamy, and their wings deep black, fringed at the edges. The fringe lifting or falling according to which current of air they were sailing on. Their beaks curve in a frightening droop, and their outline is sometimes disturbed by another animal hanging from the mouth. Their control is perfect and beautiful, perfect coordination between environment and being. Just above our heads, in a miniature imitation, butterflies and dragonflies flutter, no less in control but more dainty and immediately beautiful. The butterflies, buttercup yellow, blend in with the yellow-green of the ferns and grasses, hover on a stem and shake off a mist drop. Other large, even vulgar, electric blue, brown and white spotted soar above them then the dragonflies: a long thick streak of blue, green or brown, gauze double wings like a prop for Midsummer Night.

One could convey a rice field by the sound. The whack of the stick as it raises the caked dust on the back of the oxen; the creak of the leather as the plough is heaved round the corner; the "huh, huh, a-cha", of the man riding the plough; the squeak of the rice thong as the girl lets it slip from the seedling bundle; the slight splash as she slips another seedling in; the muddy, loud splash of the hooves of the oxen as they slide through the mud. There is a pale green wavering reflection of the seedling bundles as they wait behind the girl to be planted singly, wavering in the clearer water of the quiet field now still of the plough. The girl bends without ceasing, from the hips, only stopping to lift up her back, and retie her head cloth, with deft movement, one fold, two folds and then the quick tuck in. It will be lose again in ten minutes. Even when they are supposed to be in full spate of work, four women hang around the middle field, crouching near their 'syaku', smoking, having done their rice bundling from the seed bed. The Untouchables plough and make the mud fortifications around the side, the two male Gurungs doing nothing. They pick a mushroom, very white with orange earth clinging to its thick stalk. We have a little family, they have a big, so we must have it. They make bubbles for us from a large curly leaf with a lot of sap poured from the stem into another leaf. Then a piece of grass is picked, tied round in a rough circle, dipped into the sap, and blown through, gauzy bubbles float through. The children do this a lot. They believe a rainbow comes from the mouth of a large crab who lives in the river.

Welcome when we come back [to?] from the village - all the children lined up along the edge of the courtyard where they were playing and said "Namaste Sita". Seeing I am so tired I can't open the huge lock on the door, a small boy firmly takes it from me and tries. We are told who has been ill after the first greeting. There is two damp feet up the back walls, a bit of grass coming through and white mould on the floor. Conversation at night just as valid as the evening before where we had had a European party with flowing spirits. Talk on Pokhara's dirt, filtering water, food available, children's illness, thinness of the Nepalis, how mountains were not everything in this world. Here in the village, from Prem and Comal, concern that we came back later than we had said, guessing as to what we were doing, perhaps we were lost.. Much joy and scrabbling over photos, every one gone through in the school photo.

Food coming in as soon as we got back; Untouchables saving up eggs for a week, thrilled with four rupees. White shiny maize, like small goblets of pearls clustered on their thick stalk. Endless beans, marrows, egg plants. Nansubar already courting us for the old stove which we have temporarily discarded for the new shiny red and blue one. Everyone notices. I go down to grind black peppers with the two stones at Bhuwansing's; Nansubar asks what we have as we pass their house on the way down; she demands some black peppers, a kind of road tax. She says she has a stone too, to do it there.. They are eating rice when I go, I am asked to sit on the bed facing the doorway. No one hurries there is little feel [sic] we should make conversation. They eat chicken and scoop up rice. Bhuwansing gives his bone to the youngest boy to suck. They eat out of the pans, pouring juice from one to the other. Bhuwansing and his wife have a quiet, ritualistic smoke after meal; Mrs B. has a cigarette, Bhuwansing gurgles at his hookah, old fashioned but relaxing. Dankumari goes outside to wash the brass plates and pans, the children potter and kick out at the dog. They have just got their own, no one knows where she is. 
Rain in the evening after a hot, sunny day. Gill continues to be well and seems recovered of her amoeba. Have resigned myself to not getting much fresh material at the moment so we are analysing, etc. Also went out and drew a few rough sketch plans of the village fields. Started dipping into Goode 'World Revolution and Family Patterns' - most exciting and makes me long to write a history of the family from mediaeval to modern times in England what a lot of myths would be toppled! Really, I become more and more convinced that the combination of anthropology/sociology with history will be of infinite benefit to both of them. I may be a pretty poor anthropologist, but at least I now have a feel of how anthropologists obtain their data, etc.

\section{DIARY Tuesday 22nd July}

Again hot and sunny, clouding over in the evening, temperature in the 60's. Went down to Prasad's father but though better with the medicine I gave him., he was still not ready to do the 'Tirige' so I went on doing sketch-maps up the hillside. In the afternoon did Pignede - Gill continued with cutting up fields. Maldo's mum asked us up for a drink of milk. Finished Weber and started Goode, 'World Revolution'. Weber fantastically mature and majestic, but too grand a scale for me. I tend to prefer detailed and more limited work - such as Goode. Small green peaches, cucumbers in village - told that oranges and mangoes also grew well in neighbouring villages.

\section{DIARY Wednesday 23rd July}

Heavy rain during the night and thunder - raining when we got up after a rather late rice at about 7 o'clock. Gill continues to dream a lot - mostly anxiety dreams about catching trains, etc. concerning her mother/Leslie, etc. I also dream a bit. Continued analysis in the morning and then in the afternoon went down to watch Prem finish his 'Asar lava'. Most people now finishing. Then a little talk with Totra's father. Am a bit frustrated that the facts aren't pouring in - but it gives us a break to analyse, which is useful. Again rain in the evening.

\section{DIARY Thursday 24th July}

Hot, but with showers. Went down to Brikaras but we only did one 'tirige' since he is still not fully recovered. Gill working hard on the land records, etc. I started the large map. Nani and Gran came back yesterday evening - much helloing and smoking. Gunga from house below spreading discontent about us (ie. arguing with those who come here - probably because he is jealous). Continue to enjoy Goode: all the way through he is frustrated by absence of good historical data - hope to rectify that. He makes it clear that sociology is interested in trends/change, etc., not static cross-comparisons. Similarly, anthropology should be 


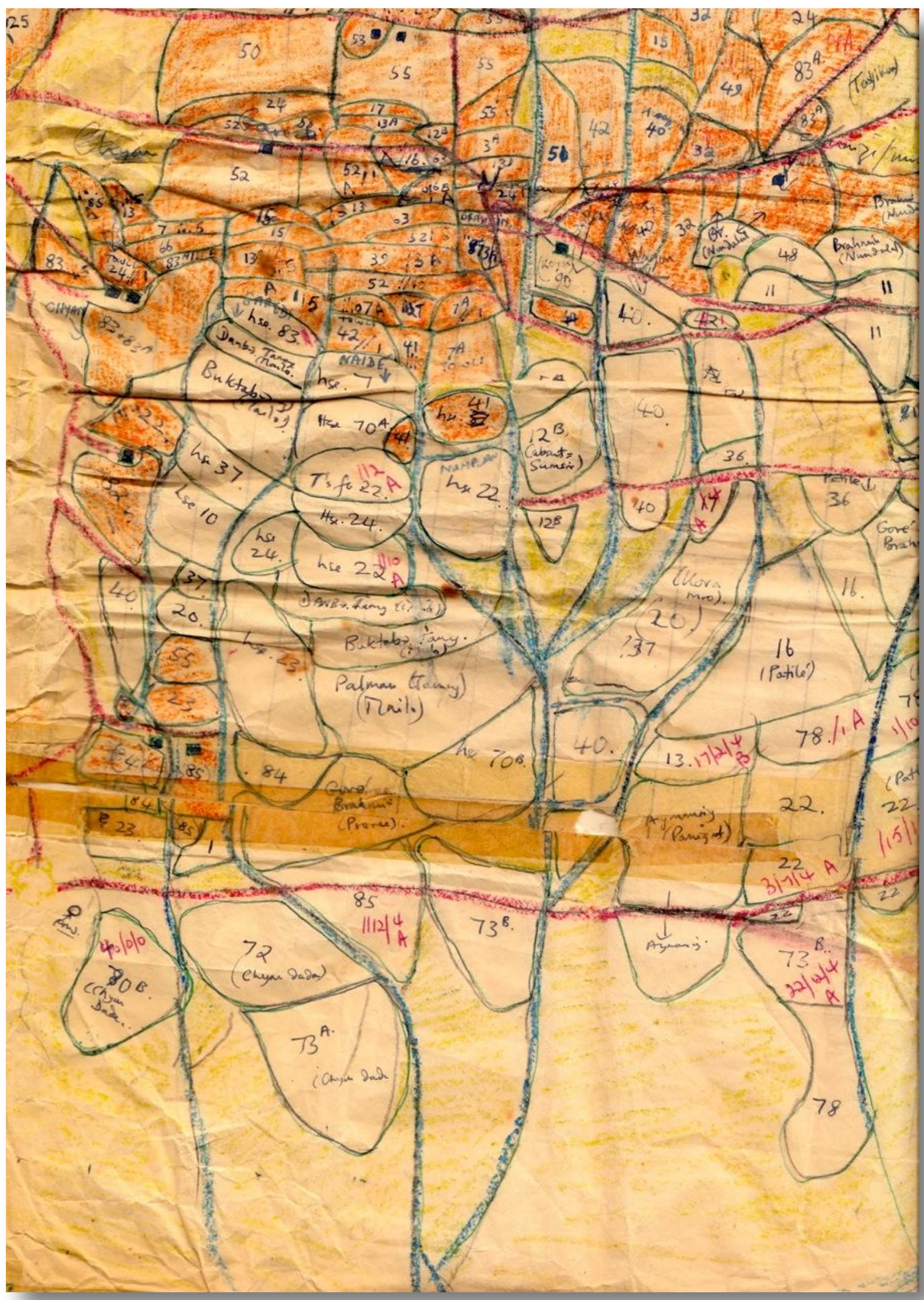

A small part of the final field map. 


\section{DIARY Friday 25th July}

Rain in the evening after bright day. Got a sweet letter from Rupa's father - indirectly asking if his wife was pregnant. Yesterday given rice-ring by next door - today went to Prem's where we had rice rings with honey and 'pa'. Gill unfortunately again with diarrhoea, gurgling tummy. Started on 'Furamide' again, but praying it isn't amoebic dysentery again. My map of Thak nearly finished. Goode 'World Revolution' fascinating - must send him 'Josselin'.

\section{DIARY Saturday 26th July}

Gill slept badly last night - awake much of the time and rats also noisy. She felt very seedy when I got up and stayed in bed with a temperature of 101 when I went to Uli to do another 'tirige'. Went via the end of the village as I wanted to draw another map and had rather a hair-raising scramble down. Prasad's father definitely better now and his wife returned from Pokhara. Returned to the village but Gill still bad and unable to eat anything for lunch. Very worried as her temperature was 105 at $3.30 \mathrm{pm}$. - now (6.00pm.) dropped slightly to 103 . Reading the medical books suggests she has malaria, amoebic abscesses of lung, typhoid, etc! Trying to work out how to carry her down to Pokhara now that the river is swollen and almost impassable: idea of negotiating the rope (bamboo) bridge on a stretcher, pretty horrible.

\section{DIARY Sunday 27th July}

Another trying day as Gill almost as ill as yesterday - from about lunch a high temperature about 104.5 in the mid-afternoon. Her breast also very sore in the morning and unable to sleep or turn on her side. Managed to stagger up to the toilet in the rain, however. Prem came for a couple of hours in the morning. We filled in the map, etc. Rest of day did little wrote a letter, read to Gill, etc. Frustratingly little work getting done - but hope things will liven up and pray Gill will recover soon. She is certainly paying for field- work. Seem to have lost contact with village.

\section{DIARY Monday 28th July}

Thank goodness, Gill a little better today - her temperature normal most of the day, though she felt a little wobbly. Much relieved and consequently felt worn out myself? Wrote letters most of the day, though did a little analysis with Gopal as well. Rained intermittently. Headache now - will try a little 'pa' to see if it gets rid of it!

\section{DIARY Tuesday 29th July}

Gill, though weak, still much better today, thank goodness. Very blue and hot and beautiful, and we managed to see the Himalayas - fantastic again - this morning. Prem meant do come, but didn't so worked with Gill in the morning and then went down to talk to the Lt. and grandpa's group re lands and genealogies, etc. Getting easier to talk once one makes the effort - the Lt. agreed to run the dispensary. The 'lowri' from next door came in to borrow 100rs. rather difficult but lent it to him. Feel rather awful as I refused 10rs. to an Untouchable on loan. 


\section{Letter from Gill to Iris and Mac on 29th July 1969}

Thought I had better get this down as soon as possible after Alan's letter (written yesterday) just to assure you that I haven't been bonked on the head with boulders and buried by the Gurungs. None of the things Alan was so feverishly picking up from our terrifying Handbook on Tropical Medicine (I think we would have been better without it) did apply to me, and although I did feel very ill for two days with a temperature soaring between below normal to 105, I have recovered very quickly. Feel very wobbly, of course, but can get up the hill and still thrill at the mountains which came back today, the first time for months, as we had a pre-monsoon glorious blue, blue, morning. We have just being seeing the lowlands, soft and flowing like English dales and had almost forgotten that there was that great white cragginess beyond, covered in cloud and mist as it has been. My dysentery seems to be clearing up as well, as I started on the Furamide again, which I don't find depressing. However, if you could answer some of Alan's questions I should be grateful as I don't like not to know what is going on inside me, and the Mission Hospital were a little vague, I hate going there anyway and feel such a fraud with 60 half-starving Nepalis waiting to be seen as well. I only feel justified if we go on behalf of the villagers.

The first week back from Pokhara was much easier and more enjoyable than anticipated. For one thing we were made to feel so welcome, rows of children lining their playing courtyards to chorus us back, the Gurung women beaming and my adolescent admirer saying he thought we had got lost, we were two days over, and an Untouchable that she had missed us, and I could only remember seeing her once before. The village was still quiet too, most of them away doing the rice in the fields, so we were let down gently into the ever present presence of others. We both got out for long stretches, to watch them in the fields and me up to my favourite little mountain, as the rain kept off till supper, where I read and darned, and watched the Wordsworth pool, with the hawthorn tree and the grey stone wall and the tottering old Gurung with his stick, hobbling after the goats and the children tumbling down the hill beside them. The path up is like walking though raised green tapestry, which with ferns and mosses of lushest greens... We also watched them finish of their terraces near home, and this had the same minute impact. It could be conveyed by the sounds... All the children long to help with the rice when they are babies, rather like driving an engine, the only formal admission to adult society, an informal initiation rite? (I feel there is something very significant in the fact that there is no formal initiation ceremony, asking of course where it has been sublimated to).

We were invited down for ' $p a^{\prime}$ (millet spirit) and fresh roasted corn by the Lt. on the second night and enjoyed our Malayan glasses and thick wool rugs and the rows of beer mugs on the plank shelves, and hoped the bear would get away which the rich widow had asked the Lt. to shoot as it would not stop eating her maize. The next night we went up "when the moon was shining" as we had been instructed to what must be the smallest Gurung house in the village, one room with no window, with a bed, the bedding rolled up on the beams so we could sit on the 'gundri' laid out on the bed, and a 6" high lamp, glaring over the wooden joint that held it and 3' of warm cream wall. Our hostess has been up to now an entirely inaudible, gap-toothed 65 year-old, springing lithely up the same path talking to her buffaloes, Nani and Kaji (eldest daughter and younger), croaking at us and glinting warmth from her burnt old eyes, had we eaten rice, yes we had, had she, not yet, getting grass for Kaji.... then we had this invitation. She couldn't give us 'pa', or tea, but would we have a cup of milk. We did, and she said "you have come?, "we have", "I have only a little milk as everyone has come for a sip today", but it was warm and thick and sweet and undoubtedly straight from Kaji... We loved this visit, she is very poor, having a rather dotty, little girl bottom rubbing son, who doesn't fit in anywhere as his mother is a Magar and father a Gurung, but Mum is a pet, only eating about 4 corn on the cob for supper (what we saw that night) and as agile as someone half her age. A lovely contrast to the Lt.'s, as the village disconcerted that we had appeared to have enjoyed it.

As Alan said, he is rather chafing at the moment because he feels he is not "working", only reassembling old material but he has got off this afternoon to get some more genealogies and tomorrow we are starting the diet survey of one or two families. Apart from illness I feel better in general about the work here as I have given up grand designs of doing important work on my own and I suppose at last faced my boundaries. I am still surprised about how shy I feel with these people, especially in family groups, and have tried to stop this coming out in being rather pompous and stiff, and they are infinitely accepting and patient as a people... 
DIARY Wednesday 30th July

Again very bright and hot - a perfect washing day! Gill still feeling better. Went down to Uli and did a long 'tirige' - Prasad's father still getting better. Many people came and we had a long session checking records and discussing sex on which I got a lot of interesting information. Then Gill and I went for a walk along beyond Sarki houses to see if we could find an alternative washing place. Though very beautiful, the streams were too small and steep to wash in. Picked her some flowers on way back.

\section{NOTES 30.7.1969 Alan Incest}

Incest: father-daughter, mother-son, is "very bad" and does not happen in this village. If it did and the elders heard about it they would meet and a) be bribed off saying anything b) call in the law and the man would be taken off c) tell the concerned couple, especially if brother and sister, to go off to another village far away if they wanted to do such a thing. Did this ever happen? About three years father-daughter at Gownigota (a village far away) did this - when found out they disappear elsewhere. In Khilang, also there had, some time ago, been an incestuous marriage. The couple concerned fled. Prem thinks that in incestuous marriages the couple should go elsewhere (thus the feeling is not that it is wicked in itself, but wicked in the community, destroying the natural order). Prem thinks "very bad" but doesn't seem terribly shocked. All forms of close incest, equally bad.

\section{NOTES 30.7. 1969 Alan Birth Control}

Bhuwansing says that birth control propaganda has been coming over on the radio for the last 2 years - every day it is on the radio. 'Paruwa Nividan' - I asked how it was done, the family rather vague on methods and said that people hadn't these in village. One could get such methods free from the state hospital in Pokhara or buy in bazaar. Told that one Chetri had 11 children (Dote - awful). Untouchables generally had many children and hence were poor and could not support them (sympathy/sorrow shown). I asked how Gurungs kept down their numbers. The family (Bhuwansing, Mrs, Dankumari) offered no explanation, affirming that abortion did not occur and people 'toi ala' (did nothing) about stopping children. The Lt. thought that it was something to do with climate - India and China had many many children in a hot climate. Mrs. Bhuwansing thought 3-4 children the right number. Dankumari thought she would like 3 ( 2 sons and 1 daughter). Lt. $=2$. All thought people would take eagerly to contraceptives if brought to village.

\section{Letter from Gill on 30th July 1969}

I thought I had better write as soon as possible on this startlingly clean sheet of paper A. has left me (apologies, the rats and the soot and rain have all been at that part of the loft where we keep paper) to say that I am now fine again, despite temperatures of 105 three days ago! Half the village seem to have been down with it, so I got much sympathy and little cups of milk and boiled corn as presents and many admonitions to eat 'many eggs and much rice'. We have 50 of the former, scrubbed ones appearing every hour or so, so I should be well on those alone... We are very intent on the land at the moment, so have the Gurungs been with the rice at last transplanted and they returning from their three weeks in the valleys, tired and aching and covered with sores from paddling endlessly in the feet of mud and water which miraculously produces a pearl-like grain out of a spear-thin pale green stalk. All the families more or less finished at the same time, and tramped back into the village again. It must have been like the end of the war, much jollity and spirits drunk and rice bread fried, popping in and out of each other's houses, and inviting us in as well.. 
As Gill said, there had been rather a quiet period in my work since we came back from Pokhara, but things are beginning to liven up again now. I have been making a coloured map of the village to show where all the fields are and what type of crops are grown. The whole area under cultivation - supporting over 120 families, is only 1 mile by 1.5 miles long, and half of this is cliff and scrub. About two thirds is under rice. All the crops down in the lower fields - ie. all the rice - lie some 2,000 feet below the village which means quite a climb whenever one wants to do anything in the fields. I hope to make a relief model when we return and will show you what it is like then. The average family holding is about one acre - compared to English farming one can see what tiny strip they have. This only keeps them occupied for about 80 days in the year - the rest of the time is filled with wood and water fetching, looking after one or two buffaloes, endless talking and singing. Most of their money comes from the men who are away in the army. In hardly any houses do the young children have their fathers present. It is like a nation constantly at war.

\section{DIARY Thursday 31st July}

Last day of the month - had a little 'pa' to celebrate! Gill washed at spring and sun got out in the afternoon. Wrote up notes from yesterday, quietly. Most people busy fetching in maize. Went along to maize fields and read 'Oedipus' plays - very peaceful and beautiful it was. Gill still well. Evenings beginning to draw in? Nansubar has put off going to Pokhara for a few days, sadly. 


\title{
AUGUST 1969
}

\author{
DIARY Friday 1st August
}

Cloudy and rained hard most of the afternoon - temperature in upper 50's. Went down and finished 'tirige' with Brikaras. Delighted to have them finished (except one which is missing), but quite sad also as I enjoyed doing them. In the afternoon analysed them with Gill, who had been busy indexing in the morning. Quite exciting seeing them beginning to take shape, comparing them with 'bali', etc. Still enjoying Goode, "Family Patterns", though possibly he overdoes his argument - industrialization and conjugal families aren't indissolubly linked as Greenfield has shown. Gill wrote a few further letters.

\section{Letter from Gill on 1 ${ }^{\text {st }}$ August 1969}

...We have recently returned from a week's stay in Pokhara. The monsoons are half-way through. This, in fact, merely means heavy rain in the evening and night, soothing on our slate roof, and occasional cloud in the day. It also means that the short route to Pokhara is blocked by a flooded river and we have to come and go by a much more mountainous path, which includes a small, but nevertheless rather frightening bamboo bridge over a raging torrent. The villagers have just finished the main task of their year, the transplanting of rice, and are consequently happy and tired. Meanwhile I work on trying to work out who is a relation of whom, how much land each family owns, how much and what they eat, what are the main diseases etc. The last is particularly relevant at the moment as Gill is under the weather. The hospital confirmed that she has amoebic dysentery and gave us some medicine for it - it cleared up for a while, but now she is in bed with a temperature. Don't know as yet whether this is connected or not. I have been pretty fit most of the time. There is a good deal of free time at the moment with everyone so busy and we both fit in a lot of reading - 'Middlemarch', 'Tess of the $D^{\prime}$ Urbevilles' and other books, including a lot of poetry. Make ourselves homesick by reading Matthew Arnold and Wordsworth. Our little house keeps out the heavy rain well and we are well supplied with tinned and packeted food, wood, rice and kerosene, so feel very snug. If we walk a few minutes up the hill we get superb views of the Himalayas when they are not in cloud....

...We are at the stage when we can think very little further than Gurung Land. Great frettings about the monsoon being late and the rice not being transplanted... The whole village felt like this though, much pacing to and fro and bemoaning of fate, and we just waiting to be thrown out as the baleful influence! However, the rain did come eventually and all the able bodies tottered sown the 2000 foot slope behind their oxen and ploughs and installed themselves in the valley for three weeks, and didn't stop work from then on. We would trip down gaily and watch them, neat and clean and prom on the bank whilst the men slushed through two feet of mud and water behind the oxen, the dust raising up from their caked backs as the men would whack them round a tiny edge of a corner on the edge of a terrace, about 50 feet long and 10 feet wide. The older married women would be in the seed beds in the middle of that terrace, crouching down and gathering clumps of pale green seedlings together, knocking off the orange earth from the roots and tying a bunch together with another seedling. The young girls would then go to the churned up terrace now full of slimy, evenly distributed water, and begin darting the seedlings in with incredible speed, only stopping to adjust their headcloths, one tuck, then another and down would go the back, bent from the hips down. Mist would be obliterating the other side of the valley, and there would be occasional quarrels for the precious water, money paid over for it not to be diverted, the cries of 'huh, huh, a-chaa' of the ploughmen as they croaked at the oxen, and the kites wheeling overhead, cream and brown tipped at the wings, graceful and huge, as much at one with the environment as the family of rice planters. One morning we had all this, and found a huge white mushroom as well. We must eat it as the person who found it had a large family, and we had only a very little one. He then told us that rainbows come from a big crab living in the river below, and when he opens his mouth the colours come out; he then showed us how the children blow the gauziest bubbles imaginable by getting sap from a certain tree, dripping it into a large leaf, twisting a piece of grass into a circle, dipping it in the liquid and then blowing. He showed us and the bubbles 
did come! I can't get over the immense satisfaction one gets from tiny things like this information, or watching a bird controlling the air for ten minutes. Perhaps it is the most satisfying thing about being here.

... Occasionally brought down to earth by illness, as I have managed to pick up amoebic dysentery. All the Gurungs are riddled with it from children onwards, and village type fevers which laid me low last week with temperatures of 105. Alan is always well, thank heavens, as he would be the most dreadful patient, not bearing not to be working all the time. I have now gone down to below 8 stone though, which I am pleased about, feeling much fitter and able to leap up the occasional mountain without too much strain, but the village is terribly worried, saying I must eat many eggs and much rice, rice especially, Sta, they say, giving me a heavy look as by now they have realised that I quietly loathe their beloved food. At one stage there was much jubilation because they thought I was pregnant, bringing back one's rice and not stomaching it being A Sign. Had to disappoint them though, they are very hurt I am not producing in their village.

The village goes on being quietly undernourished and ill, of course. We has one dreadful night when we were knocked up by and Untouchable to say his wife had just had a baby, but the placenta wouldn't come away, and would we go and help? I in my pink pyjamas and clutching a candle rushed to Merck's Manual. Useless. If the placenta is not away by 20 minutes it is serious, fetch a doctor, go to hospital. Not a thing about what one did. She died the same night, eight other children, the eldest deaf and dumb. Alan met the funeral procession the next day.

The work is going very well, and we are getting a lot on the land and economics generally. I am indexing all the fields at the moment and we are hoping to tie this in with marriage patterns. The people are still as forthcoming and affectionate. I have a current admirer in the throes of an oedipal passion with mum, working it off safely on me, stroking my ankles by the firelight as I drip over the fried cucumber (we have endless cucumber at the moment) and saying, as he is learning English at school, "You have such very white body, Sita", in a cracking but heartfelt voice! We are also heartened by the fact it is August and Time is Going..

\section{DIARY Saturday 2nd August}

Started doing diet survey - of Goof's house. Particularly sad - we watched him boil up and children eat with relish the maize which is all they eat morning and evening. No foodstuffs in the house at all. They spend only 16s. a year in Pokhara apart from on salt. Yet cheerful and good humoured. Then indexed. Prem in for a long talk, as yesterday evening - about going into the army, and England, etc.

\section{DIARY Sunday 3rd August}

Went to the river. Our usual place too dark so we went up a little side stream: rather rushed against impending rain, but very thankful that we had at last washed our things and ourselves. Fell into the river together on the way back - and very soggy when returning. But when we returned had some hot maize and 'pa', a sleep, and felt better. No longer do we get a sinking feeling when we approach the village after a day away.

\section{DIARY Monday 4th August}

Went down to Yunga to collect the last 'tirige', which I did (except left a bit out) with Brikaras. Warm in the morning though rained later in the day and village in cloud. Gill read some "Martin Chuzzlewit" aloud to me - delightful. Went on indexing landholdings. Both feel well. Hope for letters tomorrow.

\section{DIARY Tuesday 5th - Wednesday 6th August}

Prem came for five hours and we filled in various gaps in census, etc. Gill worked on at the fields. We went up the hill and read "Oedipus". Hills beautiful with cloud. We both feel contented - though both spent day hoping Nansubar would return with post since it is three 
weeks since we had a letter. Scanned Moja hopefully to see if anyone was coming down. Very much hoping witchcraft proofs will have come.

\section{DIARY Thursday 7th August}

The letters did come - some 14 of them, including ones from Trevor- Roper, Rex, Anne and Erik, Mummy, Nick Allen, etc. and Lucy Mair's book and some books from Freddie. Read for one and a half hours last night. As a consequence we were rather homesick/tired this morning and have spent the day thinking of home, reading "Past and Present" articles, etc. No witchcraft proofs however. Also went down to Prasad's father's and at last the 'tirige' is finished. Now to analysis and kinship for next three weeks, then religion.

\section{DIARY Friday 8th August}

A rather boring day - indexing lands, etc. Hardly anyone around in the village and little to do. Gill still a bit stirred up and miserable from the letters. Odd that no anthropologists have noted their boredom - lack of work to do. The anthropologist's underemployment rivals that of the natives! Enjoyed reading Stone's article on "Education and Literacy" in "Past and Present", very much indeed.

\section{DIARY Saturday 9th August}

Evenings beginning to close in now - beginning to get slightly dark at about 6 o'clock. A bright day with clouds. Prem came for some four hours or so - a red-letter day as I finally got the names of some 23 or so witches, as well as a considerable amount of information about witchcraft, etc. Prem very hesitant and reluctant to tell me - less because he was afraid of wrath of witches, than because he feared the consequences - social and legal - if I wrote a book with their names in. Also continued with 'Bali'. Gill went on cutting up 'tiriges'.

\section{NOTES 9.8.1969 Alan - Witchcraft}

Sometimes when one encounters a dog or cat a good distance from the village one knows it is a witch in disguise. In the Terai, powerful men ('guruwa') turn into tigers and kill those with whom they have fallen out. This is not a bad activity. Witches meet at the intersection of 3 paths and also meet where 7 paths intersect and on Chogon Dada hill.

Some 40 or so years ago a lot of people used to see a little thing about the size of a clenched fist jumping about on the paths just in front of them at night. It was impossible to overtake or kill it. These 'pamri' did not frighten people or make them ill but Prem thinks they were made by witches or evil spirits.

Witches congregate on Chogon Dada exactly half-way through the night ('polerada') but Prem does not know why they do it. They used, however, to eat the flesh of dead people. Another favourite activity is swinging on the lintel of their doors ('mra kudi mweba'). They don't dance, or have sexual intercourse with each other, though they do sometimes utter guttural, throaty noises like "how, how". They probably know each other. Nor do they fly, but sometimes run very fast.

Witches often bewitch people for no apparent reason, without provocation. They also harm those who refuse their small requests or who argue with them. Very often they, from a distance, put evil substances in the food of people whom they happen to see eating especially tasty food and this makes a person sick. Witches may bewitch any member of their own family or clan, including their own spouses and children. They may also cause all types of 
disease. Although many people believe that they can kill adults, Prem thinks they can only kill small children or make adults very thin or swollen.

If a small accident occurs to one, for instance a slight fall one accepts that it is probably that it is one's own fault, but if one falls very badly one may wonder if a god or 'bhut/pret' has caused it. Prem says that he has seen two witches at a distance, at night, and these seemed to be lights or shadows which did not answer to his enquiry and disappeared quickly. Sometimes people who are a little drunk hit witches if they meet them. People may become witches from 17 or 18 years, they learn this from parents or friends. The children of witches are not always witches themselves. There is no especial initiation rite. Prem thinks they have a few spells and a very few medicines. They also have an iron petticoat which they wear all the time. This 'gowri' sometimes clanks a bit at night. It is a strong protection against the poju's mantras. They never travel around naked. They also wear a small belt, 'koni', which is just the belt part of a loin-cloth which all men used to wear in the village.

Prem denies that there is any wealth correlation, they can be very poor or very rich. 'Bokshi' is used as a term of friendly abuse, as for example Prem calls Haricola 'bokshi dzidza'. A poju's family may include witches if a poju by accident marries a witch from another village. Prem admits that they are a little greedy but there is no special stress on this.

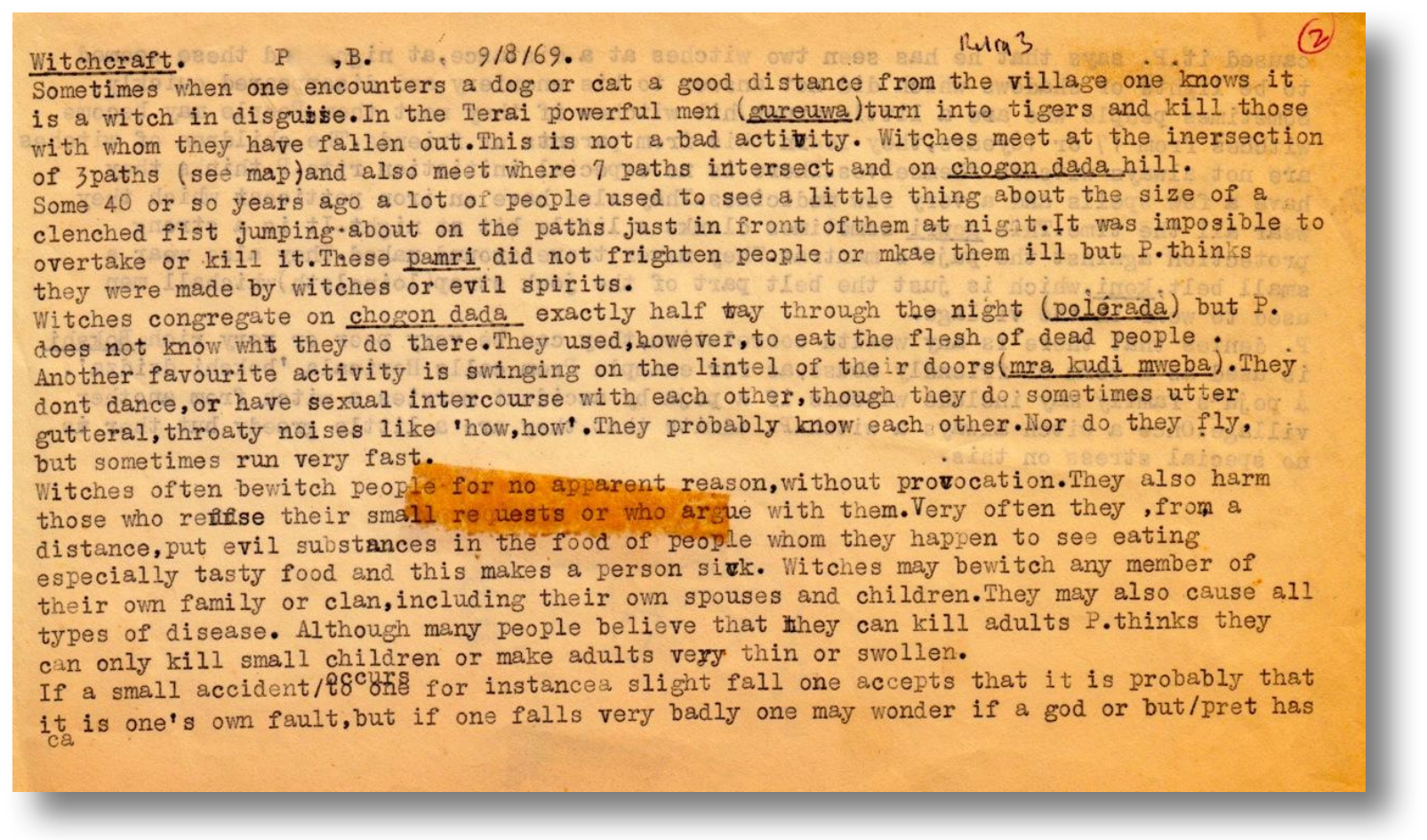




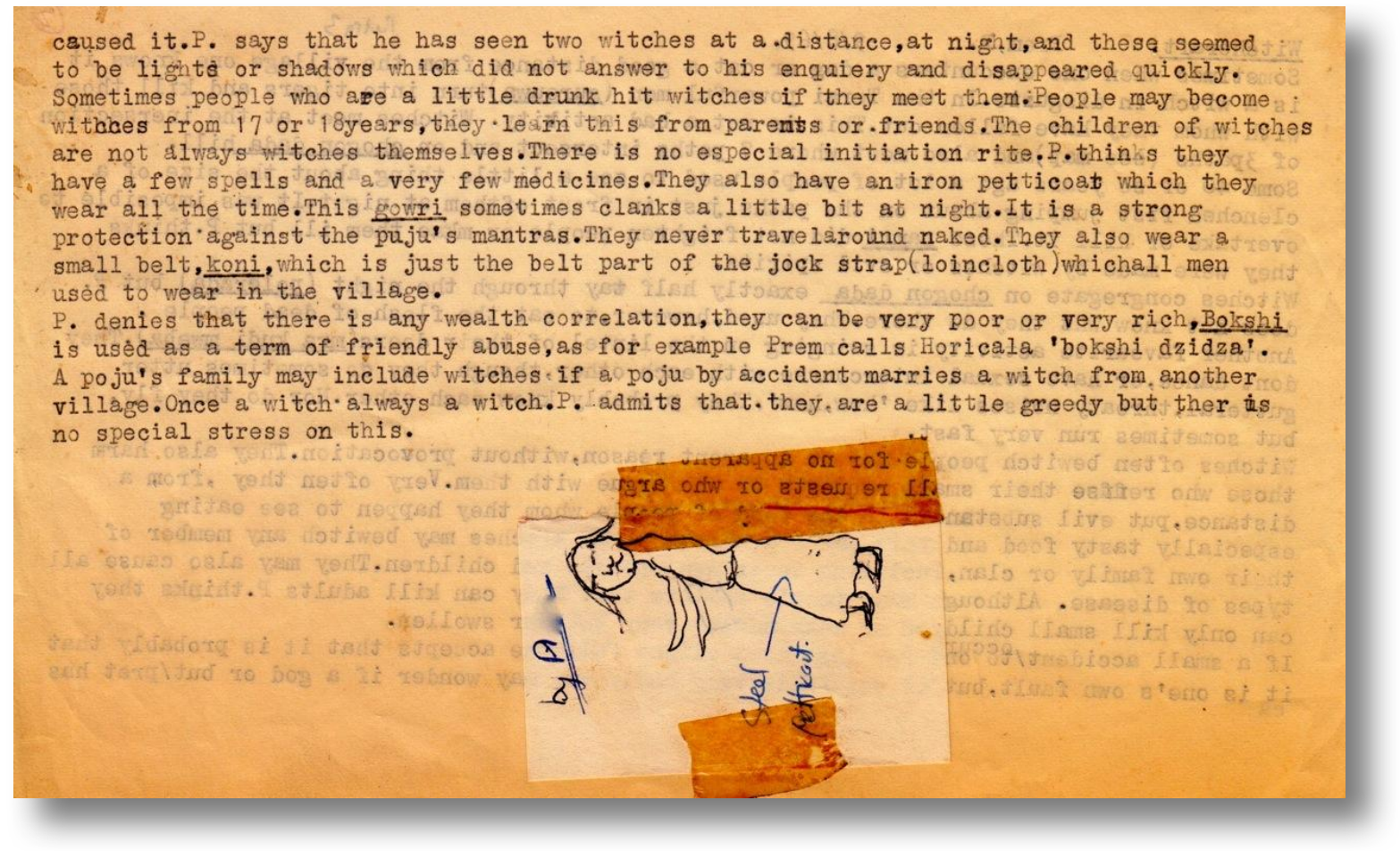

Typing up of notes on witchcraft

\section{DIARY Sunday 10th August}

Bright and cloudy in the morning, but rained heavily in the evening. Our house now chock-ablock with maize hanging from the ceiling, making it very difficult to do anything re cooking etc., like working underwater among cobwebs. In morning went down to Brikaras and did a little economics and had a chat on social mobility, etc. After lunch, since our expedition to get mangoes at Chachock with Gopal had been frustrated, we went up the hill to Garedi, via. our hill, to look for remains of previous village. Found foundations of six houses - houses much smaller then - only about 10'x20' with tiny 'kota'. May excavate a little.

\section{DIARY Monday 11 th August}

Very heavy rain last night, but bright today. Morning working and afternoon watched millet planting, etc. Time goes slowly.

\section{DIARY Tuesday 12th August}

Very tired today for some reason - and have been irritable and snappy for a couple of days why under the weather? Had a look at Servajid's family preparing food - then went to Chachock with Gopal - officially to get mangoes (of which there were none) - but got masses of cucumbers, maize and a good walk round. In evening a bit depressed since Servajid and Comal again complaining about the pressure of other villagers who told them not to come here to eat our sweets/chocolate/drink, etc. - also rumours that this village was "poor" in Pokhara. 


\section{NOTES 12.8.1969 Alan Reaction to food enquiry}

Servajid's family - when we had returned from house, Syebahadur (eldest son) came about half an hour afterwards and made his way upstairs and asked to look at photos, even though we were working. He stayed until he was asked to go. In the evening Servajid came and said would we only go tomorrow as his mother was 'adidiba', 'sorongnaba' (flustered, anxious) and did not like us being there. Implication they had put out all the food they could prepare so as not to be "shamed". Also apology that the buffalo had not given much milk, so we could not have full glasses (also subconsciously protest against us taking milk when there was so little to spare). Serv. then asked "what had we done going up the hill afterwards?" - great concern with what we had done with knowledge afterwards, i.e. how had we disposed of them? (cf. Syebahadur coming later). It seemed to have been lot of upset after we had gone and emotional investment in the food considerable. Also, from comments coming out later in the evening, there would seem to be a problem of neighbours comments - how much they would get out of it personally by the 'gorimae' coming - fear of neighbours suspicion and standing out in any way.

\section{DIARY Wednesday 13th August}

Prem came for three hours and we continued to check Pignede. Gill read me a bit of the delightful "Martin Chuzzlewit". A hot, bright day. Not so tired as yesterday. Just off to do food survey with Servajid's family.

\section{DIARY Thursday 14th August}

Finished various tasks today - reading "World Revolution" - a really stimulating and thorough book with some excellent propaganda for the historical study of family patterns - putting parental deaths onto punched cards, name and field indexing the maize fields. Hot during day and teemed with rain in the evening. Feeling more cheerful generally. Next door very friendly nowadays. Walked down to watch them sowing millet below Sarki houses. Started reading A.S.A. "Study of Religion" - continued "Oedipus". Servajid's food survey completed by request!

\section{DIARY Friday 15th August}

Did a couple of hours with Brikaras - on labour involved in various activities - from washingup to herding goats. Came back latish. More analysis etc. in afternoon. Dark and dreary evening - read a little more exciting "Martin Chuzzlewit". Finished Clifford Geertz's essay on religion - a lot of philosophy, but some interesting suggestions interspersed in it. 15.8.1969 Thak Alan

\section{DIARY Saturday 16th August}

A good work day, though Gill's tummy playing up a little and consequently a little apprehensive. Worked with Gill on the fields this morning - really beginning to look as if something fascinating might come out of all these records, though the amount of paperwork is fantastic. Then Prem came for three hours and we did some 'bali', etc. Our loft now festooned with 'mokhai' like Christmas decorations since one of the supports broke 
downstairs. Untouchable whose child died came to borrow 10rs. on security of a 'pela' - to pay for its funeral. We now have 140rs. out on loan. Lt. came next day and borrowed another 200rs.

\section{DIARY Sunday 17th August}

Overcast and drizzly and again foiled in hopes of going to river, so worked on analysing 'tirige' instead. A hectic start to the day with Lt. tumbling in among others to borrow money, etc. Gill did some washing. Her tummy in control, but a lot of wind. Working out how much land people used to have and how long it takes to do various tasks. Read Turner on colour symbolism - interesting though I find him a little pedantic and somehow superficial - can't tell why. Bought 'pa' and cucumbers, etc.

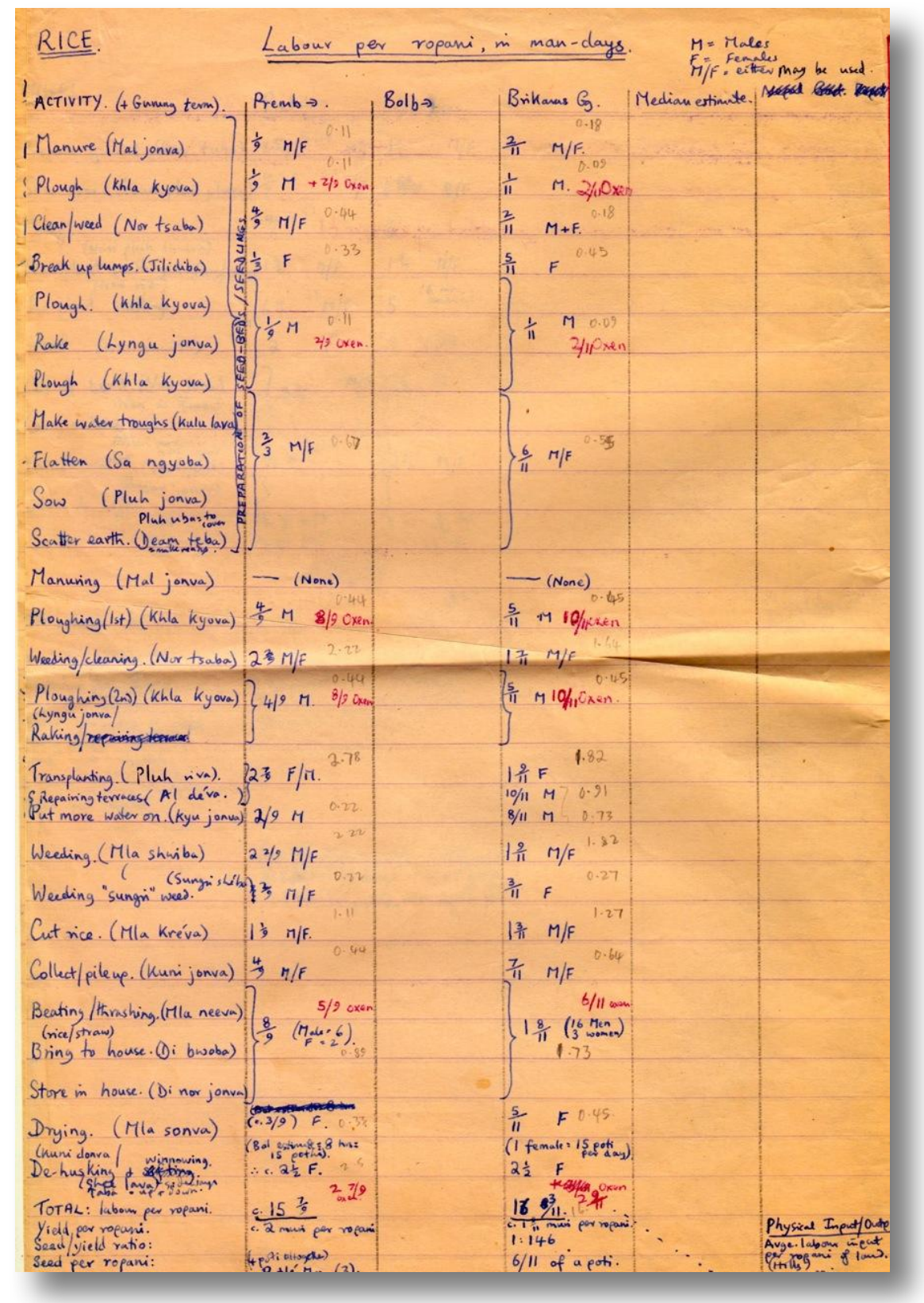

Input and output in rice production, two households 


\section{DIARY Monday 18th August}

A grey drizzly day: both of us need a break. All villagers milling around, doing pujas etc., since 'naas priba'. Prem here for a couple of hours, read and indexed a bit, but day generally seemed rather fruitless - except for the list of ancestors which Prem brought which tallied well with genealogies and showed village to be about 180-200 years old. Rather a chilly reception from Comal's mother to our request to do food survey in her house.

\section{DIARY Tuesday 19th August}

Listening to "Beatles" as I write this! Wet and dreary day. Indexing most of the day - also did Comal's diet and inventory - rather hair-raising, but did it in the end. Almost finished A.S.A. on religion - moderately interesting, though nothing fantastic - could there be in this field? In the end only witnessed half of Comal's eating - but his mother, apparently with menstrual troubles, more friendly.

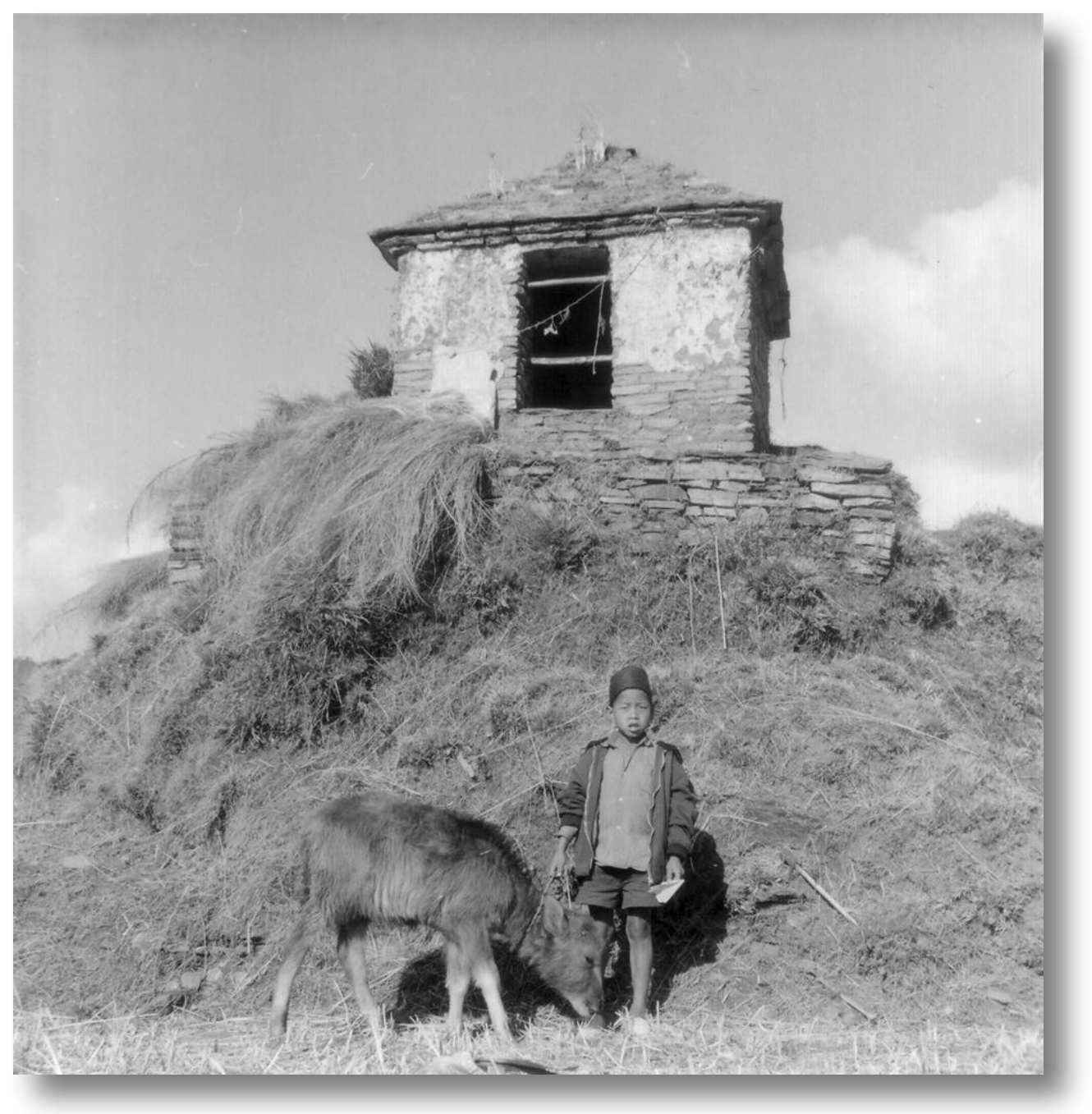

Gungabahadur with a small buffalo for sacrifice in front of shrine to Debi, 19th August 1969 


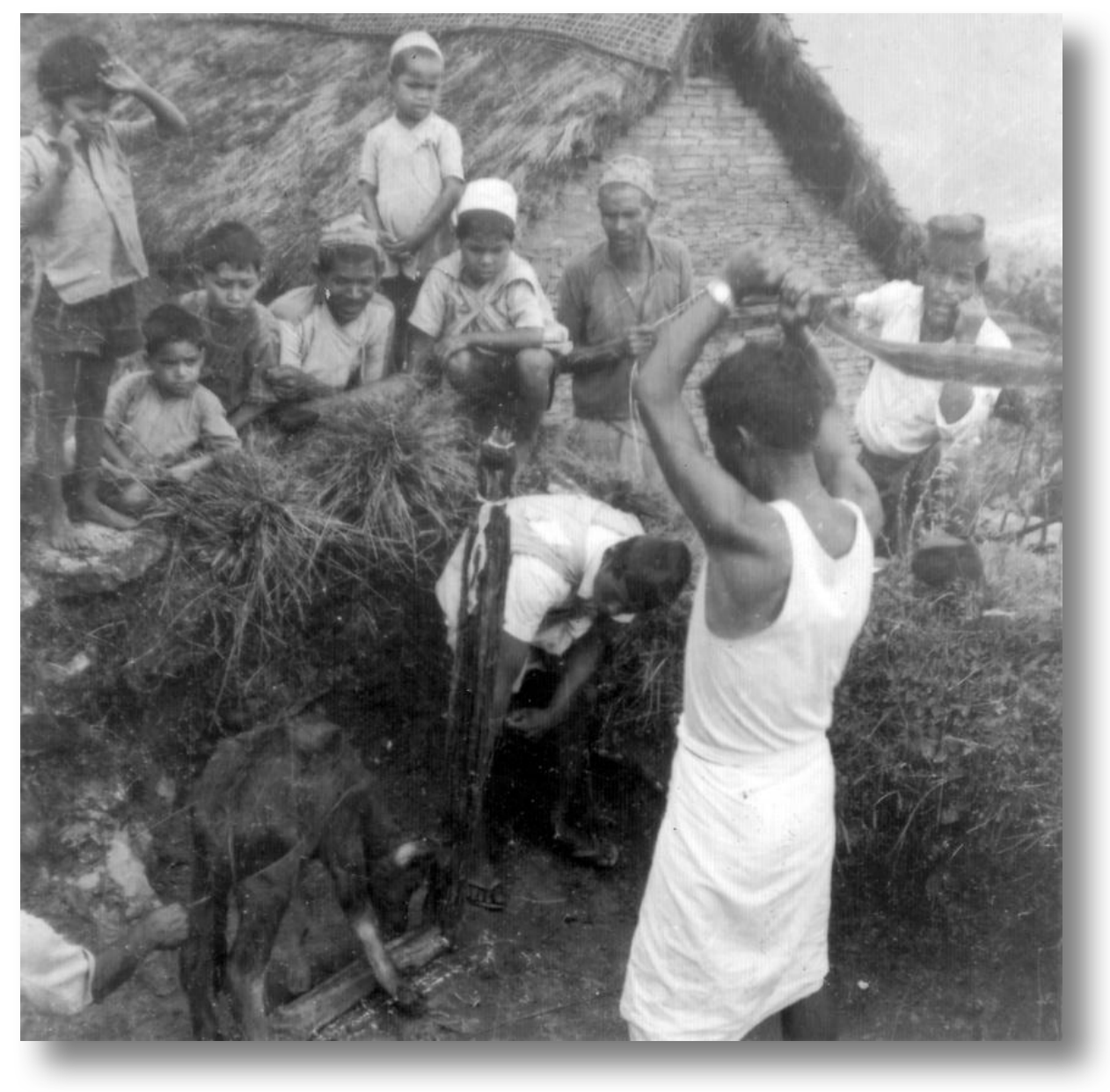

Little ox being sacrificed at Debi shrine on 19th August

DIARY Wednesday 20th August

Packed up and ready to go down to Atigar, but it rained practically the whole day so decided not to go down. Instead did various adding up/indexing jobs, which take an awful lot of time. Gill at one time rebelled, so we went for a walk through the mist and drizzle towards Taprang and read more "Oedipus" - longed for home and planned how we would go for long walks, with stops for lunch at little country pubs, and come home to tea and crumpets! Started rereading "Genetic Influence on Life and Death" - also continually staggered by poverty of families here as represented by inventories. Goof, for example - all his family's clothes worth less than 30/-. Gill well physically. Alas, the roastable maize running out.

\section{DIARY Thursday 21st August}

Again misty and drizzly. Went to Uli and did some work locating fields on map. Villagers busy weeding rice and millet, and village quiet. Our larder piled high with over 50 eggs. Indexed further - finishing 'tirige' - and went for a walk this afternoon. Gill working hard and feeling well. Discusses rituals/funerals - prompted by Gill's reading of Durkheim. 
DIARY Friday 22nd August

Weather much as yesterday - though some beautiful lights in the evening when we went to read "Oedipus" along towards Taprang. Indexed and added up various land records most of the day. The diet survey, such as it is, more or less finished. Very tired after fleas in our bed last night, but both feel basically well, though longing for letters and a break next week.

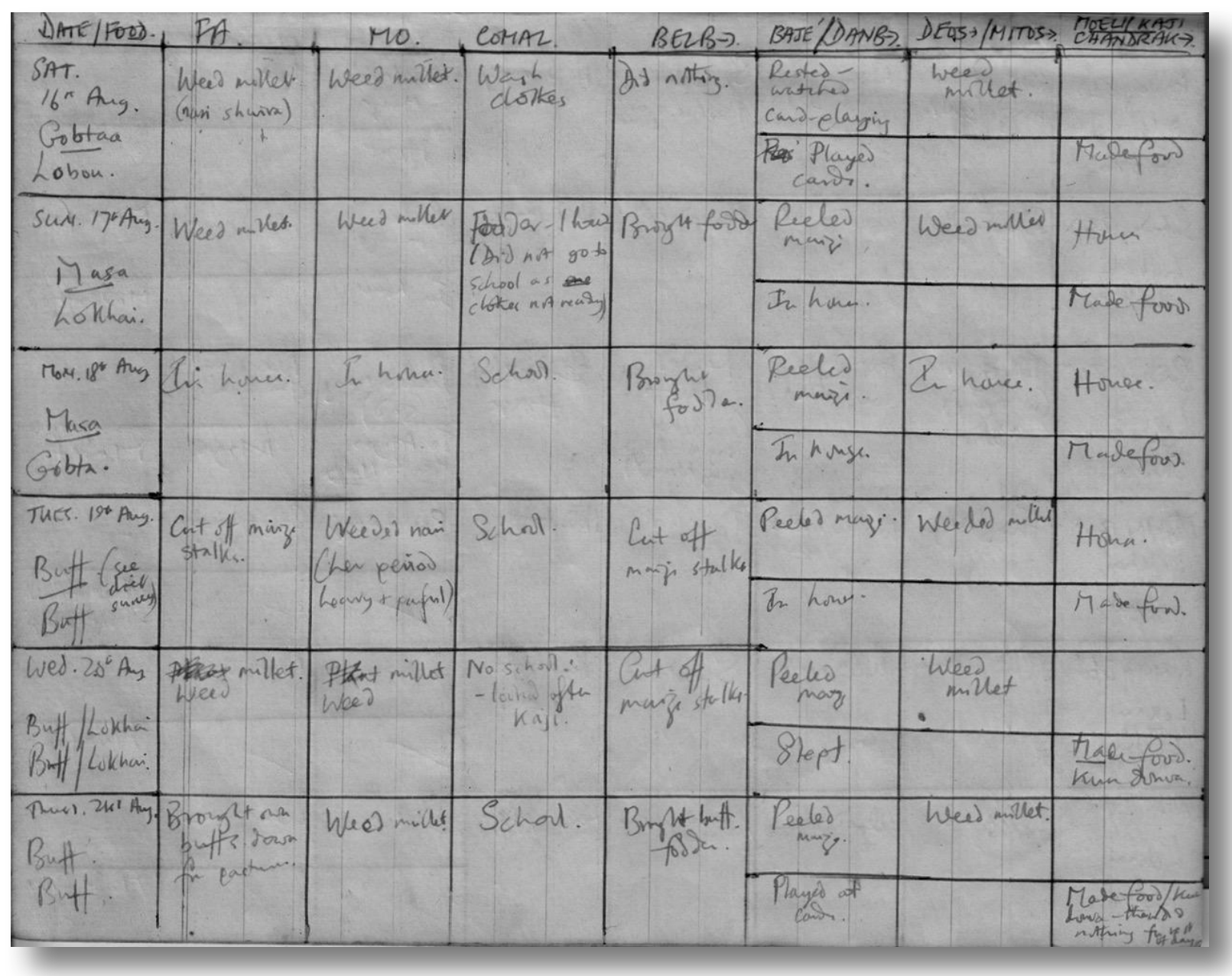

Survey of food and activities in Comal's household, 16th-21st August

DIARY Saturday 23rd August

Again misty and wet. Wrote a couple of letters - Nick Allen and Haimendorf. Counting through my material began to feel more hopeful that we are gathering some useful stuff - if only on economics. Started reading Durkheim - magnificent from the very beginning - on space/time/categories, etc. Everyone very busy in the village - weeding rice and millet. All the maize now safely in. Drew a graph of land-ownership in 1933 fascinating. 
At last we managed to get to the river, and despite infinite leeches, almost incessant drizzle, etc. we got heaps of clothes (3 pairs of jeans, etc. - took 3 hours) washed. Had a lovely "Horlicks" curry sitting under an umbrella with rain streaming down. Gill is fit physically, it seems. Collected some very pretty wild flowers on the way back.

\section{NOTES 24.8.1969 Alan - (New) religion}

Brikaras expounds a little of the dogma in a large book which he teaches to Potamkumari, etc. 'Issor Premiswa' - a person who does much 'darma' work (always defined as giving large sums of money, e.g. 25,000rs for public works such as building a rest place or good paths, or a water supply, will be repaid by being rich in the next life. (n.b. the stress on good actions rather than thoughts - and conspicuous ones). Those who are now very poor, says Brikaras did bad things in their last life - he himself must have done some good things to be moderately well off, whereas King Mahendra must have been very good (n.b. Brikaras frequently almost flippant, joking on this question, not at all in awe of divine matters). One can move from Gurung to Untouchable and vice versa in reincarnation. Sometimes people even become the worms under dry faeces. 'Pab' consists of killing people, indiscriminately killing wild animals in the forest etc.- 'Papi' people. Goats, buffaloes, cows etc. are close to becoming humans, while wild animals are far off. Creatures go through 84,000 lives as other animals then become men - may even be cucumbers etc. Plants etc. however, have no understanding ('sa a'cheeva') while wild animals have a very little. Everywhere and in everyone is 'Brahma', we are all godly. But we should not, the book says brag thus. Nor should we try to force the gods by reminding them of our good deeds. God is not "up there", he is here, within us. No-one has seen any other God. When a person dies it is as if God is shedding one suit of clothing - he quickly goes into another woman's womb. Brikaras says that though he wavers, on the whole he does not believe in witches, bhuts etc. (on the other hand 'garda sheba saili' is often cured from supposed witchcraft attacks by his mantra). Heaven ('sorga') is a place where there is no work, one eats what one likes, people are all truthful and speak well. But, Brikaras says, heaven is here, as is hell; for those like King Mahendra heaven is on earth and Brikaras himself is in a comparatively heavenly position. Many poor people, however live in an earthly hell.

\section{DIARY Monday 25th August}

Went down to Prasad's and discussed religion, checked his 'bali', etc. Now 'bali', inventories, 'tirige' are finally finished apart from analysis. Wrote a couple of letters when returned. Felt very bleary from our trip to the river.

\section{Letter from Gill 25 th August 1969}

...We are going down this Thursday or Friday (28th or 29th) and plan to stay for a week as Alan has some more work to do in the local administrative offices, and we both feel we need a break after 6 weeks of quite intensive work, and more than the usual village trials to put up with, mainly because of the weather. I enjoyed Pokhara last time so much because of the people there and lots of stimulating talk that I am really looking forward to it this time. However, there is a chance that our favourite African restaurant, which provides the only European food, will be shut up for holidays, and not many people as the air strip may be temporarily out of action due to the rain. So, I am trying to curb my enthusiasm and only look forward to having a dreary time. 
On the whole this has been the best six week stretch we have had, mainly because I have been very well the majority of the time, and have felt fit and energetic. It is such a relief not to have to drag oneself about all the time, every action an effort, and as a result I have done quite a lot of work for Alan, mainly sorting out the locality and ownership of rice and maize fields and also working with him on the diet survey, which was more difficult, but more of that later.

... The weather has only been really dreary during the last fortnight, with not a lot of rain, but heavy mist and hours of not being able to see the opposite side of the valley, and damp penetrating into everything. I am wearing my kilt and sweater now, for example, much to everyone's approval, as they love tartan, wearing it imported from Malaya, which the men in the army bring home as presents when they come home on leave. Mine has already been (hopefully) marked to be left and used as a head cloth as of course the women never wear short skirts...(cont.)

...Food has taken on an added interest since we started the diet survey, mainly its symbolic value which I still don't think we have quite appreciated. The Gurung equivalent for 'How are you?' is 'Have you eaten (rice) yet?' whereas in another society it might be 'Have your slept well?', and I think this stresses how food is the pivot of their social life, and possibly emotional. This was brought home to us rather strongly by the (underground) opposition we have had in making food enquiries, the first antagonism we have had. Alan has two small boys (a 12 and a 15 year old) who come every evening and tell him what they ate that day, mainly to see how much meat is consumed. One night they came in very upset saying that their neighbours were telling them not to come any more and get sweets for telling us things, as we might laugh at the food they ate and put down 'bad things' about the Gurungs. There had been a little trouble earlier when the fact that we ate differently, did not have rice with every meal, at a lot of sugar etc. They said that Pokhara people had been thinking that Thak was not a good village as there wasn't sufficient food for us to buy in it. We were horrified at all these mis-impressions and really should have been forewarned that there would have been difficulty in doing detailed work on food, and actually going into their homes and watching them prepare it. The first house we took was a Blacksmith untouchable but here they accepted Alan going for a week, the wife only anxiously asking me would it mean any trouble for them, and why were we doing it. This visit rather shattered me as in a family of four, two adults and two small children the only thing they had to eat that night was boiled maize. They had nothing in reserve, not even rice, and literally live from day to day, begging milk and meat from the Gurungs and the man getting paid rice in lieu of wages for any ploughing etc. he does for our Granny next door. That clay pot of boiling corn on the cobs, which at best have little nutritional value and boiled for 4-5 hours have even less, was between them and starvation. Their little plywood house, where the planks didn't fit flush and one could see daylight through the cracks, had the barest of necessities. Alan did an inventory later and their entire household possessions consisted of: one blanket, four straw sitting mats, one wooden box, one tin trunk, three drinking bowls, three platters, two cooking pots, one ladle, one water pot, one mirror, one comb, one rain shield, and the clothes they stood up in. Apart from his house and a small strip of maize land in front, Alan reckons he is worth $\mathrm{f} 16$ in all.

The Gurungs live on a much more expansive scale, but one which we still find worrying. The first house we took was the family of the 15 year old informant we have, with three adults, a 17 year old sister and two younger children. We arrived as the mother was preparing the first meal at about 7 am. She was in a great flurry, fussing where we should sit, and how many blankets we should sit on, the men shouting at her to calm down, but she rushed everywhere, grinding peppers and chillies, feeding the baby (breast fed at 3 years), milking the buffalo, boiling rice, roasting maize, full at it and answering our questions. She had to give us some warmed milk and maize with a little of their precious oil rubbed in, a great extravagance for them as they only use a teaspoon at a time even when frying their vegetables. Apart from feeling guilty about this and stressing next time we would only come and watch, not to share anything with them, we enjoyed it as I love watching the way they prepare their herbs. However, mother wouldn't eat her portion whilst we were there and that evening the boy came when we were eating and said his mother had been so anxious and flustered that she was asking us not to go for a week, but just to watch one other meal. This was in fact cooked by Servajid himself (our informant) as mother was away working in the fields, and this time it was much plainer fare, with not even rice, just ground and boiled maize as the staple ingredient. That first meal we had seen had obviously been one when they had cooked everything they could lay hands on, so that they wouldn't feel ashamed in front of us. It is so delicate and 
touchy, but we did one other family, being told we could only go for a day, and Alan thinks we have enough material to draw some conclusions - shown by the fact that we wonder how the children ever grow up at all, never mind the beautiful white teeth and lots of energy.

When we get back from Pokhara we are hoping to understand their religion a bit more, and this we think will be the most difficult of all. Defining 'religion' at all is a problem, and where does witchcraft and superstition have to be fitted in? I think one has to be a very special kind of person to get inside another society at any depth, which really means being secure enough in one's own to drop its assumptions for a period and take over another culture as it were, and neither of us have to gift to anything like this extent...

\section{DIARY Tuesday 26th August}

Wrote letters, analysed inventory, etc. Finished "Oedipus at Colonnus". Hot in morning, but rained in evening. Trying to fit in everything before Pokhara. Village quiet as people busy weeding, etc.

\section{Letter from Gill - 26 August 1969}

...Part of the problem is of course the weather - we are going down to Pokhara this Thursday and it will be the first break from the village for six weeks, and the first chance we have had to post letters... the rains have brought more than their usual trials, mildew in the raisins and Alan's good jacket, bed bugs, which I refuse to call fleas being just about bearable under the name of bugs, in the sleeping bags, ants in the thrown our tins and rats squeaking downstairs, nibbling at the maize which is hung from the beams to dry and makes walking downstairs rather like floundering in the weeds at the bottom of a damp and dreary pond. For the last fortnight we have not had a clear day, not a lot of rain but continual mist and cloud which obscures the other side of the valley for hours on end, damp penetrating into everything ... Washing is a problem, as you can imagine, and we have been going for three week stretches without a sud of soap touching our hair - you can imagine the bliss when we do wash, even if the rain is just about to pour down, there are pebbles at the bottom of your washing pool and water fleas there as well as in the house!

...Work has been going very well. I have been concentrating on indexing all the maize and rice fields, as Alan had got hold of some land records which go back 96 years and is very keen on doing combined historical, economic and anthropological approach. Then we can find out here why there was not a rise of the landed gentry as in the equivalent period in English history. This ties in with all sorts of unexpected things like witchcraft, as we find that every house which has one (at least amongst the Gurungs) has more often than not a man away in the army, which means a steady flow of capital back into the village and a gradual rise in status. It seems the society is going to make it tough for man to advance socially, by ostracising the family to some extent. Very tentative ideas like this are emerging and it is all rather exciting when the prose and the poetry do begin to connect.

... There has been little ritual lately, everyone being occupied with weeding the rice and millet fields. They do all this in groups and have several work parties out every day. There was one exciting break when a leopard was killed and the poor beautiful creature was stuffed and put on a bamboo stretcher and had red powder dusted over it and flowers put behind its ears, as well as the man who killed it, with guns shot off and a general parade round the village. It hadn't been killed near here, and the man wasn't from Thak but nevertheless it happened and we still haven't sorted out why. There was some happy muddled the day we decided to visit another village across the valley to go and get some mangoes which grew in profusion there. The first Tuesday the boy we were going with, and whose father's youngest brother owned the tree, failed to turn up. He had decided to go and weed rice. Much panting round in the evening and apologies. We would go the next Tuesday. We were not cross? Good. Next Tuesday Alan's best informant had discovered this expedition, became jealous and said he would go too; Gopal (our host) put out as rather intimidated by the latter. However we would all go. Prem (informant) dithered on the doorstep for an hour, then at a little persuasion beamed that he had decided he would go. We are about to set off, we see Prem in the working party weeding the paths. He had to 
stay. Half way round the mountain we were hailed by his younger brother in a bright primrose shirt and patched umbrella. He had come instead. Arriving at the village, father's youngest brother was out in the fields, the mangoes had long ago finished. We came back with bananas but with gen on how to procure a herbal abortion and how to cure coughs by chewing a pink moss flower... a day in the life of a Gurung plus anthropologist.

\section{DIARY Wednesday 27th August}

Didn't sleep well last night, preparing for Pokhara in my mind and today, in fact. Wrote letters, finished off inventory analysis, etc. Bucket full so spent some time wandering in and out with little tin of urine. Stream of strangers came, mostly from Khilang; they have been gambling here. School holiday, apparently.

\section{Letter from Gill 27th August 1969}

... We also tackled the diet survey, much more difficult than anticipated because of the firs opposition we found and we felt quite disconcerted by this. It made us realize the immense value food has to these people, not merely on a practical level but on a social and emotional one as well... The first difficulty we had was when some adolescent boys Alan has coming every day telling him what they ate in their two main meals, said that neighbours were telling them not to come as we would only laugh at the food they had and learn 'bad things' about the Gurungs. Then after we had watched one meal cooked by the mother of one of these boys, we were told in the evening that she had been so flustered and anxious that she was asking us to go and watch one more meal only, and not go for the whole week, as had been hoped. At this other meal she was in fact away in the fields, and the cooking was done by the boy, much less elaborate fare this time, obviously cooking everything they could lay hands on so as not to feel ashamed before our note-taking. It is so delicate and touchy, but also very important, so we persevered with another family, but only doing the morning and evening meal this time. There was a bit of aggression at first, mother not being well and not appearing until she actually ate and food cooked by the husband's sister. However, the latter is quite normal but I do think a Gurung's reaction to stress is to withdraw. I noticed the mother of the girl who ran away to get married, became ill and had to lie down when the daughter returned plus husband and relatives to try to conciliate her own parents.

The second house we looked at is one of the wealthiest in this part of the village, so of course we were interested to see if there was any substantial difference, but we think they might eat meat slightly more than another family - ie. once every 5 days instead of every 6. However I am glad we went as watching the cooking process and the eating, one gets into the very heart of family life, and at least begins to feel to a very minor extent what it is like to live in a pre-industrial society. We sat on straw mats and blankets on one side of the hearth, the cook always sitting on a small round straw mat on the side facing the window. She was often streaming with sweat from leaning over the fire, stirring the meat and pounding down the maize flour, and her head cloth would come continually unfastened so she was always looping it back and tucking it in to the back of her head, and then taking an occasional drag at a cigarette whilst waiting for things to boil. There were pots of already cooked rice keeping warm in the cinders, strings of meat hung over a stick to dry in the smoke and mother's hair braid looped over one corner of the bigger frame that is stretched over the fire, suspended from the low, blackened ceiling. Two huge water pots are in shadow in the corner, and the smoke drifts in a choking haze towards the wooden window, slightly lop sided with the carving of the squares not quite symmetrical. Chickens cluck in and out, occasionally shooed out by the cook, next door neighbours pop in for a bit of grain, really to check up on us, one of the village dogs sniffs round and then wanders out again. Only the smaller children of the family are about, cuddling up to us, hoping for sweets. Facing the window there are the wooden plank shelves with huge copper cauldrons which they use as cupboards, stuffing clothes and oddments into them, leaning up against the wall, and with the copper bowls, plates and jugs in dusty rows on the lower shelf. Beneath is a wooden kist, padlocked and with dog-tooth decorations round the lid, like a Norman cathedral door, and then the cast off maize cobs, underneath, showing that roasted maize has just finished, all excess food landing on the floor, as they eat there cross legged, plates on the smoothed down mud. It seems as if all is just contented, smoky 
confusion, split grain in one corner, the maize strewn grey and old, all over and humans and animals drifting in and out in apparent relaxation and ease. However, mother was sleeping in an extension outside, resistant to 'gorimae' (white people/strangers) and at the beginning of her period when work in the fields is one long drag, the neighbours who casually popped in were the ones who had taunted the boys before, telling them not to cooperate, and the cook was in fact shy and diffident, answering questions with apparent reluctance and not quite as rhythmical and at ease as she seemed. We were there two hours, and emerged cramped and blinking and coughing with the smoke, from darkness to light in more ways than one

... [Repeat of leopard story and quest for mangoes at Chachok] ... neighbour appears with a torn mat and a huge cucumber. Would we eat some and sit on the mat? We then wander round the village, this girl there had an abortion from such and such a herb having been made pregnant by our youngest schoolmaster, and this woman here with a baby was Lalijd's first wife wandered off from her marriage in Thak back to her maita. Finally we ate maize burnt by me, since father's brother's wife also not there, in his house billowing with maize cobs and returned with bananas to Thak, primrose shirt carefully re-donned before entry back into village, taken off as the way to the Brahmin who owned the banana tree was one long sweat away...

\section{DIARY Thursday 28th August to Friday 5th September}

To Pokhara - long path via Bisgu - today, back in a week or so.... A nice restful time in Pokhara, only letter-writing, an afternoon at Bomissida's office and reading. Read Oscar Lewis, "North Indian Village", half of Veblen, "Leisure Class", three books on social history and a couple of novels. Then returned on Friday 5th September. Everyone most welcoming. The journey not too strenuous, though heavy rain most of the way made it worse. Arrived back with 550rs. (and 100rs. owed by 'lowri'). 


\section{SEPTEMBER 1969}

[First six days of Diary under August - in Pokhara]

Undated photographs of houses, outside and in

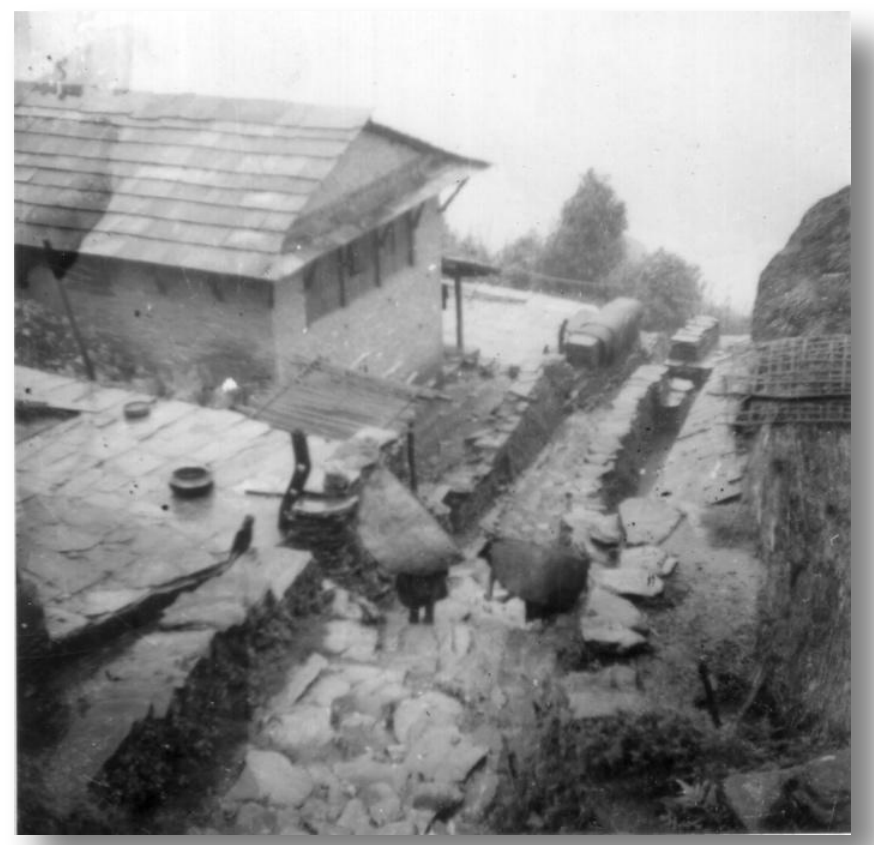

House24 on left beside the path

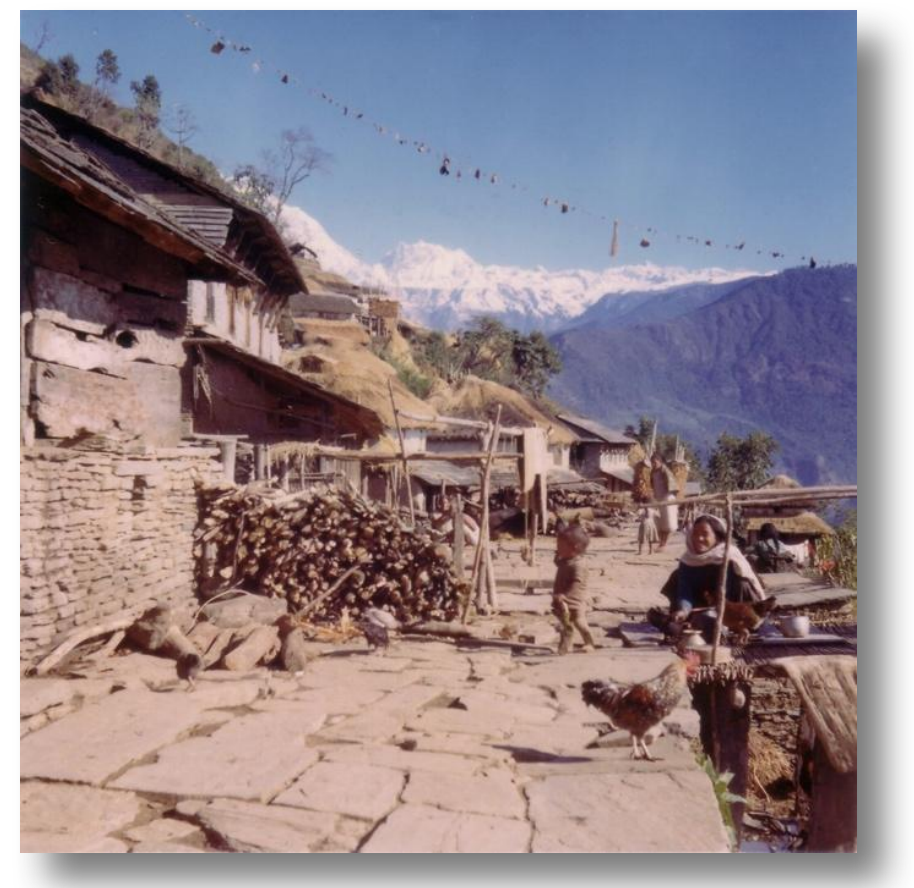




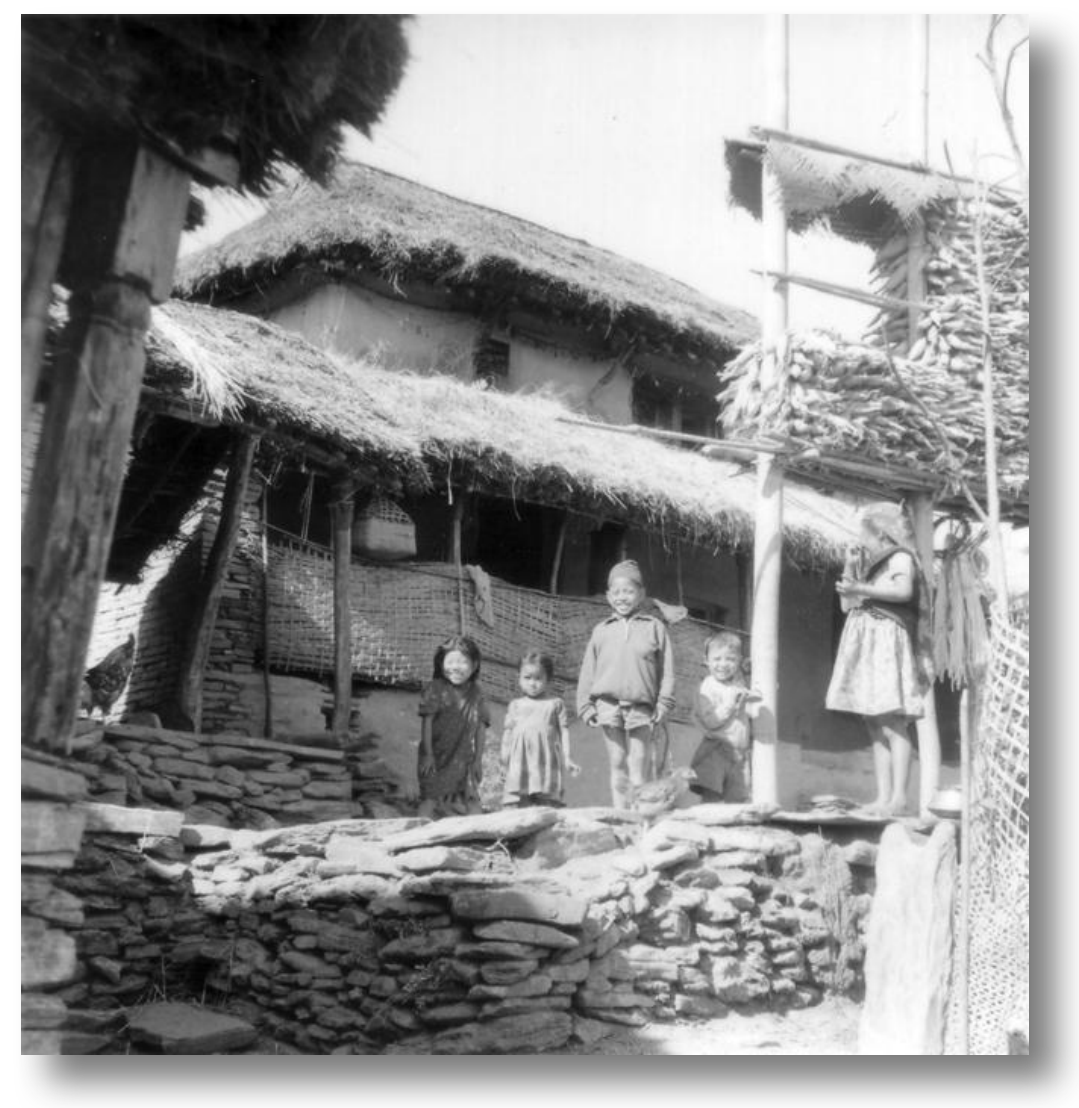

Medium Gurung house (House3B)

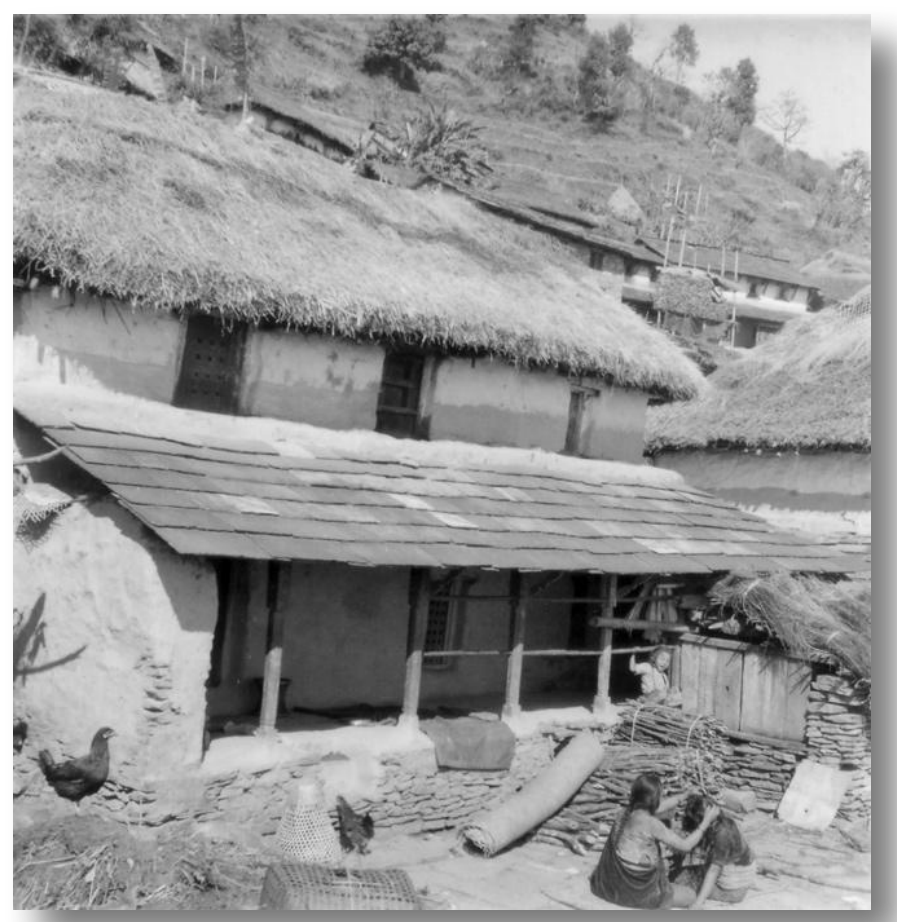

Wealthy household - median house (House1) 


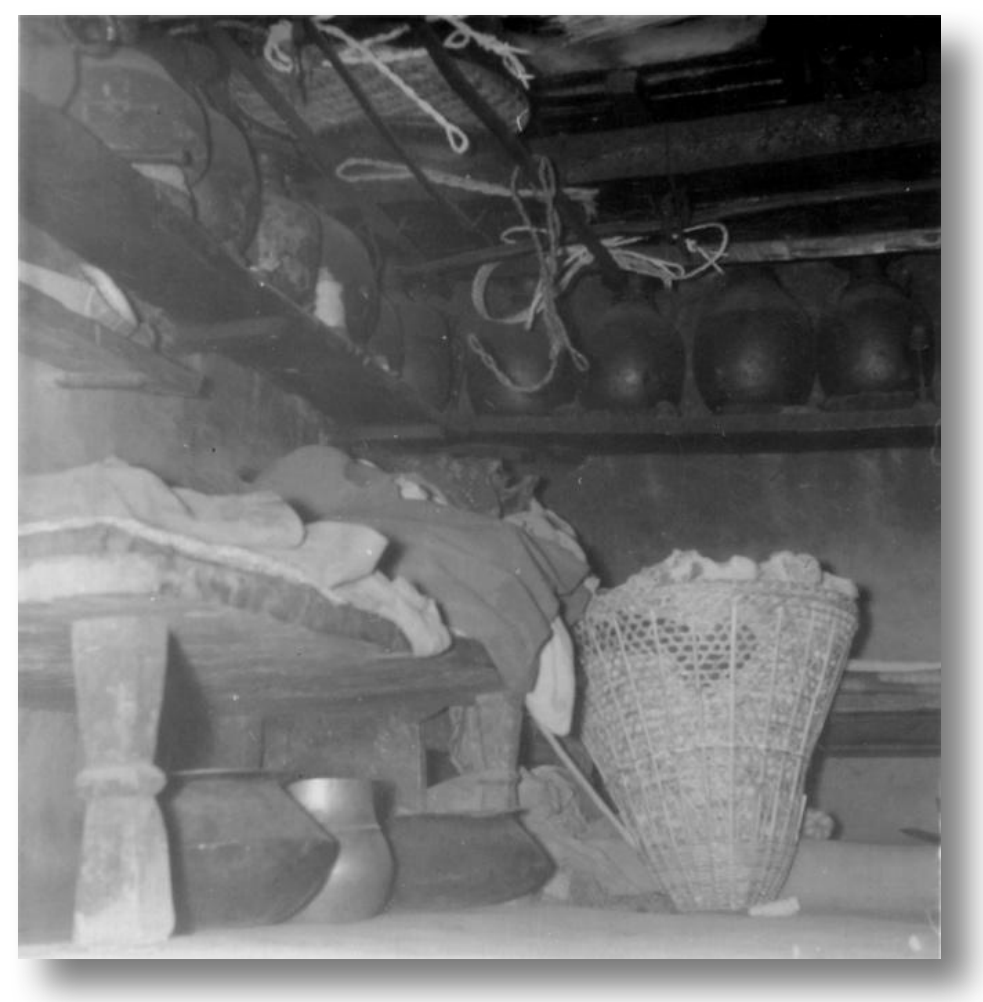

Bed and storage jars inside House40

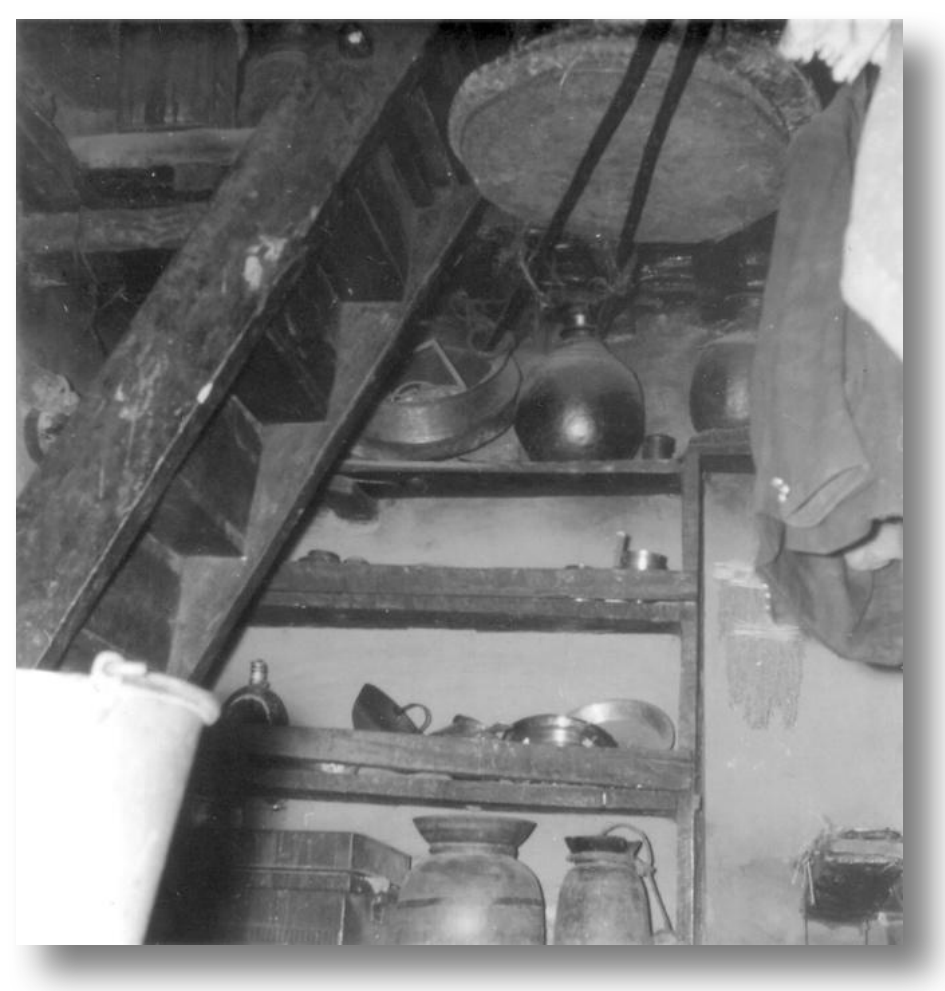

Stairs with cooking and storage jars in House3B 


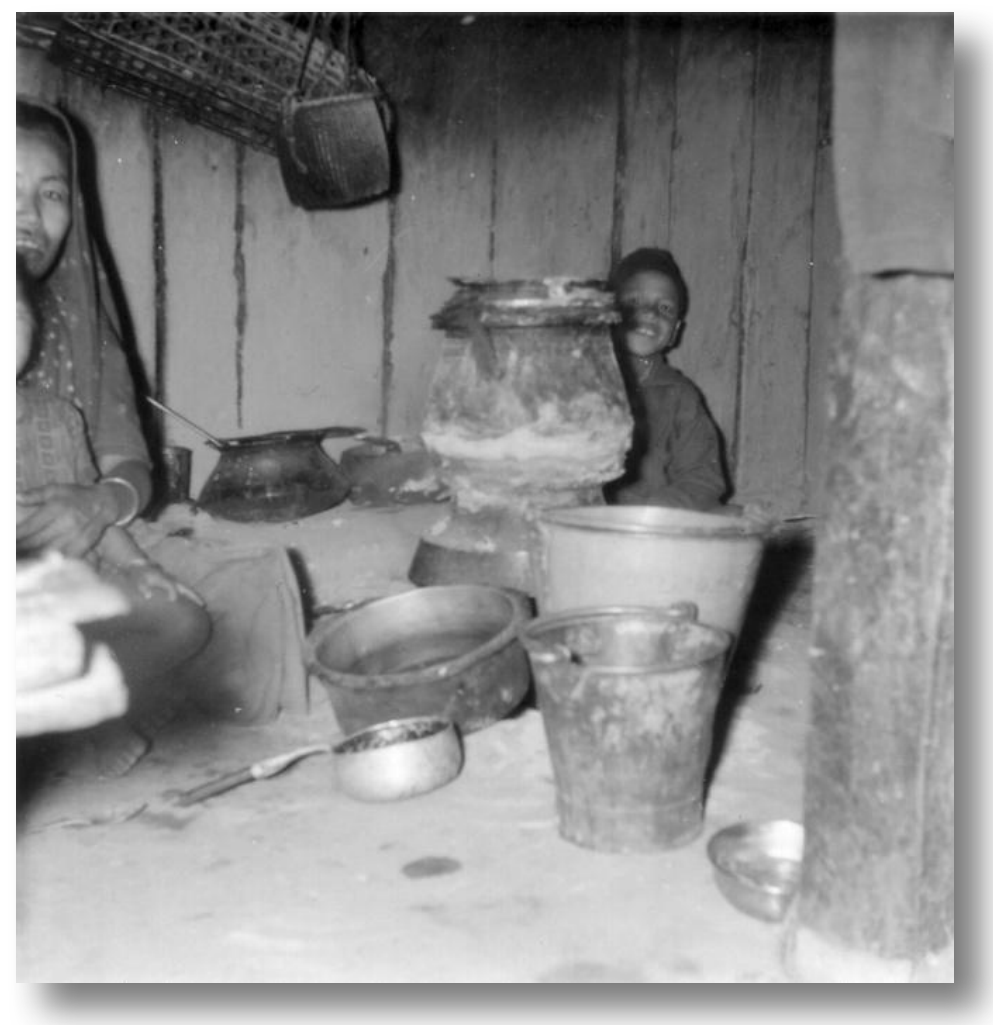

Making 'pa' inside House3B

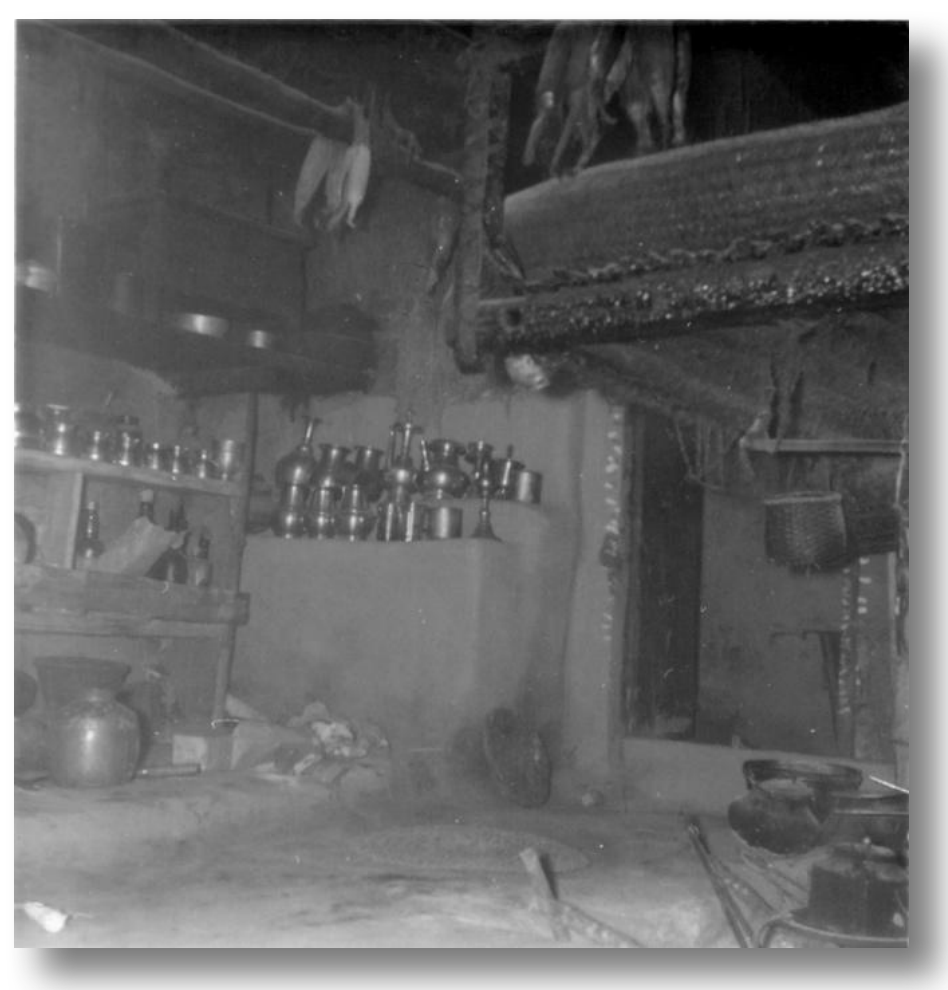

Wealthy house. Hearth and utensils in House24 


\section{Letter from Gill on 1st September 1969 from Pokhara}

... Upset about these wretched letters being opened, but this is the first time anything has ever been abstracted. Fortunately we take carbons of everything we write, so I will have another copy of this in the village, which I will send off in our next letter from there. They are having so-called 'political' difficulties in Pokhara (Communist pockets) but I can't feel these are genuinely worrying. Might be an explanation of postal interference though. Alan will write about the films, but many thanks for dealing with this... By the way, you have never mentioned the films we sent you, and whether you have managed to get hold of a projector yet. Do tell us what they were like, even if they were awful, I hope the very last one of me beaming from under an umbrella, with the mountains and the village on the ridge came out, it was meant especially for you! Thank you for the vivid bit about the moon, the boys in the village who have transistor radios (ugh) told us, but either they were hazy or our Gurung is worse than we thought as they thought the name of the men were Appollo and they had somehow paddles up there of their own accord; we had to explain rockets and what not in Gurung, so none of us ended up any the wiser, so many thanks for sorting it out!...

Pokhara is proving as relaxing as usual, and Alan thank heavens has only done half a day's work so far, so it is a real rest for him, which he needs at the moment. I had a bit of a cold the first day, but this soon cleared up, caught off the village children and also having a very wet trip down, and it poured for the first two hours, and the Indian umbrellas do leak a bit. The rocks were also like glass with the moss and water. However we met two hearty Gurung groups coming down at the same time, as there was a special festival in Pokhara that evening and they were coming down from the hills to have a fling. The women looked so pretty dresses in their best saris and jewellery floating through the brilliant green of the rice fields; the Brahmin women look best though as they have a passion for scarlet and wine reds, and you can imagine splashes of this amongst the green of the fields as they are working there. It was a beautiful walk down, the rocks alive with blue and pink moss flowers, and I much prefer this longer monsoon route to the dry and arid plain.

On our first evening, having hardly recovered from the walk, we staggered back into the bazaar again as there were supposed to be dance groups and drumming in honour of the dead of any family, a rite we couldn't quite sort out. The place was alive with mostly hill people, very few tourists, and we did see men dressed as women dipping and swaying in the light of lanterns, drums booming away, quite exciting, but nothing like the slow and haunting Gurung dances, but I suppose we are getting prejudiced! We were exhausted when we got back to the Tibetan hotel, as we had to walk the three miles back, which must have meant about 25 miles in all in that day, and not on the flat! (cont.)

The next day I more or less spent in bed, just relaxing and not having the Gurungs watch me do it, and Alan did his half day's work. I even enjoyed a detective novel... Forgot to say, when we called at the Post Office when we first got down, what should be there but your parcel with the shirt and dresses, but this doesn't mean a thing in Nepal. First of all the customs duty of 82rs. was asked for (about \&3 $^{3}$ 10s). Then the slip from Kathmandu which went with the parcel said The British Embassy, Pokhara, instead of the British Library. The Chief Postmaster! said because these two addresses did not tally we could not have the parcel. Even when the surname was the same and the man in Kathmandu obviously couldn't transcribe English into Nepali, and the three code numbers corresponded, parcel and slip, and we were prepared to hand over the 83rs. Can you imagine anything more frustrating. They have dealt with us thousands of times before, we had our passports, but they couldn't get out of the bureaucratic maze they are in the middle of, without understanding why they are there. So the nett result of this is that we still haven't got your beautifully packed parcel. They are "having" to send it back to Kathmandu.

...We enjoyed ourselves last evening going to visit a Peace Corps boy who lives in a Brahmin village half an hour from Pokhara, teaching there. He is a bubbly, sensitive New York Jew who seems to have done well in his village, especially as Brahmins aren't the easiest of people to integrate with, We had a gorgeous Nepali meal cooked by his Nepali cook who obviously rules the household with a hand of iron, but looks after Ira very well. He had a most lush house, in comparison with ours with electricity, mats all over, pictures on the walls, a study (sighs from Alan) and a lovely selection of books from Spanish poetry to sociology... We ate on a verandah with no smoke, and a little clay pot of flowers and it was delicious... 
...Am writing again this early since we will be off to the village tomorrow and won't be able to write again for 3 or 4 weeks when we send someone down...

...Gill very fit still, despite a strenuous 8-hour walk down from the village. I have a few leech bites that have become a bit infected, but Savlon should soon clear them. Still fairly hot in Pokhara, but not nearly as bad as it was and a nice breeze. It only rains at night. The mountains occasionally show through. A stream of curious people continue to flow through - including young, anxious Peace Corps boys, photographers from Denmark, social workers from Chelsea etc. Incredibly depressing hearing the gossip of the way in which those administering aid - from US Ad to Swiss-run Tibetan refugee camp, to the young German agriculturalists (who we had a beer and whisky with once) - live. Deluxe houses, endless imported drink/food etc... But perhaps we're a bit envious too - and we do succumb to Thyssen House when in Kathmandu. US Peace Corps seems a bit better than the rest - but they employ students and not career-minded experts. The place really is a mess...

\section{DIARY Sunday 7th September}

A rather dreary day (spiritually! - physically a lot of sunshine). Perhaps we are still tired, but we both felt a bit depressed. Spent some time trying to work out a questionnaire on religion fantastically difficult. Finally, after getting furious with the cat, we went down to watch Prem and co. in the fields. Then some more punched cards. Finished Veblen - a lot of waffle, but parts splendid. 


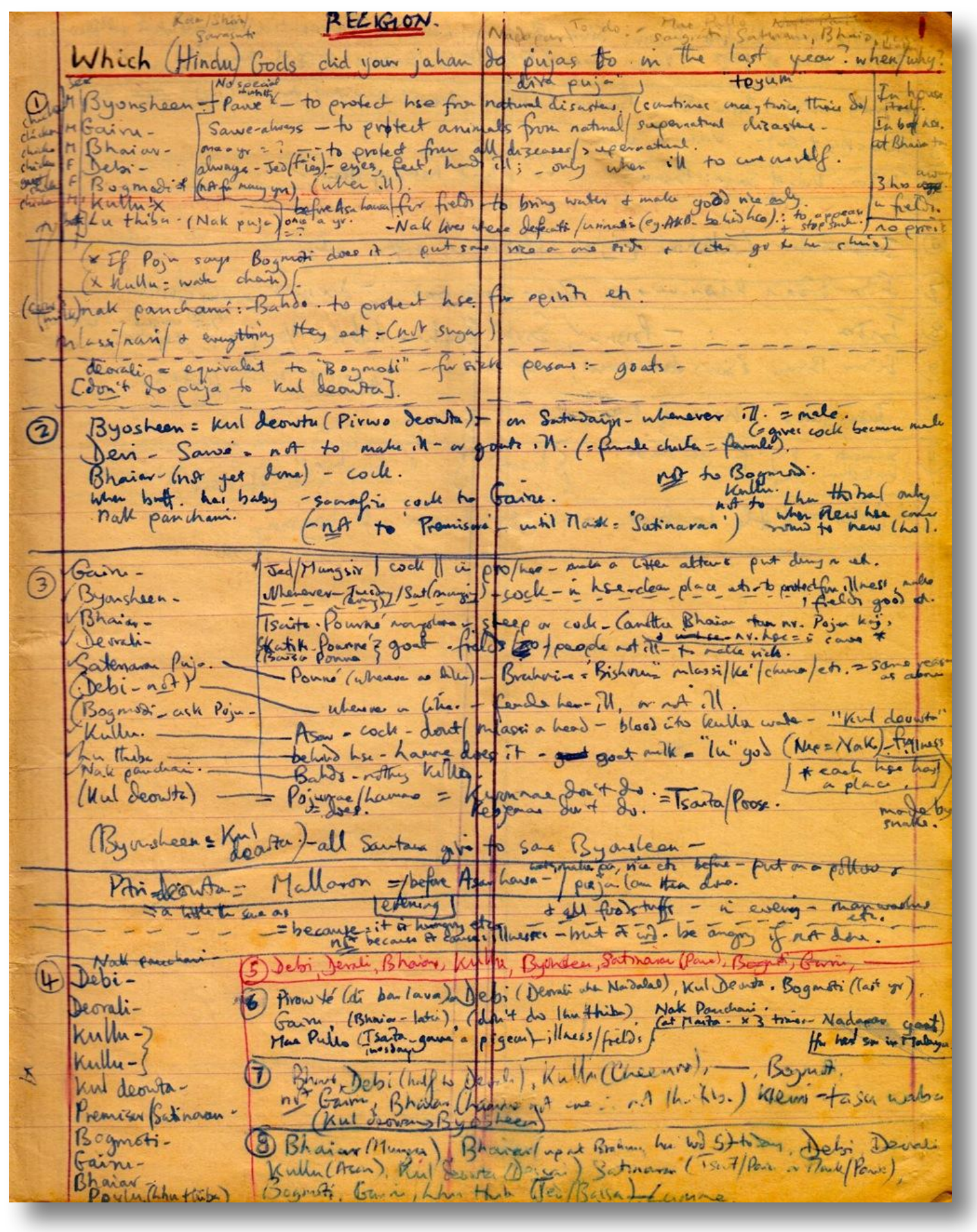

Part of the answers to the answers to the questionnaire on religion

DIARY Monday 8th September

An awful night with thunder and lightning (within 300 yards), and torrential rain (a little dripping through), fleas in profusion, rats gnawing the maize, etc. Hardly slept and late up. Went down to Brikaras who was bad again - but woke up when I gave him some 'Craven A' and asked him re religion. A whole party of "religious" came down and I watched him 
reading loudly to them in Nepali. They seemed fairly absorbed for Gurungs. Prem came for an hour and translated family planning questionnaire - then I took some information and devices up to Pradhan Panch and enlisted his support. Seemed quite enthusiastic. Continuing with Durkheim. Felt a little more chirpy. Moved maize downstairs. Gill bad boils and blisters.

\section{DIARY Tuesday 9th September}

As usual nowadays, a mixture of sun and cloud, with the Himalayas showing through magnificently. A lot of people for medicine, as usual nowadays. Prasad came of his own free will! and we translated the essays of the school-children. Then typed up religion and worked out questionnaire. People just coming to end of weeding - cleaning up paths, etc. 
Comal (hee 17) What thengs are you most fuy 'Tighent, beari', Thieves' bhut/gret, untikes, masan, Thes thee but all people say they are dangerous. In the firest 'tigen' 'beari bite me. Sometimies bhat/poct, wntives, masan. make people XI. Therefor I am afaid I will sue these things.

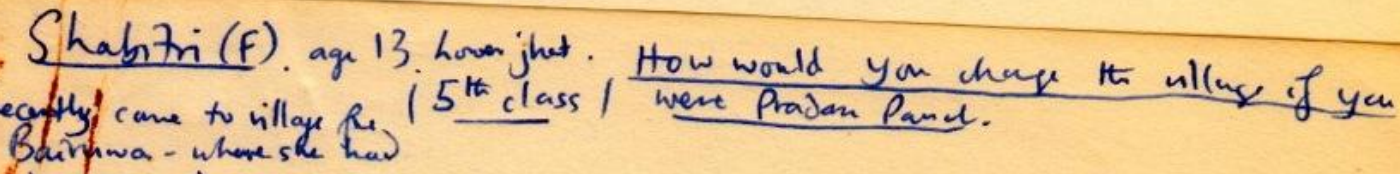

been 2 (m) .

Slowhy develope my village, firsth I will establist a hospoidol, a schul-house, brioges, roads, water-pipe, and soon is this way I will change my village. I womld gatter the villagus wer give thems goos advice. I would give everyme a job, if anyme

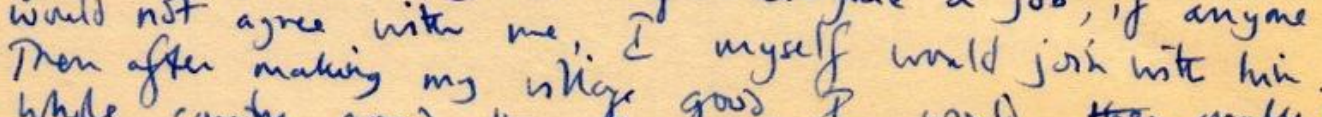

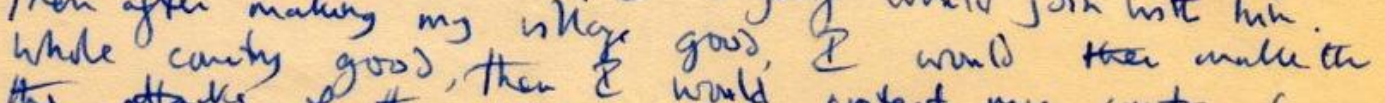
the attakle of the enemy. Would protect my comatry form

Kayks $\rightarrow$ : (wo.9: age 12-13). What thing one you

3. Man frostur of tiga, bear, thief, snake. My house is ini a very high place, wha I gu to herd goonts, butts, cows at ite forest 2 am very frighteras of aninide living. vithe farest. Bears who see people ent them ismetives

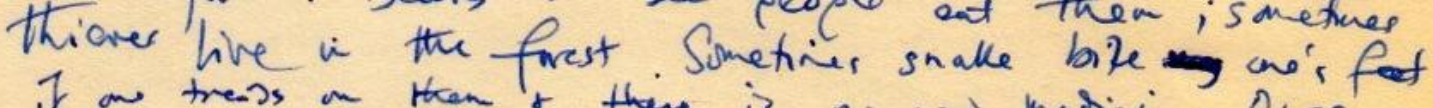
if or treess on Hean of then is no gool meticin. Once I wae coming to schorl from my kouse when I saw a. snake on the way, the snake sam ine a came to bite re, so I ran aray very fust. I therefore lok very coufully for snake.

Translation of three children's essays. 
Occasional rain, but glorious evening when we went up hill to read and write out religious questionnaire. Interesting to see enthusiastic discussion and reading of little booklet on family planning we gave out to Prem. Prem said he would come in the afternoon but failed to turn up, perhaps because tired out from fishing the day before. We indexed, read Pignede, sorted out our index cards on religion. Now getting up earlier, at 6.00am., and stopping work earlier, at the same time.

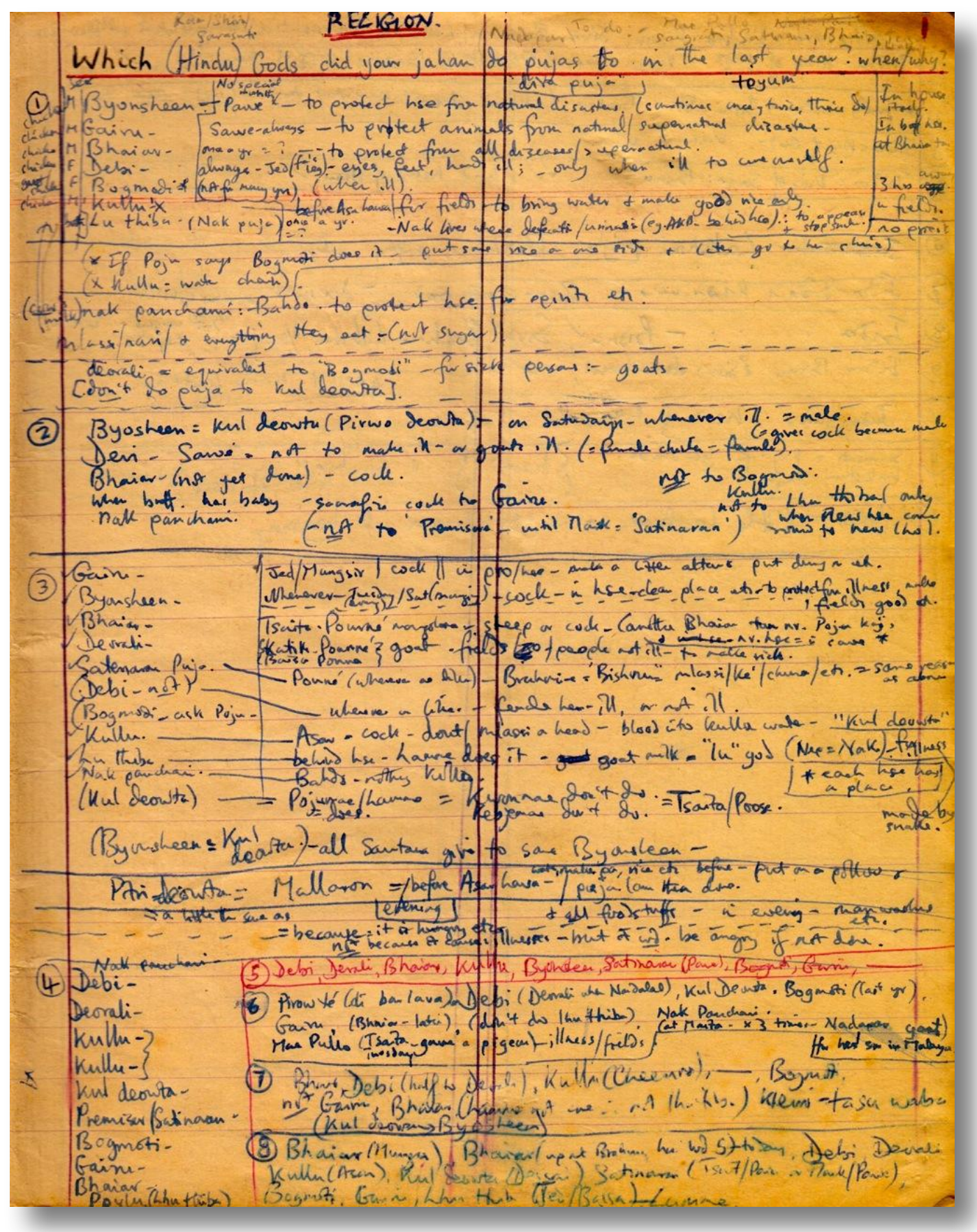

Part of the religion questionnaire 
Quite a successful day. Prasad came for a couple of hours early in morning and we gave him questionnaire for school and also started religious questionnaire with him. Then did Mrs Ramchandra's religious questionnaire and later in day did that of Pradhan Panch. Rest of day thinking about religion etc. Bright and beautiful with occasionally specks of rain.

\section{DIARY Friday 12th September}

Went down to Uli. Prasad's father a bit better. We did three hours on religious questionnaire. Gill, poor thing, indexed lands. After lunch started "Antigone". Gill dreaming a lot and not sleeping well. I also am dreaming a lot - half nightmares, unusual for me. Although things easy and language quite good (though masses of people in evening which is difficult) still counting the days. Masses of beans and eggs and cucumbers.

\section{DIARY Saturday 13th September}

Got up at about 6.00am. Prem came at 9.00am. and we did three hours on religion. After lunch did Servajid - same. Then went for a walk along towards Taprang and read some more "Antigone". We are both a bit tired, it seems, and look forward to a break going to Taprang tomorrow.

\section{DIARY Sunday 14th September}

Poured nearly all day - disappointing as we had wanted to go to Taprang. Instead had an easy day - went to watch Poju divining an old man's illness, then slept. After lunch did a couple of religious questionnaires. Read a good chunk of Durkheim. Very homesick. Had 'pa' with the Bhuwansing's who wanted to borrow 200rs.

\section{DIARY Monday 15th September}

A pleasant day - drizzly at first but beautiful from lunch on. In morning we put the 'mokhai' out on the 'mokhai suli' - still bending in our house at the places we used to bend at! Then went to Taprang to watch the 'jaatra'. A sort of bazaar/fair with little stalls of simple toys, bangles, cooking pots, rat-traps, balloons, etc. and tea houses. Some dancing - both male and female, and Tailor band. Festival atmosphere and also gambling, etc. Everyone in their best majority were non-Gurung. Came back collecting wild flowers on the way - masses of them now. 


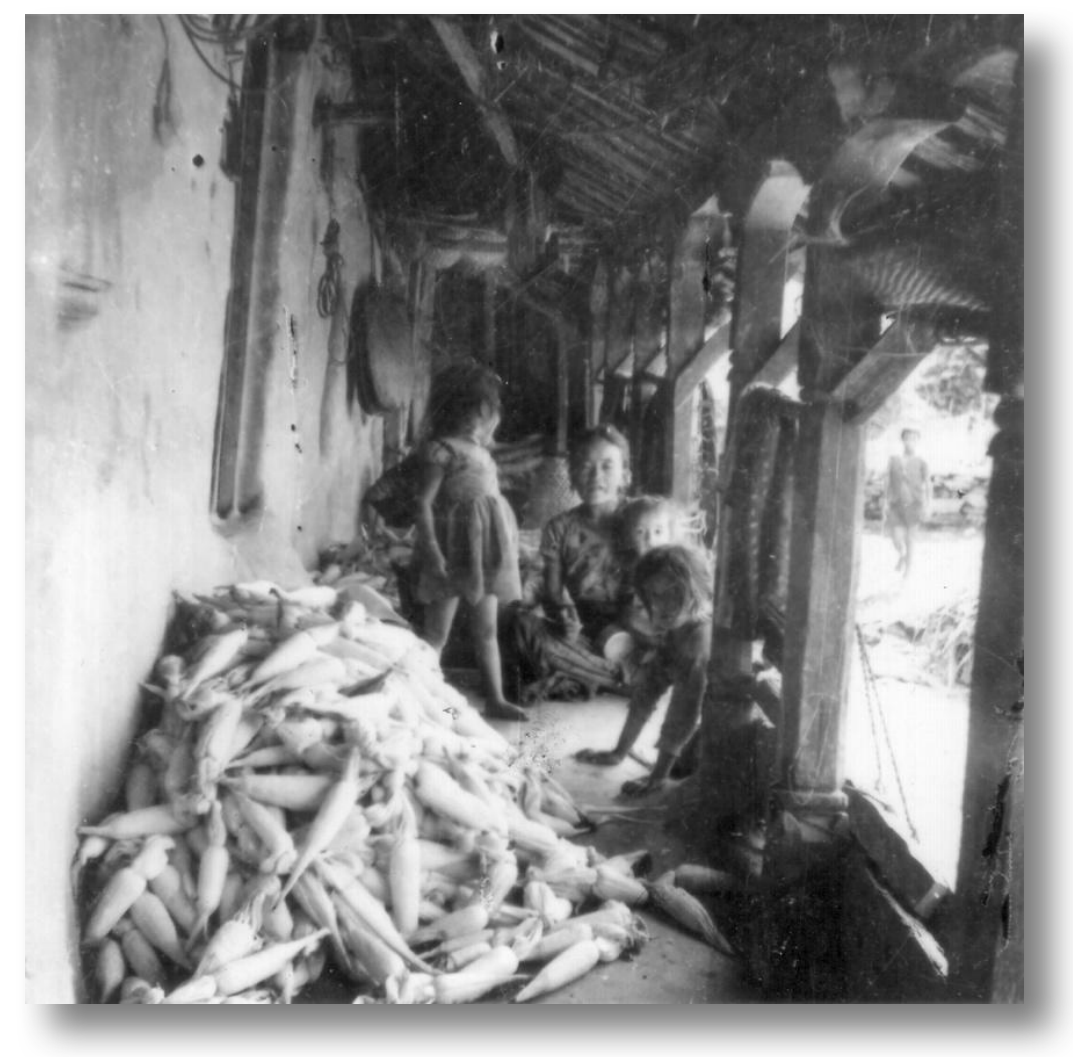

Verandah in front of our house, piled with maize

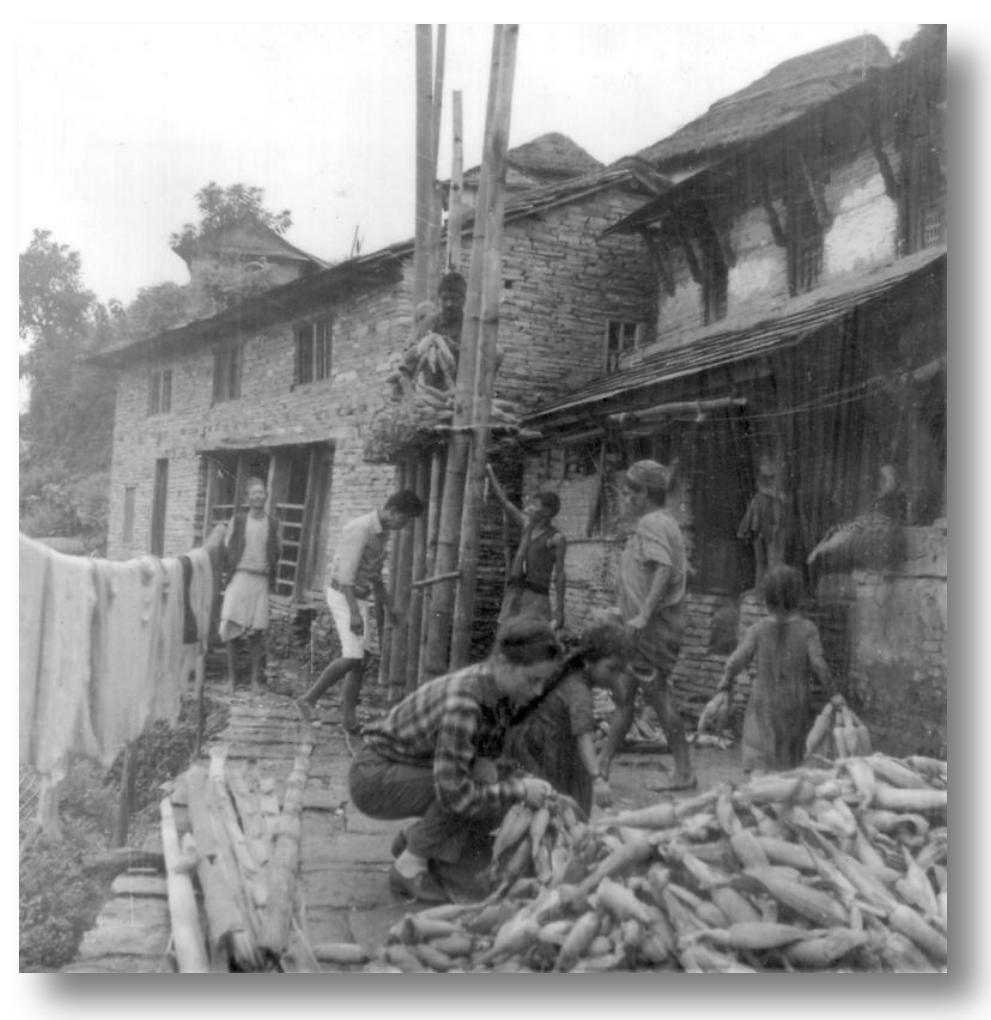

Putting maize out onto the 'mokhai suli' in front of our house 


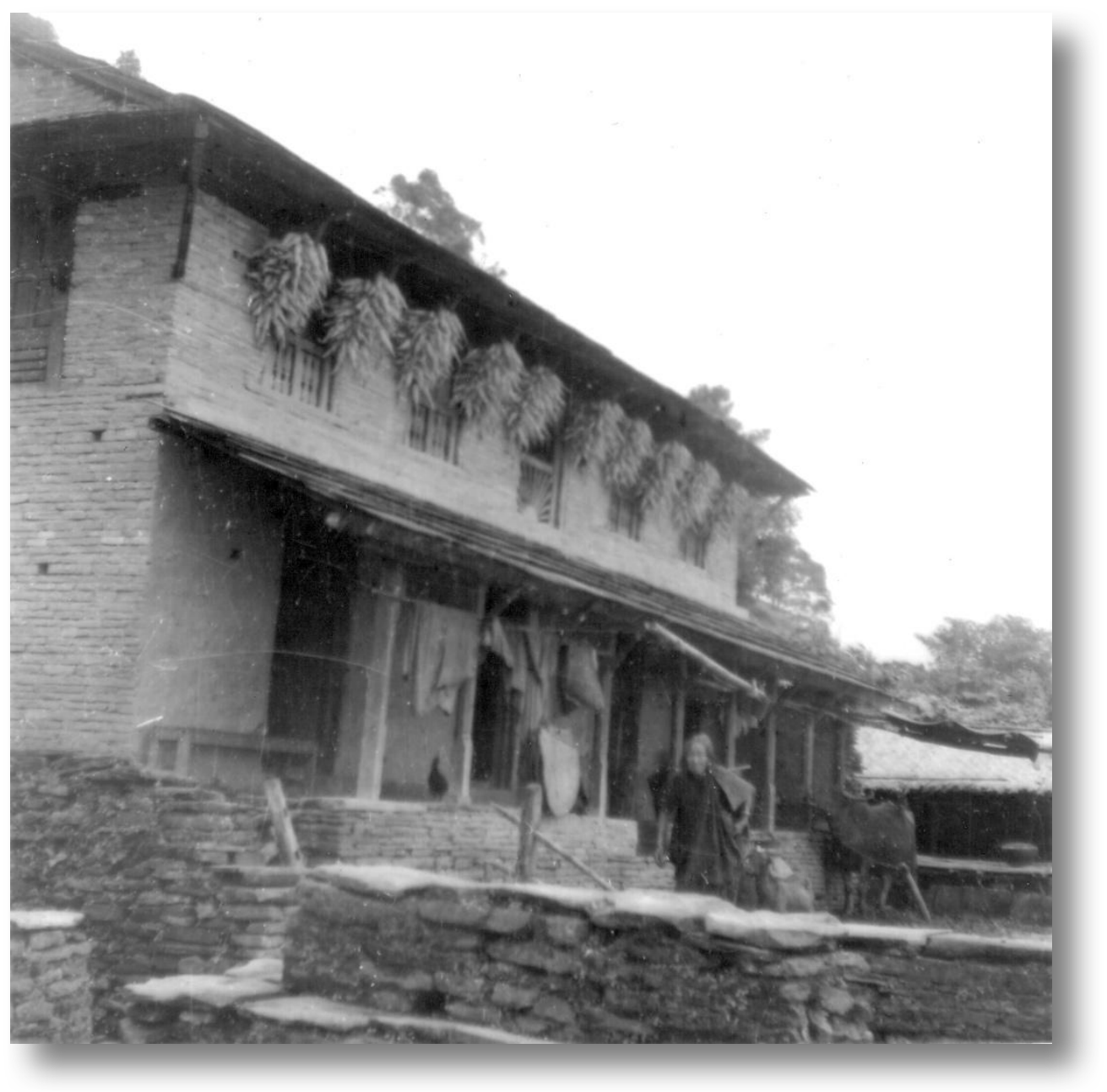

Maize hanging to dry at Lt. Bhuwansing's house

DIARY Tuesday 16th September

Gill slept very badly and woke me a lot - today the Poju came and we did about three and a half hours together - some really fascinating stuff on rites and myths. Fabulous. Finished Durkheim. Getting dark very early now. Started Middleton, "Lugbara Religion". Ramu and co. off to their 'maita'.

\section{DIARY Wednesday 17th September}

Prasad came at 7 o'clock and we did a couple of hours translating the school questionnaire: interesting. Also did one man's religious questionnaire - Posbir. (He was slightly slow in answering and was treated with some intolerance - as rather stupid - by children and Comal present). Finished "Antigone". Analysed religious notes somewhat: difficult to reduce this to order. 
Trame: Kamal

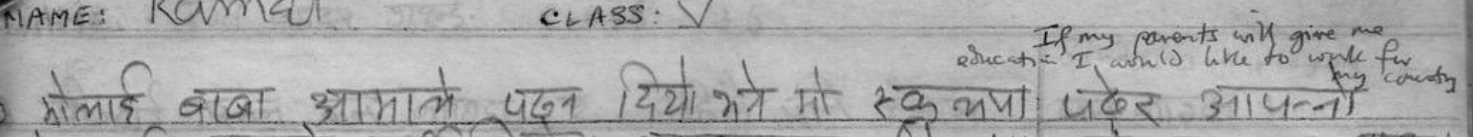
देसलाई उड्यालो पार्मी थियो त्यसकारारा मी चरै जसी पढन मा लाग्टा

2 यती तोलाई 90 रु पायो भने यो पैसा साची इस्टने यियो ? कापी कमय सबने बेलमा तो पेसाले किन्ने भिया।

3

मो बाग बाल देखी सारे दाउदा Tigens/Beas

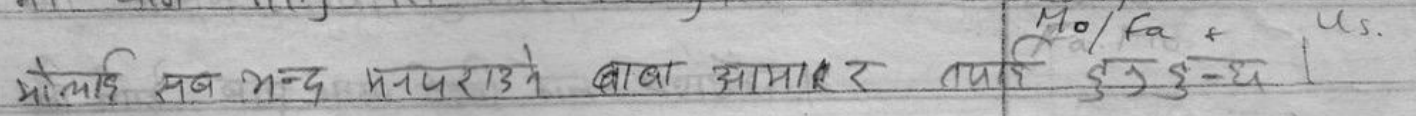

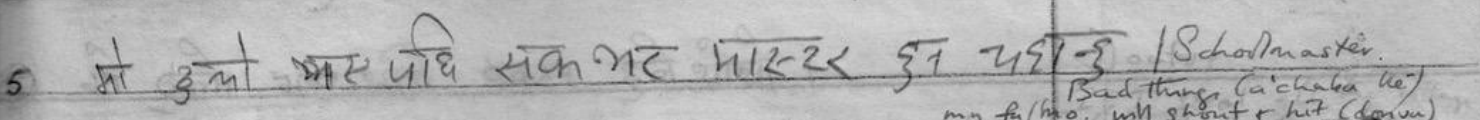

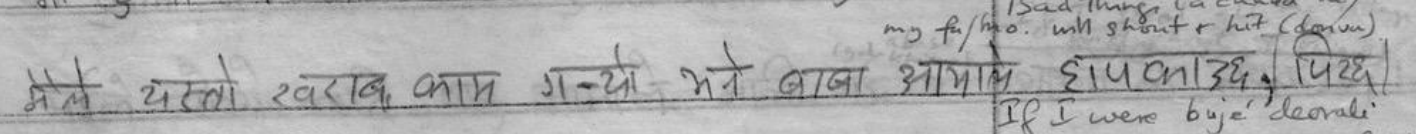
I would like tomuke thinss earry far aw 7. तो दुजे देडायी मो $x$ ए मैले को गाउलाई दरवी सुलीस्त गराउ था 8. पो गा $र$ फोदोर उद देखी सारे घिनाउह ।

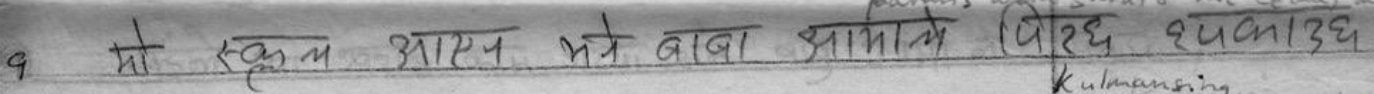

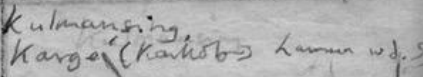
10 मैले गाउको सब भन्द क यमानसिद पर केखके मनपराओ

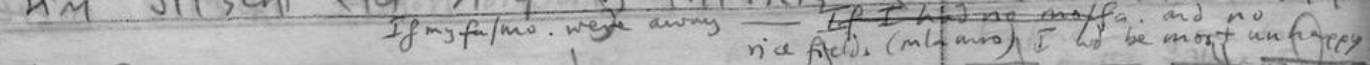

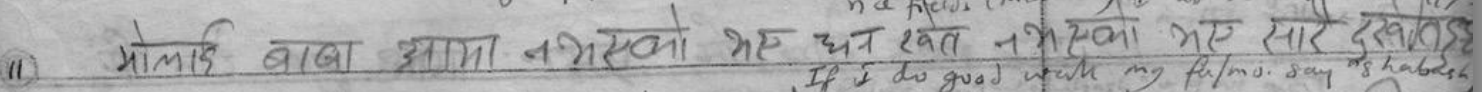
12. मर्षले सोरे काम गरेकी चिदो वाब आमाले स्थाबस दिए। 13 मेरो बाबा आया निएकी यए मोलाई घरकी जका-म्ले पार्या)

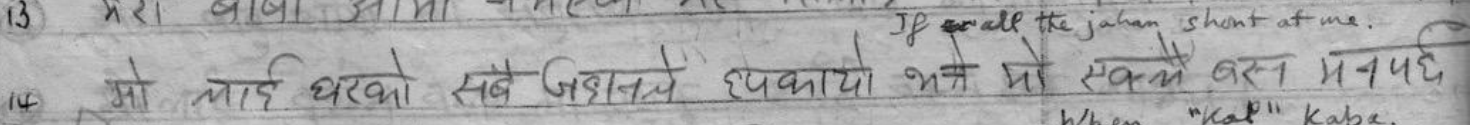
गे When "kat" kaba. 15. मानीस आपनो कात्ते मर्धन। 16. मानिस मो-्यो भने घरको सबै जना दुखीत हुन्थ। 
Response to School Questionaire: questions asked. by Prasad, headmaster, at the school on

1. What do you like doing most?

CLASS V; Studying and washing my clothes and body.(Palman). If my parents will give me money I would like to work for my country.(Comul). Studying and playing.(DurgaB.)

Studying.(Sabirtri). Studying.(Kesari). Going to school daily. (KharkaB.)

CLASS IVe Studying(Kulmansing). I like studyung and I dont like playing.(\%urkaKu,ari) Studying. (Himakumari). Studying(Rupakumari). Stadying(Kalpana). Like studying a lot, and phay ingia lititilor to (Hom.).

CLASS III:Studying(Kalpana). Like studying a lot and playing a lit le also(HomB.). Stud ing (Beta).

2.If you were given icrupees, what would you do with it?

CLASS V:I would save it and then take it to the jhatra(Local festival/fair then taking CLASS V:I would save it and then take it to the jhatra ( place at a neighbouring village). (Palman). I woula. paper when needed (Comul).Buy a dici).Books, paper, pencils (KargaB.)

I would buy paper and pencils (Kesari). Books, paper, pencils (Karga. paper(Himakumari). Frock and paper and pencils(FupaKumari).

CLASS III. Save it(Kalpana). Shoes, socks, paper, pens(HomB.). Socks and shoes(Beta).

3. What are you most frightened of?

3. What are you most fan. (Palman).Tigers and bears(Comul). Masan because they eat people. CLASS V:To see a masan. (Palman).Tigers and bears (Comul).

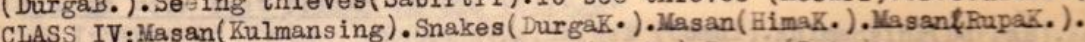

CLASS III:Tosee a thief(Kalpana). Masan(HomB.).Bears(Beta).

4. Who is the person you like most? and us.
CLASS $\nabla_{1}$ the goramae(us). (Palman). Mother and father/(Comul). Father and mother(DurgaB.). Wother (father is dead). Sabitri). Wother (father abroad)Kesari). The King because he is the father of all (Khargab.).

CLASS IV: Comal. ( $K_{n}$ lmansing). Bhaikumari (DurgaK.). The Queen( $\left.H_{1} \operatorname{maK}.\right)$. Nother and father and the king and queen. (Fupak.).

CLASS III:Himakumari (Kalpana). Belbehadur(child at Panigat)(HoaB.). I like sil my friends (Bets).

5. What would you like to be/to do when you grow up?

CLASS V: to be a pilot(Palman). Schoolmaster. (Comul). to be a doctor(Duricab.). To be a Coctr(Kesari). To become a Ninister (KhargaB.).

doctor(Sabtri). To be a doctr(Kesari). to be a doctor(DurgaK.). to be a schoolmaster CLASS IV:To be Prime Minister (Kulmansing) to be a doctor.

(HimaK'). When I become olde I would like to study(

5. What is thw worst/most naughty thing you could do, and if you did do something bad what would happen?

CLASSV:To be a thief when the king would arrest me.(Palman). If I did bad things my father and mother would shout and hit me(donva).(Comul). If I steal all the villagewould shout and mother and curse me(DurgaB.). If I lie theut and abuse me.(Sabitri). If I stole some money my and notpaying, then people would shout and auld be taken to goal (KhargaB"). mother would shout(Kesari). If I stole I would be taken to goal(Khargab (Kulmansing). If I CLASS IV: If I did bad things my mother and father would hit meldonva). (Kulmansing ). steal something my parents would beat me and the government put me in gother and father If I killed someone I would be taken to goal (Himak.) in goal (RupaK.).

will hit me.If I kill someone the king would put me in goal( Rupak.). (Kalpana). If I lie

CLASS III:If I study well my parents would tell me to go on studyi

no one likes me(HomB.). If I did bad work I would go to goal Beta).

Summary of part of the school questionnaire answers

DIARY Thursday 18th September

Off to bad start as Prasad had sore throat and could not come, but instead Poju came for over 4 hours and we went through various rites and 4 myths - again fascinating. Read some more Middleton and worked on religion. After lunch heavy rain and cloud so Gill was pinned in 
the house. River still fairly high and leeches abundant. Much quieter without Rupa and Ramu here. Time passing quicker.

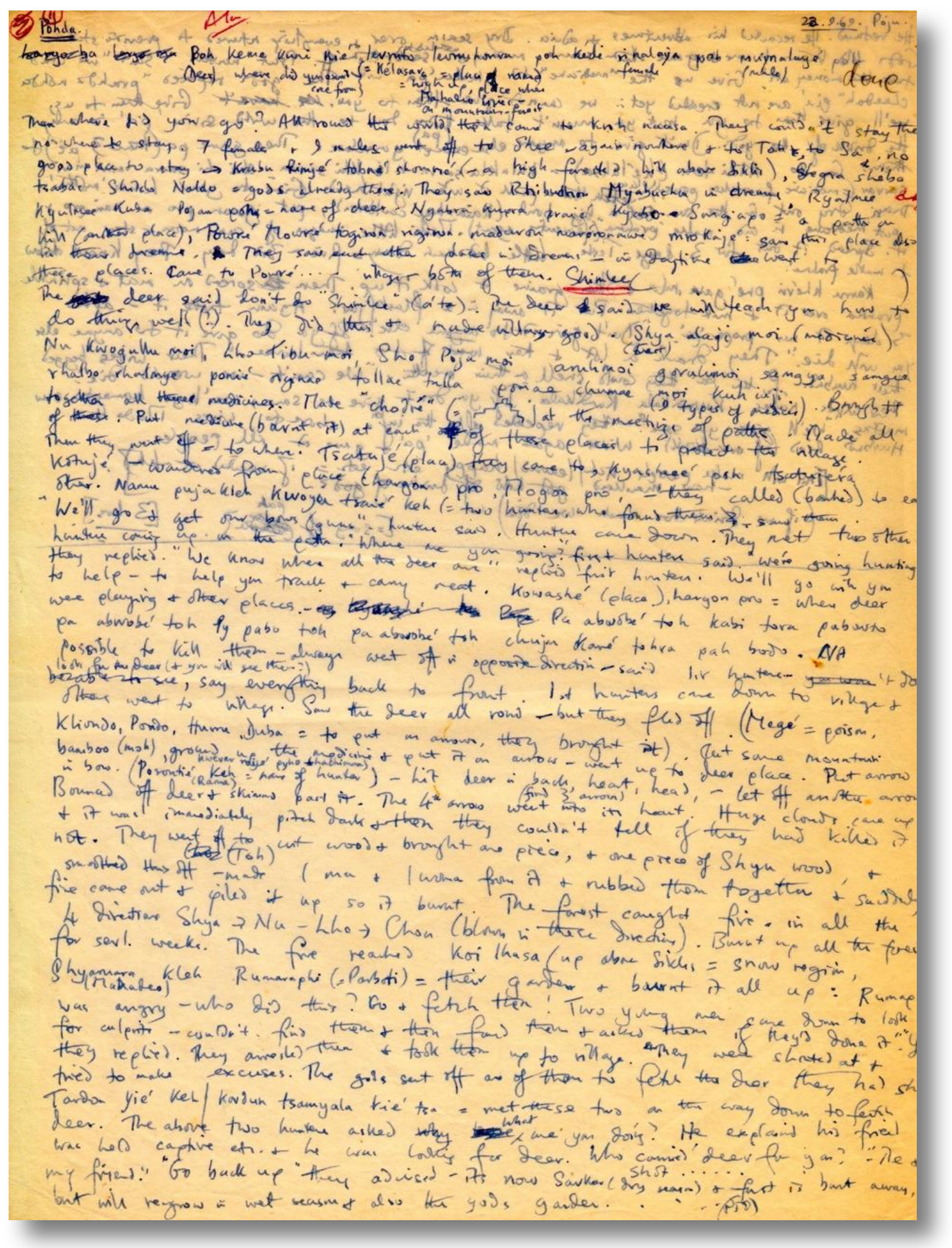

Transcript of part of one Gurung myth 
DIARY Friday 19th September

Flood of beans, cucumbers and eggs as usual, and the usual moral difficulties over the distribution of bottles/tins, etc. with Servajid playing wronged innocence, etc. Poju came for another three magnificent hours and gave me two long rites. Felt sleepy most of the day. Weather very bad with heavy rain until about $3.00 \mathrm{pm}$. When will the monsoon stop? Wrote letter to Mummy as hope to be busy next week. Hardly popped out of door all day and Prasad did not come.

\section{DIARY Saturday 20th September}

Weather bad - rained nearly the whole day and swirling mists. Prasad came for two and a half hours in the morning and we finished off the school questionnaire and his religion questionnaire, and also did the latter for Guru aba - unable to get out all day. Read Mary Douglas on "Myth" and Levi-Strauss on same.

\section{DIARY Sunday 21st September}

Again lousy day - with solid rain and cloud and cold. Poju came for several hours and we continued with work. Feeling very cooped up and unable to wash clothes or hair. A lot of people down with 3-day 'flu that Gill had. The loft beginning to be snowed under with papers. We both seem to need a lot of sleep nowadays.

\section{DIARY Monday 22nd September}

Trying to write this against the background of a woman who is in the loft showing me her sore breast and demanding medicine. Up to now a good day - the poju here for 4 hours - the weather superb in evening with tremendous views. Gill, a quiet day writing to her mother, washing, etc. Started reading Goethe "Selected Writings" - enjoyable.

\section{Letter from Alan on 22nd September 1969}

...We've finished diet/landholding/property inventories, debts and loans and other economic enquiries and halfway through kinship and social groupings. The main thing now is religion and "mental structures" - testing 'concept of limited good', 'culture of poverty' etc. Have elicited the names of 23 witches, now indexed etc. and land reform records also. "They" refuses to let us see the detailed map of the village fields I mentioned - It apparently needs an injunction from the Supreme Court to open the seals and Upraity thought it would take several years to get this...

\section{Letter from Gill on 22nd September 1969}

Am having to type lightly as Alan has got our local priest cum magician in the loft at the moment, being taught all kinds of esoteric rites, against infertility, fire, and witches, to name but a few, so feel I am impairing their concentration, but there is nowhere else to type! Alan is hoping to go to Pokhara this Friday to get some more supplies in, we are running short of sugar and potatoes, as well as get letters and post them. If it does not rain overnight he will be able to go by the short river route, as the rivers drop very quickly even when raining a lot in the week before, as it has been doing here. In fact, as Alan says, there has been more rain and miserable weather since the monsoon officially stopped than when it was on!

...I shall enclose the carbon copy of the letter which went astray, I think it must have been the one written on 3rd Fuly - a bit out of date I know, but I thought you would like to see how much we appreciated the food 
parcels. Of course, there is no need to send another parcel off now as it would arrive too late, and also our stores are lasting amazingly well...

...We have been concentrating on the religion, which presents chaos at first, and second glance at their beliefs are an amalgam of Hindu beliefs from India, Buddhist from Tibet and pre-Tibetan Buddhist, a crude sort of magic cum nature worship which was rife in the C7 before Buddhism came to Tibet from India. The difficulty consists in getting behind these labels to see what the people really believe in the feeling sense. We tried to do this by getting together a questionnaire of nearly 50 questions.

We asked a selection of people from old women to young boys and the main result was the incredible flexibility of these people, answers ranging from the gods and witches making people ill to unboiled water, and nothing happens to people after they are dead except the destruction of the body to the spirit becoming an evil ghost which makes people feel ill by haunting the village. The gods seem merely to be localized, there are five main ones in the village each with their little shrine, mostly to control the weather to whom constant blood sacrifices are made, as people believe they are ill because the gods are hungry and want a chicken's blood. There is little sense of expiation and even less of guilt, sin and sickness being interrelated, as in the case of Josselin's C17 England or with African primitive tribes which have an almost Old Testament system of gods and punishment from one god for man's sins. Here it is certainly not monotheistic and I have the feeling that ghosts and witches have more reality for the people than the more distant, vaguely formed gods - their imagination and fear seems to be able to encompass the two former phenomena as both are, or have been, human, whereas the concept of a god is much more of an intellectual process.

The most difficult aspect of trying to think and feel as these people do is not to take connections for granted and as the entire work is in fact one of making connections, two conflicting processes have to go on at the same time. I am thinking of pain and sin, which Alan has been interested in since his witchcraft book, as the most important find there was that people felt they were made sick by witches because they had sinned against them. Also such things as marital happiness as being the basis for a happy life generally - I think the intimacy that we expect from marriage is not an ideal here, and therefore we should not draw automatic conclusions from a lot of the men being away in the army for most of their life, and leaving the women and children back in the village. Also it is hard to realize the full impact of the judgement of the group, a child's contemporaries very much bring him up, I think, and the fear people have of doing anything out of the way because of one's family's and neighbours comments - it is such a tight knit community, about 20 times more so than an out of the way C20 English village - witchcraft still being extant is proof of this I think.

I have tried to get into the child's world to some extent by devising another set of questions, which the schoolmaster gave them in Nepali, as this is the language they use at school, and then translating them back to us in Gurung. I really want to do some analysis on psychoanalytic lines, such as their relationship to their parents, punishments, relationship to peers, basic fears etc. I haven't finished thinking about the answers yet but so far fears seem to be evenly distributed between bears, and 'masan', a ghost who haunts the river where bodies have been cremated, and out of thirteen children only one would seem to be deeply insecure in that he feels no one would look after him is his father died, and all his answers were negative and desolate. This fitted in with our original impression of the boy who is a sad little shrimp, with an equally pathetic father who has been in the British Army. However, it is all intriguing as you can see, and gives rise to endless speculation between Alan and myself, the main thing we want to do in a book or thesis is to convey these people as they seem to us, that is as unique and individual personalities, and not churn out the usual dreary 'village study' which is of interest to no one else except those others who have done other 'village studies!....

There is very little going on in the village at the moment, as they have just finished the rice and millet weeding, and the rice harvest won't take place until the beginning of November. Everywhere is brilliant green and last evening when we took a walk before supper, the first time in three days that the rain had stopped, this green against the indigo blue of the hills, saturated with wet, was beautiful. On top of this there was a gentle, peachy sunset with the pink running the whole expanse of the sky, right along the tops of the hills towards India and this was lovely too. The maize, which was drying from the beams of the house, has at last been stacked outside and we have the bamboo frame outside the window, about 8' deep in maize cobs, their tassels maroon with the wet dripping onto the courtyard below. 
On the day we helped them stack the maize we also took a break and went to a Brahmin fair in the next village along the valley, called Taprang. Everyone had been very excited about this for days beforehand, and there had been much discussion round the fire at night as to whether they would go 'up' or 'down' beyond Chachok, opposite Thak on the ridge to Pokhara. We went up, and after plodding right through the village, much more spread out than Thak, we found a whole mass of people on a grass flattened open space, crushing round some dancers, playing cards in the tea houses, or wandering from one little shop to another, all their wares spread on the ground, from rubber balls to glass bangles for the women, very gay and colourful and hot. Everyone wore their best sari and the colours were resplendent, like a mass of fluttering butterflies, the Brahmins out-topping all in their gorgeous scarlets and wine reds, put with the most brilliant emerald greens and oranges imaginable - but the combinations come off out here. The walk back was lovely, through dappled sunlit paths overhung with exotic plants, and I picked an armful of the most gorgeous wild flowers, mainly purple, pink and white. Sadly they don't last long in the loft, as the smoke comes up from the fire in the evening and kills them, but there are masses more. We will not be down in Pokhara for another month (26th October), so I'm afraid there is be a long gap between this letter and the next, but not to fret as we are both very well.

\section{DIARY Wednesday 24th September}

A brilliant blue day with Himalayas superb so we went washing after nearly three weeks. Everything clean. A lot of leeches and streams still high so we went up to our little side stream. Last night went up to poju's house to see rite which involved putting bowl of fire on sick woman's stomach

\section{DIARY Thursday 25th September}

Poju came for two hours and we finished off a very long myth. He was then called off to a sick man in Panighat so spent the rest of the day going through myths, preparing for Pokhara, etc. A fine day, though not so lovely as yesterday. The Comal saga goes on apace - all except Comal friendly. Surprising how paranoid one gets - expecting to be thrown out at any moment. 
D(1)

Wyth recited when anyone dies an unnatural death by falling over a cliff.It takes about an hour to tell. Ama toduma peebudé kyaman peendré kamon peejé kumon Ali tsadsa kyudong parmé palar myeh moi pie.

WAma T-mother. Peebadé kyama-nani, eldest daughter.Peendré Kamon-liaeili,next daughter, Peejé Kama-kadji, youngest daughter.

This family (no father,no son) had a house at Samodi Kelsa(Tibet).T ese 4 went off to the fields after breakfast, and on the path(da) they found a little boy-Ali tsadsa.Mother $t$ tells Nani to take little boy back to the house while they go to the fields, to give it food and to play with it.At about $3 \mathrm{pm}$. (lunchtime)the little boy becomes a giant,ragas. He kills llani,eats half of her and puts the other half of her flesh into a box. He then became a small boy again and started to cry. At night fall mother and daughters come back.'Where has Nani gone, the child is crying', they asked.Nani did not come.They called for her everywhere-they shouted from the roof and upstairs and an answer, 'whe, whe' comes from the box where the flesh is hidden. They unlock the box and find half of the body there, and cried,' What has happened to her?' That night they slept and woke up, and Mother and Kanji went off to the flelds, leaving loeli to look after the child. Child again became a giant and ate Moeli. He started crying again when he had become a child. In the evening mother and Kadji came from the fillds and heard the child crying. They shouted for Koeli and the same things happened as with Nani, and they foundher flesh in the box. The next day Ama goes of to the fields and leaves child with Kadji. She eats a lot of $\mathrm{keh}(\mathrm{rice})$, meebto(ash from the fire), lots of chicken feathers,part of kwedo robu -pant of a weaving loom She then went upstairs to find out about the flesh. The boy became a giant again and called for her. She said,' I'm upstairs, come up,'. Whble he was coming up she went through the floor at the other end and ran away. He rushed after her wanting to kill her on the path. She threw the keshi tro (pait of weaning equipent)

on the path behind her.The Ragas stopped to eat it and then ran after her.He shouted that he would kill her. She then threw the myabru poh(ash powder)into the air, it became a thivk cloud and she ran away. He followed her, still shouting. She threw feathers in to the air and it became a forest, she ran on and he,with some difficulty, followed. She threw all the bits of the kwedo sada.They became a huge forest of bamboos andshe ran on. She came to Ama Palar 1kyehre(cow). The cow asked why she was running. She said a Ragas was chasing her to kill her, and that it would eat her if it caught her up. She asked if she could go into the cow's stomach. The cow said yes, so she went in. Then the fragas came up and looked all round for her, to the north, the south, the east and the west.He could not find her so came back to the cow. He said,'I could not find her, have you got her in your stomach which is so large?' 'No, I've eaten and drunk a lot and have a baby inside', 'No, she is there,' said Ragas, 'No, she is 'nt,' 'I will eat you up,' gaid Ragas.The cow was Prightened,'I will give you Kanji at Lirdung Pro,'fthe, cleff is wi rend of the nillaxe) and Ragas went off first with the cow behind him.They come to the place,wich is the edige of a clief.Ragas is at the edge of the eliff with the cow behind him.She tells him to wait with his hands out and Kadji would come out of her bottom. She then kicked out with her hind legs and Ragas toppled over the cliff backwards and died. Kadji then came out of the cow's mouth and went back to her house.

Whenever they read this the Koh will be killed all over again.

Comments arising out of this: evil life-evil end? Not so with Gs, originally with Tibetans? ili-moh,prototype of those who meet an evil end. Battle of power between Ali/Kadj1Noh/po ju-Supernatural/Natural, Magic/Common sense, wits. Poju is able to be absorbed into the Sacred/cow and wit its help(plus other accoutrements,ash, rice,feathers which he has around him in the rites, meaning of these, elements, fire, air,earth, all transformable into something else, mutable, that is everything good/natural is at his disposal?) expel the evil. Note everything at the most basic oral/anal level and the whole is very much like a child's fantasy. (intake, output, eating, excreting, the whole and the pieces, destruction and construction). Joining of the poju/cow is very sacred, as he maes the cow pregnant, sacredness made powerful, the whole an ideally godd combination(sacred animal in calf). Note poju comes out by mouth as he went in, not transformed by sacred once he is outside it,as he would have been if the good had colluded with the bad and he would have come out as excrement into the giants/evil's hands. This would have been the supreme symbol of evil winning.

Note, absence of mle figures in myth on side of good- a feel that the world is already naturally enfeebled? Also evil is found in places most unexpected/natural-on the path to work. Ivil's method of destruetion-absorbs haf into himself and leaves ether half for people to discover if they will/can?

Typescript of one Gurung myth 


\section{Letter from Gill to Mac and Iris on 25th September 1969}

Have just had a Gurung woman in asking if she can use our keys to unlock one of her cases where all her best clothes are hidden away; she's lost her key. Sadly ours didn't fit, so she shall have to go off to Pokhara without wearing her best clothes - heaven knows where it will be in her house, midst the goats and chickens and rice baskets, we had trouble enough finding it in the loft! Alan is going to Pokhara tomorrow and we are looking forward to letters as usual...

...We will have been back from Pokhara three weeks tomorrow and have another month to go before we go to Kathmandu, and a bath. (Have just had another interruption, and Untouchable boy with an unmovable bit of lint stuck to his finger, could be wet it off? Also an Amazonian lady who must be a Brahmin, selling three eggs, to add to our 11 already bought this morning). The first few weeks passed very slowly, we are now daring to imagine what it will be like to be back home and this doesn't help the time here. The village has also been quiet, the work reduced to transporting dung heaps, debugging the family's heads and weaving in the sunlight outside, clicking the wooden sticks and washing the vegetation, which turns into a kind of tough linen [which] they get from the forest, in ashes (mostly from our fire which means Alan has to blow like fury every evening through our bamboo blower.) However the work is leaping ahead, Alan closeted with our doormouse of a poju in the loft for five houses a day. The poju sits unhappily on one of our stools, curled up with enthusiasm for the work, emitting excited little squeaks and hops every time he comes to a James Bond chase in one of the myths - the Goodies hurling feathers, and ash and rice at the Baddies, which turn fortunately into forests and snow storms and whirlwinds. I have made some carbons of these which I thought you would like to see...

We also managed to get a questionnaire completed for the schoolchildren, which also gets us nowhere but might turn into something fruitful put with other conclusions. The questions ranged from - What are you most frightened of? to What is the worst thing you could do and what would happen if you did it? and from What happens when you die? to If you had 10 rupees what would you spend it on? The idea behind all this was to get at basic feelings like fear, ambition, reaction to punishment, if punished and how and by whom, any conception of saving, ideas of pollution (what is the dirtiest thing you know) and reaction to death. The general impression was one of great security in the world as they know it, and this was heightened by one especially desolate paper written by a lad we had noticed previously as being very alone, with a disturbed family background. He was the only one to say he would do nothing when he grew up, the others saying they wanted to become an air pilot, a doctor, a schoolmaster etc., and that no one would look after him when and if his father died; he liked no one in the village in answer to Who is you best friend?, and that his father gave him nothing if he did anything good. I was trying to get at reward and punishment systems here. He never liked to be alone, when asked if he ever liked this and for what reason, and that "everyone cried" when someone is dead. The others had a mixture of rather outgoing, boisterous answers like, When people die they turn to earth, or they like to be alone when they feel angry, and their mother gives them a rupee for sweeping the house, and they liked their mother and father and us most of all! What ideally I would like to do is to have some sort of control and give the same list to a set of English children, preferably in a country school; I can't think of anyone who would do this for me, can you? In my next letter I will enclose a carbon of all questions and answers so that you can be having great thoughts about it at that end - I haven't finished getting them together yet.

We had one lovely day's break in the first fortnight when we went to a Brahmin fair in the next village down the valley: it had been pouring for days beforehand so it was good to get out at all. The maize had been stacked that morning which meant we could walk upright in the house again, and the millet was shooting up in the fields, the heads like green lavatory brushes, with dead brown stalks of maize in between. The butterflies had come out to dry as off well, small coffee brown ones with a yellow bar across the wing, and white and black gauzy ones that looked like lace amongst the lavender. The sun dappled the path into Taprang, a much more spread out village than ours with steep flagstone paths and exotic vegetation. The fair was at the far end on a square of trampled down grass, tea houses with men gambling on one side, and the stalls on the ground on the other. These sold everything impractical from bangles to rubber balls, and we bought pink and green combs for the girls next door, and a pink plastic Hindu goddess who squeaked if you pressed her in the right place, for the baby. The place was alive with Brahmin women who wear the most gorgeous colours imaginable - emerald 
green and wine reds, and scarlet and orange, which come off out here and makes one feel very drab, even with my new raspberry wine bangles which I had been bullied into buying by the women - no self-respecting married woman should be without them. The Gurung girls also had their best saris on, and fluttered among the stalls like butterflies themselves. I picked masses of wild flowers on the way back, pink and white and purple ones and though they dies quickly from the smoke in the loft, they did look lovely at the end of that day.

After this things went very quietly but we had one diversion the day before yesterday. It had been heavy and lowering all day and at night the storm broke, the lightning stabbed across the sky and the thunder rumbles. We picked our way across the puddles of the poju's courtyard and were just in time to see a saucepan of fire placed on a prostrate woman's stomach, lying flat on her back on a straw mat and grey blankets. The weather fitted in with the rite somehow, the woman had a sick stomach caused by a witch, unnamed, but the solemnity was broken up by the fact that the poju got the giggles in the middle of his intonations, and the old grandfather was sitting crouched on the bed with nothing on but a cap and loincloth and kept interrupting to tell his son what to do. The youngest child, Bopal aged five, also kept rolling off the bed and was in danger of landing on the sick woman's head, so grandpa had to fend him off and this kept him quiet for a bit. The next son, Buddy, was assisting his father at the rite, but had never done it before and kept having to be nudged violently to fling rice into the fire on the woman's stomach at the right time. He got the giggles too, and flung rice so heartily at the wrong time that he hit his mother instead of the saucepan, where by this time the fire was going out. Since the eldest son, Prem, who should have been keeping it alight was escorting a relation to Moja, another village, his place was taken by Maldosing, a goofy half-Gurung half-Magar, who pinches babies bottoms and gets roped in for all the dirty work in the village. He wandered off in the rain to pee, and then had a leisurely cigarette leaning against my ankles, so by this time the fire was quite dead and had to be revived by dripping kerosene and next by half a bowl of oil, so that the poor woman, who should have been quite dead by this time from suffocation with the smoke had to shield her face from the heat. The poju had recovered by now and was at the stage of telling the beads of his brown nut rosary, in between passing more sticks with kerosene and enamel plates to fan the flames which kept disappearing as Maldo forgot to put more wood on. The saucepan kept slipping too, poised on a chicken board, and only Alan, interfering as a bad and involved anthropologist, kept it from tumbling all over the woman's legs and setting her and the entire place alight. As solemnly as we could, we asked if the woman was feeling better, the poju's wife leant solicitously towards the flames and heaving cooking pot, rising and falling with each gasp and breath of the woman, and got a faint answer, that, yes, it was feeling better. It would either have been that or death by immolation and suffocation. We later learnt that the present head of the village, 19 years a Serjeant in the British Army, had had the rite done to him too; as he has an overhanging pot belly, the thought was even more hilarious and fraught with danger than the above.

I have been reading a lot as usual, and am particularly thrilled by Evans-Pritchard's book on 'Nuer Religion', the only book on anthropology I have read yet which gives an immediate and profound picture of the native's world and mental life. It is most scholarly and sensitive too, with fascinating material, very akin to C17 Fosselin as the religion has this one God the Father, who causes people to be sick for some sin they have committed against Him, and this can be only expiated by blood sacrifice, man being substituted by animal. Their whole world is suffused with this conception of the spirit, as satisfying a monotheistic religion as the Old Testament. What makes it especially pointed at the moment is that the Gurungs are completely different and provide the perfect contrast, their religion I think being essentially human being orientated, the spirits they most fear being those of humans most recently dead and the village gods having a very thin time of it, not being strongly felt or realized at all. Why of course, is the problem. I think the main achievement of E-P's book is the fact that he aims to give the impressions of the people, and not his impressions on the Nuer-the anthropologist in the right place for once. He says constantly: if we wish to seize the essential nature of what we are enquiring into we have to try and examine the matter from the inside also to see it as the Nuer see it...(p.122). 
Q) Questinen adring out of the Muer Ch.l.

God

Conception of God-enation of all thing.'

Respensitile for dects bir? mans position in life?

How was canth created? made?

Man's relationship is Gad-father/fen?

Gencelogy commetion?-Gad = wtimate ancestor.

Is keling / truest in Gol taher for grounted?

Any ansivalence of feching towads God ("common to all theisic veligion?) Ary comuction betreen hearen scarth (repu mytz (pio) of Pśladden) Ary comp asuines belween man/Ged. - avaritide la sufferiz vefleds attitude to Ged. (p/2). Co (Nuer say that the stomace praye is Goce independently of his luat). It is supe not 6 have boo numes qoed abalsture. Woent offene is to paise

Gill's notes on 'The Nuer' by Evans-Pritchard

297 


\section{DIARY Friday 26th September}

Rained heavily the night before - depressing as I hoped to go to Pokhara today. Managed to go all the same accompanied by "Goof" - had to go the up-and-down route via Kapre village and the river high but on the plain spread out and never above my knees. Rice, scarlet dragon-flies and yellow butterflies beautiful. Picked up 16 letters and a parcel of clothes (customs 81 rs. and took since April by air- mail). Journey back - or the last bit at least - a bit of a nightmare. Bought most of the stores.

\section{Letter from Alan to parents on 26th September 1969}

The monsoons, the Gurungs tell us, are not 'over' and fine weather beginning. As with all Gurung statements this needs some adjusting - in this case to the fact that it has been raining heavily all day and the village blanketed in mist. In face the weather seems to have got worse over the last week, thought we are occasionally beginning to get glimpses of the Himalayas through the clouds. I also hope to carry this down to Pokhara myself by the river path which is, apparently, not blocked unless there has been heavy rain the night before. So things are slowly clearing. But leeches still abound and the paths are squelchy. The weeding of rice and millet has just ended and people are doing their last chores before a 6 week period of no work and rest putting the maize out onto a high bamboo frame where it is stored. These maize frames were one of the first things to attract our attention when we arrived and it is cheering to see them up again and to know that the year has almost come full circle again. Another sign of this is that the time for spinning and weaving on the porches (by old women) is here again - always accompanied by interminable gossip sessions. It will be towards the end of October when the rice, which is already quite high, will be reaped.

....Not much news really, and what there is Gill will give you. Work, however, is going well again. The schoolmaster comes occasionally and we have 13 essays and 13 questionnaires from the school-children to analyse (as well as pictures). Gill will tell you about this. She is also working very hard adding up figures of land-ownership and putting them on punch cards - very soporific work. Meanwhile I'm trying to sort out the incredible chaos of Gurung religion. The groundwork for this has already partly been provided by Pignede - but we hope to fill out, modify and interpret his description. Apart from observing various rituals we are doing this in two principal ways. Firstly, I've got a longish list of questions which I'm asking a dozen people - things like "Which gods do you worship? What happens to a person after death? Are people punished for misdeeds in this life? What makes a person ill? Which dead ancestors did you sacrifice to this year?" etc. The answers to all this shows the Gurungs usual flexibility and vagueness. Some say a person merely becomes dust, others say he is reincarnated, others that he becomes a vaguely malicious spirit, others that he goes to heaven. On some things they do agree, however - for instance that it is witches that prevent buffaloes from giving milk, or that one is not punished/does not suffer in any way in this life, if one commits an offence.

Their idea of sins or virtues are similarly vague. In fact I don't think they really have the idea of moral 'sin' at all. Probably their vagueness is due to the fact that they do not hold a fixed code or intellectual system in their minds - actions are judged in their particular context. One could, if one wanted, see their religious world in many aspects as a 'reflection' of their social world. Fust as the past lineage is not important in everyday life, so 'ancestors' are not important in the religious life and only a very limited range of kin are thought of as occasionally afflicting a living Gurung - his dead father, mother, brother, son, daughter. Women/men/children have equal power as ancestors, just as there is great equality between sexes and ages in everyday life. Likewise, the lack of status and hierarchy in social life fits with the fact the gods are not ranked - there is no 'supreme God' and then various levels. They are all 'equal' we are told.

There are a maze of good gods. There are five principal village gods - to whom the village sacrifices communally at fixed points in the year. They control the weather, crops, epidemics etc. Although they mostly stem from Hindu gods they have become Gurungised - now called 'Buje' or grandmother. Some informants even visualized them as not wandering beyond the village. They are offered blood sacrifices. Then each household holds up to a dozen private rites per year. To dead close relatives down by a stone in the fields (which I think we described), to long-dead collective kin - on a pillow by the hearth, to a snake god who lives near the place the 
family use as a toilet, to the rice water-channel god before work begins, to the god of the household etc. Some are given blood-offerings, others just rice, rice-beer etc. As a counterpart to these godlings are an even greater number of evil spirits from witches downwards - I have a list in one of the myths which names some 30 or so types of evil spirits. While godlings may cause illness and death, it is principally the evil spirits who do it. They are kept in control by the 'poju' or priest.

The village poju has been here for days during the last week and is going to teach me all his skills. He has shown me how he divines by the age etc. of a sick person, by his pulse beat etc. Once he has diagnosed that an illness is supernatural he decides whether it is caused by a witch, the spirit of a man who died an evil death, a dead ancestor, a bhut/pret, and angry godling, or the fact that a person is in an unlucky astrological position. We watched him the other morning drawing little diagrams in the dust and consulting his magical books to see why a certain old man was ill - he decided that it was an evil spirit and held one of his healing rituals in the evening. He has a repertoire of some 40 or so of these 'teh' or healing rituals and they last for between a half and 12 hours. The general aim is to call down the evil spirit and expel it, or call down luck, fertility (in the case of a sterile woman) or whatever is desired. They are often fantastically complicated.

That for a sterile woman, for example, starts with the construction of some twenty or so little figures, moulded out of rice and millet. Nine of these are placed in a basket, on top of them a dog's skull with a piece of wood from a bridge through its ear. A basket of bird feathers and various other paraphernalia are placed round. Then the poju begins to chant a series of 'pie' (or myths). Each rite has a number of them, each lasting from 10 minutes to 3 hours in length and there are over 50 in all, used in various combinations in the rites. Am writing them out and enclose a copy of one of them - plus and analysis by Gill of $i$. Then the poju protects himself against evil and consecrates his bead necklace, drum etc. over some burning herbs. Ash is sprinkled in the doorway, the light put out and the door closed. Meanwhile the woman wanting a child has had a large basket put over her head and water has been boiled up. The poju splashes her with boiling water and very hot millet flour for about 10 minutes, in the dark, while she squeaks and tries to escape.

An assistant had, meanwhile, overturned the basket with the dog's head, thus catching the spirit of fertility. This animates the little figures inside the basket which are said to hop up and down. When the light is put on the poju throws some pebbles from the river (where people are cremated) at the basket and then at the sterile woman. Then they examine the ash at the door to see what has come in during the darkness - ant, dog, human or whatever. A goat is killed over a wooden plough (later stuck in the doorway) and the poju grasps the goat in his teeth and waves it over the woman. Then then process, drumming and shouting, beacons flaring (the whole rite is done at night) to a nearby hill where, after further reciting, a lighted arrow is fired and also a gun. They then return for a meal. These are just the main features. How one interprets all this I don't yet know, but when we have read something on Tibetan ritual and myths I expect things will be clearer. Anyhow it is a nice change from listing rice fields and working out kinship terminology and makes one feel that at last one is attempting to probe into another 'world view'.

...We have done the usual field-work jobs - census, a few genealogies (the people are very forgetful and hardly interested above the generation of their parents)...

... The whole society is based on army service in either the British or Indian armies. Nearly all the adult males are absent most of the time and there are no economic surpluses produced in the village - the money for buying things in the local market all comes from pensions and army pay. The whole system is threatened by a) cutting down of army recruiting; b) growing over-population; c) deforestation. Tet the people, despite a huge belief in witches, evil spirits etc. are apparently very happy. The language if comparatively easy and though we still find it difficult to follow conversations, even after 10 months, we can work without an interpreter...

\section{DIARY Saturday 27th September}

Grey and cold. Cloud all day with drizzle and rain in the afternoon - when will the monsoon end? Spent a gentle day recovering from Pokhara journey - re-read letters, planned when we would have a baby (in view of the fact we would be chronically short of money - the book not coming out till 1979). Decided that Gill would take off 9 months per baby and we would hire a baby-sitter, house-cleaner for mornings when Gill went to work again. Poju came for four 
and a half hours and had to break news to him and Prem about upper age limit for British Army. Felt a little depressed, but only four weeks to Kathmandu.

\section{DIARY Sunday 28th September}

Poju came for another four and a half hours and we skipped on with 'teh' and 'pie'. He was quite lively. A lot of people with cuts for medicine and a lot of people in in the evening. Comal now reconciled again. Went up the hill and read more of Goethe's letters - not very inspiring. Very tired in evening but restored by listening to the "Trout" on tape.

DIARY Monday 29th September

Poju off to Pokhara. Prem came instead for a couple of hours - somewhat bored. Sunny, then rained in afternoon. Heard Prasad's father giving religious lecture from Potamkumari's house and arranged to do work with him tomorrow - also to come to supper. We checked Pignede against my rites. Finished reading Middleton: a competent, tidy, but ultimately not vastly mind-opening piece of work. Started reading Levi-Strauss on "Myth of Asdiwal".

\section{DIARY Tuesday 30th September}

Brikaras managed to pull together a few people - especially the Poju ('baje') so that we finally managed to do some sorting out of the 'tirige' names etc., also genealogies, etc. Very useful though somewhat of a mental strain urging them (mentally) not to be too bored. Gill and I both a bit snappy with each other - perhaps because of strain and thought of Brikaras coming to the village. A lovely day otherwise. Supper taken up to Brikaras - a lively evening with crowd meeting, etc. 


\section{OCTOBER 1969}

\section{Undated photographs of craft activities}

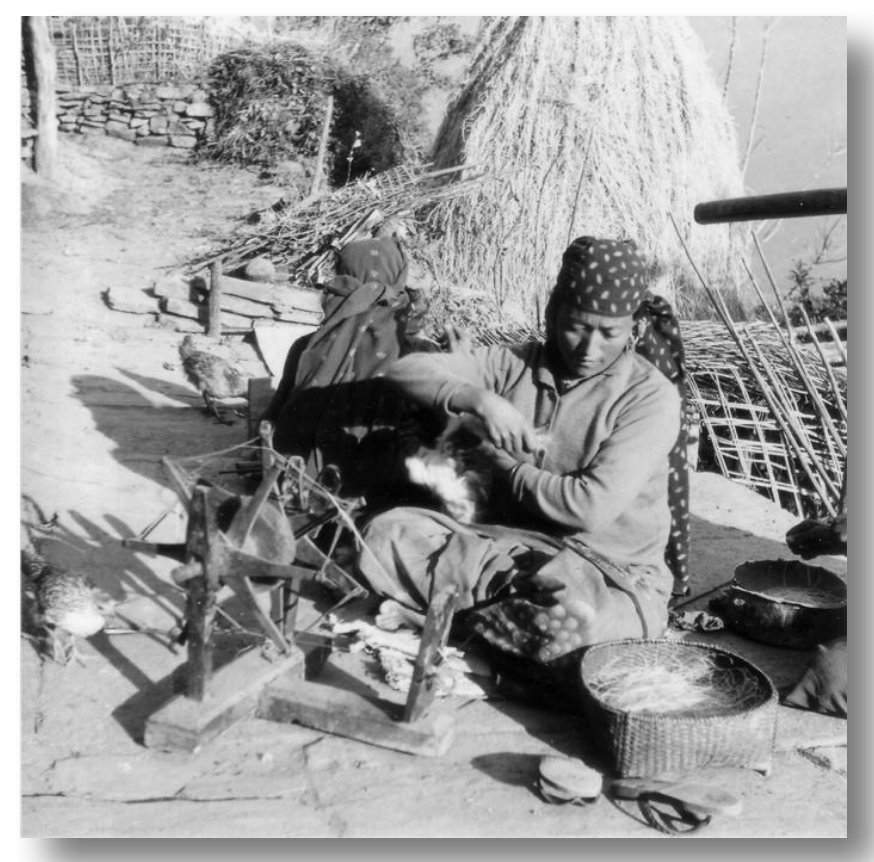

Asmaya spinning

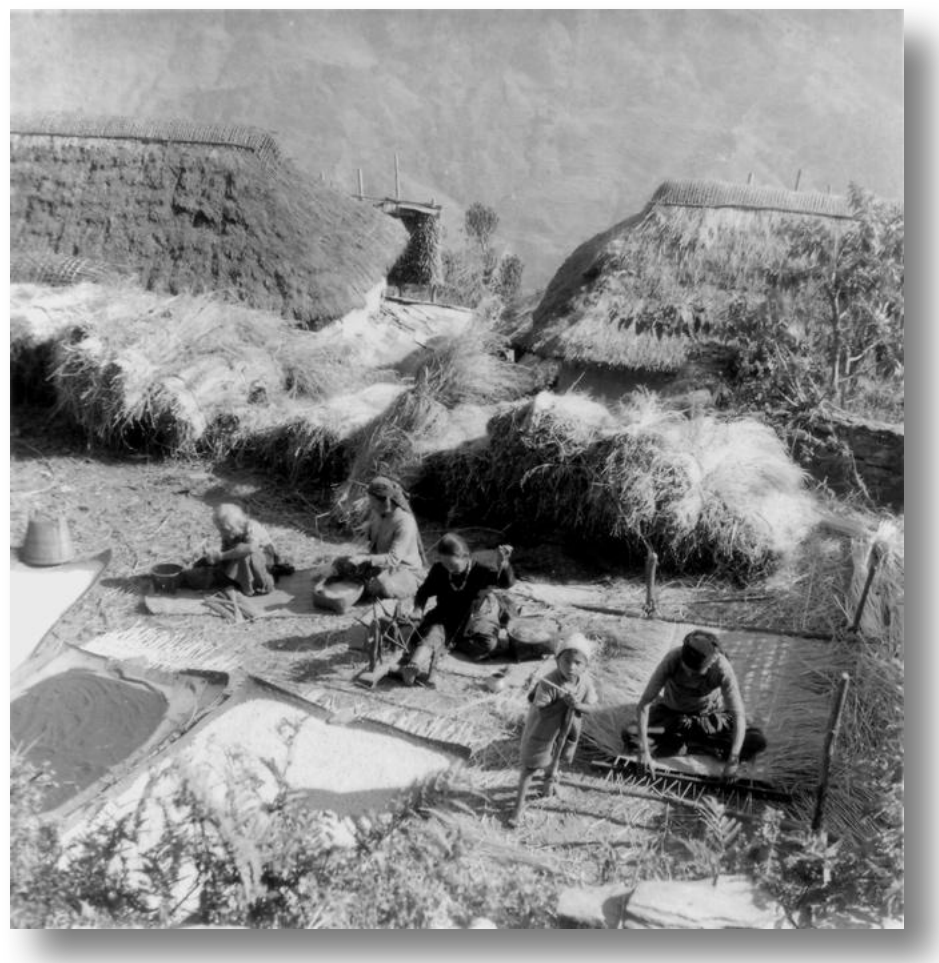

Women carding, spinning, and making a 'gundri' below House34 and House35 


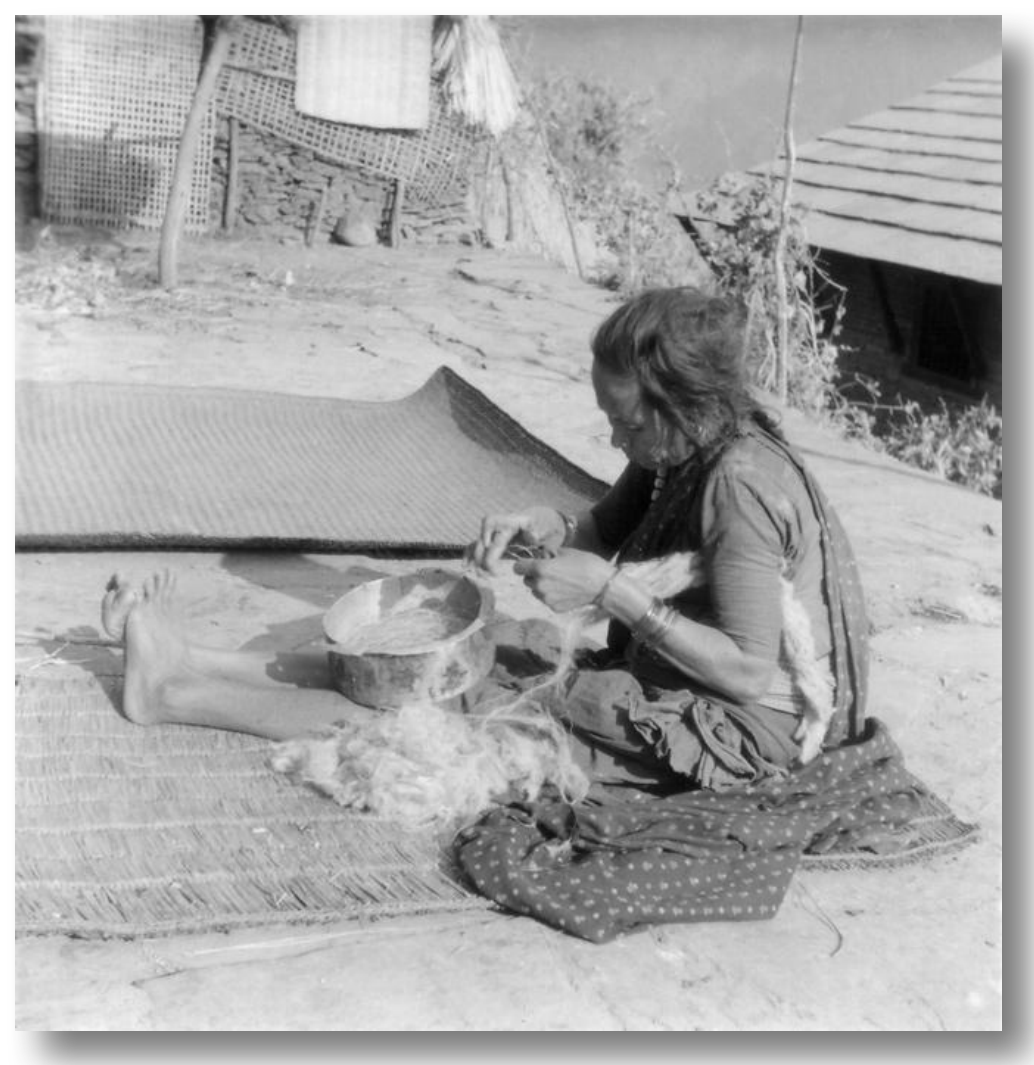

Nansubar teasing out 'nangi'

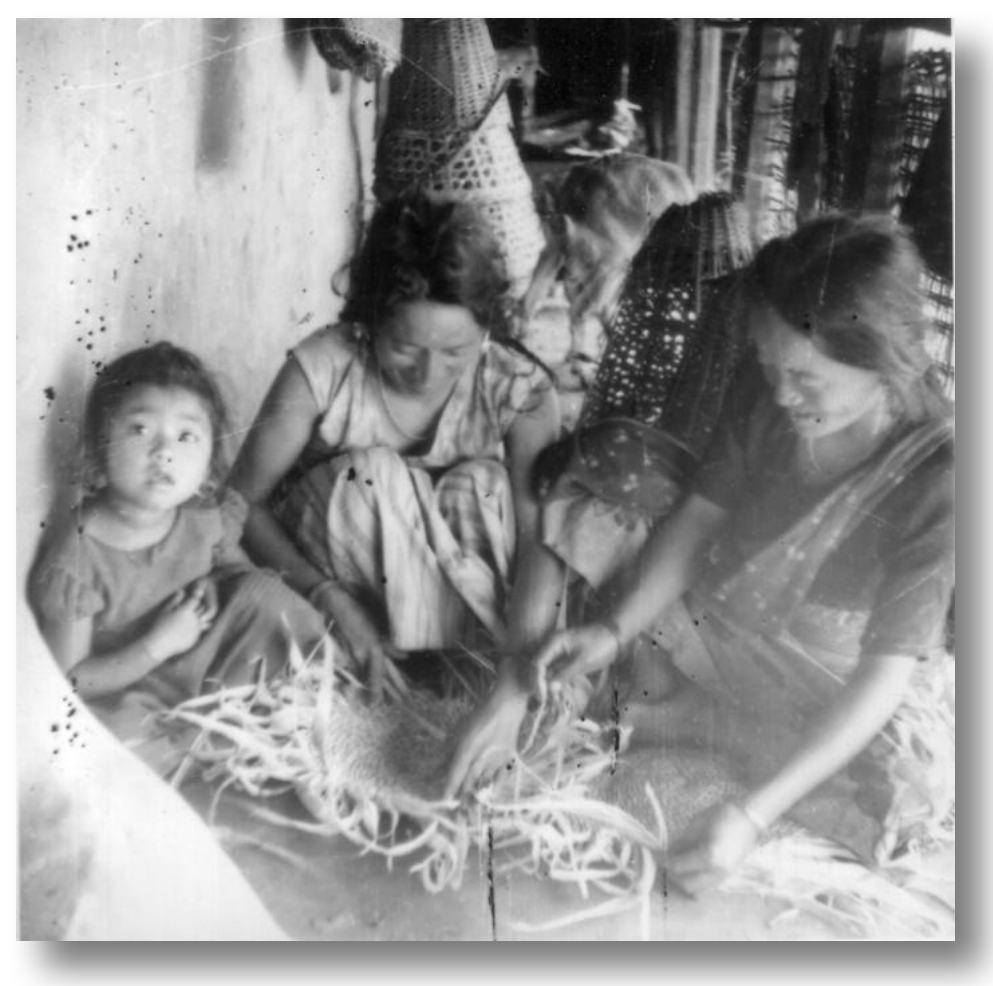

Rupa (left), Asmaya and Homkumari making a 'tsowri' (sitting mat) 


\section{DIARY Wednesday 1st October}

Got up early to watch House3B making 'cugu' - purified and unpurified butter: interesting. Then we went down to the school at $10.00 \mathrm{am}$. as we had been told that the yearly Panchayat meeting was to be held there - but it was not until some 5 hours later that the quorum of 100 ragged individuals had gathered. In the meantime we went off to take some photos from Chachock. Meeting (q.v.) amused re birth control, but suspicious and argumentative in other proposals. We returned at about 4.30pm. I have a heavy cold - perhaps connected to the bright, beautiful weather we have just started having over the last week.

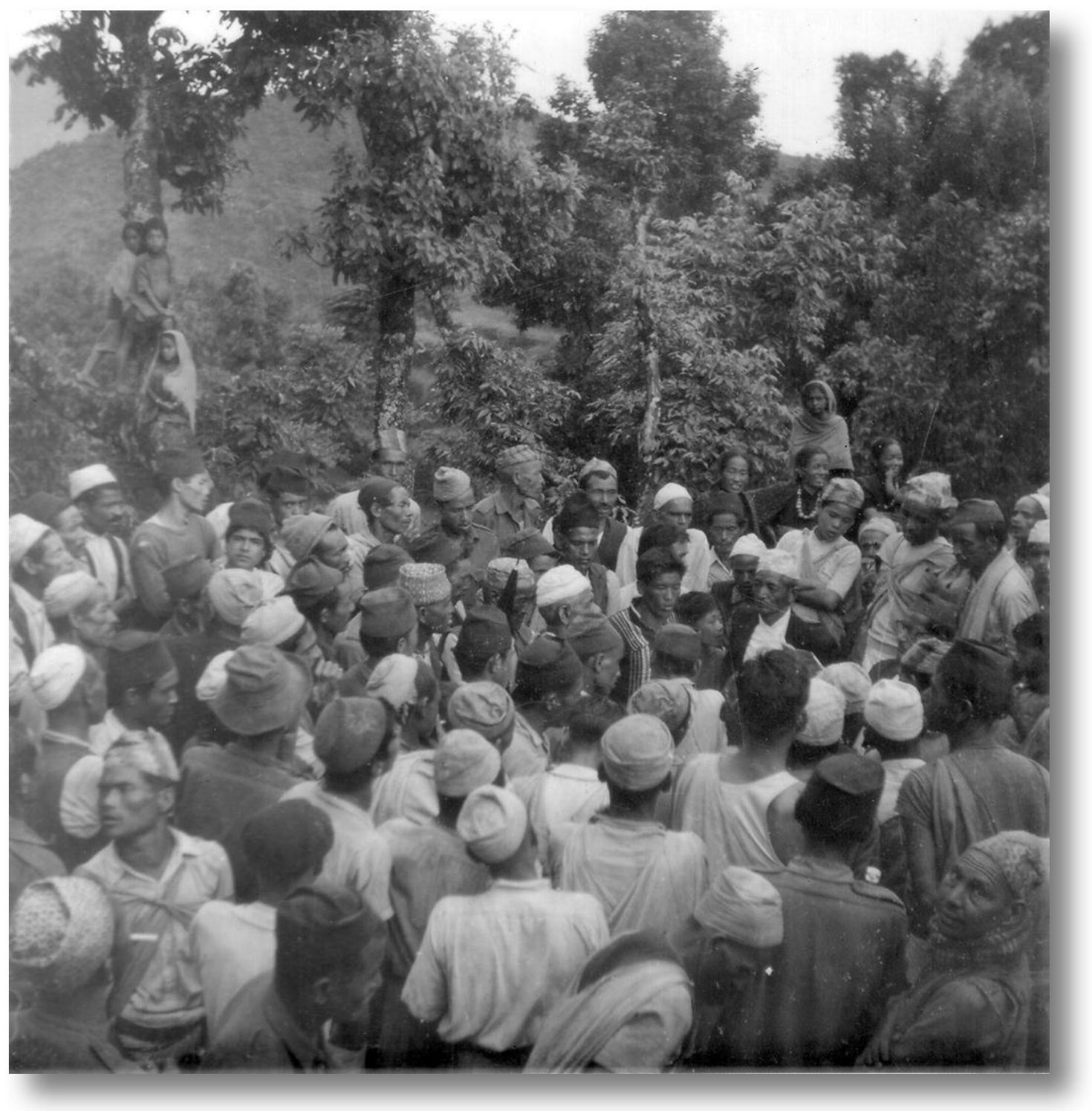

Village meeting

DIARY Thursday 2nd October

I now have a heavy cold - just as the fine, warm weather arrives. Poju came for 3 hours in the morning, then we went down to watch him perform a 'di-plogu' at Chyan. We were 
hospitably treated with rice rings, hot sauces, 'pa', etc., and watched the poju reciting as the gloom came in. Returned by torchlight with the poju. Came back and played the guitar a bit.

NOTES 2.10.1969 Alan - Di Plogu Waba' puja

Went down [to House84] 3pm. with Kaila. Poju already sitting on a 'shyaku' and rug facing door with his back to the bed, reciting 'pie'. In front of him is a basket of maize with a bottle of 'pa' half immersed in it, a leaf stuck in the top with a yellow thread on the leaf. A 'dodu' with burnt-our cinders in it. These are replaced with live ones from time to time, and a brown powdered medicine sprinkled on which smokes and smells like old socks. A 'pela' with a little 'pa' in it. Brass plate with 'mlassi', which is scattered over the rest from time to time, 4 rupee notes, and a metal bell [sketch], and a leaf with 'prahm' on it. The medicine is in a little bag by side of plate. A brass jug with water which is later used for sprinkling and later has some red dahlias stuck in the top. Later a smaller basket of maize is added with another rupee not on top. Poju himself just wears his brown beads and an ordinary cap.

No one specifically listens to Poju, and he would be quite happy sitting by himself reciting if no one else is there. Occasionally the buje squats against the wooden partition to do some 'nangi' teasing, but this is more a gesture of politeness than an attempt at participation. The rest of the women cook, peel potatoes on the verandah, split 'karella' and green chilies. They make a cucumber sauce for us - clean hurricane lamp with ashes and are generally busy all the time. Buje soon abandons her teasing and potters in and out generally overseeing everything. They even have to interrupt poju to get things out of a locked metal trunk which is at his side.

Kaila joins in with poju occasionally, not really knowing sequences but hopefully trailing after, eyes glued to his father's face, pulling up his striped socks proudly. Poju chants with his eyes shut, sometimes yawning but generally keeping up a fairly steady chant. One feels on the whole it is a labour of love. Again one of the women looks in the trunk. The tongs are sent clattering across the floor. There is little of the nature of "sacred" in the participation. From time to time the poju sprinkles rice over the little area in front of him (at any special point in 'pie'?) taking his hands up in a praying gesture with a few grains between the tips of his fingers. Throws it delicately.

Baje comes in after bringing in buffaloes. Poju breaks off to greet him - "hadzur". Girl rinses small bucket and goes off to milk animals. There is a pause when 'pie' is finished. Poju and us are given 'pa' to drink and tea. All members of the household go off to wash their hands and feet, and those of chicken they are going to use in the rite. Kaila goes off to get a rope with which to secure the foot of the chicken. The children prepare a blanket and a 'gundri' for their parents to sit on. The old man is told to change into fresh clean clothes, the 'kasa' being got from the trunk. He goes off outside to change. We are told the 'plah' at this point is confined in the cemetery and this next stage is the bringing down of the soul. Buje is already quietly prepared and sits cross-legged on the 'gundri'.

Poju having resettled himself, starts to ring bell, slowly and evenly at first. He then throws more rice and powder on the cinders. Both parents are now sitting cross-legged on the mats, having food put in front of them. Kaila has captured the chicken and secured the rope round one leg. Bell tinkles, chicken squats, murmur of conversation from family behind partition. Very relaxed. The chicken is released, puzzled at the restriction and the rice being sprinkled over it. One of the women crouches by the partition and scrapes the floor with an 'ashi', encouraging the soul to come down. Poju absolutely intent on the chicken, and at the slightest ruffle of its wings, increases pace of the bell, tells Kaila to grab chicken and they both rush over to the grandparents and do a 'shya lava' with the chicken.

The poju then sits on a 'gundri' and recites more straightforwardly. He and Kaila then do about 6-7 'shya lava' standing up, swaying from side to side with the bell, the chicken and the 
vase of flowers. At every 'shya' the girls rush forward and put strings round their parents' necks. Cat watches movements of Kaila swaying uncertainly backwards and forwards, in amazement. One neighbour comes in - nearly interrupting the chicken rite. Last bit has strong rhythm and excitement. At end poju comes back to seat and throws a cloud of ashes towards door. They then stow away the maize and eat rice with the family. [Sketch of seating plan, Poju opposite door with Kaila on his left. Buje with Baje on her left sit opposite the fire beyond Kaila. Girls sit behind the fire, facing the length of the room] (Note. Buje came about 6 days ago and poju diagnosed trouble as both in bad 'parga' [opposed] so said he would do yesterday $=$ auspicious day for their 'lho'.)

\section{DIARY Friday 3rd October}

Still very coldy - but a beautiful day. Took photos of our neighbours, etc. - the children will be going soon. Then the poju came in for 4 hours: did some more 'teh'. Gill started ruling out forms for kinship/land. Gill finished reading E-P up on hill. I went on myth/totemism book.

\section{DIARY Saturday 4th October}

Went to see 'chop cheba' at House7 in morning and poju came after that for four and a half hours. A lovely day and my cold a little better. In evening, a puja next door - which I went to - threw flowers, etc.

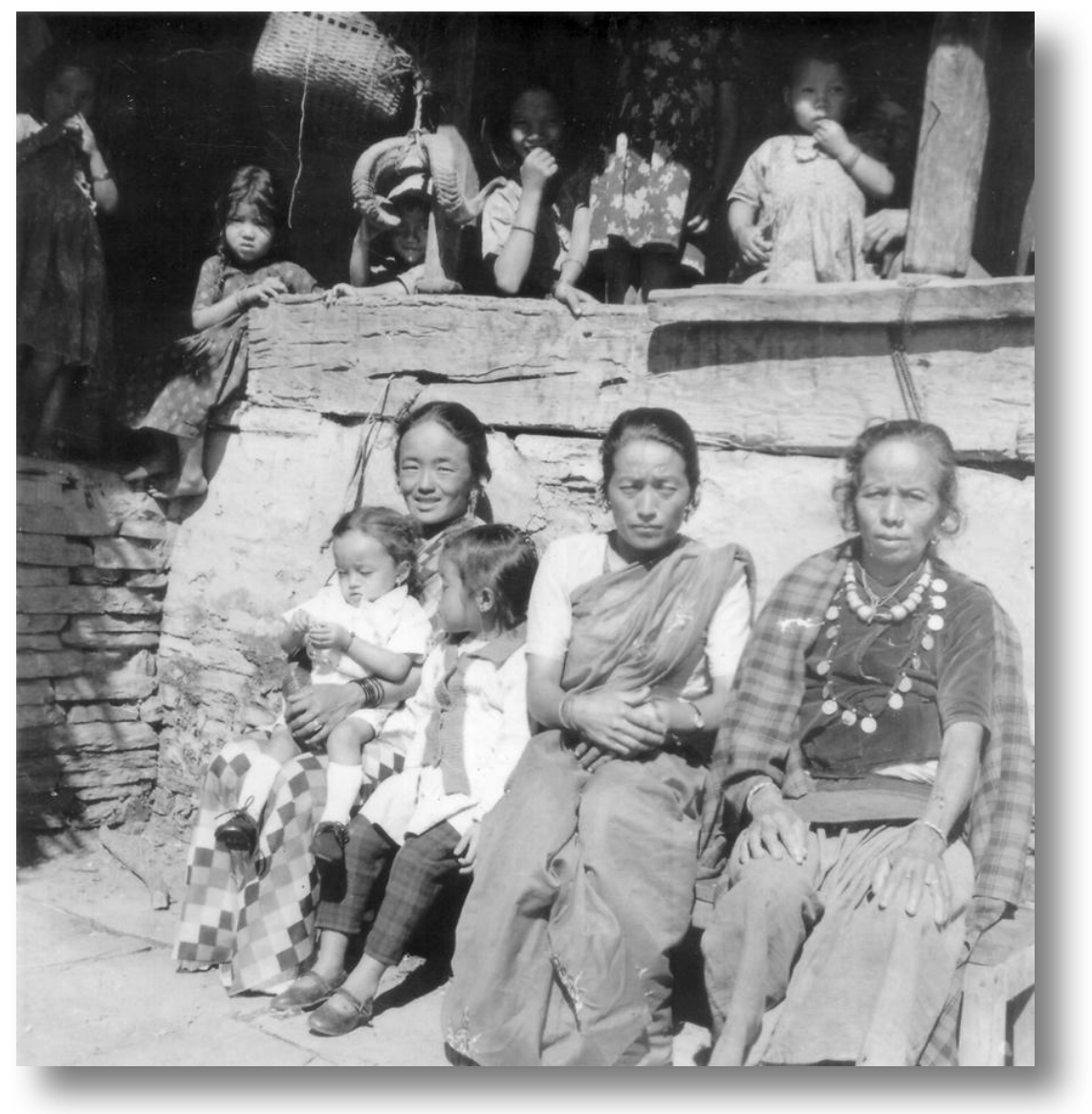

Dansuba, Asmaya and Homkumari holding Ramu (Robin) with Rupa beside her 


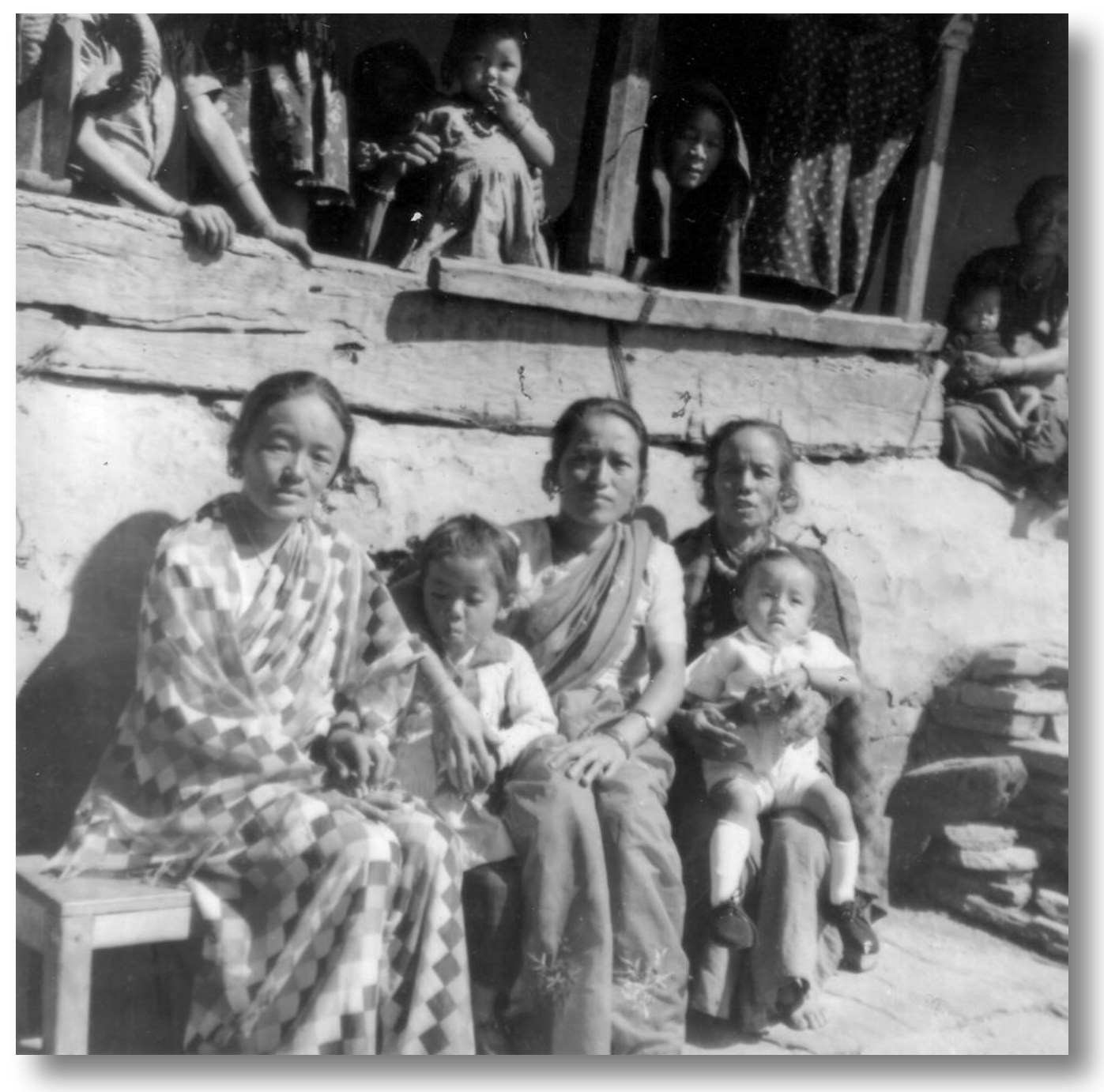

Another photograph of our neighbours

DIARY Sunday 5th October

Chaos - people came for birth control medicine (now 4), and then Totra's father. Did three hours on field map with him - then did another three hours with poju who was rather hurt that I had worked with someone else in the morning. Again lovely, and I had a brief spell on the hill. Cold better. Gill a bit seedy.

\section{DIARY Monday 6th October}

Day passed in rush of informants and information. Got up before the dawn (about 5.30am., sun now rising at $6.30 \mathrm{am}$. and setting about $5.00 \mathrm{pm}$.) and did an hour on field map with Totra's father. Then, after a short break did 5 hours work with poju. Finished the 41 rites but still have 44 'pie' and the 'pae lava' to do. Gill went up on hill. Continuing to read "Myth and Totemism" - moderately interesting - obsessive reverence for Levi-Strauss. 


\section{CHA}

RITE. (What savraficio etr.).

See description in our notes:- alo Pornide.

(1) Brings goot and puts on magical clistres

(2) kills animals, throws egge et.

(3) Then sticks in nails, arks + eat goot

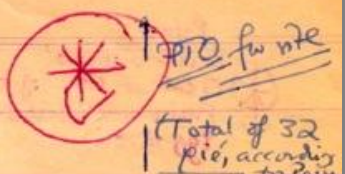

Posontie' keh kweba roye' pyoh, sheméraker rumérakn, prada nolida if

ondah I Aba kargore' Ama kroyupih. Moyurphi. Tsakn themae Mokm 'song bi pré titkargore' "tsadsa tidne ewe' Plaba tsé bwomba tse Tojic sheeva 'om, Pendre' Ky amon, Pije' Kyamon, Troi pis' Toji shive' rih T Abi kallow, kwe

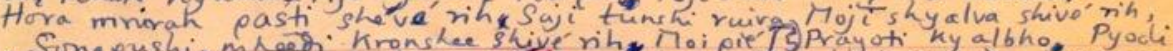

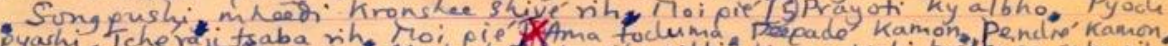

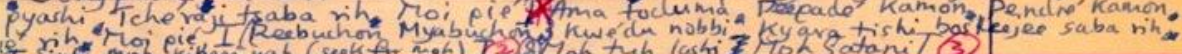

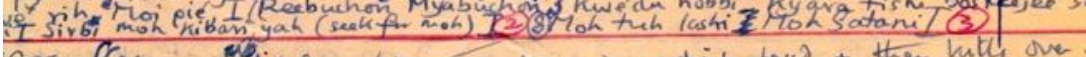

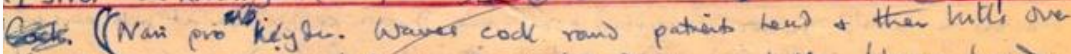

Qoesn't weu recuice hat: Bon't hit grmen or bell. Wean beads

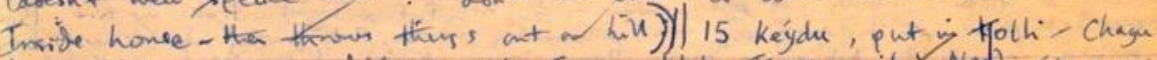

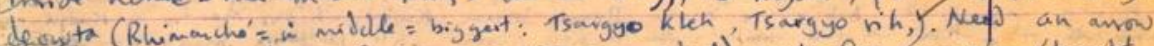

with tip of inon-pebibles from niver (Masen ghat), water form same place (bompht

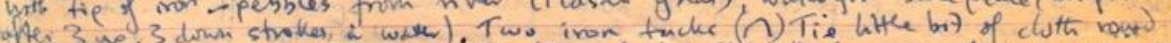

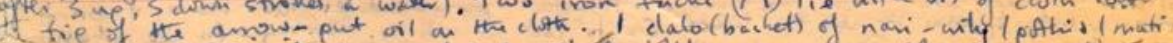

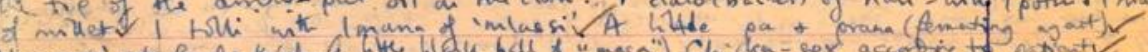

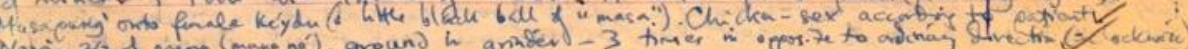

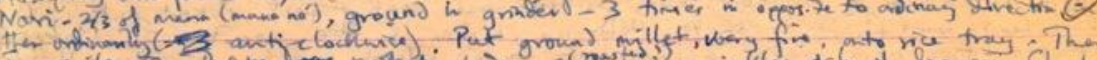

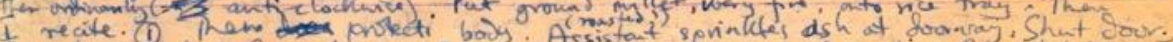

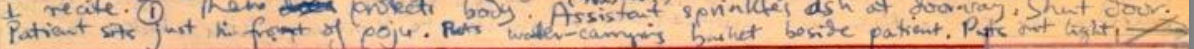
Nari prodi ke'ydu: kyoshee tangra. Kosthe (4talo of ther plant fun furest), - puts stries for an to thy atue of puts ke'ych o top. + puts are between. Cock sacrafices is spe-id way. "Put heas

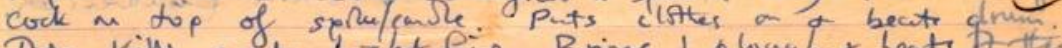
The vilu gout. Light fine. Brings I plocay ho heats fot the

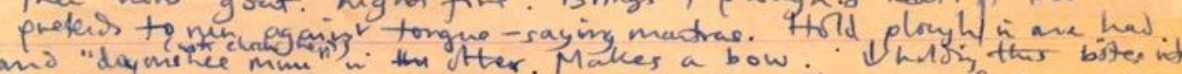
goat. Rurles aroud wMais - wsic the two thiss as fert, samig

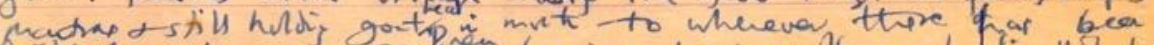

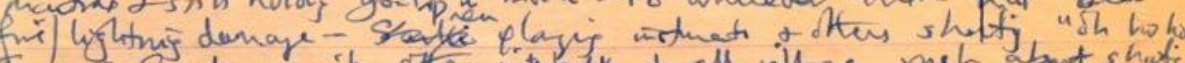

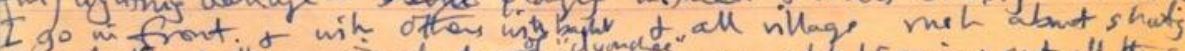
Wirthy \& thruers ria abut. Ifalce 17 avay abt. 15 min s put all thys

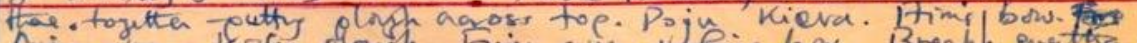

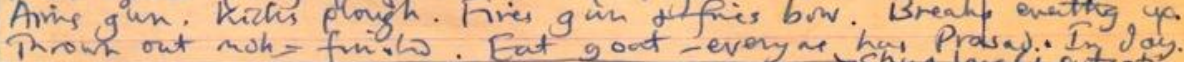

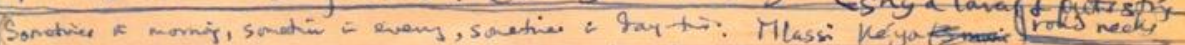

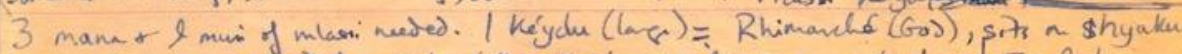

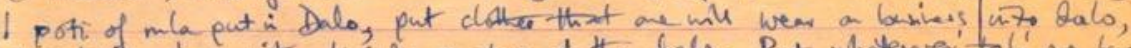
+ Peut rita tray nite ke'ydu on the of the dalo. Put whitewrer tah' mo has

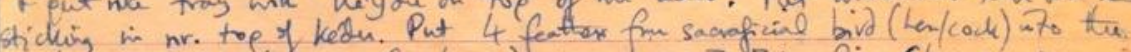
put in 7. Duba (Shingn - fo bagnars)- ineorren = 3. Bring frie. Cleanke my

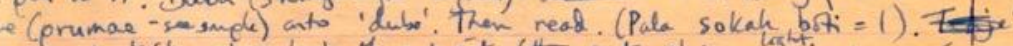

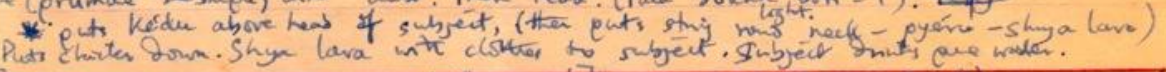

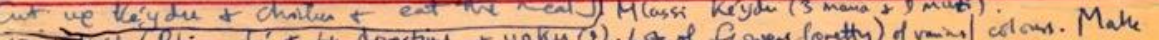

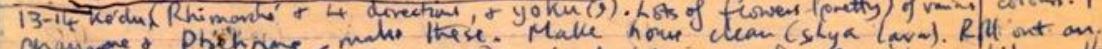

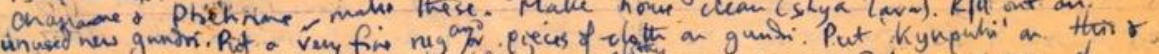

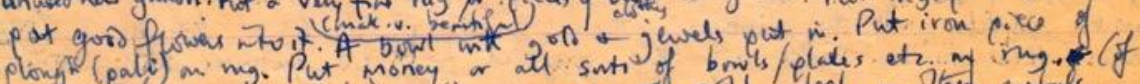

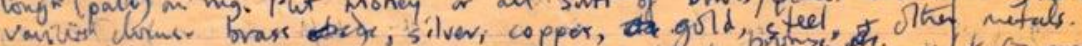

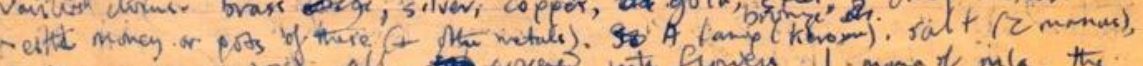
ric (2 manar - 20is), all coveres inte flowen, I mama of inla, the

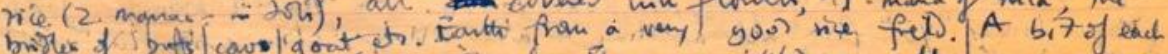

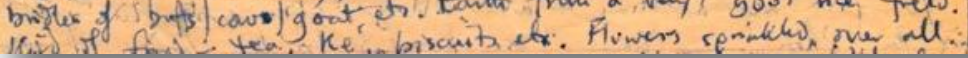

Part of the transcription of the poju's rituals 


\section{Letter from Gill 6th October 1969}

...A second was rather beautiful in a jolly, kind Gurung sort of way. The house was away from the main part of the village, fifteen minutes walk along the ridge through shaded, dappled walks and emerging into a garden with a full on view of the Himalayas, full of scarlet dahlias and white bean blossoms. The family were sweet, with a kind, ironic gran who loaded me with green chilies and spiced cucumber, and didn't mind Alan falling asleep on the family bed in the middle of the rite, which lasted for 5 hours. The aim was to call down a wandering spirit from the cemetery, whose absence was causing gran's husband to be ill, and had gone because their dates of birth clashed, and their spirits were fighting each other. The poju sat cross-legged on his woven rain shield, chanting rites and ringing bells and flicking rice in front of him towards the open door, where the chickens were clucking, the baby white buffalo chewing on his grass, and the women pattering in and out, cutting up potatoes, chili, karella, a veg with a back like a dinosaur, and cleaning the hurricane lamp with ashes from the fire. The climax came when a mother hen tied by a string to one leg fluttered her feathers to show that the spirit was in her, the poju rushed to the gran and grandpa with the chicken in his hands, and blessed them by placing the hen on their heads, crying, 'Shaa-ar', as an invocation, and then swaying in front of them with a quick insistent beat, the daughter of the house rushing forward at every blessing to put white cotton round their parents' necks, to keep the spirit in. We came back with the poju, thousands of stars glimmering in time to the crickets, and the path lit by flaming bundles of sticks, as we had all forgotten a torch. It was one of those experiences where one felt one was really experiencing what it was like to be a Gurung. I could feel the spirit coming down from the hills as the bell tinkled out into the night. The Hindu rites, which are also in demand and done by a Brahmin called in for the occasion, aren't half as evocative and the family is not so completely involved, at least that is the impression I have got.

We have also had an area village meeting which was a riot in its own way. We had a special interest as Alan wanted to introduce birth control via the Pradhan Panch (head of the village), so we went down the hill to the schoolhouse at 10.30 clutching our condoms and pills, and a crude poster depicting the good and the bad, the nine children family and the two: always feel embarrassed when this is waved as it is so untrue, but they don't seem to question it. The meeting didn't start for five hours, people forgetting to come, and the Pradhan Panch had just mumbled his first few words when it started to rain, so he was then hidden by an umbrella and then by the school house, which only he and ten other people could squeeze into. However, much laughter and leers, at the birth control, points sorted out - Do you eat the condoms, for example, and later some people requesting help. They then got onto their letter box, fertilizer and water pipe, had a fight over the latter as the people in one village, which is lower down than another thought they would therefore get less water...

It is only just after 9am but I've already put medicine on two nasty sores and bought some fresh beans and the usual rock hard green tomatoes. Alan has started work and is drawing maps of the fields on the verandah of one of the more lively men of the village, and it is a lovely morning too, we watched the sun rising over the opposite hill at 5.30am, and it is now making warm patterns on the clay floor, pouring through the wooden carvings of the window. As hoped, am getting this extra letter in before we leave for Kathmandu in a little over a fortnight (we go down to Pokhara on 24th), as we are sending a porter down for supplies this coming Friday...

Time is speeding up however, as the weather has been superb for the last week, blue blue days, with the mountains brilliantly white against the sky, every detail of Annapurna can be seen, and I think the monsoons have really finished. Also we have been to some fascinating rites by the poju, and this is fitting in well with the material obtained on religion. There was the above mentioned village meeting (birth control) as well, which was a riot in a typically Gurung way. It was meant to begin at 10am, but by the time we had staggered down the hill at 10.30 there were 4 people there out of the potential 500 or more - the head of the village, his secretary, the vice head and Brikaras, one of the most powerful men in the village, who has been most helpful to Alan, but can't take part in politics because he has had a lame leg since he was young. Alan entertained them by showing all his pamphlets on birth control which he had got from the head office in Kathmandu, and then we went off for a walk along the ridge as only two or three more had trickled in. When we came back, me clutching wild flowers which were to wilt by the end of the day as things didn't wind up until 4.40pm, there were perhaps 15 or more people, sitting haphazardly round the school house. 
A little shop had been set up selling fried rice goodies and pickled cucumber, and there was a tailor with his sewing machine clicking away under a bamboo tent. All the men not from Thak but from neighbouring villages wore their best and most brilliant outfits - yellow nylon shirts bestrewn with blown red roses with orange corduroy shorts; pink terry-towelling with fern green socks; a red and green tartan skirt reaching to the ankles, with yellow sandals and red army belt. There was a plethora of army equipment, patched khaki jumpers and shirts, shorts and balaclavas, and black creaking army boots which the owners clumped about unhappily in, worn without socks. The meeting starts about 1.30, with entertainment, ie. our birth control programme; roars of laughter and much leering - does one eat the condom? Is it the same kind of medicine as the pill? However, at least attention was held and the Pradan Panch (head of village) is keen.

Other topics were the setting up of a post box, the laying of a new water pipe, and fertilizers on crops. There was a battle (literally) over the water pipe, one village thinking they would get less water than the other, because they were lower down. Much shouting and hurling of fists; the Pradan Panch gazes at his notes and stoutly chews a sweet, the lines of people have lost themselves, and everyone is crowding around his table, which already collapsed when he put his foot on the cross bar at the peaceful beginning so with a crushing fight in progress it is likely to tumble down completely. One of the men from Thak tries to act as peacemaker and looks like an appealing mouse with whiskers trembling in front of loud and surging tigers, none of the men from Thak argue, only the savages from other villages. We retire, slightly exhausted up the mill, my new dress slightly crumpled, Alan wondering whether it is the first or the fifth day one starts on the pill.

Watching the poju's rites was more aesthetic and relaxing, at least one session which lasted 5 hours and we followed throughout. The house was away from the main part of the village, 15 minutes walk away along the ridge with a complete view of the mountains when you stepped off the verandah, and a garden full of pink dahlias and white blossom of the beans. A spirit has to be called down from the cemetery where it was residing instead of in the body of the sick person, and the poju's bell went tinkling out into the night to guide the spirit in, and the chicken was tied up by one leg so that when it fluttered its feathers we would know the spirit had entered the house, and could then be secured into the patient by the tieing of a white string, and a blessing and the swaying of the poju and his assistant in front of them. Ashes were thrown in a cloud towards the assistant at the end to get rid of any evil contact with bad spirits, as he had just put food out to appease them. Somehow one feels one is really entering into their lives at a depth when one shares this kind of rite, a satisfying feeling; we came back under the stars, flaring in their thousands and a burning brand to guide the way as none of us had brought a torch...

\section{DIARY Tuesday 7 th October}

Had a slight row with Gill over my decision to get up at daybreak. Did one and a half hours with Totra's father on fields and then another four and a half hours with the poju. Went for a beautiful late walk toward the mountains and started Faust. Then about 8 o'clock we went along to House 10 and watched the poju perform a rite ('no ngeh sheba'). We dozed a lot and it ended with firing of lighted arrow after midnight. Hospitably received.

\section{DIARY Wednesday 8th October}

Finally we got off to river - a bright sparkling day though it rained heavily when we were returning. Rather an effort washing, but nice to get back to our old washing place and hardly any leeches.

\section{DIARY Thursday 9th October}

Did another four hours with the poju - delightfully interrupted in the middle by the arrival of ten letters and two parcels of books sent up by Mr Pant. Depressed to hear airstrip being repaired, but glad to receive a letter requesting an article with payment of 50 guineas. Bright and then stormy. 


\section{Letter from Gill 9th October 1969}

... The night before last we followed the poju's middle son, who will take over from the poju when the latter dies, and acts as chief assistant now, into the house of a kind very musical Gurung who had been diagnosed as being made ill by witches. The poju was already there sitting cross-legged on his rug, blessing his equipment with mantras, a blown kind of spell, and making an arrow out of bamboo which was to be fired alight into the sky at the end of the rite. His son started on the fifteen little poju gods which he modelled out of ground millet and put on a brass plate later to be circled with more invocations round the sick man's legs and put above the lintel of the door as a protection for the house. The women of the house were teasing out vegetation which grows in the forest and which they turn into a kind of strong linen, and later on with only one oil light flickering and the poju chanting these three women looked like the Three Fates, teasing out man's existence with a God predicting the future, everything silent and filled with shadows, the women bent and crouched and the poju omnipotent with his muttered spells. They were sweet and hospitable as always and gave us a bed on which to go to sleep if we felt like it, as the rite wasn't finished until one or two in the morning, starting about 8pm. It was lovely lying there in an utterly relaxed atmosphere, the women quietly gossiping as they tugged at the linen, the beams glistening, soot-black with age and smoke and the brass pots catching white vertical rays of the candle, which shone bright against the orange wood of the milk casks, and a woven square bamboo basket. The climax came then the old man was put in a woven basket they use for carrying grass for the buffaloes, crouched on the floor, the poju blew his mournful phallic horn, and then threw river dust at the basket and then millet through a burning clutch of sticks, which flared round the old man making him hop inside the basket with the heat and scorching. Great amusement for the onlookers and the poju, who chortled every time the millet fizzed and the flames leapt, one could feel the witches fleeing and the evil spirits cowering in corners. Finally the chicken was sacrificed, and the poju went outside into a fresh star-dazzled night, and fired his flaming arrow, with us standing on a dung heap and hoping it wouldn't catch in any of the thatches which were thick around us, being in the middle of the village. We returned to eat spiced potatoes, so hot they made one gasp, and refusing a full scale meal of chicken and rice, tottered back about 2 in the morning.

\section{DIARY Friday 10th October}

Poju only able to spare one and a half hours between dashing to see his various clients in Panighat ('di nyova'), a sick child in Queregon, etc. Totra's father also not free. So I started reading "Land, Labour and Diet" [Audrey Richards] and thought out ways of analysing the anthropological material.

\section{Letter from Alan to parents on 10th October 1969}

We are sending this down by a porter, so, since we can't register it, are only sending an air-letter as this is more likely to get to you. Hope you got our letter and enclosures sent two weeks ago...Apart from leech bites which have occasionally turned a bit septic we are both very well - a better stretch so far than we have ever had. The weather has suddenly emerged into glorious sunshine also and every day Annapurna rises furiously white against a calm blue sky. In a week Dessai comes and after that, a week later, we go to Kathmandu/Pokhara for a break of a couple of weeks. Then there is less than three months before we set off for home.

... The poju now comes every day for about four hours and sits twittering away excitedly, describing rites and giving me the meaning or myths. Have not completed all his rites (except the long ones at the funeral) - some 41 in all. There are rites against witches, bhuts and prets, spirits of those who died badly, banquettas (evil little men who live in the forest), against the spirit of lightening and fire, to bring fertility, wealth, health etc. Often they verge on conjuring shows, with little snake heads disappearing and then dancing round the room, sometimes they are macarbre, with the poju grabbing a dead goat by its bleeding and severed neck and rushing round the village - but I think I've already given you a partial description. With 21 myths done, there are still over 40 to $d o$. 
Before the poju comes in the morning I go and fill in a map showing where everyone's fields are situated with the tiny holdings this will take about 10 days... Unfortunately the Gurungs (unlike the tribes one reads about in anthropology books) are not at all interested in their ancestors beyond their parents or, possibly, their grandparents and consequently vague about their names. But with the help of the schoolmaster's father we have managed to sort part of the kinship structure out. At Dessai, where they all "first foot" round their relatives, we should be able to see which people, in practice, recognize each other as close relatives...

\section{DIARY Saturday 11 th October}

Woken up by the poju calling out to explain why he had been unable to come yesterday. $\mathrm{He}$ had been called down to Queregon for a sick baby who had subsequently died. We were also told that Comal's grandfather had died in the night, that next-door's buffalo had calved, that House 13D father had returned on leave, etc. - all at 5.30 in the morning - then had a drink of 'pa' next door and crawled back to our house. Did a bit on map, but poju unable to come because of the funeral. Watched this for a bit but had a headache and spent most of the day lying down or reading "Land, Labour" and "The Egoist". The evening, next door did 'chop chueba'.

TAPE REGORDING - 11 th October

Poju's 'pie' (recitation of myths)

Poju's 'pegar songvar pie'; 'plogu waba (teju)'; 'Aba Kargore pie' (from time he is asking for weapons in loft down to sending son off as 'moh').

https://sms.cam.ac.uk/media/2733078

\section{NOTES 11.10.1969 Gill - Cremation}

Went down at about 11.30 a.m. the grandfather having died at 4 a.m. that morning. In the courtyard six kwonme (Kumbasing (37), Syeb (83A), Totra's father (22), father in 38, Gungab (38) (sic), Prasad (70B) were making balls of rice - about the size of croquet balls into which were put a morsel of goat meat and smeared on a little oil. House 41 scooped out the oil from the pan (Gopal (19) that evening said this could be done by lower jhat 'ke lava mee'. They were called 'Pohla kae' and one was given to each house (to put up in roof or verandah) - 63 were made. Lower jhat and a few lower were sitting round watching. Those making rice balls had their hats off. Girls on the porch (neighbours children) were making flower, pop-corn, garlands. Mrs. Comal was wearing her hair down and Mr. had no hat on. There was the stereotyped wailing from the house. The poju recited a little, sitting on a rain shield and then the lama arrived and went inside and recited, sang and played his bell. The 'stretcher' had already been made. Everyone was giving advice and general relaxed confusion. Family obviously very sad. The 'a-la' or flag was made (just a short bamboo, split at top with white cloth) - tied to verandah roof near door. The flag was made by house 21 father with advice of house 29. Odd comments - there were about 150 spectators at the actual ceremony of taking out of house. The son and house 1 father thrust the spear through the loop, as did the 'ke lava mee', Bhuwansing's elder brother (maila) who was arranging cigarettes and giving money to the dead person. When the weeping relatives (mostly old women, sisters etc. of dead person) were pulling away, this was done indiscriminately (of jhat) by other oldish women (e.g. grans from houses 32 and 25). During the strapping of the person onto the stretcher (done by lower jhat 'ke lava mee') the doors of house were closed. Relatives, we were told, brought two little parcels of food (done up in leaves, not grains of any kind - which were eaten down by the river by the work people) one was for the dead man, the other for dead relatives generally. But, in fact, non-relatives like houses 24, 32 brought them too. At the end of the rite we 
should have sprinkled ourselves with "gold water" but there was none available in village so too bad. Young folk went to sing, but nani from house 19 said she was too "frightened" to go. Gopal (house 19) said he was only a little ('cugude') unhappy.

Both went down to see approximately 1.00p.m. Verandah crowded with men, 14 sitting cross-legged and chatting quietly - all upper jhat? Two rice drying mats laid out in yard on which other mean came to sit - Bhuwansing etc. Untouchables also ranged round the yard at a distance but when the body was brought out Gurungs also standing watching with them, close together. Children of the family sitting around desultorily outside, Comal playing with a spinning toy, upset and Maila also, but the younger boy and girl bewildered by seeing their mother upset, but uncomprehending. Comal did not go down to the river and none of them went in the house when the body was being prepared. The youngest girl was at first happy because so many people were coming to visit at her house...children have white threads round their throats. Garlands suspended from verandah, with cigarettes stuck in them. Leg joint of goat hanging from a post in the yard. The floor of house badly needing doing, everything messy., all the equipment shabby, rugs, mats torn, cinder container broken at edges, one would never guess this was one of the richest families in the village. People came regularly and put their food parcels, 'pogu', into the special basket, 'chulu' which Maldosing always seems to carry to the river. Tekansing also doing chores, like splitting canes at the last minute when those holding stretcher together were seen not to be strong enough. Everything chaotic inside house, with women wailing, neighbours blocking up entrance, baby goats and hens on steps and Maldosing a crude unheeding force in the midst trying to clear gangways and get the grisly things done. Lama tinkled bell at beginning; when he changed to drums everyone did a 'shaar lava' on children and immediate neighbours. Crying on verandah started (gran next door) as this is near the point when body will be brought out. Relatives will not eat salt for 13 days. If father dies they don't eat meat either, if mother, do not drink milk. Comal's father will wear white, hair shaved? Closeness of family to physical side of death, laying out etc. No undertaker to take this side away. When they are tying body on stretcher, doors closed and when a child tries to see (Picksniff's nani) she I shooed away emphatically, but children can generally watch. Rupa worried by wailing. Comal's Mum grieved a lot, stopping dramatically in doorway, 'kramu' over head, hands raised to lintel. Old man on verandah, trembles and seems troubled and reflective, his turn soon? When body is ready lama takes cymbals and white cloth which trails in front of bier, poju drum which is carved and two sided. Maldosing has conch. Leaves stuck on middle of bier and the women kneel and keen, 4, smoothing leaves with oil, bodies shaking under saris. Comforted by other older women, Noise goes on whilst money is organized and the piercing of the circle is done. All crowd round courtyard, thick with people.

\section{DIARY Sunday 12th October}

Felt less coldy today, though Gill worse with her bad cough back again and a cold and period pains. Bhuwansing's son came so were unable to do map - but did a bit on religion with Gundasing's father instead. Poju came for four and a half hours and we finished off 'pie'. Getting low on food - eggs, 'chura', rice, etc. 


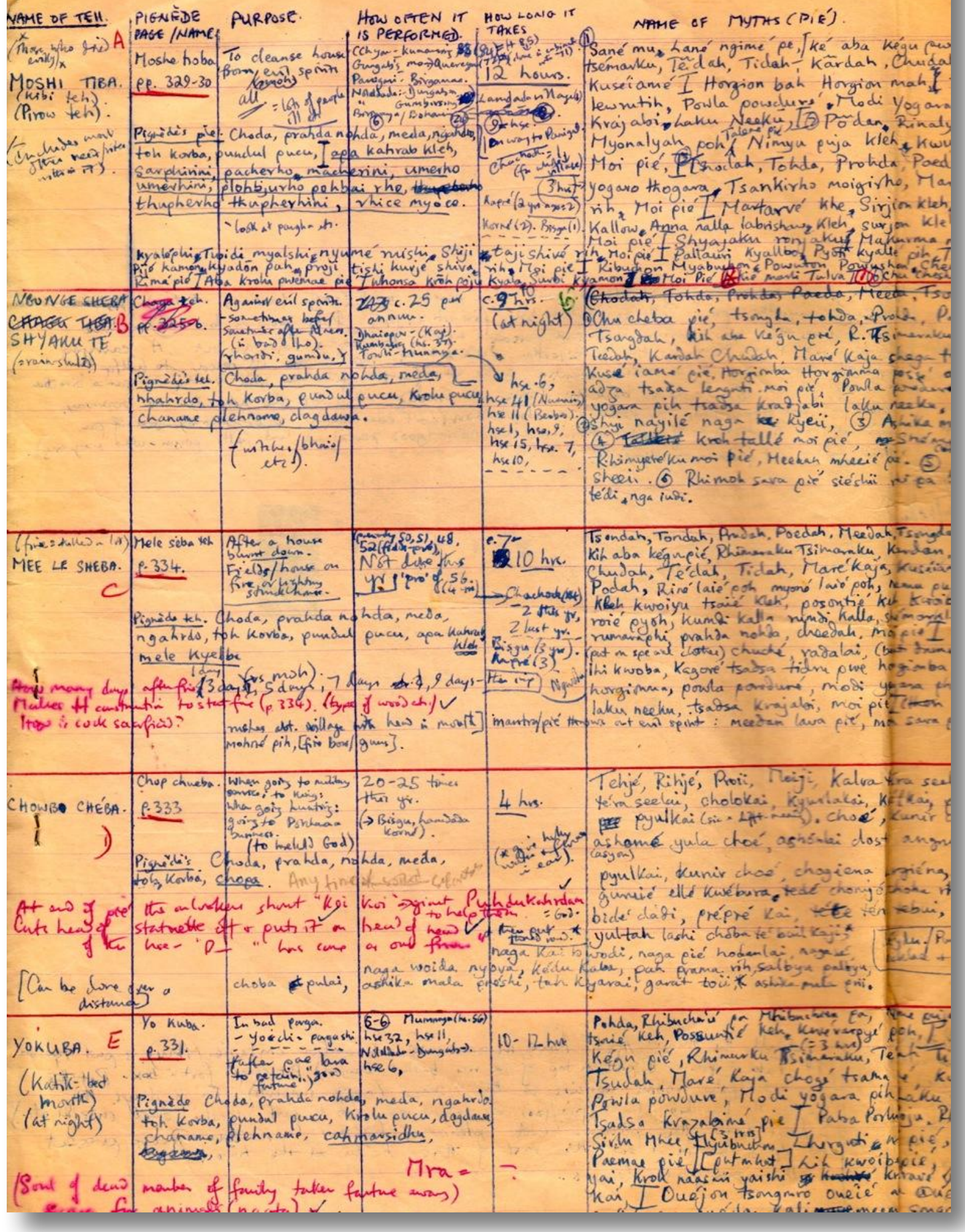

Part of the transcript of five Gurung myths (pe) 


\section{DIARY Monday 13th October}

Went down and did three-quarters of an hour with Totra's father - then two and threequarter hours with poju on burial ceremonies. After lunch were told Brikaras had come up to finish off the 'tirige' so did that - having to round up Pradhan Panch first. Had to put off Gopal too, who was meant to be doing Gurung songs with me. Got back 100rs. loan and then lent it to Brikaras. Gill very seedy, but weather lovely.

\section{NOTES 13.10.1969 Alan - Dreams}

Gopal and Comal's dreams. Bad dreams (and their meaning):- riding a horse (leads to death or serious illness since 'plah' has gone); flying in plane (same as horse); seeing buffalo meat or blood (other people will die); forseeing marriage (especially bad for a girl) (Comal describes how mother about a year ago had a dream about this - a death); faeces (will be ill); a running oxen chasing one (one will have a dispute or law case); ride in car or horse ('plah' gone); if see parents, they will be ill (Gopal saw his father in a dream while at Bhairuwa and wrote a letter - his father had cut himself). Good dreams:- drinking milk (not at breast); eating; milking cow or buffalo; if a dead person appears and gives one something; fetching water. (Both informants said they dreamt quite frequently).

\section{DIARY Tuesday 14th October}

Gill's cough and cold a little better, and my cold vanishing. Again lovely. We now get up at about 5.45am. before the sun rises behind maize stacks. Did good hour and a quarter on field map and then four and a half hours with poju. Went to collect Gill from hill - usual superb sunset with skies pink and mountains also. Finished one of the 'pae' done by poju. Longing for home all the time.

\section{DIARY Wednesday 15th October}

House was 'di shu lava' - confusion as we had to move everything out of the way so that they could coat floor and walls with mud. Managed to squeeze in a few hours with the poju as well. Gill rather miserable.

\section{DIARY Thursday 16th October}

No one around to do map with - but had tea and 'kyuni' (rice crunchies) with Lt. Later, after seeing poju doing a 'mula plogu' rite up on mountain side, went down and finished off the religious questionnaire with Gundasing's father. Poju came for four and a half hours and almost finished 'pie' of the 'pae lava'. Fetched Gill - who was most excited by Sartre reading down from hillside. Young men beginning to make 'kudi' for Dessain.

\section{DIARY Friday 17 th October}

Did a couple of hours on Gurung songs - with Gopal. Poju unable to come as there was another death and cremation. Sorted out notes, etc. Went for a walk with Gill to examine Pradhan Panch's fields where he had put fertilizer - fantastic 2.5-fold difference. Why doesn't whole village do this? A lovely walk through soft-green rice fields. Then wandered round village counting maize stacks ('suli'). Dessain tomorrow. 


\section{DIARY Saturday 18th October}

The first day of Dessain celebrations. Were awoken by Untouchables' horn. Before breakfast saw them doing a puja next door and had blood and rice daubed on my forehead. Later invited down and had 'pa' and rice crispies and rice and chicken. Reeled back and went to sleep for an hour or so. Then wrote letters to parents, etc. Went for a read on the hill and in the evening entertained the dance party to 'pa' and cigarettes, and went to another house to watch a little dancing. They danced round the village all night.

TAPE RECORDINGS - Un-dated, around 18th October 1969

Nepali song

Nainasing (?) singing a Nepalese song which goes "Tasala tama ko phero bachan sautini ama ko...". The song tells about the harsh words received from the step-mother.

https://sms.cam.ac.uk/media/2733432

Nepali song

Prem singing a nepalese song which goes "Pani ma khelera, lau maya dhago jhai jelera..." https://sms.cam.ac.uk/media/2732927

Nepali song

Prem singing a nepalese song which goes "Sali dhan ko biyu, Narau maya nasukau timro jiyu..."

https://sms.cam.ac.uk/media/2733485

Nepali song

A man singing a Nepalese song which goes "Bau ko ansa, dhuwe bhai lai bara bar, ae basyo dil ..."

https://sms.cam.ac.uk/media/2733502

TAPE REGORDINGS - Dated 18th October

Gurung song

This song is sung by Comal, who is talking about Alan (Ramu), who has come from England to learn Gurung language. The whole song is written below with the explanation.

'Nyo thonele khamu, Nyo thonele khamu

Nye fakarna akhai mhu oh Ramu

Whaley gobara, Nye khai mhu rho tamu-ghi lobara'

We can go and meet, and we haven't come without reason Ramu. We came here to teach you Gurung language.

'Chow belaye bakhar, chow belaye bakhar

Nyo-ye Ramu fakarna rish aakhad

Whaley gobara, Nye khai mhu rho tamu-ghi lobara'

At around this time, our Ramu don't get angry without any reason. We came here to teach you Gurung language. 
'Nyo kamija khiba, Nyo kamija khiba

Khiji nga lai talija kho bhiba

Khiji whila-wa tamu-ghi lobara'

We wear shirt and why did you call me, did you call me to teach you Gurung language.

'Fultin kha sidha ladhu, fultin kha sidha ladhau,

Nye khuwye arrha, Nga lai dhi mahaf ladhau

Whaley gobara, Nye khai mhu rho tamu-ghi lobara'

Make the fountain pen's lid straight and I don't know song very well so forgive me for that.

We came here to teach you Gurung language.

'Nyo fakarna mha-ji, nyo fakarna mha-ji

England ley tamu-ghi lobara khaji

Whaley gobara, Nye khai mhu rho tamu-ghi lobara'

We were just lost for nothing and from England he came here to learn Gurung. We came here to teach you Gurung language.

'Jhula bheki sari, jhula bheki sari

Rhemey muyumeh chur khamu ngesari

Whaley gobara, Nye khai mhu rho tamu-ghi lobari'

Women and men come here in the evening and we came here to teach you Gurung language.

'Chaba-sey nyo ji chaba, chaba-sey nyo ji chaba

Nyo jammana talija chur khaba

Whaley gobara, Nye khai mhu rho tamu-ghi lobara'

We eat food and why do we all come here? We came here to teach you Gurung language.

'Ta chamu khuw whamu, ta chamu khuw whamu

Nge kwayumi chagana nuwhamu

Whaley gobara, Nye khai mhu rho tamu-ghi lobara'

Eats curry and throws away the soup but my grand-daughter can eat all that. We came here to teach you Gurung language.

https://sms.cam.ac.uk/media/2733519

\section{Mixed Gurung and Nepali song}

A group including Bopal and friends singing a Gurung song which goes as "Que thuba karuwa, dharima ladho nirimaya..." This song has the mixture of both the Gurung and Nepalese language. In our house at Dessain

https://sms.cam.ac.uk/media/2733536

Nepali song 
Singing in our house at Dessain

https://sms.cam.ac.uk/media/2733553

\section{Letter from Alan on 18th October 1969}

I hope this letter will not be too befuddled, but I am still slightly reeling after a drink of the local millet beer plus a large curry. it is the first day of Dessain and we were invited down to eat with our ex-Gurkha Lt. friend. For three days there is a constant round of hospitality. Tonight, for example, no one must sleep (to do so would shorten one's life by a year) and the villagers dance and drink their way from house to house. Numerous little rites to household gods, ancestors, village gods etc. are being done and a huge swing or rather 'big dipper' is being made up in the fields above the village. The proceedings are a little marred by the fact that two of the men of the village have died in the last week (one of them yesterday) and some of the villagers therefore can't eat salt etc. But there is a generally festive air and much slaughtering of animals - poor things. Even before breakfast this morning I was having chicken's blood and rice squeezed on my forehead. Meanwhile, with all the business of dividing up buffalo meat and making swings no one has the time or inclination to repair the village water pipe so that now we have to walk half a mile to get water!

... Talking of growing things, had a most exciting experience yesterday. We had heard that the village head had put a little fertilizer on one of his rice fields as an experiment so we decided to go along and look. After a delightful walk through dappled fields of paddy which flowed down the hillsides as far as the eye could see we reached the spot. He had chosen his worst plot. On most of the narrow strips the rice was unripe and thin - a meagre harvest. Right in the centre, however, it grew lush and yellow. This was where he had put fertilizer on. It was two feet four inches high on the unfertilized bit, a foot higher (on average) on the fertilized and the yield was just over 2.5 times the amount - some 160 (plump) grains per head rather that 50 skinny grains. The really amazing this is that people in the village are not really interested and many still doubt whether they will put the fertilizer on. For a mere 50rs the average farmer could almost double his rice crop, yet he still hesitates. Meanwhile the son of our Lt. friend has just returned on leave from the army with a 6-band, fully transistorized radio on which the Nepalese customs alone was 560 rs. The cost plus customs must have been 3,000rs (c.E120). This would be enough to double the rice crop of the whole village - or feed some of the Untouchable families for 4 years or so. Still, as an anthropologist it is not difficult to understand, and, in its own way, is little different from Vietnam and moon probes while the world moves towards starvation. ...After much red tape Gill's parents have at last been able to send out \&35 of movie and still films through the Thyssen House customs-free 'bag'. We will then buy the movie camera and bore you all to tears with endless films when we return - I suppose buying expensive film and cameras when the money could be spent on medicine or fertilizer is just as criminal as the behaviour described above.

\section{DIARY Sunday 19th October}

Second day of Dessain. Main event was the slaying of a sweet baby buffalo at the 'kot' to local god, accompanied by drumming and trumpet-playing. Apart from this a quiet day that passed quietly in collecting names of those given rice at Dessain, writing letters, etc. and reading. Gill very restless to be off. Went for a walk to Taprang in the evening - passed the young people playing on the 'kudi' swing. Thought of home a good deal.

\section{Letter from Gill on 19th October 1969}

I hope you got my last airmail form written on the 6th October and posted, we hope, on 9th or 10th. There is some doubt as the as the British Library forestalled us by one day by sending one of their men up to Thak, instead of us sending a porter down from the village, as the Librarian wanted information from Alan re his qualifications, as Alan is giving a talk there in November. Also planes are not flying between Kathmandu and Pokhara, as they are laying a concrete air strip at the latter, so we don't know until we go down this Friday whether mail has been getting through, or going out. There is another possible route, from Kathmandu to 
Bhairuwa and from Bhairuwa to Pokhara via a road, and if the planes still aren't flying when we go down we shall take this route ourselves to Kathmandu. In any case we had arranged to go to Bhairuwa first as the British Recruiting depot is there and Alan has written to the officer in charge whether he can look at the medical records of men who have enlisted in the Gurkhas from Thak, as this would be a general method for getting a rough picture of their health, at least of adolescent males.

...Meanwhile we are struggling through the last week of our 7 week stretch. I say struggling as no matter how ideal everything is, and it is in theory at the moment - superb weather, day after day filled with blue and yellow and the white mountains, health excellent, and the village ultra friendly and cooperative - it is always a strain to be here, communication wise most of all, and hardly any privacy, and then towards the end, the physical drawbacks like no running water and feeling dirty most of the time. The village water pipe has just broken down to add to the strains, and everyone is having to trudge more than half a mile away for a pitcher of water. Nothing is being done to mend it as we are in the middle of the Nepali version of Christmas, which means endless sacrifices to the gods, much slaying of buffaloes, goats and chickens, and much inter-visiting between houses of relative. Most of the village are all interrelated some way or another, and give each other food gifts and drink the home made spirit (millet beer).

Last night there was also dancing, with no one supposed to go to sleep, if one did it would lessen one's life by a year, and groups went round from house to house, dancing and then drinking and generally living it up. They started off in our house and Alan played his guitar and one of the Gurung boys accompanied with a drum, and about twenty others crowded in and clapped and sand, and we felt quite festive. We went and watched one other group outside another house, and this was pleasant with a crescent moon and overcast stars, and the fireflies dancing in and out of the horns of the buffaloes, which were tossing them wildly, much upset by the throbbing of the drums. The young Gurung males glimmered as they danced in the darkness, and the hills stretched away to a smudgy infinity towards India, the village cats prowling along the roofs, shadowes slipping by in the night. We did go back to sleep after that, but not a very deep one, wakened several times, so feeling slightly smudged myself this morning. Today is the main village sacrifice at the temple and the Tailor musicians have been drumming and playing their horns since dawn, and the children up on the hill making swings and the Gurung version of the Big Dipper, everyone going up this afternoon and having a kind offair time on the mountain. (cont.)

\section{DIARY Monday 20th October}

A jolly day spent drinking 'pa' and having milky rice squeezed into our foreheads by village grans. Gill was visited by Sheila (Peace Corps) and we went up to swings, etc. together. Today first Tibetans came begging again. Did a test with maps to see who had field in 1883, 1933 and present - very satisfactory results. Should be fascinating. 


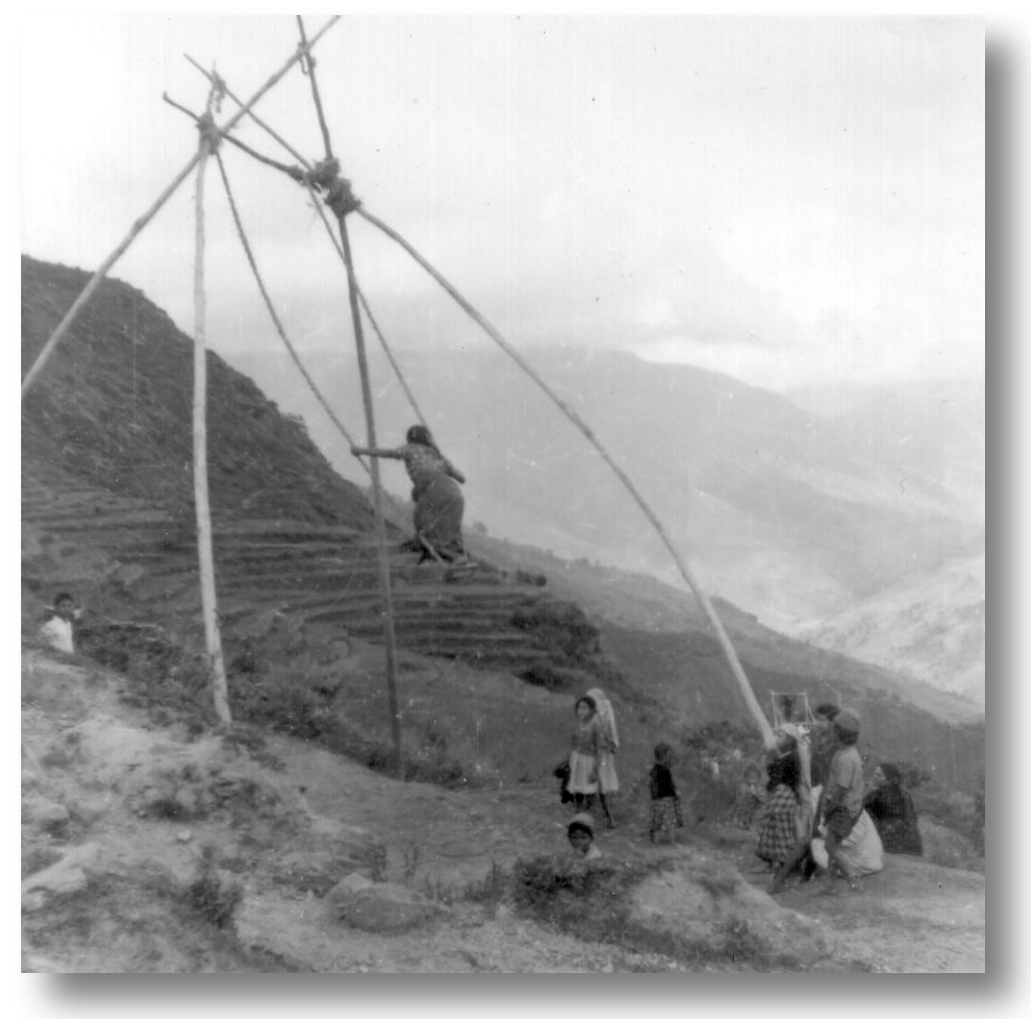

Tall bamboo swing for Dessain - 20th November

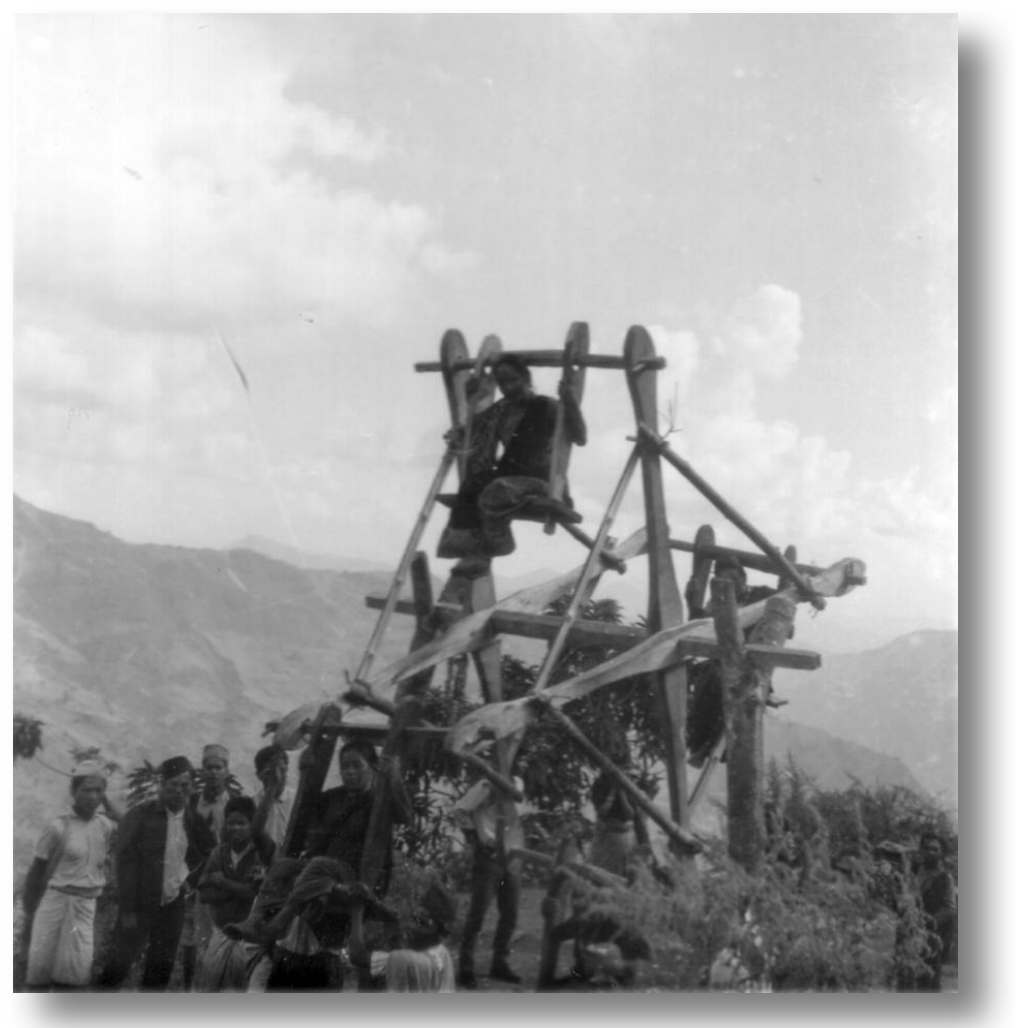

Girls swinging on four seat wheel put up for Dessain (three photos) 

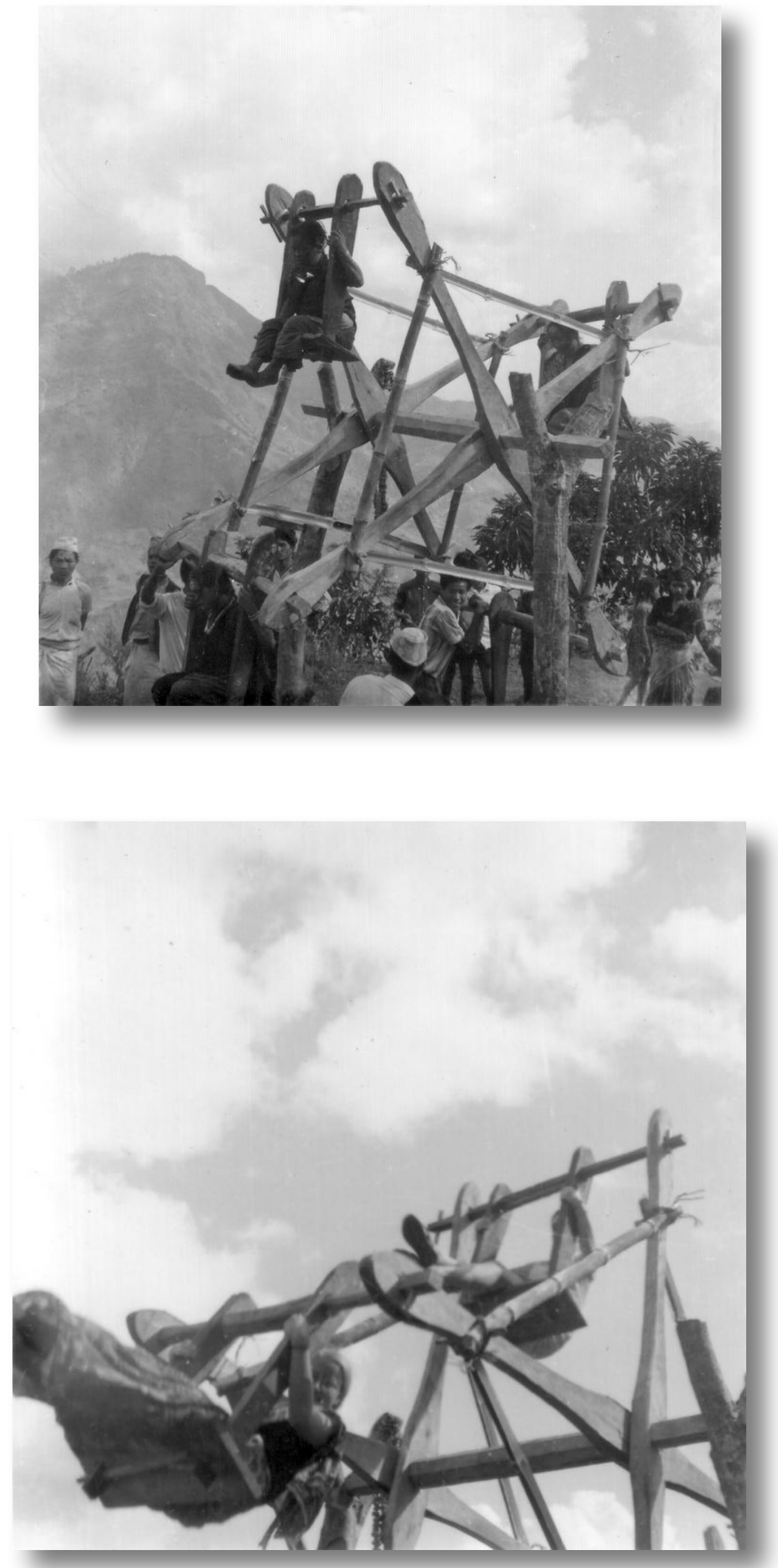


\section{Letter from Gill on 20th October 1969 (cont. from 19/10/69)}

Took a break offyesterday to go and watch the village sacrifice. More gory than usual as they were decapitating a sweet, little grey baby buffalo and one felt that this beast at least had a right to live. It was done near the main temple of the village in a hollowed out part of the ground which is supposed to be a very old (about 200 years) sacrificial spot. The only comfort is that the deed is over so quickly that the animal can hardly feel any pain, although what with the drumming and singing and the expectant waiting of the onlookers it must feel a little unease before the sword comes down. Later in the afternoon we went to watch the swings, a huge one made out of bamboo potees that must have been at least 25 feet longs, and a more sophisticated structure which had been carved out by the young men of the village, a kind of revolving wheel which has four seats suspended from $i t$, so four people can be creaked round by hand. Both structures were creaking and swaying furiously when we went up and looked as though they would crash down at any moment. Much pretended horror that we were too frightened to go on them and Alan getting invitations from the more luscious, flirty females to go and join them on the swings at night.

Alan has been working extremely hard with the poju, having four to five hour sessions in the loft nearly every day. I have been breaking down the rituals onto index cards to see if we can make out any meaningful pattern in the structure and content of the rites - extraordinary ones like the poju rushing around the village with the head of a goat between his teeth, and ropes suspended through the roof with flowers at intervals which, if they shake, means that the spirit is returning via the rope. We have also been going to see a few of these in the flesh, the most spectacular of which finished about two in the morning, having started at 8pm. The sick person was an old man who had felt ill for some time, and whom the poju had diagnosed as being made sick by witches. When we went along the poju was already sitting on his rain shield, cross legged, purifying his instruments by a blown type of spell called a mantra - these consisted of plates of millet and rice, brass bowls with pure water and marigold type flowers stuck in the top, and iron cup with a satisfying curve to the handle which had red hot embers in it, a long wooden horn, a leather bag containing his medicine which he sprinkles on the embers and smells like old socks.

Meanwhile more millet was being ground on the verandah between two round stones, the last three turns to be done against the direction the women usually grind, as a precaution against witches. This millet was to be sprinkled over the doorway so that by looking at marks in the dust the poju could say for sure what kind of evil was afflicting the old man. This time and ant walked through it and since this is a very small insect it was a good sign and meant the evil wasn't too overwhelming. Since the poju went on for hours chanting in incomprehensible Gurung we stretched out on the gritty bed which had been sweetly prepared for us, and Alan went to sleep despite the smoke and the bugs, but to refrain from itching too much I watched the scene lying down. The whole was lit by a flickering oil flame, and the three women of the house were teasing out some vegetation from the forest which they make into a kind of tough linen, sitting crouched over it on the floor, round the three sides of the fire, their shadows cast on the walls making them look like the three ominous Fates, the poju being the God murmuring his irrevocable laws. The light was extinguished about midnight, and the sick man was woken up and put inside a bamboo basket, and ashes from the river were thrown all over him, the poju blowing his mournful horn. Then the lights were put on again, and some sticks lit at the nearly dead fire and then the fine millet dust was also thrown over the patient, through the fire of the sticks so that it flared and fizzed round the poor old man, who hopped in his basket with the scorching, much to the delight of the poju and onlookers who chortled with glee every time the millet flared up. This was apparently extinguishing all the evil spirits in him, and when this was done the hen was sacrificed, waved over his head, and then the poju went outside and fired a flaming arrow, to keep the spirits in their rightful place, up there, whilst we stood on a dung heap and sleepily hoped the arrow wouldn't set fire to any of the surrounding thatches. The poju then returned to eat a full-scale meal of chicken and rice, we only having curried potatoes, so hot they made one gasp, and then staggering off to bed. Again this sort of experience is where I really feel we are seeing the Gurungs as they see themselves, and most of the defences are down so that we get a feel in depth as to how these people are... 


\section{DIARY Tuesday 21 st October}

Went to watch the poju making a 'jantra' etc. and wrote letters. Also did three and a half hours with poju and finished the 'pae lava' 'pie'. Overcast day with rain in evening. Heard Prem and his Gopal had gone off to (Indian?) army.

\section{Letter from Gill to Mac and Iris on 21st October 1969}

Sitting in out freshly spring cleaned loft, a faint whiff of cow dung instead of polish, with the sun making warm patterns through the carving of the window on the clay floor. The women do all the houses before Dessain which means replastering all the walls and floors with clay and dung, so you can imagine the chaos upstairs when we had to move nearly a year's pile of papers, files, rat dirt, rice husks and stray feathers from the sleeping bags - in the midst of all the dust clouds and confusion one gran plus a baby tottered up the ladder wanting medicine, and then two visitors from another village demanded a chat, all they got was a baptism of water pouring through the cracks from the loft upstairs... The buffaloes are producing here at the moment and there are lots of furry grey heaps in the courtyards, their noses between their hoofs, with the bony old mother licking it, looking even more ravaged but contented. A baby was decapitated at the general village sacrifice, which was horrible and the only consolation is that the killing is efficient and they can hardly feel any pain.

We are longing for the break from the village when we go down to Pokhara this Friday...I feel very tired, can't think why as it is Alan who has been straining four or five hours a day in the loft with the poju, but we have both got these bites which turn septic and which refuse to heal, obviously our diet is lacking somewhere but I don't know where. We have had fresh greens every night in this 7 week stretch - beans, spinach, radish leaves etc. and take vitamins, must ask the doctor when and if he comes, as the villagers are riddles with these sores too. However they are very minor compared to dysentery and in many respects it has it had been one of the best sessions we have had. The last few nights have been rather sleepless with all the celebrations, and last night we had just got off when there was a thudding at the door and shouts of 'Ramu!, who stomped off very cross in his pyjamas to be faced with a little finger practically sawn off, it had been crushed in the swings on the hillside. I stomped down even more cross and sleepy, but melted a bit at the sight of the boy who was in pain and got Dettol and bandages with a little more good grace, only to lose my temper with his elder sister who was chattering hysterically saying he would lose his nail and his finger but finally got some peace to bind it up as best I could. The entire family descended on the verandah at Gam even before we had boiled up the porridge, much shouting and abuse from mother (at the boy) who delighted in refusing to believe me that nails do grow again, mother and three sisters shouting at the boy for being so stupid, no sympathy whatever. Fortunately there were not any more serious accidents, as the swing poles were over 25 feet high and someone could easily have been killed. (cont.)

(cont.) Testerday was fun as an American Peace Corps girl teaching in Pokhara came up to pay us a visit, and I enjoyed showing her the village, and the swings and our favourite people, as well as my retreat spot up the mountain behind the village, which she agreed was lovely too. I had a hard time of it from the women as Shirley was wearing a sari, and they said this was what I should look like, not my normal, graceless Western self. Shirley felt we lived much more 'basically' than she did, euphemism for strong smells from the bucket in the corner of the loft, no chairs and pitch darkness downstairs I think, still she had been here 21 months so should be immune to side effects of primitive living.

As you will gather from Alan's letter, he is rather thrilled with all the material gleaned from the poju, he is with him now watching him make a 'jantra', a spell which the children wear round their throats as a protection against sickness and evil spirits. We have had some of our best experiences by going to his various rites, one of which he must perform on an average of one a day. Magic must surely be their religion above everything else. We managed to get ourselves invited to an eight hour session which must have finished at $2 \mathrm{in}$ the morning. The patient was an old man who used to be the song master for the dancing groups, very sweet and kind, asking me if I was sure I wouldn't like a fried egg (great delicacy) at midnight, just before a basket was turned upside down over him and he was sprayed with river dust and flaming millet by the poju, the millet (having been ground by the daughter just before, the last three turns against the usual direction as an anti-witch precaution) 
was flung through a clutch of burning sticks and fizzed and flared all round him, poju and daughters chortling and the old man hopping with the heat and scorching. When the evil spirits had thus been driven out of him, and the poju had shot a flaming arrow into the air to keep the evil where it belonged, us standing on a dung heap underneath the stars sleepily hoping the arrow wouldn't set the surrounding thatches alight, they all went back to the house, very lively and ate a full scale meal of rice and chicken curry.

We had been given the main bed to sleep on whilst the poju was chanting and blowing his mournful phallic horn and throwing medicine which smelt of old socks on the embers - all preparatory to the fire and dust exorcism. (There should have been boiling water too, but the old man asked to be exempted from this - that might hurt.) Alan went to sleep, despite the grit and the smoke and the bugs, but I lay on my back and tried to absorb the atmosphere... There were three women, as well as the old man, a daughter, a cross-cousin relative and a neighbour, as well as the daughter's little girl, and all four females were teasing out vegetation they collect from the forest which turns into a kind of tough linen. They sit on the floor, one leg up and one horizontal with the clay, heads bent over the stuff, one oil lamp burning, their shadows like the Three Fates teasing out our existence, the poju being God chanting out His irrevocable laws. From my position on the bed looking into the light, I saw the rectangle of the woman's head with the head cloth coming into a kind of tucked bustle at the back, her hair divided into thin strands by the light at the ear, the earring large and round, capturing the hair in the centre; the daughter with the bony, angular face tucking her head cloth back with a surprisingly fluffy movement, as it is made of the finest tulle instead of grimy cotton bought from Pokhara bazaar. The way the daughter recharges the cold fire, laying three burnt out sticks end to end with infinite precision and then putting empty corn cobs to catch the flames when they are blown from the embers; the cobs looking like glowing pine cones when they are almost burnt through, the ridges black and clear. The brass pots catching the light from the oil lamp in shining vertical lines tripping themselves on their fat little bellies. The beams glistening black on top of the gossip the daughter having to go upstairs for potatoes and chillies, the creak of the beams sounding surprisingly strong. The cat tucked up on the old woman's chest, asleep beside the girl in her clothes. The white thread to be put around the old man's neck, looped over a corner of the fire frame, dripping with soot. The rice baskets and drying mats rolled in through the beams of the ceiling, as if they were immutable objects, never used but an extension of their surroundings. Finally the rusty trunk from Malaya where the lamp is sitting and lights the orange wood cask and the wicker basket like an C18 French interior, at play with shadows. What a mixture in its way, with the relaxation and blending in of objects so satisfying to look at together with the dirt and the bugs and the fug of the atmosphere with the doors closed...

\section{DIARY Wednesday 22nd October}

Rupa/Ramu and co. went very early in the morning and we felt rather lonely and sad without them. Our plans of going to river foiled by a thunderstorm - the worst we have had in our whole time here. Water even came in through the back wall and we had to eat 'chura' inside house. Even some hail and we were horrified to think it might have carried away the rice crop. But don't think it did too much damage. Did two and a half hours with poju and packed up things for Kathmandu - in case we can get to river tomorrow. Went to a meeting to decide who should do Comal's grandfather's 'pae' - decided it should be only lama. Gill wrote letters. Our sores won't clear up, despite penicillin and gentian violet - curious. Young men playing cards a lot today. Gopal and Kaila off to 'rodi' in Noledada.

\section{Letter from Gill on 22nd October 1969}

... We are midst grime and dust at the moment, clearing out before we go away on Friday for three week's break in Pokhara and Kathmandu. I have just cleared out our medicine chest (my small green case) and a heap of yellow and brown and white pills have just been thrown to the chickens, hope they've got dysentery so that it will cure them too. Sweet of you to worry about mine - you will be pleased to hear that I haven't had any trouble at all in this 7 week session, and neither of us has ever been so fit. The only trouble we have had is leech and ant bites turning septic and refusing to heal, but penicillin clears it up after a week. The Gurungs have these sores 
badly too and I must ask the doctor when he comes up to help us with the medical survey what the lack in the diet is. Can't think what we are lacking. We have fresh greens for every evening meal (beans, spinach, radish leaves etc.) eat eggs daily and take vitamin pills. We should have gone to the river today for our fortnightly scrape down but it actually hailed this morning, after a month of blue and yellow days, not a wisp of cloud round the mountains, which have been looking magnificent. Much gloom and fear in the village as a lot of hail can ruin the rice crop, due for harvesting in 2 weeks. Horrible to think of near starvation just because of a whim of the weather. It has been looking so beautiful too, every terrace a forest of gold and green, every stalk so tall and elegant with its dipping grains yellowing at the top. However, when we went to the loo this morning after the downpour only the millet looked a little flattened and the lower lands where the rice is were probably okay.

Despite being well we both feel like a break. Alan has been working very hard as always, mainly with out poju (magician) taking down all the rites and myths and also trotting off to hearty Gurungs' verandahs to get them to draw up a detailed map of the fields, who owns each terrace etc., so that an idea over time can be got of landownership and growth of families economically. Talking about growth of families we have at last introduced our Birth Control Programme, at the annual village meeting where it provided the entertainment, diagrams of the loop being waved against the Himalayas, and the condom (do you eat it?.) glistening in the sunlight held between the fingers of the head of the village. There is a beautiful poster at the water tap, stuck with cow dung, the 'good' two children family and the 'bad' seven. Despite its resplendence it always embarrasses me slightly, it is so untrue, but the Gurungs love it, and it provided conversation whilst waiting for the buckets to fill. We have had six requests for pills so far, hope to goodness they can manage to take it regularly, they love the little arrows which tell them where to stop and start.

Concentrating on the rites in theory we have also been to see as many as possible, the poju must do on an average one a day at least. The most exciting one was a six hour session finishing at two in the morning, where an old man had been made sick by witches. He is a poppet, the songmaster of the village and kind and hospitable - they gave over their bed to us so we could sleep it we got bored, and he tenderly enquired whetier I wouldn't like a fried egg (great delicacy) at midnight - just before he was popped in a basket and had burning maize and dust from the river thrown at him. The poju had been incanting for hours, sitting crosslegged on his rain shield, with and array of instruments in front of him - bowls of rice and maize for the gods, ground millet, the last three grinds done backwards as an extra precaution against evil spirits, his long, mournful phallic horn, and his magic medicine which has a spell blown over it at the beginning, and which he sprinkles over embers in an iron bowl and the smell is like old socks...

... The village has just finished the national version of Christmas so it is relatively sleepy at the moment, the men having drunk themselves heavy with home brewed whisky, and the adolescents dancing all night, playing drum to Alan's guitar, and going up on the hillside to play on home-made swings $25 \mathrm{ft}$ high, hence accidents. There was much sacrificing of goats and chickens, as well as a sweet little grey buffalo for the village which was rather horrible. All relations and friends visited each other and had rice and milk stuck on their foreheads with a blessing from the eldest member, so this gave us a chance to check on kinship etc. Alan doing one group and I another....

\title{
DIARY Thursday 23rd October
}

Storm last night. Tidied and prepared for Pokhara. Gill washed and did most of the packing while I did another four hours with the poju. Finished almost all work with him and had a look at his old scrolls, etc. Managed to salvage a pile of old manuscripts from him [PHOTO IN KING'S] - might make a future thesis for someone. Read some Meredith.

\section{DIARY Friday 24th October to 13th November}

Off to Pokhara today for up to three weeks holiday - have been longing for this...

\author{
Letter from Alan on 26th October 1969
}


... You will be interested to hear of the result of an experiment tried by the headman of this village. On his poorest rice fields he put some government fertilizer and instead of the thin, unripe, 2'4" (average) high, 50 seed per head rice of the surrounding fields, he has fat, ripe, 3'4" high, 160 seed per head rice. Yet though it would cost very little to double their rice yield - the total cost for the whole village would be little more than the price just paid by a young serviceman who has come on leave with f100, 6-transistor, radio (on which the customs alone was $f^{22}$ - they seem uninterested in doing so. As at the moment when the villagers are willing to spend immense energy constructing swings etc. to celebrate a festival, while they cannot be bothered to repair the village water-pipe so they have to walk a long way to get water, so in the case of rice their motives are not our motives. Profit-seeking, individualism etc. are not so strongly developed as in our society. After all, there is only a certain amount of rice they can eat and what would they do with the rest.? There is no conception of selling to Pokhara. Here they contrast very strongly with the Brahmins who, say the Gurungs, will starve themselves so that they can sell their crops. Here prestige is only partly derived from how much you have stored - it comes more from how much you give away and whether you have been in the army etc.

My work goes very well and my mind is full of the strange rituals and myths told me by the local magician. It seems impossible to believe that there is a world of shops and telephones and television sets and comfortable chairs. But after a few days at home it will be equally impossible to imagine that this little world under the high mountains really existed - hence the importance of films...

(note added: Fust arrived in Kathmandu (29/10/69) - waited till we got here to post. Very well just savouring thought of a bath! Also films have arrived. Saved about f112 on customs. Many, many thanks!)

Visit to Kathmandu, late October 1969

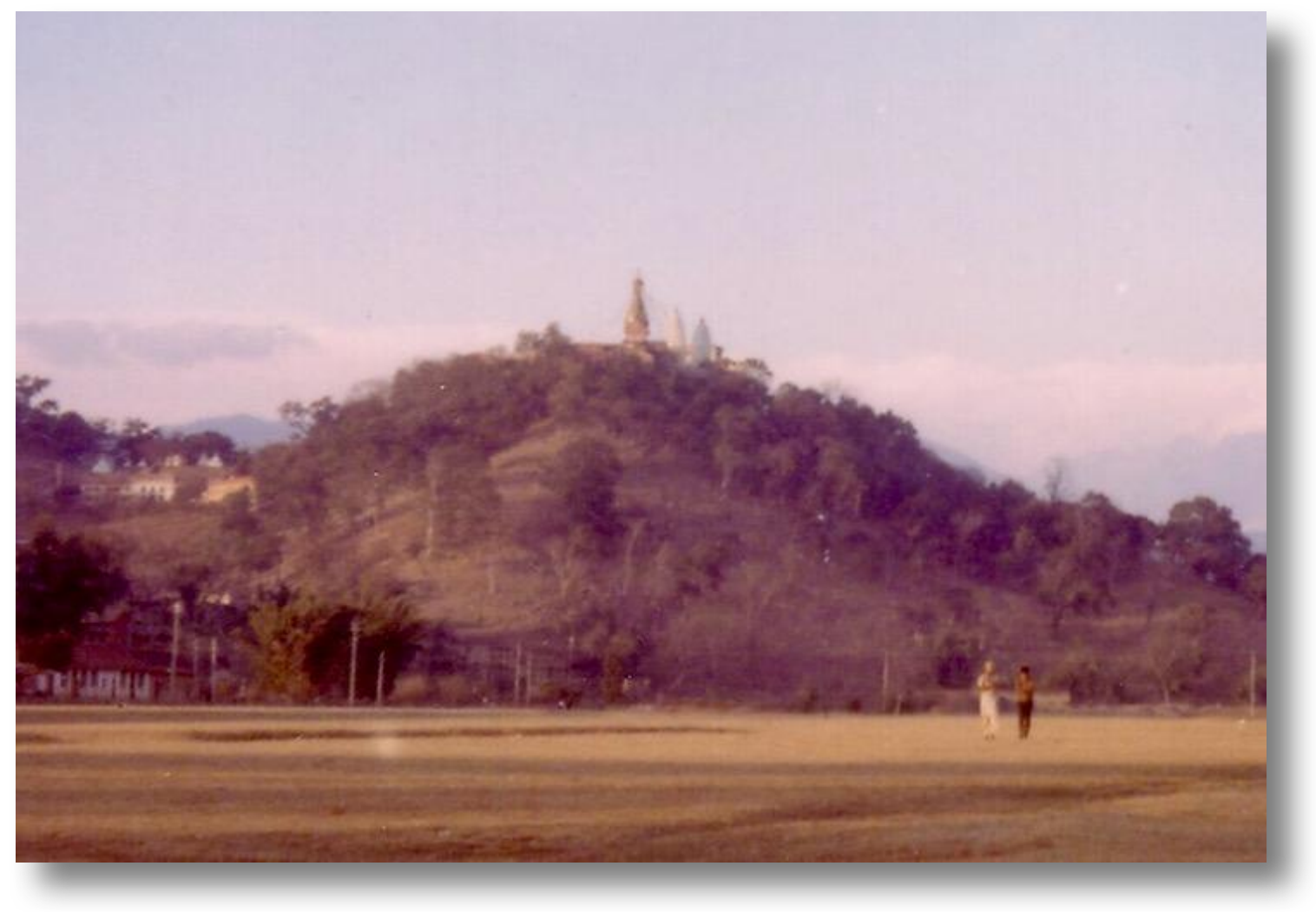

Swyambunath Buddhist Temple, Kathmandu 


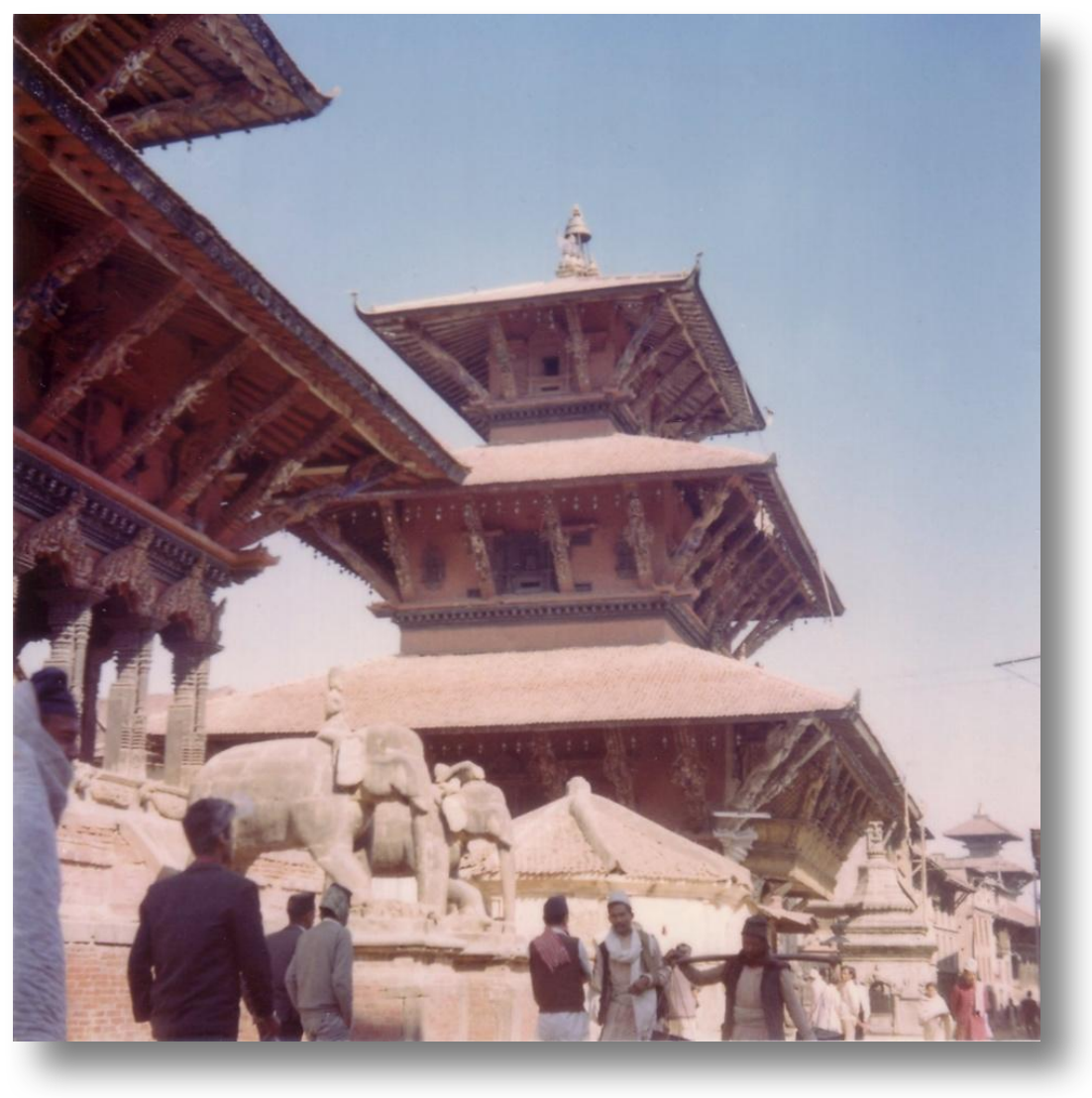

Temples in Kathmandu

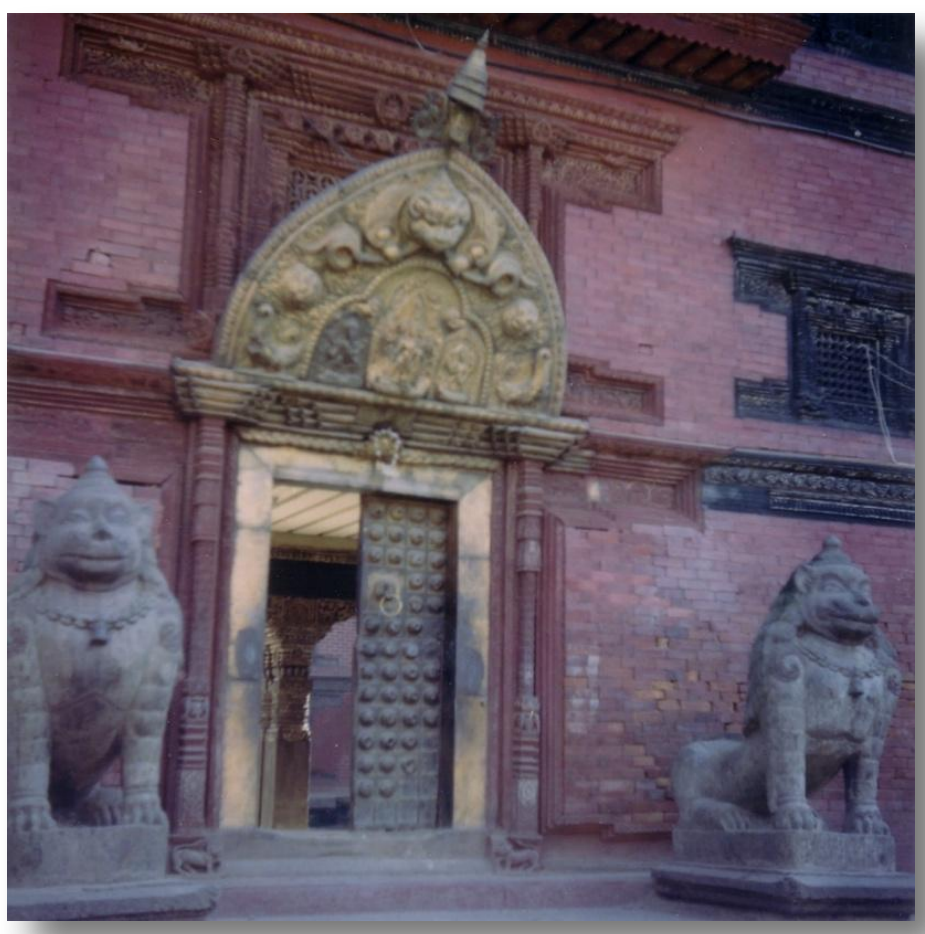

Kathmandu 


\section{NOVEMBER 1969}

\section{Agricultural photographs - undated}

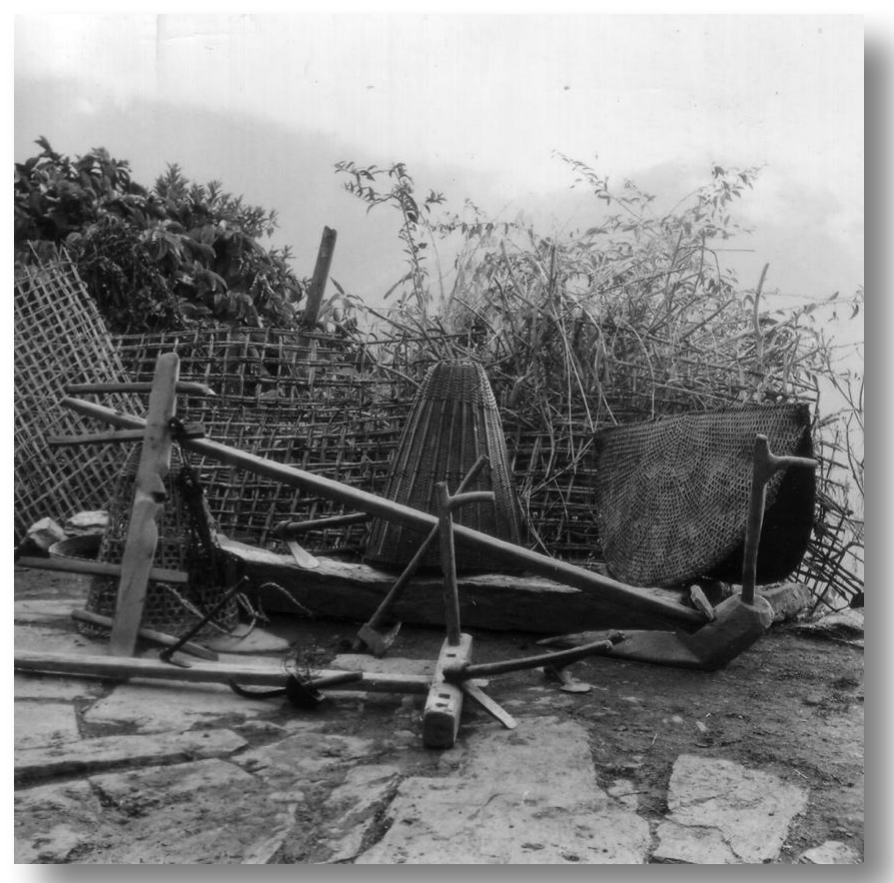

Agricultural tools

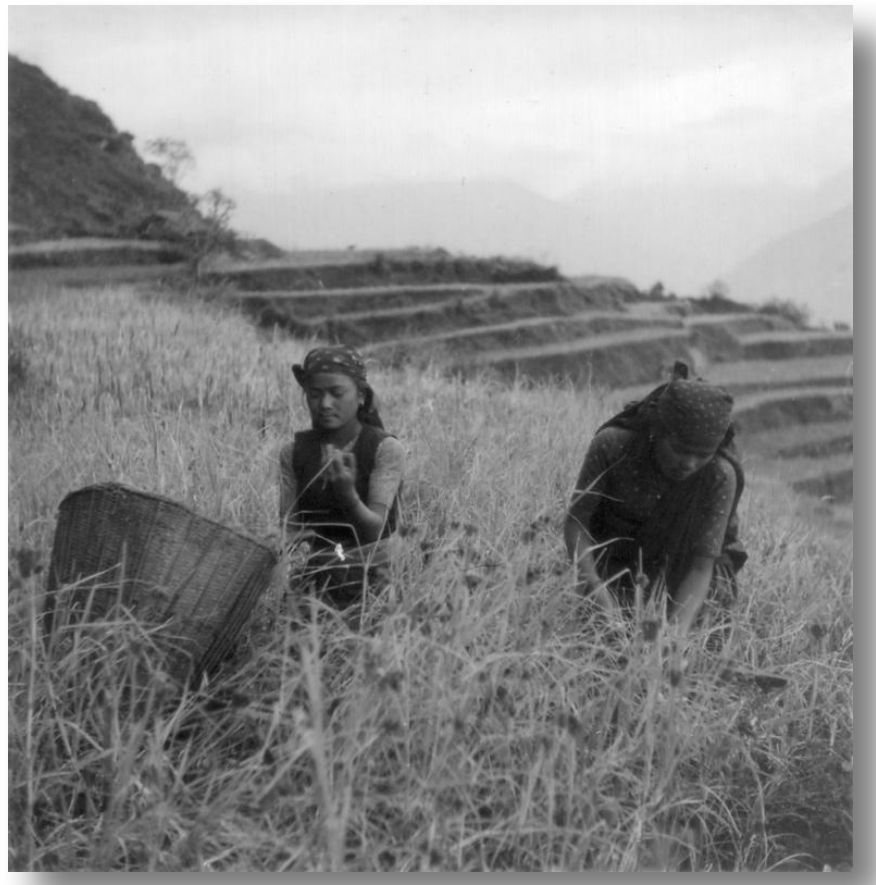

Two girls picking millet 


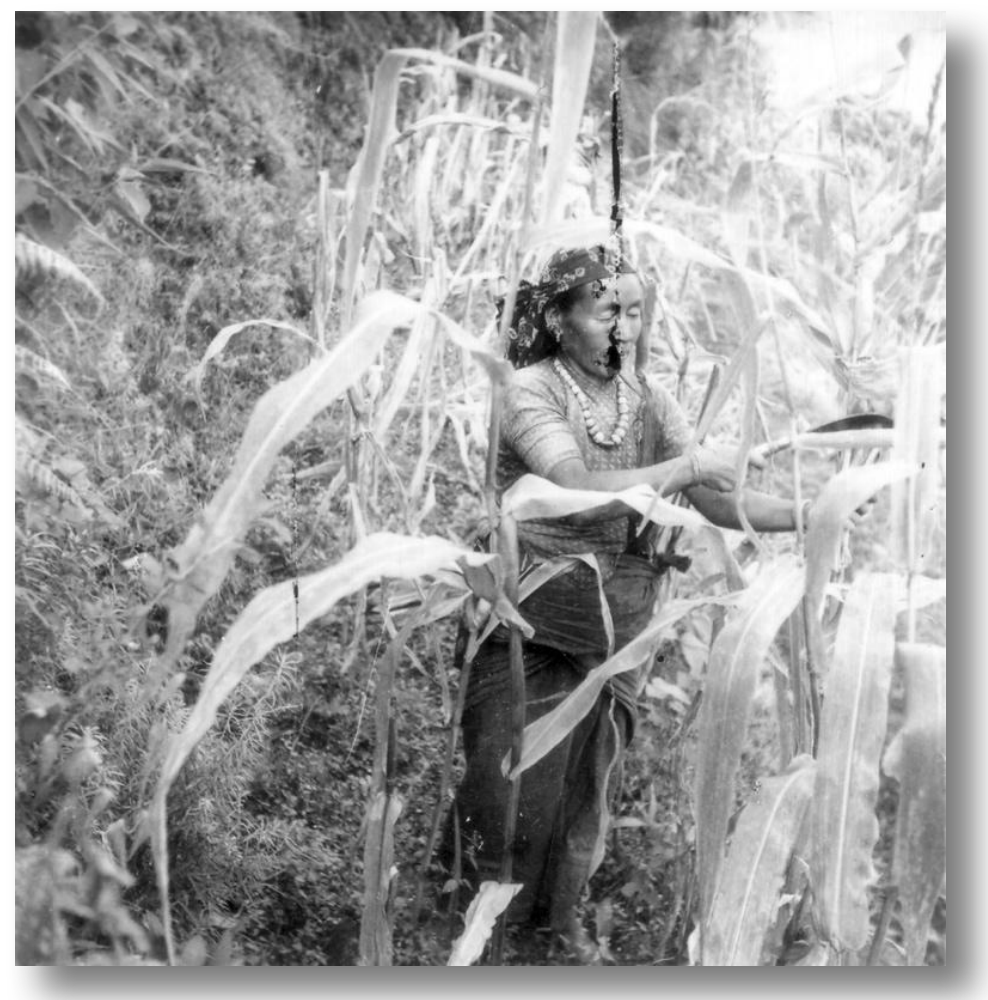

Woman cutting maize

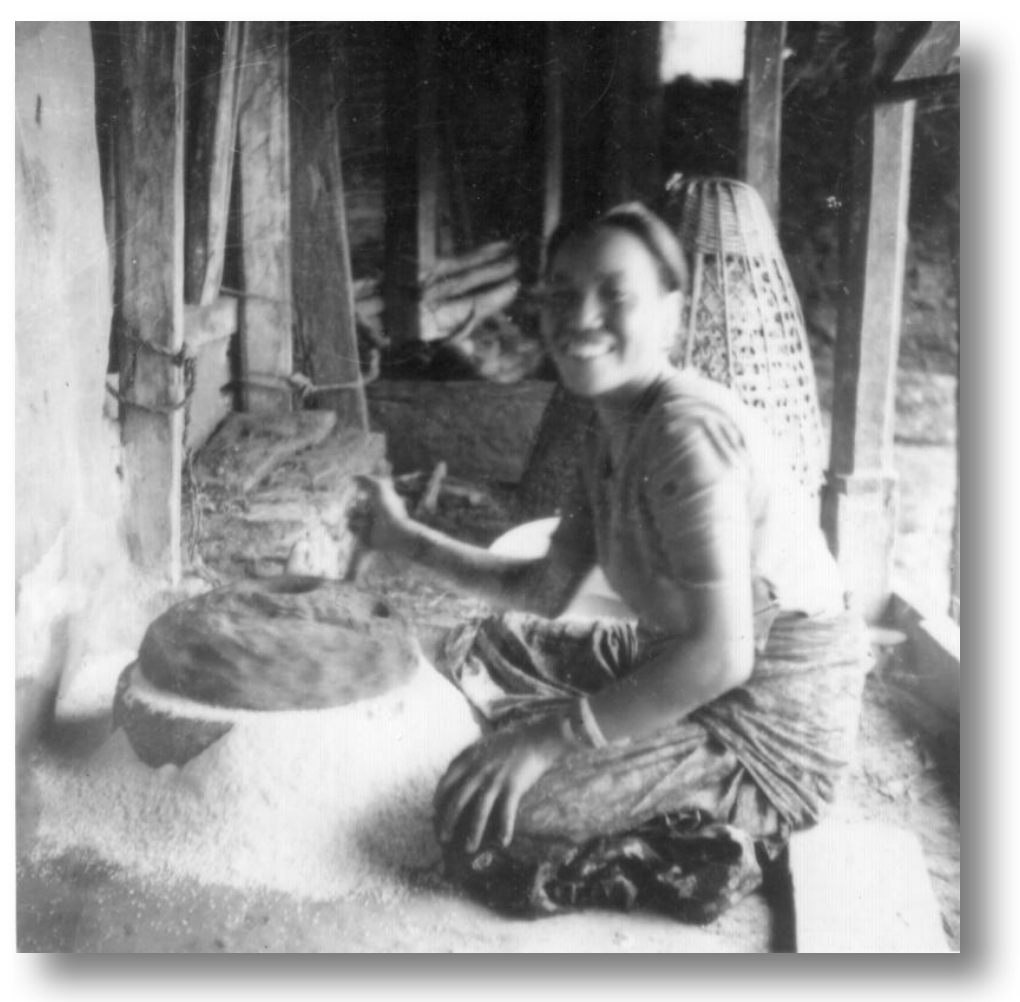

Dankumari grinding maize with a quern 


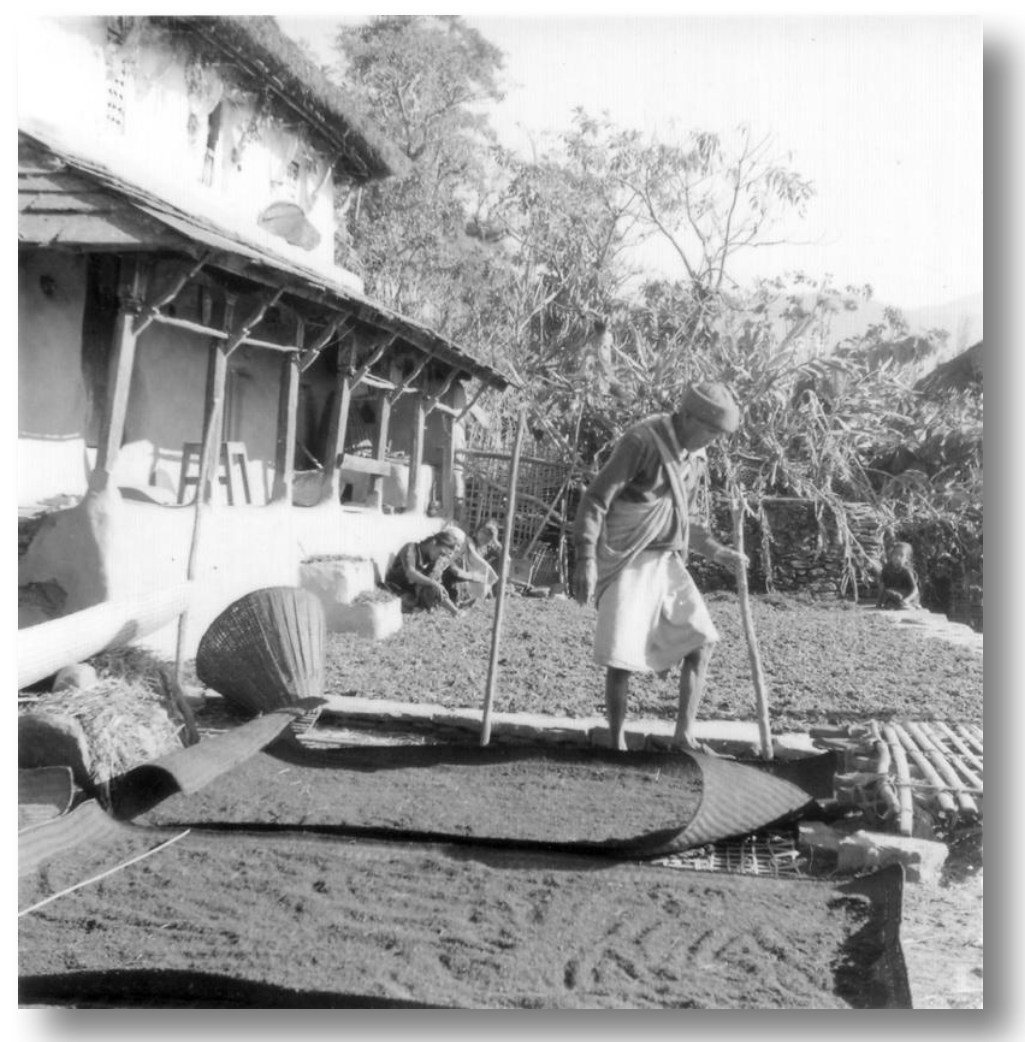

Millet drying outside House40 - with Narbir

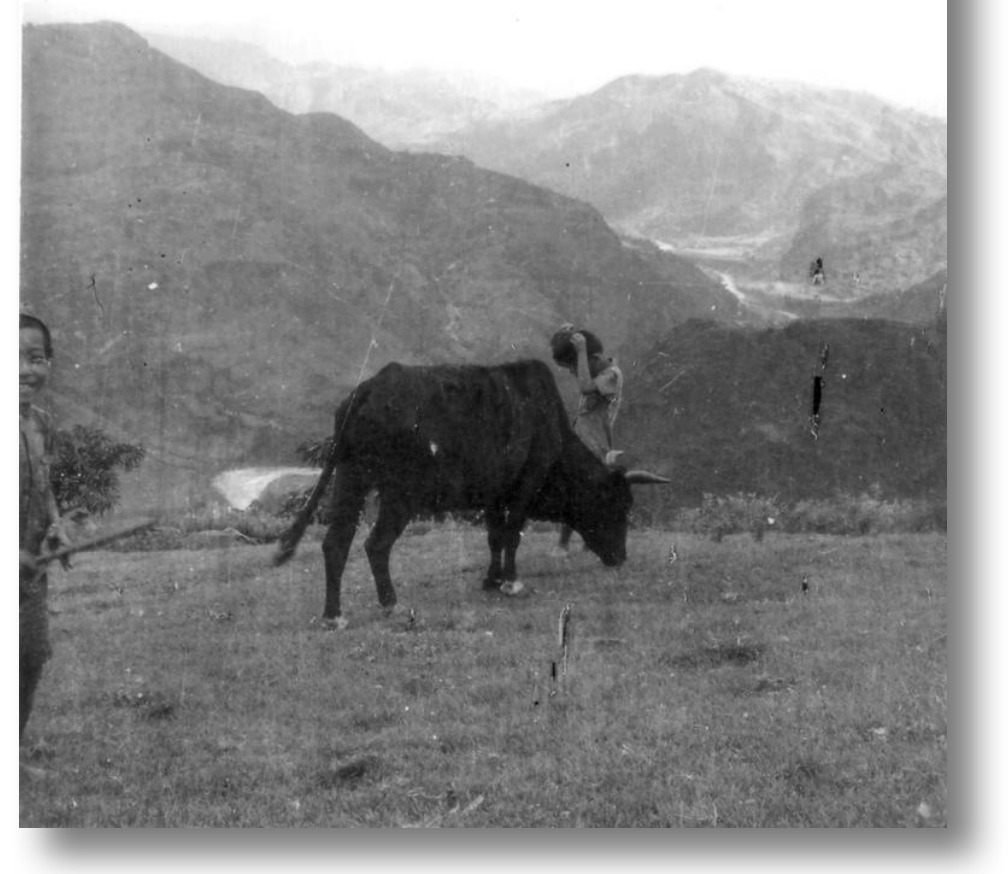

Boys herding cattle 


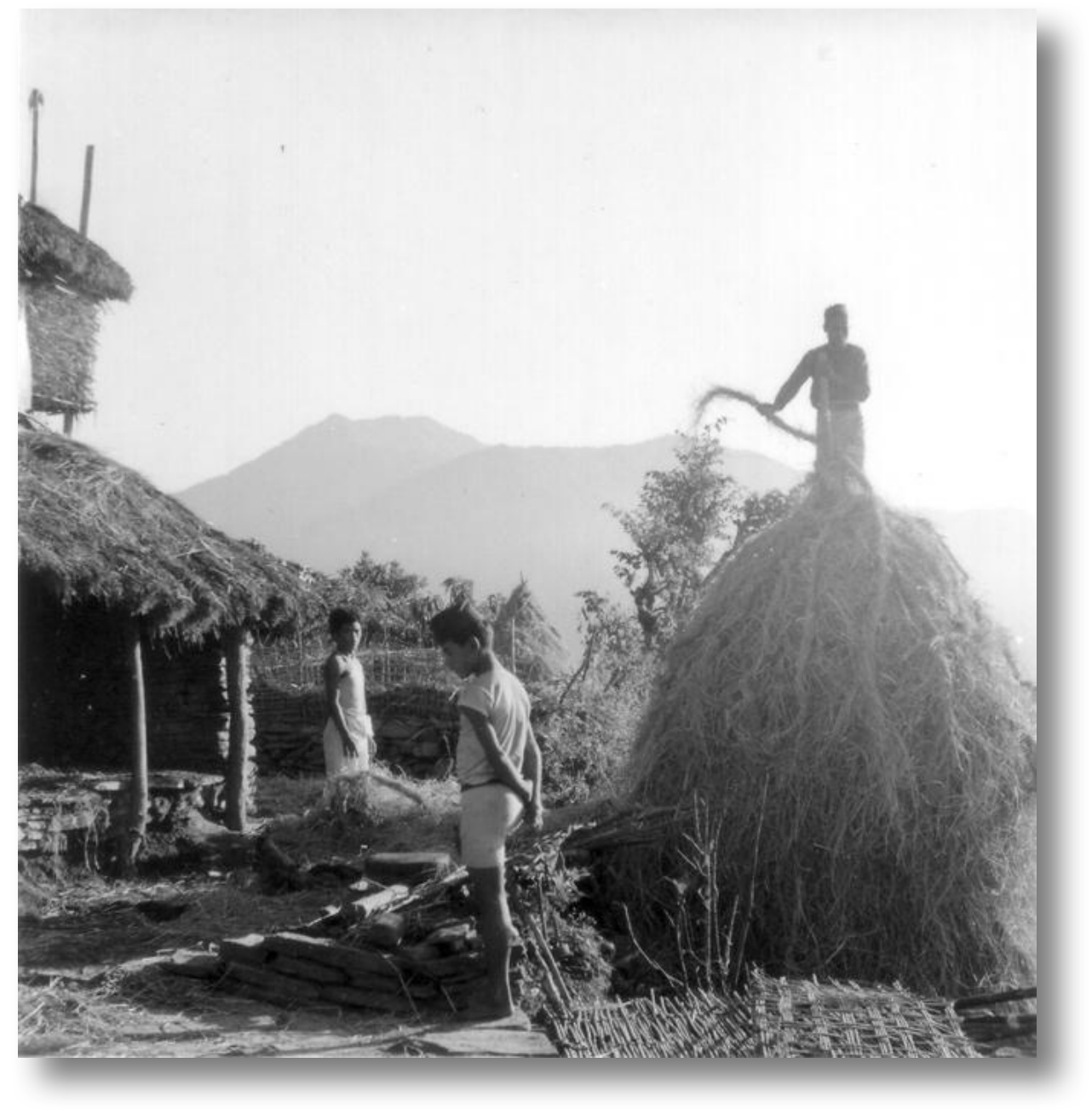

Making a straw stack

Letter from Gill on 1st November 1969 from Kathmandu

...Nepal Research Centre, Thyssen House... We are both physically well at the moment, just irritating things like my getting dandruff, which I never had in my life, and which I think must be due to a lack offruit. We are eating masses here though as the markets are chock a block with oranges, apples, bananas, mangoes, lemons etc. Pokhara could produce these things, but lacks initiative and interest. However, we are not enjoying this place, which is idyllic, as much as we feel we should - for many reasons, for me I think the main one is knowing I have to go back to the village again, like an operation looming on the horizon, even though one is perfectly fit at present. Alan feels guilty at all this lushness when there are beggars in Kathmandu, and the fact we are the only guests here at the moment. Also he is writing a talk for the British Library in Pokhara on Aid, and this is so appalling and depressing that it is blackening our total outlook at the moment. Nothing succeeds, thousands of millions of dollars have been poured into this wretched country since the revolution (1950), and there is a total lack of responsibility on the part of the Aid givers, notably USA, in that they don't bother to enquire what the country really wants, nor do they care, Aid being merely a political gambit to keep a balance of power in a buffer state which is between China and India...Alan would like to work with Aid programmes when we get home, having been out here and experienced the situations where it is most needed. The majority of Kathmanduers haven't been out of the valley, and there is very little feel of a nation - hence one of the reasons for the failure, the country just isn't ready for sophisticated outside help... 
Letter from Gill to Mac and Iris on 4th November 1969 from Kathmandu, Thyssen House.

Back to decadence again in this De luxe research centre, where even now I fancy they are dusting the cacti, and three gardeners are crouching lost on the lawn looking for a weed. We have been the only ones here so far, up till last night, and feeling is a bit like a convalescent home, facing each other at meals across acres of sterilised tablecloth and feeling guilty if one leaves a pillow out of place - and like most hospitals it is run for the administrators and not the patients so any upheaval is met with a frown. However, I don't know how I have the nerve to complain after all the dreams of ice tinkling in the orange drinks and the cool green bathroom when we were in the village, and the loo is still a treat even after a week of sitting down and being able to contemplate, instead of ducking down in a series offrenzied dives when a wood collecting party come up our hillside from the village. Also the view is just as comparable - the oldest stupa in the valley, over 2000 years old and beautiful, glittering in the sunshine with its 13 tiered top on a wooded hillock about three miles outside the city. We should have been going back today, after arriving last Wednesday, but the planes were so booked up to Pokhara that we couldn't get a seat until Friday. Alan was a bit frustrated as you can imagine, as if I find the place less than paradise you can imagine his Puritanism running rampant! However he has found work to calm his guilt and had biked off happily this morning to the Bureau of Statistics to copy out a national census which includes Thak done in 1954.

We came down from the village on 24th October...the whole beginning was a bit anticlimaxish as the Tibetan hotel we always stay in was full, the showers weren't working and the loos stank, so although they offered us a bed on the table in the dining room, we declined as we heard mosquitoes were raging. Actually we managed to find a thatched barn, much cooler and quieter for half the price - three rupees a night - and the beds were canvas instead of board so sleeping was much more comfortable. I missed the exotic Annapurna clientele though, so we trotted along for breakfast and a wash under the field tap, hiding the sponge bag in case the owner of the barn might be hurt by a refusal of his buckets! At the tap...

...I don't know whether you can remember your last letter, but it brought us round to discussing things a bit you said you felt we found Nepal, and more especially the village, disappointing, and could not I have done some teaching etc. and improved the language and our knowledge of the Gurungs that way, and generally be more relaxed in the village itself. First let me say that Alan is fairly fluent by now in colloquial Gurung and can even follow the poju for five hours with spattering's of old Gurung when they are discussing texts or rites etc. I am not half so good as I have a very bad ear for tone to begin with, and don't have as much contact on specialized topics with the Gurungs, for another. Also I have found out that I could never be an anthropologist as I hate extracting information, especially when I think they are reluctant to give it, and I have often sat beside Alan squirming inside with embarrassment, but he has gone on regardless even though just as miserable as I in the beginning, but persevering and thereby lessening the tension. It is so odd this - as my work exactly consists of dealing with unwilling and suspicious people and winning them round to a degree of trust. I think the difference is that I feel in control at home and think I understand the situation, whereas in the village I feel sometimes I don't know what on earth is going on and a quarter of the language is sometimes worse than complete incomprehension as the strain of getting the drift but not the details is very frustrating and also paranoiamaking! The bit about being in control gives rather sad food for thought, almost that one has to have the upper hand in order to relax. Also in the school they teach in Nepali as a matter of principle and anyway I would feel hopelessly incompetent in the teaching field, apart from the language, and am too feeble to overcome this feeling.

I think we have given the impression of having less contact with the villagers than we do - in fact we often feel we have too much and long for privacy. We never eat or prepare an evening meal alone, and can often have six or seven Gurungs, mostly children sitting round, and this can be fun and it can be frantic and reduce me to screaming point. We don't love the villagers en masse just as we wouldn't love an entire group at home, but I think Alan has more affection for them than I do. We both feel a little that it is sentimental to talk of friends in any meaningful sense, although it is a cult with anthropologists to talk about their tribe in this way...I feel much about the village as I do about my clients, ambivalent, with acute affection in patches and much frustration and a sense of distance in others - without any responsibility in the case of the village which perhaps makes me give up more easily and thereby lose the rewards of trying very hard to understand/love them. Sorry - 
this sounds very defensive, and of course it is, and I do feel bad about getting angry and fed up and tired with the Gurungs. On the other hand these are absolutely real feelings and by now I do feel secure enough to let them show, which might give more dimension and meaning to the times when I doctor them, or talk about babies, and sons going away to the army, or the fear of illness.

One other aspect of all this is that being constantly together we do tend to talk about and perhaps magnify negative feelings. In many ways I think Alan would have been better and more contented on his own, and learnt Gurung quicker and better not having the relief of getting back to English again. Of course it would have been lonely, but this would have driven him to the Gurungs more and they in their turn might have felt more responsible and given even more than they have done - which is a lot. I introspect too much and this influences Alan, even though he fights against it and I think in the field one can lose a whole world by just concentrating on one's own reactions. Finally - just to get the whole business off my chest - I do miss my work, even now I dream about clients and wonder how they are, and have had to get used to the position of a woman in this society, where education is restricted to men in practice, and open equal discussion between the sexes has not been accepted. There is often bewilderment with informants when Alan wants to discuss a matter, especially money, with me and some of the men are hurt if I go along to take notes and not Alan, me being very much second best! Admittedly this is funny more than anything else but if one is feeling a bit low then it can make one feel even lower! However the last 7 weeks were the most relaxed and accepted that we had and I think we will me much happier in our last 3 months, especially with the knowledge that we will have to get as much out of it as possible and the feeling we are beginning to understand the village a fraction and ourselves even more. .... sad about the fruit and veg being ravaged, we had the same feelings in the village just before we came downwhole terraces being wiped out by half an hour's hail, near starvation just because of a whim of the weather. Here at the moment it must be well into the 70's with a slight breeze blowing the typing paper, lovely for biking and temple-trotting which we did yesterday. Poor Alan looks so sad and resigned when I drag him from his books on aid and economics (giving a talk on this at the British Library on the 9th, our fee for the librarian dealing with mail!) but we will never see the like again and am getting quite excited by the Buddhist and Hindu art here. Yesterday we went to the main Hindu temple by the river Bagmati, Pashupatinath, and were frustrated at not being able to see the silver doors and golden cow at close quarters only Hindus are allowed in and an officious and insolent Gurkha soldier to check that infidels were kept at bay. However, found a lovely C6 Buddha, standing, half submerged in the soil and a fat and luscious Lakshmi three hundred years older standing on a sleepy tortoise. Much preferred a Buddhist stupa which we biked to afterwards for atmosphere, lots of gay independent Tibetan children playing games, instead of Hindu beggars which made us flee the other place, despite the water and the bridges and the echoing rows of temples lining the river bank. Sadly the all seeing eyes with lovely blue eyebrows and the curly nose painted on the four sides of the temple were swathed in scaffolding so even the gold was lost in the sun, but there were lots of baby temples around, and the houses sat in a circle facing in towards the shrine, lopsided and wobbly, were completely engaging.

Had a hilarious if isolated morning at the Museum just along the road, took fifteen minutes to get a ticket, the doorkeeper away and great discussion as to who should take his place especially by the man holding the key to the tickets; and then my bike was parked in the wrong place, and I could not take my bag into the museum so could I please leave it on the handle of entrance door? When I finally did get in only other people there were cleaners, sloshing water energetically over the floor and my feet and dribbling cloths over the glass cases so what with the dribbles one couldn't see what was in them. There was what one might say a catholic collection - full length portraits of Queen Victoria with roses in her hair and Prince Albert in uniform over a vigorously obscene god of war, all pairs of arms waving with a splendid erection just about to invade some grovelling female goddess in an appropriate post. Also a lot of tankas and lovely metal Buddhas with a helmet on the staircase which nearly tippled over with a fearsome clank when I walked past and then on to hideous 1930'ish portraits of the Ranas. This must just have been the gems of their collection as the museum proper was closed so I dread to think what was housed there!

... We have also met Macdonald who works in Paris and who edited Pignède's book on the Gurungs which has been our basic reference book out there. He was a strange man, lively but disparaging everything he could lay his hands on, from the Sherpas themselves, stupid and pretentious he said, to the food at Thyssen House, tasteless, God knows what they do to it. However, he did think we could look at Pignède's notes and more or 
less gave us and invitation to go to Paris, and for Alan to talk to the students. He had been working amongst the Tamangs studying their people who become possessed by gods and trying to pick up written Tibetan texts, as there is a lot available if one knows where to look... We had an Australian couple to dinner, the ones who were very kind when we first came here and were miserable - they are linguists working in some kind of cooperation with the University and have written a few articles on Gurung syntax and have compiled a small dictionary, very useful for us at the beginning. Unfortunately there is some kind of religious complication which makes some areas embarrassing. Their main aim is to translate the scriptures into the vernacular, although in reality they are much more academic, at least the husband is. It is rather sad when one instinctively likes people very much and then realizes that one's total outlook is basically at war. Fessie talked of the 'spiritual darkness' of the Buddhist monasteries for example and this just shut us both up like a clam. They are going out to their village again on the same flight as we, and we have had an invitation to visit them, so that should be interesting and busy enough to keep off awkward topics!

... We came down from the village on 24th October...fly back to Pokhara this Friday, 7th...Sadly we have been the only ones here [Thyssen House] up till last night when a German professor from Hamburg arrived.

However, we invited the Australian linguistic couple I have spoken of before (Jessie and Warren) for dinner and endlessly compared notes (they are working on the Gurung language). By coincidence they are leaving for their village this Friday, and have booked on the same flight as we and have invited us to stay for a few says when we are in out last stretch, so this should be a welcome break. Also met a French scholar who edited the only book on the Gurungs there is, as Pignede, the author died before writing up his notes, and have got an invitation to go to Paris and look at his notes, and perhaps talk to some of the students. He in his turn brought a young and lively Englishman along, who turned out to be learning Tibetan and earning his keep by teaching English at the hospitals in the mornings. He invited us to see a French film at a pukka hotel tomorrow evening, and so we invited him back here for dinner... so our social life is beginning to flourish!...

...We went to the University one day, a lovely site banked in with purple hills, and the women taking the last of the rice in, the fields golden and green in the sunshine...I looked at books on art and prepared for visits to Buddhist and Hindu temples the next day, whilst Alan visited the Vice Chancellor and tried to get permission to copy out the 1954 census, to no avail. a law of Parliament will have to be revoked to allow him to do this!

Yesterday we biked to the sacred river Bagmati and were frustrated at not being allowed to see the temple proper, with its huge golden cow and worked silver doors - Hindus only. However, we wandered on the opposite side of the river and found some lovely C6 stone carvings of Buddha, half sunk in the ground and a sweet little wooden temple with erotic carvings round the frieze. We took some photos with the movie camera by the way, there were some sweet baby monkeys eating bananas on the Hindu goddesses, and Alan is very thrilled with the camera [Alan notes it cost f20]. He thinks with your effort re the films we must have saved over f 35 as the films cost over double here. Thank you very much, they were beautifully packed and arrived absolutely safe and sound... 


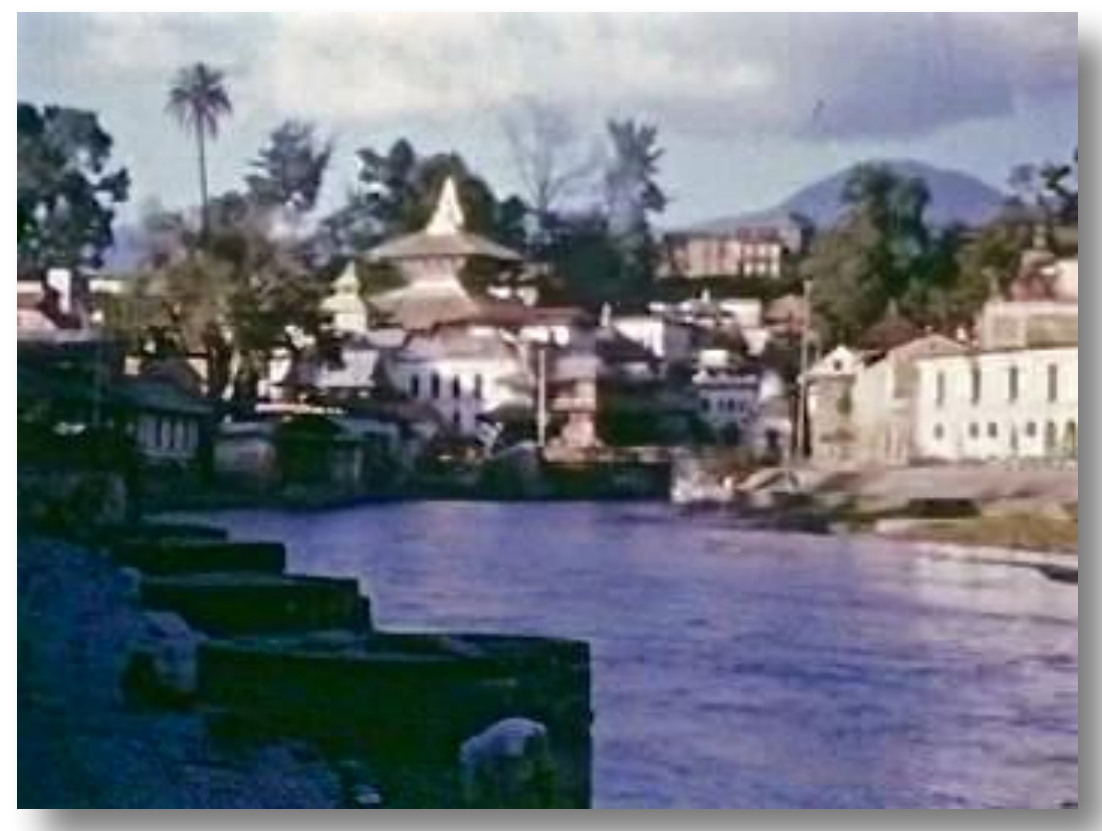

FILM in Kathmandu, 3rd November 1969 Pashupatinath Temple

https://sms.cam.ac.uk/media/2735116

Pokhara buildings and scenes in November

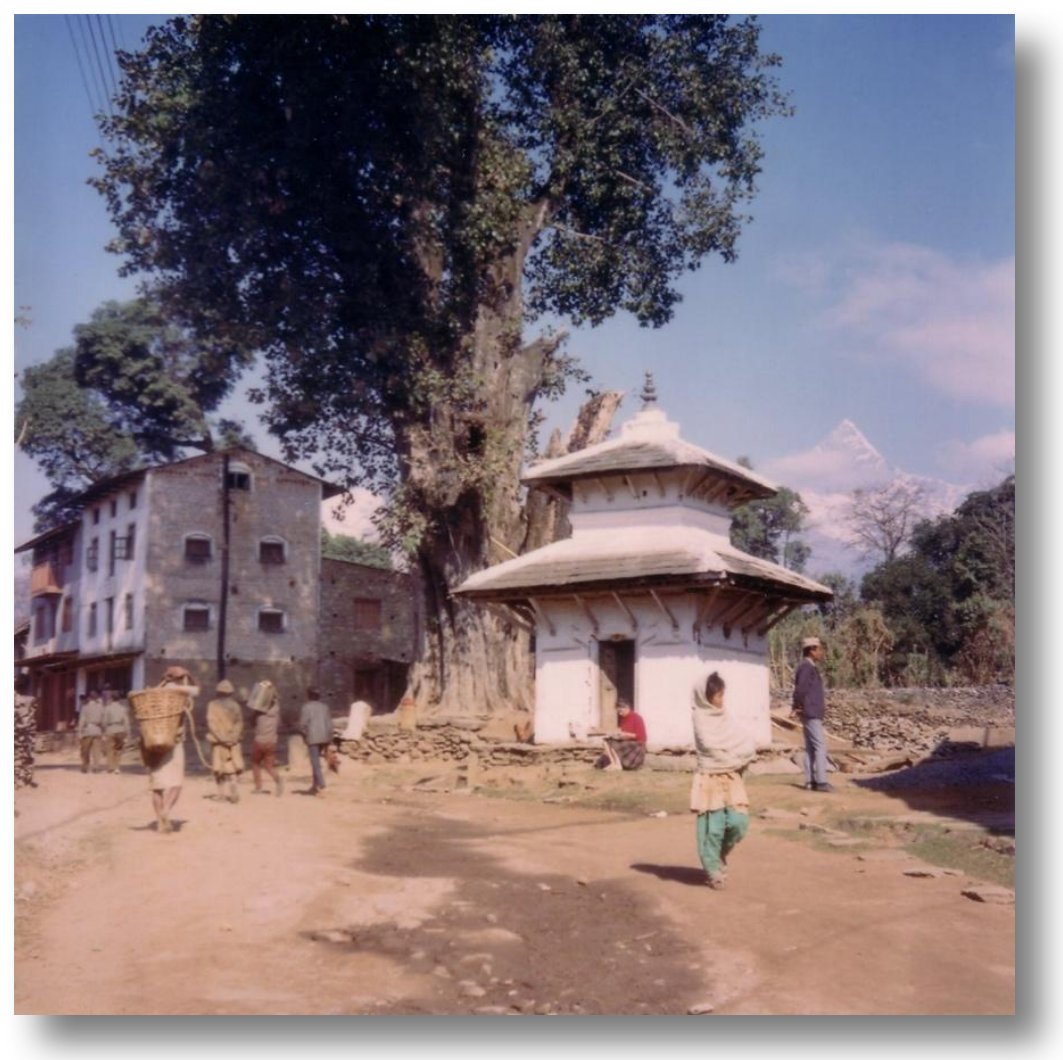



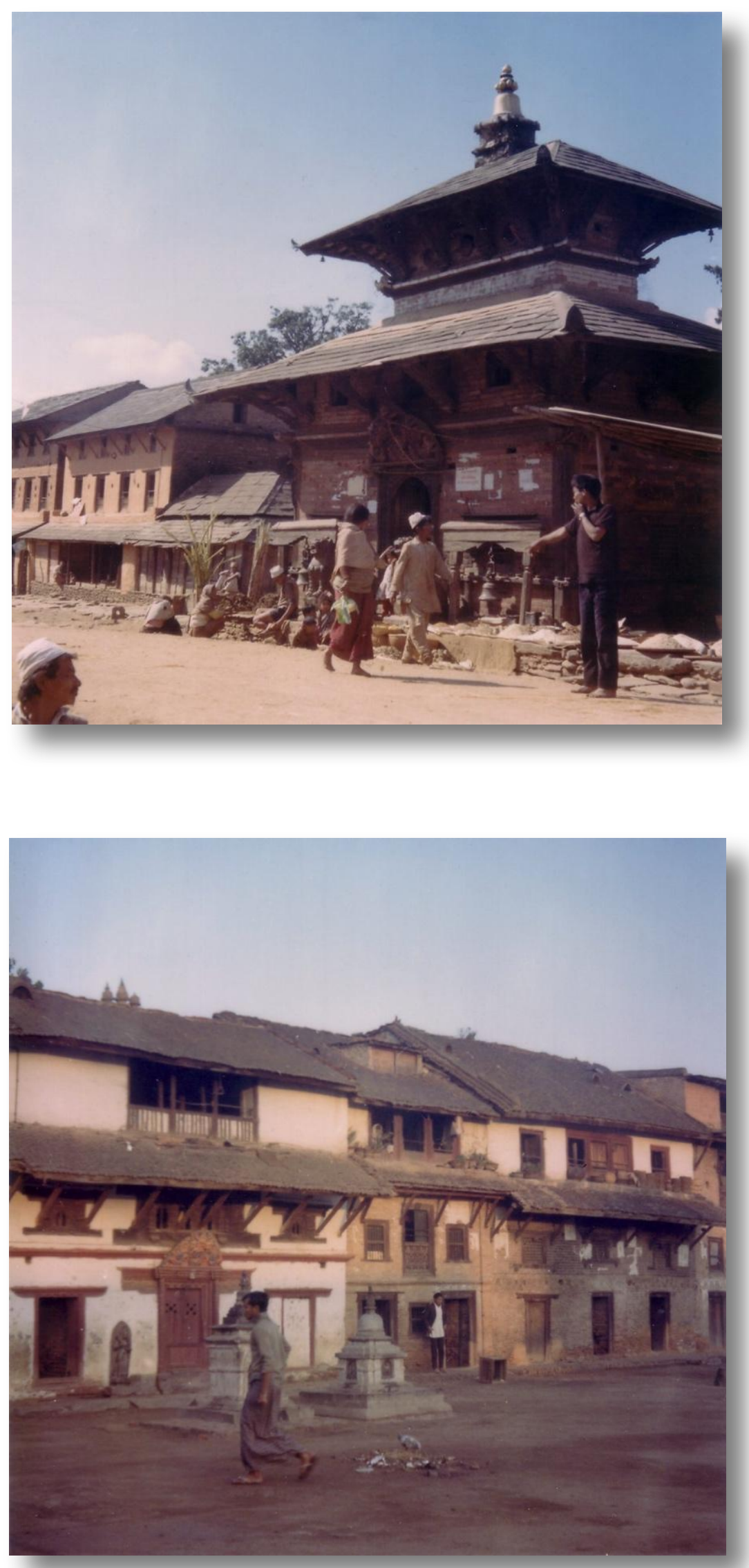

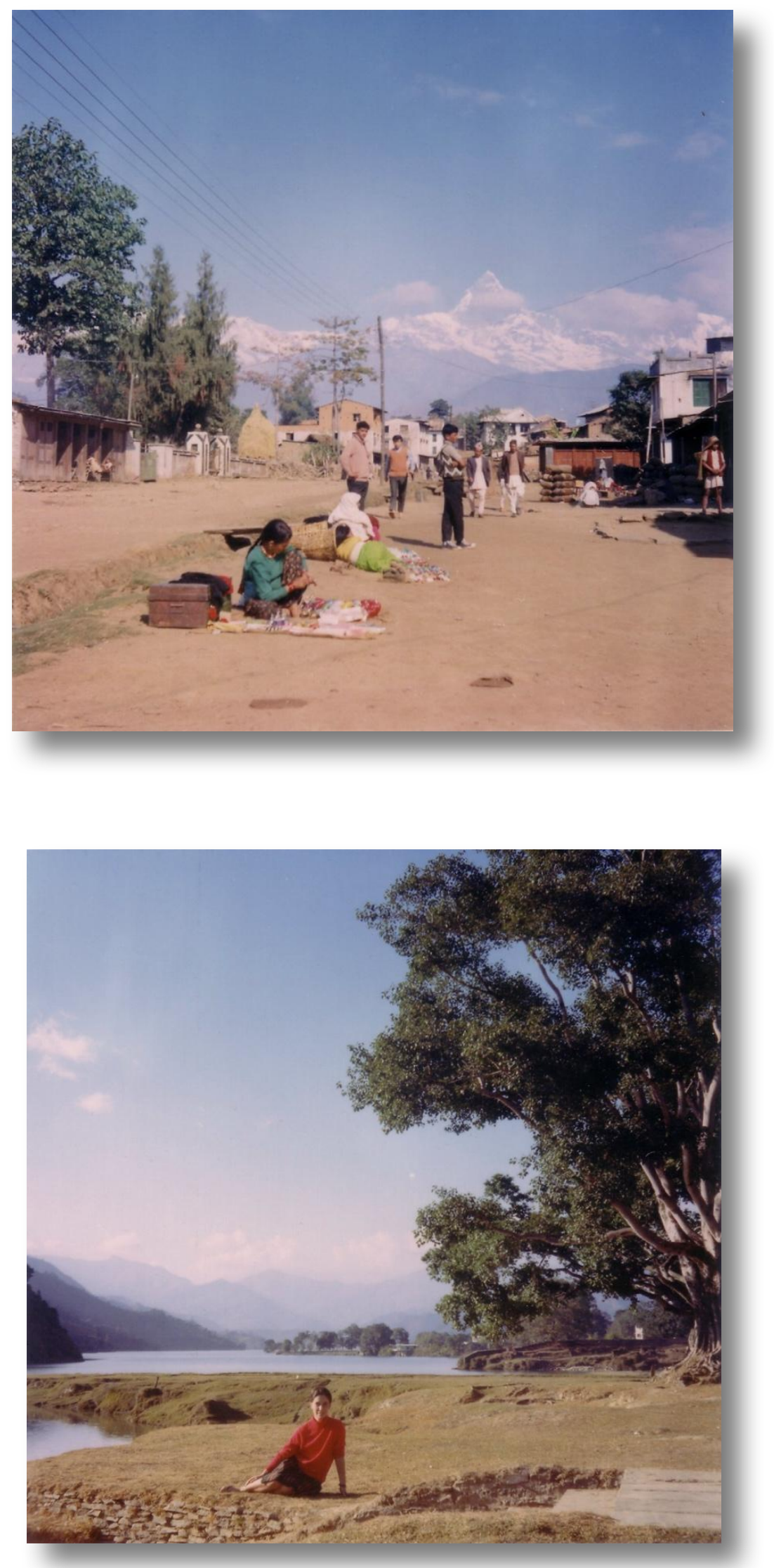

Gill sitting beside Pokhara lake ('Phewa Tal') 


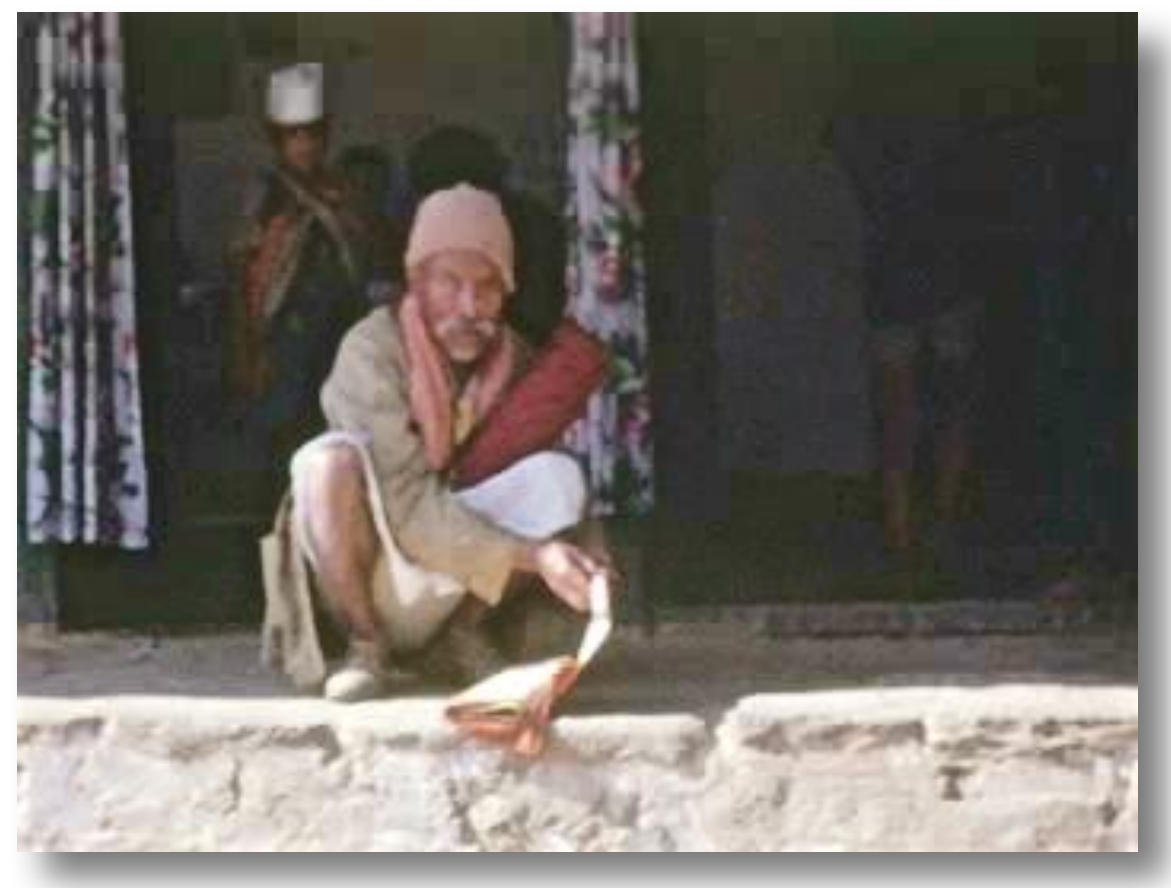

FILM. Old man sitting outside a restaurant with a scroll, Pokhara https://cam.ac.uk/media/2735088

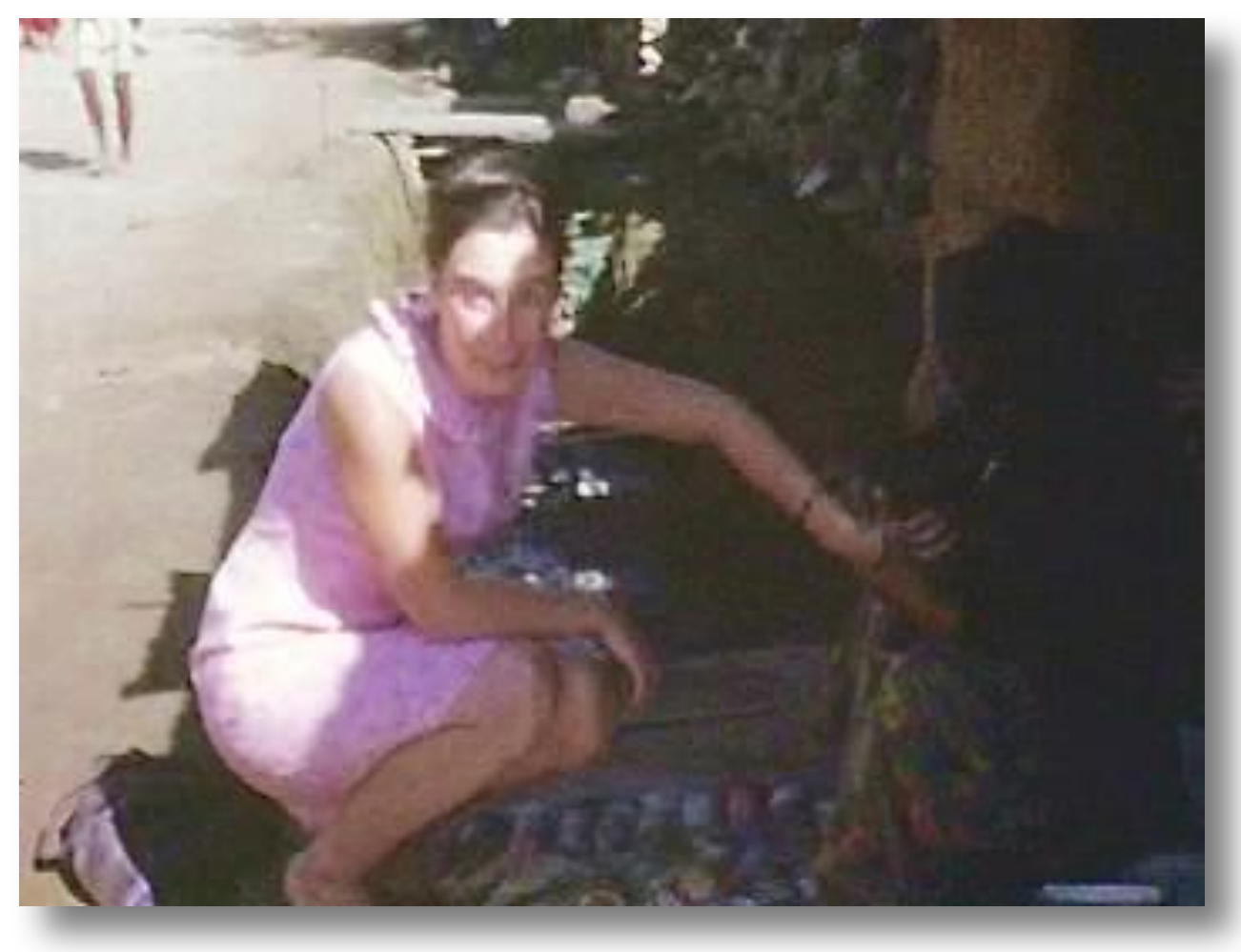

FILM. Gill having bracelets fitted in Pokhara bazaar, November 1969 https://sms.cam.ac.uk/media/2735144 


\section{Letter from Gill on 9, 10, 11 November}

Back again in dear old Pokhara with the half acre trip across the field to the toilet and the cows eating any washing you might leave on the line overnight, but happy to be back, almost feels like home again with greetings from all the people we know here, and the mountains soaring and inevitable as always...

Monday 10th Nov. Continuing this at about 7.30am as breakfast isn't yet ready and next door the Glovers, whom I've mentioned before as the friends we met in Kathmandu and who were going out to the field at the same time as us, are preparing to set off. They have two babies, the boy aged three and the girl 7 months, how Jessie manages I just don't know, and yet she takes it quite calmly that it is the only thing to do to take a baby into a place seething with infection, no running water or electricity. And they'll cope perfectly well with this attitude. The baby has been crying ever since they got up and Jessie says she is the most wakeful child they've known, so with cramped circumstances in the village and tring to work on a crash programme of linguistics, they are coming sown at the same time as us in Feb., it should be even more of a strain...

Tuesday 11 th November. I'll finish this today! Have just come back from a breakfast of two fried eggs and Tibetan bread at out old hotel, sneaking past the one we're staying in as I wanted to shower as well and only the Annapurna has them!... Alan gave his talk at the British Library on Aid and Development on Saturday. We were quite pleased to see that the majority of the audience (about 55) were Nepalis, mostly teachers from the training college in Pokhara. Unfortunately, Alan was attacking the giving of aid in its present form, indicating that it had retarded the growth of the country more than anything else, and saying how most of the money got stuck in the Kathmandu valley and was absorbed by the educated elite, not wilfully but inevitably - or went back to the country from whence it came, American Aid workers get their salaries paid out of the American grant and this consists of 40\%! The unfortunate aspect was that we were of course talking to this 'educated elite' in Pokhara, and they still went away with the idea that faint imitation of the West via industrialization was the only way of developing Nepal, instead of the conservation of natural resources, and the building up of a sound agricultural country, which would avoid urbanization and all the horrors that go with that. Alan is getting quite concerned about this problem, and might even think of working in this field when he gets home, especially on the population control level...

\section{Letter from Alan to parents on 12 November 1969}

...feel especially refreshed after the comparative luxury of a couple of weeks holiday in Pokhara and Kathmandu. We have been buying in stores, being inoculated, and gossiping and reading. We have also bought a cine camera and some films so look forward to boring you with home movies when we return...During the last few days there had been another festival in Pokhara - the 'festival of lights'. Each house puts a row of candles on its verandah and a few are put up into the trees. Then the children go singing and drumming along the houses, demanding small sums of money or sweets...

\section{DIARY Friday 14th November}

Returned at about 5.15 with two porters and Buddi after a most successful and enjoyable holiday in Kathmandu and Pokhara. For the strange characters we met, what we did there, see letters of these dates - checked witchcraft, wrote talk and article during that time - also read some of "David Copperfield", Rosalind Lehman "Swan in the Evening", and Galbraith "Affluent Society". Fairly exhausting journey up as I am overweight - very aching and tired when we retired to bed after a bowl of soup. Everyone very welcoming and chuckly granny actually hugged Gill! Delighted with their photographs. [About 570rs. brought back (and about 30-40rs. lost)].

DIARY GILL Friday 14th November 
Owner of hotel very sweet - salt wrapped in paper and free 'roti'. On edge, excited feeling as we set off - lost and disorganised trying to buy sugar/potatoes. Slightly amazed Goof turned up with only Kaila instead of other man. Letter from Chris and Josselin's index which cheered Alan. Usual taking over of postmaster's office and pretending not to. Frenzied search through last of bazaar for potatoes - only got seed. Somehow the last emotional seeds of civilization. Alan's bot sore, had to carry rucksack, bit cross. Looked at that little white square of a house overlooking Pokhara hill, mixture of sadness/resignation that we had started walking. Rice - sweet, sweaty smell of the sheaves with the grass-hoppers clicking through in blue- brown clouds. Brahmin women all stopped to look at our party - lovely reds. Met Ramchandra on path, actually felt quite fond. Had lunch by tumbledown bridge - porters eaten rice earlier in bazaar, Alan feeling queasy. Paddled a bit before we started climbing - no big blisters - climb a sweat, as usual. Those dull maroony-brown marble steps towards Noleghat help a bit. On way up last hill after all eating a sweet at bottom, met Guru aba's daughter - usually unbending and poker-faced - most welcoming, offered me rice from their 'prokan sae', after misunderstanding. Asked me for some garlic. Then met Betta's grandmother - almost hugged her. Waited for Alan to come into village together. Felt quite fond - usual children round house - Gran away in the field - very tired, not a smile when she saw us, but she fed our porter. Nani came in at night and called up at the window. Felt very affectionate toward Haricola who reciprocated. Comal came - left us alone to have a soup on stove. Alan pretty exhausted, me not so bad.

\section{DIARY Saturday 15th November}

Spent the day recovering from our walk and sorting out the cottage. Warned by Bhuwansing that XX was a thief and had stolen several sums of 35rs., 10rs., etc. in last two months which probably explains where some 30rs. or so disappeared to on the way back. Ira turned up about 4.15pm. and we spent evening with him and Gurungs. He slept up in our loft.

\section{DIARY GILL 15th November}

Bit disheartened at thought of Ira's coming - black gloom and fear spread over me as soon as I woke and I could happily have stayed in my womb of a sleeping bag and not come out for three months. Why can't one just sleep for a long time and wake up ready to go home? Just this feeling of filling in dead time (senselessly for me) when people might be dying. Sorted out food brought back with Alan - few people came for medicine. Good to go up our hill again. Alan dug another hole. Saw lovely black/yellow/orange beetle by side of it. Opened its wings like the clasp of a broach - black inside. People so friendly and sweet, saying they had missed us. Bhuwansing came round whilst I was resting in the afternoon to warn us re XXX - now fairly sure he did take the $35 \mathrm{rs}$. that are missing. How uncomfortable - complications with that family from the start. Ira came soon after, tired, full of the journey and blasted Gurung woman who had directed him wrongly. Good to see him - very much so, against expectation. Came in with Ramchandra - made a nice contrast. Enthused kindly (not too) about house, saying he thought we were in some sort of bamboo hut/ had a nice kitchen/ how he needn't feel so sorry for us, etc. Enjoyed evening meal, stretched out endlessly in front of the fire (all 
six foot of him) - kept tripping over his ankles! Slept upstairs with us - like a double T. Did not sleep too well.

\section{DIARY Sunday 16th November}

Spent a nice day showing Ira round and filming. [FILM] Took photos of mountains and rice/'kwoia' harvesting. Went down to 'byanshi' and had a picnic down there. Wandered around and then back up. Showed Ira the village. Lots of villagers around following us.

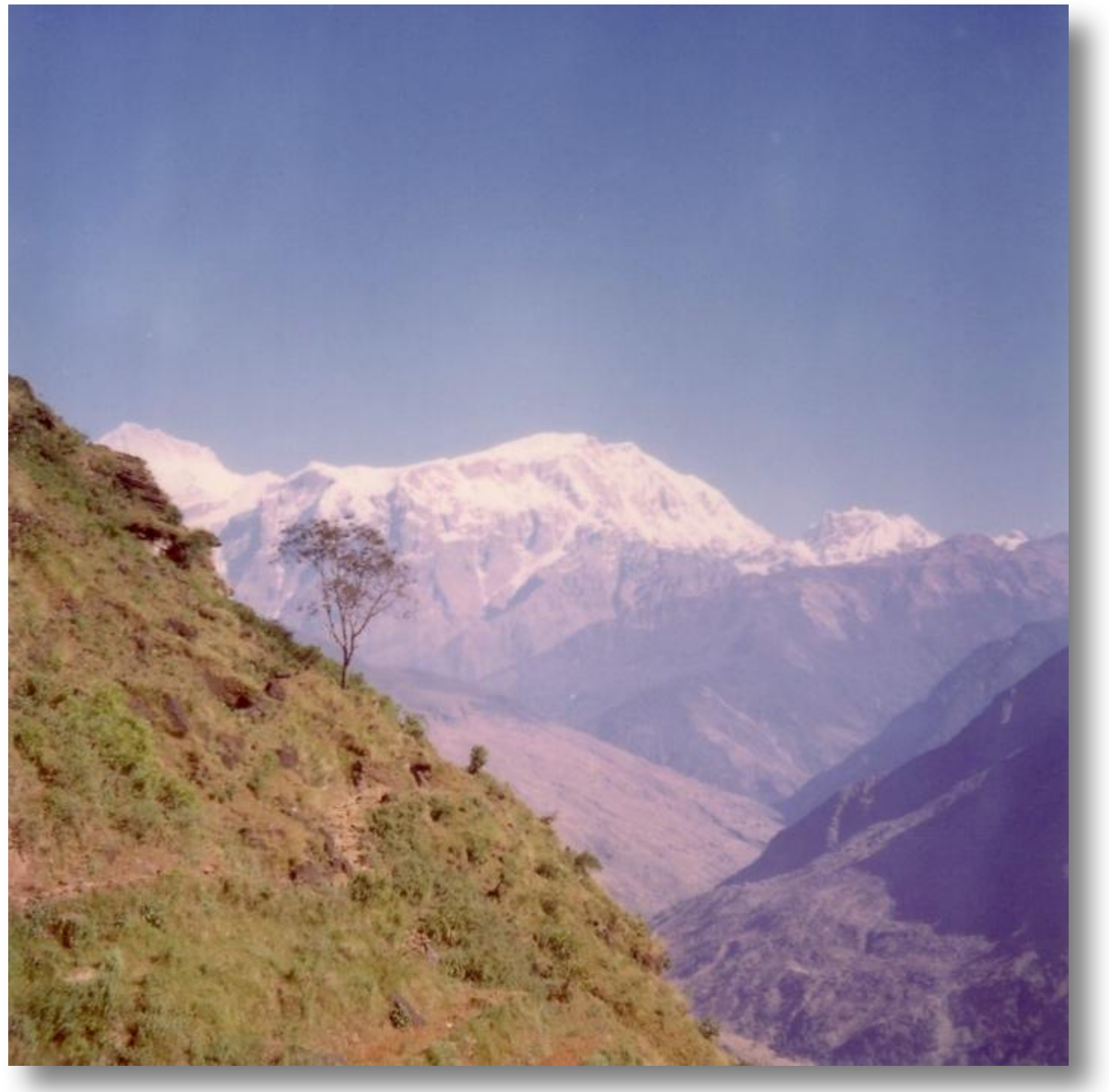

Looking north from the village towards Annapurnas 


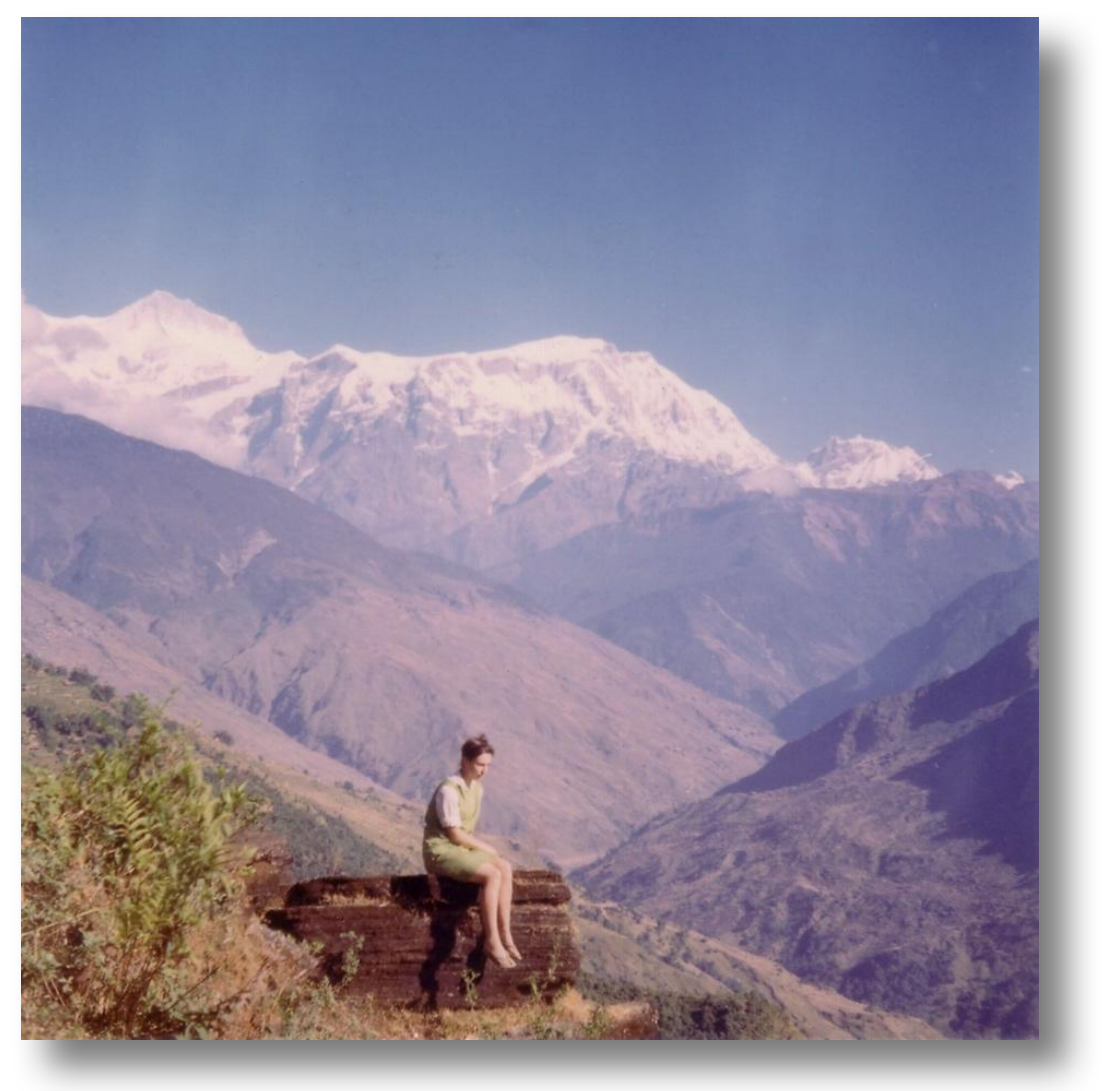

Gill sitting on resting place, beside the spot where each evening we placed a stone to signify the passing of time. Looking toward Annapurna. 16th November.

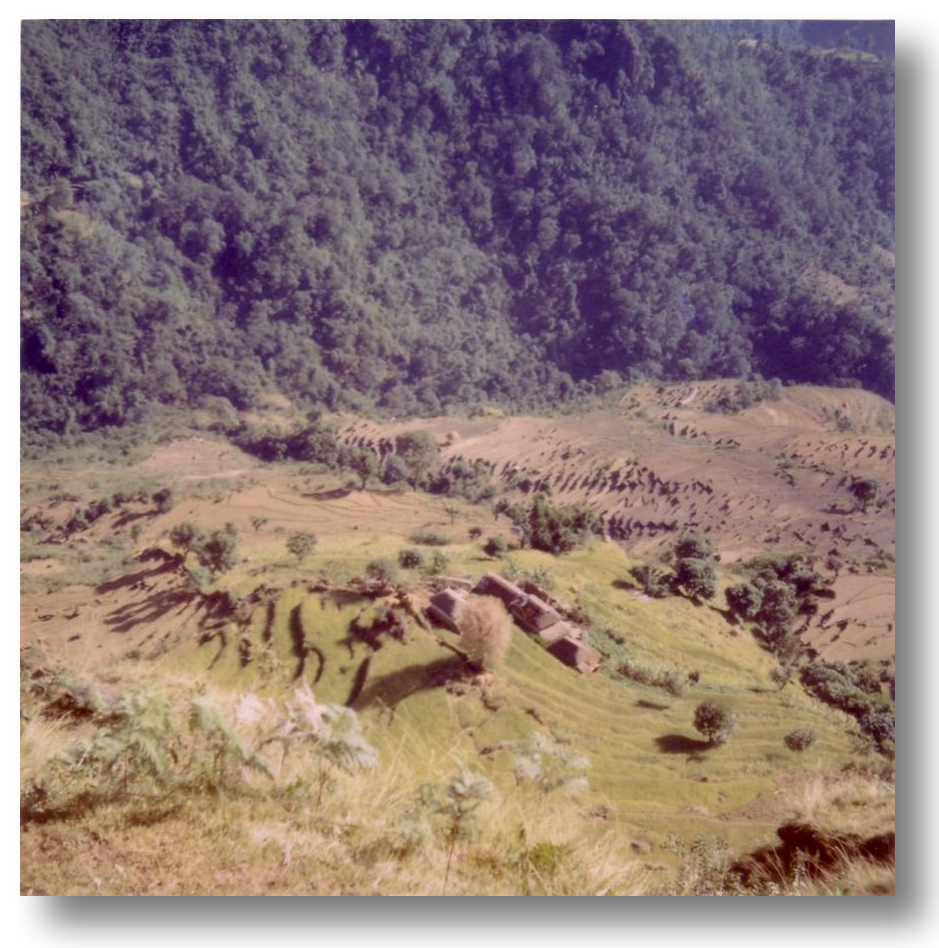

Brahmin's house below the road to Taprang. 16th November 


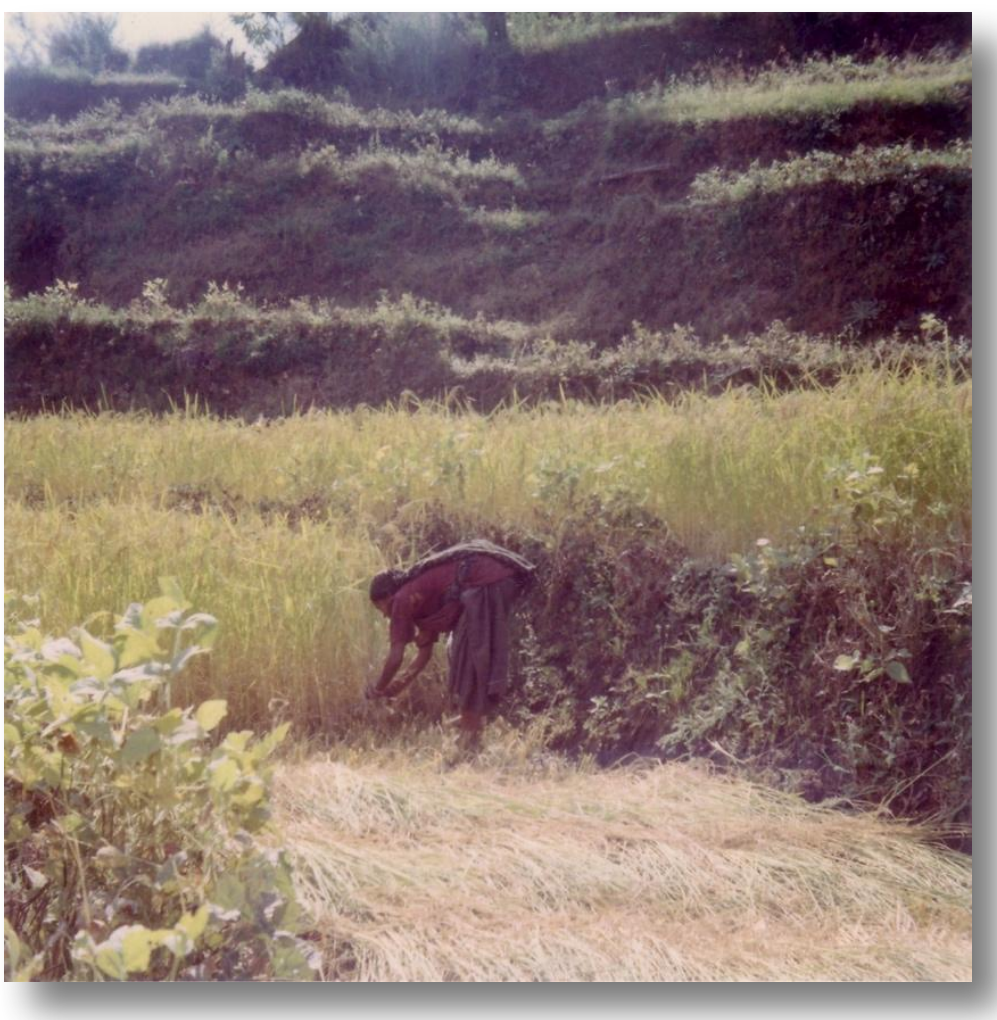

Woman cutting rice beside Taprang road - 16th November

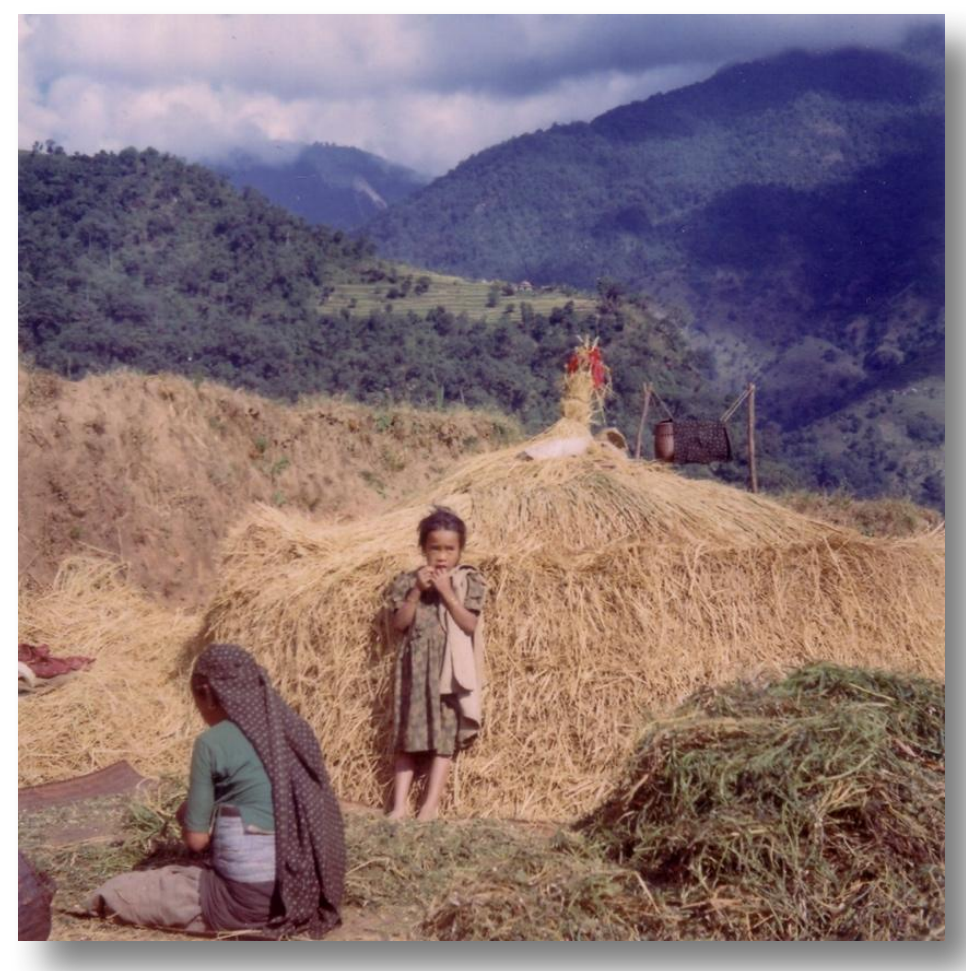

Woman shedding beans ('kwoia') beside a half-built rice straw stack - November 11 th 


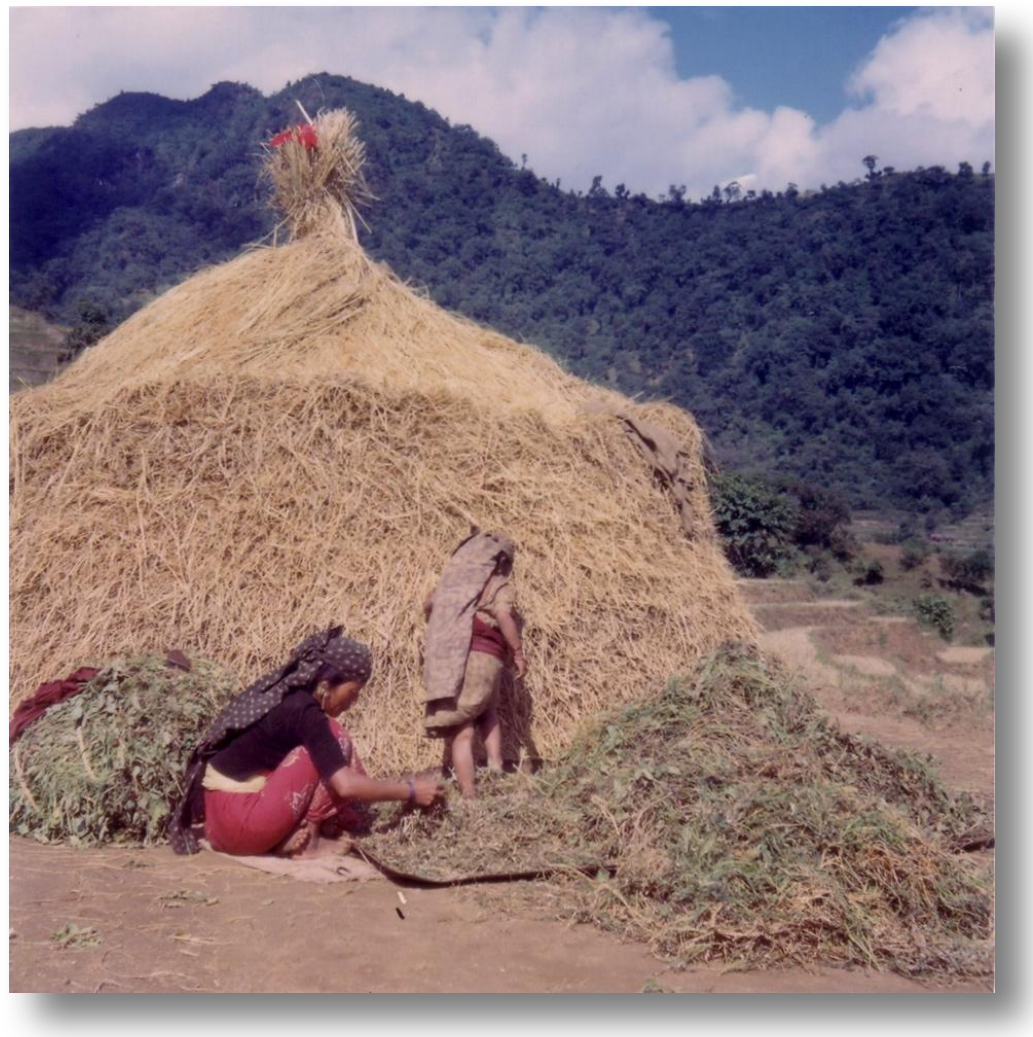

Asmaya shedding beans beside a rice straw stack - 16th November

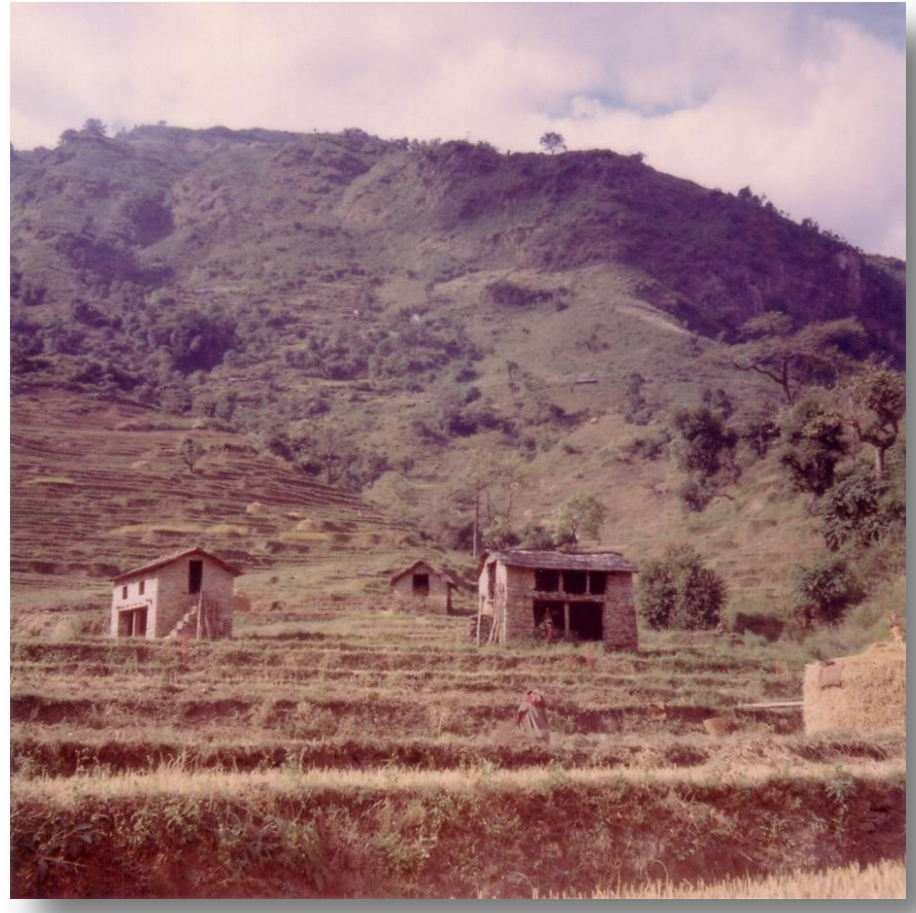

Field houses in the low fields (byanshi) - 16th November 


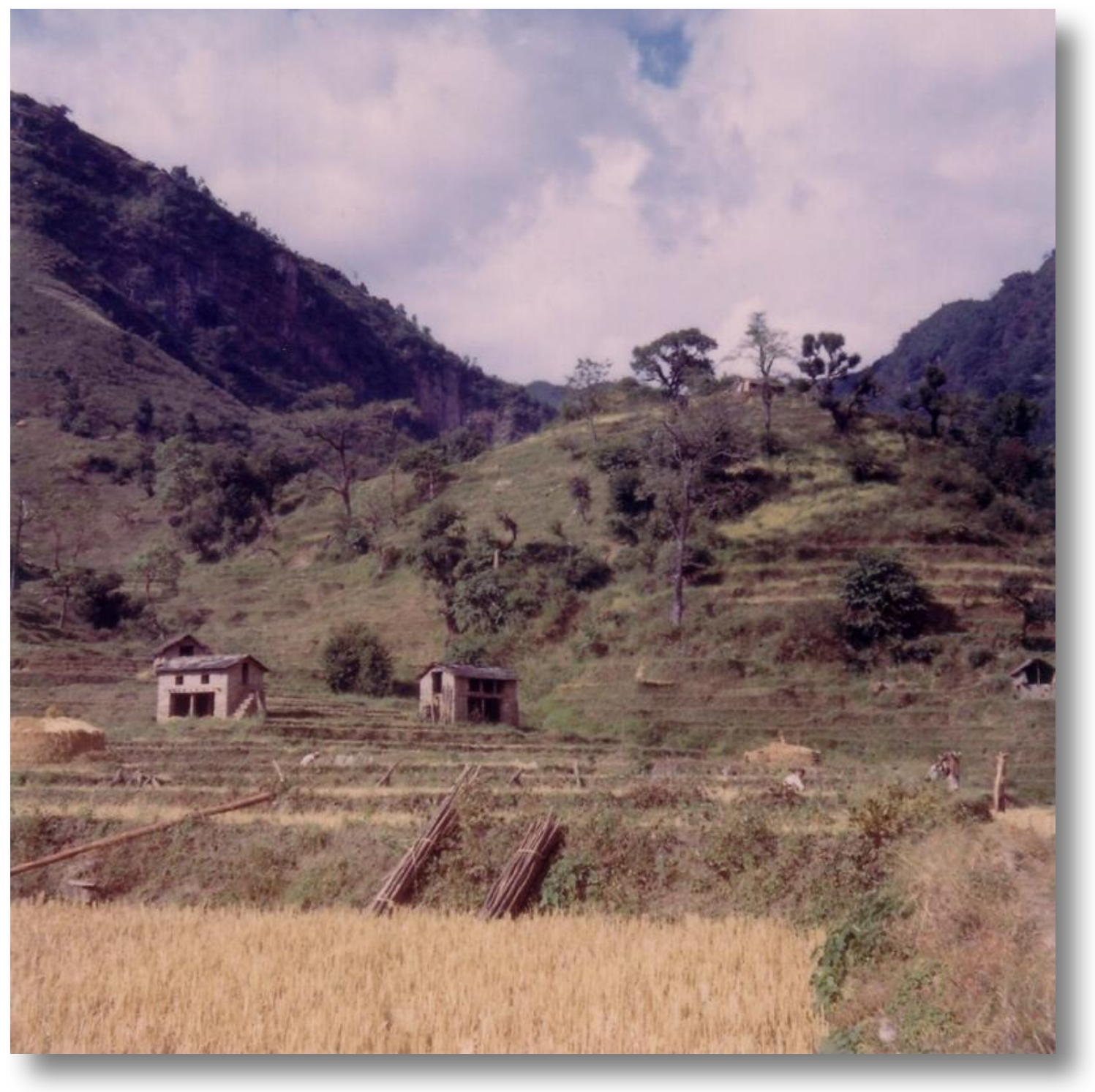

DIARY GILL Sunday 16th November

Good day - spent it along our favourite walk to Taprang (Machapucha had a cloud around her head and looked as though she were blowing her nose) - and then went down to the rice fields by the river and got nearly all the processes on the camera - nice rounded, tall stooks of rice, like layered crumpets dripping with [?] - and poinsettia stuck triumphantly on top. They knead rice with their feet to get the initial grains off. Lovely crunching movement. Grasses tall against sky - big haul back up. Ira went asleep when we went off to the oxen - nice to see Bhuwansing and Dankumari. All tired. Hardly any water. Ira went for it, kindly. 
FILMS Taken on 16th November 1969

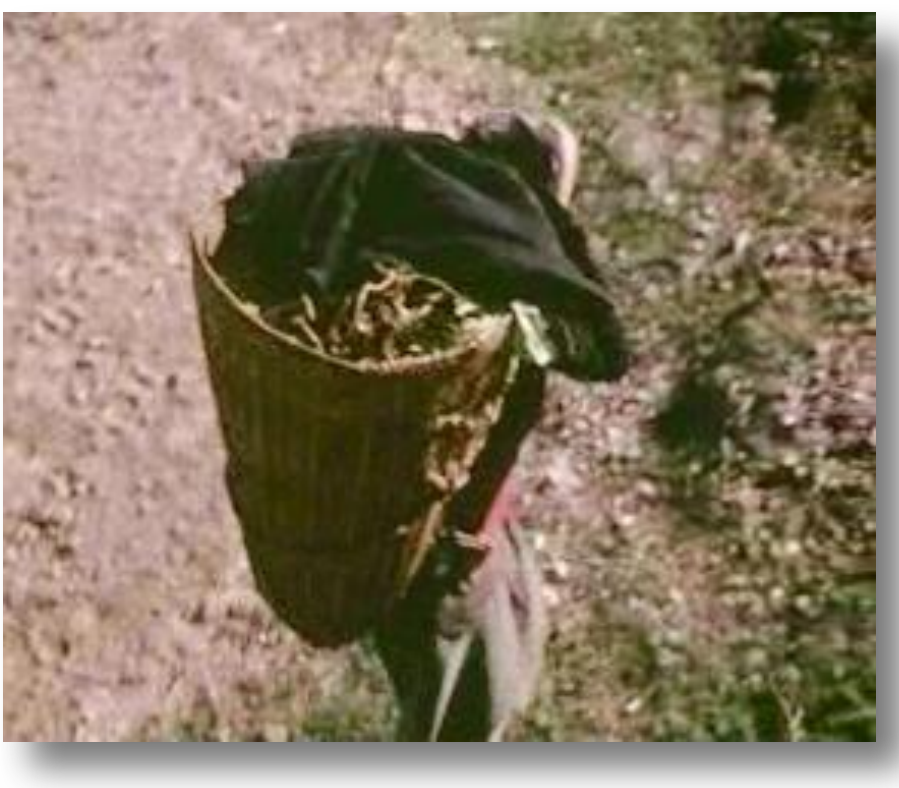

FILM. Woman carrying a basket of millet up from the fields https://sms.cam.ac.uk/media/2735178

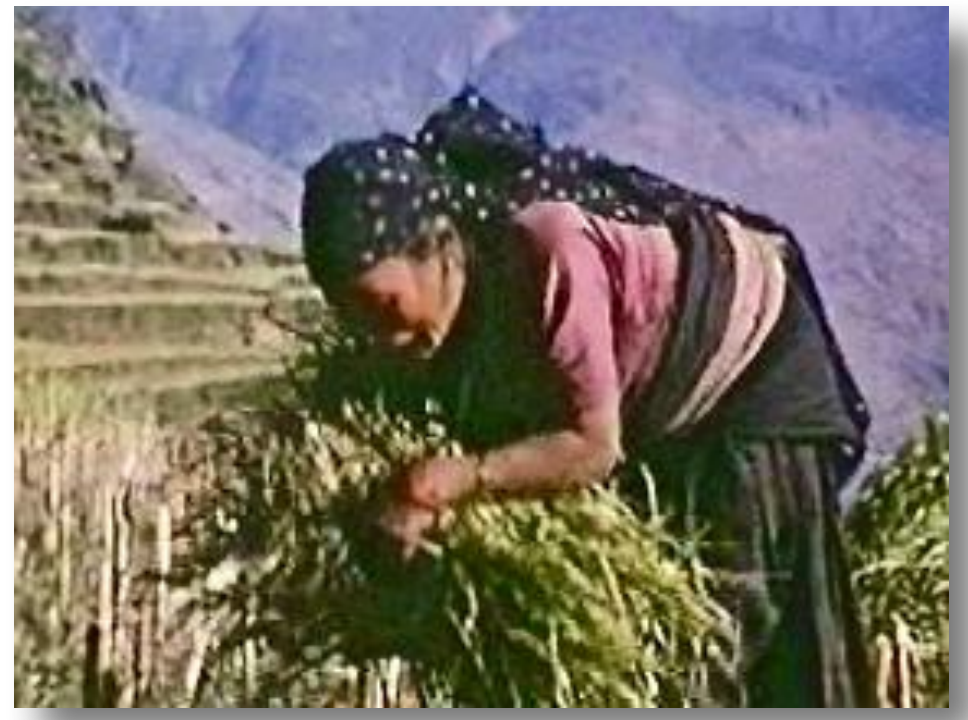

FILM. Woman harvesting millet with mountains behind https://sms.cam.ac.uk/media/2735206 


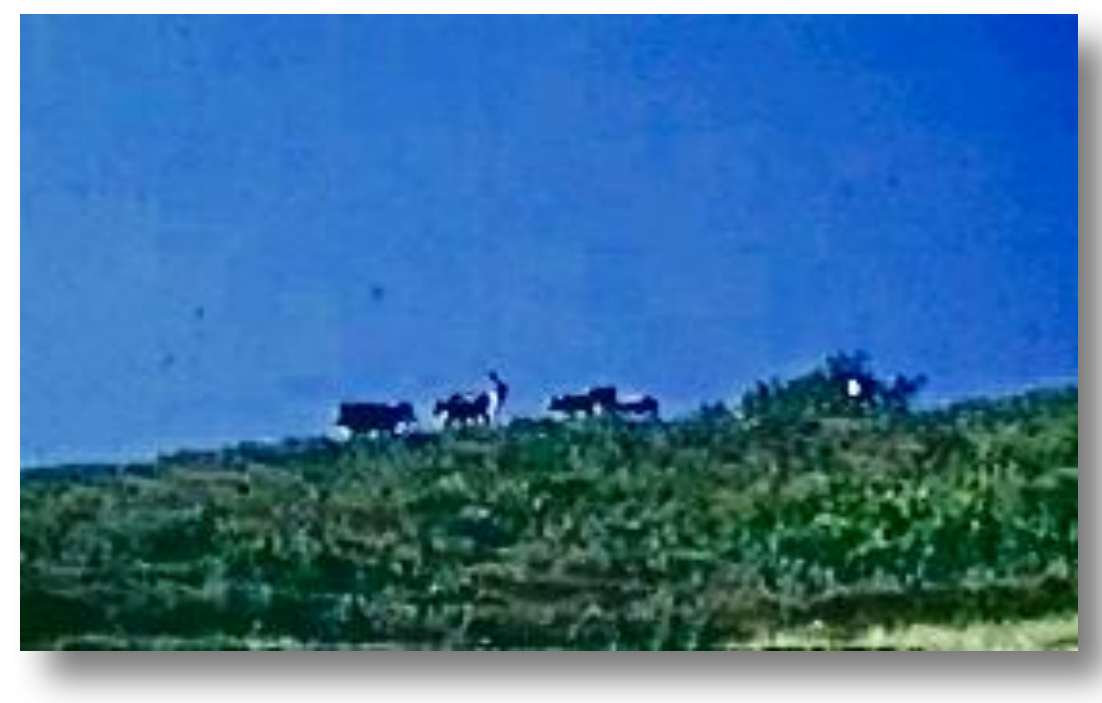

FILM. People bringing buffalo and oxen back to the village from grazing https://sms.cam.ac.uk/media/2735234

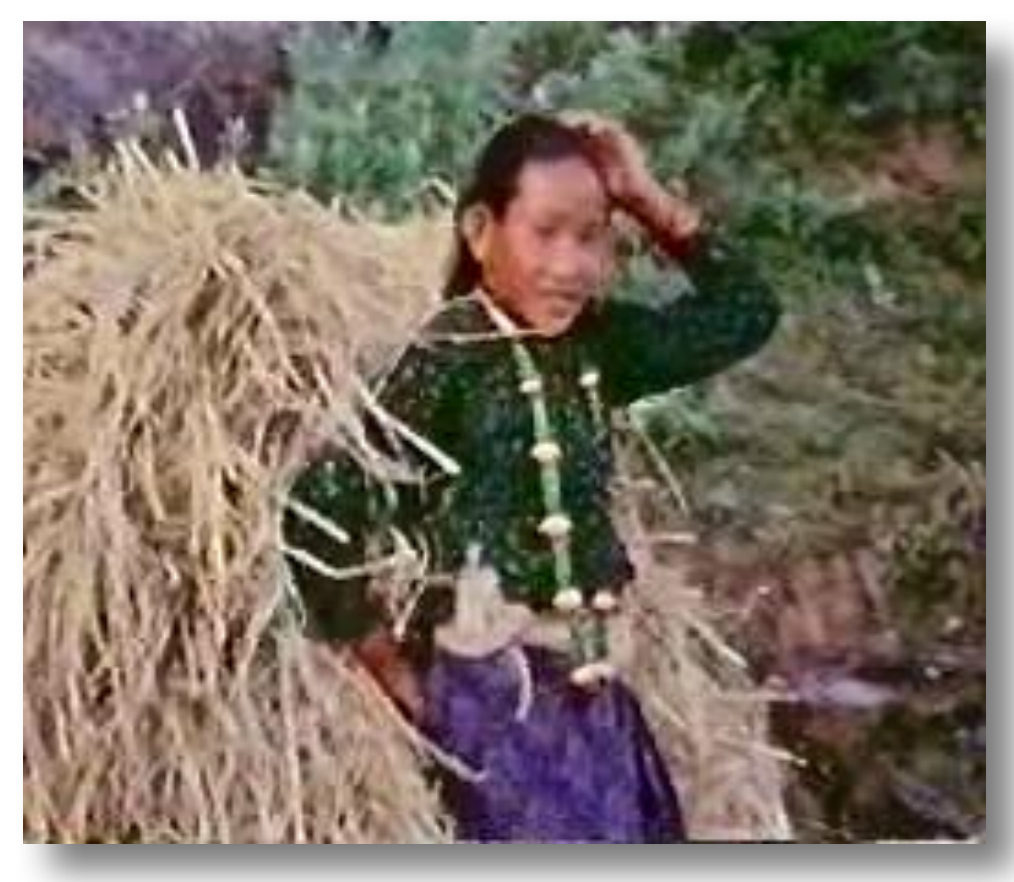

FILM. Dilmaya and another girl carrying rice straw up the path https://sms.cam.ac.uk/media/2735262 


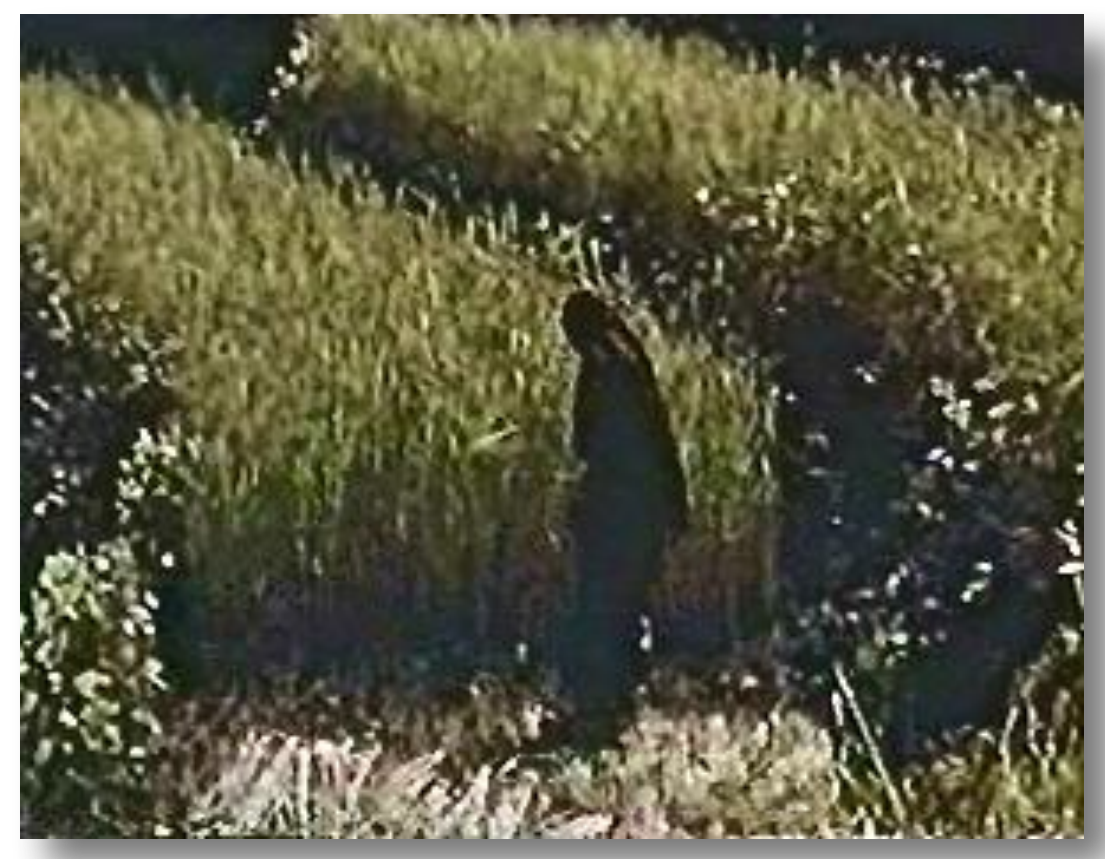

FILM. Dalit woman cutting the last of the rice https://sms.cam.ac.uk/media/2735290

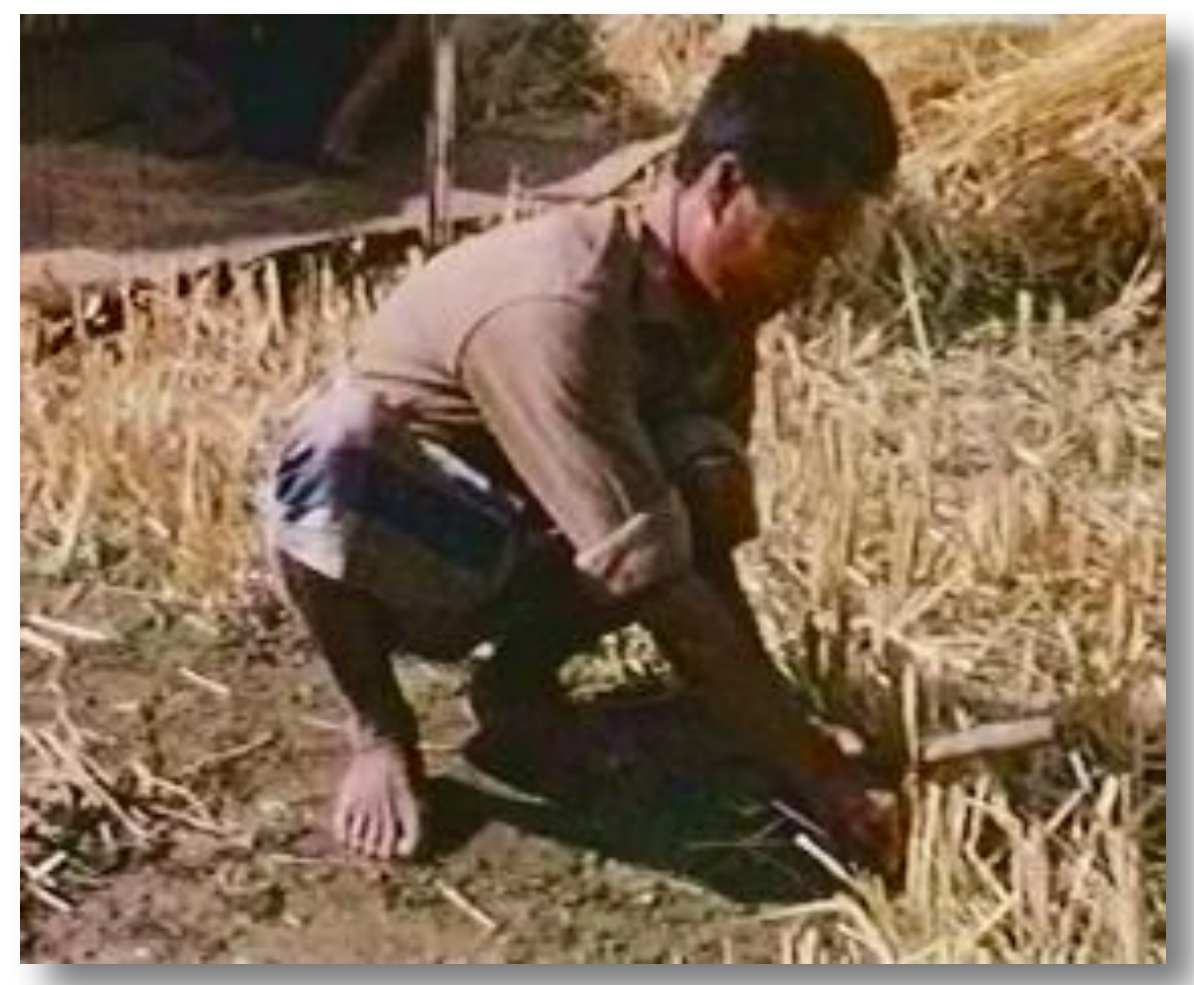

FILM. Bhuwansing cleaning ground of rice stalks for a threshing area https://sms.cam.ac.uk/media/2735321 


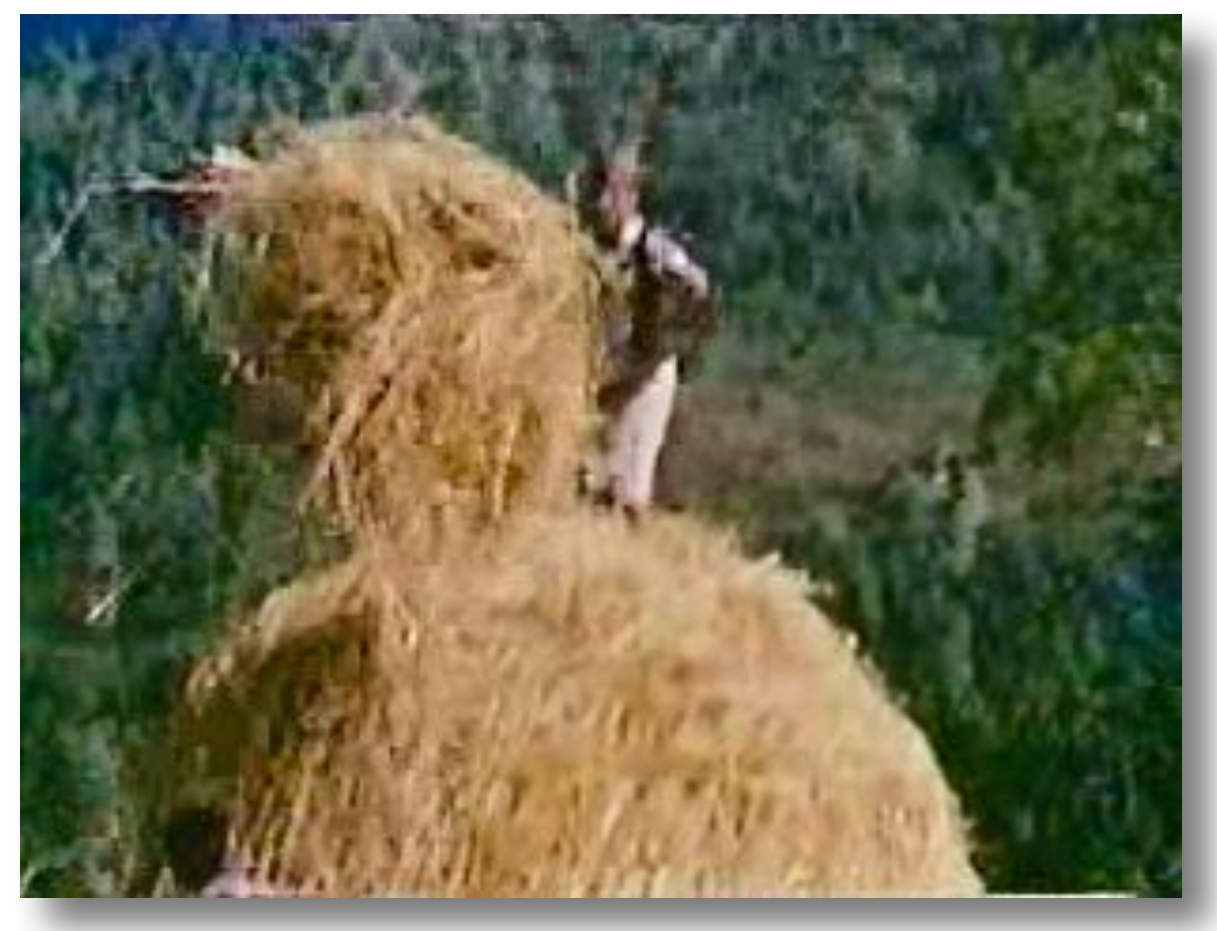

FILM. Dalit threshing rice with his feet, others clearing up the straw which is thrown onto a stack

https://sms.cam.ac.uk/media/2735349

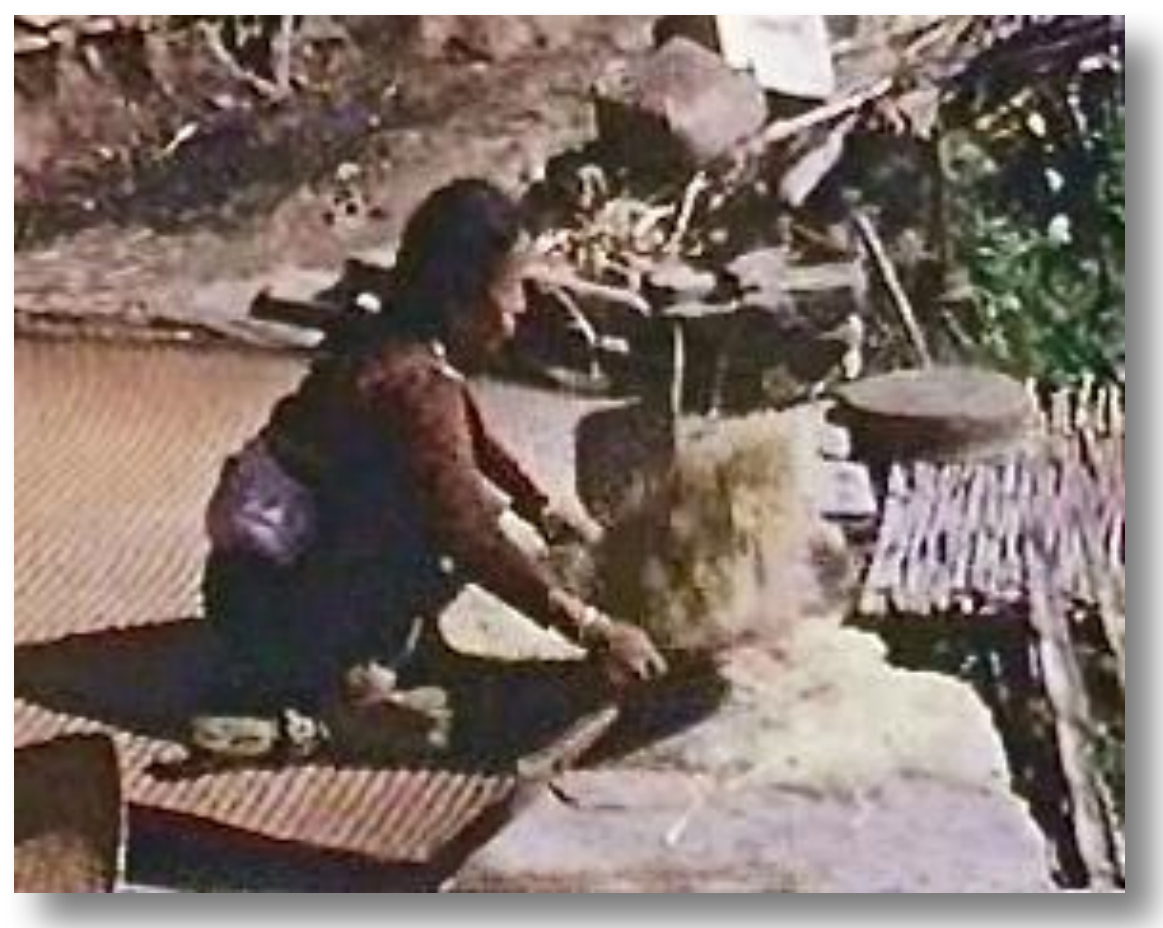

FILM. Dansuba winnowing rice

https://sms.cam.ac.uk/media/2735377 


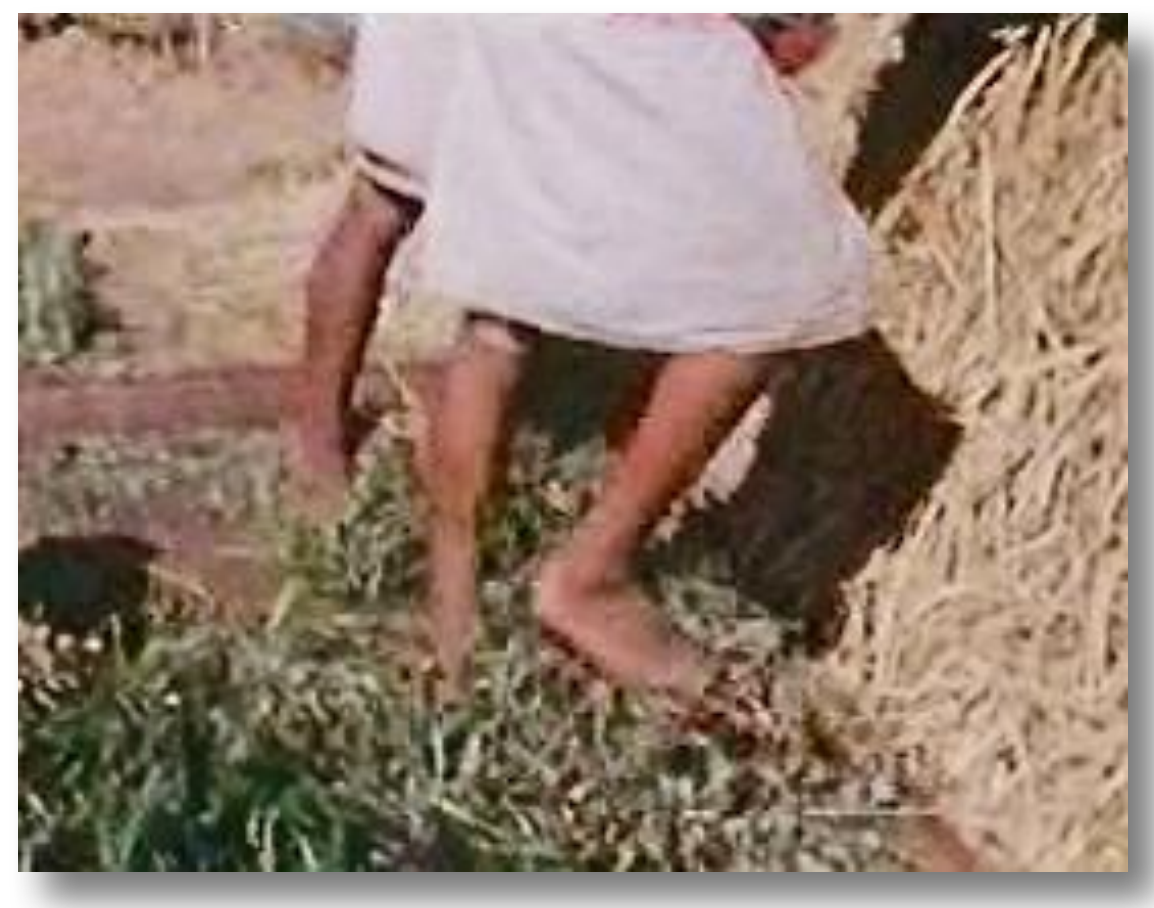

FILM. Men threshing 'masyan' with their feet while a woman winnows it https://sms.cam.ac.uk/media/2735405

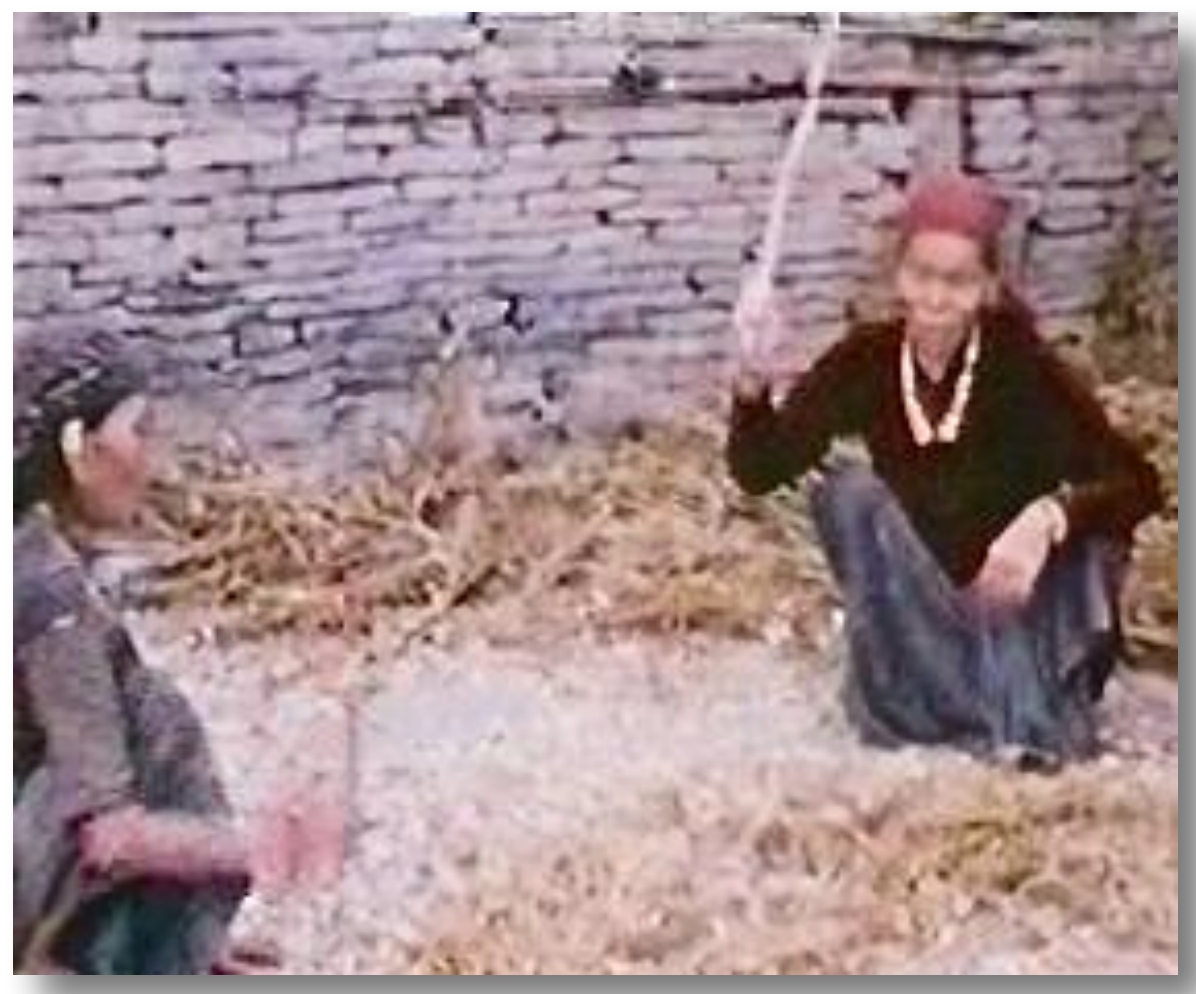

FILM. Old and younger woman with child beating 'kwoia' at House70B https://sms.cam.ac.uk/media/2743852 
Ira went after lunch - it was nice having him and I think he enjoyed it, but as he went we both felt a little depressed as it then seemed as if our stay had really begun with the last thread snapped. Tried to get XXX to cough up the money he had stolen. Otherwise sorted and filed and worked out a schedule for the next seven weeks. Gill depressed. Villagers busy bringing rice and 'masa' etc. up from fields, some of which is drying on our roof.

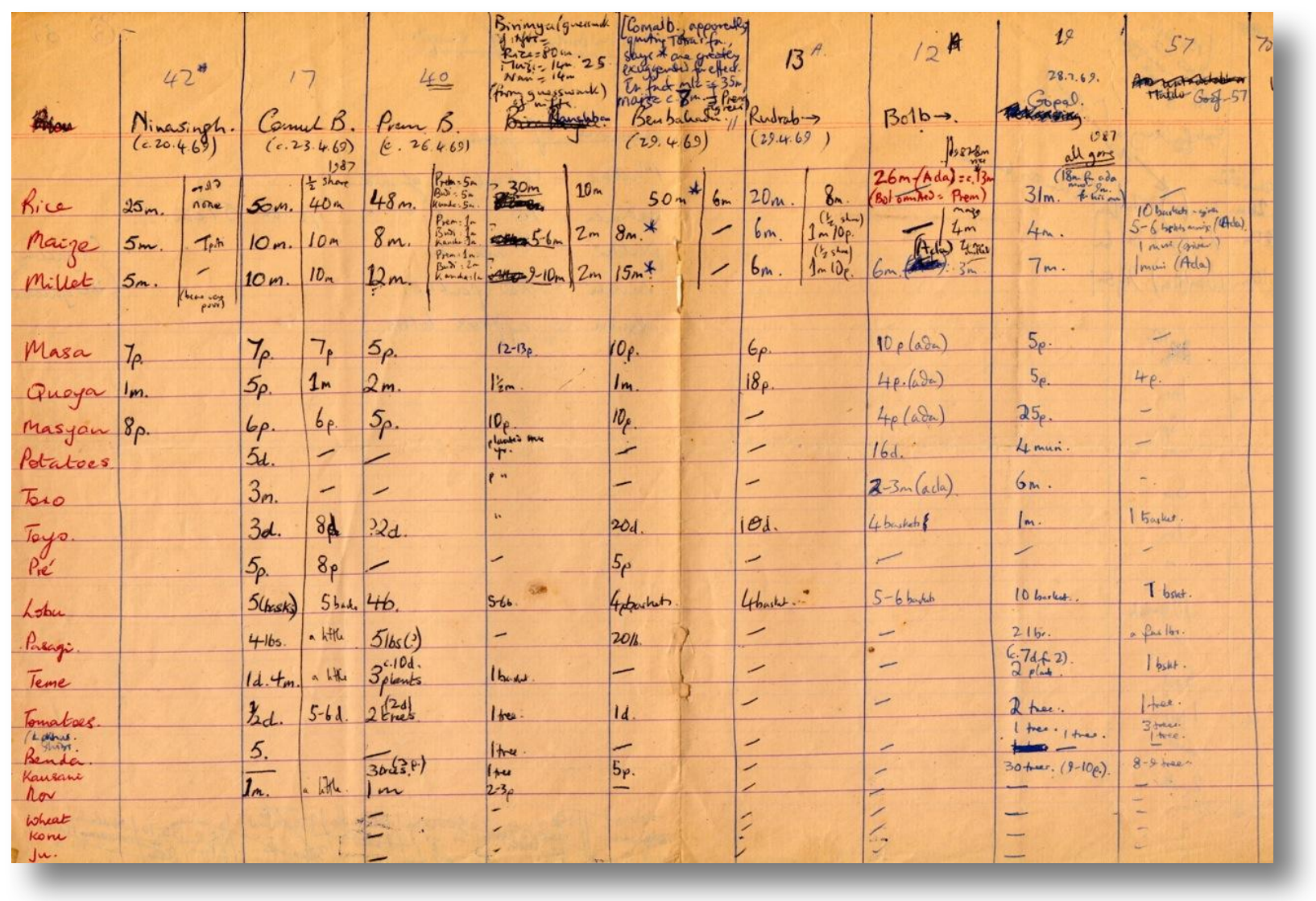

Production of grain and vegetables in selected households

\section{DIARY GILL Monday 17th November}

Still woke in acute depression - engulfed by it until we got up and discussed Taj Mahal vis a vis Michelangelo's pieta's with Ira, brushing my hair! Had hectic breakfast - as soon as I got down mother (unknown) with two children who looked half white, with terrible sores - some reaching down into their anus. I hadn't even washed my feet before they descended. Ira kind, saying he couldn't stand this sort of thing every day (admirable!). Then Grans came to buy cigarettes, people to look at photos, other medicines, Prem to see Alan, Servajid to take gentian violet away, etc. etc. The boys had cold coffee and I hadn't time for my Horlicks. Unwound slightly on the hill - watched kites wheeling and shadows on the hills - slightly overcast. Kite coming low in over our heads when on hill - could hear swoosh of its wings and see its mean and hungry eye - could easily have strength to attack us. Alan went down fretting to start work, and I went up "my mountain" with Ira, who loved it. Must have talked for two hours - about girlfriends, sexual frustrations, impossibility of making "honest relationships" out here - hence my problems, XXX and the stealing - "better to steal from us rather than 
anyone else". Made early lunch and set him on his way at 12.30p.m. - quite looking forward to getting back to his Brahmin village, which he can only stick for a week as they are so nasty to one another. Slept after he'd gone - a depressive sleep - and felt so low and weepy when I had to get out of the sleeping bag. Alan fretful because not a lot of work to do - bits and pieces - but went off determined to do some with Ramchandra. I wrote this and felt better. Children affectionate round fire - only XXX marred it all with his nervous jollity. Afraid I gave him a loathsome look which quietened him. Ombahadur very funny imitating Ira driving a car, all dressed up. Also the girlfriend he wanted from Pokhara with a wiggly walk and high heels! Nearly full 3/4 moon. Alan fetched water by it.

\section{DIARY Tuesday 18th November}

As always now, a sunny day, but chilly when the frequent clouds go across the sun. Sun is now rising at about $6.15 \mathrm{am}$. and we don't get up until then or later. Sun sets at about $5.00 \mathrm{pm}$. and by $5.15 \mathrm{pm}$. it is too dark to read. The village is rather deserted for most of the day as the villagers are down in the rice fields pounding rice and bringing it up. Started to read EvansPritchard "Nuer Religion" - extraordinary similarities to Josselin in themes of pain and sin. Spent the day writing up my fieldwork report for London- Cornell/Tribhuvan. Having doubts whether our fieldwork is, in itself, worth publishing. Would probably be better to devote my energies to exploring the same problems from the historical angle.

\section{DIARY GILL Tuesday 18th November}

Felt light and airy this morning - not sad at all - probably result of 11 hours sleep (albeit with a series of dreams (1) client-telephone conversation (2) Jessie having miscarriage (3) me getting married with nothing to wear day before and not caring). Had breakfast free of interruptions, only cranky Gran wanting to buy cigarettes. as the shop is shut - because of the rice harvest? Enjoyed the hill too - watched a group staggering up the hill with sacks of rice on their backs caught them sweating up as we swung down. Worked for Alan - preparing for Dr. Turner. Afraid the old counting-the-houses is back.

Started "David Copperfield" after lunch - really delicious descriptions - Miss Murdstone being metallic - mixed with quite vicious emotional scenes (biting of hand). Only Lawrence after Dickens had gift of extending emotion to environment. David looking out on "some shrubs that were drooping their heads in the cold", when David first comes back from Yarmouth. Went up hill for 2 hours and read Fromm (whom I find indignantly depressing) and Kardiner whose jargon is irritating. But lovely gold yellow flowers poking out of the mosses, which I later pressed.

Grans screeching at each other when ox got in millet fields. Boy ahead of goats jangling a bell all way down, insanely, tumbling stream of goats, kicking their heels downhill, followed by yelling of children and hobbling of 'baje'. Felt embarrassed to be wearing anorak - noted by all. Alan restless until Dr. T. comes. Hawks settle in tree by graveyard - chatter up out of it in a cloud. Just going to bed (in pyjamas - 7.00pm!) when we were called next door to see poju do a rite - for Nani who was ill (cold/feverish by turns) - 'kyulumoh tchegi kreba' (2D). She was lying down being massaged by Gran (I was pleased to see, quite affectionately) - poju sprinkling rice and incanting - Missiri and House7A man sitting cross-legged on bed. When they flicked water on its face and rushed to tie thread on, Gran asked Alan to 'shya lava' too Misiri said we must stay, sad when we go. Another great whiskery man there who we didn't know. Immediately after rite, asked us for medicine! Both in pyjamas and overcoats, me with 
my hair down. Prem had come earlier and suggested we slept down in the rice fields tomorrow night - might be fun?

\section{DIARY Wednesday 19th November}

Went down after lunch (having finished my fieldwork report before lunch) to see them harvesting the rice. Took sleeping things down and after beans and cold rice for supper we slept in a little temporary shelter made beside the rice.

\section{DIARY GILL Wednesday 19th November}

Another black day - starting with Alan fretting about work and stressing uselessness I feel all the time here. We tried to piece maps together (Alan in fact did it) but even he couldn't manage it, so we gave it up as a dead loss as far as I was concerned. Man with a bad gash came at lunch time and I felt better patching that up, although the hand should really have had stitches. Then Alan was over half an hour getting water as it is only a trickle at the moment. Got ready to go down to fields, everything seemed a tremendous effort and I could easily have laid down and slept. Alan felt the same. However we got sleeping bags, bit of food together, and camera and staggered down - me being stupidly hurt by all Alan said. Lovely warm afternoon, sun casting long shadows on the rounds of the hills. Found only the poju on his fields, others were coming down in the evening. We wandered round and went over to where girl who has just lost her twin sister was looking after cattle. She looked sad and drawn and did not say much. Oh! the limitations of language. At home, although difficult, I would have said something about it. I think people grieving want to talk about those who have died. Above, bellowing and snorting of oxen, who were quite lively. We saw a jay perching a long time on the corner of a large rock. When it did open its wings it was amazing. One flash of blue. Went back and got warm by the poju's fire, and had a somewhat scrappy and metallic meal as they had not prepared anything for us, as anticipated. Went to bed early under a bright, opaque $3 / 4$ moon - lying on the rice straw under rice matting. About 6/7 men came about $7.00 \mathrm{pm}$. and bunked down beside us. Children were very affectionate and used tree for holding oxen as a maypole - played beautifully together.

\section{NOTES 19.11.1969 Alan - Rice harvesting in Poju's fields}

Rice harvest in Poju's fields - Barmorde. Went down from village at 3 p.m. Only Poju in fields, preparing for the men coming down that evening, putting shields up at the side of field of rice mats, making a sleeping place with the same, next to the bank with the straw from the rice to sleep on. Made a fire, for warmth and perhaps against the leopards who were said to be prowling. Masanta brought the poju some food already cooked, rice and 'ta'. Children use the tree for attaching the oxen as a maypole and play games round it until it is dark. Go to bed about 7 p.m. when the rest of the men come down - Goof, Prem, Prem's wife (in charge of cooking), Gopal, Rudrabahadur, Nainasing (Bl.), Tekansing's younger brother, Tekansing (7A), Purnabahadur ('lauriemae'), six children (four from 21, Haricola, Bopal). They have their job in urging the oxen round the pole, to do the final threshing. One child to an ox. Goof is the first to get up at 3 a.m. Rekindles fire, then others gradually stagger out, lot of stars, but not much moon. The poju puts a burning log on the side of the field, with some oil over it to the gods. He incants. He then jumps down into the rice arena and sprinkles chaff (?) round the pole. The mantle is lit. The head of the rice stack decorated with flowers and plaited, is saved and put on the bank. The men start tossing the hay down and they make 
their own bundles, securing them with twisted rice straw and bring them with a thud to the ground, three or four times, to bring most of the rice grains off. They are then tossed to Masanta, who loosens the bundles and sprinkles the rice evenly round the pole. When there is a pile four oxen are brought in and attached and beaten round by the children. The men worked steadily (the man in the army noticeably the strongest, always bringing the stack of rice down with a solid thud) until the pile was diminished. One man leaves off to make little brushes from the rice stalks, chopping them short and efficient with an ashi. The loose rice was then swept up by all and the loose straw put on a pile to be burnt. The rice mat shields were taken down from the sides and lain on the ground, end overlapping end for the winnowing. The rice grains were swept into a pyramid and offerings to the gods of fields (Bumi), flowers, a radish, an ashi, an orange, stuck on the top and a bowl of 'pure' water. All this was done before dawn, the ashes from the burnt straw being sprinkled round the base and then scattered carefully along the side in the shape of a trident (for good luck?) [note: protection against evil spirits]. Then most of the men went off to eat rice and two were left with round rice trays as winnowing instruments, whilst one dipped another into the rice pile and sprinkled the grains evenly down the length of the rice mats, the two men following and swishing in turn with the trays to blow the chaff away. When there is a large, almond shaped pile again ash is sprinkled round the base, tridents drawn, and the round of the rice map imprinted on the side, as well as the following put on: chicken head, twist of straw, flower, orange, 'ashi', pure water, trident, rice tray patterns, ash from burnt straw heap marking rim of tray (see original card for sketch). They sacrifice a chicken by tying a straw round its neck and holding it against the pole where the oxen are still plodding round (chicken led round the pole once like oxen), and then running three or four times round the whole field, one with the body and one with the head and finally sticking the latter into the rice pile (by inserting a stiff piece of straw in its mouth) and tossing the chicken over the pole (great fun). Blood has thus been sprinkled round the whole. The rice is then stacked evenly into the bags (some old army kits). Holy water sprinkled on rice just before it is scooped into the sacks. First winnowing tray full is put at far end ('mla pwhi' - pure - to be used later in rituals) and the men take it slowly up to the village. They do this three times. About fifteen rice stooks are stacked against the bank, to be kept for making 'gundri'.

\section{DIARY Thursday 20th November}

Got up at 3.30am. to watch the threshing and driving the oxen round: exciting. Did a lot of filming. Very cold in the night. The men worked for 4 hours winnowing and beating rice, then, with a little breakfast, started up the hill with huge loads of rice. They carry up three of these in a day. We staggered off with our puny loads and I went to Noledada to meet Dr Turner - who didn't appear - trying, as a number of people had been told he was coming and wanted to see him. In evening discovered that another 150rs. had disappeared - strongly suspected XXX who must have climbed in when we were down in the fields. Have only told Prem so far. XXX has disappeared.

\section{DIARY GILL Thursday 20th November}

Thak Noledada Alan Quite a day - getting up at 3.30am. in the star-light, shivering slightly in front of the fire, watching men, then shadows long and looming because of light from the mantle (very harsh after star- light). They worked hard in the square of the rice pile, unloading and banging rice and then throwing the stalks for the oxen to pound. Children drove latter round. Amused when I helped to clear up rice grains and when Alan took over the ox. The men were carrying rice up in bundles by $9.30 \mathrm{am}$. We went up on their second 
load - picking yellow and mauve and white plush like flowers and seeing another jay in full swooping, dazzling blue, flight. Alan left me at Uli to meet Dr. Turner and I came up behind the men and managed it easily at their laden pace. Had feeling we were being discussed all the way up in Nepali - frustrating. Shadows and rustlings of the peepul tree lovely. Village very friendly. Nani still sick, I managed lock - I always do manage on my own! Cleaned round, arranged flowers, swept downstairs, washed myself (in perpetual fear that someone would charge in) fetched water (took 40 minutes) made soup, then went to meet Alan, who was picking gentians for me on the way up. No sign of Dr. Turner. Enjoyed rest after lunch, and "David Copperfield" - something so sad and haunting underlying it all - not sentimental (thought there are here and there patches of course). When sun is not out there is definite chill in the air - like early October in England. Alan not too put out by Dr. not turning up. Think I have caught a slight cold from my toes getting dew-bitten last night! Gran all but turned the bucket over, arranging the rice baskets for their crop, which comes in tomorrow.

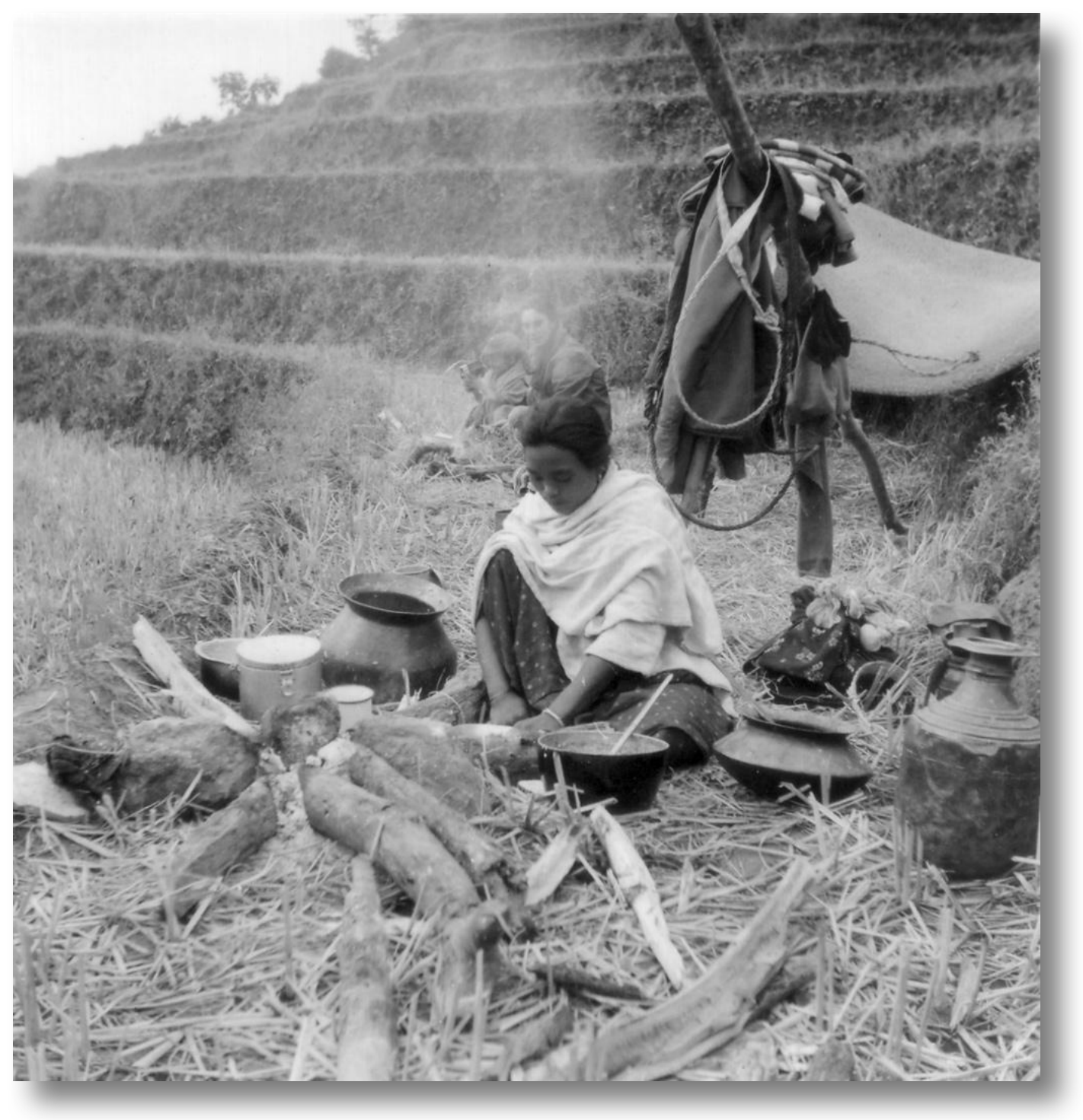

Yokmaya preparing food during rice harvest 


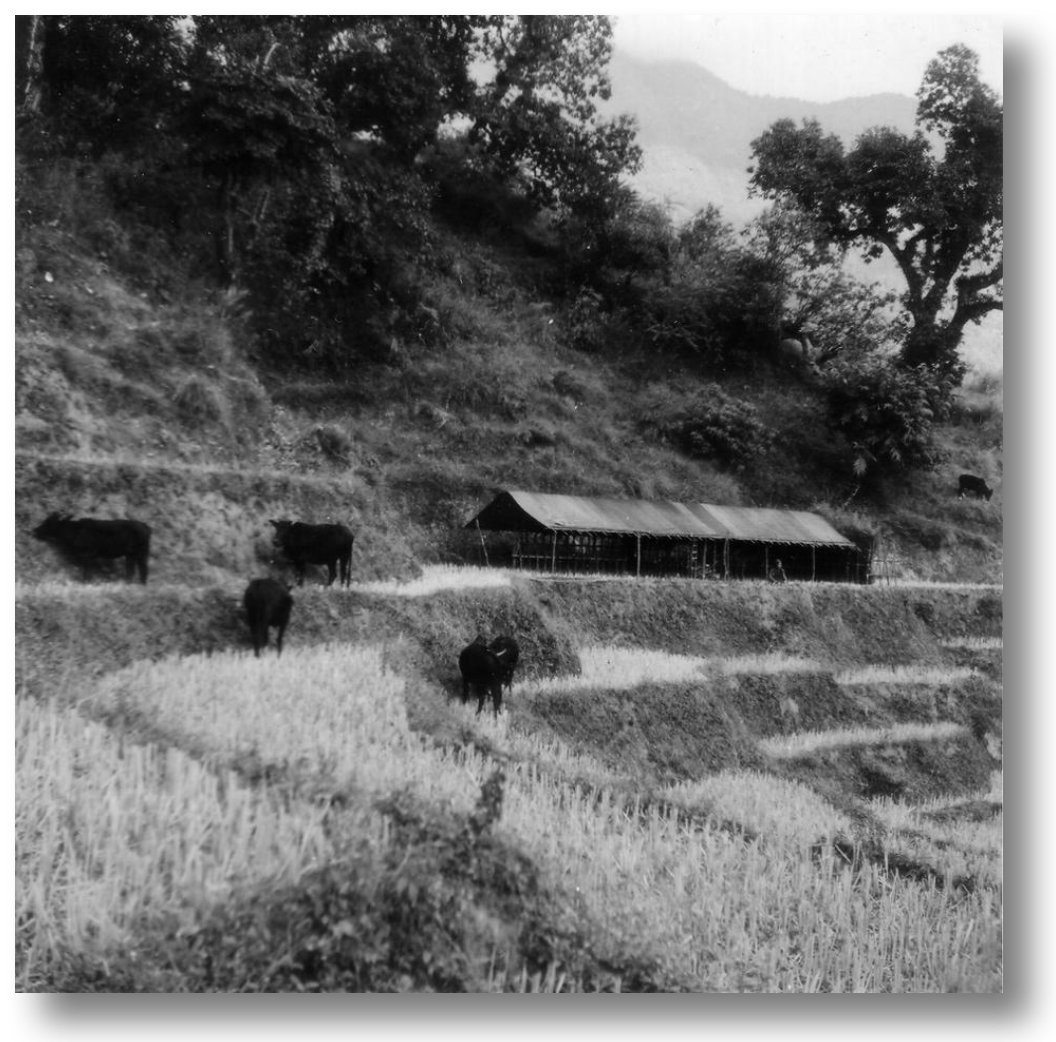

Cows down at field shed or 'pro' on 20th November

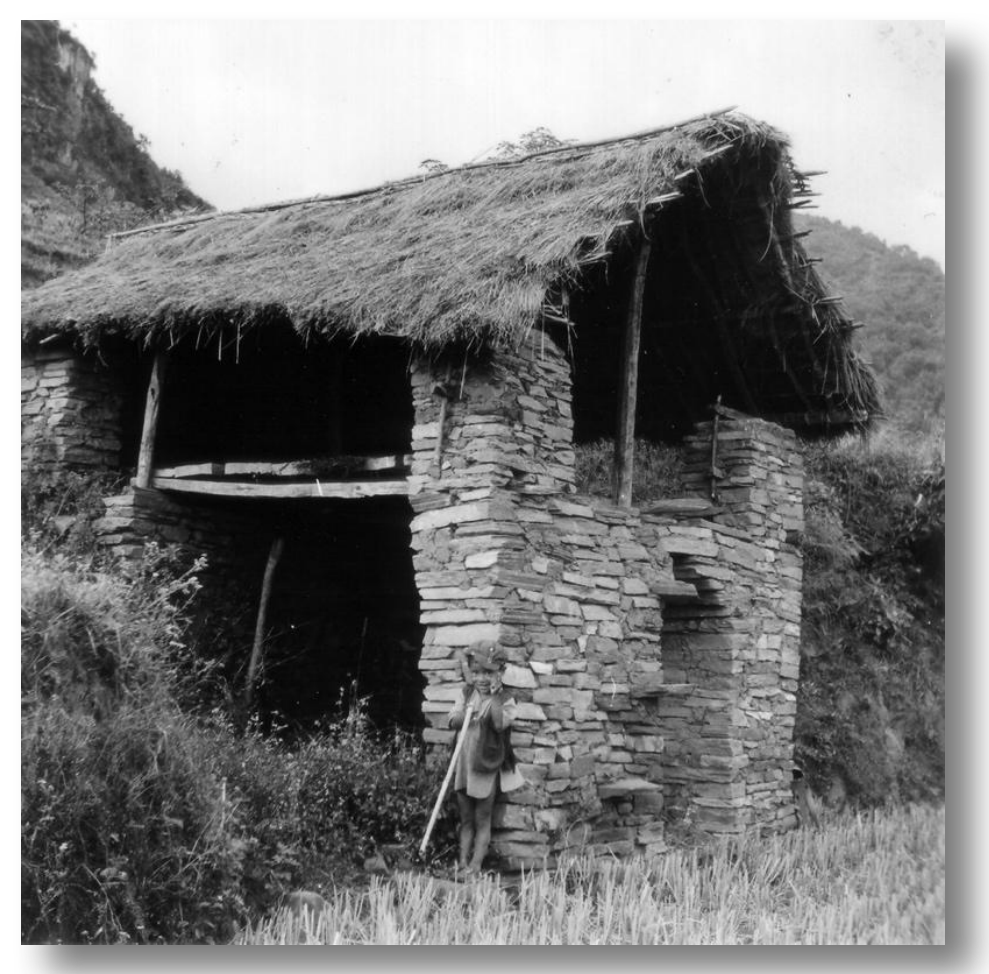

Bopalsing, poju's youngest son, in front of his father's 'tarva' or field house 


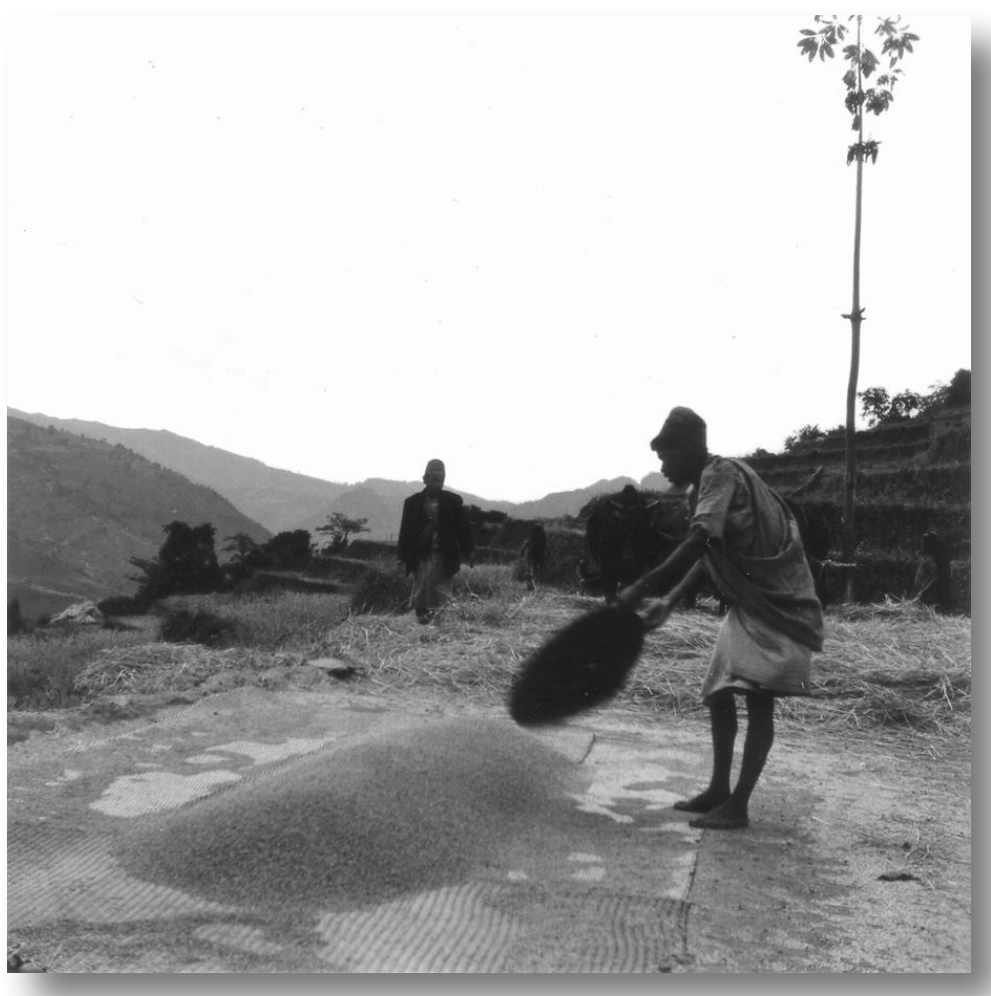

Blacksmith winnowing rice - 20th November

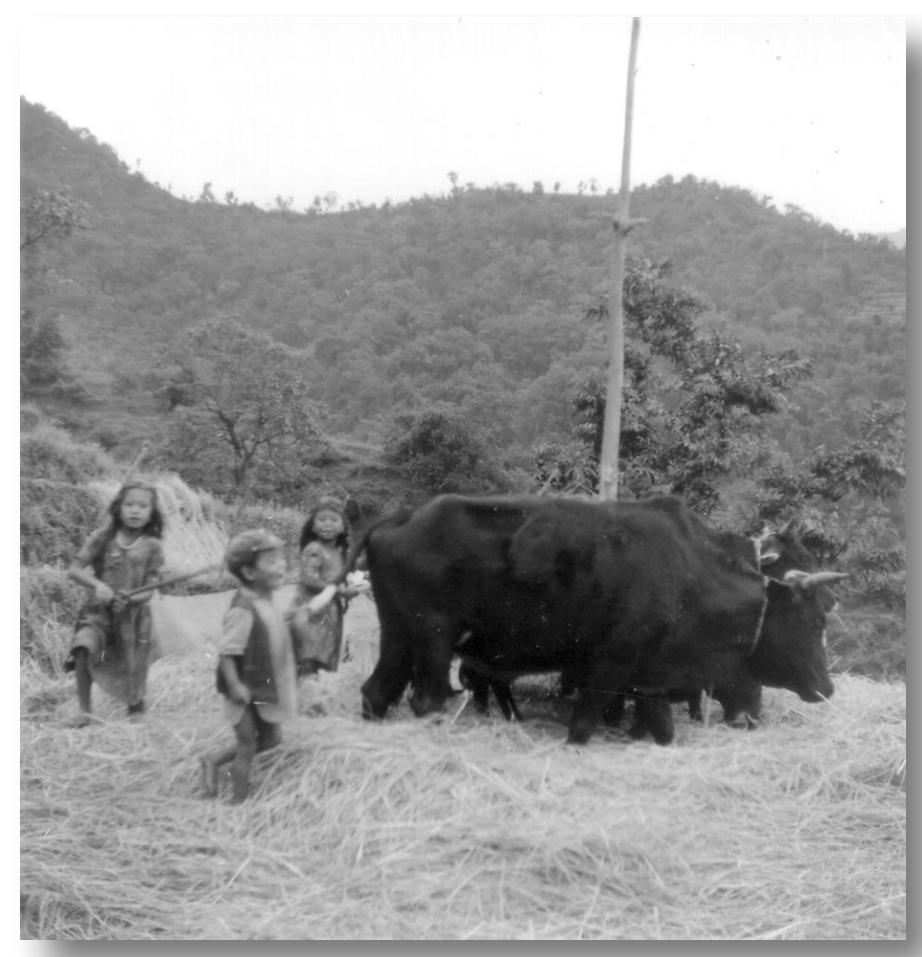

Children, including Bopal, driving round oxen in threshing 


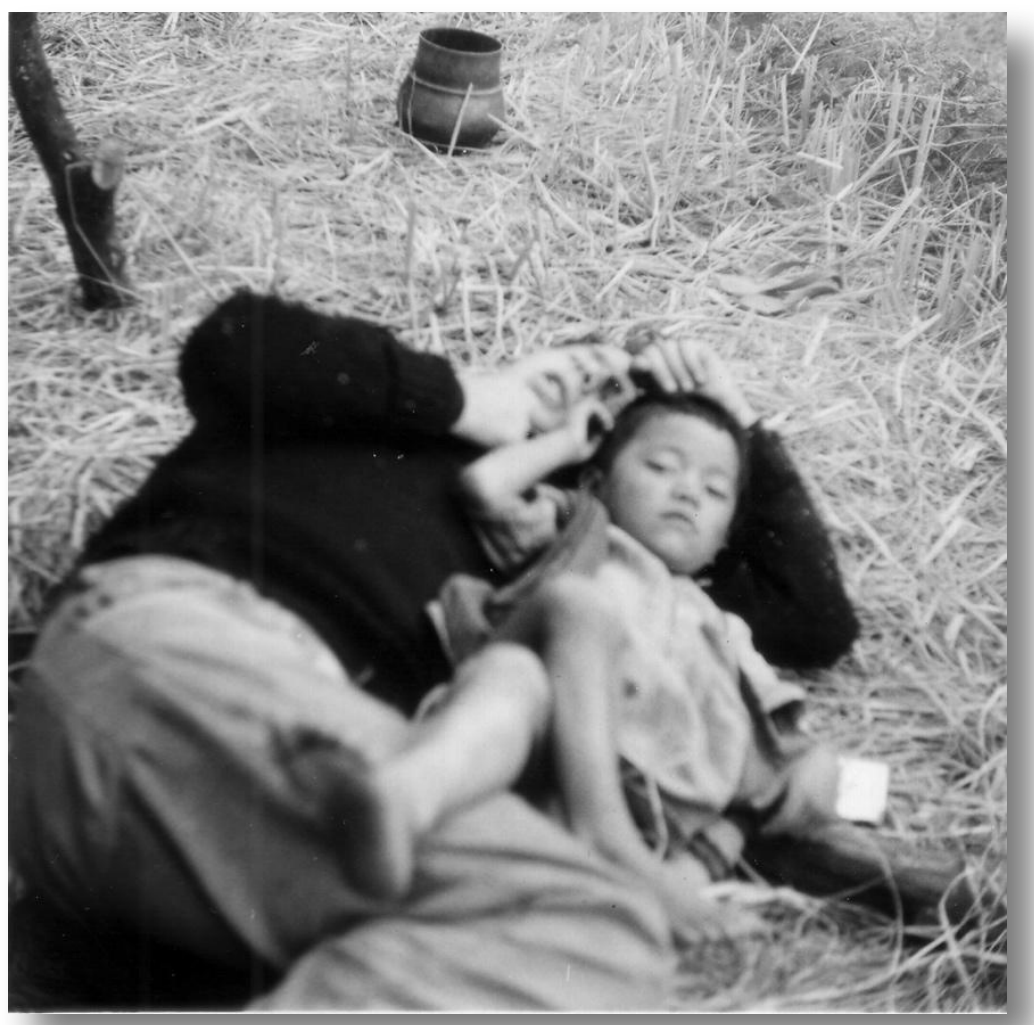

Alan with Bopal on straw

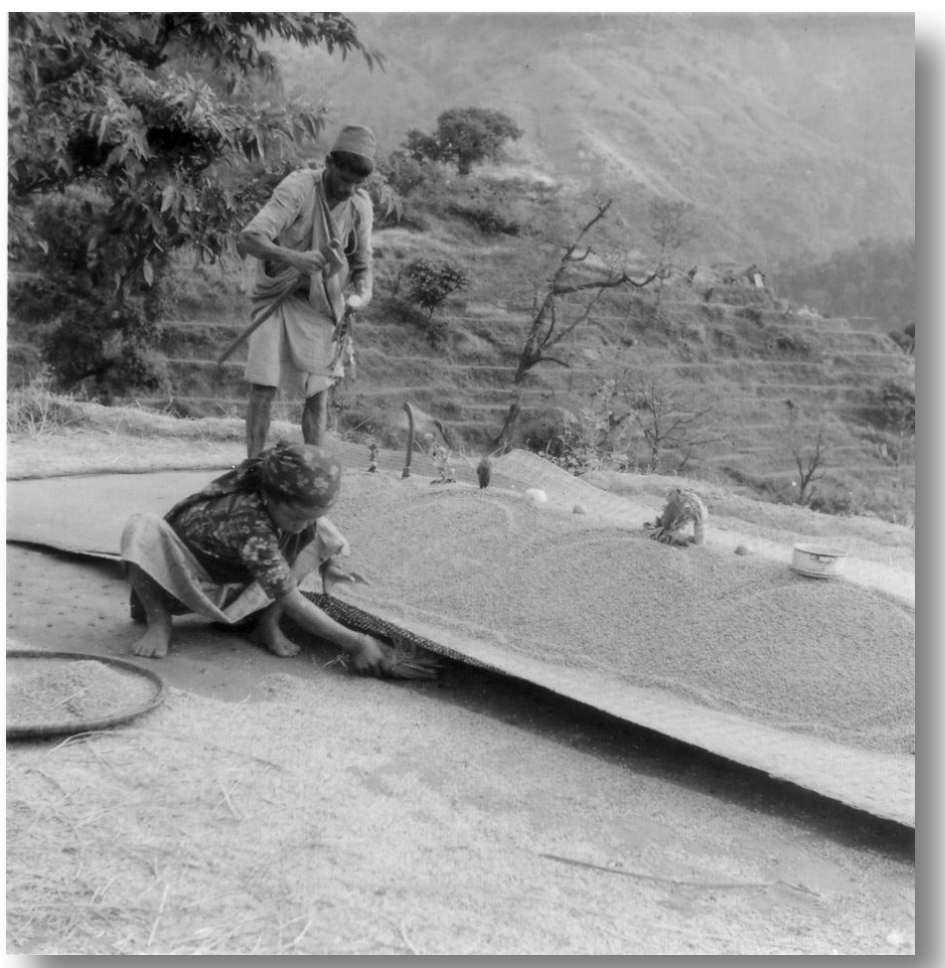

Rice pile decorated with magic symbols 


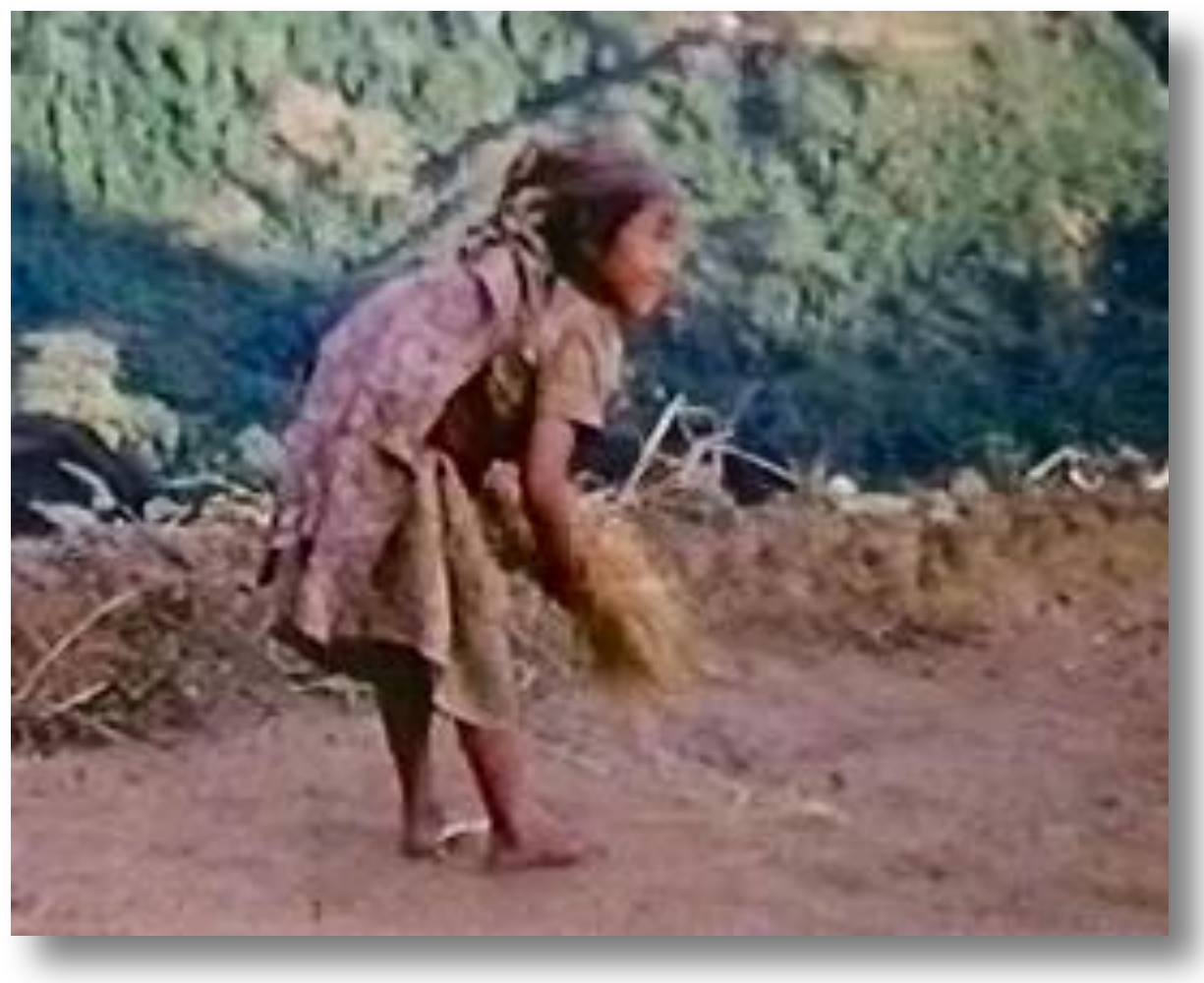

FILM. Haricola sweeping up the rice threshing ground https://sms.cam.ac.uk/media/2735461

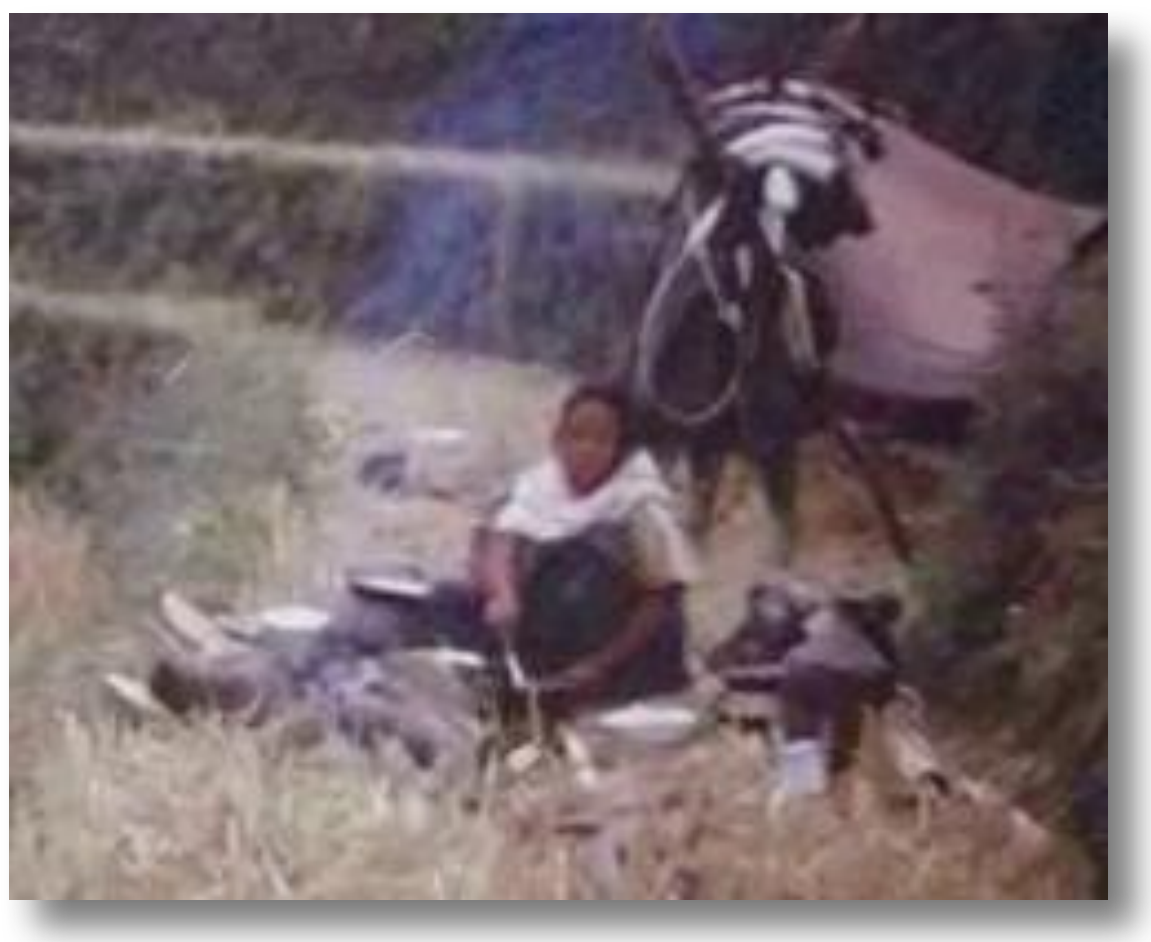

FILM. Yokmaya preparing food on an open terrace during the rice harvest https://sms.cam.ac.uk/media/2735489 


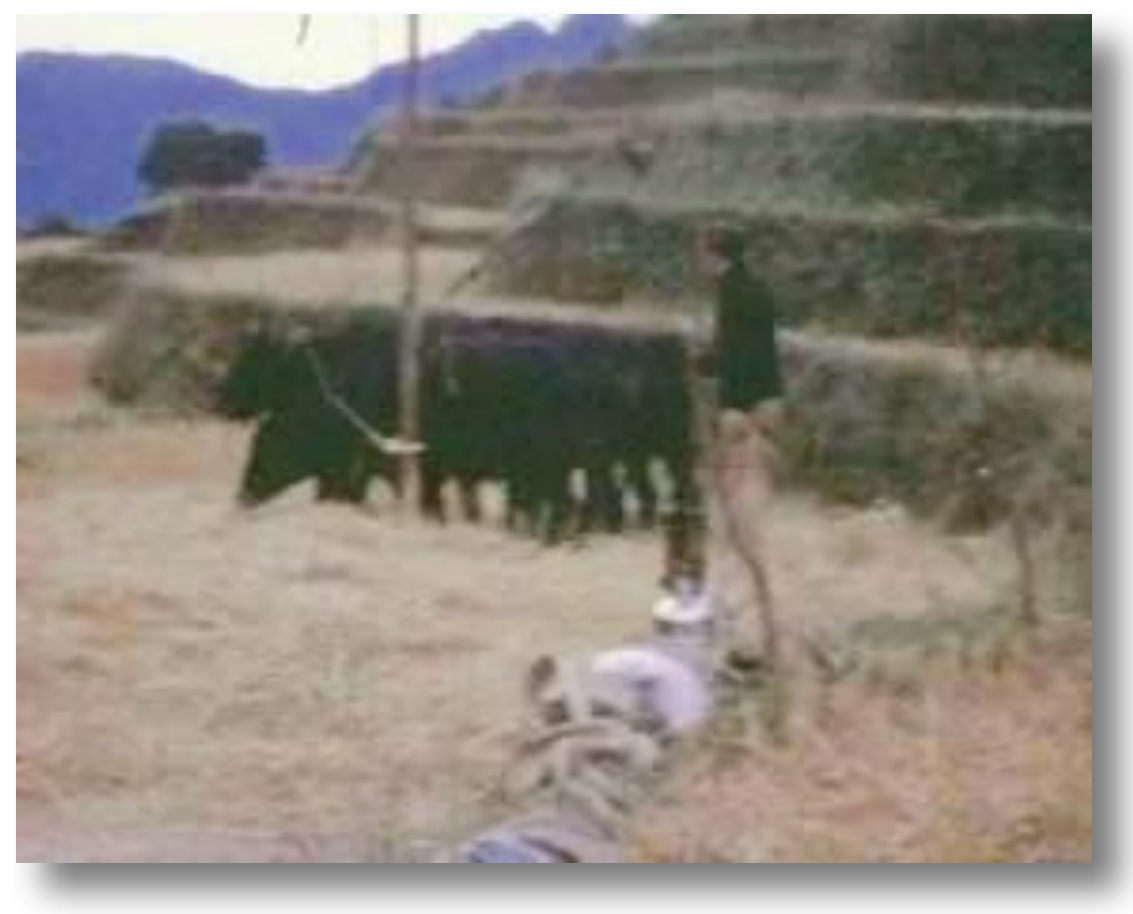

FILM. Alan beating oxen in a circle to thresh rice down the fields during harvest https://sms.cam.ac.uk/media/2735517

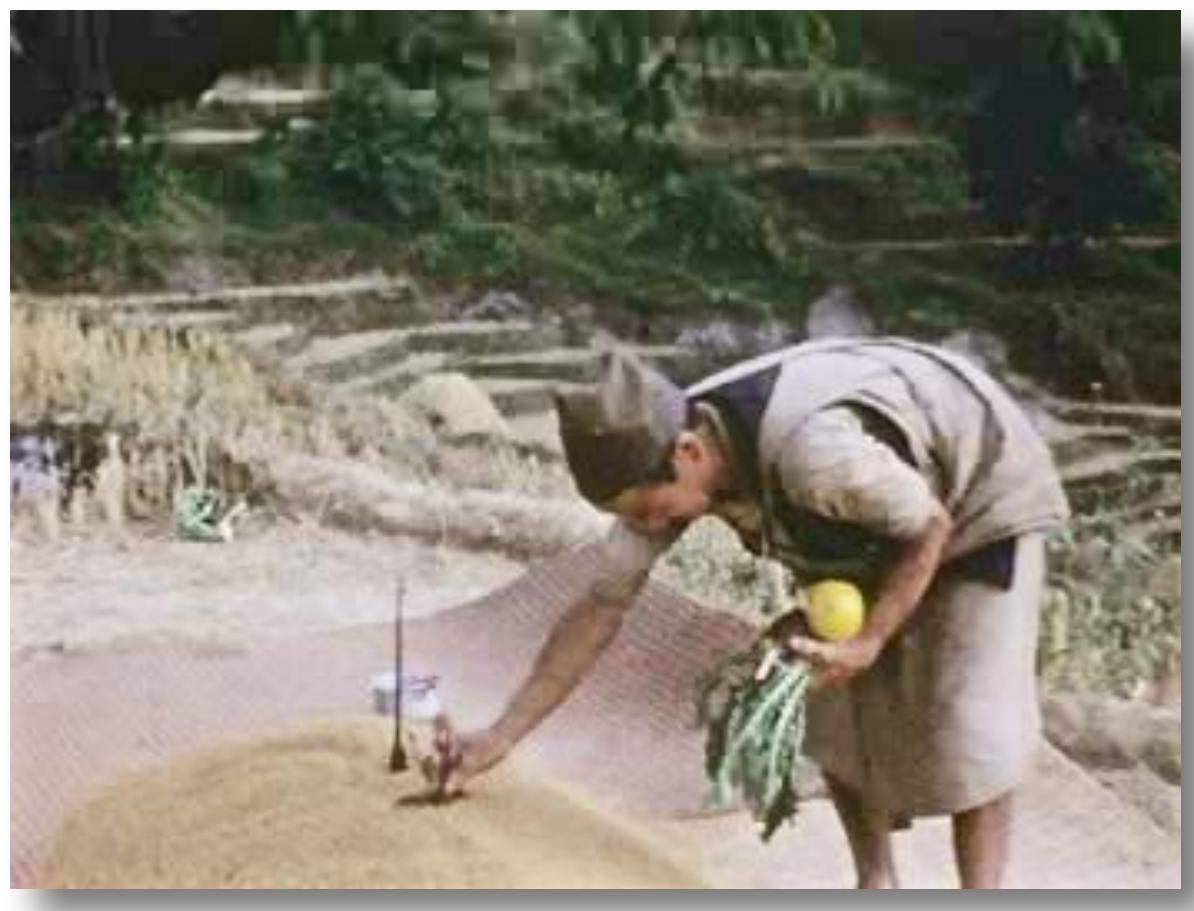

FILM. Poju putting fruit and vegetables into the rice heap

Man circles the heap with ash and then rolls a winnowing tray round to mark the inner edge.

Poju checks the liver of a dead bird. The other man marks the heap with ash trident https://sms.cam.ac.uk/media/2735545 


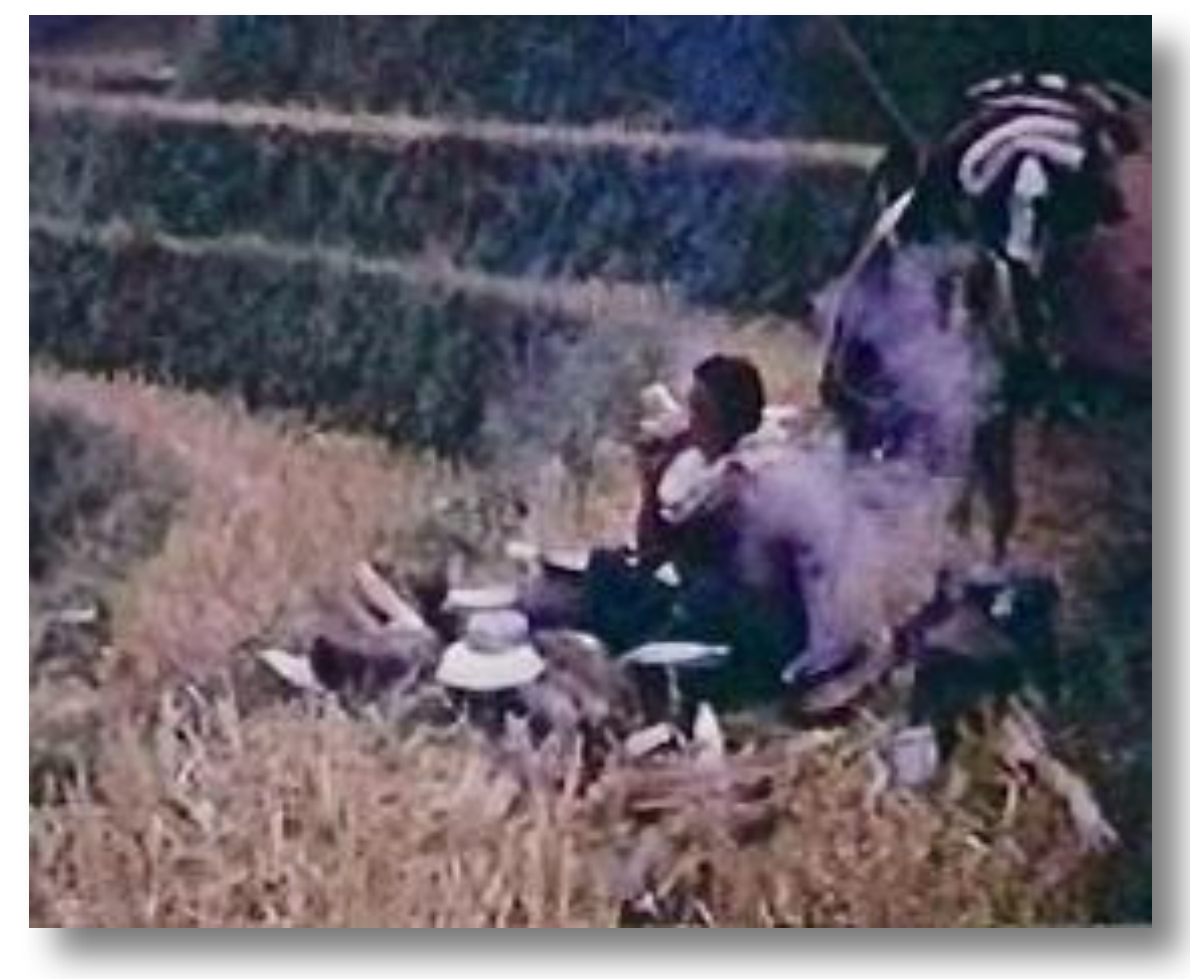

FILM. Yokmaya preparing food down in the fields https://sms.cam.ac.uk/media/2735573

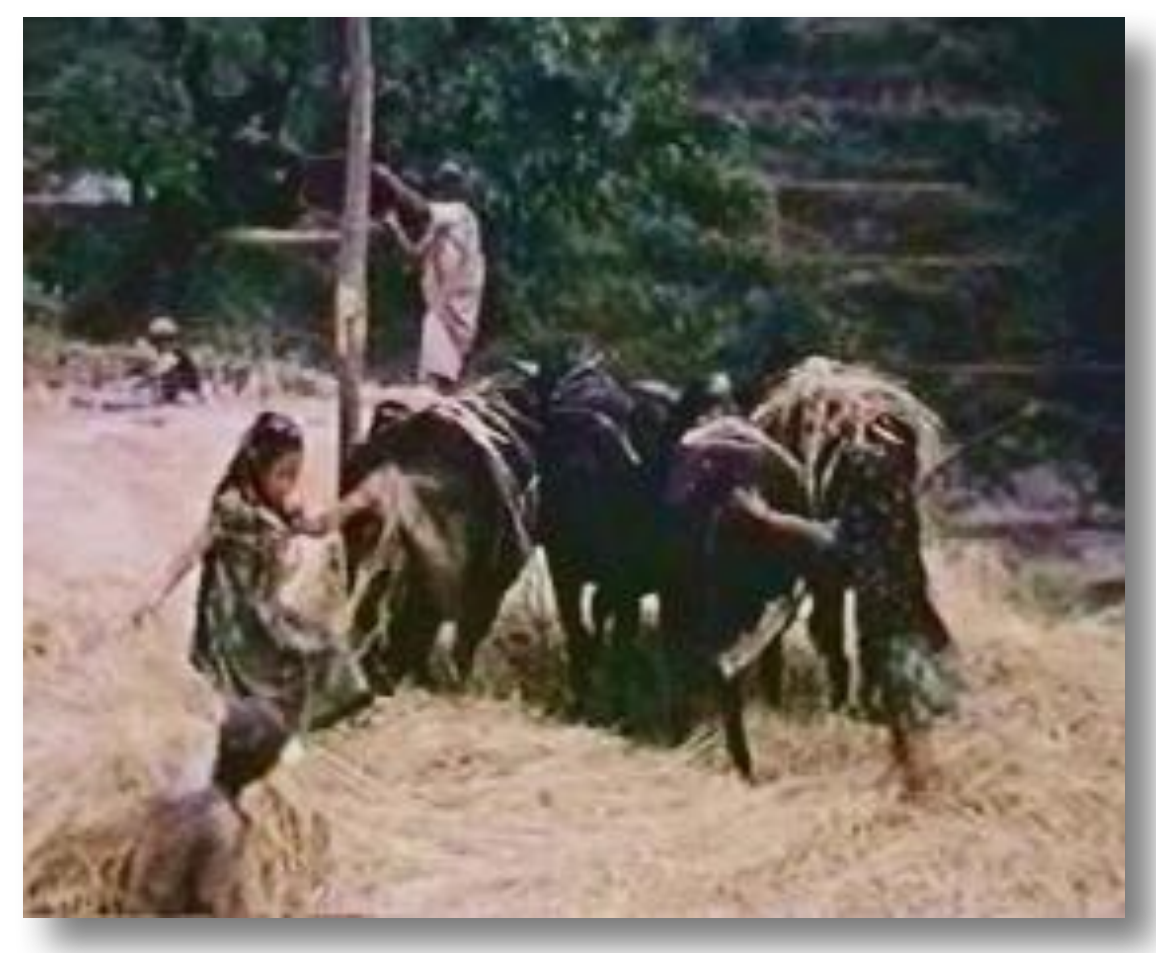

FILM. Children driving oxen round to thresh rice, joined by Alan https://sms.cam.ac.uk/media/2735601 


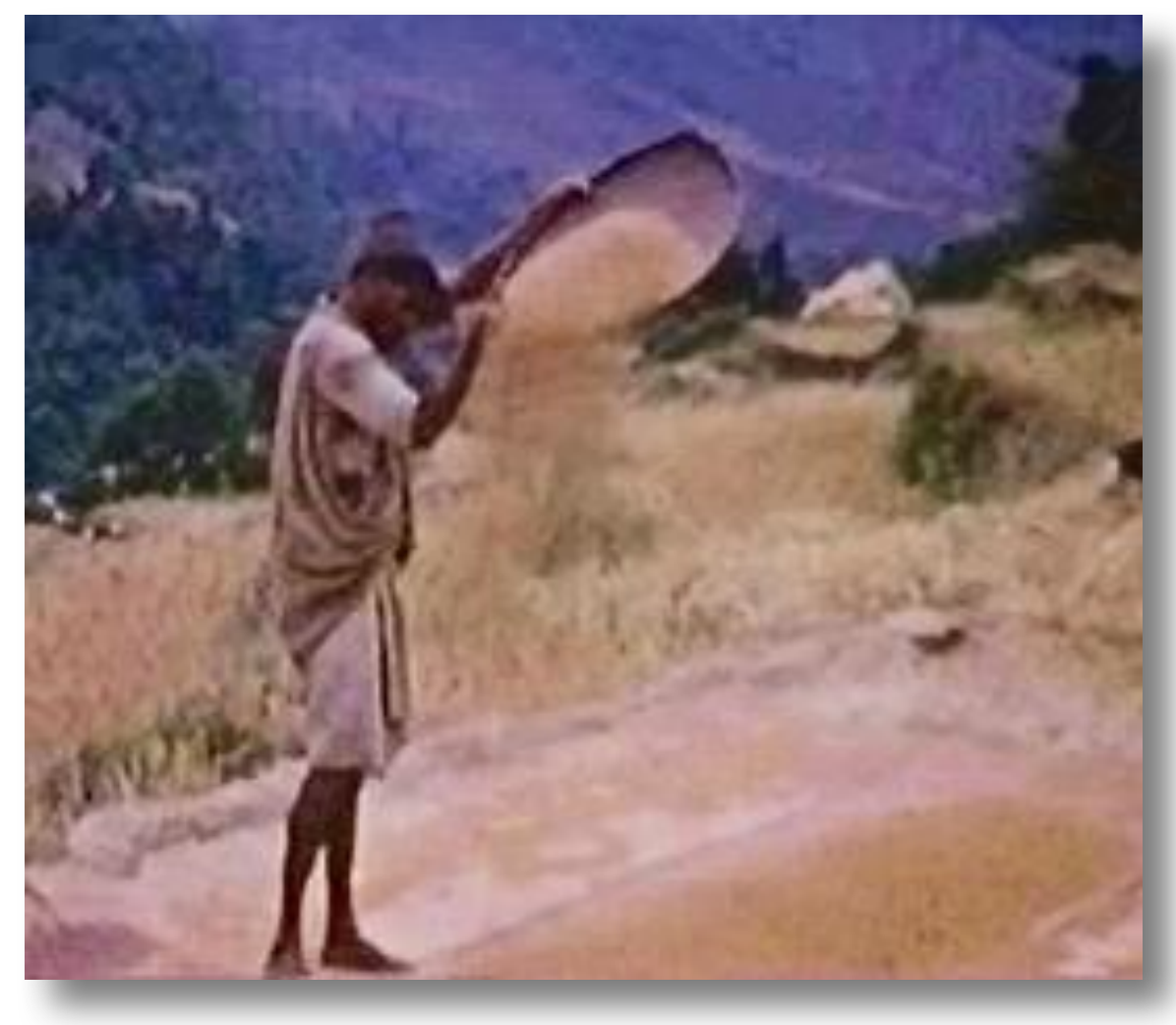

FILM. Men fanning rice with winnowing trays https://sms.cam.ac.uk/media/2735629

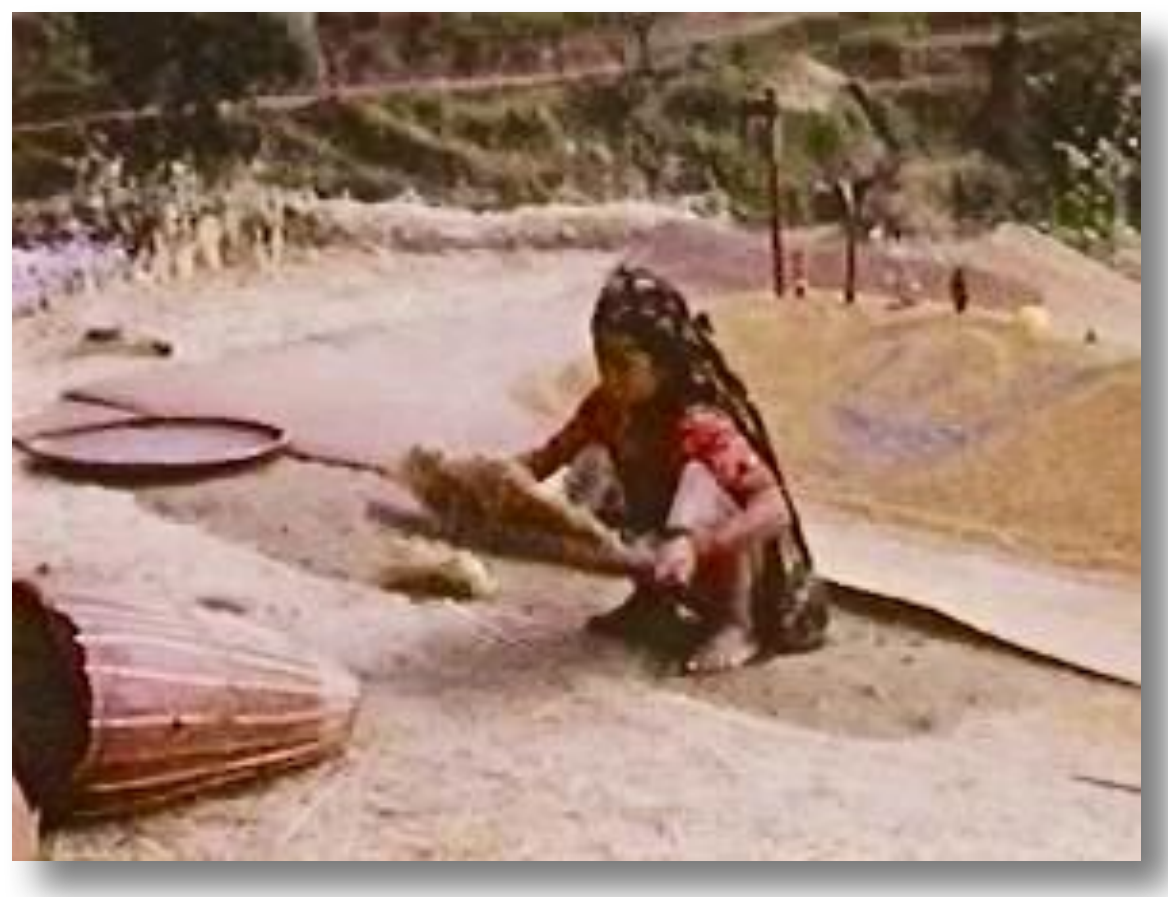

FILM. Tulsikumari winnowing beside the rice pile marked with ash https://sms.cam.ac.uk/media/2735657 


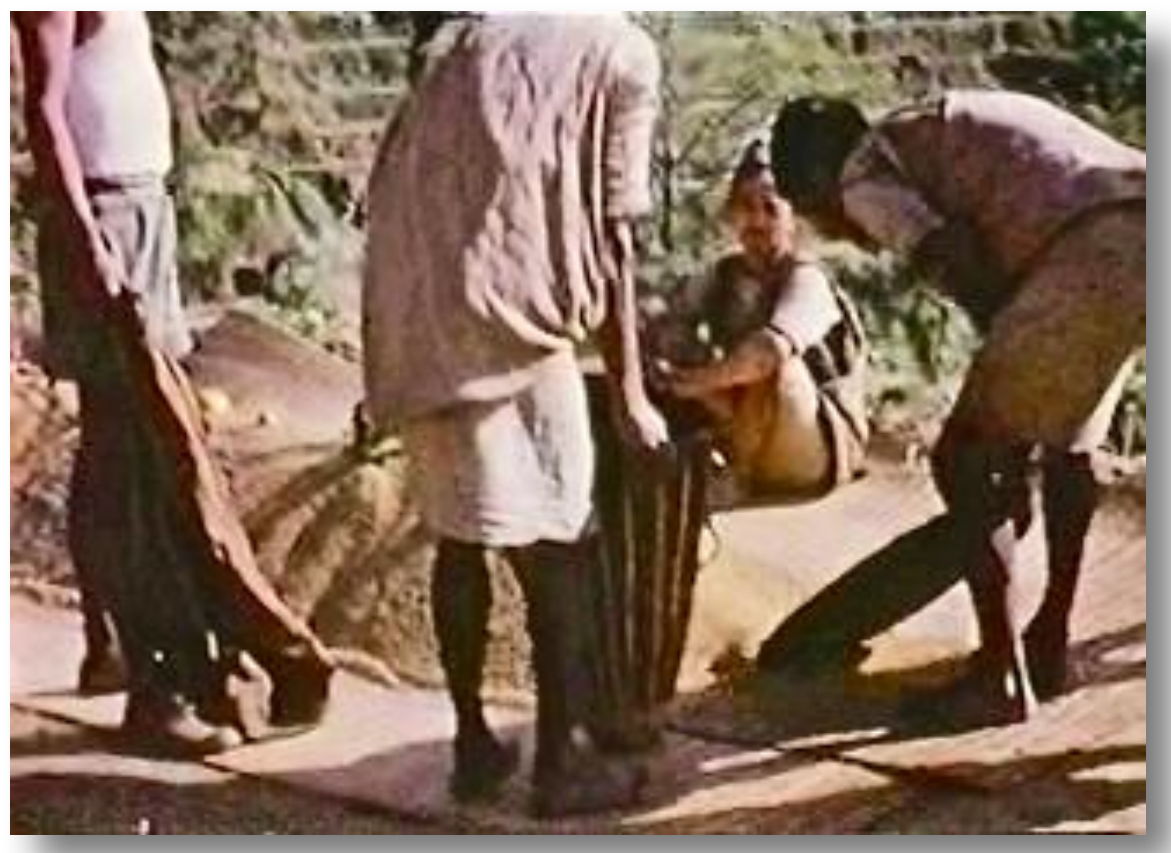

FILM. Ujesing doing final ritual before the rice is loaded into sacks and carried up the hill https://sms.cam.ac.uk/media/2735686

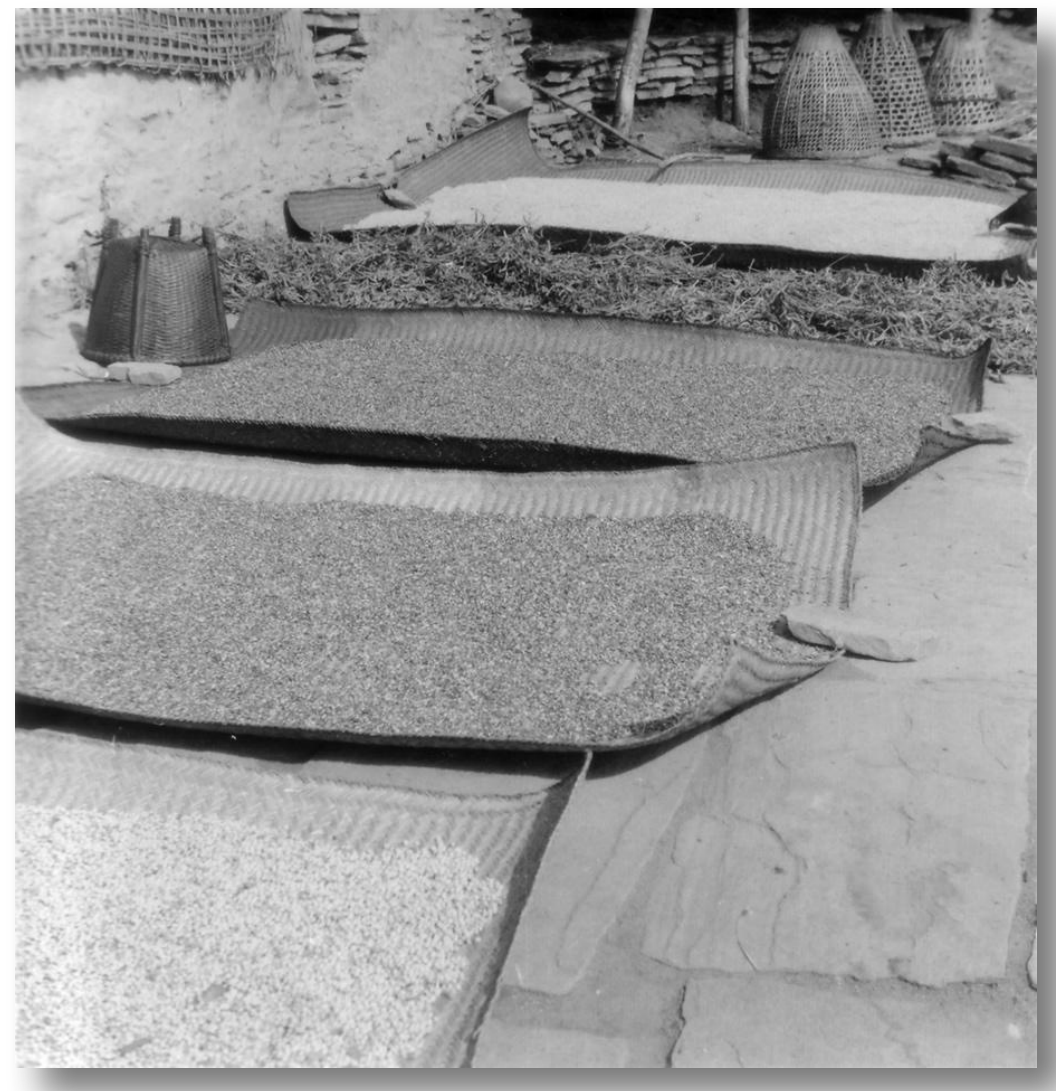

Grain and beans drying on mats in the village 


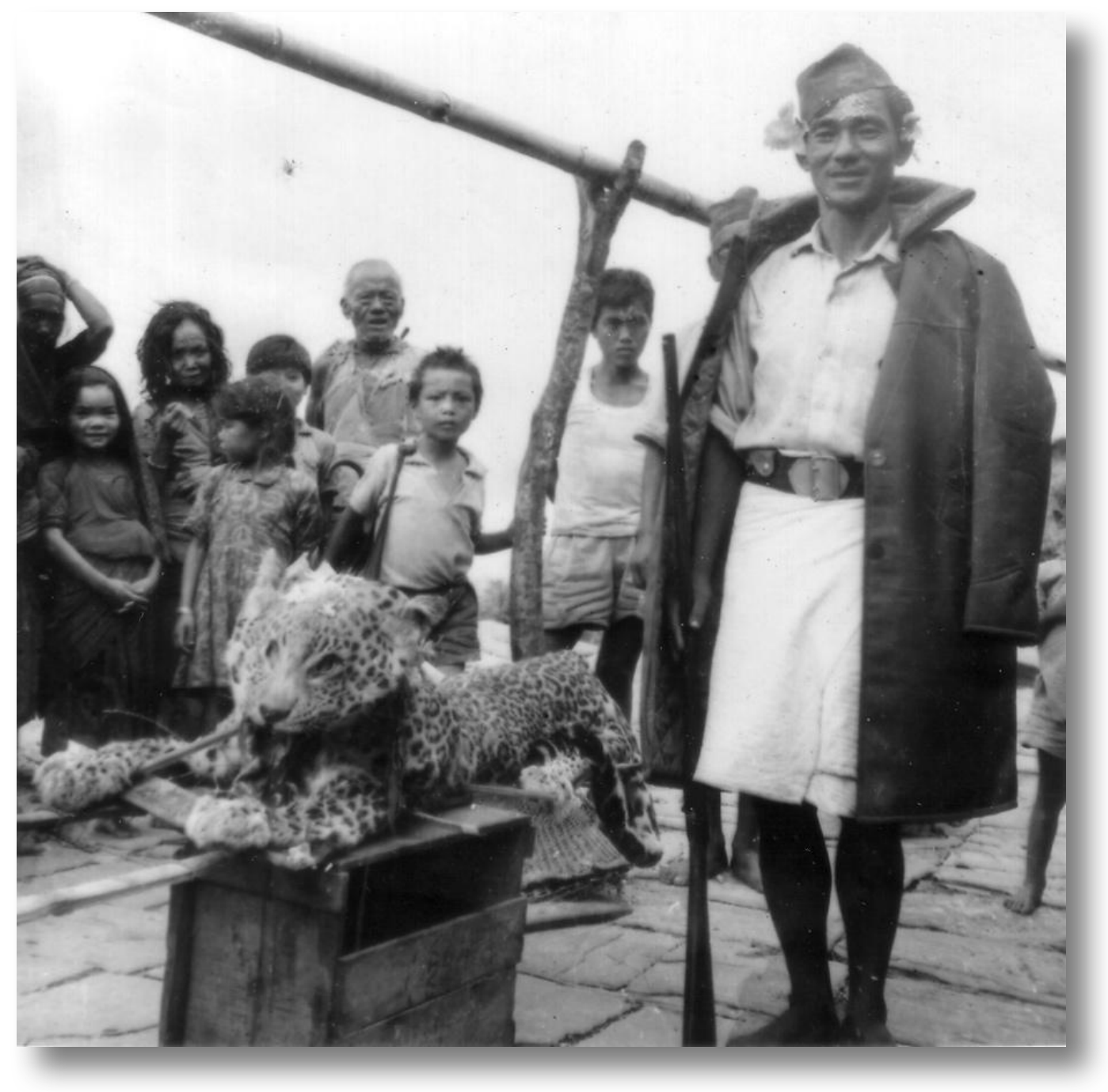

Purnabahadur, Surchief, with a leopard that has been shot, 20th November

\section{DIARY Friday 21st November}

Am feeling very frustrated at not being able to get down to work/checking - but most people have been down in the fields for last few days and will not have leisure for a few more. Wrote up notes after Totra's father's visit last night, then went out on two sorties and extracted quite a bit of information from Mr and Mrs Comal and Posbir. Had showdown with XXX and his father about theft - but so far no result. Men busy climbing up and down from fields. Girls and Nainasing came in in evening and sang a little. 


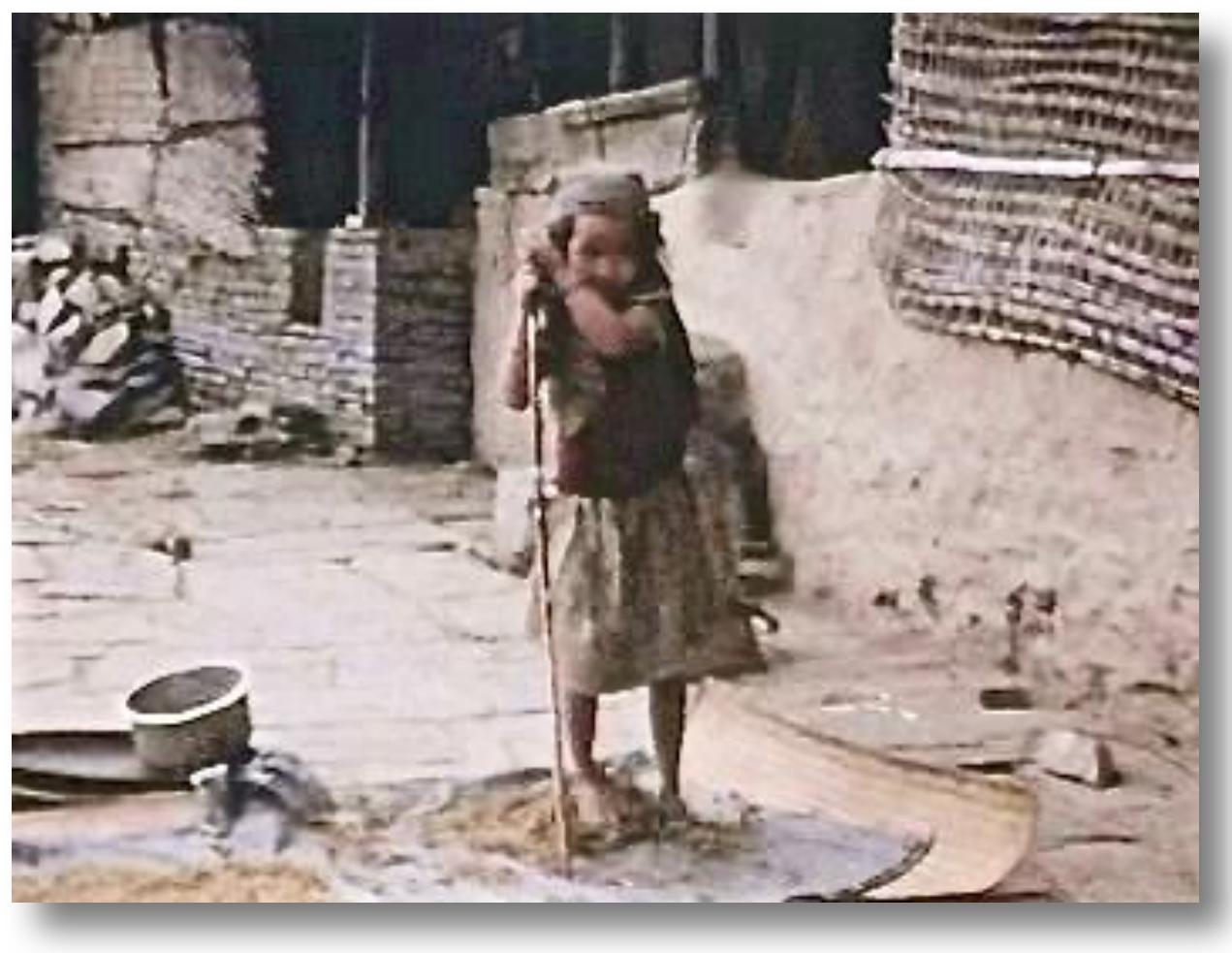

FILM. Haricola trampling beans or lentils https://sms.cam.ac.uk/media/2735729

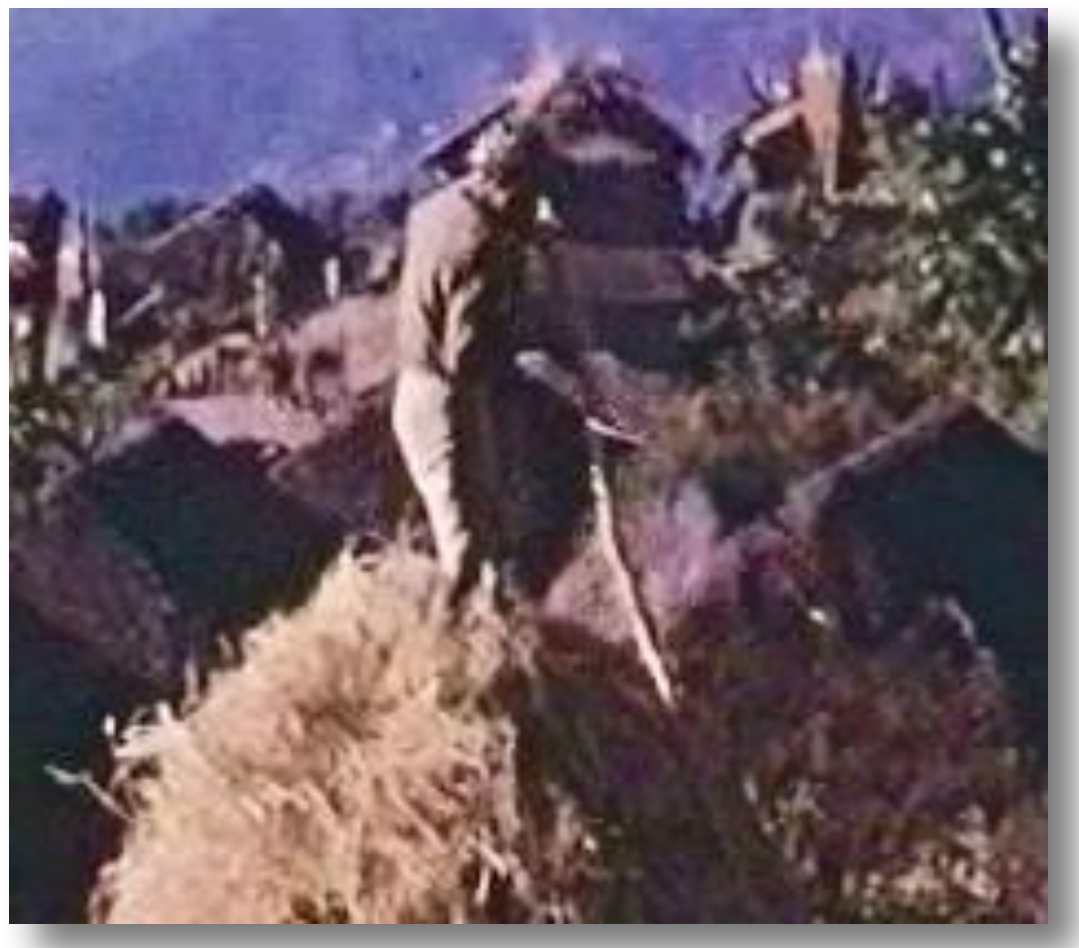

FILM. Prem and Manseram making a rice straw stack https://sms.cam.ac.uk/media/2735760 


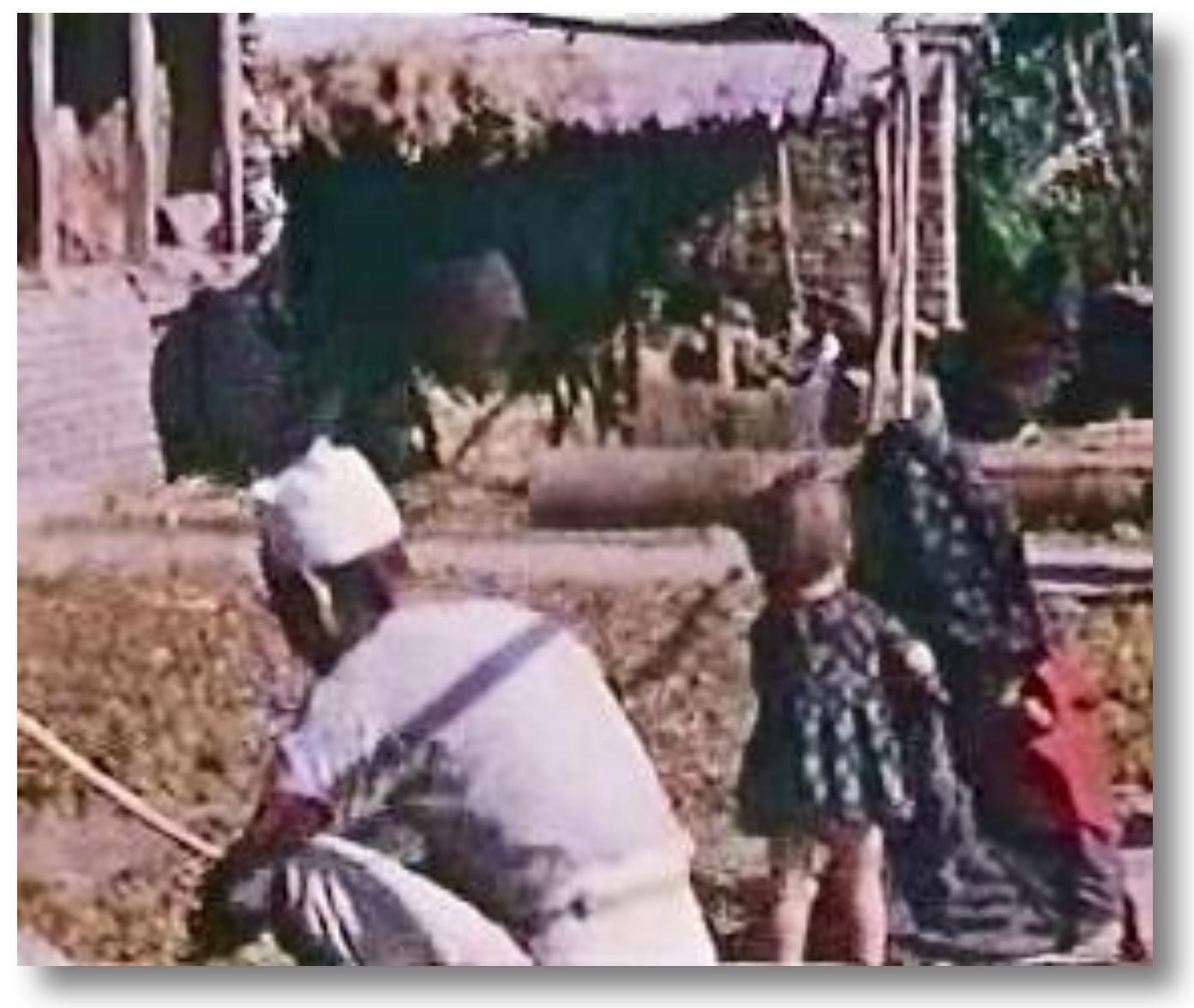

FILM. Woman with young child beating beans at House20, joined by Posbir https://sms.cam.ac.uk/media/2735788

\section{DIARY GILL Friday 21st November}

A lazy day which I feel continually guilty about - the old conflicting feeling of looking about for work, not finding much and not making it either. Guilt as far as Alan is concerned - also irresistible yearning to read "David Copperfield" which has got some real bitterness in it at moment - his time (real) in Murdstone's (Murderer!) wine business. Also amazing (for his time) conception of Mr Dick's "madness" - Charles I being "an allegory".

Got up 6.00am as we knew they were about to trample all over us at any moment bringing Gran's rice in. They did not in fact come until 7.00am. when we were up on the hill. Lovely morning - low clouds over Siklis making swathes of drifting shadow over hills, Annapurna immutable behind. I visited spastic child who has some sores (not many) - he can feed himself, and speak a little, but I noticed grandmother (whom I hadn't connected before) was a little distasteful in clearing up mess. [Her daughter came to look after Nani when she was ill. Slept night there. Later learnt (when she came in round fire at night) that Gran's father and hers were some relation(?).] She gave me one egg, and two to Haricola to sell to me later indignity of selling. For first time felt happy in that part of the village - taken nearly 11 months.

Everyone very friendly (we say this to each other in slight amazement at least once a day). Came back to write up rice harvest of yesterday, and Alan went off to do some work on his own. He also is much more chirpy. Really cold indoors, wearing a twin-set. Crisis at 
lunchtime when XXX returned. Sent in an Untouchable girl in to get me - in a chattering, almost hysterical state. It now seems almost certain that he has taken up to 200rs. from us. Alan went to see poju, who already knew (Prem had told him) - many requests to keep thing hushed up, with no certainty that we shall be repaid. It seems it is up to XXX who hasn't admitted what he has done with the money. Had slight fracas with Alan about him being soft and not saying he definitely wanted the money back - said he didn't want to disturb "good will" of family which made me cross, as its already disturbed

Four visits up to loft in all. Nainasing gurgling with childlike delight over "his" photo which we gave him, said it made him terribly happy to have this! Refused to look at any which did not have him in. Slept after lunch as I felt very coldy - got one from sleeping in the fields.

Everyone seems to think it is very cold down there. Another child came covered in sores - had come from abroad at Dessain and it had just taken him this time (month) to get infected wonder if it is something active in the water! Or deficiency in diet! Dr. very vague about cause - surely this is first thing to aim for if one is really concerned about healing. Lovely white light in the evening and the garlands waving in the wind, from house to house. Village very deserted with everyone down in the fields bringing up the rice. Went on walk with Alan as sun was setting - hills giving out pearly colour. Ramchandra's wife complaining that Benbahadur's oxen were getting onto their fields and eating millet. Their's is slow-ripening.

\section{DIARY Saturday 22nd November}

Unable to gather any information today, though I tried, as everyone (all males) were away in the fields. So wrote letters and read, etc. instead. In evening went to watch the lama preparing things for Comal's grandfather's funeral - little 'khedu' and lights. Kaila came in, but we shooed him out - telling him to come back when he had the money. Snatch glimpses at "David Copperfield".

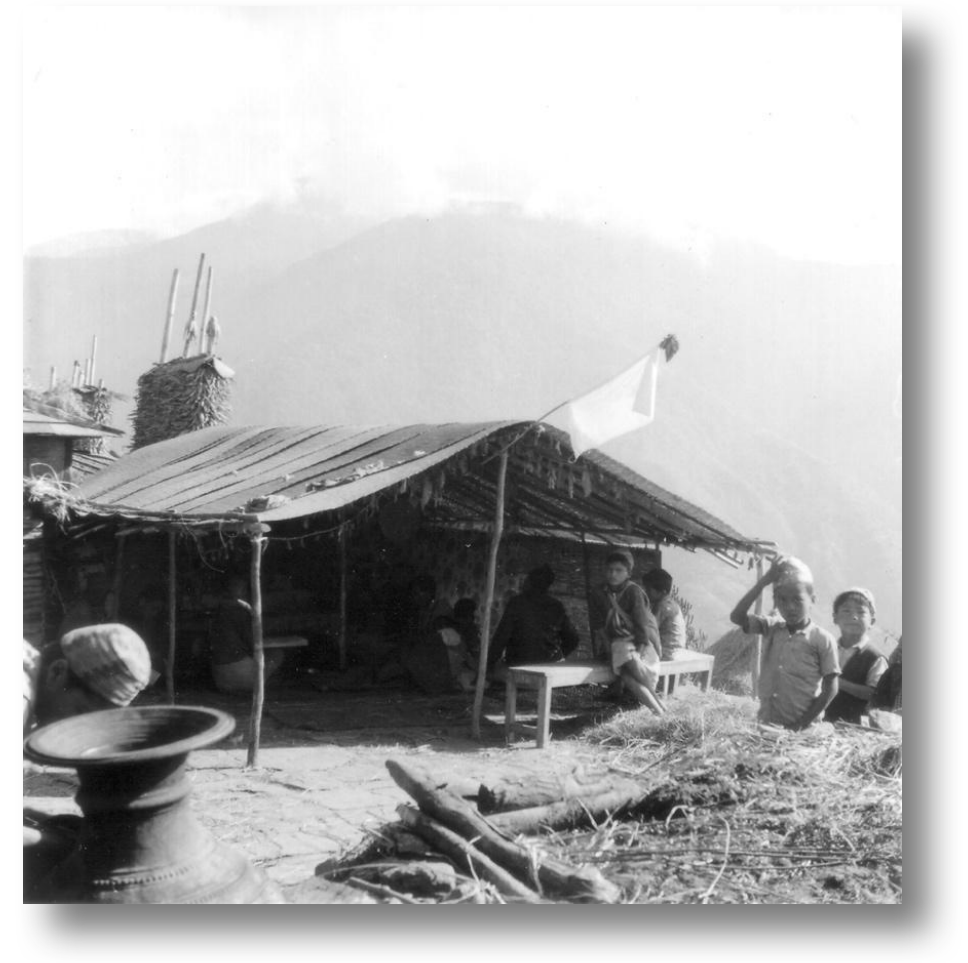

Preparing for 'chempa' at Kulmansing's house - 22nd November 
We have been back just over a week, and it almost feels as if we have never been away. Have just gone down to put gentian violet on a little girl's sores. The children are covered with them at the moment, especially those who have just come from abroad and haven't been in the village long. Must be something to do with the diet. Pity the doctor didn't come. I am smothered in purple, hands looking as though they were in the last stages of gangrene, and they have been that colour since we came back. We feel a little breathless, mainly because of Ira's visit, who was sweet and heightened our morale - our medical work and patience were admirable, and he loved the way Alan fitted in so well with the children - and also tearing down to the rice fields twice, and sleeping overnight. The rice was almost all cut when we got back, the fields looking very bare and stubbly, but the grains had not been got off the stalks. We went down with the poju's family, going to sleep under the stars and scanty rice mats, on straw, the sleeping bags getting sodden with dew at the ends, and staggering up with them all at 3.30am. The men just looked like the biblical shepherds crouching over the fires in their striped blankets, the stars giving the only light, except for a mantle which was lit later (and kept going out) for the threshing. The excess straw is tossed out onto a pile round a maypole, round which the children had danced the night before, to which four oxen are attached, plodding round in spirals being whacked at by the children. Alan also took a turn at this, shouting 'yaha-ho', to everyone's delight, and getting nowhere with the oxen, patting their rumps tamely, and not moving them an inch! We then all tumbled in the hay, helped them sweep up the rice with brushes made from stalks, and took photos of the brown heap of rice which had just had a sacrifice done over it, and oranges and flowers and sickles stuck in, looked like a very pretty large brown whale. To complete all this, saw a fantastic jay on the way up, flashing blue right across the mountains, and collected a bunch of flowers, mauve, white and yellow. Our rice is now stacked in the loft. Alan had rather a desperate time with Gran, moving rice baskets and buckets for peeing in at the same time, so she didn't enquire about the latter!

\section{DIARY GILL Saturday 22November}

Beautiful mornings, every one with a peachy, yellow dawn, and a chink between the cobwebs before the sun towers over the hill. Our hill is very beautiful and we get lost in the surroundings, feeling always - it is so beautiful, so why do we long to be home. Spent most of day reading - preparing for my child-rearing questionnaire and getting irritated by Kardiner's unquestioned Freudian basis (and so narrow). Alan could find no one in, all busy doing last of rice, except Comal's father who was repairing the courtyard in preparation for lama and funeral starting tonight. XXX is trying to be as jolly as ever, though it is a strain, even for him; we have decided to forbid him the house until he pays back the money. Very peaceful next door with Nani ill inside and Gran away and only cocks clucking and goats skipping about courtyard outside - one chick has broken his leg and Mrs Goof very amused when Alan gave some of his porridge to it!

Went up my hill after reading "David Copperfield" after lunch - love the way Dickens' imagination gets carried away with him. Dr Strong's gaiters being a good example! Also his awful plot-laying - so awful it is nice - a bit like the funeral this evening. Seemed a crime to read on the hill - so lovely, women down below in blue blouse amidst the yellow ripened millet fields, snipping away, their empty baskets looking like deserted acorn cups from my height up. Lovely the way butterflies catching the breeze and fluttering wildly down the mountain-side, as if a race against time in the wind. A large bank of cloud ready to roll across Annapurna. Did read "Orlando" though, and found a nice passage to describe my hill Orlando climbing his hill behind the ancestral home. Then picked up Fromm - who rather depressed me and I feel more affinities with Sullivan's point of view - there is no "inner true self in man" but one changes to one's people and circumstances. Alan came up later, but the sun was down and the wind quite cool so we went down again quite soon. 
Crisis in the middle of a quiet supper - XXX bounced in, we told him our decision and he looked very shocked and hurt and gave me a tummy ache. We went to the lama's do afterwards (meeting Warren's informant on the way, both disliked him, disloyal about Jessie not giving out cigarettes). They had made a large rice-mat tent in courtyard and at back were four Buddhist 'tankas', a bed covered with a grubby embroidered cloth which had silver ornaments, brass bowls full of flowers, baby 'tankas', feathers, a transistor radio and plastic sheeting round walls - blue vases. The lama had a yellow blouse, maroon waistcoat, brown beads and checked 'lungi' on, shaved, quietly spoken. Made phallic 'kaidu' and one large one like "Victoria and Albert Memorial" out of rice, and several little Buddhas. Second schoolmaster prepared butter lamps, and Totra's father shouted orders to all most of all to Comal's father. An 'ala' was made. A Gran was fetched unwillingly from across the fields by the boys (Servajid, Gundasing, Comal). Comal had new white plimsolls on and creaked about uncomfortably in them, also new hat. Feebleness of his father's authority, sweetness of Maila and his usual ragged clothes, Maili coming "for a hug" - very spoilt. XXX around, ignoring the poju when he came up. Poju looked sad and tired, but treated with respect - sorry for him! Women from Gachock sleeping in the coverlets on the verandah.

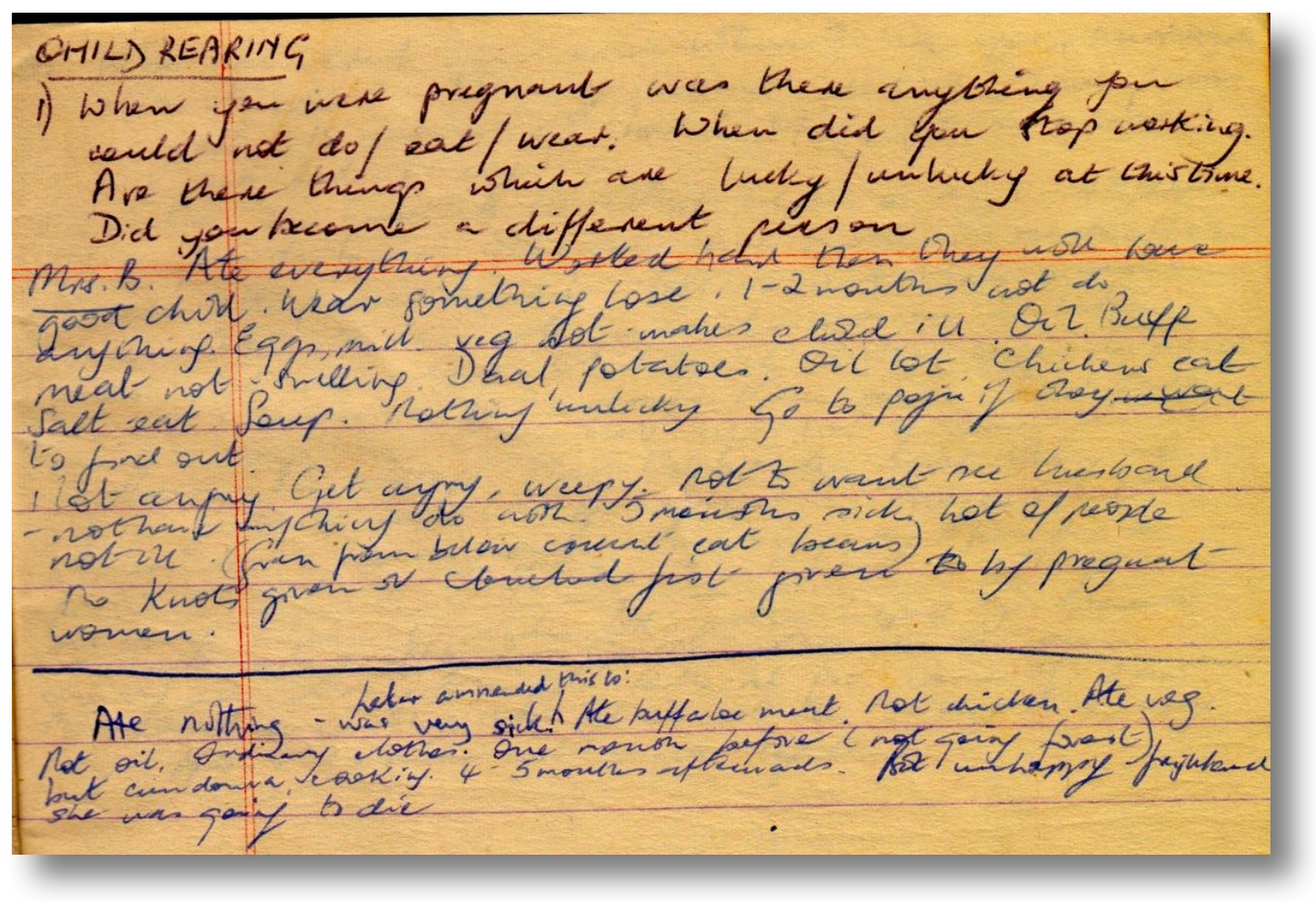

Part of the original childrearing survey 


\begin{abstract}
CHI LD REARING QUESTIONNAIRE. RESPONSES TO: 1 ) House 23,Mrs.Bohansing •
$11 / 1 / 70$.

Mrs. cleaning out the buffalo house,scraping up dung and sodden twigs with her hands, when we went down.B.was writing a list out in Nepali.Tank.was combing her hair and replaiting it.Buje just sitting warming herself in the sun.No, they were'nt busy, even tho parents going off to Kathmandu tomorrow. We were given a gundri on the verandah and Mrs. B. soon came after washing her hands. The buje from the house down below also came, much declaiming, bowing down to my knees, and then she sat herself on the gundr1 and e entually squeezed me onto the uncovered verandah. Wowen were interested at once when A said what he wanted, and started telling him before e had the questionnaire unfolded about breatfeeding, how often they gave $\mathrm{milk}$, and Mrg B in particular said that in Fngland mothers only breastfed their babies one year, and that this was very bad. The interest and feeling behind this topic was considerable and breast feeding seemed to be an important factor for the mother in childrearing, one which she took pleasure and a certain amount of pride in, three years being the most satisfactory ength of time.

1) At first did not immediatej take to the idea that pregnancy involved diet restrictions c.Mrs.B. sid she ate everything and worked very hard, if they did this they wark have a good, healthy chlld. Implied a lot of back belding, lifting and carrying would make the child strong. Only in the last one or two months would they do no work.Diet restcitions eventually emerged,esp from the two grandmothers who again were vehement on this subject of feeding. $T$ hey ate a lot of eggs,milk, oil, but not eegetables as this makes a child ill. Buffalo meat was an abhorrent idea to them, much wrinkling of noses and sour expressions. If they ate this their arms and legs would swell.Mrs.B indicated how much her arms would burst out if she ate this meat. Chicken meat was alright,as was salt and soup. Wonder if the buffalo taboo has any connections with other vaguag sexually associated buffalo taboos we have noted beforeinsult connota tions. Buje from below was very expressive about how much green beans made

her feel sick.They were puzzled about lucky/unlucky signs and Mrs.B obviously thought the idea rather barbaric when I gave the example of a black cat crossing a pregnant woman's path being unlicky. However Bohansing, how sitting on the wall, eventually said, when another subject was being discussed that it was bad for a mother to tie any knots in her clothing or anything else.Then Mrs.B.said there was a certain way a pregannt womenhad to pass things to another person-with an open hand, not clenched up. She illustrated this with a box of matches which she gave to A, touching his hand lightly with the box, spreading her fingers out and not letting the fistj clench upfirhis was also a way of communicating that you were pregnant, Towards the end $\mathbb{M r s . B}$.also said that they wore their clothing loosely. On ch ange of personality all three women we very lively and it seems quite a lot of tantrums, tears, bad temper and rejection of husband in an openly ggressive way is tolerated, and even enjoyed, by the women, at this time.They showed me how I would treat A if I was pregnantpretended coyness, anger, blame, with the face hidden hehind the headcloth and an attitude of not wanting anything to do with shown by the shooing away with the hands.Mrs.B. said she did'nt even want to see any man, a sort of relished distaste,as if at last this was the women's open rule of power.Mrs.B. also said she was sick for 5months but this seems to be unusual and she said a lot of women in the village were'nt ill at all.
\end{abstract}

Part of the later analysis of the childrearing questionnaire in November 1970

\title{
DIARY Sunday 23rd November
}

A very happy day. In morning had long talk with Gundasing's father and did another interview. After lunch poju and another man came in and we tried to unravel kinship for some two hours. Poju very concerned and agitated about his son. We then went to watch lama's rite, on the way getting a drink at Bhuwansing's. A lot of people from Atigar/Chachock - including the Glover's informant, Deobahadur. But managed to crawl into our bed at our usual time, about $8.00 \mathrm{pm}$. Suddenly my language (and also Gill's) has become fluent and I feel fairly confident - have managed to learn quite a lot of the little.

\section{Letter from Gill on 23rd November 1969}

...Alan is out at the moment trotting round the village gathering facts about the rice harvest, which has just been gathered in, and I have come back from a little funeral ceremony done by a lama, dressed in maroon waistcoat and corn yellow blouse, with a shaved head and a sweet way of modelling little Buddhas from rice, one looked like the Victoria and Albert memorial, there were so many lumps and ascending pinnacles! The Gurungs are an extraordinary mixture - next to their beautifully shaped brass jugs holding red poinsettia leaves is a transistor 
radio, and the tankas are stuck over and altar (one tine trunk with a grubby embroidered cloth over it) next to plastic sheeting smothered in blue roses. What I love most is working down in the fields with them - we spent the night by the river, sleeping on rice straw, the stars winking through the matting which was the roof, and getting up at 3.30am to watch the men threshing the rice (manually, bringing each sheaf down with a great thud on the mud of the field so that the grains bounced off) and the children whacking at the oxen, attached to a kind of maypole where they trundled round in spirals getting the remainder of the grains off the sheaves. Alan took a turn at the latter, shouting 'Yahoho' with great aplomb, but the animals not budging an inch - four of them swishing their tails and looked puzzled through their eyelashes! The children tumbling in the hay and grabbed the tails to give them a tug and they started off again, Alan patting their rumps gently. It was lovely sitting on spiky, sweet smelling hay watching the men crouched over the fire in their striped blankets, looking for all the world like the biblical shepherds, shadows cast long across the night, alive with stars; or see them winnowing the rice in a long low brown shape like a warm whale which the priest has already done a sacrifice against, tossing the decapitated chicken over the maypole, and sprinkling the blood and ash from burnt straw round the waiting heap of rice, to be carried up in sacks to the house.

There is still some of the millet to be harvested, and I can see the women chopping the heads off from my mountain where I go a read and get peace from the shriekings and life of the village. Yesterday there was a woman bending down in a blue blouse amidst the yellow ripened millet, with her basket waiting beside her for the heads, like an empty acorn cup, and it was a perfect Van Gogh setting. The kites were whistling over my mountain too, swooping down so low I could see their mean and beady eyes (they dive into the village for the chickens), and there was a tawny butterfly on the rock opposite, and gently bending grasses against the white mountains and the deep green valley. It is so lovely, and yet we still have an ache for home.

Work has gone more than well, getting unexpectedly rich material from the local magician who has the most fantastic rites and lovely myths, which I want to analyse when we get home. There was a little rite the day after we got back, as the girl next door is ill, and we were invited in to take part, putting white threads round her neck to keep her wandering spirit in, and blessing her with hands and invocation - 'shyar', whilst the poju sprinkled rice and went through a myth. I am busy at the moment doing a questionnaire on child-rearing, on a Freudian model to see if it can be applied here. In a few weeks we are going to see some other Gurung villages and compare notes, and after that it will be only three weeks and then we start for home (at beginning of February). We are hoping to go to Assam, Calcutta, Istanbul and Persia...

\section{DIARY GILL Sunday 24th November}

Every morning a lovely one - sun cascading over hill at about 7.30am. Went to see funeral briefly after going up hill - only a few children and women about and everything a bit desultory, women incanting. Alan went off to Gundasing's father and I came back to the house to write letters. Poju came, looking worried, for Alan. Made 'pasagi' salad - a success (lemon juice instead of vinegar). Gachock people interrupted our rest after dinner and then poju came up with a friend to the loft to see everything, and Alan very thrilled when they helped him with genealogies. Couldn't type so hand-wrote letter to Warrens and attempted to type outside. Poju had an emotional session with Alan re XXX - they beat him in the loft last night, apparently, but could extract nothing from him (both he and Prem had a go), and begged Alan not to throw his pride away ('ichu waba') by telling people as Brikaras of this world would use it against him. Shows how insecure this family is and how far apart we are regards us somehow as an upper jhat - he says he is willing to do any amount of work for Alan to make up for XXX - still no conception of repaying the money of course! On way to see funeral (poju had also let all his anger about this out in loft too - laughing at way lama made 'plah') dropped in to Bhuwansing's. They were sweet and welcoming as always, giving us maize dipped in fresh honey and very strong 'pa'. Talked openly of eldest boy getting married in a few days - would we go down, and I wear a sari, etc. Bhuwansing reminisced about his time in England - getting lost on Circle Line and trying to decipher 
cockney - "In it terrible" - perfect reproduction! Looks very handsome at the moment. Laljid dropped in for a chat and joke.

Later went to funeral reeling a bit and met up with Brikaras also reeling - very few people there, though lama dressed up in his curved cap, and making elaborate ritual gestures with thunderbolt and belt and hands. Butter lamps were lit and cymbals and drums were being rung, but Gurungs hostile - a lot said they were even going. First time we have seem a community spirit about abstract concept (it isn't abstract at all of course - when we went finally in the dark, man from Atigar was arguing fiercely with Brikaras about advantages of 'pae lava' centring on fact that one should slaughter a buffalo). Arguing aggressively in a lull of poor lama's ritual - as Alan said, felt we were missing a whole world of delicate intricacy, much beyond us and the Gurungs. Had rice party in before they went down finally to the field - quite jolly, drunken Ombahadur flirting with Omkumari, to the jealousy of others who haven't got his 'joie de vivre' or the 'pa' for that matter.

\section{Letter from Gill on 24th November 1969}

...We have just had three weeks break away from the village, ten days in Kathmandu and the rest in Pokhara. It had to be so long as the proofs for the witchcraft book came through (coming out next March, they have been very slack about it) and Alan had to give a talk to the British Library on Aid and Development in Nepal. You may well ask why he was told to give a talk on a topic on which he is hardly qualified to speak, but the librarian has been very kind and has endless faith in British education, never having been to Britain, and this means Alan can talk on any subject demanded... Fortunately, they didn't listen to a word although there were over 50 of them, much more smooth and glossy than Alan, as his message was that neither industry, education nor tourism would help Nepal, but only population control and development of natural resources, Aid having retarded the country more than anything else. All of them having entire vested interests in both education and industry, being the middle class elite which aid had helped, and only them, to foster it was not unnatural that emotional ears were blocked.

...In the village at the moment a horn is sounding and drums and cymbals are playing at a funeral, conducted by a Buddhist trained lama (but Gurung), an innovation in the village rites as the Gurungs have their own very beautiful funeral which has been outvoted on this occasion by an upper sect of the village for this much more esoteric and sophisticated affair. As a result very few people have attended, except the close relatives, and usually a funeral is an occasion for the whole village to flock to the house and give presents and comfort generally. This one is such a curious combination too, tankas pinned on the rice matting walls, nylon saris with blue roses all over them on the opposite wall, Buddhas modelled out of cooked rice on the altar (a rusty trunk with a grubby cloth thrown over it) and a transistor radio displayed in front of all. If the latter is not the chief civilised curse of genuine communication I don't know what is, it is the chief prestige symbol out here. Against all this the lama himself with a shaved head and a curved embroidered hat on, with a corn yellow waistcoat and maroon coat performing the most delicate and intricate ritual with his hands, a bell and the thunderbolt, as well as incanting for hours a text which is far above the Gurungs' and our heads, a great shame really, we would all have been much happier with the original...

DIARY Monday 24th November

Funeral still going at Comal's and we visited it once or twice and were given goodies - but spent nearly all the day sorting out information on kinship so that I knew what questions to ask in final check. Read a little of "Nuer", which excites me less that it did Gill but is very good ethnography, and some more of "David Copperfield". No sign of poju or family. Lovely weather as usual. Gill with a headache. 
Woke with a bad head, I hoped because of Mrs Bhuwansing's strong 'pa', and not because of Nani's illness, who is still not better. When we went to loo saw a beautiful scarlet - orange scarlet beetle, minute, but such a lovely colour. Put it on the bark of a tree to get the better effect. Wrote letters in morning, but the clicking of my typewriter did not improve my head, not even putting medicine on other people, which is a sure remedy usually. Comal's mother sent me some goodies on a dusty silver tray from the funeral - went later with some sweeties for the children to thank her - still very preoccupied producing endless cups of weak tea for the Gachock relatives, who came and gauped somewhat while I was sweeping floor this morning. Funeral still sparsely attended - learnt from Gopal when he came wrapped in his blanket to see us at night that they were sacrificing a buffalo tomorrow - as it wasn't the day of the rite it was alright - Gurung elasticity!

Wrote another letter in the afternoon and then went up my hill even thought it was cold and clouded over, read Kardiner and "Orlando". Smoke from the fire made by the children herding the goats to keep themselves warm wafted up the hill, sharp and hazy, and there were occasional bursts of warm sunshine in the Pokhara valley or burned across the village on the opposite side of the valley, which is always light even though the villagers here say it is an ugly village - lots of goitres. Saw flower like white bells on a stem on a tree I always pass - never seen fruit there before. Sadly my feeling that I don't want to meet people on the way down is coming back. Found Alan a bit gloomy in the loft - after all his protestations the poju didn't show his face today. V. Woolf made me want to read Sir T. Browne - discussed him over the fire with Alan with 8 sharp little brown eyes looking on in silence for the whole children from Uli who had never been in before - very beautiful and elegant in new head cloths - made me feel sore in contrast in my dusty jeans. Birimaya and sister looked very pretty earlier - like Turkish princesses in blue pantaloons, emerald green and bright maroon 'kramu'. Played "Jupiter" in bed and the music seemed only thing existing on this earth.

\section{DIARY Tuesday 25th November}

Couple of hours interviewing in morning - then sorting out the kinship relations and further writing up. A short walk in the evening. Weather almost frosty in the morning and evening. Much gambling and a little getting in of the rice/millet. Tap desultory as it was cut off for a while by the Uli people. Enjoying "Nuer Religion" more. Torn between a desire for time to go, and desperation that there are still so many gaps in my knowledge.

\section{DIARY GILL Tuesday 25th November}

Wrote three letters, enjoyed doing it very much and they came out quite well. Did not go up the hill but read Kardiner in the loft and then went for a walk with Alan along the maize fields. Girls very cold getting in last of millet. Overcast night - bodes ill for wash day tomorrow. 


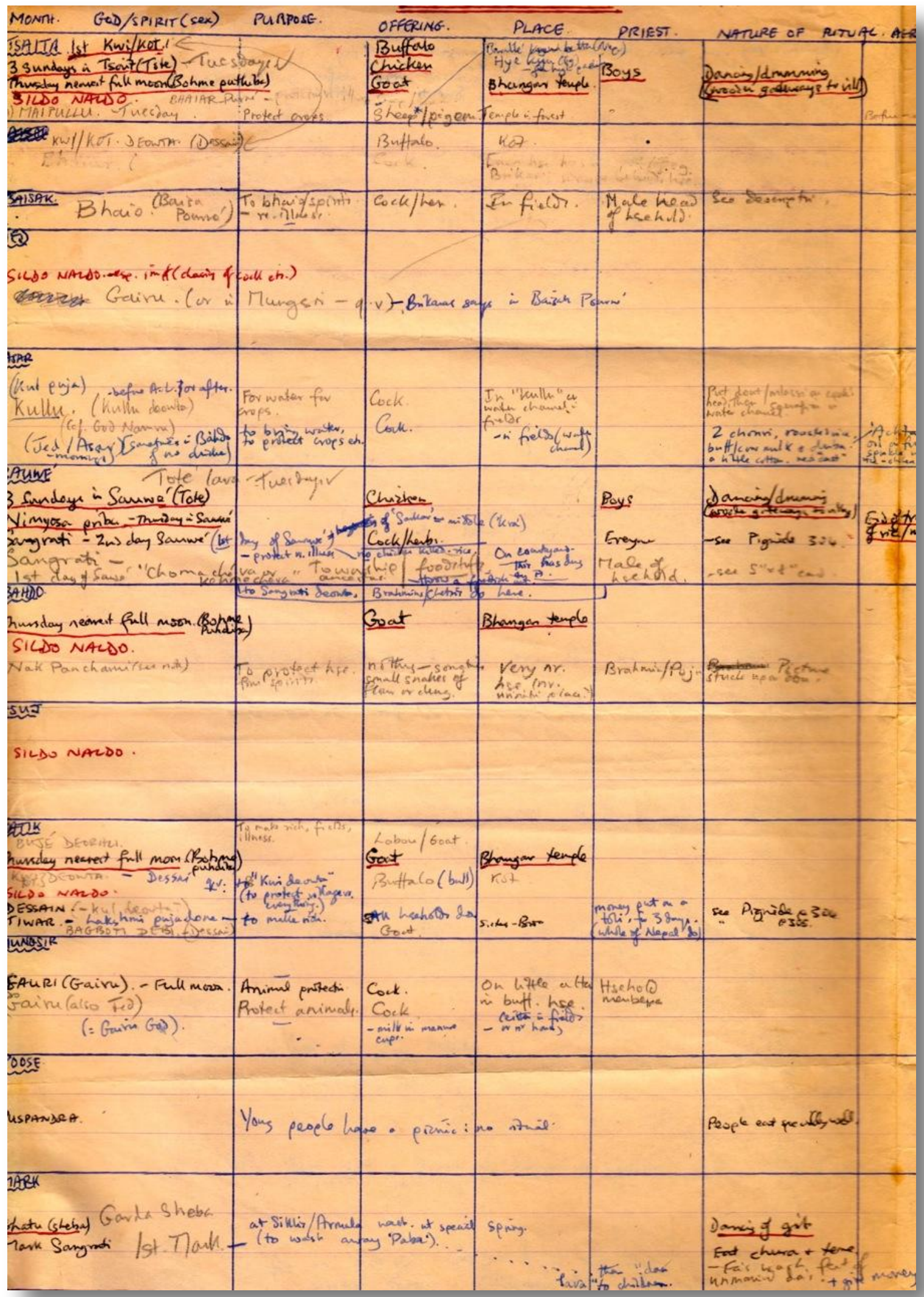

A list of annual festivals in the village 


\section{DIARY Wednesday 26th November}

Only ten weeks today! Last night Gill very sick and a little diarrhoea. Probably the fish we had had the previous evening. Slept very little after 4.00am. - fainted twice and rested in bed all day, gradually getting better. Day off to a slow start with various jobs, but then managed to get hold of Kumansing (House 15) an excellent informant who produced a little pocketbook with various interesting things in. Even more frustrating, he said that grandma next door had a book with masses of other information in eg. ancestors of all the lineages, history of the Gurungs, ways of doing the 'pae'. It was last seen some two years ago and may have been taken to Malaya by her son, but there are still hopes that it will turn up when Nani (who has been ill nine days) recovers and has a chance to look for it. Keeping fingers crossed.

\section{DIARY GILL Wednesday 26th November}

Woke up at about 2.00am. feeling sick, asked Alan to get the basin when he went down to deal with rats. Dreadfully sick about six times all night long, fainted twice, acute diarrhoea. Prayed it was food poisoning and not jaundice - only new thing we had for supper was sardines. Alan was wonderful in nursing me although the business was very horrible. Only sick once in morning latish - about 10.00am. and then I managed an orange for lunch and two eggs for dinner. Read "David Copperfield" which was comforting but felt lot better by evening, still had to think to keep things down.

\section{DIARY Thursday 27th November}

Gill a bit better, but stayed in bed most of the day. Sun in morning but by lunchtime had clouded over and it was very cold indeed - had to wear about three layers and was still cold. After a bribe of $15 \mathrm{rs}$. managed to extract the book I was looking for - though a much torn and depleted version - from next door. Poju and Prem started translating it - only moderately interesting so far. In evening cooked supper, instructed Goof on what to get (he was going to carry Nani down to Pokhara - she was still not healed), bought tomatoes, etc.

\section{DIARY GILL Thursday 27th November}

Felt much better, and even quite hungry. Breakfast in bed but got up to go to loo - felt a little wobbly but not sick. Lovely crisp morning as always. Arranged my flowers (pink) that Birimaya had brought me yesterday - tidied up a little but Alan had done very well. Feel bit of a fraud going back to bed but Alan sweet and did not make me feel guilty. Read "David Copperfield" and got to within 100 pages of finishing it. Emily business is getting a bit sickening and I cannot help thinking heretically as a reaction against all this sentimentality that thank heavens she did do something exciting with a dreary life! Thank god for Betsy Trotwood - even Mrs Gummidge has turned saintly - a whole ship-load of saints and Mary Magdalenes. He even very nearly spoils the fruit of honesty in marriage to Dora by reiterating the fruit too much (child wife) until it almost turns to ashes.

Alan worked hard all day first with Prem and then poju - looking at this ancestor book which they have dug up next door to Alan's excitement. Feel it might prove disappointing; has been printed. Tried to get up for supper but felt I couldn't bear people staring and in my feebleness even poor Mrs Goof craning round the door was too much. Alan sweet again he has been a Panapen - but not like Dora's servants!) and pushed me back to bed while he did supper. Organised Goof with letters and things to bring back from Pokhara, dealt with Kaji and beau 
flirting, also with Sarishaw and her begging and madness, did supper, fetched water and checked up on von Maldosing haring with his poor old mother - hitting her. Great sobbings and wailing outside house.

\section{Letter from Alan to parents on 27th November 1969}

We returned a couple of weeks ago and time has gone very quickly since then. The day after we arrived we had an American Peace Corps boy to stay for a couple of days. He appeared to enjoy sleeping on a mat and being covered in smoke and ash and thought the Gurung's delightful and friendly. The villagers have, in fact, been particularly nice since we arrived back. As Gill will describe, we were invited down by one family to attend the rice threshing. The mission doctor was due to come up here a few days ago, but there has been no sign of him so much for my attempt to do a medical survey. Still I will try to check my census findings with him. Our health has been good so far and the weather superb. Our main problem has been the adolescent son of my poju informant, the younger brother of my best young informant. He insisted on helping to carry our things from Pokhara, and has since hung around us more than anyone else since we arrived. Now two hundred rupees ( $\left.\mathbb{f}^{8}\right)$ is missing - some of it taken when we arrived back from Pokhara, most of it taken the night we were down in the fields with the rest of the family. The boy has apparently stolen on three occasions (including 200rs from his own family) in the last few months, and acted very oddly when we accused him. His family, of course, want to hush the matter up, though they seem to think him guilty. Anyway, it causes a bit of a distraction, as well as making us temporarily short of money. Very odd among the Gurungs, who are usually so honest.

... We have started taking more films now - including cine. As always I think these are too bitty, but must try to do better on the 13 more we still have. The camera is very neat and terribly easy to handle...

...I realize how much I am missing the excitement of contact with other minds and big problems... This was also emphasised for us both recently when we went to Kathmandu for a week's holiday. We met an extraordinary selection of people, from a gold and purple robed Tibetan monk who spoke to us in a flat East Anglian accent and turned out to have been born in Bury St Edmunds and to have once been a Benedictine, to a Sherpa who wore a tweed coat and plus fours, and spoke French, English and about five other languages fluently (he was assistant to David Snellgrove at SOAS). We slipped from the crowded dirty streets of a medieval town into the plush surroundings of our German research centre base or the local American hotel where we went to see a Godard film, with disturbing rapidity. I was working on a small lecture I had to give on 'Development - how is it to be achieved', and the excitement of working for this, plus the new contacts made us realize what we were missing. But enough of missing things. We are now more contented than we have ever been; the weather is superb, the villagers have never been so friendly, and nearly all my material is collected. In a couple of weeks we will go for a tour of some other villages and then it will be time to think of going home. ... What do you think the chances of development of a socialist society in Tanzania are?... Things are not too good in Asia, despite the promise of a postponement of actual starvation thanks to the new wheat and rice grains. Again, it is one thing to have the technology - whether of birth control, medicine, sanitation, agriculture or whatever, an entirely different thing to get anything done. This village is a pretty good mirror of the general reluctance to adopt things which everyone agrees, in principle, would be a good idea - like birth control, new crops, pit latrines. Of course, it is not difficult for an anthropologist (or anyone else) to see why this should be. Sometimes I even wonder whether, given the obvious contentment and happiness of the villagers now, they aren't sensible to ignore "progress", although I know this is supposedly a romantic snare. Certainly, considering the huge amount offoreign aid that has poured into this country, fantastically little has been achieved. But I had better reserve that subject for later publication since letters are sometimes censored. India is also in a pretty bad way. Have just been reading and enjoying Galbraith, 'The Affluent Society', very much, though I think he has one huge blind spot (and especially in his book on 'Economic Development'), that education is the answer. It certainly isn't here, where it merely creates more frustration, unemployed school leavers - or will do. But then, we each have to have one hope - mine happens to be birth control.

I think another frustration is the knowledge of the day of 'village anthropology' is really over. One does useful works filling in the chinks left by the Heroes of the past, or in providing ethnographic information on hitherto unstudied people (not true in our case since there was already a book on the Gurungs), but it is unlikely that one 
will shake the foundations. Of course if one wants a cosy readership or professorship at a new university, there is nothing better. But the future of the social sciences is elsewhere. There is comfort for me, however, in the thought that I am not really here to add yet another Turkish/Mexican/Irish/Greek etc. village study to the list, but to learn how anthropologists work and what questions they ask so that I can approach my historical material more sensibly. This I think we have achieved, and hence historical studies might, indeed, shake the anthropological foundations by showing how impressionistic/disputable a static, structural/functional approach is...

\section{DIARY Friday 28th November}

A lot of barking in night and rats very noisy - also Gill a slight cough. She also felt sick when she got up and spent some of the day in bed. Again cold by lunchtime and again the poju came after lunch to carry on with the book - which was much more interesting. In morning went to see the 'deorali puja' and took some photos but very poor attendance at it. Little groups of boys in in evening - Comal and co. - gambling, etc. Hoping for letters tomorrow.

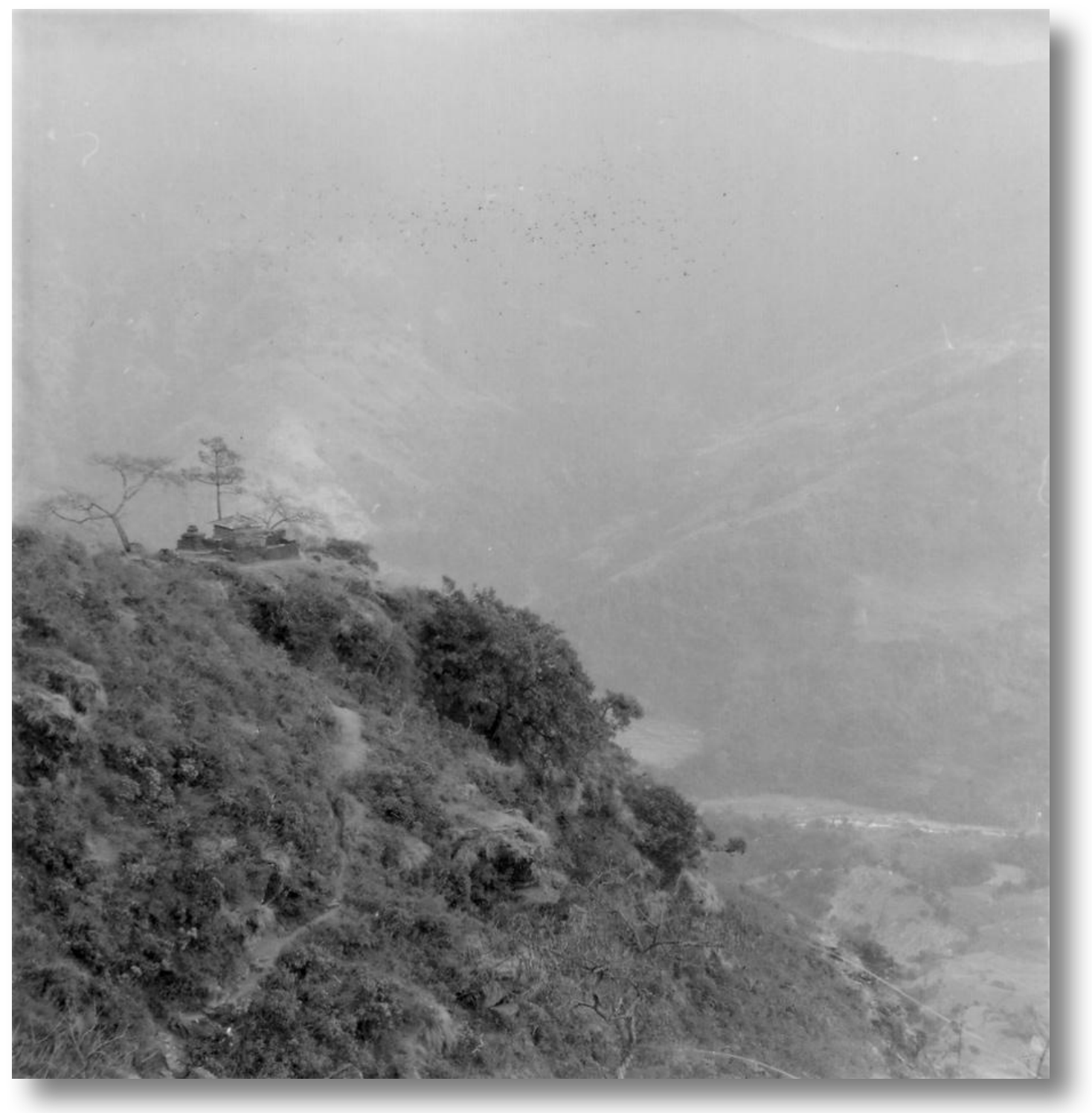

Shrine at Buje Deorali 


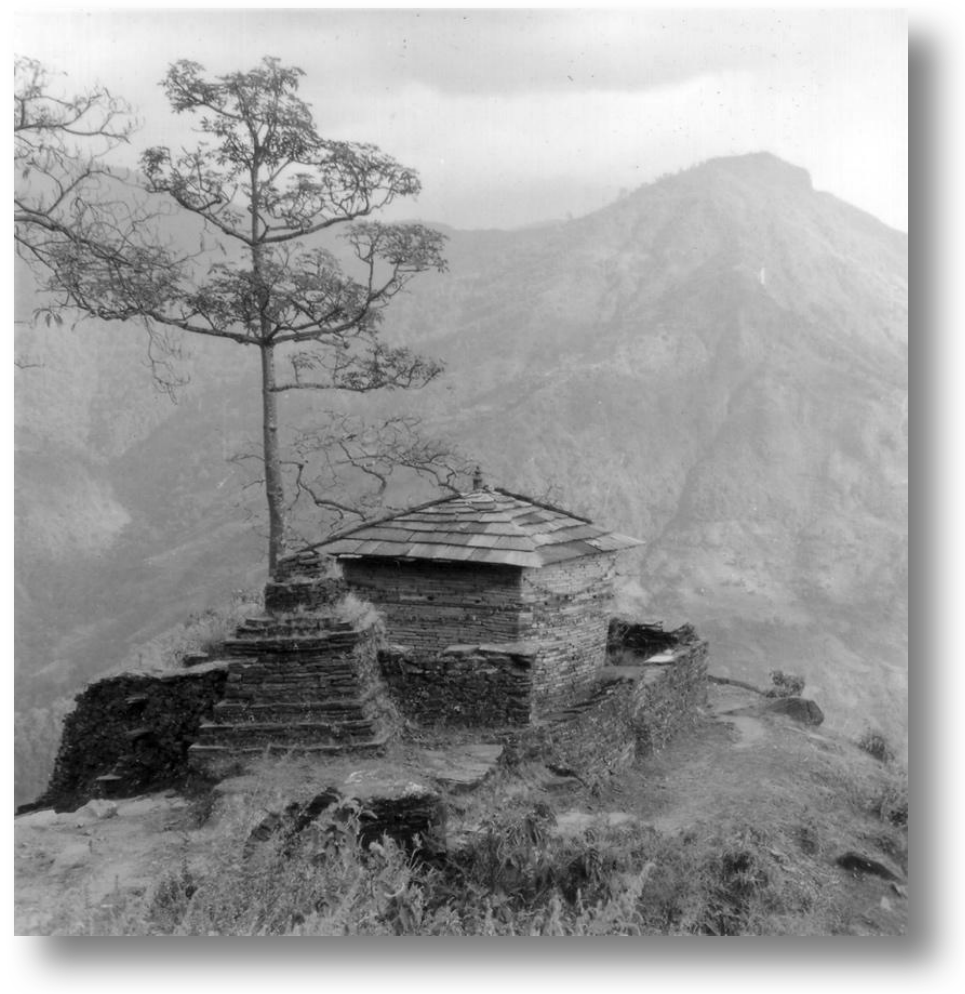

Shrine at Buje Deorali

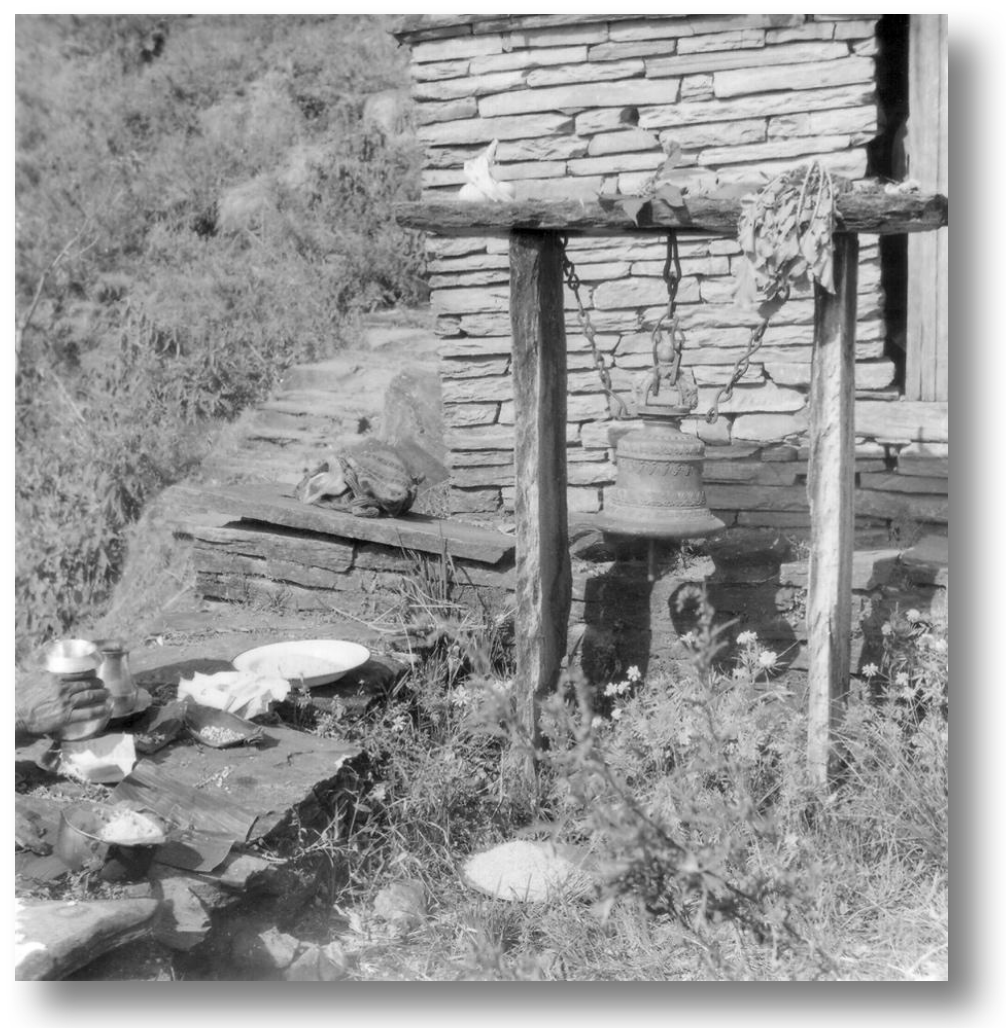

Puja at Shrine at 'Buje Deorali'- 


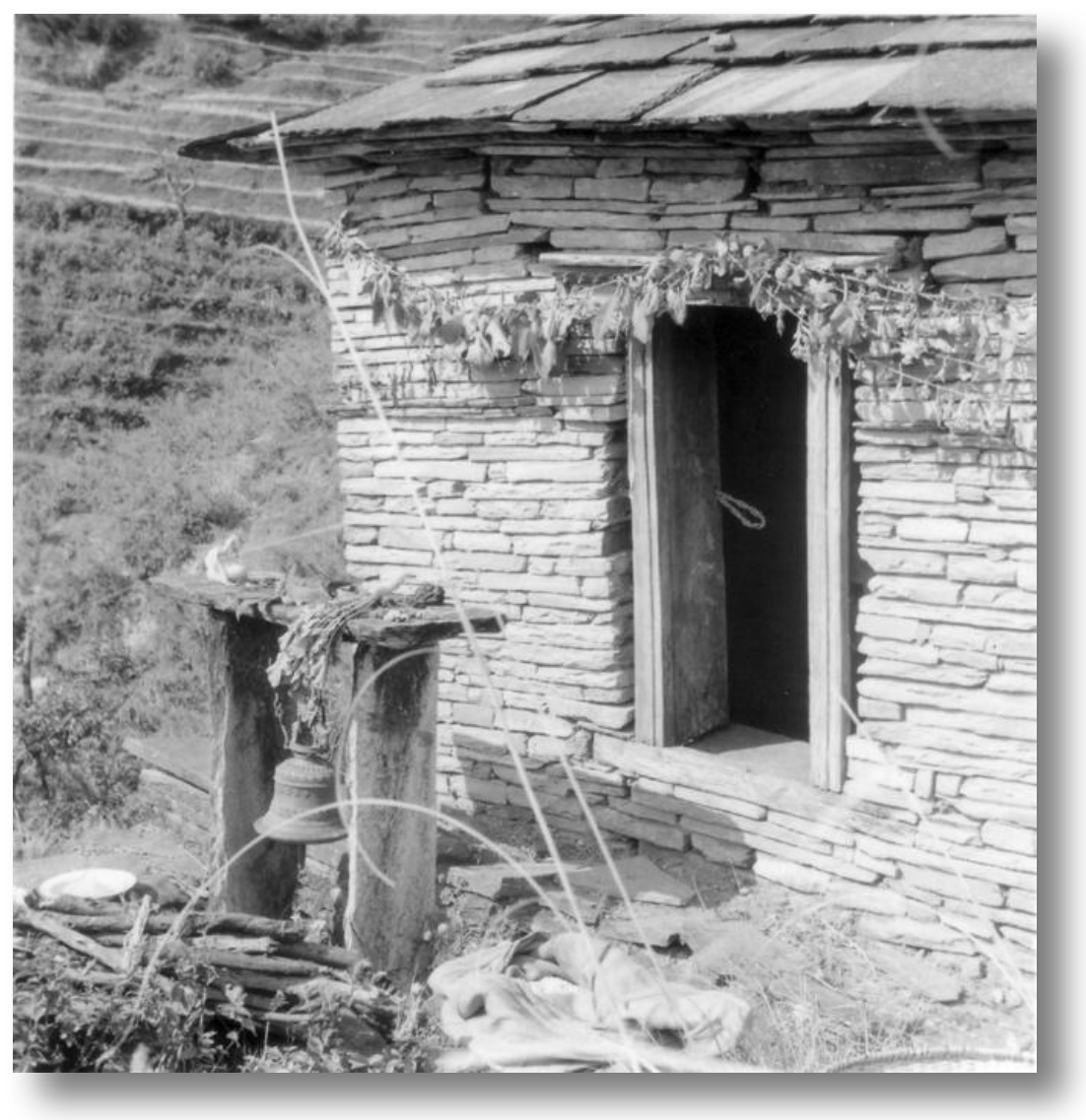

Puja at shrine

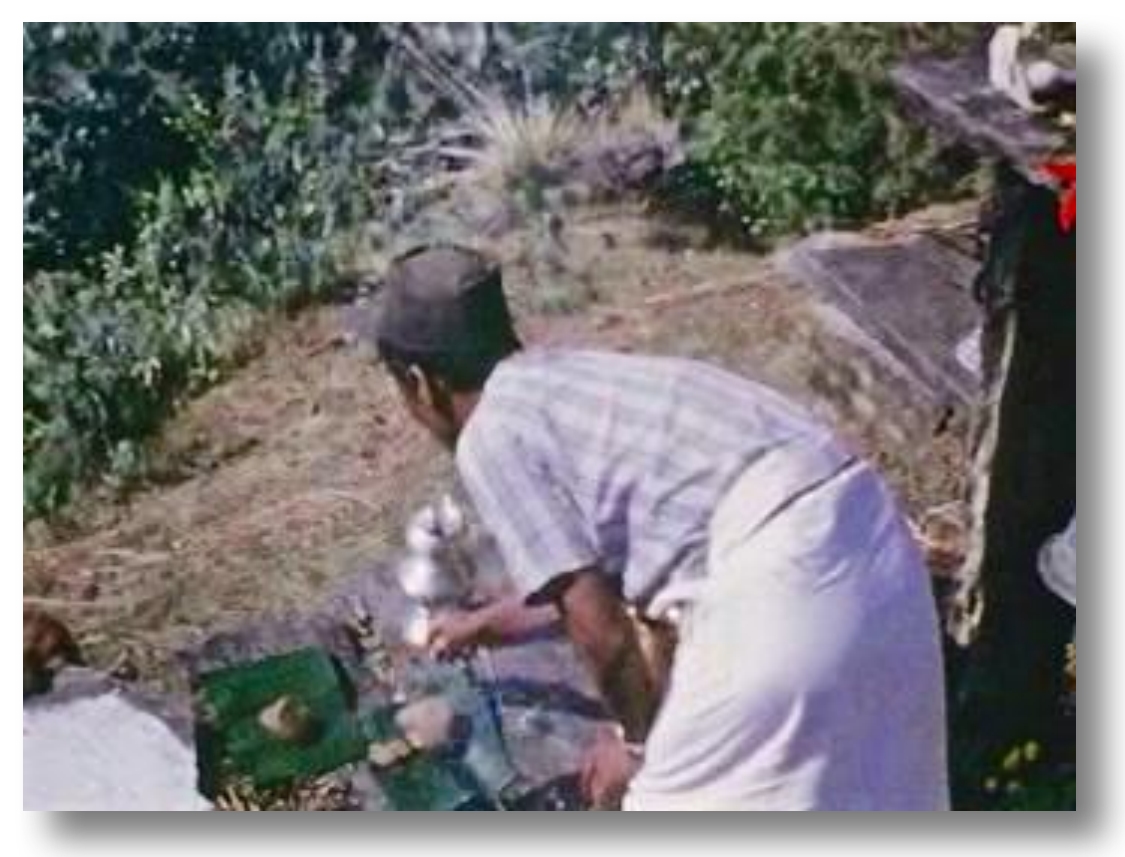

FILM. Ritual at Buje Deorali being done by pujari https://sms.cam.ac.uk/media/2735836 


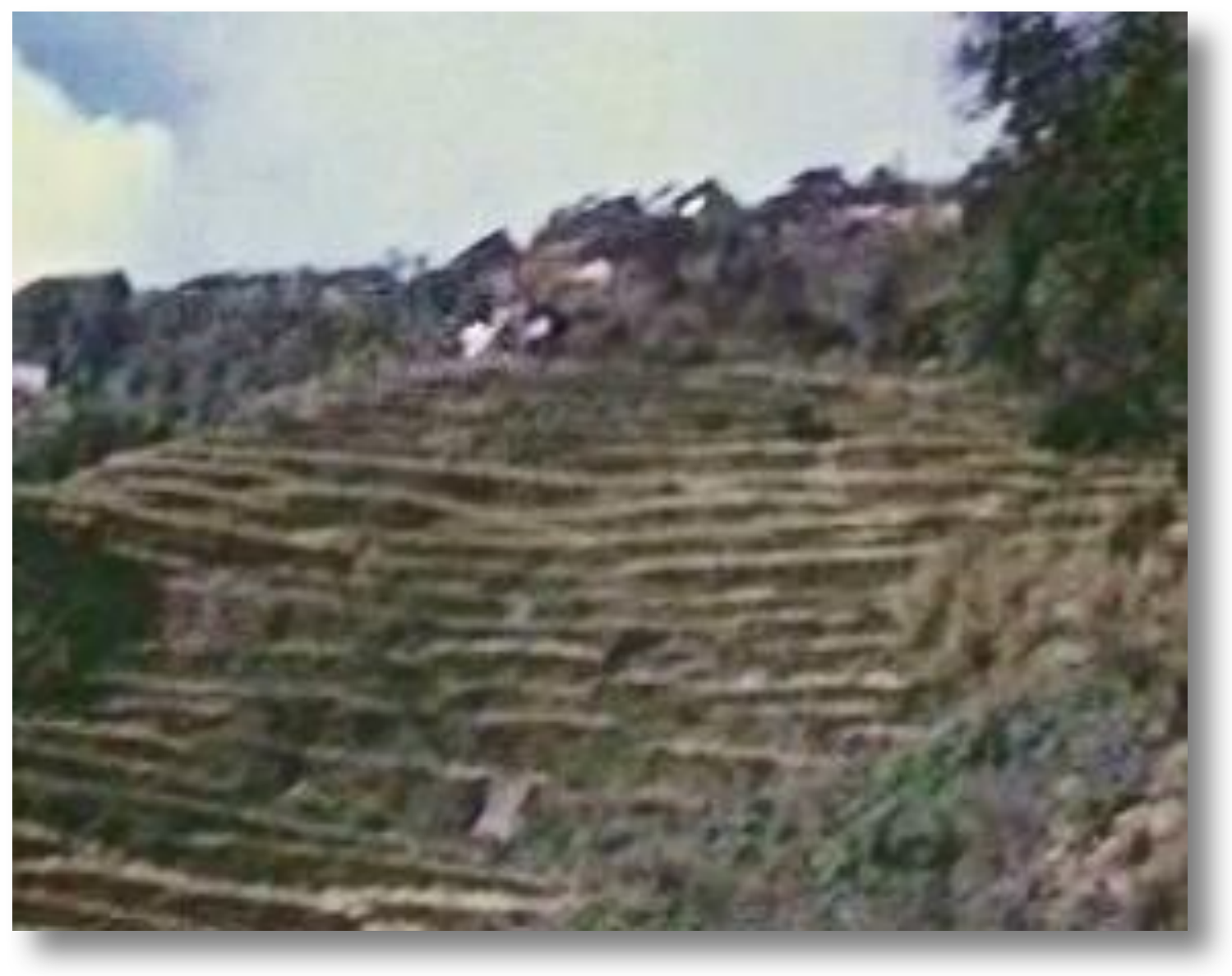

FILM. View from Buje Deorali up to Thak and down to the valley below https://sms.cam.ac.uk/media/2735864

\section{DIARY GILL Friday 28th November}

Much to my disappointment felt queasy again this morning, could hardly take much porridge and had bad diarrhoea when I went to loo. Coupled with feeling depressed - wonder if this is a return of amoebic dysentery. Alan thinks it might be a hangover from food poisoning. He is very well if dirty - even he looking forward to going to the river! Cross-stitched my petticoat in morning whilst Alan looked for poju and couldn't find him so went to watch village sacrifice (of radish) at Deorali. Only about four people turned up, Gurungs thoroughly bored it seems, playing cards on Totra's father's porch. About 15 years ago apparently whole village used to go to have a picnic - rather sad.

After lunch which I did manage to make and eat, I finished "David Copperfield" - always terribly sad when I finish a novel like this. Interesting how one's personal pre-occupations can slant a whole interpretation of a book. I thought his treatment of Miss Moucher/Mr Dick/the Peggoty's etc. was to show that the "lower species" do feel - and counteract Rosa Dartle's remarks - "that sort of people - Are they really animals and clods and beings of another order?" - "its such a delight to know that when they suffer they don't feel". (p. 352). However, it seems that Miss Moucher was not meant to point any particular moral, Dickens just inserting the message scene in when he had complaints from the original woman who inspired the character. Still feel, however, that people tend to regard "lower species" in this 
way as if intellect/education, were somehow an essential compound of feeling. I know I must have harboured this delightful version once. Trouble about living here is that one can harbour no illusions, either about how useful one is or how close to people one is - being stripped all the time is discomforting.

Felt so blue this afternoon and Alan is being so saintly he is making me feel worse. He had poju in and they froze by window deciphering their book - it is so cold. Alan even put a vest on today and I just cowered in my sleeping bag all afternoon. Did do dinner - must have been nice for Alan to have fire again. Comal and crew came in to play cards - what a row, but anywhere else they get shouted at. Turns out Maldo knocked one of his mother's teeth out because she sold some of their oil to the poju instead of at Pokhara - poor old thing. Alan carried her bucket for her this morning to the amusement of rest of village. Another man 'shyaa'ed her. Got a cough as well as everything else - poor me!

\section{DIARY Saturday 29th November}

A rather fruitless day waiting around for letters: no-one in so could not get any information. Now mainly waiting to finish land map and work with poju. Gill now has a bad cough and rats more noisy at night. Letters finally arrived at 3.30pm with Goof - 19 of them - including review article by Mummy and letter from T-Roper etc. Lovely to have them, though Gill disappointed there wasn't one from her mother.

\section{DIARY GILL Saturday 29th November}

Another very depressed day, although letters were expected and came at about 3.00pm. Really feel black this morning. I think it is not having anything committed to do. Do not feel physically ill. Alan also restless - we are infecting each other and not finding much work he can do. Gets so frustrated at these times. Slept for two hours this pm., decided to get on with some work when Goof returned with 18 letters! but none from M \& D. Chris had written again, bless him (mixture of wrens, music and office!) and Anne P. - two letters, very happy saying she had met this American sailor and all was very well. He does sound sweet and I was so pleased for her sake - first reasonable man she had had. Touched she wanted to tell me about it. No news from Fiona - letter but baby late. Of course this cheered us both up everyone saying how they're looking forward to having us home - which will be March 3rd (5.30pm!). Tickets are organized. Odd being taken back to the world we love out here. Determined on river tomorrow.

\section{DIARY Sunday 30th November}

At last managed to get to the river: a fine day when the sun kept shining later than usual and we got everything washed and quite enjoyed it into the bargain. Had our usual Horlicks by the river and thought what we were doing this time one year ago. Gill seems a good deal better in health and less depressed (she was quite bad yesterday).

\section{DIARY GILL Sunday 30th November}

River day - and warmest and most sunny we have had since we've been here. Took one colour film. [FILM] Went to old place by pool - not too high and no spray. Although stove leaked, was very slow, fell in water twice, maggots in soup, walnuts bad - enjoyed day! Gorgeous getting so clean and washing everything - even all sugar bags! Alan so good as 
always, rushing round hanging up line, rinsing, scrubbing jeans, etc. Read few letters but chilly when sun went in. Cut Alan's hair not so drastically as usual. Collected flowers on way home for pressing and felt cheerful. Lovely blue berries in a green shade on way down (blue thought in green shade!) and massed of yellow-tipped flowers by river and on rice banks. Saw red, red birds and delicate yellow-blush ones - not many butterflies. Grasses tall and stately, beautiful. Cosy time in evening with children playing, by the hour, with packets of macaroni, making Nehru-type hats and masks out of cellophane. Birimaya, Kaji, Bibi's granddaughter and Haricola - loved it when I tickled her. Went to bed at 8.00pm (so late!) - getting up 5.45am. for river. 


\section{DECEMBER 1969}

Undated photographs related to rituals

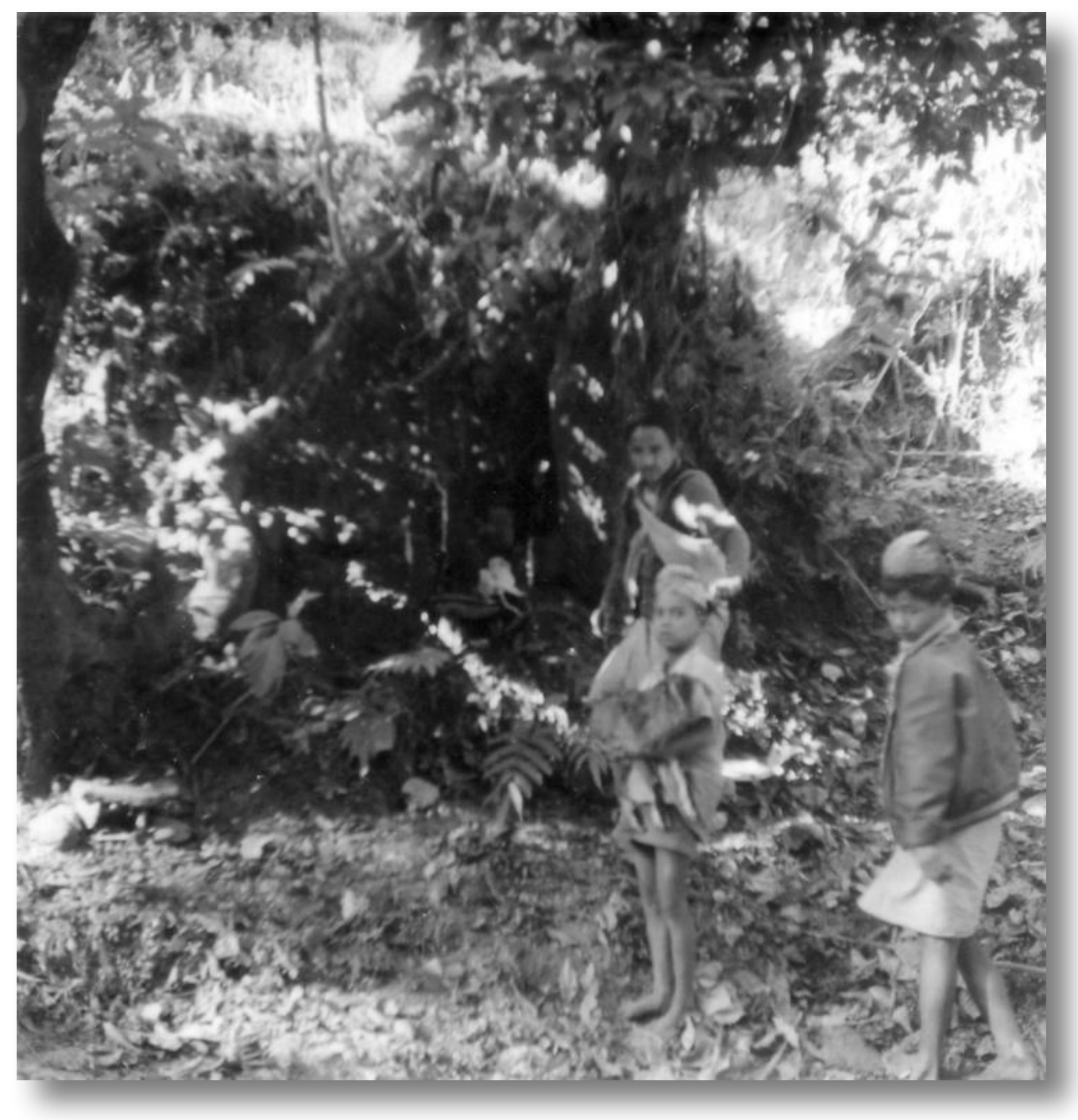

Boy carrying a goat for sacrifice 


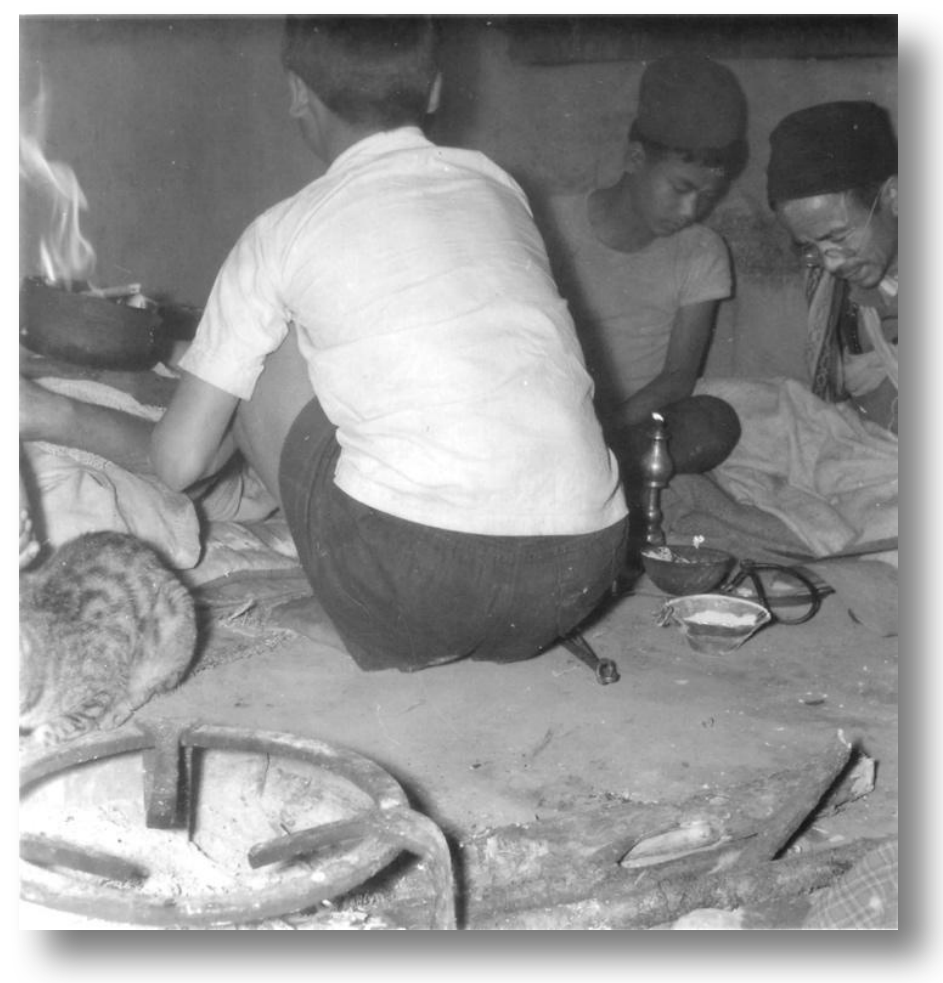

Poju, Ujesing doing a ritual in a house

\section{Miscellaneous}

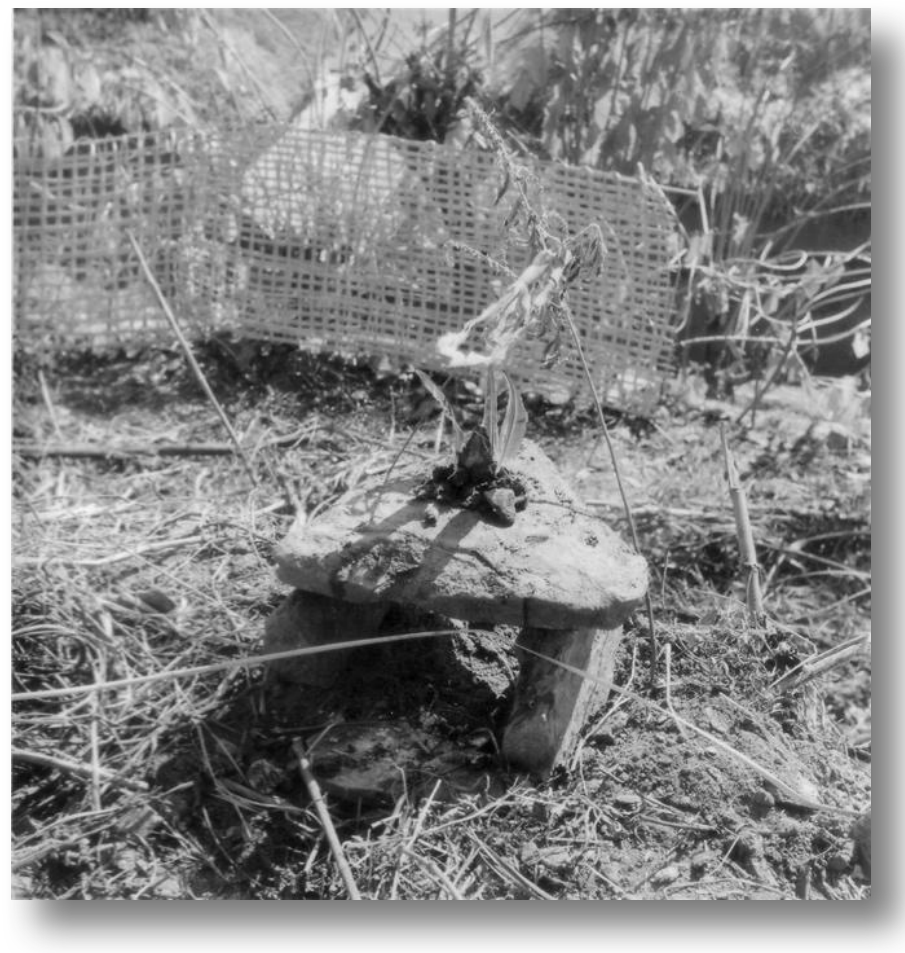

Small offering put up below House 17 with dung and feathers 


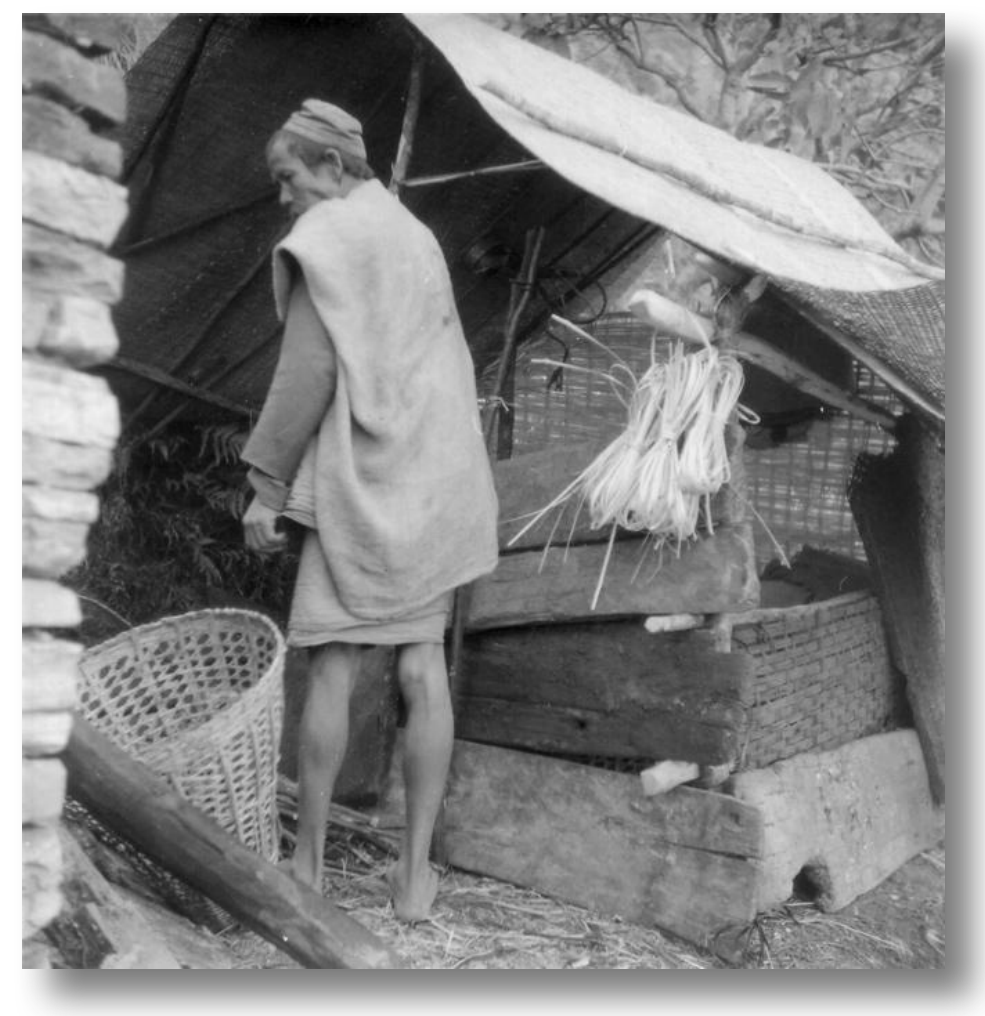

Temporary shrine for sacrifice

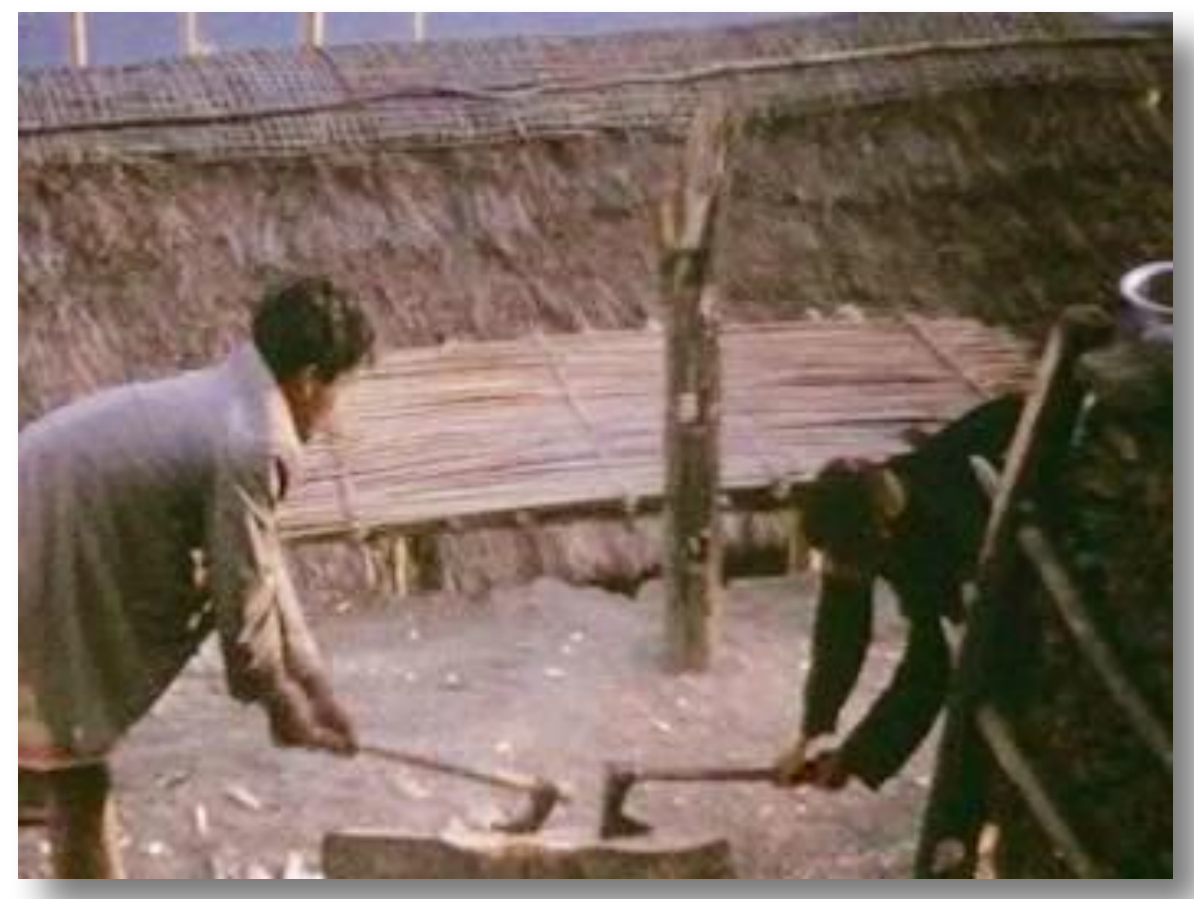

FILM. Two men chopping wood

https://sms.cam.ac.uk/media/2735916 


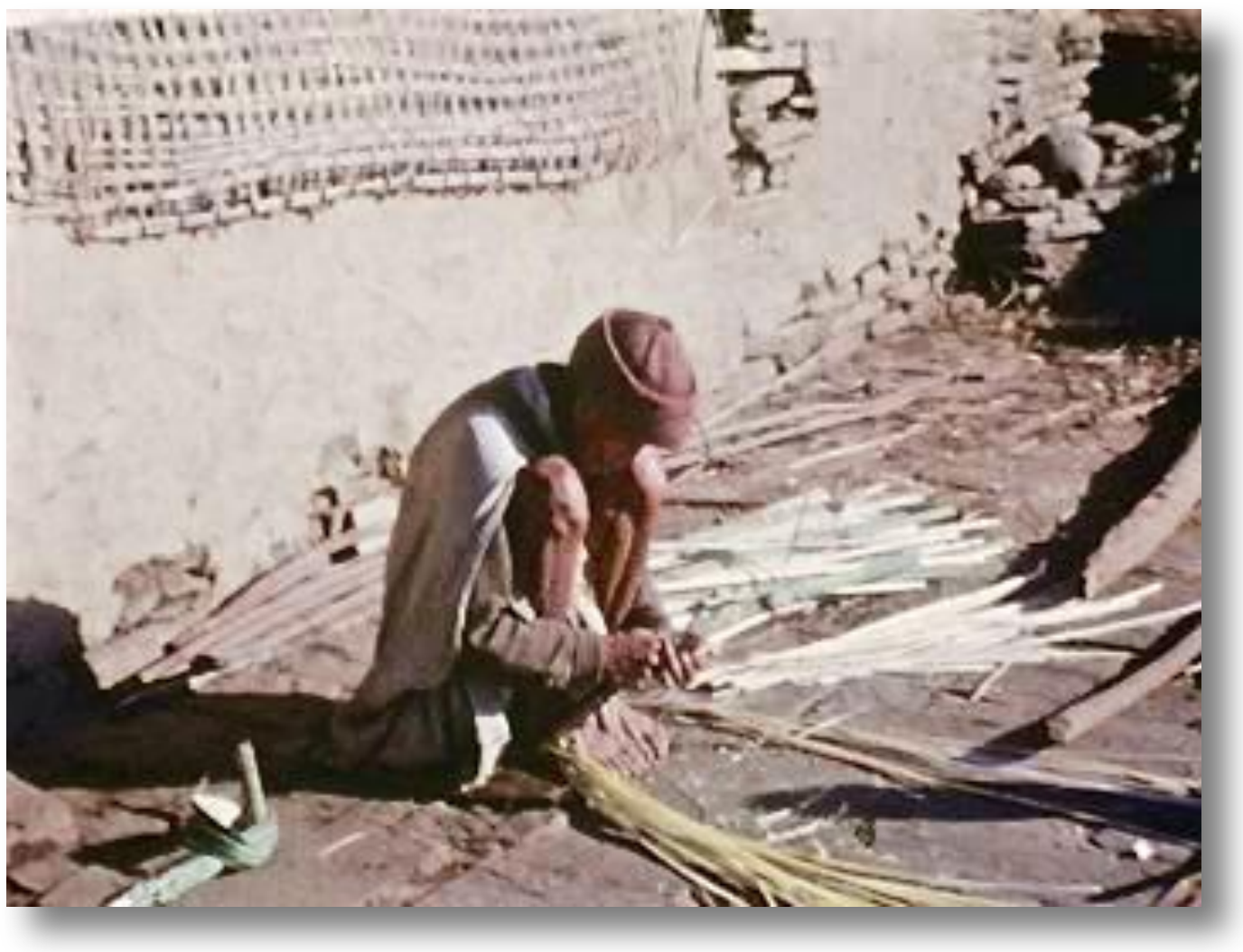

FILM. Narbir splitting bamboo for baskets https://sms.cam.ac.uk/media/2735944

\section{DIARY Monday 1st December}

A year ago today we drove down to London to catch the 'plane. What a year! A frustrating day as no-one appeared to be in - at least, to work. This is one of the worst aspects of fieldwork - and one wasn't warned of it - frustrating at slowness with which information comes in: it is so different from history where one can get through a predictable amount each day. Instead this work favours the constitutionally lazy/spontaneous/disorganized who like fraternising, etc. Probably made a little more difficult by having Gill which ties one to fairly regular, Western-style life. Went down and did a couple of hours with Brikaras.

\section{DIARY GILL Monday 1st December}

Overclouded day but some sun in morning - enough to get clothes finally dried. The whackwhack of millet still outside and Gran sifting it on a tray. Prem was meant to come and help Alan but failed - also no one else in and Alan very frustrated and upset. Feeling he is doing nothing at moment. His turn for depression. Can't bear it when people look bored when he comes up. He was all for rushing off to Garedi at 11.15 but we had an early lunch and took up my suggestion of going to see Brikaras and getting religion sorted out. I finished sewing my petticoat but put off going to see Dankumari to ask about it partly because they might be busy with wedding (Bhuwansing came to borrow money this morning for this) and partly shyness.

Had short read - "Tin Drum" - very difficult to get the feel of after Dickens and then went up my hill and read more Kardiner whose bland assumptions I find irritating, and "Orlando" 
whose superficiality is disappointing. Does it say more than it takes 300 years to write a good poem? Still millet cutting in field below - millet stalks when laid out look like abandoned eyelashes. As usual oxen got it - much cursing and tumbling after them. Found Alan in when I got back, little calmer, had sorted some things out. Prem came in during meal with our radio, now playing as Gopal had brought some batteries back from Pokhara - always struck by way they use this when they think other forms of communication might fail. Learnt Bhuwansing's plans have fallen through as letter arrived from Siklis saying this girl did not want to marry his son - poor man, all his plans seem to go awry. Nainasing came in very rueful with a thorn in his foot - solemn and slow and sweet, just like Pooh! Comal had great time before just wearing my red anorak (which came down to his knees) pretending to be a soldier. Exams in three days so he had taken to learning English again in the chanting way which is pretty but gets a bit monotonous! Plan to go to Garedi and Mai Pulo tomorrow.

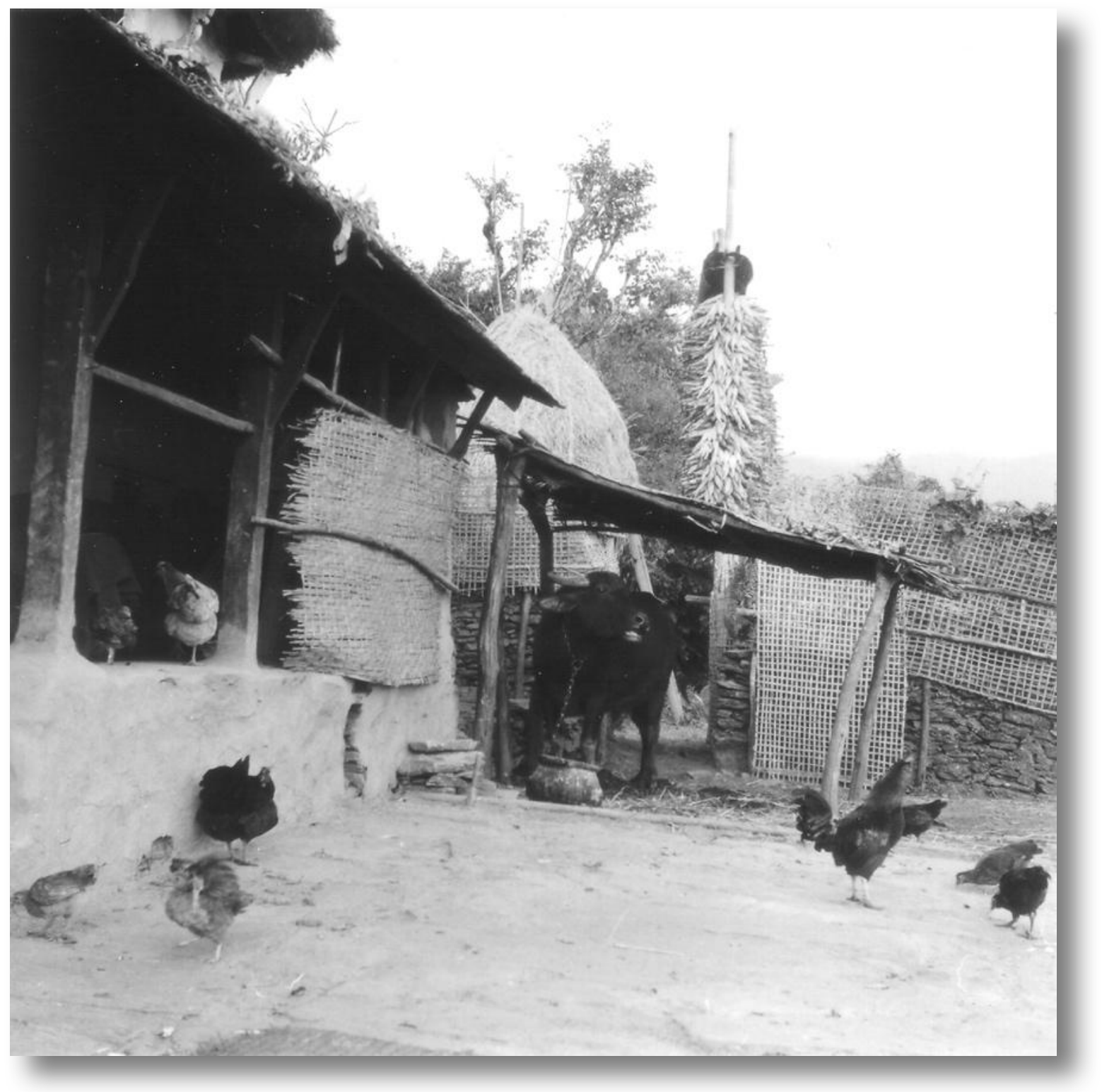

Stalled buffaloes at house 25 - 1st December 


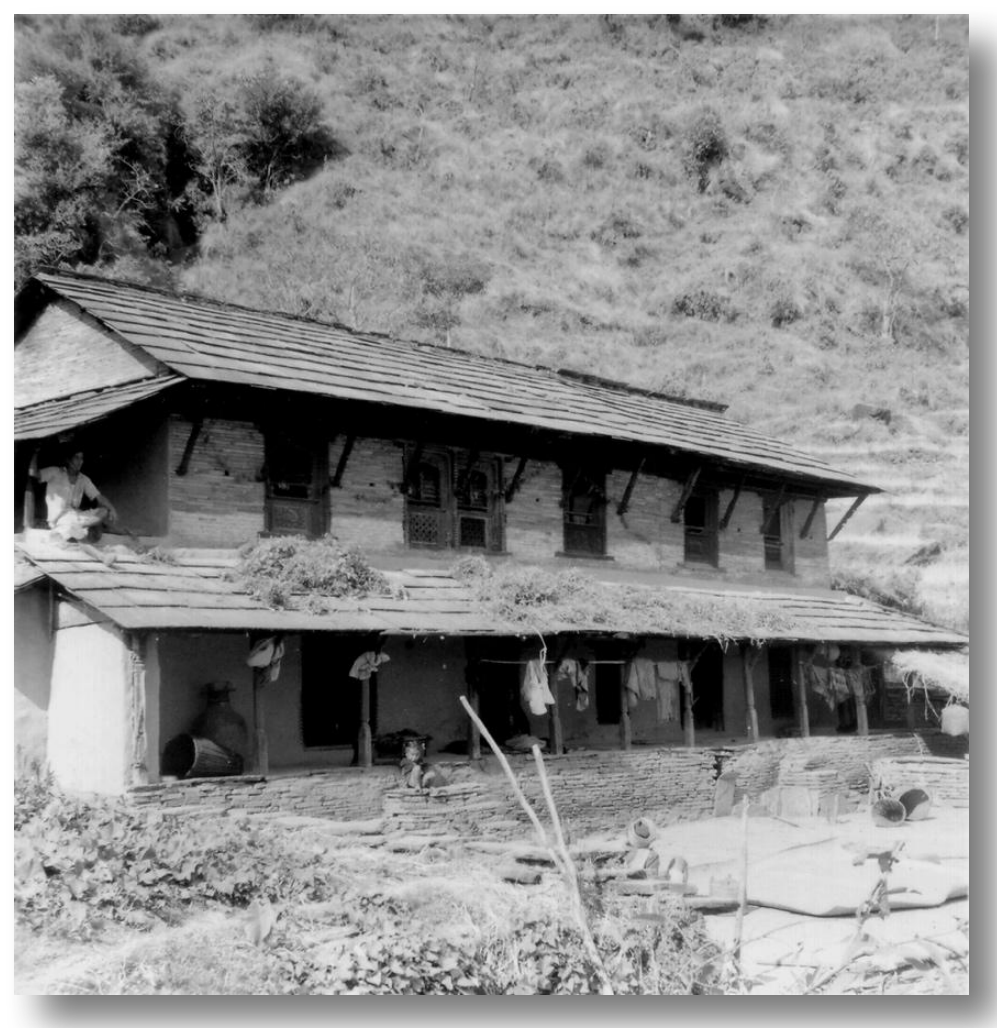

Wealthy houses, 70A and 70B. On left A.K. Prasad's father's house - 1st December

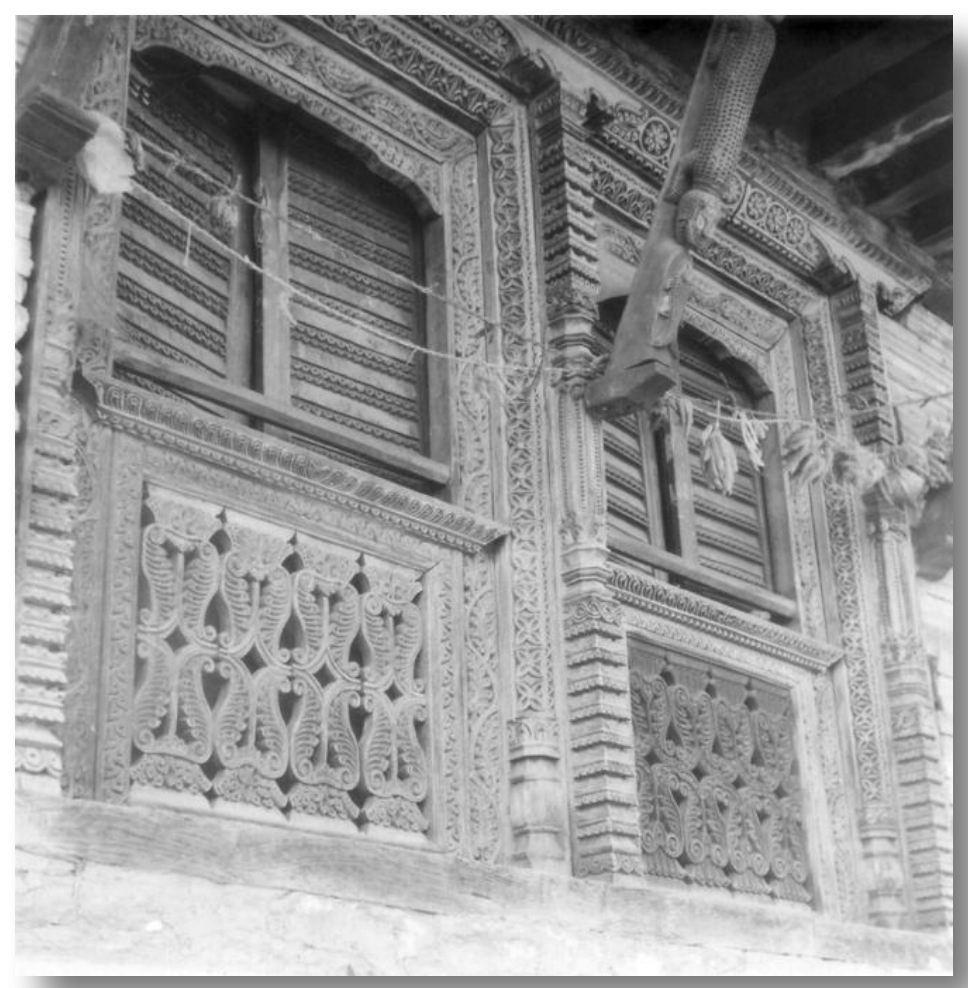

Decoratively carved window at house 70B - 1st December 


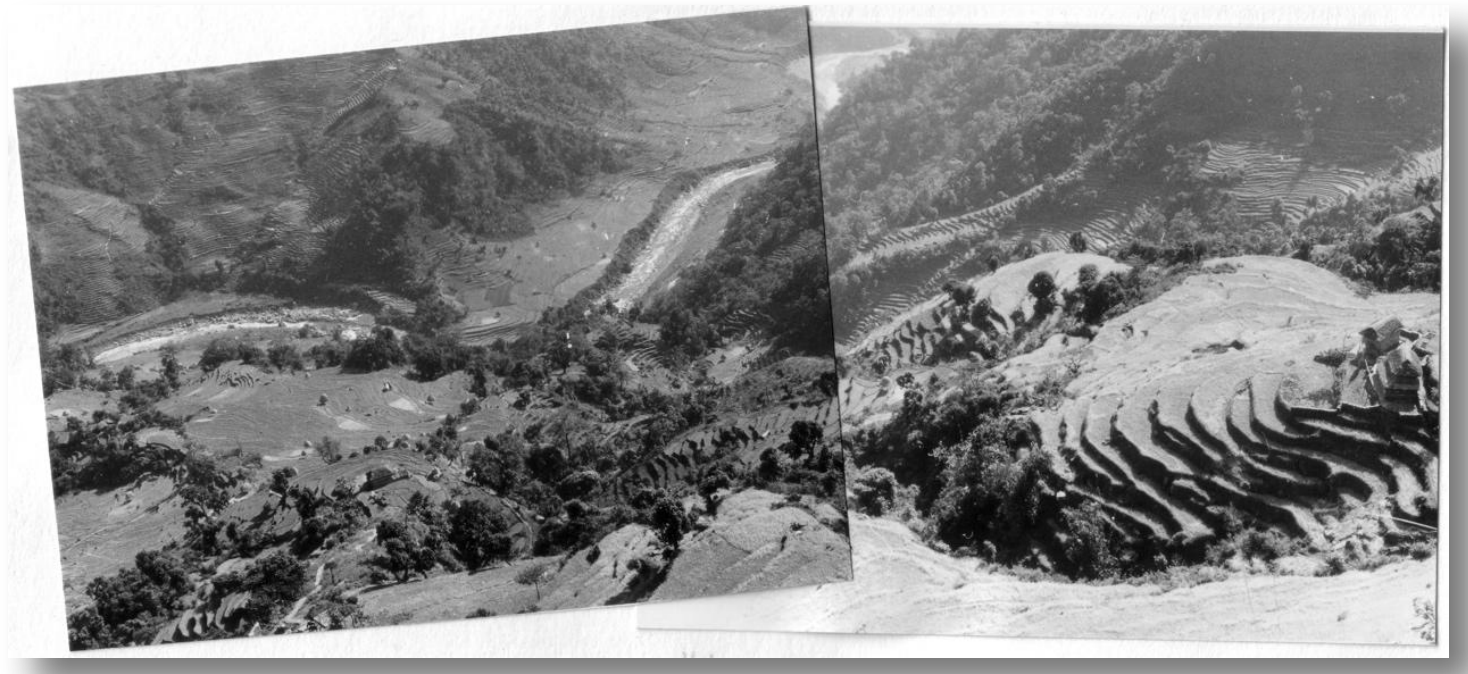

View of fields down to the river from Uli, house 70B - 1st December

DIARY Tuesday 2nd December

Went up to see Mae Pullo temple in forest and got caught up in 'toya' digging party which we went with to see them uprooting the 'toya'. Had a picnic and then came down. The most important decision I came to was that from henceforth I would start to plan and make a first draft of bits of the thesis when nothing else was happening and no information available. This would save me from present frustration and boredom. Felt more cheerful.

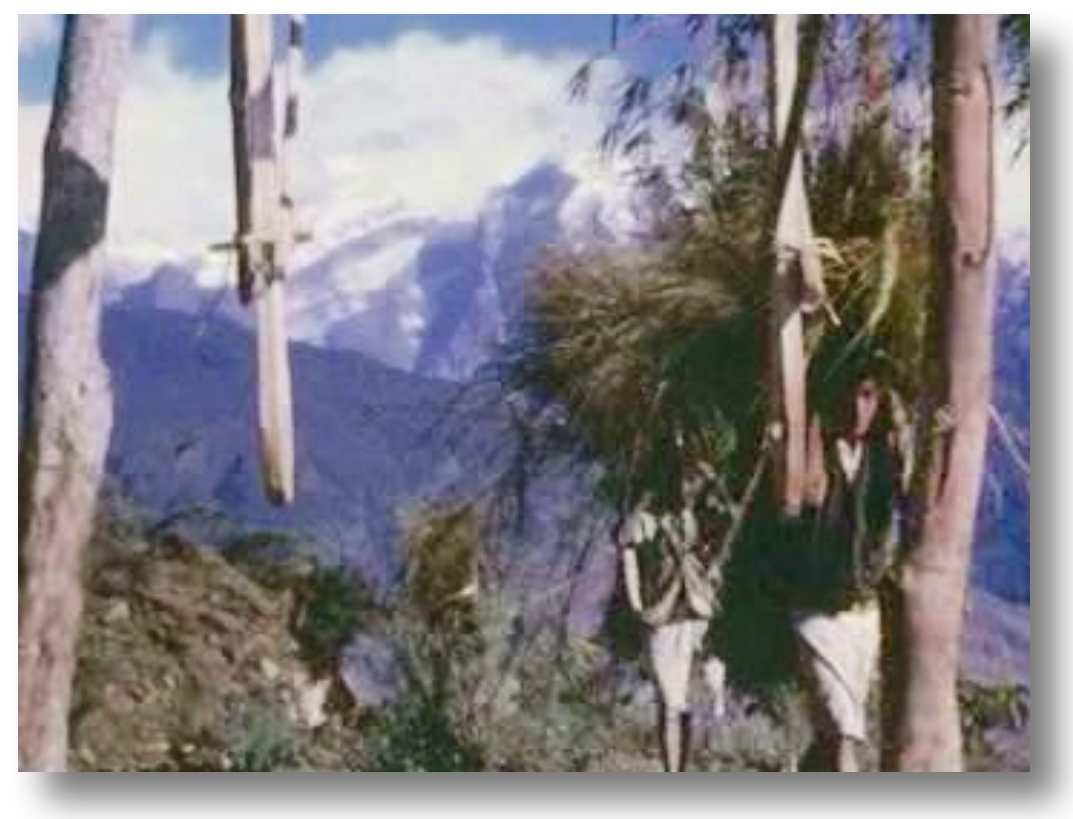

FILM. Men carrying thatching grass down past the Dessain swing with the Annapurnas in the background. Benbahadur's brother https://sms.cam.ac.uk/media/2735972 


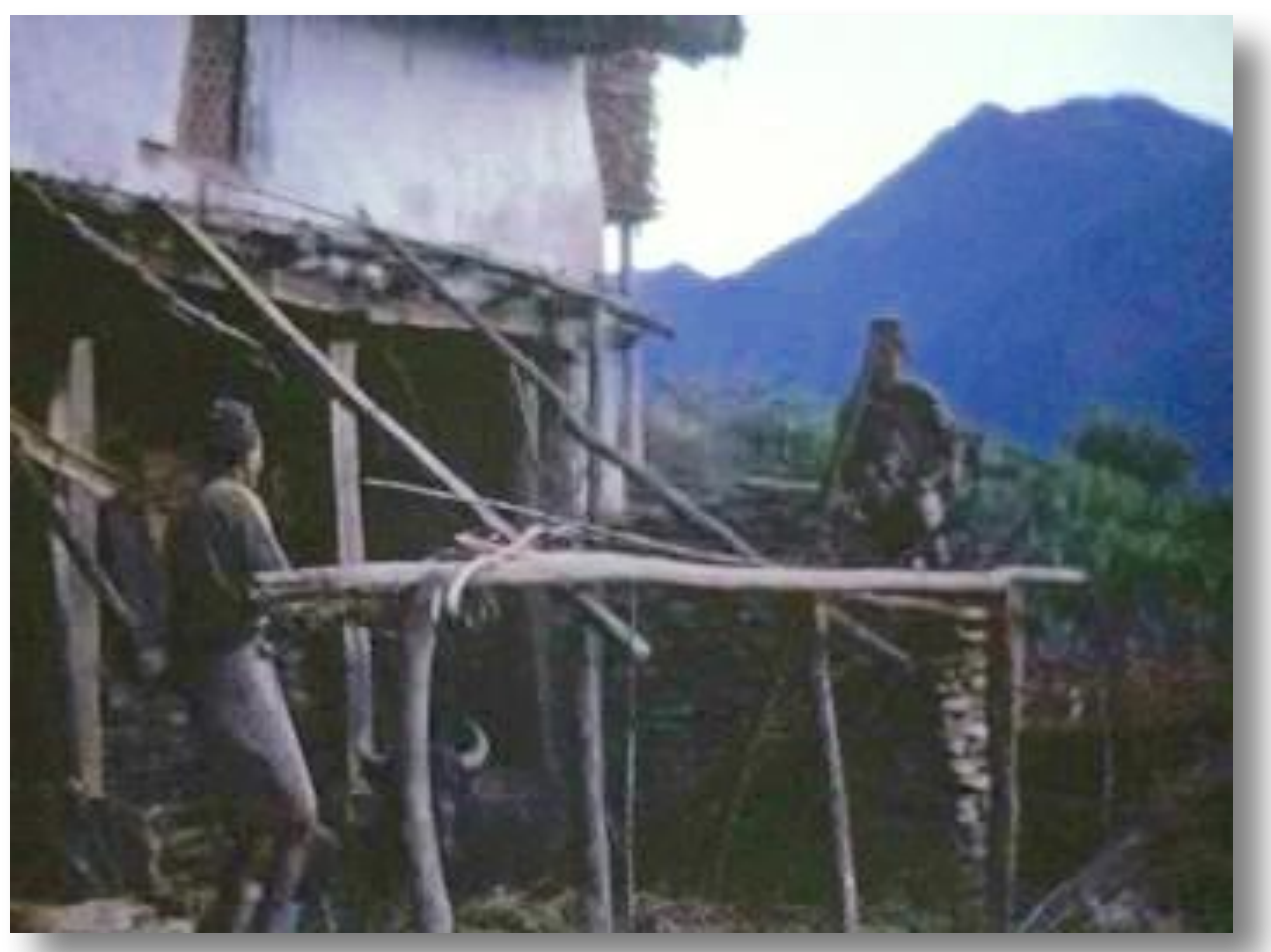

FILM. Two men, one Manseram, stripping old thatch off cow shed rood next door https://sms.cam.ac.uk/media/2736000

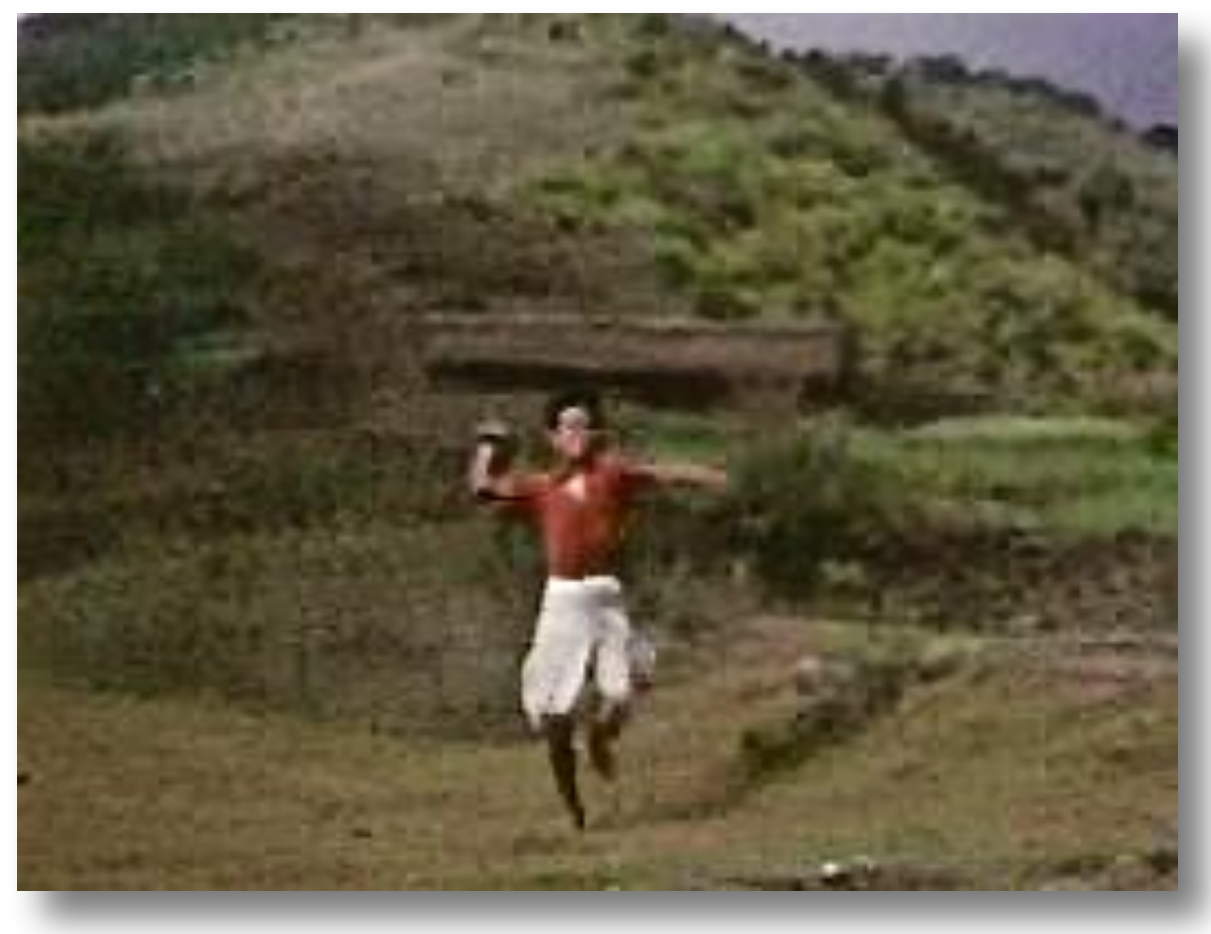

FILM. Prembahadur and another man throwing stones 'chola priba' at Garedi https://sms.cam.ac.uk/media/2736028 


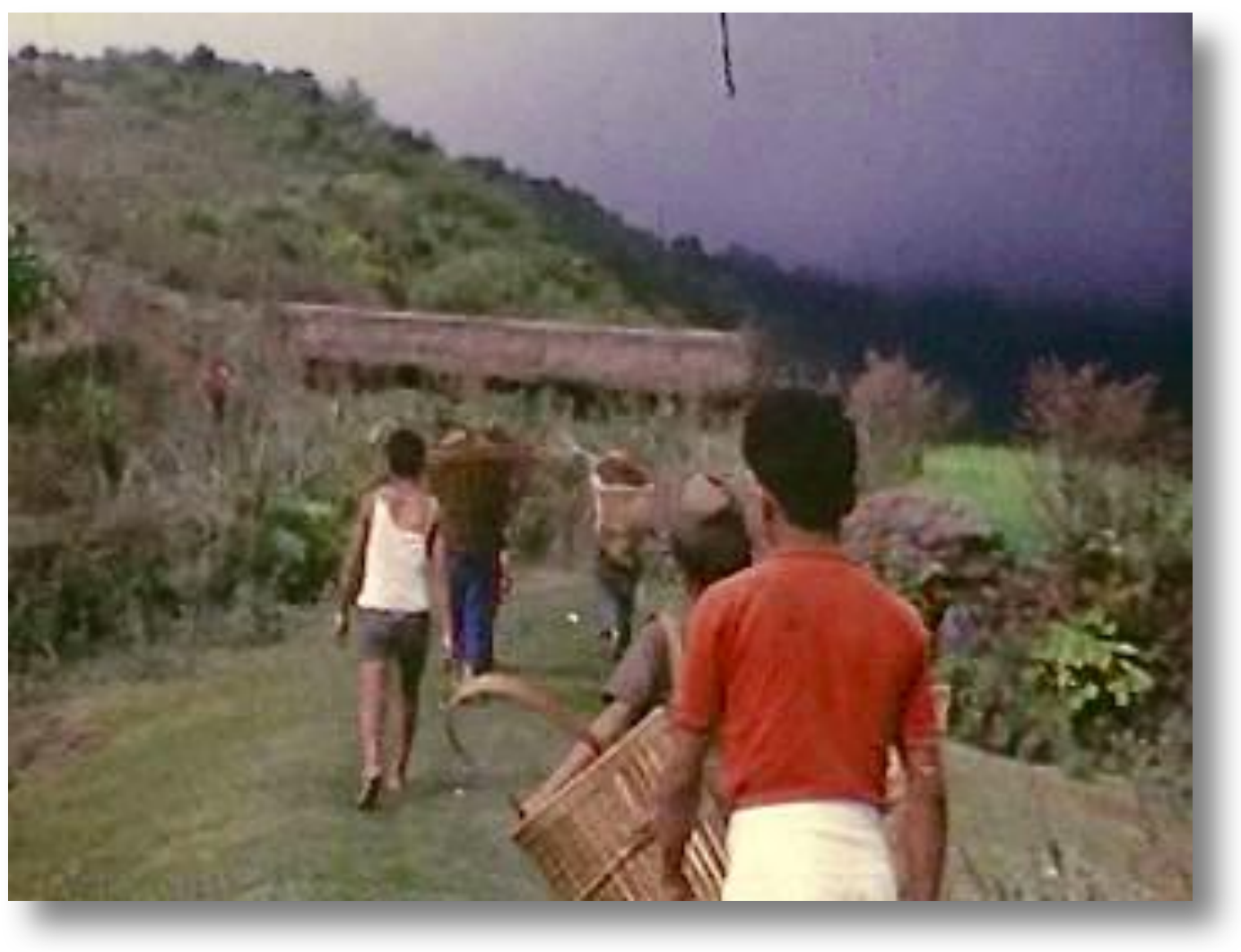

FILM. People walking up to the forest from Garedi to dig 'toya' Prembahadur with his brothers in the rear https://sms.cam.ac.uk/media/2736056

\section{DIARY GILL Tuesday 2nd December}

Boiled up eggs etc. for a picnic lunch and set off as soon as we were organised. Prem came when we were having breakfast and said he was going in same direction too and brought some 'pasagi' (free) as an appeasement - held behind his back! Tried to get Nainasing's thorn out but no amount of digging around with a needle could reach it. Gave him penicillin.

Gungadebi came along to watch, corrected my Gurung and asked if I didn't have medicine to make her nose less black - it had got worse later! This was after she had commented on the whiteness of my hands. I stroked her nose and said it was a very nice one - Nainasing very amused and she wrinkled it in appreciation!

Sun out when we went up the hill but walking towards cloud and chilliness. Not many flowers - only yellow dewlap ones, few red mottled leaves, and three main primulas. Found Prem on top throwing stones with Gopal. Alan filmed him. Then whole crowd came up to dig up 'toya' and we filed along with them, the men plodding and women laughing and giggling and picking red and black berries - seeds. Passed temple on way amidst a shroud of trees and damp, trees had all this shaggy pelts of moss covering them - very warm and soft to touch. All disappointed when they got to the 'toya' field as they had grown very stunted and tubers were poor. They leapt for a radish bed and ate these first of all. Bets mother, as always, offered us some. Her Kaji tried her hand at hacking away at tubers and managed quite a steep walk well. We went off to eat lunch - on a damp rock facing forest - creepers and overgrown trees. Met some men who had been killing birds and had five in a bag. Saw small yellow-tailed birds all in a cloud in a bush. Prem said two white men had stayed there two 
months studying birds. Came back quite early as it was chilly. Alan started sorting out index cards and I carried on with Kardiner. Very quiet evening - only Omkumari came in to sell me some oranges she had brought back from Pokhara.

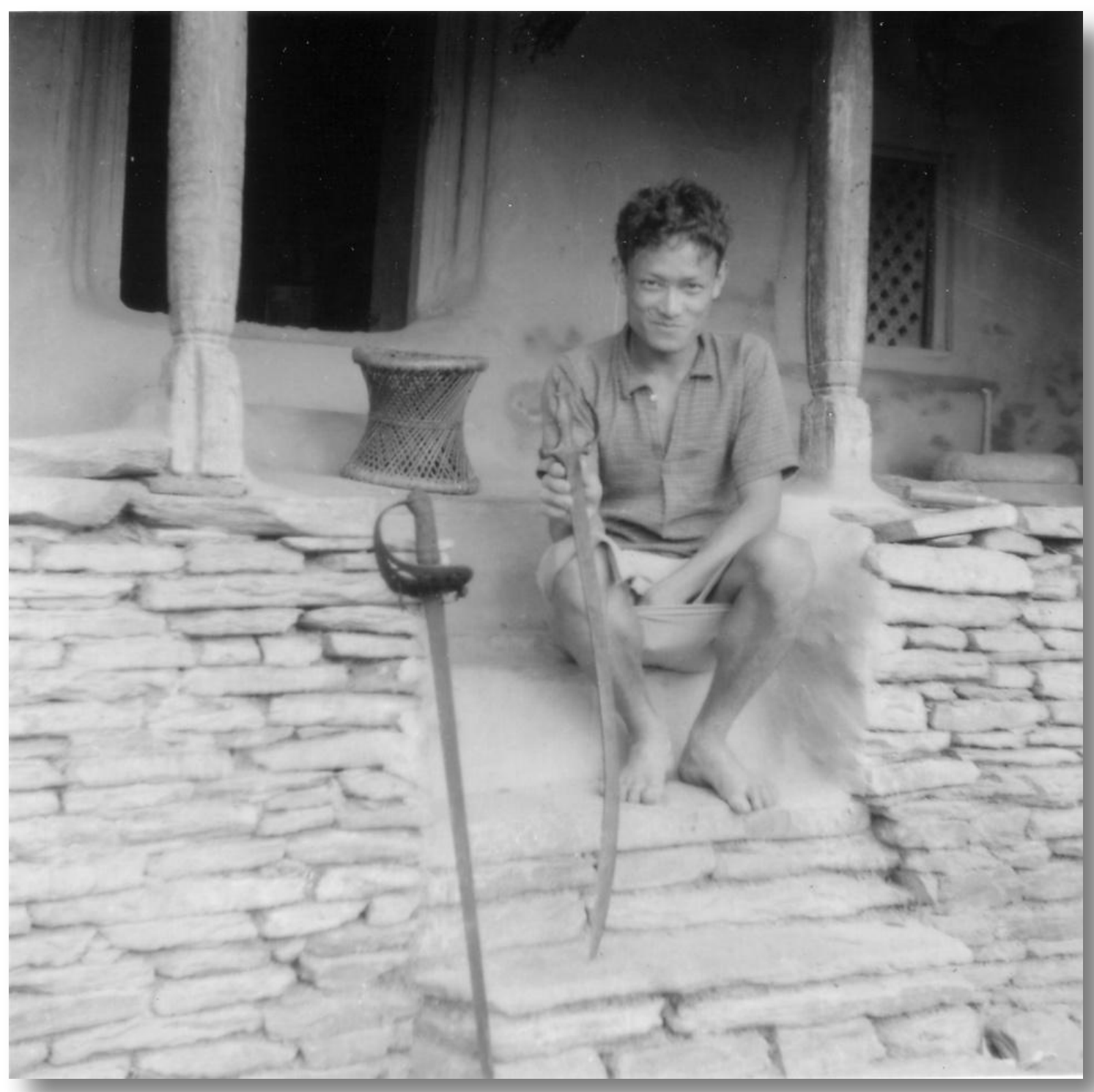

Benbahadur showing old Gurung weapons, the 'tarwali' (long sword) and 'bala' (curved sword) - 2nd December 


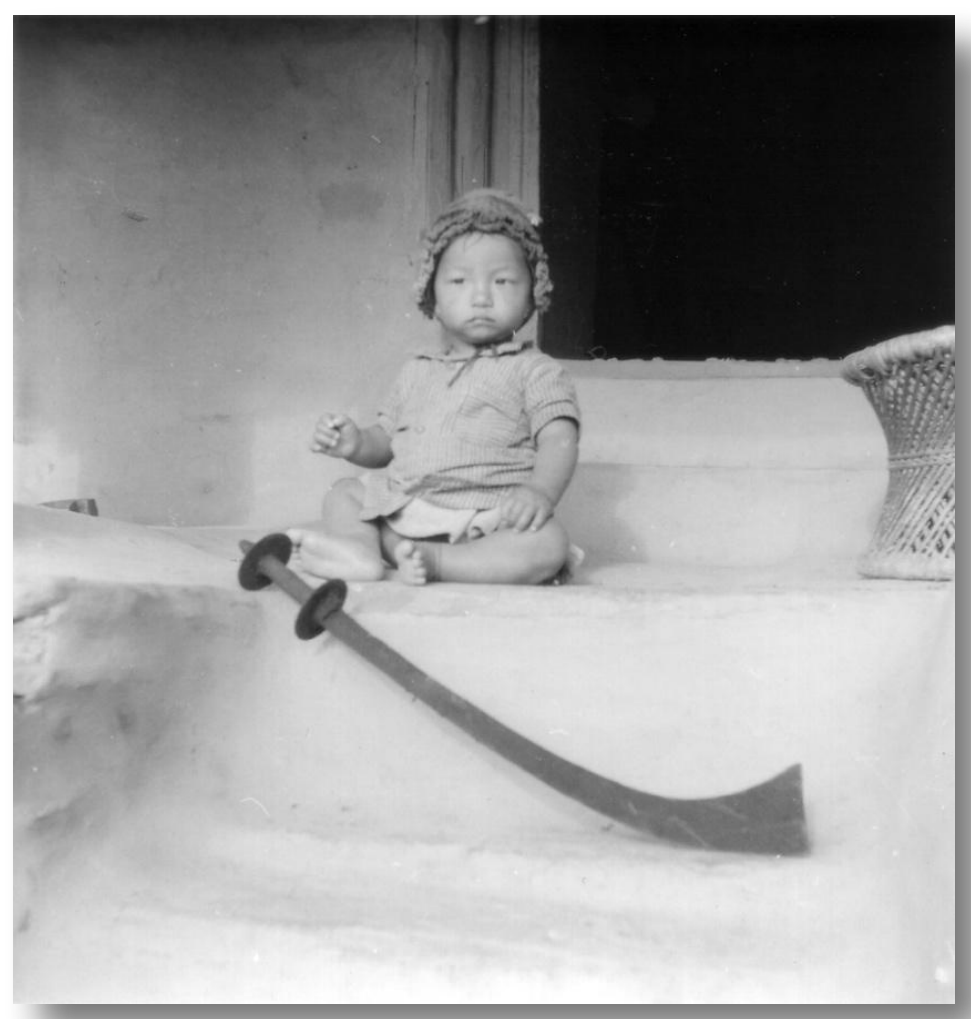

Benbahadur's son, Tekbahadur, photographed with an old Gurung sword, a 'dala'

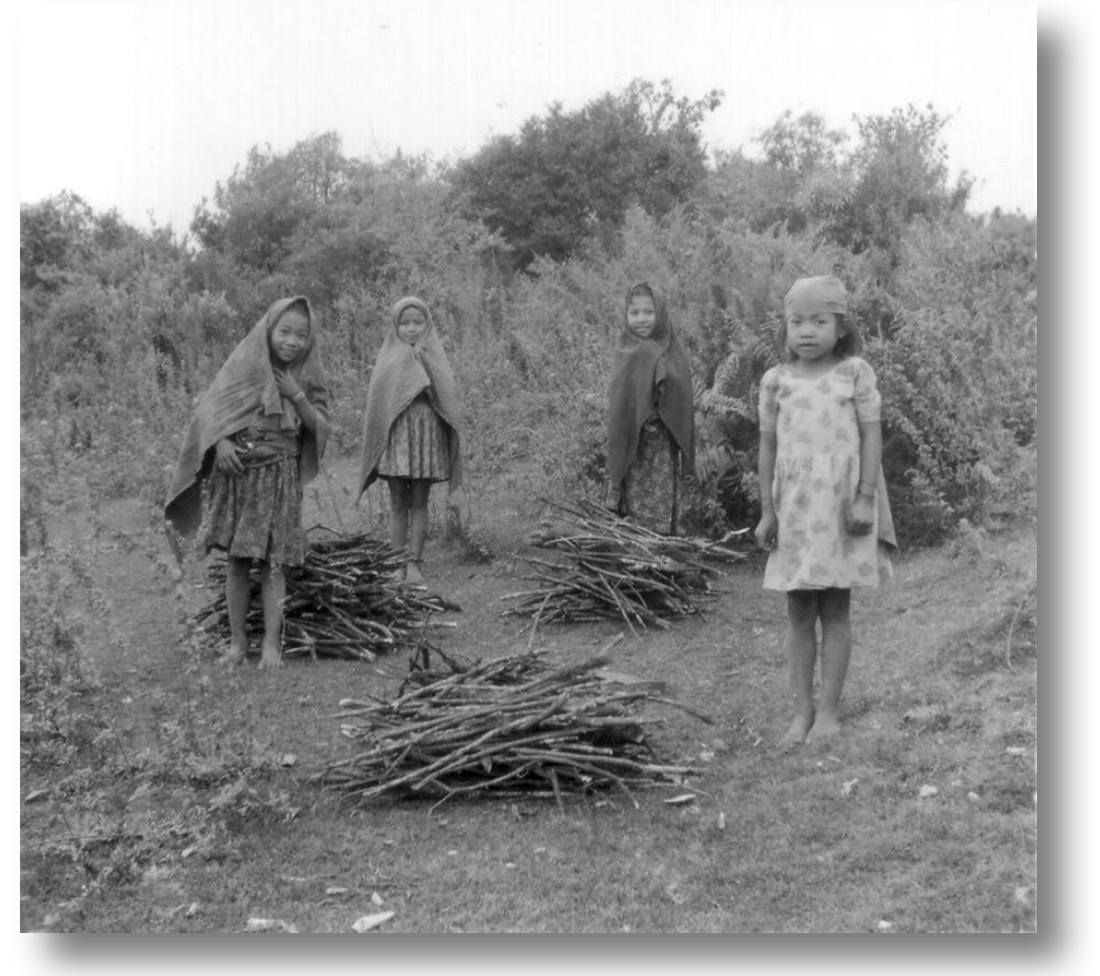

Four little girls collecting firewood near Garedi - 2nd December 


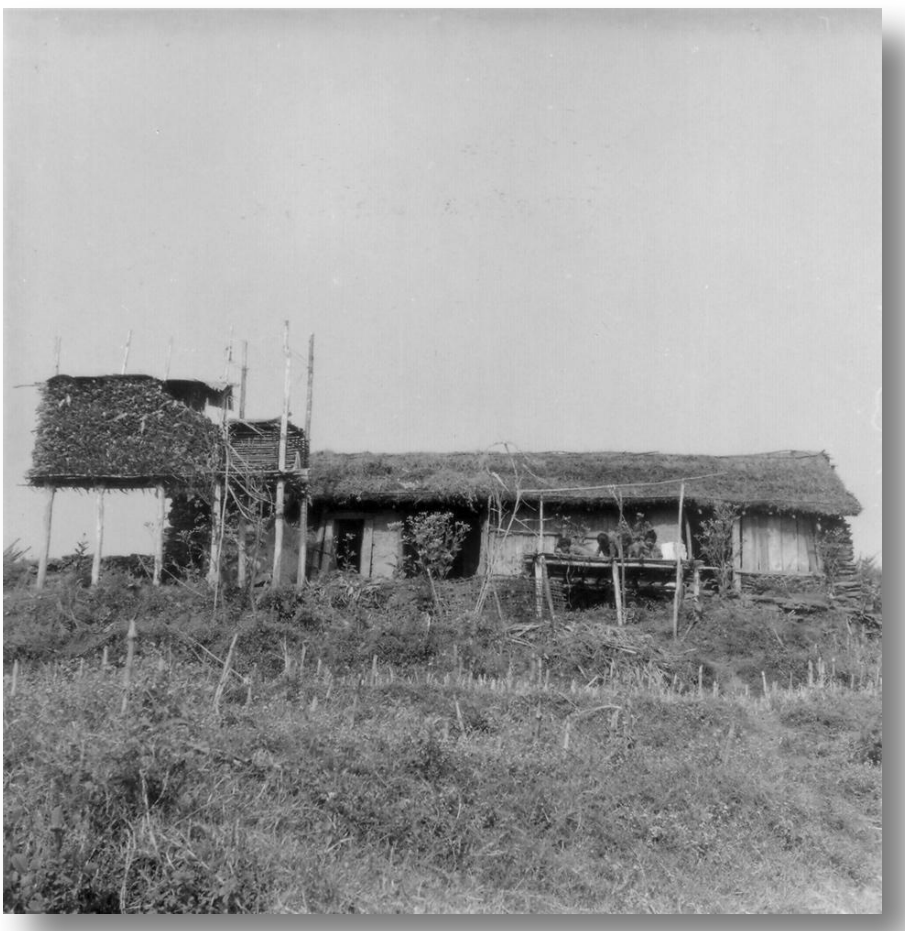

Old wooden house near Garedi (non-Gurung dalits)

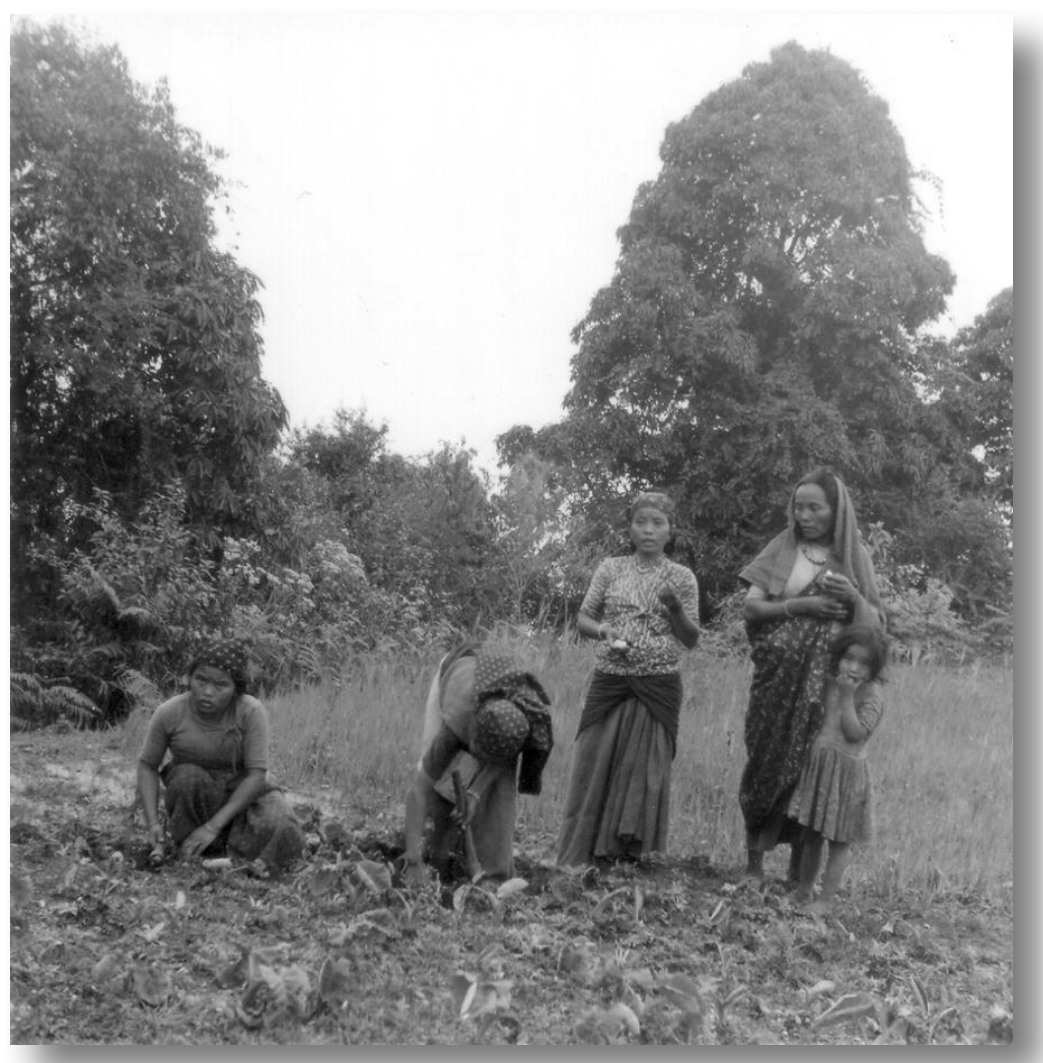

Hoeing for 'toya' (yams) 


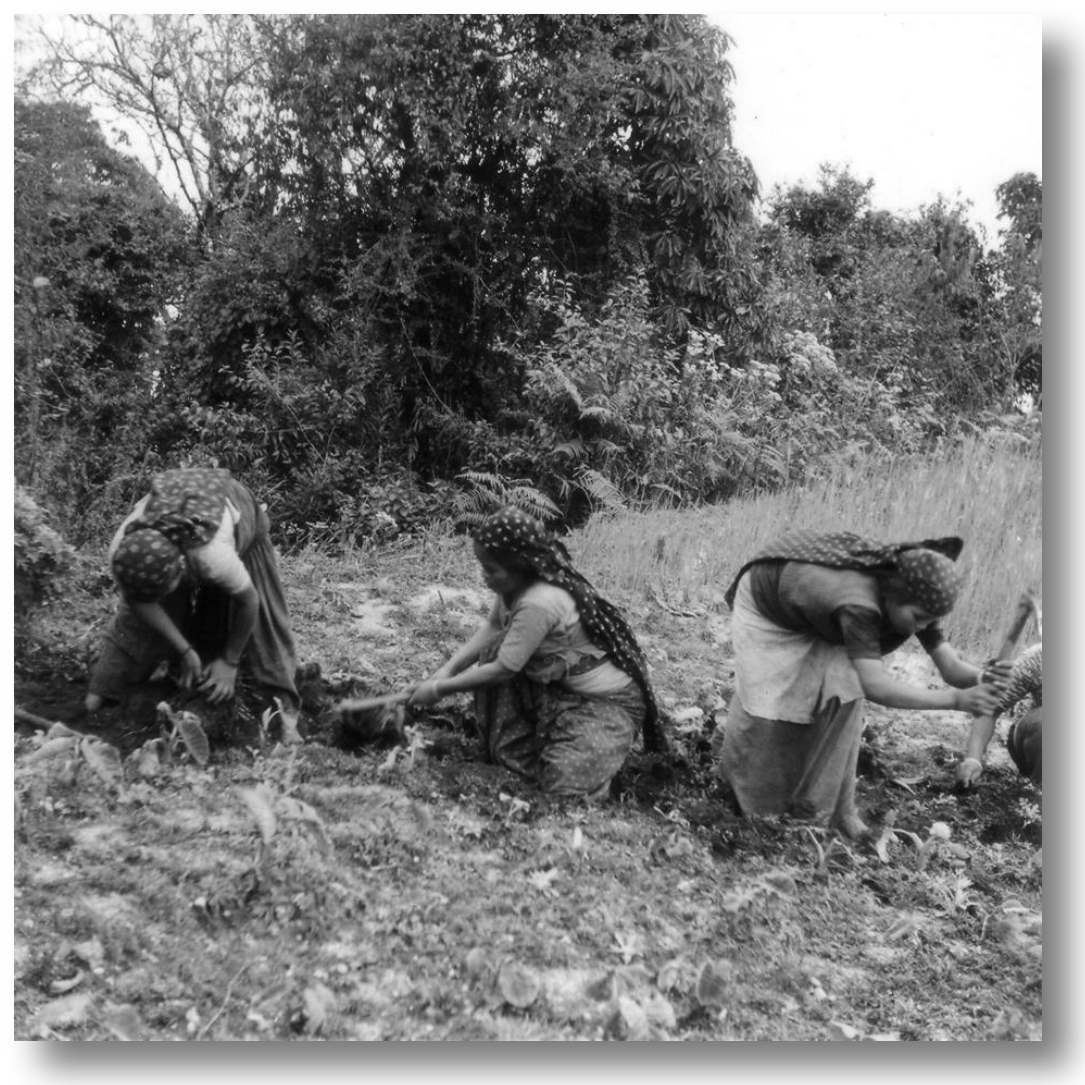

Hoeing for 'toya' (yams)

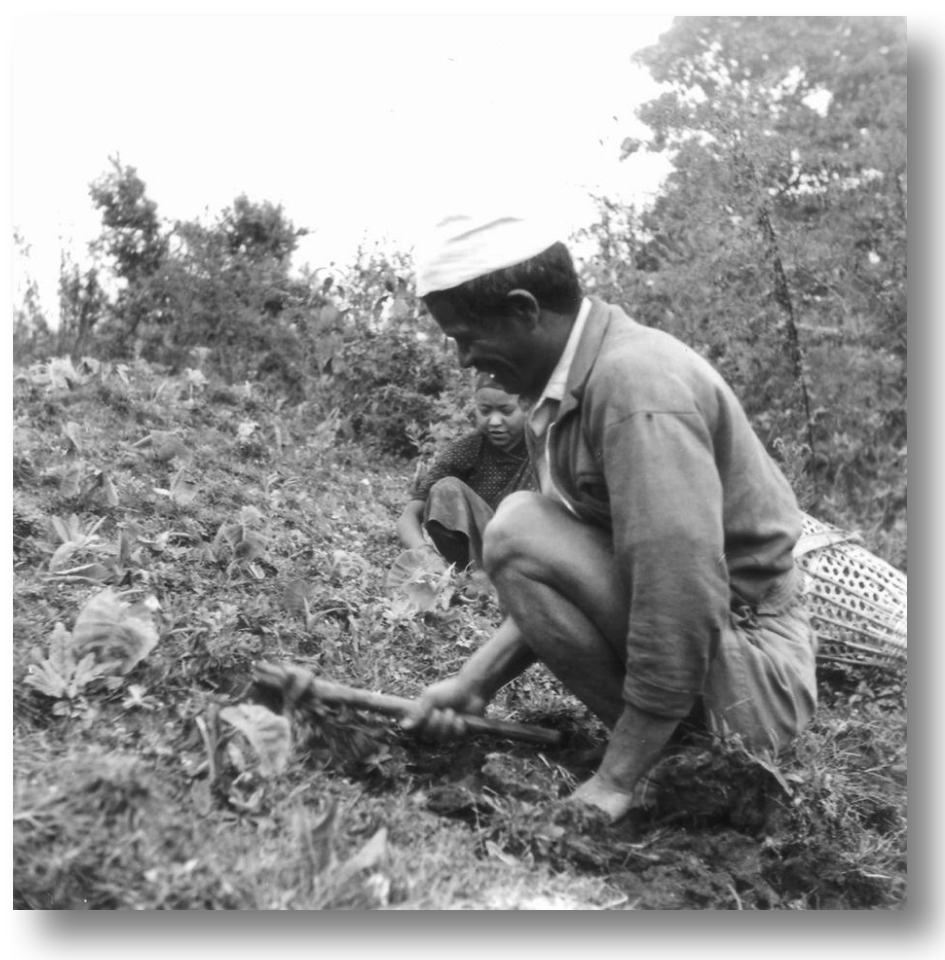

Man hoeing for 'toya' (yams) 
Started sorting out notes in preparation for writing. It is now overcast nearly all the day - and fairly cold. We sit wrapped up in jerseys, coats, etc. most of the time, but Gill managed to get up her hill for the afternoon. She is working on poju's rites and childrearing, while I go on as above. Time seems to pass very slowly now that we are so near leaving.

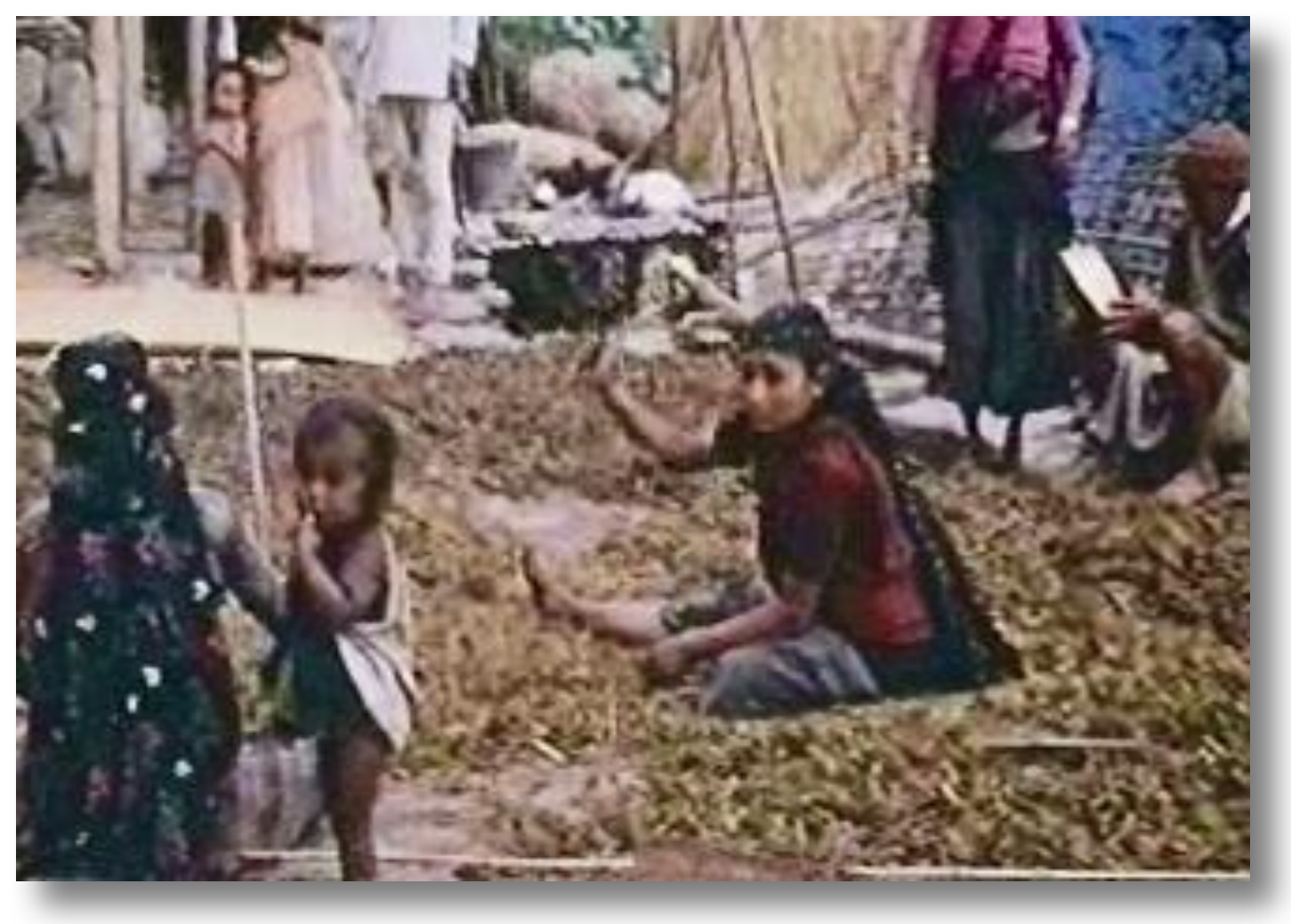

FILM. Kaji beating millet in a courtyard with another woman and small child https://sms.cam.ac.uk/media/2736140

DIARY GILL Wednesday 3rd December

Determined to do some organized work for Alan as I felt so much less guilty - so spent morning half on Kardiner book and half on poju's rites - checking and analysing and getting ideas. Source quite fertile, but still feel I'm working at half-steam all the time and essentially very bored. Feel sadly that anything would be a waste of time in comparison with going home. Nine weeks today. Alan sorted index cards all day, pleased with amount of material we have got but I think he feels we could just as easily be doing this sort of thing at home. Weather has something to do with it, I think, dull, cold and overcast all day - chillier in the loft than out, I think. Both wearing coats, etc. over our knees. Read "Tin Drum" after lunch which doesn't brighten the horizon either, a tour de force indeed but a cold and arrogant one. Will be happier when I feel I've got the "message" - interesting play on national tension Polish/German - compare Kafka's same tension on Czechoslovakia/Germany theme. "Productive tension"?

Went up my hill just to give me the feel of doing something - continued Kardiner and started Lenin's biography, which promised interest and written with bourgeois background 
(doctors, school inspectors!) Remained uniformly blue and dull all afternoon, men now clattering down hill with canes for weaving from forest, children with wood. Millet nearly all picked! Lot of people seem to be hopping off to Pokhara. Met Alan at bottom of hill and we went the round walk - briskly. Had lot of people in for supper - about 11 males. Felt a bit like a jolly pub atmosphere. Gopal just returned from Pokhara, held conversation about happenings there - accidents, amount of cars, meeting old school friends, peculiar white people, etc. Had fish - bit uneasy it would make me ill again.

\section{DIARY Thursday 4th December}

Went on with indexing and arranged for Prem to film 'pae lava'. Heard in the morning that Bhuwansing would be getting his son married in the evening so spent the rest of the day off and on down there - escorting the bride back in the dark, etc. - watching dancing, etc. Didn't collapse into bed until about 11.30pm. - about 4 hours after our normal time.

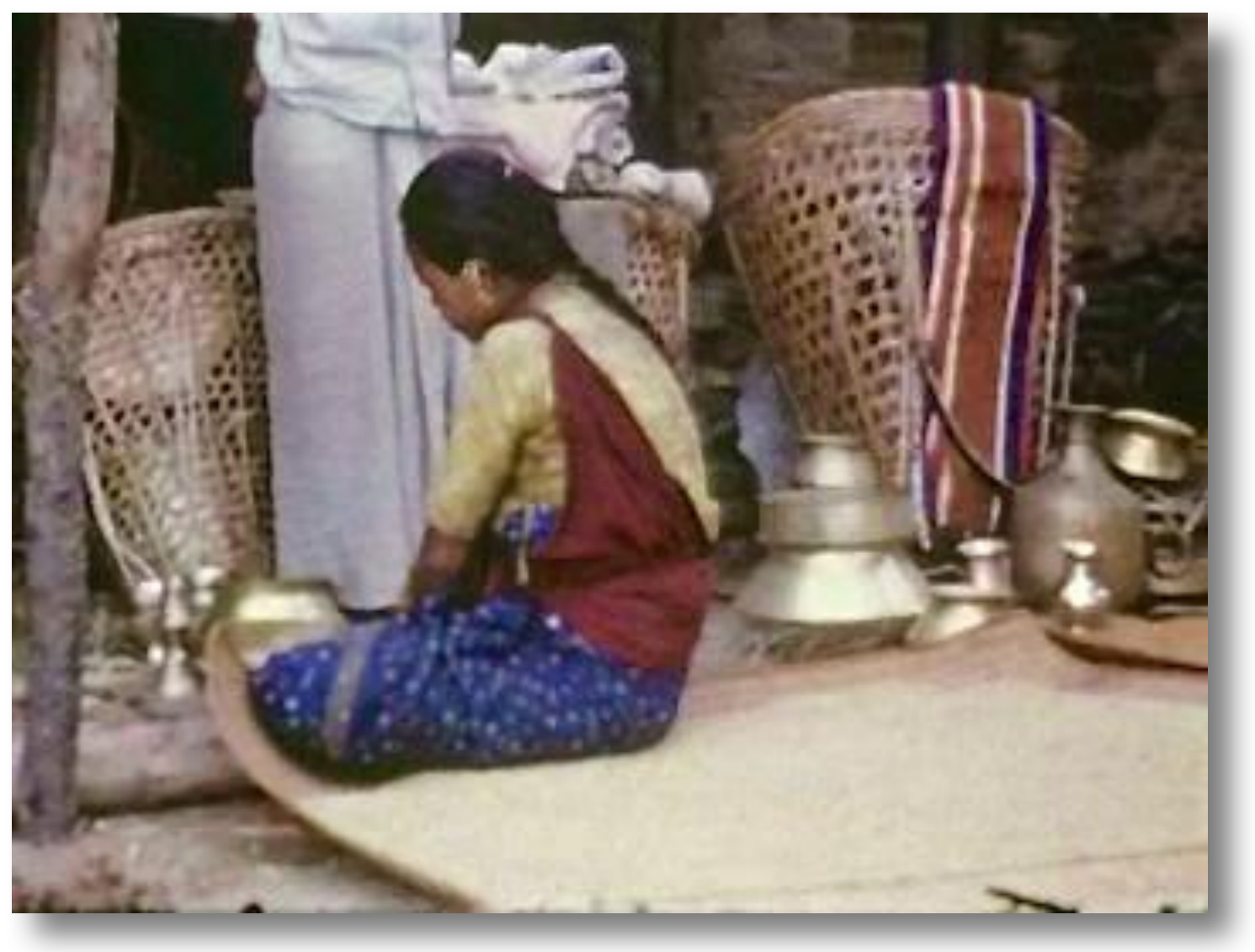

FILM. Girl sitting on a grain drying mat discussing brass pots with a salesman who has brought them up in baskets

At House 40

https://sms.cam.ac.uk/media/2736168

DIARY GILL Thursday 4th December

Learnt early this morning that Bhuwansing's wedding was today and a girl was being brought from Yangjakot. Did some rather desultory work this morning. Still very cold and 
overcast. Had early lunch and went down to Bhuwansing's house about 12.00pm. They were preparing the courtyard - sweeping out (bridegroom in black satin shorts and white string vest) and erecting a sort of marquee with rice mats. Bhuwansing a bit on edge in his baggy green trousers with green sweat shirt on, but Nandalal, it seemed, hardly at all. Mrs B. was away in Yangjakot and the place lacked the warmth and organization without her. Dankumari sweet, but a little panicky. Prasad was there in an irritatingly tailored jacket making a "Welcome" sign out of white paper pinned on a red cloth. This was attached to two banana trees by door. Men engaged rice cooking, goat and buffalo were killed. Much anxious scanning of the opposite horizon looked through a one lensed binocular - lot of people swore they saw groups dotted everywhere, under this tree and that on the opposite hillside.

Bhuwansing getting cross when they hadn't come by the time it was getting dark.

I tried to read "Tin Drum" but Comal's Maili was disturbing and Alan attempted E-P but Gurungs wanted to look at the pictures. We went down eventually, after drinking 'pa' and eating 'keh' under hearty supervision of Mrs B.'s younger sister, who also seemed to have done quite well for herself, to 'Deorali Deota' and waited there whilst sun set and the guns crashed and the horns blew - everyone trying to ignore fact that they had some when crowd arrived. Bride smothered in a white coverlet on someone else's back. Village amused I came up with them. Door knocked and mother called for by bride and 'tikas' were put on bride and groom - former still smothered and latter gay and curious. Great chaos over food - over 40 people had come - crammed courtyard out. We went back for quiet supper and then watched a 'tetara sheba' by Yangjakot group - rather restrained and tame, village saying it was "medium", loudly. But courtyard packed. We took flash but tape-recorder not working. Left quite early - some of them seemed to dance all night. Very tired by time we got back about $10.30 \mathrm{pm}$.

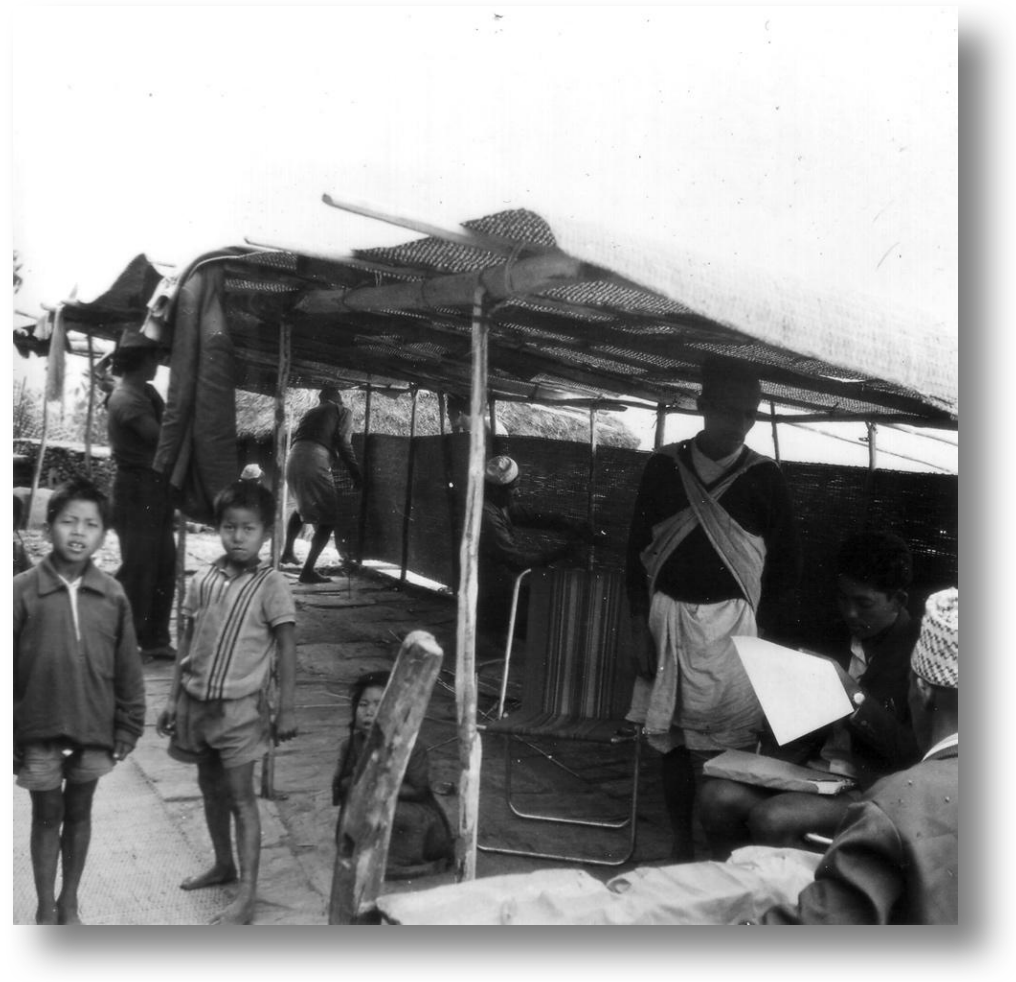

Preparing for Nandalal's wedding at Lt. Bhuwansing's house 


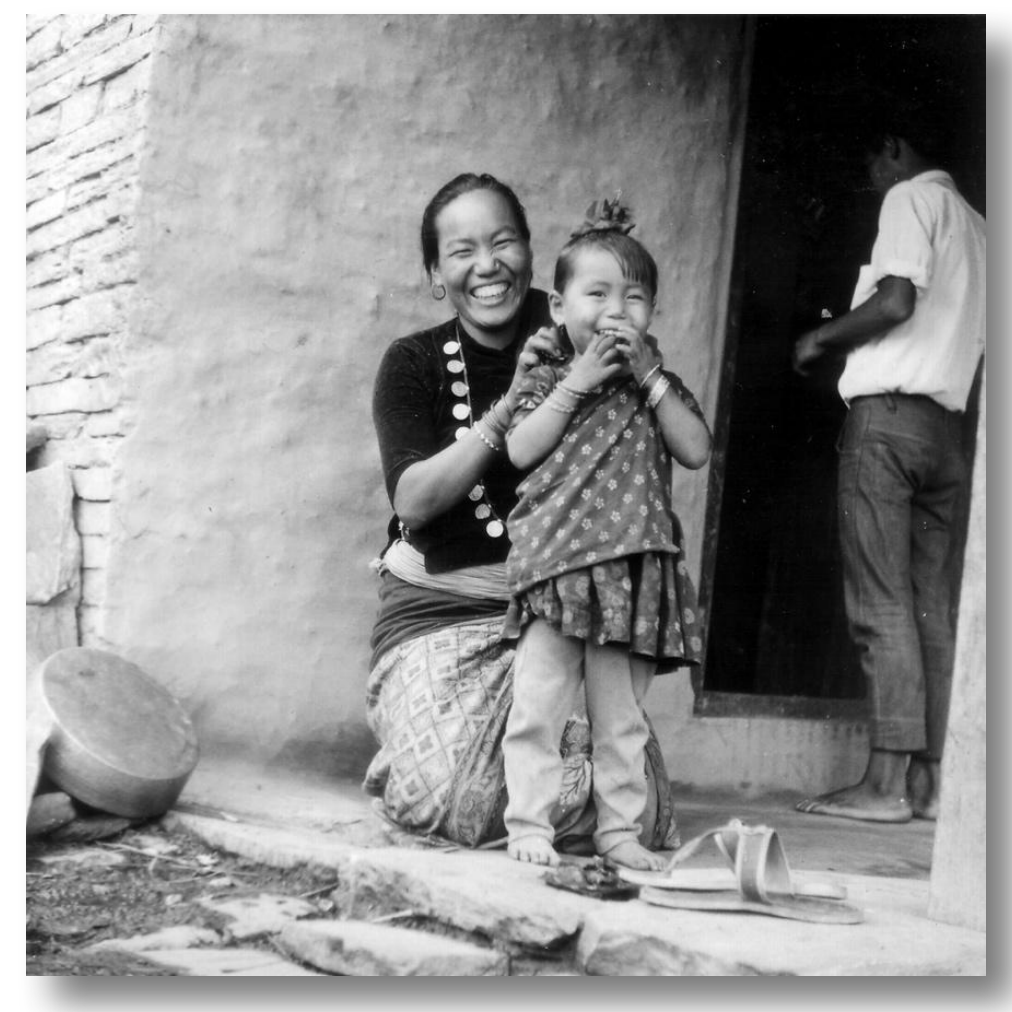

Dhankumari helping Sobadebi her sister to dress for their brother Nandalal's wedding

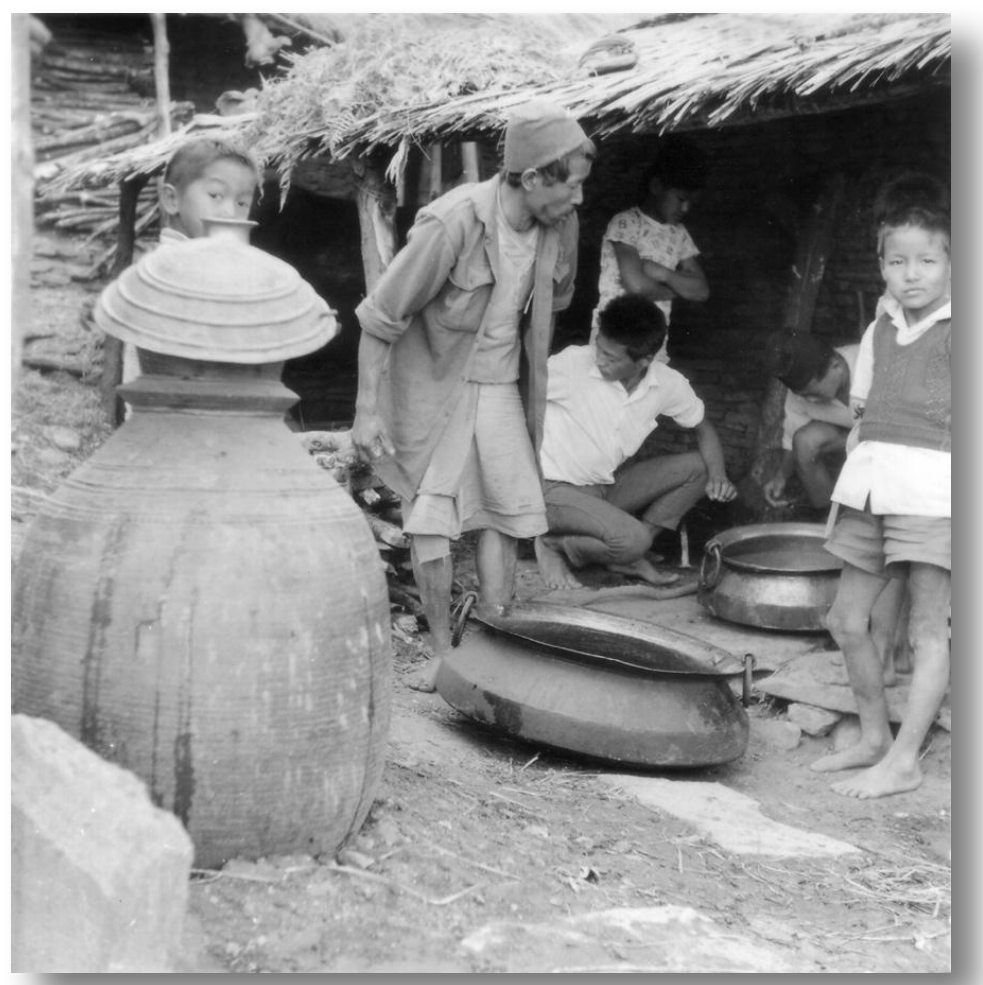

Preparing cooking area for Nandalal's wedding 


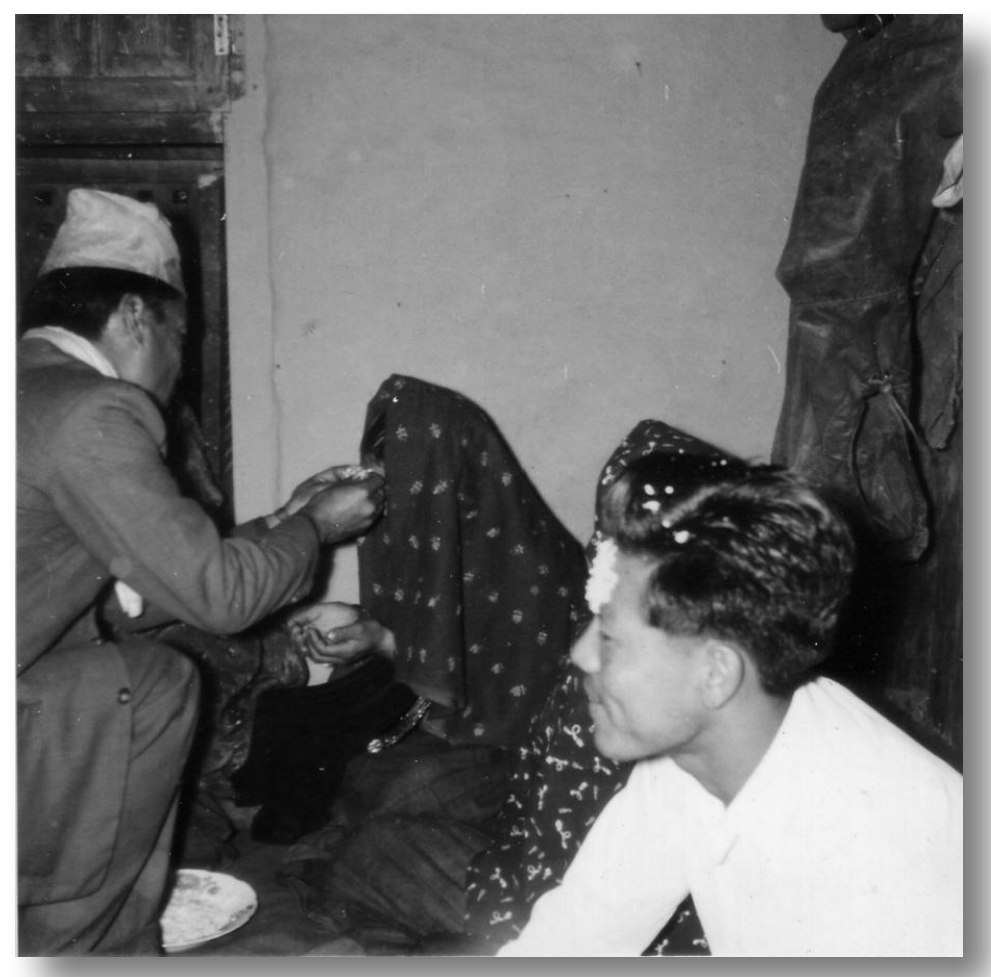

Bhuwansing putting rice on bride Sunkumari's forehead at wedding, with Nandalal in the foreground

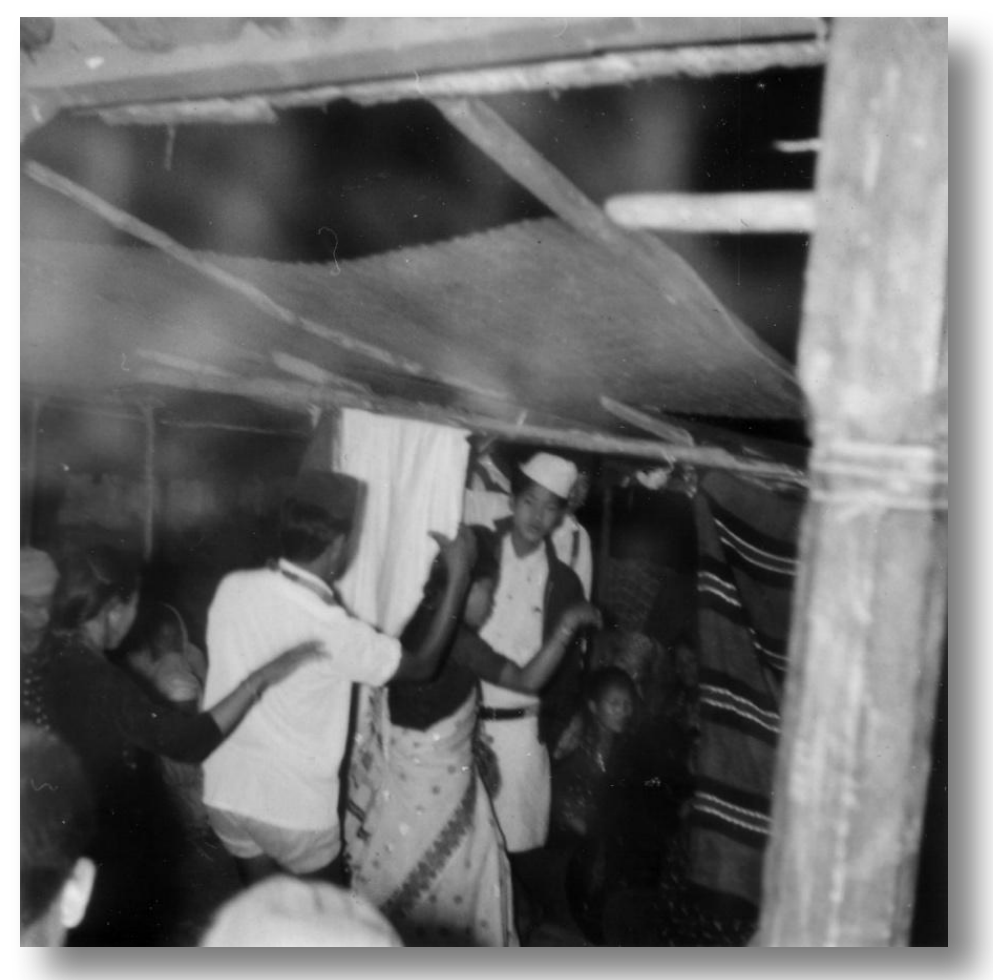

Dancing at the wedding 


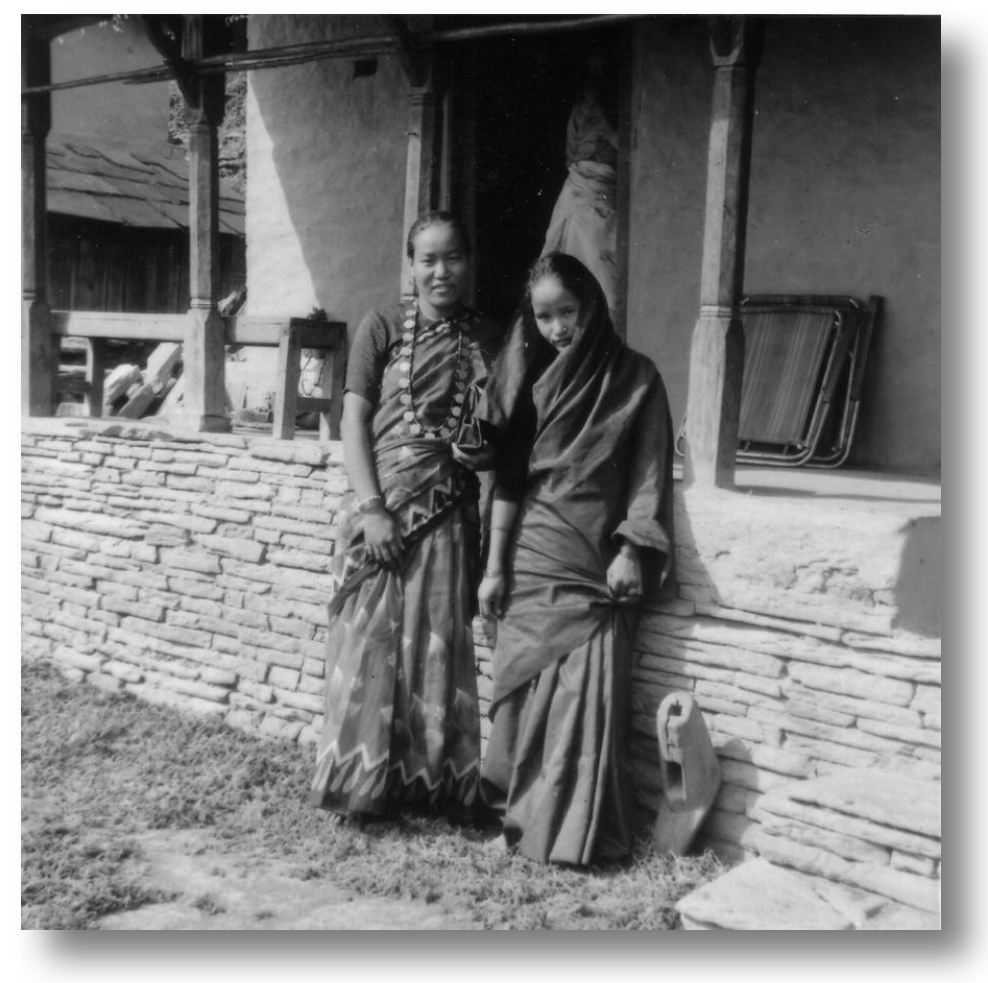

Dankumari and Sunkumari outside Bhuwansing's house

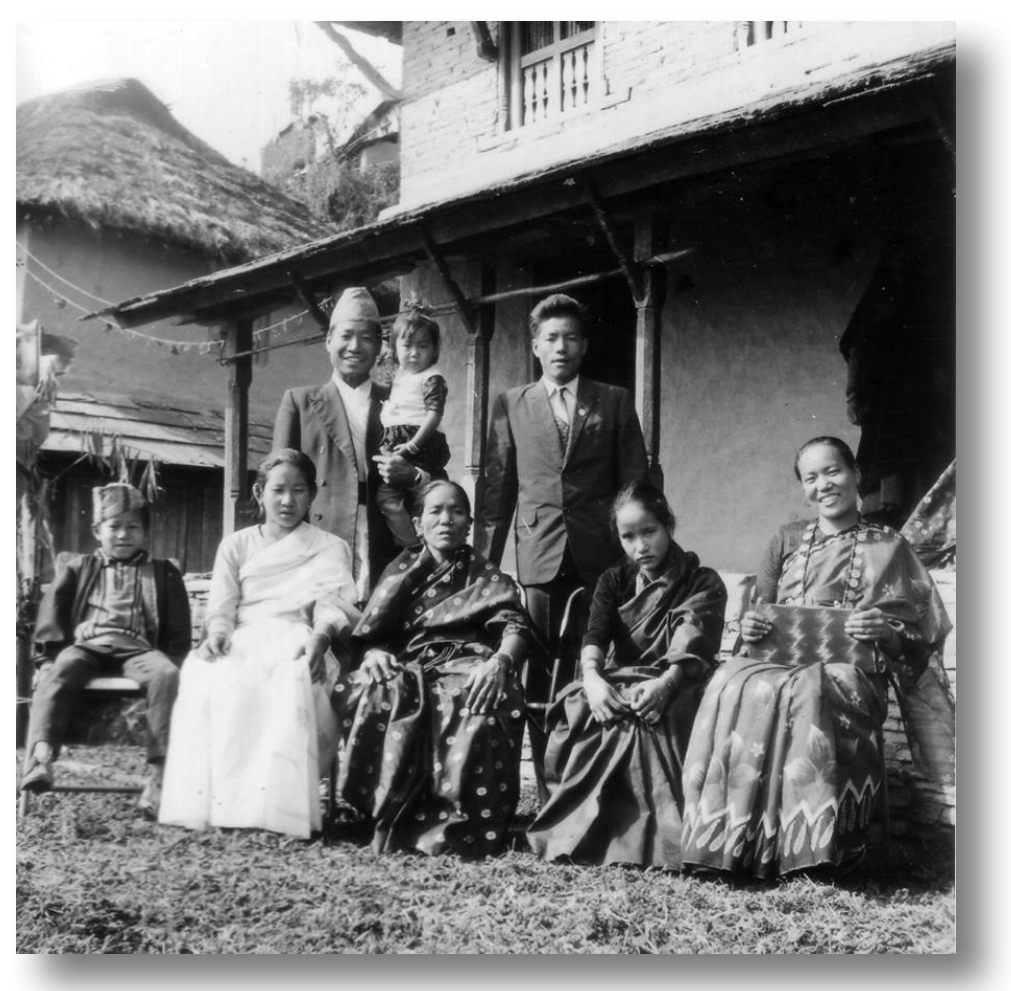

Bhuwansing and family at wedding (from left, younger son, Dilmaya, Bhuwansing with younger daughter, wife, Nandalal, Sunkumari, Dankumari) 


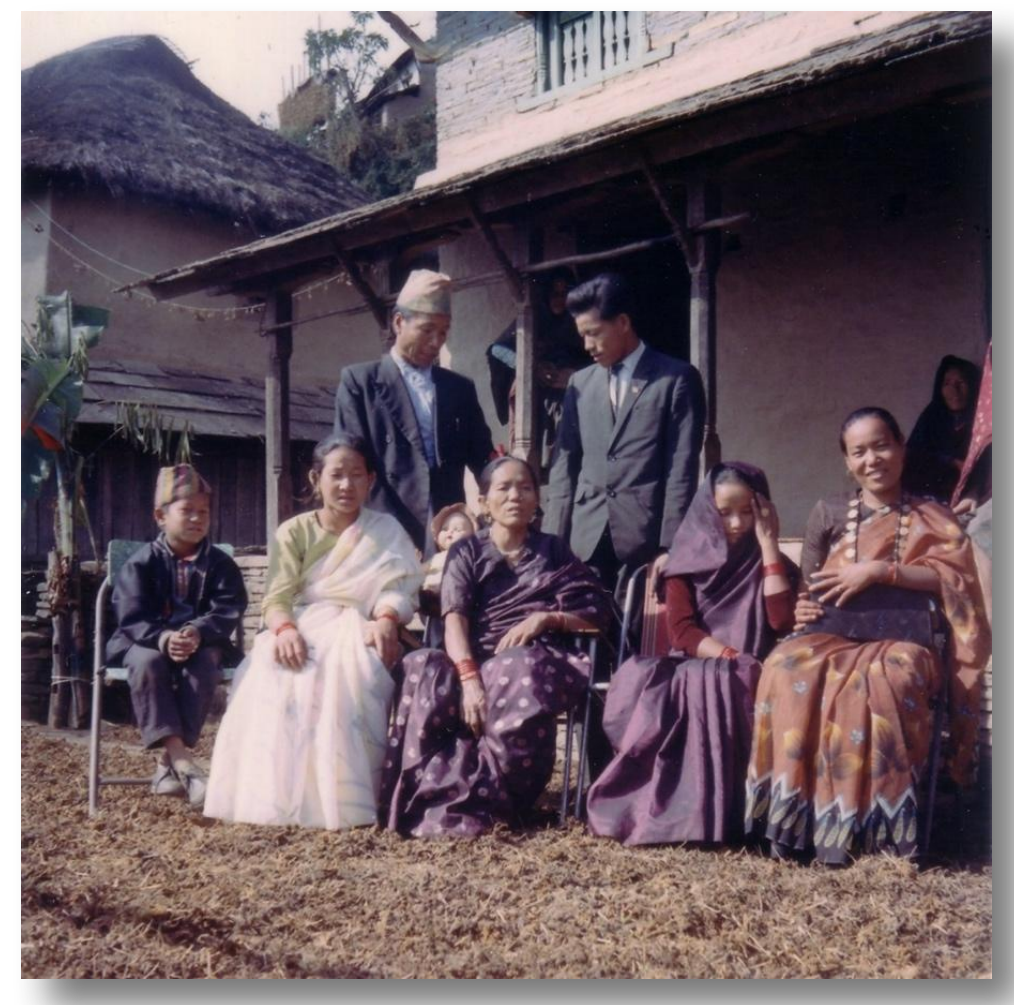

Wedding photo. From left - Dilmaya, Nandalal, Sunkumari, Dankumari and Sobadebi behind

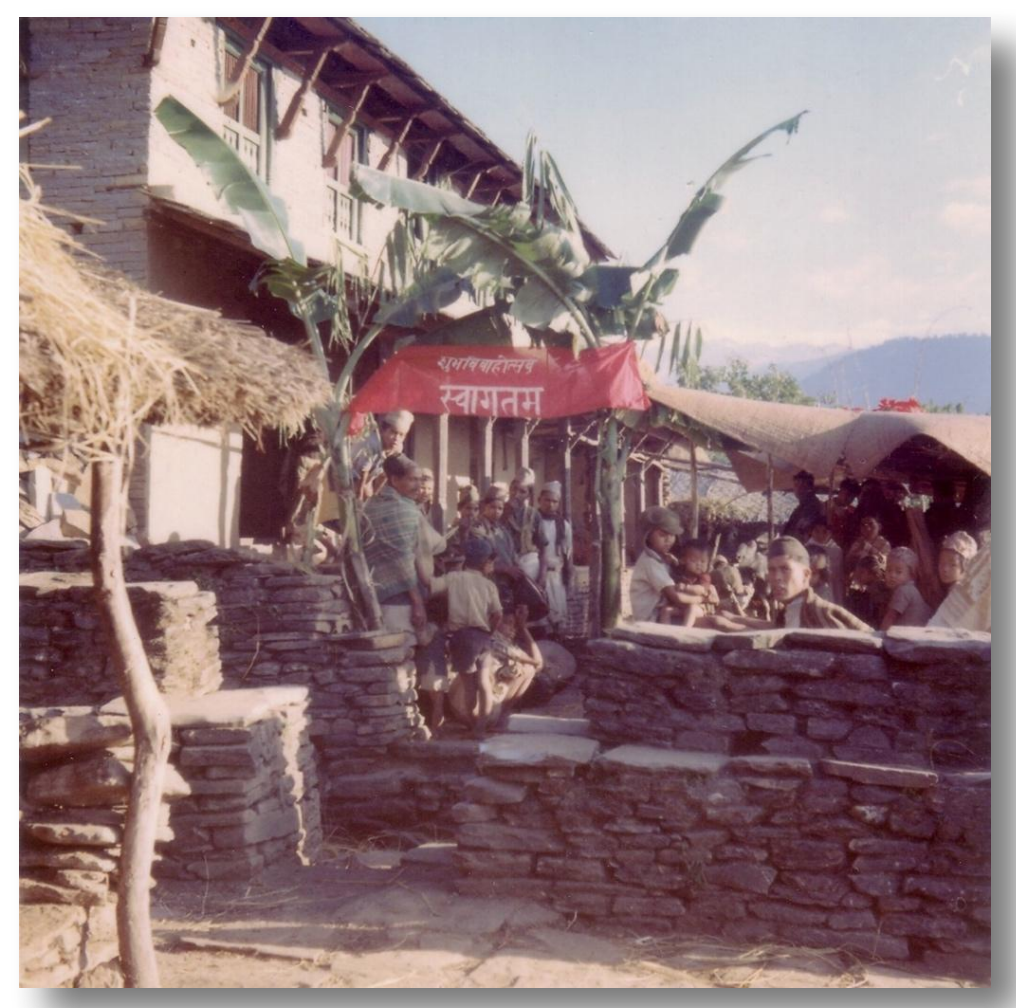




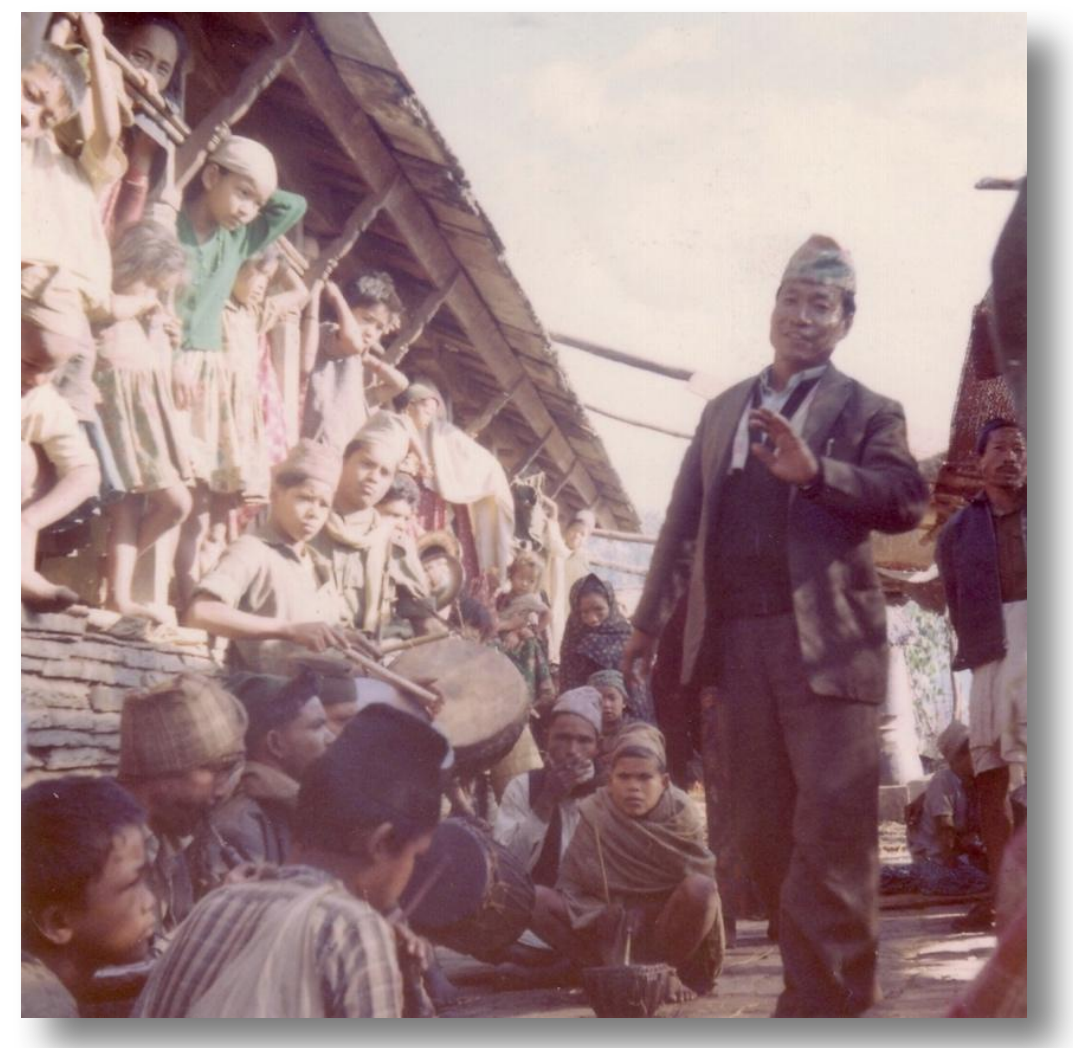

Lt. Bhuwansing dancing to Tailor's band

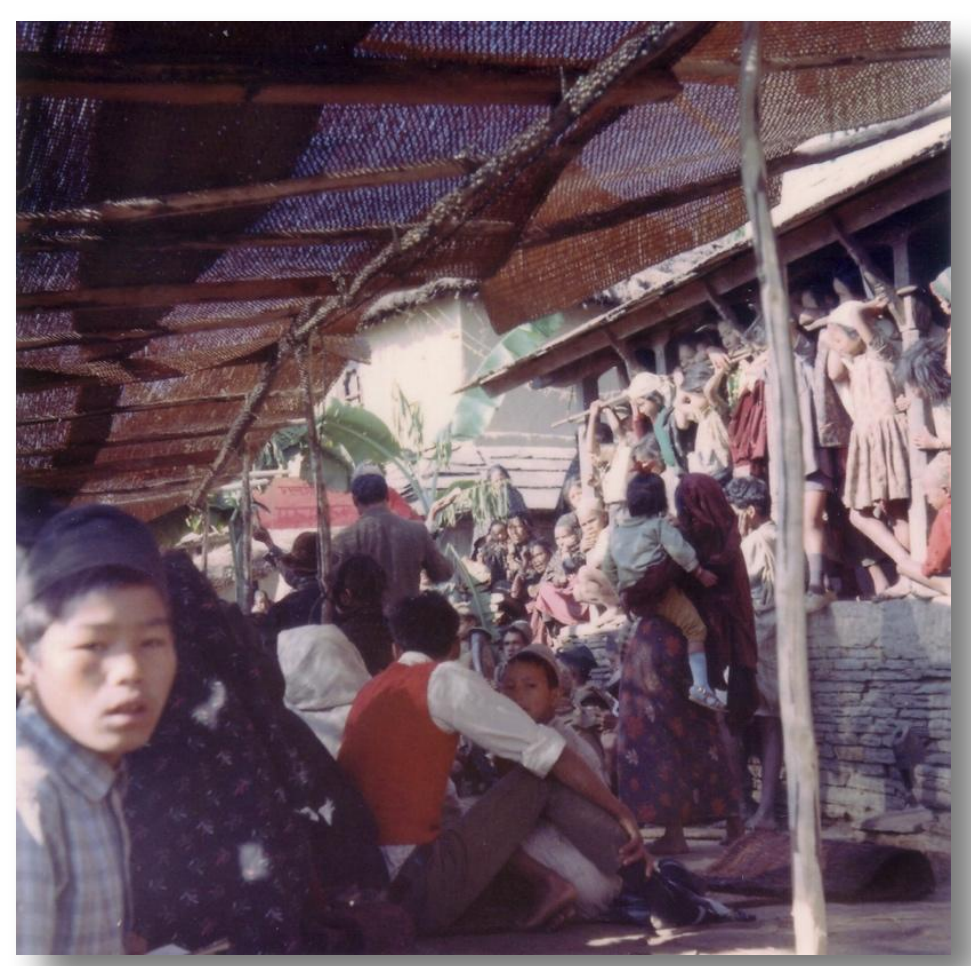

Wedding guests 


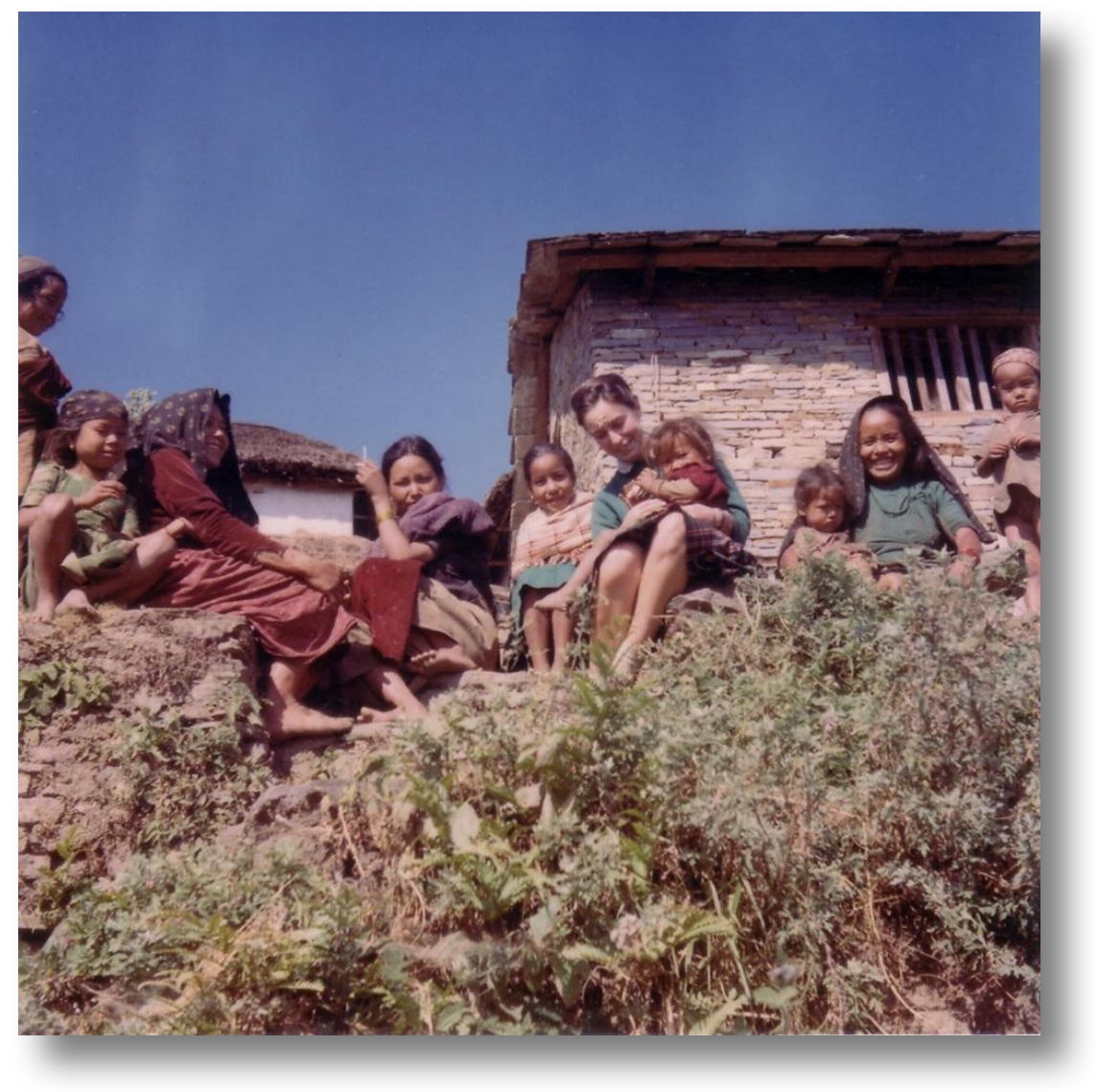

Gill sitting on the terrace in front of the night school with Sobadebi on her knee - 5th December

NOTES 4-5.12.1969 Alan Ritual at marriage.

Wedding party bringing the bride was expected at about mid-day from Yangjakot but in fact arrived, all fifty of them (about 2/3 women) at dusk to dark into village. For preparations bridegroom sweeping courtyard out in black satin shorts and white vest. A marquee had also been put up over whole of tent. Prasad making a "welcome" sign, men setting up a cooking shed outside - borrowed our 'jongo' (large) Nansubar's cauldron. Dankumari was rowing, other woman (B's wife's sister) cutting up radish. Boje's father making banana tree gateway. Gun was prepared by Boje. Goat and buffalo waiting to be killed. Ramu playing on verandah. Dankumari dresses Kaji's hair. B's wife away in Yanjo. Anxiety about party not coming - scanning horizon. Went down with Tailors and groom to meet party. Bride carried on back. Cigarettes given out by Boje's mother on way up. On way up hill they were offered cigarettes and then just at the bottom of steep steps of house 24 a 'gundri' and blanket put out and some cigarettes put on it. Just done for a few seconds with Bhuwansing explaining and apologizing saying he would have done it further down if it had not been dark. Dilmaya and Boje's mother as boy's 'rimeh' do this to men and give cigarettes. (A 'proken saba' at house 78 also had to be skipped). Two Untouchable bands joined up below village and led the procession up. Guns fired at intervals on way up (three guns, each fired twice, as guests approached and one as bride entered house). In courtyard great excitement and confusion, lights flashing etc. Guests file in under "welcome" sign and huddle up in rows under matting cover - some touch Bhuwansing's toes and he does same to them. They are given cigarettes 
and 'pa' (see flash). Then bride, who was carried all the way on a man's back all wrapped up in coverlet is brought to house door, with groom alongside. They have some rice put on forehead (by Bhuwansing and Poju) and rs. note - bride rather unwilling - has to be slipped under coverlet. Then girl's hand taken to knock on fastened door and men call out "open up Dankumari" (mother not allowed in house at this point). Open door and girl plus consoling girl-friends rush round to window by fire and a mass of people surge in. Shortly after the groom, bride and her friend have rice and then milk put on their foreheads by Bhuwansing etc. and then Nandalal goes out to call in his mother who has hitherto been absent. Later guests are fed and there is dancing with a very large attendance - a special 'tetara sheba' party brought over with the guests. Went on past midnight. Next day, gun fired. Tailors playing and Bhuwansing and others dancing. We watch, take photos and drink 'pa', then, to shooting of gun various people (see appended list?) put 'tika' of rice and milk on groom's forehead and give him money and wish him luck. (n.b. some 5 potti or 40 manas of rice were cooked up, about sixty people ate, yet there was still quite a bit left). Bride is meanwhile outside. Then people in house put 'tika' on each other. We are told the same thing has been done the day before to bride in her own village and will be done again to the groom when he goes over there. People get very happy and the old bujes (eg. house in front of 24, another about sixty year old woman and Mrs. Bhuwansing's younger sister Saeli) all dance round and clap in house. Then guests are fed rice and meat outside. We leave. Some of guests go up to see 'pae' at Khilang we are told. Tailors have been playing all the while and have been given food and drink. Father and mother have white thread put on necks. We are told that normally only ten to fifteen guests come, more come from the North and East than from the South. Buje (in front) does 'tika' to herself. Dambasing (house 51 sic.) is the writer of giving list.

\section{DIARY Friday 5th December}

Spent the morning drinking 'pa' and watching the rest of the wedding celebrations at the Bhuwansing's. They were very hospitable and the village seemed very interested. We were too tired to go to another dance ('tetara') in the evening. In afternoon went on indexing. Weather now brighter after about 4 days full of cloud - but still pretty cool - like an English September, I suppose. Rats and dogs very noisy at night. A bit apprehensive about the various things I should be checking, but can't - but nobody seems to be available. 


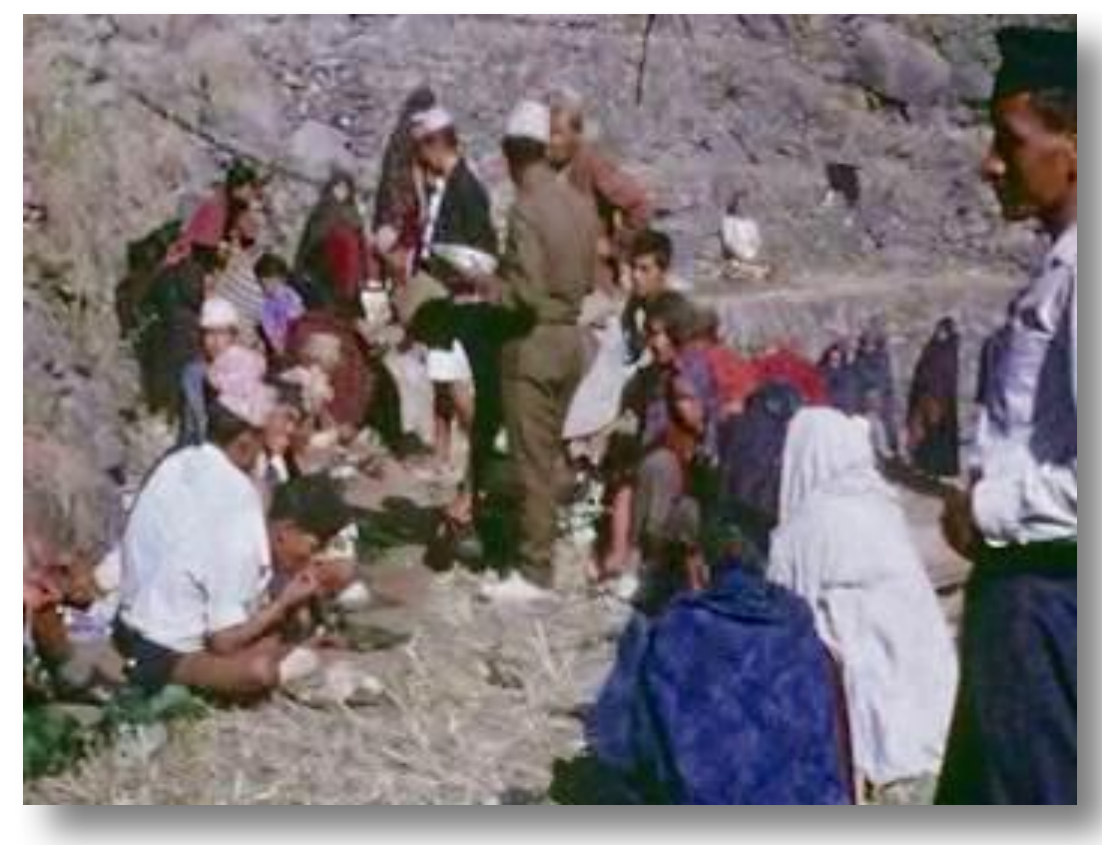

'Pae lava' (not Thak)

Film taken by Prem. Battle between the 'moh' and klehbri ('rih teba') Guests eating - 5th December https://sms.cam.ac.uk/media/2736196

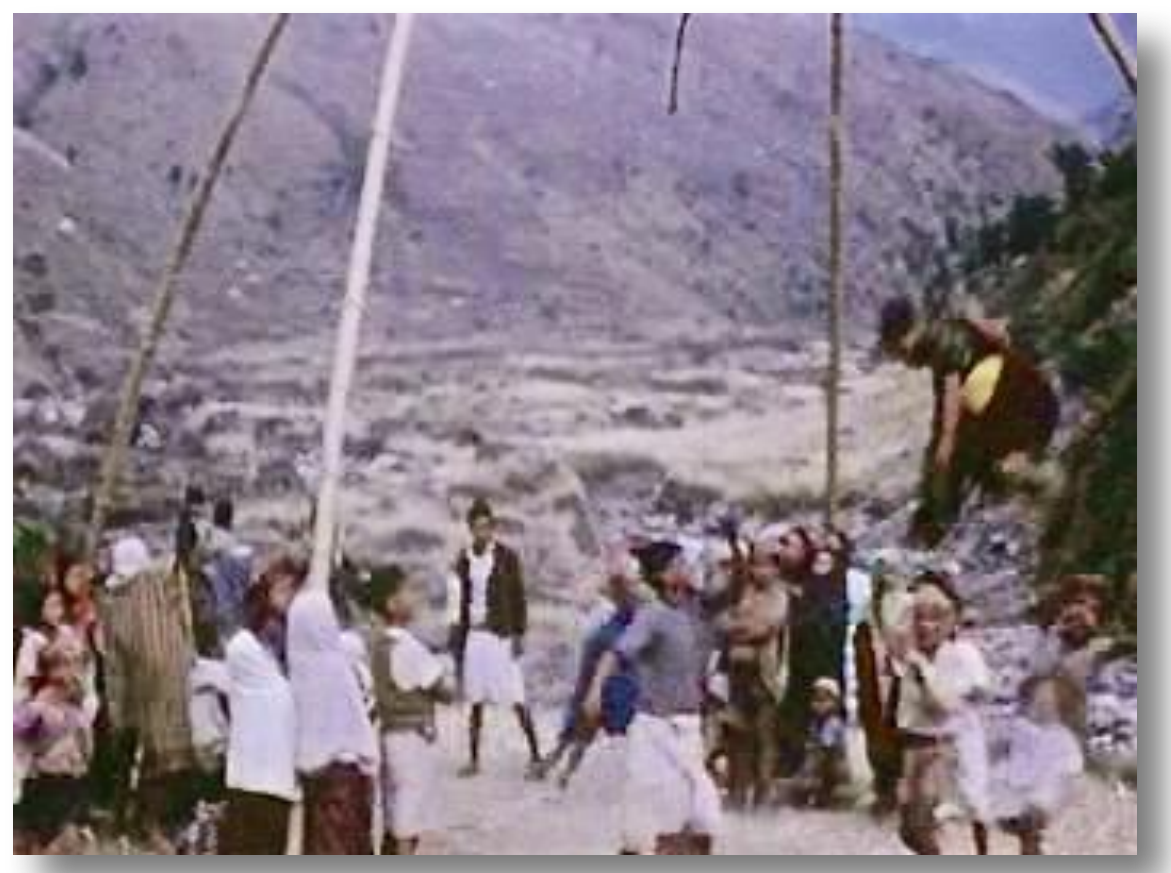

Dessain swing

Film taken by Prem at a 'pae lava' https://sms.cam.ac.uk/media/2736224

DIARY GILL Friday 5th December 
Got through breakfast quickly to go down to Bhuwansing's where Tailors were playing away desperately and Bhuwansing was dancing, very gay and happy. Lot of villagers watching, Yangjakot people still under awning. Bhuwansing's brother joined him and there was a lot of joking and pretending asking for money. Tailors very amused. Girls rushing to and fro with breakfast things, rice boiling away in huge cauldron by buffalo shelter. Bhuwansing's mother suddenly burst out to embarrassment of Bhuwansing and there was some covering up laughter but rather awkward. We went in to see 'tika' put on Nundalal's forehead and money given him, mostly by female relations. We were 'tikad' then and had 'pa' and rice rings given and Mrs B. gave a sweet little speech about thinking of her as 'Ama' and Bhuwansing as 'Aba' and how we were to write to her as such. Then some of the women danced inside, Mrs B.'s sister with great gusto and back-slapping, and Gran from house below, someone else losing their nose ring in the foray. Alan a bit constrained as I think he is still fretting about not getting much "life" work done - completed index. We went to sleep after lunch, what with 'pa' and having a late, disturbed night. Woke up feeling very heavy. I struggled out a letter to Leslie, had to go up hill in the middle and rush to loo, but read bit of Lenin among the ferns. Old man before he was 25, started on Marx before he was 18. Had fairly early supper - treat of 'teme' and potatoes. Betta's gran came in and was quite jolly and warm with us - what a difference. Still more dancing down at Bhuwansing's but we didn't feel up to a repeat of last night.

\section{DIARY Saturday 6th December}

Went on indexing, etc. and then went down to Uli where I was given tea and some roasted maize and spent a couple of hours working with Brikaras. Felt more cheerful now that I have decided to get on with work myself if no-one is around. We now usually have about 3-4 people in in the evening. Prem returned cine camera having taken half a film. Took some photos of bride and family at Bhuwansing's.

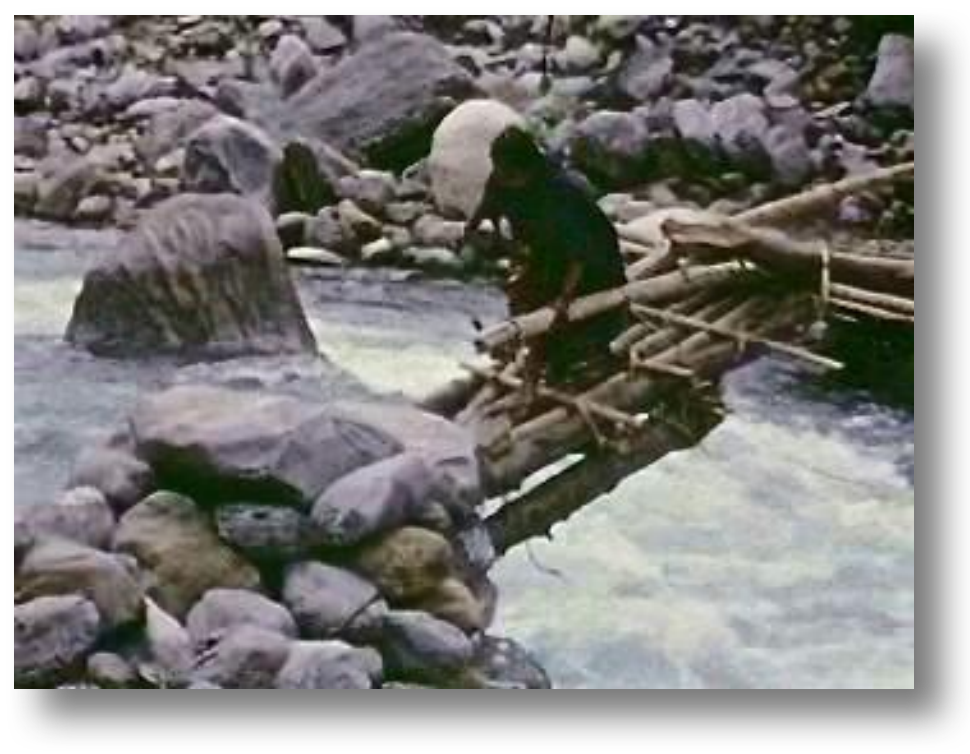

FILM. People crossing a bamboo and wood bridge over a rushing stream, the Modi, at Khilang - taken by Prem https://sms.cam.ac.uk/media/2736252 


\section{DIARY GILL SATURDAY 6th December}

Alan went down to take more photos of wedding party - took hours of gentle coaxing to get bride into a sari, apparently, and even then she wouldn't sit next to Nundalal. Mrs B. called her 'sang dzi-dza' which we thought was rather nice! I was busy writing letters to Auntie Don - and at last, Lyn Castro, which I was glad to get off my chest. Had early lunch and Alan went down to Brikaras's with some relief at doing some "proper" work again, I think. Wrote another short note to Tom and then went up my hill, although cold and blue and overcast. My tree with little white bells had sprouted more and saw a hawk against a Leonardo landscape - green, dark and mysterious. Alan still wasn't back when I came down, half expected to find little family of Glovers on doorstep. Bopal helped me do the beans and I made "goose cakes" which were a new fiddly but tasty.

\section{DIARY Sunday 7th December}

Spent morning on input/output analysis and then went down for afternoon to Brikaras where did as yesterday. Expecting the Glovers today, but no sign of them. Covered up the rice 'bagari' properly after struggle and the rats less troublesome. Did no reading. Lt. brought us a bowl of meat. Gill more cheerful.

\section{DIARY GILL Sunday 7th December}

Spent day writing what I hope was an amusing version of wedding to Iris and co. Alan worked out more analyses and then went to see Brikaras again in the afternoon. Rather gory information on infanticide and who had last killed babies, etc. I found this a bit shattering especially when I know how fond of babies they are. But as Alan says, they don't strictly regard them as human beings at such a stage. Read "Tin Drum" after lunch, since death of the mother it has got even more inhuman - perhaps to keep march with inhuman political events. Hitler is now in power. Wrote to Anne and said how pleased I was about Bob. Thought I had better wait in in case Glovers came. Bhuwansing brought a bowl of goat meat. Alan pleased with afternoon's work. Had easy evening, just Nainasing full of aches and colds. Another 'tetara sheba' at the Blacksmiths. Got a cold again but otherwise feel quite cheerful even with prospect of Mohoriya. Great fun about building a wall around Pot's temple - she is shrieking away, morning and evening now.

\section{Letter from Gill to Alan's family on 7th December 1969}

Have just been struggling with the rice baskets in the loft, to try to make them rat-proof; since the harvest has been in we have had what sound like monsters thundering down the main beam every night, leaping joyfully onto the feeble wire netting (ours) covering the baskets and frolicking about throughout the early hours, squeaking us and themselves to distraction. We might be having visitors tonight too, the couple with the two children who are working on the language in another Gurung village, and as fessie seemed put out by one minute nibbler in the Pokhara hotel where we stayed together, heaven knows what she will make of our army. I'm pretty sure they never come down to the floor and nibble at us, but she has an 8 month baby to consider, so this must make one a little more anxious...

...We go to Pokhara on 11th... This is prior to living in Pignede's village for a few weeks. In my stuck-in-themuddish way am not wildly looking forward to this, mainly the prospect of being gawped at ad infinitum all over again, but maybe they won't feel much like it as we have heard they have lost the whole of their rice crop. They might not even want white people as it has been known after a crop failure that strangers weren't allowed in the village. We are also going to visit an agricultural project run by the British Army, which A. is particularly interested in. They are in the midst of building a 'model farm' with help from ex-Gurkhas, 
encouraging fruit growing etc. We must try not to be mean and sceptical, having met the couple involved this is a bit difficult, they hadn't bothered to find out a thing about the Gurungs, and almost seem afraid of them, not having any contact with the village and speaking neither Gurung nor Nepali.

Meanwhile everything is much the same in Thak. We have had a lively wedding since we last wrote, but informants are thin on the ground at the moment... We have also lost more money than at first thought and the culprit shows no sign of returning it, only appearing distracted and spotty in our courtyard every three days or so, sporting new striped shirts or black creaky shoes sizes too big for him...

...I had a bout of food poisoning (Chinese pilchards!) after I last wrote which rather took it out of me for a few days, but A. was perfectly alright thank heavens...

The wedding was that of Bhuwansing's son, the Lt. who has been so kind to us, and who was intent on getting his eldest son married off during his 6-month leave from the army. This is quite a common marriage pattern we have found. The daughter, by the way, who ran off to get married to a doubtful case in another village, returned with her tail between her legs saying loudly to me that I must wear red bangles since I was married, all the while jangling a whole armful of her own at me, but there is no husband around and an attempted reconciliation with Bhuwansing and wife resulted in both refusing to speak to the prospective husband's parents, who had apparently come down to try and sort things out. This is such a pity as Dankumari is far too intelligent and strong willed for any of our feeble youths, and she would be an ideal wife, running her own family with a flare when Mrs B. is away - like she was before the wedding, as the bride came from the village she was born in, so prospective bride and mother-in-law came back in the wedding procession together. There had been some strain before this as several prospective candidates let them down, Bhuwansing setting himself about ten days in which to find the bride and leaping up and down the entire valley, apparently in vain, letters following after him saying that this girl had cried all night and was refusing to come, so the parents weren't pushing her. Bhuwansing also come to borrow money from us, but we could only lend him 50 because of our domestic mishaps, but what struck us was the complete ad hoc arrangements behind the marriage - so much for carefully calculated multilateral cross cousin marriages!

We went down in the afternoon the bride was supposed to have arrived, and there was the bridegroom in black satin shorts and a white string vest sweeping the courtyard, and the women were chatting over cutting up the radishes, Bhuwansing's brothers erecting a sort of rice mat marquee and the village schoolmaster sitting cross-legged cutting up pieces of white paper for a 'Welcome' sign to pin onto creased red cloth and suspend over the doorway, two baby banana trees holding it up! This, and getting huge cauldrons (again borrowed) of rice, and a buffalo and goat organized for killing, took up the whole afternoon, apart from washing Kaji (the youngest girl, aged three) and putting oil and a new red ribbon in her hair. Everyone took about half the time up by scanning the opposite hillside where the wedding procession was supposed to be marching, saying "Can you see them? Have they set off yet?", confusing trees and boulders for the bride in a white coverlet and her retinue of protective maidens. We wouldn't have been surprised if no party had turned up at all, and neither would Bhuwansing, I think, moody and anxious, scanning the horizon and saying what 'achaba mih' (bad people) they were, not to have set off yet. Alan didn't help matters by producing binoculars with only one lens working (a relic of army days from another boy in the village) and this added to sight confusion ever more.

Eventually we were invited in for 'pah' (beer) and rice rings, which we ate with relish despite a buffalo's head spilling out its contents on the wall next to me and the men coming in holding the hindquarters by the tail and sticking the whole up in the rafters. I'm afraid I even enjoyed liver just roasted on the tripod, Bhuwansing's wife's sister was helping whilst the mother was away, and was very hearty and back-slapping, loading us with endless goodies. Warm and reeling from the 'pah' we went down to meet the party, now pitch black and the guns very likely to kill us or the wedding party, the guns and the Tailors' horns wheezing and popping at every opportunity. When the bride did come, carried on someone's back the entire walk and smothered in her coverlet, we all pretended not to notice, nothing was said, the musicians only started upwards again and a few desultory torches lit the way, the bride very likely to tumble down a cliff or something else very Walter Scottian. About fifty or so from her village had also come, and these ranged themselves under the marquee, and the Thak people were facing them, silently, on the verandah, for all the world as if a battle were about to take place. We didn't even get a glimpse of the bride until well into the next day, peeping and coy behind her headcloth, tenaciously guarded by maidens, three flanks deep - neither did the bridegroom, which must have been even more frustrating. 
There was dancing by the Yangjakot people the first evening, pretty youths in white trousers and black leather belts, rather restrained because of being on foreign soil, although the audience was packed, but loudly saying it was only a 'middling' performance. The next morning was more lively with our own Tailors playing and Bhuwansing himself dancing and the back-slapping aunt whacking us even more on a morning's 'pah', and Mrs B. putting tikas on our foreheads, the milk running down A. 's nose which rather spoilt the solemnity of it all - we all got quite tearful too, result of the 'pah' and Mrs B. saying we had to regard her as our 'Ama' (mother) and we seemed like her children to her. Then the old ladies danced in the house, skirts flying and nose rings getting lost in the fray, all very jolly and kind and warmth-making! We took endless slightly drunken photos, so I hope you will get a flavour of it when we get home...

\section{DIARY Monday 8th December}

A cold day with no sun. Wrote a combined letter home in the morning, then poju came in at about 11.30 and returned 100rs. (for that stolen). We finished off the 'Bunxavhole' book in the afternoon - tailed off a bit in interest - and then I thought I'd quickly check 2nd marriages in the Census. But soon found that the Census was so inaccurate that I had to check the whole thing - so have got to no. 10 with all sorts of new information. Rats awful in the night.

\section{DIARY GILL Monday 8th December}

Alan wrote to his parents in the morning, using the typewriter so I did their Christmas cards very pleased with them when finished, although fiddly to do. Poju and wife interrupted us - to give some 'pasagi' and a 100rs. note and Alan some work on book! Pleased about note, he will work for the rest. Wife looked at photos and we made it a cosy social visit. Had late lunch and then Alan went on with poju and I went down to Bhuwansing's and ground black pepper. Also took my sari but Dankumari wasn't there. Always people in for a chat and a cup of tea gave me a very peppery one, and one Antheba took over the grinding when she saw how feeble I was at it - very sweet! Did wear my wrist out, took about an hour. Alan getting vital information from poju when I got back, had to revise whole of census. My boyfriend came in for the first time in weeks and was quite jolly, wanting Alan to take a documentary of him! Had altercation with Comal over bananas where he said blithely I was lieing which made me wild. Interesting now adults equally consider children's part. Very coldy.

\section{DIARY Tuesday 9th December}

Overcast with sunny intervals. Went down to Uli and did about one and a half hours with Brikaras before Pot. and others came down. Then went to Chyan where poju was doing a 'moshi tiba'. Took some photographs and cine. Then after going up for lunch and a tearful session with Gill who had a bad cold and was desperately fighting with how to wear a sari, we went down to 'moshi tiba' again and stayed there until about $10 \mathrm{pm}$. We ate there, took flashes, and went to watch them firing arrows, etc. The novelty of these extraordinary rites had worn off a little, but it was still most dramatic. 


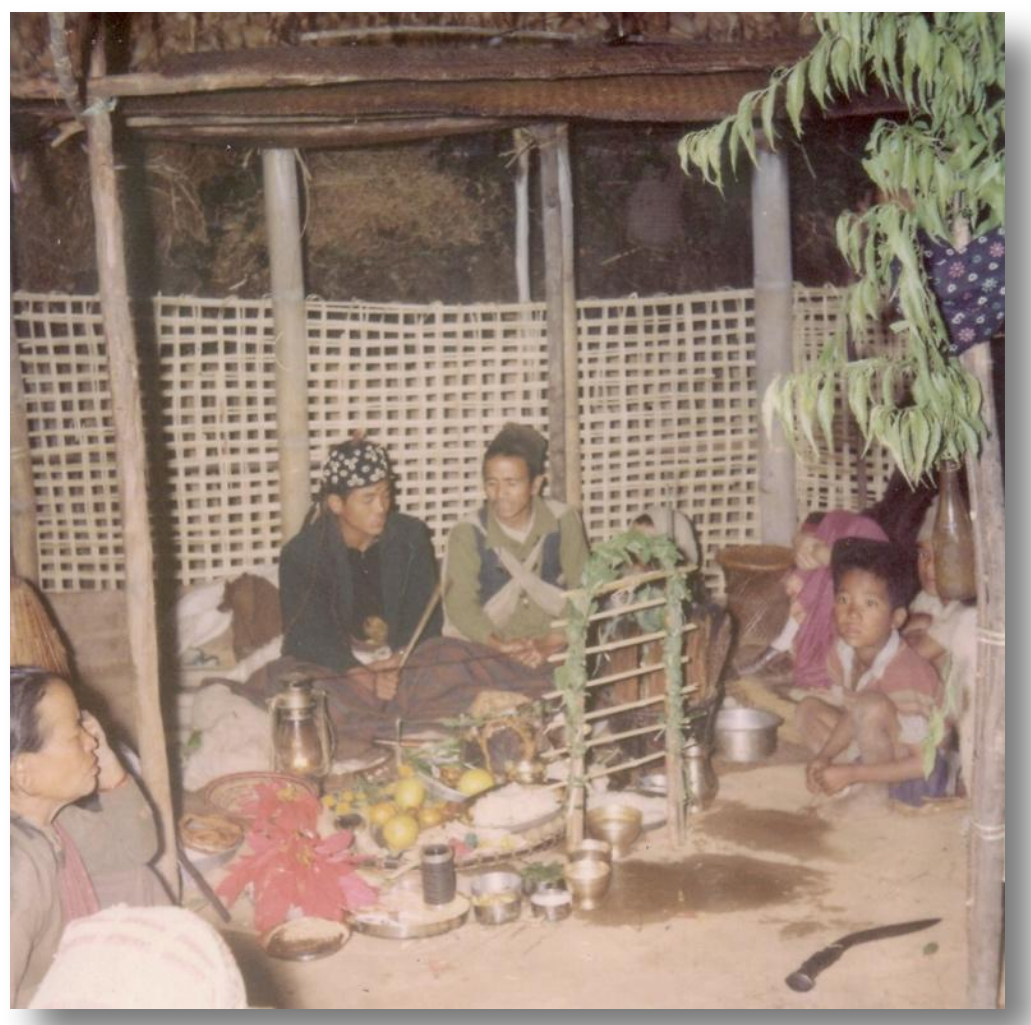

Poju performing 'Moshi tiba' at house 84 - 9th December

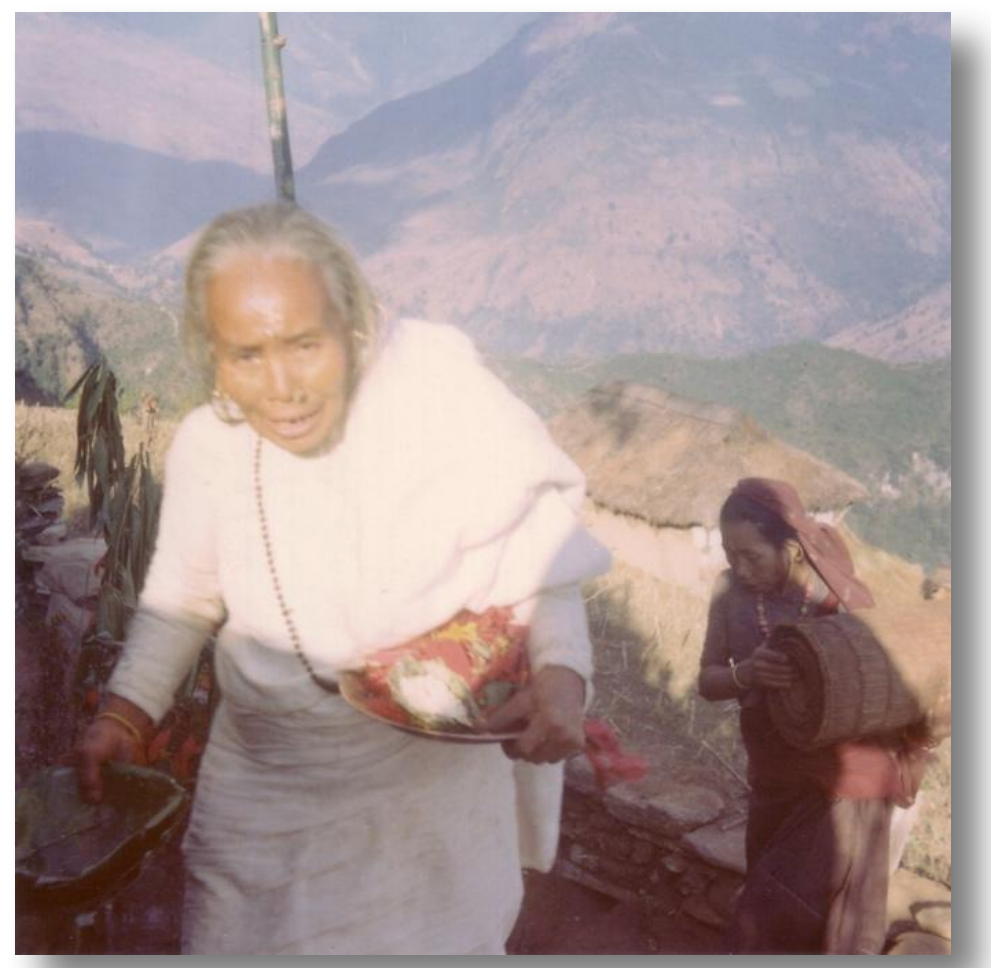

Women arriving for 'Moshi tiba' 


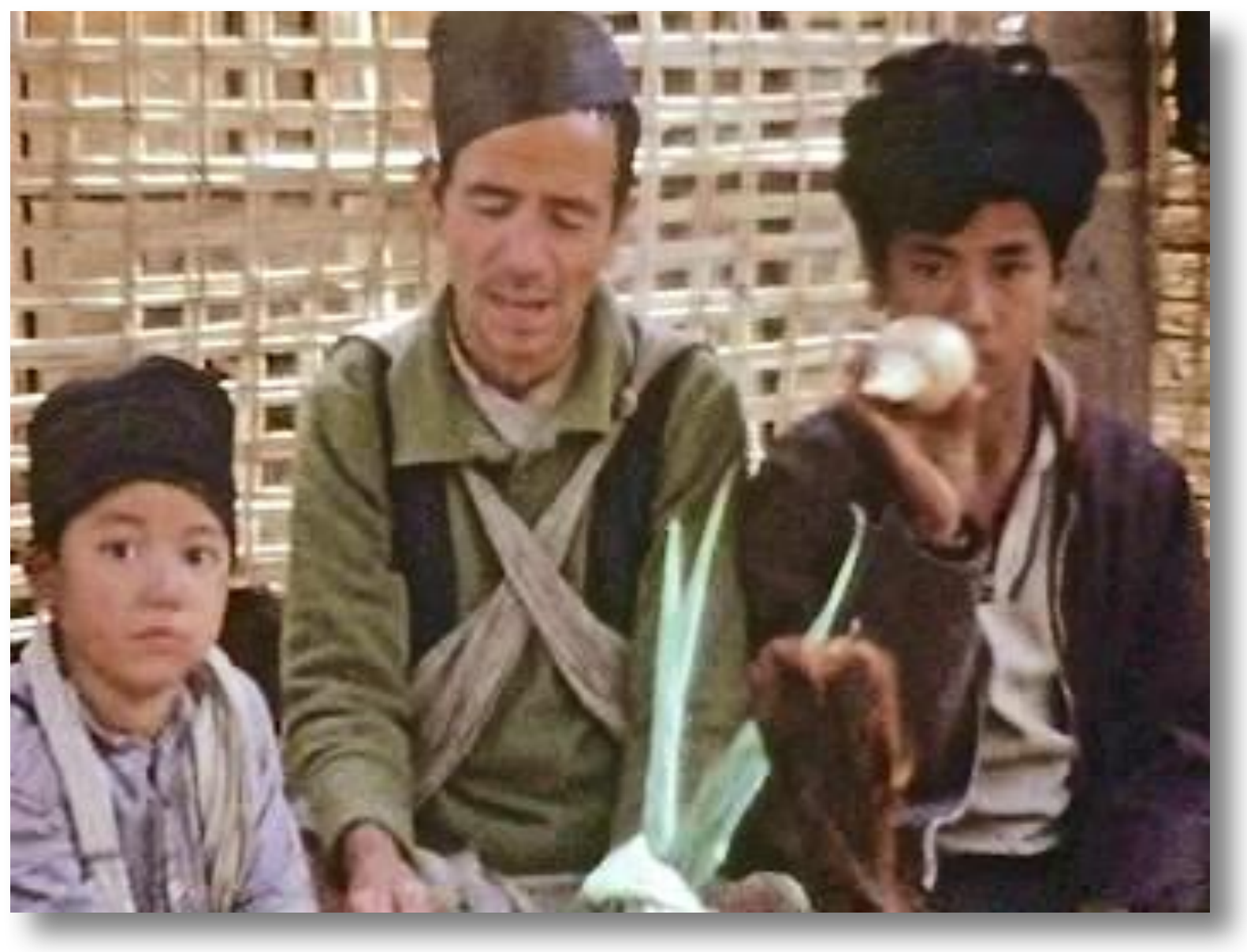

FILM. Poju and his sons doing a 'moshi tiba' for a dead girl at House84 https://sms.cam.ac.uk/media/2736280

DIARY GILL Tuesday 9th December

Had shocking night with rats rampant - saw one quite clear, a huge creamish-brown monster. Alan chasing them all over with torch. Also my cold not improving. However had prospect of a 'Moshi Tiba' which poju was doing all day at the house where the girl died, falling over a cliff. I went down to Bhuwansing's again with my wretched sari and spent about an hour with Dankumari teaching me the pleating, etc. - she was very patient and intelligent. Numerous men crowded to the door, which didn't help. Also wearing my clomping brown shoes was at odds with all. Spent the rest of the morning writing to M \& D. Alan at Uli and filming rite. We went down about $3.30 \mathrm{pm}$. after I had struggled with wretched sari reducing me to tears and Alan to bad temper wasting both our times. However struggled down hill in it and the Gurungs very sweet. Rite as usual quite exciting with egg throwing, drumming, cymbals, gun shooting, arrows flying. Lovely rice trays full of goodies for the girl - mother and sister very upset. Also kind of 'ala' made and then thrown away. After this the fire rite with 'pa' and oil held outside. Dramatic, though only Maldosing marring things by his goofiness and clumsiness. We ate rice down there too - they were very kind although Alan couldn't bring himself to eat goat meat which had been gambolling around earlier. We came back with poju by torchlight at $10.15 \mathrm{pm}$. Very tired but nice day. 


\section{Letter from Gill on 9th December}

...we go down this Friday prior to living in another village for ten days, a little over two days walk from Pokhara and one where a study was done by a Frenchman in 1958, whose book we have translated and whose facts we want to check, and see what the major changes have been over the last ten years. I am not especially looking forward to it, you know how incorrigibly stuck in the mud I am, mainly because of the prospect of being gaped at ad infinitum all over again, we have just about got the whole of Thak used to our presence, so starting all over again with another set of villagers might be a bit of a strain: still ten days will hardly kill us. We are also visiting an agricultural project based on another Gurung village on the way, financed by the British Army and run by a middle-aged British couple we have met briefly in Pokhara. They are encouraging fruit growing and the like, and fencing off crops to prevent the animals getting at them. They are used to ex-Gurkha officers but none of the ordinary villagers, neither do they speak Gurung or Nepali, so we must try not to be mean and sceptical of their efforts. The couple were ten years in Africa prior to this, and are missing that country I think, Mrs Flack seems to find it hard to settle here, for which I don't blame her. We might also go and stay with the Glovers, the Australian couple I have spoken of before, they were supposed to be coming here round this time, but no sign of them, the children must hamper getting about a lot.

For the first time in the village I am sitting around in a sari, a 13/6d I bought in Pokhara, quite pretty, a wine colour with yellow and blue embroidery on it and fairly warm, for which I am grateful as it is so cold at the moment, and we are sitting huddled in the loft swathed in anoraks and duffle coats. I suppose its like early September in England, with the sun occasionally breaking through, but we find it terribly cold, I wonder if we will have difficulty in adjusting to temperatures when we get home? I spent an hour down at one of the Gurung girl's houses and she was very patient in teaching me how to wear it, terribly complicated at first with all sorts of taboos about wearing it right to left and so on, also the pleating in finicky and they do it with such speed that it is hard to follow. However, I managed to do it on my own when I came back to the loft, no one to admire me unfortunately as Alan is down in the village with and informant, but the villagers were very sweet, even the men crowding to the door to appreciate everything!

Our arrangements generally are that we leave here in about eight weeks time on February 4th, fly to Kathmandu, spend a few days there and then take a bus into India, which should be interesting and cheaper than flying, and get to Assam by rail. Alan has written to some old tea garden acquaintances of Iris's so we are hoping that we might be able to stay with them in Shillong and travel around seeing some of the Indian villages. Then we go by rail again to Calcutta and we fly from there to Tehran on February 25th...

Rather coldy and sniffy at the moment due to the weather, I think, the poor Gurungs are much more frozen and coldy, clutching their scraggy cotton skirts to them complaining of the number of sweaters we have, I'm glad they don't know how many we've left behind. I also had an acute attack of food poisoning about ten days ago (Chinese tinned pilchards, sounds lethal and it was, although Alan was fine, thank goodness, and marvellous in nursing me). However, my tummy is fine now, although it did take it out of me for a few days. Alan has been a little fretful re work as whenever he goes out to check some material the men are busy going off to the forest to get grasses for thatching, or going off to funerals in other villages. Also there is no major topic to work on and merely checking can be tedious, so true to form, he has started planning the actual thesis itself and has already indexed all material so far gathered in the field. We have had a wedding to liven things up, our favourite family in the village, the Lt. who was in the British Army, decided to get their eldest son married off whilst he is on leave, he has followed in his father's footsteps, and did it all in about ten days flat! Several prospective brides refused to come so in the end it amounted to two days and on the actual day no one was very sure whether the wedding party would come at all. This would have been awful as a buffalo and a goat had been killed, rice boiled outside in huge cauldrons for fifty people, and endless radishes cut up and bottles of 'pa' bought. The courtyard had been swept with a broom by the bridegroom himself dressed in black satin shorts and white string vest, and the village schoolmaster had cut a 'Welcome' sign out in white paper and pinned it onto a very creased red cloth and then put it between two wobbly baby bamboo trees, dug up for the day and put at the doorway. A rice mat marquee was also made, but the party didn't come until nightfall despite everything, and we went to meet the procession by the temple, and the Tailors played their horns and pipes, wheezing away every time a gun wasn't exploding, traditional way of welcoming the bride. At last they arrived, everyone pretending not to 
notice the fact even though they had been waiting for this event for five hours, and the bridegroom lit the way with a desultory torch and the bride was carried on someone else's back swathed in a white sleeping coverlet and not letting her prospective husband get a glimpse of her for days, guarded by a tenacious retinue of maidens. Next day and that evening there was lots of dancing and ' $p a^{\prime}$ drunk, and we got slightly woozy and were slapped on the back and loaded with rice goodies by hearty, plump aunts who had come for the occasion, and it was all great fun. There is no religious ceremony, just parents and in-laws putting tika marks (rice mixed with milk) on the couple's foreheads. (cont.)

This afternoon we are going down to see one of the poju's biggest rites, held for a girl who died a few weeks ago by falling over a cliff. We know the family from another rite we watched there, when the girl was still alive, so it will be very sad going again, but we have checked the family don't mind. The rite is being held as all those dying an accidental death are in danger of their souls turning into evil, avenging spirits.

\section{DIARY Wednesday 10th December}

Very cold day, from lunch onwards. Gill worked at washing in morning while I finished checking the Census and did a little other work with poju. Otherwise quiet - though Pot's. post-funeral preparations beginning to warm up.

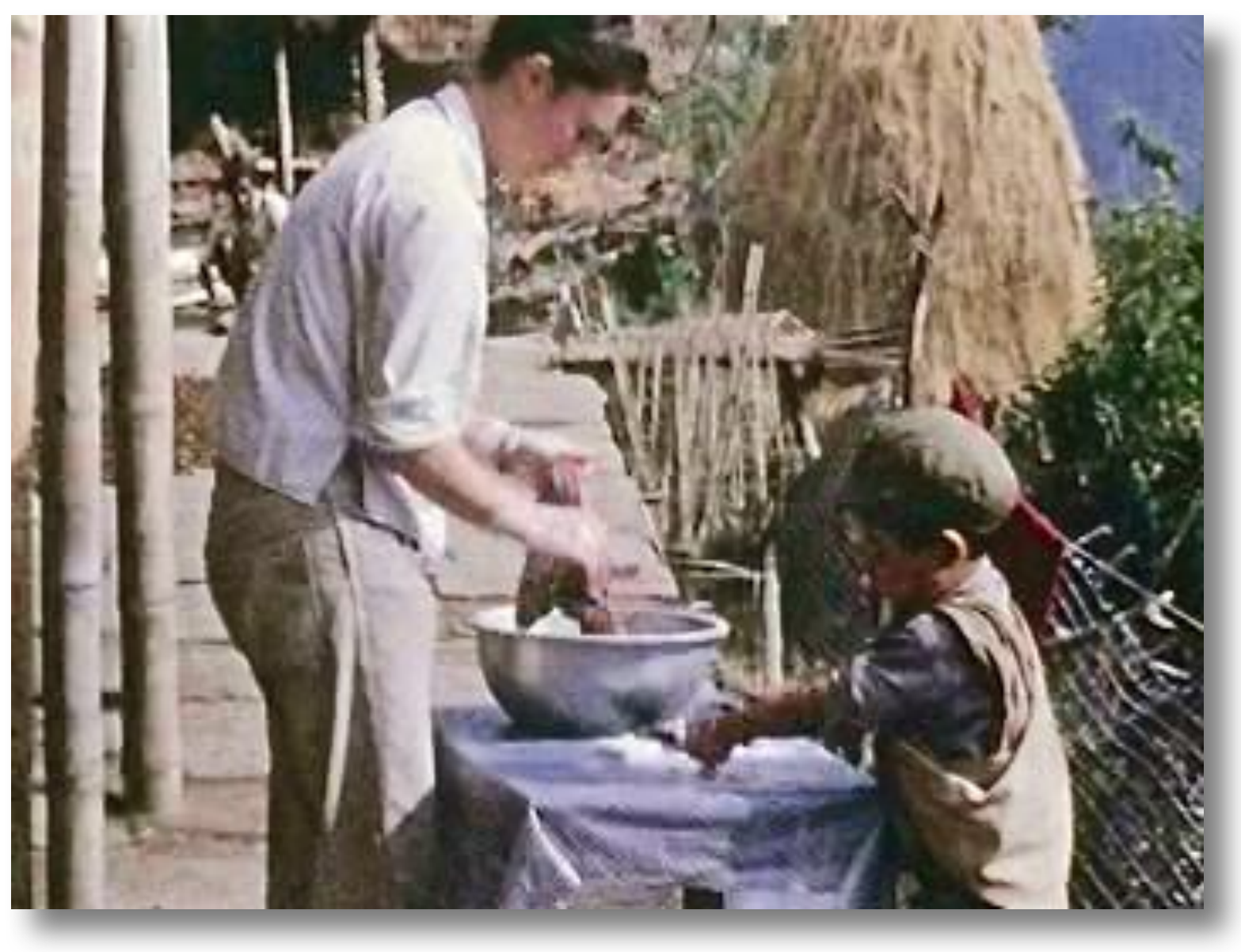

FILM. Bopal helping Gill with washing https://sms.cam.ac.uk/media/2736308 


\section{DIARY GILL Wednesday 10th December}

Some early sun, washed all morning with help of Bopal who did the hankies - very well, I might add. Had endless people to watch and children in - even when I was doing lunch. Had Kaji sitting on my knee when I was frying the egg-plants, Gopal's mother asking for contraceptives, and Kaji putting the egg shells away for me. Alan was in the loft checking census with poju and then Nansubar crowned it all by asking to buy some cigarettes - the fourth that day. Bit wearied but had good lunch and read "Tin Drum" - against my note I have got caught up with it and can even appreciate writing - the subject matter rather blocked appreciation before. Read Kardiner and then got early supper as had masses of potatoes to peel - using them up. Maldosing came down to ask for medicine for his mother and then just as we were getting into our sleeping bags, Gopal's mother came again and Alan had to explain by lamp and in his pyjamas the vagaries of contraceptives. Cold rest of day and washing still sopping wet - also my cold worse. Woke at $1.00 \mathrm{pm}$. with sore throat and didn't have a particularly good sleep after that.

\section{DIARY Thursday 11 th December}

Packed this away in afternoon - after missing Pots. 2nd burial rites. In evening couldn't sleep because of row made by combined Gurung/Brahmin dance/songs so went up to watch (and sing "Hey Lordy") for a couple of hours. Still couldn't sleep when I returned as Brahmins played all night.

\section{DIARY GILL Thursday 11 th December}

Managed to dry off washing, we organized packing in afternoon and managed to miss Pot's. puja - went up when they were all coming away - felt slightly foolish and guilty and rude - not a calming trio! Alan more put out than I but that was probably because he has been so much in his good favour recently and for us to do something "wrong" upsets balance! Terrible racket at night by Brahmins, just behind here - drumming and tambourines, had two tunes and played them all night with half-hour rests so just getting off to sleep and woken up again even though we slept downstairs. Alan went up to join the Gurungs at some point, with the guitar and spoons - to their delight, and didn't come in until 2.00am. Had about three hours sleep in all - rats knocking washing-up scrubber off.

\section{Letter from Gill on 11th December - continued from letter of 9th December}

Well, we had quite an exciting time at the above, Alan taking quite a few flash photos of the poju drumming and calling down the wandering spirit by twanging on a bow. There was a lovely tray of foodstuffs offered up to the dead girl, full of oranges and huge oval lemons, coloured rice goodies, pink and blue, eggs and brass bowls full of milk. Foss sticks were stuck in the lemons and the smoke drifted past the lighted lantern and made patterns against the vibrating bow, and what with the colours of the fruit, clashing of cymbals and smell of the incense it was quite beautiful. They had a little tree in front of all the food, with the girl's head cloth attached to it, and a bottle full of ' $p a$ ', and at the end when a chicken had been sacrificed, the tree was torn up and the poju and his assistant, jangling with bells which he wore round his waist, went off to a nearby cliff, drumming and clashing the cymbals, shot an arrow through the tree and then threw it away, the hills purple smudges in the darkness and the stars only a pale overcast glimmer above.

We all went back to the house and yet another rite, which was supposed to clear the house of evil in the future. This consisted in pouring oil over the boiling ' $p a^{\prime}$ alcohol and flames shooting up in one dramatic whoosh, and consuming the paper with the names of all those who had been made sick by evil spirits. This was done several times and then the poju and others danced slowly round the dieing fire, breaking off the stick which 
had held the piece of paper into the fire as well, clashing cymbals and drumming with an open ended drum. it is amazing how we take this sort of thing for granted now, but I did suddenly think what another person's reaction would have been just coming across this scene in the courtyard, the three figures slowly circling and playing their way round the embers of the fire, a pot blackened and scarred with the heat from the ' $p a$ ' and oil, and the poju's instruments ranged on a rice tray - little square baskets full of peacock's feathers, skulls of birds and pieces of dried white bamboo twisted into symbolic shapes...After all this the family were sweet and hospitable as always and gave us rice and goat meat just boiled over another fire, as there had been a goat sacrifice as well, the smell of burnt fur still heavy in the air and the sparks shooting up like orange snakes every time they turned the goat over it. We tottered back up the hill with poju and family and found it was $10.15 \mathrm{pm}$ when we got back, and we had set off about $3 p m$.

Before I get carried away with the above I mustn't forget to ask you whether you could possible give us dates of all letters received from us, as we will then destroy the corresponding carbons here and this will mean there will be less to carry. Also, if you can remember, could you give a brief description of all the slides so far seen so we can take more of certain scenes if these have not come out. We are going to do a lot of filming in our last month here, so we can fill in the gaps then...

I am just about to cook lunch, spinach, fried rice with egg plant, tomatoes and onions and fired eggs, as we are using everything up, and then we shall go up the hill where they are holding a puja for a holy man of the village buried in one of his maize fields. We then have to pack for Pokhara and our trip to this other village, we are taking all our food and cooking pots etc., hoping to get another house during our ten day stay, We set off on Monday and will probably spend Christmas there. Tomorrow we walk to Pokhara and will draw breath there over the weekend - it is very nearly a year ago that we arrived!

\section{DIARY Friday 12th December - Pokhara}

Sent Goof and friend off with two loads for Lumle: chaos as usual with odd Germans, people with bad burns, etc. all turning up at the crucial moment. At last got off and had an easy walk down. Delightful to get 12 letters and Josselin proofs and magazines from Mary McCullough and food parcel from Mummy. Stayed at Parbat as usual and ate at "Moganbo" with the usual cuisine, etc.

\section{DIARY GILL Friday 12th December - Pokhara}

Being so tired, I thought walk down might be rather grim, but in fact it was easiest walk yet everything being so dry and not yet hot. Porters went off to Lumle straight away with minimum of fuss and we only filled 2 baskets with medium weight. Prem was in way hanging round but he is coming to Pokhara on Sunday. Omkumari thought I was going finally and rushed down - but others were very calm. Hope Alan won't be too upset by our cool send-off. Met German boy going up to Siklis studying architecture and he asked me to look up his wife, who was expecting a baby in Pokhara. We got down about $1.30 \mathrm{pm}$. and there were over 10 letters. M. okay and Fiona had William! Also Mary's articles came through with one from her. So excited by post, possibility of seeing Glovers who were down, gossip and chat at the "Mogambo" (this not so nice - pulling people reputationally to bits as if this were only way of making group of us). Also met German boy's wife, who is sweet, forthright and uncomplicated and loves it here - all very refreshing. Result of all this was didn't sleep much again. I wrote an article for social work in my head. Ira gone to Ceylon, which is sad.

Letter from Alan to all his family on 12th December 1969

... The weather is getting decidedly colder and we sit wrapped up in the loft; days are also very short and we sleep for about 11 hours a night, as there is nothing much else to do... The villagers are just entering into the long winter slack season. The last of the rice has been sweated up to the village, and the millet has been 
harvested and the village still resounds to the thumping as they beat it with sticks and tread it to get the little grains off. Groups go up to the forest each day to cut bamboo canes to make fencing with and tottering piles of long, beautiful, grass pass us on the hill - destined to become new thatching. Otherwise things are much as even; little children bringing endless supplies of beans and spinach, the water pipe breaking every few says and no one doing much about it, the schoolmasters off at another village gambling (supposedly watching a funeral) while school exams are supposed to have started. Our one excursion was up into the nearer forest on a grey, misty, autumnal day to watch them digging up toya (yams.') and to look at one of the old temples. It was very old, creeper infested, forest and reminded me of Assam; apparently a bear was seen where we had our picnic and Cadbury's chocolate, yesterday. We have been taking cine and stills of these various activities so hope we can bore you with them. Now off, via Pokhara, for three weeks. Will be finally leaving Pokhara on about 6th February and, via Assam, reaching Calcutta on about 20th February, leaving about 25th...

DIARY Saturday 13th December - Pokhara

Checked Josselin proofs and went over to see Leprasorium in afternoon and showed round agriculture.

\section{DIARY GILL Saturday 13th December - Pokhara}

Felt very tired with so much sinus and phlegm. Spent morning lazing, adding onto letters, whilst Alan read his proofs. I think it looks a very exciting little book - even Alan pleased with it! Went to leprasorium p.m. and were shown round by pleasant agriculturalist (Brian Mede) who was sane on subject of missionaries, but still is one. Atmosphere very cosy and relaxed and not as grim as expected/(hoped? visions of G. Greene). Christine (Swiss girl) came with us as she might get a job there - (physiotherapy) after she has had her baby in April. We were shown round newly built operating theatre - discussed world pollution. Aguila etc. lolling on sides! Got no tea - cold when sun sets. Had tasteless meal at Himalaya and met a grim/cosy Finnish missionary working at Gurkhas. Frightening combination of intensity and shyness and (almost) malignancy. He had worked for a famous Finnish architect until she was converted at 39. Is now 55, worked 3 years in French Congo. Alan went away fearing to get involved in a religious argument. In morning met Marion again with baby, who looked very well and invited us vaguely over. Washed my hair - that was good!

\section{DIARY Sunday 14th December - Pokhara}

Went up to bazaar to see bank and collected a few more letters and cards. Then returned and wrote letters while Gill went to talk to Marion at the lake.

\section{DIARY GILL Sunday 14th December - Pokhara}

Bit dazzled and confused by all article reading - it always makes England seem such an incredibly small world. Went shopping and to bank, and picked up 5 more letters! - Xmas cards - Iris re. William. Arranged money, had late picnic lunch at hotel and then Alan walked me to lake to see Marion. I had forgotten how pretty hotel was. Irritated with Marion, possibly because she was calmer than I thought! but she is getting obsessive about who was swathed to death, and edgy - arguing with Fred I found uncomfortable, as I wouldn't exist in that sort of atmosphere. Marion is reckoning on 2 years but has no interest whatsoever in hotel/me/anyone except herself and the baby who is a direct extension of herself. Felt, in my equally unselfish way, that it was a waste of time going to see her and she upsets me despite precautions - to be shown so blatantly how she couldn't care less is a bit crushing. Honest I 
suppose. Had early meal and talked to a South African from Durban in British Army in Calcutta - rather gorgeous super laid back type - ticked by his vocal - "bored" = frustrated/miserable/pointless - "a good thumping" = killing 25 people who happened to be on opposite side off. Kindly offered to let us stay in Calcutta. Wife withdrawn and pretty.

\title{
Letter from Gill, in Pokhara, on 14th December 1969
}

\begin{abstract}
... Having our usual Pokhara time of buggy beds and Tibetan prayer flags, interspersed with Finnish missionaries, gentle white-haired ladies of 55 one could suddenly imaging burning heathens at the stake for nonbelief, and solid pregnant Swiss girls, indestructibly sane knitting gloves for husbands' Sherpa informants. Visited leprosy hospital yesterday, cosy and relaxed with a new pukk operating theatre just built (where did you get the money from? Three year's prayer). British mission run it, called a rather sickly 'Green Pastures' saw agriculturalist appropriately, who showed us round the shrubby, boulder filled 30 acres and was first mission person to half-admit that missionaries might have done more harm than good. This afternoon going for tea at the new lake hotel owned by 2nd prince - we know the manager and his wife has just returned from the States. (A. is declining to go but the lake should be beautiful, mountains reflected in it every day and the hotel is raft - visited on an island). Tomorrow back to 15 mile treks and approach to this other village...
\end{abstract}

DIARY Monday 15th December - Lumle

Set off for Lumle at 8.00ish but didn't leave Shining Hospital until about 11 o'clock. Much longer walk than we expected and Gill very tired - but beautiful. Arrived about 5.00pm. Prem, also, who came with us, tired. He said he was sad to be alone without anyone he knew and worried about his wife who was sick. Sadly the Flatts were away when we arrived - met about 200 workers streaming off Lumle estate.

\section{DIARY GILL Monday 15th December -Lumle}

Felt tired and old and not at all like walking - quite stiff. But we staggered up at 6 and got to bridge at 8 . No Prem - I went onto library to have my read there. Alan and Prem came later. We called in at a relative of Nani's - who had had typhoid! - very sweet, then went to hospital and confirmed this. Dr Turner couldn't come because he was ill. We then met up with Christine again who had paid a somewhat abortive visit to Sugana. The slog began - pleasant walk with lots of Tibetans singing - sounded like a Bach "Kyrie" at one point - beautiful. But not being fit - very tired - much longer than we thought - didn't get there until after 5.00pm and no Flatts. However tents very comfortable - good meal which they cooked, but Prem miserable in such foreign surroundings - his wife ill and will probably go back with Ramchandra. Really a little boy - slept well and warmly.

\section{DIARY Tuesday 16th December}

Spent a sunny day at Lumle waiting for the Flatts. Walked down to village and later in day toured the "farm" which consisted mostly of nice steps and about 10 half-built houses - few crops as yet. I gather H.M.G. gave 2.5 laks rs. (c.12,000) for the 800 ropanis of land, while O.D.M. gave capital of $£ 87,000$ and will pay the yearly expenses (=? about $£ 10-12,000$ per annum?). Director $=$ Brigadier Richardson. At present the staff about six skilled men (the H.M.G. agriculturalist and another man get 300rs.? per week plus a "hardship" allowance (25rs.? per week) for being out of Kathmandu. Ridiculous if cf. to teachers/postmen/doctors, etc. (Doctor in Mohre gets 300rs. per month). 
I was very dissatisfied with whole set-up and the pat formula of Flatt - though he and Mrs Flatt were kind on a personal level. The non-use of fertilizers (leaf-mould and manure used instead); the attempt to get Nepalis involved; the reliance on labour rather than machines (thus employing about 500 men at moment at $5 \mathrm{rs}$. each) = good. But the whole basic optimism on which it was based seems ludicrous - especially in view of the imminent break-up of the Swiss farm (now torn between Panchayat and Agriculture Ministries). Nor does Flatt who has learnt very little Nepali in 18 months - really appear to know anything whatsoever about local agriculture - eg. what vegetables the villagers already grow; that women do the gardening, etc. Nor has he explored the possibilities of selling his new products. Fruit may not be a bad idea, but it is changes to basic cereals - rice, wheat, maize - that are important. Above all, of course, if one had $£ 150,000$ odd to throw away it is ridiculous spending it on building an expensive institution - much better have demonstration plots in a number of villages with advisors touring round. But above all - how much can such a farm increase Gurung production in next 10 years? - perhaps by 5 percent if one is optimistic. But in that time population will have gone up by $30-40$ percent at least.

\section{DIARY GILL Tuesday 16th December - Lumle}

Felt very chirpy in morning - prospect of a sittable loo within 100 yards! A bit on edge and miserable - anticipating Mohoriya, I think. I had a good morning's wash - lashings of water very soft brought by pipe system from a spring which should get interfered by animals. Calm, relaxing atmosphere with no one staring. Flatts came back at about $1.00 \mathrm{pm}$. - looking well and seemed pleased to see us. Had brought their son from England. Tasted English cheese! went round farm in afternoon and Alan a bit sceptical and silent, so I had to make up for it by bubbling, which I did. I was impressed by his stress on getting Nepalis to do things and take decisions, but Alan thought there were too many flashy buildings and stress was on wrong things - fruit trees, for example. Mrs Flatt (Hazel) was much less on edge and defensive and I think was pleased to have us, although Mr Flatt (John) very taken up with farm and not really able to concentrate on anything else. We had a very pleasant dinner together, they producing some whisky and lamb! from the German farm. Went to bed very warm and cosy. Bit apprehensive about tomorrow.

\section{DIARY Wednesday 17 th December - Mohoriya}

Set off from Lumle - Pradhan Panch having arrived - at about 10.30am. and arrived at Mohre after a nice walk up about 3.00pm. A very steep climb up to the village. Strange to tread in Pignede's footsteps. Nice reception and meal in Pradhan Panch's wife's sister's house and a little loft for us to sleep in. A number of people seemed to remember Pignede and we were lucky to be next to the house of his informant Chandrabahadur, whose elder brother was keen to help us. 


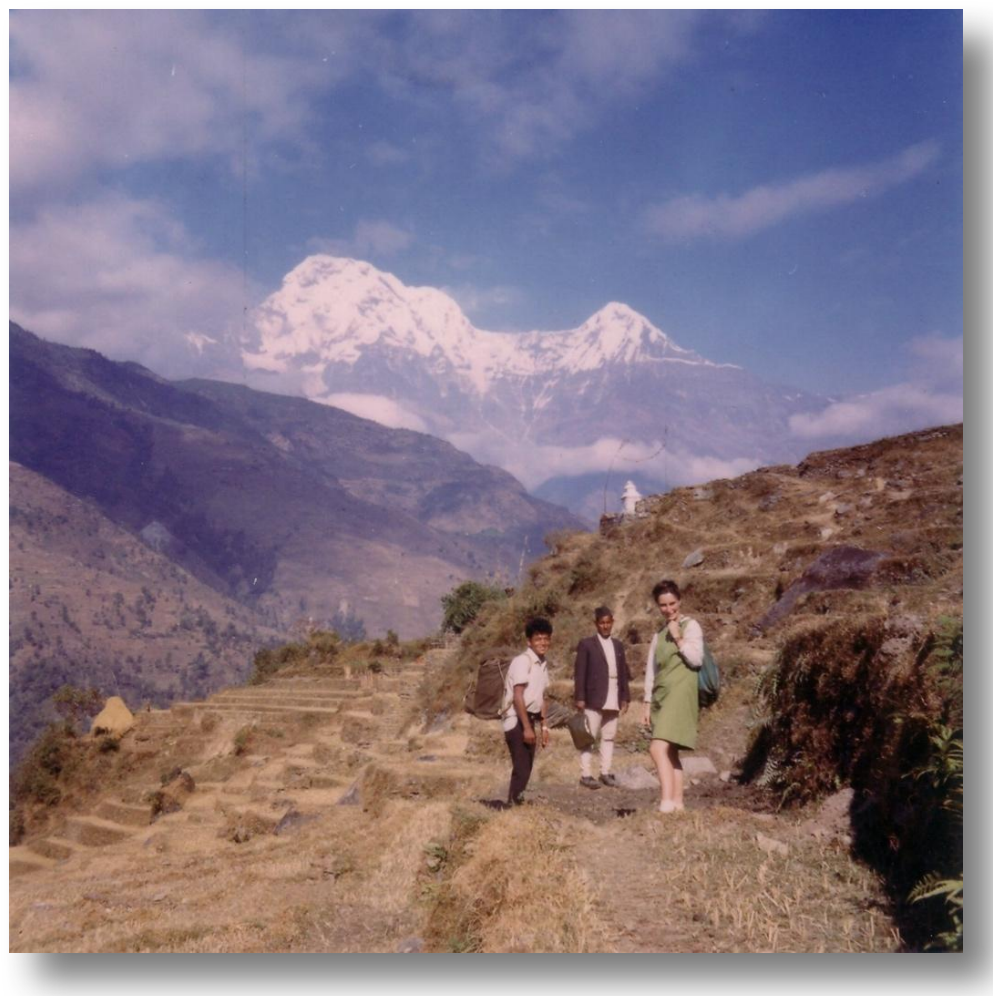

Gill with Prem and Ramchandra on the way to Mohoriya - 17th December

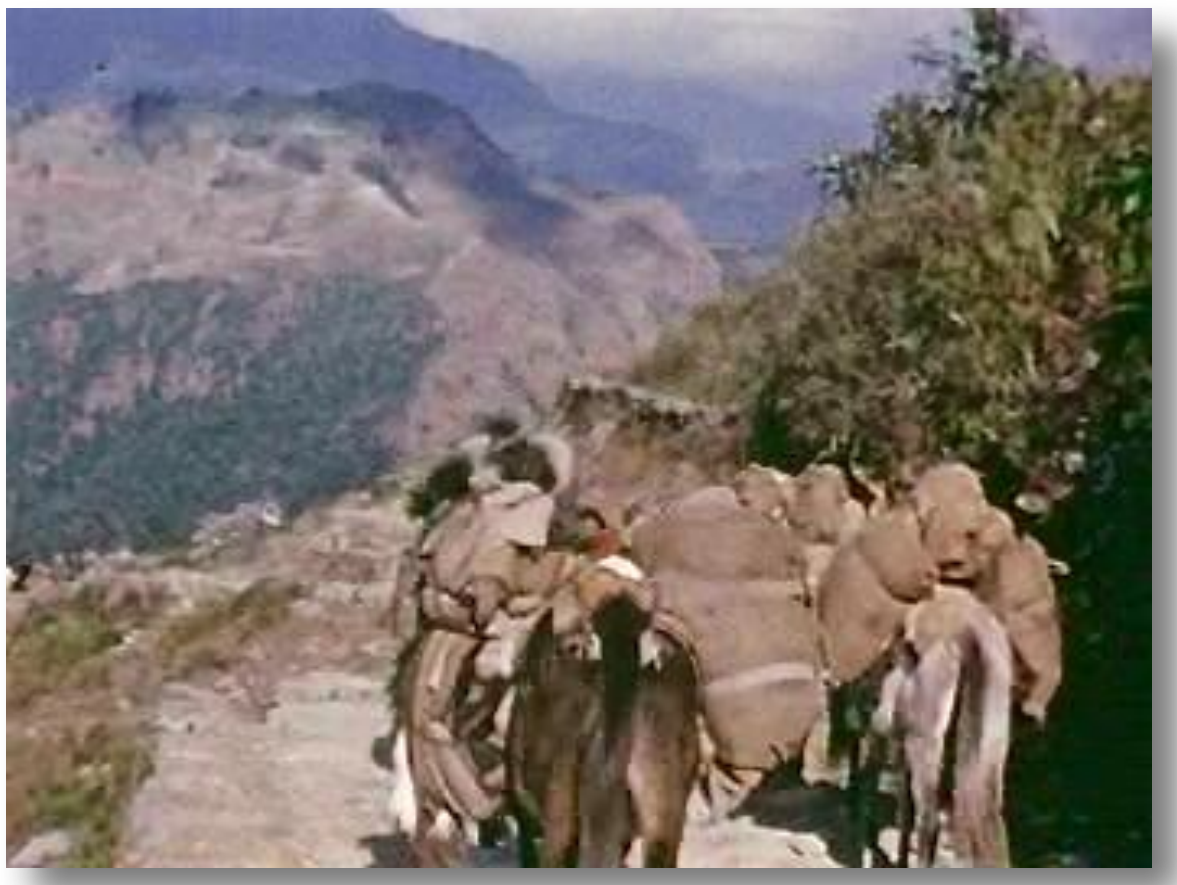

FILM. Tibetan mule train - 17the December https://upload.sms.cam.ac.uk/media/2736336 


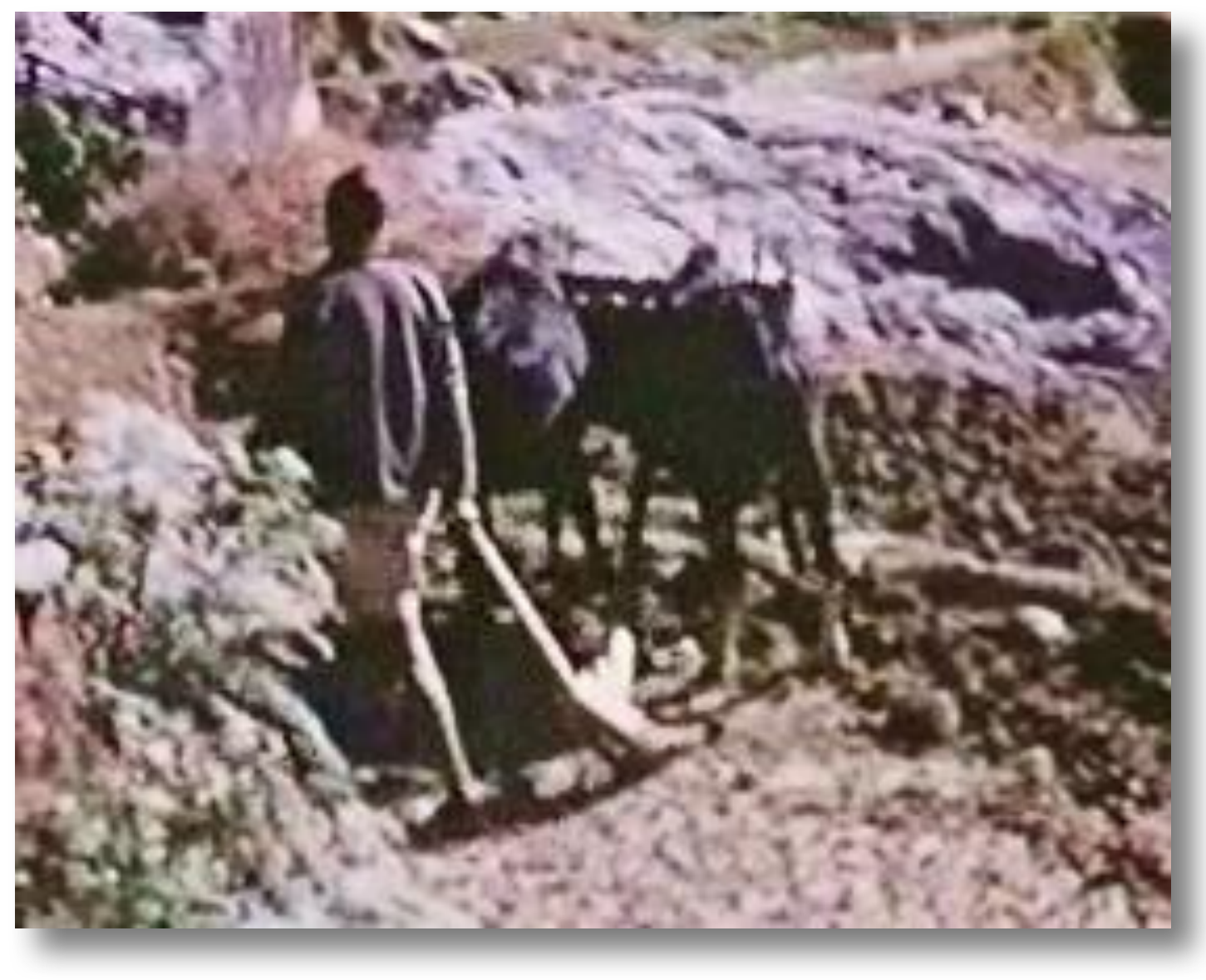

FILM. Man ploughing with oxen near Lumle https://sms.cam.ac.uk/media/2736364

DIARY GILL Wednesday 17th December - Mohoriya

Felt a bit blue lying in but not at prospect of hike ( 5 hours) but at being stared at again, and no loo etc. - so much for the adventure in my soul! Saw round farm again with Ramchandra who arrived yesterday in one day from Thak. Arranged porters and then cavalcade set out - 2 porters, Ramchandra, Prem, and us two - behind Ramchandra so that everyone thought we were his slaves - which was indeed very pleasurable walk - half way down hill - passing lots of affluent- looking Tibetans jangling on their horses - red and orange yak hair decorating them.

We turned right round into Machapuchare and Annapurna I - lovely views, steep climb down to Modi - lovely slate-green colour - tiny bamboo bridge and we tossed our lunch of orange peel into it. Saw lovely bright yellow and orange butterflies on nigger-brown dung by river - in the cut rice fields. Like an old man's one day stubble - prickly and wide apart and vulnerable. Climbed for 2 hours from river - quite stiff climb and then came to Ramchandra's wife's Maili's house - sweet and hospitable as always. Got tiny little room with a pillow and bed! and fancy cushions above animal's stall and there we were brought tea, rice goodies and omelettes - and then we had a full meal on top of that in house - sitting round fire and eating (badly) with our hands - to their sympathetic amusement. Notice houses seem less cluttered because there are no shelves - lot of small children affectionate and interested as usual (one looking over my shoulder as I write this - looking at my nails, my 'tsauri'.) Slept rather tight with Alan on bed and Prem on the floor. Little irritating having him here but could be useful. 
He was very good at Lumle. Think my tummy is upset already - hope not as could make this a nuisance.

$$
\text { DIARY Thursday 18th December - Mohoriya }
$$

Two things about the houses immediately struck us - that they had little tridents in the roofs and that they were slightly different inside - having a central beam [sketch]. People - with dispensary and water-tank - seem full of initiative, but the path even more faeces- filled than Thak. Did quite a bit of checking with Chandrabahadur's brother and then we went for a walk round the village. Watched 'chop chueba'.

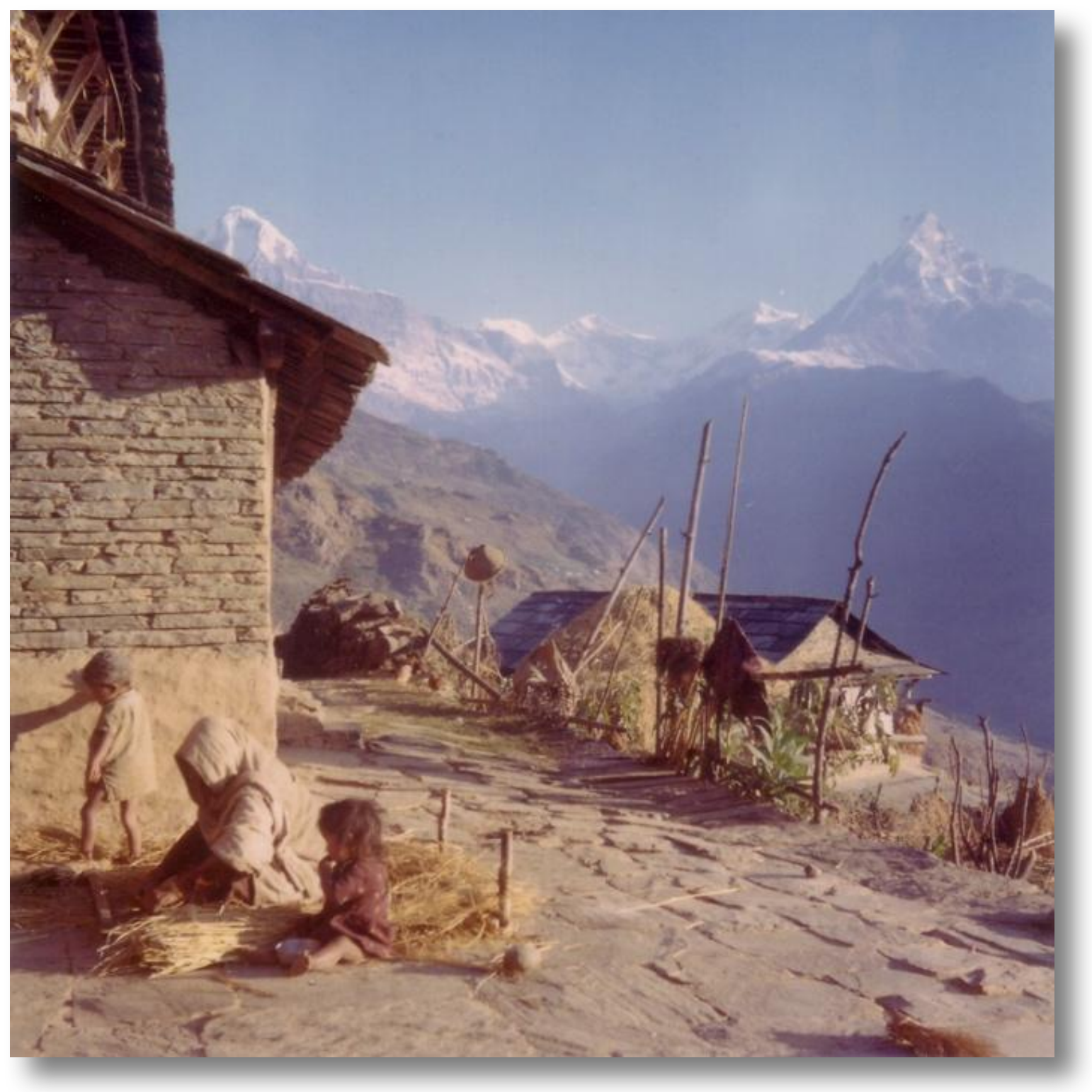

A house and street in Mohoriya 


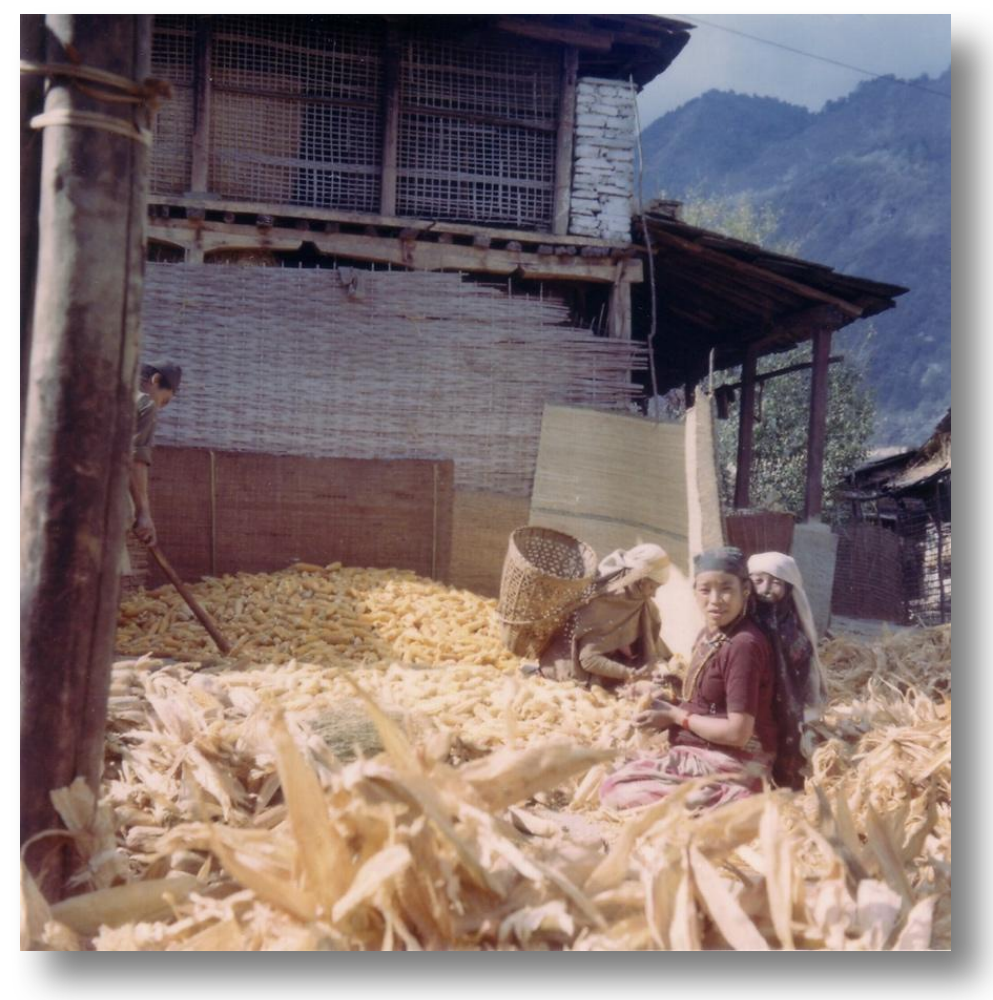

Mohoriya - husking maize

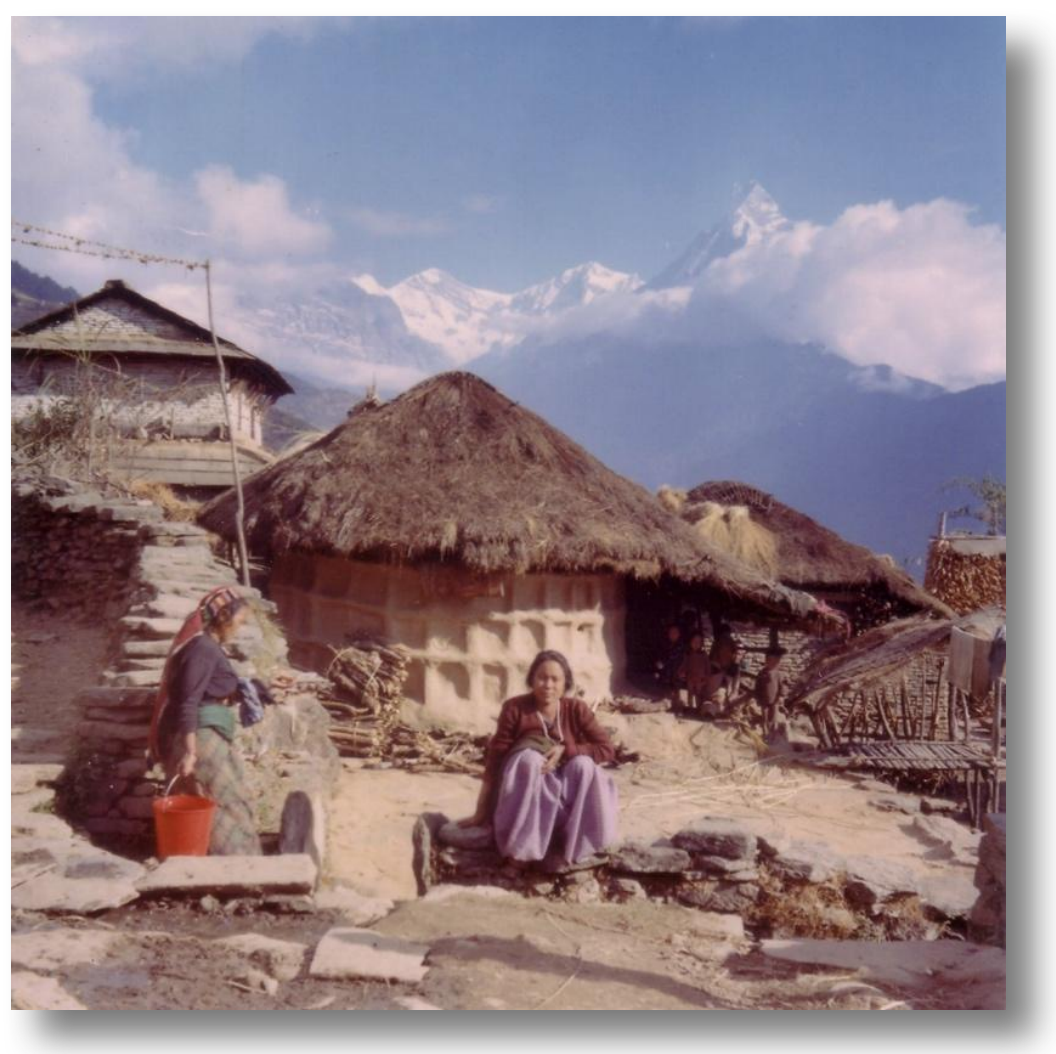

An old round house in Mohoriya 


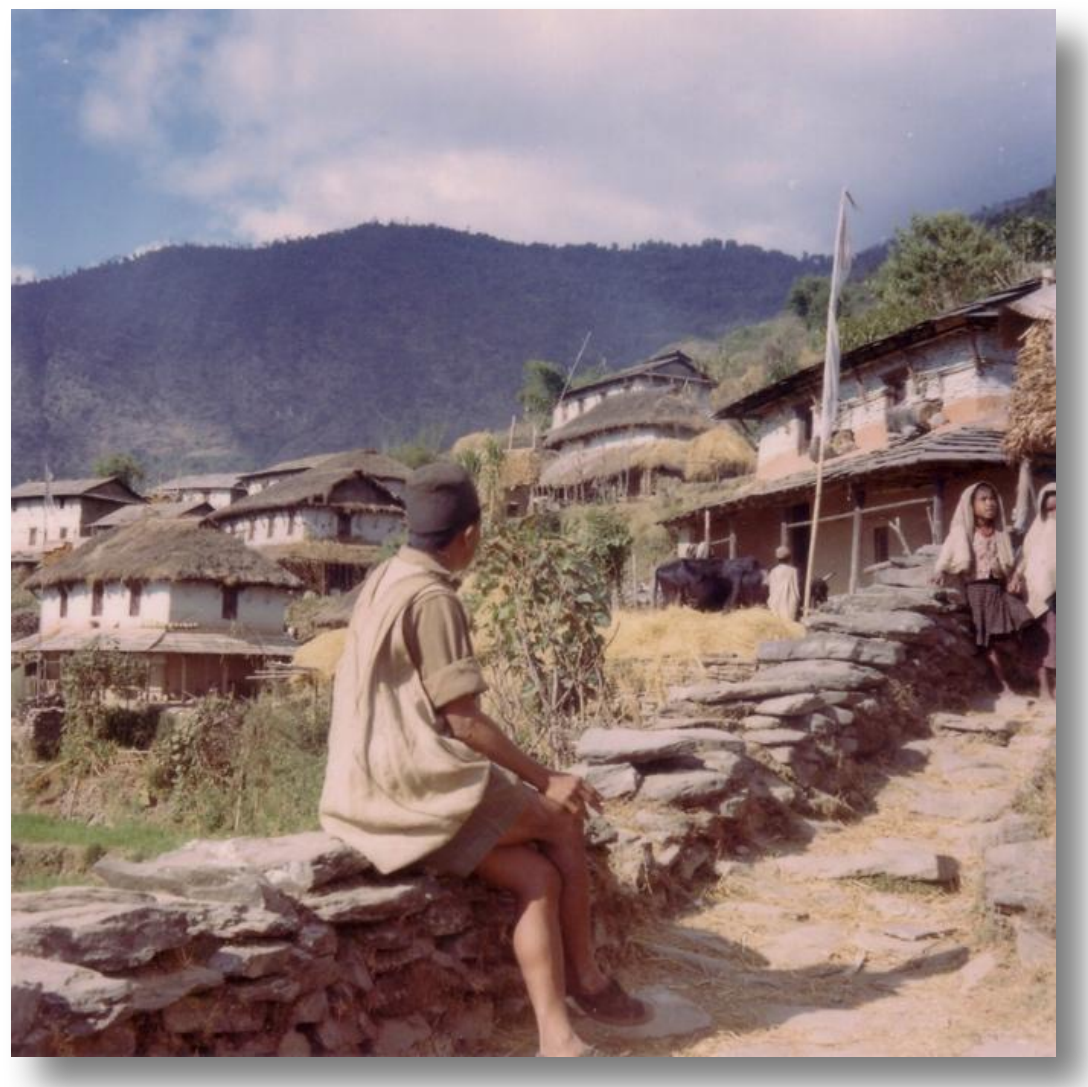

Village street in Mohoriya

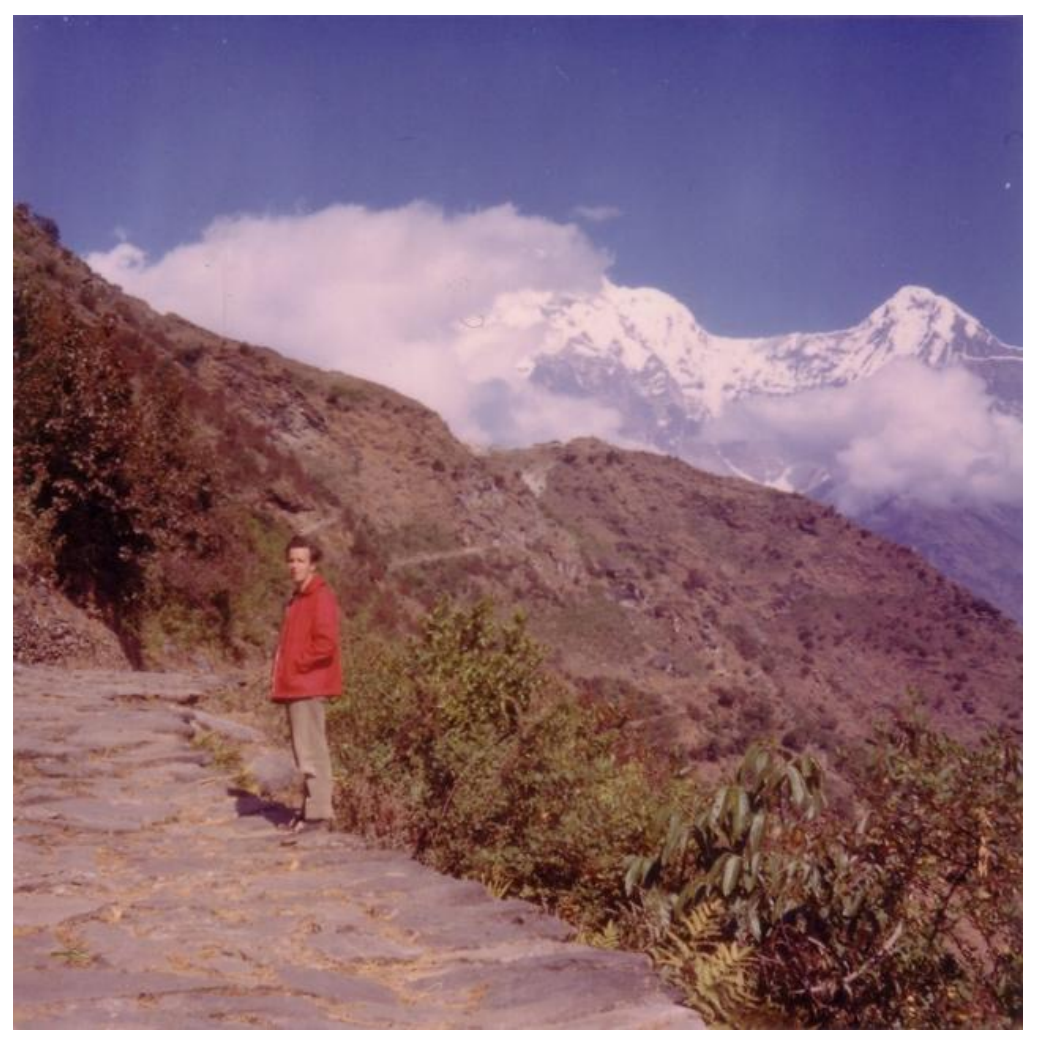

Alan on route to Ghandrung 


\section{DIARY GILL Thursday 18th December - Mohoriya}

Sitting here on 'gundri' and assaulted by flies and children, and baby trying to take my button off and fantastic view of Annapurna 1 and Machapuchare off the verandah. Alan already started work - as Pignede's informant's brother is still here and of course they are very interested in pictures. Have got dysentery. Taking medicine, as I don't want to get stuck here and go back to Lumle. Alan surrounded by helpful people all morning - had early lunch and then had conducted tour round village and lands. Impressed by little house they have built for water and they also have a dispensary! Dir. at present in Pokhara. Ramchandra didn't seem especially interested in what this village was doing so he could take it back to Thak.

Difference here is that they are growing mustard, wheat and peas altogether - patches of bright yellow like an English buttercup summer. Also jasmine out by stone, many more boulders, better paths, more faeces. We were shown a temple cracking to pieces in its clump of trees - Pignede had photographed it before. Seem to sacrifice sheep more? Gets more and more like Dales country and I get correspondingly more homesick!

Slept in afternoon as my tummy felt sore, and I had bad night previously with dog barking. Also just to forget, I'm afraid - home seems such a long way off, even now. Things chirped up when I got up. Made supper - arranged to cook rice on their stove and eat there, but all our food which should settle tummies. We then went to see one of the local pojus do a 'chop chueba' next door - slightly more Tibetan influence I should say - one butter lamp, flowers (jasmine) and black beads put round 'kaidu', and kind of rag-doll god made from torn strips of red and white cloth (these were also in all the temples we saw), a much neater chicken sacrifice, head not stuck in 'kaidu' and 'shya lava' done - family threw rice. Nice houses - pets piled on top of each other near fire, baby bonking cat on the nose, who later nestled against Buje's skirts. Children gay and cheeky, told off by poju for wriggling and shrieking. Way women use sticks from fire as light to see how food is cooking. We are given endless little woolly mats to sit on, fried bread and herb tea to eat. Babies are wrapped up warmly and lovingly handled. Notice how they become an extension of the mother again - cradled in lap and sometimes breast fed at the slightest whimper. Somehow people here seem more intelligent and receptive and sophisticated than Thak people. Went to bed early after I had made a sexual gaffe (by mistake) which had Ramchandra and Prem in stitches. Bad night again with wretched dog barking. Alan thinks he can get the work in 3-4 days.

\section{DIARY Friday 19th December - Mohoriya}

Prem and Ramchandra went back to Thak and we felt relieved to be alone. Sunny day. Went on hill and drew map of village: Pignede's map a bit skew-whiff. Then in afternoon went to look at Dangsing with Chandrabahadur's brother, and did not get back until about 4.30pm. Entertained kindly but got little work done. Found all our food - delicious chicken - left from yesterday had been given to children. Our male host returned.

\section{DIARY GILL Friday 19th December - Mohoriya}

Tummy well again, thank goodness. First time those pills have worked. Alan well too and we found a nice little spot in a bamboo clump - leaves like fingers of an arrogant hand prepared to pounce. Managed to get breakfast in some sort of peace - but still bringing us beans which Alan loves as they are similar to baked beans! We went up hillside afterwards. I read "Tin Drum" on a lovely craggy rock with a 1 foot lizard beside me and good view of Machapuchare which is first to be obscured in cloud. Alan found he couldn't sketch village from there so had to go down. Jasmine are really triumphant. Came down to get lunch to 
find that the family had eaten it - children. All that gorgeous chicken. Horrified at first - awful to find how such small things put one out. I conveyed it to the Gurungs too.

We went to Dangsing in afternoon with Pignede's informant's brother - only 15 mins. away on the ridge - large rather superior village which lot of prayer flags and red and white ribbons. Went to one of his relatives - a tall, shy strained woman who was making 'pa', which we later had, straight from the distilling pot! plus omelette - sweet made of 3 eggs. The other villagers liked looking at photos. Some were quite drunk on the hot 'pa'. Came back quickly via happy haze but had a cold, stared-upon supper in our loft as we have given up trying to arrange things cosily. The husband (Jila Panchayat man) returned and had a rather bumbling conversation with Alan. I tried to warm up and get organized but the family insisted I went to sit by fire instead - such friendliness can be oppressive. However, we taught a very pretty girl English by the fire - she was very quick to pick it up - and went to bed about $8.00 \mathrm{pm}$. Alan had promise of census for tomorrow.

\section{DIARY Saturday 20th December - Mohoriya}

My birthday: Gill gave me a large bar of chocolate and a man hopped over from house behind with lots of vegetables. Spent the morning rather fruitlessly pursuing the 'janasankir faram' and meeting Pradhan Panch. Then looked at 'Tirige' which Pignede apparently didn't look at, and finally discovered there were not copies of the 'janasankir faram' so we would have to do it ourselves. My heart sank, but in fact it was probably as well, and thanks to my two eager assistants it only took one and a half days hard slog, and we finished it on Sunday evening, more or less. People very co-operative and not shy, even about lower jhat. In evening again went round and did some round fireside.

\section{DIARY GILL Saturday 20th December - Mohoriya}

Alan's birthday and our anniversary - 3 years! Had a ghastly night with dogs, cats fighting, etc. Alan very tired with leaping up and down. Woken with beans and 'pa' at 7.00am! which Alan had just gulped down when Jila Panchayat man came to take him off to Dangsing. No chance to have porridge. Just had time to give me a kiss for 4 rupee chocolate bar I had bought! I thought I had better get up as we had already had a visit from this house, and next door with huge radish (1'6"), chilies, beans and egg plants and then just as I was washing up and tidying round - bent-in-two Gran came round saying she couldn't see a thing but looking well round nevertheless, asking if I was a man or a woman (I had orange jeans on). I gave her a fag and then went off to my bamboo forest and had a good time there. Lovely patterns of sun, of leaves rustling and a patch of marigold flowers which I picked to give the house who had given us veg! Stayed relaxing on wall quite a while just getting feeling of sun and not being watched. Alan not back when I came to house - mended sleeping bag with a crowd round and then wrote this with just little boy of house who has taken a fancy to me and v.v. Alan working all time - had to drag him away to get some lunch. Disappointed with his visit to Pradhan Panch as it seems to have got no censuses - and it took till $11 \mathrm{am}$. to say this or rather for Alan to draw the conclusion. However, decided it would be best to do our own - so drew forms after lunch, after revisiting our wood where it is so peaceful and the wind rustles the bamboo leaves all the time. Now I am coming to an end of "The Tin Drum", know I'm going to be sad - such is the power of the book - very infamous touch to put an outsider's viewpoint (Brun. his keeper at point where he "grows" - to get us fully in sympathy with him). Also evocation of post-war Germany, excellent. Enjoyed reading it here. In afternoon (late) we started on census - fortunately he's indefatigable - even keener than Alan and I - insisted on doing some after supper. We did some Tailors at other end of village. One woman had 
lost $6 / 7$ children - horrifying. Much crying because I missed out on giving some of the children sweets. Chaos in the evening when we wanted to eat and even had a positive invasion of Gurungs wanting to take Alan off, wanting me to teach them English - all this in middle of cooking/turkey/veg. on a stove meant just for boiling water. Afraid I panicked and would have left them all and followed Alan but had to go back and do my duty. Unfortunately the girl who came for her English lesson was intelligent and realized I would have got shot of all of them at one go given chance. Got very anti-social here. We had dinner in peace shooing them out and then I went straight to bed fraught with dealing with Gurungs - all the time.

\section{DIARY Sunday 21st December - Mohoriya}

From 8.00am-5.00pm. (with just one hour's break) did the 'janasankir faram' and almost finished it. A beautiful day, but cold after lunch. Four people have brought us vegetables and we get 'pa' and baked beans every morning. Considerable demand for birth control pills about five families asked. Decided to give 36rs. for buying more pills.

\section{DIARY GILL Sunday 21sst December - Mohoriya}

Felt slightly better this morning - but still having them (Gurungs) in whilst I was eating beans in bed. Alan tearing off to work at 7.30 before having porridge. However, I insisted on having them out - even then a sweet little wrinkled 'buje' came with ten tomatoes, 2 glasses of spiced radish and a bunch of 'pasagi'. Managed just to accept latter and gave her a fag and she went fairly quickly. Can't make out whether it is just kindness and return for medicine. Alan sensible and kind re my failing yesterday. Lovely morning with mountains just white against blue - fine powdering of snow on lower, grey reaches. I went to my little forest and read "Tin Drum" in morning and admired new bamboo leaves - great fallings off of shiny shield like base which is very slippery to tread on.

Came back at 10.30. Alan had just finished from 7.30am. - very pleased with all this effort. I went round with him later and Jila Panchayat man - other seemed to be holding village meeting. Some silent hostility but some offerings of milk. Did house where Pignede had stayed - big, affluent-looking families, 3 storeys, large courtyard. Gran with specs weaving lovely woollen rugs - loose weave, very warm I should imagine. Had late lunch and then Alan trotted off again and I read M's letter and went to my wood and finished off "Tin Drum" - an entirely satisfactory ending, gives rise to all sorts of allegory searching but maybe we have been taught to laugh at all that? Got much warmer in tone towards end. Quite brilliant but disturbing to the last. Sat near a clump of jasmine and bamboo shoots, orange- breasted birds - tiny - darted from tree to tree, very silent on the grasses. Alan just finished when I got back so we had an early dinner of turkey (too much) and Alan went down to sit by the fire, but I went to bed - to be interrupted just as I was dosing off by two little adolescents wanting Pignede's book. "I'm asleep." "We want to look at the photos". Sitting cosily on edge of bed. " Really don't want anyone here". Nervous giggles. They just want to look at book. Start searching. Pick up "Tin Drum", then my pants - found underneath underwear. Sit round in a circle, prepare to leaf through. Thankfully Alan comes at this point and shoos them downstairs.

DIARY Monday 22nd December - Mohoriya 
Went up to Ghandrung - 2.5 hours each way, and a lovely walk passed waterfalls, birches, fields of young barley, etc. Superb views of mountains. Ghandrung itself impressive with about 400 big houses, a white rabbit, but no tea-house. Had an icy wade in a shadowy stream and boiled eggs and chocolate at the other end of Ghandrung. People in Mohre very friendly as we left and came - more so than in Thak. Many houses had prayer flags and many of those in Ghandrung had 3 storeys. More substantial than Siklis houses. The valley generally is much more wooded than ours.

\section{DIARY GILL Monday 22nd December - Mohoriya}

Today really a day for avoiding Gurungs. A 'theba mih' relation (in Indian Army) came from Pokhara last night (sheets, pillow for him) and suggested he came to Ghandrung with us today. Also Jila Panchayat man looked as if he were ready to leap off with us. Maila and he were competing and both producing lists of houses forgotten for Alan, none of which correspond! Alan did two hours work after we had been given tomatoes, potatoes and beans by Gran in black suede shoes, whom I had decided to dislike - always seemed to be where we were. Village very friendly as we went through lot of people hailing Alan "Sahib".

Had leisurely walk, took about two and a half hours more on less on flat in middle of mountain side. Very broad slab paths, numerous chalky landslides which had just sliced path away. (Very Lord of Ringish). Little streams in each gully as we came down to Ghandrung. We washed (hair, body) in a freezing stream without any sun just before we came into village - water so cold it numbed head immediately and was quite painful. Ghandrung very large about 500 houses in large spacious clumps, with pink tea roses and nasturtions climbing up white-washed walls. A black puppy played with a white rabbit whose black pads were dirt brown when he tried to lollop off. Houses large, still doing maize, flowers in kerosene tin window boxes, mountains just behind but hidden in cloud. Large scree-laden brown hills behind. Had our lunch facing this. Alan looking like a baby hedgehog whose prickles are still soft - not having shaved but just washed his hair! Some houses decorated in orange/black circles - air of solidity about place. More walls, archways, like a mediaeval town. School on outcrop just before village - with a wind screen courtyard, sandy building. Reminded us of Pissel's book.

Came back after an hour's wander. Couldn't find a tea house there. Quick return back, Alan flirted with some Gurung girls and then we caught up a party carrying 'khi' (thatching grasses) and wearing peach suede shoes - have never walked behind this combination before.

Returned at $4.30 \mathrm{pm}$. pleasantly tired and had good supper of mackerel and then went down for a chat with 'theba mih' from Pokhara who didn't seem to bear any grudge about this a.m. Very kind about giving us.

\section{DIARY Tuesday 23rd December - Mohoriya}

A rather hectic day - fine till lunch as always. Went to film 'Gairu' puja at Jebahadur's house and then besieged by (a) people wanting medicine, (b) little gifts of 'prasad' and breakfast - in all 4 bits of food, from delicious rice-rings, to yogurt, to spiced potatoes, to baked beans. Didn't finally sort ourselves out from this and washing until about 12.30, when Jebahadur came for 2 hours of checking Pignede. He was extremely good and very nice. Sorting things out for Sikha tomorrow. Have enjoyed Mohre much more than I thought - much nicer and friendlier than Thak. 


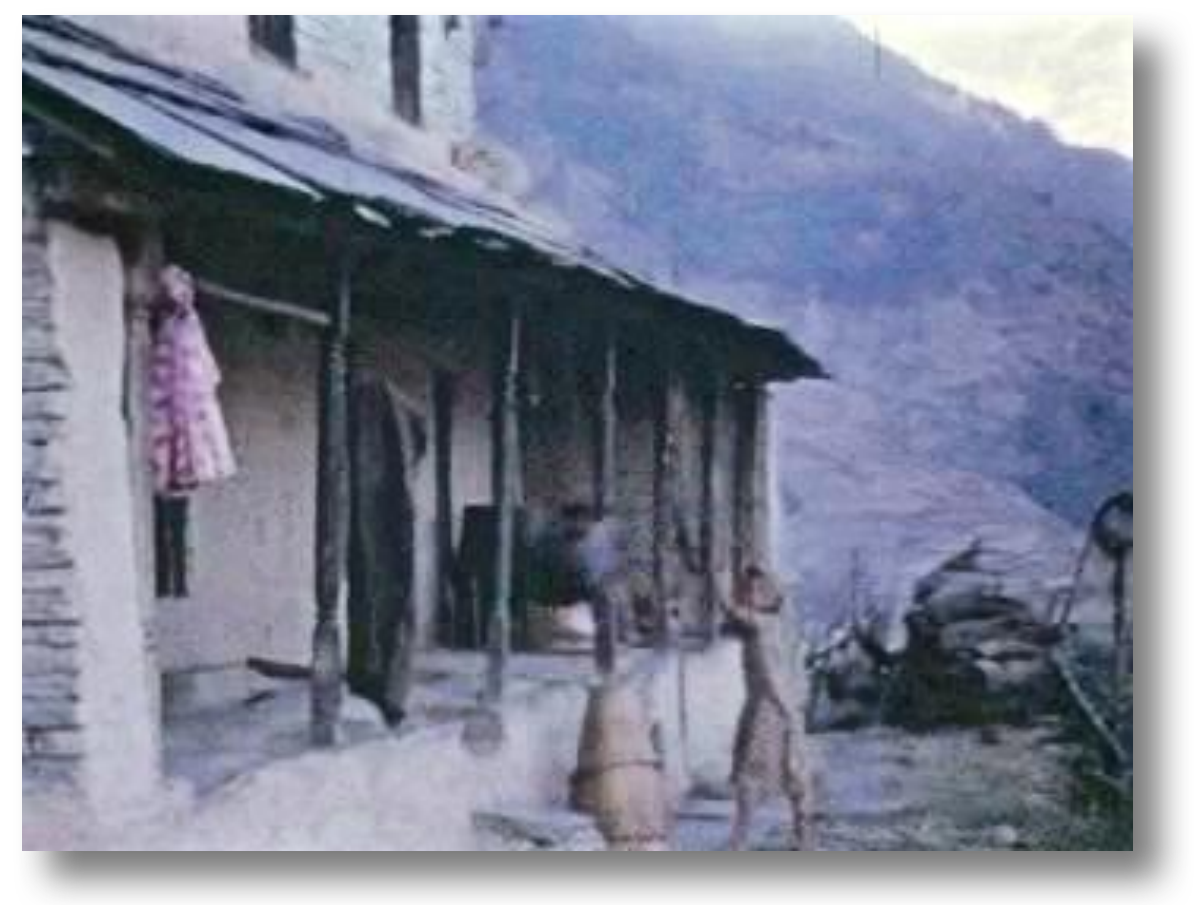

FILM. Girl swinging a cradle hanging from a veranda View of mountains - 23rd December https://sms.cam.ac.uk/media/2736392

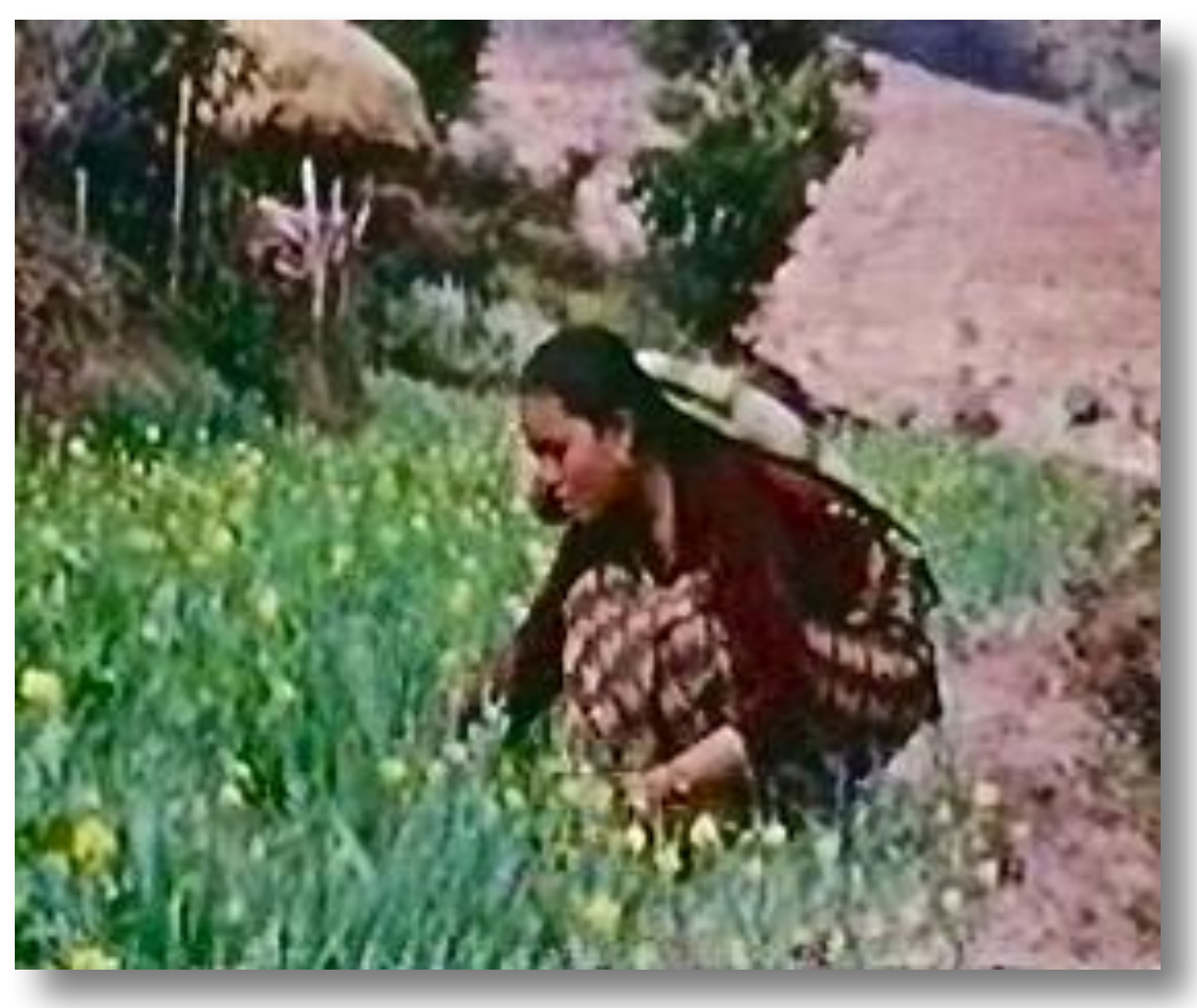

FILM. Girl picking mustard at Mohoriya https://sms.cam.ac.uk/media/2736476 


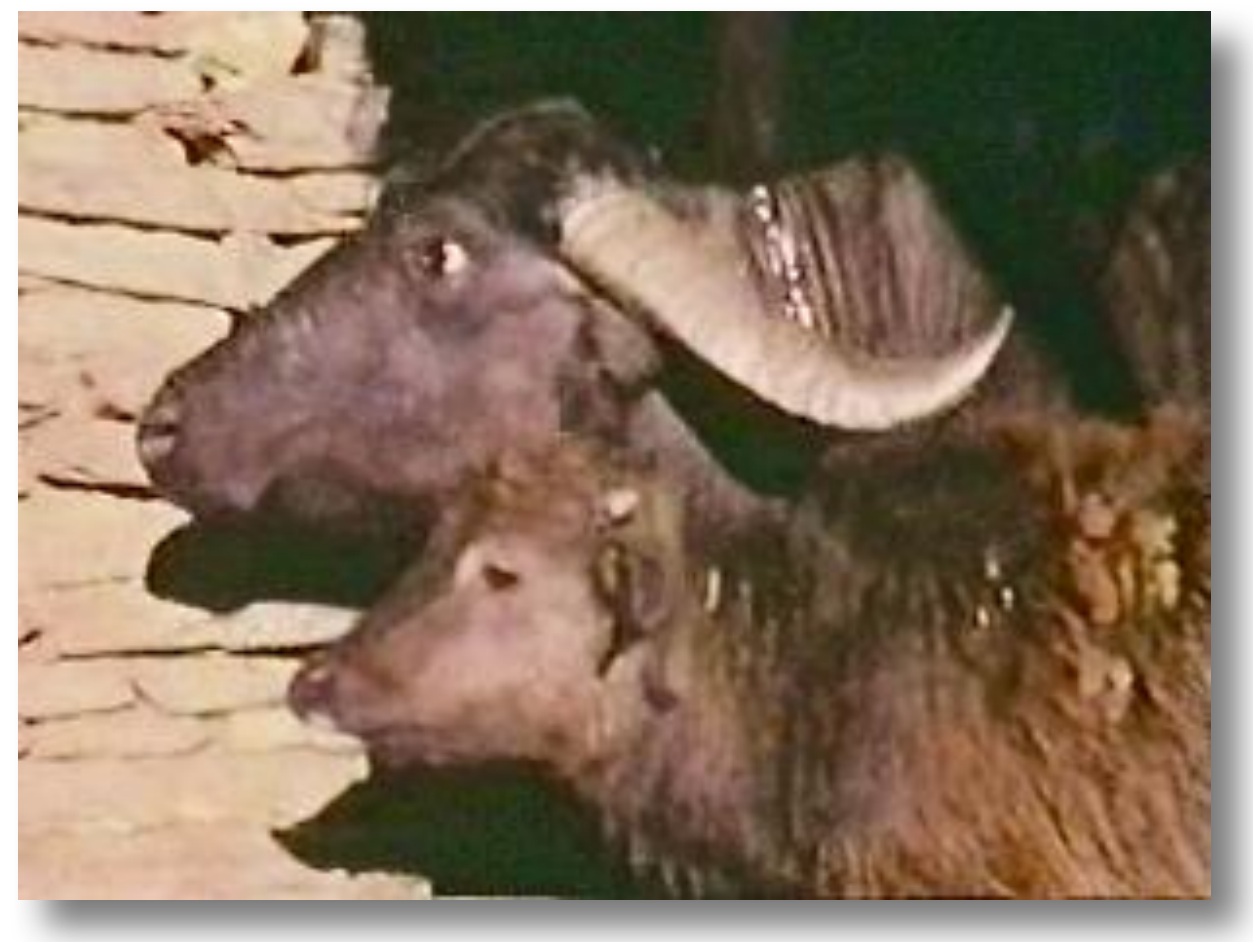

FILM. Mother buffalo and calf

https://sms.cam.ac.uk/media/2736448

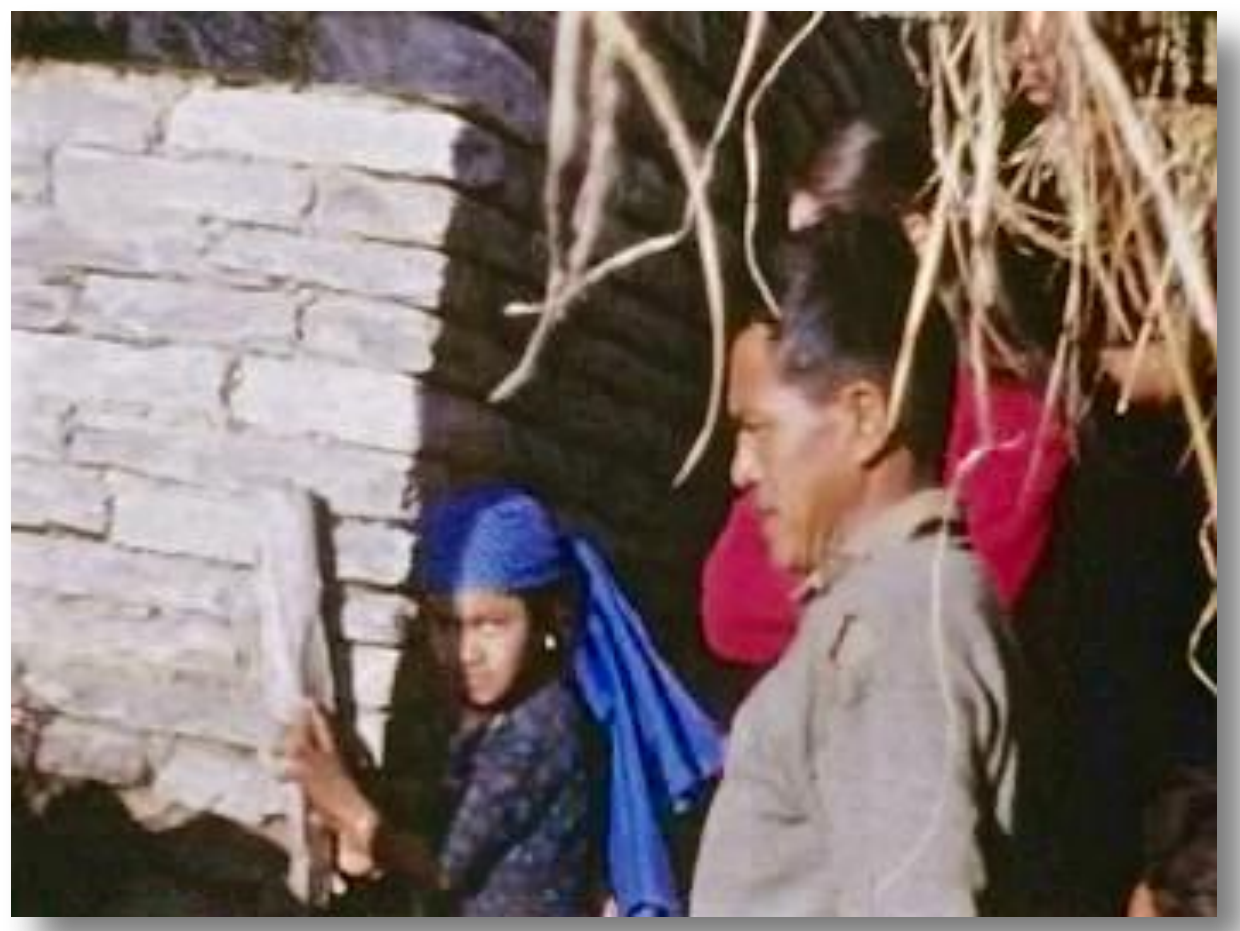

FILM. 'Gairu puja'

Jaibahadur sacrificing a cock for a buffalo blessing rite

https://sms.cam.ac.uk/media/2736420 
Gairu puja' (see cine film)Do twice year. Jed and Mungsir/Poose pourne. Circle buffaloes three times sprinkling water and smoking incense (ewe?) and with cock. A little altar of stones, with two little dung bowls for milk and blood; fronds of lavender sticking up out of it. Plate of rice, plate of fried goodies - Prasad/bwok. Under the altar a little pattern - five lines of white (rice flour) and four of yellow (bissaro) - for a big puja they do nine lines of each colour. Attached to lavender fronds were two strips of cotton cloth, red and white. Jaibahadur said the colours did not represent sexes, but had been used since ancestors. For Debi they used a bit of woman's cloth only. During rite he simply asked for protection -'he premisua ngllai rachinla-o' while sprinkling 'lawa' (roasted maize and rice) over the shrine. Then kill cock and sprinkle blood over shrine. End. Fairly casual, only children attended, though they were quite interested. Every household apparently does.

\section{DIARY GILL Tuesday 24th December - Mohoriya}

Bad sleep with wretched dog barking and Alan going down to throw stones at it. Dreaming of home and getting excited. As usual woken by a Gran bearing goodies - the black suede gran again with the most delicious 'roti' I have ever tasted, (must have had heaps of honey in it), with hot peppered tea - gorgeous. Then our family brought us our little brown beans. Then later some spiced chicken. We then went to watch a puja which Alan filmed, for the animals, a buffalo appropriately licking his bottom the while, and they brought us yogurt and 'prasad' and then another girl came along with 5 large potatoes and asked us to tea and 'procan sain'!! Overwhelming.

We gave out medicine and I did some washing, then we went for our elevenses given metal chairs, covered in new rag rugs dyed oranges, blues, reds, then wobbly table which Alan helped to put up as woman couldn't, it was so long since it was used - then this was put on a 'gundri' and we had spiced potatoes and my favourite crackly rice, and speckled tea (with black pepper) on stainless steel plates, and the women oiled sewing machine, or their hair, putting some oil on with lavender leaf, and girls decided that cloth to sew on what - black polka dots on red and white, lacy stuff.

A grey baby buffalo with pink ears was tethered to the next mokhai post, and Alan talked of Wingate Raiders and John Masters to an ex-Gurkha Hon. Captain who claimed to know Richard. Machapuchare still had tips of her tail clear of cloud and we had and uninterrupted view over our wobbly, cobwebby table and the shiny sewing machine. Later went to loo and grey laced up wall to the green corn shoots, and trumpet-like jasmines blazed yellow from the wall. Unfortunately faeces all over the place to put all this lyricism in perspective. Fields of yellow mustard, green spiky barley and purple and white pea flowers - lovely. Much more wooding

\section{DIARY Wednesday 24th December - Sikha}

Set off on our trek to Sikha. Took it very slowly, and thanks to the "one 'koss' to..." complex, we misjudged the distance. Went via Sabit, a pretty village after some pine trees, then climbed an hour up to Uleri. By now it was about $3.30 \mathrm{pm}$. and we thought we'd walk on to Nangar Tati easily, but it was 2.5 hours hard climb up through the grim and darkening forest before we reached it. Gill almost exhausted and cried with relief when she saw the little clearing with smoke going up. 
Spent an icy night in the little matting-built hut with rain and frost outside and wind howling through. But as always the rice and 'daal' and eggs and 'pa' tasted delicious. An early start over the icy track and made breakfast over a camp fire. Then walked down through monkeyfilled forest and a long slope to Sikha - by lunchtime. Sang Xmas carols on the way down. The nurses at Sikha whom we met invited us to spend the night so we dumped our rucksacks at the Dispensary and took out Xmas picnic up to a little marble-strewn stream high above with superb views of the mountains. Had an idyllic picnic and read Mummy's letters. Then down to beef and dumplings and a discussion of Christianity etc. They admitted that they had little work to do and we discussed latrines, BCG campaigns, etc.

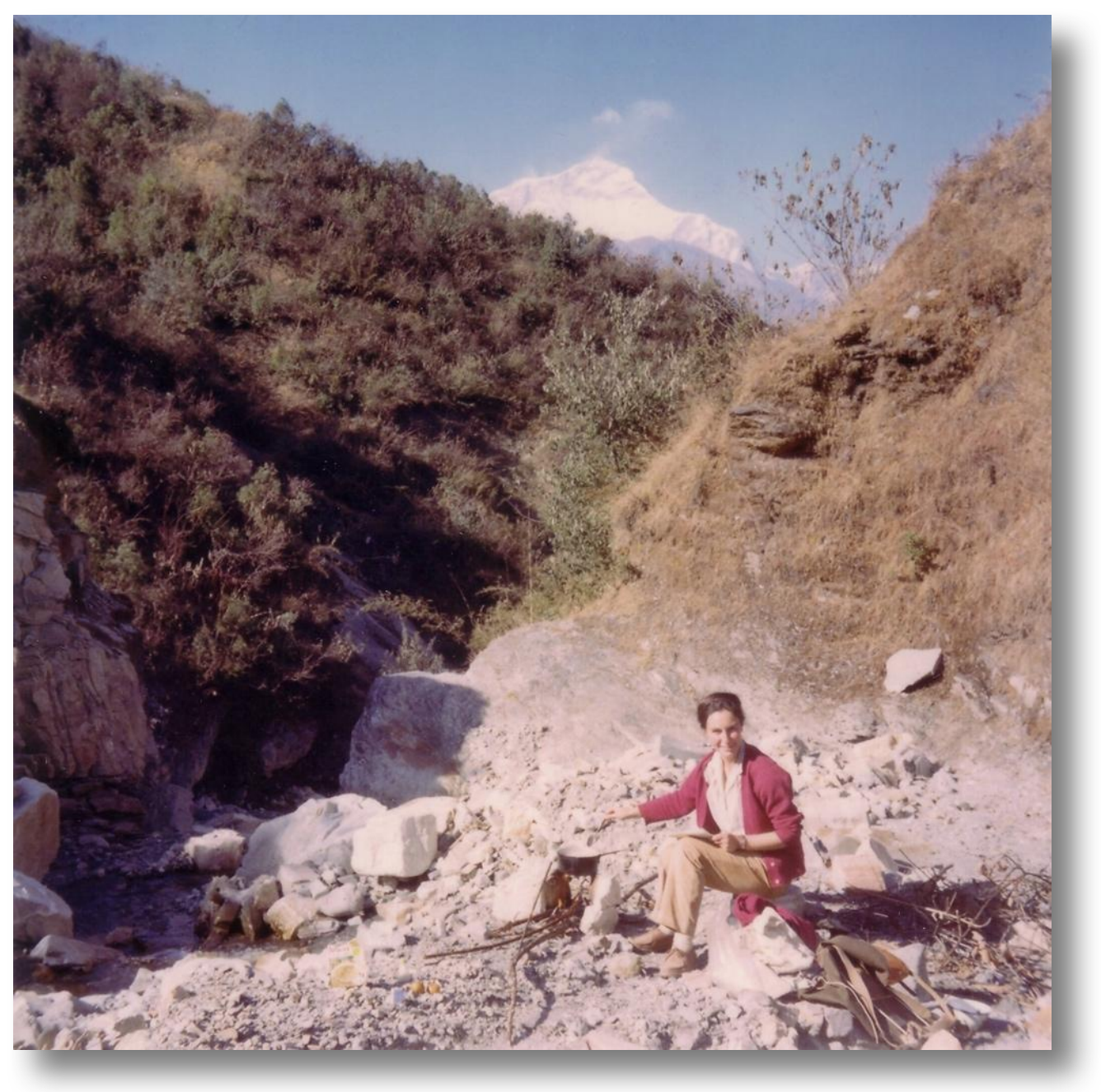

Gill during picnic on Christmas day

DIARY Friday 26th December - Uleri

Set off after marmalade and brown bread and had a pleasant walk to Uleri - passing through a less grim (now that dappled sun shone) forest and the gravestone of Benbahadur Hitchcock. Food at Uleri tasted fantastic. Discussed evangelical Christianity a lot. Throughout the walk have been thinking a lot about home - major themes: a) teaching history at York/Oxford, etc. 
and how to organise student lectures/ reading parties/ Xerox and libraries, etc. b) Organizing my study/seminar centre at Dent/Hebrides. c) Organising my research/study centre cum fish farm in Hebrides.

\section{DIARY Saturday 27th December - Mohoriya}

Made our leisurely way back to Mohre via Biretanti. As always we picnicked with a little fire and Horlicks soup, biscuits, oranges, chocolate, etc. A long climb up, but were warmly welcomed with 'pa' and brown beans - both of which we again got for breakfast.

\section{DIARY GILL Saturday 27th December - Mohoriya}

Woken early by baby howling, belonging to other Nepali couple who stayed there too. Had a good cup of tea which hadn't been made for hours, and then took the way slowly down the hill, sleepily, the dog from the house following us. Had views of mountains through the gap which had been shrouded in mist and damp when we first went up. Met an American couple who were having difficulty on the way up, poor things little did they know they had only just started. Washed in the river with a woman cutting grass by the side, cold with bending fronds and climbing jasmine almost falling into the water, ropey bridge for mules to cross. Smiled at woman as we went and she returned it and became a person. Leisurely walk by a Scottish type river, green slate and blue in patches, had a picnic and then started the haul to Mohoriya. Climbed up to two ridges in the end, irritated by what I thought another Comal giving us the wrong directions, but Alan has more faith in other people's advice, and of course it proved to be sound. Soothed ourselves under huge, warmth smelling pines with barks like skins of pink crocodiles, lovely, the cones in the midst of a spray of sea- green needles. Rounded it through Dangsing to Mohoriya, and arrived to a sweet welcome and beans and 'pa' immediately from Gran.

DIARY Sunday 28th December - Lumle

Set off to Lumle at about 10.30am. having spent an hour and a half organizing a porter to take our stuff to Thak. Very warm good-bye, with Gran slipping a bottle of 'pa' into our rucksack, Maila refusing money, etc. Got a little Chetri to carry my heavy rucksack to Lumle Farm and I carried Gill's. We got lost and went rather a detour, but still arrived at Lumle before him, so were rather worried. But he turned up and we had a late soup at the Farm (where Gill learnt that recruits had told Langland - (a) they weren't paid enough; (b) were made to work too hard; (c) had been forced to come by their Pradhan Panchs. How true?.) Then hobbled on to Noledada, for by now I had blisters on the top and bottom of my toes since my shoes were too narrow. Fantastic evening views of Annapurna I and IV (with Machepuchare in middle) as we walked down the ridge to Noledada. A very good sleep for a change and a cosy meal and sit-down by the fire. 


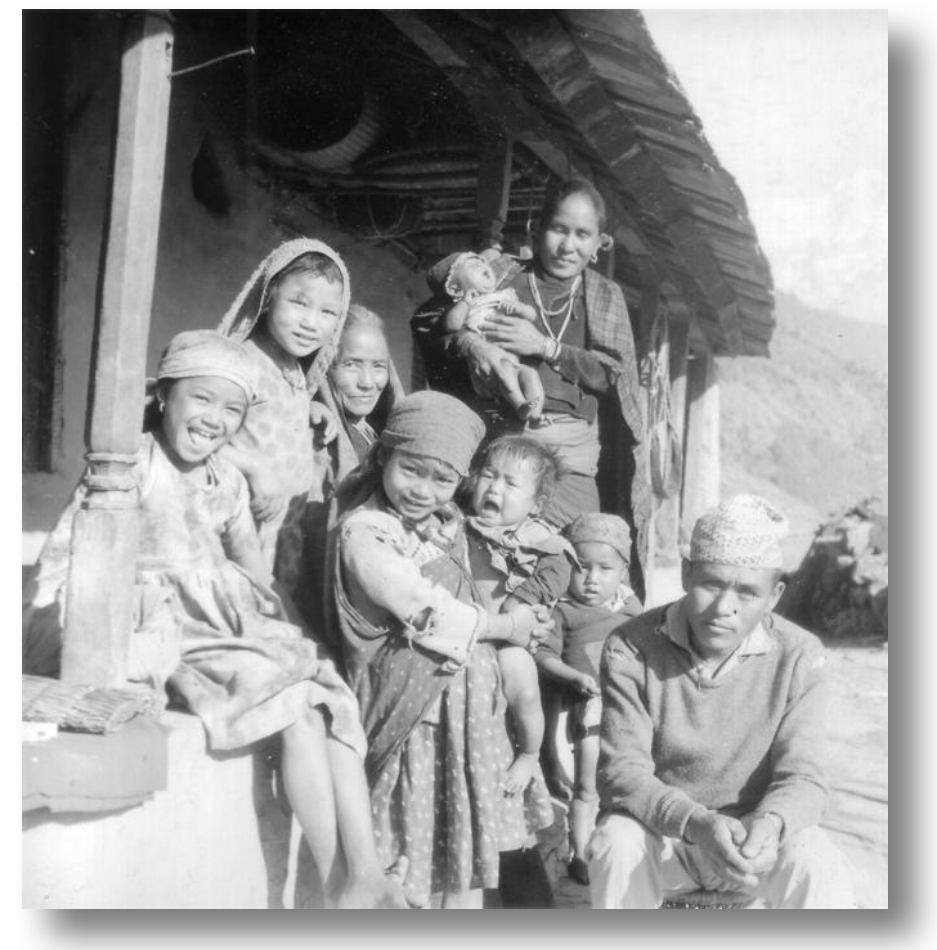

Family with whom we stayed in Mohoriya

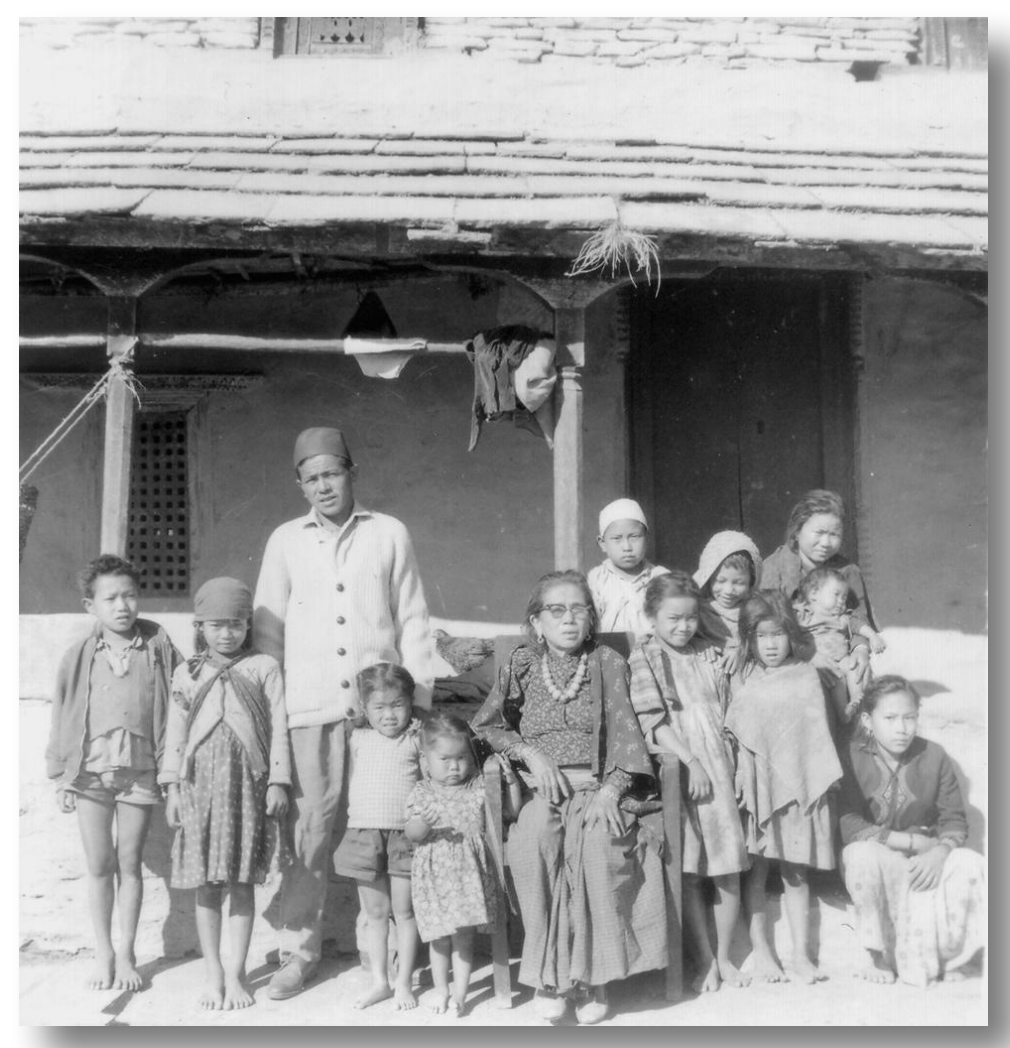

Pignede's informants elder brother and family in Mohoriya 


\section{DIARY GILL Sunday 28th December - Noledada}

Slept well if tightly in our funny head-cracking loft, had usual beans and kindness for breakfast. Alan had to go off and do some filming [FILM] so I packed things for the porters, we had a rather heavy load to carry. Difficulty in getting a single man to go, claimed they didn't know the way. Our Ratty-like Jila Panchayat man lost his temper, especially when his wife put in some advice. Eventually they set off and then we had to start our photos.

[PHOTOS] Our family sat, the babies all howling and the adults beaming, and then Alan's informant's family took 15 minutes to get themselves together, the husband going off to put cavalry twills on and a beautiful mushroom coloured buttoned sweater. Then his spoilt little girl struggled five minutes to get a mauve gingham over her fat little tum, running up to her father afterwards and hugging his legs. The matriarch's chair had to be found, then dusted, it had not been moved for centuries. Then mother looked incredibly sluttish and down-at-heel and had to be coaxed to sit. She hid behind a pillar in the end. Then other family's children were dragged in. Nani from our family had missed out on hers, and Alan with a sigh, took it. Even when we set off and I had given them all the oil, sugar, kerosene etc. left over, and kissed Kadja, a green tinted gran pursued Alan down the path pressing a bottle of 'pa' into his hands and holding them at the same time. It must have been 10.30am. when we got away.

We hired the man who originally wouldn't come to carry Alan's pack to Lumle, so he could take mine. Skidded our way down the hill, took an hour, whereas it had taken two and a half to get up. We lost the porters after we had crossed the river, and missed the path too, so rather a dank struggle up on little rocky paths. Very tiring, we seemed to climb a long way up and eventually came out on the route from Biritanti, about ten minutes below the land mark tree. The porters weren't there so we went on, to find them not at Lumle either. Nice, prosperous looking village with pretty orange and cream houses, lined with pumpkins and squash. I went on alone to the farm, whilst Alan waited for the porters, and interrupted the Flatts in the middle of their lunch. Pleasant, though Mr Flatt looked strained, had bad attack of asthma. Relieved we weren't staying the night and I had a drink of water and we had lunch in the cook house and got off as soon as we could. Had a slow but nice walk to Noledada with marvellous views of Annapurna range stretched out in a white craggy girdle across the horizon. Lovely through a feathered field of barley, green and white and grey and rose at sunset. Found a helpful porter who found us a house. They spoke Gurung too so that made us human and they lit up when we talked. Mother with grey hair in a red plait and pretty daughter with a grasping grandmother. Cooked us rice and potatoes and eggs, grinding the salt and chilies in a mortar. Granny always doing it. A row of breast-plate lids catching the light leaning up on a shelf. Love the way the steam from the cooked rice puffs its way through the hole in the top. A light on a stand and house with pretty white dashes round the clay cubby holes on top of the orange, beautifully clean. Meat hanging up high to dry over the fire in kerosene stoves. Occasional woven doors put over the gaps in the wall which make such even at (sic) satisfying doorways. Photos on the wall of sons in Western clothing.

\section{DIARY Monday 29th December to Sunday 4th January 1970}

Walked on to Ghachock - quite easy except for blisters. Happy two days with Jessie and Warren - eating their nice food, listening to "Messiah", discussing Gurung, etc. They have a much more decorated room, and seem much more civilized with excellent typewriter, wireless, tape-recorder, etc. A couple of "Aid" Americans dropped in and we walked down to Pokhara with them - most interesting on collapse of aid in India, etc. 
Spent New Year's eve with them, eating salami and drinking brandy and discussing birthcontrol. Sad to say goodbye at Ghachock and to the Americans. 26 letters at Pokhara and spent 3 days answering these, organizing birth control for Mohoriya, copying out hospital records, etc.

Then gathered together our possessions, met Goof, and returned to Thak. The easiest walk we have had - an easy trek because of our fitness. A lot of people in to welcome us. Like our photos (enlargements) of poju and Ramu. [After paying off porters had 572rs.].

\section{DIARY GILL Monday 29th December}

Had the best night ever in our cosy little white and orange Thakali house. I slept by the fire, gran moving next door, and Alan at my toes. Watched the woman get up, light a fag and lean on her elbow under the blankets smoking it, looking out at the open ended house at a cold blue dawn. She raked the ashes in the kerosene tin and prepared some mash for the buffalo, clanking the tin with a long wooden spoon. I went to pee early and the mountains grey after an earlier flush of pink, but the lake spiralling and pearly in the distance. Found a fat grey pig snuffling behind me as I crouched. Had biscuits and tea for breakfast and then had an early start and were down in the valley by half an hour. We sang across the plain, me trying to harmonize with Alan! and then met Brian from the Leprasorium with two girls he had picked up on the trek and another boy. Bouncy but we revelled in the knowledge that we had been and come. We cut off left for Ghachock, a bit uneasy as to how far it was, but had a two hour break by the river where Alan collected spare driftwood and we had difficulty in getting the soup to boil. Alan even shaved though and I borrowed his brush and lather to do my legs as I was beginning to look curly and hairy. We plodded off to be told it was two hours to Ghachock, but found it near after an hour, no climbing and soon got to the house. Much more spread out village than Thak, lot of Brahmins, etc. Jessie out "marriage counselling" when we got there, but Warren seemed pleased to see us. Sweet little loft like ours very cosily set up, many more luxuries than ours, tables, chairs, curtains, screening off, endless cooking things. Children are let in with restraint, so in fact then have much less privacy than we do. Had long easy chats, but a very cold wakeful night as we didn't ask for a blanket and Meryn cried almost throughout. Jessie had to light the candle about ten times. How they don't scream with frustration, I don't know.

\section{DIARY GILL Tuesday 30th December Ghachock}

Had sleepy relaxed day, wandering round village. Alan helping them draw a map and going up "their" hill with the children. Had a getting it off the chest session with Jessie about those wretched missionaries and I was pleased to find that they weren't so closely allied to them as I had originally thought. She thinks them "narrow" and "stuck in a groove", which was mild to what I think, but comforting! Had a somewhat abortive argument about freedom and religion, avoiding buffaloes and calves and chatting with Gurungs the while, so couldn't quite get into it. Darned and chatted during the afternoon. They seem pleased to have us. The children a constant fret, the girl has been labelled cry-baby by the village, disapprovingly. Gurung babies just don't cry for apparently no reason

We were interrupted by an American couple who bounced up the stairs, because they were "curious" and had come on a trek out there. Decided to dislike them because the wife seemed on edge and too sharp and the man too bonhomie and bouncy jolly when not really. Also they told a tale of sleeping on a verandah and spraying the place with louse powder and lice coming out, and not being killed by their powder, so they moved onto another place. They sprayed this and not too much happened. They made a joke of it but put out, we really 
laughed at their softness and the wife felt it and wished she hadn't told their story - they are living in India too, AID. I think amazed with Jessie's set up too, as they have three children of their own. Wife told a typical Fromm-like story - "The Sane Society" - of their last child being very tiny, and being born in an Indian hospital and getting the size they paid for - everything reckoned in dollars, even babies. Still I liked the way they bounced up and were honest about the curiosity. Had a lovely, soft evening listening to "Messiah" which they had on tape and read the texts from Isaiah afterwards. They very sweetly gave us a bible. Had delicious Indian recipe meal with buffalo meat. Nice day.

\section{DIARY GILL Wednesday 31st December - Pokhara}

Had good warm night at Jessie's and lovely breakfast of eggs, fresh brown bread and marmalade. Set off 9.00am. after fond farewells and easy sleepy walk down. Saw with some horror the Americans in the distance and after I/we had decided not to like them - didn't really want to walk all way to Pokhara. However, it happened and of course found wife terribly nice. Alan absorbed with husband so I forced myself to talk - she proved intelligent and sensitive - and had quite got the message yesterday when we laughed about louse powder. Famine in Bihar hit her badly, had a lot to do with adoptions - just taken on a Tibetan girl - couldn't have brought up children up in Jessie's surroundings. Met in Ankara, married after 3 months, husband had a rough childhood - overcompensates with need for food. Apologised for bringing so much with them. We had a picnic by river - we shared their salami and our onion soup - with Jessie's bread it was marvellous. Tibetans (after they had just eaten) bothered us. We dropped off their porter at hospital (bitten arm) and she told me about dance groups they put on and which she directed. Mr Pant not at library when we went - sad - so I went back up pm. and found 26 [letters] for us! Alan had a sore bot. We had dinner at "Mogambo" and Rudd's came over and French couple we had met - and we argued over birth control - me getting surprisingly radical. Drank Lee's brandy in coffee and really had a good New Year's Eve - so nice, the Americans. 


\section{JANUARY 1970}

Photographs of Alan and Gill, January

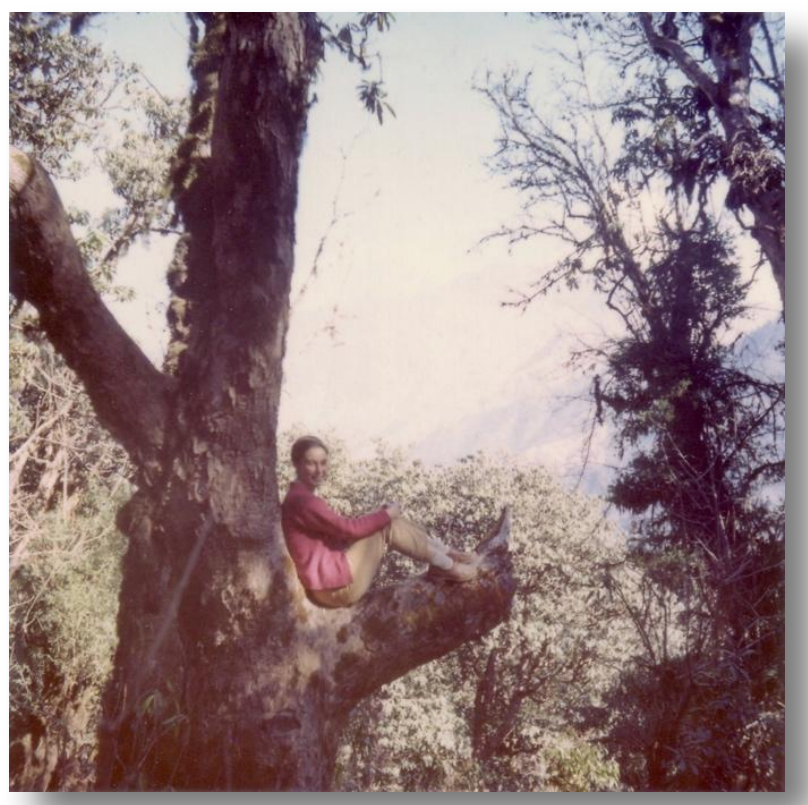

Gill in a tree

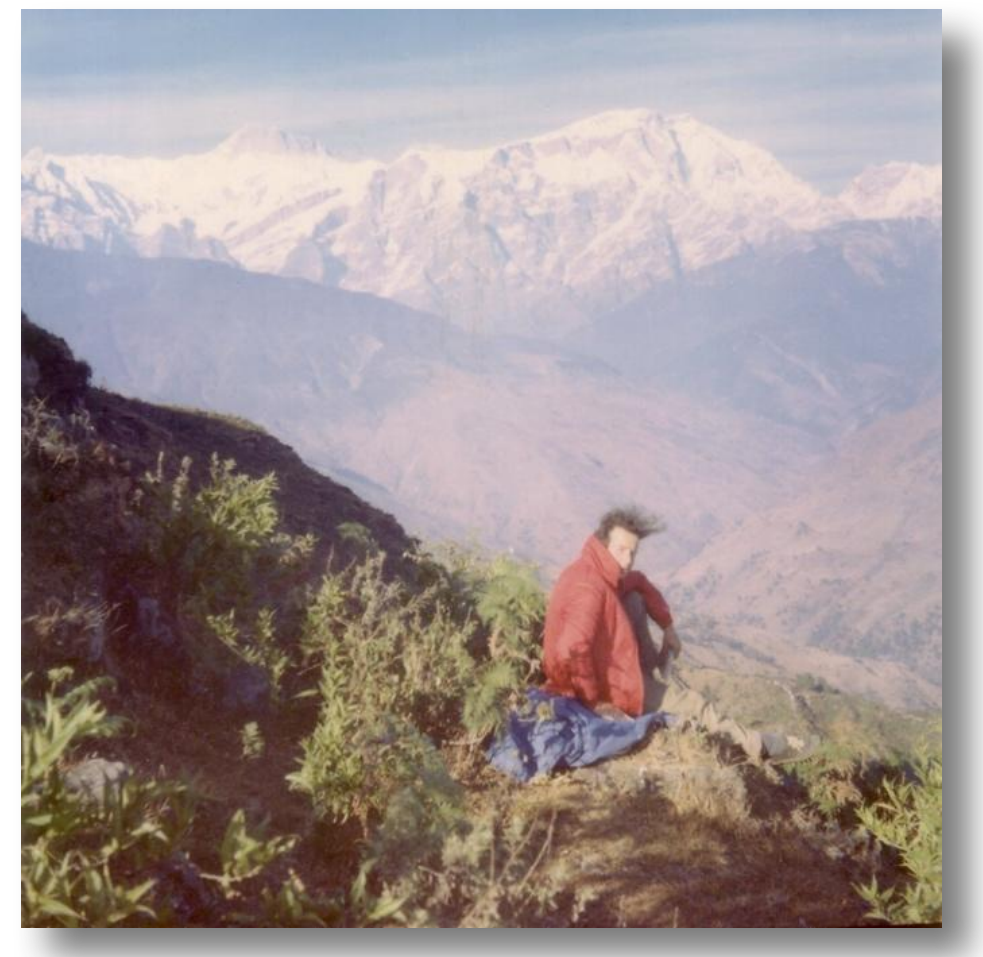

Alan sitting on path towards the washing place 


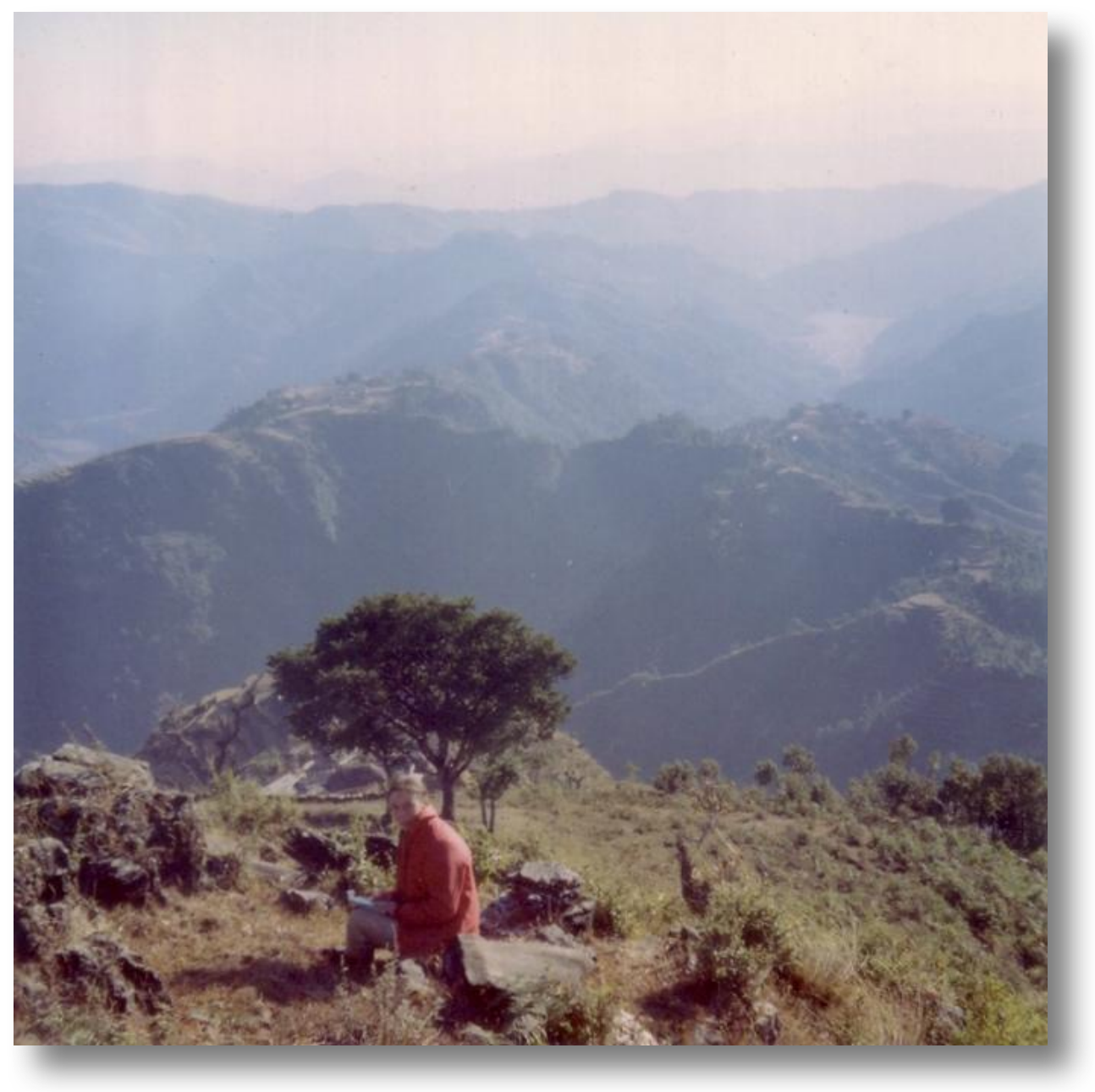

Gill above the village

DIARY GILL Thursday 1st January - Pokhara

Had our ritual "Annapurna" breakfast and then washed hair - had a lovely time with nice neurotic American from Sikla area discussing Gunter Grass. [Not transcribed]. Then American AID couple joined us - don't know why we like them so much - perhaps Len reminds me of Amal - a great galumphing baby really with a very soft heart. Said an embarrassed goodbye as they were hoping to get plane today. Went up to the library and the college in hopes of seeing butterfly collection. Only saw Gavin who looked a bit down and had a bit of a strained conversation when he said how guilty he felt tearing the Mission to bits, me tearing it happily the while. Then met Mrs Turner at hospital - Scotswoman with nice children (four) one with a bad stammer. Went back to library where I didn't feel like writing letters at all but managed a bit to Iris. Bad tempered over badly organised dinner. 


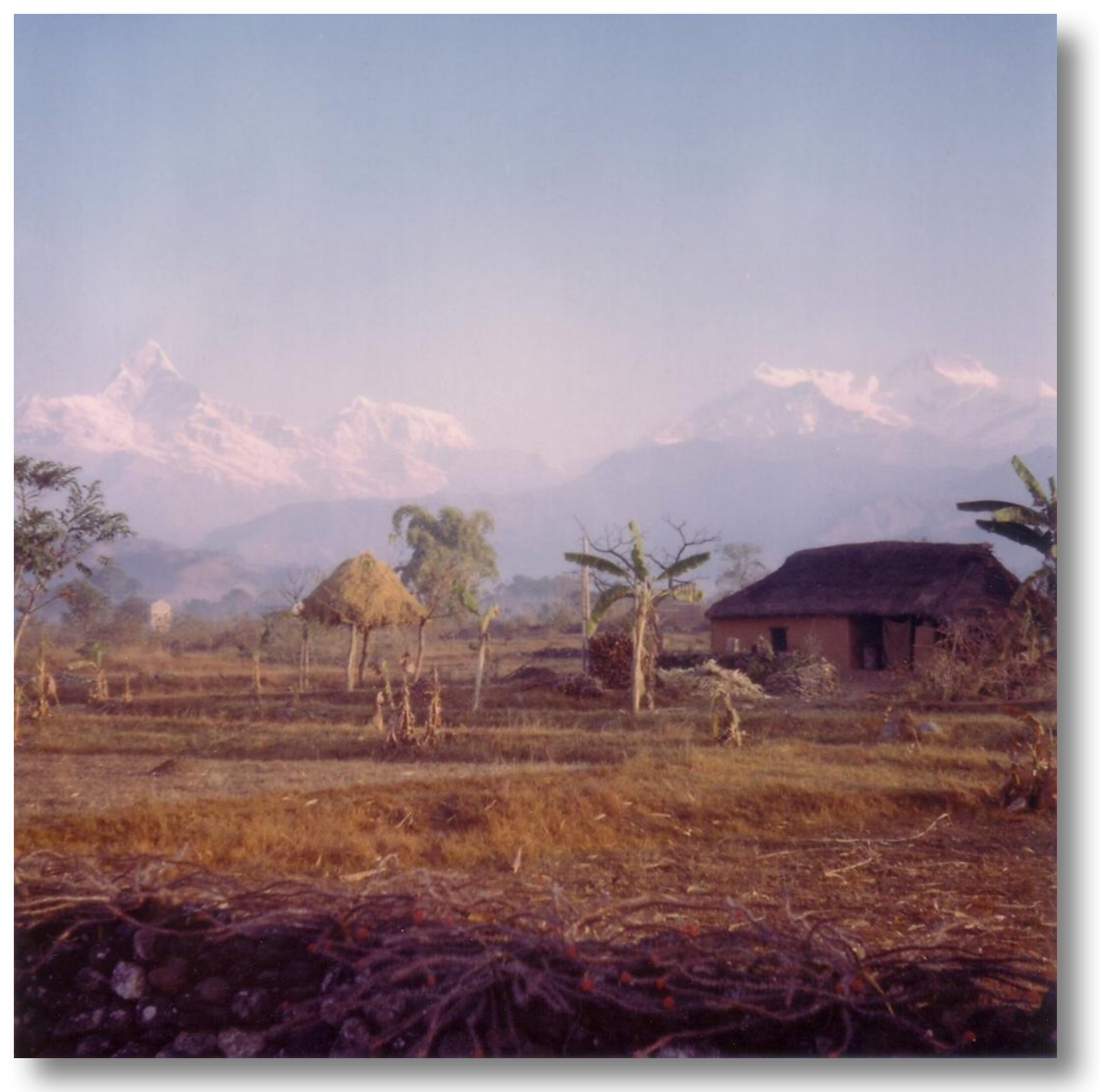

In Pokhara, looking towards the mountains above Thak, on right

\section{Letter from Gill on 1st January 1970}

Am rather hot and gritty at the moment having just walked through the Bazaar, teeming with life and buffaloes, but am borrowing the machine at the library which is its usual haven of peace (have spent a somewhat evangelical Xmas so phrases like this will keep emerging) and where Mr Pant has just brought me a cup of tea. A. is guess where, at the Nepali hospital with the head of Pignede's village stocking him up with, hopefully, condoms, pills, and the like, as we sold the idea to him during our six day's stay, from which we have more or less just returned.

...We are returning to the village this Sunday, getting more and more bubbly and manic, will have to contain it as don't want to hurt Thak, but of course they know my feelings. We have just been trying to arrange with the Mission Hospital that Dr Turner might manage to come again, or rather to come as he was sick in November and couldn't make it. Have also tried to see a butterfly collection at the Training College which is exceptional I'm told, but it was locked, so rather a nothing-gained day. However we had a shower this morning and A. discovered fleas round his midriff, it not having seen the light of day or water for nearly three weeks. Reread what we couldn't absorb in the letters last night, and generally let our tummies recover from brandy on New Year's Eve, Danish salami, Kathmandu cheese and Pokhara chicken. You will gather from this lavishness we have been in contact with Americans, and AID to boot, but despite the above exceptionally nice, a joy to talk to 
as they agreed with us in everything from birth control to the waste of institutions in countries like this and India (they are in Delhi and were clearly shattered and radically changed by the famine in Bihar, they have been there 15 years). We met them on the way down to Pokhara in a Gurung village where some Australians are doing a linguistic study. The husband had just been peed on by a Gurung gran as they were sleeping on the verandah and was a little shattered, but the wife tickled, more used to Indian villages I think. Last night was spent over the food in discussing what is becoming a monomania, they have actually had something to do with the birth control drive in India, and it was the first time I have met people who have felt nearly as strongly as A. on the subject. There was also a French couple who had worked in Patna, calm and rational about it, but still very concerned although not really prepared to do anything.

\section{DIARY GILL Friday 2nd January - Pokhara}

Washed in the morning, hotel marvellous about bringing me hot water. Alan wrote letters and then after lunch we went to the Indian Pension Camp to find rather a gorgeous Indian Major with a curling moustache, and willingness to flirt. Most helpful even if he couldn't give many facts. Also met our man from Mohoriya there, even more nervous and anxious than in the village, but very sweet. Brought him back to the hotel and Alan gave him 'pa' and fried eggs. We then wrote letters and had early, cold night. Washing not dry because of overcast day.

\section{DIARY GILL Saturday 3rd January - Pokhara}

Alan had to change plans this morning as I thought the library was closed in the afternoon, so we went straight up after breakfast to find that it wasn't. We read and felt jittery and cut in half with all the British newspapers. I got the typewriter again and we had lunch at "The Prince", a new place run by a confident/nervous Sikh. Had minute portions of fish and Alan curry without rice, but expensive, the place filled with a rectangular machine for making Espresso coffee. It frothed all right, but tasted of salt. Alan went to work at hospital, on the records, and I went back to the library and wrote letters until $5.00 \mathrm{pm}$. So good working at a good table, with cushion and chair and sun streaming in on my back, with a dictionary, lots of them, at hand. We got a very crushed ride back, one Gurung with his hand affectionately on my knee and Alan getting cramps with crouching. Read Bible over dinner, the anthropological bits from Isaiah, superb, especially bits on magicians who "peep and mutter" $(8,19)$ and "let everyone wail for Moab/Mourn, utterly stricken,/ for the raisin cakes/Kirharesheth" (16,7)!

\section{Letter from Alan on 3rd January 1970}

...We both feel fit, if buggy and a little blistered, after our 2.5 weeks hiking round. Everything went surprisingly well. We reached Mohoriya after two nights stay on the way at the British Experimental Farm at Lumle. On a personal level the British couple (ex-Africa, agriculturalist, stiff upper-lip to the extreme) were hospitable and well-intentioned and there were many good features, in the plan of building a demonstration farm to which Gurungs (bot only ex-British Army Gurungs - though the money comes from the Ministry of Development) some for 3-week courses to learn how to grow fruit trees, vegetables etc. Won't go into a critique of it now, but if I had approx. E100,000 capital and another f25,000 approx. per annum to spend, I wouldn't spend it on building elegant chipped stone buffalo milking houses, paths etc., and introducing tomatoes from abroad when they already grow perfectly good local varieties. The problems in the Gurung hills are forest depletion, over-population, failure to use rice and wheat properly etc. - none of them will be touched by this scheme. Of course, cynically, the trouble is that those in charge know/care little about the Gurungs (or Nepal) and would rather the thing was conspicuous aid (ie. buildings etc.) than that it really got to the heart of things. 
Hence, nil research before embarking, expensive plant, ludicrously high salaries for "experts" etc. (paid by Nepali government, admittedly). That is the thing about aid - concentration on institutions/showe, rather than needs. But it is easy to criticize when one has done nothing beyond distribute a few dozen birth control pills oneself. Doubt, however, whether I will be able to resist the temptation to write on aid/development when we return. It was especially nice to meet the American Aid man from Delhi who agreed with me wholeheartedly. He said that the thought "Aid" would be packing up in India soon and that the self-seeking among the staff scrambling to prolong their huge-salaried jobs was depressing (he himself gets approx. f12,000 pa! - but is leaving in May to return to the U.S.)....

\section{Letter from Gill on 3rd January 1970}

... We went to the British run agricultural farm at first, sleeping in army tents and being shown round the lettuce beds and new paths by the couple in charge, the Flatts. Alan was worried and sceptical about it all as he felt they were missing the real needs of these hill people, and an emphasis was being put on buildings, institutions and the like, which would look good on paper and showing interested AID personnel around, but what about the Gurungs?' Alan felt more strongly about it than I as he knows more, but we both felt uncomfortable being kindly entertained and yet unable to accept the premises behind the project, and not really being able to discuss their openly as Flatt was obviously worried, although bluff and hearty on the outside, but having asthma attacks at night, the farm being at an early crucial stage, when they don't know that the locals are going to latch on.

We then went onto this other Gurung village, which I was rather dreading, but of course it turned out to be the warmest, outgoing and generous Gurung village we have been in. To Alan's delight there was one marvellous informant, the brother of the man who had helped Pignede in 1958 and who then wrote the only existing book on the Gurungs, in French. We had presents of fresh baked beans and millet beer, veg and rice goodies every day, and I found a warm little bamboo grove to read in whilst A. worked on the census and checking Pignede's book. We walked to the edge of the valley right to the base of the Annapurna range, to one of the biggest Gurung villages in the country - a gorgeous place full of thatched houses with nasturtiums running over the white washed walls and pink roses - can you imagine! - rambling over the thatch. I nearly sat on the path and cried! The people were so cooperative that we finished all the work in six days, and decided to go on another famous trek up towards Tibet and China, where you get beyond the Himalayan range and face the arid, wind-howling plains which precede Mustang and the forbidden area. This takes 7 days which we decided we couldn't afford, but we still got as far as seeing the whole Dhaulagiri range and the beginning of the Gandaki gorge, the sacred river, and climbing up to 9,300 feet in about five hours. We spent Christmas Eve at this height, in a brushwood and cane matting rest house in the middle of a black, dank forest full of crashing grey and white monkeys, eating rice and lentils and spiced potatoes, and freezing on the floor on a rice mat and dripping mud floor. However, we made off early on Christmas day and sang carols through the now sun-filled forest which would have done for a setting of the Midsummer Night's Dream, full of bluebirds and sparkling streams, where we had smoked porridge for breakfast over a fire and cleaned our teeth sitting on moss-covered logs, like great calm animals with new pelts. We came down to Secka for lunch and found two British nurses from the Mission Hospital at Pokhara who had set up a dispensary there, and since they really did seem pleased to see us, we had dinner and a gorgeously warm and comfortable bed there, Alan drumming songs for all the Nepalis who were dropping in, and me exhorting them to clap, the Welsh nurse singing in Nepali and the one from Wembley with an accordion. We even had home made bread and lemon marmalade for breakfast, as well as our porridge and fresh thick cream from the buffalo! It was rather marred by the fact that we had got onto religion the night before, and Evangelicalism to boot, and were mutually bewildered by each other's attitudes, it was rather shattering to find myself classified as an Evil person, Alan getting off lighter as he was more with their jargon and concepts, Richard being allied to this type of faith.

We returned via the village to have 20 people to see us off pressing yoghurt and baked beans to us to the last, Alan having talked the head to come to get stocked up with birth control in Pokhara, and then we went on to the Gurung village where the Australian Linguistics couple are working, with two babies. This and the walk down, seeing Annapurna rose and apricot coloured at dawn with a view of the Pokhara lake, pearly and luminescent 
at the same time was perhaps the nicest part of the holiday. The Glovers have much the same loft as we, but have much more equipment so it was much more cosy, and we heard the Messiah on their tape recorder and I had a good getting-it-off-the-chest chat with fessie, whom I am very fond of...

\section{DIARY GILL Sunday 4th January}

Woke with usual tense feeling before we start off to the village. Alan got up first, lovely apricot dawn. Had fried eggs and toast and coffee and left with Thakali man who is sweet, having to look for 300 porters for a British Army Annapurna Expedition next month. Couldn't get our pastry from "Mogambo" until late as all sleeping and not cooked. Taken up in open jeep a new dust-free way. Filled with fat Tibetans with braided hair and red ribbons, wearing stone red and blue necklaces. I shopped for sugar, kerosene, onions, garlic and chili and Alan dealt with the letters, none for us, we were sad about. To my amazement, but not Alan's, Goof turned up so no fret about a porter. We had to unpack everything, pyjamas and kilts sprawling in the dust, to get new stuff in and Goof made heavy weather of the load generally, said he had been ill with colds and he did pant and puff more than usual. Shopped for special biscuits and sugar for Nani, and helped advice on Haricola's dress, bargaining, to no avail.

Found myself walking much quicker than usual, even with a little pack. We only had one stop for lunch under the tree at the beginning of the plain where it turns the corner, and then just at the beginning of the small river valley up to Thak where Goof had his rice cooked. There was an ex-British Army man there, drinking 'pa' at every resting place, and flirting with two Gurung women at this one, bemoaning the fact he had been turfed out. He seemed to be being successful with the women though as we saw them 20 yards on getting them to drink 'pa'. Much giggling and stuffing of 'kramu' into mouth. I washed my feet at the last river crossing, Alan carrying me sweetly over the others, lovely being hauled over, and had a row of six Brahmin boys watching me peel the skin from the soles of my feet and rubbing off the grime. Lovely. Remembered almost a year ago when we were stopping every 20 yards, me from exhaustion, and I ate an orange at the foot of the climb to Noledada, burying it in the rocks. This time we leapt up steadily, not even panting, except Goof, and made it all the way up with only three rests. Met Pot. at schoolhouse who seemed tired, collecting poinsettia which looked well against her tartan headdress. She was tired so I carried her little bundle, a kettle with a lid tied on with string, and a shiny horribly nylon jacket. We stopped two-thirds up the last hill. Good feeling of looking through that leafy tree into a green light with a yellow tit dancing - happiness and colour through the branches. What a view.

Met Totra's father's brother at the top, never seen him so pleased, and an Untouchable and then a rush of children from the poju's place, then Nani who looked pregnant but said she was slowly getting better, very proud of it being typhoid, had mud and cow-dunged the house yesterday ready for our coming home. All very happy and jolly, a goofy grin from Nani in the house down below. Saw they were weaving a 'gundri', and didn't that bring back memories. Also noticed rustling, new bamboo and a sycamore type tree that Mohoriya had been full of, so maybe it will give a fresh impetus for Thak.

Had enough energy to sort out the two baskets and then open a tin of macaroni for supper with rice and eggs. Lots of people in. Comal looking like a Baby Beatle with his hair down to his eyelashes and very cross when he forgot that a child had died, and Prem, who bounced in gave it to Alan before Alan even asked (baby boy of the woman I don't like, there is another son). Prem now an authority on Mohoriya, holding forth with the book on his lap. Servajid also came and was his most off hand and reserved which meant he had something vital to give. Stayed to the bitter end, had done, very proud, all three weeks of what he had eaten, 
etc. Now going to school at Taprang with ten others, loves the gym and did me a demonstration. Alan was having to fetch water as ours left was filled with ants. Gran and Nani came in, left the 'zogimae' cooking up his own maize. Pleased with photo of Ramu. Fed up with the fact Gran will never acknowledge the fact I am here. Nainasing galumphed in. Not too tired when we got to bed.

\section{DIARY Monday 5th January}

Recovering and sorting out from our return from Pokhara/Mohoriya - also finished last of 3 chapters of E-P, "Nuer Religion" and indexed a couple of chapters of Pignede. Rather cold with mountains in cloud, but a little sun. Quiet, with few disturbances. Plan to go down to school to get 'Janasankir' foiled by fact that Pradhan Panch did not go. As we suspected, even more impatient than ever now that we are this near the end and are literally counting the hours.

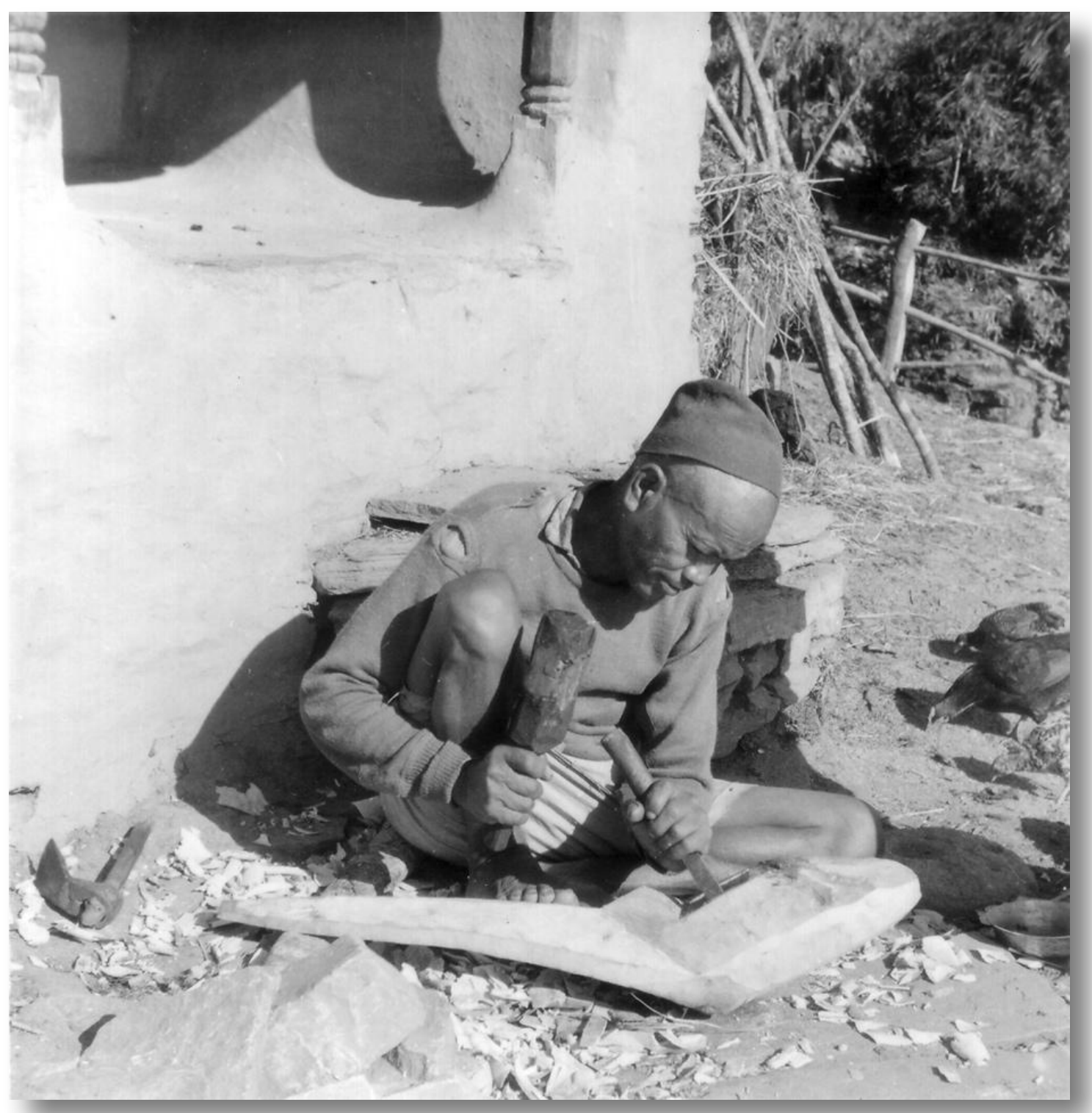

Tekansing making a plough 


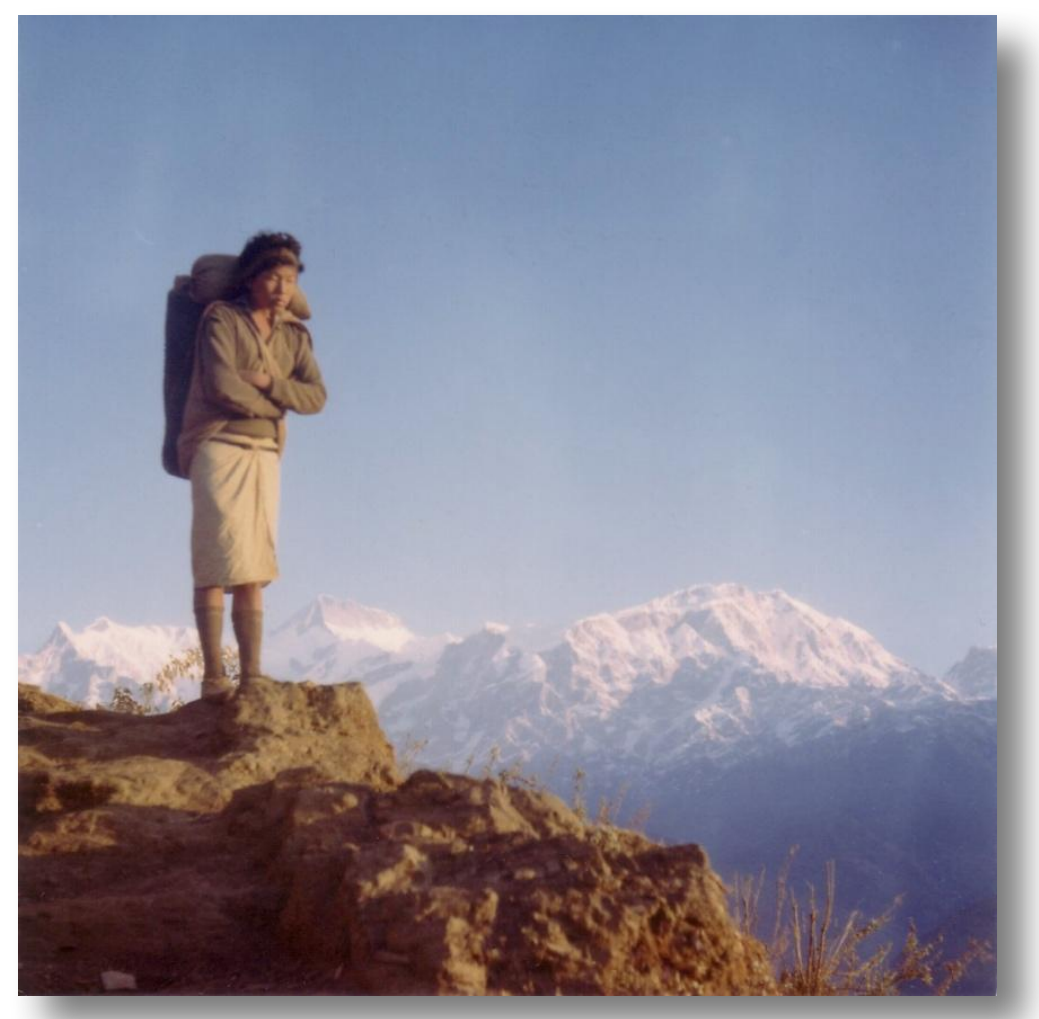

'Togari' with pack on his back, on path to Taprang

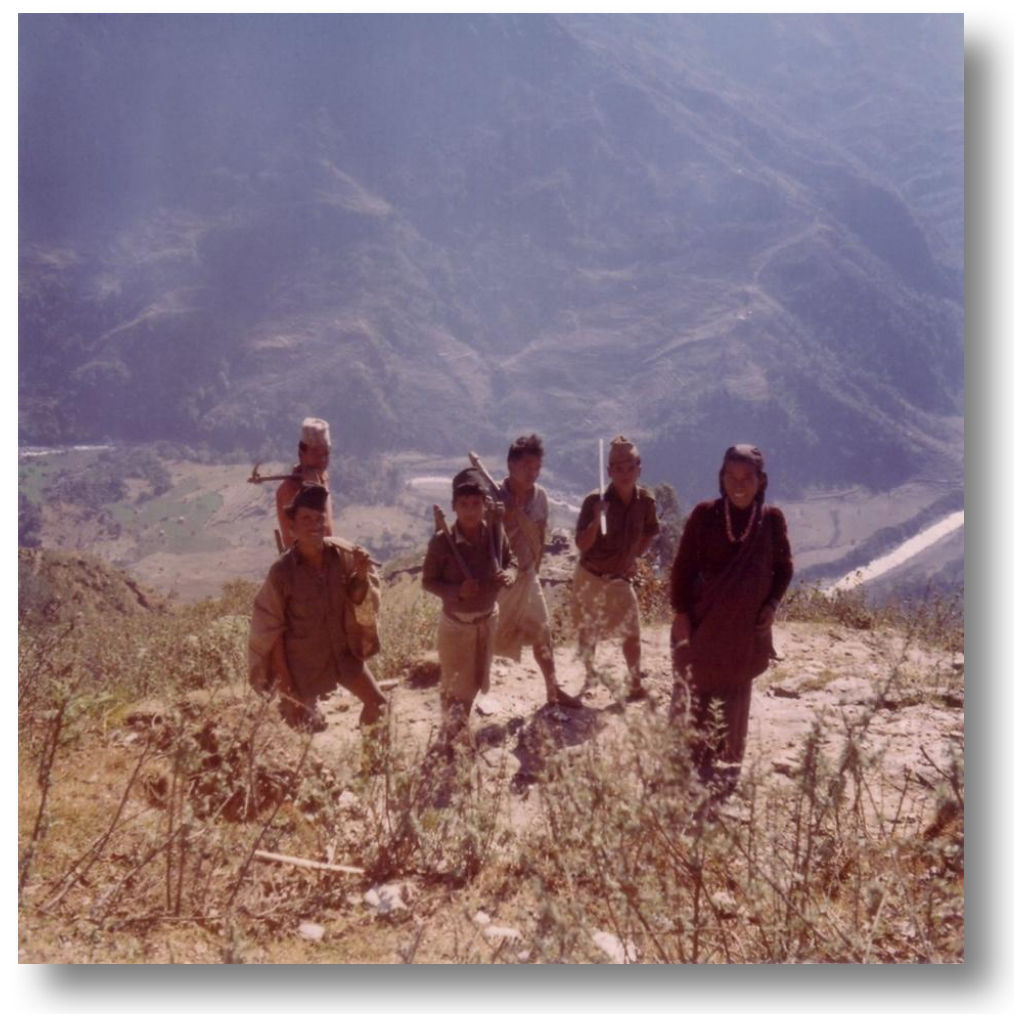

Young people off to hoe 


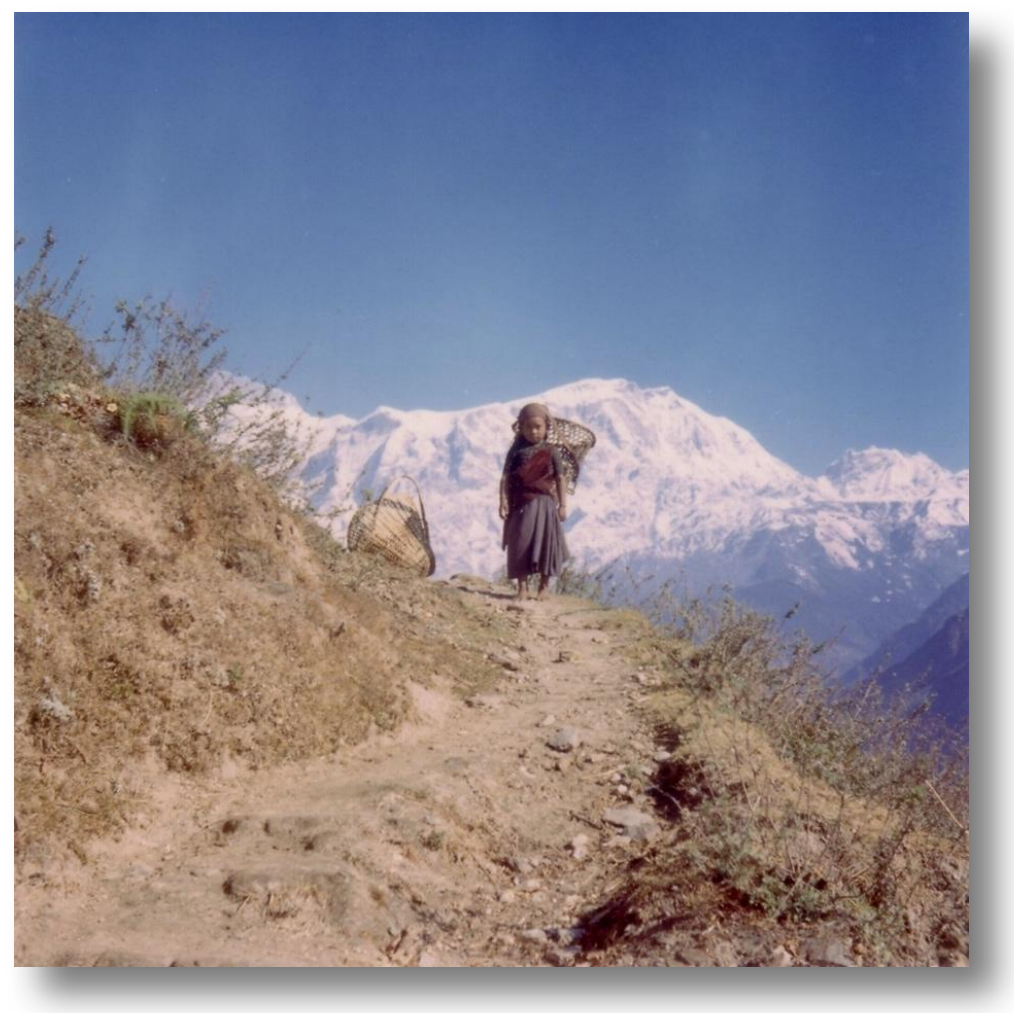

Haricola with basket on her back, on path to Taprang

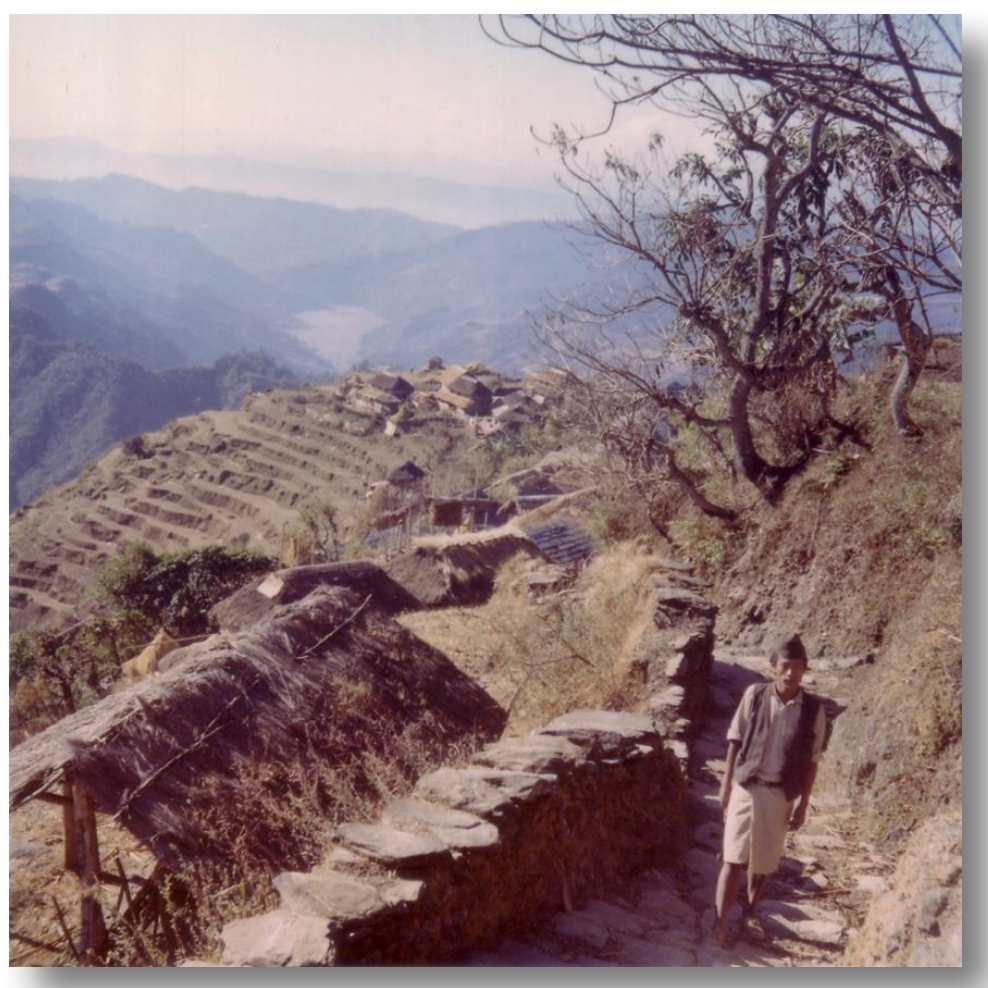

Man on path above the village 
Rather moody day, half in Pokhara, 3/4 in England, and not at all in Thak! Spent most of the time wondering how we were going to manage the rest of the month here. Alan felt same, counting every hour, even though he got down to indexing Pignede straight away. Usual first day blues, I suppose. sorted out and filed all correspondence in the morning - whilst Alan was landed in the usual Thak situation of promises held out by informants and then finding they weren't there. Was to have gone down to school with Ramchandra, but latter did not turn up. Rather grisly when we went to out toilet in morning - child's grave with white stones and flag roughly stuck over it. Hadn't quite realized that that side of hill was used for cemetery. Also very fierce dogs guarding sheep in fields below - after Jessie's experience in her village bit worried about this. After lunch and a brief attempt to get into "Jude the Obscure" (so like "Tess" at beginning that I wonder he didn't have qualms about it), but simply fell asleep until $3.00 \mathrm{pm}$. Again usual depression sleep - feeling that we just want to close our eyes and wake up day before we leave - not tiredness after yesterday's rapid walk.

Went round village after that, bought some 'pa', said hello to Mrs Bhuwansing who presented me with some ancient drooping 'pasagi', some Aspro, and got dinner ready. Alan disappointed to find poju out and then later, that he had gone on a month's trip to Pokliaba... had quiet supper with just Haricola and Gopal's mother - latter amused when Alan called Haricola his baby wife - after checking that I was amused too, and told us that the baby's mother who had died had not cried much - and had a "strong spirit" - 'saw bon' (hardhearted?) but father had cried a lot. Child had swollen overnight round throat - lovely baby, just getting big. Then Gopal same in with a pigeon he had just shot, dangling it temptingly before us, and Nainasing with his usual aches and beams - saying how he would miss us - with a big beam. Then finally, Servajid with his list, very bouncy after going to Pokhara and back in one day, Boje's younger brother saying how fat we were now, and Gundasing with a new pair of shoes he couldn't keep his eyes off, and which I was asked to admire - 11 rs., blue and white, and would look lovely with socks he said! Reminded me of my first suit and waking up at 4.00am on Sunday before going to church - to admire it!

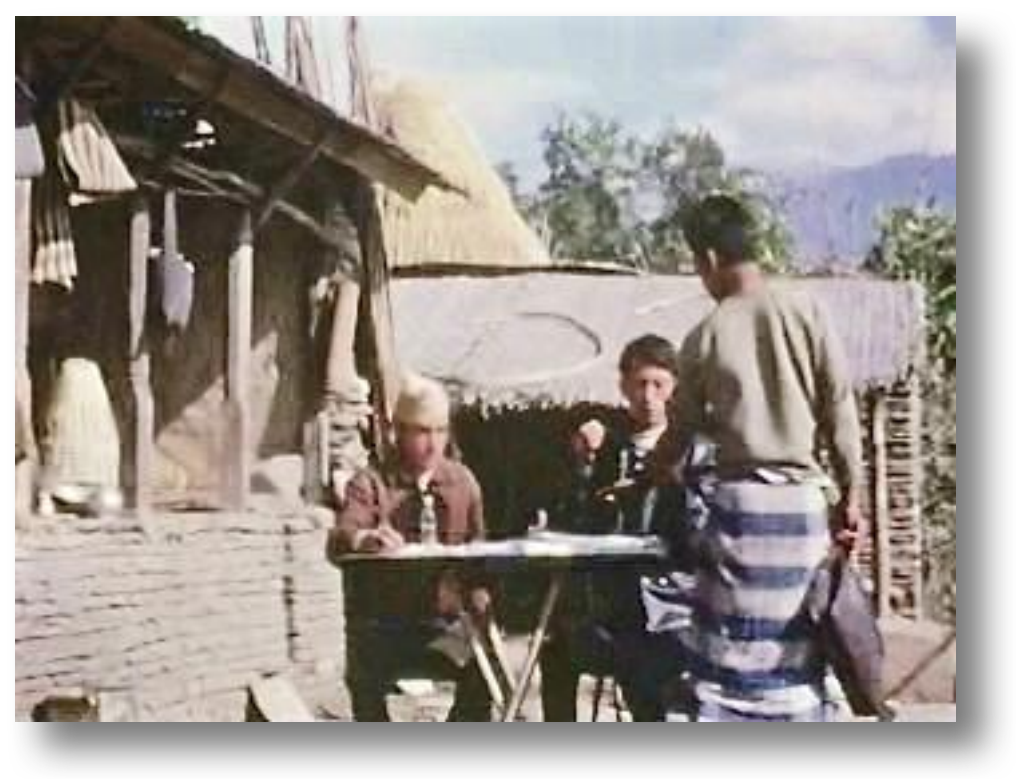

FILM. Health workers giving people smallpox jabs in courtyard of House24 https://sms.cam.ac.uk/media/2736524 
A better day as more work to do - though Gill's tummy a bit upset. Village all being vaccinated - why don't they do birth-control/BCG with it? Did Bhuwansing's 'gola' book (after which he proudly showed me his passport, a sanitary towel and some condoms). Then from about 11.00am. onwards did another 'bunxawhole' with Kumansing - up till about 4.00pm. Usefullish. Villagers very friendly.

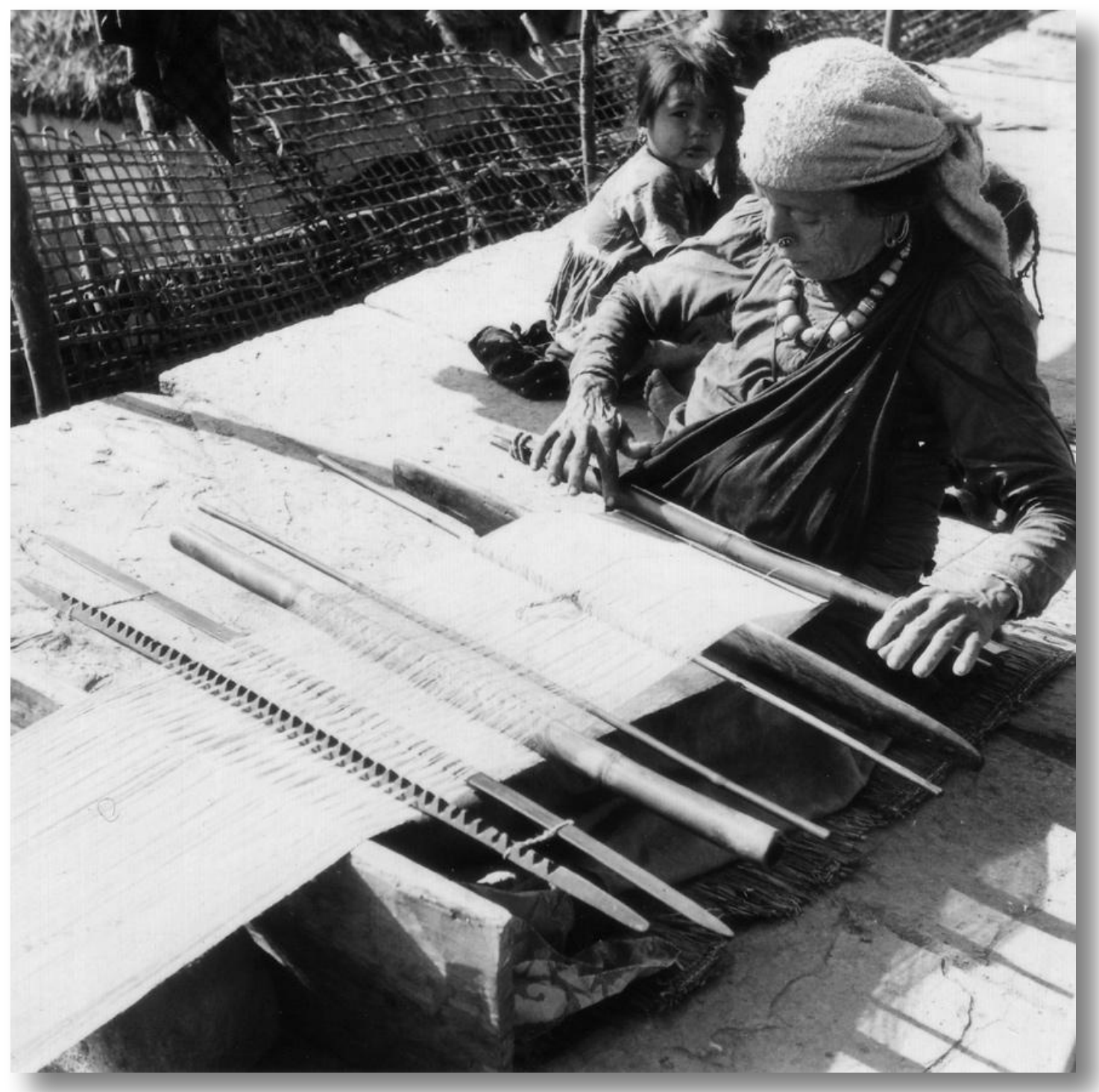

Dansuba weaving 6th January 1970 

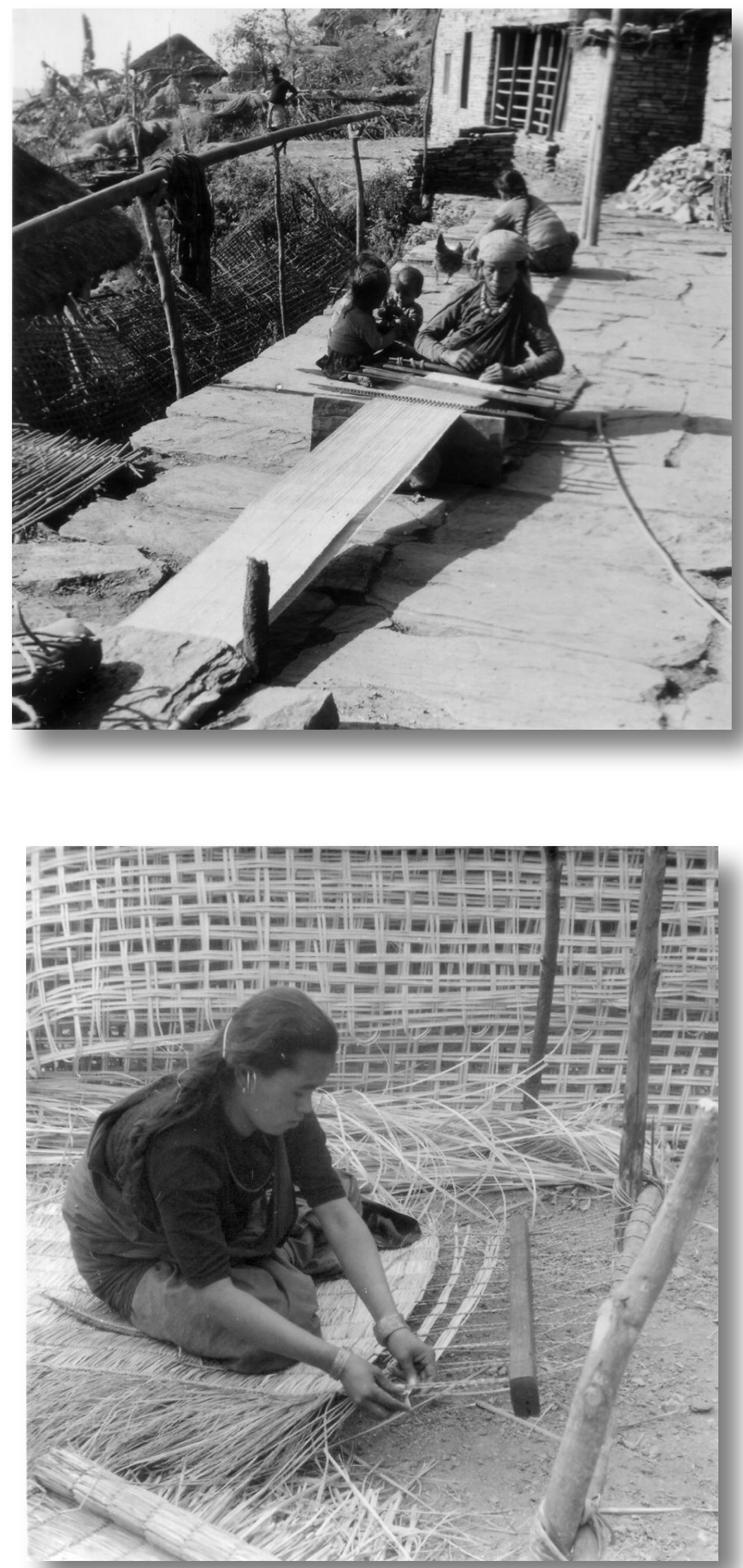

Bima making a sitting mat ('gundri') on 6th January 1970 


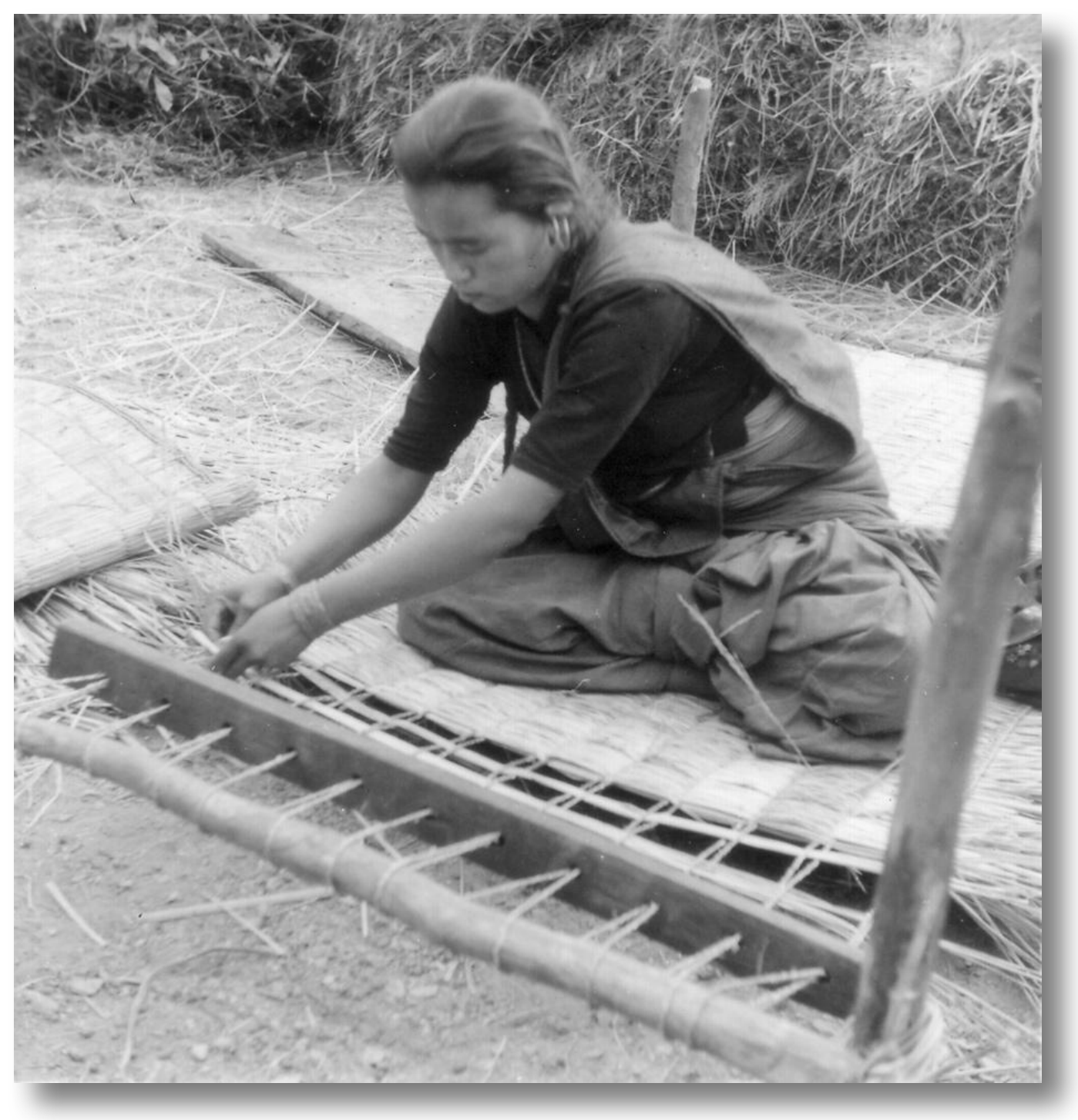

DIARY GILL Tuesday 6th January

Felt much more cheerful and able to accept fact that we were back in Thak, like it or not. Spent morning on drawing up my child-rearing questions and typing out some Pignede. Alan very cheerful as he pinned Bhuwansing down for a 'gola' list and worked with Kumansing on some old documents. It is so good to see him cheerful with a sense of doing something. I went up my hill after lunch - after finding out that Ramchandra's wife's sister - the one I liked so much at Mohoriya - was here. She looked pleased to see me too.

In the morning I had gone to put some penicillin ointment on the spastic boy and everyone was very sweet along there. It was quite windy but warm on my hill, seemed to have the whole world to myself - not even many flowers to share it with. Only 2 or 3 jasmine out. Read "Lenin" with much pleasure - love his combination of sense of mission with ability to give up the closest ties for sake of an ideal - even though that ideal might merely have been Lenin himself. He had a ruthlessness which was impressive with his sense of humour and deeply happy marriage. Unfortunately my tummy seemed upset and I had bad diarrhoea twice, and it was an effort to make supper, with pains, etc. A lot of people came of course - but went quite promptly as they wanted to play cards. My poor boyfriend thinks I don't like him when I do, but too queasy to explain ins and outs. 


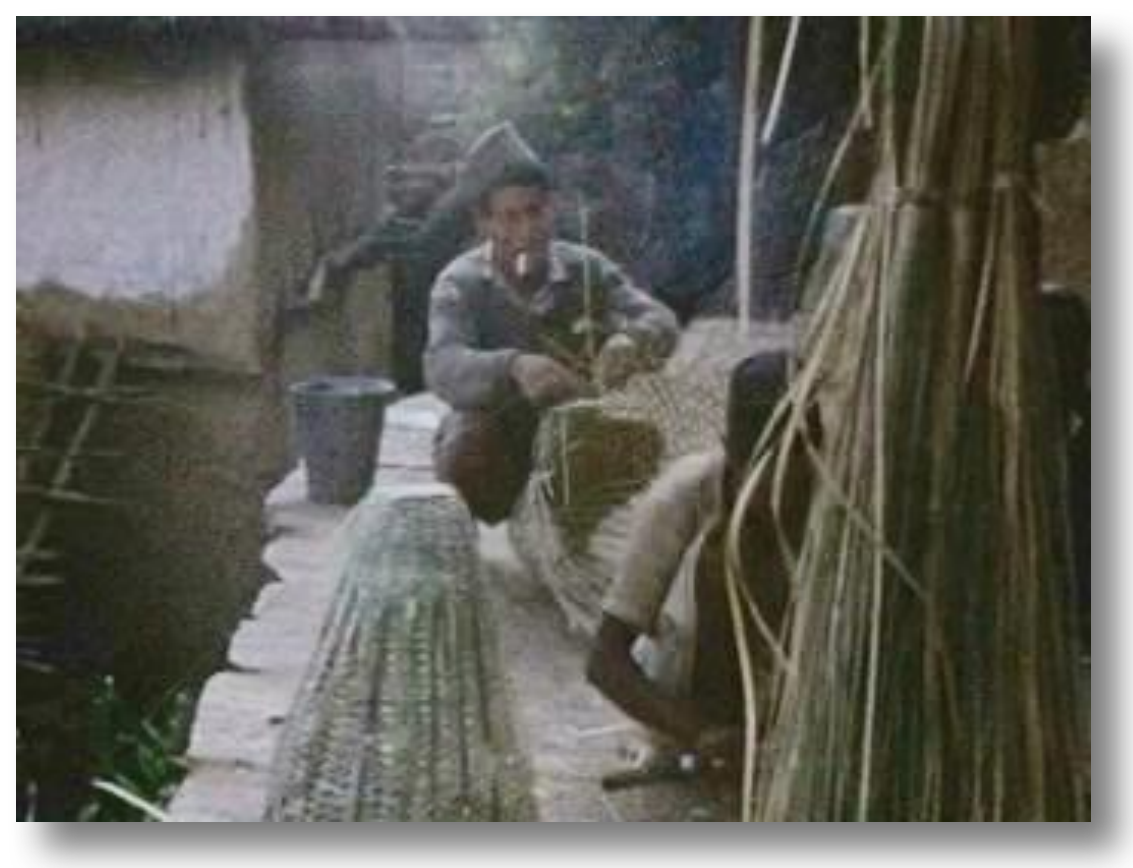

FILM. Two men, at House28, (the one with the cigarette looks like Gunga's husband, Jitbahadur), making bamboo baskets

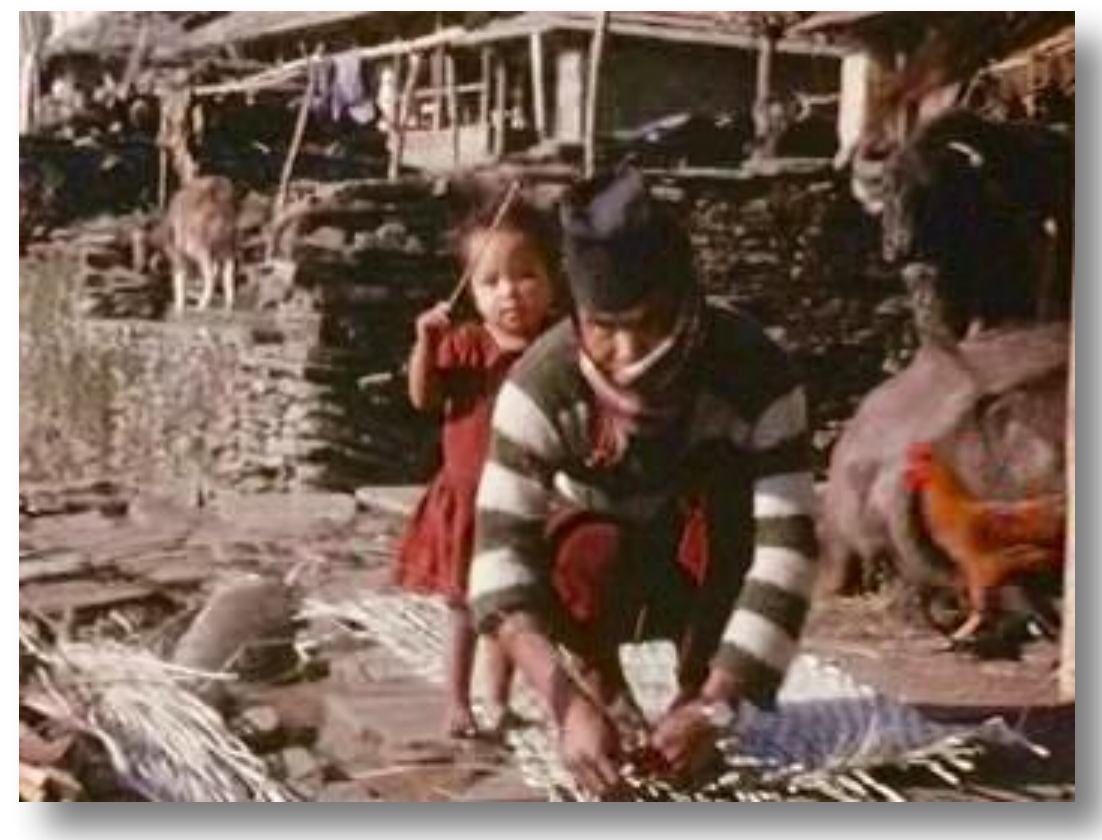

FILM. Bolbahadur ("Posbir's maila"), on leave, with little daughter, Kesari, hitting him with a stick, while he makes some bamboo fencing https://sms.cam.ac.uk/media/2736580 


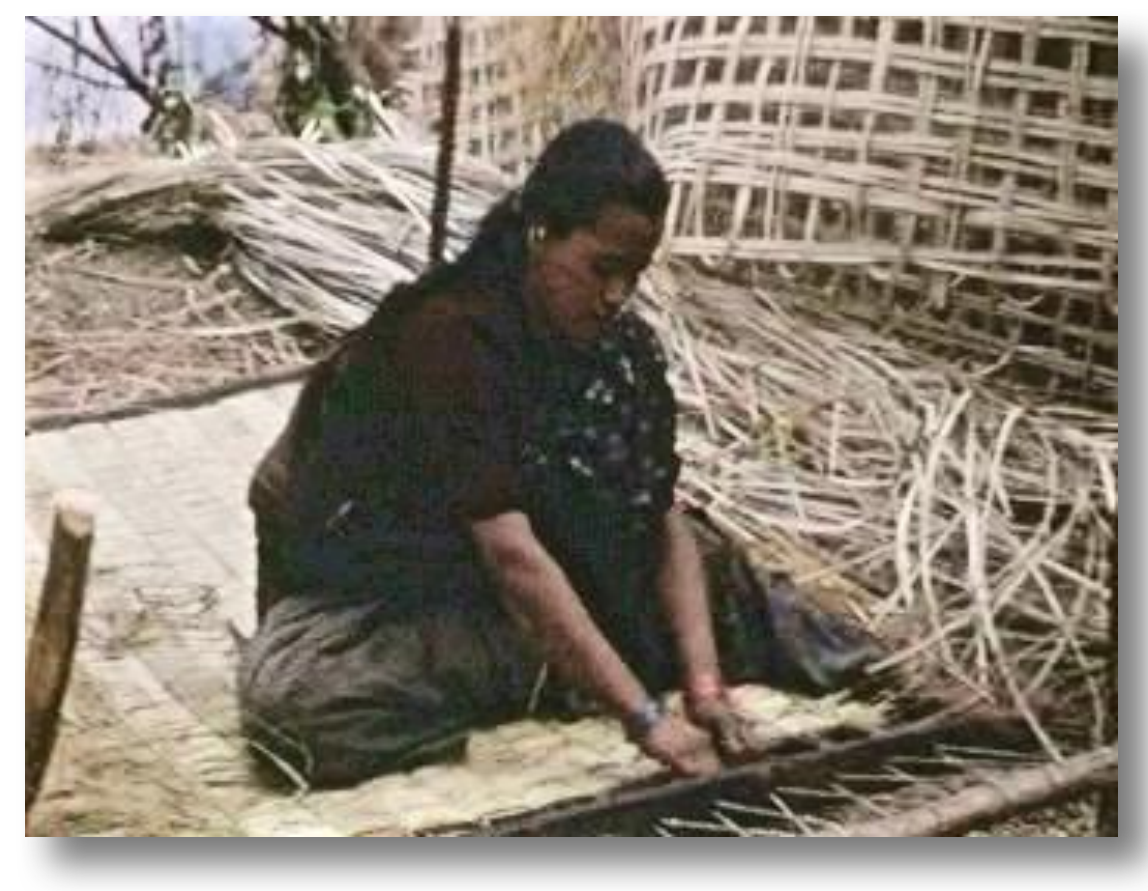

FILM. Woman (Kumansing's 'song', Bima) making a 'gundri' at House15 https://sms.cam.ac.uk/media/2736608

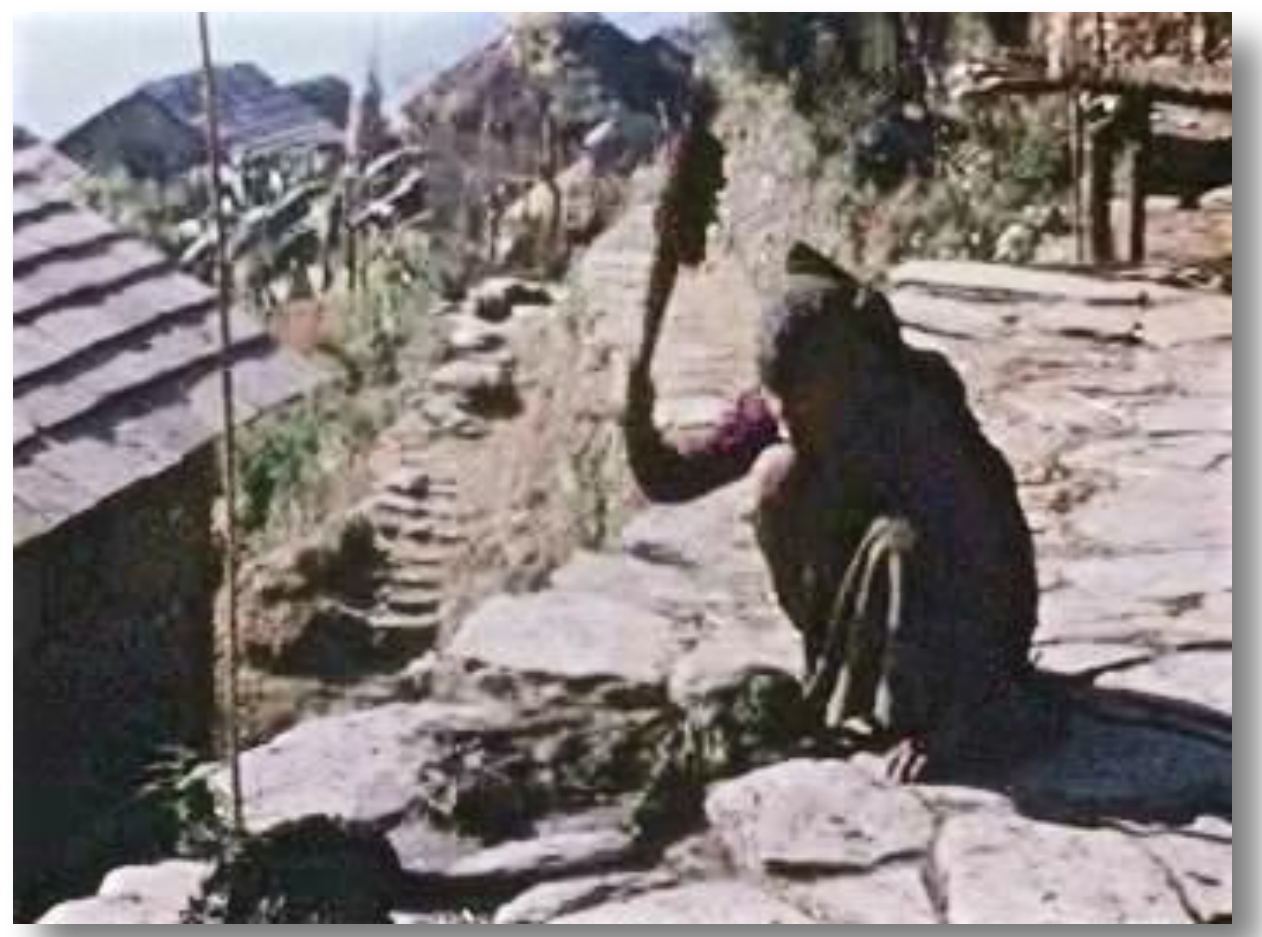

FILM. Old woman ('dogon' gran.) beating 'nangi' on terrace above our house https://sms.cam.ac.uk/media/2736636 


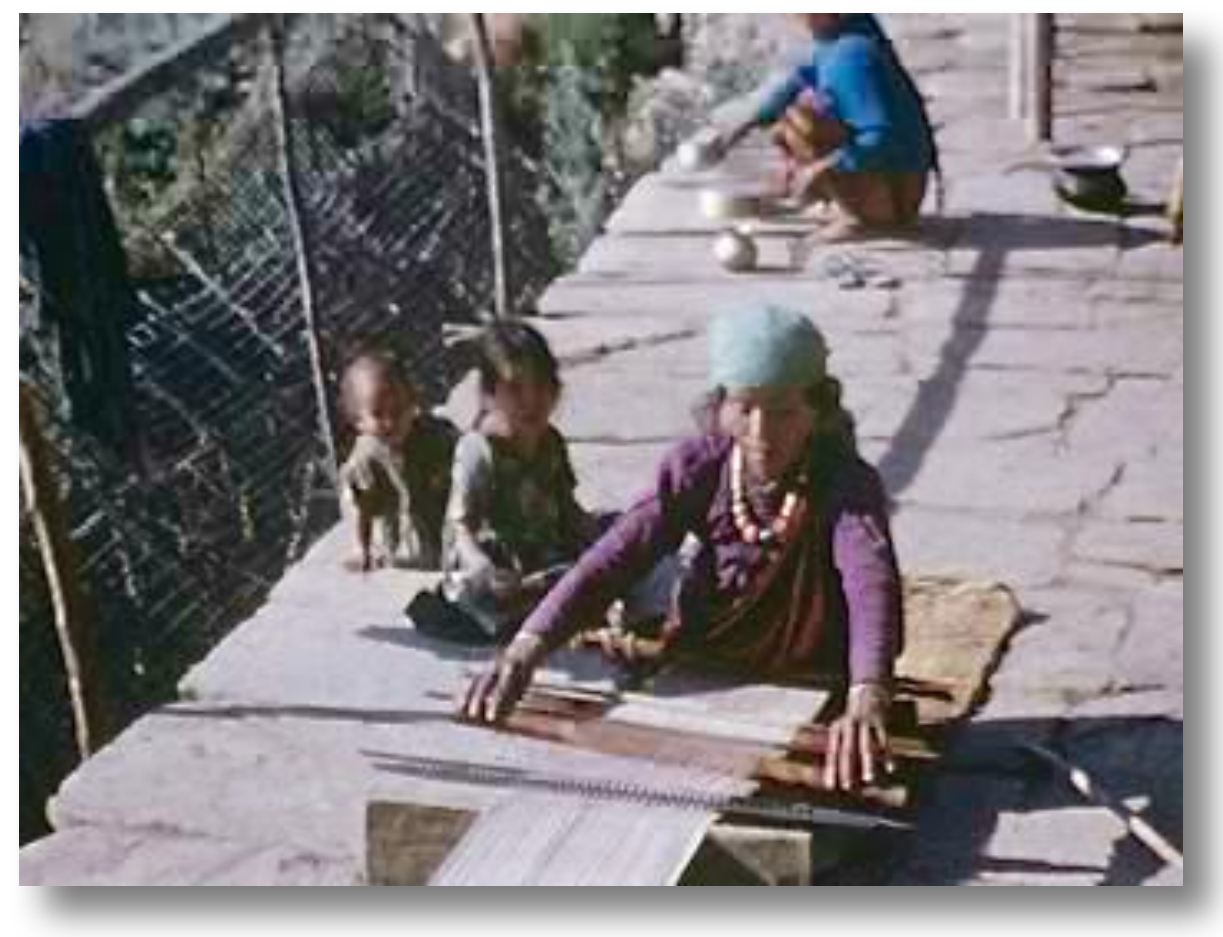

FILM. Dansuba weaving with Asmaya in the background and three small children https://sms.cam.ac.uk/media/2736664

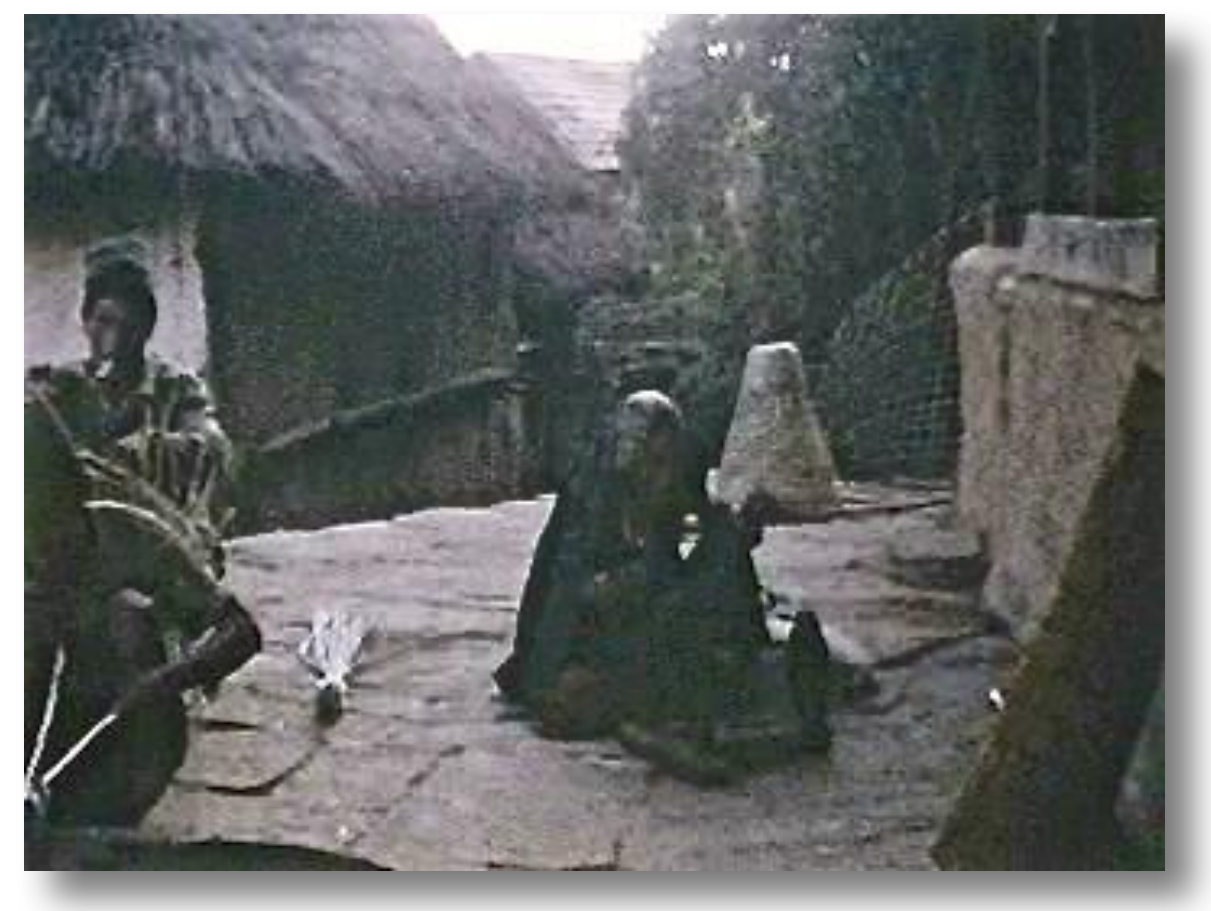

FILM. Old woman, Basuntikumari, spinning on the platform of House28 Two men are making baskets https://sms.cam.ac.uk/media/2736692 


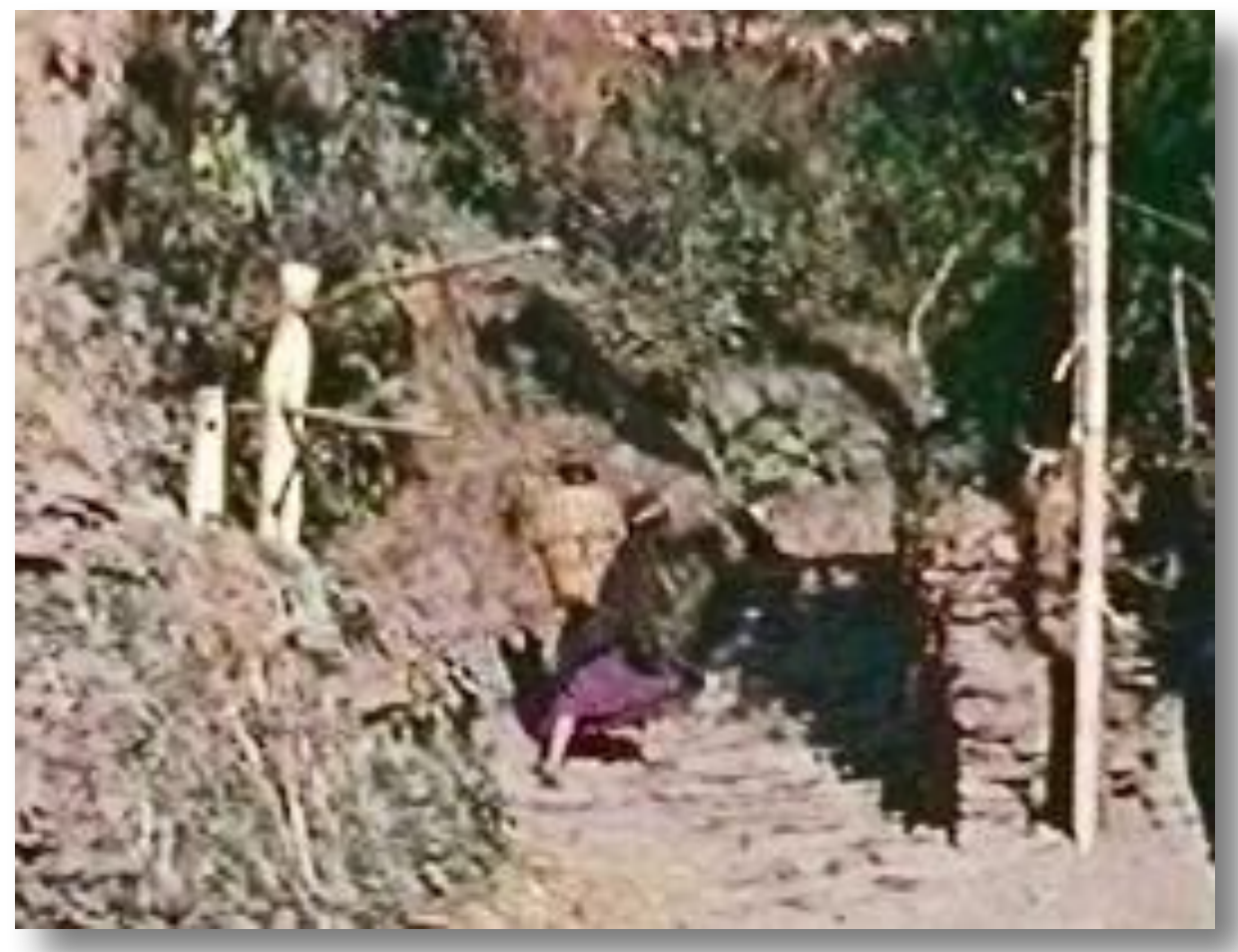

FILM. Bolbahadur's sister on her way to get water and oxen standing beside the 'hotel' https://sms.cam.ac.uk/media/2736717

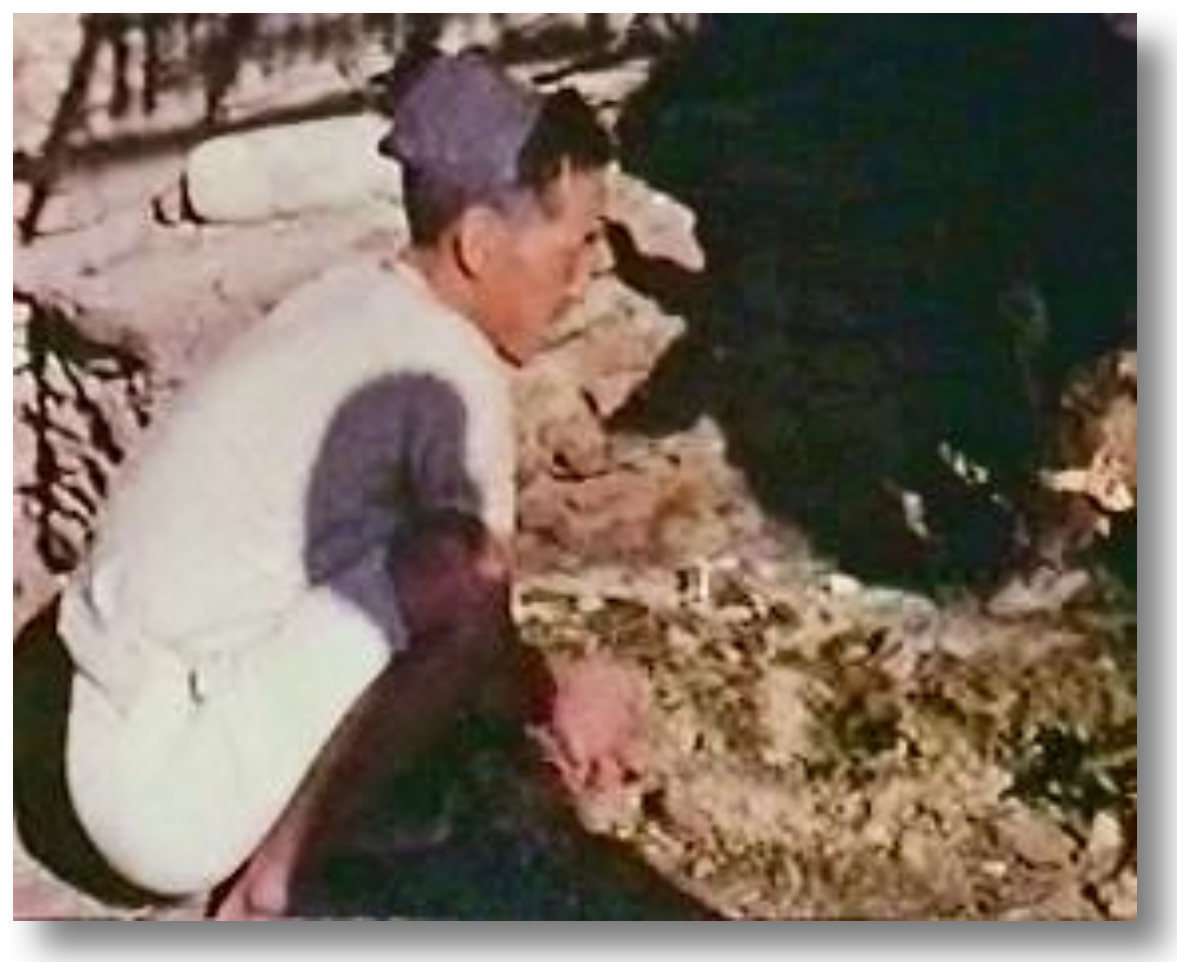

FILM. Badrasing clearing up buffalo manure https://sms.cam.ac.uk/media/2736745 


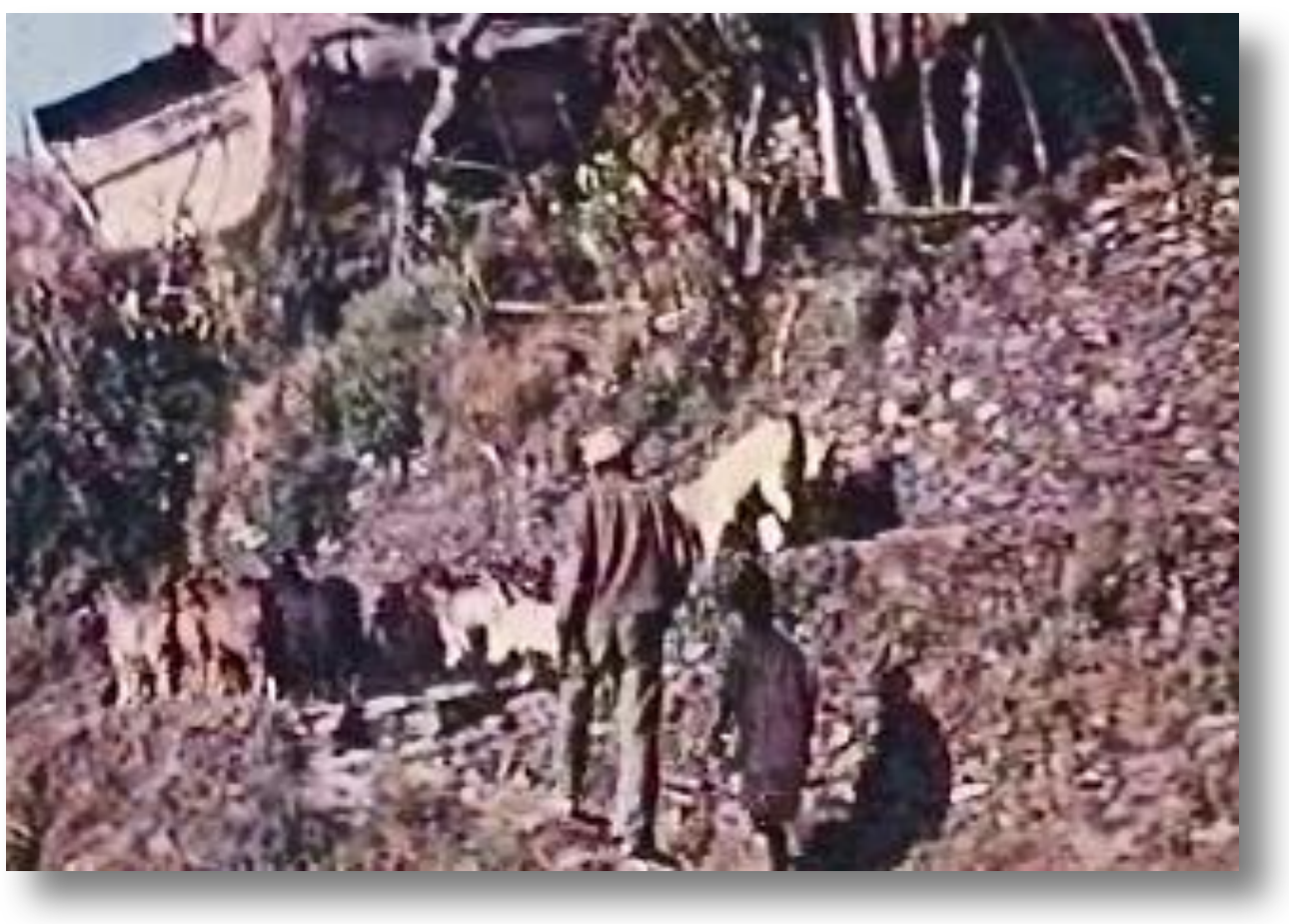

FILM. Herding goats out of the village https://sms.cam.ac.uk/media/2736773

DIARY Wednesday 7th January

Hailed a bit in afternoon! Cold, with gushy winds and great banks of black cloud. Gill with bad dysentery - had to go a number of times including the middle of the night. Headache and feeling a bit wretched. Less interviewing work for me, so took films and indexed Pignede, but time dragged somewhat. Started to read M. Mead "Technical Change and .." - quite interesting.

\section{DIARY GILL Wednesday 7th January}

Had a very bad night, with nightmares (trying, trying, to get planes and never succeeding will we ever get home?). Had to rush outside at 2.00am. with bad diarrhoea and gripes, and just as I was forcing myself to get up in the morning, had another attack and had to use the bucket in the loft. Alan very sweet, making me comfortable in bed - gazing at black as sin sooty cobwebs - oh for the virgin freshness of the twin bedroom at home! Felt lousy all morning, had to go again before lunch - usual problem of whether it is bacillary/amoebic. Managed rice and oranges for lunch and then read "Jude" all afternoon whilst Alan restless, went out and filmed. I do love him. Impatient with Hardy, unsympathetic with Jude and Sue, seeing them as 2 neurotic children. Not as fine as Tess, I think. See why Lawrence liked all intense complications. In afternoon the wind got up and it even hailed a little - reminiscent of last year. Felt little steadier and enjoyed potatoes and eggs Alan made for me, sweetly, even though he felt rather chilly and wanted to sit by fire. 
Gill still bad and stayed in bed till evening. I went down to Uli and finished off Pignede with Brikaras and took cines. Warmer, sunnier day. Felt a bit faint on way back and slept when I returned. In evening some Tibetans came in and we had a bit of a guitar sing-song, although Gill still didn't feel well. Still the time seems to drag past very slowly indeed.

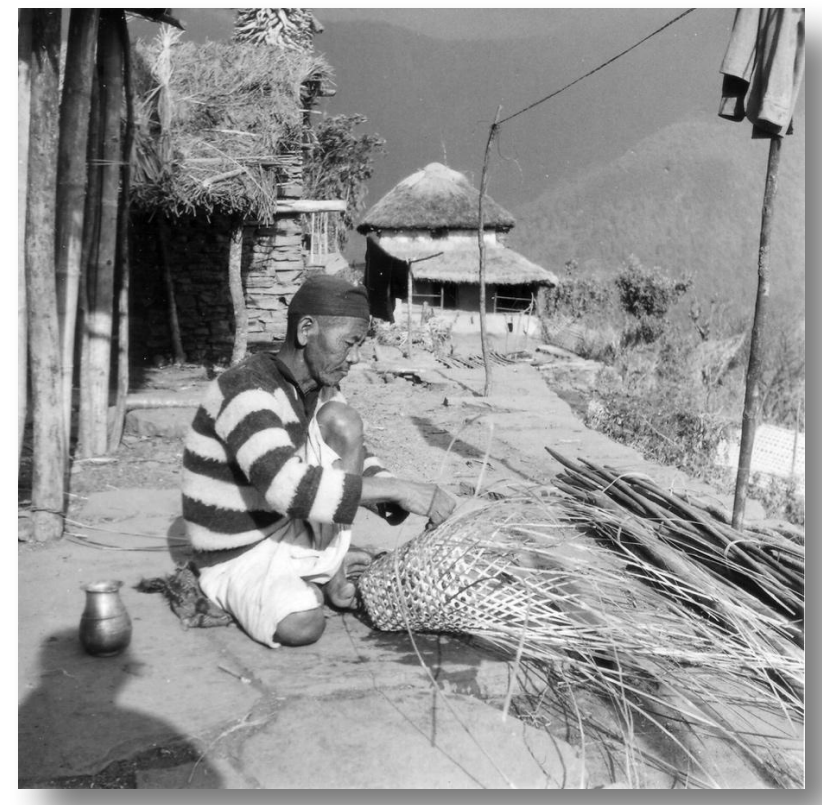

Posbir making a carrying basket for dung - 'mal kwova pih' - 8th January

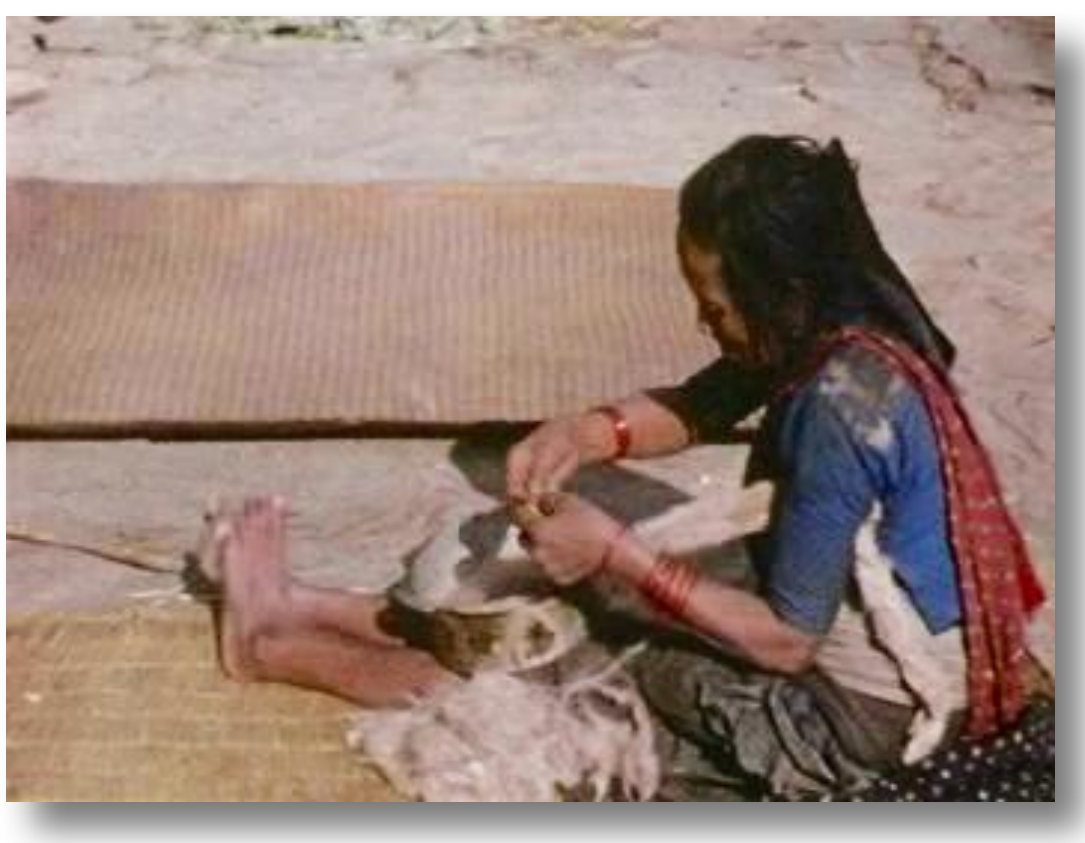

FILM. Nansubar teasing out 'nangi' thread https://sms.cam.ac.uk/media/2737755 


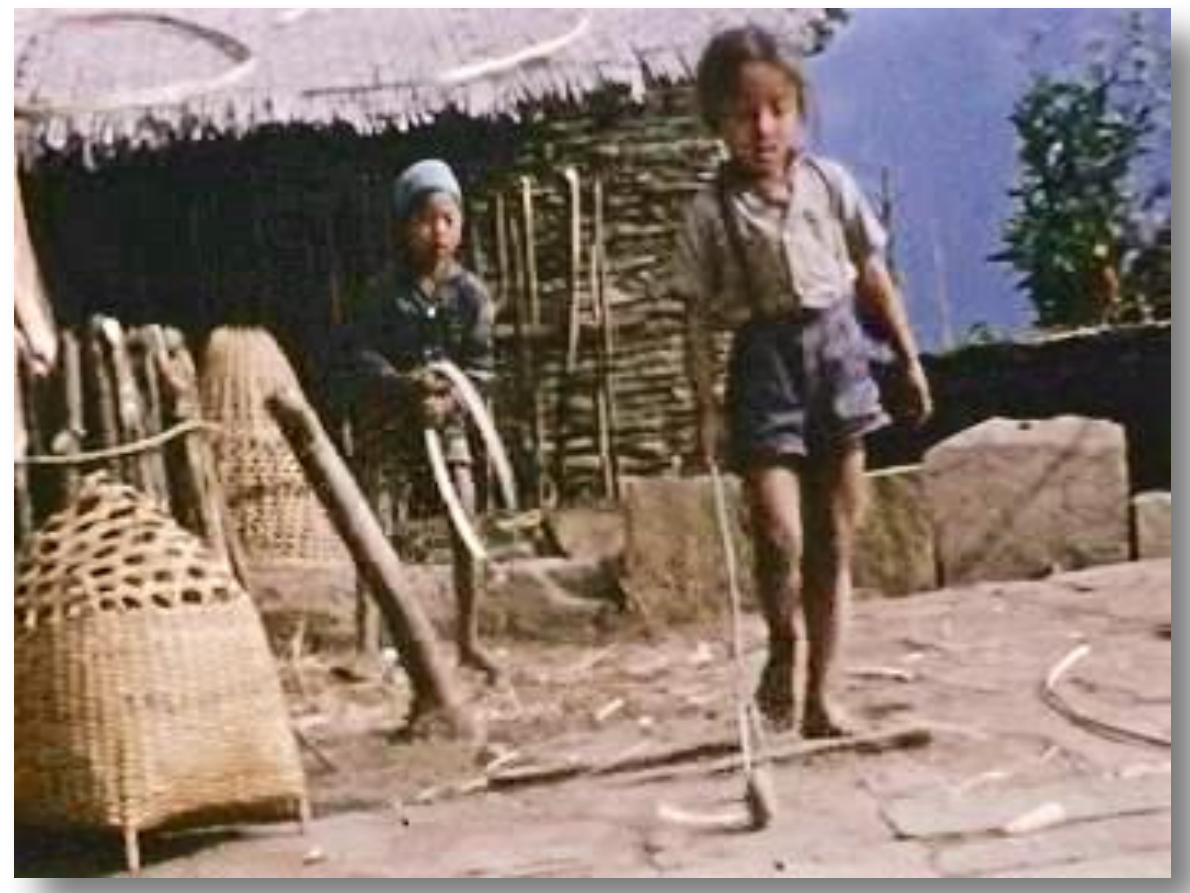

FILM. Totra and Syebahadur playing with a wheel on a stick and a hoop https://sms.cam.ac.uk/media/2743796

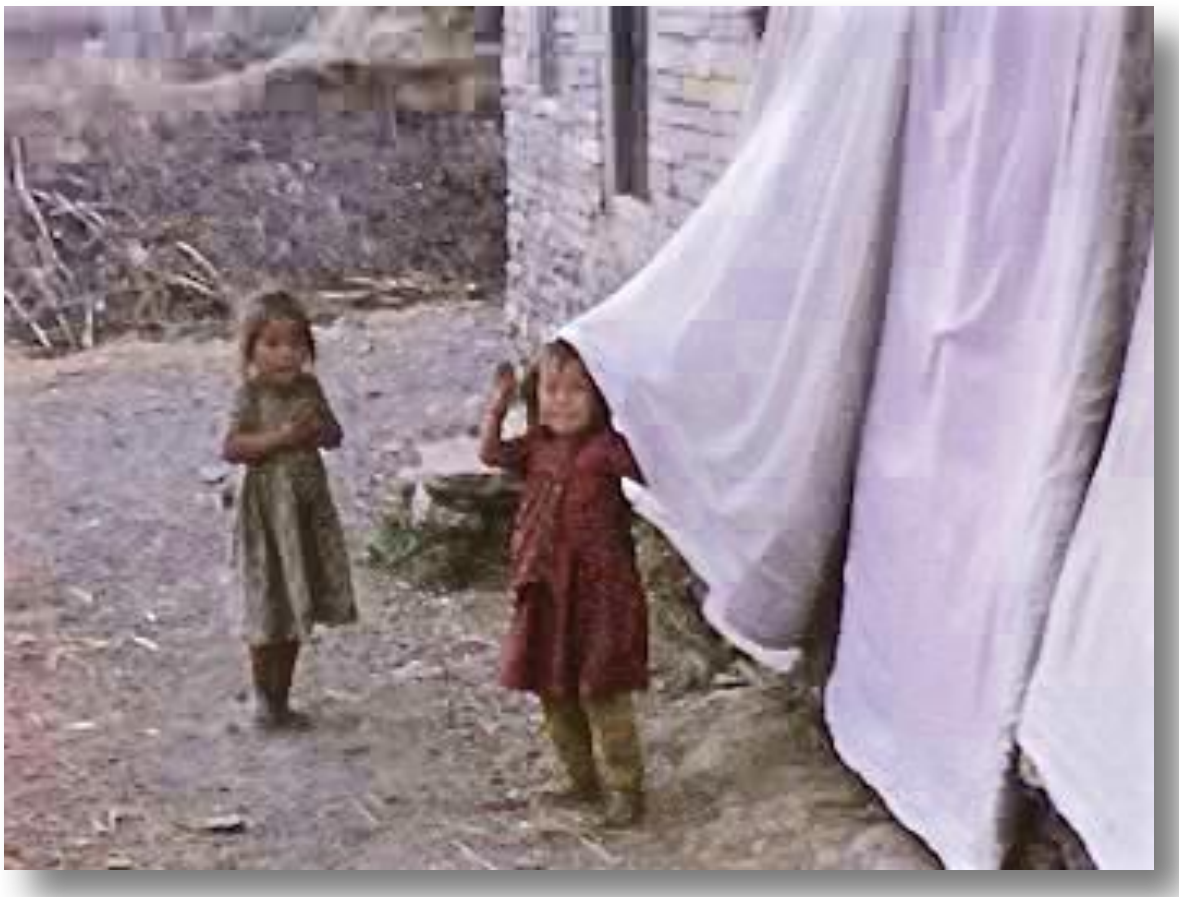

FILM. Sobadebi playing with bedding hanging out to air, another little girl beside her Sobadebi playing in front of House24, another little girl on a swing in the animal shelter https://sms.cam.ac.uk/media/2737811 


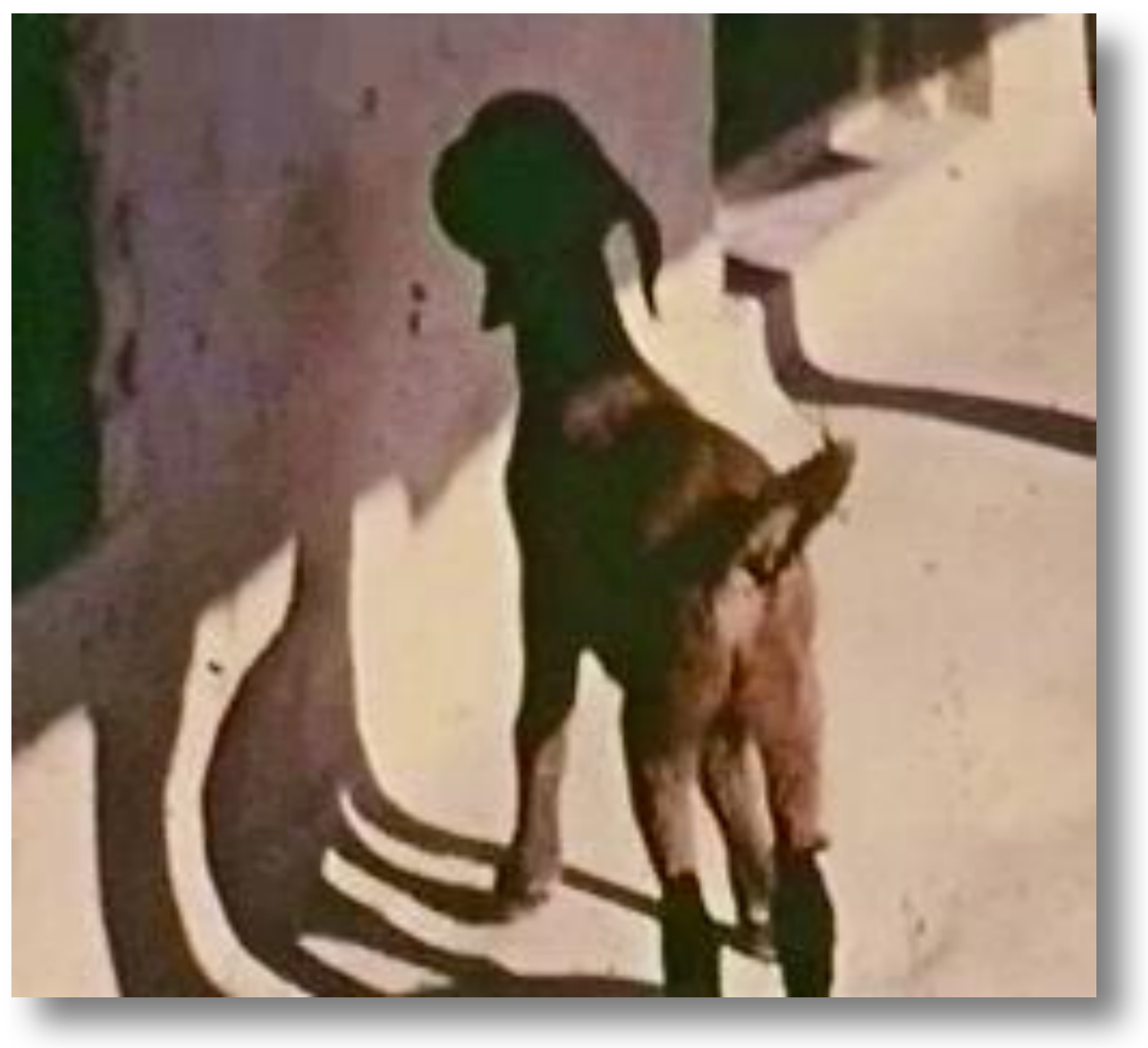

FILM. Baby goat leaping on a verandah https://sms.cam.ac.uk/media/2737839

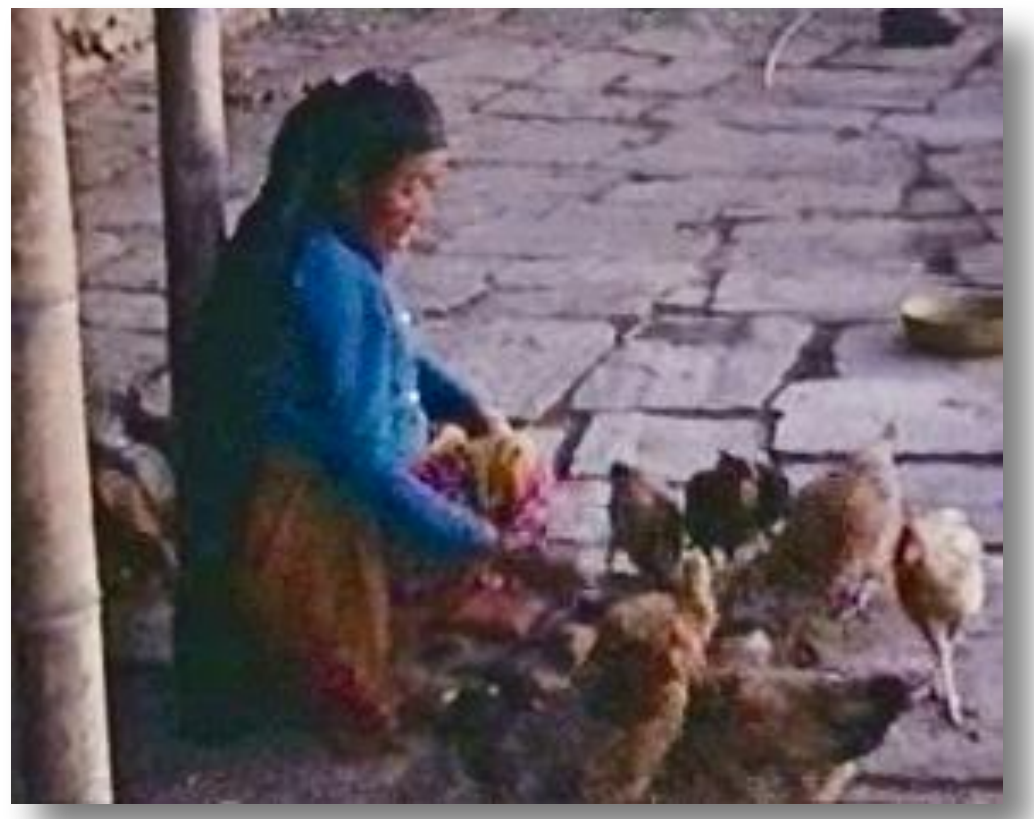

FILM. Asmaya feeding chicken

https://sms.cam.ac.uk/media/2737887 


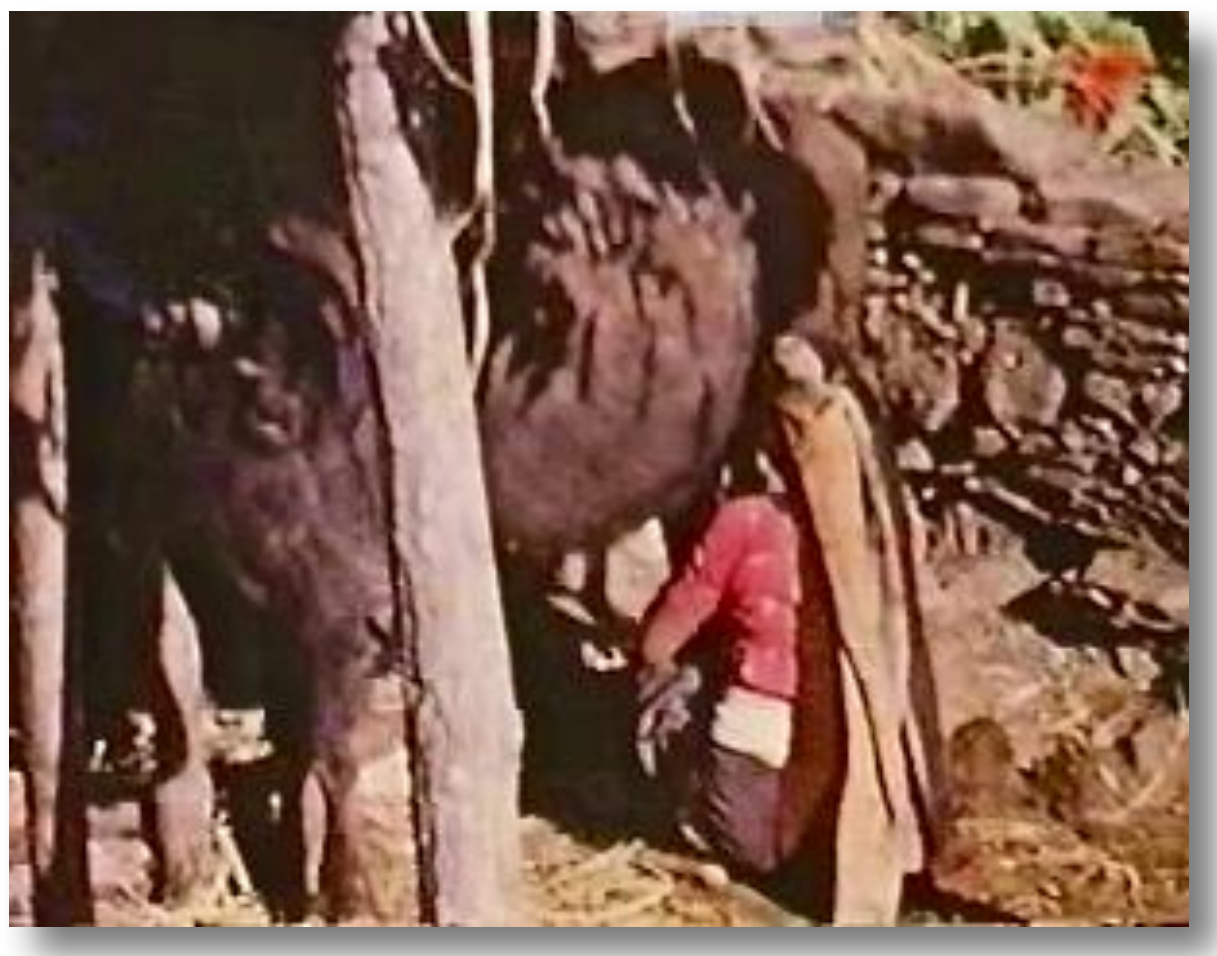

FILM. Nundakumari milking a buffalo https://sms.cam.ac.uk/media/2737915

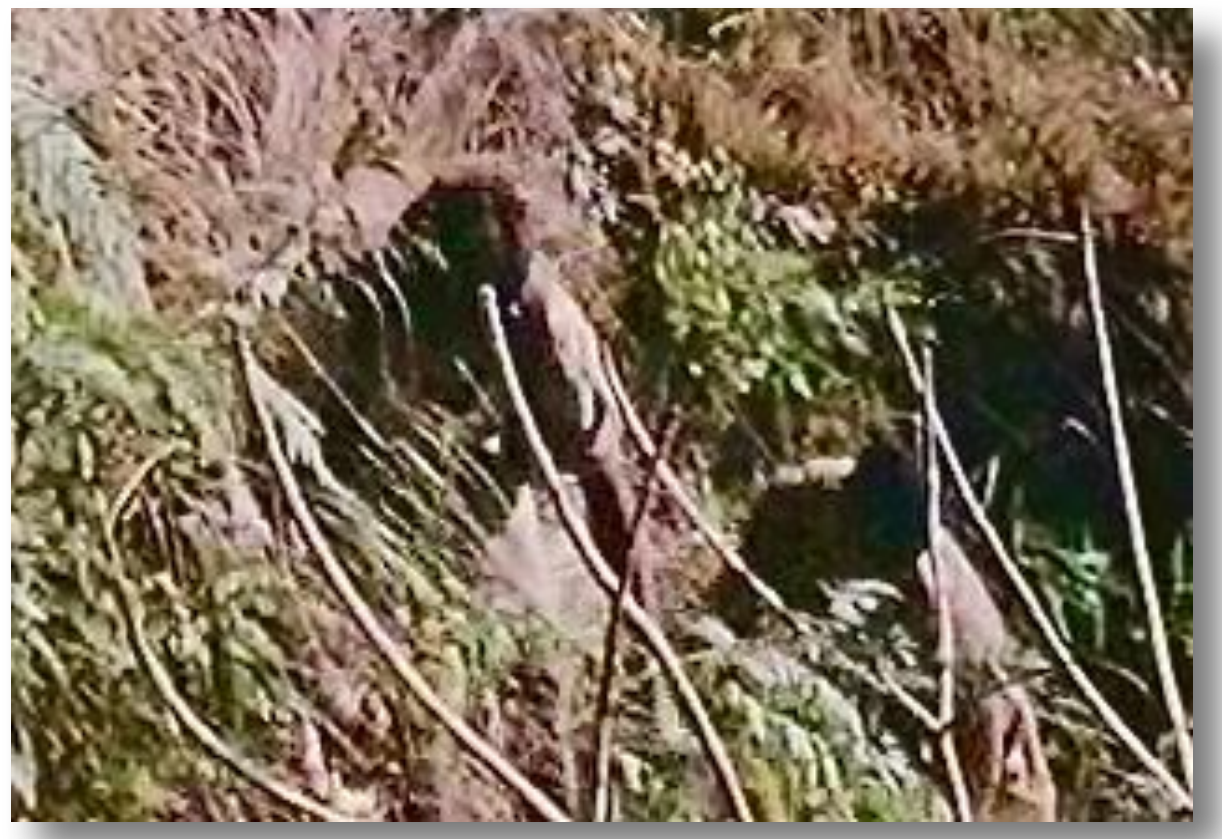

FILM. Dalits cutting grass on the way to Uli https://sms.cam.ac.uk/media/2737943 


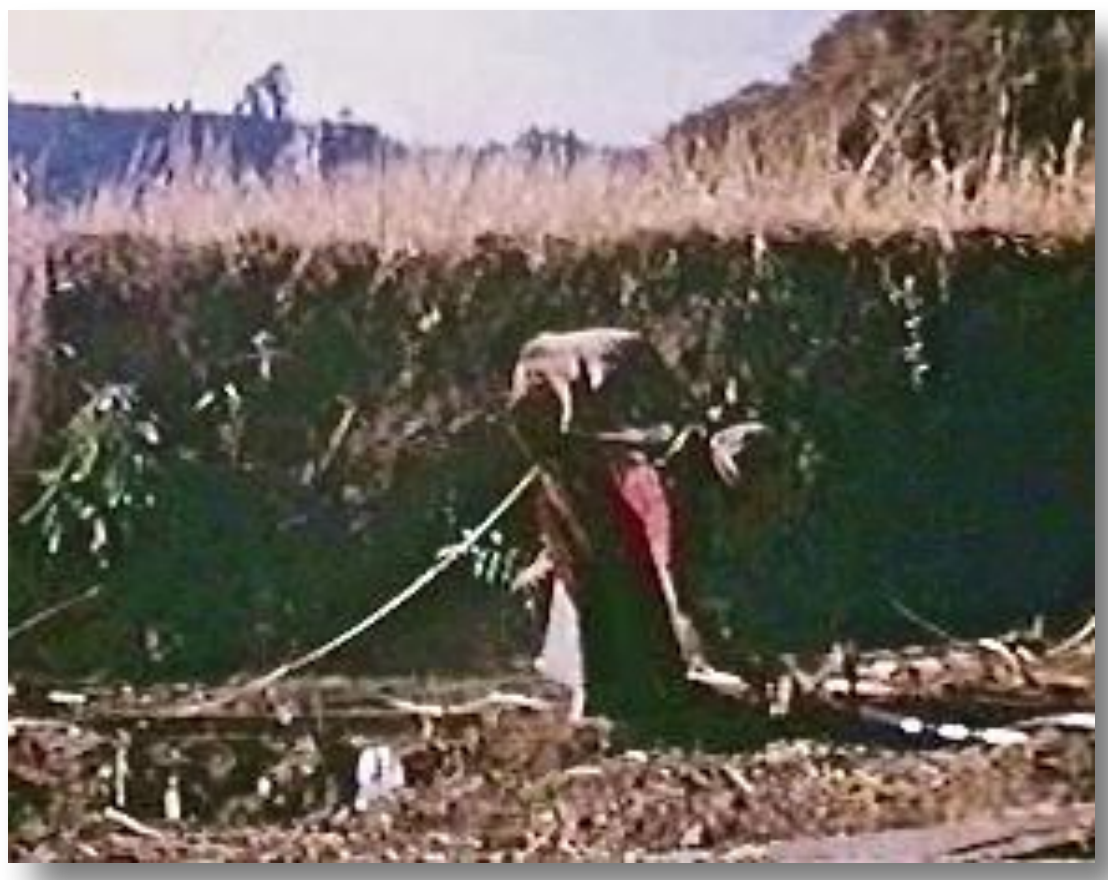

FILM. Nundakumari using a hoe to find 'teme' (sweet potatoes) https://sms.cam.ac.uk/media/2737971

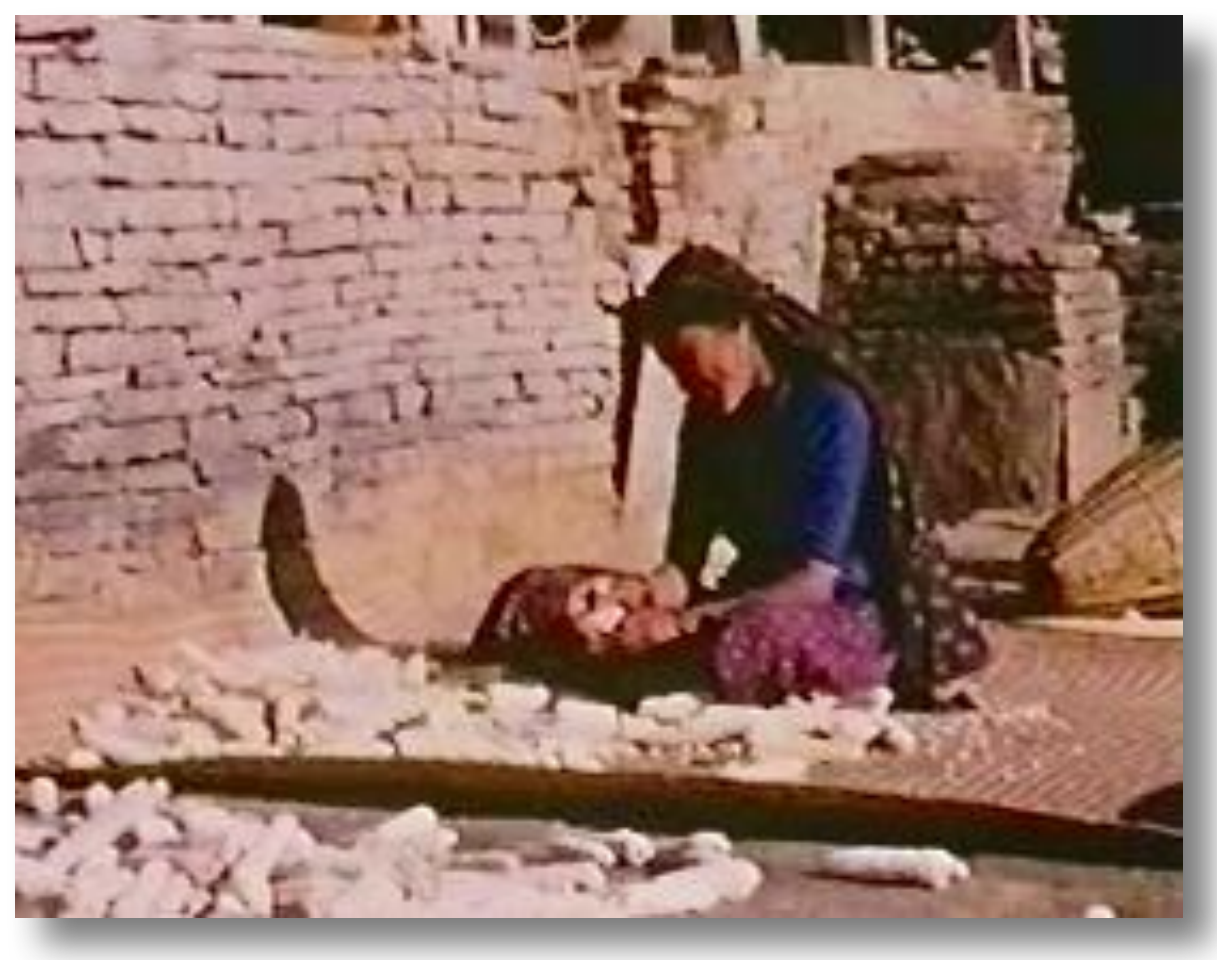

FILM. 'Kaili' (servant) taking maize off cobs at House70B https://sms.cam.ac.uk/media/2737999 


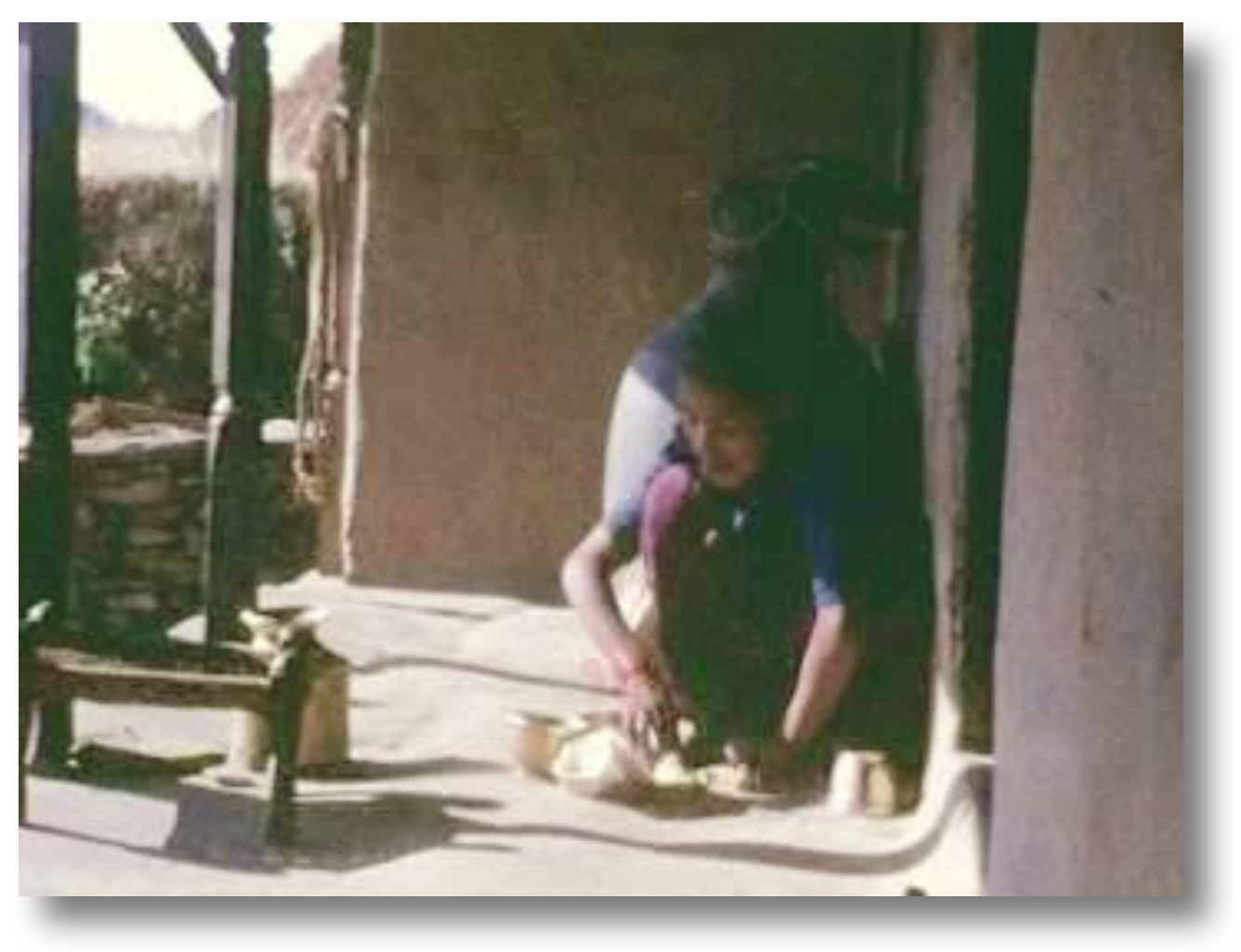

FILM. Girl eating rice on the verandah of House70B https://sms.cam.ac.uk/media/2737724

\section{DIARY GILL Thursday 8th January}

Felt slightly better, not having to go in night. Got up after breakfast and went up hill as Alan went down to spend a morning with Brikaras. Lovely warm pale blue, misty morning with the lavenders cracked and brown, the dust peppered into little brown balls with the sleet of yesterday. The tree faintly budding and the long withered-in leaves cracking onto the ground. Still had diarrhoea (bottle green!) and had to sit on hillside for a while afterwards in warmth until I recovered. Lay down when I got back but managed to type some Pignede, reading and finishing "Jude" in between. Puzzling book - very bad/artificial in patches. (Suicide of children, Jude's speech on Remembrance Day) but quite beautifully emotive in others. [Omitted]

Helped Alan a bit in afternoon - he is gradually finishing what he wants to do - but time is still crawling for both of us. Started "Chartreuse de Parma" - how incisive, ironic, witty, clear cut after Mandy. One feels in C18 and very much at latter end of C19 with other. Got up for supper when I really felt like having it upstairs but Alan had very poor supper yesterday. Of course, whole village seemed to crowd in - even when I was peeling onions - but later quite jolly with Ombahadur getting Alan to play the guitar and 5 - whom I thought were Tibetans coming in to listen. Turns out they are Lama Gurung from behind the Himalayas, speaking something that sounds like Tamang. Tall, broad plump-faced girls with round black eyes and braided hair, and loaded with broad white clicking bracelets, and bell girdles, the men looking like frowzy Othello's with flat, arrogant faces and huge looped earrings with turquoise blue stones in them. Alan played well as did Ombahadur using our tin plates as a drum and fire tongs as a rattle. Felt rather spinning and exhausted after it, but it certainly made me tired for bed. 


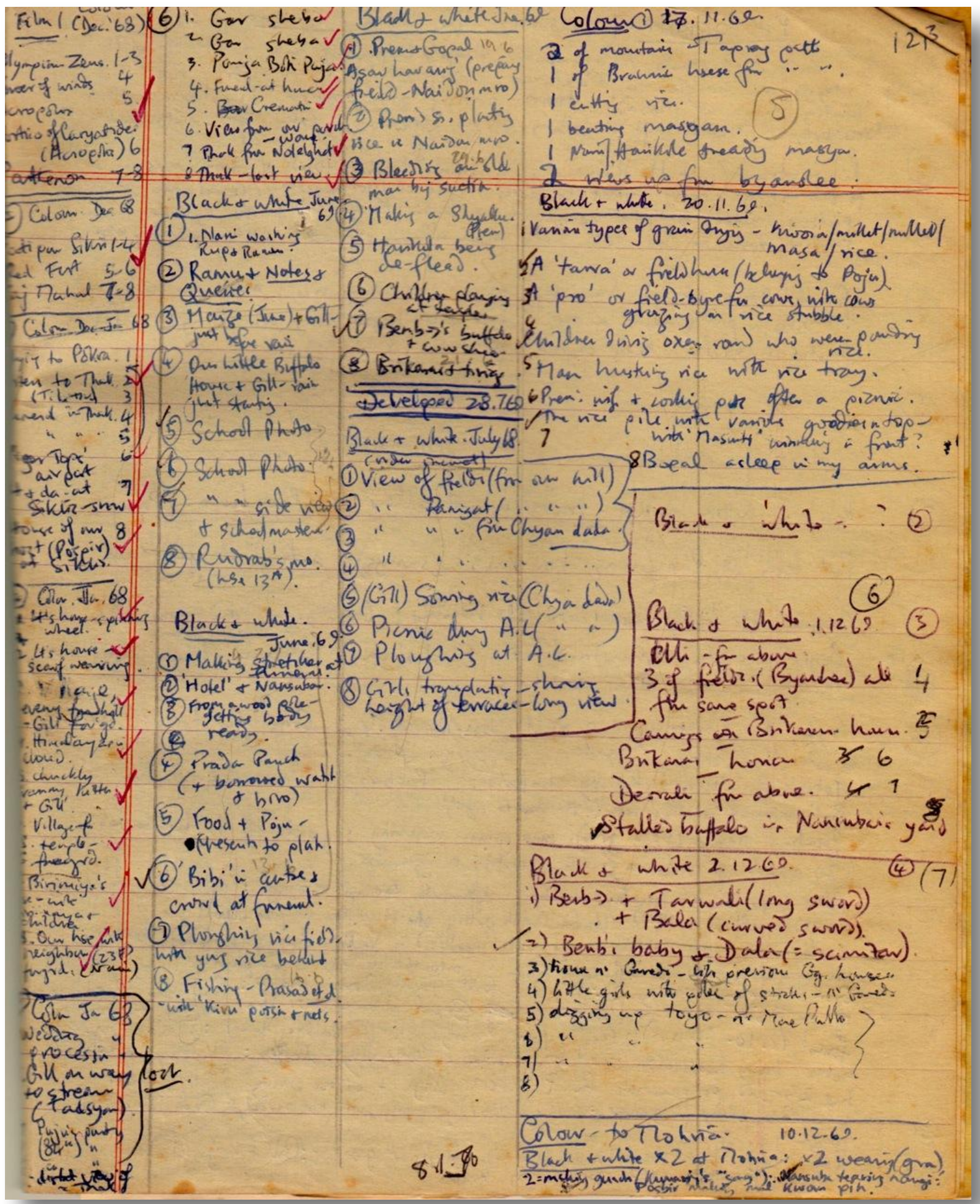

Index to photographs made on 8th January 1970

DIARY Friday 9th January

At last managed to do some more of the map with Totra's father and Bhuwansing - from 810am. Then took some films (cine) up towards the hill. Gill a lot better, though still churns when she eats. Then did various tidying up (indexing) jobs and in the evening went for a walk 
towards Taprang. A little sun, but definitely colder nowadays. Continued M. Mead which am enjoying very much. Discussed child-rearing questionnaire - very much on her lines. Sleeping an enormous amount - boredom? For some reason feel very loath to actually get down to analysing/writing

up.

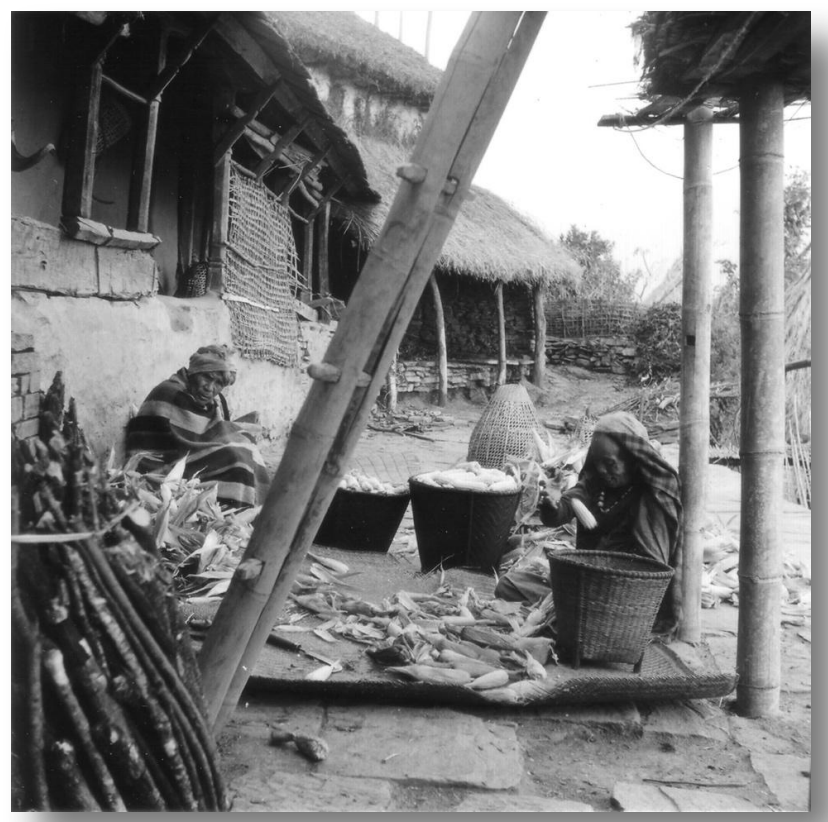

Dansuba husking maize in front of her house next to ours, with Narbir - 9th January

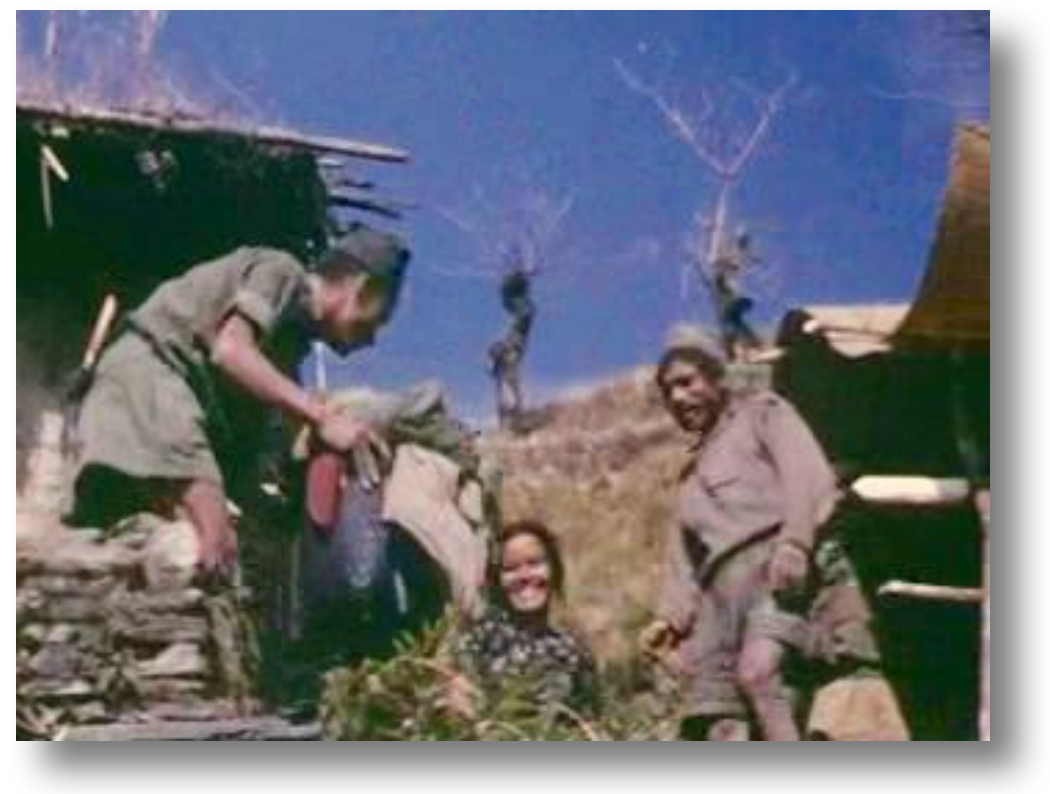

FILM. Moving goods from Maldosing's old house into a temporary shelter Tekansing and two other men. Could woman be Harimaya? https://sms.cam.ac.uk/media/2738027 


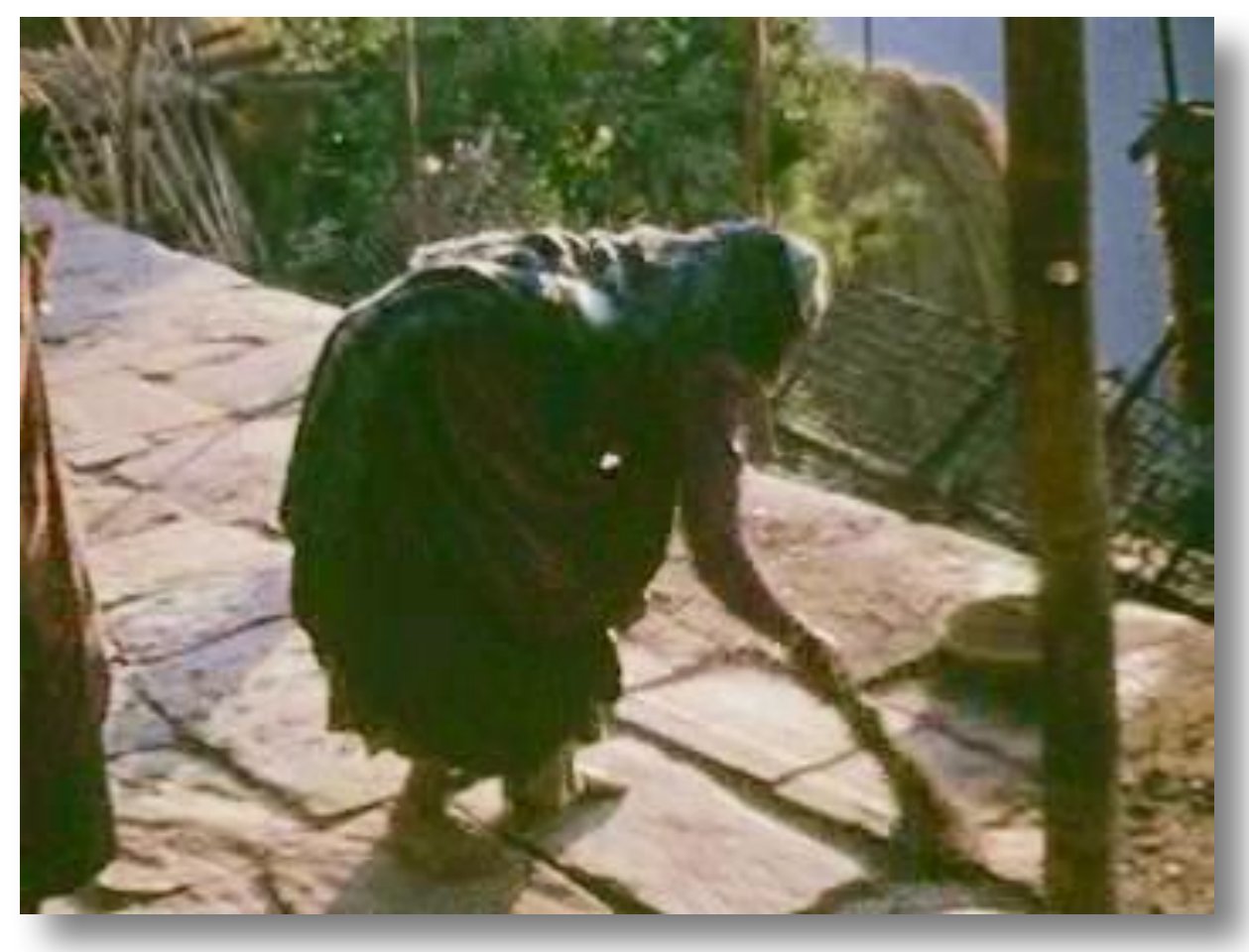

FILM. Dansuba sweeping the courtyard in the early morning https://sms.cam.ac.uk/media/2738055

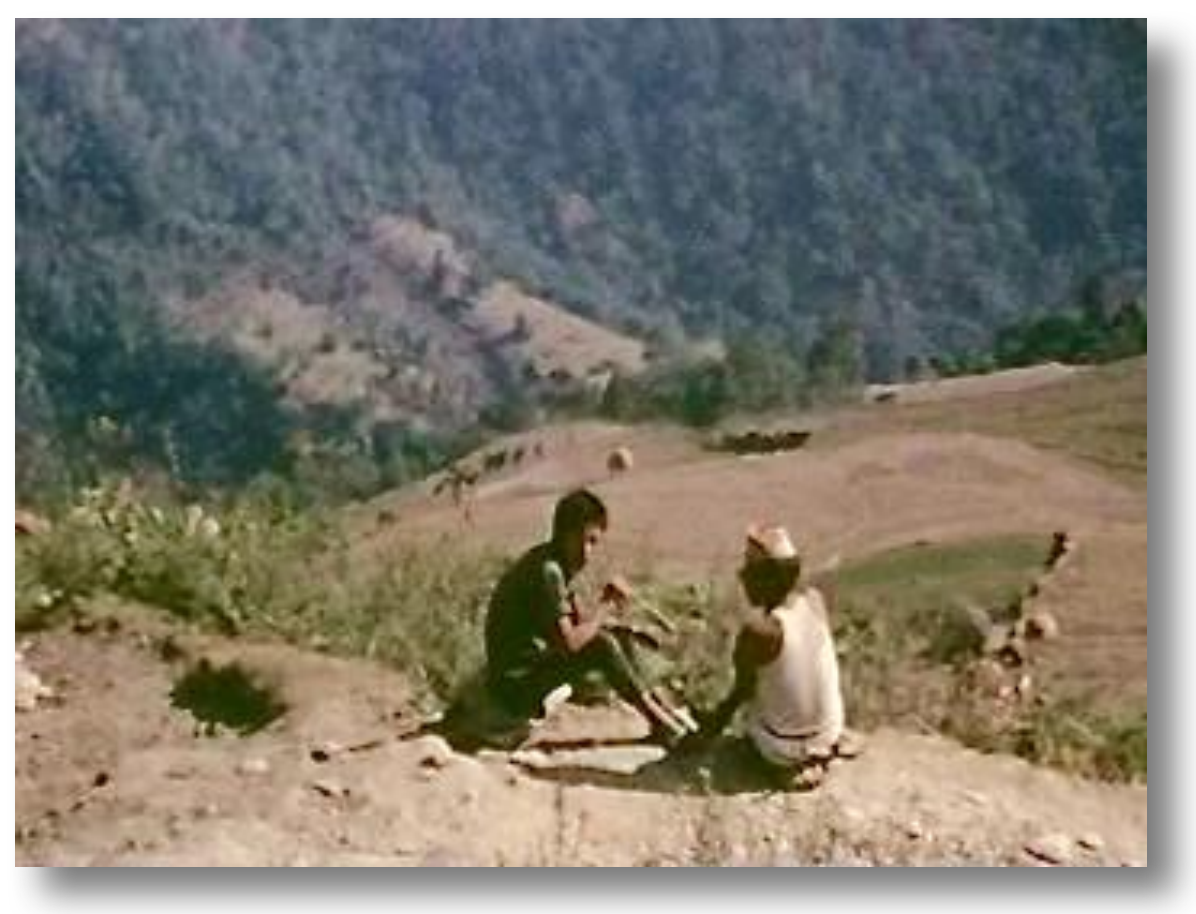

FILM. Two men sitting on a rocky terrace with fields below Gopal and Surje ("baby brother's brother") resting on way to the forest (c10.30am). https://sms.cam.ac.uk/media/2738083 


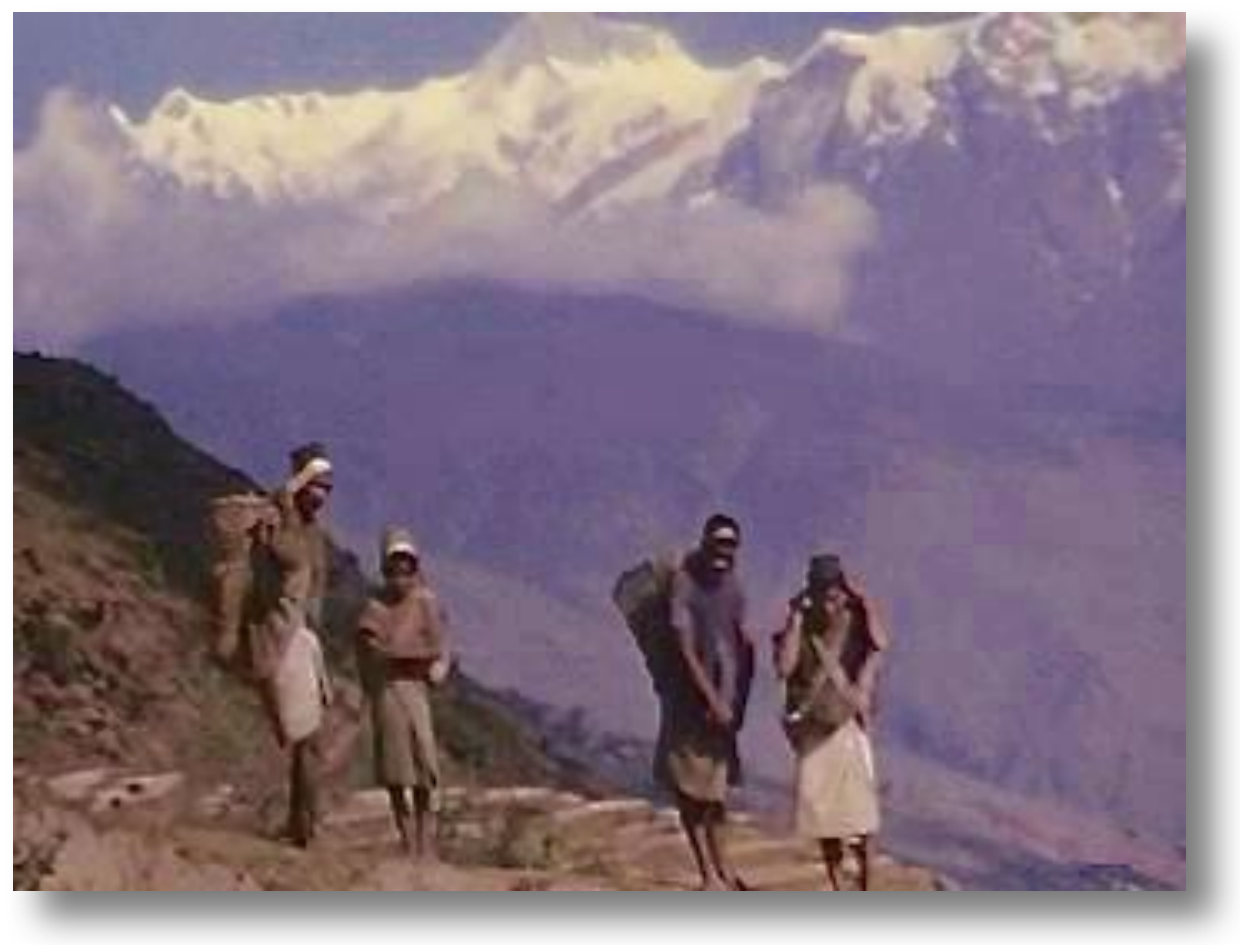

FILM. Four men, including Manseram, carrying heavy baskets of stone down the hill for Maldosing's house

Snowy mountains in the background https://sms.cam.ac.uk/media/2738111

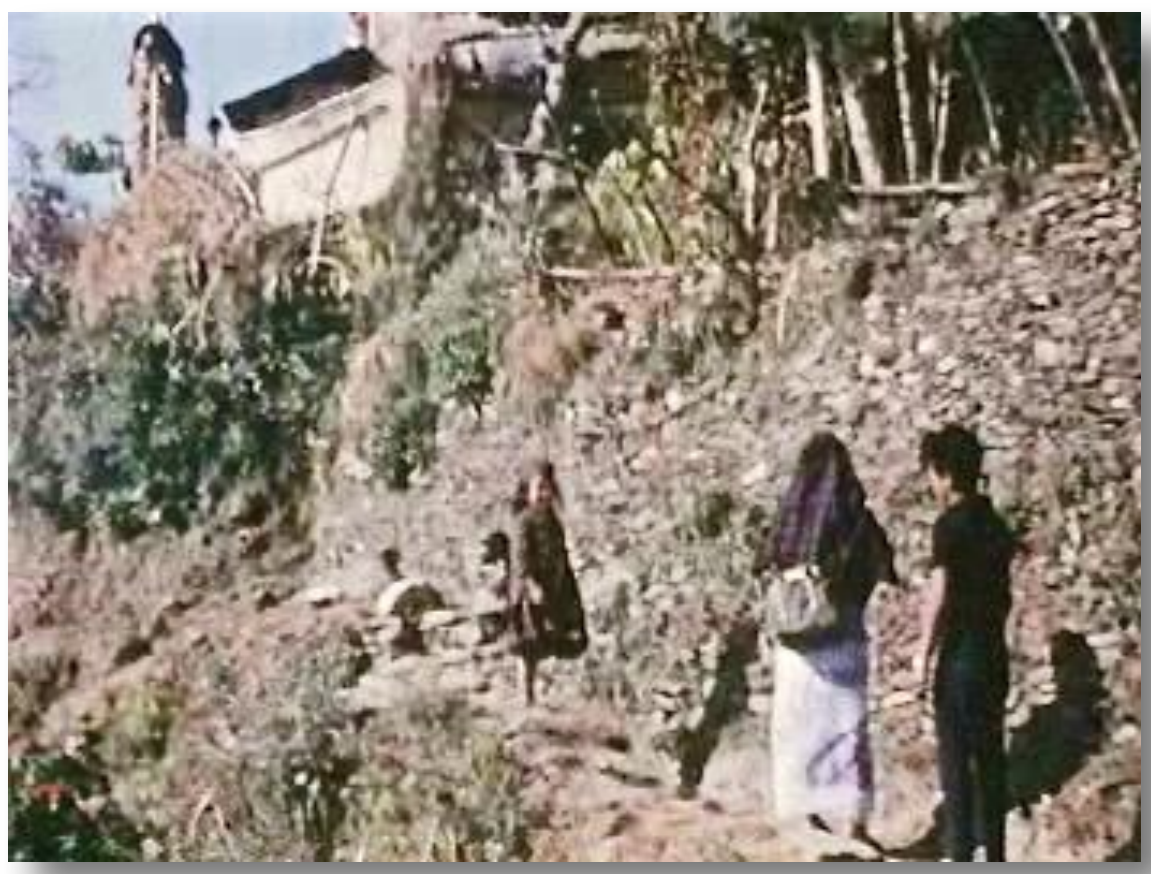

FILM. Prembahadur, Yokmaya and Haricola setting off for Pokhara https://sms.cam.ac.uk/media/2738139 


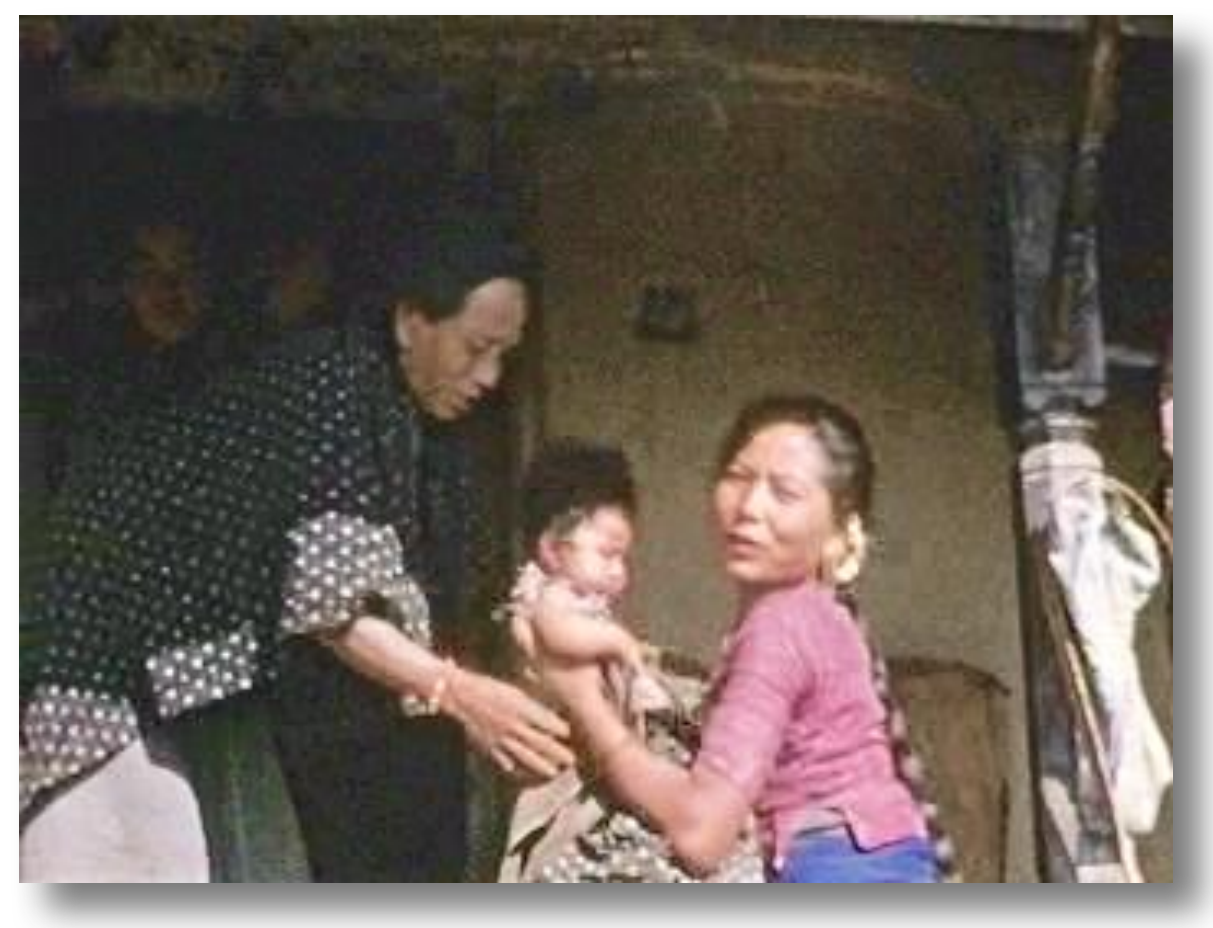

FILM. Munmaya, and brother's baby, Tikakumari, preparing for family photo House23 Mother, Nansuba, puts a shawl around the baby. Joined by father of the child, Buktabahadur His wife, Yokmaya, joins them for the photo https://sms.cam.ac.uk/media/2738167

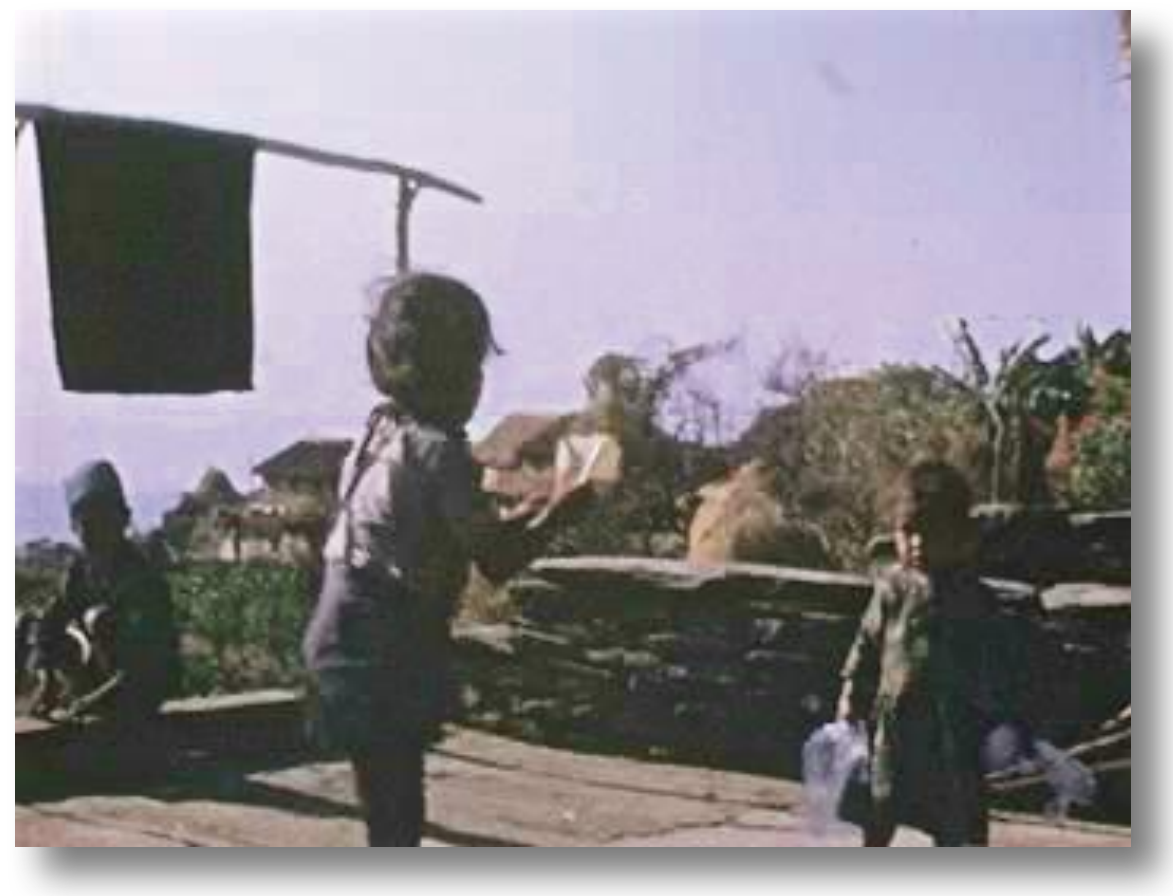

FILM. Totra playing with a paper dart Syebahadur with him and a little girl carrying plastic bags https://sms.cam.ac.uk/media/2738195 


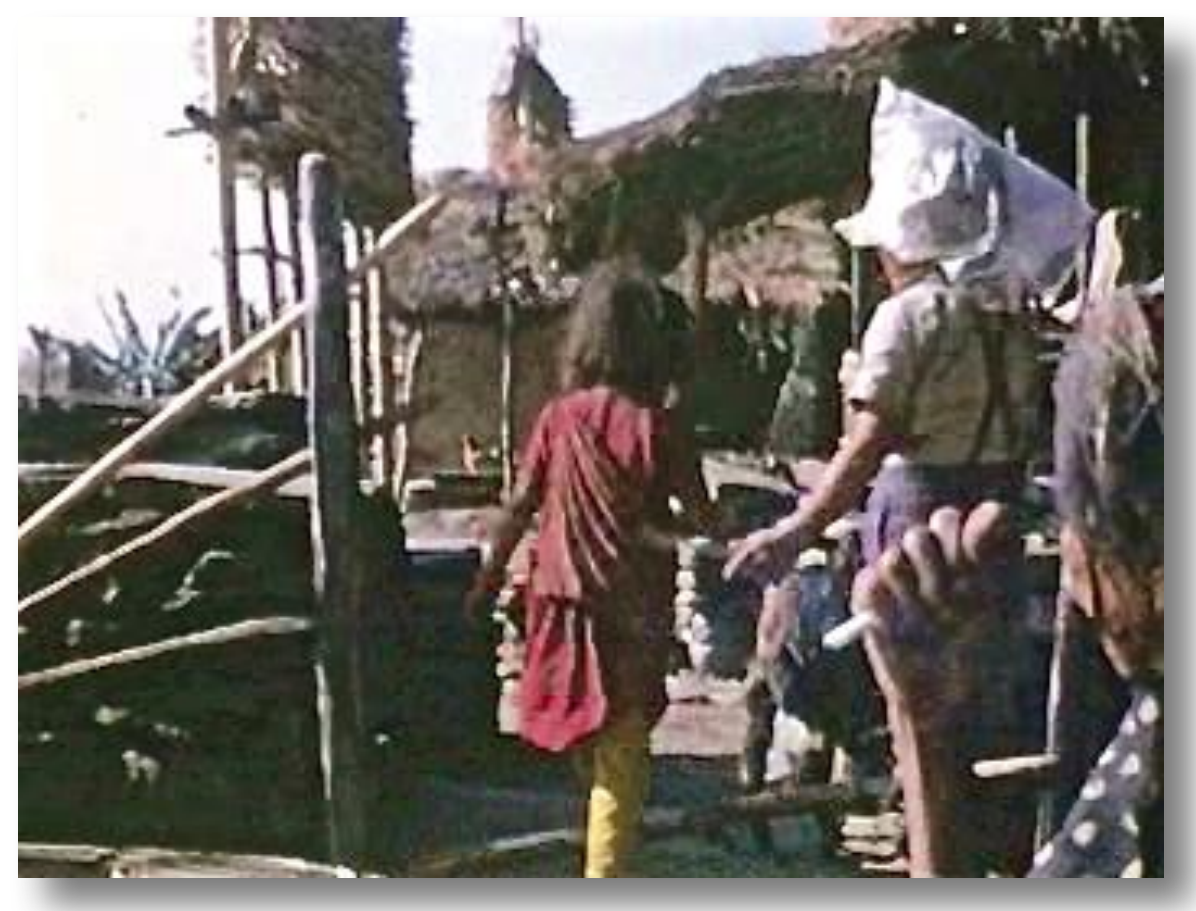

FILM. Totra with a plastic bag on his head with Sobadebi hitting a passing ox, little girl beside them. Sobadebi hitting goats out of the gateway, old lady smoking https://sms.cam.ac.uk/media/2738223

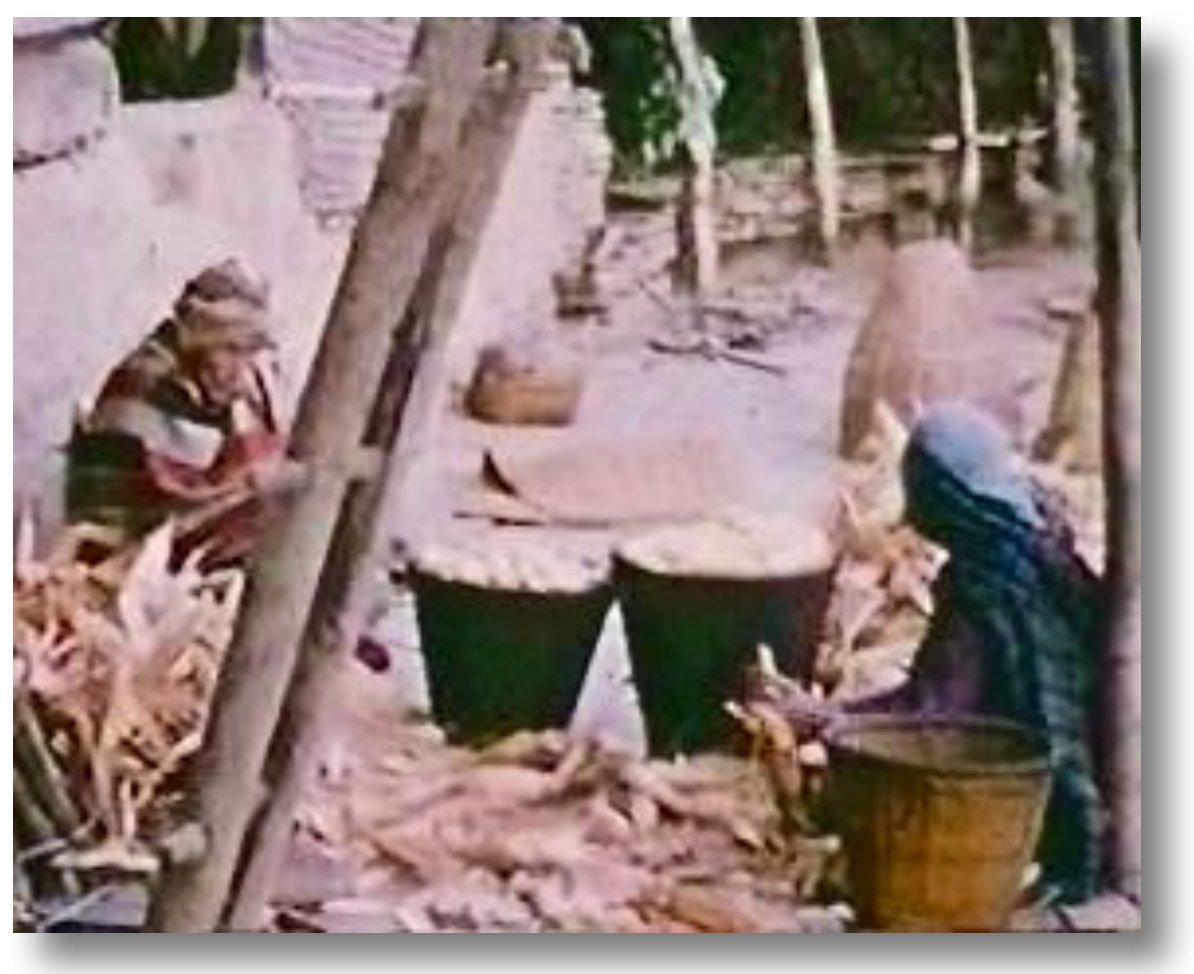

FILM. Dansuba taking maize off cobs, Narbir sitting with her https://sms.cam.ac.uk/media/2738251 
DIARY GILL Friday 9th January

Felt lot better, reluctantly agreed that I would not have porridge in bed. Crowd of people for medicine - Bibi, Kaila and Totra's father, with red eyes like a fox insisted that Alan went straight away to draw map. I do dislike the man. He must be one of the most intelligent in the village, only Gurung to show his impatience and displeasure openly - too much like me perhaps! Felt quite sing-song up the hill, bubbly, as if I could write poetry. Read the Degree speech - "Degree being regarded" - magnificent but how reactionary! Can't remember how it fits in with the play. One always feels Shakespeare should be uttering! Orange dog disturbed me, so I came down to typing. Alan doing map. Had late lunch, light sleep, get bit more into Stendhal, darned, then went for our walk towards Taprang. Blue mist and chilly. Pleasant evening with Ombahadur and Alan saying what a good cook I was.

\section{DIARY Saturday 10th January}

Again time dragged though was satisfied with two and a half hours spent on the map which will only need one more day before it is finished. Went some way down towards Uli before Comal called me back: Prasad was busy. As Gill says, the village has grown stale and we are no longer really noticing things - taking all these wondrous ways of doing things for granted. Wandered around and took some photos and then came back to a shave and a listen of the Beatles. Little children very friendly - we are hailed from all sides. But all we can think of is home and everything (except food) has really lost its relish. Miss Haricola who is in Pokhara. Evenings a lot of people in. A bit of a headache for most of the day.

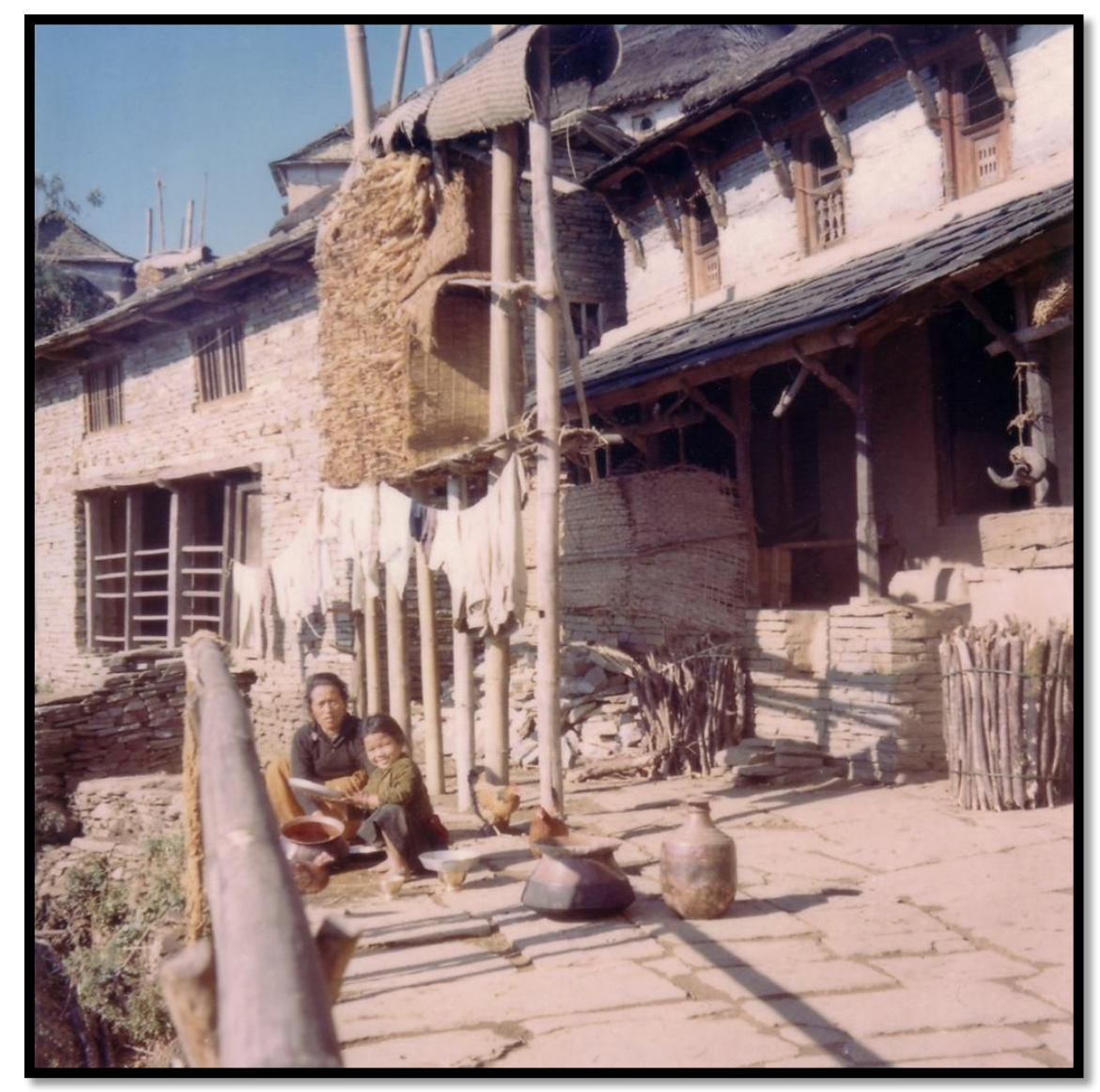

Our house, with maize stack and Asmaya and Haricola - January 


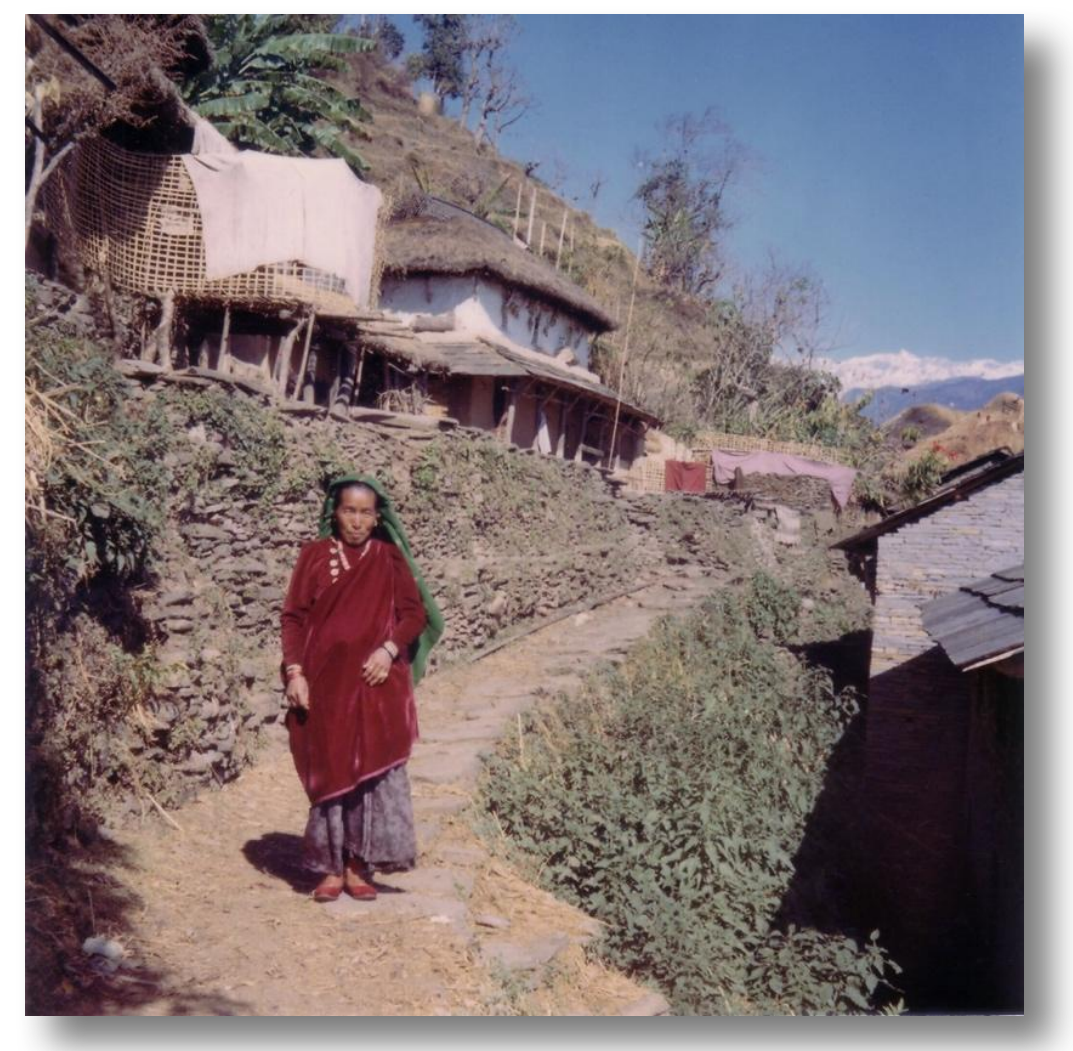

Lilakumari on village street with House 33A above

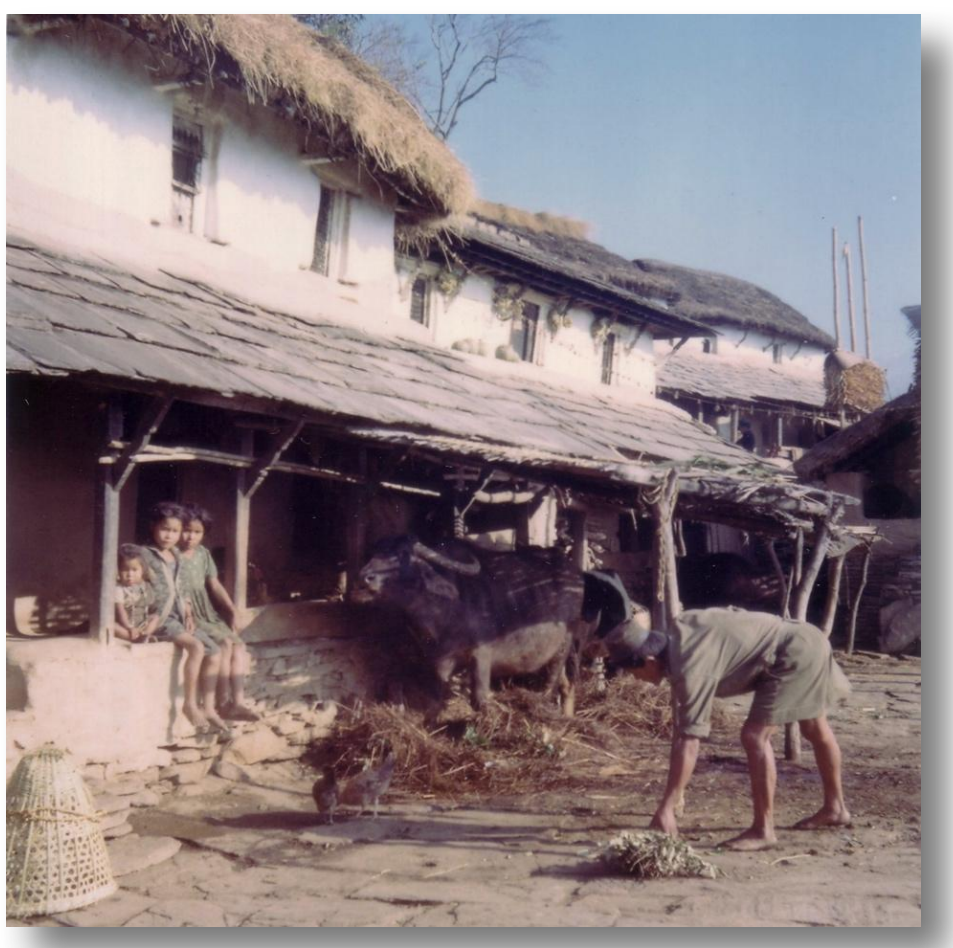

Man cleaning yard, buffalo stall and three children 


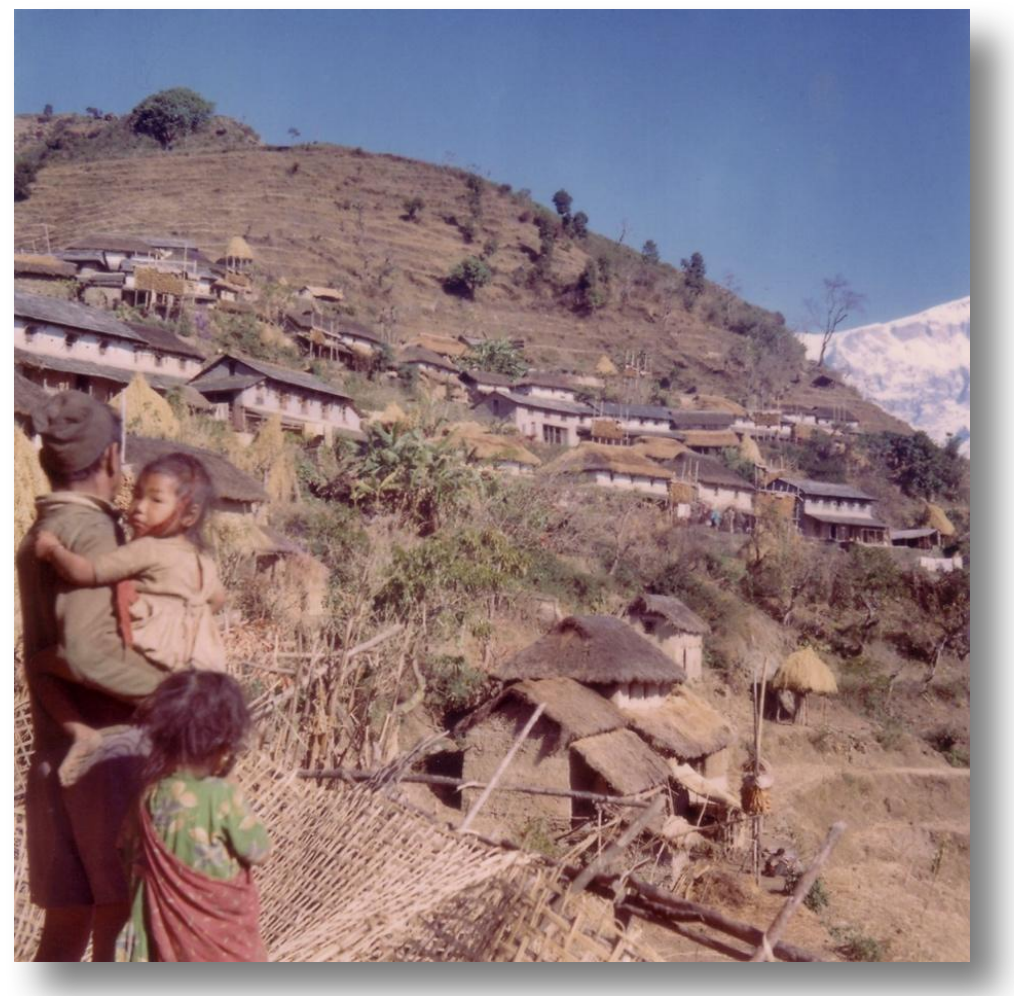

Looking up at village, with Blacksmith houses below - January 1970

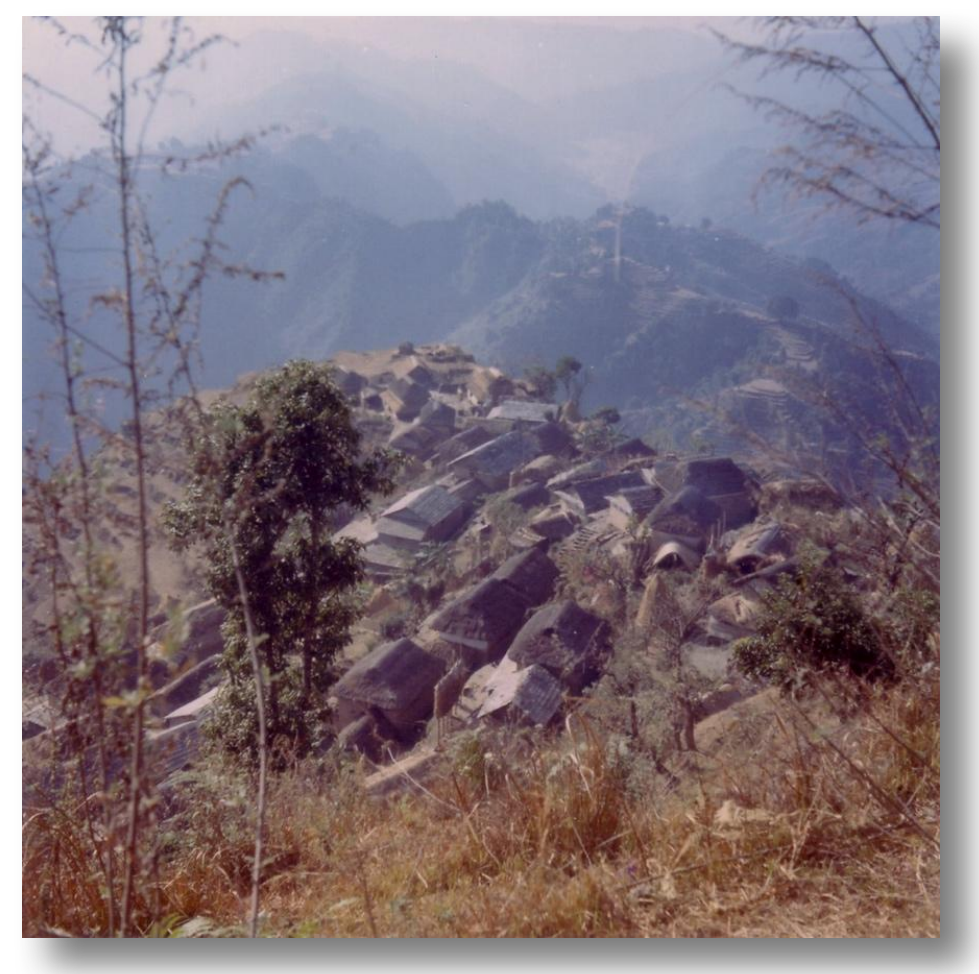

View of the village from above 
A frustrating morning which Alan took well but I was cross about - he went straight after breakfast to do map and of course Bhuwansing had gone after goats and Totra's father nowhere. Then he decided to go straight down to Uli and five minutes afterwards Comal appeared with a message from Prasad telling Alan not to go. I sent Comal running after him and he caught up with him about a third of the way down. I was furious with Prasad's usual fecklessness and the fact that he still owes us 100rs. and, after all his fine words, has made no attempt whatsoever to pay us off. Alan reluctant to ask as it was asked on behalf of Brikaras whom he would willing give 100rs. However, Alan eventually tried again with map and they did work all morning on it and a good chunk done.

I wrote out questionnaire and then typed up remainder of Christmas diary. Felt I was wasting time doing this but little else to do. Cold, bleak outside. "Charterhouse" is not cheering cynical tolerance and worldliness is not, especially in this environment. Moreover from a lordly introduction I find to enjoy book one must be mature - so of course I have to read on. Miserable afternoon spent by both of us at a loose end. We did go out and take a series of photos but grey overcast weather didn't make it very exciting. We had a bathe and a shave to cheer up, also the Beatles, which I jigged around to with very little on - so couldn't have been so cold. Warmer out than in. Had Comal's father sitting solidly with us all evening, didn't even go when we washed up. All flirting with Omkumari who has descended to be affectionate again, teasing her that she is getting married in Baisak. Amazingly egalitarian nature of this society - men of 35-40, girls of 20 and adolescent, 10 year old boys, all laughing at same jokes, exactly on a level with each other (Kumansing pretending he was Mahendra and Alan elaborating on this fantasy - all without exception loved this).

\section{DIARY Sunday 11 th January}

Colder and the day dragged again. Took photographs, went for a walk towards Taprang with Gill discussing Lenin and revolutions. In the morning did a child-rearing questionnaire with Mrs Bhuwansing: extremely fruitful and valuable. 


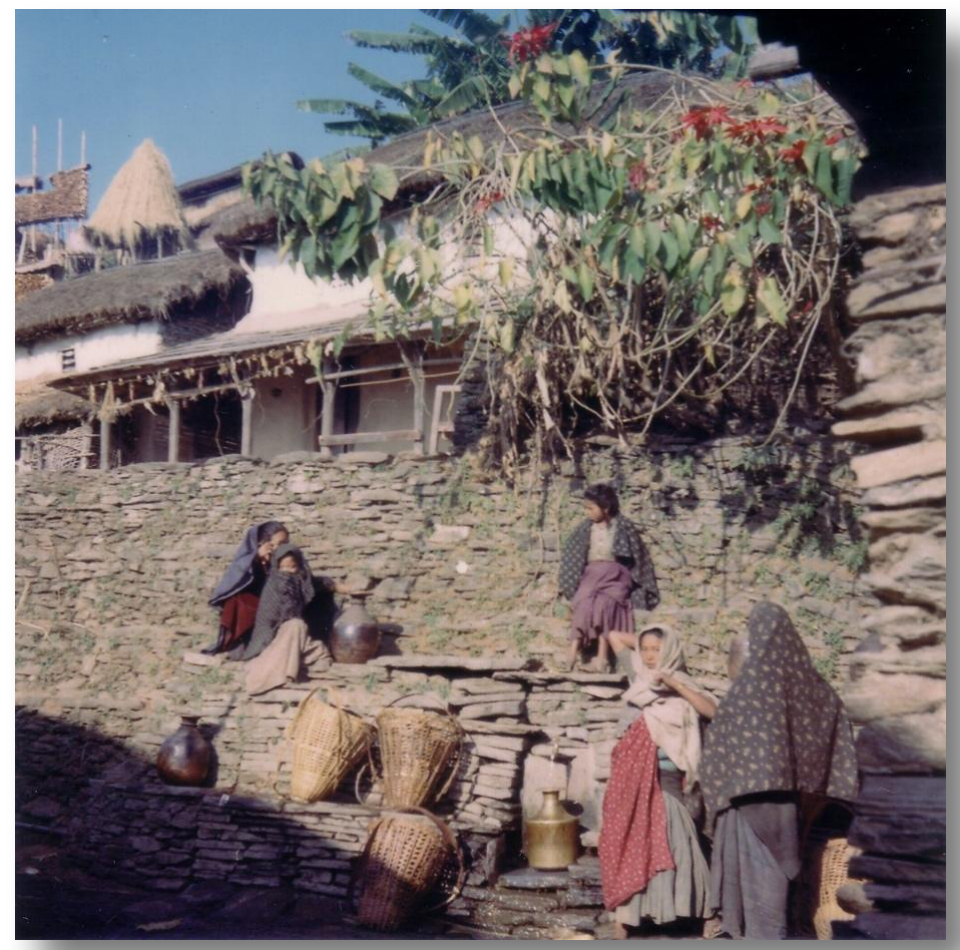

Women at the water tap - 11th January

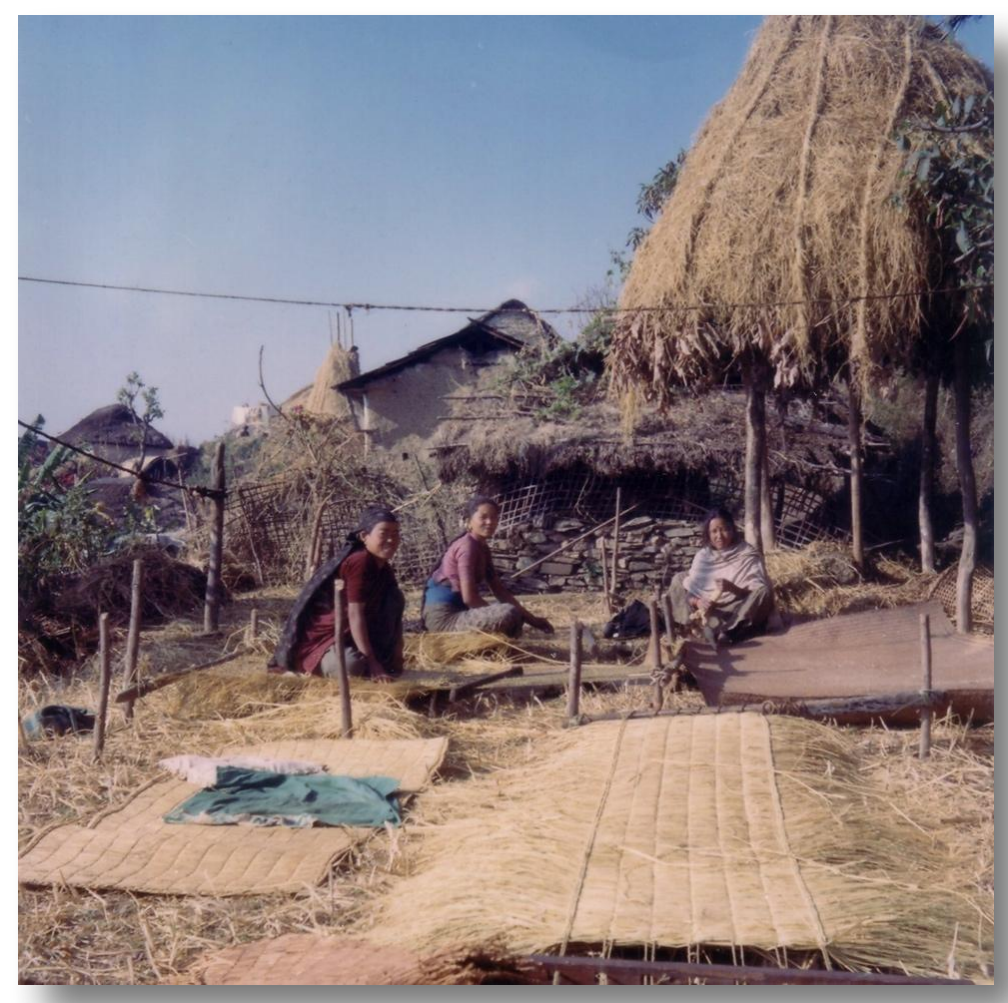

Women making a sleeping mat or 'gundri' - 11th January 


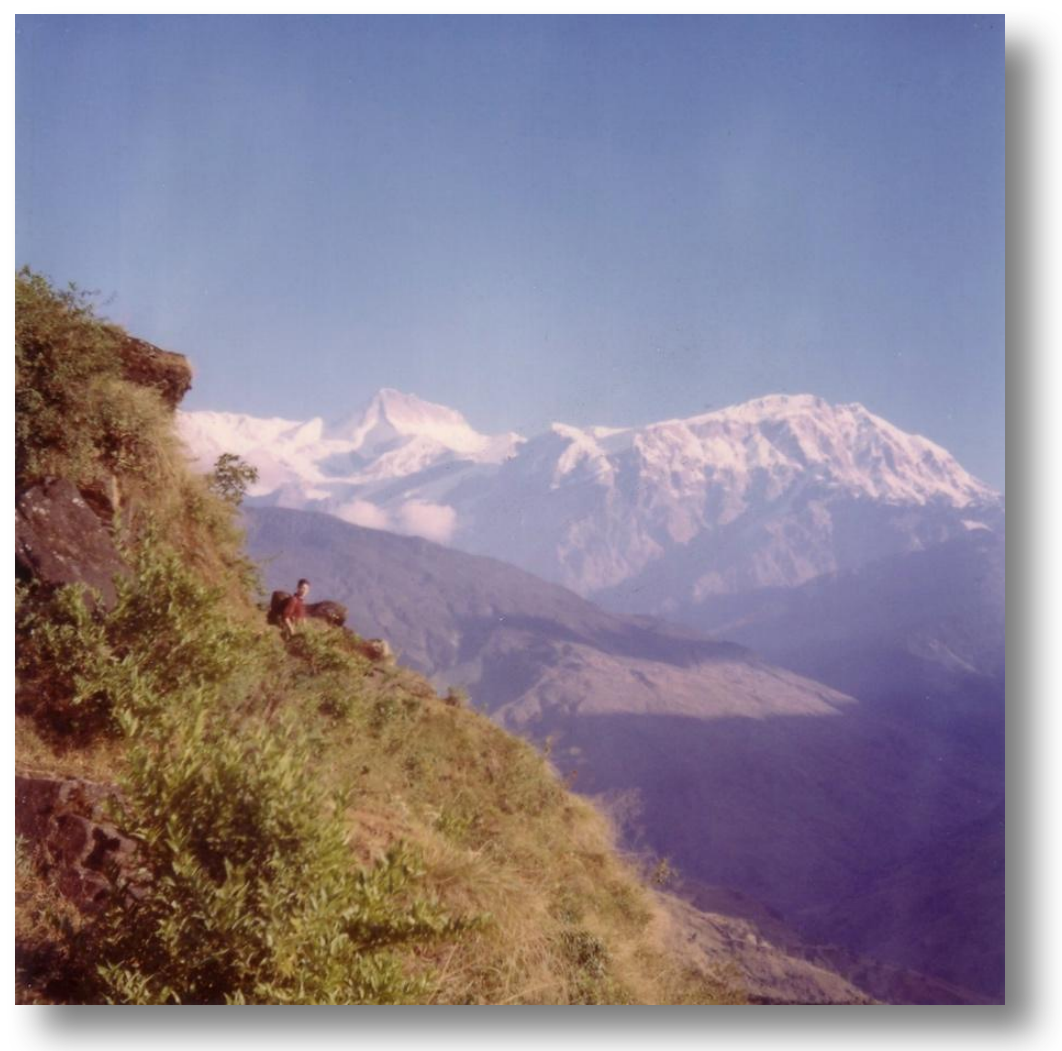

Gill on hillside above Puje fields - 11th January

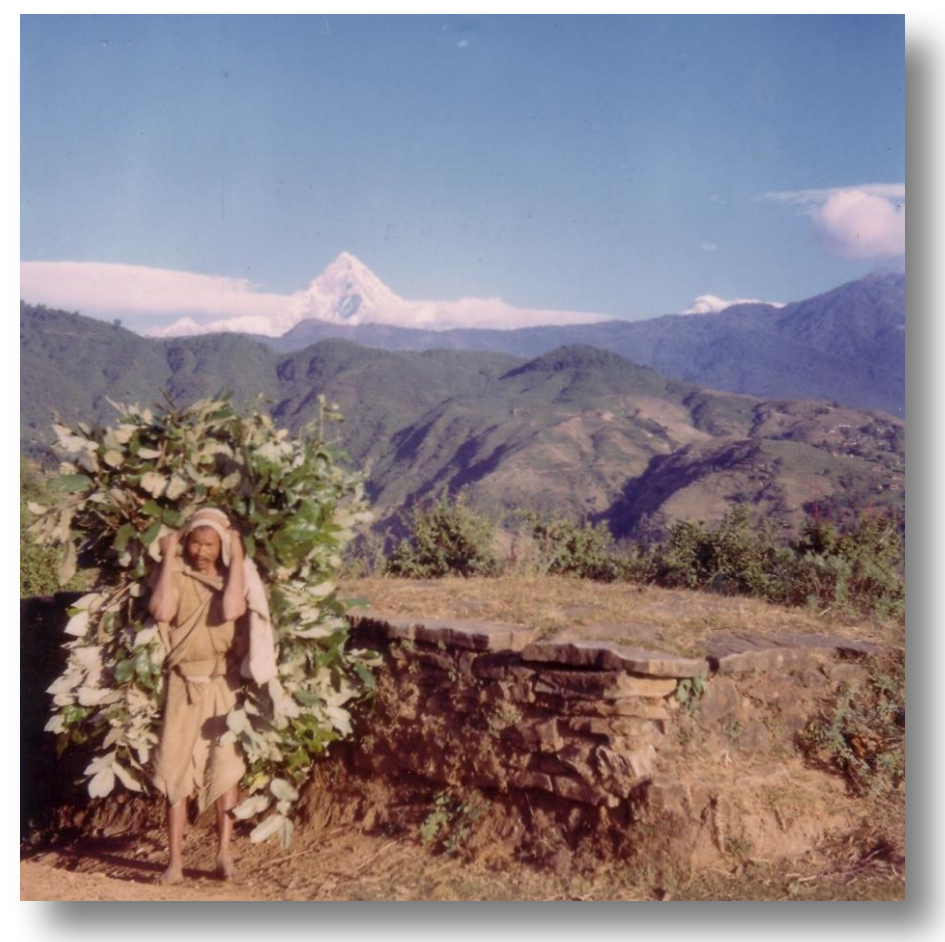

Man with bundle of leaves by resting place (chautara) on path to Taprang - 11th January 


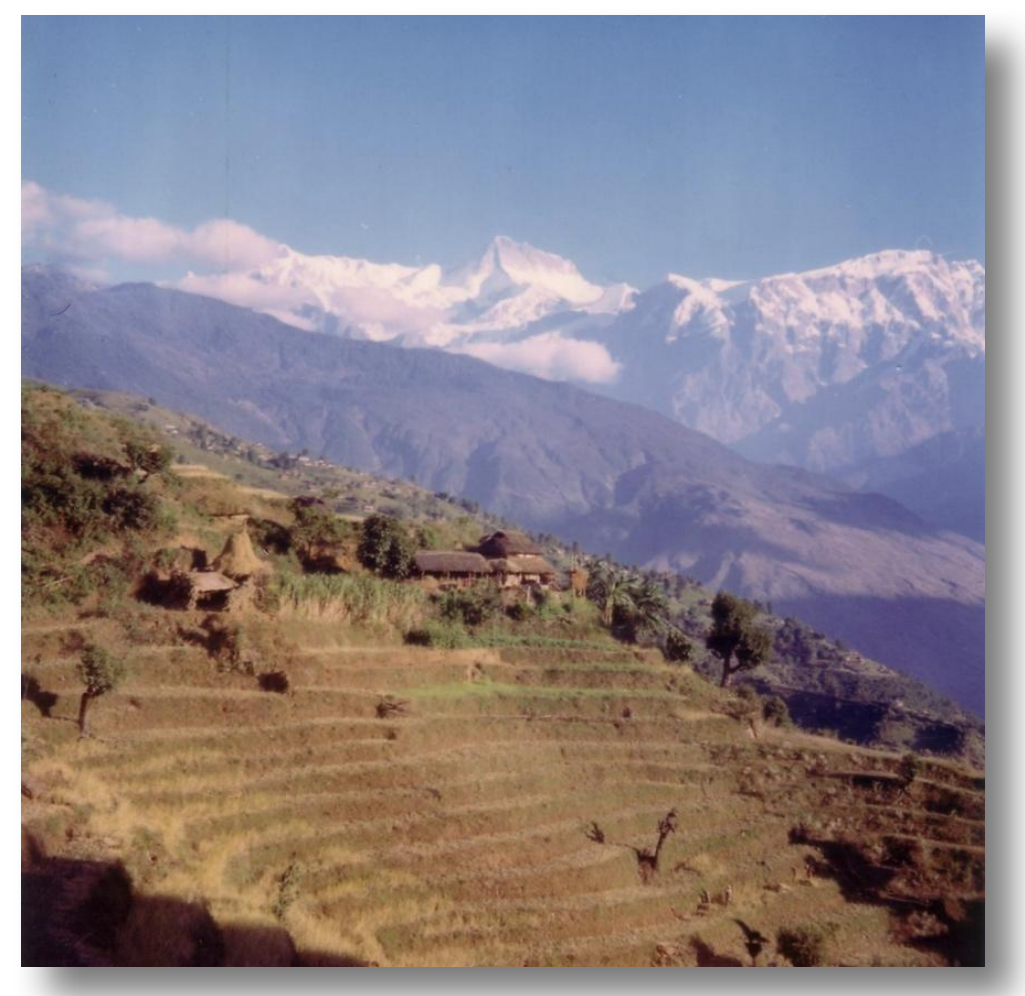

Houses with Taprang in the distance - 11th January

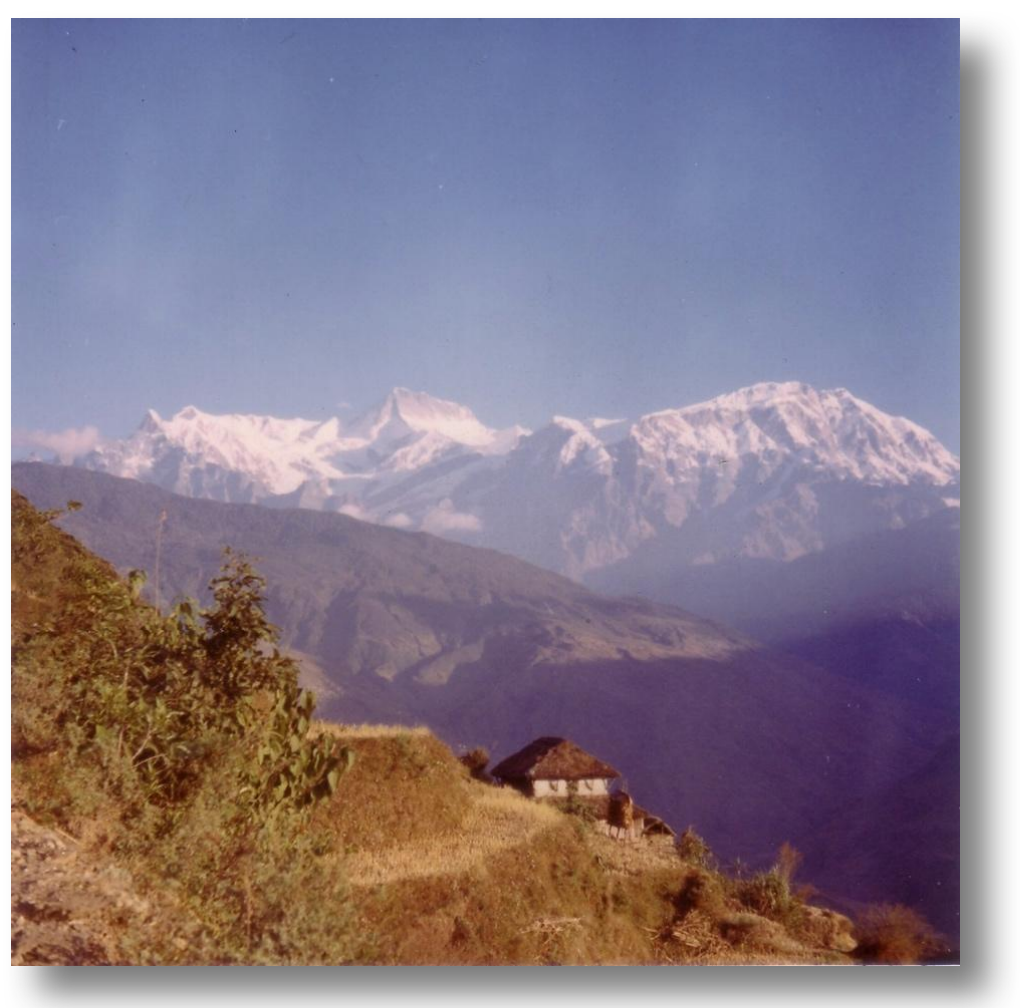

House below the Taprang road - 11th January 


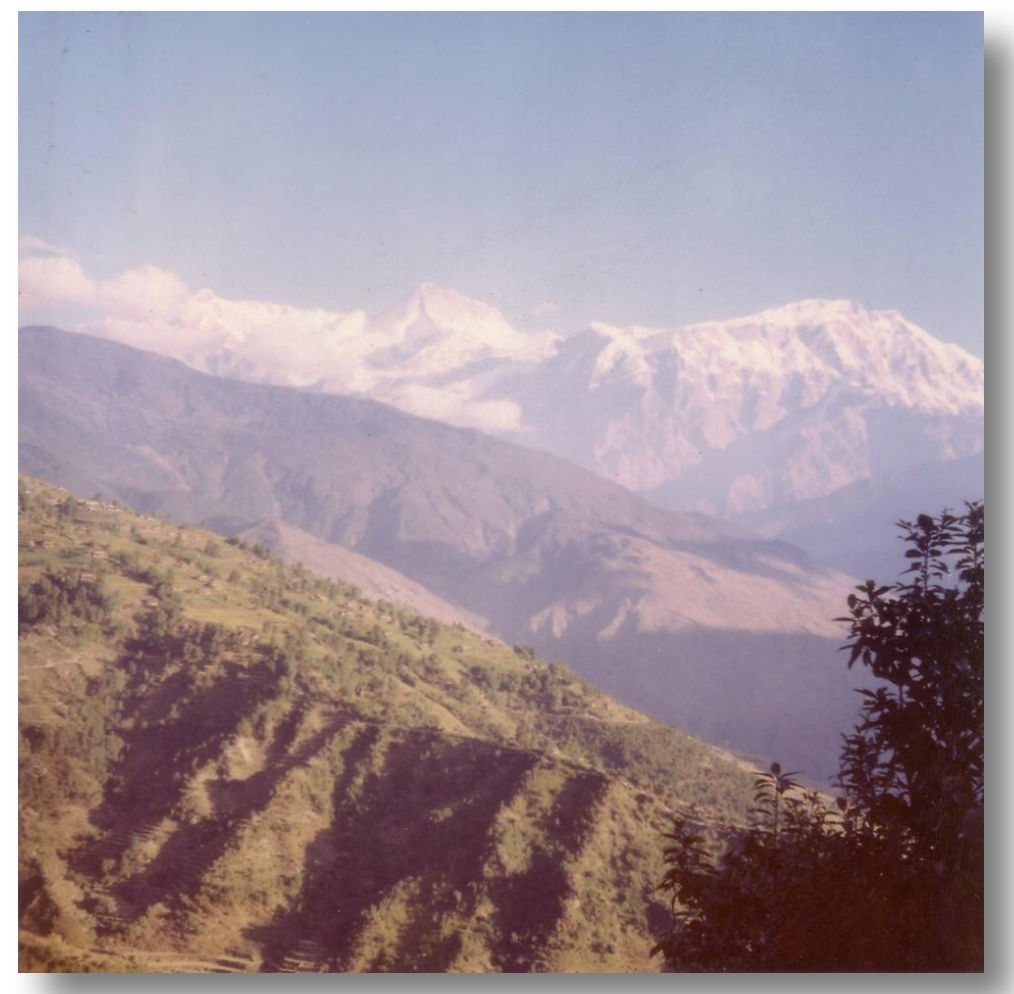

View towards Taprang and beyond - 11th January

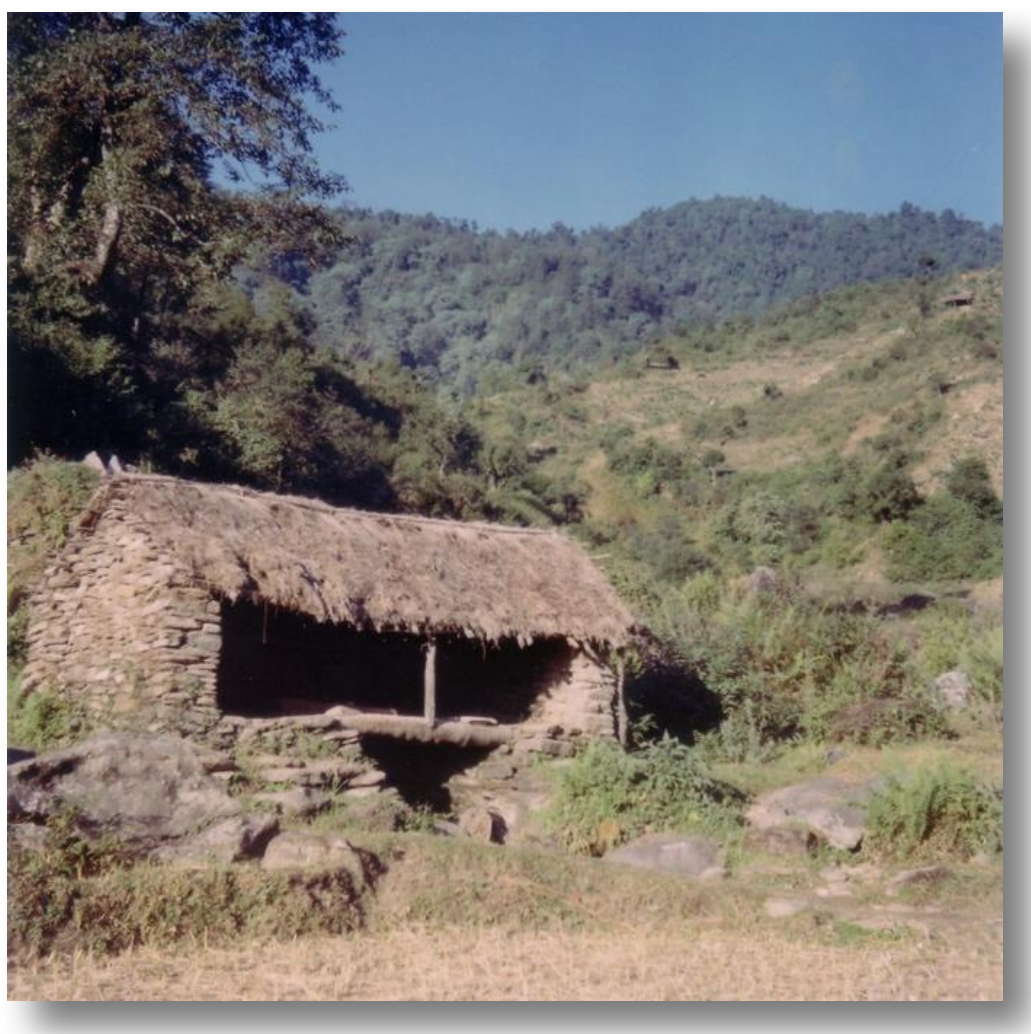

Mill at the Ghatta Kola, on border of Thak and Taprang - 11th January 
Got up late and had a row over Goof and Alan being soft over breakfast. Poor Goof moved away realizing he was object of row! People pouring in with 'teme', cooked or otherwise. Everyone is searching for them, usually fruitlessly, in the forest. We took photos on way up hill as it was a good day. Nice one of them making 'gundri'. Took birds before nuts but not too good. Felt very jangly and on edge, as if permanently before period. Must be stopping pill and some sort of hormone adjustment. Also very thirsty. Typed out my questionnaire for childrearing and went down to find Mrs. B. not doing too much and several grans squatting round who contributed - loudly. Mrs. B. very concise and good and we worked about an hour with her and got some nice results.

Had lunch, got more into Stendhal and then went up my hill and really got involved on my book on Lenin which is an eye opener - being totally innocent politically. His sense of ruthlessness and violence made me wonder if, emotionally it was the means that were important and not the ends - if he cared at all for this enslaved proletariat he talked so rhetorically about. There seem deeper, personal forces at stake. Alan brought up my same query when we went for our walk afterwards. He was interested that Lenin had a clear methodology of propaganda etc. Again dull, stolid people talking round fire drearily all evening - this time Ramchandra's brother who casts a bleak gloom over everything he talks about. I remember the first thing he said to me at the first funeral was that we would never understand these complicated things. Came (again) for medicine "to make a baby". They have a daughter 4, and no son. Also said he wanted a bucket when we had gone. Getting to feel like Volpone, and with increasing irritation. As Alan says, in the last week it will be a huge stream of give this, give that.

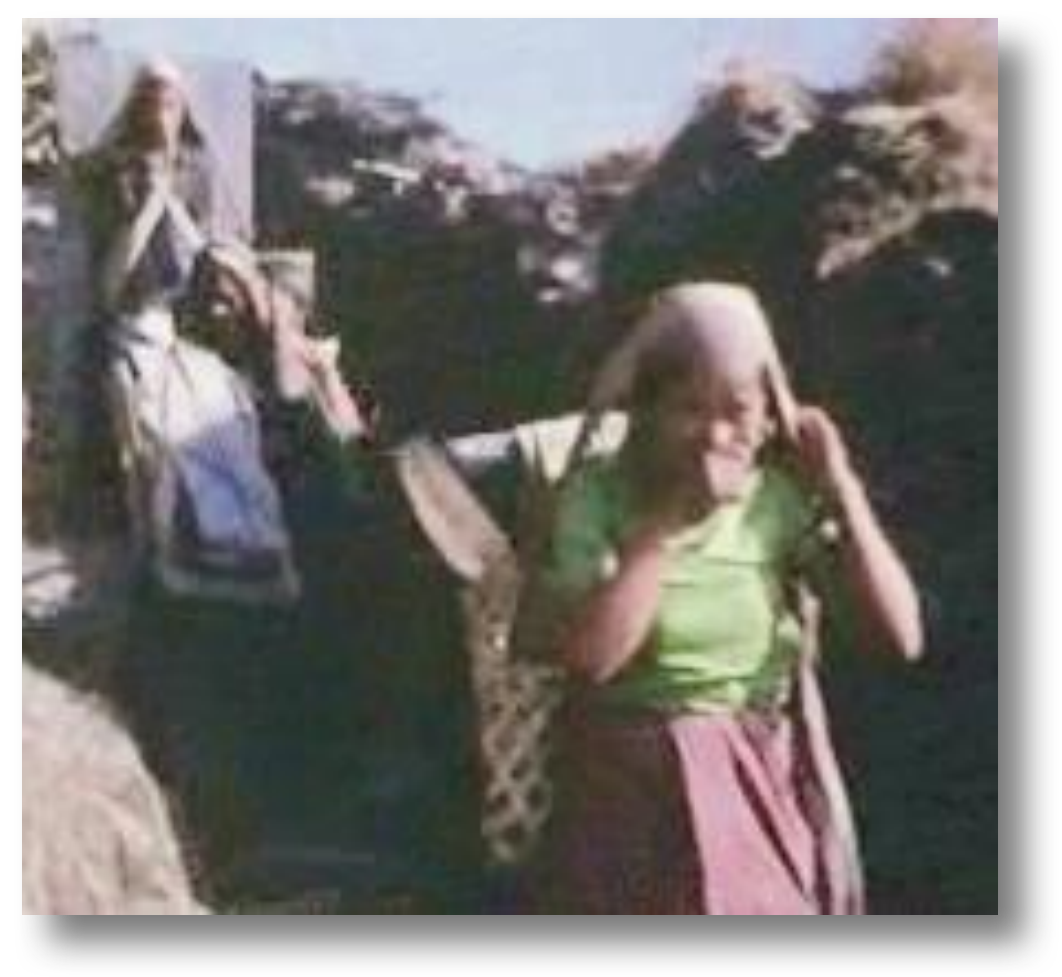

FILM. Women carrying roof slates into the village for Bhuwansing, walking past the water tap. Gill standing beside the wall

https://sms.cam.ac.uk/media/2738279 


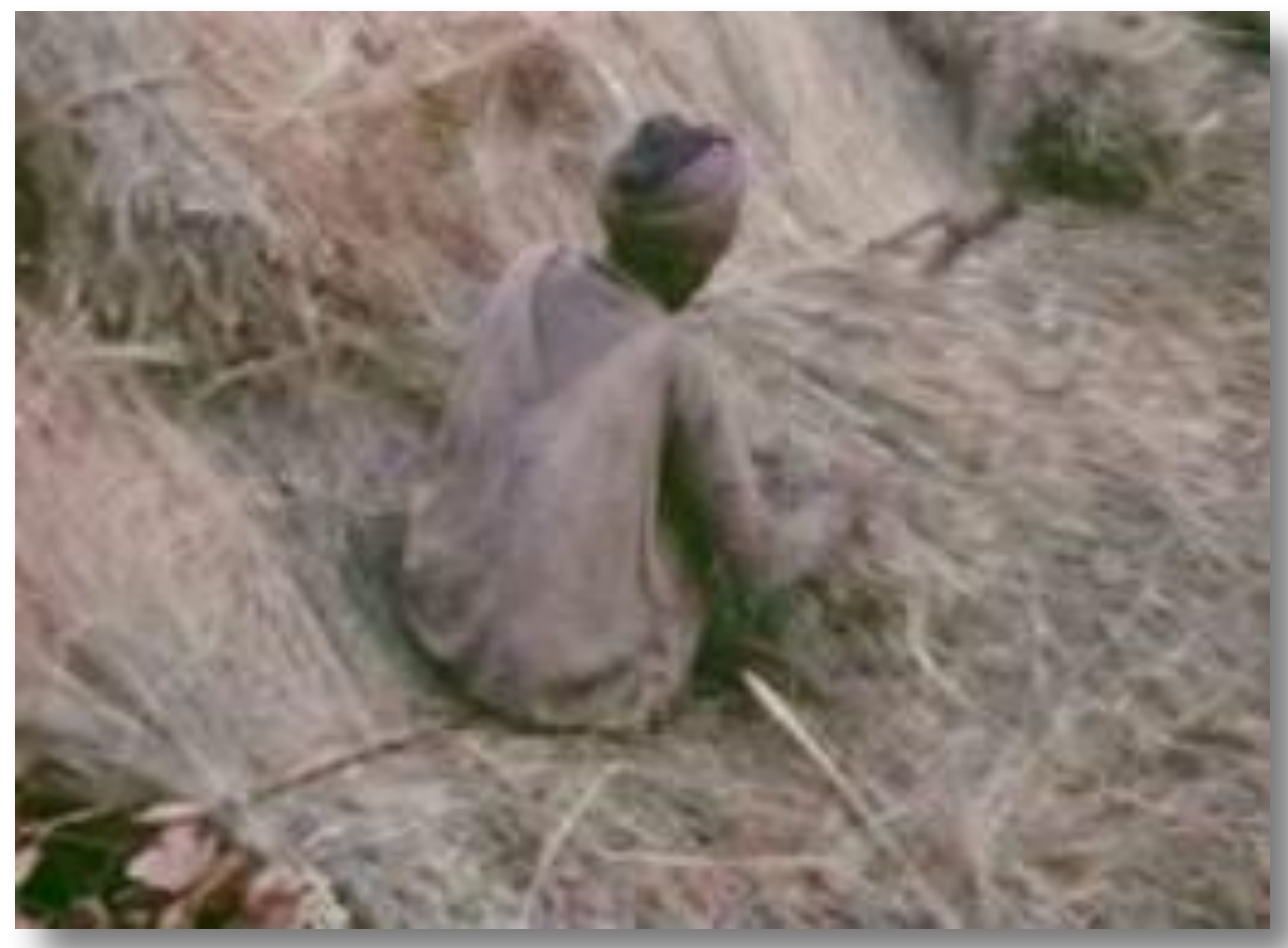

FILM. Kumansing thatching house https://sms.cam.ac.uk/media/2738307

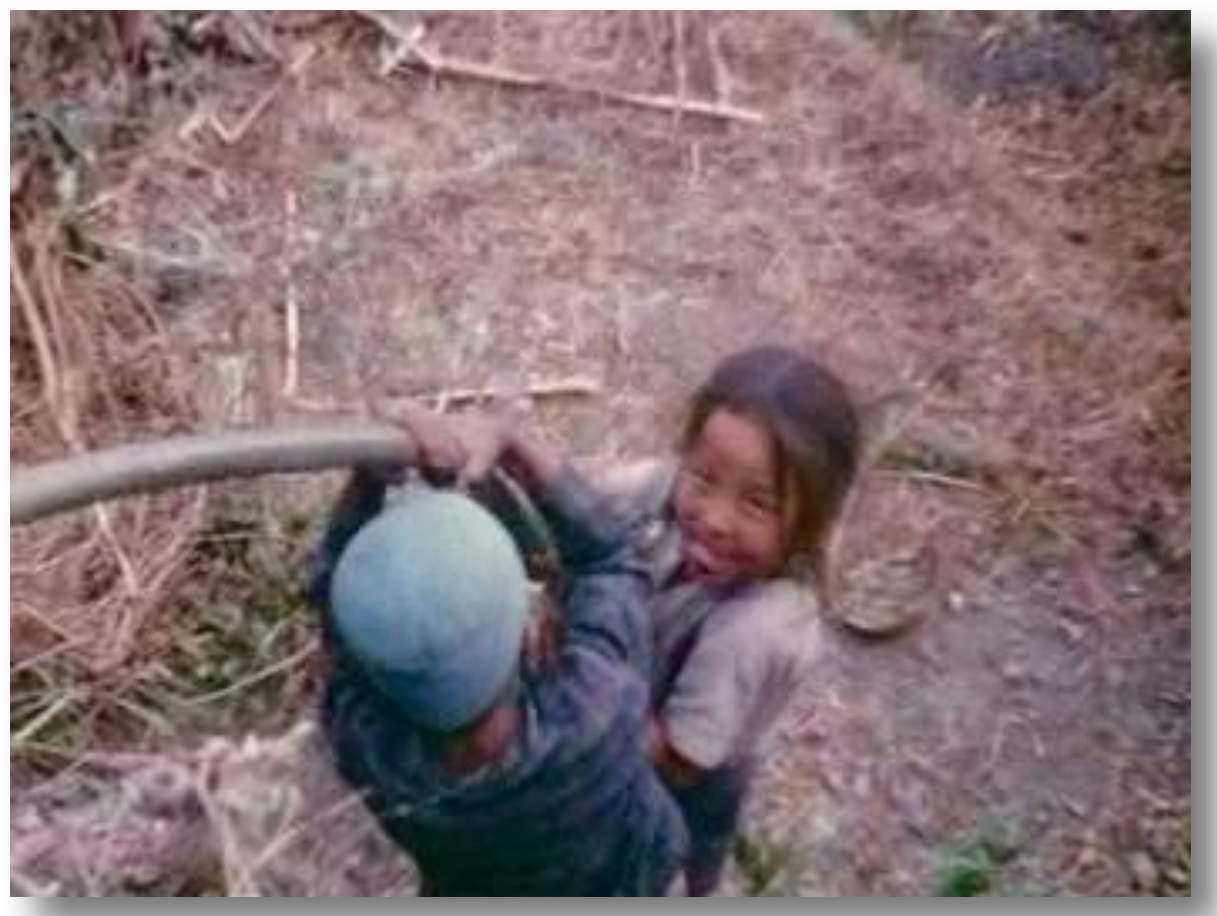

FILM. Two small boys, Totra and Syebahadur ("imp face") sliding down a water pipe https://sms.cam.ac.uk/media/2738335 


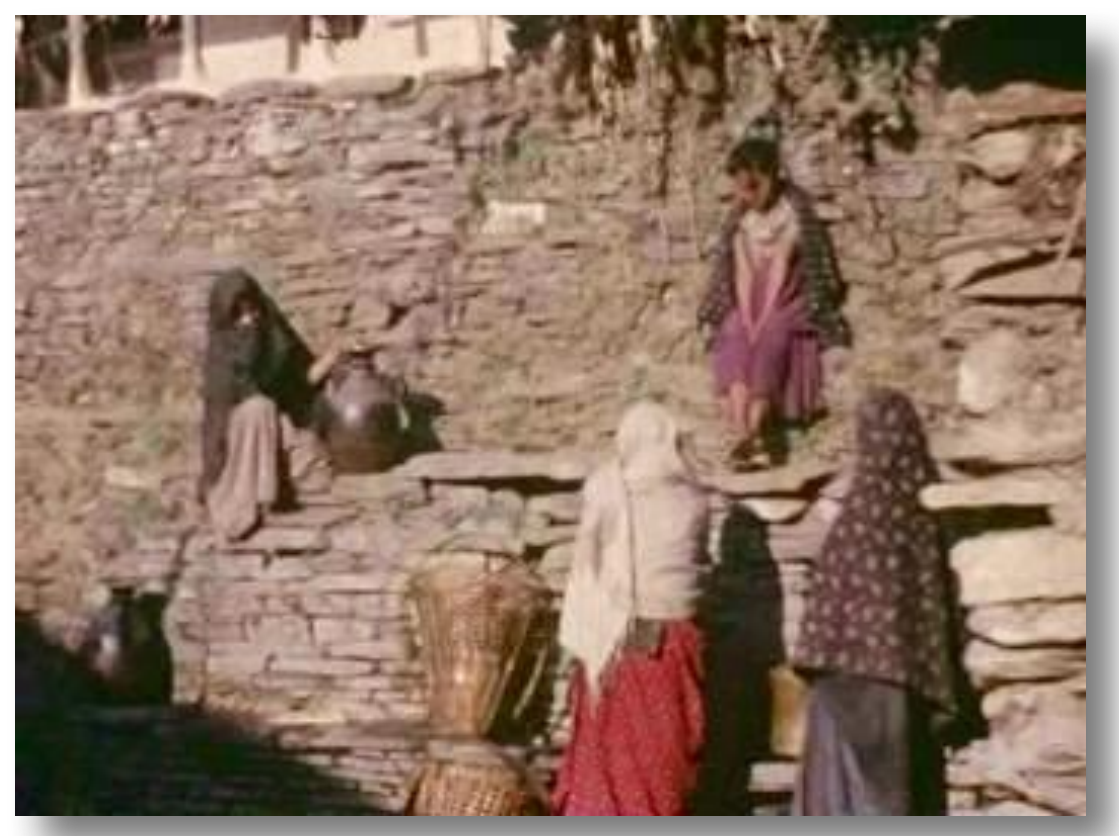

FILM. Girl ('Moili') climbing up a steep path to collect water Women at the water tap

Woman carrying fodder and a man, a slate, pass by https://sms.cam.ac.uk/media/2738363

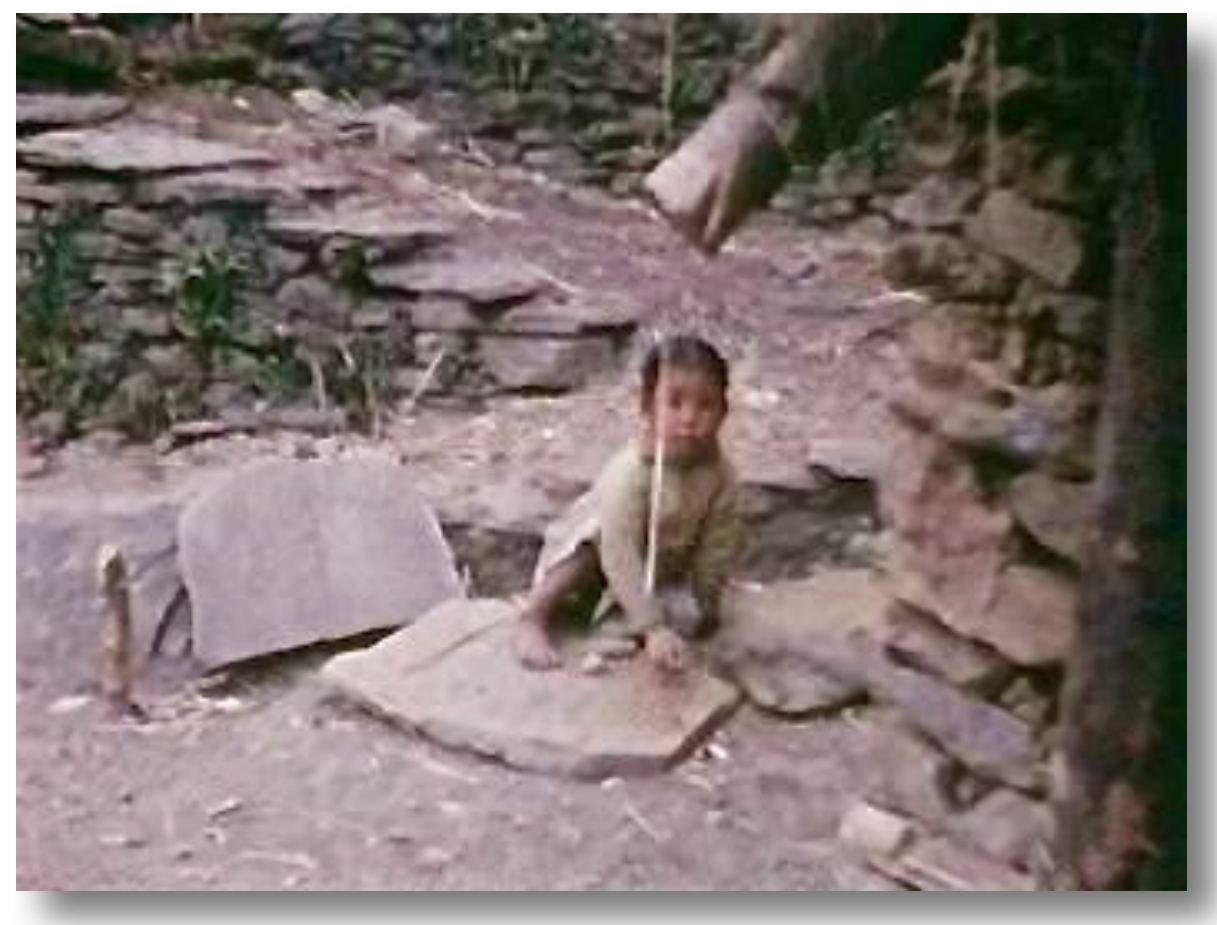

FILM. Nadakumari ("nani House14") playing at grinding near 'hotel' https://sms.cam.ac.uk/media/2738391 


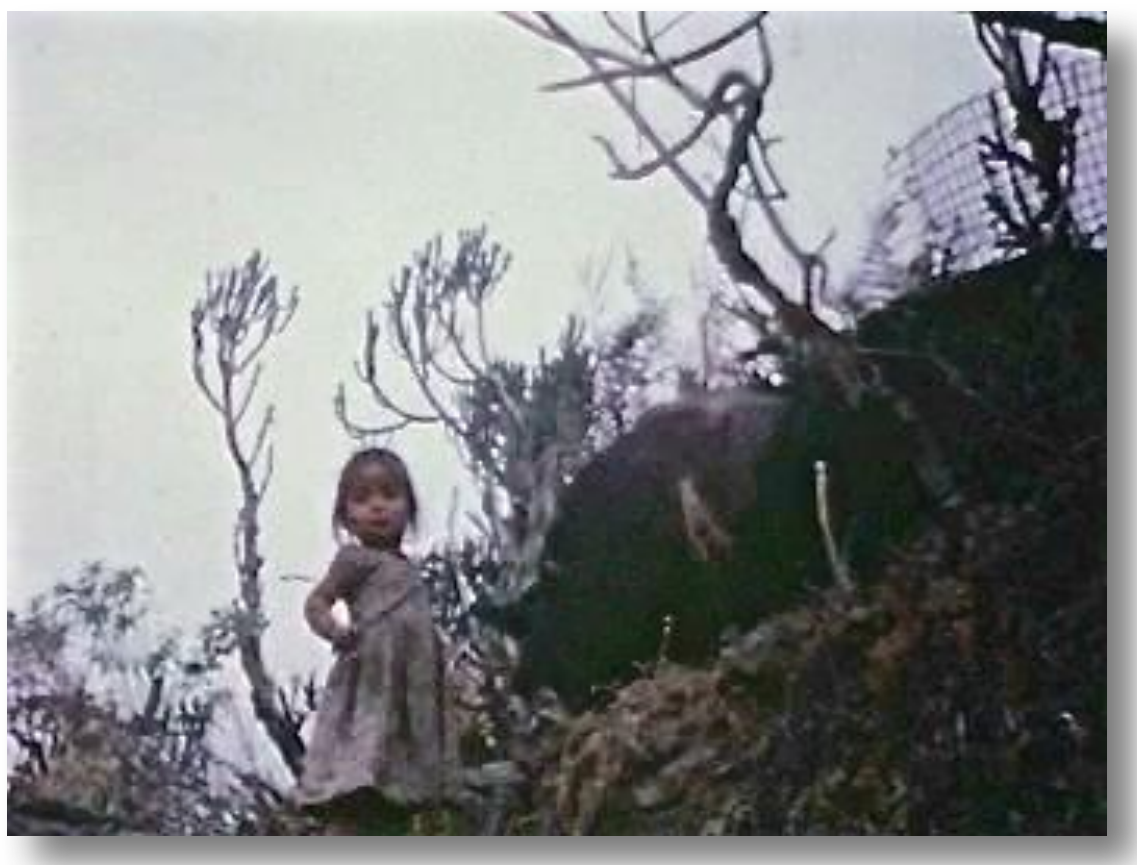

FILM. Little girl ("maili") hitting oxen with a stick https://sms.cam.ac.uk/media/2738419

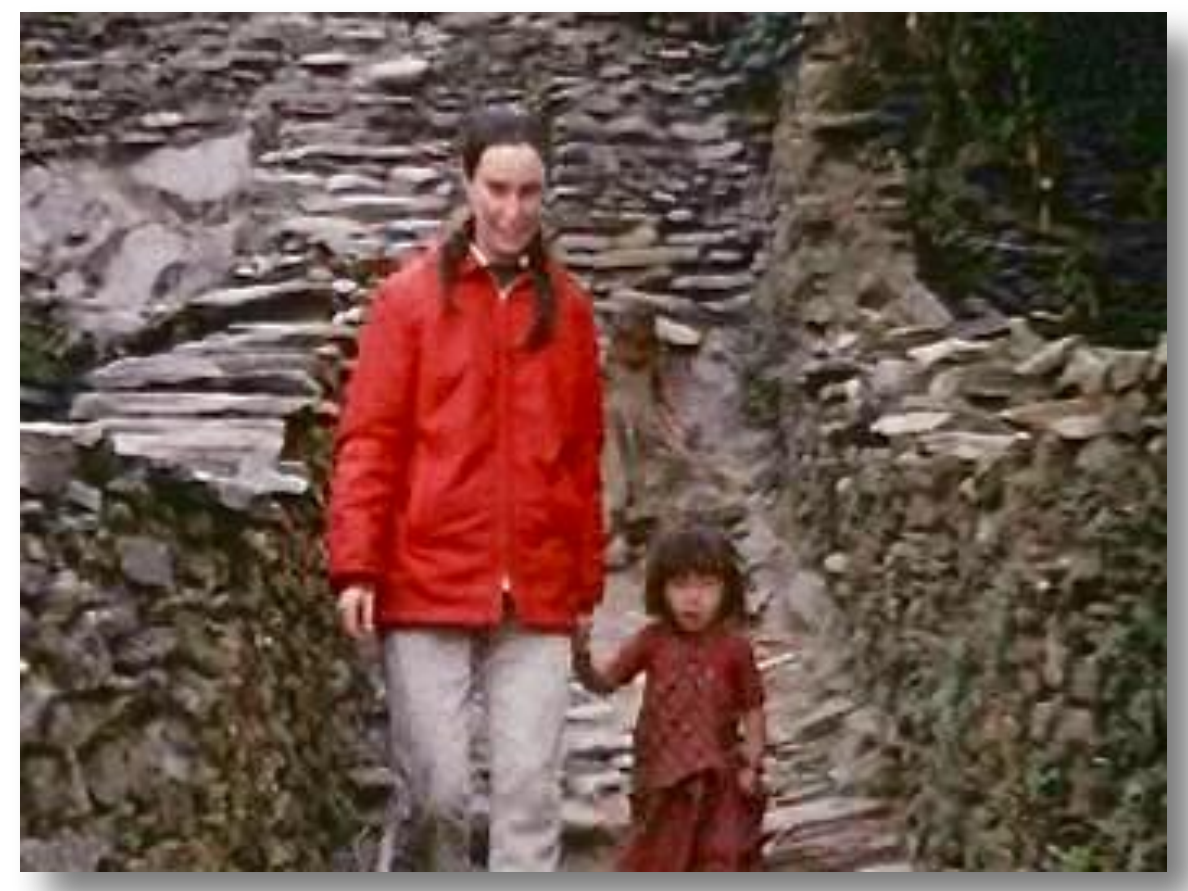

FILM. Gill walking down the steps holding Sobadebi's hand https://sms.cam.ac.uk/media/2738447 


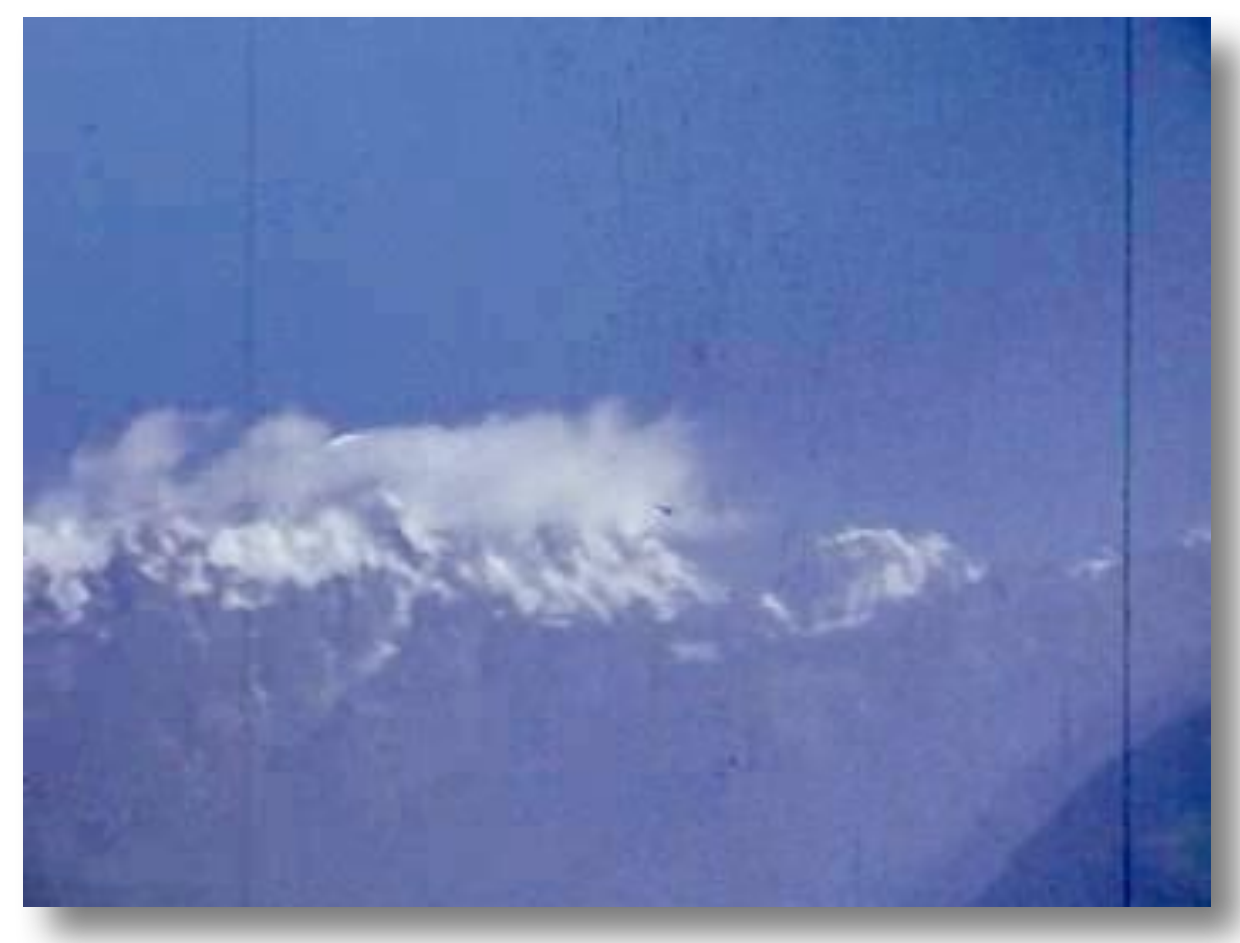

FILM. Eagle flying with mountains in the background https://sms.cam.ac.uk/media/2738475

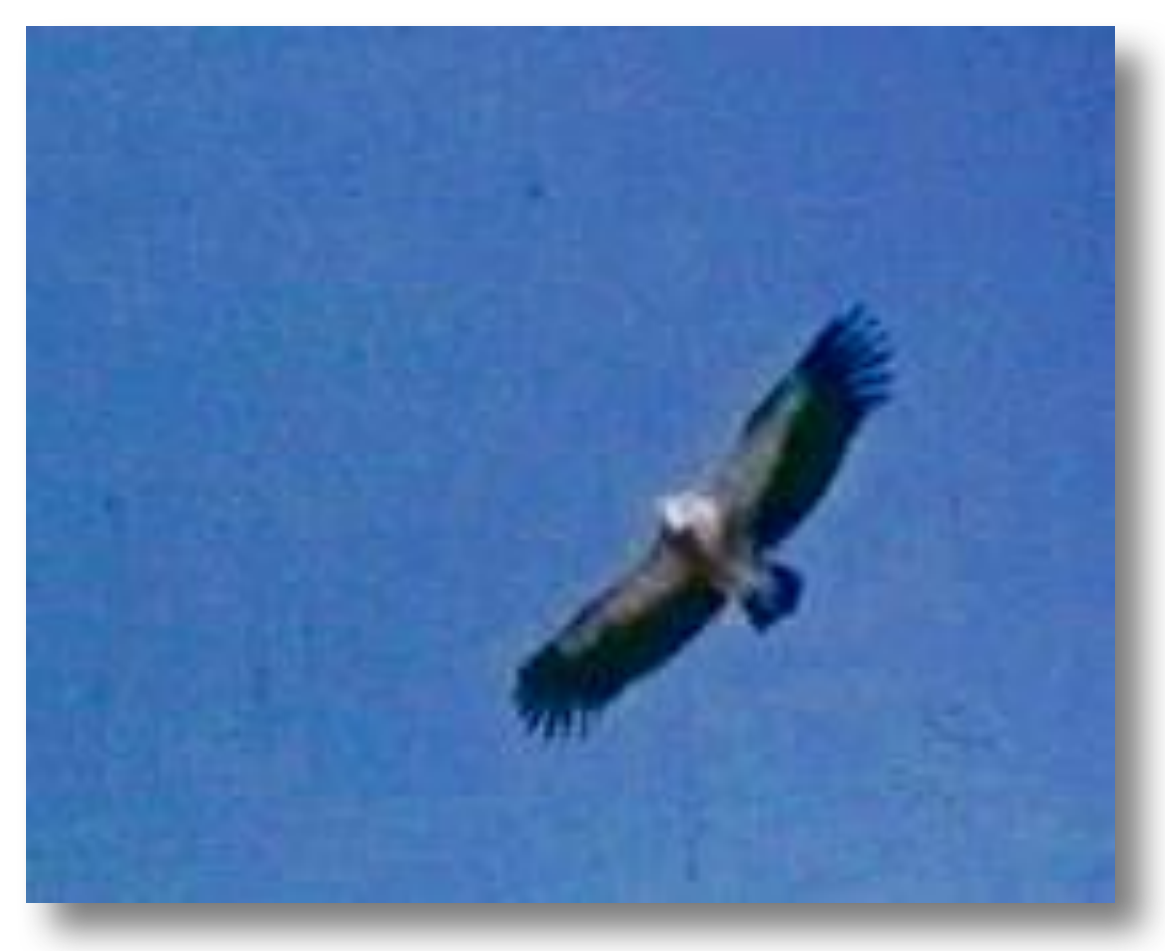

FILM. Hawks, mountains and Thak village https://sms.cam.ac.uk/media/2738529 
DIARY Monday 12th January

Went down in morning to do school records with Prasad who hadn't yet arrived. He came down soon after and we did the records - half at his house, half at the school. During the latter it began to rain and hail and we had some tasteless cold 'pa'. Shot up the hill in slight hail with the 'pa' inside me. In the afternoon did some more photographing. Discussed Kaila's theft at tea-time - everyone seemed to know about it, but only half angry/half amused. A pleasant day. Gill's boyfriend in with much joking in evening.

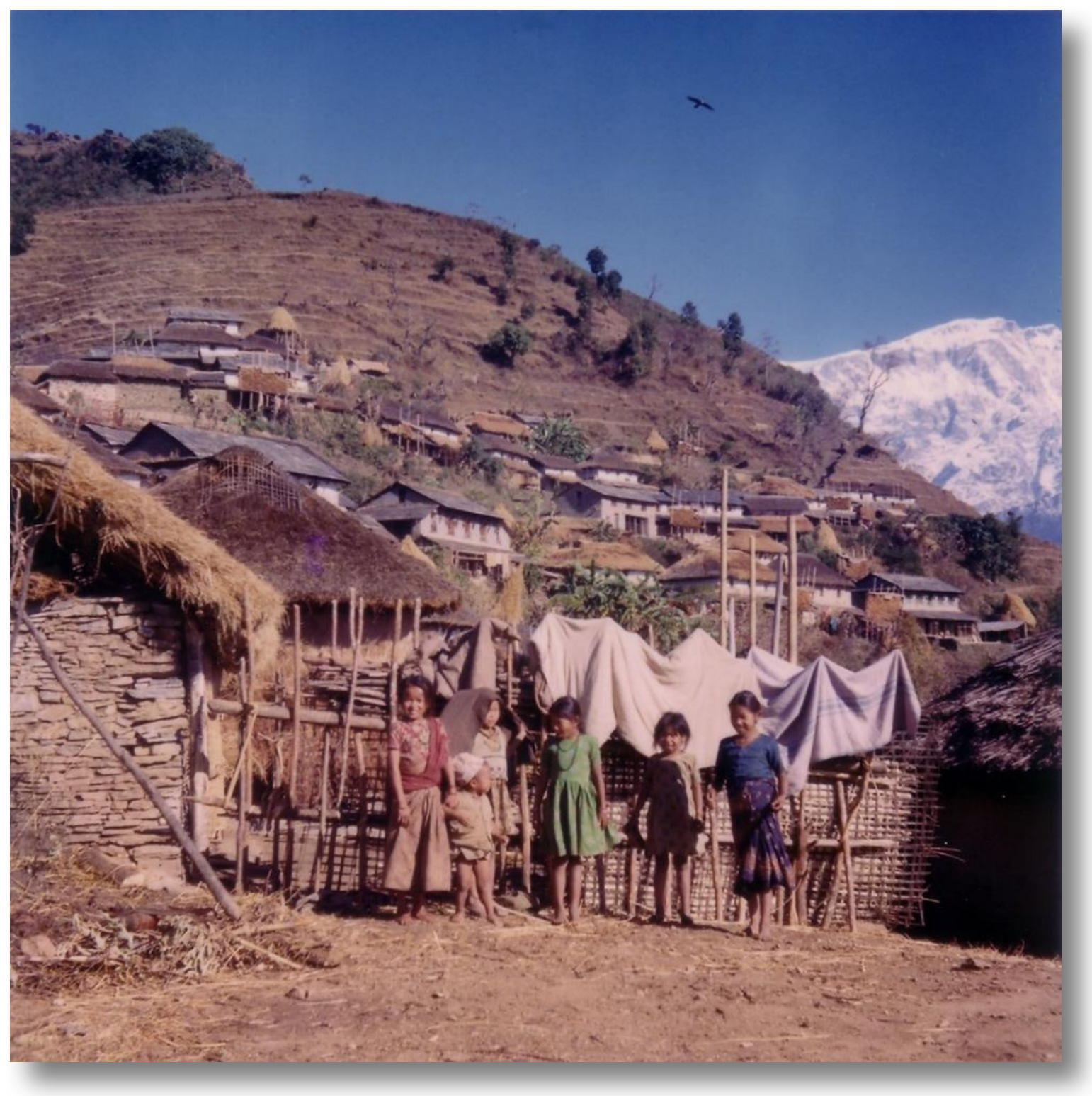

Children at end of village, 'Kwi Nasa' - 12th January 


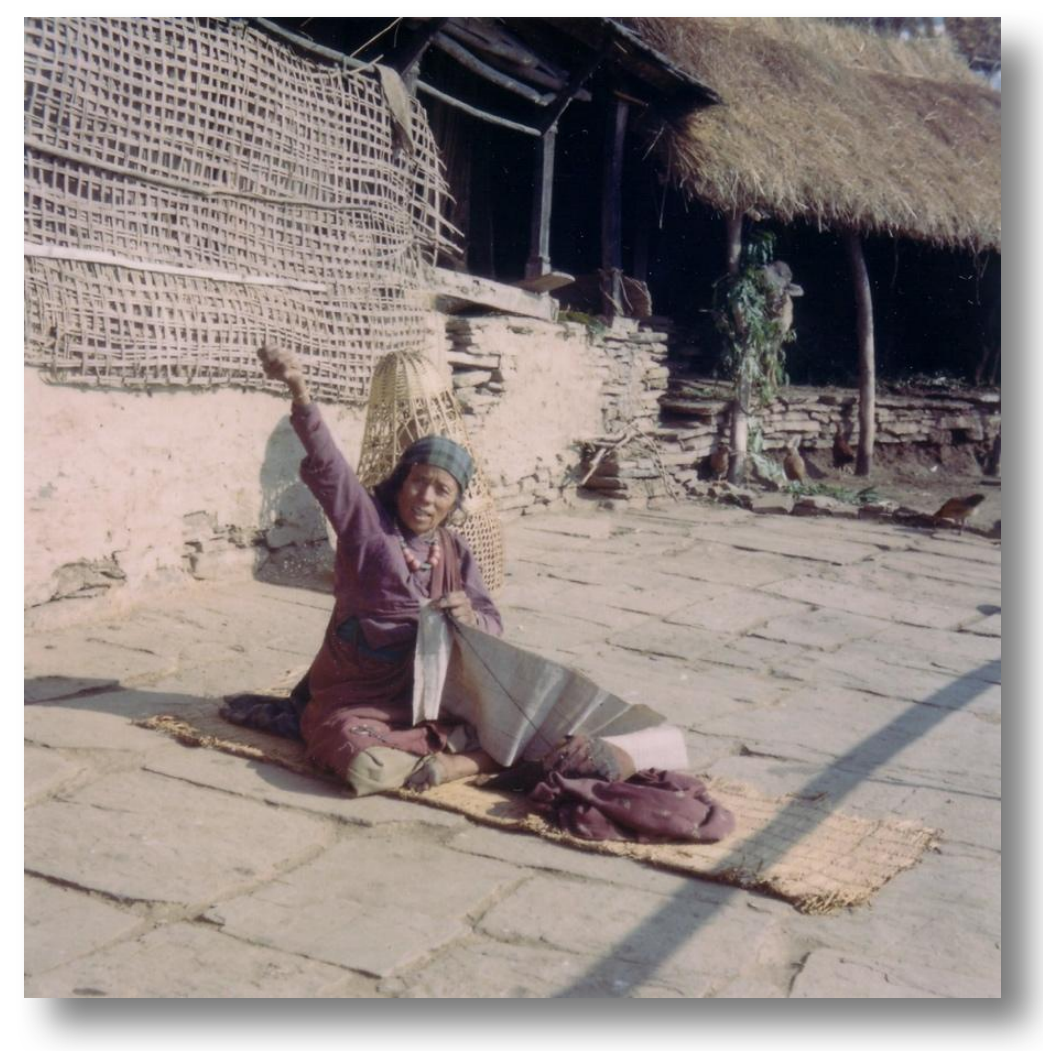

Dansuba sewing up a 'renga' or overgarment - 12th January

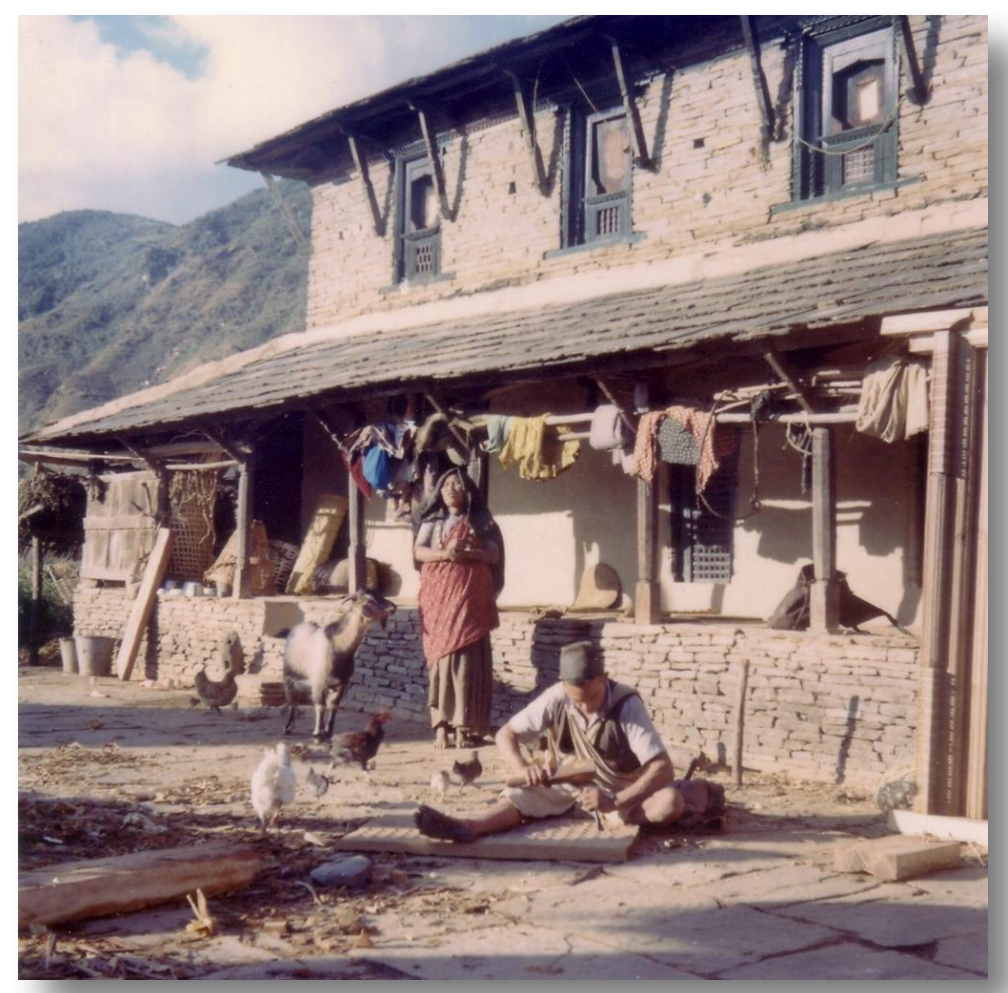

Chandrabahadur Sarki carving a window at House 6 - 12th January 


\section{DIARY GILL Monday 12th January}

Alan went straight down to Uli to do school records with Prasad. When I went up the hill the hills down to the level of Siklis were all powdered with snow - white specks on a grey background, and I got a sudden lunge of homesickness - on the walk through the snow at home, all somehow, associated with my father. There had been a lot of hail and wind in the night, but the morning was blue and yellow with sunshine. At about 11.00am. though it suddenly started sleeting, with the sun still on the opposite side of the valley. Nani was just washing her hair and it must have been very chilly. Then a wind got up and more hail and it was quite bleak in the loft. Hoped Alan wasn't getting a soaking. I froze till I had to close window and type in near dark. Did three hours of typing up Mrs. B.'s interview yesterday. After lunch, where I have at last accepted Stendhal and am enjoying cynicism and revelation of anomalies esp. re religion and court life. Found an example of formalized type of guilt for Alan.

We photographed rest of time [PHOTOS] and I was pleased to find out how they make 'chura' - put unhusked grains in a black pot to heat, flicking with bundles of sticks to stop them from catching and then pounding heated grains straight away. This flattens them and makes them tacky in taste. Looked at spastic boy again whose arm has still not healed. He asked for a tin to feed his pet dove from ('dogori'). Came back with a splitting headache from having strained my eyes. Made fish cakes and we had quite a jolly evening with Ombahadur imitating poju and teasing Gundasing, whom they call 'baje'! Clear star lit night, but quite cold.

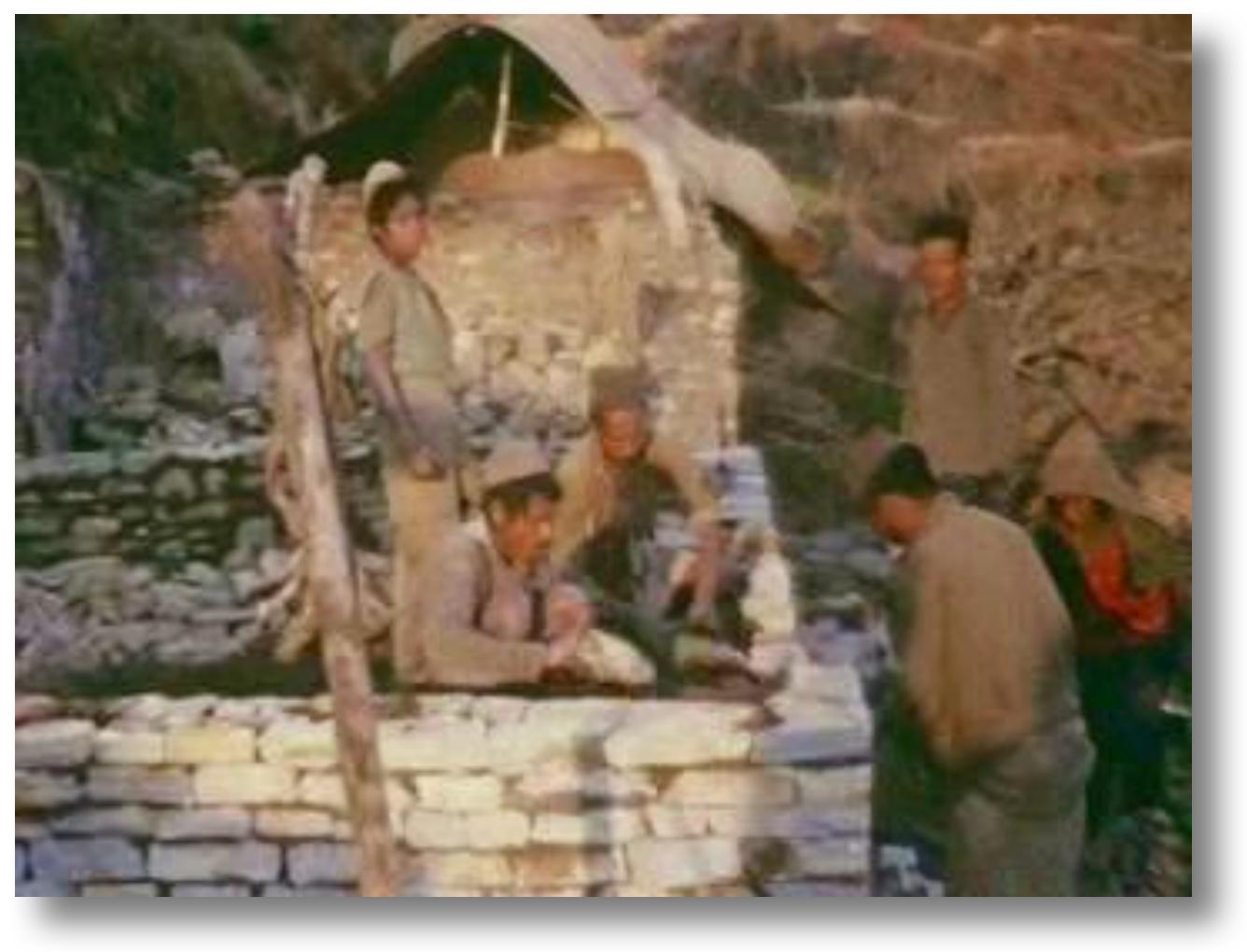

FILM. Men building a stone house https://sms.cam.ac.uk/media/2738557 


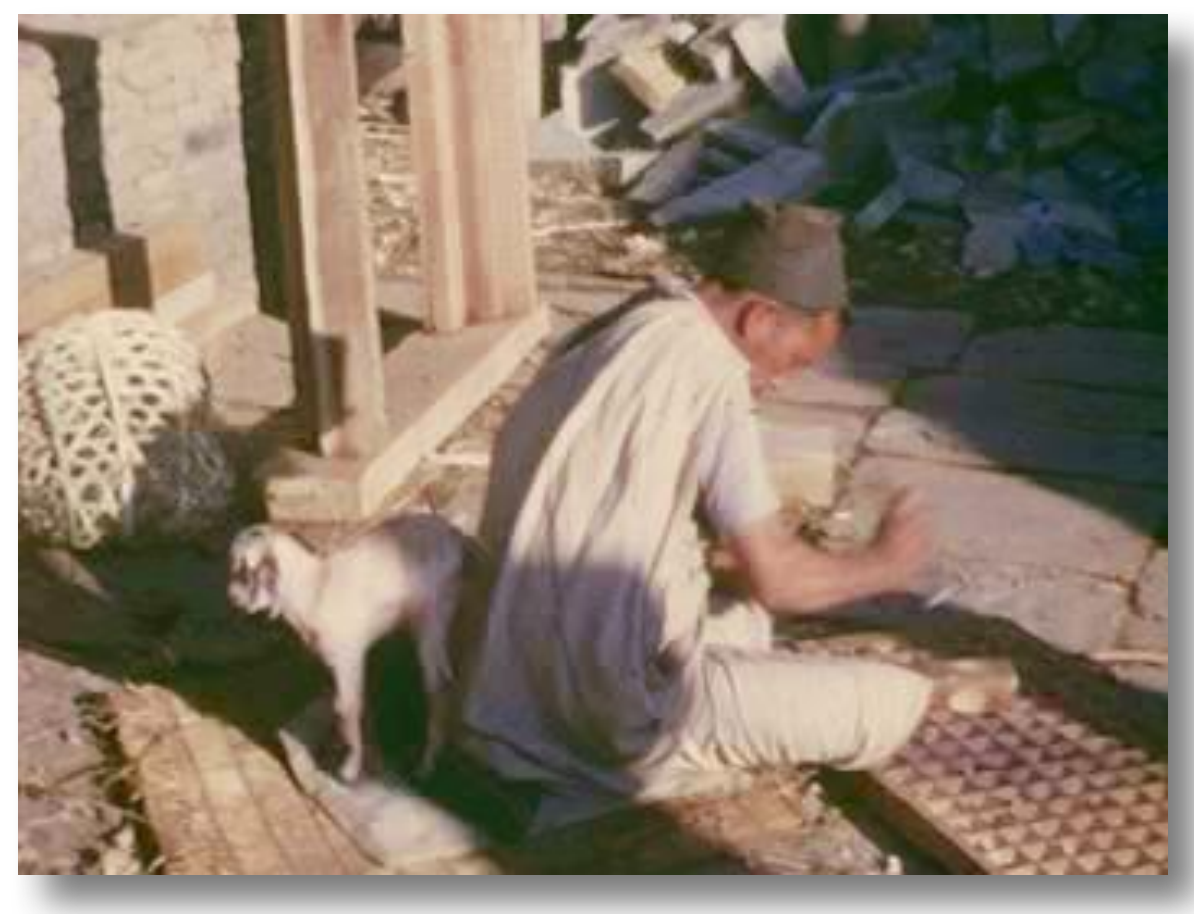

FILM. Chandrabahadur Sarki carving a window for a new house https://sms.cam.ac.uk/media/2738585

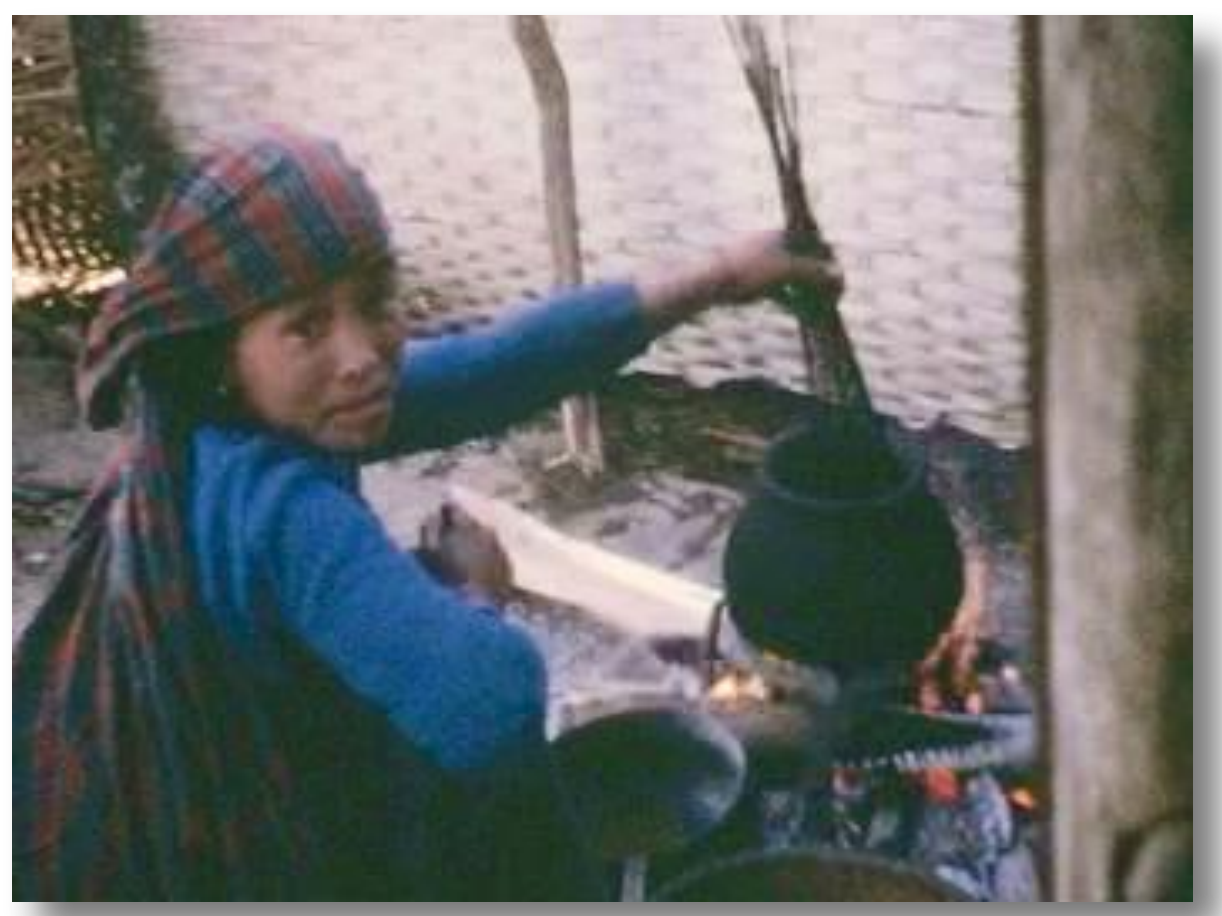

FILM. Girl stirring a boiling pot with twigs in beside the 'kuni'

Woman winnowing beside her (looks like Kowshila (House9)?). Small child eating. Some beating beside them

https://sms.cam.ac.uk/media/2738613 


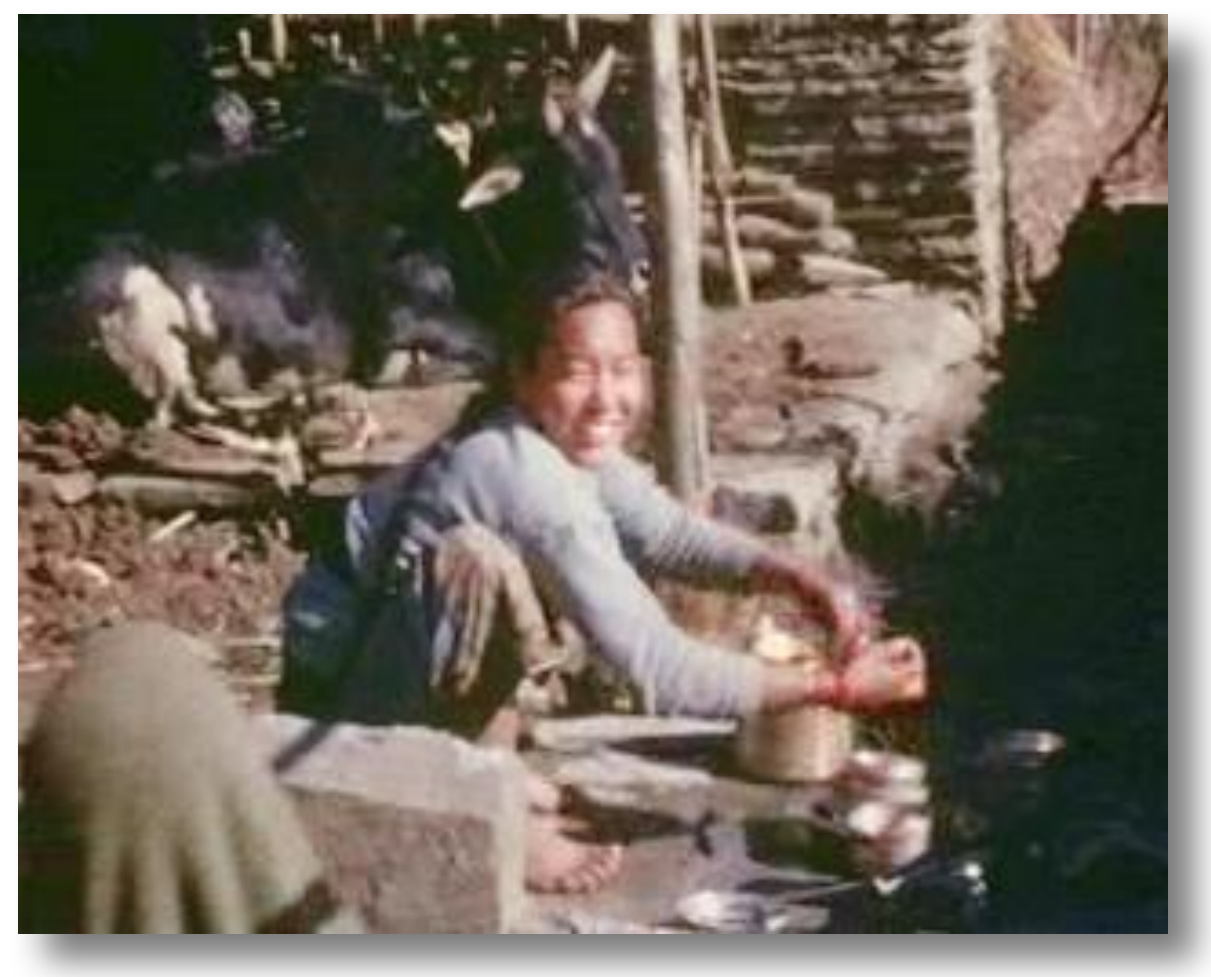

FILM. Dankumari washing dishes beside stalled oxen https://sms.cam.ac.uk/media/2738641

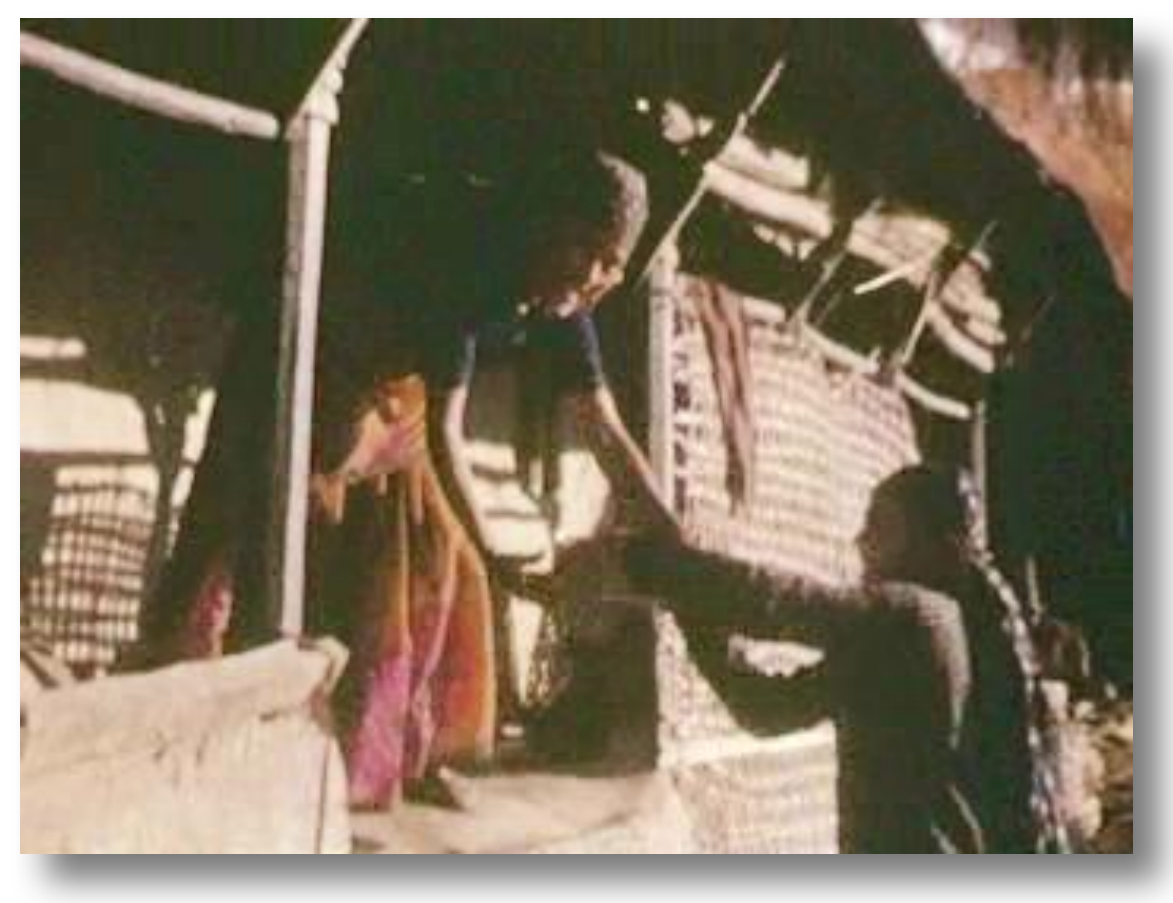

FILM. Girl from House23 bringing 'Mark' rice to House32 where Asmaya takes them from her

https://sms.cam.ac.uk/media/2738669 


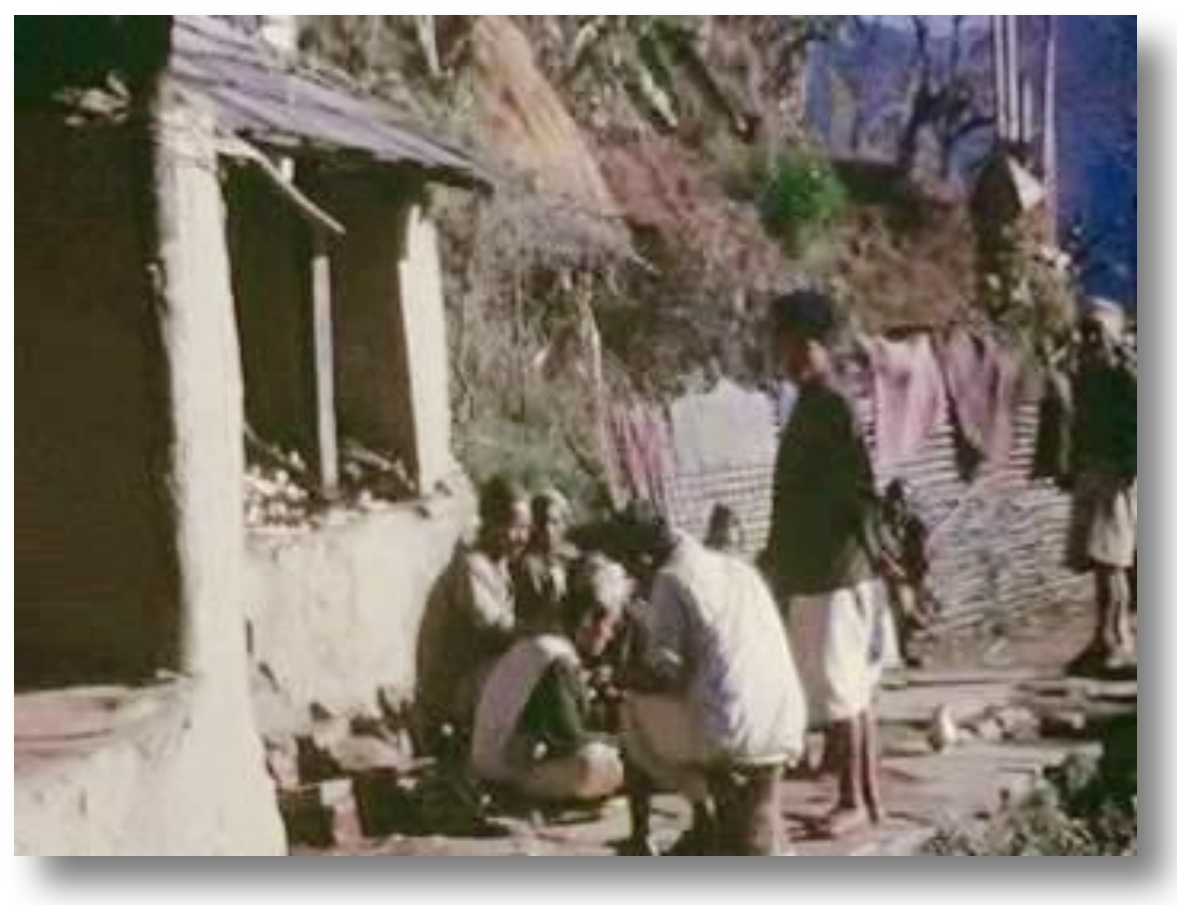

FILM. Group of men talking on a narrow terrace, one of them writes something down (Ramchandra?) https://sms.cam.ac.uk/media/2738697

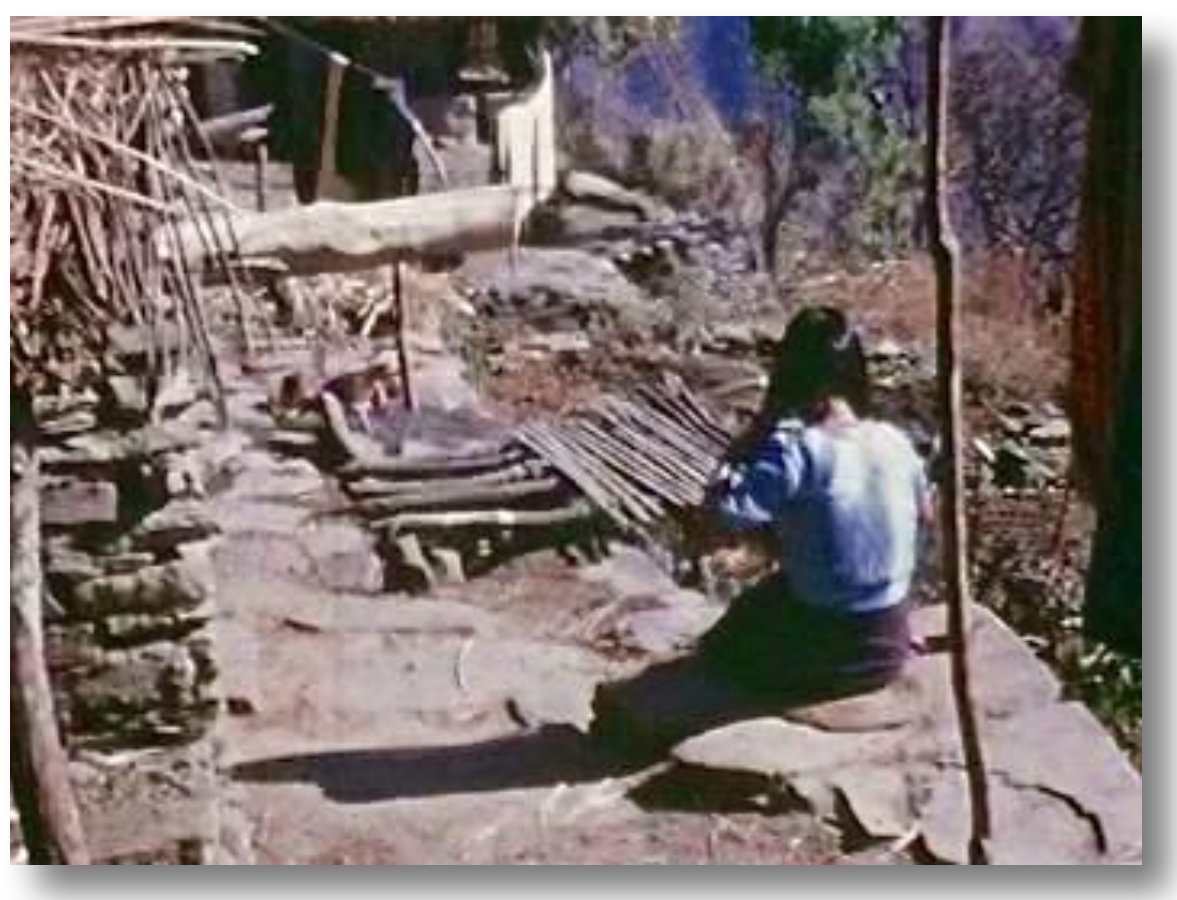

FILM. Girl in a silk blouse combing her wet hair Talking to Gill

https://sms.cam.ac.uk/media/2738725 


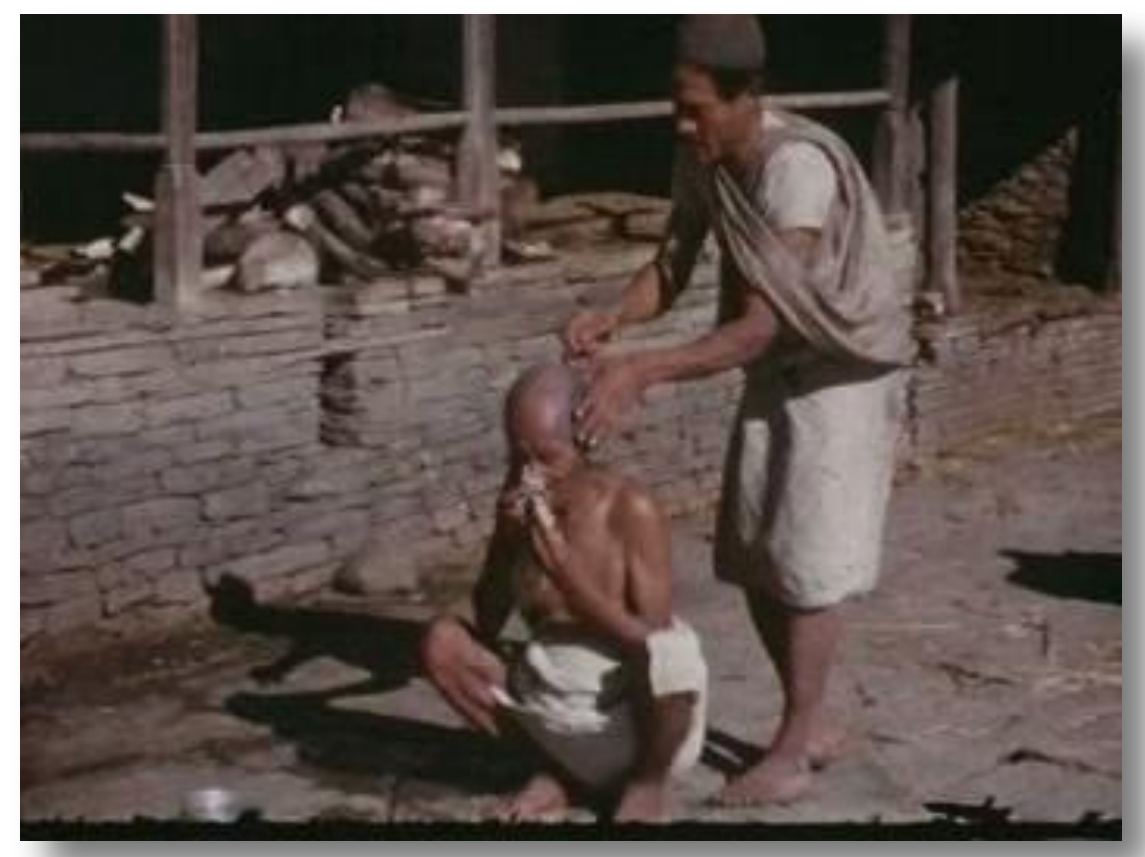

FILM. Kumbasing shaving Dilbahadur's head https://sms.cam.ac.uk/media/2738753

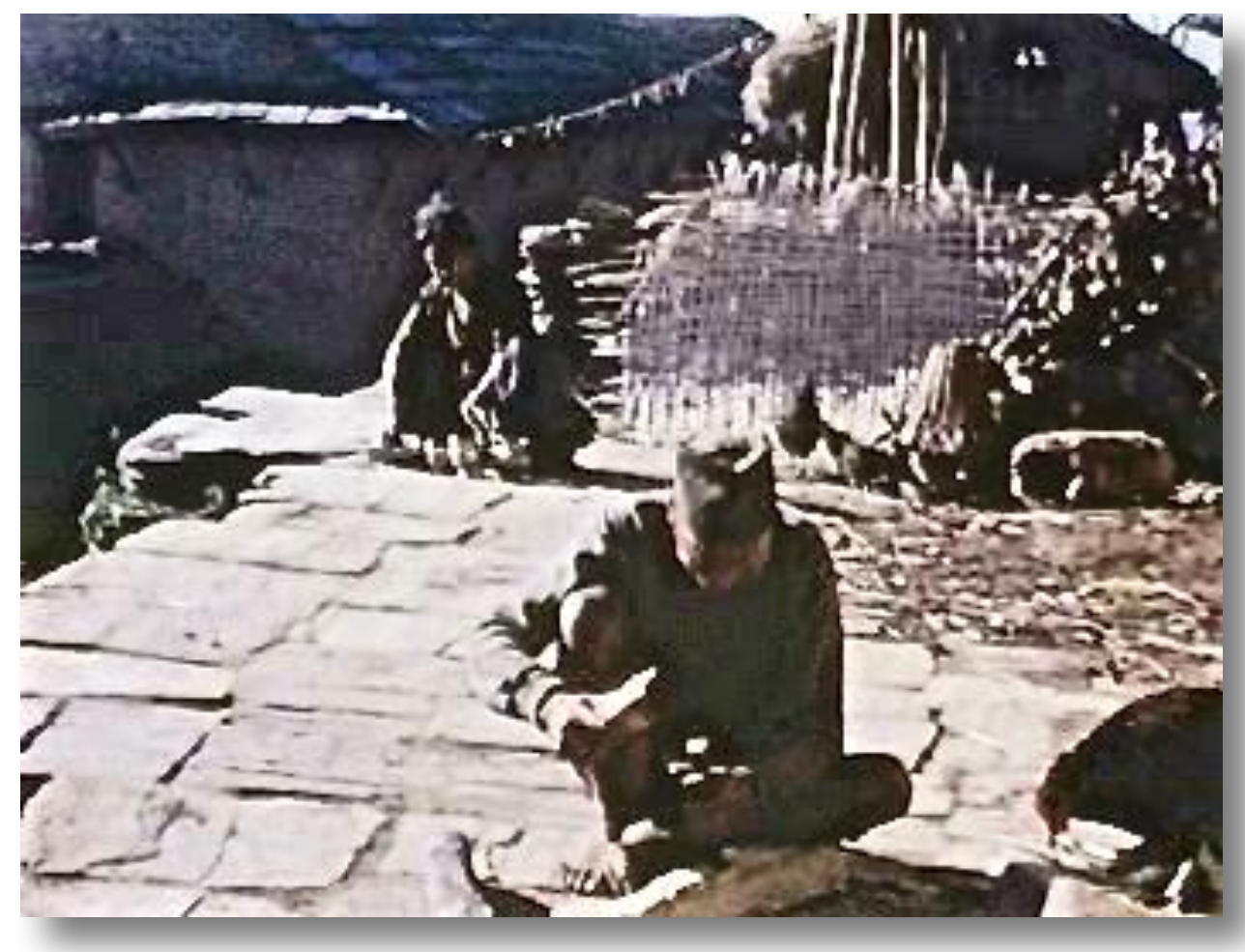

FILM. Tekansing ("Bol's father") encouraging a goat to lick his fingers. Shaping a wooden plough with a chisel. Woman (probably wife, Sunkumari) washing dishes in the background https://sms.cam.ac.uk/media/2738781 


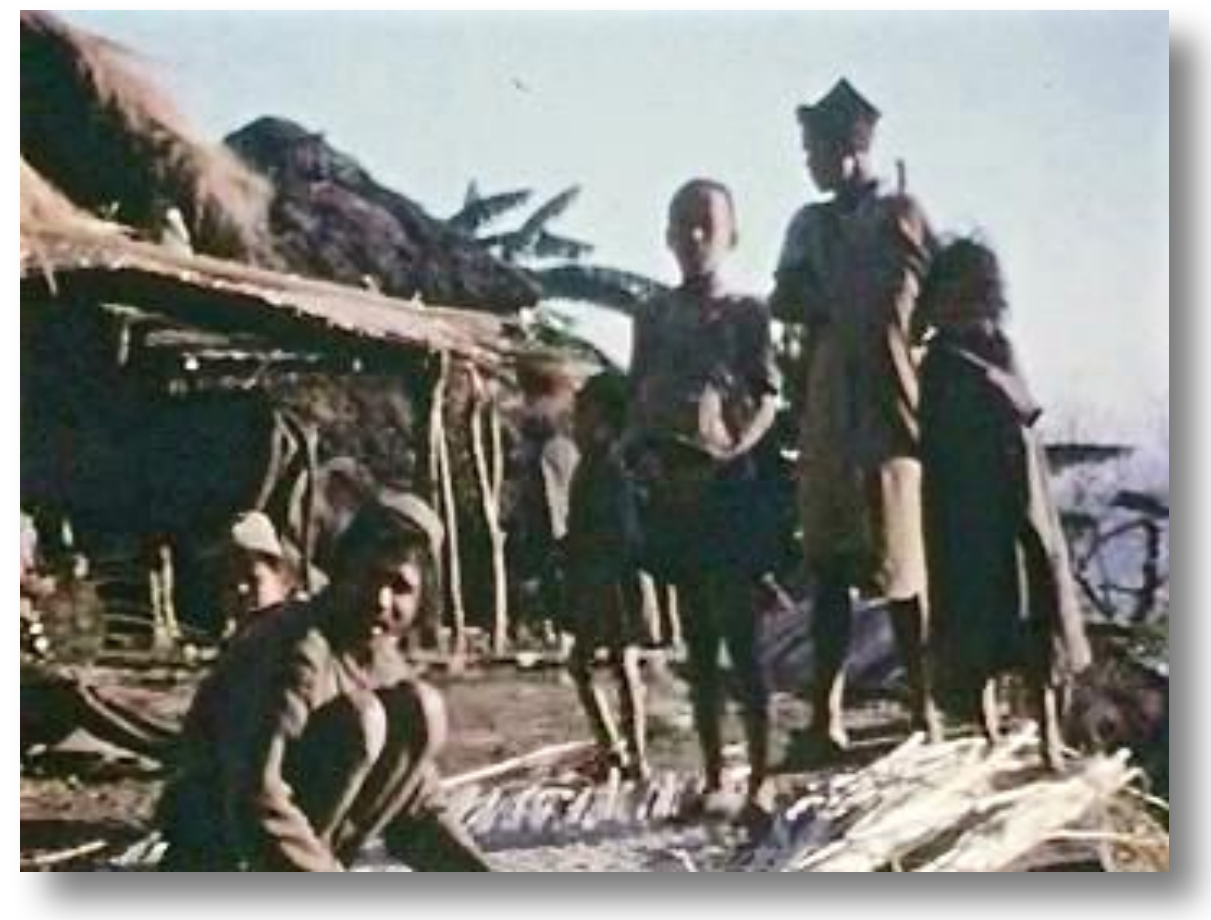

FILM. Blacksmiths making bamboo mats for fencing and baskets https://sms.cam.ac.uk/media/2738809

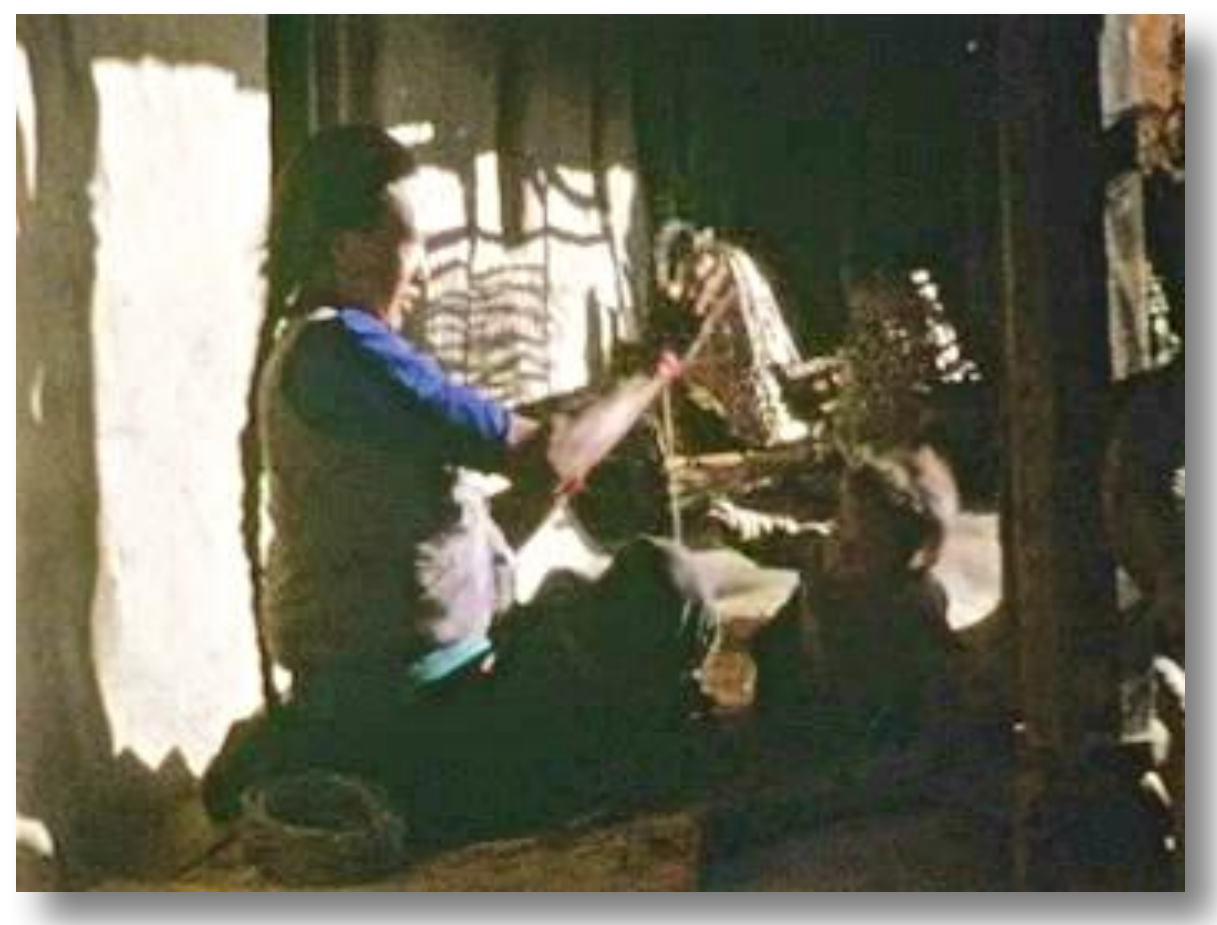

FILM. Woman ("nani's sister") with a small child sitting on a verandah (House32) making twine

https://sms.cam.ac.uk/media/2738837 


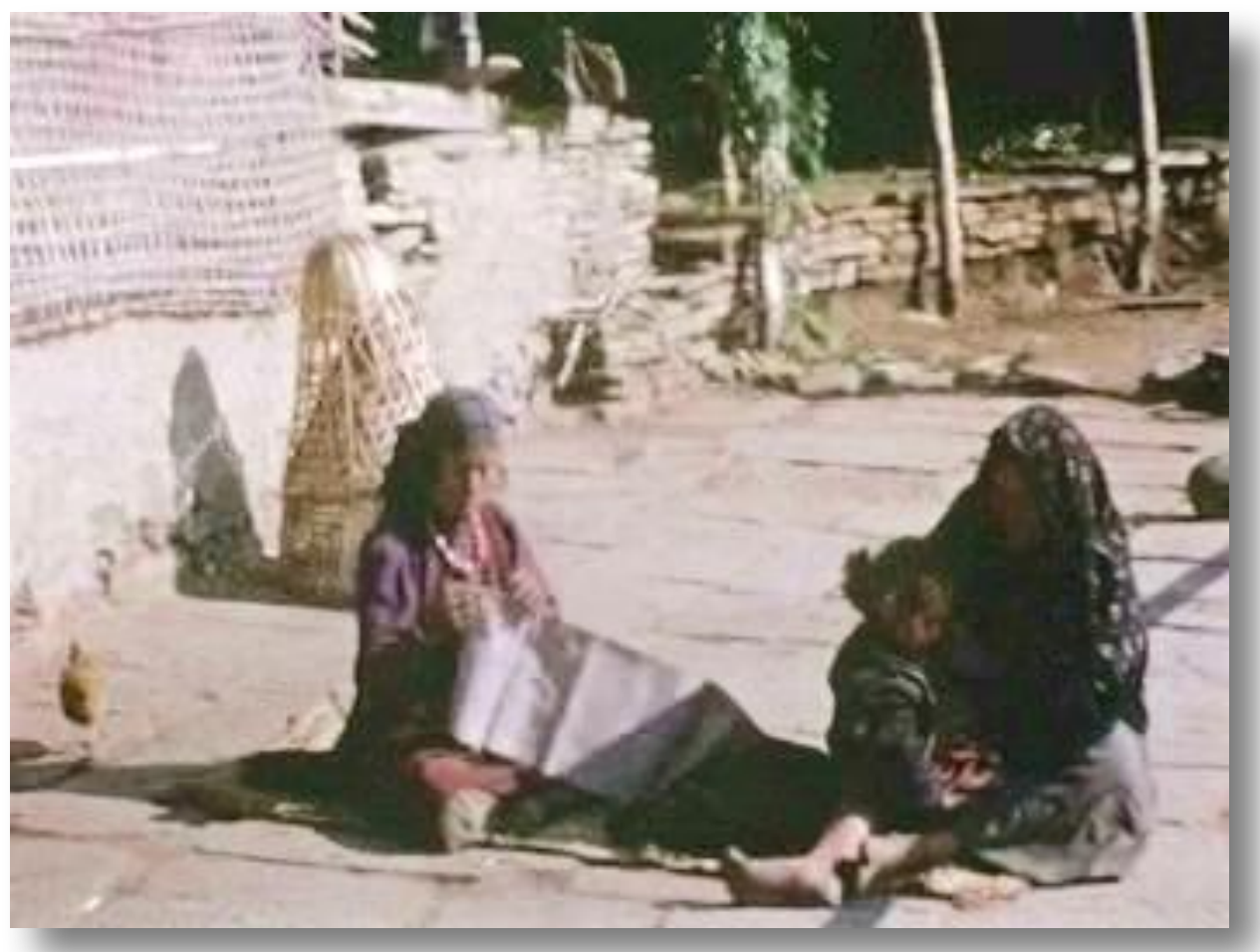

FILM. Dansuba sewing up a 'renga' with a Palman's mother, Humkumari, and small daughter, Lilkumari, sitting beside her https://sms.cam.ac.uk/media/2738865

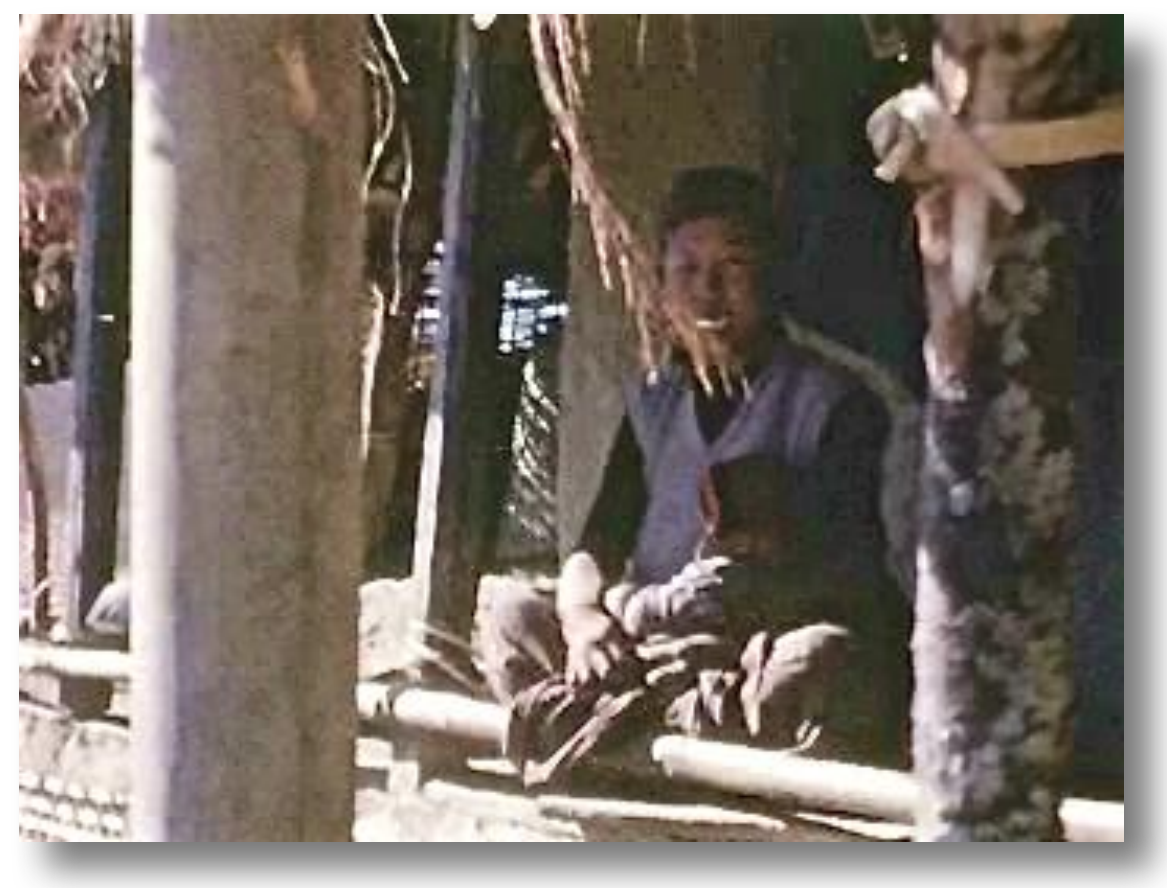

FILM. Haricola sitting on a veranda with a small child in her lap at Housel https://sms.cam.ac.uk/media/2738893 


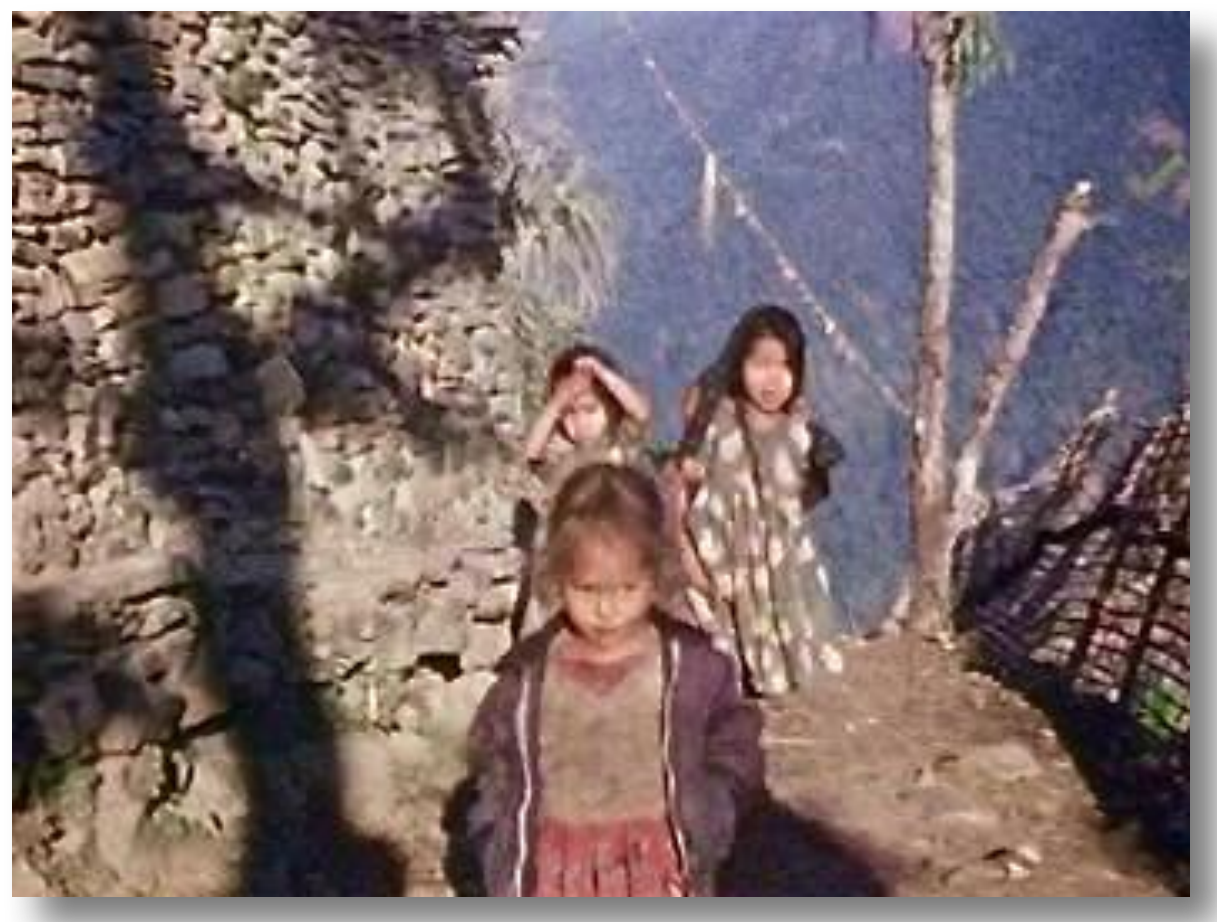

FILM. Three little girls, one with a baby on her back, walking up the path https://sms.cam.ac.uk/media/2738921

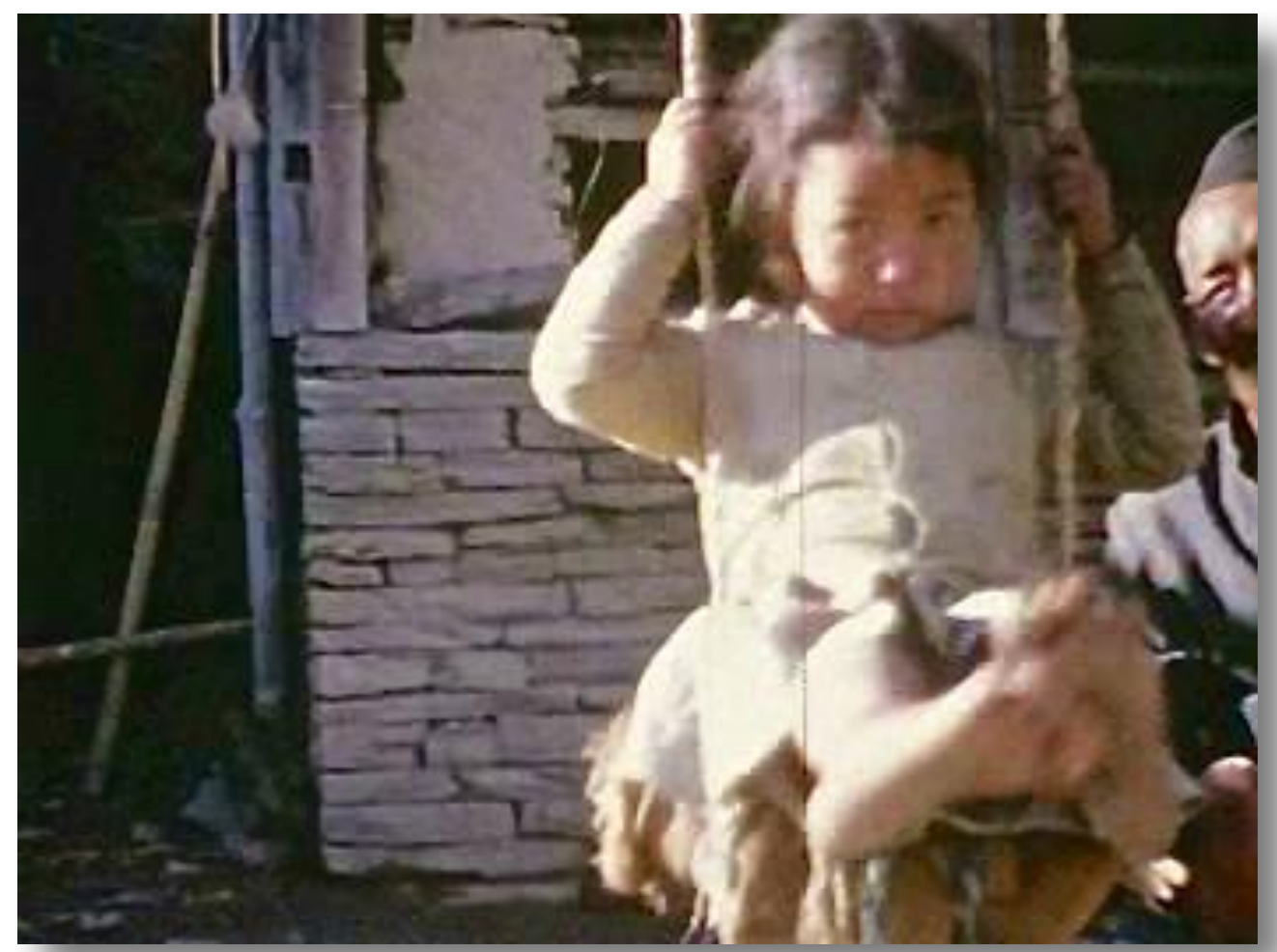

FILM. Old man pushing a little girl on a swing https://sms.cam.ac.uk/media/2738949 


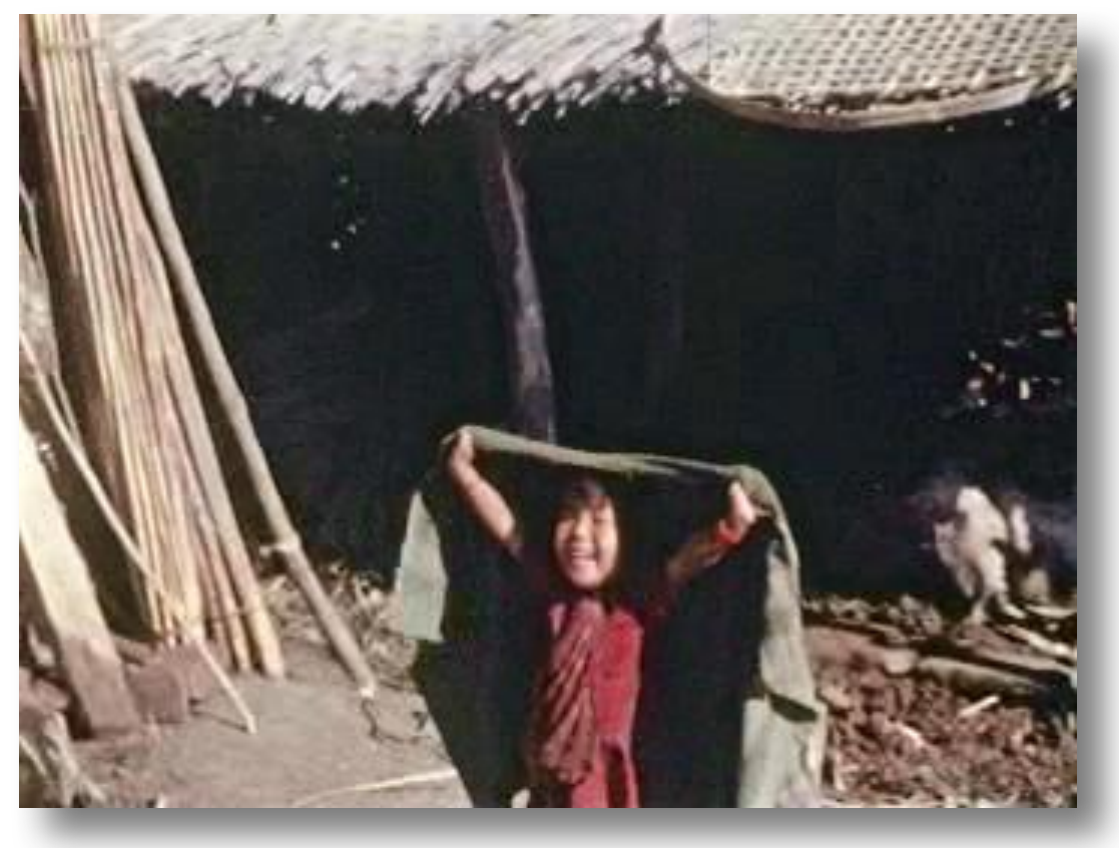

FILM. Sobadebi with a towel on her head, covering her face Nansubar adjusting the towel into a 'kramu'. Youth comes out with a stool and sits on the veranda above https://sms.cam.ac.uk/media/2738977

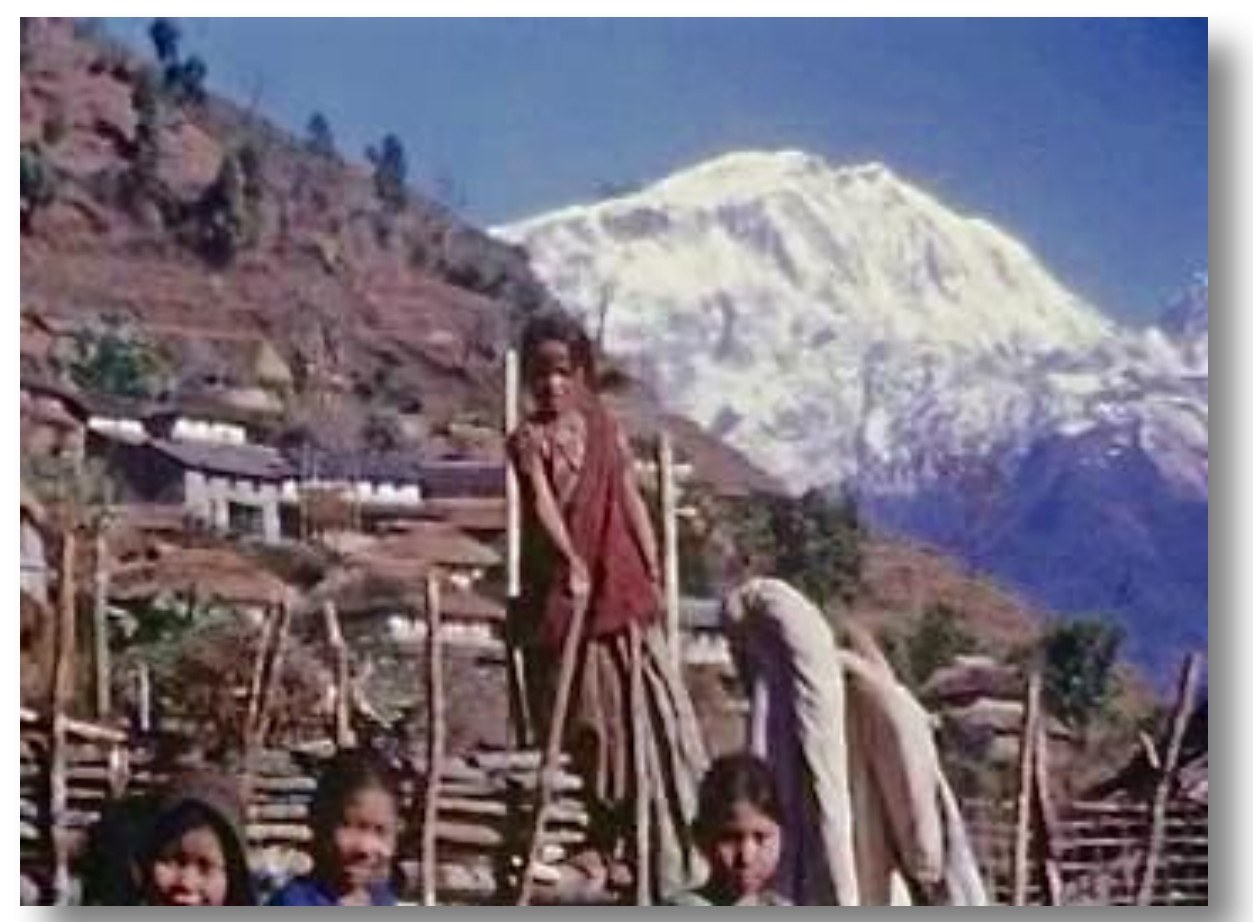

FILM. Maitasuba at Kwi Nasa, one hanging out bedding on a fence https://sms.cam.ac.uk/media/2739005 


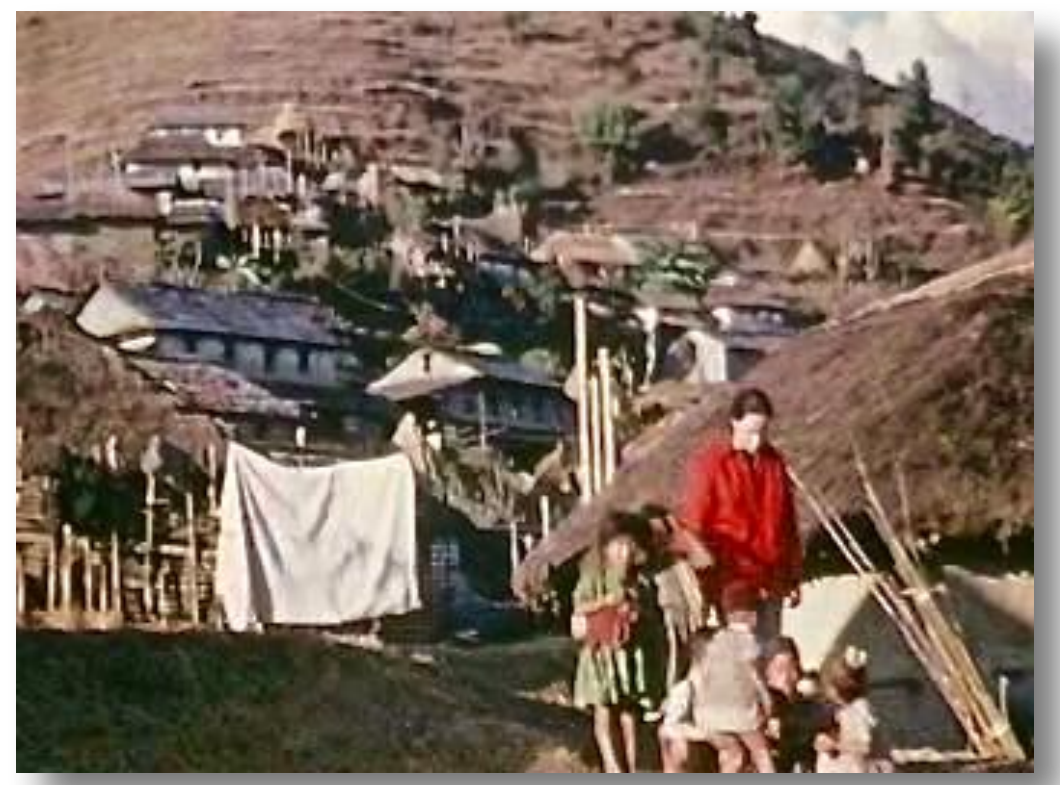

FILM. Gill with children at Kwi Nasa

Kamiri is the girl in the green dress

https://sms.cam.ac.uk/media/2739033

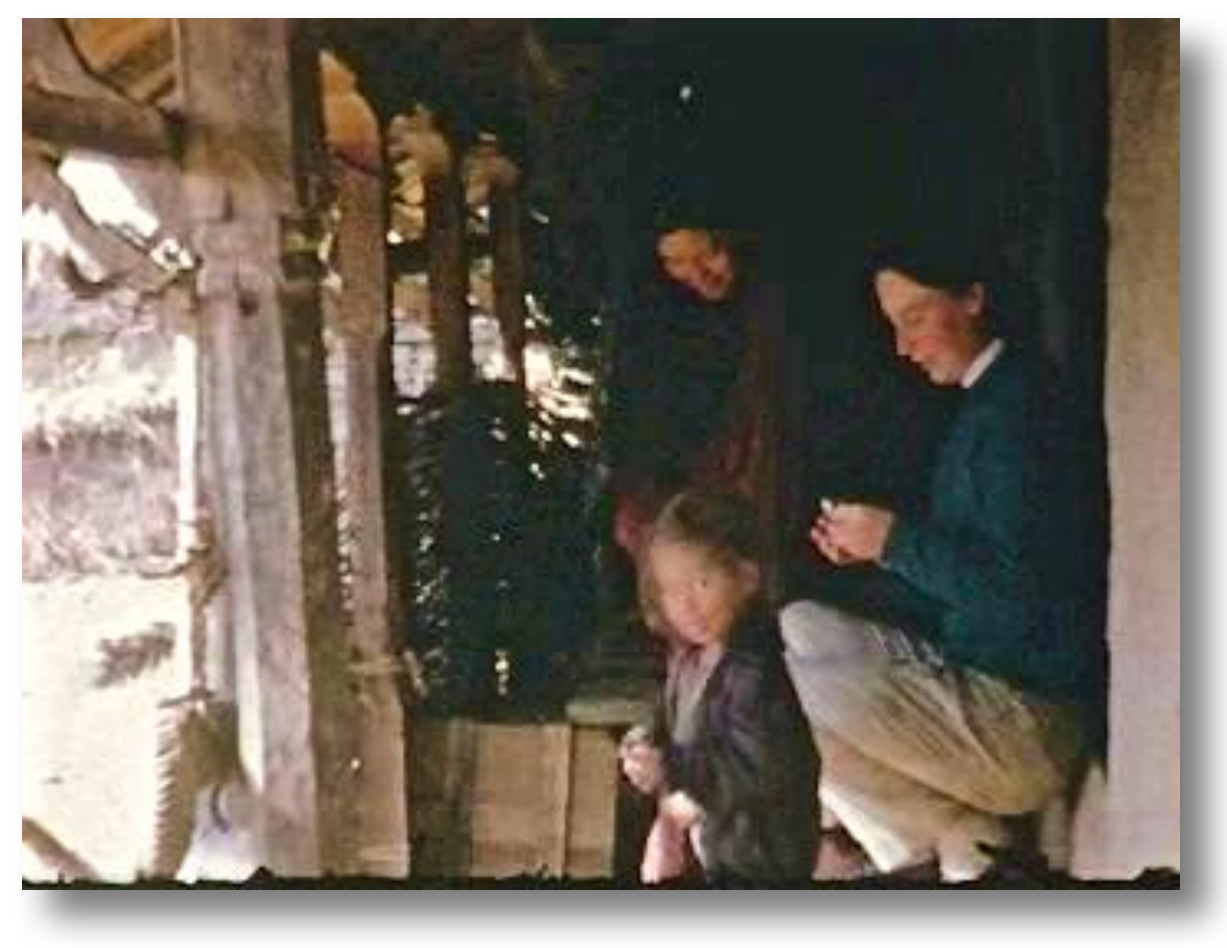

FILM. Gill putting ointment on a woman's leg https://sms.cam.ac.uk/media/2739061 


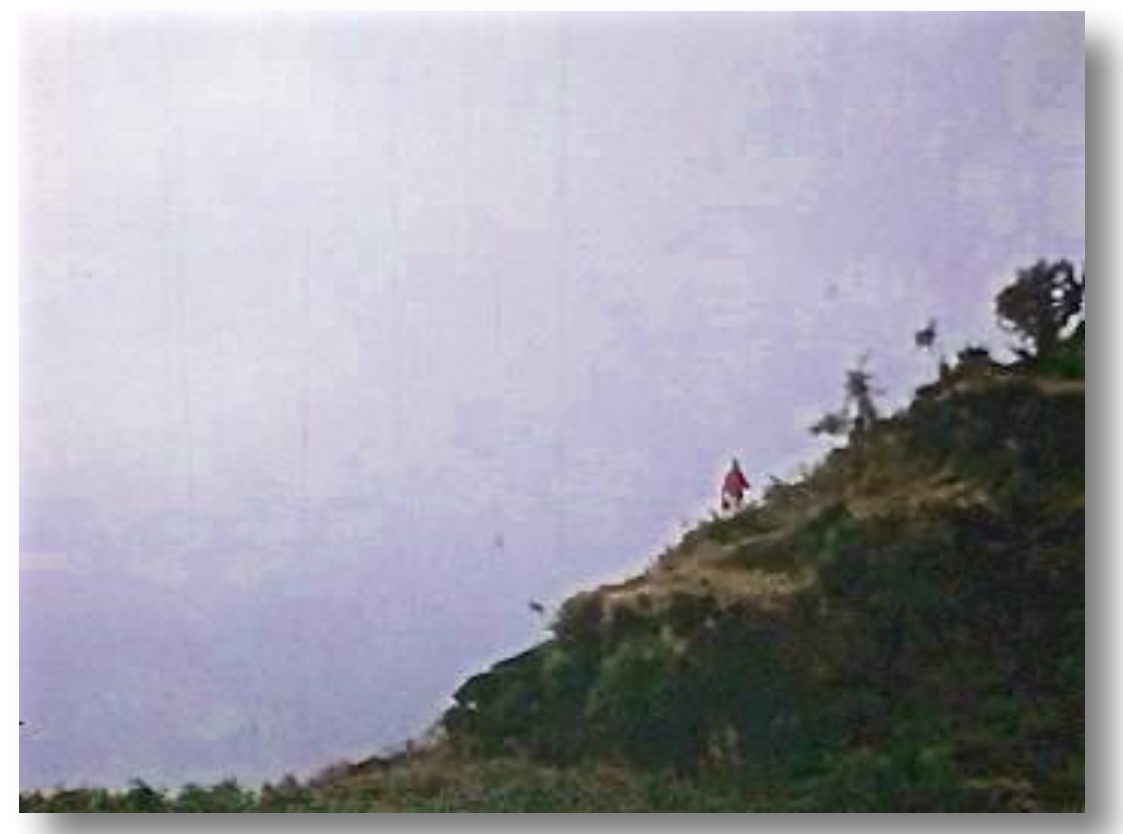

FILM. Gill walking down a hill

https://sms.cam.ac.uk/media/2743824

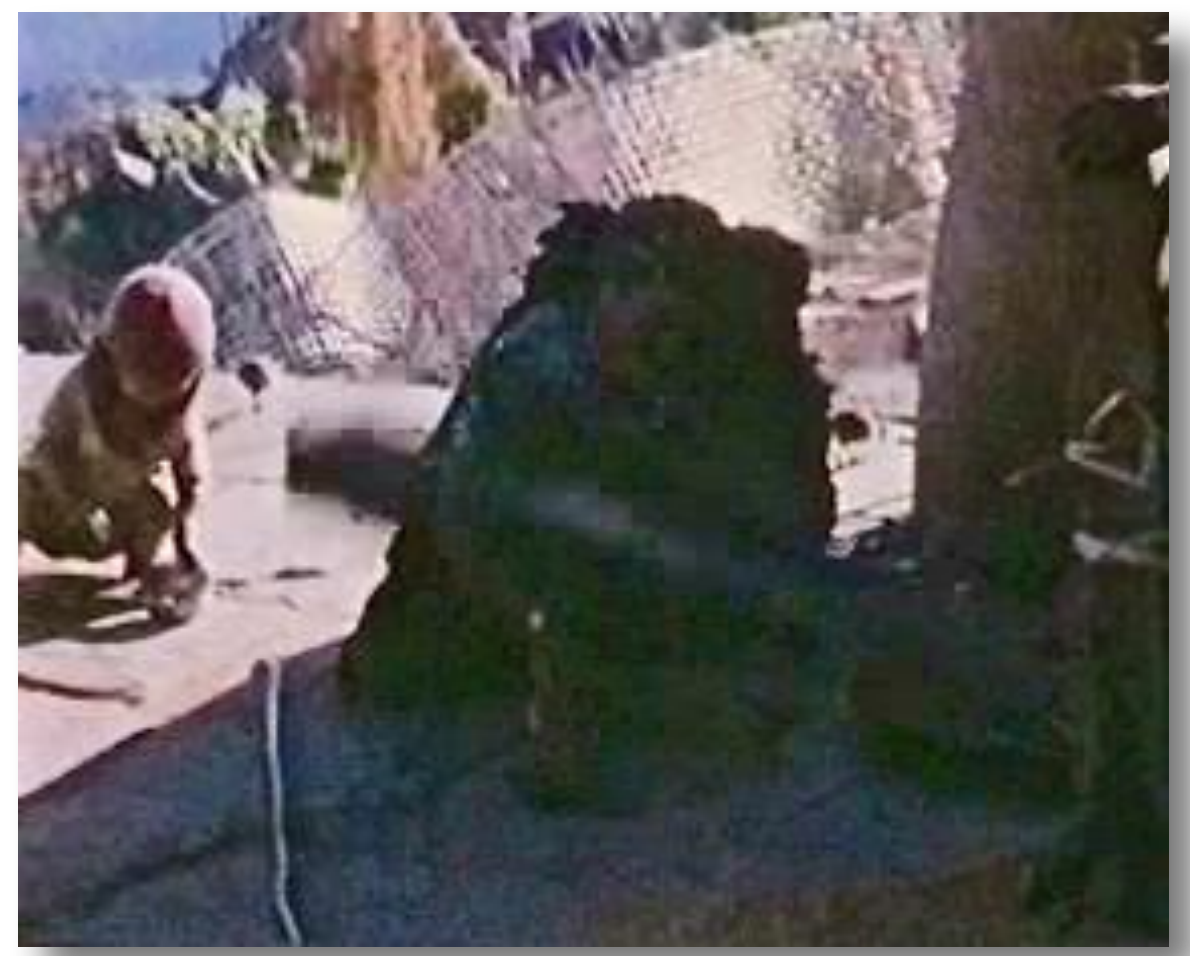

FILM. Women, one with a child in her lap, husking rice at a 'kuni donva' https://sms.cam.ac.uk/media/2739089 
Took quite a lot of photos of village etc. Did Palman's mother's child-rearing questionnaire she was quite eager to help (after a gift of a tin!), then indexed Pignede. Gill with sore throat. Young ones off to Mark 'jhaatra' - at Siklis and elsewhere. Beautiful day and we went up the mountain to read.

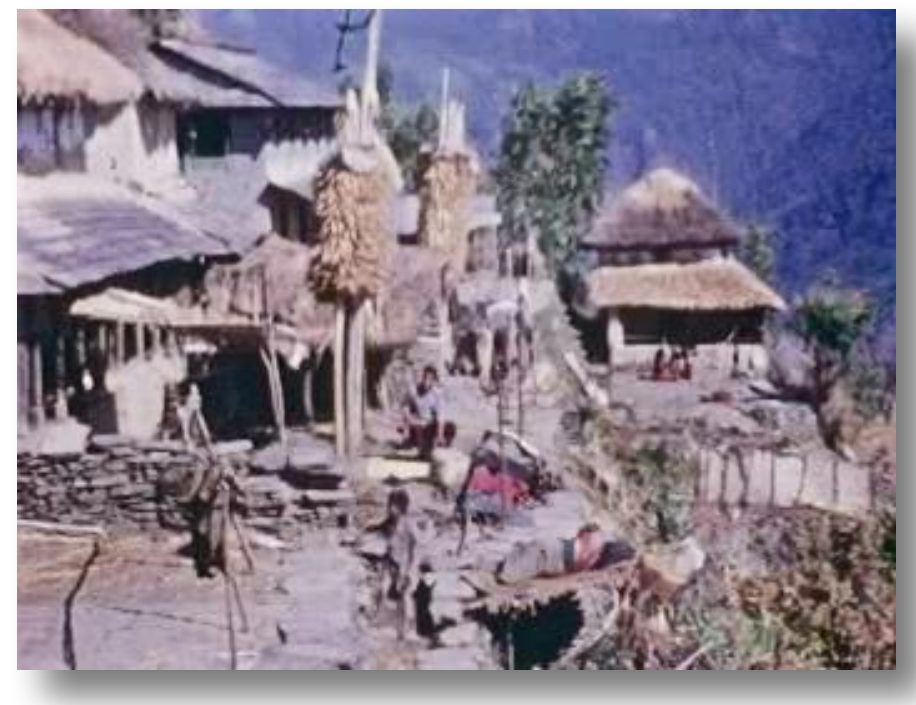

FILM. Shot taken from House 17 to House 1 showing people resting, women delousing hair, and full 'mokhai suli'

https://sms.cam.ac.uk/media/2739193

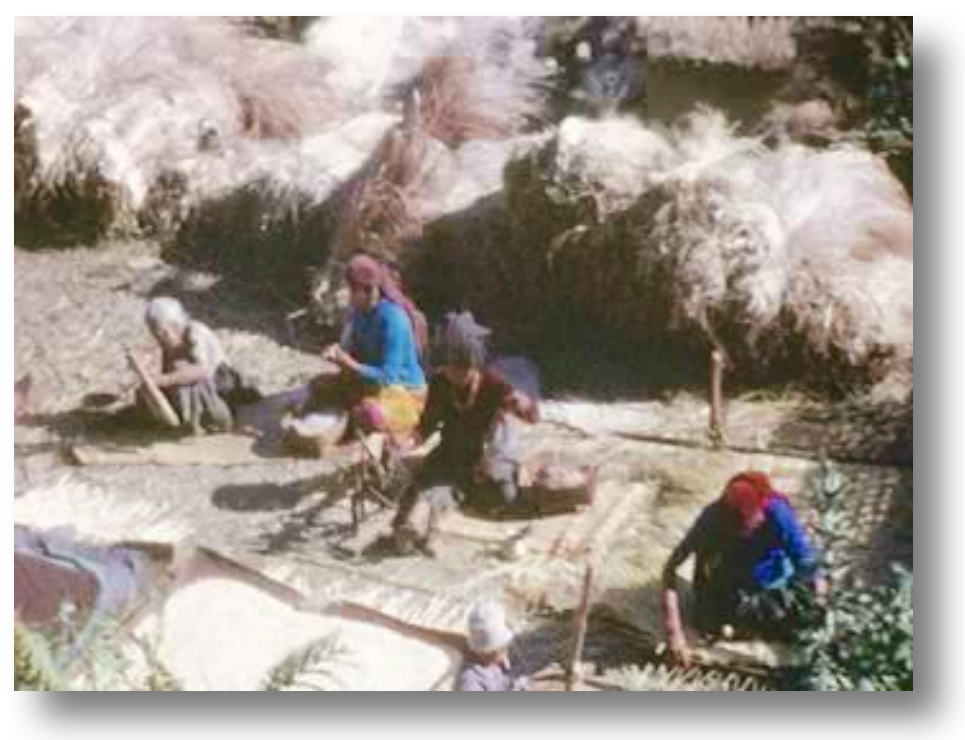

FILM. Four women doing various tasks: 'gundri' making, spinning, teasing out thread and winding thread for a warp

Bundles of thatching grass behind them https://sms.cam.ac.uk/media/2739240 


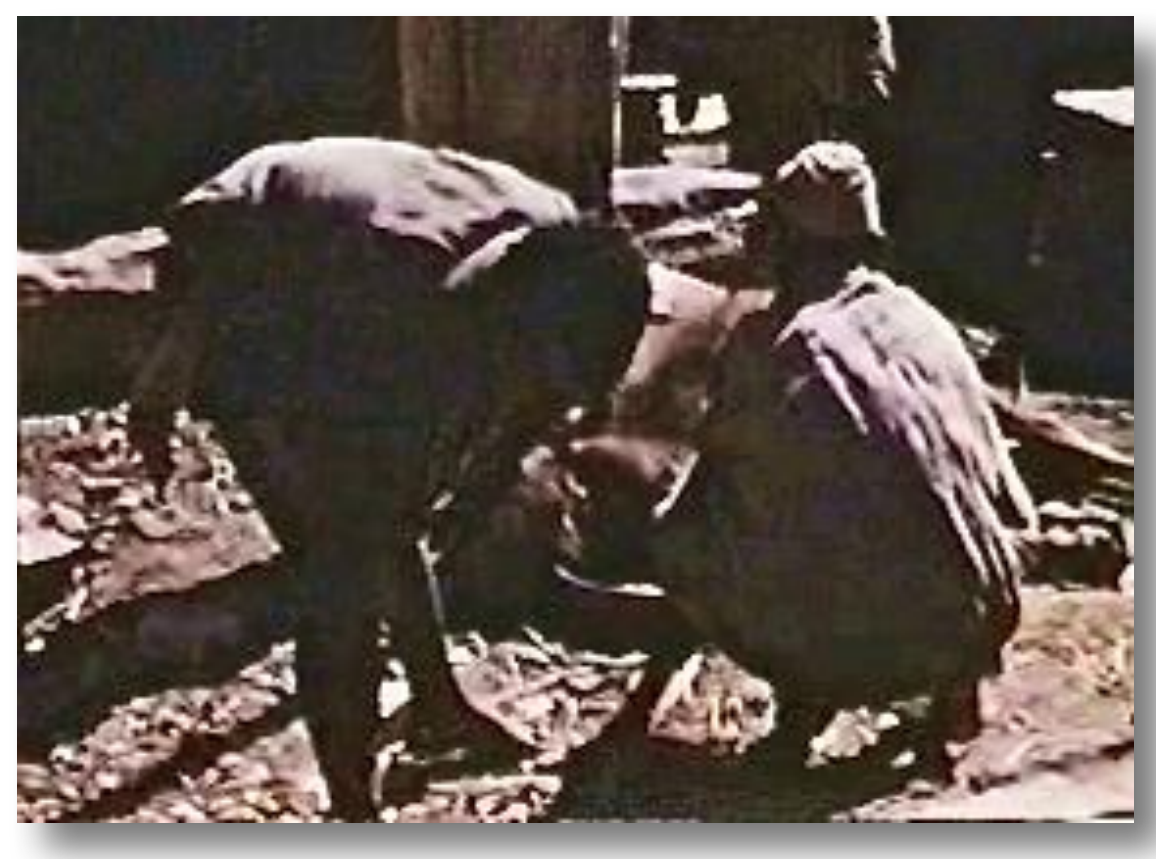

FILM. Manseram and others killing a small buffalo at House6 https://sms.cam.ac.uk/media/2739268

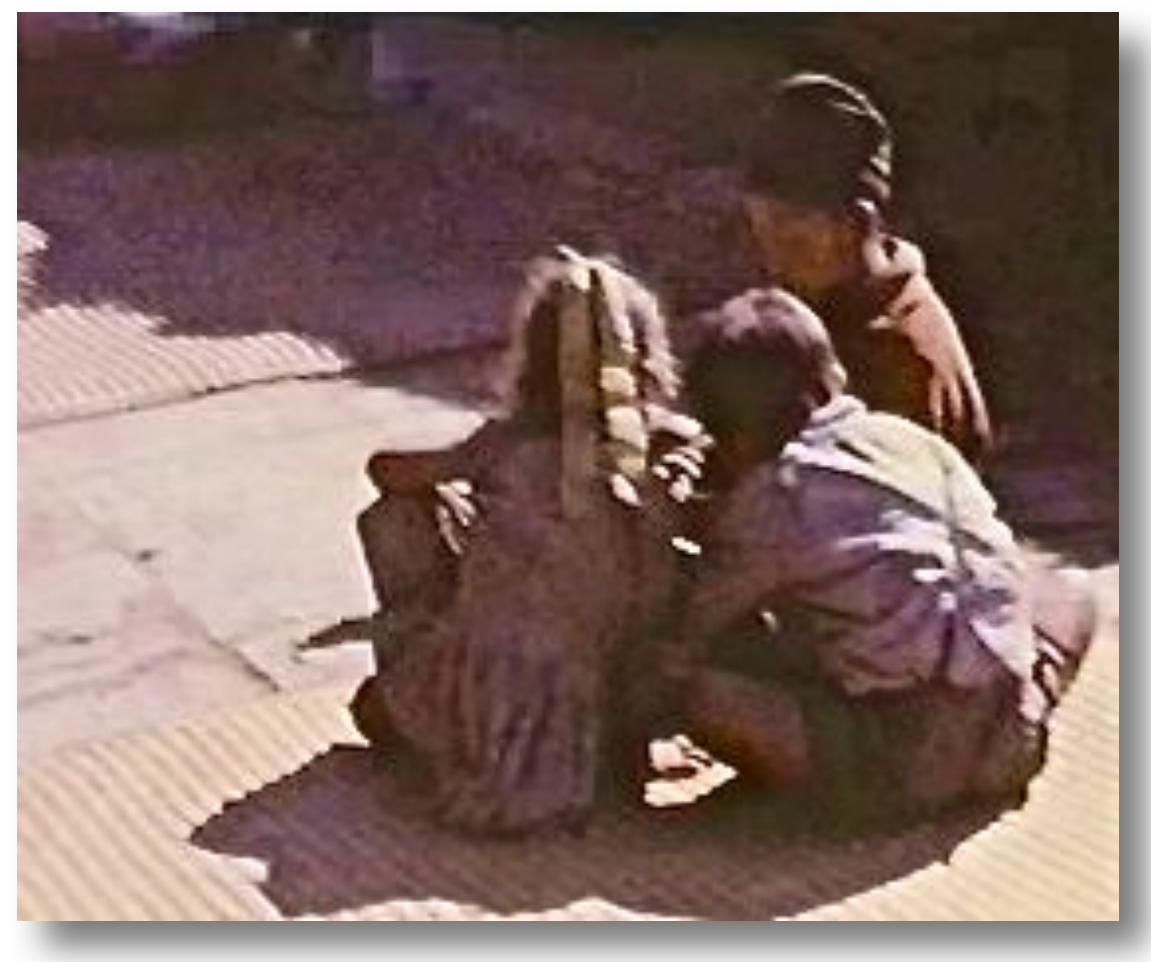

FILM. Children examining the slaughtered buffalo's penis https://sms.cam.ac.uk/media/2739296 


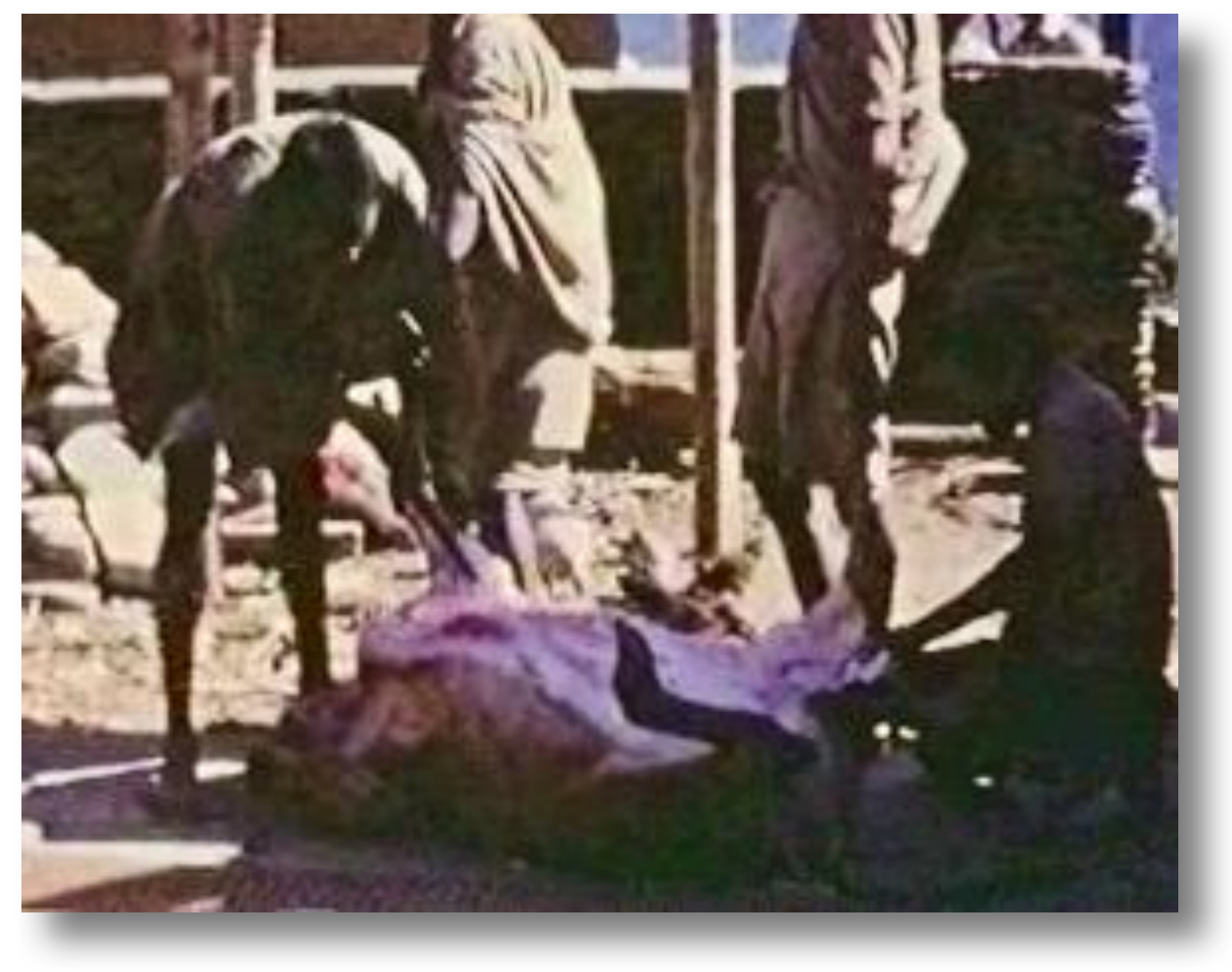

FILM. Manseram and others skinning the buffalo at House6 https://sms.cam.ac.uk/media/2739324

DIARY GILL Tuesday 13th January

Flawless morning with mountains as clear as they have ever been. Took photos of village in general - everyone very excited because they are going off to Pokhara or getting ready for tomorrow washing. Some people even going down to Modi. Did another questionnaire with Palman's mother and Gopal's mother - in essentials seem same. I had a thudding headache and sore throat after it so Alan almost literally put me to bed for two hours before lunch. Still had sore throat but determined not to lounge about. Unfortunately, when I was getting it ready Nani's sister from next door and Palman's mother's mother insisted on staring and banging in, even when I got cross. They even went upstairs, where Alan managed to be sweet to them. I feel we have just got Thak trained to when and where they can come, so it is doubly irritating when overruled by women from another village. As usual, I was upset about losing my temper - this terrible weakness of wanting to be liked.

We went up to our hill together, took photos and read Lenin which is most exciting. He is so terribly consistent. We went for rather a cold, windy walk afterwards and my earache got worse and I felt very down when it came to preparing dinner. Sore throat intensified. Dreary Ramchandra's brother came again and sat there like a stooge, whilst Nani pounded maize for tomorrow. Went to bed early but woke at midnight with an excruciating throat. The whole area seemed inflamed and I could barely swallow. Also very hot sinus got hotter when I took 2 Aspros, but that seemed to help sore throat. Kept Alan awake and we couldn't get off for a couple of hours. How tired I am of always being ill in this place! 
Spent the sunny morning photographing indoors/outside Goofs and Servajid's houses, also indexing. The poju returned full of 'pa' and friendliness. Gill's sore throat worse and we had a bad night. Very painful. Wondering whether to go to Siklis to consult a Klevri (klehbri). Lots of little presents.

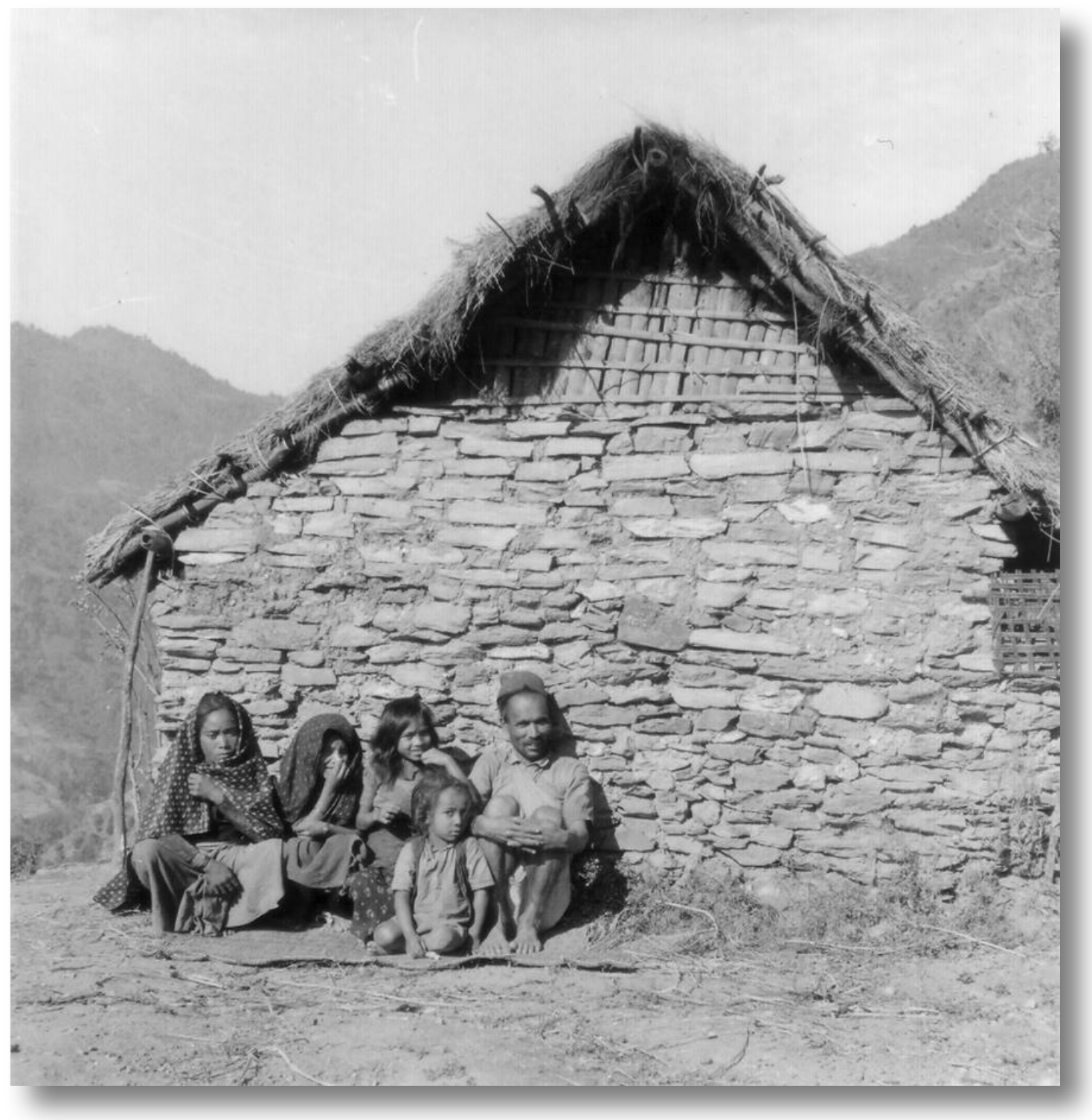

Manseram, Samarku, his wife (left) and children, Debikumari (middle) and Lilbahadur, sitting outside their house - 14th January 


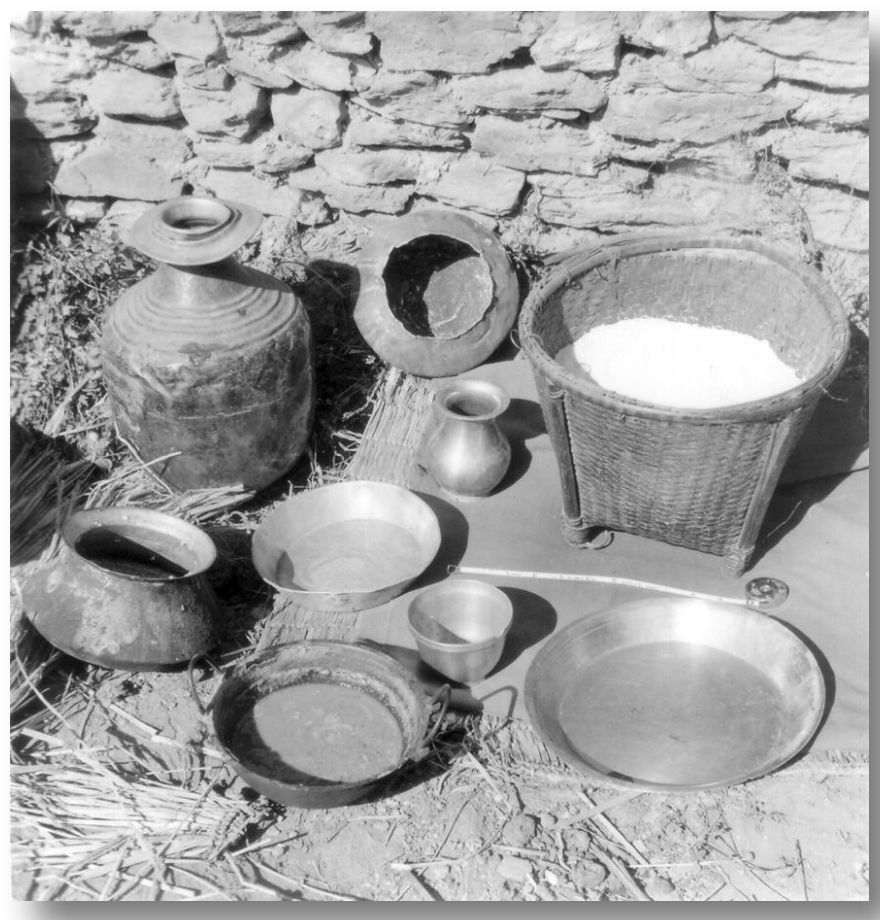

Kitchen utensils from Manseram's house - 14th January

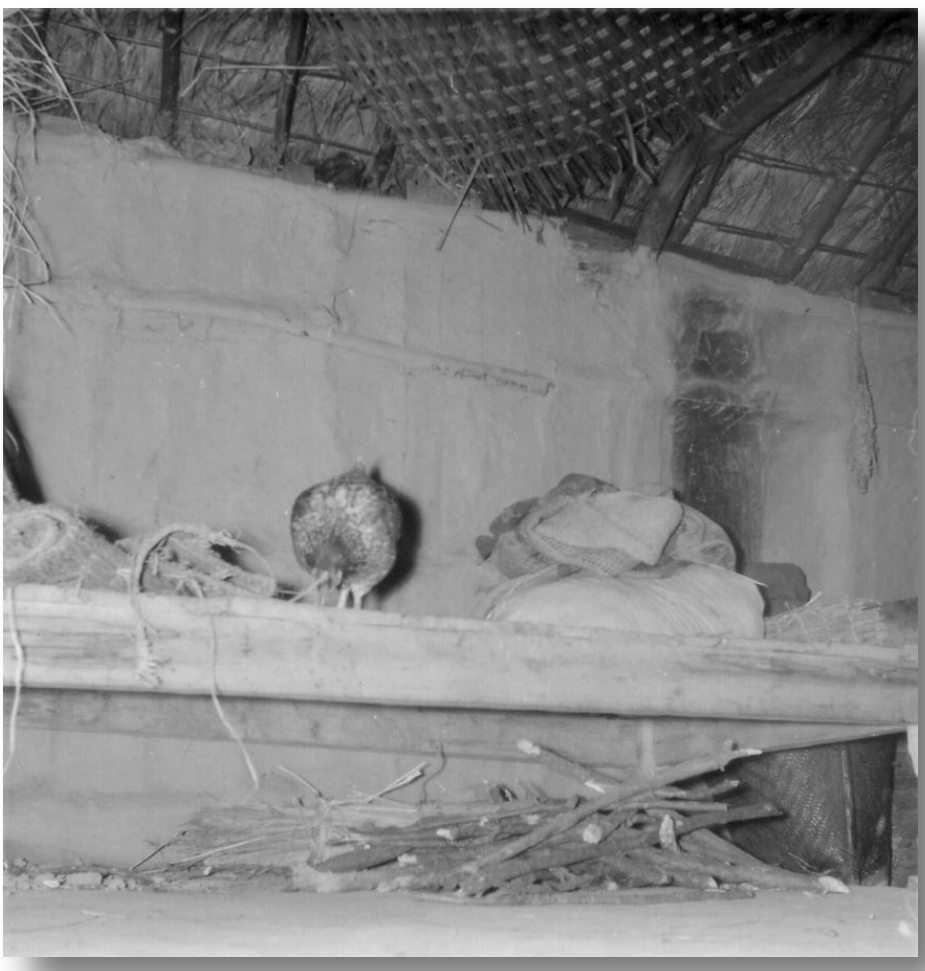

Bed with chicken inside Manseram's house - 14th January 


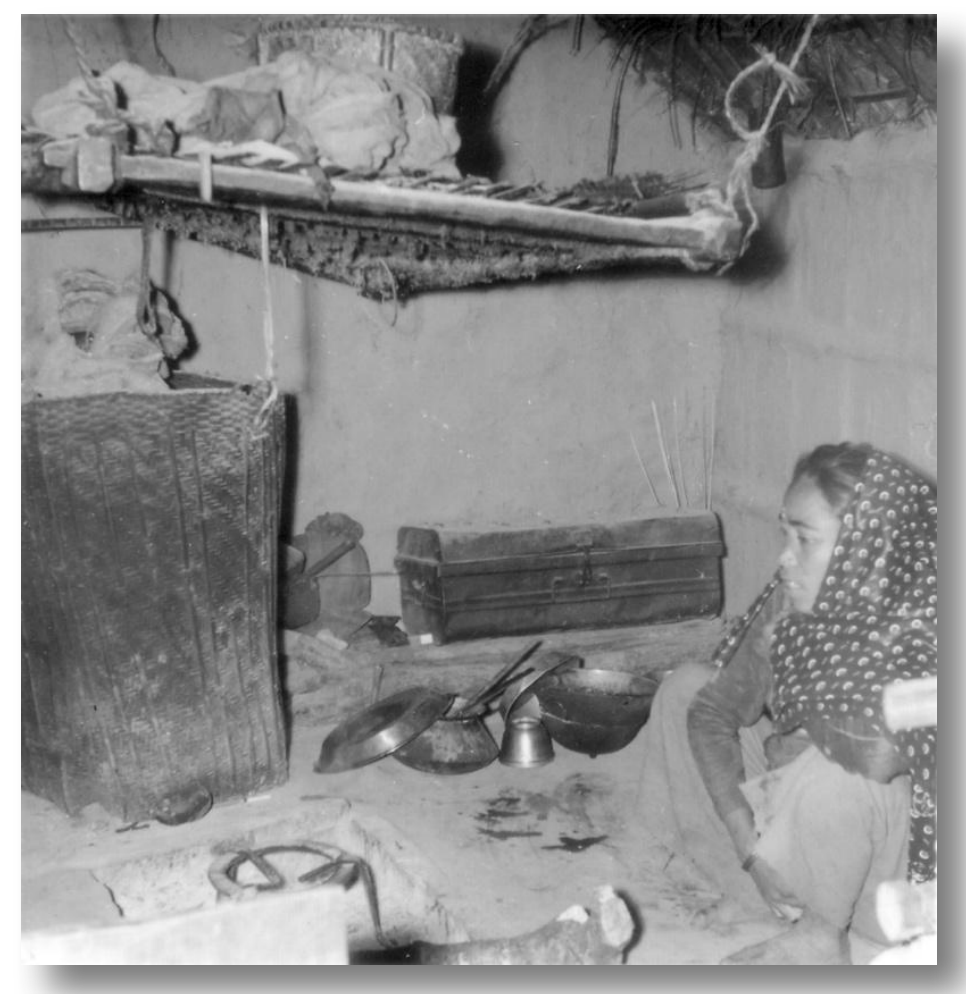

Inside Manseram's house, with Samarku - 14th January

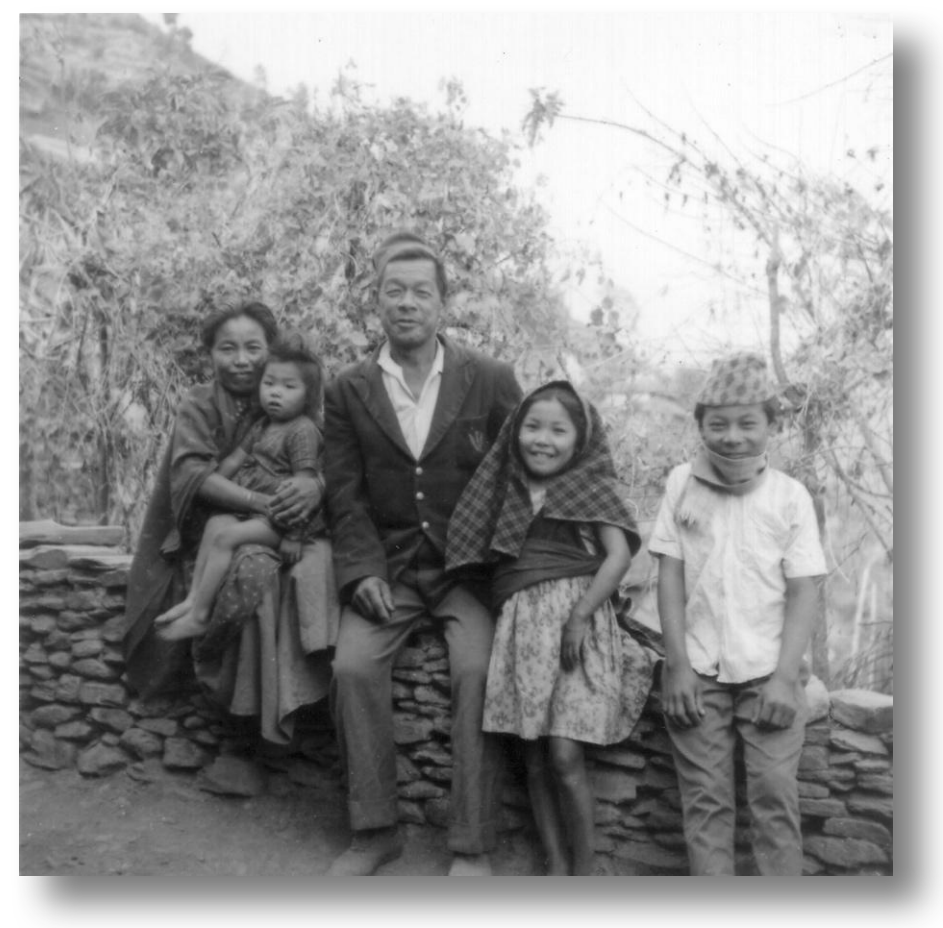

Krishnabahardur with his wife Jagatkumari, with daughter Indrakumari on her lap, Gokumari and Servajid - on 14th January 
Not a very good night with throat very sore but Aspros helping a bit. Decided to stay in bed. Alan raced off, up and down, filming [FILM] and getting interiors of houses he has taken an inventory for. A little opposition from Servajid's. "Why are you taking such a poor house which they will laugh at when they see it in England?" They have invited us for a meal, however, tomorrow, and if I am fit enough I will try and go. Got up in afternoon to go to the toilet, but this was a big effort and I am still a bit constipated as well. Came down very wobbly but Alan delighted as poju is back and had called 3 times today to try to catch him.

He suggests we go up to Siklis to see Klehbri and after Dr. Turner comes and I am better we might do this. Not very hungry but Alan got my supper on the stove - besieged with people wanting medicine, tins, etc. Read throughout day and sewed and embroidered Haricola's dress, which I think is going to be too small for her. Still lovely weather.

\section{DIARY Thursday 15th January}

Gill just having her sari put on by Nani. She has had rather a miserable day with her throat, in bed - now we are going out to supper at Servajid's. Poju busy so I wrote letters this morning and finished indexing Pignede this afternoon. A beautiful blue day again.

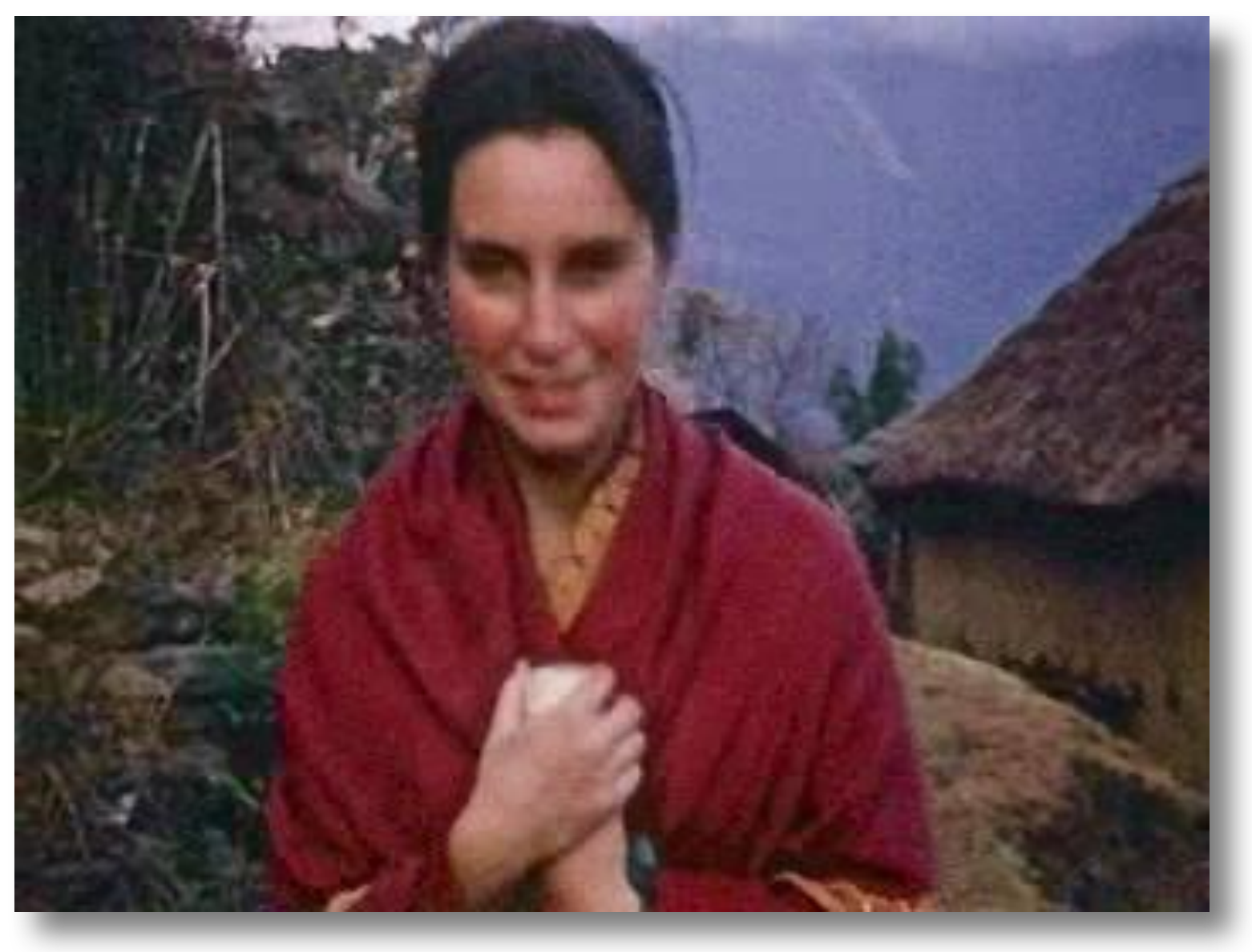

FILM. Gill wearing a sari, walking along the path towards Kwi Nasa https://sms.cam.ac.uk/media/2739352 
Had same bad night, had to cry with pain in my throat and ears. Took some strong pain killer in morning, brought from Thyssen House, and this made me more dozy than anything and I tried to sleep whilst Alan typed some letters home. Read usual combination of Lenin/Stendhal, which was satisfying. Former very exciting with return of Lenin to Russia in 1917 and attempt to seek control by Bolshevik faction. One's moralizing objective outlook goes to and one enters the arena as they said - with an immense feeling of adventure and bravado. Somehow a pack of excited schoolboys. Lenin's escapes and disguises give a hint of this.

Fell asleep after lunch to awake very cross and sickened by all grubby bed clothes, black pillows, etc. Haven't washed hair for a fortnight. Took it out of Alan who was sweet and understood. Had a sponge bath eventually and then put on a sari to go to eat at Servajid's. Throat still bad, but took another pill. Lots of sweet admiration about my sari from the women and Alan filmed me. [FILM] I felt very comfortable and warm in it. We sat by a very smoky fire, drank 'pa' and ate my favourite rice crispies. Then they said - "Well you must come tomorrow". We protested one night was enough. Then they said they couldn't feed us tonight as there wasn't any rice - just 'prokhen sai' tonight! So after that we tried to make our exit gracefully, me dressed up and Alan hungry. Came back and had quite a meal of Iris' tuna and Gopal and Ombahadur came and gave advice about selling things and not giving them away. They are sweet!

\section{The Poju and his paraphernalia - 16th January 1970}

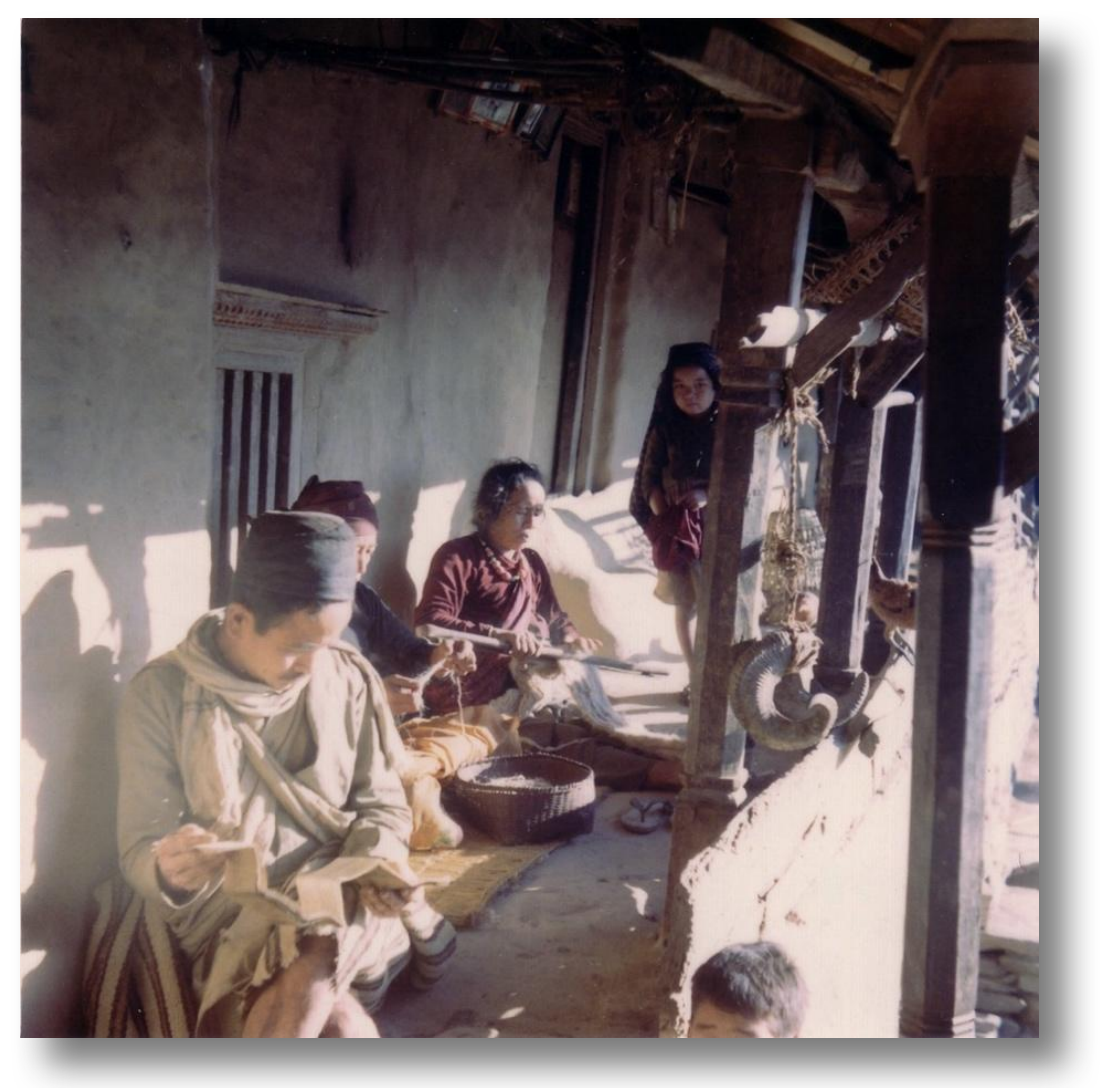

Ujesing the poju with writings, behind Dansuba and Asmaya preparing a warp 


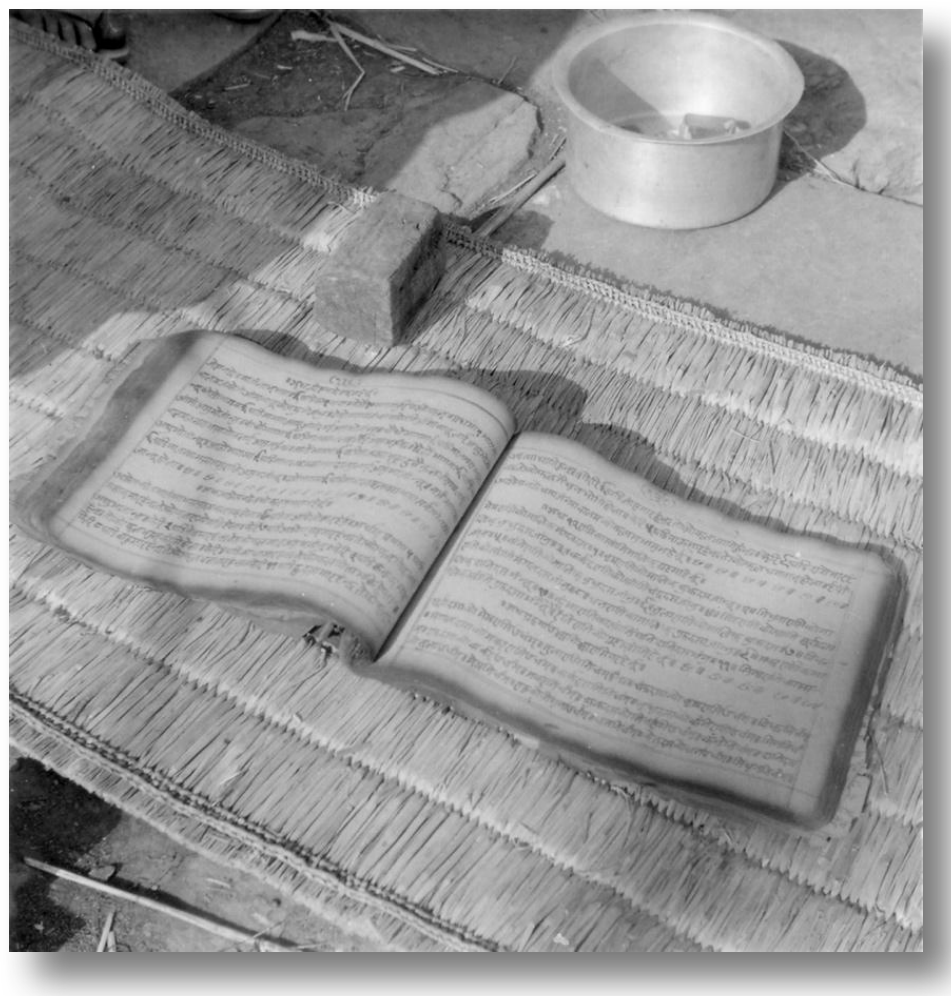

Poju's sacred books -

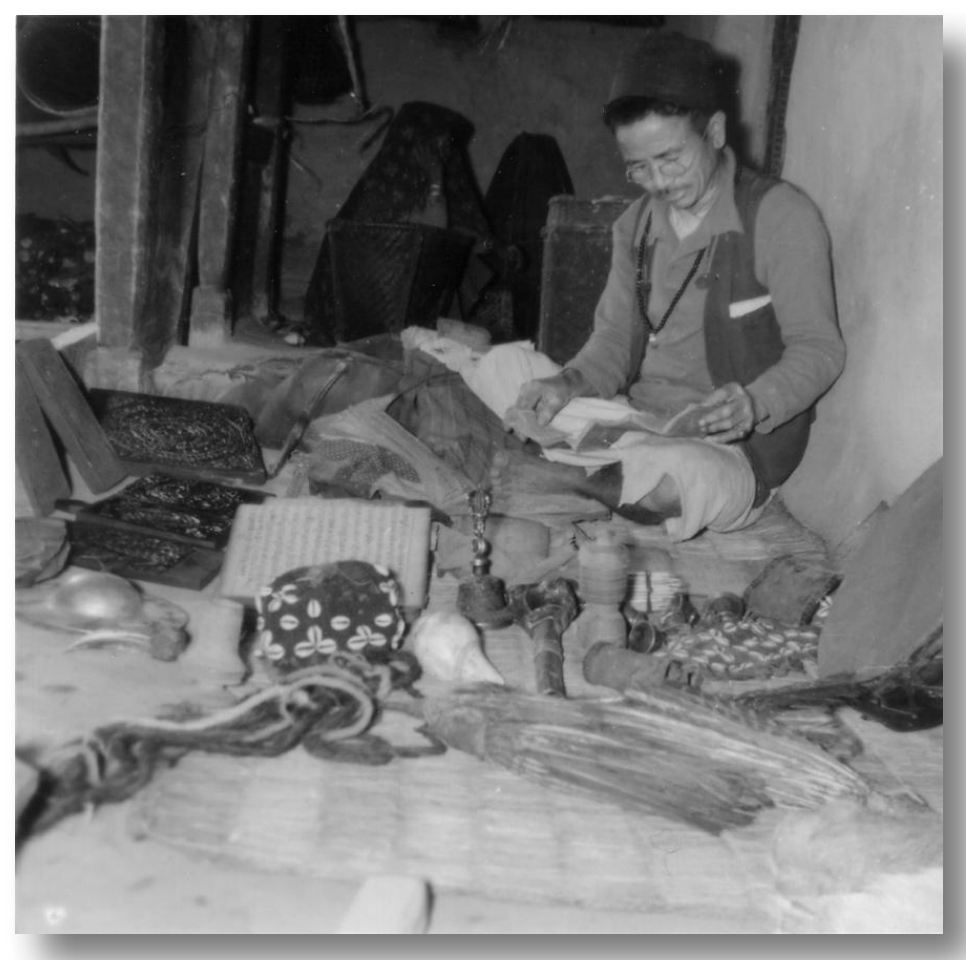

Poju, Ujesing, surrounded with his paraphernalia 


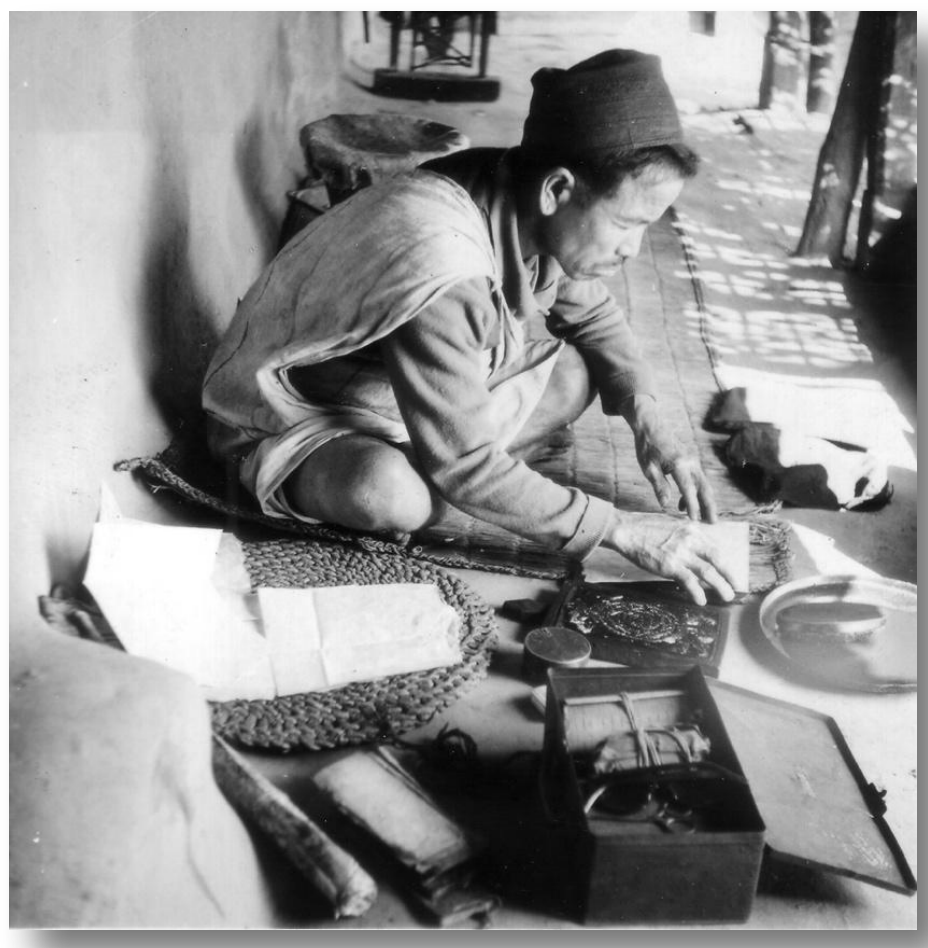

Poju, Ujesing, printing copy of an image

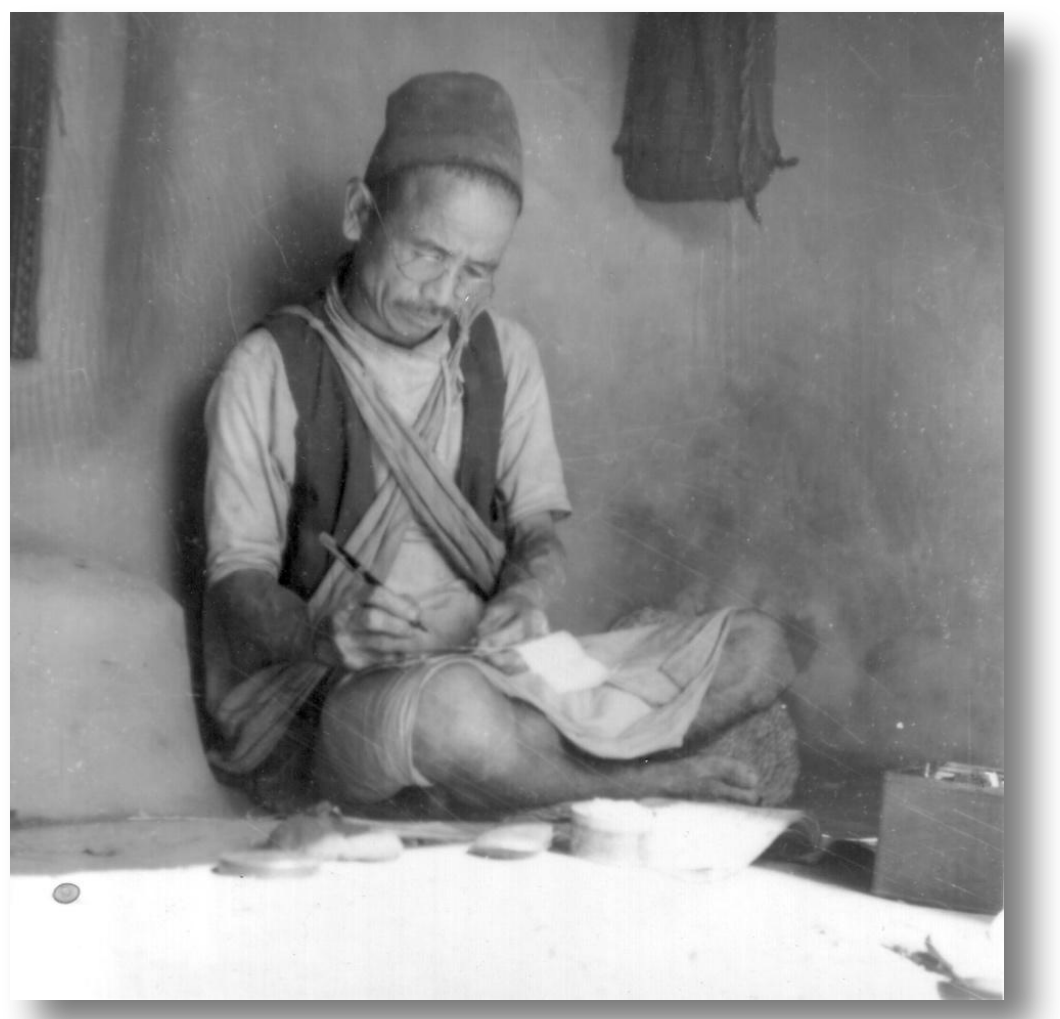

Poju, Ujesing, writing 


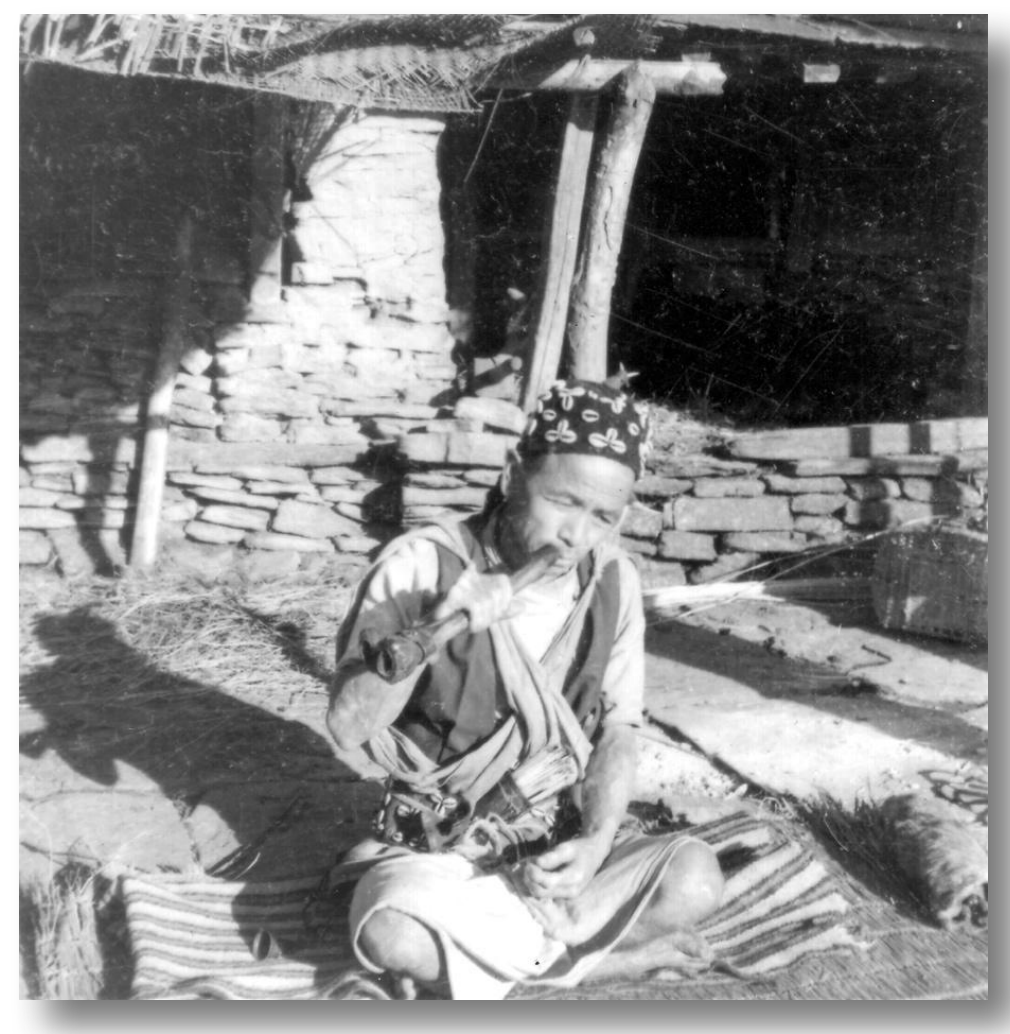

Ujesing dressed in his 'poju' costume, blowing on a bone horn

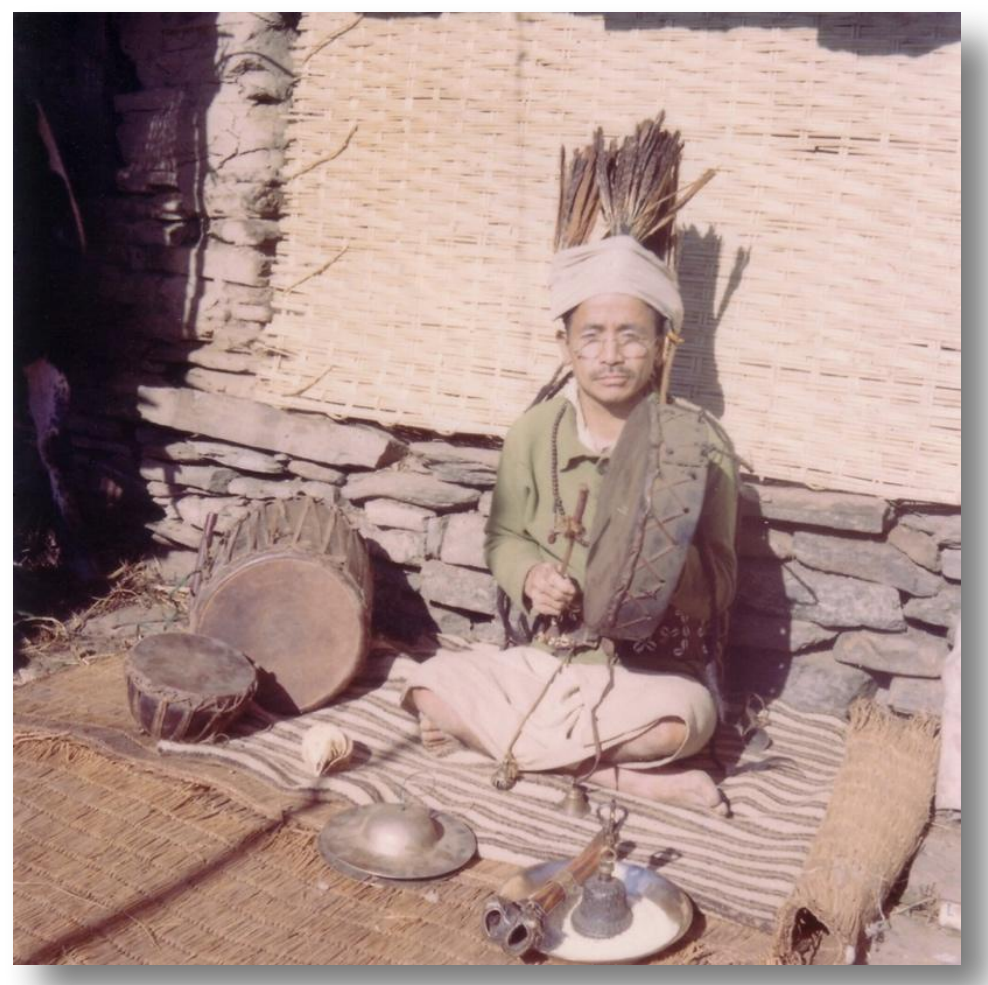

Ujesing in his feather headdress with three drums and cymbals 


\section{DIARY Friday 16th January}

A busy day. Gill's cough a little better and she was up at last. Spent morning rather fruitlessly, drawing map of Gedi etc. In afternoon filmed all the poju's books and did some work with him - also went to see him diagnose Guru aba and Bolbahadur's mother. Supper with Servajid's and then watched 'Ma bide te' at Guru aba. Itching to pack.

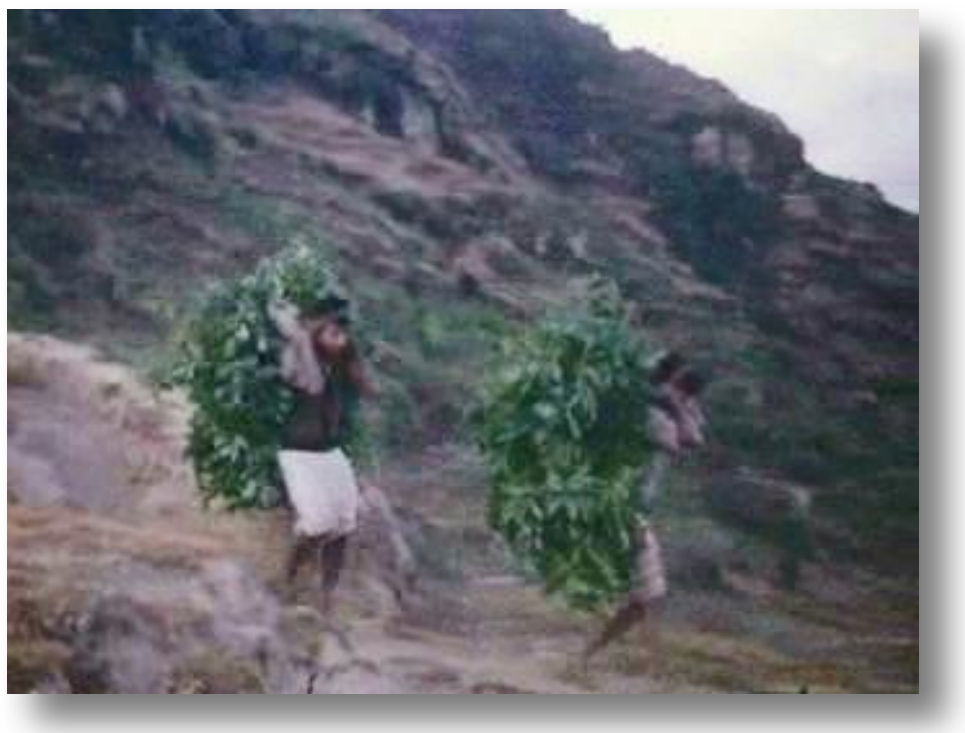

FILM. Woman with three small girls carrying wood down the hill followed by men with bundles of fodder

https://sms.cam.ac.uk/media/2739380

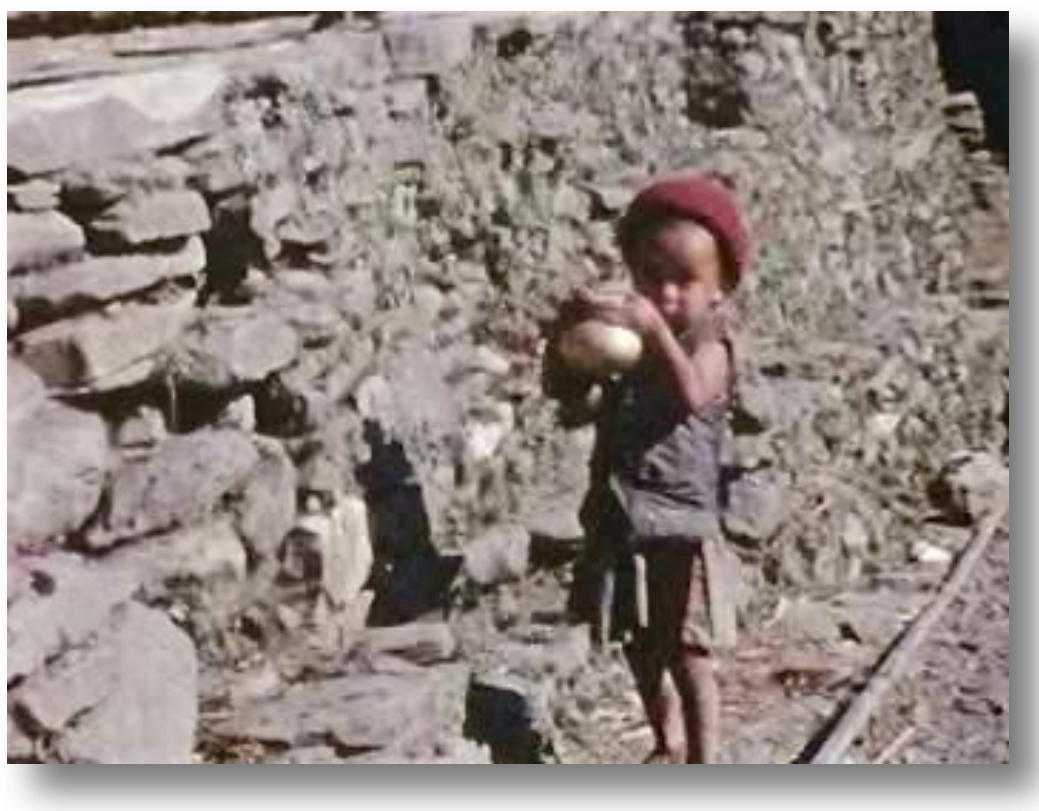

FILM. Small boy carrying a brass pot of water from the tap https://sms.cam.ac.uk/media/2739408 


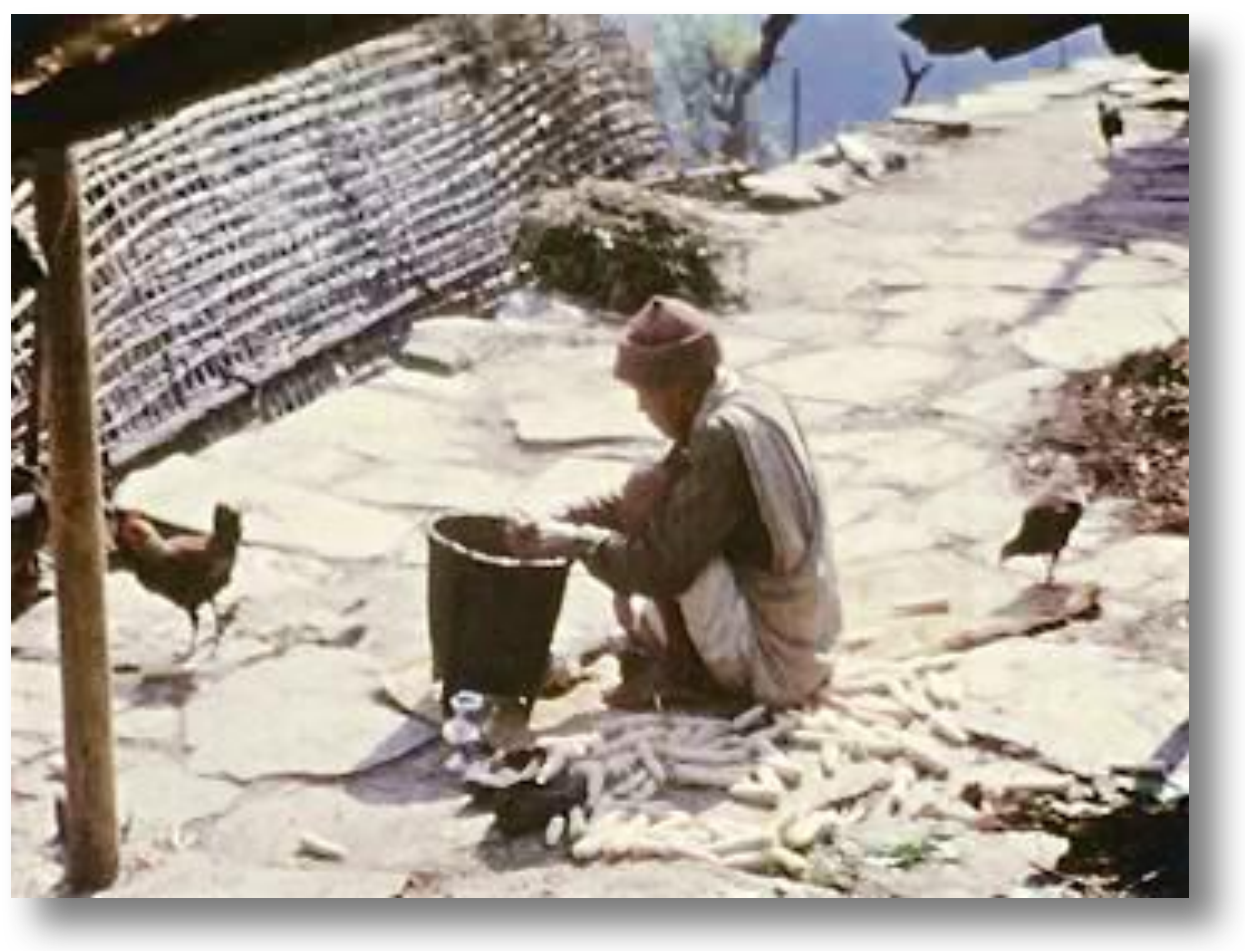

\author{
FILM. Narbir husking maize \\ https://sms.cam.ac.uk/media/2739436
}

\title{
DIARY GILL Friday 16th January
}

Had a better night and decided I couldn't be a fraud and stay in bed any longer. Still quite a bad sore throat though with a lot of phlegm. Lot of people for medicine in the morning including woman who had just lost her son. Looked 20 years older, quite dreadful with grief and bad sores on her face which came from neglect I think. I have never seen any of them so upset.

Wrote letters in morning, with difficulty as I didn't feel much like it. Alan was rushing round photographing the poju's books, etc. also thinking of packing already! I rested in the afternoon, read a bit of Lenin - curious he can only seem to urge them to revolution when he is not in Petrograd - perhaps later this will right itself. Afraid I fell asleep, quite tired with picking up threads again but got up and wrote a letter to $\mathrm{M} \& \mathrm{D}$ and then put my sari on again. Never really happy when I do it just by myself - and we went and had a lovely meal at Servajid's. Much shouting at mother who was agitated but didn't spoil rice. Lovely, sweet, Genoa, 'masata', peas with tomatoes and 'pasagi' and warm milk. Great relief when we went and the party brightened up.

I managed to go to the loo, taking rather a roundabout route as I have been constipated for several days. We then went on to Guru Aba's who is sick again and the poju did a 'Mabide' rite - one with fire on his tummy and consuming of nine threads wrapped round his body. Swirling smoke and the old man's groans and cat curled warmly up beside him, the poju with his specs and beads, and "Hello John" being the evening's bore and 3 village grans stroking my ankles and saying how nice my sari was. Alan among the cobwebs and the shelves taking photos and Kaila making a mess of things as usual, twining the thread the wrong way, poju shouting at him over his glasses - nice evening! Very cold when we came out of the fug and we expected snow. 
We have just a fortnight to go, and I think this has hit Alan more strongly than I. He is already itching to pack, even though he is still doing last minute chores in the village as well as endless photography, we still have several movies to use up. Not a wildly exciting last fortnight with the village magician away chasing debtors near the Indian border and no specific work to do for the villagers - bringing in of wood, grass for the buffalo, and weaving of mats and cloth. There is some wheat planting down by the river but only a few of the wealthier families are trying this. Also I had a bout of dysentery at the beginning, but cleared up quickly with pills, and then I got this very bad sore throat which still hasn't really cleared up...

All the villagers are asking us when we are going now, and saying we must stay and what they will miss us, and I think with some this is true, apart from the free medicine and bottles and tins we dole out all the time.

We are a bit worried about disposing of our pots and pans and bedding as the slightest inequality could mean trouble for months afterwards, also feel a bit irritated and constantly like Volpone when people come and insinuate they would like this or that, people who have never been near us formerly, not helped Alan at all. We have thought of a lottery but some of the saner villagers say we should sell things, and that would simplify matters. They were very sweet over their version of New Year, which last year we spent in a big Gurung village down the valley, and on the day they went to the river for their purifying wash there were constant little shouts up at the window and when Alan went down there were little presents of ground maize balls soaked in honey, steaming yams just cooked and a kind of warmed, flattened rice which tastes like Quaker Oats. We put sweeties and biscuits on their round brass plates and it was all very jolly and friendly.

Work wise Alan has been doing school records, a lot of photography of interiors and I devised a child rearing questionnaire and we went round and asked several women about 17 questions each - about breastfeeding, toilet training, labour, method of delivery. They loved all this, especially the older women who were past child bearing, and we got lively accounts of births, with much slapping of thighs and squealing, also how I must treat Alan when I am pregnant - not having anything to do with him, pushing away, anger, scorn, the lot! I must say I hope it isn't like this! Interesting beliefs of burying the placenta and unmarried girls not being allowed to touch the baby for twenty days, or it will wither away and die. Breast feeding is usually three to four years, or until the next baby comes and they were horrified when they learnt that European women breast feed, if at all, for a year or even less. They are incredibly warm and relaxed with the children, an ideal combination I think, if you and the society can allow for it.

Tonight we are going out to eat rice at the other end of the village, and I shall wear my sari again. We tried the above last night, having been invited then, and all the women beamed and told me how nice I looked when I had struggled to put it on. I still had to ask nani (eldest daughter) next door to help me, and then when we were safely installed inside this tiny house with a warm smoky fire, drinking ' $p a^{\prime}$ ' (millet beer) and rice goodies we were told we must come the following night as well, as tonight they hadn't any rice, mother had been collecting wood in the forest all day and hadn't had time to pound any! So we attempted a graceful and hungry exit and are going through the same procedure tonight - in fact I must stop this now as I won't be able to see if I have all the pleats in the right place! (cont.).

\section{DIARY Saturday 17 th January}

Again a beautiful day and a little warmer. Started sorting papers in anticipation and checked things with Comal's father, Totra's father, Prem and Posbir. Went along to Taprang path and threw 4 stones off. Read a Camus short story. Gill wrote letters.

\section{DIARY GILL 17th January}

Don't know what it is but I feel consistently depressed and fretted by minor things - disposal of all our things, for example. A little bit of a sore throat remains but sinus trouble has come 
back in fore. Alan is wonderfully patient with all my whining. I wrote letters in the morning while he sorted out packing and then went off to ask Totra's father some religious questions got very hot under the collar about it, apparently. Had late lunch by which time I was frozen in the loft but warm and sunny outside. Soup warmed me up and I'm afraid I went asleep in my sleeping bag until 3pm. and then read Lenin until 4pm and that wasn't wasted anyhow. Now in power - and of course the crucial part is - how will he deal with this?

We went for a walk along the Taprang path to our stones - mountains swathed in cloud to begin with but then these parted and there was a fine rose coloured sunset - Annapurna II so steep at ridge top that it can't hold the snow, which we reckoned must be even 100ft. deep in places. Very beautiful. Had a quiet evening with only Servajid hinting and spoiling things and Omkumari saying she wanted this and this and that when we went - which is much more wearing that Servajid's silent hints. Beautiful moonlit night. I ended peeling 'alu' in moonlight as so many people came for medicine, tins, money, before supper.

\section{Letter from Gill on 17th January 1970}

We did get rice last night, and lots of good spicy veg as well, and then we went on to one of the poju's rites for an old man with a sick head caused by witchcraft, and had another smoky session watching a pan of fire crackling away on his tummy and the poju tieing nine threads round him, sprinkling ash and reciting his incantations - Cring, crang, crong, shuhar! - with his spectacles at the end of his nose. Alan took a photo (flash as it was pitch black) and had to crouch under shelves and cobwebs to get sufficient distance away. Today my throat is much better, maybe the poju did me some good as well and Alan is scuttling round disposing of papers and journals... He has just given all his witchcraft proofs to the poju's son as they are blank on one side and Prem said his father could use them for doing 'parga' woodcuts - which, appropriately enough, are anti-witch drawings that are stuck on the outside of doors at certain times of year.

We are getting a porter to go down this Monday (19th.) and collect letters...

\section{DIARY Sunday 18th January}

Cloudy most of the day, but not cold. Went down with Pradhan Panch and Gill and at last managed to finish the census. Off now in hope of a little 'prokhe' at Housel. Time going quickly now. Had to break into Panchayat house for records - and then found nothing in them.

\section{DIARY GILL Sunday 18th January}

Pleasant day at last because I did something and we got out - despite bad phlegm and blood in faeces - piles? I hope to heaven not. Went down with Ramchandra about 10am. to get records for census - lovely yellow open day - and felt as if I were being let out of prison. Such a relief after being cooped up in the loft.

Great farce at school house - they have lost key to Panchayat house (so much for Panchayat system!) and when we finally broke it open - dust, rubble, a half-built building, stools and 5 ballot boxes - but no papers. We then trotted behind Ramchandra to the Secretary's house who was asleep. Half an hour for him to wake up.

Endless baby animals on porch - goats, chicks, buffaloes, cows, children. Gran asleep next to a great fat dented pumpkin, pale gold on roof. Photos from the Gurkhas on the walls. When Sec. did come exact papers Alan wanted weren't available but he had others as a substitute so we copied them out there and then. When I wasn't doing the numbers I read Stendhal and got quite carried away by the escape from the Farango Tower - identifying with my escape from here soon, of course! When we had finished we stopped half-way up the hill for a banana, met the poju drunk and twinkly eyed who invited us for a rite tomorrow. 
We came up with him, finished off a letter to Rex and then we went for our 'prokhen saba' with Gundasing's family. Of course Lemon-face hadn't told his mother we might be coming that morning so waited half an hour while she collected milk, sugar, tea together. Snug, warm little house - lovely pile of maize in corner behind a breast-shaped lamp. Drunk 'pa' and had that rice crisp and talked to elder brother who is in police from Calcutta. Came back to find stools for Flatts and gave Goof when and letters for tomorrow. Nani in during evening - with a sore leg her first day at forest for a while since her typhoid.

\section{Letter from Gill on 18th January 1970}

...At the moment we are waiting for the head of the village to call us at our little window as we are going down to the schoolhouse with him to do some last minute copying of census records, and I am chief line ruler and transcriber. However...time is the least vital thing in this type of society, most relaxing for people like me but intensely irritating for Alan whose routine attempts to be extremely rigorous have crumbled in the face of the Gurungs! (cont.) Well, he did come at this point so apologies for the above. We trotted down the hill after him, as the school is on a ridge midway between two parts of the village, only to find that the village meeting house next to the school which was supposed to have these records was locked and the key lost! This about sums up how the Gurungs have taken to a local committee system with delegations up to central government just recently introduced by King Mahendra. Not that I can blame them as it is common knowledge that democracy is nominal anyway and so we have a benevolent dictatorship going. We finally prized the lock off with a short scythe they use for cutting grass for the buffalo, to find nothing but dust, rubble and five ballot boxes inside. We then had another trot to the village secretary's house, who was asleep in nothing but his shorts, waited for him to wake up and watched a brood of pale gold baby chicks, a mushroom coloured baby goat just born snuggling into the gran also asleep on the verandah, six children all under eight having their hair plaited and red bows put on, or ears cleaned out with a spat-upon chicken feather, heads being squeezed for bugs by other grannies at the same time! Eventually the secretary appeared, beaming, and Alan got his work done...

DIARY Monday 19th January

Waiting, I hope, for Goof to bring some letters for us. A rather frustrating, but quite enjoyable day, idly watching poju do a 'Bhaio te' rite down in Panighat: we were away for some 8 hours in all. Unable to finish poju's work with him as a result. Ankle sore from sprain yesterday and Gill with bad sinus. But only a few days to go! 
Bhaio puja at Panigat on 19th January 1970
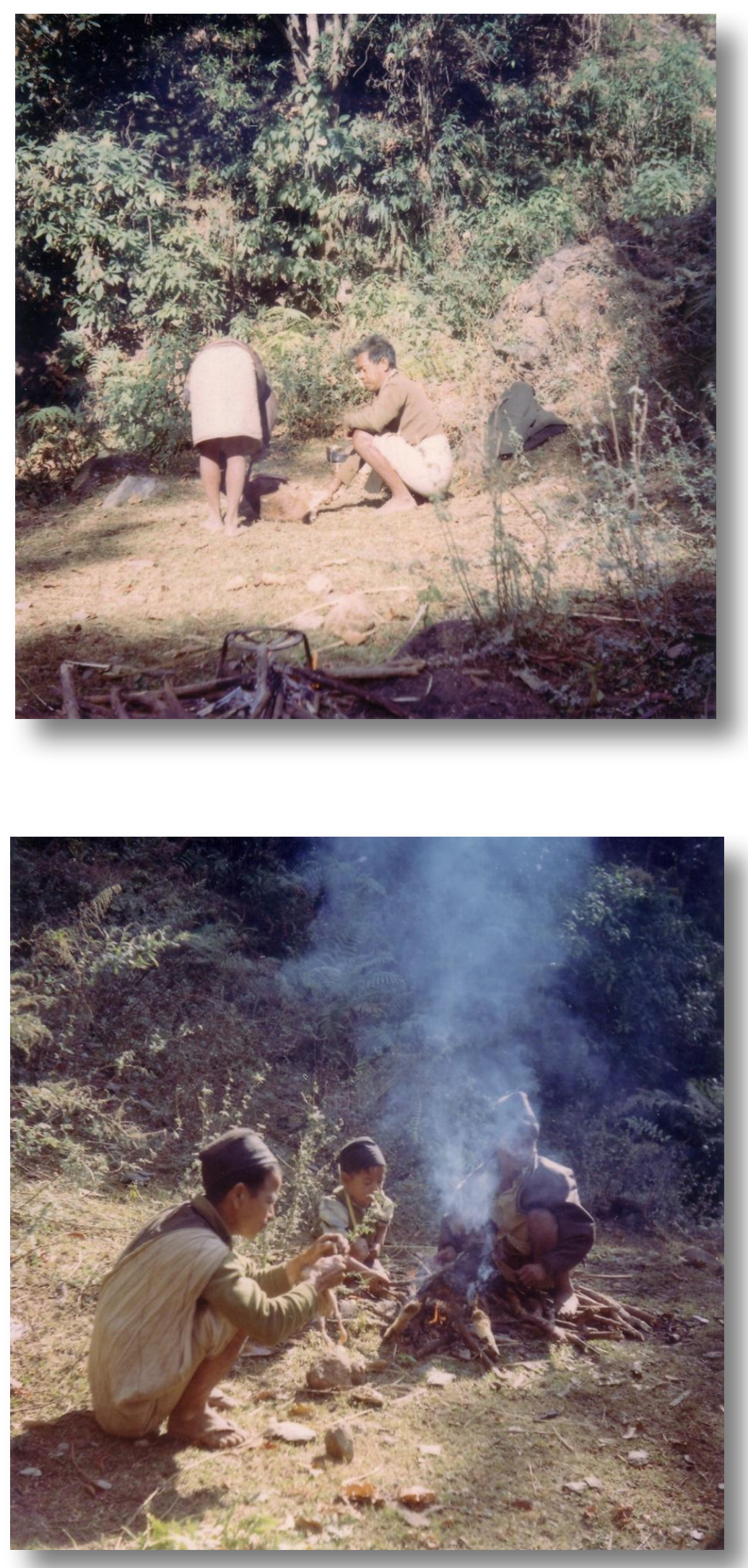

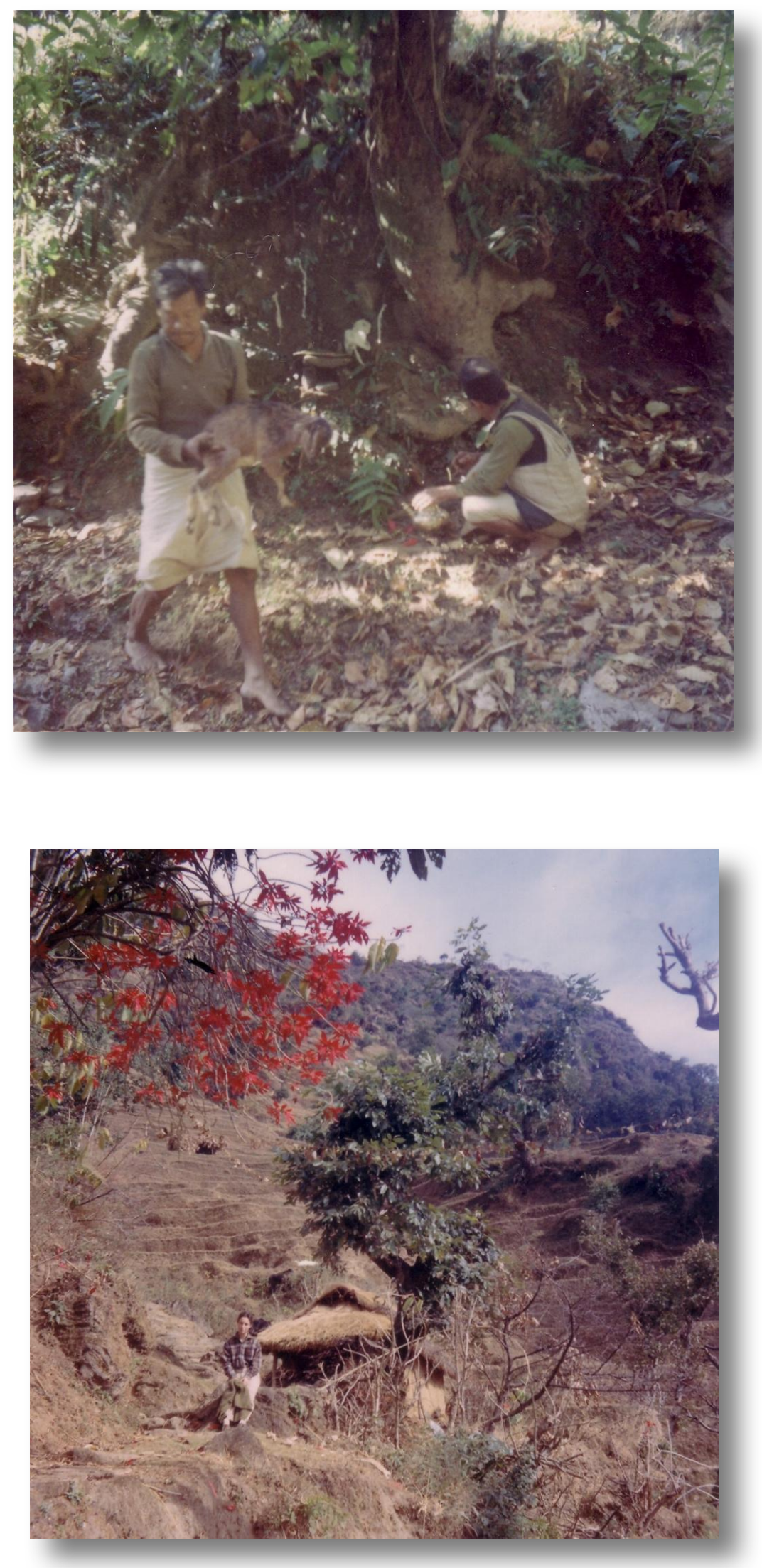

Gill near Panigat - 19th January 


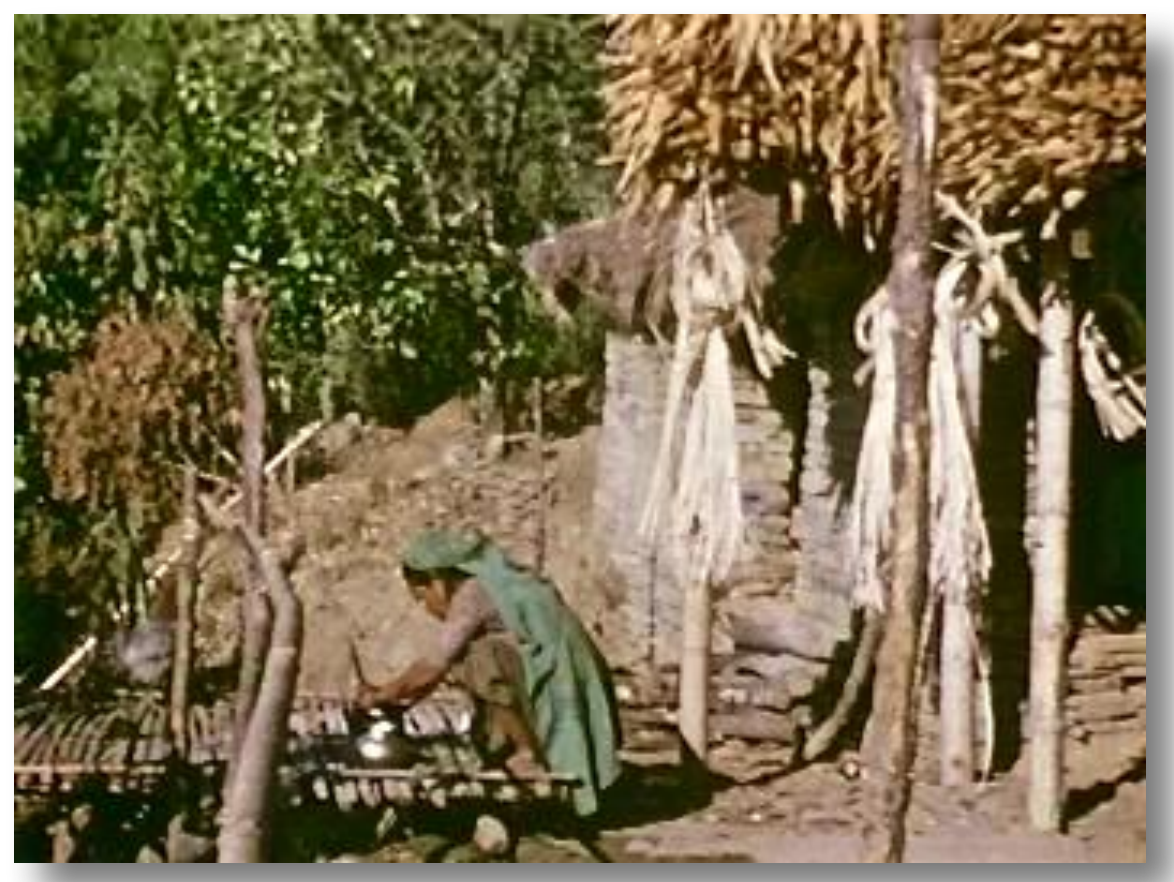

FILM. Woman washing pans on a bamboo frame (before 'bhaio te') Girl leaning against a 'mokhai suli' post teasing out thread. Verandah where another girl is sitting in shadow. Cat sitting in an upstairs window https://sms.cam.ac.uk/media/2739464

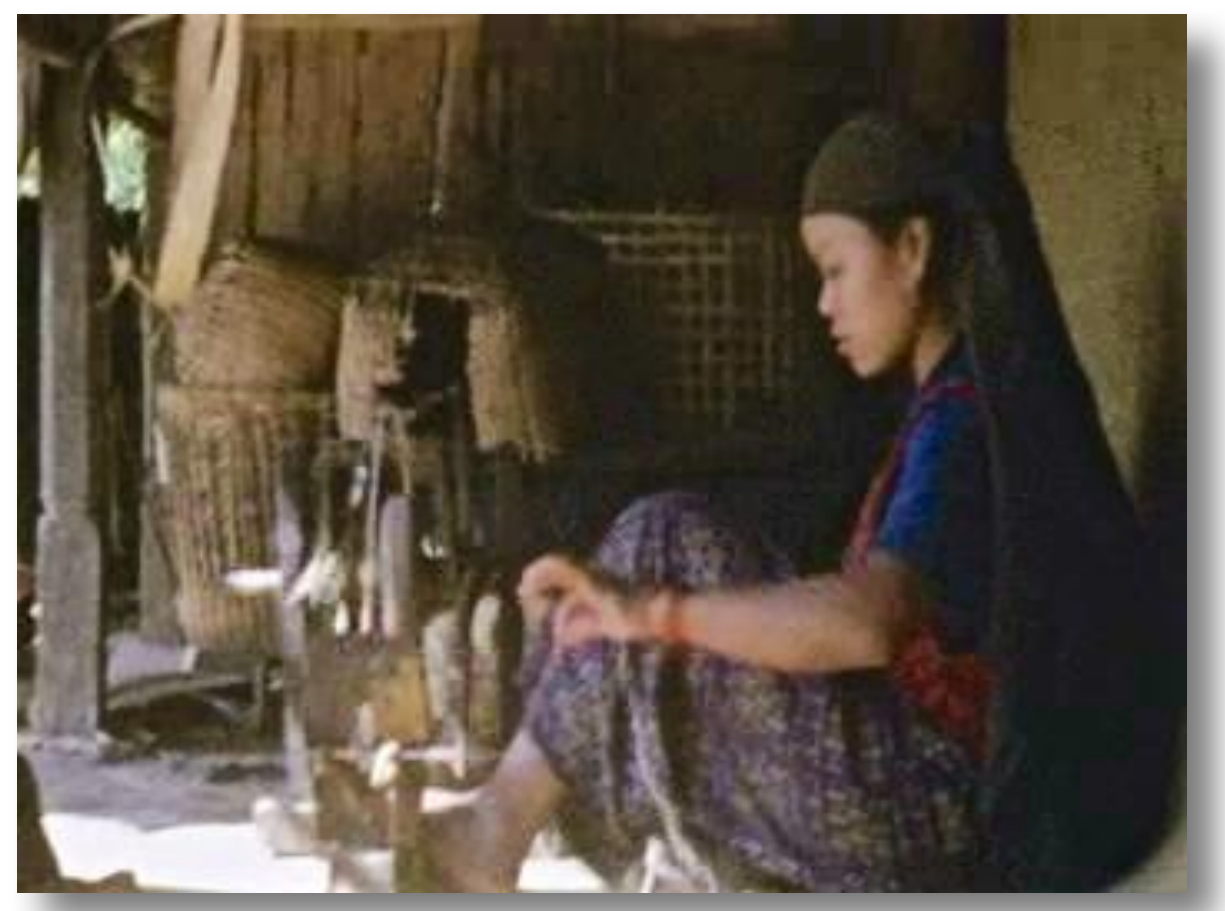

FILM. Girl spinning on a verandah https://sms.cam.ac.uk/media/2739492 


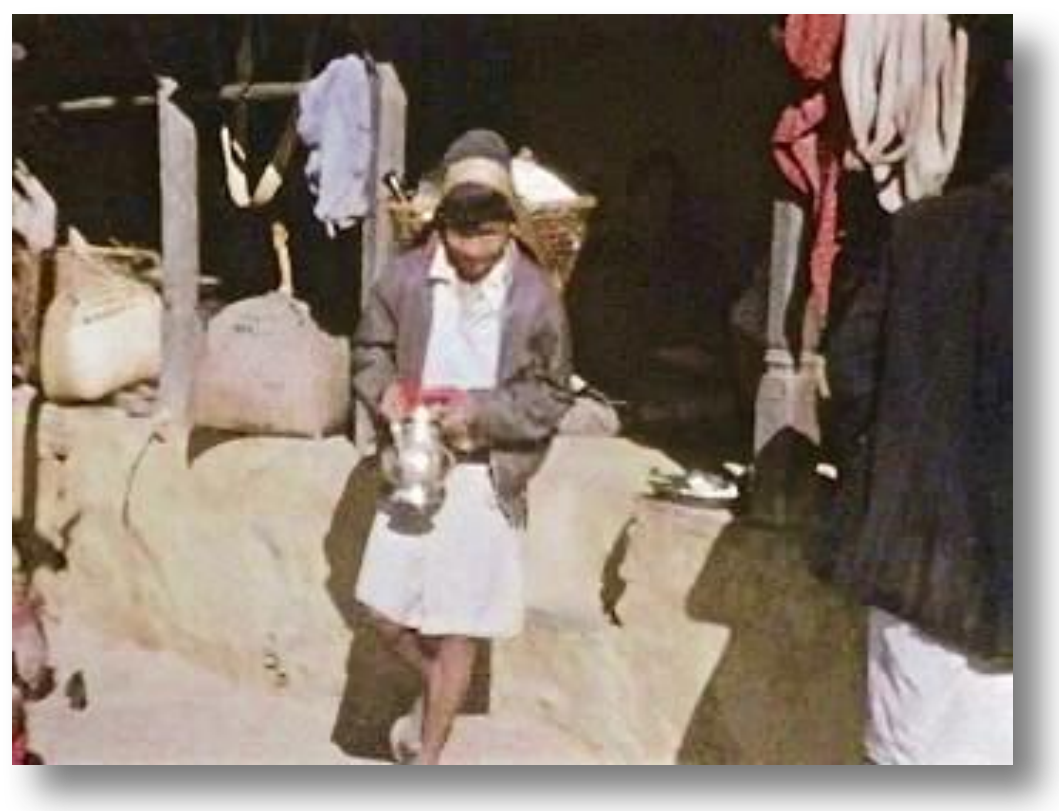

FILM. Leaving house for the 'bhaio te' (13 above) with poju and sons and relative of Krishnabahadur. Alan with tape-recorder over his shoulder https://sms.cam.ac.uk/media/2739520

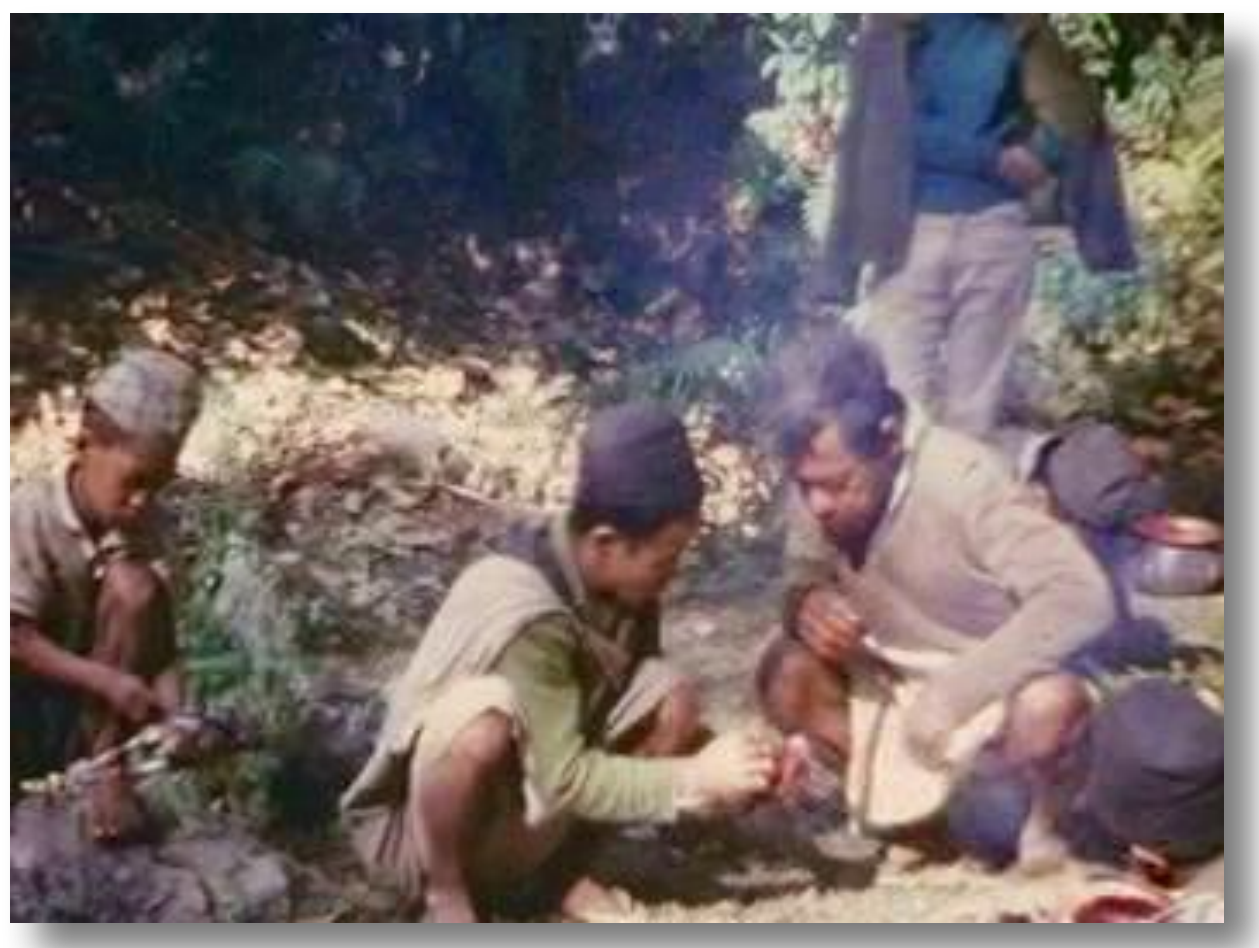

FILM. Poju doing a 'bhaio te'

Boy and poju's two younger sons there. Reading the liver. Gill in background. Woman cooking offering then Budibahadur puts some under a tree. All eating https://sms.cam.ac.uk/media/2739549 


\section{DIARY GILL Monday 19th January}

Got up 6.00am. as poju assured us he would be off to do a rite at Panighat "before you could see anything" - eventually we trotted off at about 7.30am! Nice walk down, lovely sun filled morning with light coming through trees - only Kaila gabbling inanely spoilt it all. Very pleasant house (relation of Servajid's) - pumpkins, yellow and dented drying on a rack, cane twisted into loops hanging on maize frame, the dead year's leaves on the bean poles. A huge cream dog attached to a huge chain attached to a piece of straw on the verandah had bitten someone recently.

We sat outside and had some rather horrible tea without milk and with pepper and salt in it and then the poju called us in to watch him making a pattern by sprinkling ground rice on the 'shyaed' floor [see Diary for diagram] and then making an over pattern with the yellow 'bisarro'. A pile of unhusked rice then hid this and a 'jongo' with a cleaned pan and an 'ashi' with money, lavender, grasses, butter lamps, poinsettia leaves and rice all on it placed over everything. Then the goat was brought in and had to sniff everything as a sign that all was well. A sweet little ginger goat obliged and poju told Kaila off for decorating all the pots and pans with oil and 'bisarro' carelessly. The rite was then cast in a grove where the 'bhaio' have their little altar - new one was made, goat and chicken killed much looking at liver.

I did cine films and Alan did stills. Very warm, sun-dappled afternoon - and we had a picnic with them - spoilt by me being embarrassed about eating with fingers and Gran saying with amazement that we didn't know how to do it. Afraid I snapped at her and Alan snapped at me. We then hung about on the verandah waiting for the poju, I tried to go to sleep but was too hot. Made our own way up eventually, rather disgruntled/hot.

Alan frustrated by later attempts to pin poju down who had gone off to Comal's to decide a suitable day for 'Abjon' to get married. However 18 letters came although Goof was late kept waiting at hospital - but while we were eating dinner XXX attempted to break in the upper window (he had been hanging round door all evening). Comal's Maila heard creaks in floorboards - very excited and with shining eyes he discovered thief. Hadn't managed to get anything and usual drama of finding poju who wasn't in. Rather spoilt evening - but reading letters was good - although not a line from M. although screeds from D. which was sweet. Doubts about meeting us at the airport which is sad. Sweet one from Annie.

\section{Letter from Alan on 19th January 1970}

Just eaten my morning snack of peanut butter and salt biscuits, the sun streaming into our loft. Gill painfully swallowing an orange as she lies suffering from a very bad sore throat. The village half asleep in this dead season; some of the girls off at the New Year's festival at Siklis to the north (the one we went to last year), some of the men off hunting jungle cocks, but most people sitting, sleeping and spinning in the sun. With only two weeks to go I feel the two emotions, impatience to go, and sadness at leaving friends and such beauty, with increasing intensity. Funnily enough they don't seem to be on the same plane and thus to cancel each other out, one feels them simultaneously. The days are filled with last-minute chores, principally taking movie and still photographs of the various activities and people. A series of perfect blue days after two days of cloud and hail (this is the peak of mid-winter here and there is usually snow) have helped the photography.

We had the easiest trek back from Pokhara ever since we were still fit from our hike, and have felt better for the break. Since then have been copying out school records, work-group records, finishing a map of landholdings, and doing a survey of child-rearing methods devised by Gill. Wherever we go in the village now people ask us how long we have to go, and seem genuinely sad when we tell them - they ask for photographs, letters and for us to return...But one is also slightly sceptical since some of the enquiries are obviously connected with the various pots, tins, clothes etc. we will have to leave behind when we go. Sharing these out is a bit of a worry, but have decided to give our best informants the choice articles, and then have a lottery for the rest. The last few days will 
be busy since we have also got to set up a tiny 'dispensary' as our gift to the village. The medicine should be arriving along with letters when the porter takes this down to Pokhara on Monday...

$19.1 \cdot 70$ c/o British Library, Pokhara, Nepal.

Dear Mummy and Daddy,

Just eaten my morning snack of peanut butter ad salt biscuits, the sun strephing into our loft. Gill painfully swallowing an orange as she lies suffering from a very bad sore throat. The village half asleep in this dead season; some of the girls off at the New Year's Festival at Siklis to the north(the one we went to last year), some of the men off hunting junglecocks, but most people sitting, sleeping and spinning in the sun. With only two weeks to go I feel the two emotions, impatien ce to go, and sadness at leaving friends and such beauty, with increasing intensity. Funnily enough they don't seem to be on the same plane and thus to cancel each other aut; one feels them simultaneously. The days are filled with last-minute chores, princlpally taking movie and still photographs of the various activities and people. a series of perfect blue days after two days of cloud and hail(this is the peak of mid-winter here and there is usually snow) have helped the photography.

We had the easiest treck back from Polchara ever - since we were still fit from our hike, and have felt better for the break. Since then have been copying out school records, work-sroup records, finishing a map of landholdings, and doing a survey of childrearing methods devised by Gill. Wherever we go in the village now people ask us how long we have to go, and seem genuinely sad when we tell them they ask for photographs, letters and for us to return. I expect you had this experience even more intensely when you left - though perhaps Mummy was too ill to notice 1t. But one is also slightly sceptical since some of the enquiries are obviously connected with the various pots,tins, clothes etc. we will have to leave behind when we topele. Sharing these out is a bit of a orry, but have decided to give our best informants the choice articles, and then have a lottery for the rest. The last $f e w$ days will be busy since we have also got to set up a tiny 'Dispensary' 8 our gift to the village. The medicine should be arriving along with letters when the porter takes this down to Pokhara on Konday. Hope there will be a leter from you then, perhaps describing what you did at Christmas etc. I have answered the last one from you(the birthday one) which you sent on Dec.9th. We will be writing again in a fortnight when we go down to Pokhars, and then arriving about a fortnight after that letter reaches you. I think I have given you our provisional plans bout Beb.9-19 in Assam, then leave Calcutta Feb 25.th. As I said, we will call in at Poste Restante, Calcutta, to see if there is any lat minute news from you. Wonder how Fiona and the baby are? - hope they got oür congratuadsory letter. Assumed you would all be togetier fov Christmas, so ask them to forgive a gap (and A and Brik) if you weren't. The little car sounded sweet. Gill has reminded me - did we tell you the Iweed had come, I think we did? lir. Pant was very pleased. Honder if you have got your work-room yet. Will be very exciting comparing all our notes, and I am longing to see how you are getting on. Incidentally I had. a thought about what Annie could do to start off helping with Kirby L. Among the' 'miscellaneous sources' file(or elsewhere) there should be a reference to the Censuses of 1841 (and 1851) at the P.R.0. I didn't have time to copy these out, but I think I made a form onto which they could be copied. Perhaps Annie could copy out the details (with 2 or 3 carbons) at the P.R.O. From that, which lists households by number in street, we might get a clue to how the Census is set out. We might, however, have to work back from 1841 via the hegisters before we can do this. inyway, if you find the form, perhaps you could send it down to Annie and we can talk about it when we arrive. With the three of us, all working part-time on K.I., we should make good progress(and also liary Ions).

How does the reconstruction of the croft go? Don't worry about making a little glass compartment for me; I can set up a little office in our bredroom. With all that lovezy window it shoudd be blissful. And how is your writing lummy? We are both longing to read the Seagull Book and your humerous articles. Your letters to us here would make a nice book of descriptions.

Bxcuse a dull letter, but not much happening apart from the washing and inter-visiting of the Gurung 'Hogmanny' which we described lasł year. Strange seeing it all over again. You can't guëss kow much we long to see you both. With all our love as always.

$$
\text { Alan: Git. }
$$

Example of a letter. Material not related to the village is omitted in the transcript above 
Last night XXX tried to burgle our house again, but caught him in the act, hearing him upstairs, but he fled later. In the morning Prem had him tied up on porch - but what to do? Spent day sorting letters and dreaming about what I'd do with all the money SSRC would give me - then having written an encouraging letter. Poju also came for three hours and finished off bits and pieces.

\section{DIARY GILL Tuesday 20th January}

Very overcast, cloudy day so we could not go to river - if only we had gone yesterday. XXX interrupted even breakfast when Alan was asked to go round and beat him, sniffling, tied up to the porch. They don't know what to do with him. Had a cold, dark, inside day with the poju helping Alan and me sorting out the letters/carbons and admiring all my own - also read last night's letters over again. Did this in the afternoon too, and then went for a mist filled walk to our pebbles and threw 3 away. Pity Dr Turner might put our leaving date off if he comes.

Had pleasant supper with Nani, Kaila (boy who was ill), Servajid and Maldosing sharing the crackers. Apparently XXX has stolen lighters etc. from them and took some socks off our line right at the bag - I thought it had been Nani at the time! She told us he has been known since school for being a thief. Funny I don't feel unduly worried by this. Perhaps it is minor exaltation at the thought of all this being nearly over. All trees without leaves - but they creaked, writhing one opposite where we sit on the loo has black buds like quotation marks springing from it - one can almost see sentences announcing spring! Still blood when I go to the loo.

\section{DIARY Wednesday 21st January}

Desperately trying to finish up tins and bottles - eg. of cabbage in brine. An icy cold, raining day which cleared in the evening to produce a magnificent sunset. Spent the day writing letters, dreaming re SSRC grant, and sorting out notes etc. Prem came in morning to check we still liked him - later brought a few 'teme' as a present.

\section{DIARY GILL Wednesday 21st January}

Foul, freezing day - rained all night and thick driving mist for almost rest of day. Sorted letters by window sitting cross-legged on my sleeping bag with a board across 2 suitcases to hold letters. Quite fun, took up all morning. Alan writing letters. Finished "Charter House" after lunch - even more exciting and urbane at the end - [Not transcribed]. Went for a late walk when cloud had cleared and took photos of mountains which were impressive, seen through cloud and pink/grey/white at sunset. Full moon was up, white and round like a cream cheese, and if only this and drifts of purple cloud could have been included too! Threw one of our stones off. Poor Gurungs, frozen all day - Ombahadur came in evening with horrible new coat on and teased me about my pronunciation. Pretended to be cross and Nani loved this. Drew up list for giving things away and there is not going to be much left.

\section{DIARY Thursday 22nd January}

At last we were able to go to the river: a fine warm morning and we scrubbed and cleaned vigorously. Went to our old washing place at Tadsyon and it evoked many strange memories. 
Climb seemed much easier and it was generally a very easy and pleasant day, rounded off with a cup of tea at Bhuwansing's. As always, a beautiful evening - and full moon.

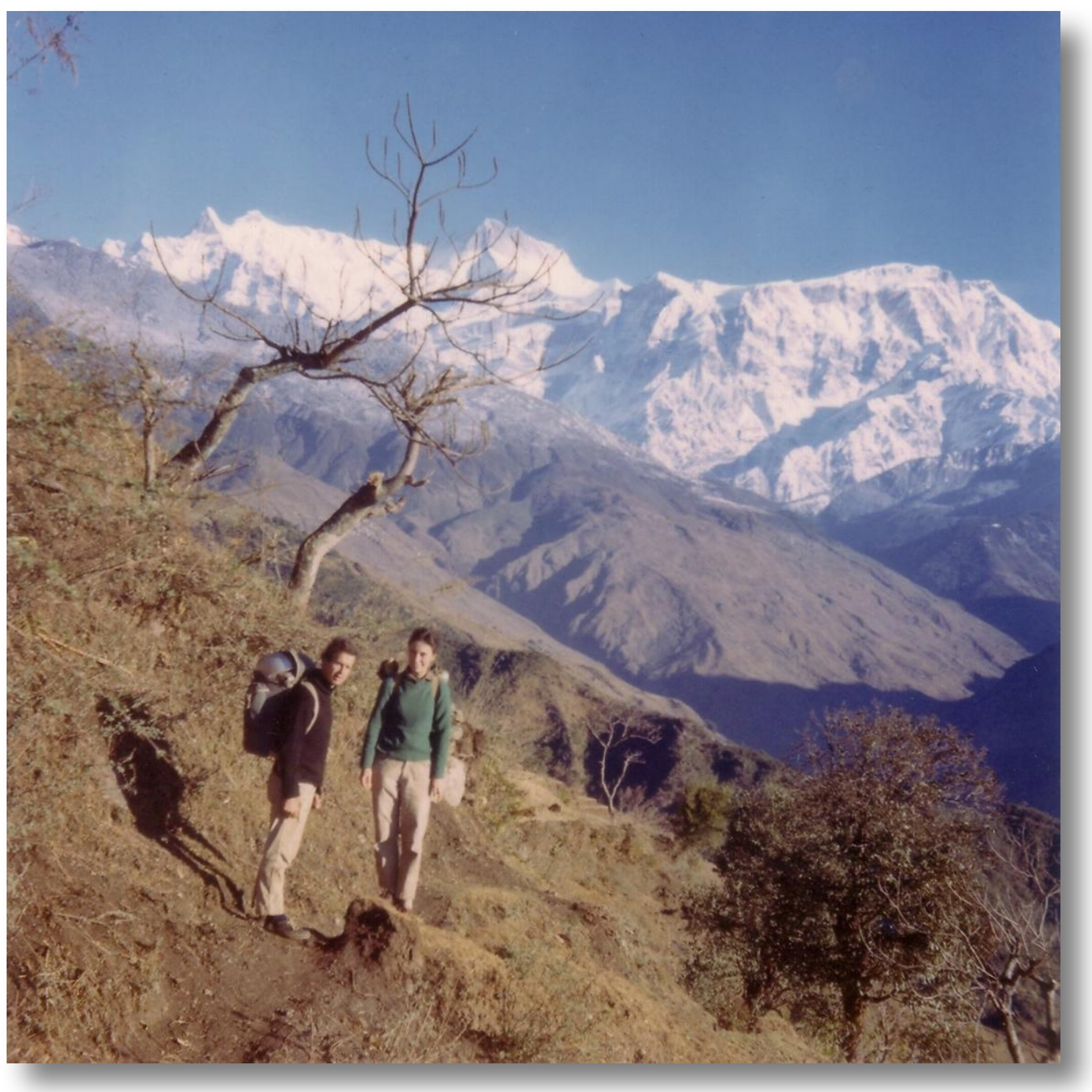

Alan and Gill going off to wash clothes on 22nd January 1970

DIARY GILL Thursday 22nd January

Woke to an orange-barred dawn and flawless pale blue sky, so immediately decided on river. Went to our old place of over a year ago - mixed memories of longing to be away and dread and resignation that we were going back to the village again. Heavenly to get so much stuff washed. Alan very good in helping me, and we managed to get ourselves done before sun clouded over. Hair had not been washed for over 3 weeks and felt oranges lighter when it was. Same yellow jasmine out and Alan took a photo. Came back about 4pm. when there were purple clouds and light drizzle and had good supper and danced to Beatles afterwards for Omkumari's and Ombahadur's benefit - latter attempted to twist in his 'kas' but said he would put his trousers and tie on tomorrow evening and then he could do the thing properly! 


\section{DIARY Friday 23rd January}

Cloudy and swirling mists - trying to dry clothes. Hoped to finish map with Gungabahadur, but he proved elusive. Wrote half of proposal for SSRC grant in morning. Then poju came and we did work together - almost finished once again - copying out contents of his books. Very cold. Gill depressed by reading about Russian revolution.

\section{DIARY GILL Friday 23rd January}

Keep waking up at odd hours - midnight, 4.30am. absolutely awake and excited as if we were going tomorrow morning! Alan is sleepy but reasonable! Keep planning presents we are giving. Felt very wan this am. - half blue half misty day - big peepul tree bathed in cloud but twinkling through with raindrops on the leaves. Later hills were dramatically regal and purple and we went to visit Kumansing to try to find out about a funeral at Siklis - primrose yellow 'gundris' hanging rolled up on the verandah and view of mother goats with baby ewes feeding made it look like a nursery - each goat tied onto a maize pole! Pale green banana leaves against purple ridges lovely - Very little other vegetation out now. Read some of Shakespeare's sonnets and they fitted somehow - "Full many a glorious morning". Alan had poju in finishing off summarizing contents of books - All very cold swathed in coats, jackets, trousers. I read Lenin - horrified by the Terror that followed his rise to power - but still cannot but admire the terrible consistency behind it all. I think the secret was that he didn't see these "counter-revolutionaries" as people but as a class who had no right to exist and therefore no reality - a mere abstraction to be disposed of - "Whoever is not with us is against us" [Not transcribed].

\section{DIARY Saturday 24th January}

A red-letter day - finally finished the field map with Totra's father, Bhuwansing etc. Had three bottles of 'pa' to celebrate. Cold day with swirling mists - did our usual trek toward Taprang to throw off some more stones. Gill finished Lenin. I finished typing up first proposal for SSRC grant. 


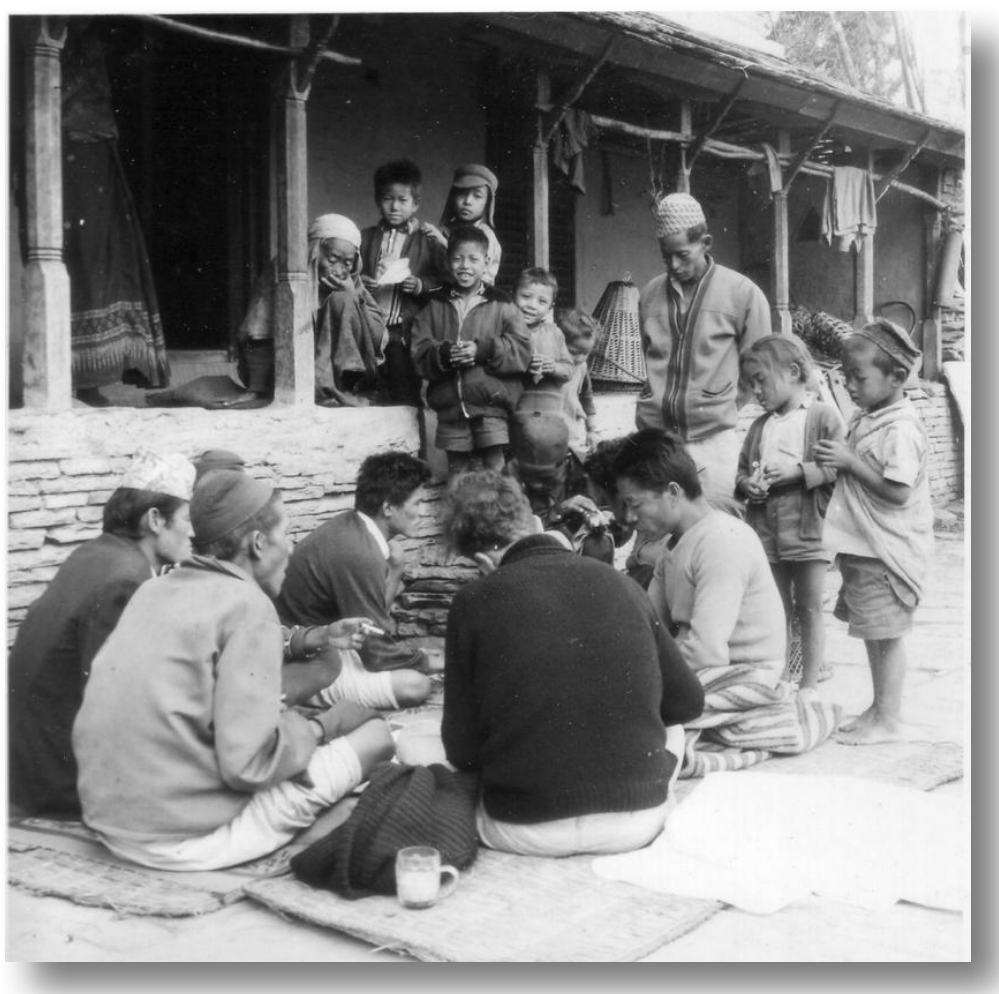

Group of men, including Bhuwansing (right of Alan), helping with the map - 24th January 1970

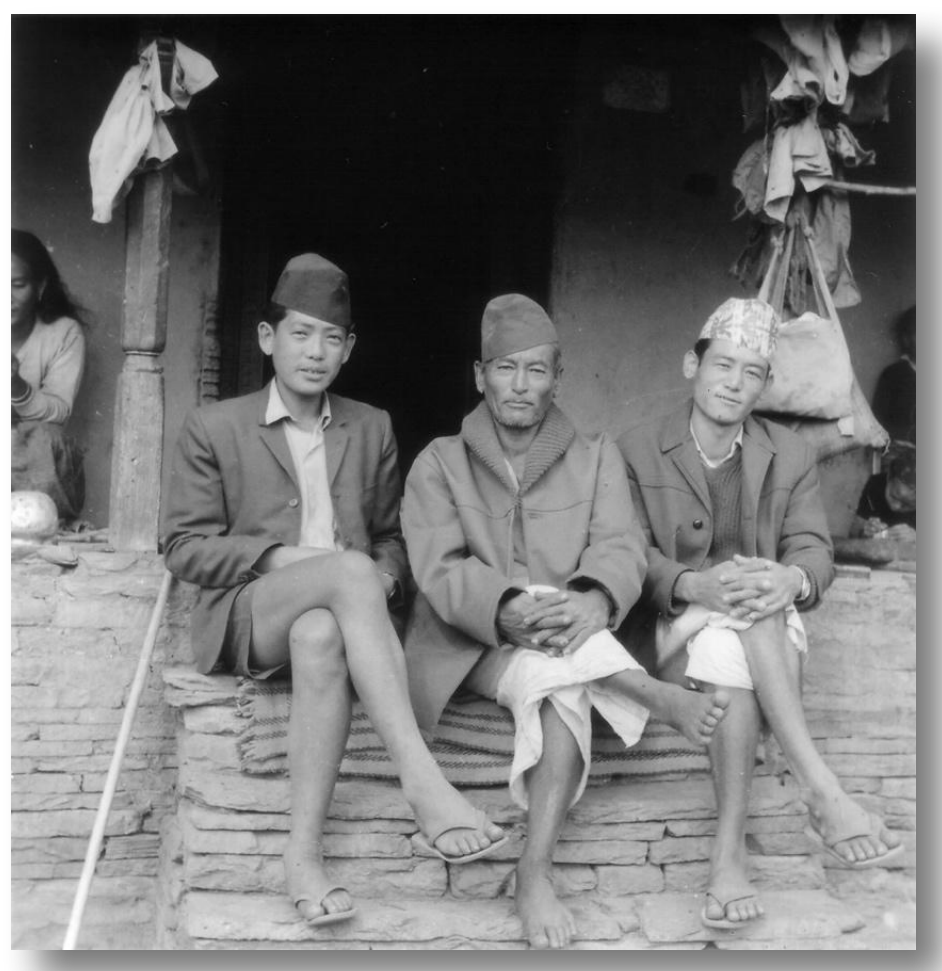

Akayprasad (left) headmaster, with his father, Brikaras and Gungabahadur, member of the Jilapanchayat - 24th January 1970 


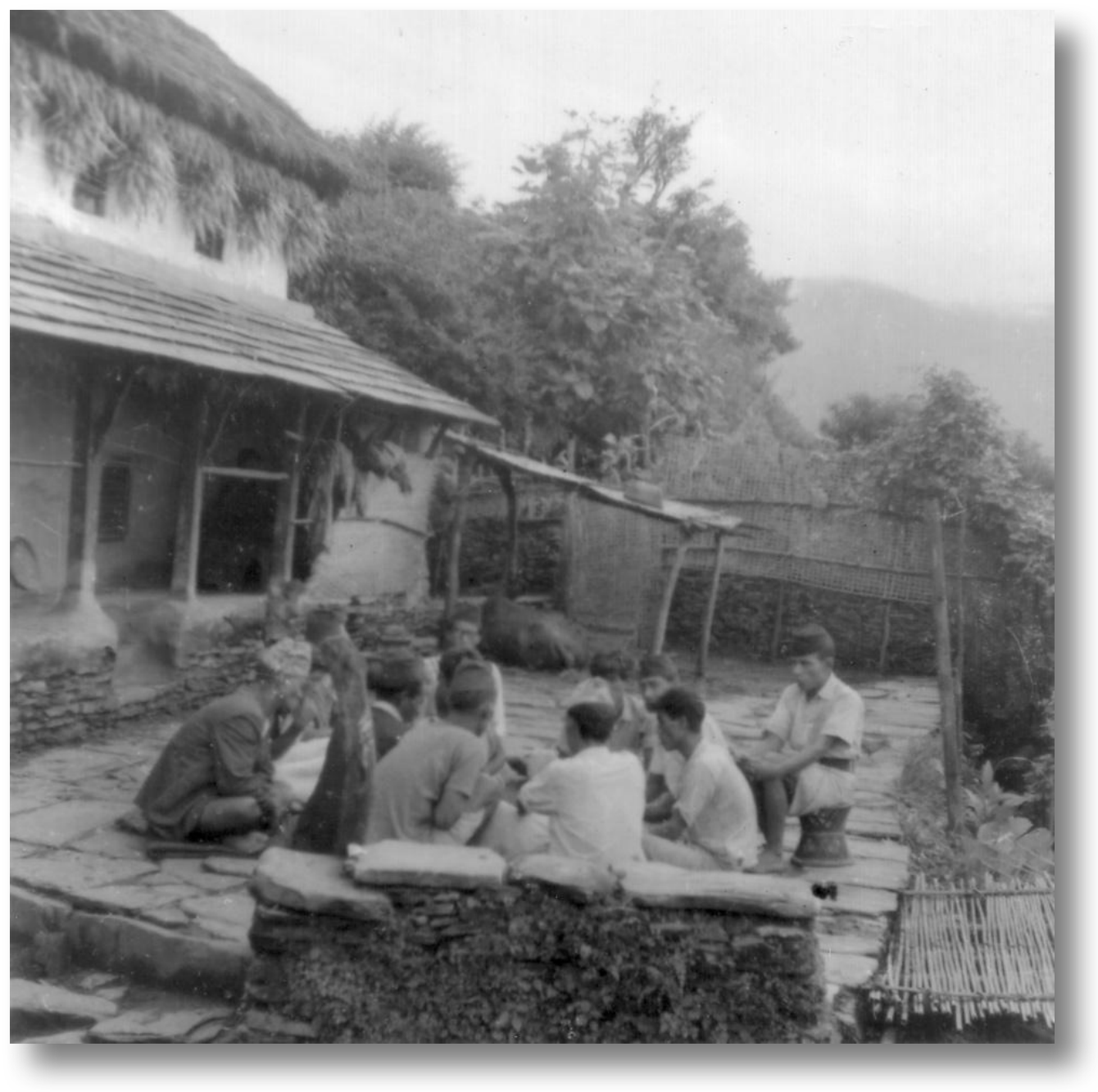

Men playing cards in the courtyard of house 25 - 24th January 1970

\section{DIARY GILL Saturday 24th January}

Still dreary fog-bound day but both cheerful. The Jila Panchayat man came as promised to finish the map - and then a whole deputation consisting of Totra's father, Gumbasing and Bhuwansing said they were all determined to finish map today and more or less took Alan down bodily to do it - not that he needed much persuasion! Also took 3 bottle of 'pa' down and I took a photo of them working together [PHOTO] - another half was gambling with cigarettes, Prem in a khaki shirt, losing but wryly resigned, 2nd schoolmaster winning and lively, Comal's father abstracted and orange loin cloth in full view, the 'lowri' on a stool, whom I don't like, with a boil on his cheek. Everyone tried on Jila Panchayat man's bottlegreen nylon ladies gloves and just about kept their patience with Alan - and then after 'pa' and tea leapt out to start dicing with shells!

I finished off Lenin in the afternoon, hugely enjoyed the book and must read others that I've starred in the back. Went for our walk and threw off 3 stones! Lot of people in - all men teasing Omkumari about sleeping around, saying she has a boyfriend in Parche. Alan offering her his torch to go off at night - much amusement! Interesting how men old enough to be her father (Kumbasing) are foremost in teasing - vaguely obscene - wanting to sleep with his dog she cried when he killed it. Also incest jokes. Omkumari spat and growled but hugely enjoyed 
it all the same. Alan played his guitar and Gopal banged the tongs, Ombahadur played drums on a saucepan lit and Prem rattled 2 sticks together - "Dimple in her cheek", "Ring around your neck", "16 Tons" - Gran and Nani in - I paranoid about former. Why am I so fickle that everyone must like me? Overcast drizzling night when I went to fill the buckets.

\section{Letter from Gill 24th January 1970}

Am sitting at the moment with my knees swathed in my sleeping bag, very, very grubby, and my 'fur' coat and an anorak over my shoulders as the mist is curling in through the windows and I can see the maize stack with a few dripping myna birds on it, and that's it, the rest of the village enveloped in a shifting fog. The rest of the loft is more or less covered in an enormous map of the village rice fields, which Alan is just finishing off with one of the richest men in the village in attendance, also one of the wildest sower of oats, and the village committee member for the Pokhara council. All those with money, a certain amount of political power also live it up with the women as well, which is a set of nice correlations - wonder what Lenin would have made of it? It has been rather foul, damp weather for the last few days, with had a day's break which allowed us to go to the river after three weeks of not having a proper wash. Ghastly. However, I stood naked shivering in the stream and rinsed my filthy hair with the Chinese bowl and it was bliss, also cut Alan's hair which was descending to his collar bone, and fed to curls to the fishes. Unfortunately, everything didn't dry so we had to resurrect the line in the village yesterday and have all the adolescents poking at my MES sprigged bras, a change from poking the buffaloes I suppose.

...We hope to have a party on the last night and Alan will play the guitar and I will do out duet with him of 'The Owl and the Pussycat' (with miaows and translated into Gurung for the benefit of the uninitiated) and give them Chinese Crackyl Prawn crackers and generally poison and bore them all to death. In a thoroughly perverse fashion it will be rather sad to go, we are very fond of the silly old things, especially Lemon Face, Goof, Hello Fohn and the Woman with the Hard face, as you might gather from their names...

...At the moment we have only four or five more days to do, depending on whether a doctor from the Mission Hospital can come up tomorrow and help Alan check his medical census... We have just said goodbye to the poju (magician) who has helped Alan so much and treats him like a favourite son. The poju is going offelsewhere today and wont be here when we go, so this morning he divined whether Saturday or Sunday would be lucky days for us to leave, and took a silent, sorrowful leave of Alan just now, sitting on our step with a scarf round his head looking sad, like a dormouse with a toothache. We took a colour photo of him earlier in all his magical rig-out - peacock feather in a black felt cap covered with shells, a belt with bells attached, a quiver full of quills stuck in it, and his three drums, conch shell and cymbals. Also his specs at the end of his nose, a bow to modern aids! Should be sweet if it comes out. [note about a village thief who robbed us, left out.]

\section{DIARY Sunday 25th January}

Spent a pleasant day wandering to Taprang and back - managed to achieve our aims namely to get ancestors of Lamme from the Lama and buy some bamboo mats ('pyoh'). Went with Gopal and very beautiful into clouds, wheat, mountains, etc. Finally got washing dried. People very insistent both in saying how much they will miss us and could we leave them.... Hope there won't be too much disappointment. 


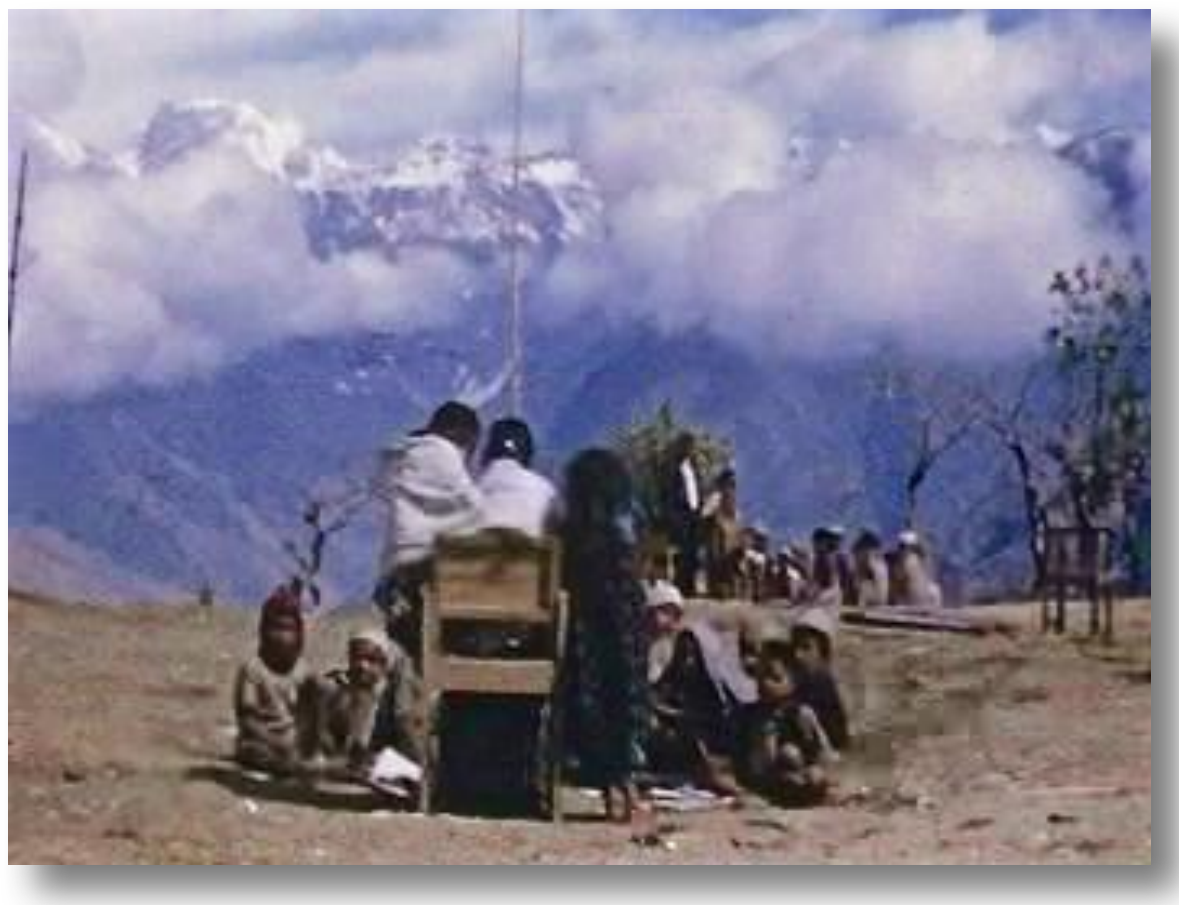

FILM. Taprang school

Children working in the open

https://sms.cam.ac.uk/media/2739584

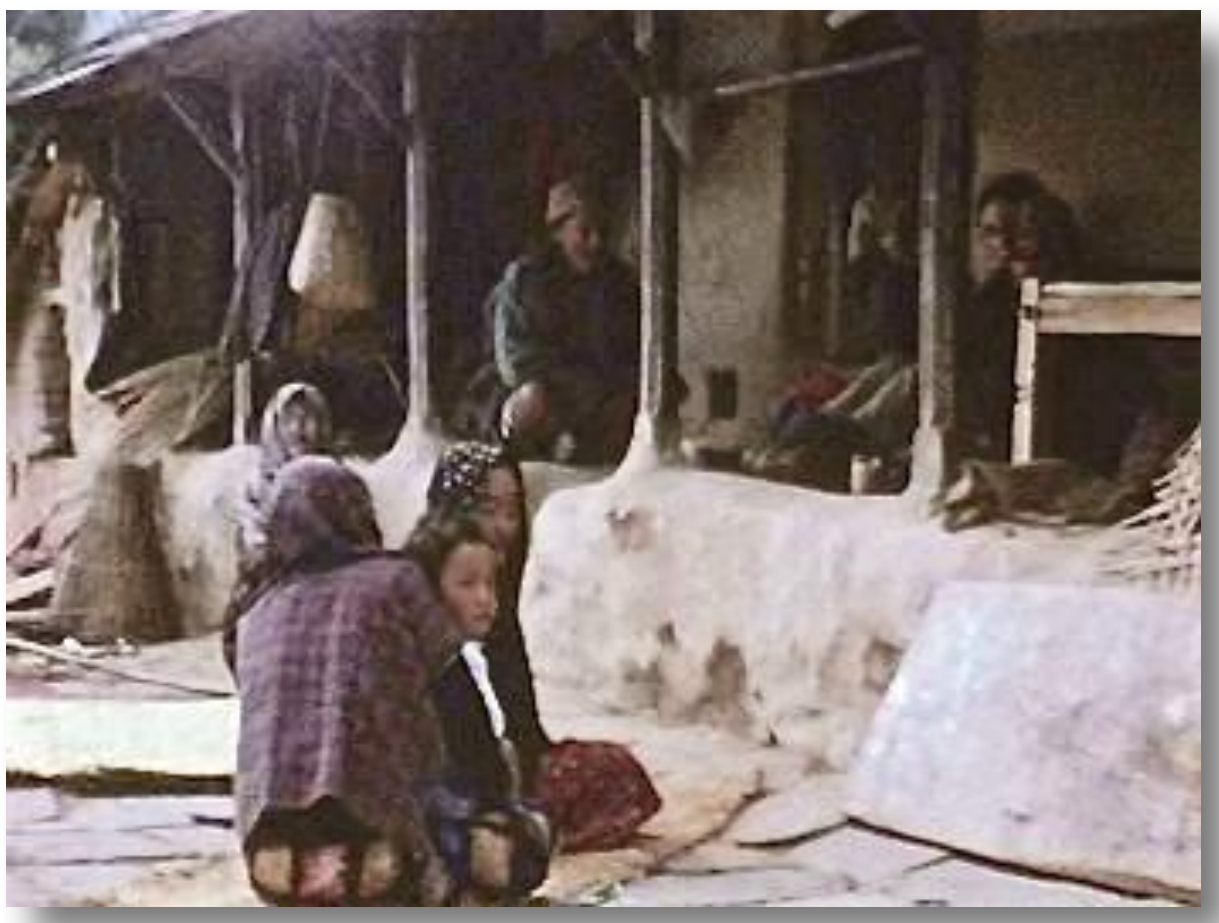

FILM. Gill on the veranda of house of Lama in Taprang with his family sitting round https://sms.cam.ac.uk/media/2739612 


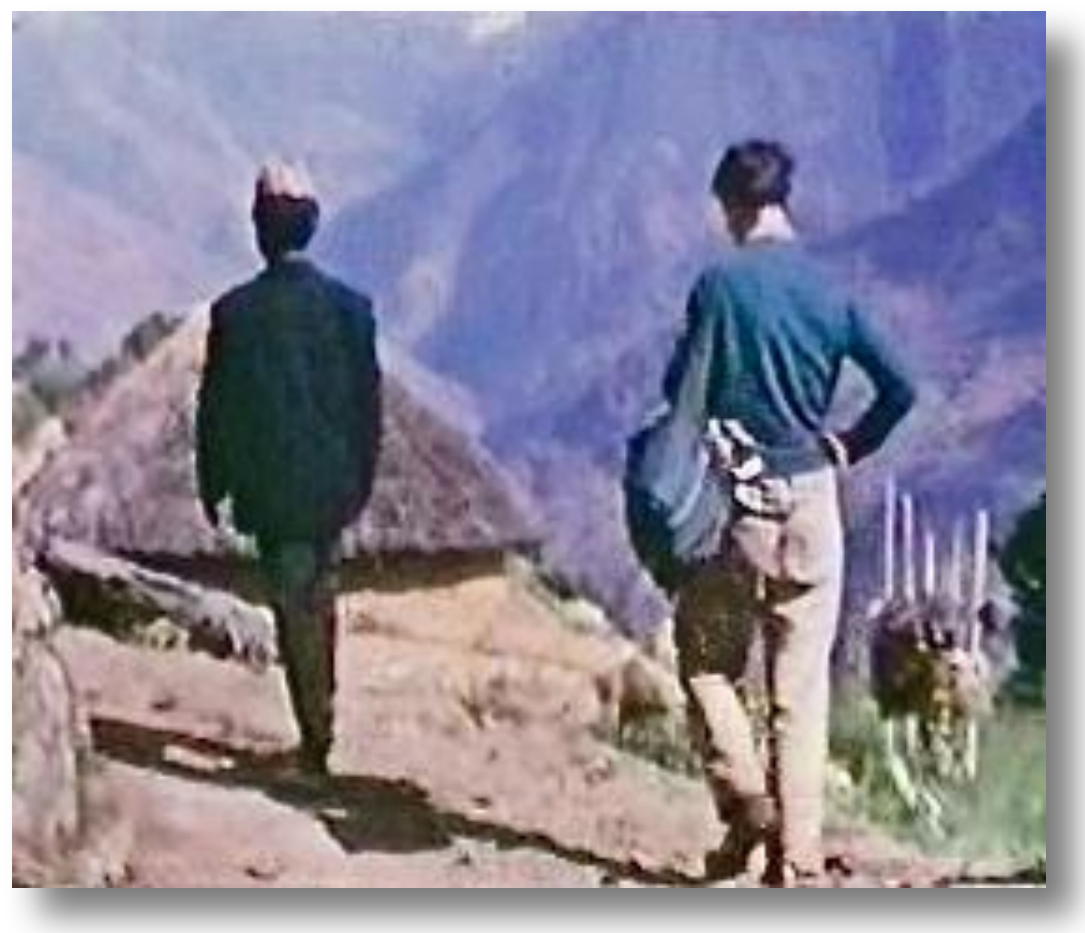

FILM. Gill and Gopal walking through wheat fields at Taprang https://sms.cam.ac.uk/media/2739642

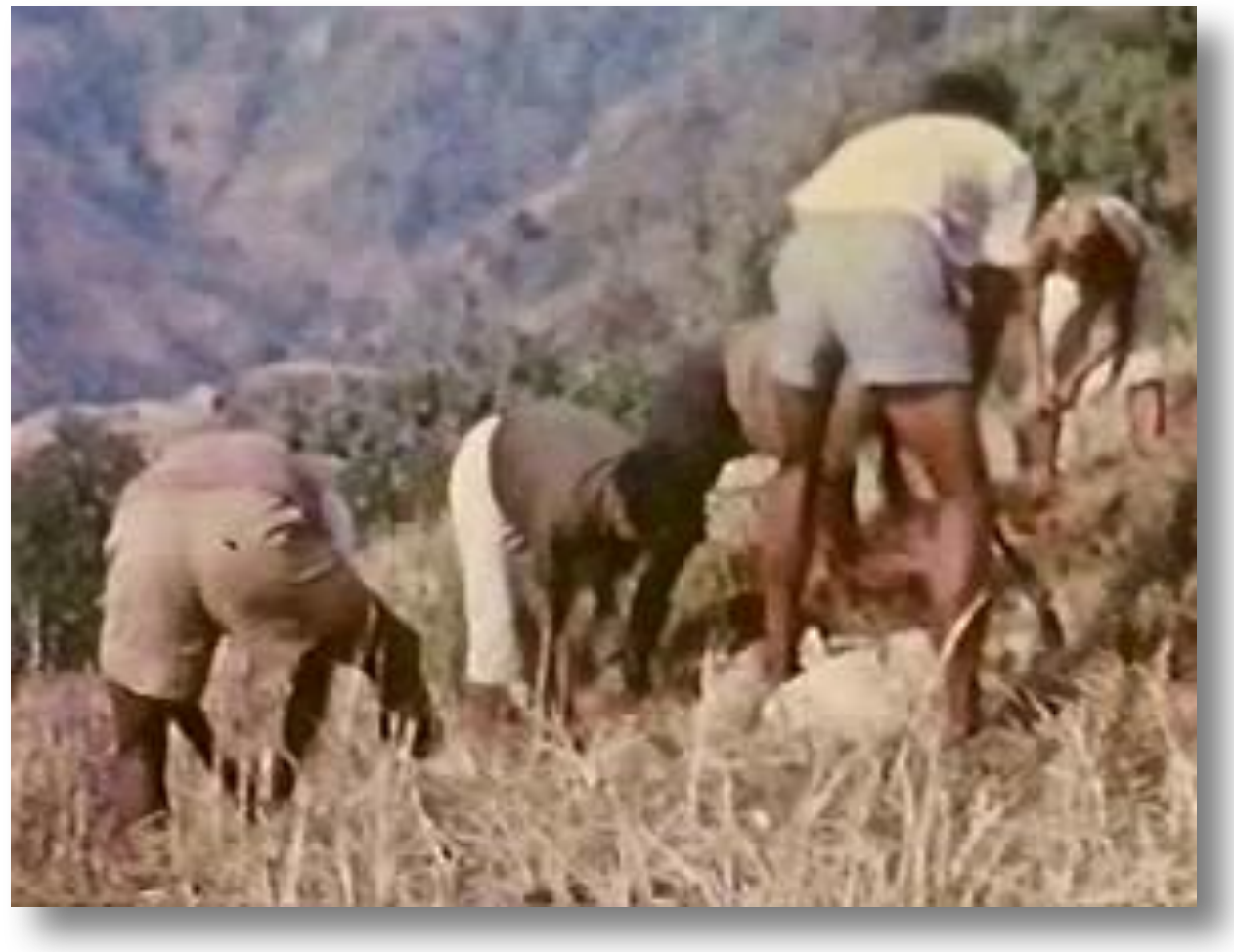

FILM. Men, including Prem, making a new maize field for Tekansing https://sms.cam.ac.uk/media/2739678 
Weather brighter with bursts of sun - decided to go to Taprang with Gopal for Alan to look up Lama and to buy some 'pyoh'. Sleepy and hot on way there although Taprang pretty as always with banks of jasmine and lavender, field of pale green whiskery wheat against mountains and round comforting orange houses in the non-Gurung part. Also barley and dashes of purple and white pea blossom - very pretty. Also saw a lovely Gurung house with curly carvings, and a mongoose (skinned)' a bear's paw, a round of red chilies, a clump of millet, a green twisted vegetable and 2 pheasants stuck through the eaves! also buff pumpkins. Bought 2 'pyoh' - a 'kanja' and a 'saila'! and Alan got material he wanted from the lama - very pleased. Came back about 2-3pm. having lost Gopal on the way - showing us all places they dig for 'teme', and training an ox to take the plough - and had late lunch.

I started "Sentimental Education" - marvelously exact description of a steam ship, for example [Not transcribed]. Then had a sleep as I was tired, keep waking up at about 4.30am. with excitement and not being able to go to sleep again. Had a funny selection in - China's mother who had woven a baby 'gundri' for us and wanted a mug in exchange for China, Prasad who took over his schoolmaster's role and corrected Alan's Gurung and who said we could have a basket he had woven - Ombahadur, silent and unhappy looking for once. Comal with 2 eggs which we couldn't buy as we have 40, and Servajid conning us about his work list. Overcast night and drizzle again.

\section{DIARY Monday 26th January}

A very cold day with blustery wind and rain - like the Dales, as Gill said. Poju came in morning and at last got that finished. Now almost everything done - another hour and some filming and then finished! Wrote letters, read Nich. Allen's thesis and a bit more of Margt. Mead on Development. Stream of people for medicine and asking for things. In evenings also more and more odd people coming - even had Prasad in last night!

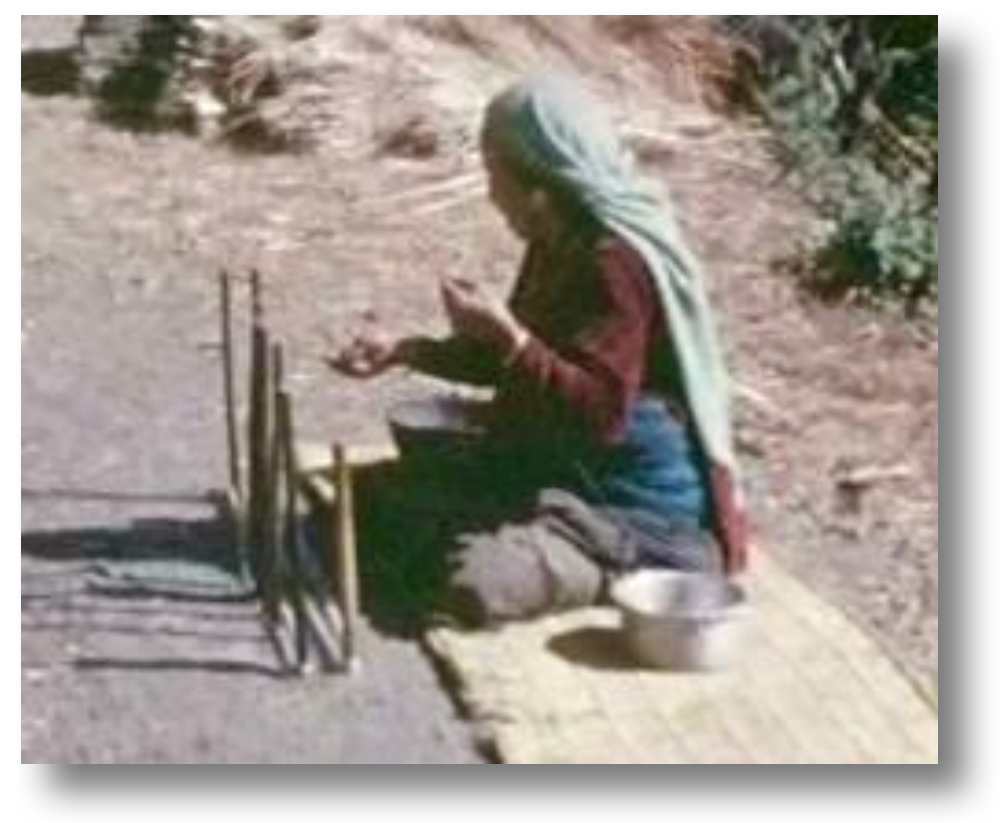

FILM. Dansuba preparing a 'nangi' warp https://sms.cam.ac.uk/media/2739741 
Foul weather again - rain drizzling down in the morning, poju undecided whether to come or not - getting soaked by the bushes when I went to the loo - also constipated! The mist rolled hills reminded me of a Dales day and that made me moochie too - how can I have the nerve to be moochie now! Put it down to "Sentimental Education" which is moochie at its best and a throbbing headache.

Typed an abortive letter to Lesley. Alan and the poju saying tearful farewells in the loft, people piling in for medicine, tins, birth control pills, change for 100rs. notes - after lunch slept for 2 hours - tired with all this waking early. Then I shouted at Alan and we went for a drizzly walk - but mountains gorgeously rose-coloured with flurries of cloud flying back from the ridges. Looked as though all the snow was being swept away by a strong wind.

Had another unusual lot in - 2nd schoolmaster who was quite pleasant and conversation didn't get too obscene, as it usually does when he is here. Comal very abstracted and silent playing with my big walking shoes. Bit bolshy and teasing Pixie Face. Alan played taperecorder to quieten them down. Enjoyable. Plan of Alan going to a funeral with Prem. I am being awkward about it, of course. Means one and a half days away - if Dr. T. comes.

\section{DIARY Tuesday 27th January}

A warmer and finer day today - took some more photos, wrote home and at last, packed up my notes: almost all of them go into one green case which is good. Dust everywhere, but a happy feeling inside. Besieged in the morning with requests for birth control, medicine, tins, etc. Beginning to feel sad as we see people for the last time. Things like sugar and Horlicks running very low. Gazing at the little photo of the croft with increasing yearning. Off now for our evening walk to the mountains.

\section{DIARY GILL Tuesday 27th January}

A rather moochy nothing day - even though we packed, a thing Alan has been longing to do for weeks. Everything is so filthy and grimy though that it takes the pleasure out of everything. Got most of his papers into the large green suitcase, which is good. A light breezy morning with showers and rainy sun, reminded me of April in England. I am still constipated too which is annoying. We went up later to film them coming back from the forest but the camera is not working well, revolving too slowly. Had a quiet evening to begin with - only Nani and Haricola but then "Pixie Face" and mother, Gopal and Ombahadur came demanding to hear tape - so we played that but didn't dance as I was feeling sleepy. Alan kindly decided not to go to 'pae' - turned out to be a dangerous route - snow in forest, anyway. Somehow it is wearing, just waiting for time to go.

\section{DIARY Wednesday 28th January}

How slowly the days pass! A beautiful day which adds to growing sadness. Walked by way of Towli to throw off our stones - only two left now. Neither of us can really settle down to anything - letter writing, etc. Read some more of Nich. Allen's thesis. Finished all work now except medical. Said a sad good-bye to poju, who seemed equally sad. 


\section{DIARY Wednesday 28th January}

Again this weary, depressed feeling especially when people come asking for things - which is not much really. Also snapping at each other. Poju came to say goodbye as he is going to India today - very sorrowful, though we hope we've got a good colour slide of him. Finished off letters to Anne and M and D (do hope they can meet us). Alan still wanting to get some information from Laljid. Bright sunny day until quite late.

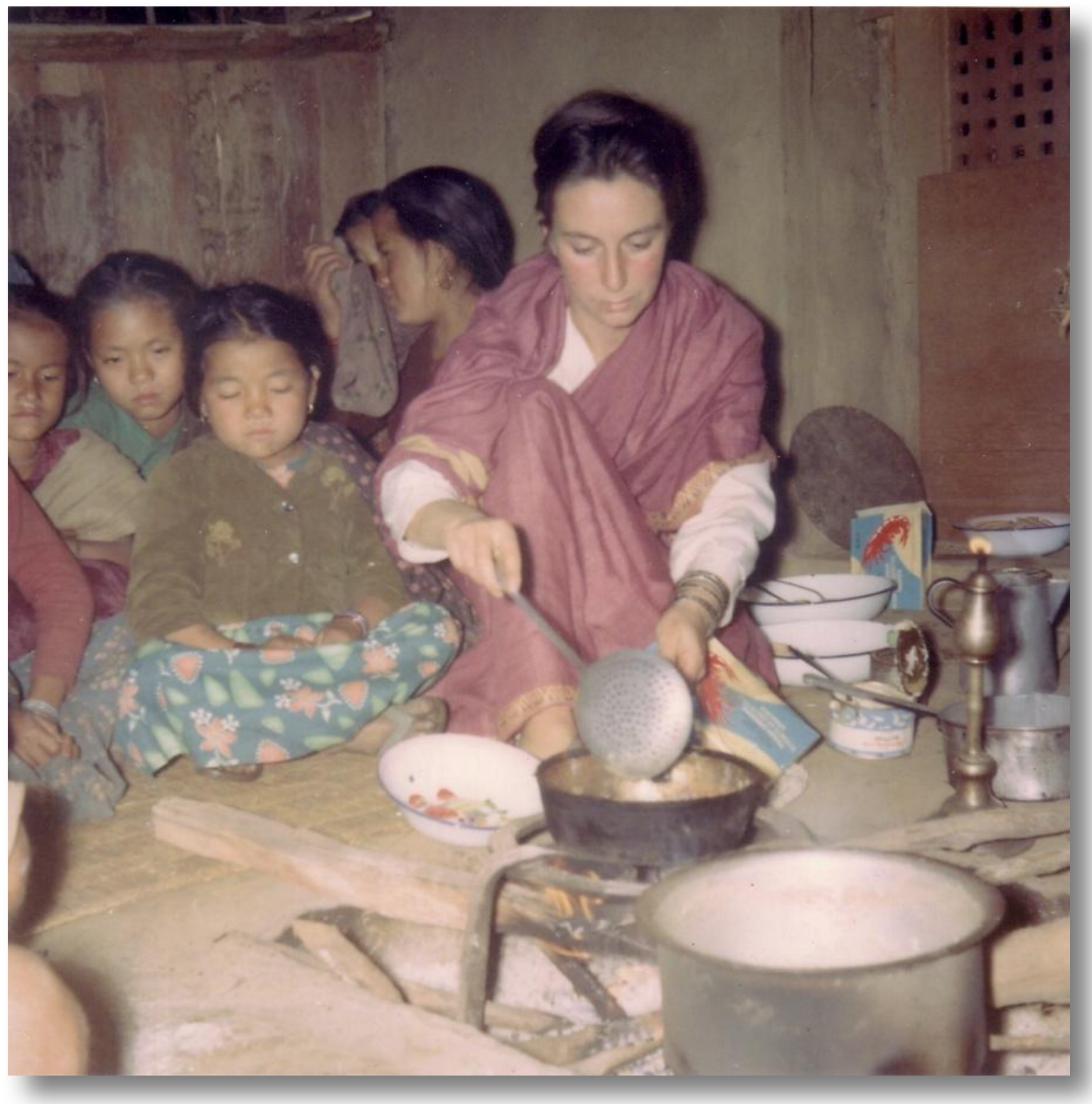

Gill wearing a sari and cooking on 29th January 1970 


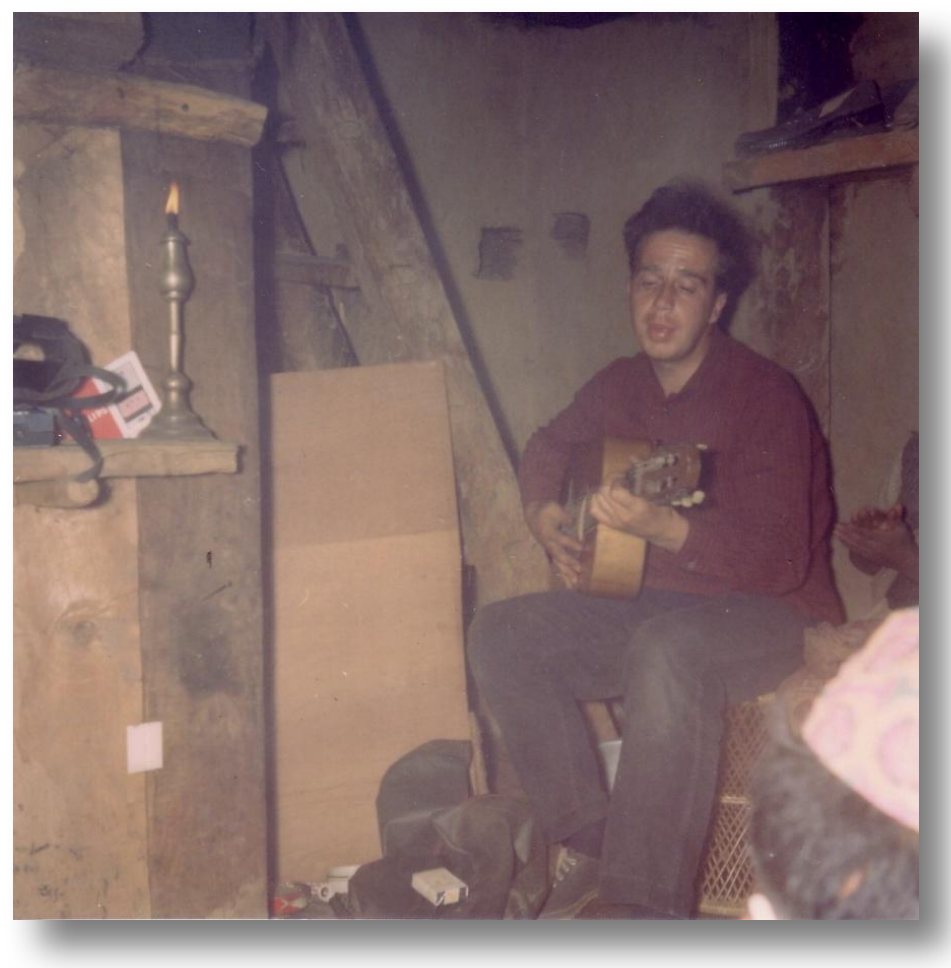

Alan playing guitar in the house - 29th January 1970

\section{Alan and Gill leaving Thak on 30th January 1970}

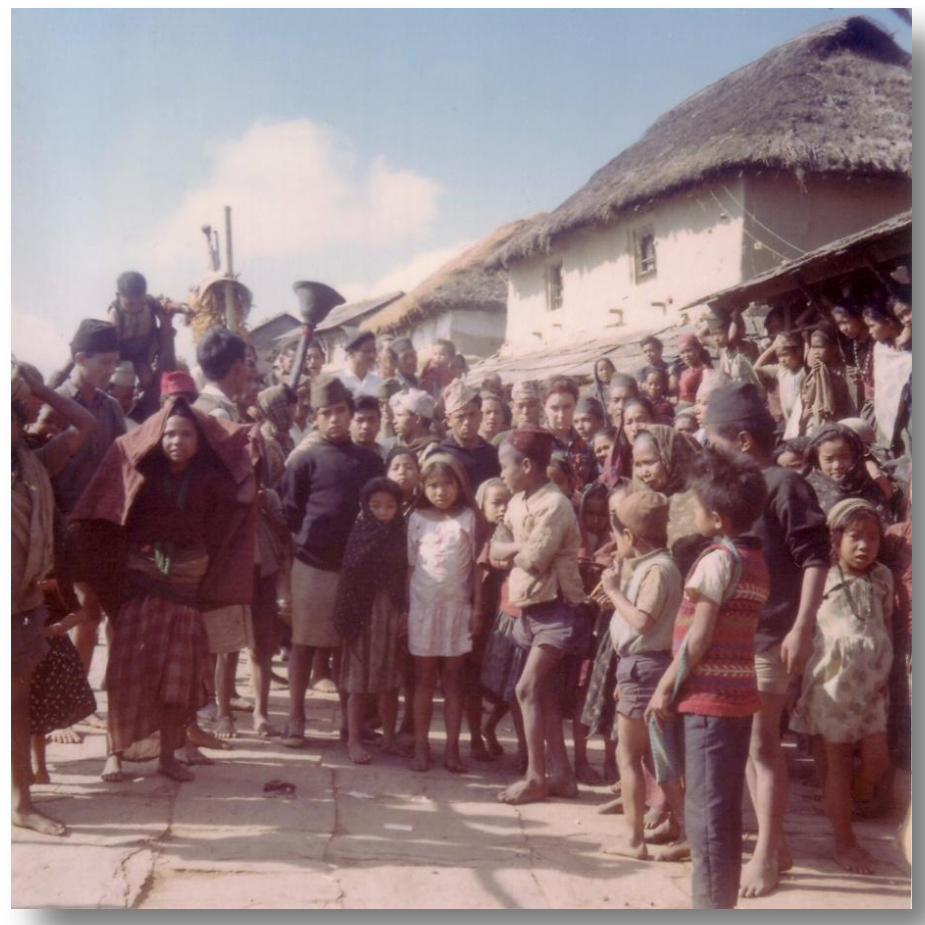



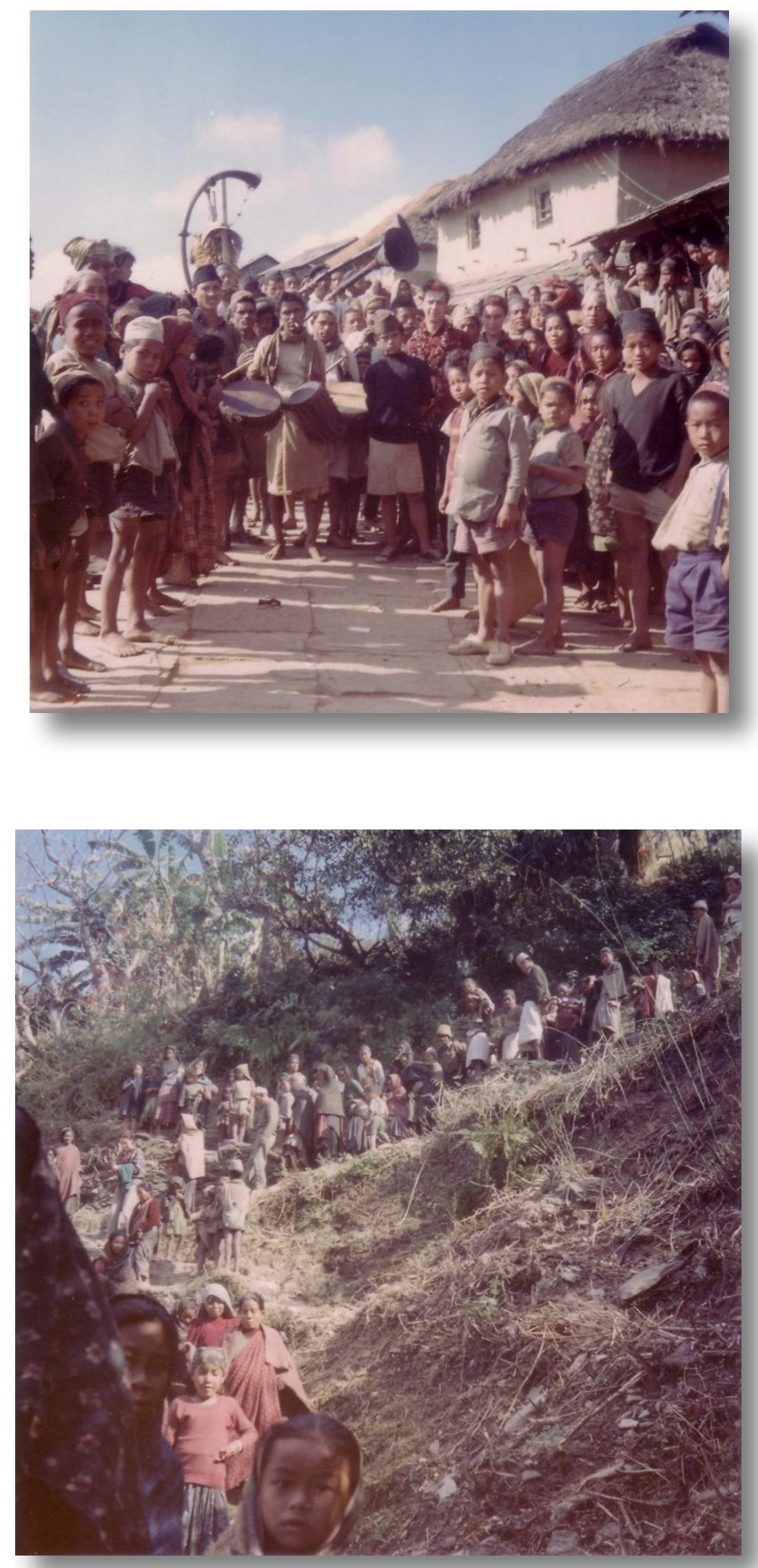


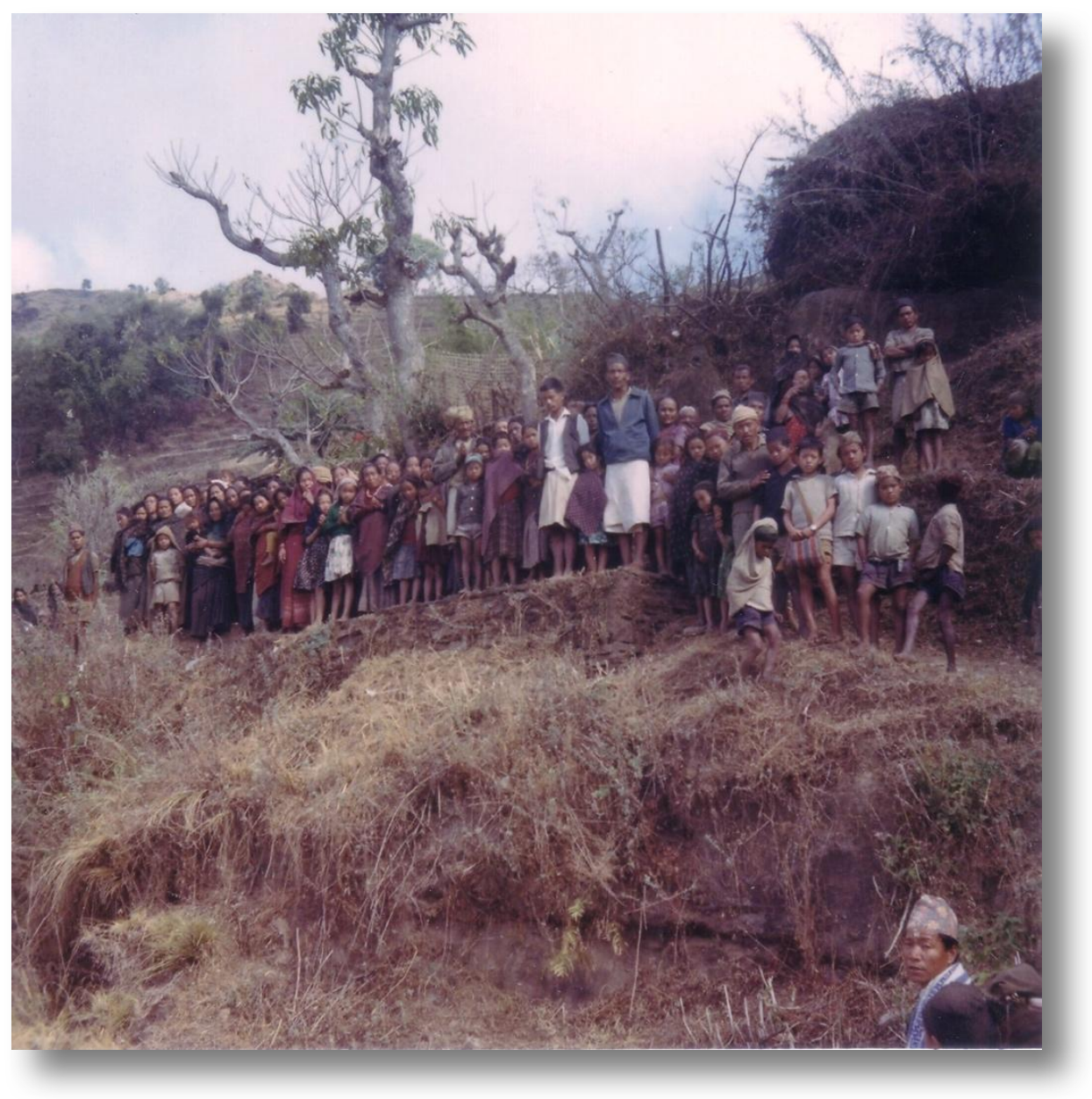

\section{Letter from Gill on 30 January 1970}

...only two days to go before we leave the village! I am just fitting this letter in whilst Alan is out with the doctor from the Mission Hospital at Pokhara, doing a last minute medical survey. The doctor is staying two nights, extremely calm, ironic and nice, a Scot from Edinburgh who has been in Nepal for 15 years and is the sort of person who soothes you out for hours afterwards, even though you have just had a five minute chat with him. He has been extremely affable about the dubious living conditions here, bearing the rats scrabbling round his head at night, and remaining unastonished when I clean out our Chinese washing bowl with lavender leaves and wash the pans with wood-ash - a Gurung habit! We are delighted he has come as our present to the village is a mini dispensary kit, a restocking of medicines we have been asked for in the last year, and he has been able to explain dosage, symptoms etc. to the man we have asked to take over. This morning we got up at six and went up the hill behind the village to see the mountains - a beautiful, flawless blue morning, the air shimmering with light and Annapurna in a haze of brightness, quite lovely and one of the nice things we shall take away with us. Then back to the innumerable goitres, dysenterys and TB's, the poor doctor, hardly a break from the hospital!

We have also been filming a lot, having bought a cine camera in Kathmandu. The last time we filmed was when the local magician was going one of his rites. An old man was being made sick by one of his dead ancestors, and a goat an chicken sacrifice had to be made to appease the dead ones, as well as a witch who also had her hand in it somewhere. We went down the hill about 7am, a morning full of green and yellows... and came to the house where the daughters were spinning, and drying cane for basket weaving, and sweeping out the courtyard with those Cinderella brooms which I would like to take home. A magical pattern was sprinkled in the house with freshly ground rice flour, and the fire tripod put over this with a freshly cleaned copper pan on 
that which had unhusked rice, flowers and butter lamps inside. Then a nutmeg coloured goat was brought in and when it had sniffed at all the things in turn, then was the time to go outside and sacrifice, as the touching was a sign that the ancestor was pleased. Then we all trekked down to a little glade where they fetched their water and the poor animal was killed and put on a tiny altar made of stones and tied with cotton ribbons and I clicked away as the magician leant over it with his brass bowls and lavender sprigs, and incantations. Then in true Gurung fashion, scared was forgotten for profane and we all tucked into a picnic cooked over a fire on the spot, even we enjoying the goat's liver and steaming rice.

Tonight we have been invited to dinner by our favourite family who have been most kind and mothered us throughout. I shall struggle into the windings of my sari...

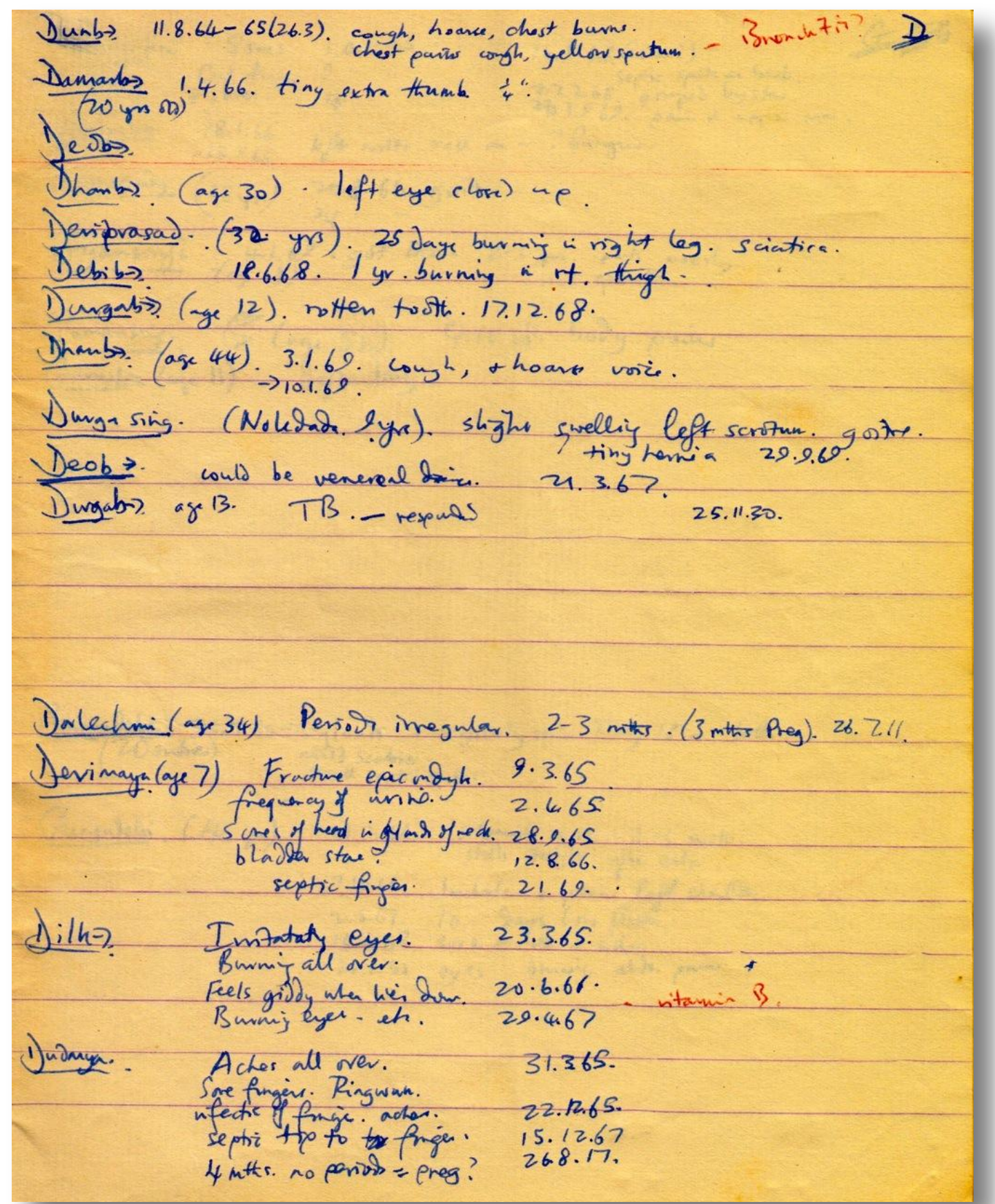

Part of the medical survey with Dr Turner 


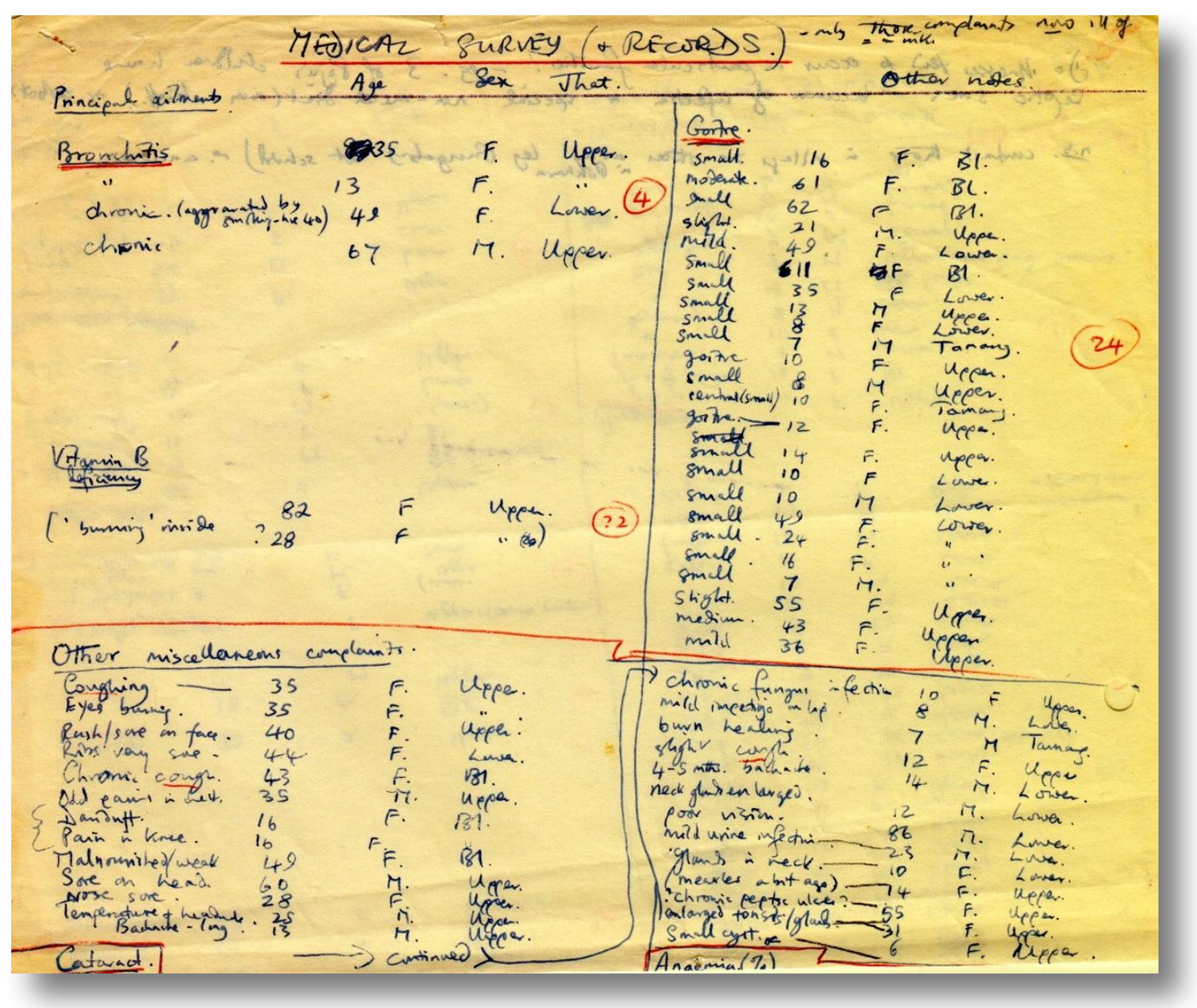

Summary and analysis of medical survey 


\title{
FEBRUARY 1970
}

\author{
Undated views
}

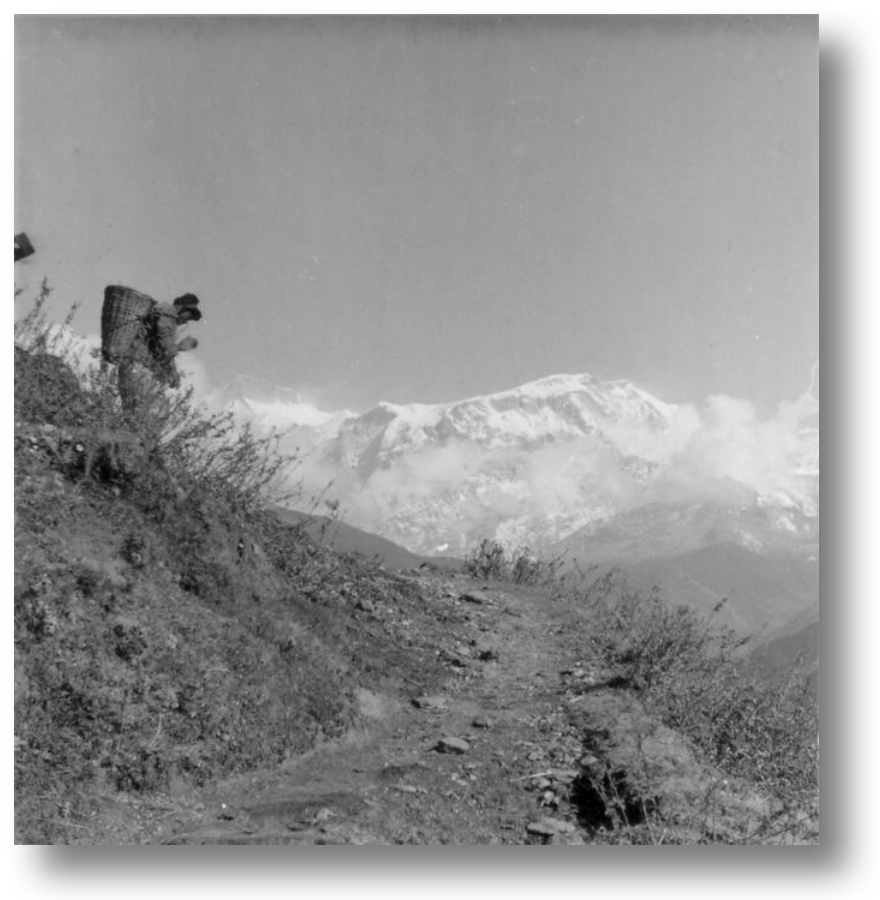

Path to Taprang with snow-covered mountains beyond

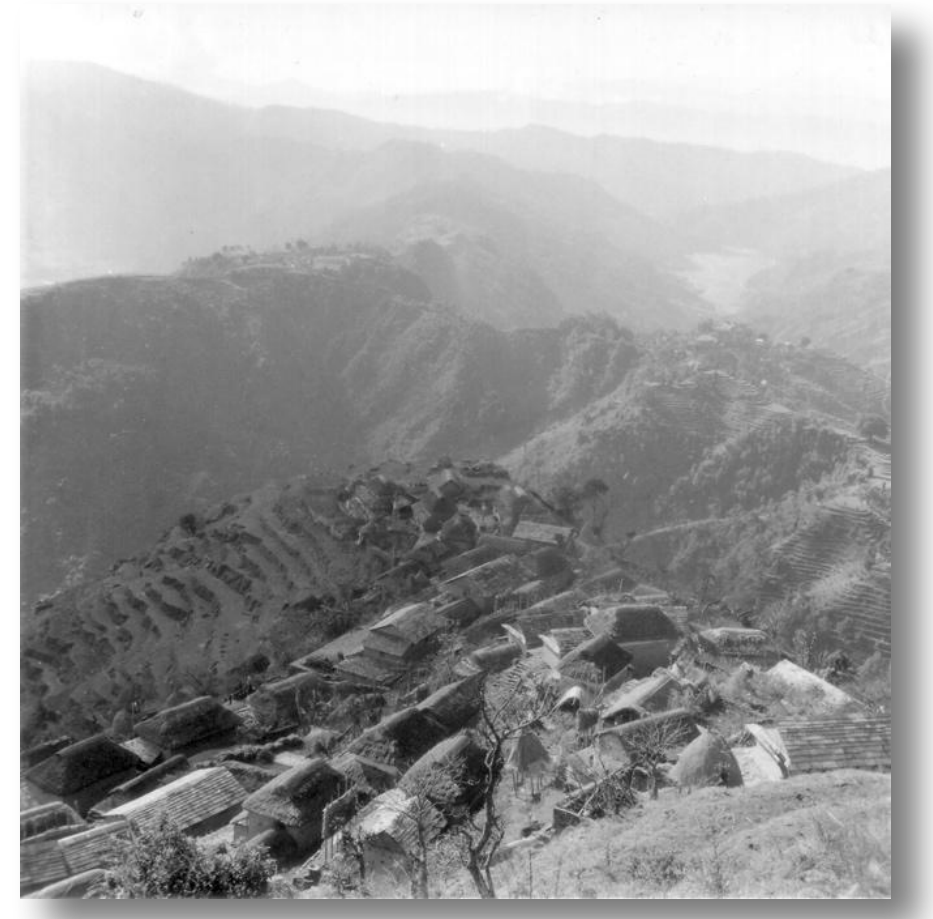

Village seen from above with the Pokhara valley beyond 


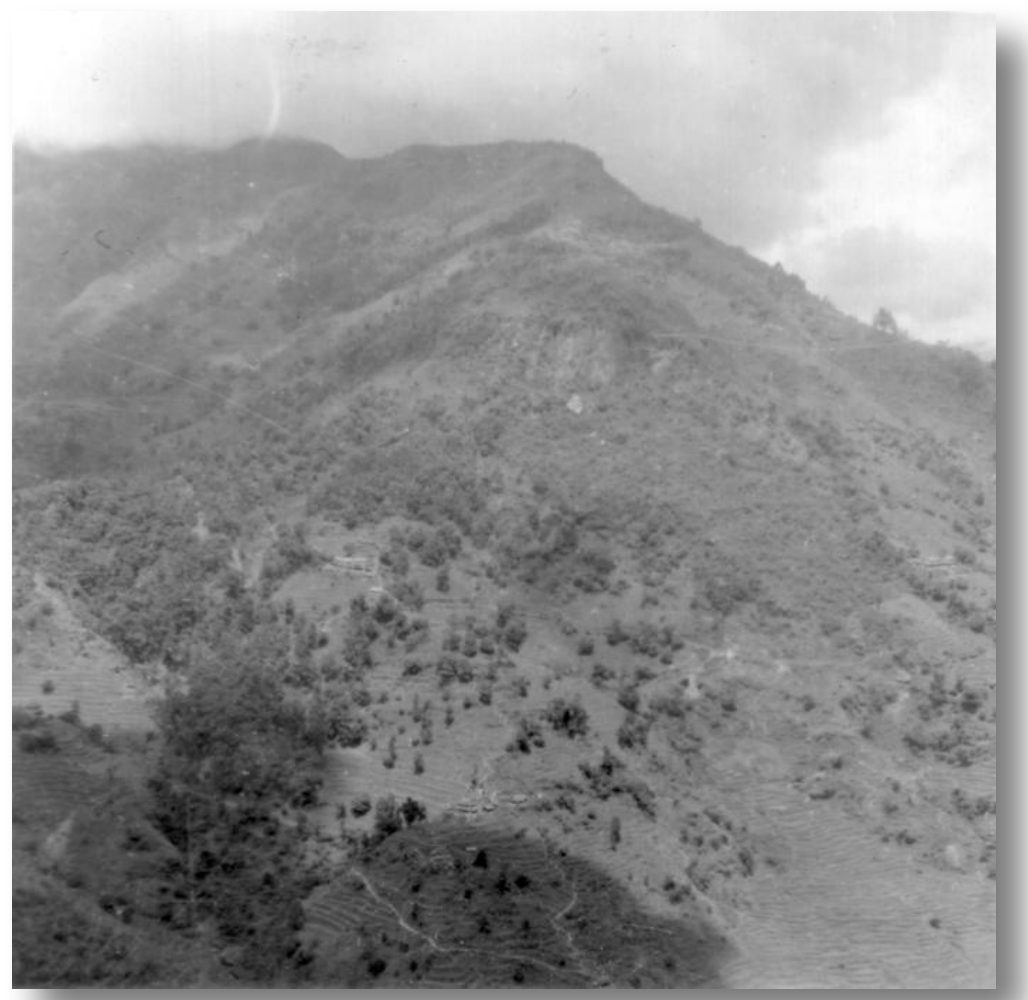

Hillside where Thak lies - near the summit of the ridge

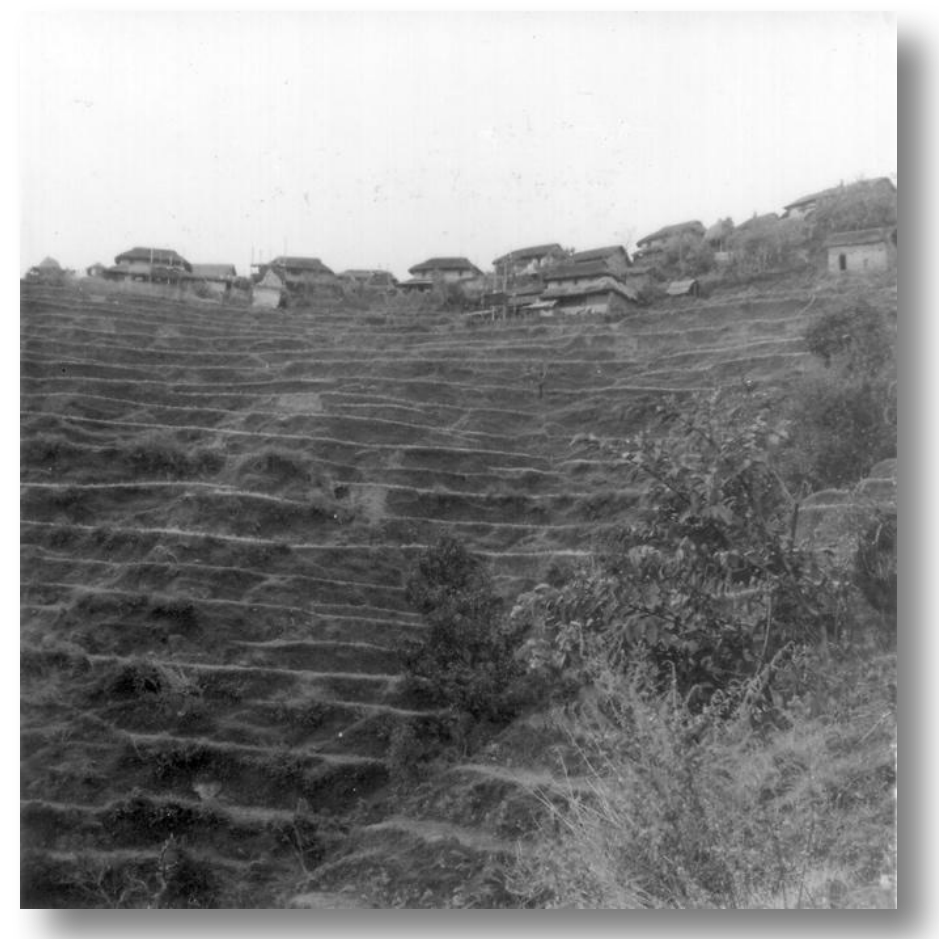

Looking up to the village from fields below 


\section{Letter from Alan to parents on 2nd February 1970}

Just a hurried letter before we set off. What magical words! In fact am writing it a few days before we leave the village, but the doctor may be coming in a couple of days and then there will be the confusion of good-byes and packing. When you receive this we will, I hope, be visiting Cherideo! ... Have finally finished all last-minute chores; a huge map of the village fields completed, the magician's rituals all transcribed, and a great sense of relief. If the doctor comes we'll do a last-minute medical survey and then it is all finished. Went for a walk along our favourite flat path yesterday, and the mountains were golden flushed with huge pink clouds whipped off the snow. Felt increasingly sad, but we are really too busy - taking last-minute snaps, dispensing to a sudden rush of patients wanting medicine, birth control, and the occasional tin or pan, packing - to think too much.

It has been a fantastic year, the hardest in our lives, and particularly difficult for Gill with almost constant small sicknesses, but I'm glad we did it and we certainly could not have chosen a more beautiful people or place. They protest that they will miss us and feel lonely and I think the feeling will be mutual once the excitement of returning has worn off. We have to promise to return one day and perversely I am already looking forward to that, though I think it may be a sad experience as the hills will be stripped of forest, less people recruited into the army, and the present joyful and relatively plentifully-supplied life will be fast disappearing before growing poverty. Awful to see the vision and not be able to do anything about it. continuation on 4.2.1970

...Please forgive just a short note answering your points but we are just unwinding after our chaotic retreat from the village and I don't feel up to much beyond reading detective stories. Gill includes a full account here; it was very moving and funny at the same time, but I still feel too involved in it to let my mind go back over the details. Being able to see the mountains behind the village from here in Pokhara makes me very sad - I didn't realize it would be such a wrench. ... Dr Turner's visit to the village a great help and will mae my bit on mortality much better. Longing to see you all in a couple of weeks! Lots and lots of love, Alan

\section{Letter from Gill on 2nd February 1970}

Well, it's over. We are sitting trying to unwind in our 2/6d hotel at the airport [Parbat Hotel], a slight breeze flapping through the banana tree, last year's yellow fringed leaves catching the sun, like a warm, mild English day, and the shaggy Tibetan ram tinkling his bell in the ploughed-up field behind. Alan is forgetting the village in a Simenon thriller (or trying to) and there is a rumble of a plane just landing, enough to give us an anticipatory thrill before we fly off this Thursday. We came down accompanied by Bhuwansing, the Lt. in the British Army whose family has been so kind and sensitive to our needs all through our village stay...

...Dr Turner...the first missionary I have met here who is unobtrusive and sure about Christianity, and just lives the ethic without attempting, verbally, to force it on anybody. Also, he does realize the social upheavals any 'conversion' causes but thinks the means are worth the ends...Alan delighted with the work he and the doctor managed to get through - he came up last Thursday and stayed till late Saturday morning, and they managed to examine 90 people on Friday, as well as organizing the handing over of the medicine to Bhuwansing, who is going to manage the mini 'dispensary' we have given the village, explaining the dosage, symptoms, in beautifully fluent Nepali and arranging for Bhuwansing to go down to the hospital and learn how to give injections. We have left about 250 rs with the hospital as a sort of account so that Bhuwansing can restock up with medicine when he runs out, so Dr Turner's cooperation has been invaluable. Nicely, too, he didn't think the villagers were too desperately ill, all having anaemia, goitre, worms, dysentery, (all things which can be easily obliterated too), but taking these for granted much as we take sanitation, meat, warmth, for granted. He was very good too about out rather dubious living conditions, suffocating without a murmur in the smoke and smiling bravely when we said he had better give the rats his sleeping pill instead of taking it himself.

We had a lovely dinner with the Bhuwansings on his second evening, I wearing my sari and Dr Turner padding around happily in his maroon stockinged feet, soothing Mrs Bhuwansing about her menopause, liking Bhuwansing's reminiscences about Beaconsfield and the course he did there in the army, and coping with my 
prodding about his missionary work all at the same time! I hope it wasn't too exhausting, the poor man had to go down to a hospital crammed to the ceiling, patients lying on the floor, not enough beds.

Up to his coming the time had rather dragged, the Gurungs coping beautifully as usual all in a rush at the end, and Alan getting all the last minute checking and map drawing done early, and even managing to get extra material which he thought was impossible to extract. This was some data from the Lama in Taprang, the next village along the valley, where we combined buying lovely pale green and cream bamboo matting, as carpets are going to be a wild luxury at Dent, with visiting an old priest, who turned out to be most efficient in giving information. It was a lovely war, yellow day, with bursts of sunlight very welcome after days of drizzle and drifting fog. The paths were paved with pink-veined marble, the banks smothered in fresh lavender and jasmine, and the pale green, whiskery barley against the mountains, with orange coloured houses like coral islands in the sea of green was so pretty, an nice picture of the village to take away with us. One Gurung house was especially gorgeous - curly window carvings, the eaves stacked with mongoose skins, two feathered pheasants, a circle of crimson chillies, a clump of millet heads and a bear's paw - lucky spirits to have such precise and quixotic attention!

When the doctor had left on the Saturday we got down to packing (although Alan had been doing this three weeks ago - my large green case already crammed with all out papers, notes, index cards, I can hardly life it and Alan is going to padlock it to his wrist when travelling, a wife lost would be bearable, replaceable, but his notes...') and I scrubbed a year's soot off the pans with wood-ash and generally had an afternoon for doing chores I hate most in the world. We burnt all the rubbish, the children scrabbling about for pieces of paper that crackled, fag ends, cardboard boxes, and a strident gran shouting at us not to set her thatch on fire, raking the ashes about and doing her best to put the village in flames. It was more or less hysterically horrible from then on, a few nice breaks but generally unmitigated hell. Before I had even started preparing supper the room was packed with children and by the time we got the rice on the Gurungs must have been seven flanks deep, I just about managing to wield a serving spoon and spill pea juice on my sari, and Alan backed to the cobwebs under the ladder, coughing and spluttering with a bad cold, voice almost gone having exhausted it with Dr Turner.

Fust before this we had given a few presents and tatty Chinese bowls out, had tea and honey sweets with the Pradhan Panch's wife, and milk and ' $p a^{\prime}$ with Mrs Bhwwansing. The eldest daughter next door had been thrilled with some red felt slippers I had brought from Kathmandu and never worn, and the little girl, whom Alan had always called his little wife, as opposed to me who was the first one, was inarticulate with thrills when I gave her a 4/6d dress I had bought in the bazaar and embroidered and put pearl buttons on. Also giving marbles and biros to the little boys was nice, and your biscuit tin with the crinolined lady in a English garden went to a very poor family with whom we did an inventory, filled with cottons and wools and needles, the wife having asked me for one needle as a great favour at the beginning of our stay. It is the only time I have enjoyed feeling Lady of the Manorish, a female Father Xmas in Gurungland, what pathetic things we gave considering how much they need in reality. Quite a few clothes also went, which was more sensible, so Alan not has one shirt and we both have a pair of jeans apiece, three pairs exhausted with darns at the knees but the tailors will we able to adapt them. (cont.)

In the midst of my burning Chinese Prawn Crackers in pitch black, smoking butter for everyone to eat as a 'treat', there was a smothered squeak from a squashed infant near the door saying another white person had just come. My warm, open-hearted welcome was 'Oh Christ' to Alan, and in struggled a six foot two, blond, blueeyed gorgeous American, a Peace Corps boy we had met by chance the evening before, going up the valley to buy blankets. We had murmured he could stay the night on the way down, if he didn't mind an hysterical evening, but had been grateful when night had come and he hadn't turned up.

All we had left of the food was some cold, grey rice and the one tin remaining was the Chinese pilchards which had given me violent food poisoning, but Alan had eaten, unharmed. I had meant to complete the gracious hostess line by saying, would he like this and risk being sick, or have just rice with charred prawn crackers - by this time smoke was engulfing all and the schoolmaster was making an even worse mess than I of the crackers, so he ate them innocently and was told at midnight, when we had finished the evening's jollities that I would nurse him if he began to vomit, but, thank heavens, he wasn't ill. After distributing biscuits and raisins and sweeties, the children screeching and the grown-ups howling them down, ... 
Alan got the guitar, and I swept out the light by getting up and turning round in my sari, two glasses of warm buffalo milk were put in my hands at the same time, a present from Kumansing - black chaos, Alan starting on 'Fohn Henry', Prem on the tin opener and plastic sugar container, Gopal on the tongs and Ombahadur on the stick and empty pea can. The singing was actually fun, our last and final 'Pick a bale of cotton' being uproariously successful, everyone, at least 40 people, clapping faster and faster, breaking their sticks with excitement, and Peter, the American, forgetting how awful the meal tasted, hands pounding wildly but at least three beats behind the children, all collapsing into shouts of laughter at the end. We then had a dance to go to, held in our honour in the schoolhouse next door, and firm competition between the Untouchables, who were very slick and professional, and the Gurungs who were totally disorganized and poor.

We managed to split our time between them and had nearly three hours of vigorous clapping, singing and rattling of tongs with bells, and thudding of drums - sitting so near that the girls' saris tickled my feet every time they advanced and I had to wait until the drums stopped thumping to talk to Peter who was loving it, having walked for nearly ten hours that day, bought five very heavy blankets and got up before dawn in the morning. We got to bed about midnight, heads splitting but the Gurungs very gay and singing love songs on the path behind well after the dancing was over. (cont.)

Sunday...the things that weren't given away as presents were sold by Bhuwansing as the auctioneer. At 6am the Untouchable women came to ask for their coverlets, promised them earlier, mothers who hadn't been given anything came to ask why, my most unfavourite Gran next door screeched in saying Alan must give everything to her, she wasn't satisfied with buckets, tongs, cooking tripods, hand cream, shoes. Bhwwansing descended and whipped off everything in sight remaining, which meant I had to crawl between the legs of the Gurungs crushed together for the sale and retrieve jeans, knives, clothes brush and spoon for latecomers promised presents.

Meanwhile our umbrellas were being unfurled, spokes flying at right angles, holes letting the sunlight through, going at 1000rs, anyone buy, down to Omkumari for 1.5rs...then the poju and Totra's father strode through the door at the same time, after the same water bottle. Alan hides it under the ladder, propitiates the latter with a flower strewn Chinese bowl, slips the bottle to the poju, his favourite, who trots out gleefully, an arch enemy of Totra's father, water bottle tucked in a blanket, to put his millet beer loot in after he has done a rite. An Untouchable woman already given a cloth, flour, a sweater and a blouse, wants a bottle. I say they are very greedy people in this village, and she is very naughty. Unabashed she goes on looking hopefully. Finally, a trembling, deaf old gran from up the hill, just hearing loot was being distributed, three hours late, totters through the door. Her cracked old hands held out in a bewildered, asking gesture. I can't bear it. I rush back to the auction, a limp blue overall with buttons dangling from Bhuwansing's hand, no offers, much despised. I crawl again through the field of legs, grab a white, chipped enamel plate, double back and hand the thing to Maldosing's old mother. A toothy grin and little twinkle and she is ten year's younger. A fact that couldn't be said of me.

We finally are destitute. Nothing in the house but sweet papers, mud dust and a potato under the bed. I sweep out, the boys helping me move the bed, a foot falling off with a wooden crash, I tripping over half a millstone. The bed hasn't been moved since the house was built. The poju reappears. He has come to do our final rite, holding a very special jantra, a one inch square of paper, a magic spell folded over and coloured threads holding it together, woven in a pattern which gives extra special protection. We stagger upstairs, layers thick in Blacks of Greenock feathers, rice husks and rat dirt. Alan and I sit on a rice mat which Granny would expire over, my hairs woven in it with the rice stalks by this time. The poju sits on another hairy affair, crosslegged, facing us. He has forgotten to bring some rice. We have just given our last away to a greedy Untouchable. Would sugar do? Being the artist he is, the poju isn't happy with this. Would we go and ask Gran next door for a pinch of rice. We explain in polite Gurung what a bitch she is and we are angry with each other at the moment. A little touchy as the poju is her brother. But, being the tactful social worker he is, he grasps the emotions immediately. Not difficult as I splutter with fury every time I think of her. Yes, sugar will do. Alan fetches the plastic bowl and the poju starts his incantations, laying on of hands, rattling of beads, signs of the cross with the rosary, touching first the head, then the right shoulder, then the left. It is wonderfully soothing and I go into a thankful half trance, rice (sugar) being flicked at my face a little disturbing and the poju's accurate spit tickling my eyelids, but otherwise calming, and much more, than any Battie in any Anglican cathedral. Suddenly, having finished with Alan, he hauls out a large spoon with a pale green handle. I sleepily 
note it as late, ours. 'Got this for 1.5rs', he says and he tucks it back with a grin into his pocket. He picks up his beads and gives us a final blessing, Alan pays out 5rs and we are safe for a month and a journey. (cont.)

There is still a crowd of Untouchables naturally asking for more, but we lock the door and make our final escape to the loo and the mountains, kindly brilliant against a sweep of pale blue sky. Two grans walk quietly up behind us twitching at their buffaloes and huhuhing them peacefully them peacefully up the hill. They rest tactfully below us and I hear them saying that we must be sad, saying goodbye to the mountains. When we finally go down they approve of our jantras, saying we must wear them inside our shirts as this is all a very private thing, and how much did we fork out? Then, instead of going on up to the forest they come down with us and when we come back to the house again there are five or six Tailors wheezing and popping away on their rusty horns and pipes, and half the village chatting quietly, the sale over.

We go down to the Bhuwansings taking back the stuff they had lent us during our stay, and walk into the house to find Bhuwansing plopping tears into his rice and Mrs B. subdued under her head-cloth, with a silver tray and glasses of warmed, sugared just milked buffalo milk in front of her. To our agony they come forward with red garlands and rice and milk to make a tika, and finally Mrs B. is overcome and starts sobbing on my shoulder saying I must think of her as another mother, and she has lost one daughter and now another.

Dankumari (the eldest who ran away before, came back, father paying out the divorce money) had run away again a few days ago and they were quite desolate this time, not angry, not even knowing whether she was in the man's village, or fled to India. Mrs B. made me terribly upset too and we both sat there in a pool of milk and tears, Alan swallowing hard and me too tired to restrain myself much. There were little eyes looking through the squares of the wooden window too, the kids crowding onto the verandah and reporting favourably that I was sobbing, alright as long as it is done inside and there are other people crying too. We finally staggered out, Alan looking like a dry herbaceous border with red leaves behind his ears and red powder in his hair, and me looking like a shrub just watered, clutching Mrs B.'s hand and saying I knew Dankumari would come back, and not to fret.

The Tailors had been thudding and piping throughout and the member for the Pokhara committee took a photo, the final honour, and we trudged off through the village paths, lined with sad, gentle little Gurungs, tapping us on the arm and saying we much travel carefully and never forget them. It was all so sad and blurred and wistful and I felt such a fraud longing to get out for 15 months and then feeling upset on out last walk through. The whole village seemed to see us off from the last little hill and Bhuwansing came down to Pokhara with us, checking on whether Dankumari's name was down on the airport ticket list and going to the hospital to learn how to give injections. He wouldn't have a meal with us in the evening as it would make him too sad, and at the end his kind little rabbit face was all warm and jolly, and then it suddenly crumpled up as if all the lettuce in the world had gone, and he turned round crying and lolloped off round the corner, a kind droopy little figure, a bunny amongst the other village foxes.

Fortunately your letter made us feel better that evening but I have had to type all this to get it off my chest, and Alan is still in paperbacks and can't write a thing. I think we are both worn out for one thing and Alan still has his cold and I a nose infection, but we are buying presents and are going to give the Bhuwansings your Country Life calendar as a present, and both looking forward to Assam, and will write from there... 


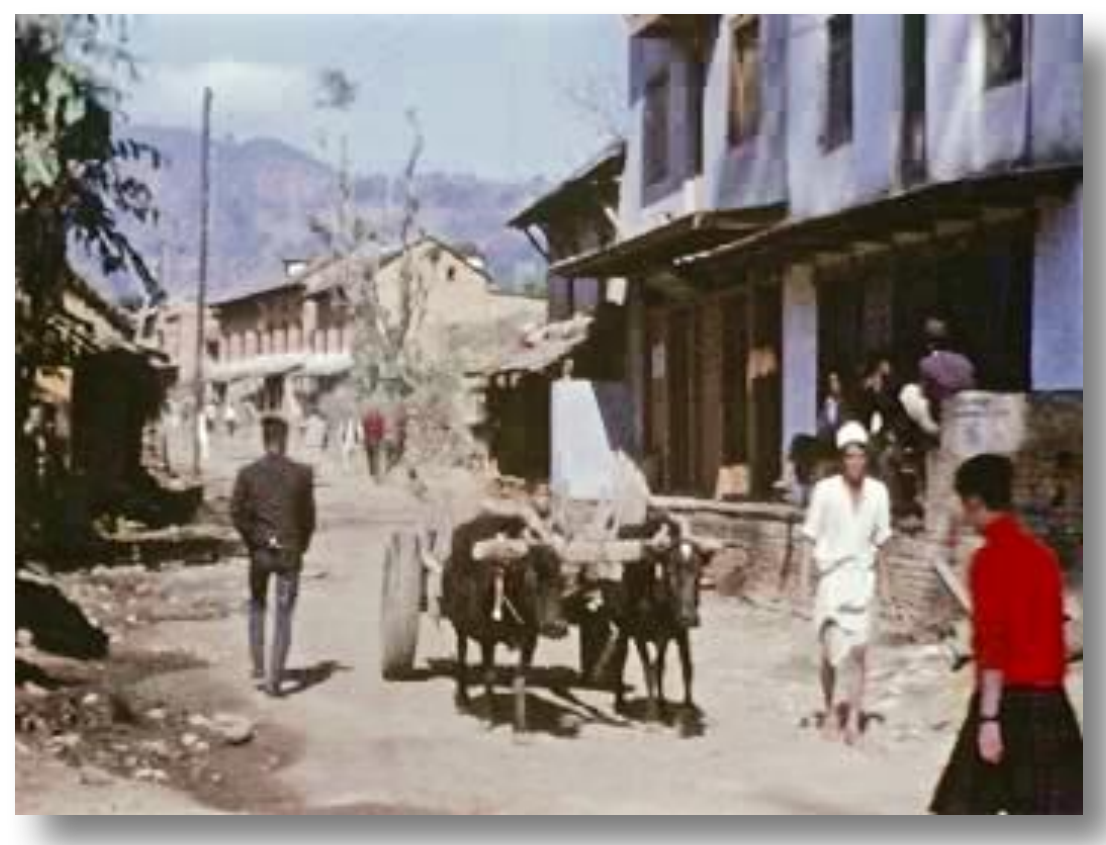

FILM. Gill walking through Pokhara street Bullock cart. Shrine at Sital Debi? https://sms.cam.ac.uk/media/2739706

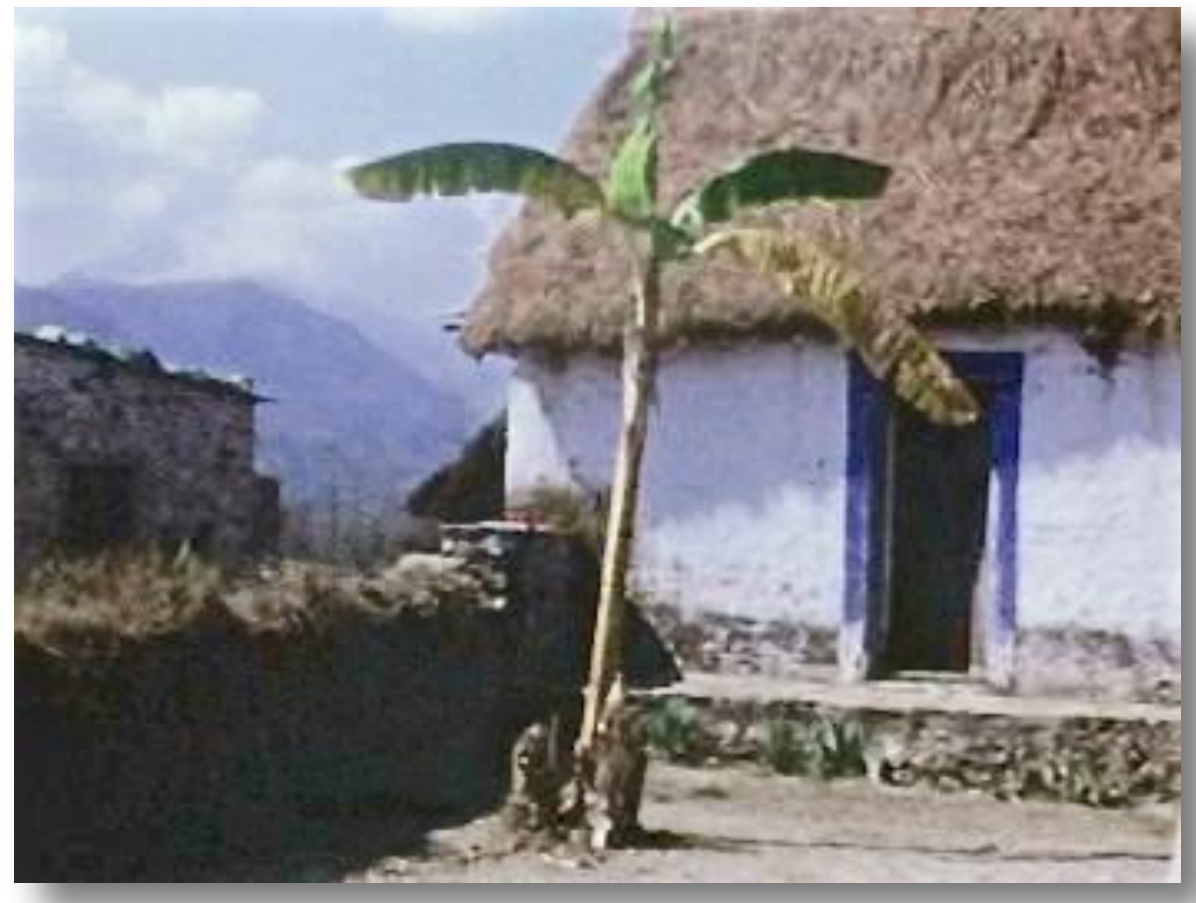

FILM. Single storey building with a palm tree growing outside https://sms.cam.ac.uk/media/2739713 


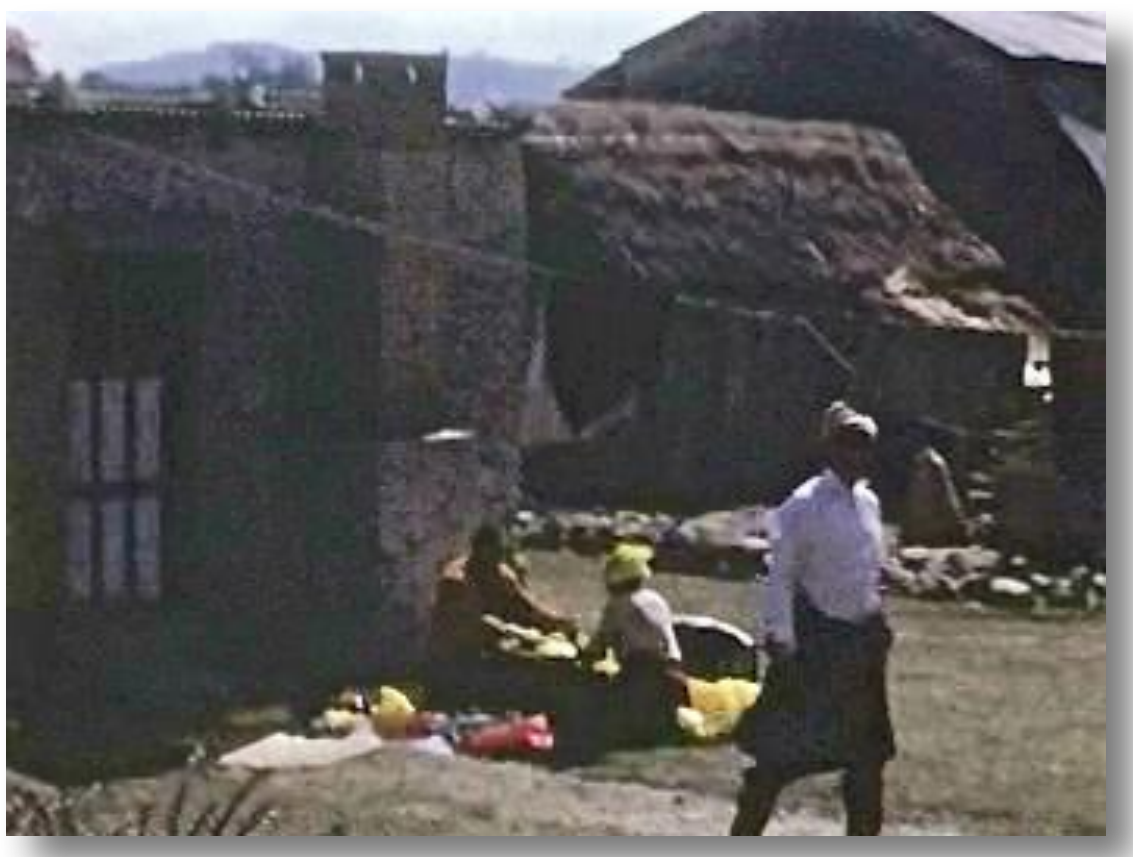

FILM. Tibetans smoothing out yellow cloth - Pokhara https://sms.cam.ac.uk/media/2739769

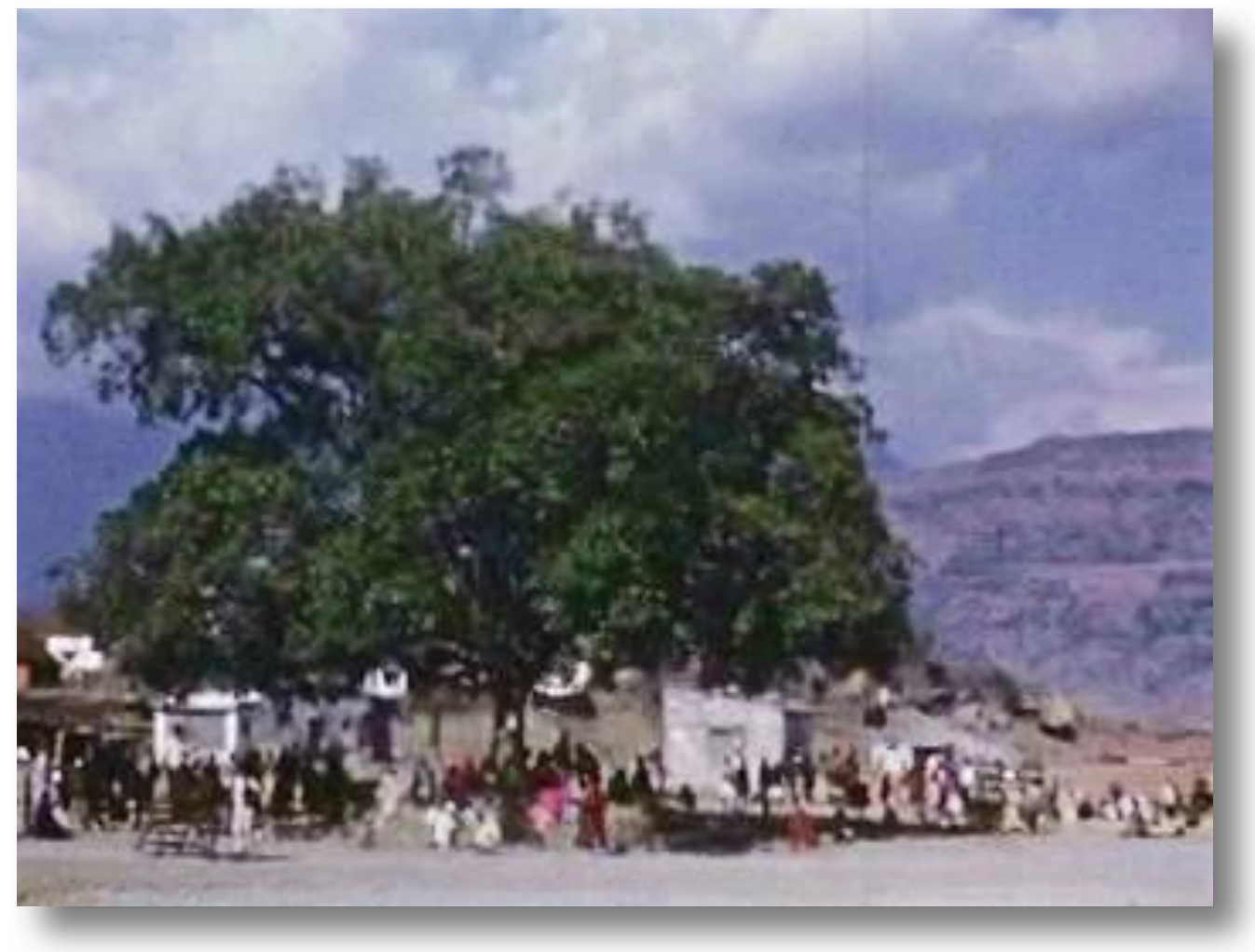

FILM. Pokhara airport

https://sms.cam.ac.uk/media/2739797 


\section{Return from the field}

The return after intense immersive fieldwork in a very different world is often very difficult. A combination of culture shock, weather, economic and career uncertainty makes it a period of mixed delight at being home and with family and friends, and anxiety and dislocation. I will not write about these feelings, but they need to be mentioned.

We returned to England in February 1970, travelling back by way of Assam. We visited Shillong, where I had been born, and a tea garden in the valley.

We spent the next 20 months living in a small house which my parents had bought in the Yorkshire village of Dent, near Sedbergh school where I had spent most of my time as a boarding student between 1955-1960. I adapted the upper bedroom into a study with a large desk and filing cases and bookshelves and spent every day slogging away at writing the draft after draft for submission as a Ph.D. thesis.

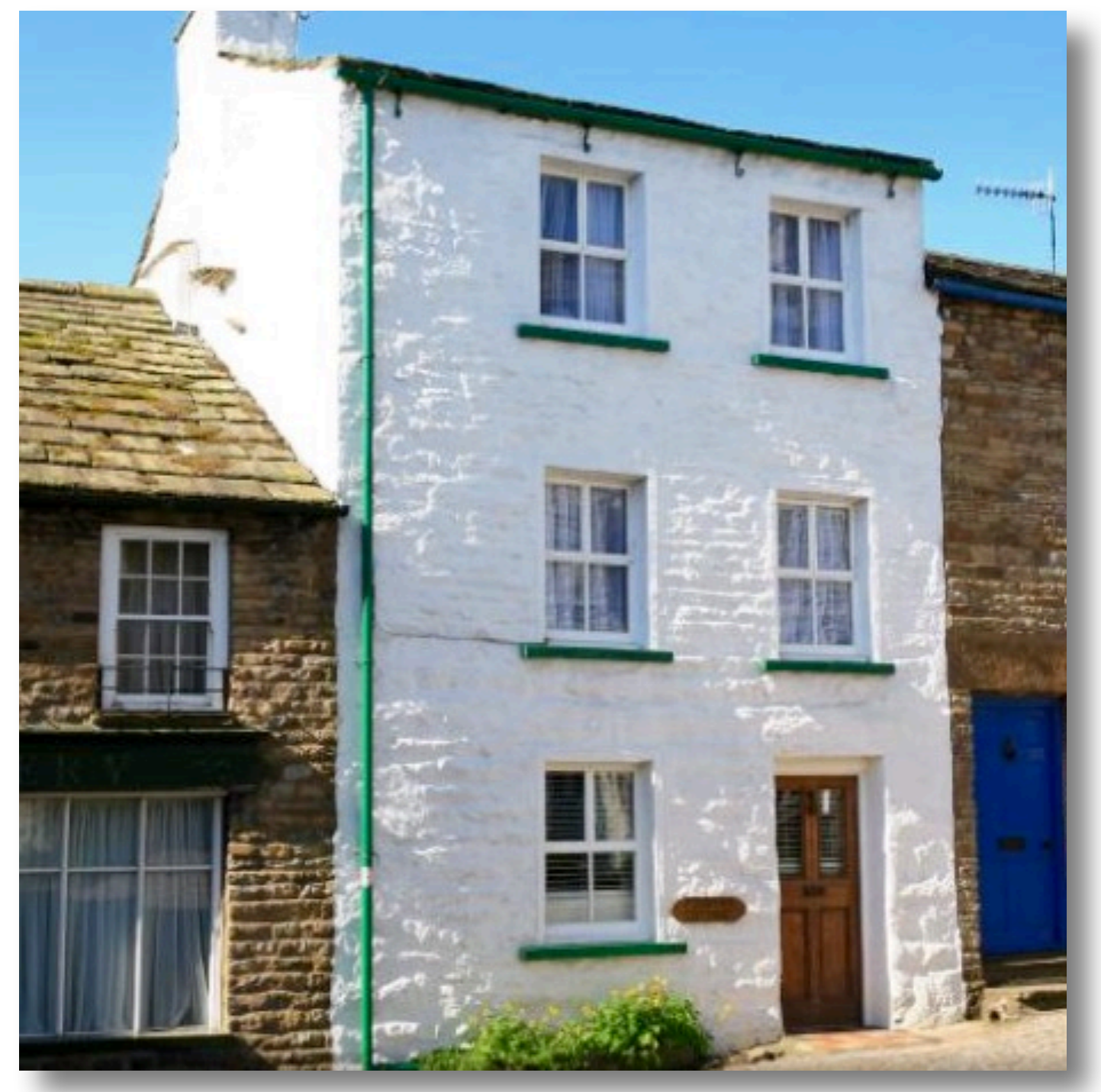

Fountain Cottage, where I wrote my Ph.D. 
Even though I had previously written and submitted a successful doctorate in history, as described in the previous visit, I did not find this at all easy. This was partly because of the mass of data, partly because we were fairly short of money, partly because I was ill for a while, partly because I was worrying about what I would do at the end of the period, when my small grant from the School of Oriental and African Studies ran out.

Yet with huge support from Gill, from my parents and from various academic colleagues, including my supervisor Haimendorf, by the time we left the cottage in September 1971 to take up a Senior Research Fellowship in history at King's College Cambridge, I had finished a fairly full draft of the thesis.

I continued in Cambridge to revise it and was examined and awarded my Ph.D. for a thesis on 'Population and Resources in central Nepal' in 1972. I then turned it into the book which was published by Cambridge University Press in 1976 as Resources and Population; A study of the Gurungs of Central Nepal. Those who would like to see how the raw data is turned into a book can look at that monograph and a few essays listed at the end of this volume.

Meanwhile, rather than giving a journal of those months, which would turn out to be rather uneventful on the surface and somewhat boring, I will include a piece written many years later which reflects on the nature of writing up, its problems and peculiarities. Much of $\mathrm{i}$ is based on that first anthropology Ph.D.

One of the most difficult yet important areas to consider is the process of turning the memories from our experiences and the notes from our recording of what we have seen, heard and read, into a new synthesis. Most of this happens at a level which we cannot easily observe. All I can do here is to describe a little of what I think happens, with particular reference to my experience of fieldwork in other societies, and to lay out before the reader a little of the magical moment when we turn our experience into a communication with others, through writing or other forms of art.

\section{The ordering of confusion}

In some ways, the most difficult 'fieldwork', certainly in anthropology and the social sciences, and to a considerable extent also for the historian, occurs in one's study when one 'returns' from collecting the primary materials, as Evans-Pritchard explains.

'I have had much, too much, field-experience, and I have long ago discovered that the decisive battle is not fought in the field but in the study afterwards. Anyone who is not a complete idiot can do fieldwork, and if the people he is working among have not been studied before he cannot help making an original contribution to knowledge. But will it be to theoretical, or just to factual, knowledge? Anyone can produce a new fact; the thing is to produce a new idea.' ${ }^{1}$

What Evans-Pritchard is alluding to is the creative re-ordering and reconstruction of the experience. Manuals on method and autobiographies by social scientists seldom pay much, if any, attention to this stage, yet it is often as long and, in some ways, intense and arduous as the actual physical fieldwork.

The reason it is ignored, I suppose, is because it all occurs in the mind and there is not much dramatic external activity. From the outside, all that can be seen is someone at a desk, or in an easy chair, sorting out bits of paper, or scribbling, or typing. They are staring

\footnotetext{
${ }^{1}$ Evans-Pritchard, E.E., 'Some Reminiscences and Reflections on fieldwork', Fournal of the Anthropological Society of Oxford (1973), 4: p.3
} 
vacantly, or going for walks, or chatting to others. All of the complex activity, the reliving of the interviews, the re-experiencing and ordering of the many sensations, happens in the brain and imagination. So it is not only impossible to observe, but also difficult to write about.

\section{Assembling the jigsaw}

The data for academic work, whether that of the historian or anthropologist, comes to us in bundles, a whole interview, text, film, census or diary entry - but when constructing the thesis or book, different parts of the bundle need to go in different parts of the final work.

The material also comes in a higgledy-piggledy fashion, different sources bearing on the same subject, bits of relevant material popping up at different parts of the fieldwork. Organising it properly is essential.

It is also the case that much of what we gather is only very partially understood at the time of recording and observing. This is partly because we know very little at the start, as well as having linguistic problems; but also because, in an interwoven social community, it is only when the context is understood and the bits linked together, that it will make any sense.

In a way, when I returned from fieldwork in the Himalayas I found myself with a huge jigsaw puzzle, one with hundreds of thousands of pieces jumbled up in my folders and files. There were many thousands of sense impressions, snippets of memory, bits of paper. The information was randomly stowed away in my mind, field notes and visual recordings. Nor did I have more than a faint suspicion of what the final picture represented by the parts might look like. I started out more or less blind but with a few hunches.

The first thing, as with a jigsaw, was to start to arrange the pieces. With a jigsaw, you first get the edges in one place, then group certain striking colours or obviously identifiable things into other piles. There is a good deal of work to be done on the frame and the separations into likely subparts before you begin.

It is the same when you arrive back from the field. You spend some months 'sorting out the field notes'. This often consists of 'indexing' them in some way. For example, you might make a name index so that you can find everything about a person, or in putting colour stickers or other marks on long texts so that you can easily see when there is material about certain sub-themes, rituals, economics, social relations.

There are stories told of how Malinowski's students were encouraged to take out different coloured pencils to the field so that as the 'facts' arrived they could be written down or underlined in different colours. This seems to me part of the process, and shows that the indexing can and perhaps should start in the field.

Yet it is also based on a rather strange idea, namely that you will know at that point - or ever - what is strictly economic, social or religious. The very nature of a holistic community is that most things, as Malinowski well knew, are simultaneously economic, social, religious and political.

\section{Filing and indexing}

When in 1970 I was writing up my first fieldwork among the Gurungs in central Nepal there was no way I could use a computer for text searching. All the materials were on paper, in photographs, or in my mind, and it was tedious to search for things or to group them together for a piece of writing. It was all a matter of shuffling cards, indexing, starting to create mental and actual maps and diagrams.

The ultimate aim of all this work was that when I started to write the thesis, I would not have to search through heaps of notes to find the half-remembered or half-forgotten information. 
The methods I adopted were aided by my previous experience and my love of filing systems. They worked for me, even if there was a huge effort. I managed, on the whole, to avoid a danger which has affected many of my own Ph.D. students returning from the field, namely the turning of weeks into months and months into years as they sort out their material and put off the writing.

This is a serious writing block caused by many factors. There is a protection from the nagging of supervisor or family for a while because you can say you are ordering the material, but simultaneously there is the circular anxiety as you begin to realise the size of the task ahead of you. The more you organise, the larger and more complex the task seems to become.

\section{Turning human lives into paper}

Where should you start? How do you know where you are going? What is the real question and set of hypotheses that should decide which bits of data are relevant and which should be put on one side? These are serious problems.

Added to this, and seldom discussed, is the growing realisation that what you are forced to do, and this applies even more to a thesis than to subsequent books, is to turn the glittering river of a vivid year or more's experience into a dry, stony, river-bed which one or two people only - your examiners and possibly the reader of an abstruse article or two - will walk down one day.

You are engaged in shredding and desiccating, reducing humans and life to jargon and statistics or dry texts, imposing artificial separations required by academic discourse on the lived reality. The seamless gown, the very essence of a non-western world you have experienced, has to be torn apart arbitrarily. You have to abstract and generalise. It is indeed a painful process and quite often students give up in despair or limp on, feeling inadequate and frustrated, year after year. Again, the de-humanising effect of writing is well described by Evans-Pritchard.

'It may be here that I should make a protest about anthropologists' books about peoples. A certain degree of abstraction is of course required, otherwise we would get nowhere, but is it really necessary to just make a book out of human beings? I find the usual account of field-research so boring as often to be unreadable - kinship systems, political systems, ritual systems, every sort of system, structure and function, but little flesh and blood. One seldom gets the impression that the anthropologist felt at one time with the people about whom he writes' ${ }^{2}$

The months of starting to write up were difficult. Above all I found it difficult to be constantly trying to re-imagine myself back into the field as I wrote. In order to go through this second fieldwork, you have to reverse the emphasis. The fieldwork puts participation first, and then there is the observation and a little analysis. In the writing phase, the participation is gone, except in your imagination. You are almost purely observing. And what are you observing? You are looking through a telescope at a receding landscape, struggling to keep the images alive: it is a process captured in a few lines at the end of Keats' 'Ode to a Nightingale' where after 'Opening magic casements on fairy lands forlorn', the poet is summoned back into this world by the word 'Forlorn' and asks, 'Was it a vision, or a waking dream? Fled is that music: - Do I wake or sleep?'

Yet as you start to move through the labyrinth of your mind, you begin suddenly to see where a piece of the jigsaw might fit; begin to see new patterns and connections of which you

${ }^{2}$ Evans-Pritchard, 1973, p. 12 
had not been aware in the field. As I wrote, I began to feel the pleasure of turning disorder into order, of turning confusion into understanding things which had at the time made no sense. So the writing started to gather momentum and I seemed to be making discoveries, finding out new things which no one else had previously noticed. The work turned from a mechanical sorting and establishing of a background, to something more creative and even, occasionally, inspiring. I started to wake up wanting to write and rewrite.

\section{Living in parallel universes}

Part of the strain of the return is thus clearly that I was living a schizophrenic life. I had to re-adapt to what often felt like trivial practical matters, how to pay for my time and the family groceries, how to interact with other people who knew nothing of what I had gone through.

There was also a growing realisation that, even if I obtained my Ph.D., that assured nothing. I needed to start to make a name for myself, give papers, publish, write reviews, network with useful contacts. All this has to be done to make oneself attractive on the job market, but all of it feels like a distraction, an interruption from the real work.

The schizophrenia was because alongside the practical existence of living in the West, you had to keep the fieldwork experience nourished and alive, otherwise the writing-up would fail. It was an effort to do so, but it was in many ways not unlike the effort of any artist - musician, painter, poet, novelist, who lives in a double world.

One difference from more flexible and creative artists who construct their own worlds, though related to life, was that you were not meant to invent anything. Proust or others could reconstruct their memories, or invent new ones. We ethnographers were meant to be objective, 'scientific'. If we did not have the information to back up our statements, we could not make it up. It was a peculiar position, made all the more peculiar for me in anthropology by comparing it to my first doctorate.

When I was writing up my Oxford history D.Phil. in a shed in the Lake District I tried to enter through my imagination the world of seventeenth century witchcraft. Yet I did not feel the same tension and strain. In the history case my mind and imagination lived in two worlds. This was true with anthropology too, but there was the added dimension that in anthropology my heart and emotions were also divided. Every time I planned and wrote about the intense experiences in my Himalayan village, I was there emotionally, as well as intellectually. I went through some of the feelings and thrill of participation.

This was not the case with writing on topics in the early modern period. I never learnt to love or hate (in a personal way) any of my seventeenth century authors. I did not even have a strong image of them. I could not hear their voices or watch their children playing. I never smelt, tasted or struggled physically in their world as I had done in the Himalayas.

When I wrote my second Ph.D. the 'writing-up' was tough in a different way to history, and not helped by the absence of any advice or explanation by any of my teachers or senior colleagues. We did not discuss the writing up process so I struggled alone.

\section{The process of writing}

There are a few very obvious but basic things about sustained creative work habits, I learnt early on; and though I sometimes break the rules, they generally guide me. One is to do with peace and a private space. It is important to have a place or places associated with writing; in my case this involved being in bed for the diary, at the desk for typing up, in an easy chair for original writing. This is why I wrote my first D.Phil. in a garden shed and my fieldwork Gurung Ph.D. in a small attic room in a remote village And it is important that these places are, if possible, separated off from distractions and interruptions - especially difficult 
nowadays with mobile phones and Internet.

Then there is the question of how we write. This is very personal. My earlier writing was mainly on a typewriter. The second draft had to be completely retyped as did every subsequent draft. So I improved a great deal from draft to draft. This filtering has disappeared with word processors, which produce a more or less perfect-looking (and spellchecked) version straight away. This makes it difficult to improve very much from version to version; tinkering seems both unnecessary and a big effort.

Although it slows things down - perhaps its great advantage - I now only go straight to the 'typing into a computer' when I am writing short pieces, reviews or articles, where I already have a strong idea of what I want to say before I sit down to write. More extended pieces I write by hand with a pen. This forces me to retype the text and at that stage it can be expanded or shrunk, the expression improved, new ideas inserted. It is a partial rewriting. It also means that it is easier to insert bits of writing done on a journey or elsewhere, when thoughts come but the laptop computer is not at hand.

There are other advantages. Even with the best of computers there is a danger of losing files. A handwritten version is the securest back-up. Also, perhaps because of my background, although I am a touch typist and can work fast without noticing the computer very much, it is always there. Simultaneously one is writing and being presented with what one has written. One mistypes more often than one miswrites, so there are constant interruptions to go back and get it looking good, correct typos and grammar. This is taking away some of the energy that should be going into creativity. There is usually a hardly audible electronic buzz which is distracting.

I have found from experience that before starting to write it is helpful to have another sheet of paper, or, even better, some small slips, beside me. On these I jot down these intrusive thoughts. Once written down, the thought can be put on one side and dealt with later.

A serious obstacle is the feeling that we cannot proceed unless we do something else first. Often this is clearly just an excuse, which comes from the fact that writing and thinking are hard work. We want to be tempted, and if the temptation is an apparently reasonable one, such as the feeling that we cannot possibly write another word until we have read something in the library, or checked on the Internet, or talked to someone, it is very difficult to resist. Even the desire to go off and consult our own notes can lead to several hours' interruption, and the thread can be lost.

So I advise myself and my students to separate off the process of creative writing from the task of searching for data. If in my writing I come to a place where evidence or further consultation is needed, I make a guess and a note to myself to check something later. It is important to keep on with the sketch, even if certain things are missing, so 'to check' or 'to read $\mathrm{X}$ and $\mathrm{Y}$ ' are put in and I work around the obstacle, to come back later to it. C.S.Lewis said research is like eating a fish; the bony parts could be taken out and put on the edge of the plate, to be dealt with carefully after the main part had been eaten.

\section{Avoiding blocked paths}

Another thing I have found helpful is to work on several different pieces of creative work at once. I did this with my history D.Phil and have continued to do so. The mind is multitasking and works better, I have found, on parallel problems. So usually I am working on a number of intellectual tasks simultaneously; for example, several different chapters of a book, several different books, and several different stages in the writing and retyping of a work I am engaged on. 
This has several advantages. If I am working on not just one but several chapters of a book or thesis, if I become stuck on one, I can leave it and move to another which may be more promising. We always get stuck and it often only requires leaving something for a while to solve the problem. The mind finds a way round without being forced. If we are only going down one path, we will be blocked. If we go down several simultaneously, we will progress all the time. We often find that we come back from behind the problem, and it has been outflanked and solved by working on something else.

Another advantage of working on several things at once is that different tasks require different types of concentration. To be writing the first draft of something, the first cutting through the undergrowth, is the most tiring and difficult. All is fresh and overgrown and confused.

Anthony Trollope rightly warned that we should not ever write at this high intensity for more than three hours a day. If we were to write for just these three hours, even a slow writer will produce about two thousand words a day, and hence in five days ten thousand words. In theory, it should be possible to write an eighty-thousand word book or thesis in two months, leaving the week-ends free! I have occasionally done something like this, but it seldom seems to work quite like this.

In fact, as well as working on the first draft of several different bits, there are other tasks. There is the typing in of the second version, or the reading through of a draft to make amendments, or the further reading and research. All these tasks need to be shuffled and varied over the day and weeks.

I have learned that it is best to work in parallel, rather than in blocks. It looks logical to write for a month, then spend a month reading or indexing, and then back to writing. Yet this does not work so well for me. I find I can only write at full concentration for about two or three hours on a first draft. Since my best time for writing is about 8-11 am, the creaming off of the best intellectual energy each day is far better than spending a week trying to write for six hours a day so that the next week I can read for six hours a day. So I ration my writing, but try to make sure that I stick at it.

Once we have allocated our best mental time to writing (for others it is late at night or early in the morning) that still leaves another four or five hours when the mind is active. If I am not teaching, administering, or, increasingly, answering emails, then I try to do a diversity of things, some reading (again I find two or three hours a day is enough), some note taking or indexing, some teaching or talking to people.

\section{Enjoying the writing}

Great artists, painters, poets, musicians, create almost subconsciously or by instinct. As academic writers, we can easily become over-cerebral, over-rational, over-conscious as we learn the craft. This is a necessary stage, but gradually it should become more instinctive. We hesitate, we try to get everything straight in our minds, everything sorted out first, and then to write. This often turns into a form of 'writer's block'.

I had this disease quite badly for a number of years. Being of only average ability, I knew that my undergraduate essays and later the drafts of my doctorate could only have a chance of competing with those of my brighter colleagues if I tried really hard and used superior organisation. So I would not start to write until I had assembled a very detailed plan, down to the paragraph level. Each paragraph was mapped out and suitable quotes and arguments written out. Then the whole was embarked on. There was little spontaneity in most of the writing, though it did help to give a plausible semblance of intelligence.

It is obvious that some ideas, plans, plots are necessary before writing. But certainly, as we gain confidence and experience, there is a wonderful liberation, and hopefully improvement, 
in our writing. We put down more of what we ourselves think, and then modify and delete it in the light of further thought and evidence.

In order to do this we have to have both confidence and enthusiasm in what we are doing. If we over-work or write, or have other deep worries, that undermines energy and enthusiasm and the writing suffers, and this then feeds back into the anxiety.

Although it seems logical to write in the order of the projected work, starting with a preface, chapter one, chapter two and proceeding on, in fact it is better to start somewhere in the middle, where the hub or centre of interest will be.

If I am lighting a fire, I do not start with the bigger, thicker, possibly wetter and more difficult branches, but with whatever will catch light most easily. Once this is alight, I can add thicker bits to the flame.

So I now start with whatever really excites you, the bit I think is the most entrancing, intriguing, amazing and mysterious. Then work out from that as the mind dictates. Do not start from the boring edges of a painting, but from the striking centre and then work out. This will help prevent artist's block and as you write or create you will gain confidence and excitement, which should grow until, without really noticing it, most of the work is roughed out. You can then tackle the most difficult and important pieces, the introduction and the conclusion, both of which should be written at the end.

Once the mind is aflame, let the flames leap as they wish. Do not try to limit or direct them too much. In other words, in Kipling's words, 'never write short'. Even if the writing goes in unpredictable directions and seems to be taking you away from your main aim, let it flow. It can always be pruned, cut, used elsewhere. But creative, excited, 'following the scent' writing, is a precious thing. When the mind is in full chase it should be encouraged, not reined in. Writing is a 'second fieldwork' or discovery, pursues clues and ideas as you write, in an amazing but subterranean way. Have trust in the mind and it may well come up in a strange, new, beautiful and fresh valley.

In other words, do not worry in the first draft about word lengths, chapter lengths, days elapsing before you get onto what you think is the real subject. The periods of writing enthusiasm never last forever and often suddenly stop. When they do so, like a light switch being turned off as Kipling puts it, there is no point in forcing the mind on. Stop there and start or continue with something else.

\section{Keeping the flow}

If I am using a bonfire to burn a lot of rubbish over several days, I do not let the fire go out completely overnight. At the end of a day I leave a few half-burnt logs smouldering. It is much easier to start a new fire by raking over these live ashes and adding more wood rather than from scratch. The same is true of creative work. I learnt long ago from W.G.Hoskins, the local historian, that if I was going to leave some writing, for a night, and more especially for a few days, I should resist the temptation to tidily finish off a chapter or section. Starting at a blank page titled 'Chapter 3' at nine o'clock on a Monday morning after a break freezes the mind and makes it very difficult to get going.

It is much better to do most of the work, but leave a little bit to be done, with some brief notes as to where you think you will next go. Then, with the still warm argument raked over by re-reading the last few paragraphs you wrote, plus the indications of what to write next in your notes, you can continue for a few hours. The mind is now heated up and the transition to a new chapter or section feels much easier. 
When you are in fully creative mood, ideas may come thick and fast. Hopefully they will form at 'the tip of your pen' (W.B. Yeats), but you will find that they also come at unexpected times through the day and night. Again they are often very transitory. Though you think you will remember them, they often flit off unless recorded. Especially in that precious moment between sleeping and waking in the morning when many ideas seem suddenly to crowd into the mind.

When I am in a creative mood, I try to carry a pen and small notebook, or even just some scraps of paper, with me. My mother tells me that from my early teens I used to carry a small tin filled with cards in it around with me. I called it pretentiously my 'Great Thoughts' box, which was later replaced by other similar systems. I now have little piles of paper around me to write on, as well as notebooks of various sizes.

I have noted that productive people of the generation above me, including a number of eminent scientists, seize envelopes, committee agendas or whatever is at hand and start to scribble on them. Thoughts are obviously darting into their minds. This is one of the joys of creativity. It is like fishing. You set the bait, relax, sit back, and, when you least expect it, there is a strong tug and you reel in to see what has been hooked.

\section{From 'writing up' to 'imagined communities'}

When anthropologists come back from their fieldwork they often refer to the period when they work through their notes and memories and write the thesis or book as 'Writing Up'. Departments arrange 'Writing Up' seminars for those coming back from 'the field', where they read rough chapters of their Ph.D. to each other and more senior scholars. This 'writing up' may go on for years.

The analogy here is perhaps with an earlier form of archaeology or history, or even the 'writing up' of results after an experiment in physics or chemistry. It is worth concluding by pointing out that such a metaphor, implying a fairly mechanical process of writing a formal account of the 'discoveries' already made, as a kind of report on gathered 'facts', is deeply misleading.

The period in the field is an active one where there is much confusion, semiunderstanding, unfinished business in the mind. Leaving the field, one does not have a box of found artefacts, or ready-made pages of 'facts' copied down in a library or archive, or a set of 'results' from the laboratory. Instead one mainly has memories of sensations and experiences, only very partially embedded or made external on paper, film, tape or computer disc. Over ninety percent of what one has learnt is not yet synthesised or organised in the mind.

So the process when you return, the collating, listing, connecting, comparing with other personal experiences and other academic works, is just as important, if not more so, than the gathering phase. If we compare it to any form of art - writing a novel, writing a poem, painting, sculpture - we can immediately see that it is the period of reflection, and the struggle to understand and then to communicate our understanding to others, that is the central process. Without the lived experience, nothing worthwhile could be written. Yet without the self-examination and articulation afterwards, nothing of value will emerge.

These observations apply to all the social sciences, but from my experience in historical research, I think it is especially the case with anthropology. Really good anthropology is more difficult than any other social science, being so subjective and forcing you to move so from your known world. You have to make a double journey, out of your own world and cosmology into that of another set of people. You have to become enough like them to enter 
their way of being, without losing your own deeper foundations. Living in such a suspended, liminal, state for months, you change greatly and look at your own world afresh.

Then you return, trying to bring some of that newly found world with you, and try to recreate it both in your own mind and imagination and for your audience. It is the same task that faced Shakespeare and Milton, Dickens and Tolstoy, Rembrandt and Goya in other forms. When the fieldwork and re-imagining works, it is, like all creative work, one of the deepest and richest experiences of life. Yet it is not easy, and not made easier if you enter the process thinking that all that is involved is the 'writing up' of what you already know.

The true test of success is to compare the time when you 'returned' from the fieldwork, and the period when the text is completed. If the finished project is not almost entirely different from what you knew when you started to write, if it is not far richer than anything you could have written in the first few weeks, it is likely that, as what you will have achieved is perhaps something useful - the collection of some new bits and pieces. Yet it is unlikely that the finished project will expand our deeper knowledge of human beings and their diversity and similarities, the true goal of anthropology. 


\section{Publications which arose from work in this period}

'Population Crisis: Anthropology's Failure', New Society, 10 October 1968

Alan Macfarlane, The Family Life of Ralph Fosselin: An Essay in Historical Anthropology (1970)

Alan Macfarlane, Witchcraft in Tudor and Stuart England: A Regional and Comparative Study (1970)

Alan Macfarlane, Resources and Population: A Study of the Gurungs of Nepal (1976)

'Modes of reproduction', fournal of Development Studies, 14, no.4 [Malinowski Lecture for 1978]

Alan Macfarlane, The Origins of English Individualism: The Family, Property and Social Transition (1978)

'Death, Disease and Curing in a Himalayan Village', in Asian Societies in Anthropological Perspective, ed. C. von Furer-Haimendorf (1981)

Bernard Pignede, The Gurungs: A Himalayan Population of Nepal, translated, edited and annotated, with Sarah Harrison (1993)

\section{Acknowledgements and dedication}

I would like to thank Gillian Ingram, who went to Nepal with me, for all her support and help then, which is described in this volume. Gill has very kindly allowed me to use her letters, diaries and other writings quoted in this volume.

Sarah Harrison, as always, read and commented on drafts of this work and contributed hugely to the final book. She has accompanied me on the subsequent eighteen visits to Nepal and the Gurungs and done a great deal of the fieldwork on those visits.

I am grateful to all others whose work is quoted or cited. If any of them have any problems with copyright in their materials, I will take due action on receipt of queries.

Above all, I would like to thank my Gurung friends and the family of Lt. Bhuwansing Gurung who adopted Gill and I. Their amazing kindness, affection, resilience and humour is shown throughout this account. It has been one of the most extraordinary privileges of my life to have known the Gurungs and this book is dedicated to them. 